NIST Technical Note 2038

\title{
Influence of Fire on the Lateral Resistance of Cold-Formed Steel Shear Walls - Phase 2
}

\section{Oriented Strand Board, Strap Braced, and Gypsum-Sheet Steel Composite}

Matthew S. Hoehler

Blanca Andres

Matthew F. Bundy

This publication is available free of charge from: https://doi.org/10.6028/NIST.TN.2038

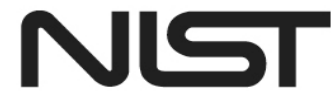

National Institute of Standards and Technology U.S. Department of Commerce 
NIST Technical Note 2038

\section{Influence of Fire on the Lateral Resistance of Cold-Formed Steel Shear Walls - Phase 2}

\section{Oriented Strand Board, Strap Braced, and Gypsum-Sheet Steel Composite}

Matthew S. Hoehler Blanca Andres Matthew F. Bundy

Fire Research Division Engineering Laboratory

This publication is available free of charge from: https://doi.org/10.6028/NIST.TN.2038

March 2019

INCLUDES UPDATES AS OF 04-20-2020; SEE APPENDIX I

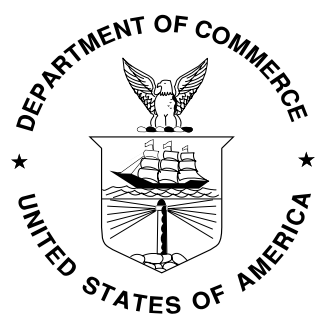

U.S. Department of Commerce

Wilbur L. Ross, Jr., Secretary 
Certain commercial entities, equipment, or materials may be identified in this document in order to describe an experimental procedure or concept adequately. Such identification is not intended to imply recommendation or endorsement by the National Institute of Standards and Technology, nor is it intended to imply that the entities, materials, or equipment are necessarily the best available for the purpose.

It is policy of the National Institute of Standards and Technology to use the International System of Units (SI) in its published materials. Because this report is intended for the U.S. building construction industry, which currently uses U.S. Customary Units, some construction drawings and product specifications use U.S. Customary Units. Where U.S. Customary Units alone are used, conversion factors to SI are provided.

National Institute of Standards and Technology Technical Note 2038

Natl. Inst. Stand. Technol. Tech. Note 2038, 296 pages (March 2019) CODEN: NTNOEF

This publication is available free of charge from: https://doi.org/10.6028/NIST.TN.2038 


\begin{abstract}
This report presents experimental investigations of the performance of cold-formed steel lateral force-resisting systems (CFS-LRFS) under combinations of simulated earthquake and fire loading. Three types of shear wall systems are investigated: gypsum-sheet steel composite panel sheathed walls, oriented strand board (OSB) sheathed walls, and steel strap braced walls. Twenty-two $2.7 \mathrm{~m}$ tall by $3.7 \mathrm{~m}$ long test specimens are subjected sequentially to combinations of mechanical (cyclic shear deformation) and thermal (fire) load. The mechanical loading setup and protocol are based on ASTM E2126 Method C. Fire loads of varying intensity that represent the characteristics of actual fires are investigated. The work is a step toward developing fragility curves (representations of the probability of exceeding a given damage state as a function of an engineering demand parameter) for these systems for use in performance-based design for fire.
\end{abstract}

\title{
Key words
}

cold-formed steel; earthquake; fire; fire following earthquake; gypsum-sheet steel composite panel; oriented strand board; shear walls; strap braced; performance-based design.

\section{Acknowledgments}

This work was funded by the National Institute of Standards and Technology (NIST). The authors thank Carleton Elliott (Sure-Board), Fernando Sesma (CEMCO), Jim DesLaurier (Marino/WARE), Brian Mucha (Panel Systems, Inc.), Larry Williams (SFIA), Benjamin Schafer (Johns Hopkins University), and Rob Madsen (Devco Engineering) for their expert consultation. The authors also thank the NIST Fire Research Division staff including Brian Story, Laurean DeLauter, Anthony Chakalis, Philipp Deardorff, Michael Selepak, Marco Fernandez, William Grosshandler and Artur Chernovsky whose efforts and expertise made these experiments possible. 


\section{Table of Contents}

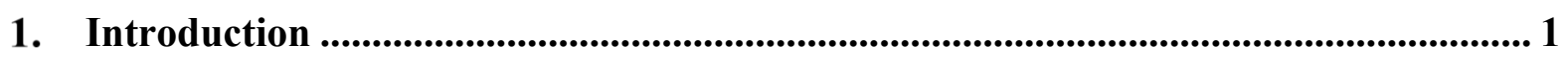

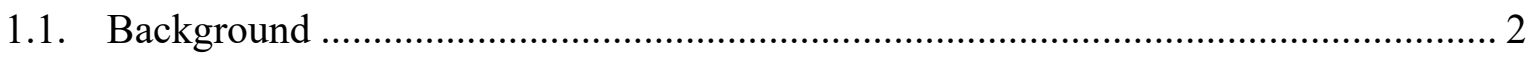

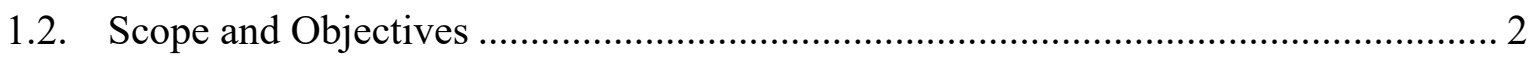

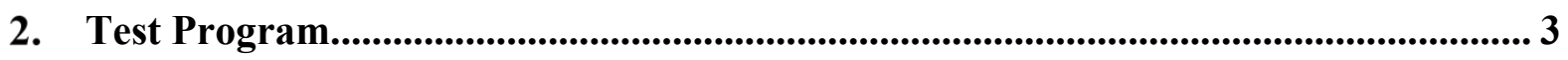

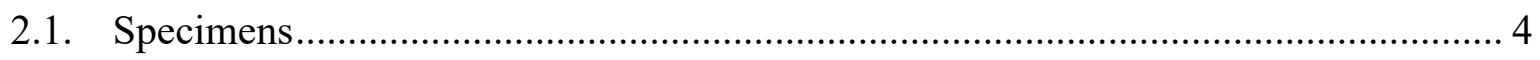

2.1.1. Gypsum-sheet steel composite panel sheathed walls ........................................ 5

2.1.2. Oriented strand board sheathed walls.............................................................. 8

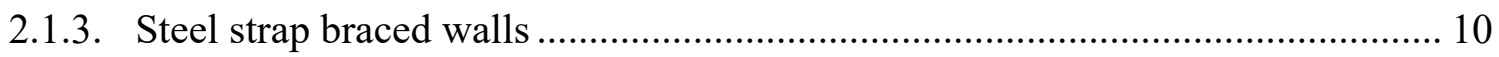

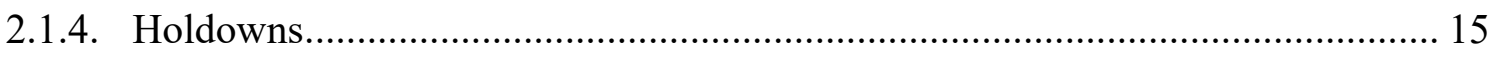

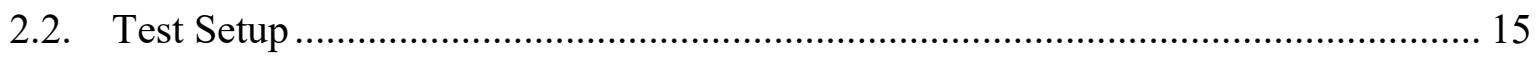

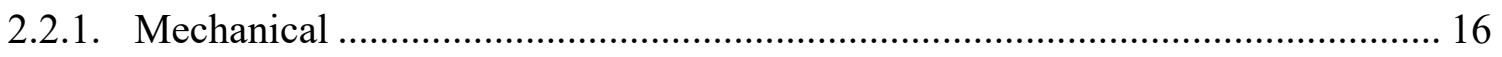

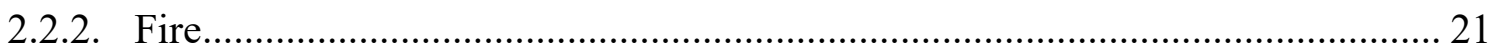

2.3. Cyclic Loading Protocol...................................................................................... 24

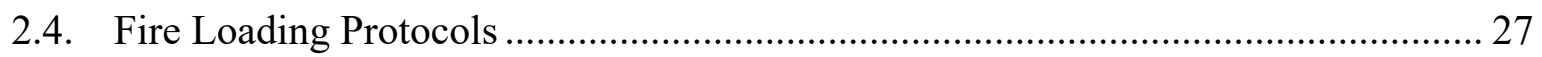

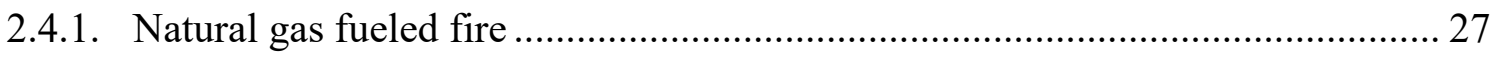

2.4.2. Kitchen furnishings fire ......................................................................... 28

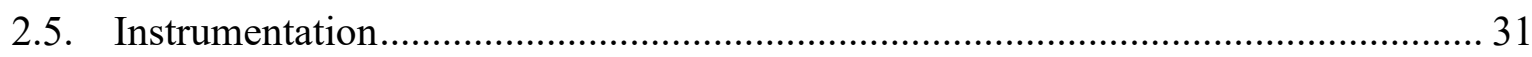

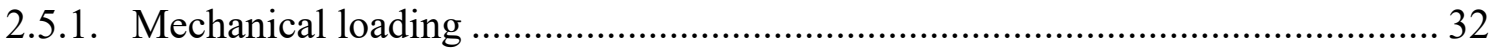

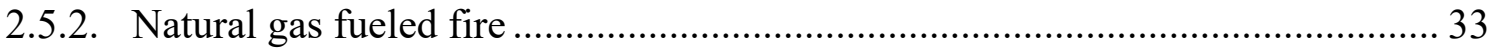

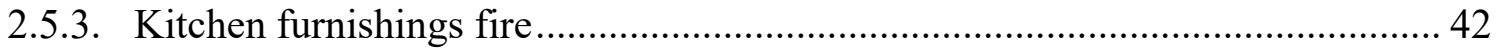

3. Results Summary ......................................................................................................... 48

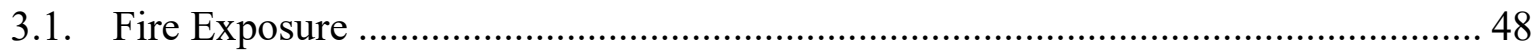

3.2. Gypsum-Sheet Steel Composite Panel Sheathed Wall Performance ....................... 52

3.3. Oriented Strand Board Sheathed Wall Performance ............................................. 60

3.4. Steel Strap Braced Wall Performance ..................................................................... 69

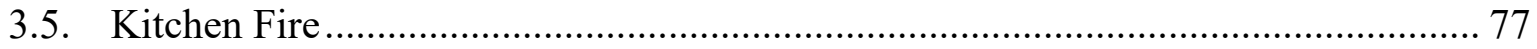

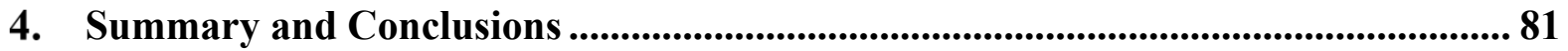

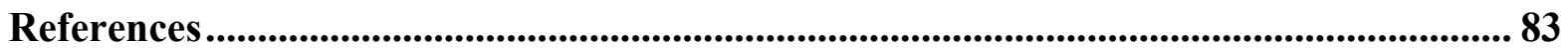

Appendix A: Detailing of Asymmetric Steel Strap Braced Wall....................................... 86

Appendix B: Screw Patterns ........................................................................................................ 89

Appendix C: Uncertainty of Measurements........................................................................... 92

Appendix D: Fire Load Development ...................................................................................... 94

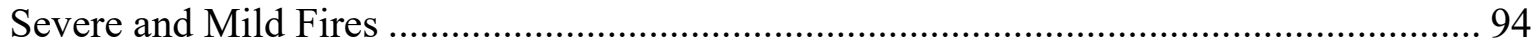


Kitchen Compartment Fire................................................................................ 95

Appendix E: Test Data for Gypsum-Sheet Steel Composite Panel Sheathed Walls ...... 97

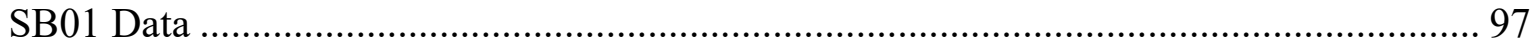

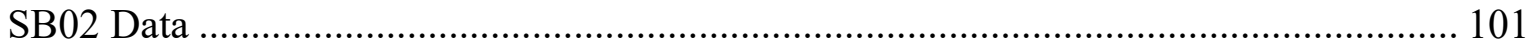

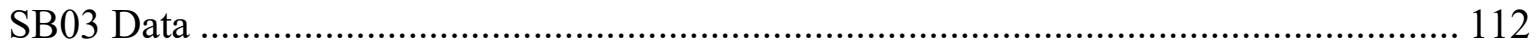

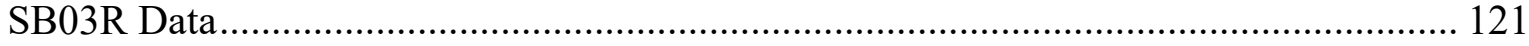

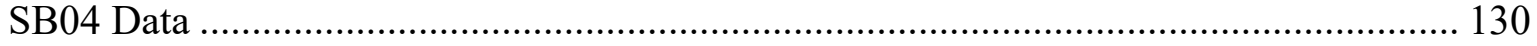

Appendix F: Test Data for Oriented Strand Board Sheathed Walls ........................... 139

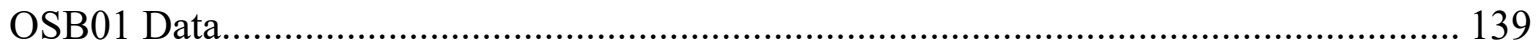

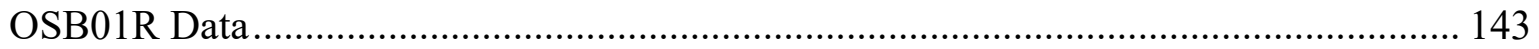

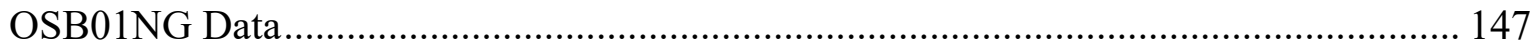

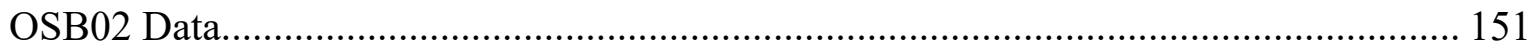

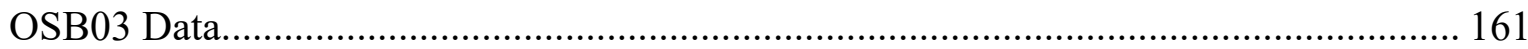

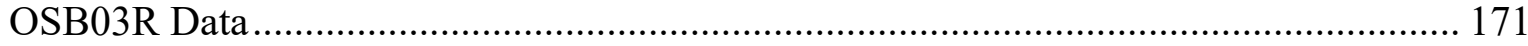

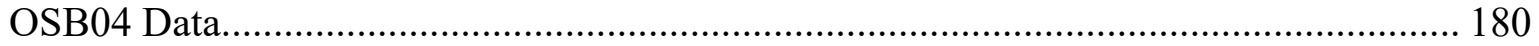

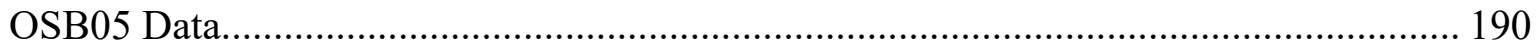

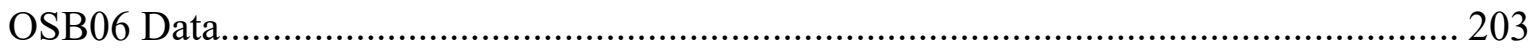

Appendix G: Test Data for Steel Strap Braced Walls ............................................... 213

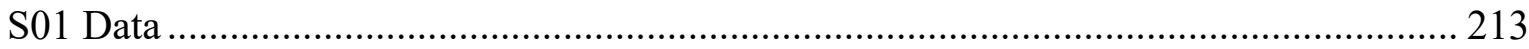

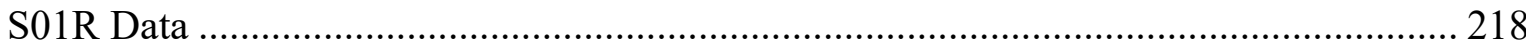

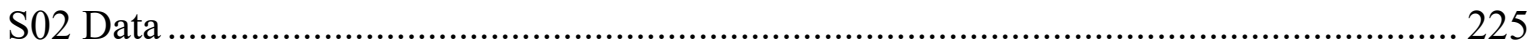

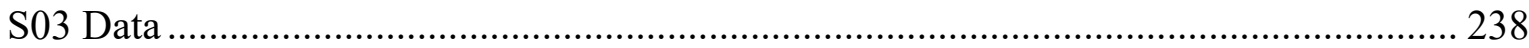

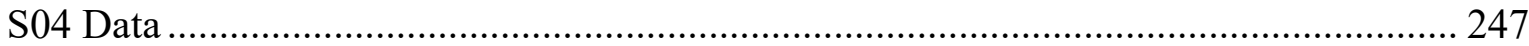

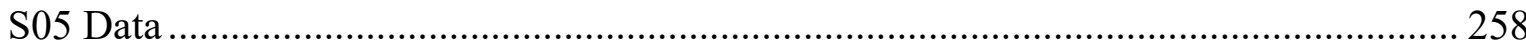

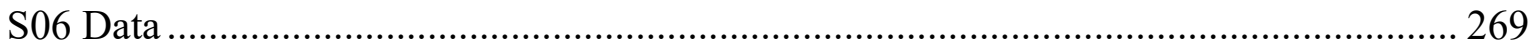

Appendix H: Test Data for Kitchen Fire .................................................................. 280

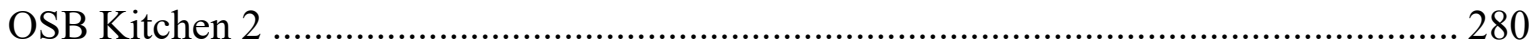

Appendix I: Change Log ............................................................................................... 297 


\section{Introduction}

In the United States, lightweight framing systems are commonly used in single-story buildings and for internal partitions in multistory buildings. However, they are also used for the structural system in multi-story buildings; sometimes combined with other structural typologies, such as cold-formed steel (CFS) framing on a concrete podium structure (Fig. 1). It is estimated that in 2016, cold-formed steel accounted for $\$ 150$ billion dollars worth of construction in the United States (U.S. Department of Commerce, 2015; Steel Framing Industry Association, 2016). With the global trend toward urbanization expected to continue (United Nations Department of Economic and Social Affairs, 2014), this places increased demand on highdensity, urban housing that optimizes land use. Consequently, there has been an uptake in multifamily housing. Lightweight structural systems using cold-formed steel currently represent about $20 \%$ of the nonresidential construction market in the United States (multifamily housing with five or more dwellings is considered commercial real estate) and are touted for their cost advantages and increased construction speed; in particular, for prefabricated systems (American Iron and Steel Institute, 2018). However, an important consideration for tall, lightweight structures is their performance in fire, because as buildings get taller, evacuation times increase and fighting a fire becomes more challenging.

In addition to the gravity load-resisting system that supports the weight of a building and its contents, nearly all buildings have lateral force-resisting systems (LFRS) to resist horizontal loads such as those due to wind or earthquakes. Although extensive information exists about the structural performance and fire resistance of cold-formed steel construction (Sultan, 1996; Takeda, 2003; Wang et al., 2015; Schafer et al., 2016), there is limited knowledge about the behavior of cold-formed steel lateral force-resisting systems (CFS-LFRS) under combined hazards; in particular earthquake and fire.

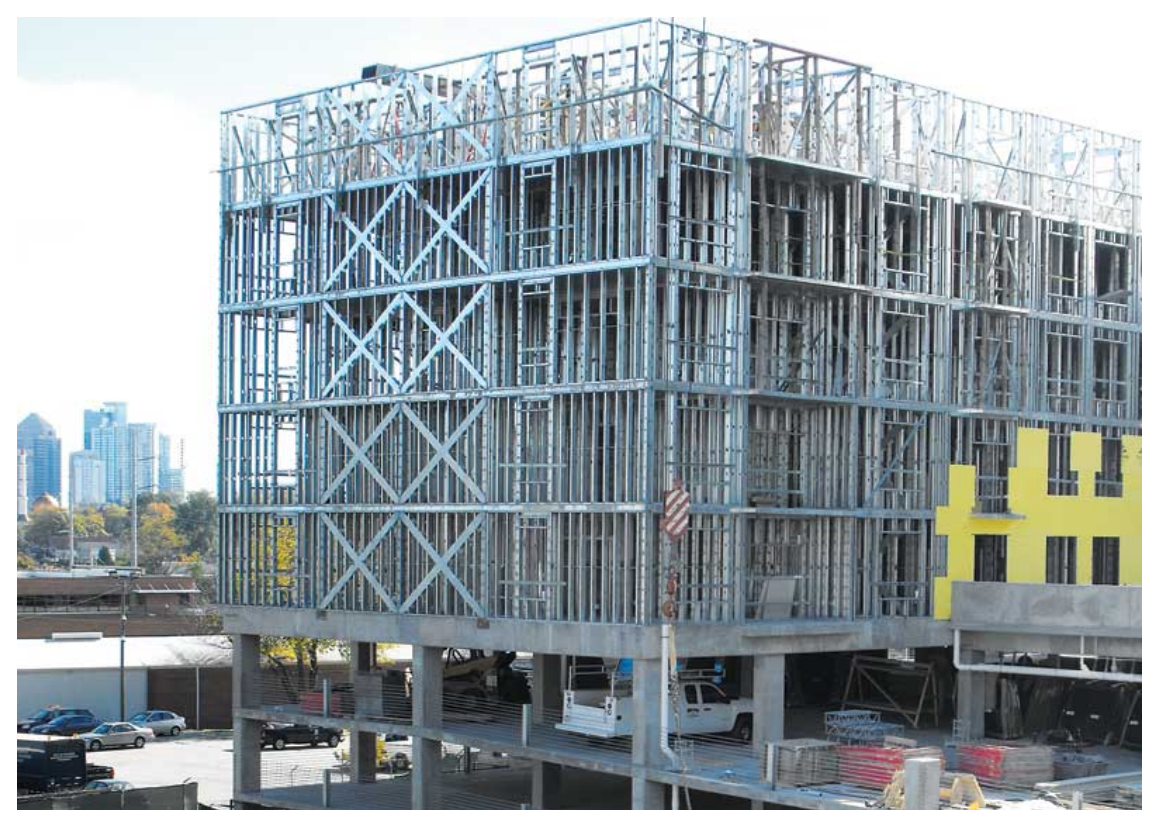

Fig. 1. Example of five-story cold-formed steel framed building atop three stories of parking (source: www.constructionspecifier.com). 


\subsection{Background}

In 2016, a series of experiments (Phase 1) was performed at the National Fire Research Laboratory (NFRL) at the National Institute of Standards and Technology (NIST) to investigate the performance of earthquake-damaged gypsum-sheet steel composite panel sheathed cold-formed steel shear walls under fire load (Hoehler and Smith, 2016, 2018). Phase I was conducted in conjunction with the project Earthquake and Post-Earthquake Fire Performance of Mid-Rise Light-Gauge Cold-Formed Steel Framed Buildings performed at the University of California, San Diego, which investigated the earthquake and fire performance of a six-story, cold-formed steel framed building (Wang et al., 2018). The NIST tests indicated a change in failure mode can occur in the walls from local to global buckling of the sheet steel following a fire and highlighted the importance of the response of the gypsum for both the fire and structural behavior (Hoehler et al., 2017).

\subsection{Scope and Objectives}

This report (Phase 2) extends the Phase 1 research and presents experimental investigations of the performance of three common cold-formed steel lateral force-resisting systems under combinations of earthquake and fire loading. Fire loads of varying intensity that represent the characteristics of actual fires, as opposed to standard furnace tests, are used. This is a step toward the development of fragility curves (representations of the probability of exceeding a given damage state as a function of an engineering demand parameter) for these systems; an essential component of performance-based design for fire.

The report provides information about:

1. Post-fire lateral capacity: residual lateral strength after a fire has occurred;

2. Post-earthquake fire resistance: fire performance of earthquake-damaged lateral systems and their ability to limit the spread of fire to neighboring spaces in a building;

3. Post-earthquake, post-fire, residual lateral strength: residual lateral strength in the case of an aftershock after a fire following earthquake event. 


\section{Test Program}

Table 1 shows the test matrix used in this study. Three lateral force-resisting systems were investigated: gypsum-sheet steel composite panel sheathed walls, oriented strand board (OSB) sheathed walls, and steel strap braced walls. Specimen names including ' 01 ' were subjected only to load cycling. Specimen names including ' 02 ', '03', or ' 04 ' were subjected to various fire intensities followed by cyclic loading. Specimen names including ' 05 ' or '06' were predamaged with cyclic loading, subjected to fire, and then cycled to failure. The influence of predamage on the performance of gypsum-sheet steel composite sheathed walls was investigated previously (Hoehler et al., 2017). Specimens with an ' $R$ ' designation were test replicates; except for S01R, which was a redesign of wall S01 to use symmetric bracing. Specimen OSB01NG was an OSB sheathed wall with no gypsum board installed on one side of the wall and OSB_Kitchen was a test where the fire load was provided by burning kitchen furnishings. Descriptions of the mechanical and thermal loads are provided later in the report.

Table 1. Test matrix.

\begin{tabular}{|c|c|c|c|c|}
\hline \multirow{2}{*}{$\begin{array}{l}\text { Wall } \\
\text { type } \\
\end{array}$} & \multirow[b]{2}{*}{$\begin{array}{l}\text { Specimen } \\
\text { name }\end{array}$} & \multicolumn{3}{|c|}{ Loading } \\
\hline & & $\begin{array}{c}\text { Cycling } \\
\text { (before fire) }\end{array}$ & Fire & $\begin{array}{c}\text { Cycling } \\
\text { (after fire) }\end{array}$ \\
\hline \multirow{5}{*}{$\begin{array}{l}\text { Gypsum-sheet } \\
\text { steel composite }\end{array}$} & SB01 & Cycle to failure & - & (2) \\
\hline & SB02 & - & Severe Parametric & Cycle to failure \\
\hline & SB03 & - & Mild Parametric & Cycle to failure \\
\hline & SB03R & - & Mild Parametric & Cycle to failure \\
\hline & SB04 & - & Standard Fire & Cycle to failure \\
\hline \multirow{8}{*}{$\begin{array}{c}\text { Oriented } \\
\text { Strand } \\
\text { Board }\end{array}$} & OSB01 & Cycle to failure & - & - \\
\hline & OSB01R & Cycle to failure & - & - \\
\hline & OSB02 & - & Severe Parametric & Cycle to failure \\
\hline & OSB03 & - & Mild Parametric & Cycle to failure \\
\hline & OSB03R & - & Mild Parametric & Cycle to failure \\
\hline & OSB04 & - & Standard Fire & Cycle to failure \\
\hline & OSB05 & Drift Level 3 & Mild Parametric & Cycle to failure \\
\hline & OSB06 & Drift Level 1 & Mild Parametric & Cycle to failure \\
\hline \multirow{7}{*}{$\begin{array}{c}\text { Steel strap } \\
\text { braced }\end{array}$} & S01 & Cycle to failure & - & - \\
\hline & S01R & Cycle to failure & - & - \\
\hline & S02 & - & Severe Parametric & Cycle to failure \\
\hline & $\mathrm{S} 03$ & - & Mild Parametric & Cycle to failure \\
\hline & S04 & - & Standard Fire & Cycle to failure \\
\hline & S05 & Drift Level 3 & Mild Parametric & Cycle to failure \\
\hline & S06 & Drift Level 1 & Mild Parametric & Cycle to failure \\
\hline \multirow{2}{*}{ Additional } & OSB01NG & Cycle to failure & - & - \\
\hline & OSB Kitchen & - & Real furnishings & - \\
\hline
\end{tabular}




\section{1. $\quad$ Specimens}

A large percentage of lateral-force resisting systems used in cold-formed steel structures are shear walls located on the interiors of building, as opposed to at the outside perimeter of a building. Consequently, this investigation was limited to interior walls. Moreover, fireresistance requirements for gravity-load bearing walls were not considered, nor were the effects of supplemental vertical (gravity) loads.

Fig. 2 shows photographs of the three investigated wall types. The walls are Type I Shear Walls; i.e. walls designed to resist in-plane lateral forces that have no openings and are provided with holdowns and anchorage at each end of the wall segment. All wall specimens had dimensions of $2.7 \mathrm{~m}$ tall by $3.7 \mathrm{~m}$ long $(9 \mathrm{ft} . \times 12 \mathrm{ft}$.). The cold-formed steel studs and track were $152 \mathrm{~mm}$ (6 in.) wide and had a thickness of $1.37 \mathrm{~mm}(0.054 \mathrm{in}$.) or greater. The first steel strap braced wall constructed was designed with straps only on one side of the wall (asymmetric bracing). The strap braced walls were subsequently redesigned to have straps on both sides (symmetric bracing) for the remainder of the experiments. All walls were designed using Allowable Stress Design (ASD) nominally following American Iron and Steel Institute (AISI) standards S100-16 (American Iron and Steel Institute, 2016a) and AISI S400-15/S1-16 (American Iron and Steel Institute, 2016b) and dimensioned to have expected shear strength of approximately equal amplitude using a mix of design provisions and test data.

Shear walls on the interiors of buildings are often placed along corridors; which provide long, straight runs. In multifamily residential buildings, a typical use for cold-formed steel framed structures, kitchens are often located adjacent to these corridors. The scenario of a postflashover kitchen fire in a room adjacent to a corridor was used as a prototype for these investigations ${ }^{1}$ (Fig. 3). For the sheathed walls and the asymmetrically braced wall, the fire was applied opposite to the shear-load resisting elements. For the symmetrically braced walls, straps were present behind both the fire-exposed and unexposed gypsum. All wall specimens were designed to achieve a 1-hour fire-resistance rating per American Society for Testing and Materials (ASTM) standard E119 (ASTM International, 2016). The influence of insulation material in the wall cavity on the thermal and mechanical behavior of the walls was not investigated.

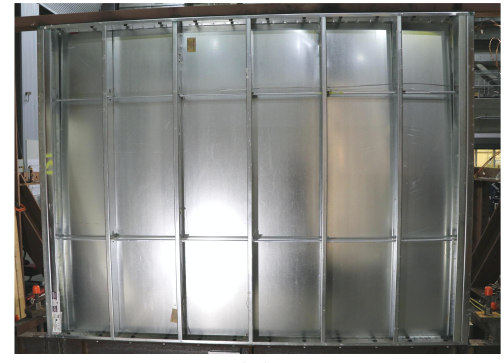

(a)

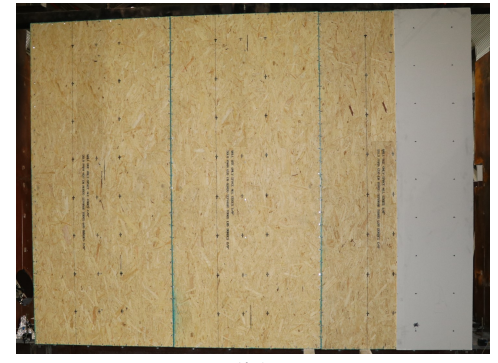

(b)

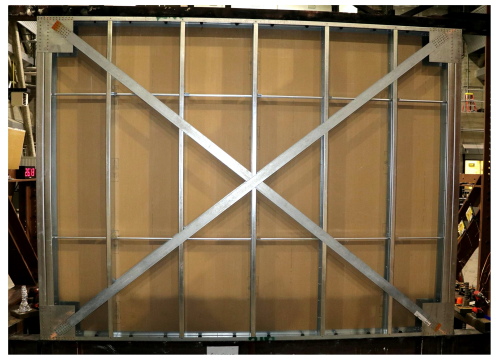

(c)

Fig. 2. Photographs of partially-constructed test specimens: (a) gypsum-sheet steel composite panel sheathed walls; oriented strand board sheathed walls; (c) steel strap braced walls.

\footnotetext{
${ }^{1}$ The location of the fire relative to the sheathing was reversed in the Phase 1 tests.
} 


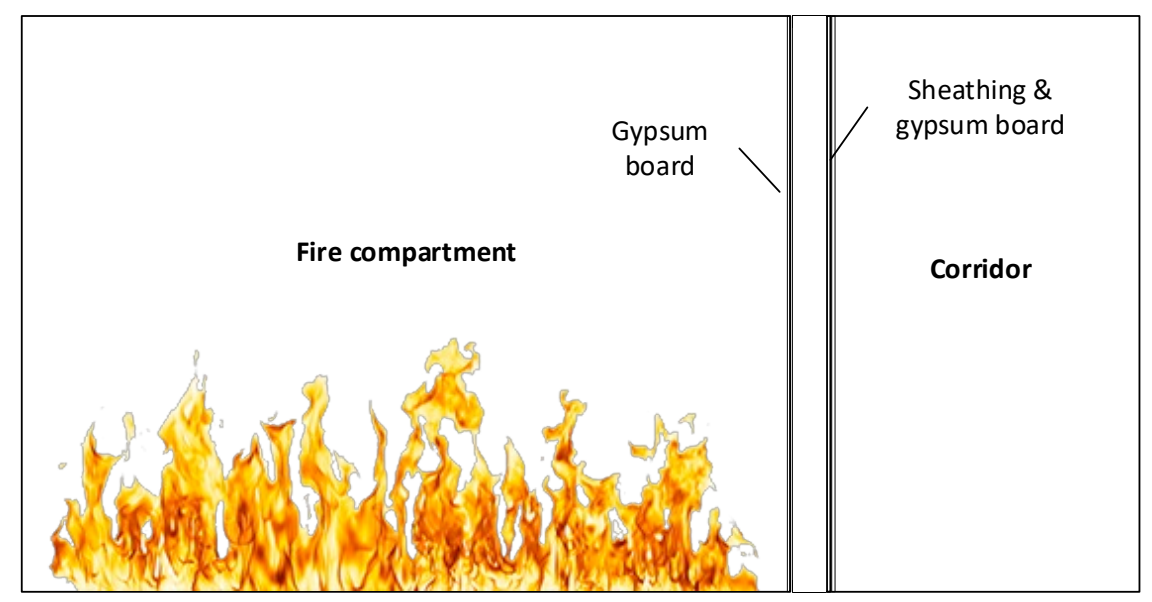

Fig. 3. Fire scenario for Phase 2 tests.

\subsubsection{Gypsum-sheet steel composite panel sheathed walls}

The gypsum-sheet steel composite panels were a proprietary product (Sure-Board ${ }^{\circledR}$ Series 200) $2.7 \mathrm{~m} \times 1.2 \mathrm{~m}(9 \mathrm{ft} . \times 4 \mathrm{ft}$. $)$ in dimension which consisted of $0.686 \mathrm{~mm}(0.027 \mathrm{in}$. $)$ thick sheet metal adhered to $16 \mathrm{~mm}(5 / 8 \mathrm{in}$.) thick Type X gypsum board. For Type I sheathed walls with height-to-length ratio $(h / w) \leq 2$, per AISI S400-15/S1-16 the nominal shear strength $\left(V_{n}\right)$ can be calculated as:

$$
V_{n}=v_{n} \cdot w
$$

where $w$ is the length of the shear wall $(3.66 \mathrm{~m})$, and $v_{n}$ is the nominal shear strength per unit length. Using Table 1 in the Evaluation Report for Sure-Board Series 200 panels (IAPMO, 2018), for a fastener spacing of $102 \mathrm{~mm}$ (4 in.) at the panel edges ${ }^{2}$ and a framing member thickness greater than or equal to $1.37 \mathrm{~mm}(0.054$ in.), the nominal shear strength is $33.65 \mathrm{kN} / \mathrm{m}$ (2306 lbf/ft.). Therefore, the total nominal shear strength is $123 \mathrm{kN}$ (27.7 kip). Assuming an expected strength factor $\left(\Omega_{E}\right)$ of 1.2 based on the Phase I test results (Hoehler and Smith, 2016), the expected shear strength of the wall is:

$$
\Omega_{E} \cdot V_{n}=1.2 \cdot 123 k N=148 k N(33.2 \mathrm{kip})
$$

For holdown anchorages located at the outside edge of the wall, for a $2.7 \mathrm{~m}$ tall by $3.7 \mathrm{~m}$ long wall, the maximum compression (or tension) force in the chord studs will be:

$$
\frac{\left(\Omega_{E} \cdot V_{n}\right) \cdot h}{\text { distance between anchor points }}=111 \mathrm{kN}(24.9 \mathrm{kip})
$$

Two 600S250-54(50) cold-formed steel studs $1.37 \mathrm{~mm}$ (0.054 in.) thick steel with $345 \mathrm{MPa}$ (50 ksi) strength which are $152 \mathrm{~mm}$ (6 in.) wide with a flange width of $64 \mathrm{~mm}$ (2.5 in.), placed back-to-back with an unbraced length of $1.2 \mathrm{~m}$ (48 in.) provide an ASD allowable axial strength (capacity) of $77.1 \mathrm{kN}(17.33 \mathrm{kip})^{3}$. Applying a load factor of 0.7 to the expected (earthquake) shear strength of the walls per American Society of Civil Engineers (ASCE) / Structural Engineering Institute (SEI) standard ASCE/SEI 7-10 (American Society of Civil

\footnotetext{
${ }^{2}$ The Phase 1 tests used a fastener spacing of $76 \mathrm{~mm}$ (3 in.) at the panel edges. The fastener spacing was increased to $102 \mathrm{~mm}(4$ in.) in Phase 2 to reduce the shear capacity of these walls and provide a larger margin of safety relative to the capacity of the loading actuator.

${ }^{3}$ Allowable compression capacity determined using proprietary design software.
} 
Engineers, 2013) and conservatively neglecting the allowable stress increase factor of 1.2 when ASD load combinations for overstrength are employed, the design demand on the chord studs is $77.5 \mathrm{kN}$ (17.43 kip), providing a demand-to-capacity ratio of 1.01 . This is deemed close enough to 1.0 to be acceptable.

The specimen framing is shown in Fig. 4 and Fig. 5. The interior vertical framing members were 600S162-54(50) cold-formed steel studs; $152 \mathrm{~mm}$ (6 in.) wide with a flange width of $41 \mathrm{~mm}$ (1-5/8 in.) spaced $610 \mathrm{~mm}$ (24 in.) on center (O.C.). The top and bottom tracks were 600T125-54(50) cold-formed steel channels; $152 \mathrm{~mm}$ (6 in.) wide with a flange width of $32 \mathrm{~mm}$ (1-1/4 in.). The webs of the top and bottom tracks were drilled with two rows of $\varnothing 19 \mathrm{~mm}$ (3/4 in.) holes at $305 \mathrm{~mm}$ (12 in.) on center to allow for attachment to the loading beams. Additionally, the web of the bottom track was drilled with two Ø29 mm (1-1/8 in.) holes $25 \mathrm{~mm}$ (1 in.) in from both ends to allow the holdown bolts to pass through (Fig. 6a). Bridging channel, 150U50-54(50) cold-formed steel channels; $38 \mathrm{~mm}$ (1.5 in.) wide with a

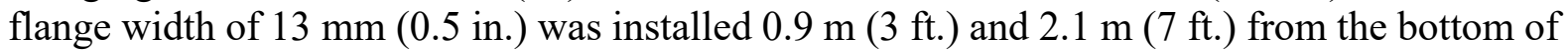
the wall and attached using bridging clips to provide a maximum unbraced chord length of $1.2 \mathrm{~m}$ (48 in.). All cold-formed steel sections were $1.37 \mathrm{~mm}$ (0.054 in.) thick Structural Grade 50 (Grade 340) Type H conforming to ASTM A1003 (ASTM International, 2015) with a minimum specified yield strength of $50 \mathrm{ksi}(345 \mathrm{MPa})$.

All framing members were fastened using $5 \mathrm{~mm} \times 19 \mathrm{~mm}(\# 10 \times 3 / 4$ in.) self-tapping, flat pan headed sheet metal screws. The chord studs were secured back-to-back with two rows of screws at $305 \mathrm{~mm}$ (12 in.) on center and stitched at the ends with screws spaced at $38 \mathrm{~mm}$ (1.5 in.) or less $^{4}$ (Fig. 6b). All other joints had one screw where flanges overlapped.

The gypsum-sheet steel composite panels were attached to the cold-formed steel framing with $4 \mathrm{~mm} \times 44 \mathrm{~mm}(\# 8 \times 1-3 / 4$ in.) self-tapping, bugle-headed sheet metal screws. The screw spacing was $102 \mathrm{~mm}$ (4 in.) on center at the panel edges and $305 \mathrm{~mm}$ (12 in.) on center in the field. Three $2.7 \mathrm{~m} \times 1.2 \mathrm{~m}(9 \mathrm{ft} . \times 4 \mathrm{ft}$. $)$ panels were installed with vertical seams between the panels. No drywall joint compound or paper tape was used on this side of the wall.

The opposite side of the wall (fire exposed side) was sheathed using two $2.7 \mathrm{~m} \times 1.2 \mathrm{~m}(9 \mathrm{ft}$. $\times 4 \mathrm{ft}$.) and two $2.7 \mathrm{~m} \times 0.6 \mathrm{~m}(9 \mathrm{ft} . \times 2 \mathrm{ft}$. $)$ Type $X$ gypsum boards $16 \mathrm{~mm}(5 / 8 \mathrm{in}$. $)$ thick. The vertical seams on the front and back of the wall were staggered by one stud spacing. The gypsum boards were attached using $3.5 \mathrm{~mm} \times 41 \mathrm{~mm}(\# 6 \times 1-5 / 8 \mathrm{in}$.) self-tapping, bugleheaded sheet metal screws. The screw spacing was $152 \mathrm{~mm}$ (6 in.) on center on the board perimeter and $305 \mathrm{~mm}$ (12 in.) on center in the field. The seams were sealed using a base coat of drywall joint compound and paper tape. The seams and fastener heads then covered with a skim coat of drywall joint compound. The measured moisture content of specimens from three randomly sampled gypsum boards was $(18.9 \pm 0.1)$ percent by mass.

The design for fire-resistance of the gypsum-sheet steel composite panels walls was based on product approval documents (Intertek, 2010). The wall cross section is shown in Fig. 7. Drawings of the screw patterns can be found in the Appendices.

\footnotetext{
${ }^{4}$ Stitching at the bottom of the chord studs was provided by the screws attaching the holdowns.
} 

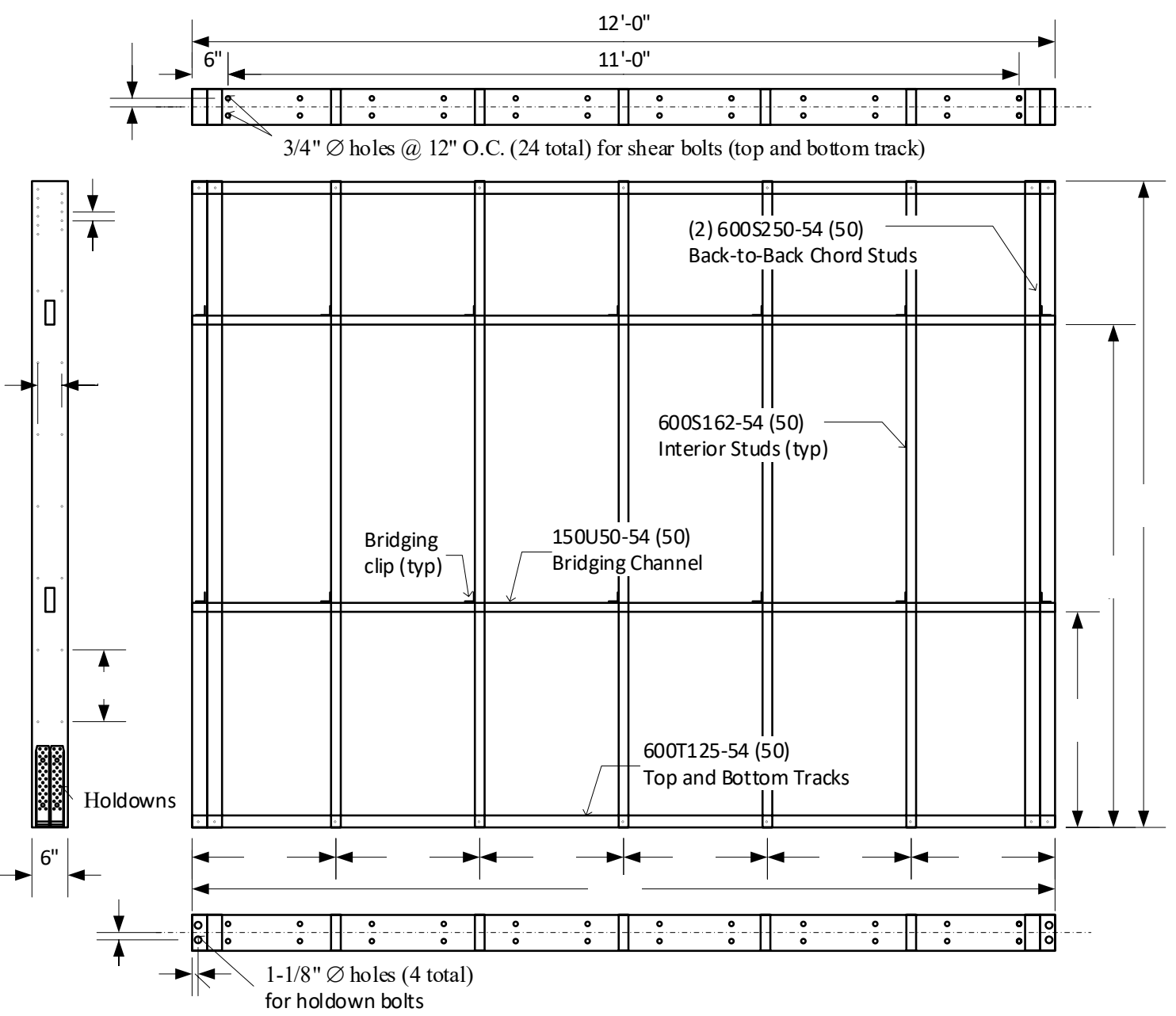

Fig. 4. Drawing of framing for the sheathed walls $(1 \mathrm{ft} .=30.5 \mathrm{~cm})$.

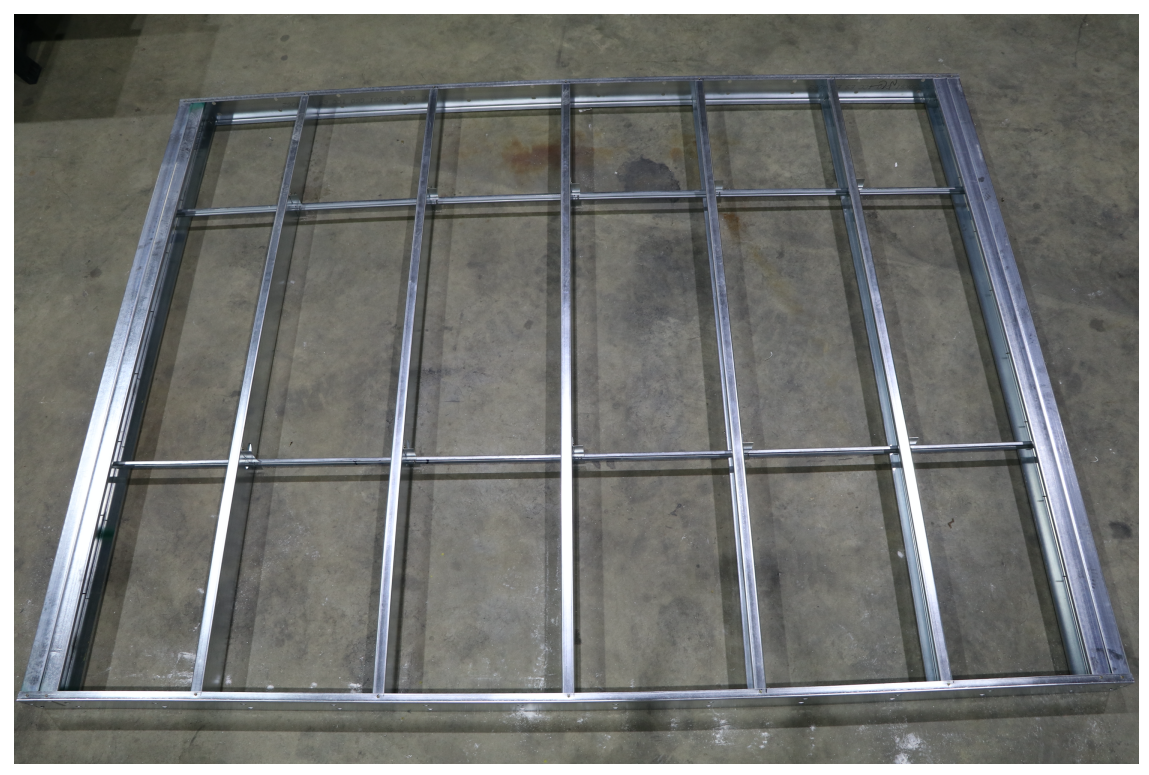

Fig. 5. Photograph of framing for the sheathed walls. 


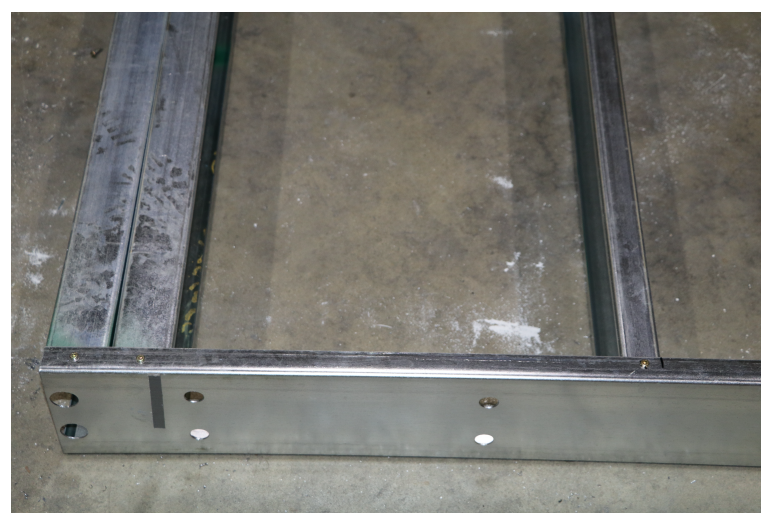

(a)

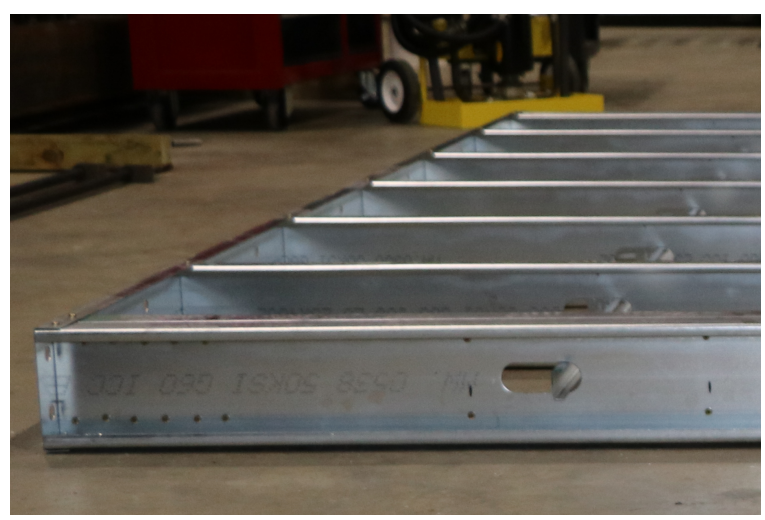

(b)

Fig. 6. Photographs of (a) framing connection at bottom track and (b) fastener stitching at top of chord studs.

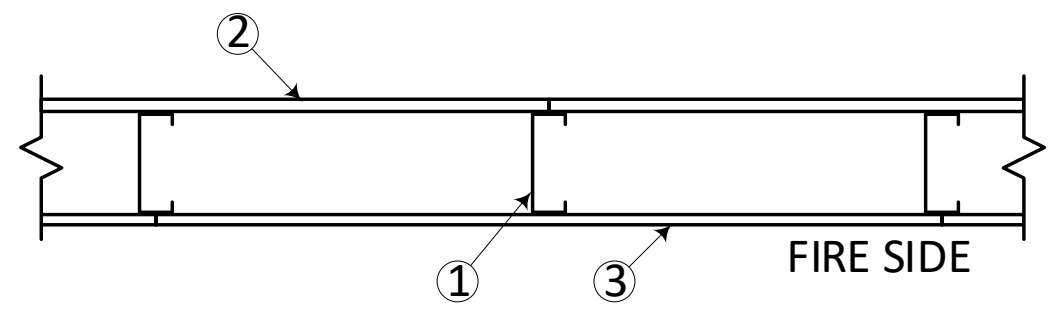

Fig. 7. Cross section of gypsum-sheet steel composite panel sheathed walls (1 - steel framing; 2 - Sure-Board Series 200 panel; 3 -gypsum board).

\subsubsection{Oriented strand board sheathed walls}

The design of the oriented strand board (OSB) sheathed walls was analogous to the gypsumsheet steel composite panel sheathed walls. The sheathing elements were wood structural panels rated for shear resistance, $11 \mathrm{~mm}(7 / 16$ in.) thick and $2.7 \mathrm{~m} \times 1.2 \mathrm{~m}(9 \mathrm{ft} . \times 4 \mathrm{ft}$.) in dimension. For a fastener spacing of $102 \mathrm{~mm}$ (4 in.) at the panel edges, Table E1.3-1 in AISI S400-15/S1-16 prescribes a nominal shear strength per unit length for this sheathing of

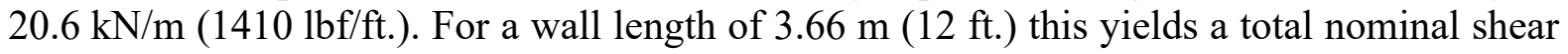
strength of $75 \mathrm{kN}$ (16.9 kip) for the oriented strand board walls.

Taking an expected strength factor $\left(\Omega_{E}\right)$ of 1.8 per Section E1.3.3 in AISI S400-15/S1-16, the expected shear strength of the wall is:

$$
\Omega_{E} \cdot V_{n}=1.8 \cdot 75 k N=135 k N(30.5 \mathrm{kip})
$$

and the maximum compression (or tension) force in the chord studs will be:

$$
\frac{\left(\Omega_{E} \cdot V_{n}\right) \cdot h}{\text { distance between anchor points }}=102 \mathrm{kN}(22.8 \mathrm{kip})
$$

Because the maximum design chord force is slightly smaller than that for the gypsum-sheet steel composite panel sheathed walls $(102 \mathrm{kN}$ versus $111 \mathrm{kN})$, the same framing was used; refer to Section 2.1.1 and Fig. 4 to Fig. 6 for framing details. 
The oriented strand boards were attached to the cold-formed steel framing with $4 \mathrm{~mm} \times 44 \mathrm{~mm}$ (\#8 $\times 1-3 / 4$ in.) self-tapping, bugle-headed sheet metal screws. The screw spacing was $102 \mathrm{~mm}$ (4 in.) on center at the panel edges and $305 \mathrm{~mm}$ (12 in.) on center in the field. The measured moisture content of specimens from three randomly sampled OSB boards was (7.36 \pm 0.02$)$ percent by mass. Three $2.7 \mathrm{~m} \times 1.2 \mathrm{~m}(9 \mathrm{ft} . \times 4 \mathrm{ft}$. $)$ panels were installed with vertical seams between the panels. Two $2.7 \mathrm{~m} \times 1.2 \mathrm{~m}(9 \mathrm{ft} . \times 4 \mathrm{ft}$. $)$ and two $2.7 \mathrm{~m} \times 0.6 \mathrm{~m}(9 \mathrm{ft} . \times 2 \mathrm{ft}$. $)$ Type $\mathrm{X}$ gypsum boards $16 \mathrm{~mm}(5 / 8 \mathrm{in}$.) thick were then attached to the oriented strand boards to meet 1-hour fire-resistance rating requirements per Underwriters Laboratory (UL) Design No. U423 (Underwriters Laboratory, 2017b); with the addition of wood panels as described in (Underwriters Laboratory, 2017a). The vertical seams between the oriented strand boards and the gypsum boards were staggered. The gypsum boards were attached to the oriented strand boards using $3.5 \mathrm{~mm} \times 41 \mathrm{~mm}(\# 6 \times 1-5 / 8$ in.) bugle-headed drywall screws. The screw spacing was $305 \mathrm{~mm}$ (12 in.) on center and positioned to avoid fastening to the framing. Drawings of the screw patterns can be found in the Appendices. To the authors' knowledge, the location of screws used to connect drywall to oriented strand boards is not covered by the building or fire codes and various practices are used in the field. In these tests, the authors elected not to attach the gypsum board through the oriented strand boards to the framing in order to maintain the $102 \mathrm{~mm}$ (4 in.) fastener spacing on the oriented strand boards panels and facilitate comparison with the gypsum-sheet steel composite panel sheathed walls. No drywall joint compound or paper tape was used on this side (unexposed side) of the wall.

The opposite side of the wall (fire exposed side) was sheathed using two $2.7 \mathrm{~m} \times 1.2 \mathrm{~m}(9 \mathrm{ft}$. $\times 4 \mathrm{ft}$.) and two $2.7 \mathrm{~m} \times 0.6 \mathrm{~m}(9 \mathrm{ft} . \times 2 \mathrm{ft}$. $)$ Type $X$ gypsum boards $16 \mathrm{~mm}(5 / 8 \mathrm{in}$.$) thick;$ except for Specimen OSB01NG which had no gypsum on this side of the wall. The vertical seams on the front and back of the wall were staggered by one stud spacing. The gypsum boards were attached using $3.5 \mathrm{~mm} \times 41 \mathrm{~mm}(\# 6 \times 1-5 / 8 \mathrm{in}$.) self-tapping, bugle-headed sheet metal screws. The screw spacing was $152 \mathrm{~mm}(6 \mathrm{in}$.) on center on the board perimeter and $305 \mathrm{~mm}$ (12 in.) on center in the field. The seams were sealed using a base coat of drywall joint compound and paper tape. The seams and fastener heads then covered with a skim coat of drywall joint compound.

The oriented strand board sheathed wall cross section is shown in Fig. 8.

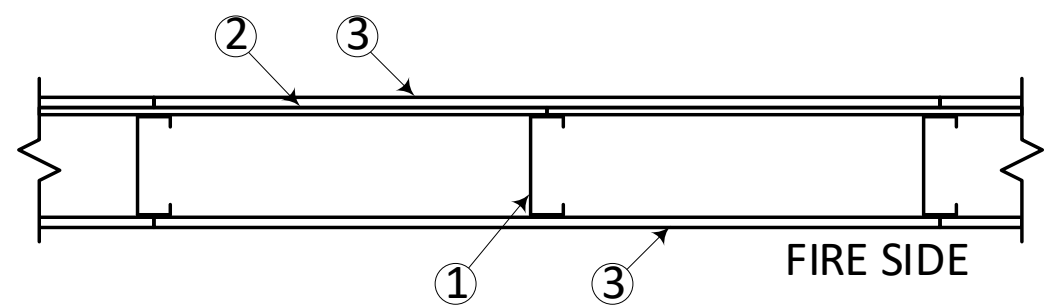

Fig. 8. Cross section of oriented strand board sheathed walls ( 1 - steel framing; 2 - oriented strand board; 3 - gypsum board).

OSB manufacturers recommend that a $3 \mathrm{~mm}$ (1/8 in.) gap be maintained between OSB panels to allow the panels to expand or shrink with changes in moisture content; see for example The Engineered Wood Association (The Engineered Wood Association, 2018). However, for interior studs with a flange width of $41 \mathrm{~mm}$ (1-5/8 in.) it was difficult to maintain a distance of 
$10 \mathrm{~mm}$ (3/8 in.), or more, between the screws and the panel edges ${ }^{5}$, which is the minimum allowable distance in the United States and Mexico per Section E1.4 of AISI S400-15/S1-16. Furthermore, it was observed during initial mechanical load tests that at an edge spacing of $10 \mathrm{~mm}$ (3/8 in.), the connections occasionally (fewer than $30 \%$ of the connections) failed by edge breakout of the OSB panel, rather than pull-through of the head through the OSB. For construction in Canada, Section E1.4 of AISI S400-15/S1-16 requires a larger edge spacing of $13 \mathrm{~mm}$ (1/2 in.). Because expansion and shrinkage of the OSB was not expected to play a significant role in the experiments and to obtain more consistent test-to-test shear capacity from the oriented strand board walls, the gap was eliminated and at $13 \mathrm{~mm}(1 / 2 \mathrm{in}$.) edge spacing was maintained in later tests. Specimens OSB01 and OSB03 had a $3 \mathrm{~mm}$ (1/8 in.) gap between the OSB panels and the screw to edge spacing was not controlled (Fig. 9a). All other tests with OSB panels had no gap and a $13 \mathrm{~mm}$ (1/2 in.) edge distance was maintained (Fig. $9 b)$.

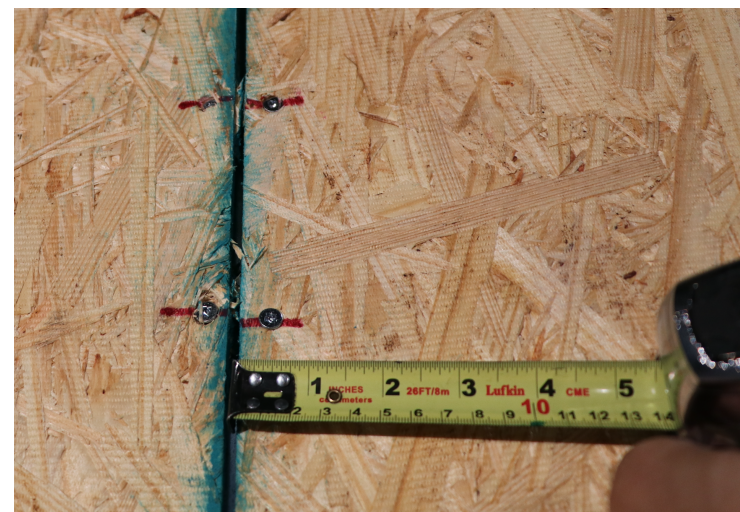

(a)

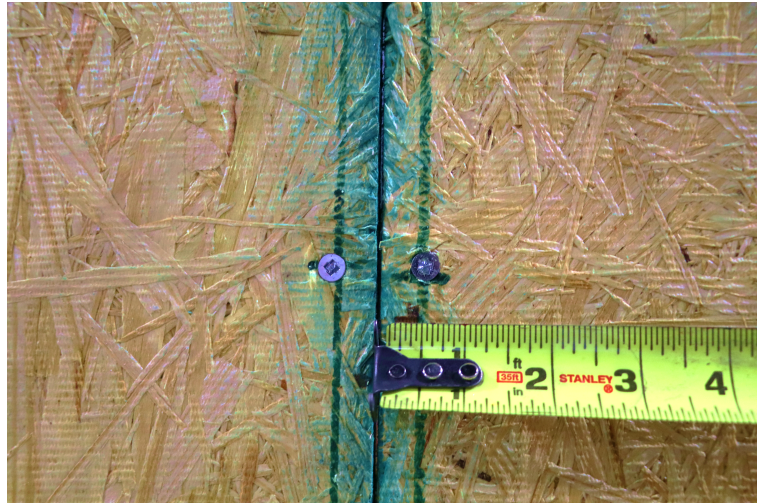

(b)

Fig. 9. Photographs of oriented strand board panel joint (a) with $3 \mathrm{~mm}(1 / 8 \mathrm{in}$.) gap and (b) without gap.

\subsubsection{Steel strap braced walls}

The steel strap braced walls were designed to achieve significant yielding of the straps before failure. Initially, the wall was designed with straps only on the side of the wall not exposed to fire (asymmetric bracing) using the same stud and track dimensions as for the sheathed walls (refer to Section 2.1.1). However, during the first test, S01a, the wall failed before the strap yielded due to a combination of buckling and torsional failure of the top track. Although this test was unsuccessful, the specimen detailing and test results for Specimen S01 are provided in the Appendices but are not discussed further in this report. The strap braced wall was redesigned using bracing on both sides of the wall (symmetric bracing) to eliminate the torsion. The symmetric bracing design is discussed below.

The nominal strength for shear $\left(V_{n}\right)$ of a strap braced wall can be calculated according to equation E3.3.1-1 in AISI S400-15/S1-16 as:

$$
V_{n}=T_{n} \cdot w / \sqrt{h^{2}+w^{2}}
$$

\footnotetext{
${ }^{5}$ The screw would often miss the stud, or the screw tip would deflect off the radiused corner of the stud and the screw would need to be reinstalled.
} 
where $w$ and $h$ are the length and the height of the wall, respectively, and $T_{n}$ is the nominal strength of the strap in yielding:

$$
T_{n}=A_{g} \cdot F_{y}
$$

where $A_{g}$ is the gross area of the flat strap and $F_{y}$ the yield stress of the flat strap. To keep the chord stud design the same as in the sheathed walls and to maintain a margin of safety in case of unexpected overstrength of the strap material, a strap width of $83 \mathrm{~mm}$ (3.25 in.) and thickness of $1.8 \mathrm{~mm}$ (0.0713 in.) was chosen; providing an $A_{g}$ of $150 \mathrm{~mm}^{2}\left(0.232 \mathrm{in}^{2}\right)$. Because there are straps on both sides of the wall, for calculation purposes one strap of double width providing an $A_{g}$ of $300 \mathrm{~mm}^{2}\left(0.463 \mathrm{in}^{2}\right)$ was assumed. For a design yield stress of the strap material of $345 \mathrm{MPa}(50 \mathrm{ksi})$ the resulting $T_{n}$ is $103 \mathrm{kN}$ (23.2 kip) and the nominal shear strength $\left(V_{n}\right)$ of the wall specimen per Eq. (6) is $82 \mathrm{kN}$ (18.5 kip). The expected strength can be obtained by multiplying the nominal strength $V_{n}$ by $R_{y}=1.1$, where $R_{y}$ is the ratio of expected strength and specified minimum tensile strength from Table A3.2-1 in AISI S400-15/S1-16:

$$
R_{y} \cdot V_{n}=1.1 \cdot 82 \mathrm{kN}=91 \mathrm{kN}(20.4 \mathrm{kip})
$$

and the maximum compression (or tension) force in the chord studs will be:

$$
\frac{\left(\Omega_{E} \cdot V_{n}\right) \cdot h}{\text { distance between anchor points }}=68 \mathrm{kN}(15.3 \mathrm{kip})
$$

Because the maximum design chord force is smaller than that for the gypsum-sheet steel composite panel sheathed walls $(68 \mathrm{kN}$ versus $111 \mathrm{kN})$, the same chord studs and bridging were used.

The specimen framing is shown in Fig. 10 and Fig. 11. A notable difference to the framing for the sheathed walls is that the top and bottom track size was increased to 600T150-68 (50); flange width of $38 \mathrm{~mm}$ (1-1/2 in.) and a thickness of $1.72 \mathrm{~mm}(0.068 \mathrm{in}$.) to increase the buckling strength. Furthermore, two additional $\varnothing 19 \mathrm{~mm}(3 / 4 \mathrm{in}$.) holes were drilled at each end of the top track outside of the chord stud to accommodate additional bolts to help distribute loads in the track near the gusset plates to the loading frame.

Load was transferred from the braces to the framing through gusset plates using screw fasteners; see Fig. 12 and Fig. 13. The gusset plates allowed for distributed force transfer into the framing and provided the required area to place the number of screw fasteners necessary to develop the yield strength of the strap. To ensure that the braces do not fail by fracture before they yield, per S400-15/S1-16 Section E3.4.1 the following conditions shall be met:

$$
\begin{aligned}
& \left(R_{t} \cdot F_{u}\right) /\left(R_{y} \cdot F_{y}\right) \geq 1.2 \\
& R_{t} \cdot A_{n} \cdot F_{u} \geq R_{y} \cdot A_{g} \cdot F_{y}
\end{aligned}
$$

where $R_{t}$ is the ratio of expected tensile strength and specified minimum tensile strength of the flat strap, $F_{u}$ is the ultimate strength of the flat strap, and $A_{n}$ is the net area of the flat strap. To determine the net area, it is necessary to first calculate the number of screw fasteners $(n)$ required to develop the expected yielding strength of the flat strap, which was used the following equation: 


$$
n=\frac{R_{y} \cdot A_{g} \cdot F_{y}}{P_{n v s} / \Omega}
$$

where $P_{n v s}$ is the nominal shear strength for a single screw reported by the manufacturer and the safety factor $\Omega=3.0$ per S400-15/S1-16 Section J4. Using the same $5 \mathrm{~mm} \times 19 \mathrm{~mm}(\# 10 \times$ $3 / 4$ in.) self-tapping, flat pan headed sheet metal screws used to connect the framing, for a $P_{n v s}$ $=6 \mathrm{kN}$ (1.29 kip), the require number of screws $n$ is 30 . Using 8 rows of 4 screws ( 32 screws total) exceeds the required number of screws, while maintaining the required screw spacing ( $3 d$, where $d$ is the nominal diameter of the screw) and edge distance (1.5d) per S400-15/S116 Section J4 and fulfilling Eq. (10) and Eq. (11) ${ }^{6}$.

A gusset plate with dimensions of $305 \mathrm{~mm} \times 305 \mathrm{~mm}(12$ in. $\times 12$ in.) was required to accommodate the connection between the strap and the gusset plate. The strap was positioned such that the centerline of the strap intersected the web of the back-to-back chord studs. A similar material to that used for the strap was selected with a strength of $345 \mathrm{MPa}(50 \mathrm{ksi})$ and a thickness of $1.72 \mathrm{~mm}(0.068 \mathrm{in}$.). The tension capacity of the gusset plates was checked using the theoretically effective cross-sectional area at the end of a connection limited by the Whitmore section (Whitmore, 1952). The number of screws connecting the gusset plates to the chord and track flanges was determined using the conservative assumption that the vertically placed screws carry the vertical component of the expected brace force, and the horizontal screws carry the horizontal component. Table 2 provides a summary of the number of screws for the gusset connections.

Table 2. Screw requirements for brace connections of the symmetric strap braced walls.

\begin{tabular}{rccc}
\hline Connection & $\begin{array}{c}\text { Expected strength } \\
\text { kN (kip) }\end{array}$ & \multicolumn{2}{c}{ Number of 5 mm (\#10) screws } \\
Required & Placed \\
\hline Strap-to-gusset & $57(12.7)$ & 30 & 32 \\
$\begin{array}{r}\text { Gusset-to-chord } \\
\text { (vertical) }\end{array}$ & $34(7.6)$ & 18 & 18 \\
$\begin{array}{r}\text { Gusset-to-track } \\
\text { (horizontal) }\end{array}$ & $45(10.2)$ & 24 & 24 \\
\hline
\end{tabular}

Both sides of the wall were sheathed with $16 \mathrm{~mm}(5 / 8 \mathrm{in}$.) thick Type $\mathrm{X}$ gypsum boards to meet 1-hour fire-resistance rating requirements per UL Design No. U423 (Underwriters Laboratory, 2017b). The vertical seams on the front and back of the wall were staggered by one stud spacing. The gypsum boards were attached using $3.5 \mathrm{~mm} \times 41 \mathrm{~mm}(\# 6 \times 1-5 / 8 \mathrm{in}$.) self-tapping, bugle-headed sheet metal screws. The screw spacing was $152 \mathrm{~mm}$ (6 in.) on center on the board perimeter and $305 \mathrm{~mm}$ (12 in.) on center in the field. No drywall joint compound or paper tape was used on the unexposed side of the wall. On the fire exposed side, the seams were sealed using a base coat of drywall joint compound and paper tape and the seams and fastener heads then covered with a skim coat of drywall joint compound.

The symmetric strap braced wall cross section is shown in Fig. 14. Drawings of the screw patterns can be found in the Appendices.

\footnotetext{
${ }^{6}$ The straps were pre-tensioned during installation to minimize slack in the strap; see S01R Data in Appendices.
} 


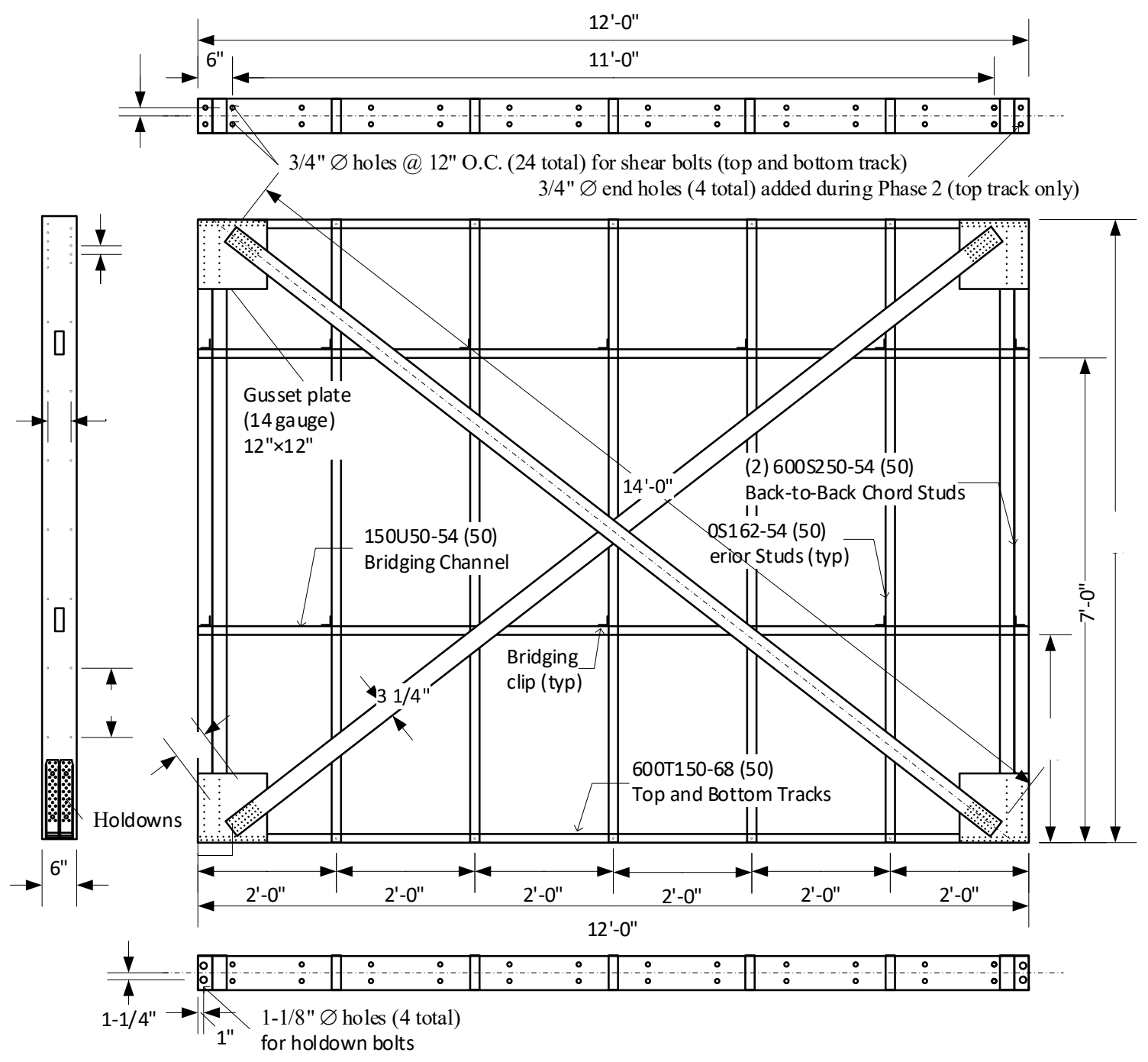

Fig. 10. Drawing of framing for the symmetric strap braced walls $(1 \mathrm{ft} .=30.5 \mathrm{~cm})$.

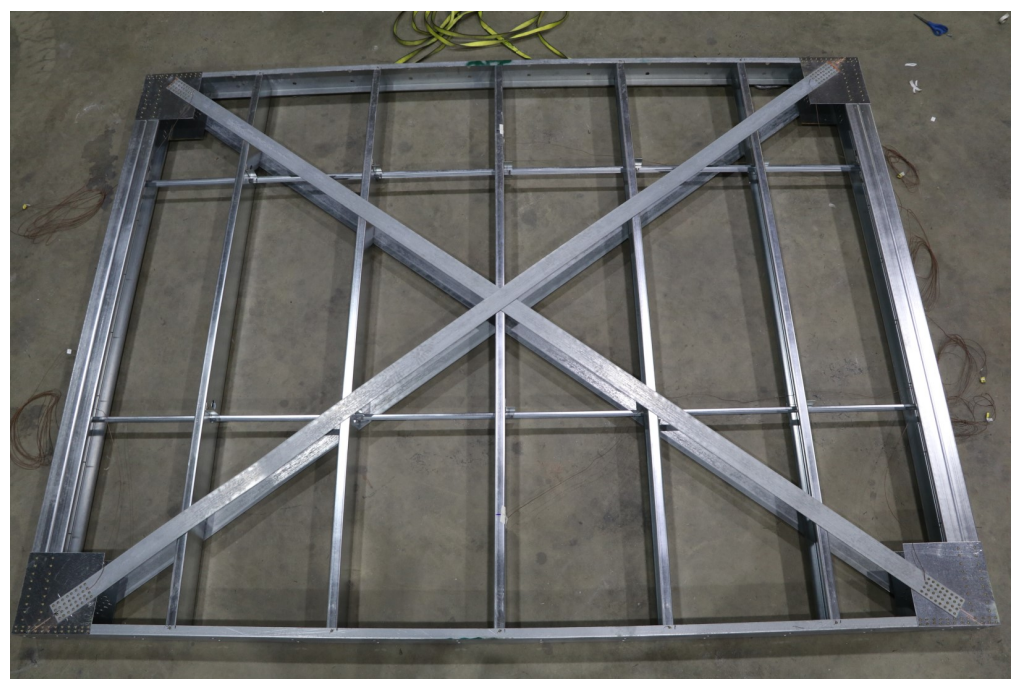

Fig. 11. Photograph of framing for the symmetric strap braced walls. 


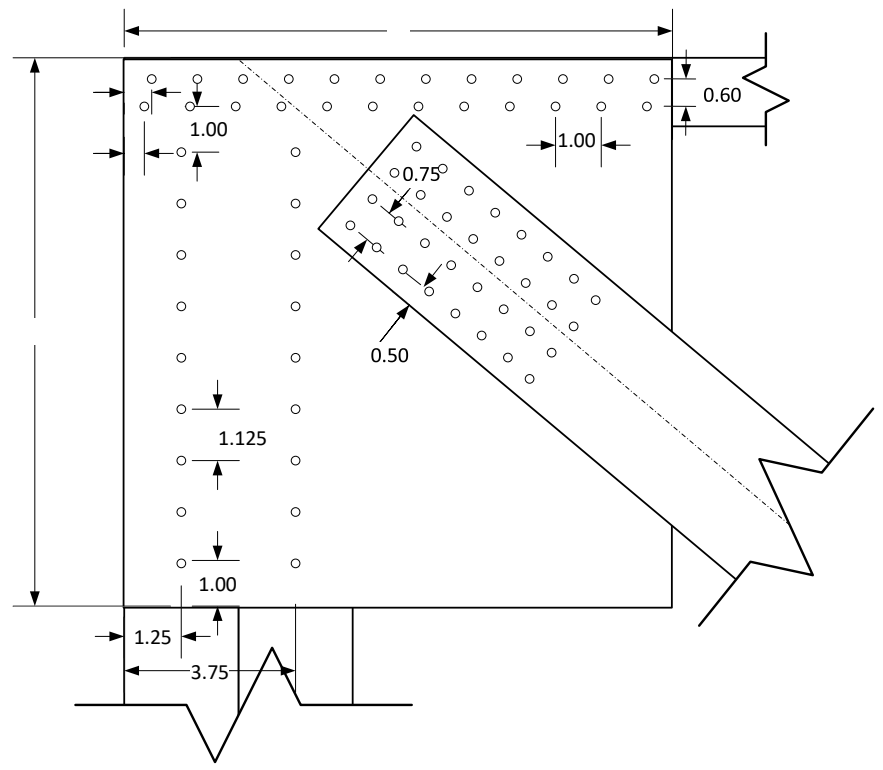

Fig. 12. Drawing of gusset detail for the symmetric strap braced walls (units in inches; 12 in. $=30.5 \mathrm{~cm})$.

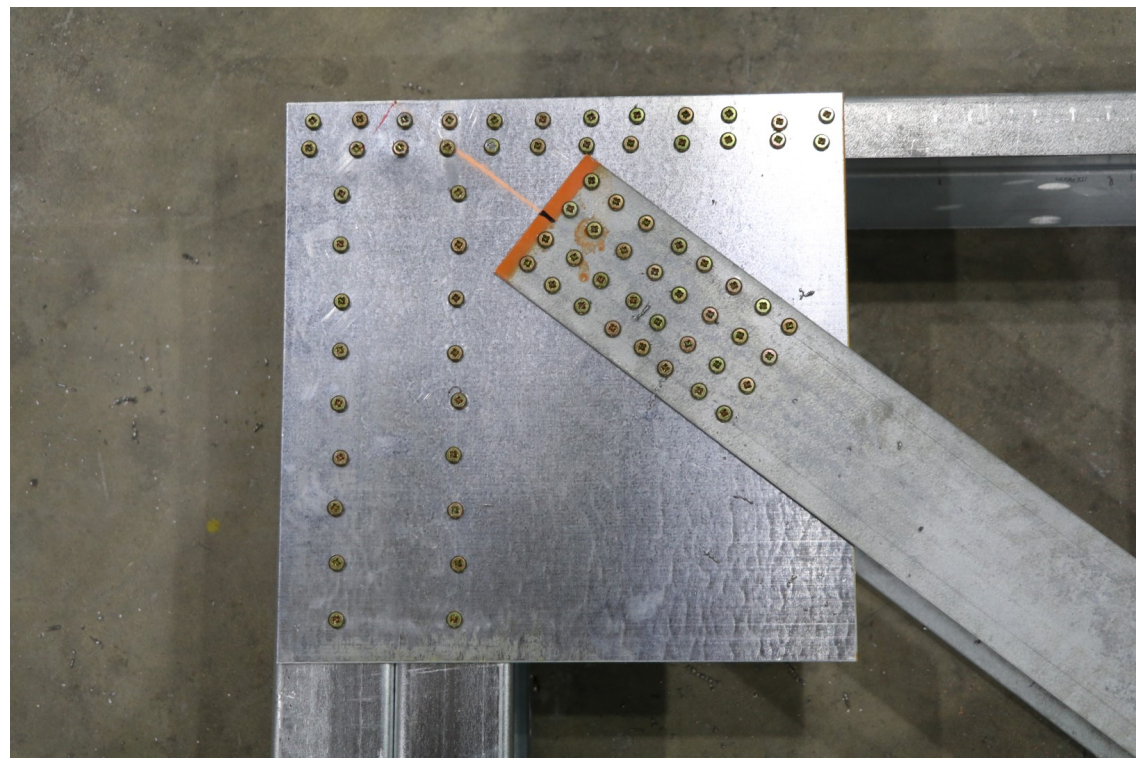

Fig. 13. Photograph of gusset detail for the symmetric strap braced walls.

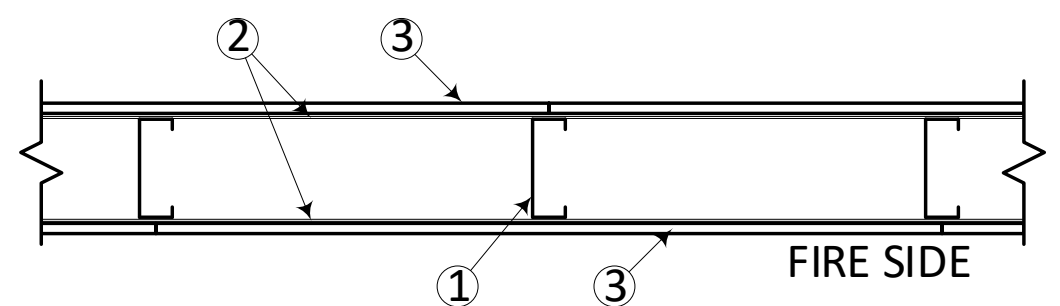

Fig. 14. Cross section of symmetric steel strap braced walls (1 - steel framing; 2 - steel strap; 3 - gypsum board). 


\subsubsection{Holdowns}

Uplift forces were transferred from the chord studs to the test frame by holdown devices. Simpson Strong-Tie S/HD10S holdowns with an allowable tension capacity of $54.4 \mathrm{kN}$ (12.2 kip) when used with back-to-back $1.37 \mathrm{~mm}$ (0.054 in.) thick studs were used (Simpson Strong-Tie, 2017). Two holdowns were attached to the bottom of each chord stud with twenty-two $6 \mathrm{~mm}$ (1/4 in.) diameter screws (Fig. 15). This provided a resistance larger than the design tension demand for any of the investigated walls.

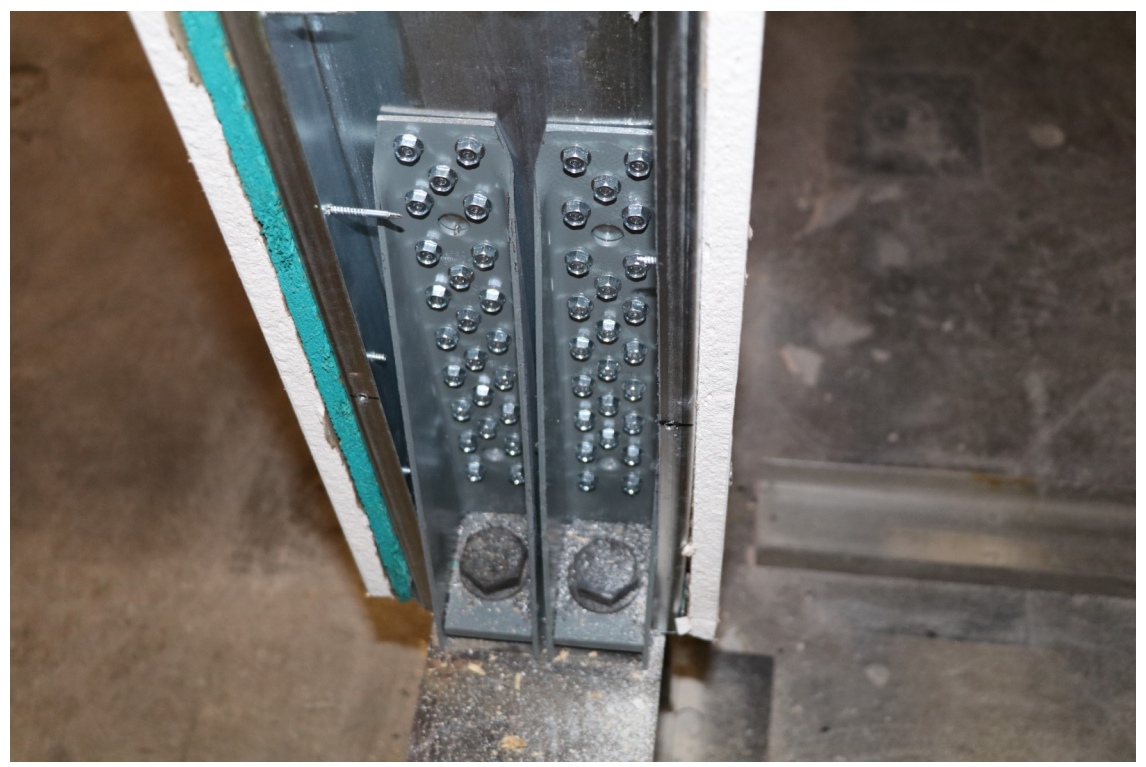

Fig. 15. Photograph of installed holdowns.

\subsection{Test Setup}

The experiments were conducted in the large test hall of the National Fire Research Laboratory (NFRL) at the National Institute of Standards and Technology (NIST) in Gaithersburg, Maryland (Fig. 16). The test setup was informed by ASTM E2126 Standard Test Methods for Cyclic (Reversed) Load Test for Shear Resistance of Vertical Elements of the Lateral Force Resisting Systems for Buildings (ASTM International, 2011), but deviations were made to accommodate a burn compartment on a rolling platform that was rolled into position and removed multiple times during testing. Specifically, this necessitated unobstructed access to

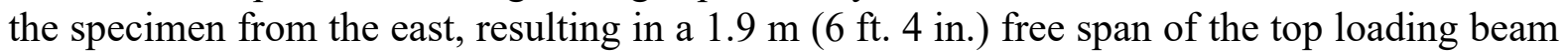
between the specimen and the actuator, and thermal protection of several portions of the mechanical loading setup.

For Specimen OSB_Kitchen, no mechanical loading was performed, so a stand-alone compartment fire test was conducted as described below. 


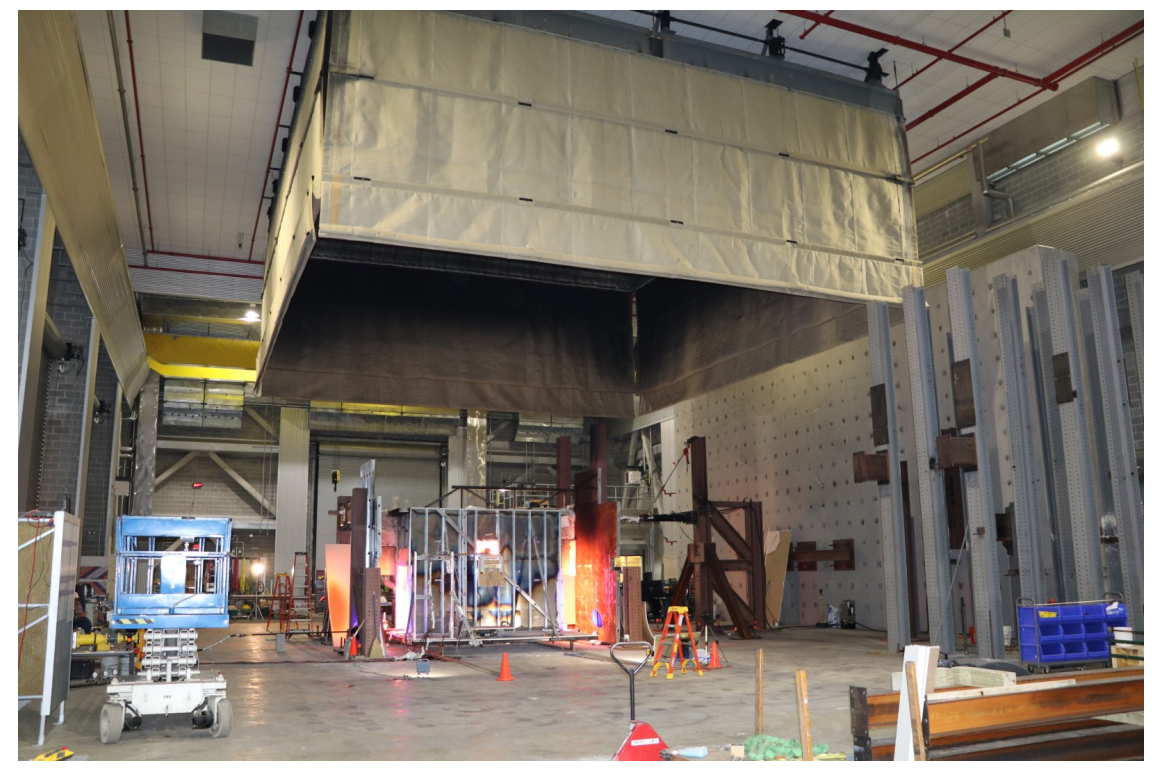

Fig. 16. Photograph of test setup in large test hall of the National Fire Research Laboratory.

\subsubsection{Mechanical}

The test specimens were loaded mechanically by holding the base of the wall fixed and applying a prescribed in-plane deformation to the top of the wall. Out-of-plane movement of the wall was limited by four steel guide frames placed perpendicular to the wall. Fig. 17 to Fig. 21 provide an overview of the test setup with critical dimensions for the erection of the setup indicated. The reaction frame, guide frames and the bottom beam $(\mathrm{W} 16 \times 26)$ were secured to the strong floor using high-strength rods tensioned to $445 \mathrm{kN}$ (100 kips) each.

In Phase 1 (Hoehler and Smith, 2016) and for the first three specimens tested in Phase 2 (SB01, S01, and S02), the top loading beam consisted of a MC6 $\times 15.3$ steel channel stiffened against vertical bending at the actuator end using a W6 $\times 12$ steel section. However, due to large vertical deformations observed during these tests, the top loading beam was further stiffened in bending using a truss as shown in Fig. 22. The friction between the top loading beam and the guide frames was reduced using Polytetrafluoroethylene (PTFE) glides (Fig. 23).

The wall was attached to the bottom beam as shown in Fig. 24 by two rows of $16 \mathrm{~mm}(5 / 8 \mathrm{in}$.) A325 structural bolts (24 total) each pretensioned to $162 \mathrm{Nm}$ (120 ft-lbs). Nonskid tape was used between the beam and the cold-formed steel track to provide more uniform friction. Each holdown at the bottom of the chord studs (Fig. 15) was attached to the bottom beam using a 22 mm (7/8 in.) diameter A325 structural bolt (4 total) pretensioned to $542 \mathrm{Nm}$ (400 ft-lbs). The attachment of the top track to the loading beam was the same as at the bottom track, however, no holdowns were present. For all braced walls, except Specimen S01, two additional $16 \mathrm{~mm}$ (5/8 in.) A325 structural bolts were placed outside the web of each chord stud at the top to improve load transfer as discussed in Section 2.1.3.

Mechanical load was applied to the specimen using a servo-hydraulically controlled actuator (MTS Series 201) with a load capacity of $240 \mathrm{kN}$ (54 kips) in tension and $365 \mathrm{kN}$ (82 kips) in compression. The maximum stroke of the actuator was $760 \mathrm{~mm}$ (30 in.). The actuator was controlled using a MTS Flextest 100 controller with 793.00 System Software and 793.10 MultiPurpose TestWare. 


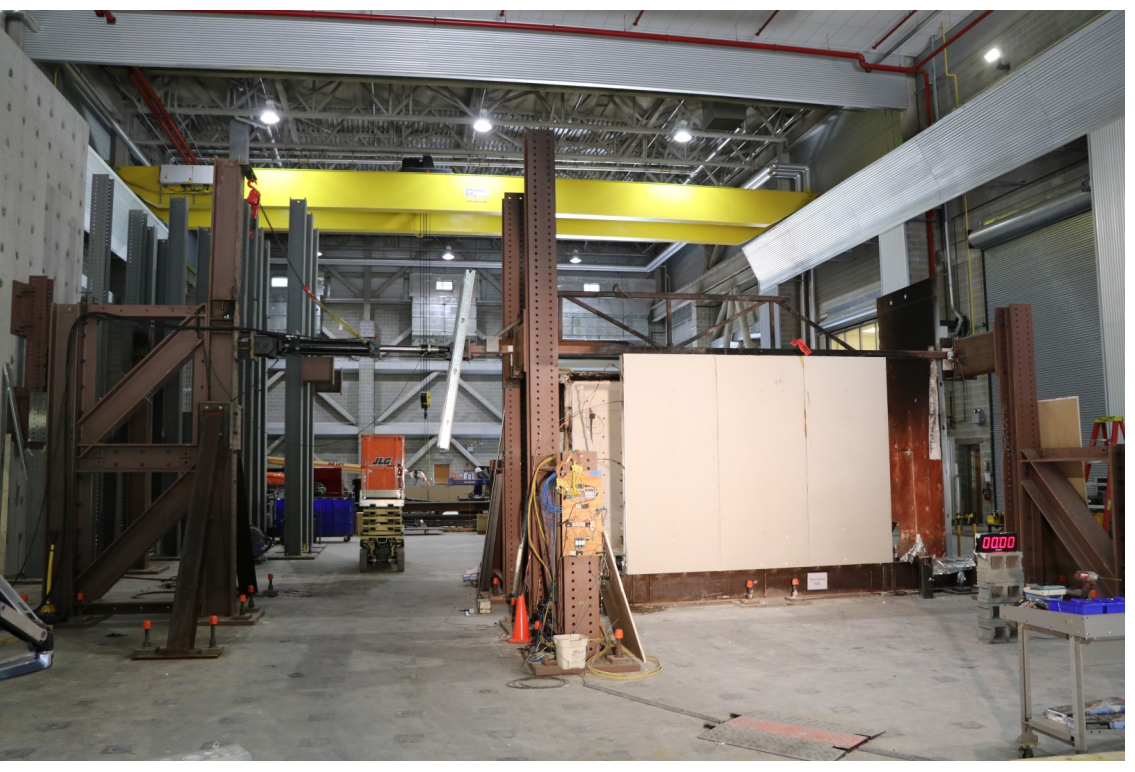

Fig. 17. Photograph of mechanical loading setup looking east.

\section{HOOD SKIRT (lower than actual height)}

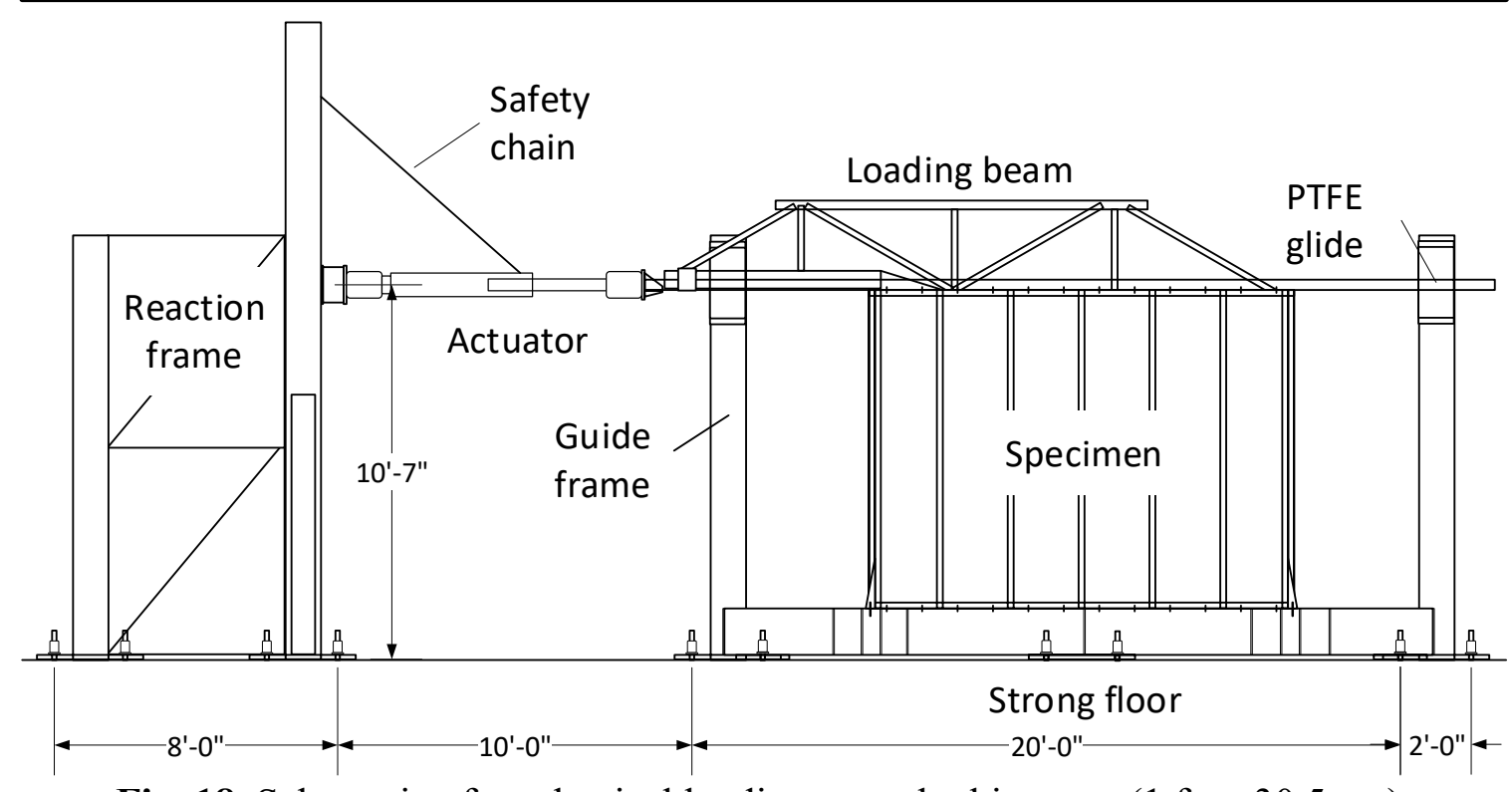

Fig. 18. Schematic of mechanical loading setup looking east $(1 \mathrm{ft} .=30.5 \mathrm{~cm})$. 


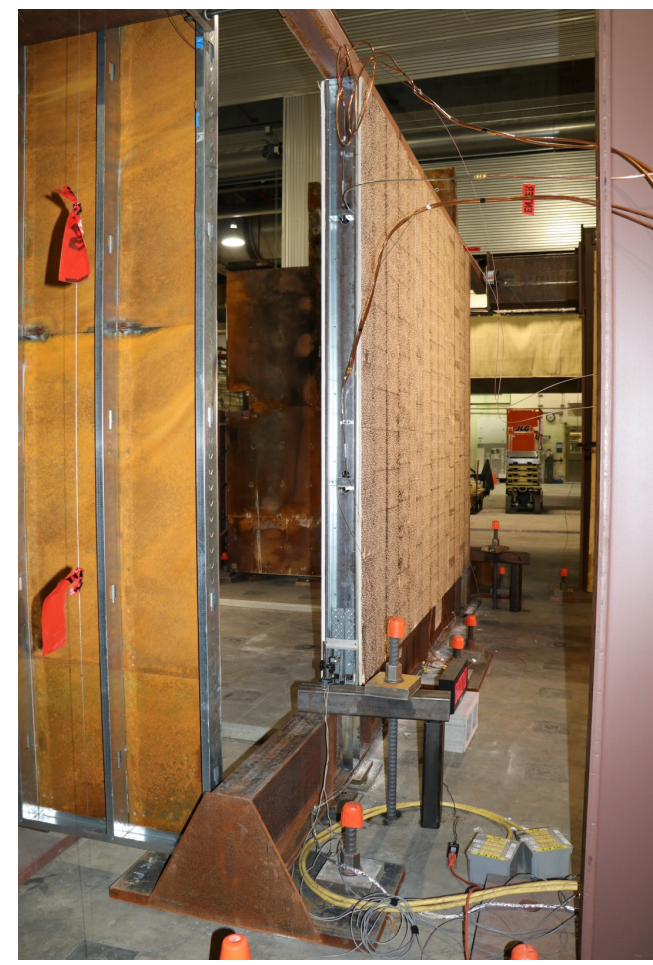

Fig. 19. Photograph of mechanical loading setup looking south.

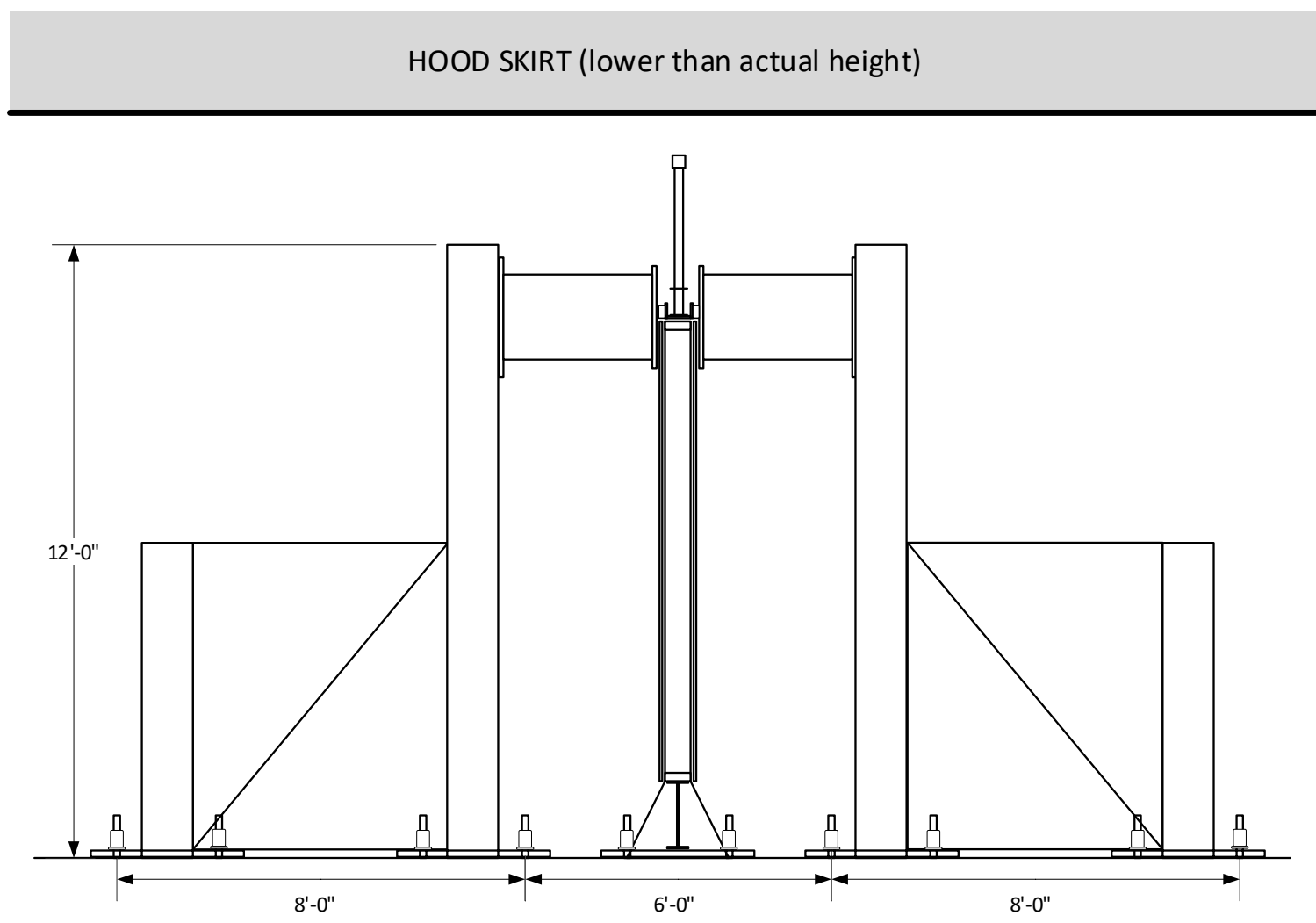

Fig. 20. Schematic of mechanical loading setup looking south $(1 \mathrm{ft} .=30.5 \mathrm{~cm})$. 


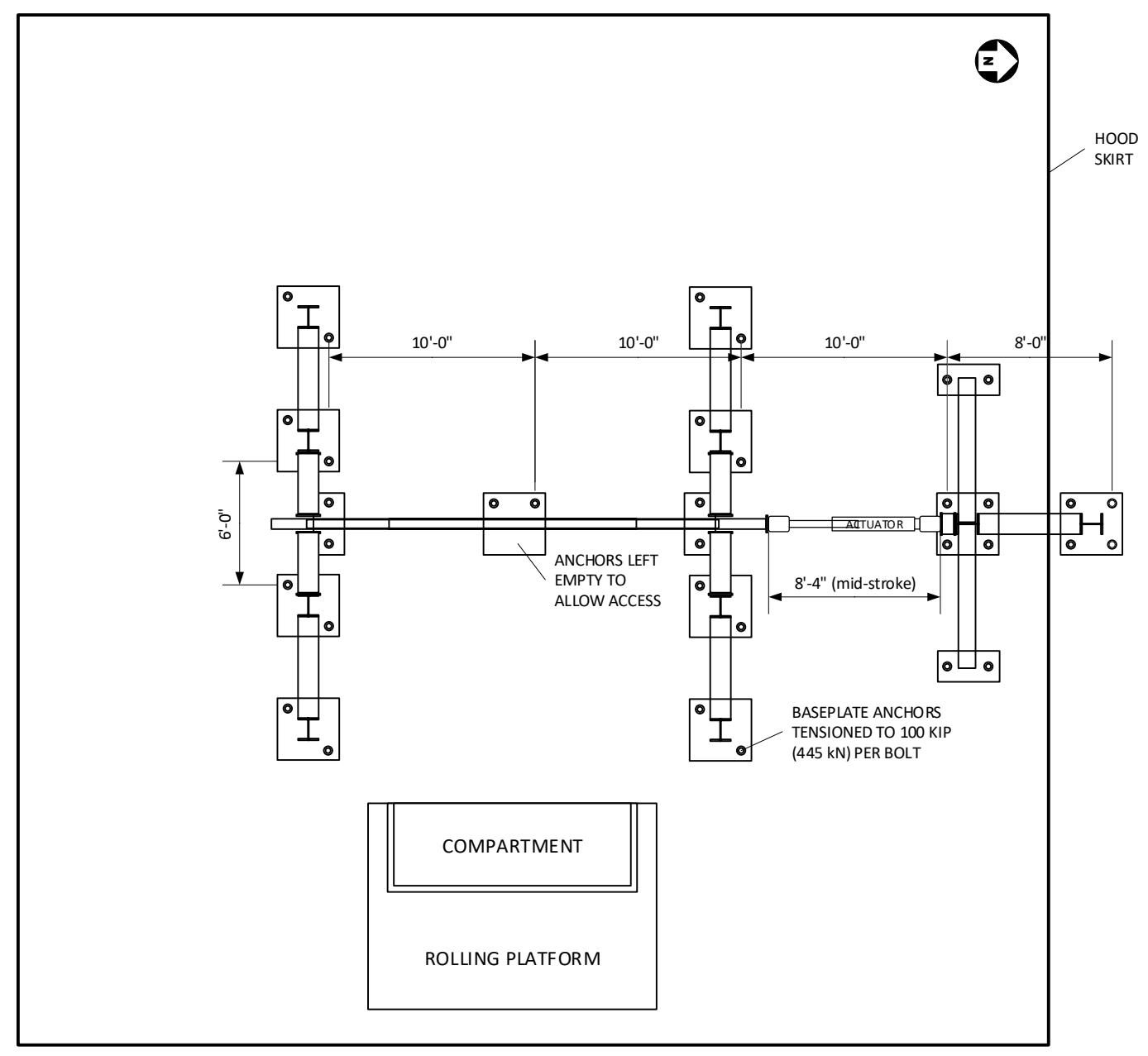

Fig. 21. Schematic of mechanical loading setup plan view $(1 \mathrm{ft} .=30.5 \mathrm{~cm})$.

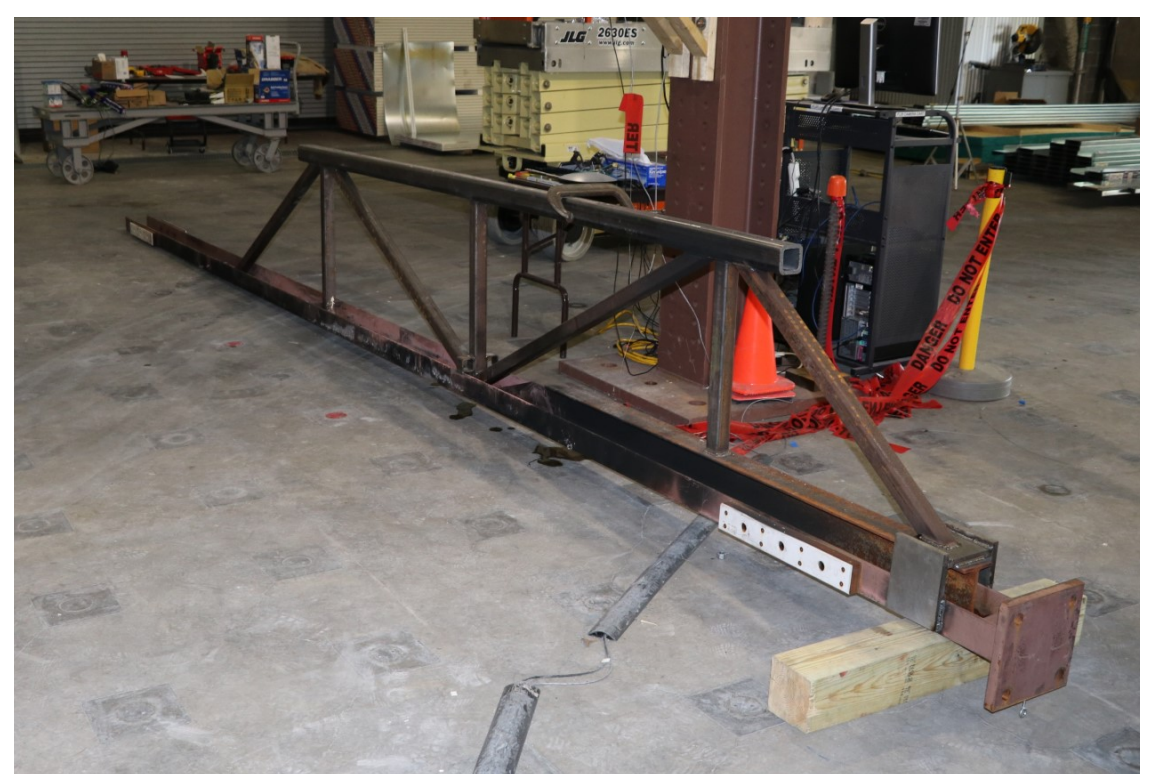

Fig. 22. Photograph of stiffened top loading beam. 


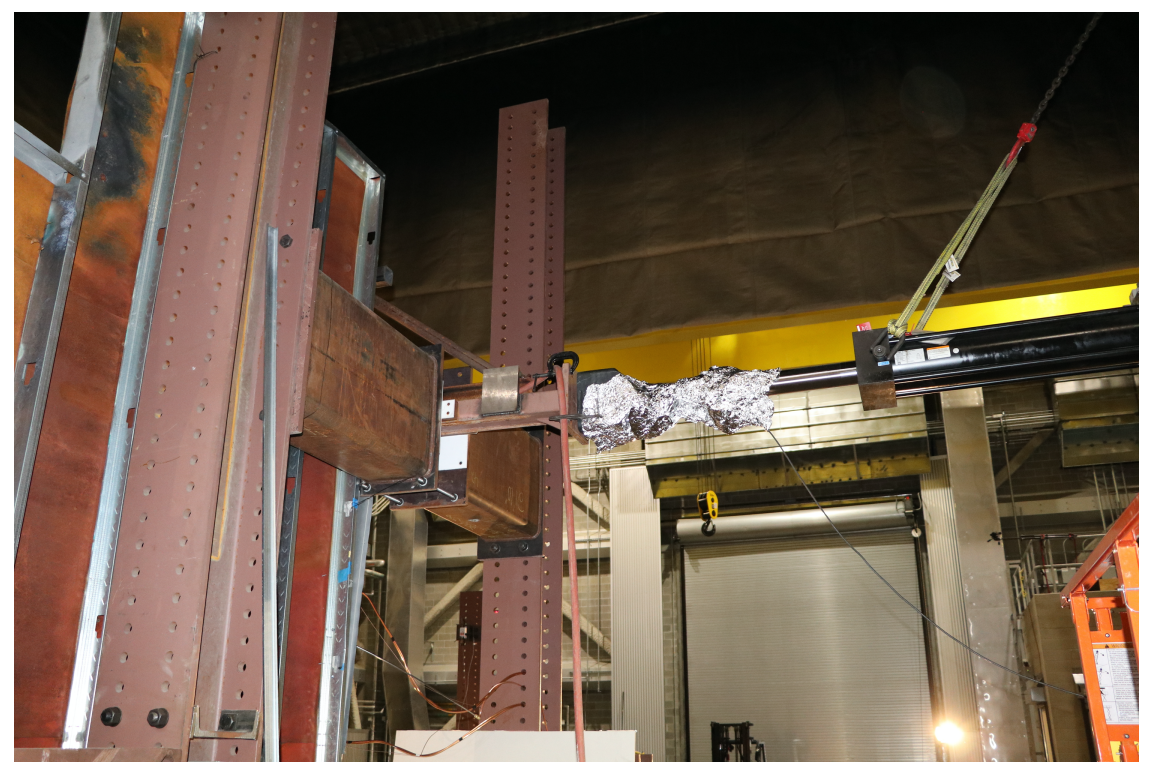

Fig. 23. Photograph of PTFE glides at actuator to limit out-of-plane movement.

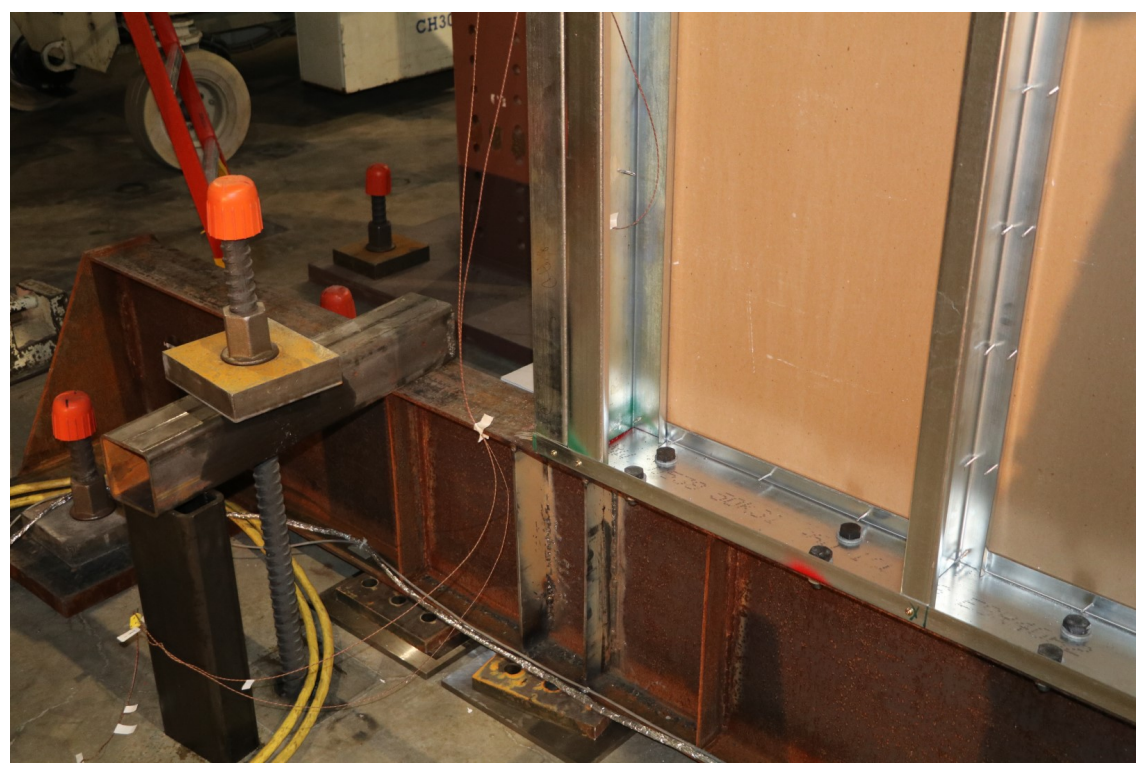

Fig. 24. Photograph of connection of bottom track to the test frame. 


\subsubsection{Fire}

For all specimens subjected to fire loading except for Specimen OSB_Kitchen, the thermal load was provided by a natural gas diffusion burner located in a three-sided compartment that could be rolled up and positioned against the specimen and removed as required. For Specimen OSB_Kitchen, a separated compartment (fixed location) was built adjacent to the test wall and furnished to simulate a typical kitchen.

\section{Natural gas fueled fire compartment}

Fig. 25 shows photographs of the constructed compartment and Fig. 26 provides key dimensions. Cold-formed steel framing sheathed with sheet metal was used to provide the structural support. The inside of the compartment was lined with two layers of thermal ceramic fiber blanket each $25 \mathrm{~mm}$ ( 1 in.) thick attached with insulation fasteners to the sheet metal. The side of the compartment that mated with the test specimen was also lined with thermal ceramic blanket to provide a seal against smoke and flame leakage. Two vents approximately $1.7 \mathrm{~m}$ tall $\times 1.2 \mathrm{~m}$ wide $(5 \mathrm{ft} .6$ in. $\times 4 \mathrm{ft}$.) each were located at the ends of the compartment. The height of the vents was chosen to create an upper gas layer similar in depth to that expected for in the prototype kitchen fire. A window made of fused silica glass was placed in the back wall of the compartment to allow viewing of the test specimen.

The natural gas diffusion burner is shown in Fig. 27. Gas entered the burner near the bottom, filled the burner cavity and percolated through a $25 \mathrm{~mm}$ (1 in.) thick layer of thermal ceramic fiber blanket to distribute the gas. Partway through the test series, an additional $150 \mathrm{~mm}(6 \mathrm{in}$.) wide by $25 \mathrm{~mm}$ ( $1 \mathrm{in}$.) thick gasket of thermal ceramic fiber blanket was added at the edge of the burner and weighed down with steel weights to prevent gas leakage at the edges of the burner as the blanket shrank during repeated heating and cooling cycles. The top edge of the burner was water cooled to reduce distortion of the burner during heating. The gas mass flow rate to the burner was measured using a positive displacement rotary flow meter, pressure gauge and thermistor. The energy value of the natural gas was determined using gas composition measured by an in-line gas chromatograph.

Fig. 28 shows the compartment rolled up against the test specimen. To reduce thermal bowing of the top loading beam and control the temperature of the PTFE glide plates during the fire, water was flowed through the channel (Fig. 29).

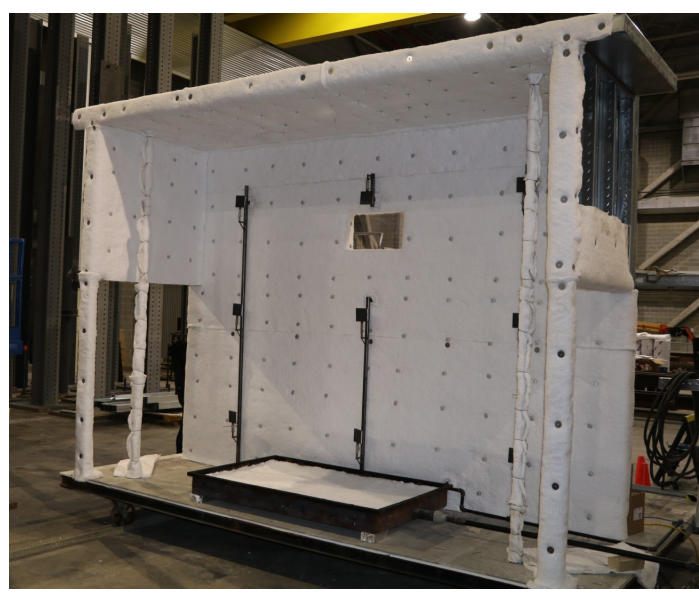

(a)

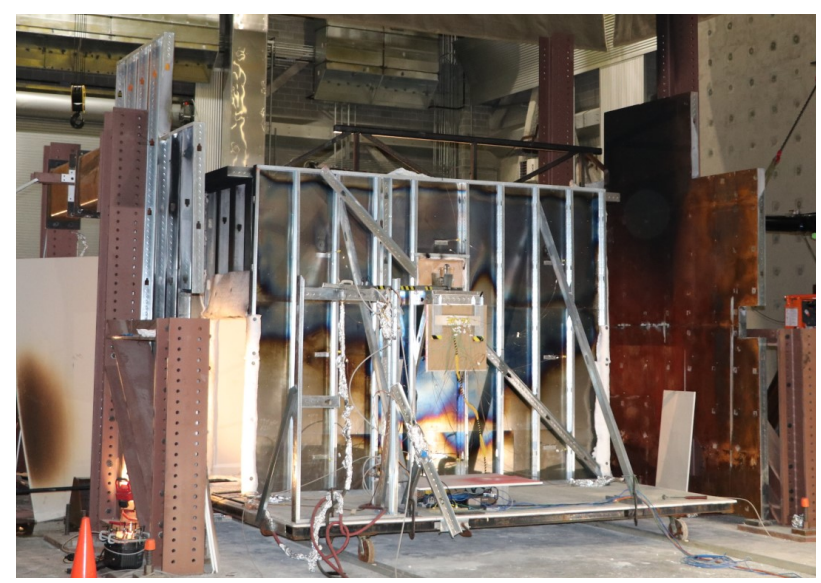

(b)

Fig. 25. Photographs of compartment for natural gas fueled fires: (a) front; (b) back. 

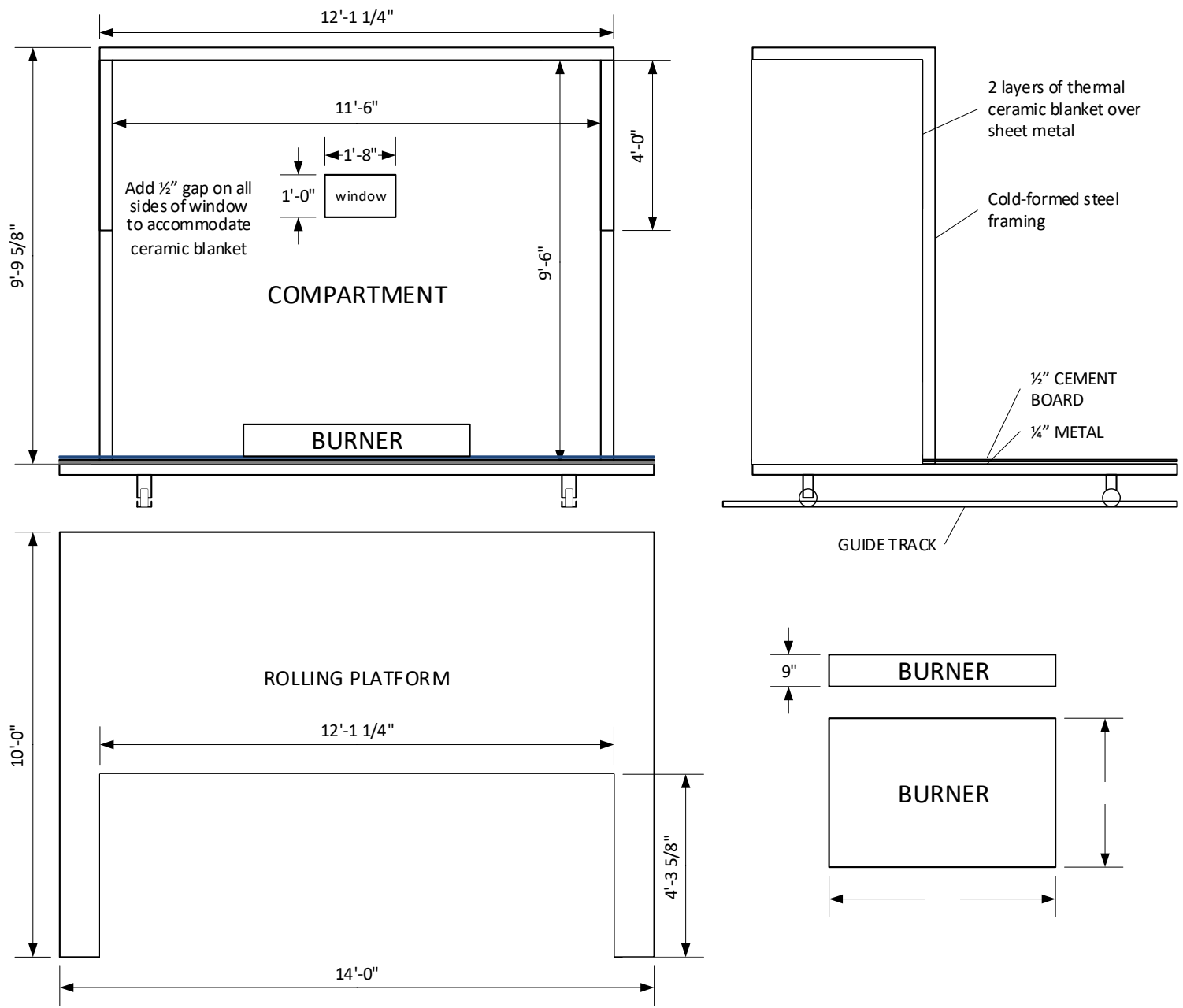

Fig. 26. Compartment dimensions for natural gas fueled fires $(1 \mathrm{ft} .=30.5 \mathrm{~cm})$.

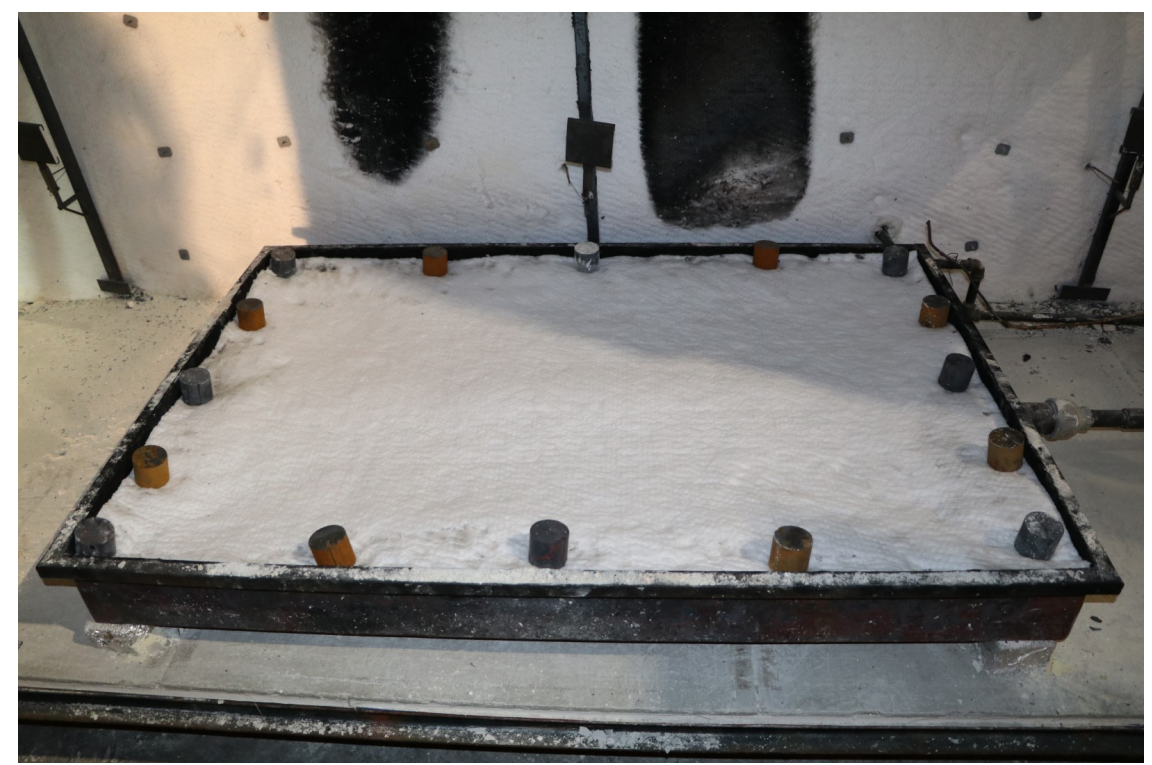

Fig. 27. Photograph of burner with cylindrical weights around the edge. 


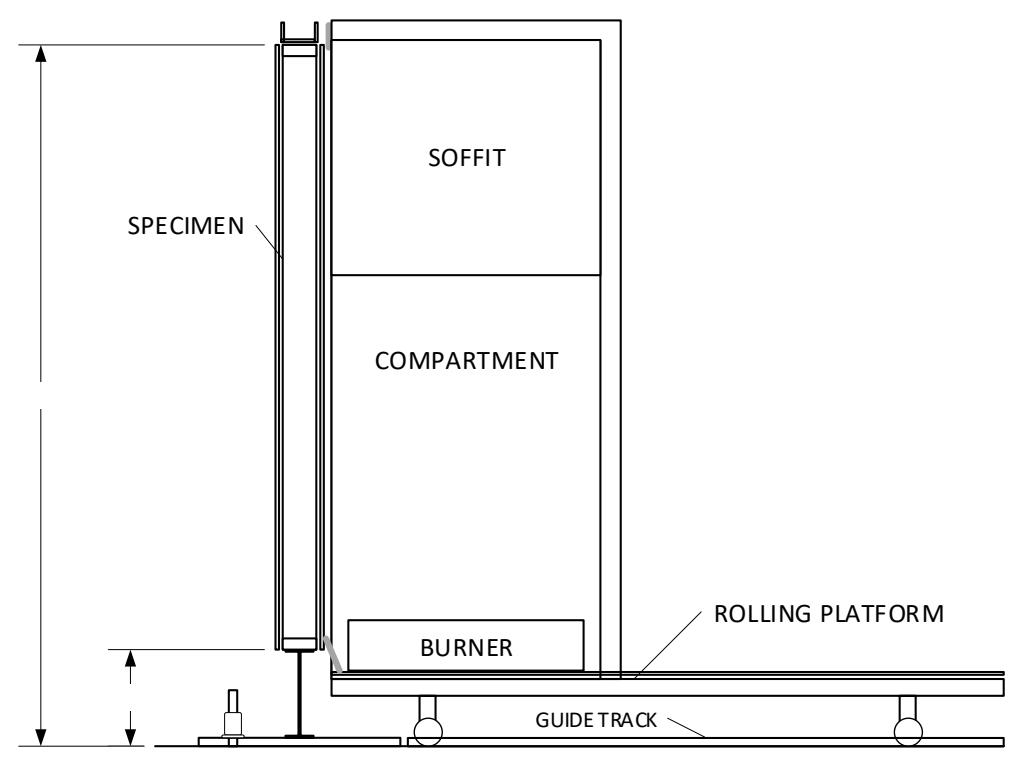

Fig. 28. Schematic cross section of burn compartment against wall $(1 \mathrm{ft} .=30.5 \mathrm{~cm})$.

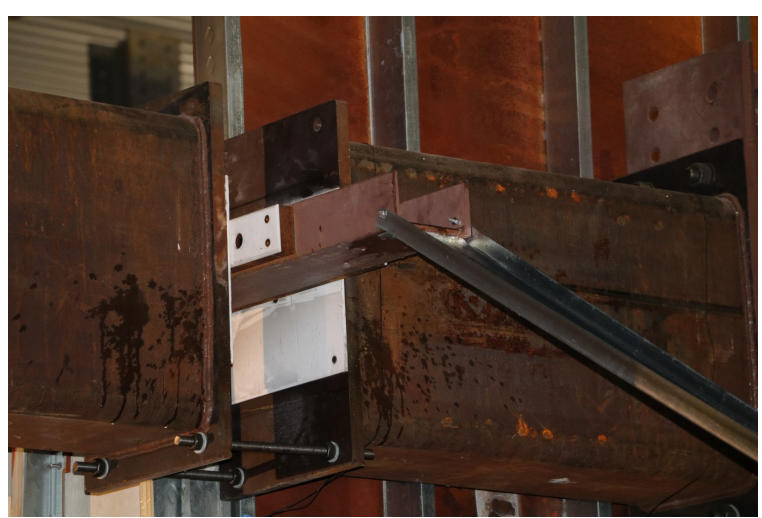

(a)

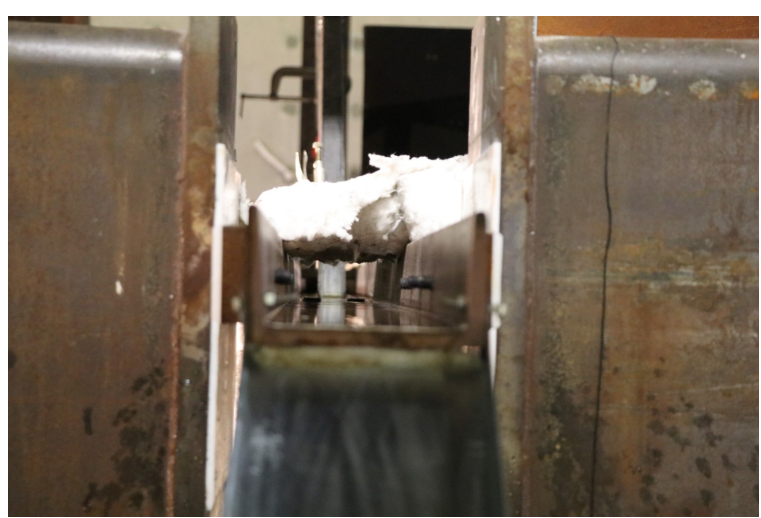

(b)

Fig. 29. Photographs of water cooling of top load beam: (a) connection between channel and drain ramp; (b) view along channel with water flowing.

Kitchen furnishing fire compartment

The three-sided compartment used to test Specimen OSB_Kitchen was constructed using coldformed steel framing lined with two layers of $16 \mathrm{~mm}(\overline{5} / 8 \mathrm{in}$.) thick Type X gypsum board (Fig. 30). The seams of the gypsum layers were staggered, and the innermost layer was sealed using a base coat of drywall joint compound and paper tape. The seams and fastener heads were then covered with a skim coat of drywall joint compound. The interior of the rectangular compartment was $2.81 \mathrm{~m}$ tall by $3.56 \mathrm{~m}$ wide by $2.83 \mathrm{~m}$ deep $(9 \mathrm{ft} .4 \mathrm{in} . \times 11 \mathrm{ft} .8 \mathrm{in} . \times 9 \mathrm{ft}$. 3 in.). A single opening $1.98 \mathrm{~m}$ tall by $1.62 \mathrm{~m}$ wide $(6 \mathrm{ft} .6$ in. $\times 5 \mathrm{ft} .4$ in.) was centered at the front of the compartment; opposite the test wall specimen. This provided a ventilation factor of $0.08 \mathrm{~m}^{1 / 2}$; defined as $A_{O} \sqrt{H_{O}} / A_{t}$, where $A_{O}$ and $H_{O}$ are the area $\left(\mathrm{m}^{2}\right)$ and height $(\mathrm{m})$ of the opening and $A_{t}$ is the total area $\left(\mathrm{m}^{2}\right)$ of all compartment interior boundary surfaces. The design of the test specimen that comprised the fourth wall of the compartment was as described in Section 2.1.2. The fuel load in the compartment is described below. 


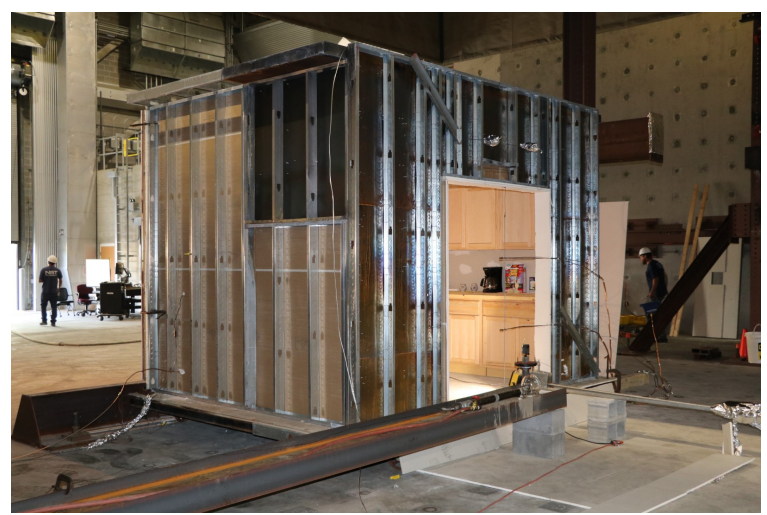

(a)

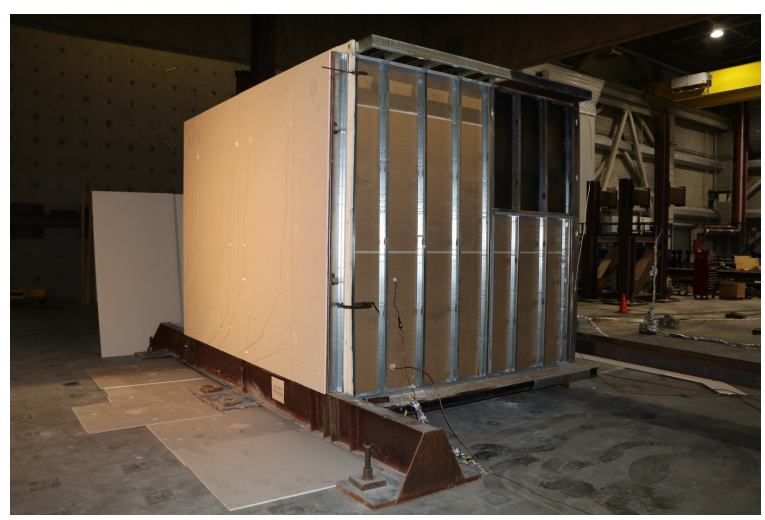

(b)

Fig. 30. Photograph of exterior of the kitchen compartment: (a) front; (b) rear with wall specimen in place.

\subsection{Cyclic Loading Protocol}

ASTM E2126-11 (ASTM International, 2011) Method C (CUREE Basic Loading Protocol) was used with a reference deformation $\Delta$ based on expected story drift ratios (SDR) for each wall at peak load. The reference deformations were selected to be $1.5 \%$ SDR and $2.5 \%$ SDR for the sheathed and braced walls, respectively. The loading procedure involves displacement cycles grouped in steps at incrementally increasing displacement levels (Fig. 31). The loading history starts with six small $(0.05 \cdot \Delta)$, equal-amplitude cycles. Subsequently, each step consists of a primary cycle with amplitude expressed as a fraction (percent) of the reference deformation $\Delta$ and subsequent trailing cycles with amplitude of $75 \%$ of the primary cycle. Four combinations (patterns) of primary and trailing cycles are prescribed. The rate of displacement was $1.524 \mathrm{~mm} / \mathrm{s}(0.06 \mathrm{in} . / \mathrm{s})$ and $2.54 \mathrm{~mm} / \mathrm{s}(0.1 \mathrm{in} . / \mathrm{s})$ for the sheathed and braced walls, respectively. These rates minimized inertial influences while maintaining efficient test durations; 36 min and 51 min for the sheathed and braced walls, respectively. Sinusoidal cycles (True sine with absolute end level) were used with the first excursion (positive) putting the actuator in tension. Before the start of a test, the actuator was brought into contact with the loading beam and the bolts were tightened while the operator kept the load under $1.3 \mathrm{kN}$ (300 lbf). Once the bolts were tightened, the actuator was moved in displacement control until the load was back to zero and the displacement was zeroed. The amplitude increments expressed as percent $\Delta$, absolute amplitude, and drift - along with the cycling frequency and step duration are given in Table 3 and Table 4.

Damage Level 1 and Damage Level 3 (Level 2 was deemed unnecessary) were selected based on test data (Ayhan et al., 2018) and judgement to achieved displacements intended to represent damage in earthquakes smaller and larger than the Design Earthquake, respectively. Damage Level 1 was $0.45 \%$ and $0.50 \%$ SDR for the sheathed and braced walls, respectively. Damage Level 3 was $1.50 \%$ and $1.75 \%$ SDR for the sheathed and braced walls, respectively. Before the fire, the trailing cycles at a given Damage Level were completed. After the fire, cycling was restarted at the primary cycle for that Damage Level. 


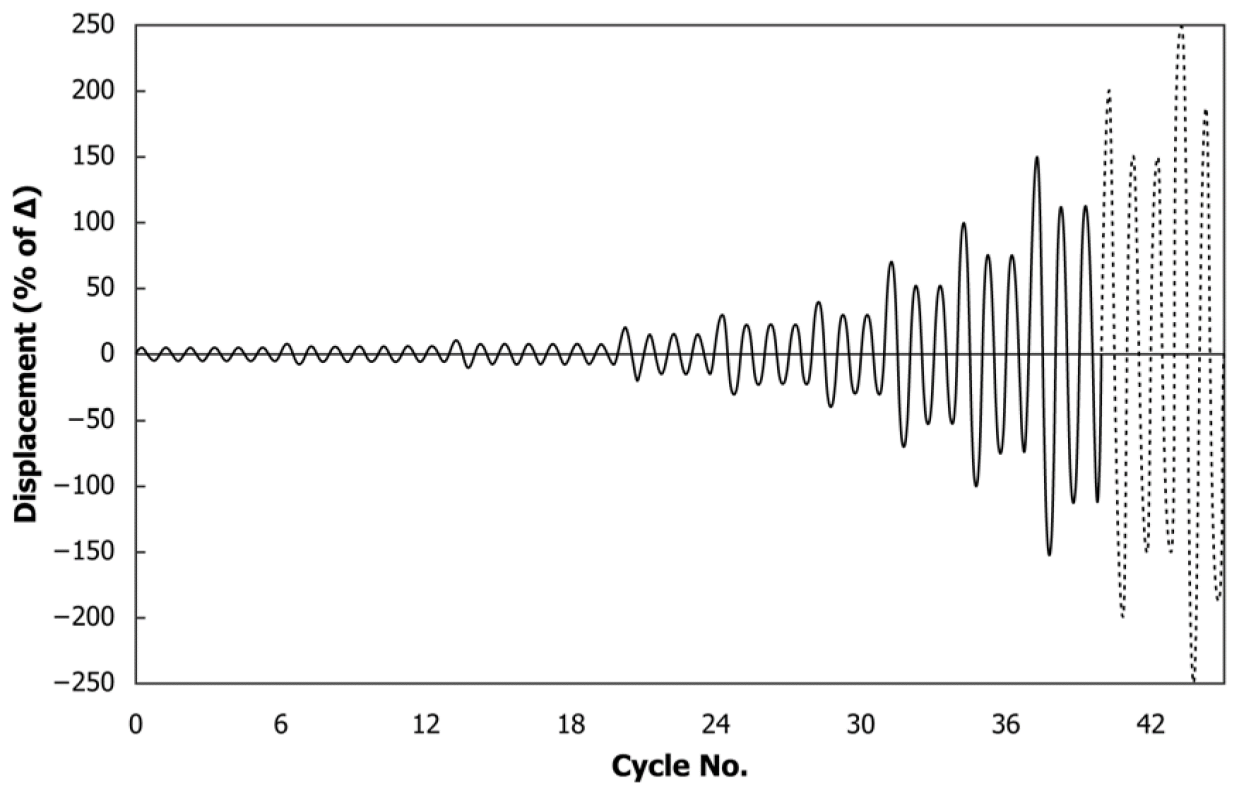

Fig. 31. Cyclic displacement pattern (Test Method C) from ASTM E2126-11. 
Table 3. Amplitude of primary cycles and step durations for sheathed walls.

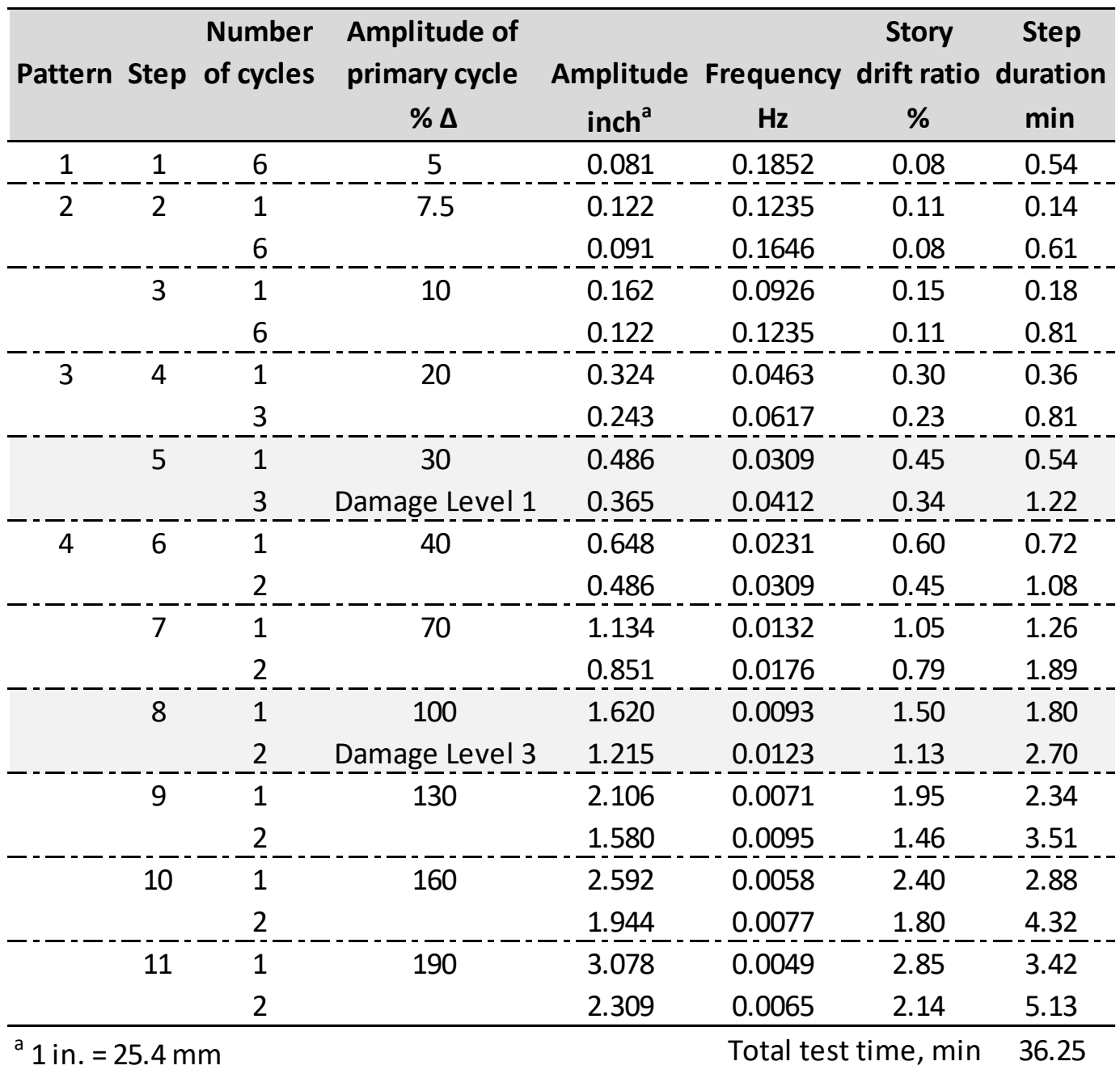


Table 4. Amplitude of primary cycles and step durations for strap braced walls.

\begin{tabular}{|c|c|c|c|c|c|c|c|}
\hline Pattern & Step & $\begin{array}{l}\text { Number } \\
\text { of cycles }\end{array}$ & $\begin{array}{c}\text { Amplitude of } \\
\text { primary cycle } \\
\% \Delta\end{array}$ & $\begin{array}{c}\text { Amplitude } \\
\text { inch }^{\mathrm{a}}\end{array}$ & $\begin{array}{c}\text { Frequency } \\
\mathrm{Hz}\end{array}$ & $\begin{array}{c}\text { Story } \\
\text { drift ratio } \\
\% \\
\end{array}$ & $\begin{array}{c}\text { Step } \\
\text { duration } \\
\text { min }\end{array}$ \\
\hline 1 & 1 & 6 & 5 & 0.135 & 0.1852 & 0.13 & 0.54 \\
\hline \multirow[t]{4}{*}{2} & 2 & 1 & 7.5 & 0.203 & 0.1235 & 0.19 & 0.14 \\
\hline & & 6 & & 0.152 & 0.1646 & 0.14 & 0.61 \\
\hline & 3 & 1 & 10 & 0.270 & 0.0926 & 0.25 & 0.18 \\
\hline & & 6 & & 0.203 & 0.1235 & 0.19 & 0.81 \\
\hline \multirow[t]{4}{*}{3} & 4 & 1 & 20 & 0.540 & 0.0463 & 0.50 & 0.36 \\
\hline & & 3 & Damage Level 1 & 0.405 & 0.0617 & 0.38 & 0.81 \\
\hline & 5 & 1 & 30 & 0.810 & 0.0309 & 0.75 & 0.54 \\
\hline & & 3 & & 0.608 & 0.0412 & 0.56 & 1.22 \\
\hline \multirow[t]{2}{*}{4} & 6 & 1 & 40 & 1.080 & 0.0231 & 1.00 & 0.72 \\
\hline & & 2 & & 0.810 & 0.0309 & 0.75 & 1.08 \\
\hline \multirow[t]{4}{*}{ 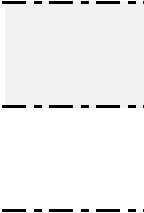 } & 7 & 1 & 70 & 1.890 & 0.0132 & 1.75 & 1.26 \\
\hline & & 2 & Damage Level 3 & 1.418 & 0.0176 & 1.31 & 1.89 \\
\hline & 8 & 1 & 100 & 2.700 & 0.0093 & 2.50 & 1.80 \\
\hline & & 2 & & 2.025 & 0.0123 & 1.88 & 2.70 \\
\hline \multirow{4}{*}{ 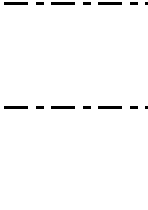 } & 9 & 1 & 140 & 3.780 & 0.0066 & 3.50 & 2.52 \\
\hline & & 2 & & 2.835 & 0.0088 & 2.63 & 3.78 \\
\hline & 10 & 1 & 180 & 4.860 & 0.0051 & 4.50 & 3.24 \\
\hline & & 2 & & 3.645 & 0.0069 & 3.38 & 4.86 \\
\hline \multirow{4}{*}{ 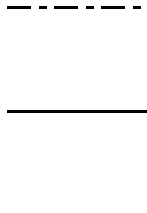 } & 11 & 1 & 220 & 5.940 & 0.0042 & 5.50 & 3.96 \\
\hline & & 2 & & 4.455 & 0.0056 & 4.13 & 5.94 \\
\hline & 12 & 1 & 260 & 7.020 & 0.0036 & 6.50 & 4.68 \\
\hline & & 2 & & 5.265 & 0.0047 & 4.88 & 7.02 \\
\hline . & 5 & & & & Total te & time, $\min$ & 50.65 \\
\hline
\end{tabular}

\subsection{Fire Loading Protocols}

\subsubsection{Natural gas fueled fire}

The target fire loads were developed to represent various fire severities. Fig. 32 shows the three investigated fire scenarios, defined as temperature-time curves, described here as:

- Standard Fire: 1-hour of temperature-time exposure similar to ASTM E119 (ASTM International, 2016).

- Severe Fire: A post-flashover fire of relatively long duration (35 min) and a peak upper layer gas temperature of $1100{ }^{\circ} \mathrm{C}$.

- Mild Fire: A post-flashover fire of relatively short duration (15 min) and a peak upper layer gas temperature of $900{ }^{\circ} \mathrm{C}$. 


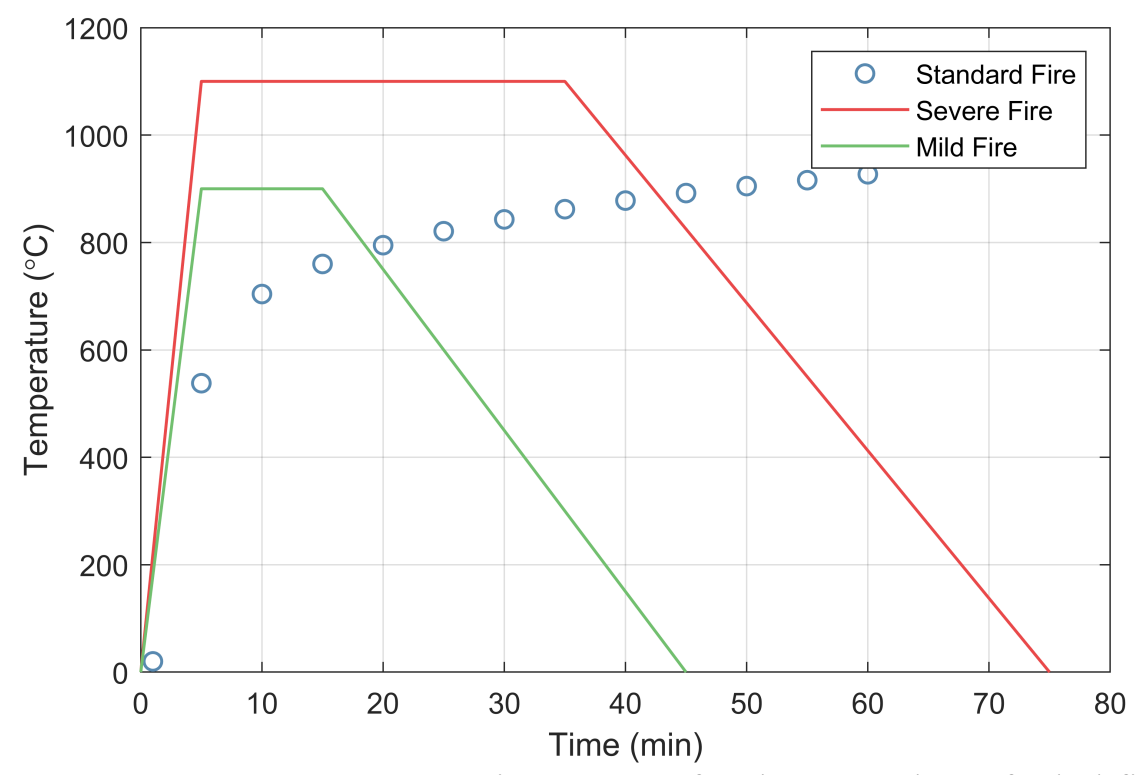

Fig. 32. Target temperature-time curves for the natural gas fueled fires.

The Standard Fire used here does not fulfill all requirements of an ASTM E119 test, however, the thermal load in the upper gas layer approximates those specified in the standard. The Severe Fire and Mild Fire encompass a range of realistic fire conditions in typical compartments.

To implement the Standard Fire with the test setup, an initial fire was run using a gypsumsheet steel composite panel sheathed specimen (non-combustible) in which the heat release rate of the burner was controlled via the gas mass flow to match the target gas temperature in an ASTM E1 19 test. This heat release rate versus time curve was then fixed for all subsequent Standard Fire tests. This was necessary because the upper layer gas temperature varied for specimens with combustible sheathing or if large cracks occurred in the gypsum during heating. By fixing the heat release rate versus time better comparisons under the same thermal load were achieved.

To implement the Severe Fire and Mild Fire, initial tests using a gypsum-sheet steel composite panel sheathed specimen were run controlling the heat release rate of the burner to match the target upper layer gas temperatures at about half the duration of the target temperature plateau. In all subsequent tests, the heat release rate was rapidly increased to the respective target levels for the Severe Fire and Mild Fire and allowed the fire growth and decay rates to be dictated by the geometry and materials of the compartment. Due to the thermal inertia of the compartment, this meant the temperature was slightly below the target temperature early in the plateau and slightly above it late in the plateau but matched on average.

For this test setup, the resulting heat release rates of the burner were: varied to a maximum of 1.44 MW for the Standard Fire, a constant 2.3 MW for the Severe Fire, and a constant 1.7 MW for the Mild Fire. Additional information about the development of fire loads can be found in the Appendices.

\subsubsection{Kitchen furnishings fire}

The kitchen fire was designed to represent average dimensions and fuel load of North American residential kitchens. The average fire load density of $807 \mathrm{MJ} / \mathrm{m}^{2}$ for a residential 
kitchen was taken from a survey of fire load by Bwalya (Bwalya et al., 2008). Fig. 33 shows photographs of the arrangement of the furnishings as installed. The primary furnishings include sink base cabinets, wall cabinets, countertops, a table with two chairs, and a supplemental wood crib placed in a wall cabinet to achieve the target fire load density. All primary furnishings were made of 'white wood' (unspecified spruce, pine and fir) or particle board. A few miscellaneous items typically found in a kitchen (knife block, coffee maker, table settings, paper towels, cereal boxes, etc.) were added for visual effect but did not contribute significantly to the fire load. A complete listing of the primary furnishings in the compartment, including the item manufacturer, article number or description, dimensions, material and mass, is provided in the Appendices.

Dimensionally accurate 2D and 3D representations of the as-tested fuel locations are shown in Fig. 34. The positions were verified using a tape measure prior to the test and varied less than $\pm 25 \mathrm{~mm}$. The measured positions and dimensions are provided in the Appendices.

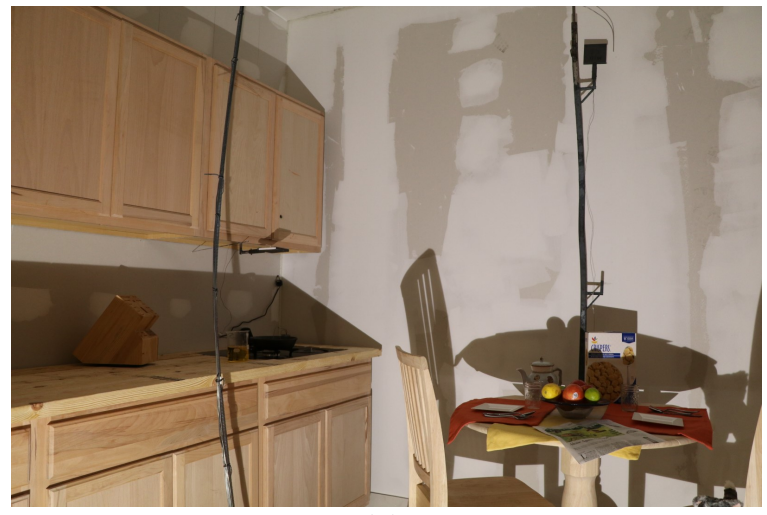

(a)

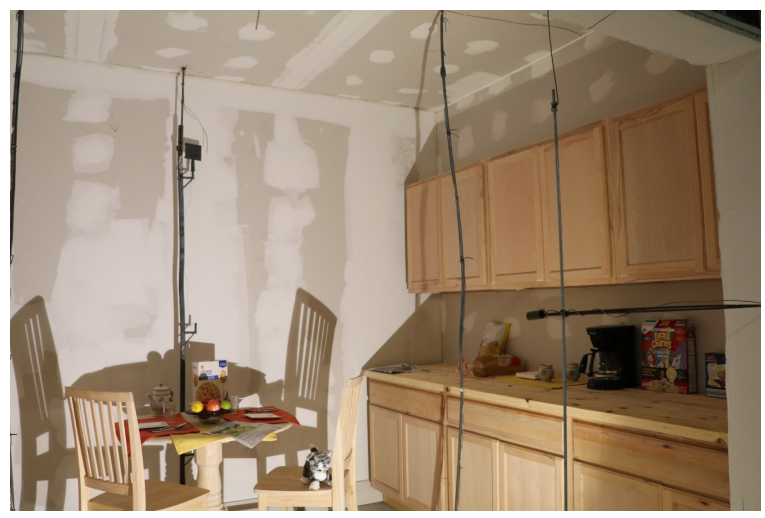

(b)

Fig. 33. Photographs of furnished kitchen: (a) looking south; (b) looking north.

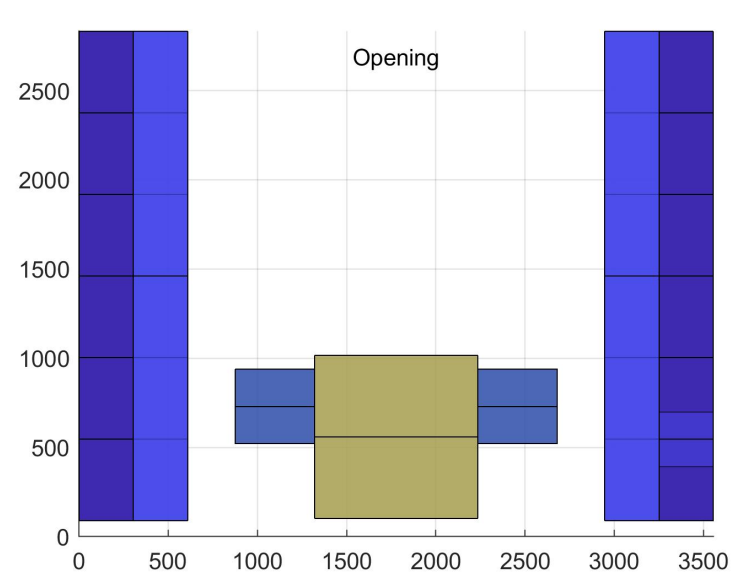

(a)

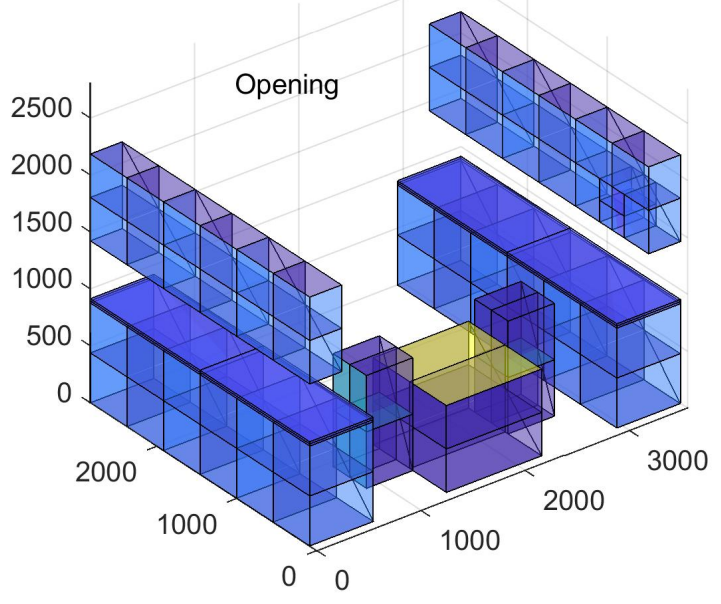

(b)

Fig. 34. Model of the fuel as installed: (a) plan view; (b) isometric view (units in $\mathrm{mm}$ ).

The furnishings were weighed prior to placement. The total weight of the combustible material was $(411 \pm 0.1) \mathrm{kg}$. The estimated energy for each item was determined using the calorific values from literature (Society of Fire Protection Engineers, 2016). Neglecting the paper on 
the innermost layer of drywall (the layer participating during flashover) which constituted 1.9 $\%$ of the total fuel by energy, the total estimated energy for the primary furnishings was 8100 MJ. The calculated fire load density was $804 \mathrm{MJ} / \mathrm{m}^{2}$.

The measured dimensional and mass information for the fuel was used to generate a fuel energy distribution. The 3D model in Fig. 35 split each piece of fuel into 8 surfaces (6 sides plus a vertical and a horizontal plane through the center). The mass distribution to each surface was estimated. The values used are provided in the Appendices. The compartment was arbitrarily divided into 99 (length) by 74 (width) regions and the energy of the content (from floor to ceiling) in each region was determined.

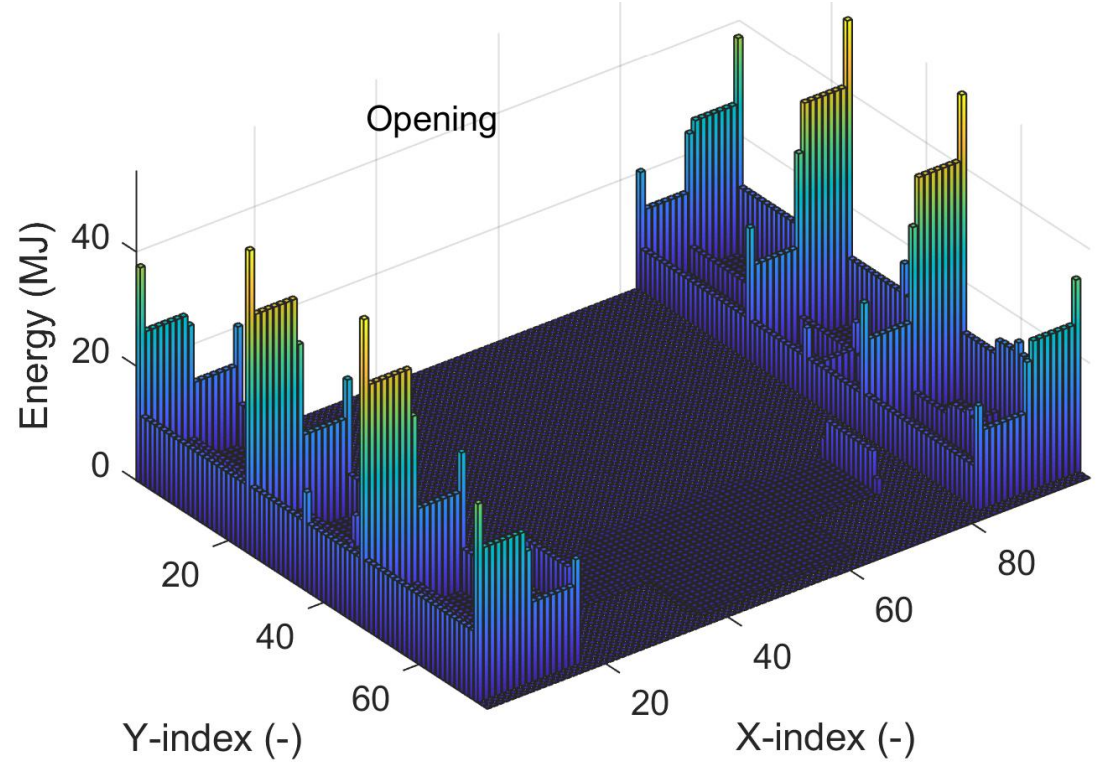

Fig. 35. Isometric view of the movable fuel energy as installed.

The fire was started by auto-ignition of a pan of oil left unattended on a stove. A $203 \mathrm{~mm}$ (8 in.) diameter cast iron pan filled with $500 \mathrm{ml}$ of corn oil was placed on the large burner of a propane-fueled cooktop. The cooktop was located $508 \mathrm{~mm}$ ( $20 \mathrm{in}$.) below the bottom of a wall cabinet as shown in Fig. 36. To ensure the spread of the fire from the pan to the cabinet, the doors of the cabinet were left ajar $(\approx 1 \mathrm{~cm}$ opening) and a small supplemental wood crib $(\approx 6.5 \mathrm{~kg})$ and two rolls of paper towels were placed in the cabinet. 


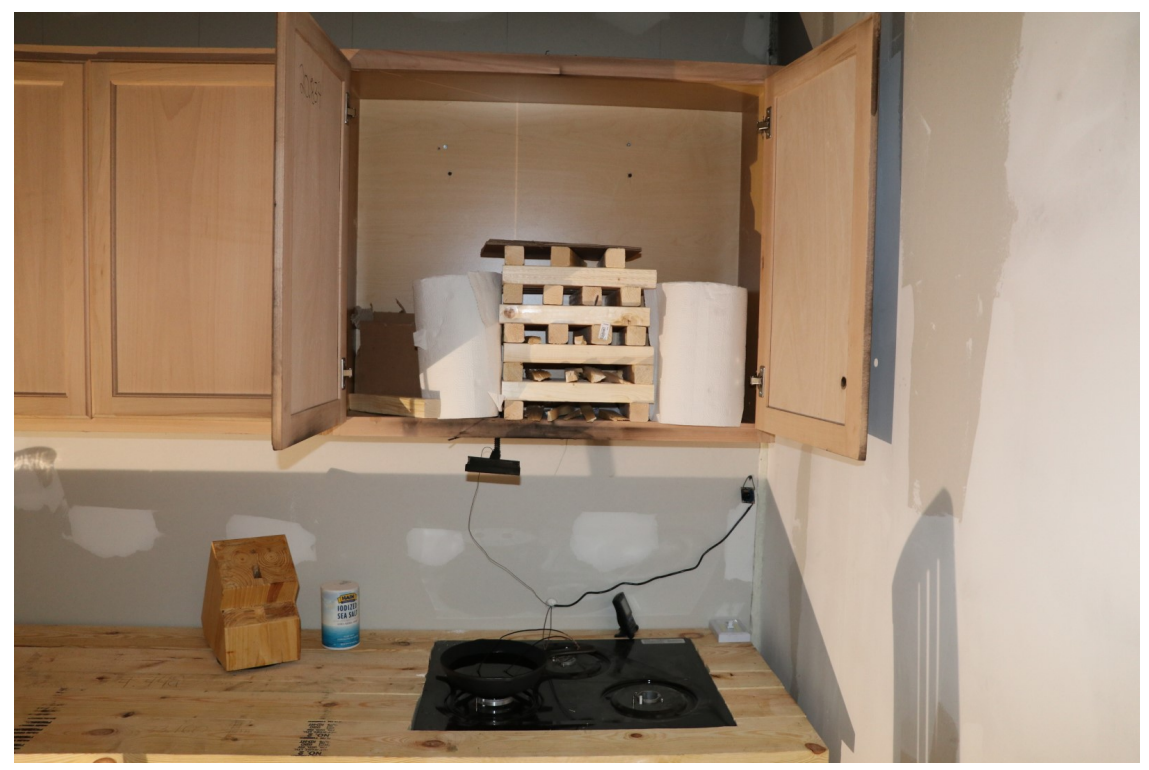

Fig. 36. Photograph of ignition source and objects of first ignition.

\subsection{Instrumentation}

This section is grouped according to instrumentation used for the mechanical loading tests, natural gas fueled compartment fire tests and the kitchen furnishings fueled compartment fire test. Each of these types of tests had a unique instrumentation configuration. The configuration used in most of the tests is presented. In select instances, thermocouple types or attachment details; e.g., screw attachment versus cloth tape versus foil tape, were varied as noted in the electronic data associated with this report, however, these variants are not discussed as they have little bearing on the presented results.

The measurements were digitized and recorded using two National Instruments (NI) cDAQ 9188 data acquisition (DAQ) chassis populated with NI 9213 I/O-Modules for thermocouples and NI-9205 modules for sensors with voltage outputs. An in-house software developed in LabVIEW ${ }^{\mathrm{TM}}$ called MIDAS (Modular In-situ Data Acquisition System) was used to allocate channels and control the data acquisition. For mechanical loading tests, each channel was sampled at $2500 \mathrm{~Hz}$ and read at $500 \mathrm{~Hz}$ providing data at a rate of $5 \mathrm{~Hz}$ along with the standard deviations from the averaging process. For the fire tests, each channel was sampled at $4 \mathrm{~Hz}$ and read at $4 \mathrm{~Hz}$ providing data at a rate of $1 \mathrm{~Hz}$. The $\mathrm{I} / \mathrm{O}-$ Modules had at least 16-bit precision, resulting in uncertainties from the DAQ that were orders of magnitude lower than those from other sources in the measurements reported.

For all fire tests, Heat Release Rate (HRR) measured by the NFRL calorimeter and the burner heat release rate (HRRburner) were digitized and recorded using a separate data acquisition system described by (Bryant et al., 2004) and the data were mirrored to the recorded data.

Where expanded uncertainty is reported, a coverage factor of 2 corresponding to an approximately $95 \%$ confidence interval is used. Additional details about measurement uncertainties are provided in the Appendices. 


\subsubsection{Mechanical loading}

Fig. 37 shows the locations and orientations of the sensors used for mechanical loading tests. Fig. 38 and Fig. 39 show photographs of key specimen displacement measurement setups.

\section{Actuator force and displacement}

The load applied by the hydraulic actuator (ActuatorForce) was measured by a force transducer integrated into the actuator with an expanded uncertainty of $\pm 2.0 \%$ of the full-scale output (FSO); FSO values are needed to determine uncertainty. The displacement of the actuator (ActuatorDisp) was measured by a transducer on the actuator with an expanded uncertainty of $\pm 0.2 \%$ FSO.

\section{Specimen displacement}

Longitudinal displacement at the top of the wall specimen (Disp_Long) was measured using a string potentiometer (UniMeasure Model PA30) with an expanded uncertainty of $\pm 1.0 \%$ FSO. The out-of-plane (Disp_Tran) and vertical (Disp_Vert) movement of the top loading beam were measured using string potentiometers (UniMeasure Model PA-10L3M) with expanded uncertainty of $\pm 1.0 \%$ FSO. The uplift (Disp_Uplift_N/S) and slip (Disp_Slip) of the wall relative to the bottom beam were measured using linear potentiometers (Novotechnik Model TR25) with expanded uncertainty of $\pm 1.1 \%$ of the reading (RD).

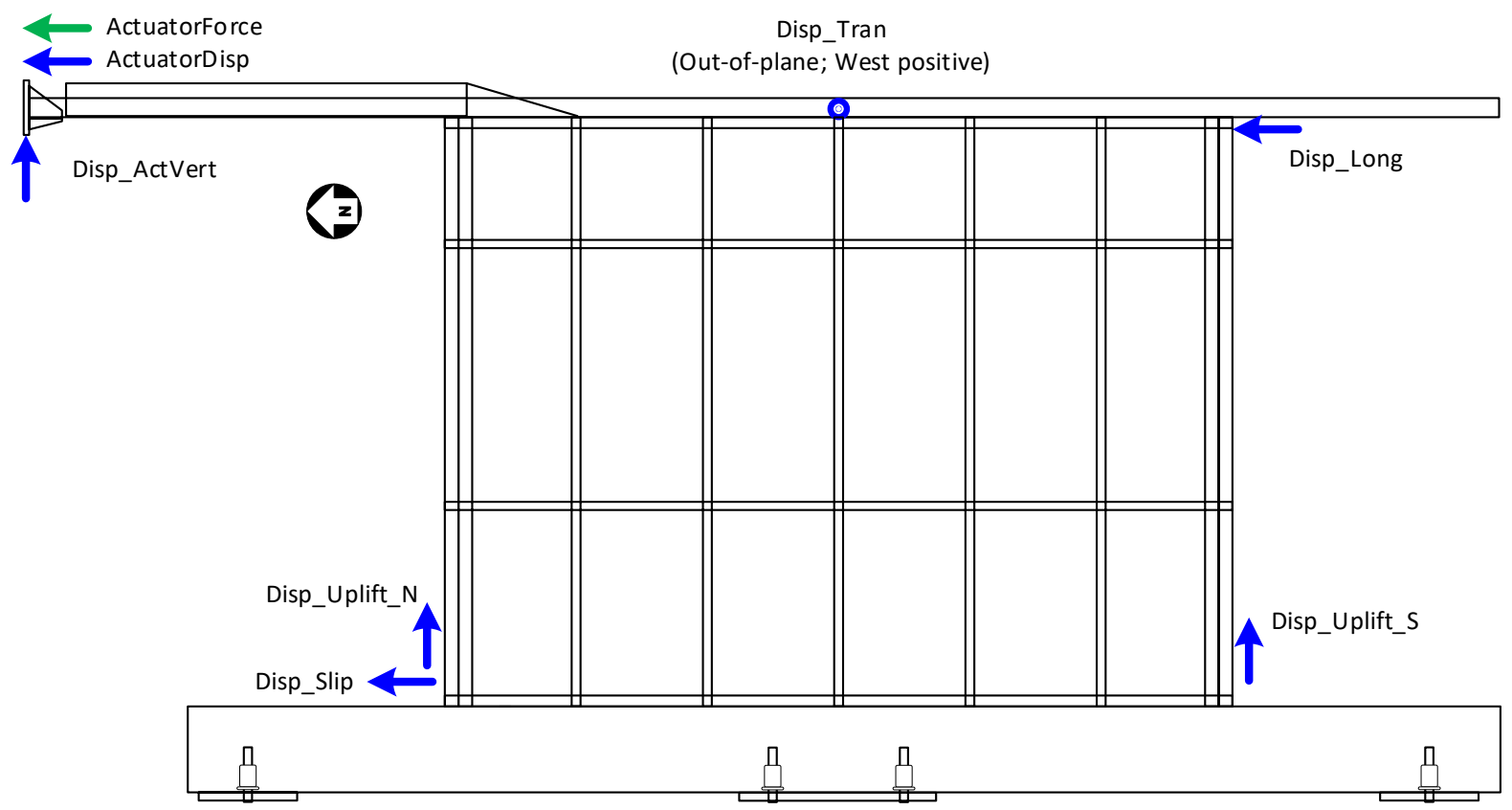

Fig. 37. Sensor locations on specimen and loading frame during mechanical loading. 


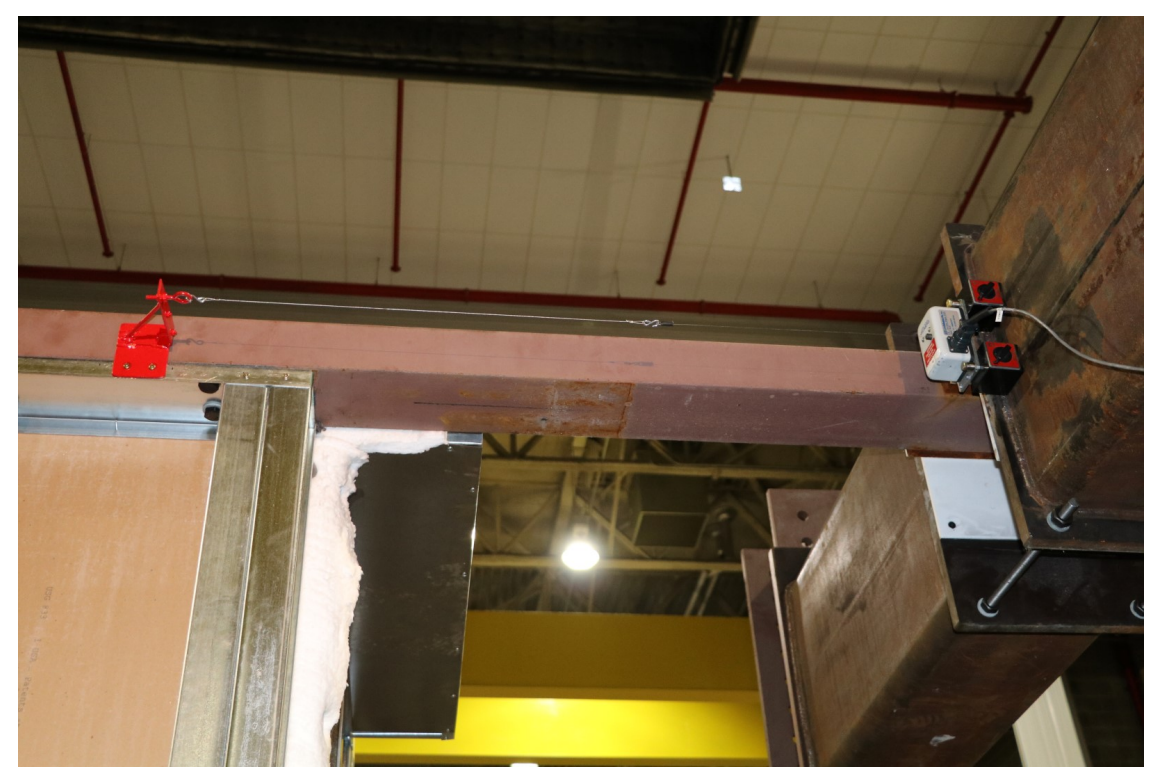

Fig. 38. Photograph of string potentiometer to measure top of wall drift.

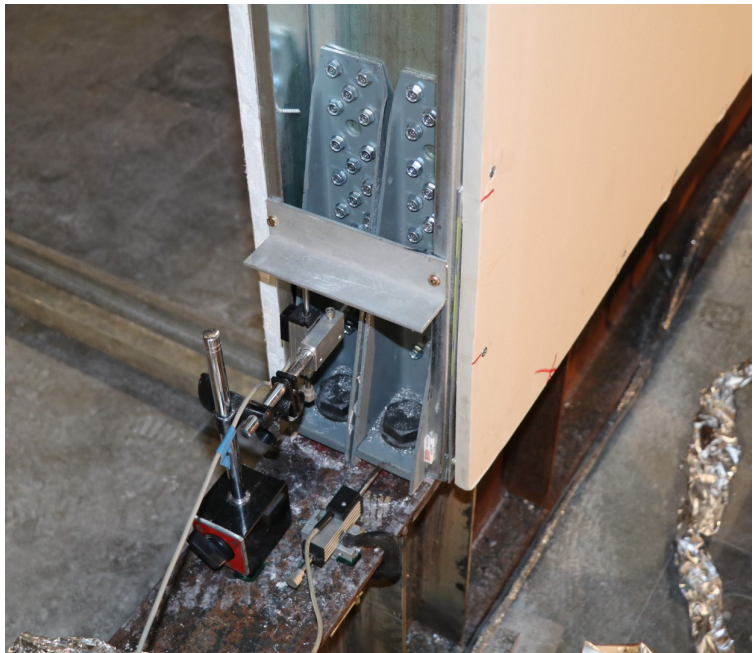

(a)

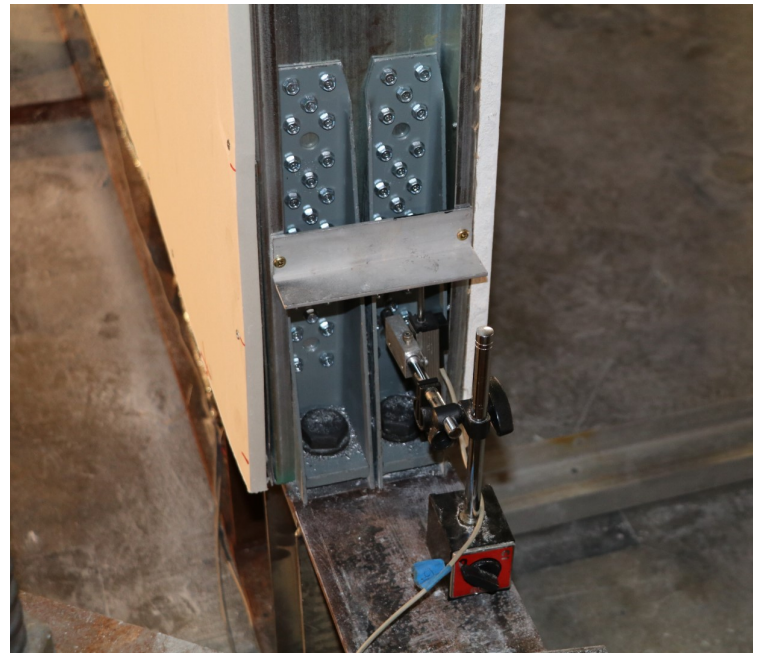

(b)

Fig. 39. Photographs of linear potentiometers to measure specimen uplift and slip: (a) north end of wall; (b) south end of wall.

\subsubsection{Natural gas fueled fire}

\section{Burner heat release rate}

The burner heat release rate was calculated using the measured mass flow and composition of the natural gas. The natural gas mass flow rate was determined using a positive displacement rotary volume flow meter, pressure transducer and thermistor. Complete combustion was assumed for the burner heat release rate values reported in this study. The carbon monoxide mass yield was less than $2 \%$ and the effect of combustion efficiency was factored into the uncertainty analysis of heat release rate. The composition of natural gas was measured using a gas chromatograph (GC) with a sampling period of $3 \mathrm{~min}$. The expanded relative uncertainty 
of the Ideal Gross Heating Value was determined to be $0.9 \%$. The expanded relative uncertainty of the natural gas burner heat release rate was estimated to be less than $3 \%$ for these experiments. Details of the gas fuel delivery and measurement system can be are described in detail by (Bryant et al., 2004).

\section{Calorimeter heat release rate}

Heat release rate measurements were also performed using an oxygen consumption fire calorimeter. The calorimeter consisted of a $15 \mathrm{~m}$ square canopy style smoke collection hood, a $2.42 \mathrm{~m}$ diameter exhaust duct instrumented for mass flow measurements and a gas sampling system for measuring exhaust gas composition. The smoke collection hood was located $12.5 \mathrm{~m}$ above the test floor and was equipped with $6 \mathrm{~m}$ retractable side curtains.

The heat release rate measurement system was verified within 18 months of this experiment using a natural gas burner reference fire. The calorimetry system gas analyzers and pressure transducers were calibrated weekly during the testing period. The heat release rate of the reference fire had a measurement combined standard uncertainty of less than $\pm 1 \%$. Calorimeter verification tests were performed on 2 separate days at heat release rate values of $1 \mathrm{MW}, 5 \mathrm{MW}, 10 \mathrm{MW}, 15 \mathrm{MW}$ and $20 \mathrm{MW}$. The maximum relative difference between the measured heat release rate and the reference fire was less than $4.5 \%$. The relative standard deviation of the heat release rate varied from $6.5 \%$ at $1 \mathrm{MW}$ to $3 \%$ at $20 \mathrm{MW}$ for a steady reference fire over a period of $180 \mathrm{~s}$. The total expanded relative uncertainty for the heat release rate measurements was determined to be $14.8 \%$ for these verification experiments. This uncertainty estimate is valid for near steady state fires. Transient events $(<30 \mathrm{~s})$ have larger uncertainty due to the effect of system response time. Additional time delays and smearing of heat release rate data related to transport of the combustion gases out of the test compartment are not quantified in this report. For further information see (Su et al., 2018).

\section{Compartment temperatures}

Fig. 40 and Fig. 41 show the locations of the sensors in the rolling compartment used for the natural gas fueled fire tests. Gas temperatures on the thermocouple arrays near the north and south vents in the compartment were measured using Inconel-sheathed, $3.175 \mathrm{~mm}(1 / 8 \mathrm{in}$.) outside diameter, grounded junction Type $\mathrm{K}$ thermocouples (Omega Engineering Model HKQIN-18G) purchased in fixed lengths with a measurement range from $-200{ }^{\circ} \mathrm{C}$ to $1250{ }^{\circ} \mathrm{C}$ and an expanded uncertainty of $\pm 2.8 \% \mathrm{RD}$. This is the uncertainty of the thermocouple bead temperature. The gas temperature may have added uncertainty due to radiative loss/gain and response time effects that were not considered here. The thermocouple arrays were wrapped with thermal ceramic fiber blanket, with the tips of the thermocouples projecting from the blanket approximately $50 \mathrm{~mm}$ ( 2 in.). The sheathing and blanket allowed the arrays to be reused in multiple tests. Additionally, a single sheathed-thermocouple (HKQIN-18G) was located $25 \mathrm{~mm}$ ( 1 in.) from the ceiling at the center of the compartment (TC_TopCenter) and another measured the outflow temperature of the burner cooling water (TC_BurnerH20).

In addition to the measured compartment temperatures, two derivative temperatures are reported in the Appendices. These are the upper layer temperature determined as the average of the top three thermocouples on the north and south arrays plus the temperature at the top center of the compartment (TC_AveULT) and the average temperature measured by the top three plate thermocouples (TC_A $\bar{A}_{\text {iveULPT). }}$ 


\section{Heat flux}

Nine plate thermocouples (Pentronic Model 5928060) were attached to the back of the compartment facing the test specimen to measure temperature and the spatial distribution of heat flux to the specimens. Pretests with plate thermocouples located opposite to each other; i.e., on the back wall of the compartment and on the specimen, indicated that front-to-back heat flux in the compartment was approximately symmetric. Each plate thermocouple probe plate had a surface area of $100 \mathrm{~mm} \times 100 \mathrm{~mm}(4 \mathrm{in} . \times 4 \mathrm{in}$.) and was specified to operate up to a maximum temperature of $1200{ }^{\circ} \mathrm{C}$. A manufacturer-reported standard uncertainty for the plate thermocouple is not available, however, the uncertainty of the temperature was estimated to be $\pm 1.8 \%$ RD. The plate thermocouples were mounted on brackets $100 \mathrm{~mm}$ (4 in.) from the back wall of the compartment. To calculate heat flux using the plate thermocouples, gas temperature directly adjacent to each probe was measured using OMEGACLAD ${ }^{\mathrm{TM}_{-}}$-sheathed, $3.175 \mathrm{~mm}$ (1/8 in.) outside diameter, exposed junction Type $\mathrm{K}$ thermocouples (Omega Engineering Model KMQXL-125E) with a measurement range from $-200{ }^{\circ} \mathrm{C}$ to $1335^{\circ} \mathrm{C}$ and an expanded uncertainty of $\pm 3.0 \% \mathrm{RD}$. For clarity, these collocated thermocouples are not depicted in Fig. 40, but are designated in electronic data associated with this report using the plate thermocouples names; e.g. PT_NT_TC.

The incident heat flux at the plate thermocouples at step $i\left(\left[\dot{\mathrm{q}}_{\text {inc }}^{\prime \prime}\right]^{\mathrm{i}}\right.$, in $\left.\mathrm{W} / \mathrm{m}^{2}\right)$ is calculated, using the measured temperature of the plate thermocouple $\left(T_{P T}\right.$, in $\left.\mathrm{K}\right)$ and the gas temperature near the plate thermocouples $\left(T_{\text {gas }}\right.$, in $\left.\mathrm{K}\right)$, as follows:

$$
\left[\dot{q}_{i n c}^{\prime \prime}\right]^{i}=\sigma\left[T_{P T}^{4}\right]^{i}-\frac{\left(h_{c}+K_{P T}\right)\left(\left[T_{g a s}\right]^{i}-\left[T_{P T}\right]^{i}\right)-C_{P T} \frac{\left[T_{P T}\right]^{i+1}-\left[T_{P T}\right]^{i-1}}{[t]^{i+1}-[t]^{i-1}}}{\varepsilon_{P T}}
$$

where the time $(t)$ is in seconds, the Stefan Boltzmann constant $(\sigma)$ is $5.6704 \mathrm{E}-8 \mathrm{~W} / \mathrm{m}^{2} / \mathrm{K}^{4}$, the convection coefficient $\left(h_{c}\right)$ is taken to be $10 \mathrm{~W} / \mathrm{m}^{2} / \mathrm{K}$, the heat transfer coefficient due to heat losses of the plate thermocouples $\left(K_{P T}\right)$ is taken to be $8 \mathrm{~W} / \mathrm{m}^{2} / \mathrm{K}$ (Häggkvist, Sjöström and Wickström, 2013), the lumped heat capacity of the plate thermocouples $\left(C_{P T}\right)$ is taken to be $4200 \mathrm{~J} / \mathrm{m}^{2} / \mathrm{K}$ (Häggkvist, Sjöström and Wickström, 2013), and the emissivity of the plate thermocouple $\left(\varepsilon_{P T}\right)$ is taken to be 0.9 . The emissivity was suggested by the inventor of the plate thermocouple based on experience.

\section{Specimen temperatures}

Temperatures were measured using two types of thermocouples. Both were K-type thermocouples with a measurement range from $-200{ }^{\circ} \mathrm{C}$ to $1250{ }^{\circ} \mathrm{C}$ and an expanded uncertainty of $\pm 6.2 \% \mathrm{RD}$. The locations of the thermocouples in the specimens for the three wall types are shown in Fig. 42.

The majority of the thermocouples were glass-sheathed extension wire, 24-gage, bare-bead thermocouples (Omega Engineering Model GG-K-24). The wire was purchased in $305 \mathrm{~m}$ (1000 ft.) spools, cut to length and a bead was created using a thermocouple welder. The thermocouple beads were held in position by fabric tape and the clamping force between wall elements (Fig. 43a) or compressed against the material using a screw (Fig. 43a-d). On gypsum on the unexposed side of the wall specimens, self-adhering surface-mount thermocouples with 
a response time of less than $0.15 \mathrm{~s}$ (Omega Engineering Model SA1XL-K) were used (Fig. $43 \mathrm{e}, \mathrm{f})$. Because these were reused from test to test, in some cases an additional piece of fabric tape was placed over the thermocouple to hold it in place as the self-adhesive wore off.

\section{Specimen air pressure and flow velocities}

Fig. 44 shows the locations of the pressure and velocity sensors in the wall specimens used for the natural gas fueled fire tests. The measurements from these sensors were made using differential pressure transducers (MKS Model 220DD) with a maximum range of $133 \mathrm{~Pa}$ (1 Torr) and an expanded uncertainty of $\pm 6.8 \%$ RD (Fig. 45).

The air pressure in the wall cavity relative to the ambient pressure in the test hall $(\mathrm{P}$ - $\mathrm{PP})$ was sampled from a $6 \mathrm{~mm}(1 / 4$-inch) diameter stainless steel tube with its opening approximately 56 $\mathrm{cm}$ (20 in.) from the top of the wall between the center studs (Fig. 46a). The exact location varied slightly from test to test.

Air flow velocities into and out of the wall cavity were determined using dynamic pressures measured at the top and bottom knockouts (P_PvT/B) in the north chord stud (Fig. 46b). The pressures were measured by transducers that produced voltages, $V_{b d p}$, related to the exposed differential pressures by the following equation: $\Delta P_{b d p}=13.332\left(V_{b p d}-V_{b p d, z e r o}\right)$, where the pressure difference is in pascals and the voltages are measured in volts. The zero voltage, $V_{b d p \text {,zero, }}$ condition is created when the positive and negative ports of the transducer are connected so there can be no pressure difference between them.

The transducers were connected to $1.3 \mathrm{~cm}$ diameter bi-directional probes (McCaffrey and Heskestad, 1976) with $4.7 \mathrm{~mm}$ diameter copper tubing. Probe leads were routed close to each other, so each lead was exposed to the same levels of heating. This installation care minimized differential heating and any resulting non-flow induced pressure differences between the leads.

Bi-directional probes enable the measurement of dynamic pressure which is the difference between the total pressure on the face where flow impinges and the static pressure on the downstream face of the probe. Using Bernoulli's principle and including a calibration factor, velocity, $v$, can be obtained from the dynamic pressure and a local gas temperature through the following relation: $v=C \sqrt{\Delta P_{b d p} T_{b d p}}$ where $\Delta P_{b d p}$ is the measured pressure across the bidirectional probe, $T_{b d p}$ is the temperature (in $\mathrm{K}$ ) of the gases flowing past the probe and $\mathrm{C}$ is defined as:

$$
C=\frac{1}{C_{b d p}} \sqrt{\frac{2 R}{P_{r e f} M W_{g a s}}}
$$

The calibration coefficient, $C b d p$, for a bi-directional probe is equal to $1.08 \pm 0.05$ (McCaffrey and Heskestad, 1976) when the local Reynolds number (defined by the probe diameter) is greater than 1000. $R$ is the ideal gas constant and $M W_{\text {gas }}$ is the molecular mass of the gas.

To generate the velocity from the differential pressure, the temperature near the bi-directional probe is required. Because aspirated thermocouples can intrude on the pressure measurement bare-bead thermocouples were used to measure temperature (TC_PvT/B). Assuming standard atmosphere values for air: 


$$
v=\operatorname{sign}\left(\Delta P_{b d p}\right) \frac{1}{1.08} \sqrt{2\left|\Delta P_{b d p}\right| T_{b d p} \frac{R}{P_{r e f} M W_{g a s}}}=\operatorname{sign}\left(\Delta P_{b d p}\right) \frac{1}{1.08} \sqrt{\frac{2\left|\Delta P_{b d p}\right| T_{b d p}}{353.06}}
$$

The measured velocities had a total expanded uncertainty of $15.2 \% \mathrm{RD}$.

\section{$\underline{\text { Cameras }}$}

High-definition video footage of the inside of the compartment during the fire was captured through a fused silica window on the back wall of the compartment using a video camera placed in a water bath (Fig. 47). The water served dual purposes of cooling the camera and filtering out the thermal radiation produced by the fire; water is very efficient at absorbing energy in the infrared spectrum. Fused silica has a low coefficient of thermal expansion, so it is resistant to thermal shock, and maintains its structural integrity at high temperatures. The camera was placed in a modified waterproof case so that power could be provided to the camera and HDMI video could be streamed from the camera in real time.

In select videos, the compartment was illuminated using narrow-spectrum $450 \mathrm{~nm}$ (blue) light and frequency-matched bandpass optical filters were placed on the camera to enhance the visibility of the specimens through the flames. Additional information about this imaging technique is provided in (Smith and Hoehler, 2018). 


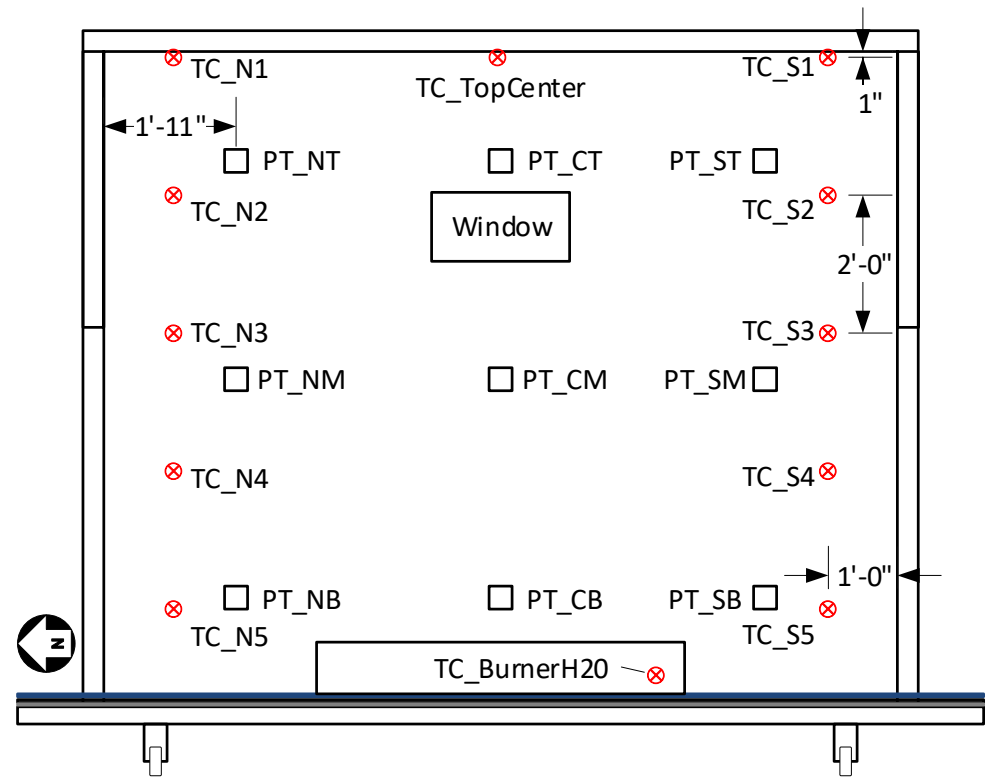

(a)

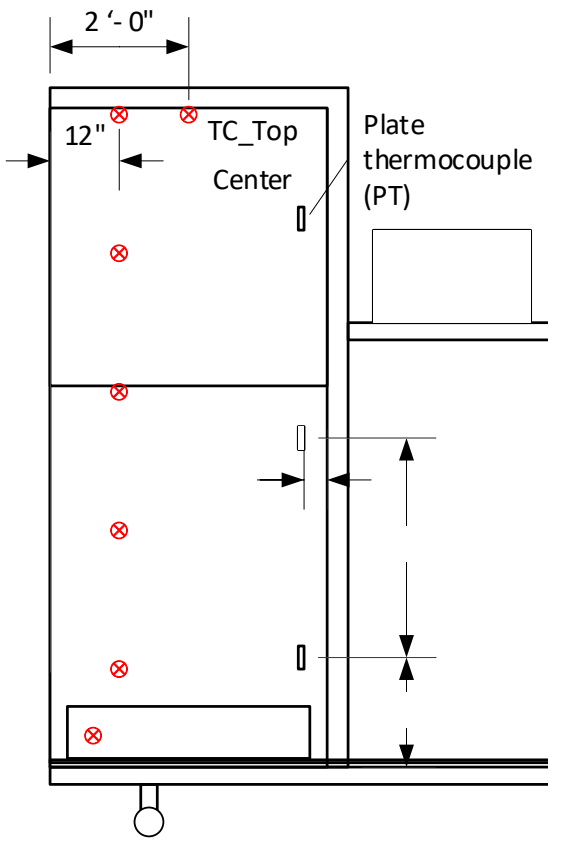

(b)

Fig. 40. Sensor locations in compartment during natural gas fueled fires: (a) looking east;

(b) looking north $(1 \mathrm{ft} .=30.5 \mathrm{~cm})$.

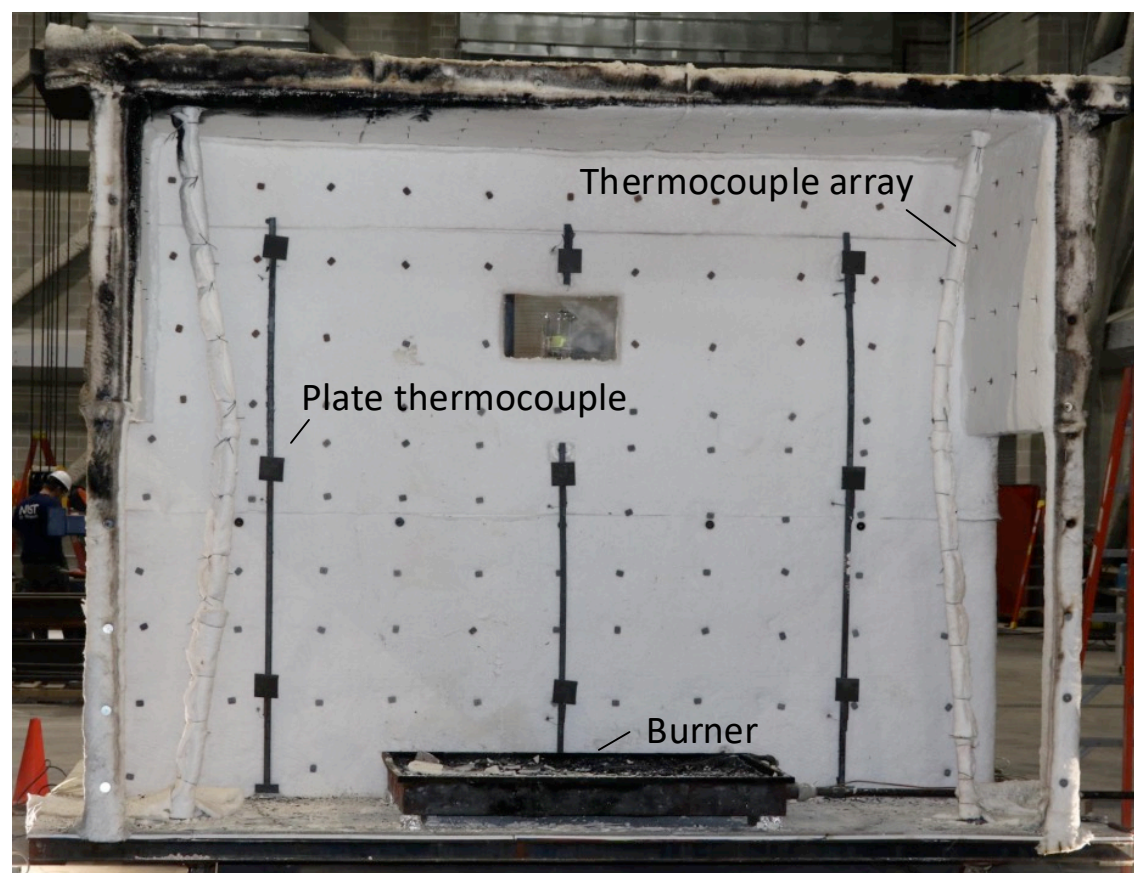

Fig. 41. Photograph of compartment sensors for natural gas fueled fires. 


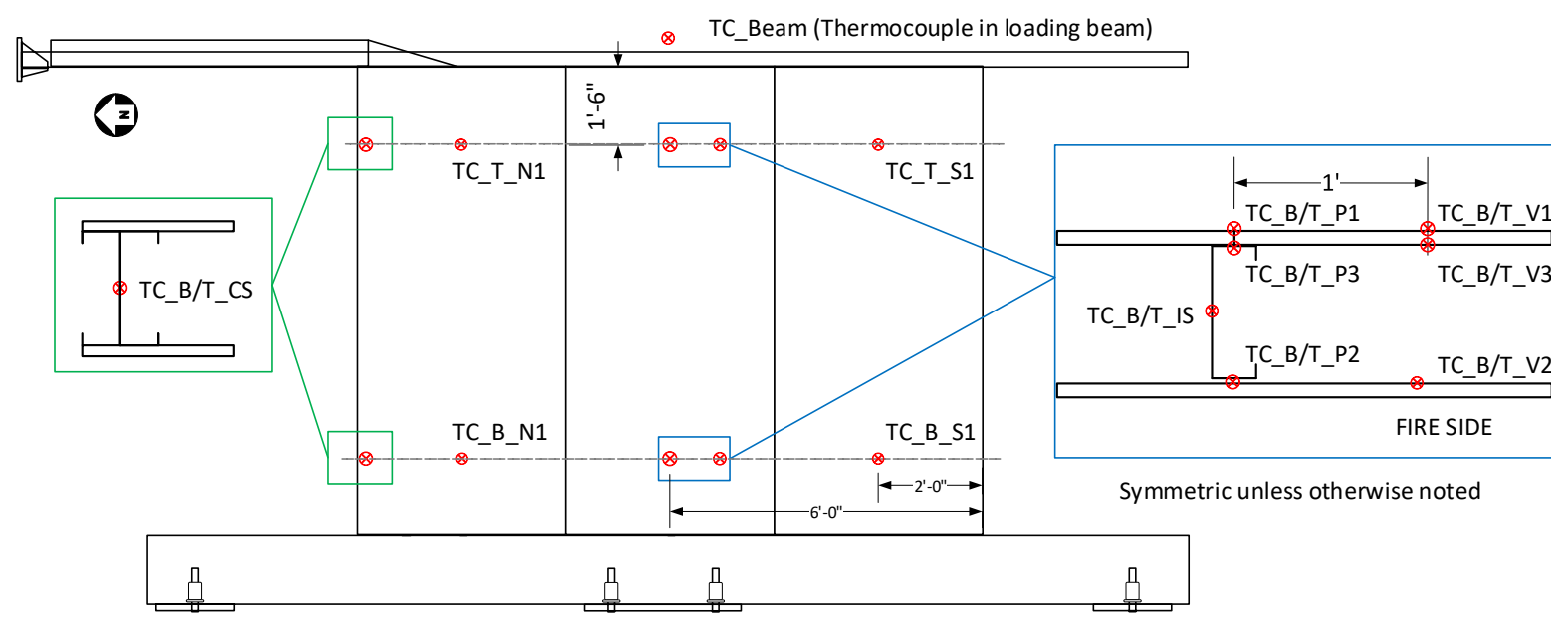

(a)

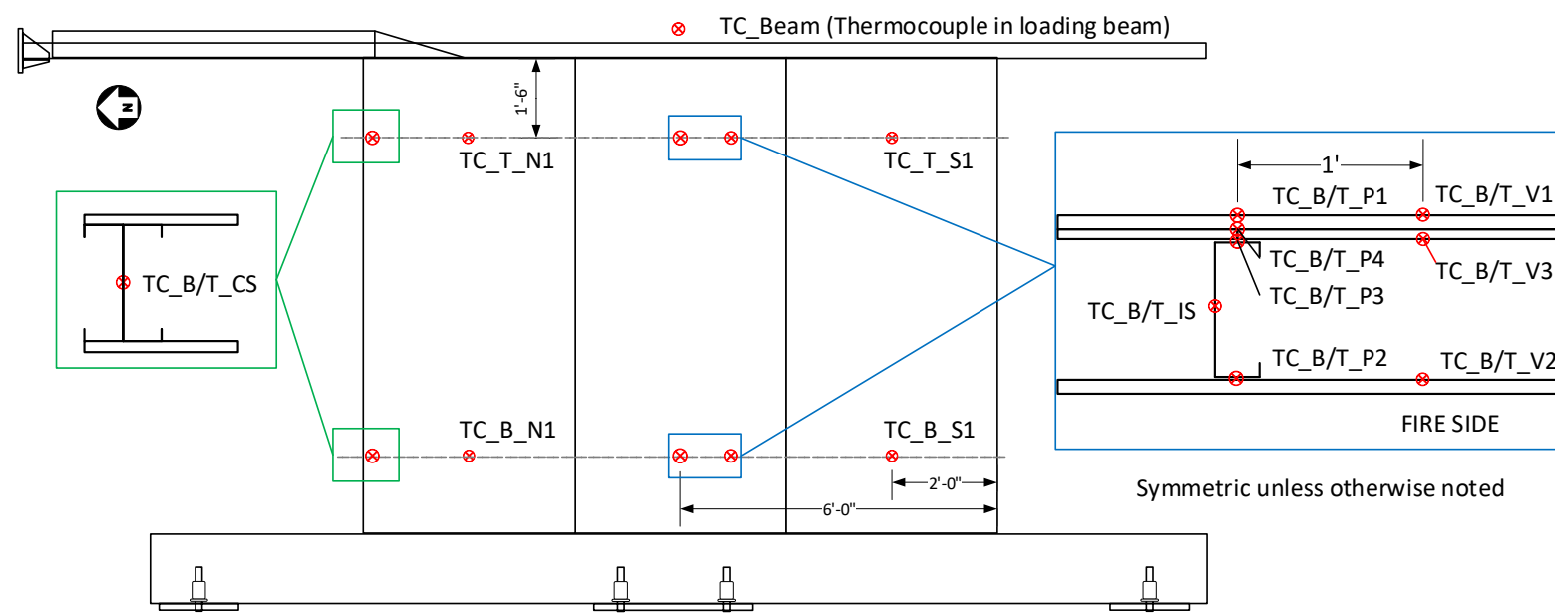

(b)

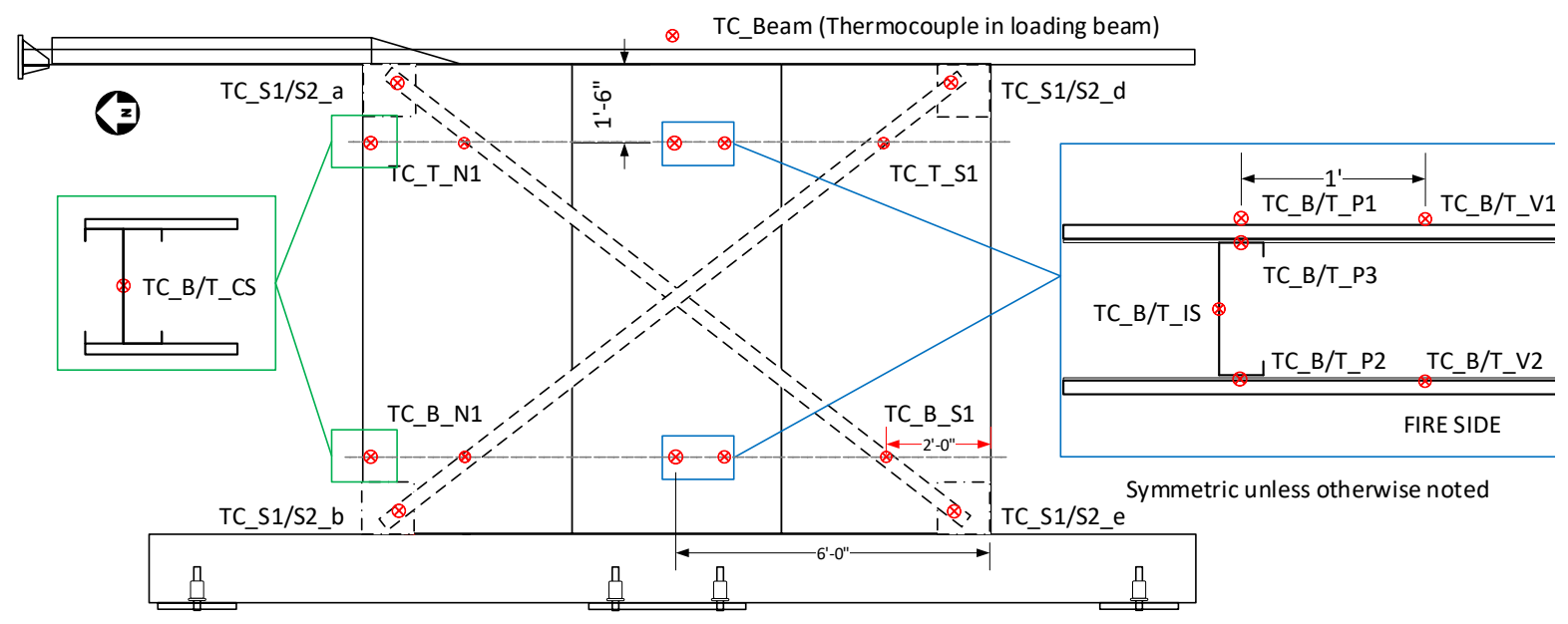

(c)

Fig. 42. Thermocouple locations in wall specimens during natural gas fueled fires:

(a) gypsum-sheet steel composite panel sheathed walls; (b) oriented strand board sheathed walls; (c) steel strap braced walls $(1 \mathrm{ft} .=30.5 \mathrm{~cm})$. 


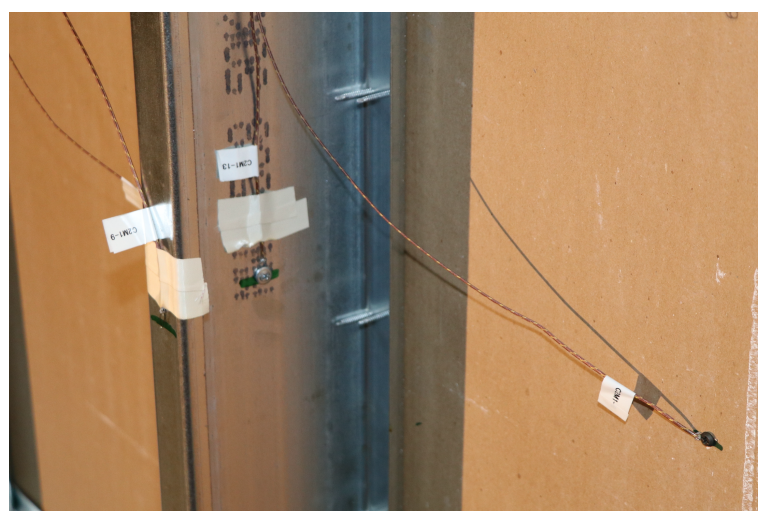

(a)

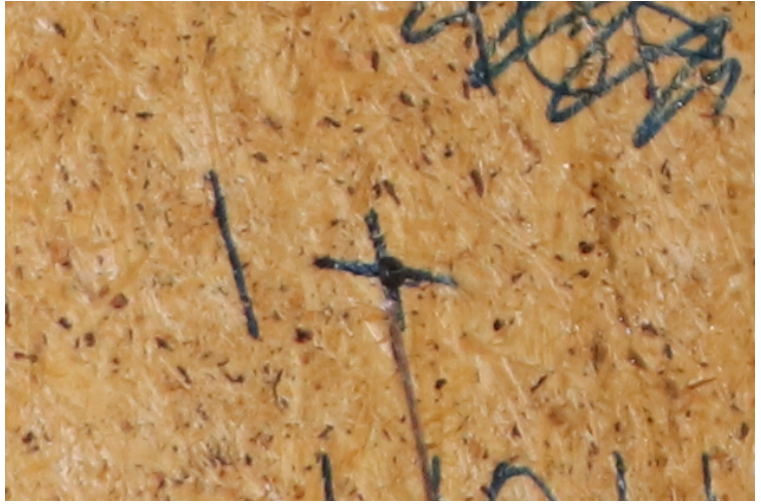

(c)

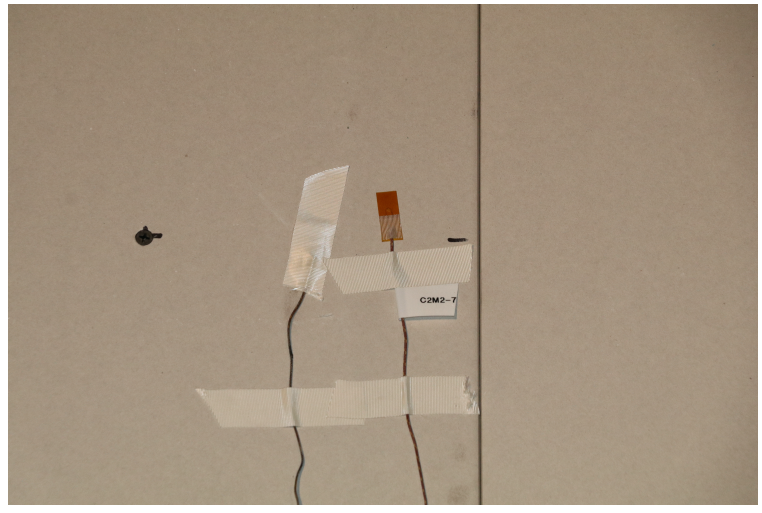

(e)

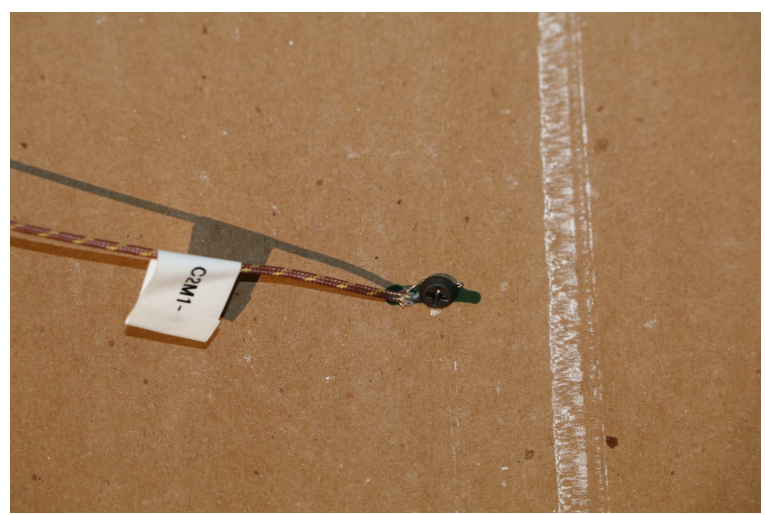

(b)

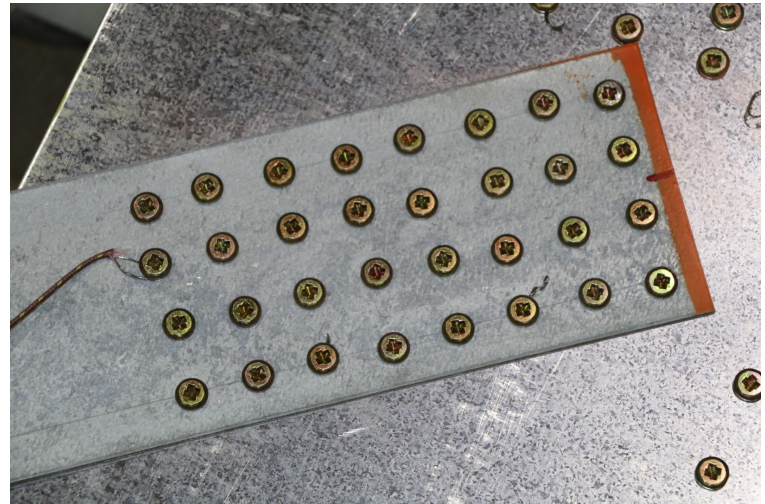

(d)

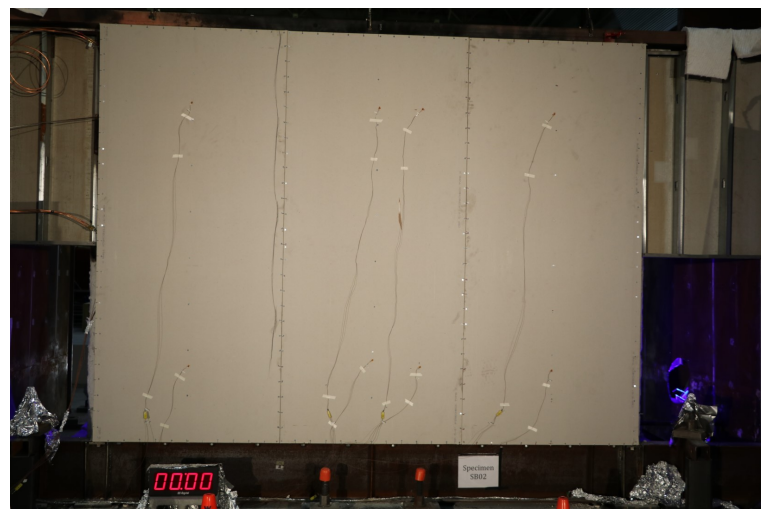

(f)

Fig. 43. Photographs of thermocouples on wall specimens during natural gas fueled fires: (a) along stud lines; (b) to gypsum board inside wall cavity; (c) to OSB inside wall cavity; (d) at strap-to-gusset connection ${ }^{7}$; (e) to gypsum board on unexposed side (detail); (f) to gypsum board on unexposed side (entire wall).

\footnotetext{
${ }^{7}$ The method of placing the thermocouple bead directly behind the screw head was used in the first fire test. For all subsequent tests the bead was clamped between the strap and the gusset plate to avoid damage to the bead during tightening of the screw.
} 


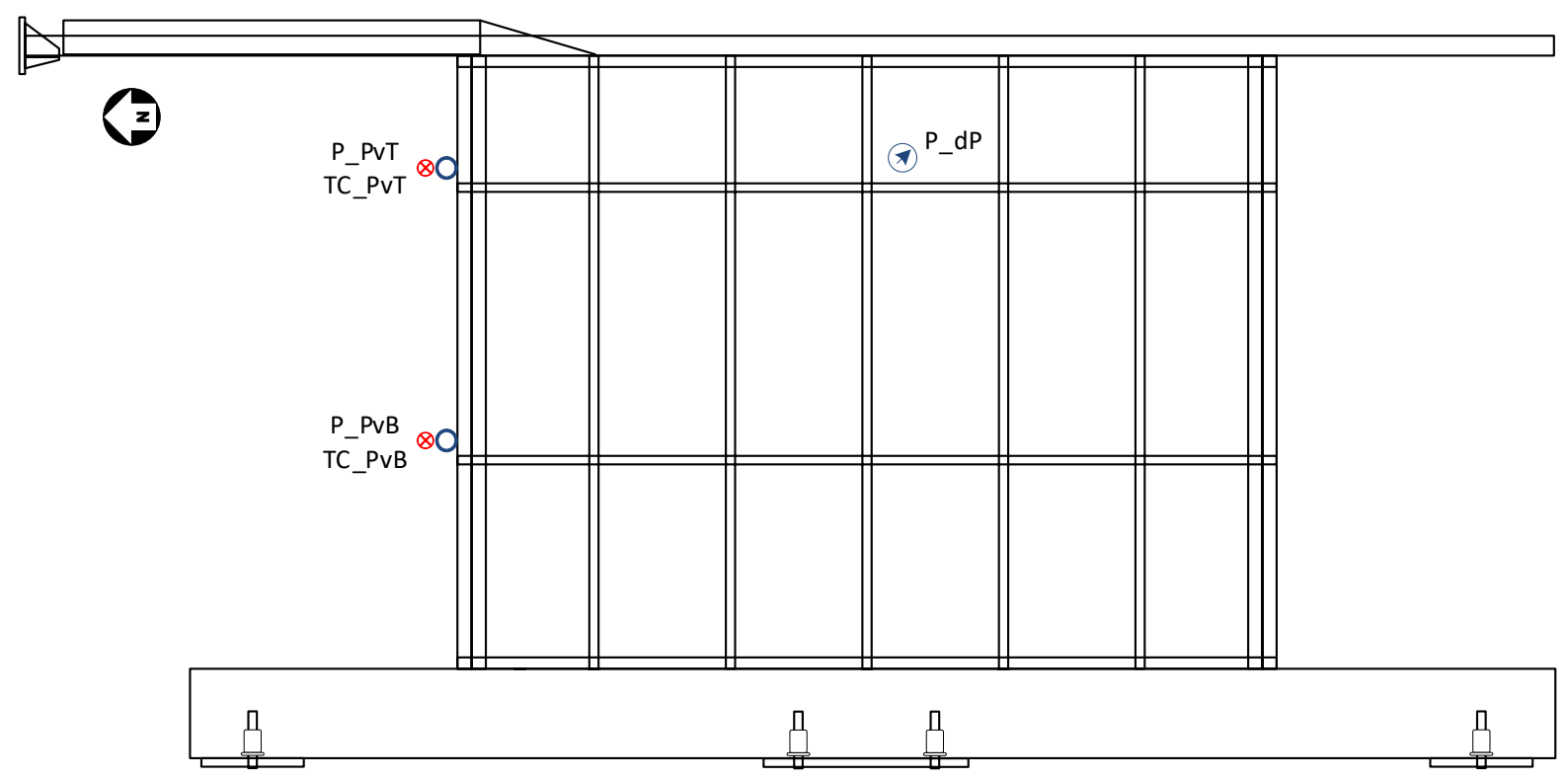

Fig. 44. Pressure and velocity sensor locations for natural gas fueled fires.

Fig. 45. Photograph of manometers to measure pressure and velocity.

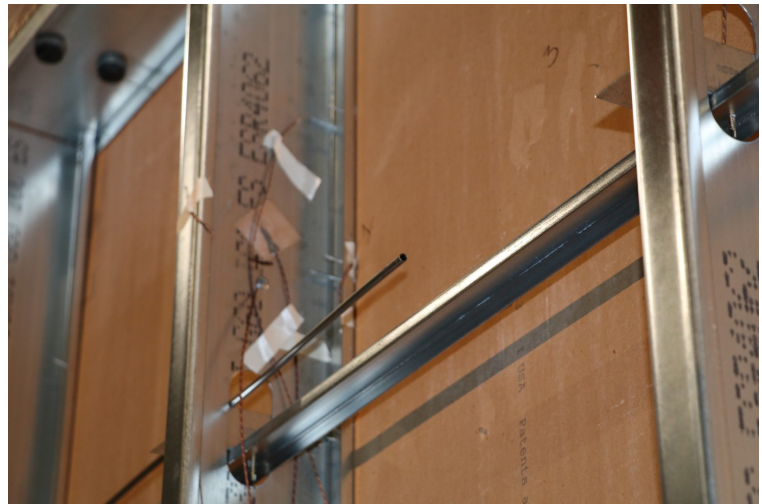

(a)
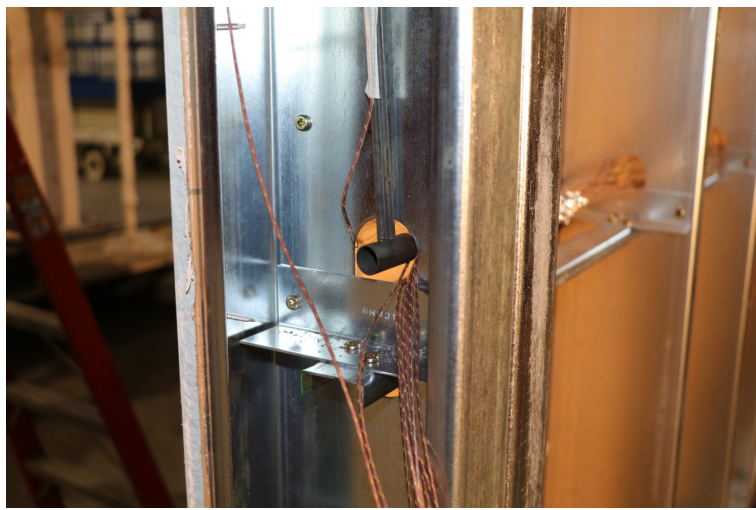

(b)

Fig. 46. Photographs of: (a) pressure sampling tube; (b) bi-directional (velocity) probe. 


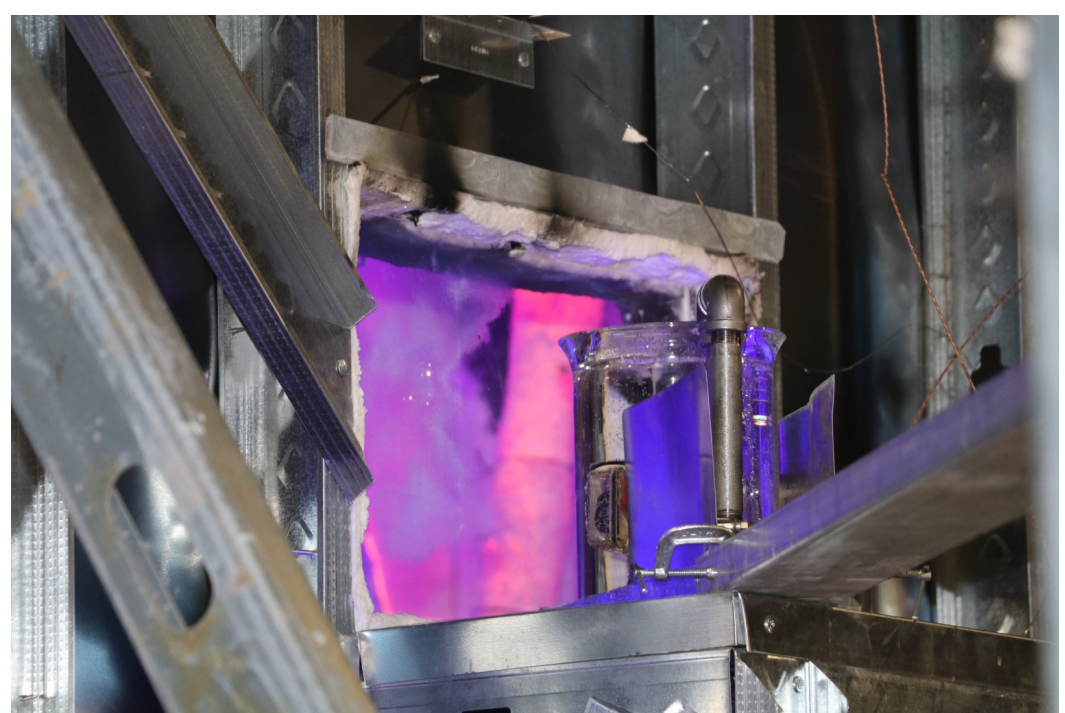

(a)

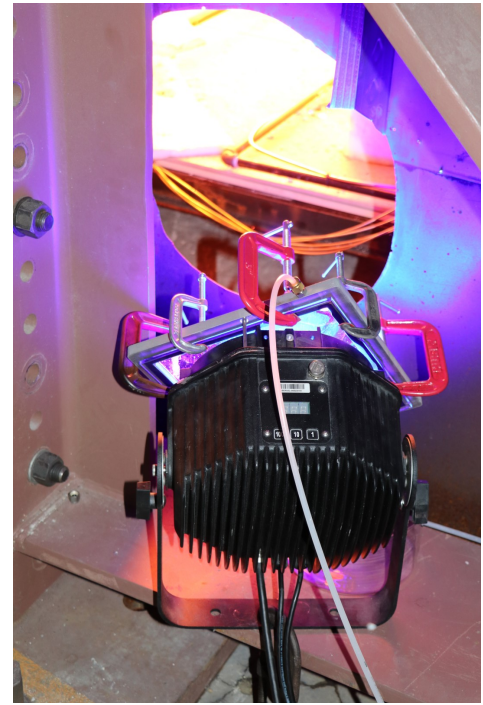

(b)

Fig. 47. Photographs imaging system on the compartment: (a) camera setup in window; (b) narrow-spectrum light source.

\subsubsection{Kitchen furnishings fire}

Fig. 48 through Fig. 50 show the locations of the sensors in the compartment for the kitchen furnishings fire. The sensors in the wall specimen were the same as for the natural gas fueled fires (see Section 2.5.2) with the exception that no air flow velocity measurements were made on the specimen because the bi-directional probes were relocated to the compartment opening.

The vertical thermocouple arrays from the natural gas fueled compartment fires were placed at the mid-depth of the compartment equidistant from the sink cabinets and the compartment centerline. In addition to a single bare-bead thermocouple located on ceiling at the center of the compartment (TC_CC), bare-bead thermocouples were placed directly above this thermocouple behind the $1^{\text {st }}$ and $2^{\text {nd }}$ layers of gypsum (TC_CC_1GB/2GB) to monitor the temperature gradient through the ceiling. The specifications for the thermocouples were described previously; Omega Engineering Model HKQIN-18G and GG-K-24, respectively.

The temperature of the ignition source was measured using two Omega Engineering Model GG-K-24 thermocouples welded to the inside bottom of the pan (TC_oil1/2).

Five plate thermocouples (Pentronic Model 5928060) with co-located thermocouples to measure gas temperatures were used in the compartment (Fig. 51): one approximately $508 \mathrm{~mm}$ (20 in.) above the pan (PT_Burner), two at the rear of compartment in front of the wall specimen $457 \mathrm{~mm}$ (18 in.) from the top and bottom of the wall (PT_WT/B), and two at the front of the compartment above the opening (PT_EN/ES). Bare-bead thermocouples were placed near the plate thermocouples behind the $1^{\text {st }}$ and $2^{\text {nd }}$ layers of gypsum (TC_EN/ES_1GB/2GB).

In addition to the measured compartment temperatures, two derivative temperatures are reported: the upper layer temperature determined as the average of the top two thermocouples on the north and south arrays (TC_AveULT) and the average temperature measured by the two plate thermocouples above the opening (TC_AveULPT). 
The bi-directional probes and co-located thermocouples (Fig. 52) described in Section 2.5.2 were located along the centerline of the opening at $1 / 3^{\text {rd }}$ and $2 / 3^{\text {rd }}$ of the opening height.

Room gases were extracted from a $6 \mathrm{~mm}(1 / 4-i n c h)$ diameter stainless steel tube with its opening approximately $305 \mathrm{~mm}$ (12 in.) below the ceiling of the compartment and analyzed using the gas measurement rack shown in Fig. 53. A Permapure MiniGASS sample conditioning system was used to filter and dry the sample gas. The sample gas flow rate was set to $1 \mathrm{slpm}$ for these tests. The delay time from the room inlet port to the gas rack was approximately $45 \mathrm{~s}$. The oxygen was measured using a paramagnetic oxygen analyzer. Carbon dioxide and carbon monoxide were measured using a nondispersive infrared (NDIR) analyzer. The analyzers were calibrated prior to the test using calibrated zero and span gases. Nitrogen gas was used to zero each analyzer and room air was used to span the oxygen analyzer. Room air was assumed to have an oxygen concentration of $20.95 \% \pm 0.05 \%$. The carbon dioxide span gas consisted of $9.0 \% \pm 0.09 \% \mathrm{CO}_{2}$ in $\mathrm{N}_{2}$ and the carbon monoxide span gas consisted of $4.0 \% \pm 0.04 \% \mathrm{CO}$ in $\mathrm{N}_{2}$. The maximum range of the $\mathrm{CO}$ and $\mathrm{CO}_{2}$ measurements was $20 \%$. All gas measurements are reported on a dry basis.

The measurement of the heat release rate was presented in Section 2.5.2.

A photoelectric smoke detector was located on the ceiling along the centerline of the compartment approximately $30.5 \mathrm{~cm}$ (12 in.) from the opening.

The water-cooled video camera used in the natural gas fueled fire tests, without narrowspectrum illumination was placed in the doorway looking toward the ignition source (Fig. 54a). The enclosure allowed 1080p resolution video to be streamed from this camera in real-time during the tests. A newly-developed $360^{\circ}$ camera water-cooled enclosure was placed adjacent to the water-cooled video camera (Fig. 54b). The camera recorded $5 \mathrm{~K}$ resolution spherical video of the test. 


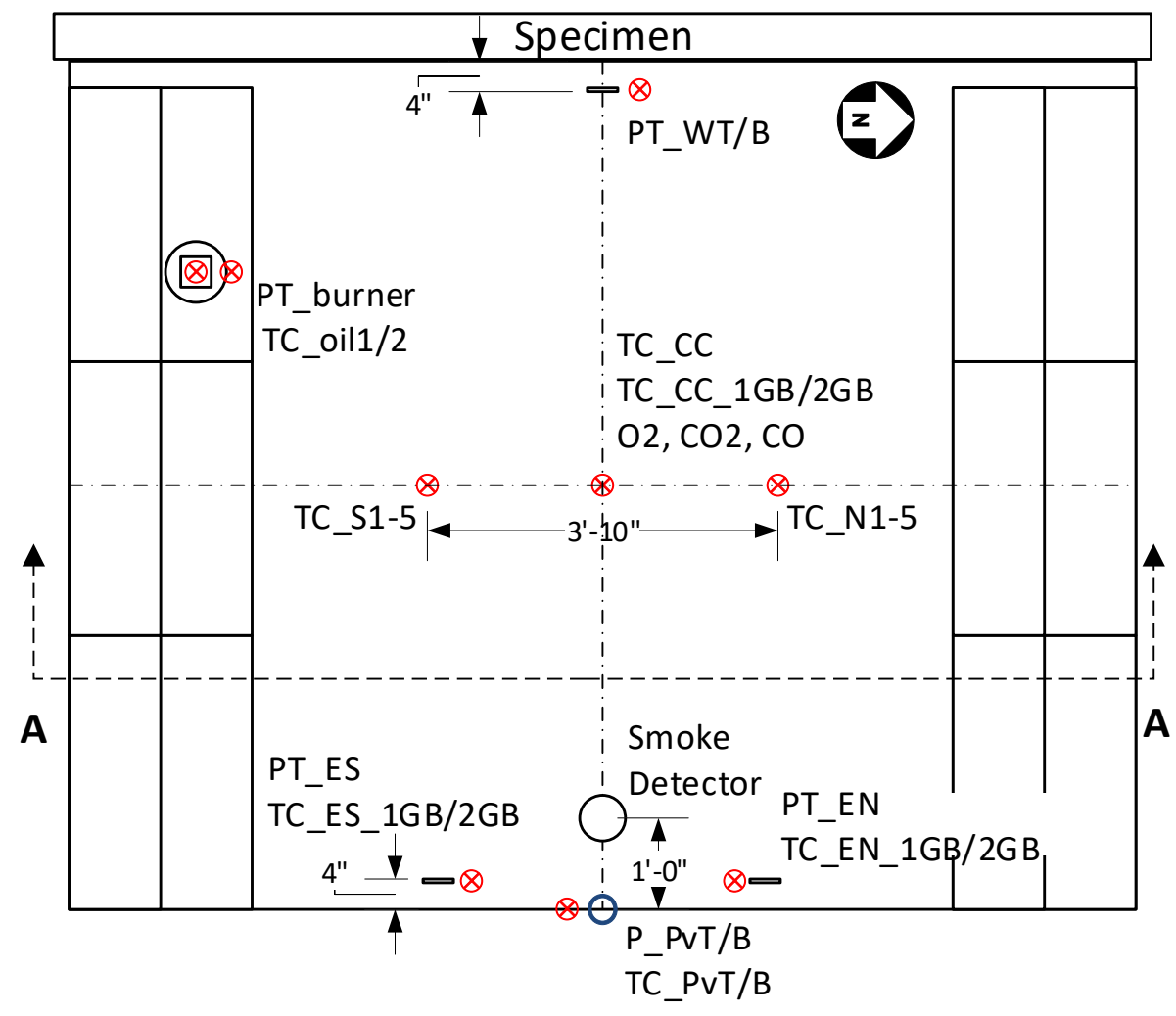

Fig. 48. Plan view of sensor locations in compartment during kitchen furnishings fire $(1 \mathrm{ft} .=30.5 \mathrm{~cm})$. 


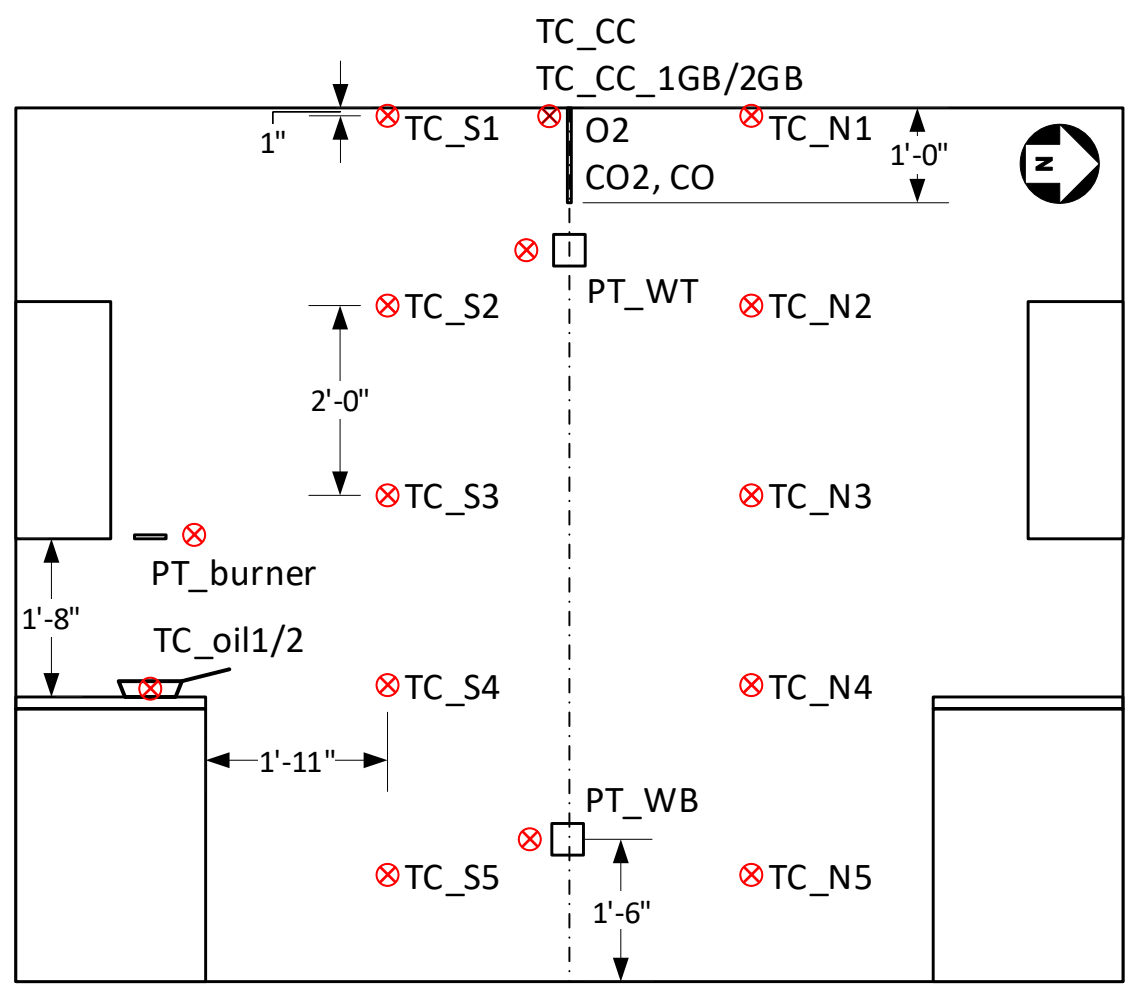

Fig. 49. Elevation view of sensor locations in compartment during kitchen furnishings fire looking west along section A-A in Fig. $48(1 \mathrm{ft} .=30.5 \mathrm{~cm})$.

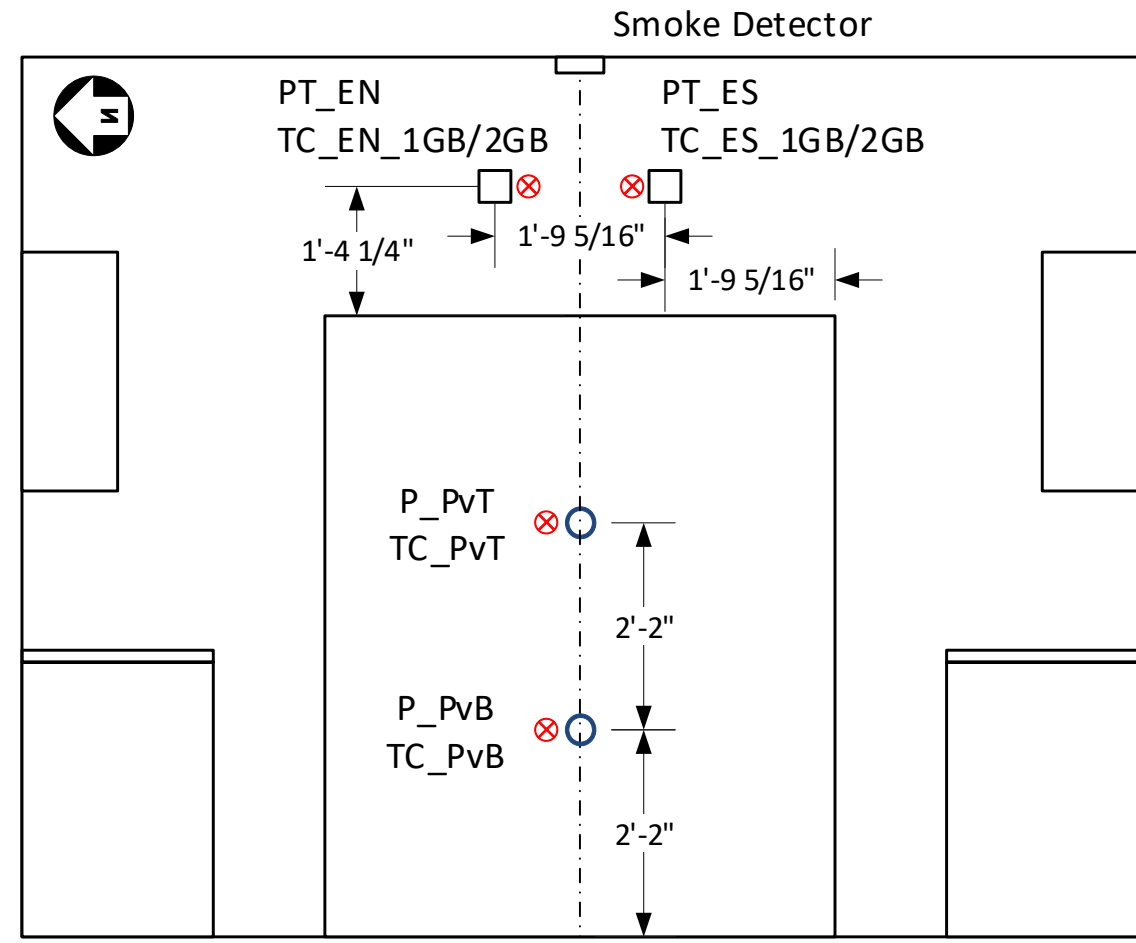

Fig. 50. Elevation view of sensor locations in compartment during kitchen furnishings fire looking east along section A-A in Fig. $48(1 \mathrm{ft} .=30.5 \mathrm{~cm})$. 


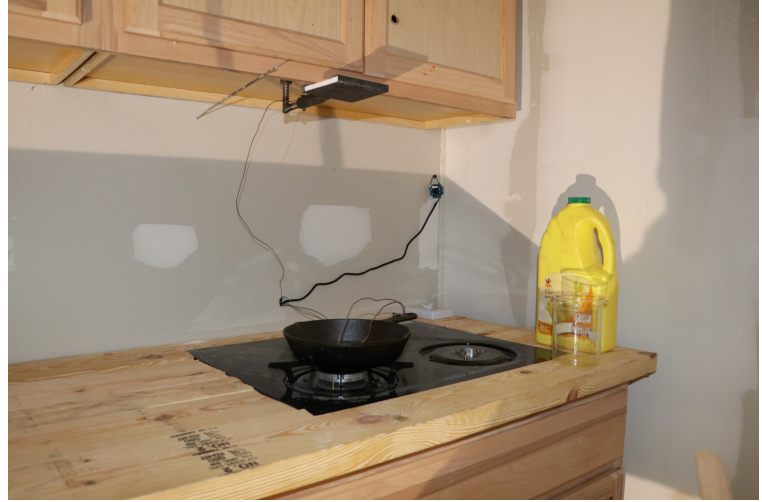

(a)

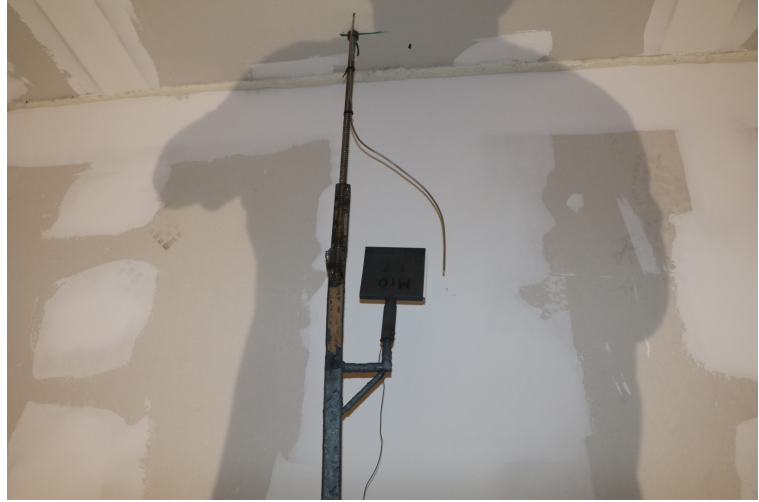

(b)

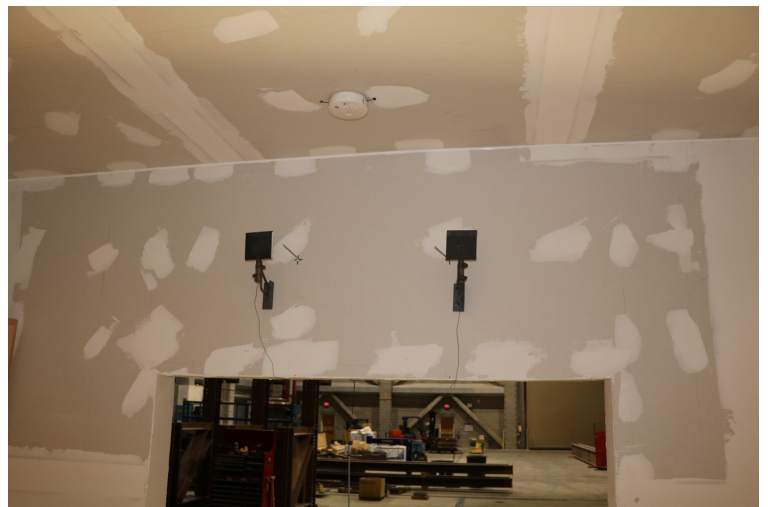

(c)

Fig. 51. Photographs of plate thermocouples and their co-located thermocouples in kitchen furnishings fire (a) above ignition source; (b) at rear of compartment in front of wall specimen at top; (c) at front of compartment above opening.

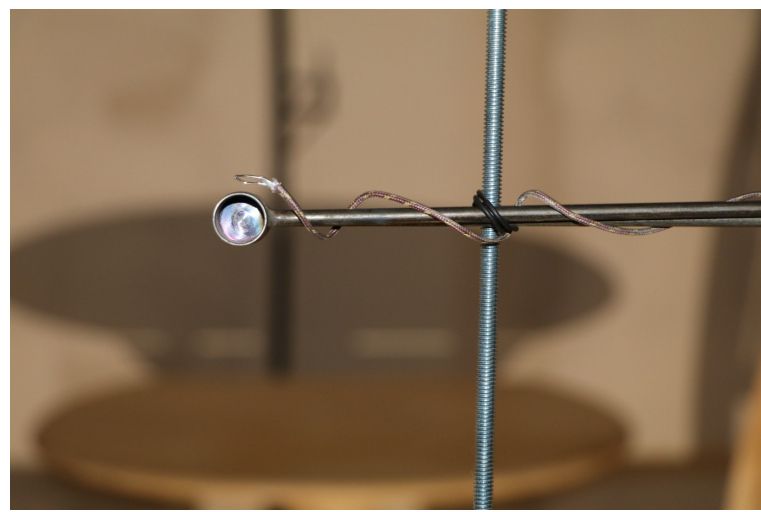

Fig. 52. Photograph of bi-direction (velocity) probe in kitchen furnishings fire. 


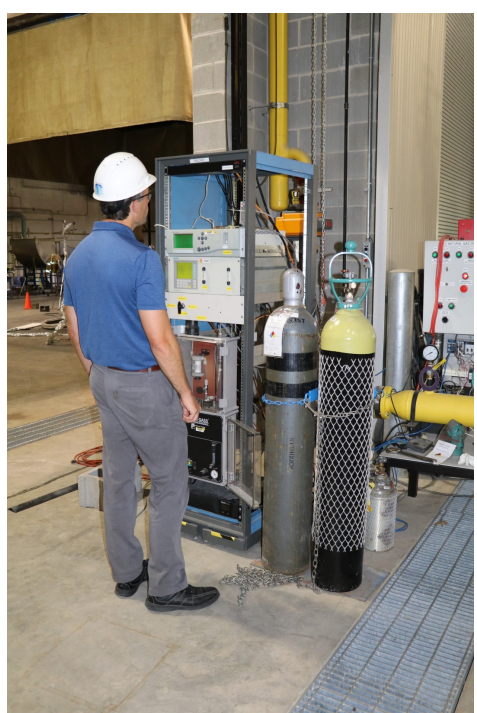

(a)

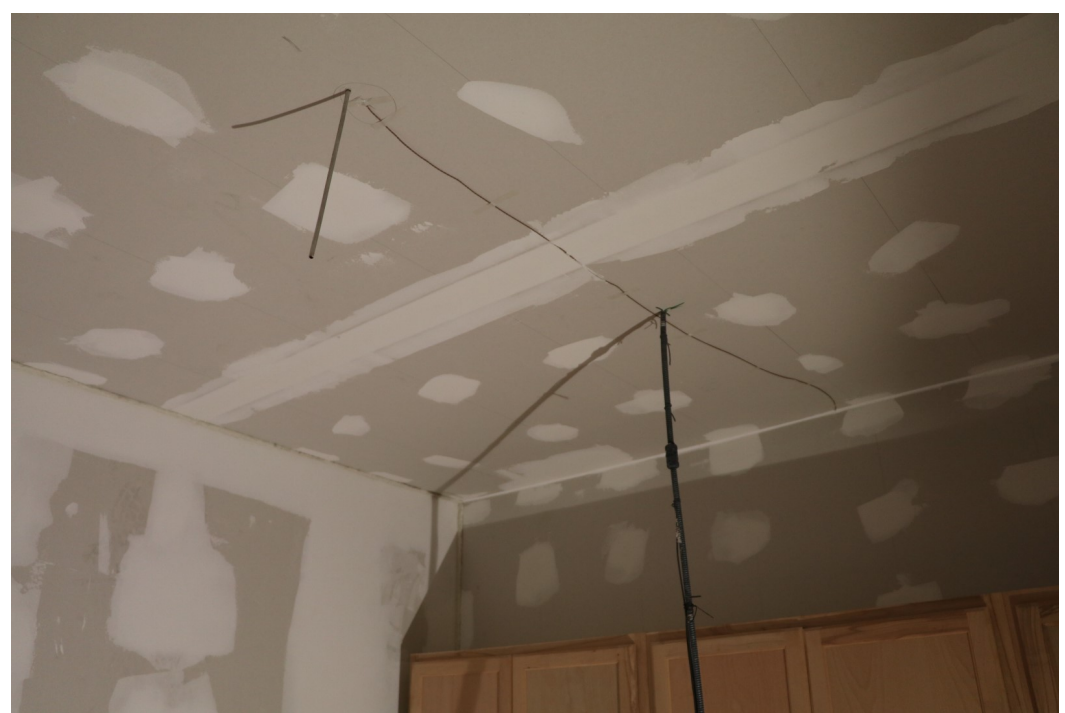

(b)

Fig. 53. Photographs of gas sampling setup in kitchen furnishings fire: (a) gas rack; (b) gas sampling tube $305 \mathrm{~mm}$ from ceiling.

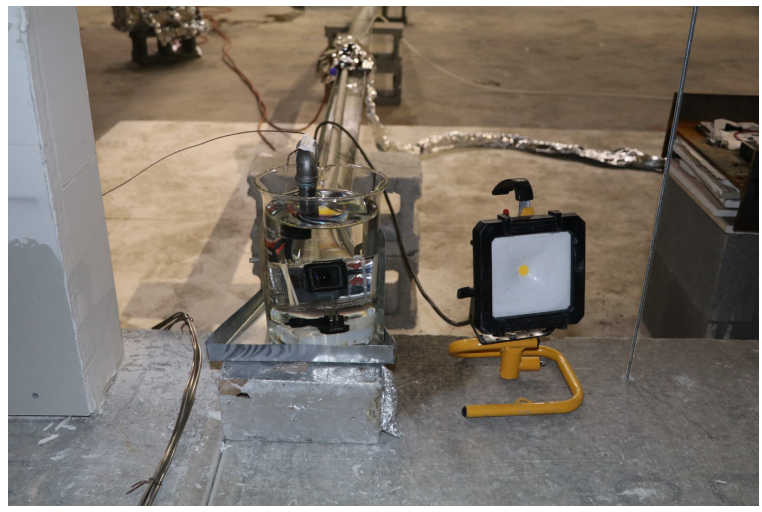

(a)

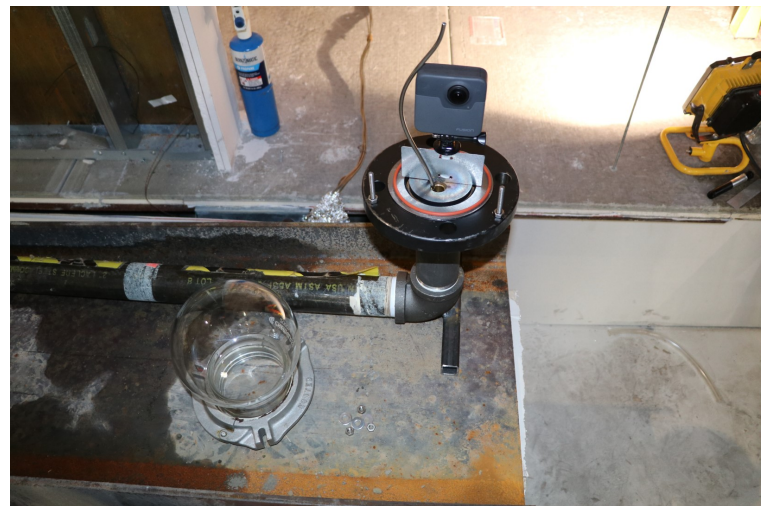

(b)

Fig. 54. Photographs of water-cooled video cameras in kitchen furnishings fire:

(a) video camera; (b) $360^{\circ}$ camera. 


\section{Results Summary}

Detailed results for each test are provided in the Appendices as well as in the electronic data associated with this report. This section presents key comparisons and discussion.

\section{1. $\quad$ Fire Exposure}

The exposure temperatures achieved in the tests are summarized in Fig. 55. The figure shows the mean values and standard deviations of the measured upper layer gas temperatures in the compartment as the average of the three top thermocouples in the thermocouple trees. The Mild Fire exhibited the largest temperature variation; however, the values are calculated from nine tests, whereas only three tests were used for the Severe and Standard fire. The temperatures generally tracked the target fire curves (see Fig. 32), with exceptions being that the rate of temperature decrease after the fire was extinguished for the Severe and Mild fires was more rapid than the targets and the temperature raise rate from $20 \mathrm{~min}$ to $60 \mathrm{~min}$ in the Standard Fire was less than in an ASTM E119 test.

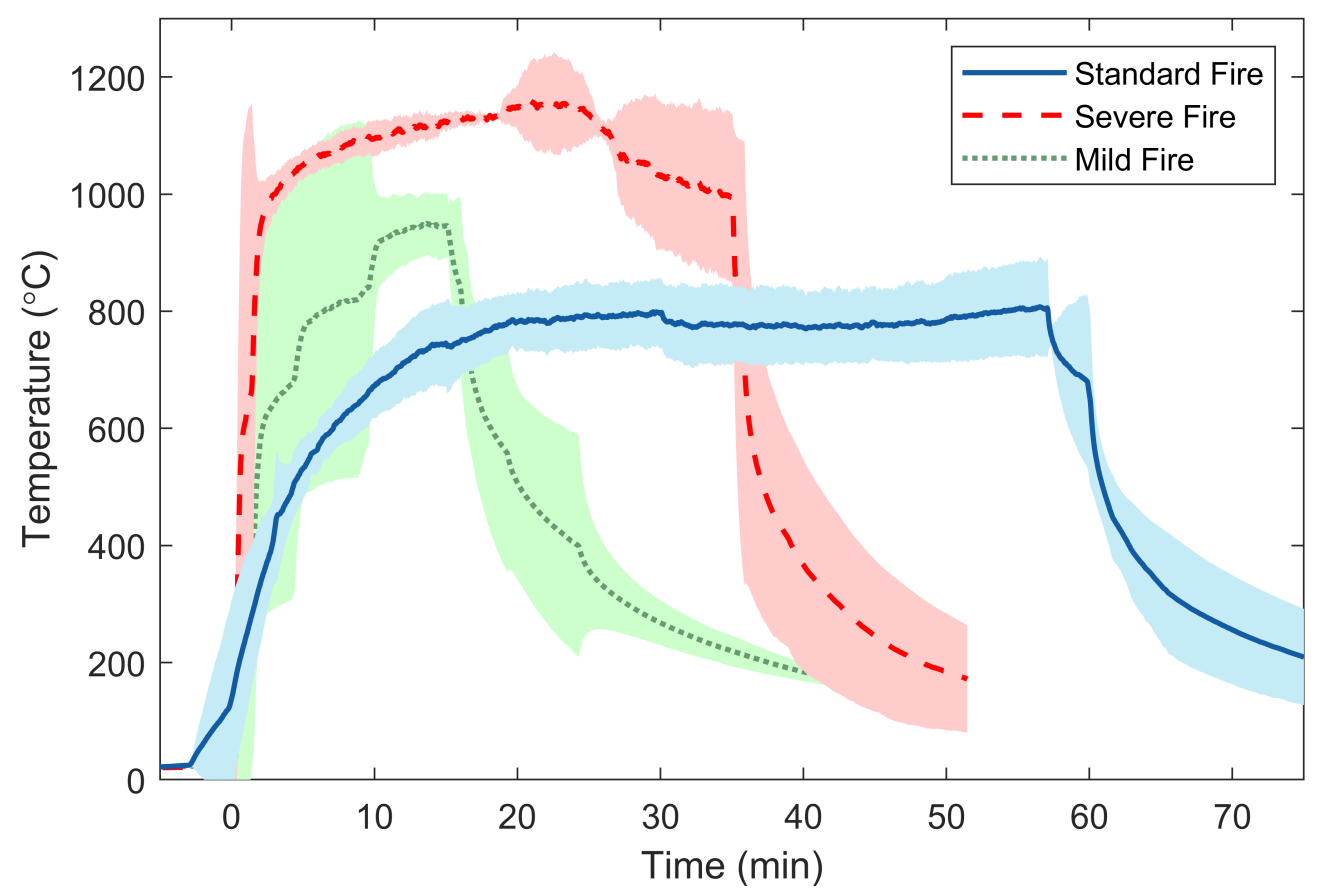

Fig. 55. Mean values (lines) and standard deviations (shaded areas) of the measured upper layer temperatures for the Standard, Severe, and Mild fires.

Fig. 56 compares the upper layer gas temperatures in the compartment measured during the tests of oriented strand board (OSB) sheathed walls for all investigated thermal exposures: Standard Fire, Severe Fire, Mild fire, and the kitchen compartment fire with real furnishings (Kitchen Fire). Each curve represents a single test replicate. The duration of the post-flashover kitchen compartment fire is similar to the Mild Fire and the temperature achieved is slightly higher; peaking to a value of $1152{ }^{\circ} \mathrm{C}$. Notably, the temperature rise rate and peak temperature in the Kitchen Fire are significantly higher than for the Standard Fire. The local peak in temperature approximately $22 \mathrm{~min}$ after ignition in the Severe Fire is due to the additional 
thermal load provided by the burning OSB. The reason for the decrease in temperature approximately 30 min after ignition in the Standard Fire is unknown but may have been due to localized natural gas leakage around the perimeter of the burner that cooled the compartment.

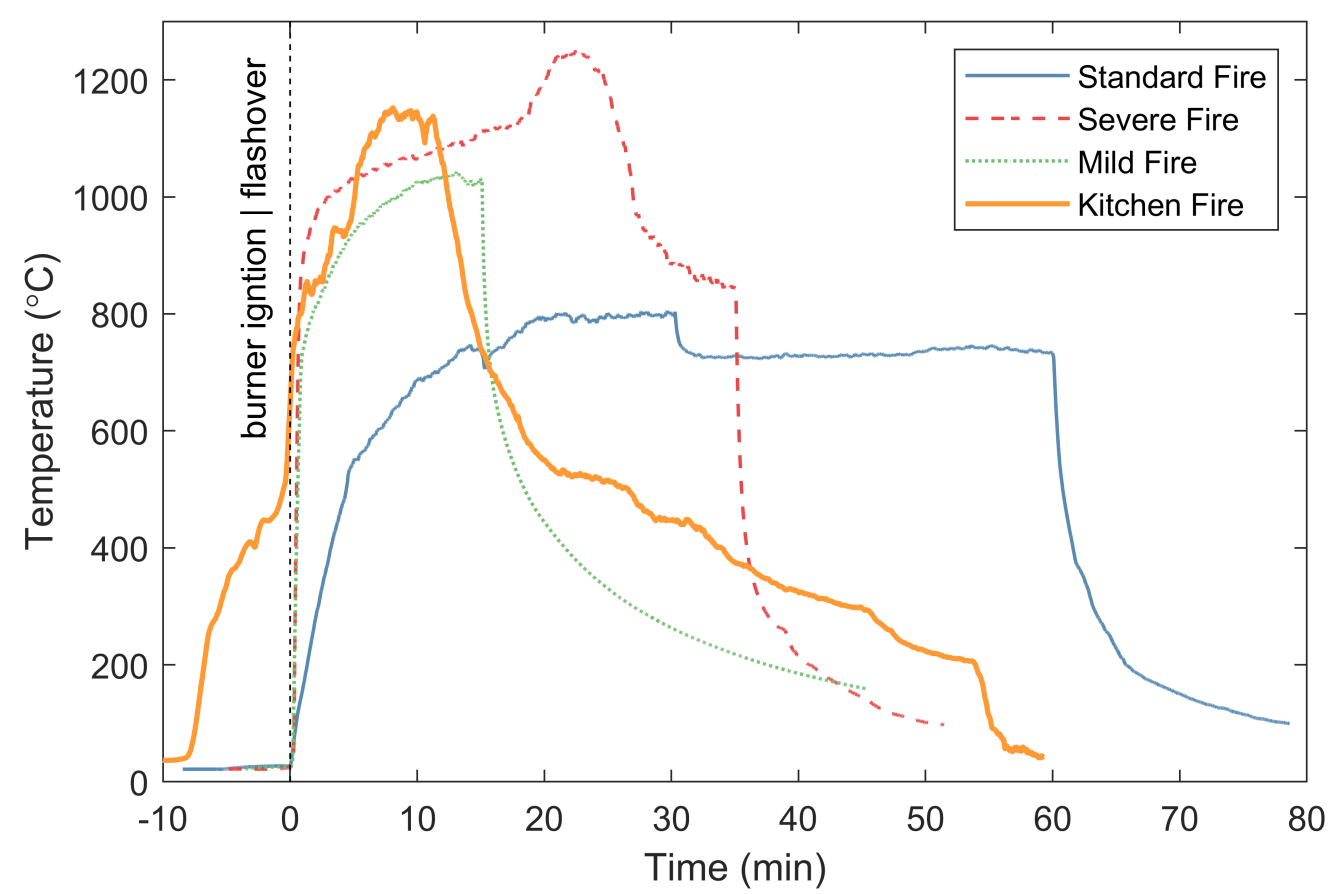

Fig. 56. Comparison of measured upper layer temperatures for OSB sheathed walls.

The spatial and temporal variation of the heat flux to the specimen is illustrated in Fig. 57 to Fig. 59. The heat fluxes are calculated from the nine plate thermocouples attached to the back wall of the compartment. The mean of the measurement for each plate thermocouple is shown by a heavy dashed line. For all fires, the heat fluxes are greatest at the top of the compartment and at the center of the compartment where the burner was located. The mean and standard deviation at the peak heat flux for each location and fire are provided in the figures. The heat flux at the top of the specimen for both the Mild and Severe Fire is significantly larger than in the Standard Fire. For comparison, the heat flux measured at the top and bottom of the specimen during the Kitchen Fire is shown in Fig. 60. Heat fluxes greater than $200 \mathrm{~kW} / \mathrm{m}^{2}$ were observed in the Kitchen Fire. The heat flux intensities and distributions are also useful to understand the performance of the wall systems discussed in the subsequent sections. 

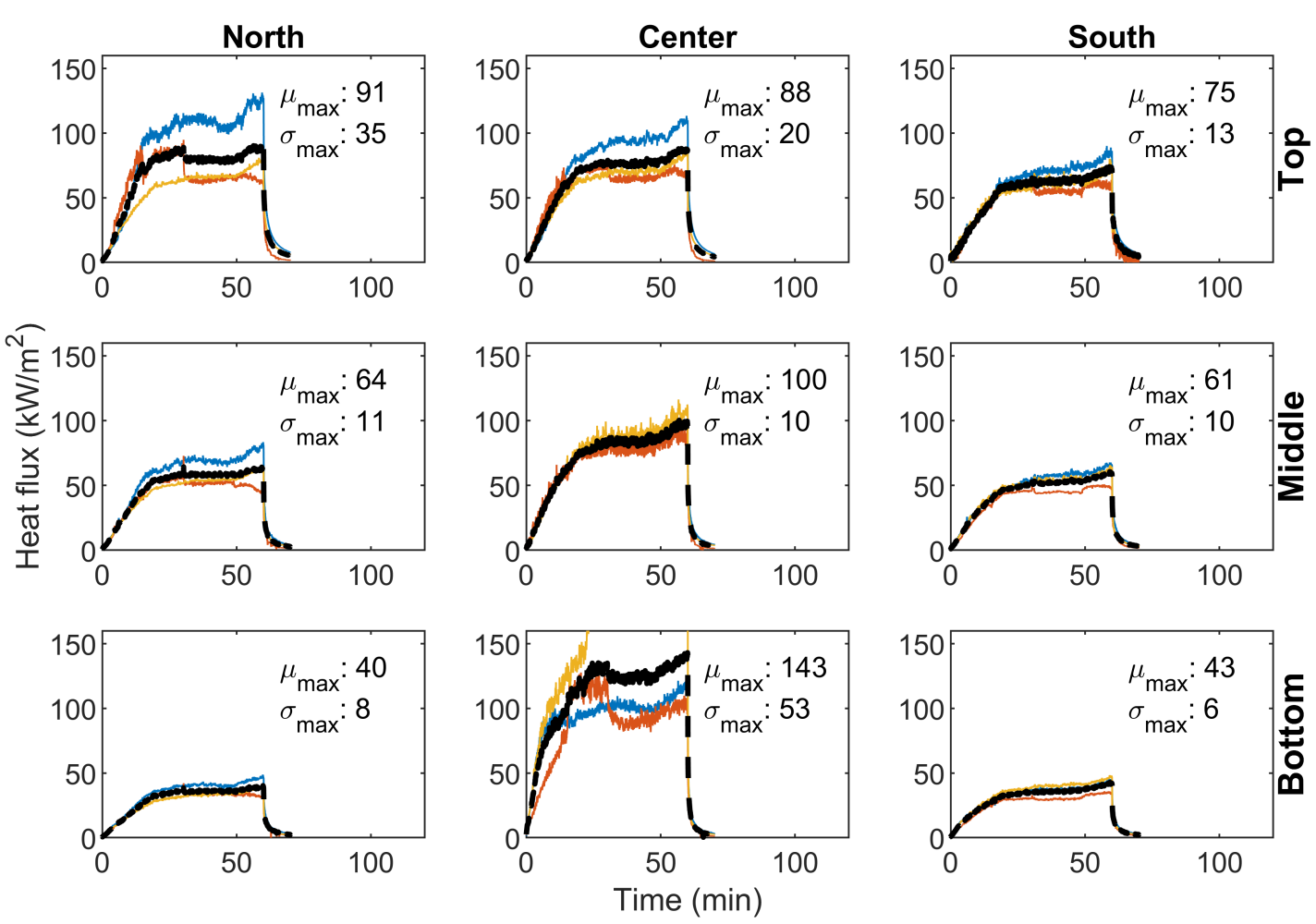

Fig. 57. Distribution of heat flux in compartment for Standard Fires.
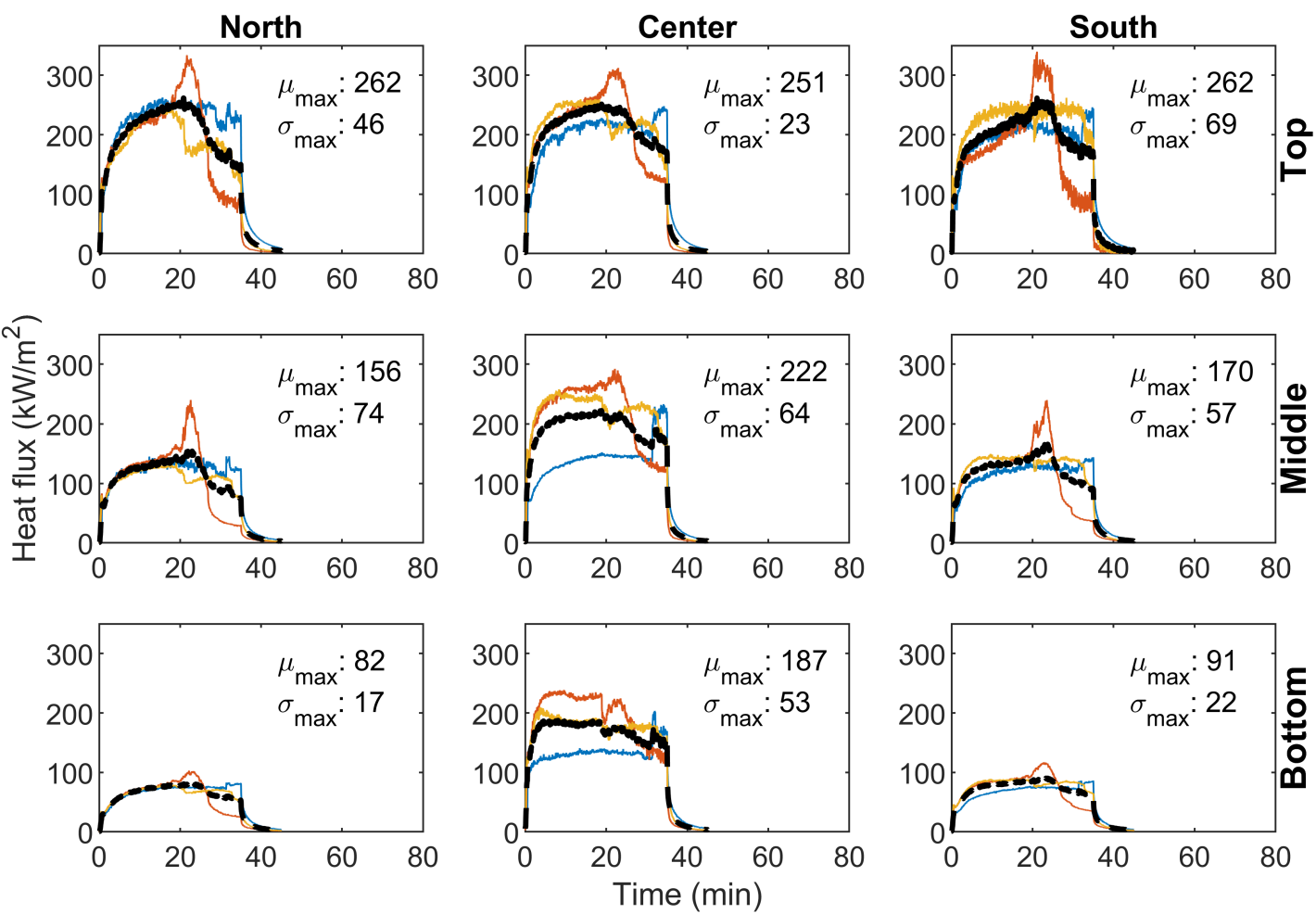

Fig. 58. Distribution of heat flux in compartment for Severe Fires. 

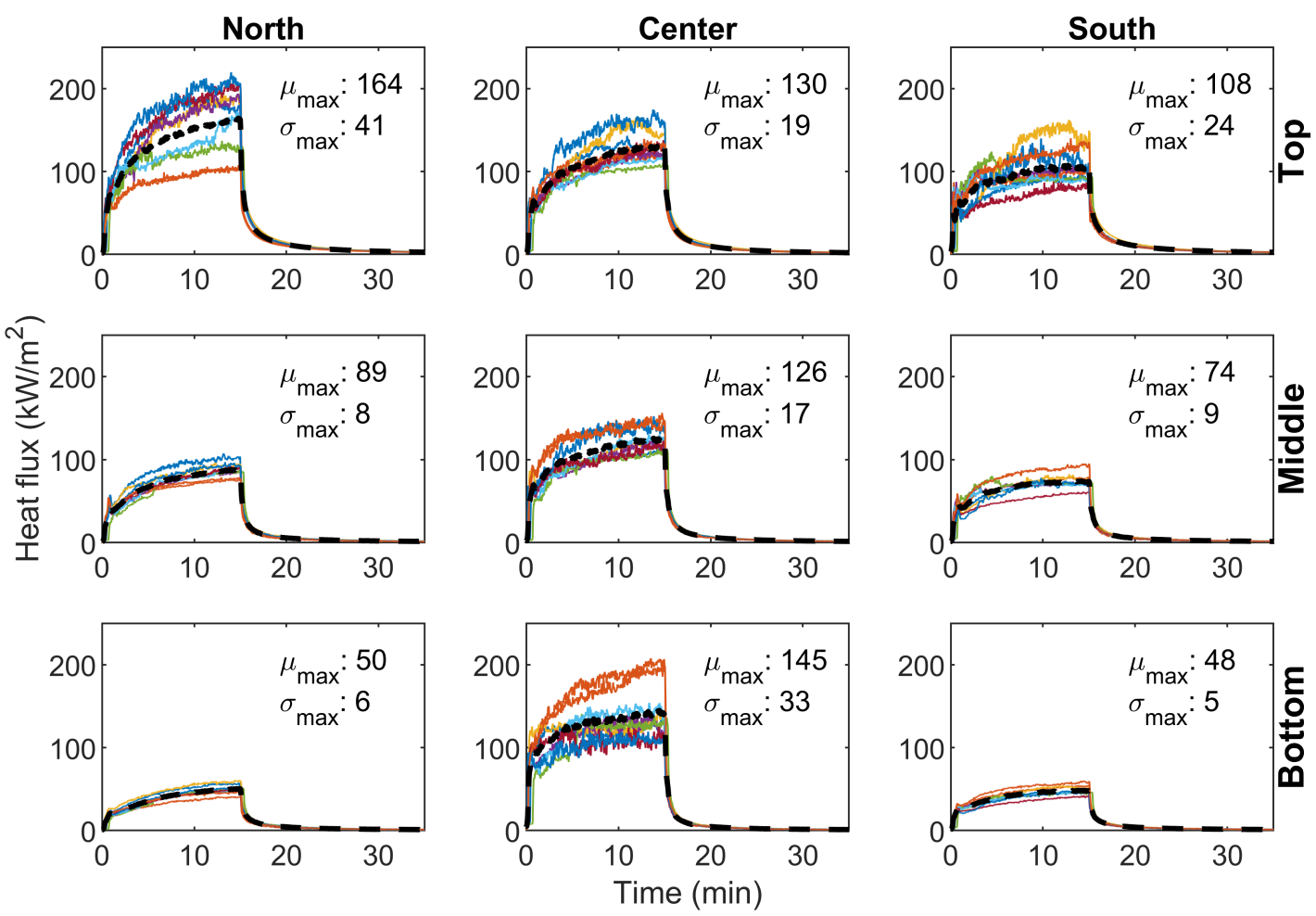

Fig. 59. Distribution of heat flux in compartment for Mild Fires.

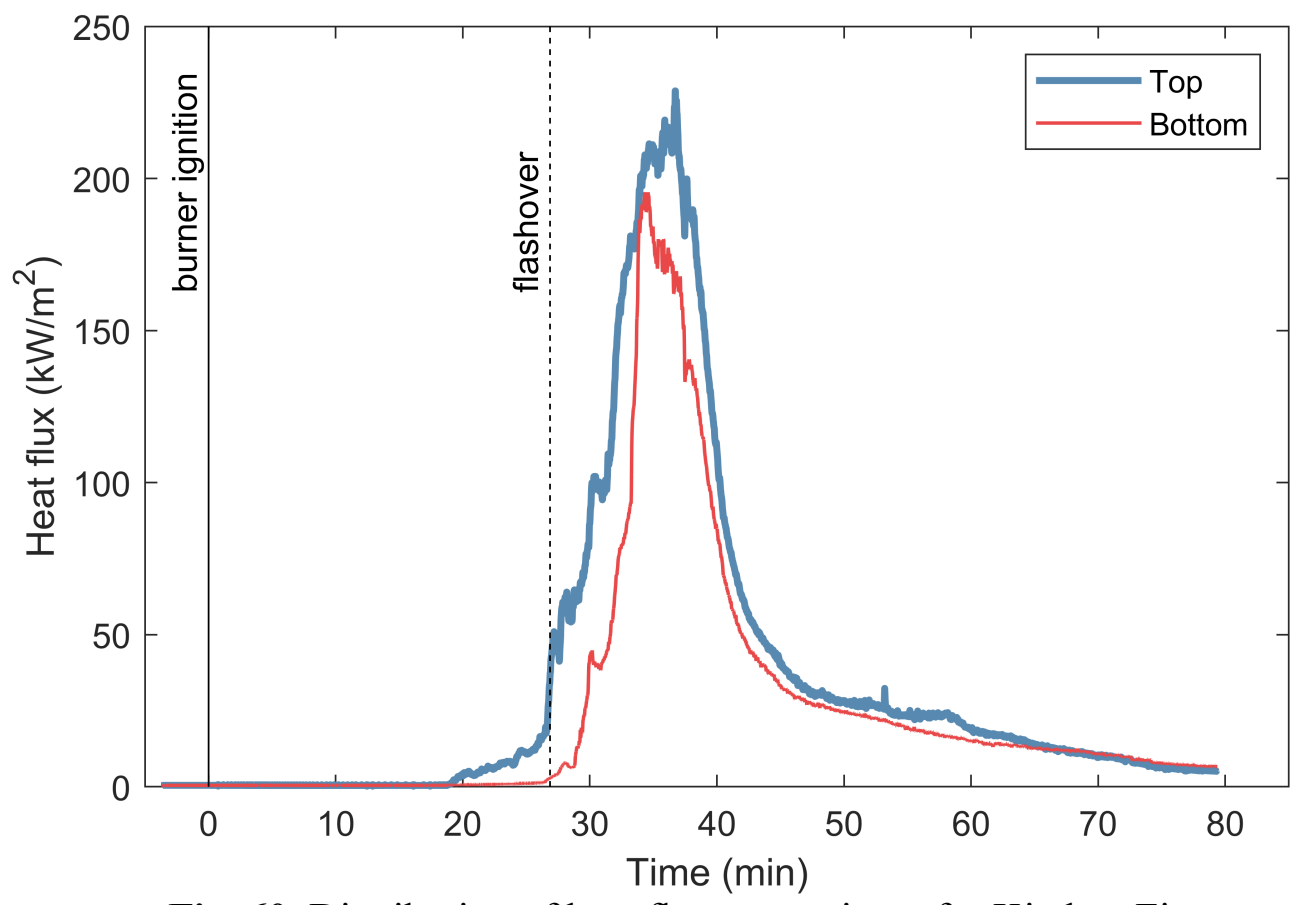

Fig. 60. Distribution of heat flux to specimen for Kitchen Fire. 


\subsection{Gypsum-Sheet Steel Composite Panel Sheathed Wall Performance}

Fig. 61 plots the applied actuator (lateral) force versus top-of-wall drift (measured at the end of the wall opposite the actuator) during mechanical loading of the gypsum-sheet steel composite panel sheathed walls for a representative case for each investigated fire loading. The peak forces achieved at each step of the loading protocol (refer to Table 3 ) for positive (circle) and negative (square) actuator excursions are indicated on the plots. The peak forces, along with the story drift ratio (SDR) at the peak force - defined as the measured drift divided by the wall height - are provided along with the force reduction relative to the wall capacity at ambient temperature (SB01) in Table 5 for all tests. The peak force versus displacement 'envelopes' provided an alternate representation of the relative performance of the walls in Fig. 62. Only the positive excursions are shown in Fig. 62, because the behavior is approximately symmetric with respect to loading direction, and the positive excursion occurred before the corresponding negative one.

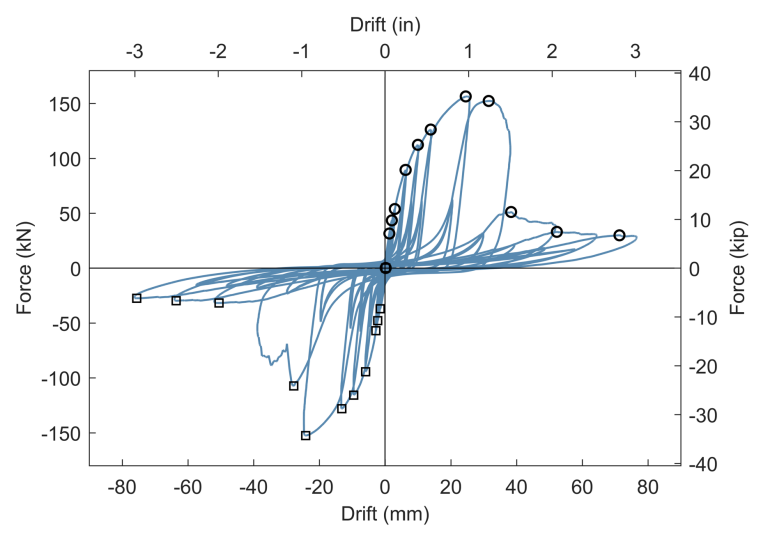

(a)

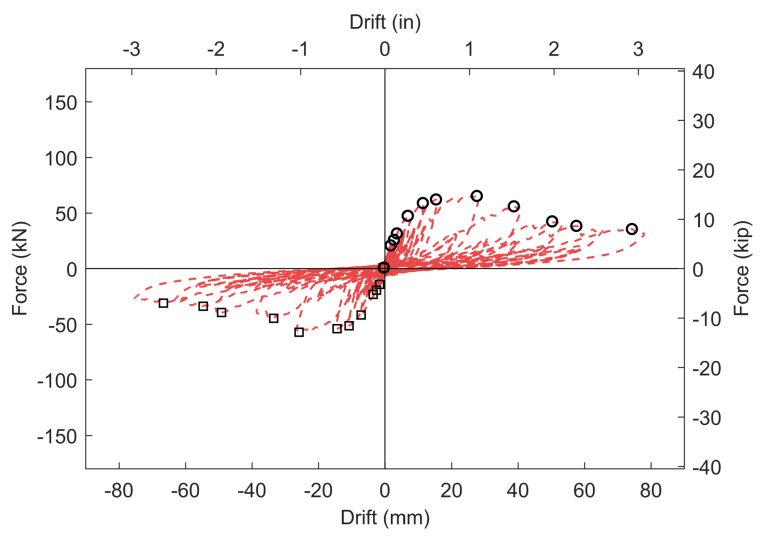

(c)

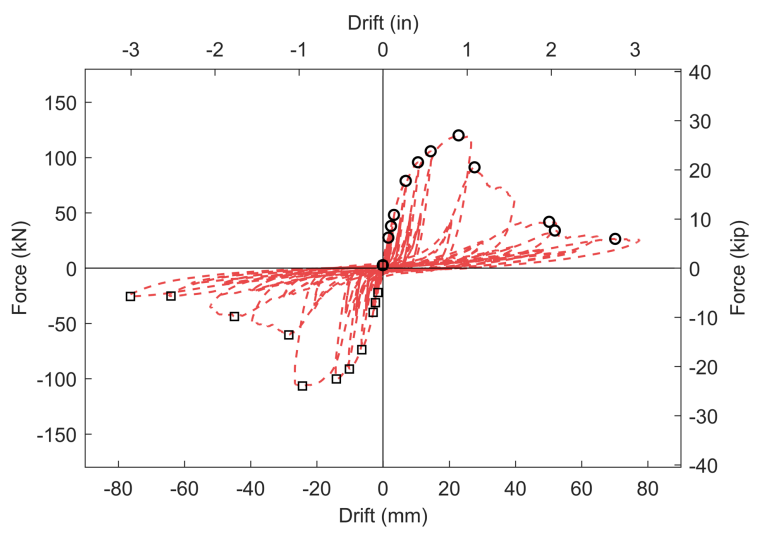

(b)

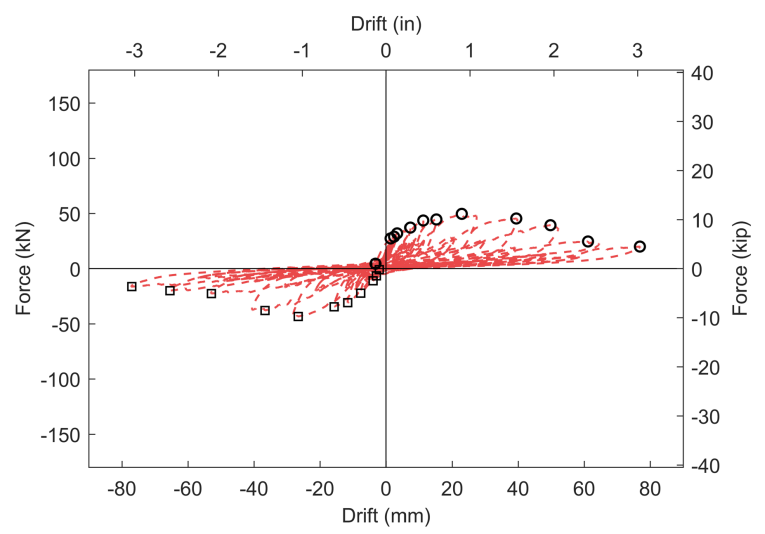

(d)

Fig. 61. Lateral force versus drift during mechanical loading of gypsum-sheet steel composite panel sheathed walls: (a) cycling without fire (SB01); (b) cycling after Mild Fire (SB03); (c) cycling after Standard Fire (SB04); (d) cycling after Severe Fire (SB02). 
Table 5. Peak forces and story drift ratios for gypsum-steel composite panel sheathed walls.

\begin{tabular}{c|c|c|c|c|c|c}
\hline \multirow{2}{*}{ Specimen } & & & $\begin{array}{c}\text { Force } \\
\text { reduction, \% }\end{array}$ & $\begin{array}{c}\text { Peak } \\
\text { force, } \mathbf{k N}\end{array}$ & & \\
\hline SB01 & 156.4 & 0.89 & 0 & -152.6 & -0.88 & 0 \\
SB02 & 49.6 & 0.84 & 68 & -43.3 & -0.97 & 72 \\
SB03 & 120.1 & 0.83 & 23 & -106.6 & -0.89 & 30 \\
SB03R & 140.5 & 0.92 & 10 & -132.7 & -0.94 & 13 \\
SB04 & 65.4 & 1.01 & 58 & -57.2 & -0.94 & 63 \\
\hline
\end{tabular}

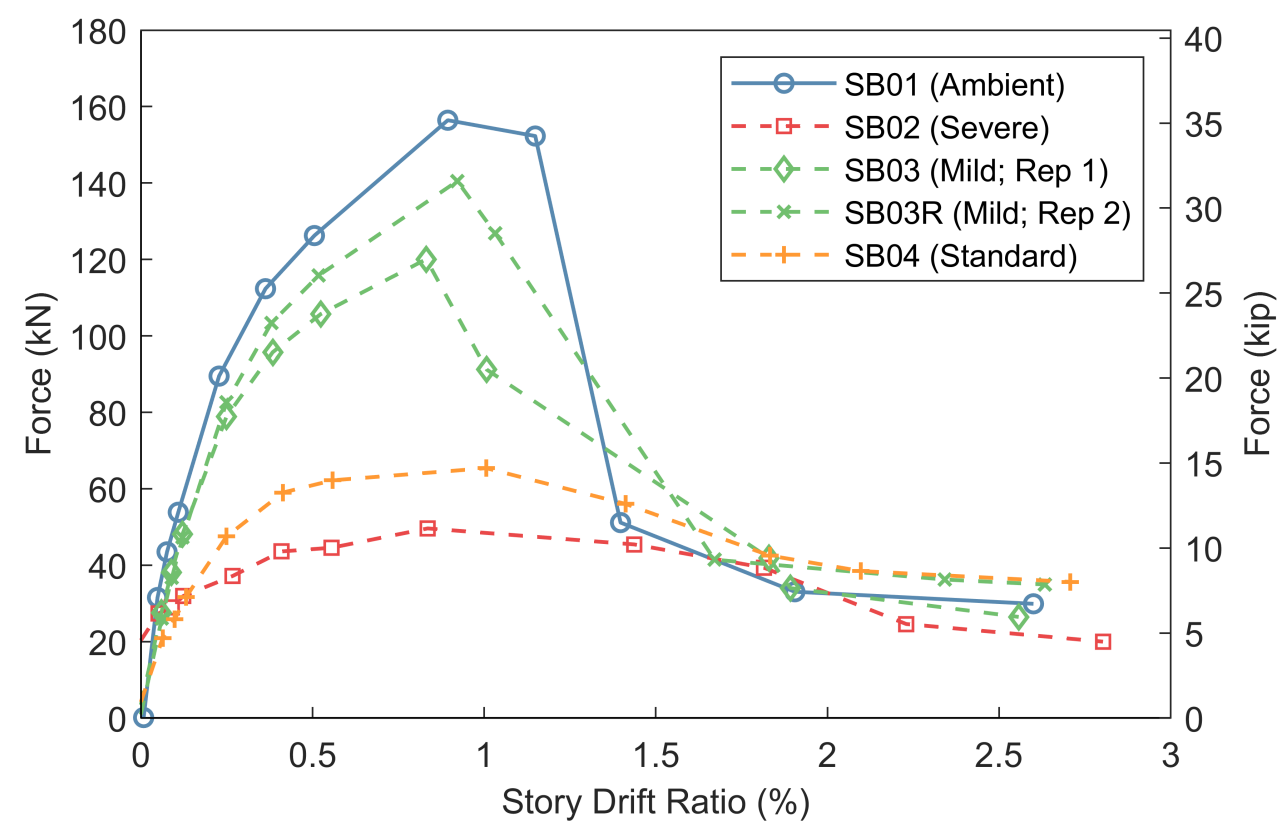

Fig. 62. Lateral load versus story drift ratio (positive excursions only) during mechanical loading of gypsum-sheet steel composite panel sheathed walls.

In this limited set of experiments, this wall system exhibited increasingly diminished post-fire capacity with increasing fire severity. The reduction in the peak force capacity (based on positive excursions) was $10 \%$ to $23 \%, 58 \%$, and $68 \%$ for the Mild, Standard and Severe Fire, respectively. The primary failure mode during cycling at ambient temperature (without fire) was failure of the shear panel connections. Connection failures were a combination of fastener failure and edge tear out of the sheet steel or pull-thorough of the fastener head through the sheet steel (Fig. 63a, Fig. 64a). The Mild Fire severely degraded the mechanical strength of the gypsum on the fire-exposed side of the wall and locally degraded the adhesive bonding the gypsum to the sheet steel on the unexposed side of the wall (Fig. 63b). Damage to the adhesive between the sheet steel and the gypsum reduces the stiffness of the panels out-ofplane, in effect, changing the specimen from a composite panel sheathed wall to a plain sheet steel shear wall with an accompanying capacity reduction. For more examples of failure mode transitions of these panels following a fire see (Hoehler et al., 2017). The smaller force 
reduction in Mild Fire test repeat SB03R compared to SB03 is due to the lower temperature and consequently less damage to the adhesive - experienced by the sheet steel in SB03R; approximately $175{ }^{\circ} \mathrm{C}$ versus $250{ }^{\circ} \mathrm{C}$ near the top of the wall. The Standard Fire further degraded the adhesive and more widespread buckling of the sheet steel occurred (Fig. 63c). In the Severe Fire, the fire damaged nearly all the adhesive on the composite panels, oxidized (burned through) several screws along the top the wall and burned through the sheet steel at a few locations (Fig. 63d and Fig. 64b). Nevertheless, the load was redistributed, and the system continued to resist lateral load. The loss of galvanization on the sheet steel (dull versus shiny) in Fig. 63 provides an indication of the extent and spatial distribution of the heating of the sheet steel.

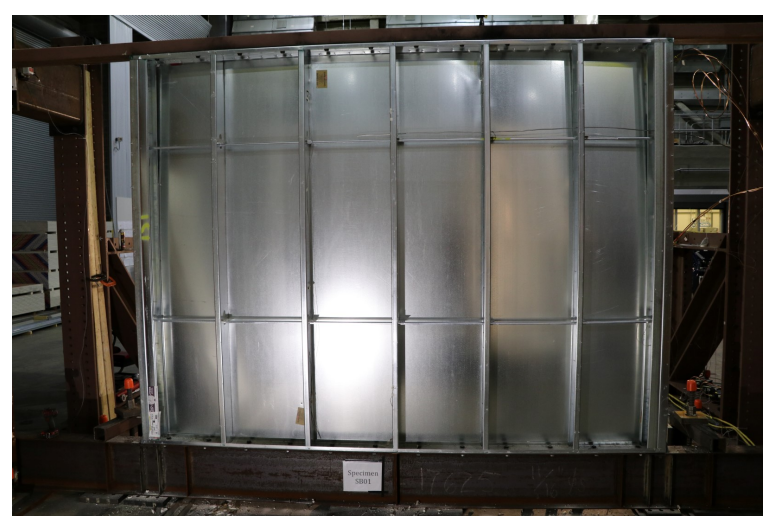

(a)

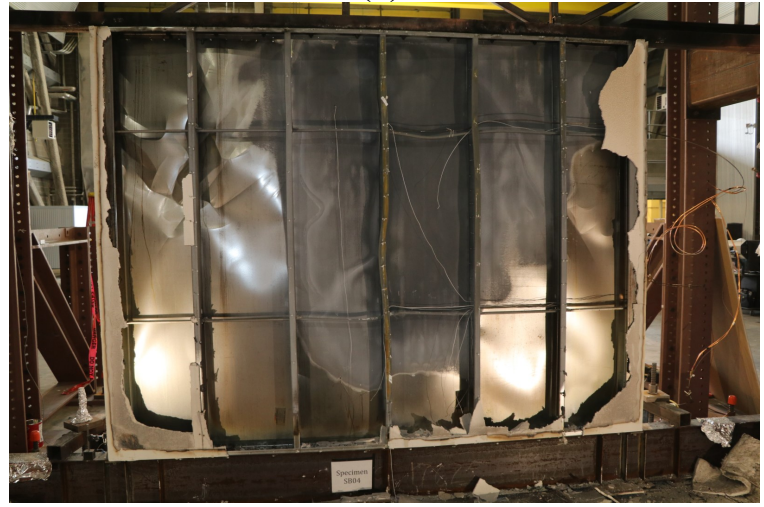

(c)

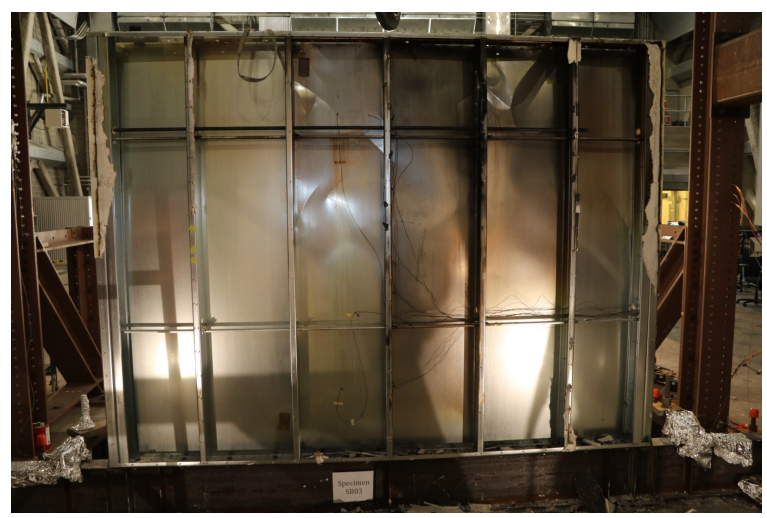

(b)

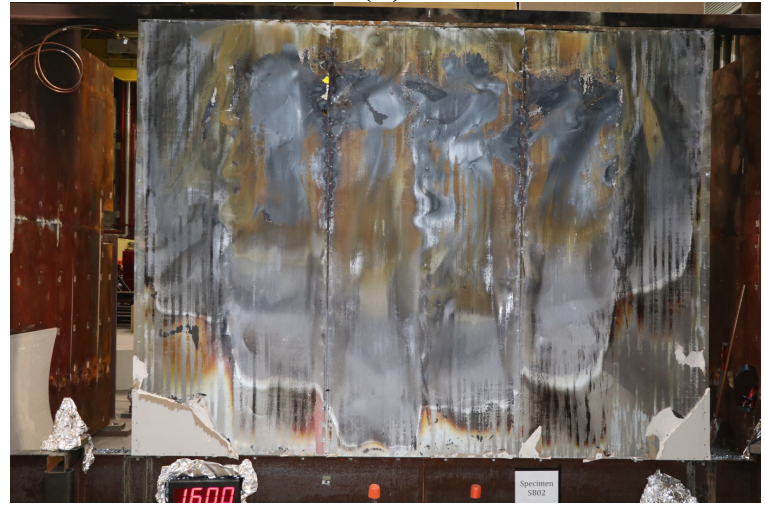

(d)

Fig. 63. Photographs of gypsum-sheet steel composite panel sheathed walls after: (a) cycling without fire (SB01); (b) cycling after Mild Fire (SB03); (c) cycling after Standard Fire (SB04); (d) cycling after Severe Fire (SB02). 


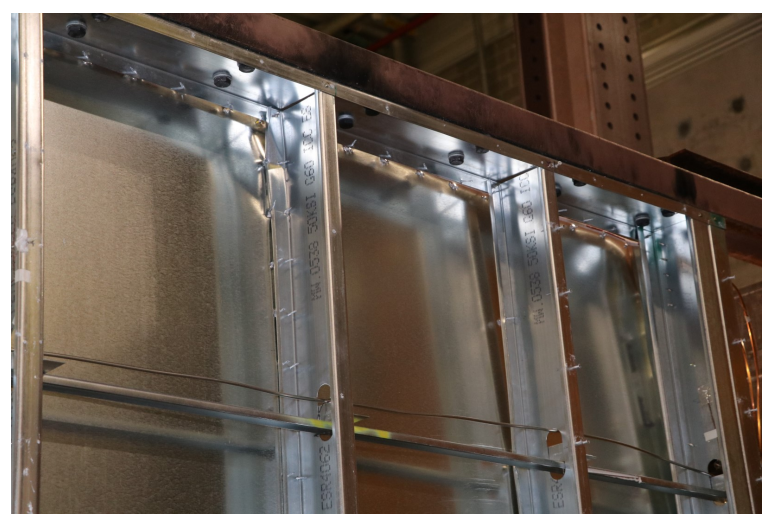

(a)

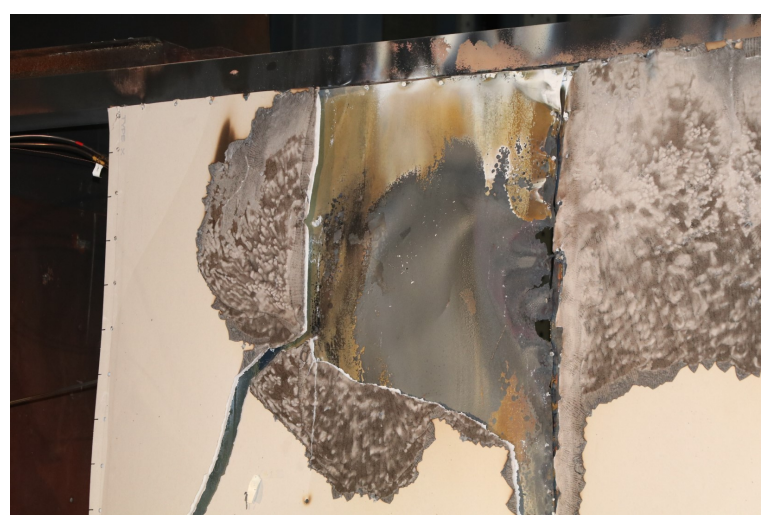

(b)

Fig. 64. Photograph of details of failure modes for gypsum-sheet steel composite panel sheathed walls: (1) perimeter fastener failure after cycling without fire (SB01); (b) local burn-through (oxidation) of sheet steel after the Severe Fire (SB02).

Fig. 65 plots temperatures on the unexposed side of the walls for the investigated fires as the mean values (lines) and standard deviations (shaded areas). The temperatures remain below $100{ }^{\circ} \mathrm{C}$ for the Mild Fire and below $125^{\circ} \mathrm{C}$ for the Standard Fire; fulfilling the temperature criteria of maximum temperature raise from initial temperature of $139{ }^{\circ} \mathrm{C}$ in ASTM E119. During the Severe Fire, temperatures on the unexposed side were observed raising above $139{ }^{\circ} \mathrm{C}$ after 30 min due to flames spreading through the gypsum board joints and burning of the paper lining of the gypsum boards. Fig. 66 shows the state of the unexposed side of the wall after the fire test. The Mild and Standard fires caused little damage on the unexposed side of the wall (Fig. 66a,b). After the Severe Fire, paper on the unexposed side has burned locally and gypsum has debonded from the steel sheet (Fig. 66c).

Fig. 67 plots temperatures through the specimen cross section $46 \mathrm{~cm}$ from the top of the wall at an interior stud. None of the specimens were subjected to cycling (pre-damage) prior to the fire; previous studies had shown the post-fire lateral capacity of these walls to be insensitive to pre-damage (Hoehler et al., 2017). The plateau in temperatures near $100{ }^{\circ} \mathrm{C}$ is linked to the dehydration of gypsum boards, which undergo a two-step calcination reaction when heated that releases bound and free water. The length of the plateau depends on the heat flux to the specimen and is therefore longer for the Standard Fire than for the Mild or Severe Fires. This can be seen more clearly by comparing the temperatures for the interior stud for the three fire scenarios in Fig. 68. For both the Standard and Severe fires, temperatures greater than $500{ }^{\circ} \mathrm{C}$ were observed at the interior stud.

The events marked as 'extinction' were the times when the gas valve to the burner was closed. Gas present in the line between the value and the burner allowed the combustion to continue for a short period after this event. The events marked 'start of ramp' are the times when the burner heat release rate first exceeded $300 \mathrm{~kW}$. 


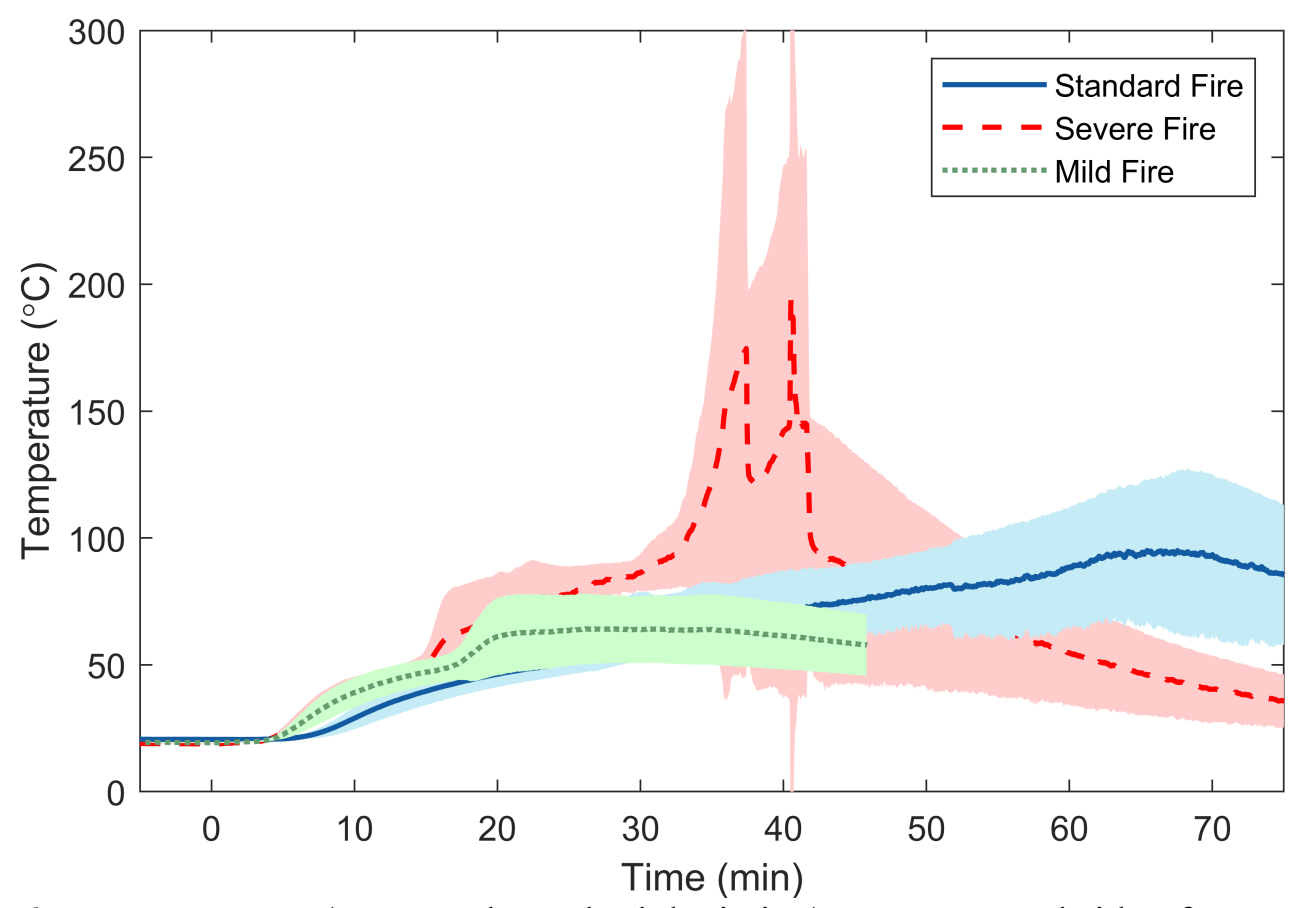

Fig. 65. Temperatures (mean and standard deviation) on unexposed side of gypsum-sheet steel composite panel sheathed walls.

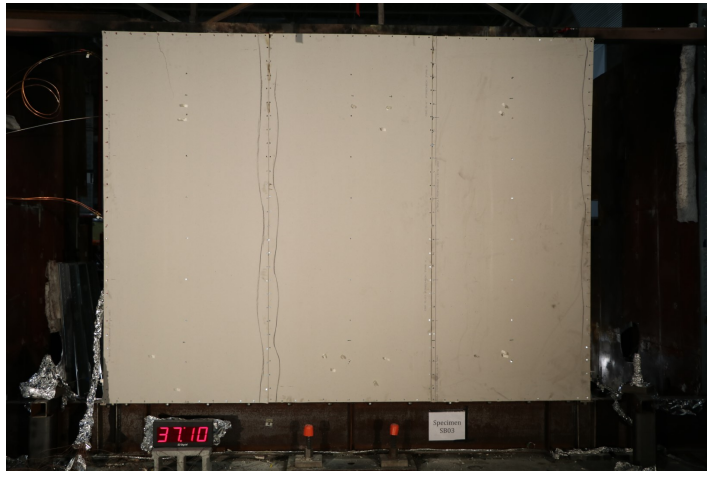

(a)

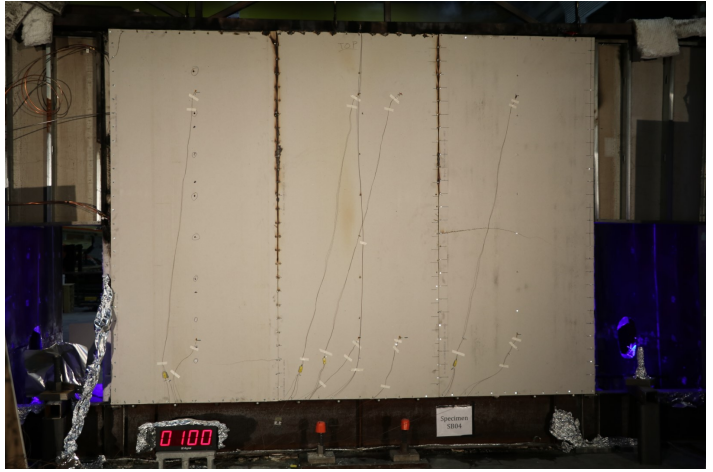

(b)

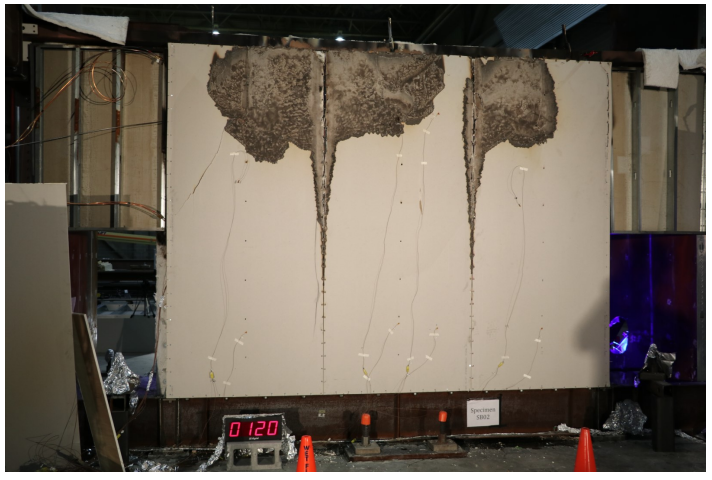

(c)

Fig. 66. Photographs of unexposed side of gypsum-sheet steel composite panel sheathed walls after fire test (before cycling): (a) Mild Fire; (b) Standard Fire; (c) Severe Fire. 


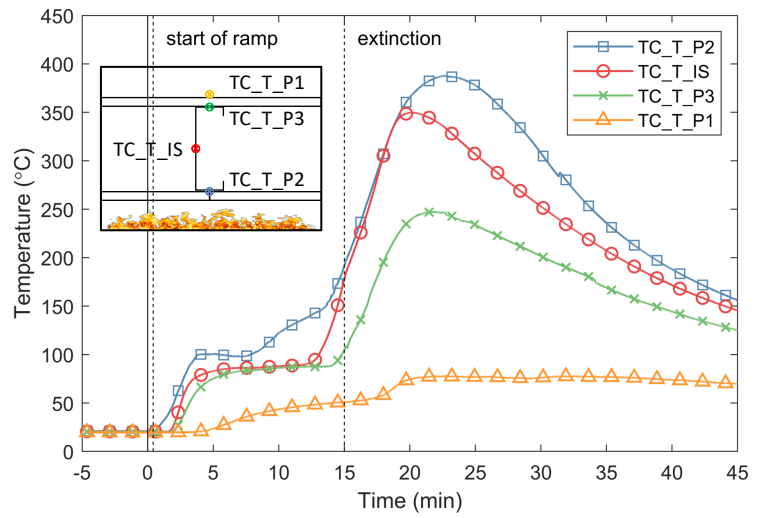

(a)

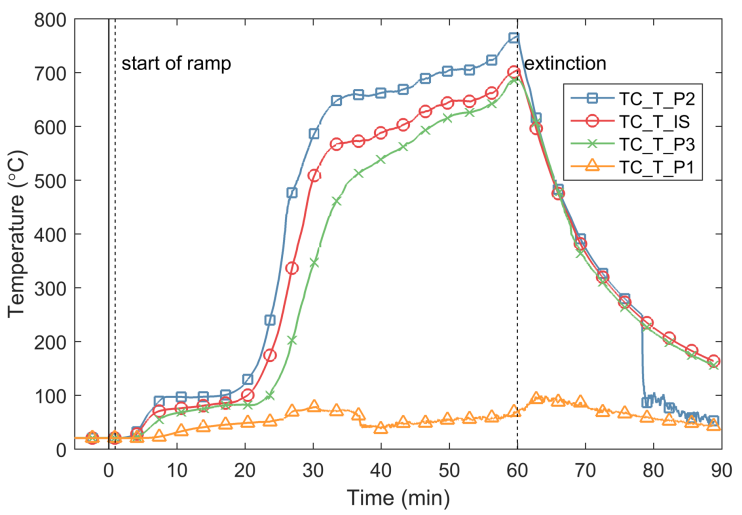

(c)

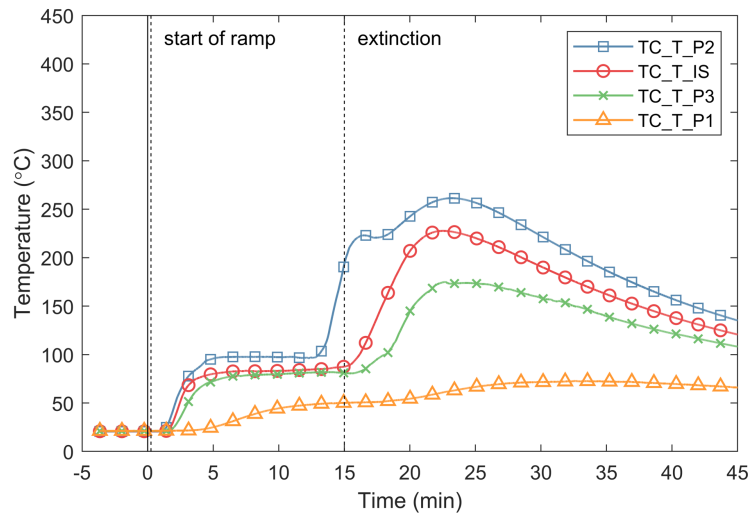

(b)

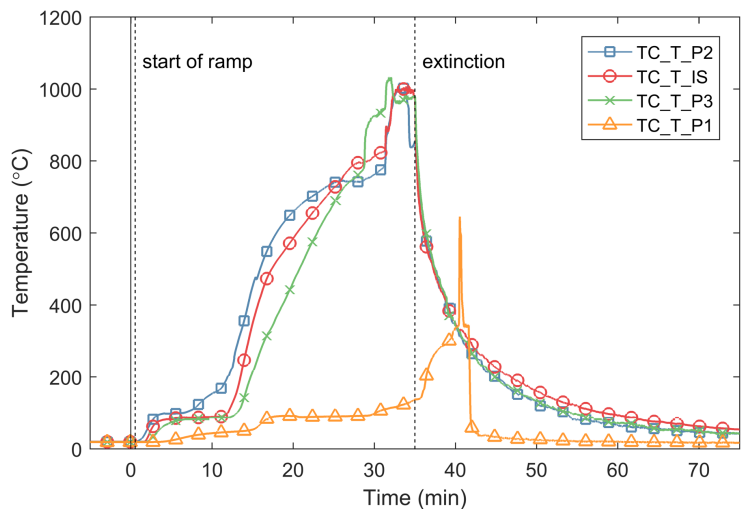

(d)

Fig. 67. Temperatures through the specimen at an interior stud $46 \mathrm{~cm}$ from the top of gypsum-sheet steel composite panel sheathed walls: (a) Mild Fire (SB03); (b) Mild Fire (SB03R); (c) Standard Fire (SB04); (d) Severe Fire (SB02).

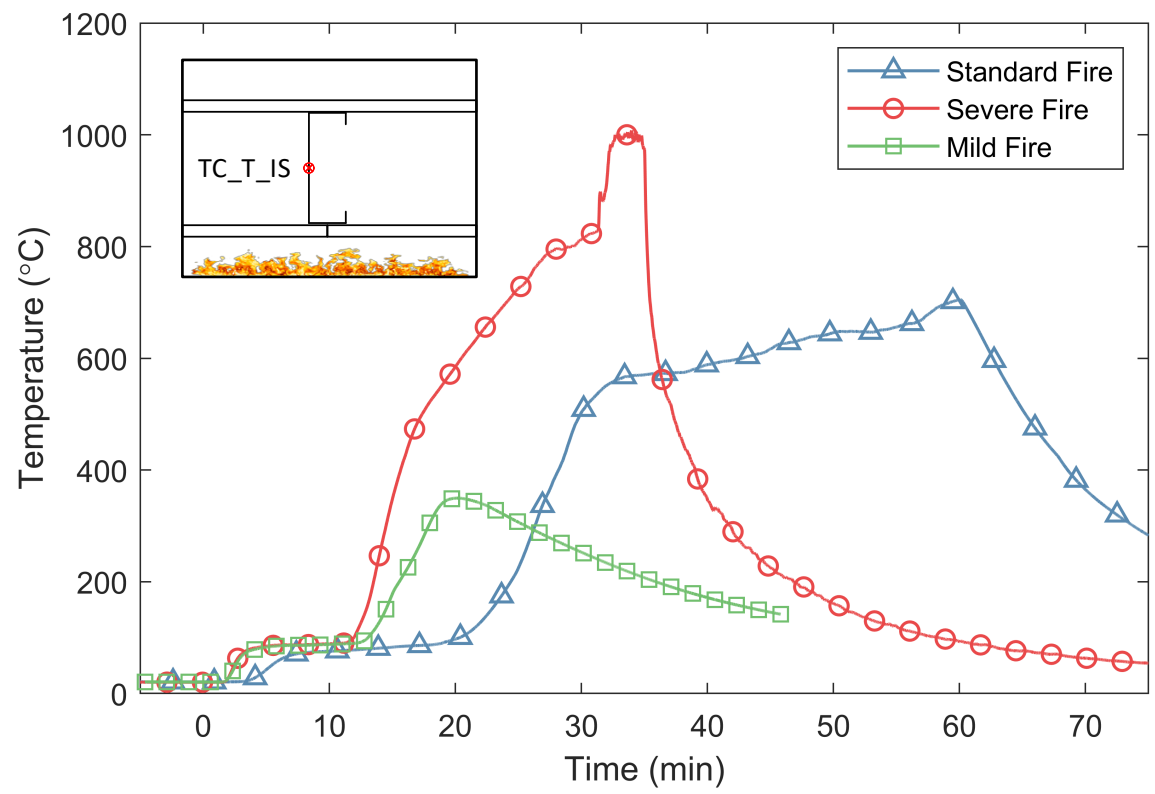

Fig. 68. Interior stud temperatures $46 \mathrm{~cm}$ from the top of the wall (TC_ T_IS) for gypsumsheet steel composite panel sheathed wall. 
Fig. 69 shows the measured pressure in the wall cavity between the center studs approximately $56 \mathrm{~cm}$ from the top of the wall for the investigated fires. The peak pressure differential between the wall cavity and the ambient pressure in the test hall ranged from about $5 \mathrm{~Pa}$ (Mild Fire) to $12 \mathrm{~Pa}$ (Severe Fire).

Fig. 70 compares the air flow velocities at the top and bottom knockout of the north chord stud for the investigated fires. While for the Mild Fire there is nearly continuous inflow (negative velocity) of ambient air into the wall at the lower knockout, for the Standard and Severe Fire there are periods of time when the is air flow out of the wall cavity (positive velocity) from both the top and bottom knockouts. It is noted that inflow and outflow of air from the wall due to leakage; e.g. at board edges and seams or when the gypsum board starts to crack during due to the thermal load, is not captured by these measurements and may vary based on the wall construction materials and quality of the installation.

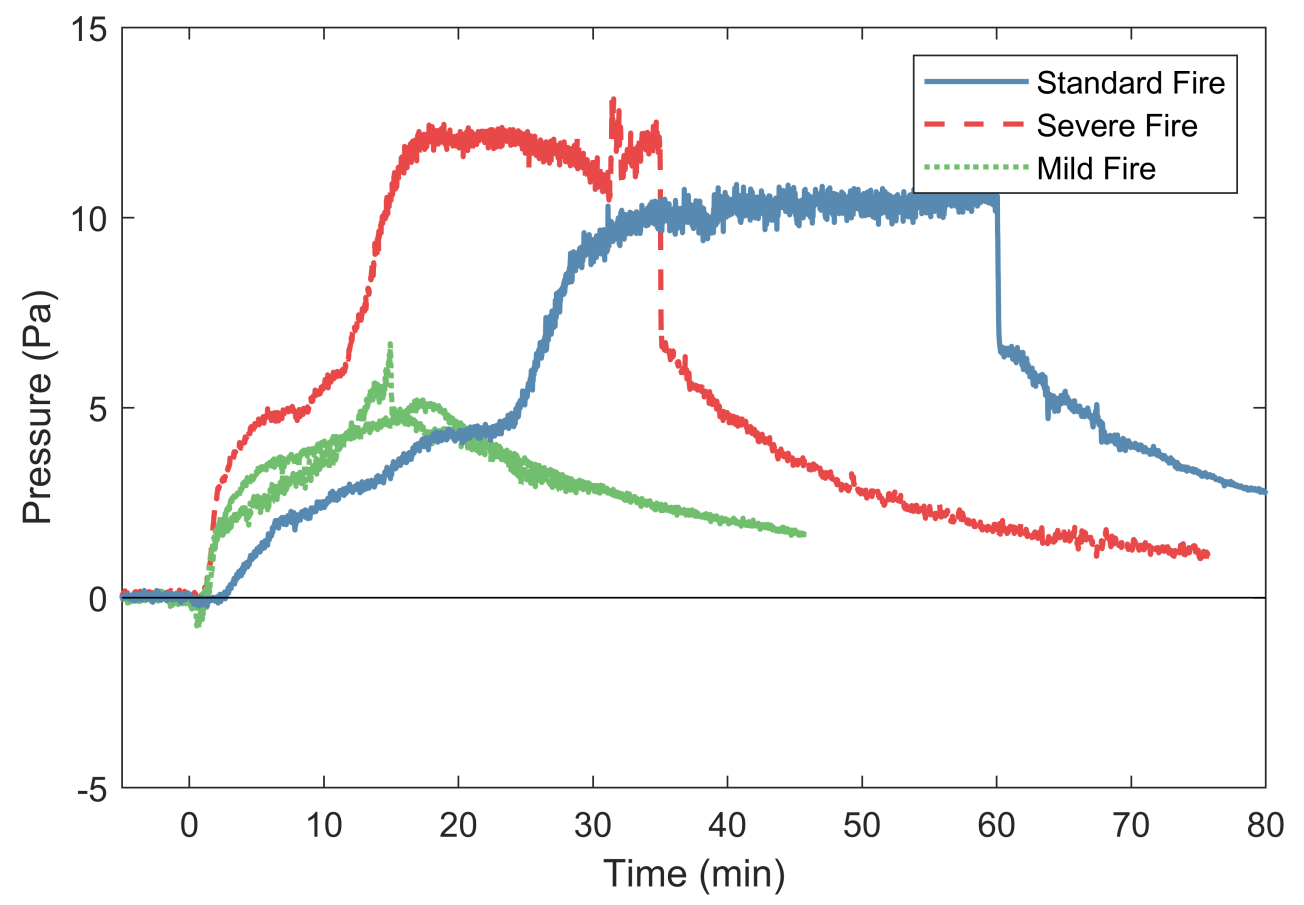

Fig. 69. Pressure in the wall cavity between the center studs approximately $56 \mathrm{~cm}$ from the top of the wall for gypsum-sheet steel composite panel sheathed walls. 

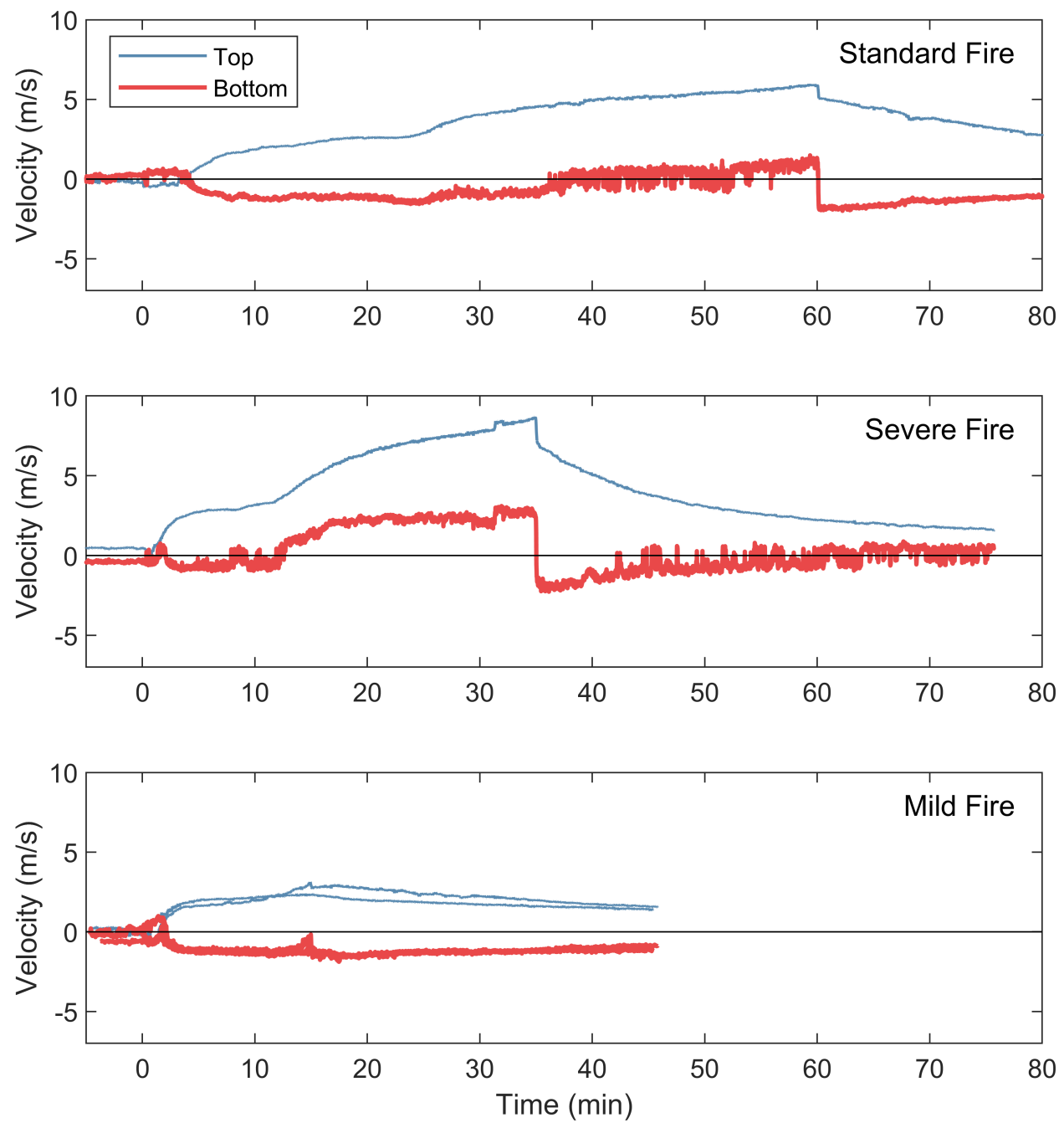

Fig. 70. Velocity of air flow at the top and bottom knockouts of the chord stud for gypsum-sheet steel composite panel sheathed walls. 


\subsection{Oriented Strand Board Sheathed Wall Performance}

Fig. 71 plots the lateral load versus drift during mechanical loading for representative cases of OSB sheathed walls with no pre-damage prior to the fire. For ambient temperature cycling, the failure mode was pull-through of the screw heads through the OSB board with some cases of edge breakout of the screw from the OSB (Fig. 72a, Fig. 73a). The Mild Fire effectively eliminated the gypsum on the fire-exposed side of the wall, caused surface charring on some OSB panels (Fig. 72b) and reduced the residual lateral capacity by $26 \%$; compare Fig. 71 a to Fig. 71b. Both the Standard Fire and Severe Fire consumed the OSB (Fig. 72c,d) and damaged interior framing studs (Fig. 73b). The reduction of the load capacity in both cases was nearly $100 \%$ (Fig. $71 \mathrm{c}, \mathrm{d})$.

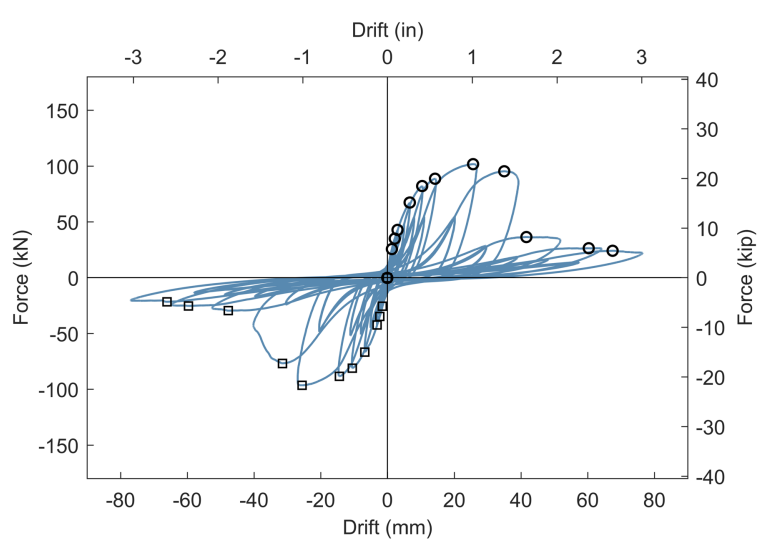

(a)

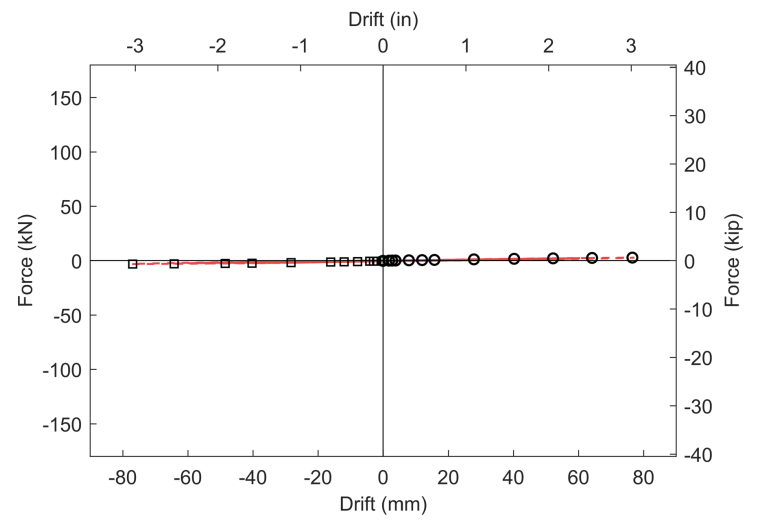

(c)

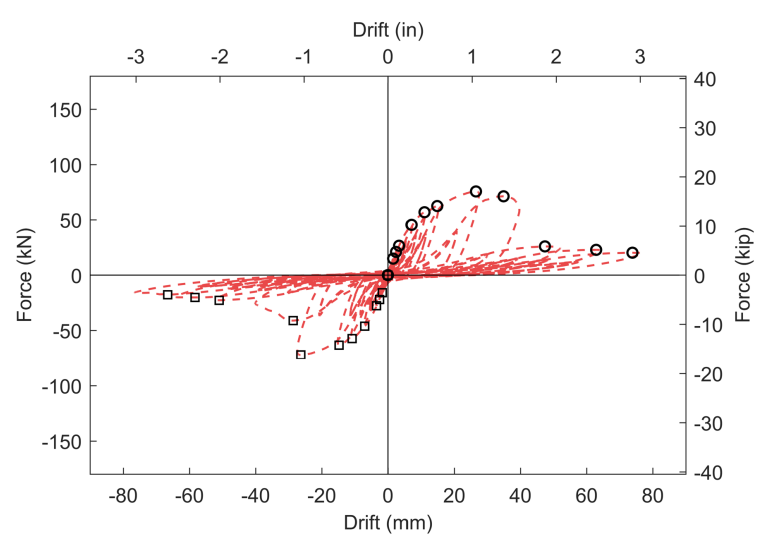

(b)

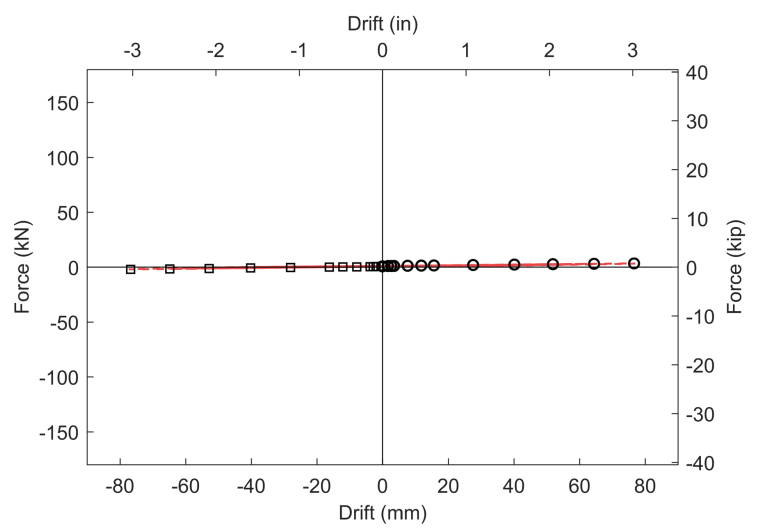

(d)

Fig. 71. Lateral force versus drift during mechanical loading of OSB sheathed walls: (a) cycling without fire (OSB01R); (b) cycling after Mild Fire (OSB03R); (c) cycling after Standard Fire (OSB04); (d) cycling after Severe Fire (OSB02).

Peak forces and story drift ratio at the peak force are provided along with the force reduction relative to the wall capacity at ambient temperature (OSB01R) for all tests in Table 6. The peak force versus displacement envelopes are shown in Fig. 74. In all tests except those with specimen OSB01 and OSB03, a $13 \mathrm{~mm}(1 / 2 \mathrm{in}$.) spacing was maintained between the screws and the edge of the OSB board (refer to Section 2.1.2). A reduction in capacity for smaller edge spacing; i.e. $9.5 \mathrm{~mm} \mathrm{(3/8} \mathrm{in.),} \mathrm{is} \mathrm{observed} \mathrm{comparing} \mathrm{OSB01} \mathrm{to} \mathrm{OSB1R} \mathrm{and} \mathrm{OSB03} \mathrm{to}$ OSB03R. This is attributed to an increased number of edge breakouts from the OSB for the 
$9.5 \mathrm{~mm}$ screw edge spacing; however, the number of test replicates is not sufficient to draw conclusions. To verify if the $26 \%$ force reduction following the Mild Fire could be attributed to the loss of the gypsum board on the fire-exposed side of the wall, specimen OSB01NG was constructed without gypsum board that could carry lateral load and subjected to load cycling without fire. A $25 \%$ to $30 \%$ reduction in force capacity is observed.

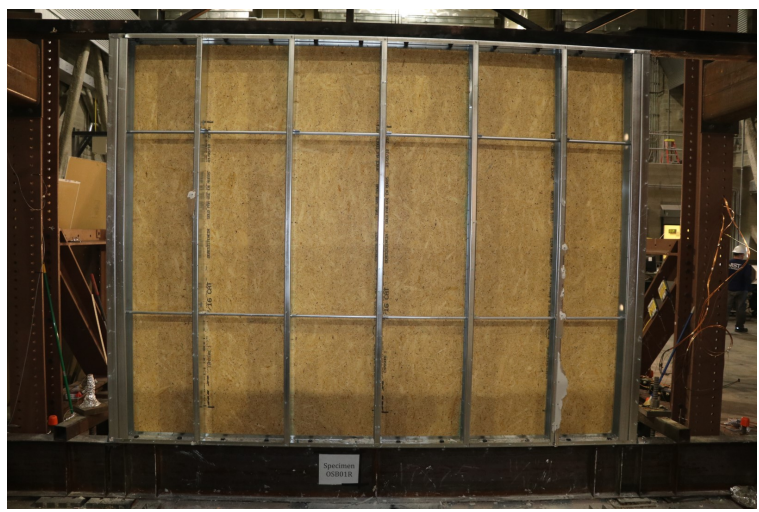

(a)

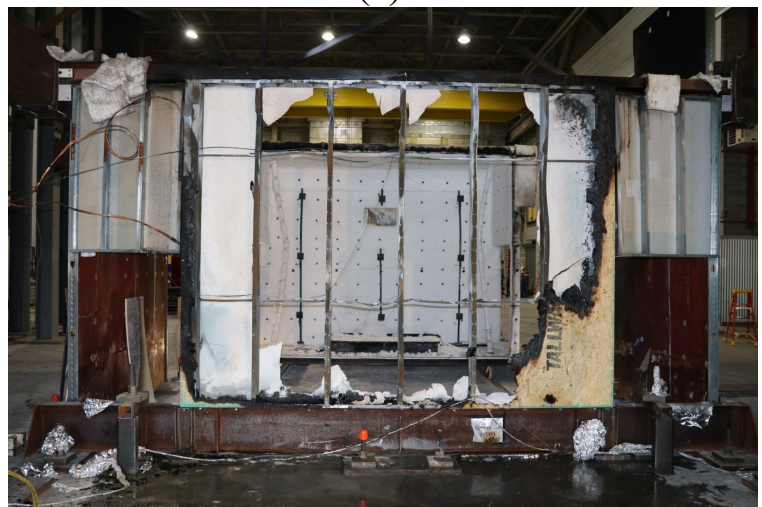

(c)

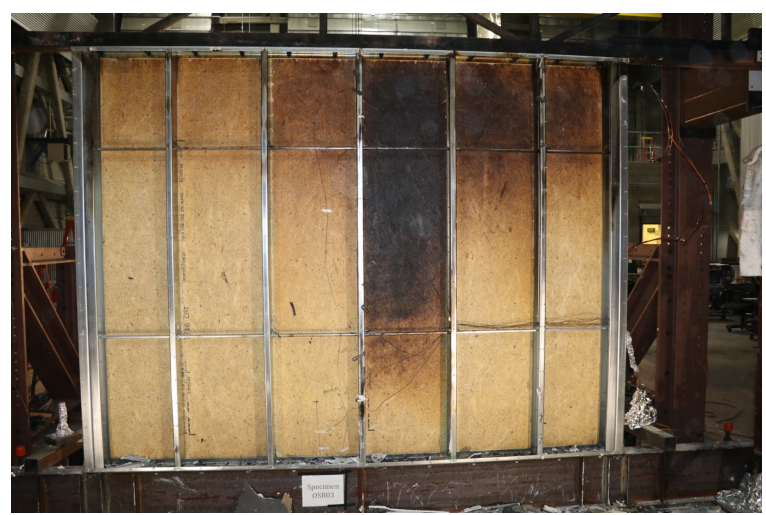

(b)

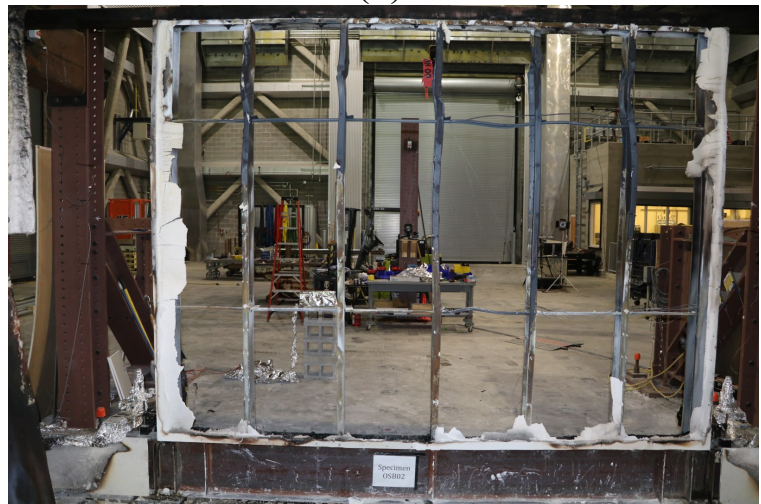

(d)

Fig. 72. Photographs of OSB sheathed walls after: (a) cycling without fire (OSB01R); (b) cycling after Mild Fire (OSB03); (c) cycling after Standard Fire (OSB04); (d) cycling after Severe Fire (OSB02).

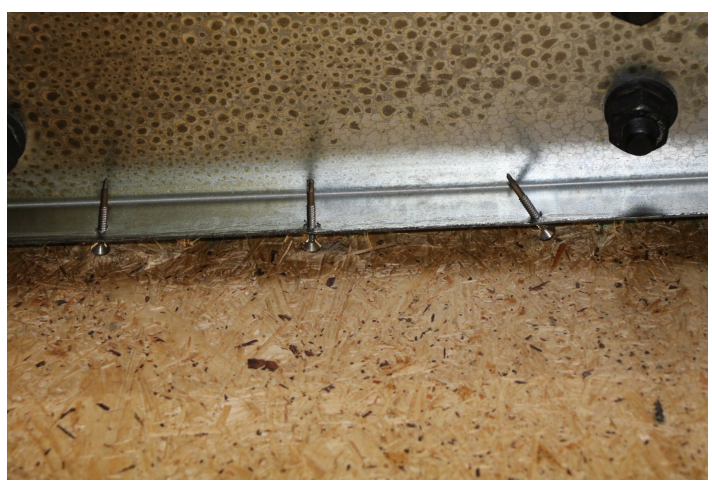

(a)

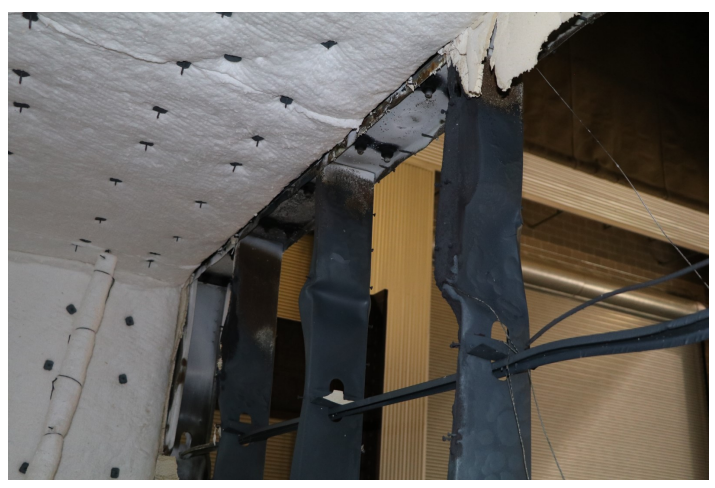

(b)

Fig. 73. Photograph of failure modes for OSB sheathed walls: (1) fastener failure after cycling without fire (OSB01); (b) interior studs after the Severe Fire (OSB02). 
Table 6. Peak forces and story drift ratios for OSB sheathed walls.

\begin{tabular}{c|c|c|c|c|c|c}
\hline & \multicolumn{3}{|c|}{ Positive excursion } & \multicolumn{3}{c}{ Negative excursion } \\
Specimen & $\begin{array}{c}\text { Peak } \\
\text { Force, kN }\end{array}$ & $\begin{array}{c}\text { SDR } \\
\text { @ peak, \% }\end{array}$ & $\begin{array}{c}\text { Force } \\
\text { reduction, \% }\end{array}$ & $\begin{array}{c}\text { Peak } \\
\text { Force, kN }\end{array}$ & $\begin{array}{c}\text { SDR } \\
\text { peak, \% }\end{array}$ & $\begin{array}{c}\text { Force } \\
\text { reduction, \% }\end{array}$ \\
\hline OSB01 a & 96.3 & 0.94 & 5 & -92.6 & -0.94 & 4 \\
OSB01R & 101.7 & 0.93 & 0 & -96.5 & -0.93 & 0 \\
OSB01NG & 75.8 & 0.94 & 25 & -67.8 & -0.94 & 30 \\
OSB02 & 3.4 & 2.79 & 97 & -2 & -2.8 & 98 \\
OSB03 a & 64.9 & 0.95 & 36 & -62.4 & -0.96 & 35 \\
OSB03R & 75.7 & 0.97 & 26 & -72.2 & -0.96 & 25 \\
OSB04 & 2.8 & 2.79 & 97 & -3.2 & -2.81 & 97 \\
OSB05 & 102.2 & 0.91 & $-{ }^{b}$ & -93.1 & -0.84 & $-{ }^{b}$ \\
OSB06 & 76.6 & 0.37 & $-{ }^{b}$ & -76.4 & -0.37 & $-{ }^{b}$ \\
\hline
\end{tabular}

a $1 / 2$ " spacing between screws and OSB edge not controlled

${ }^{\mathrm{b}}$ Comparison not applicable

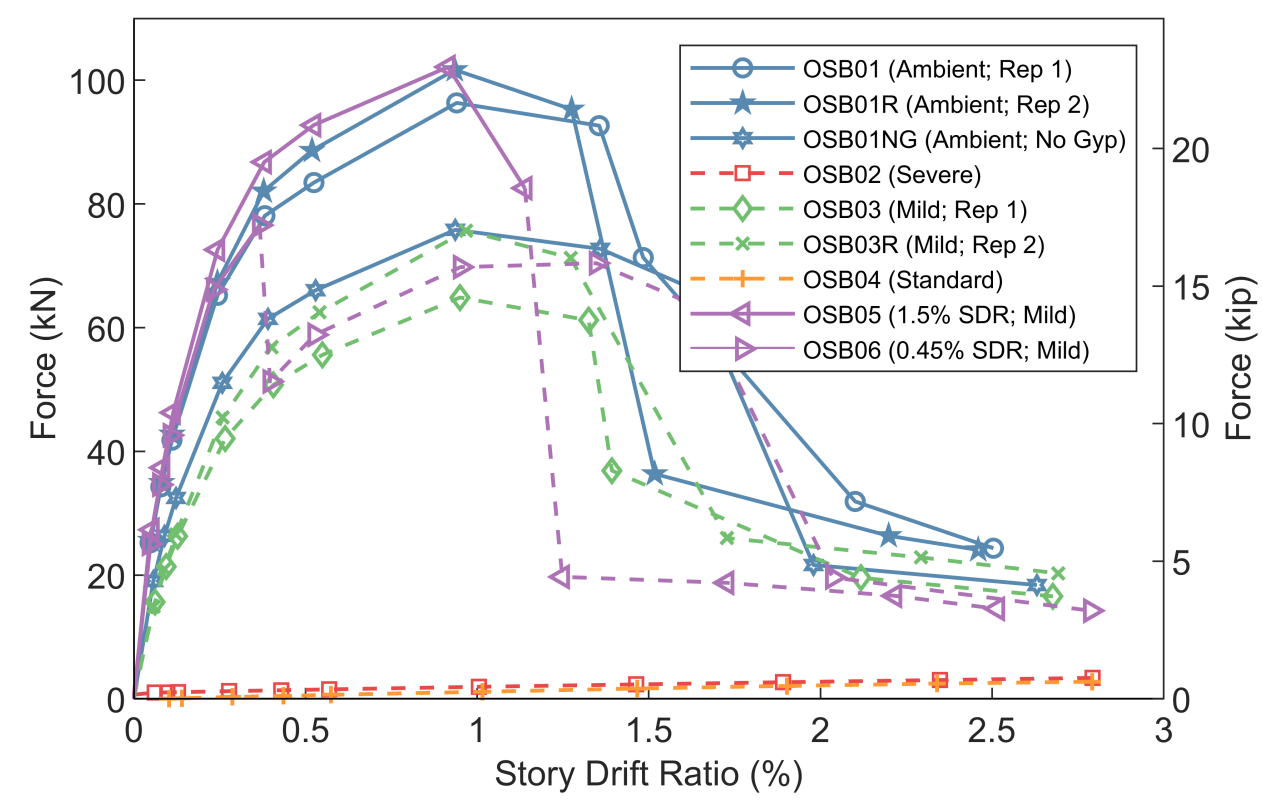

Fig. 74. Lateral load versus story drift ratio (positive excursions) during mechanical loading of OSB sheathed walls.

Fig. 75 plots temperatures on the unexposed side of the OSB sheathed walls for the investigated fires as the mean values (lines) and standard deviations (shaded areas). Data for the Kitchen Fire are included for comparison. In all cases except for those with Mild Fire, the OSB ignited at some time during the test. The times when flaming combustion was visible are indicated as 'OSB burning' in the figure and summarized in Table 7. The temperatures on the unexposed 
side of the wall remained low (mean values below $65^{\circ} \mathrm{C}$ ) up to the time when the OSB burns. However, once the OSB started burning it continued until suppression or total burnout of the OSB (Fig. 76). Fig. 77 shows the state of the wall after two repeats of the Mild Fire test and highlight the inherent test-to-test variability of the thermal load.

Fig. 78 plots temperatures through the specimen cross section $46 \mathrm{~cm}$ from the top of the wall at an interior stud. A comparison of just the interior stud temperatures for the investigated fires is shown in Fig. 79. The interior studs exhibited temperatures reaching around $1000^{\circ} \mathrm{C}$ for the Standard, the Severe and Kitchen Fire, which is indicative of the breached gypsum on the fireexposed side of the wall and burning OSB. Interior stud temperatures for the Mild Fire are similar to those for the steel-sheathed specimens.

Fig. 80 shows the measured pressure in the wall cavity between the center studs approximately $56 \mathrm{~cm}$ from the top of the wall for the investigated fires. The peak pressure differential between the wall cavity and the ambient pressure ranged from about $7 \mathrm{~Pa}$ (Mild Fire) to $14 \mathrm{~Pa}$ (Severe Fire). Fig. 81 compares the air flow velocities at the top and bottom knockout of the north chord stud for the investigated fires.

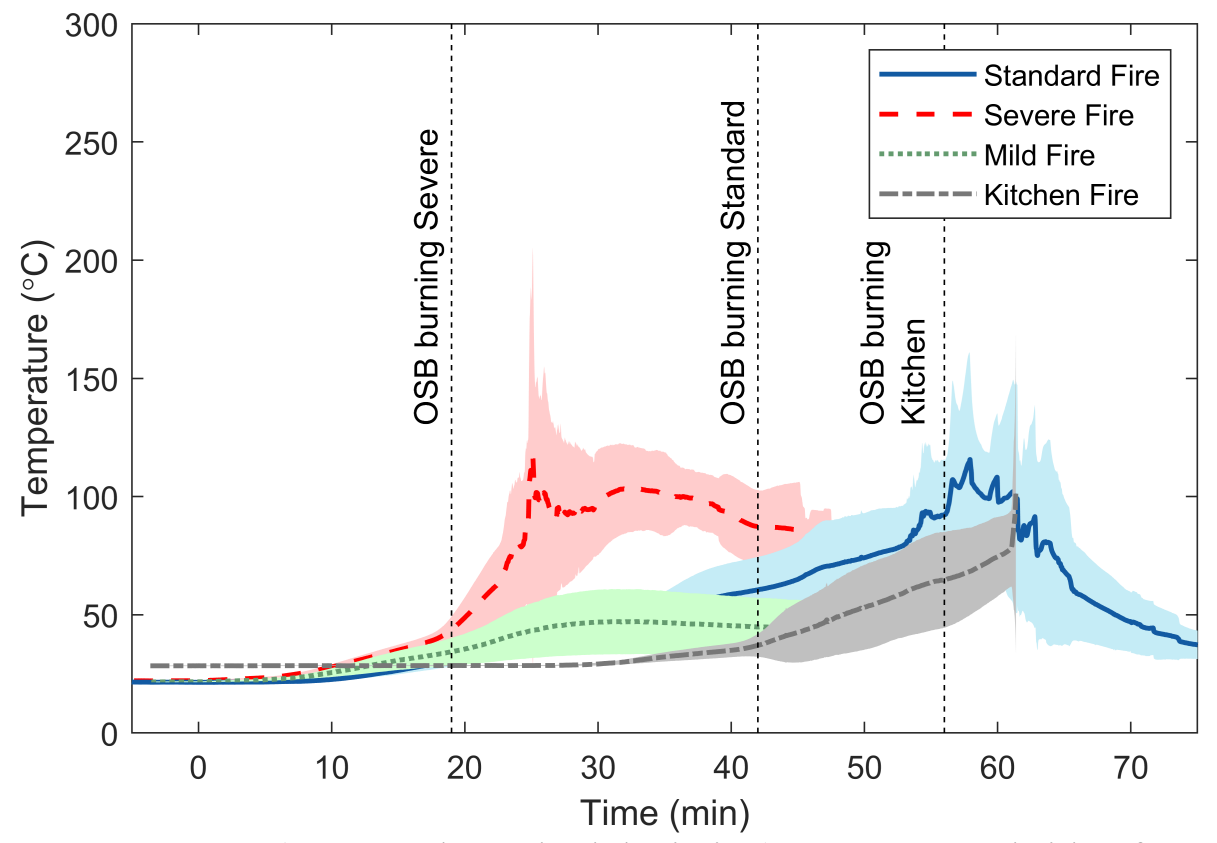

Fig. 75. Temperatures (mean and standard deviation) on unexposed side of OSB sheathed walls. 
Table 7. Time until flaming combustion of OSB visible.

\begin{tabular}{lc}
\hline \multicolumn{1}{c}{ Fire } & Time (min) \\
\hline Mild (from burner ignition) & No ignition \\
Severe (from burner ignition) & 19 \\
Standard (from burner ignition) & 42 \\
Kitchen (from flashover) & 26 \\
Kitchen (from oil ignition) & 35 \\
\hline
\end{tabular}

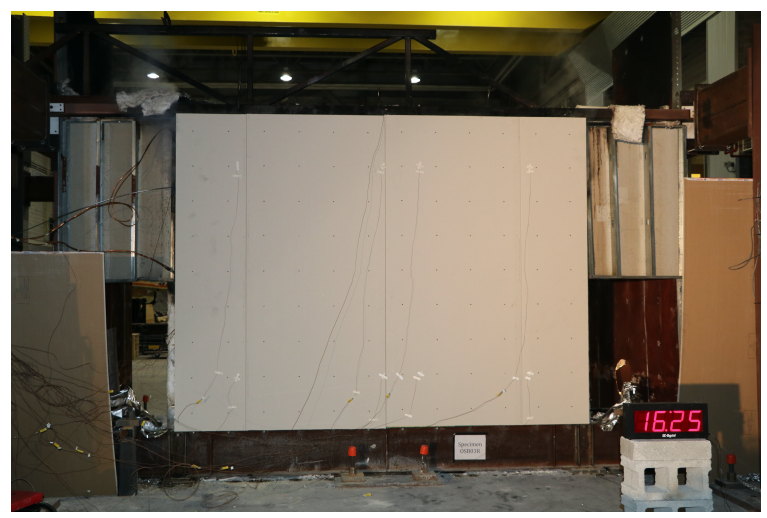

(a)

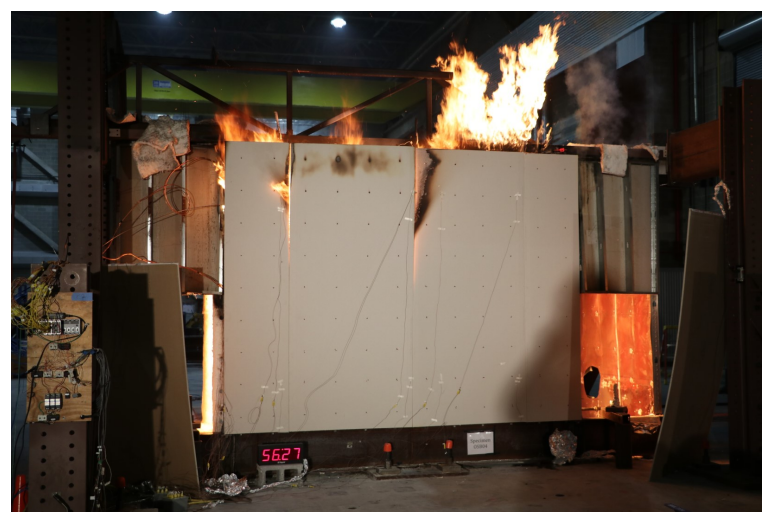

(b)

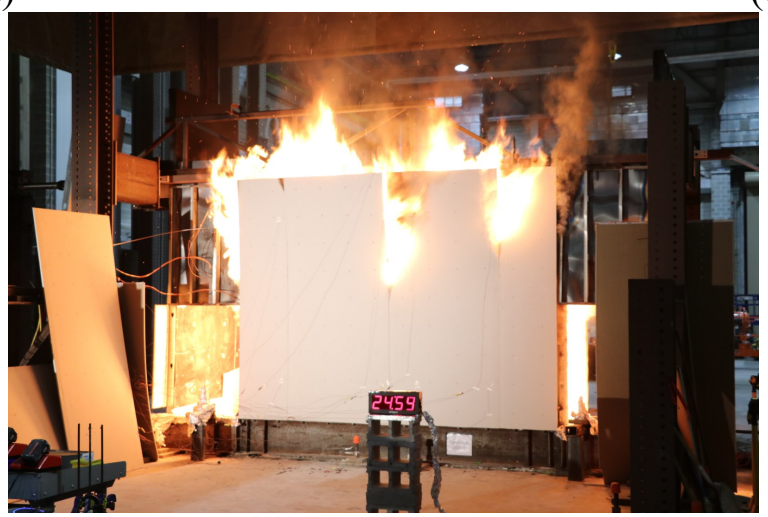

(c)

Fig. 76. Photographs of unexposed side of OSB sheathed walls during fire test:

(a) $16 \mathrm{~min} 25 \mathrm{~s}$ after ignition of Mild Fire; (b) $56 \mathrm{~min} 27 \mathrm{~s}$ after ignition of Standard Fire; (c) $24 \min 59 \mathrm{~s}$ after ignition of Severe Fire. 


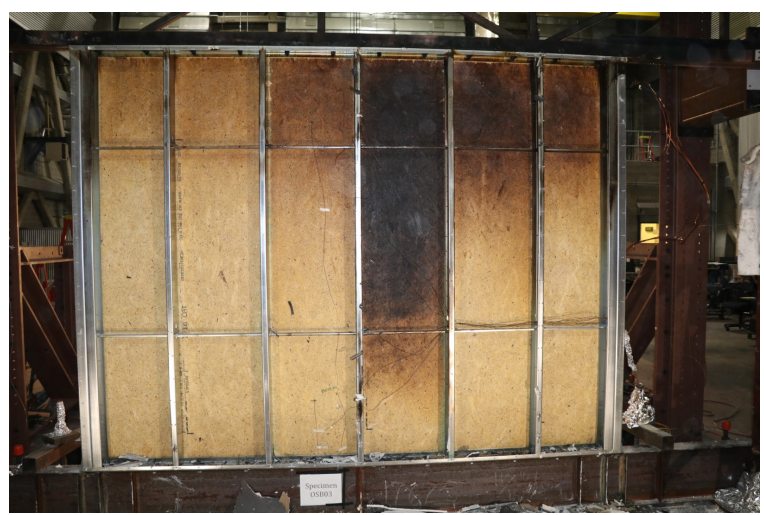

(a)

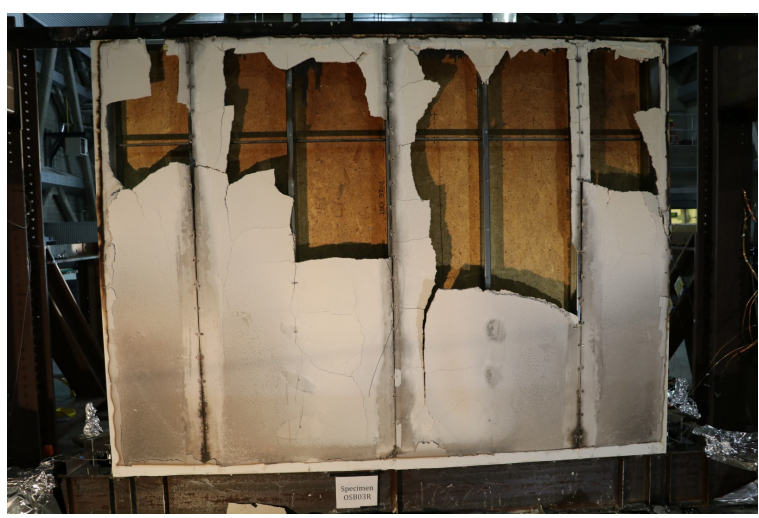

(b)

Fig. 77. Photographs of OSB sheathed walls after cycling after Mild Fire: (a) Repeat 1 (OSB03); (b) Repeat 2 (OSB03R).

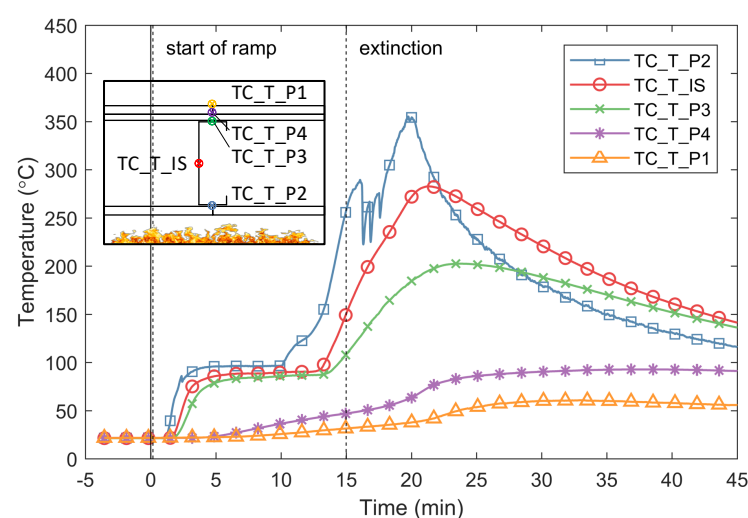

(a)

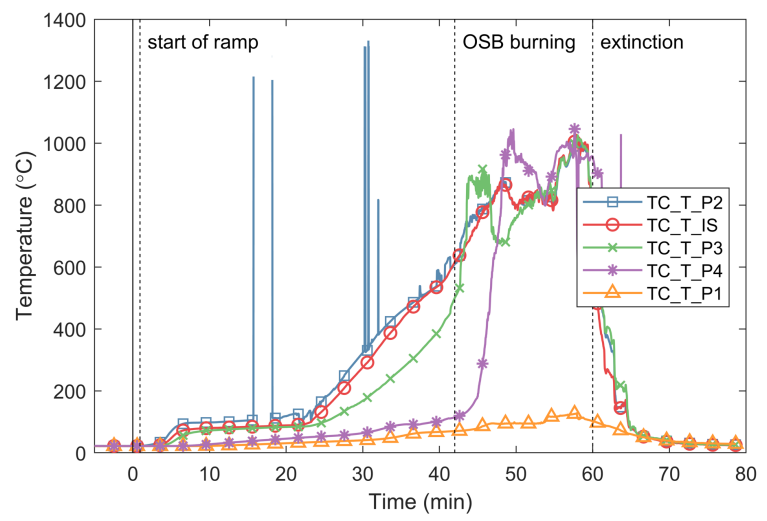

(c)

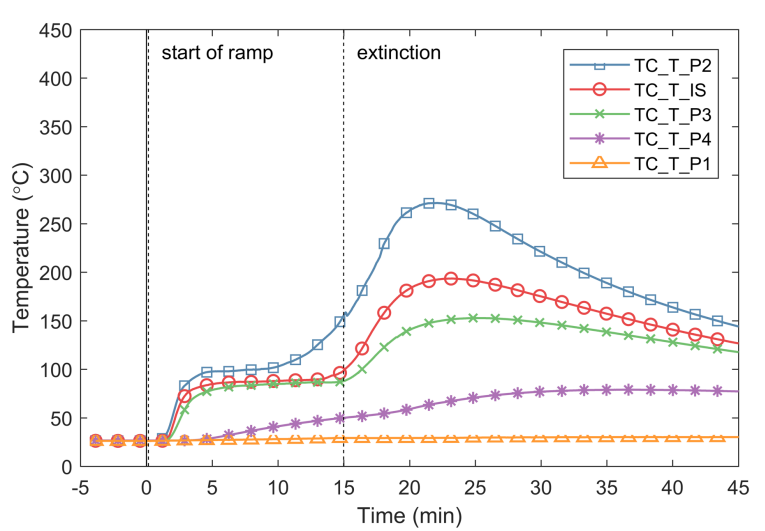

(b)

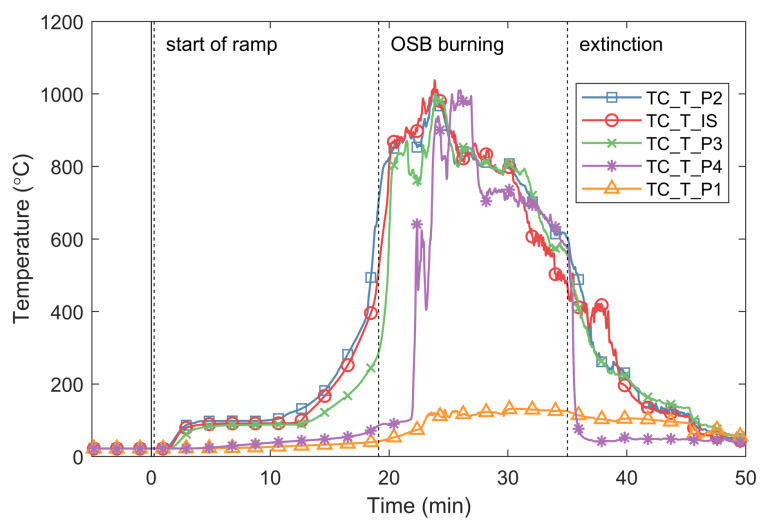

(d)

Fig. 78. Temperatures through the specimen at an interior stud $46 \mathrm{~cm}$ from the top of OSB sheathed walls: (a) Mild Fire (OSB03); (b) Mild Fire (OSB03R); (c) Standard Fire (OSB04);

(d) Severe Fire (OSB02). 


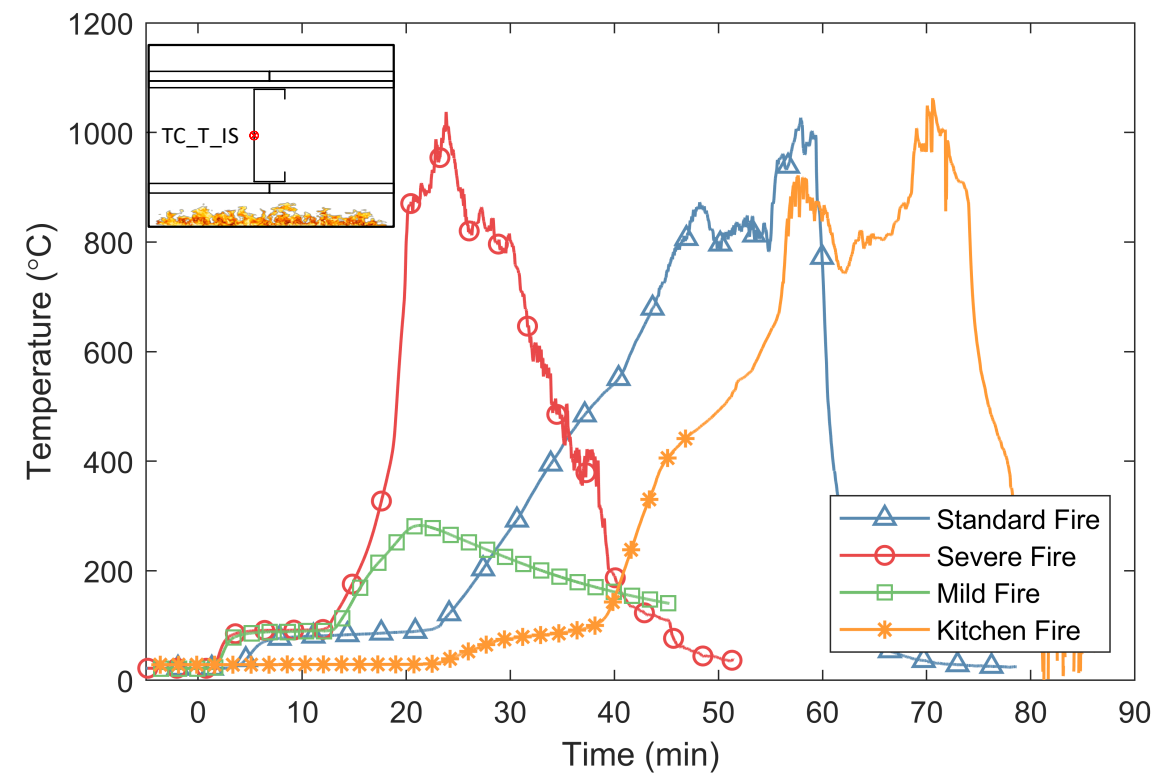

Fig. 79. Interior stud temperatures $46 \mathrm{~cm}$ from the top of the wall (TC_T_IS) for OSB sheathed walls.

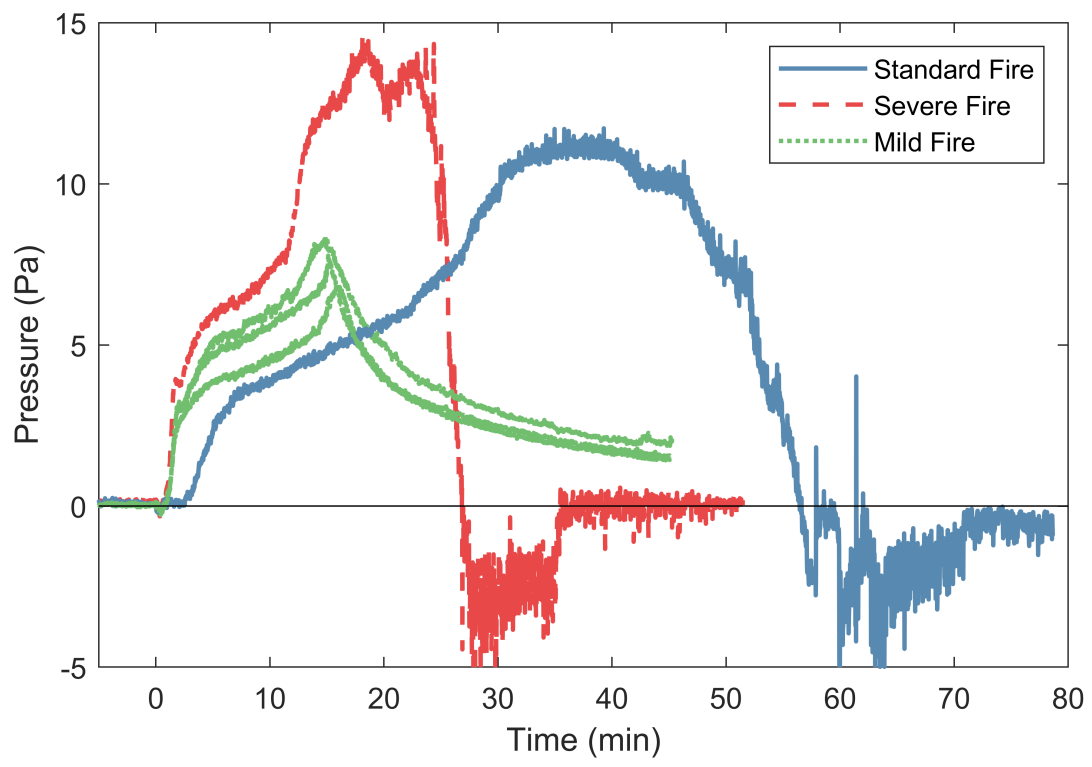

Fig. 80. Pressure in the wall cavity between the center studs approximately $56 \mathrm{~cm}$ from the top of the wall for OSB sheathed walls. 

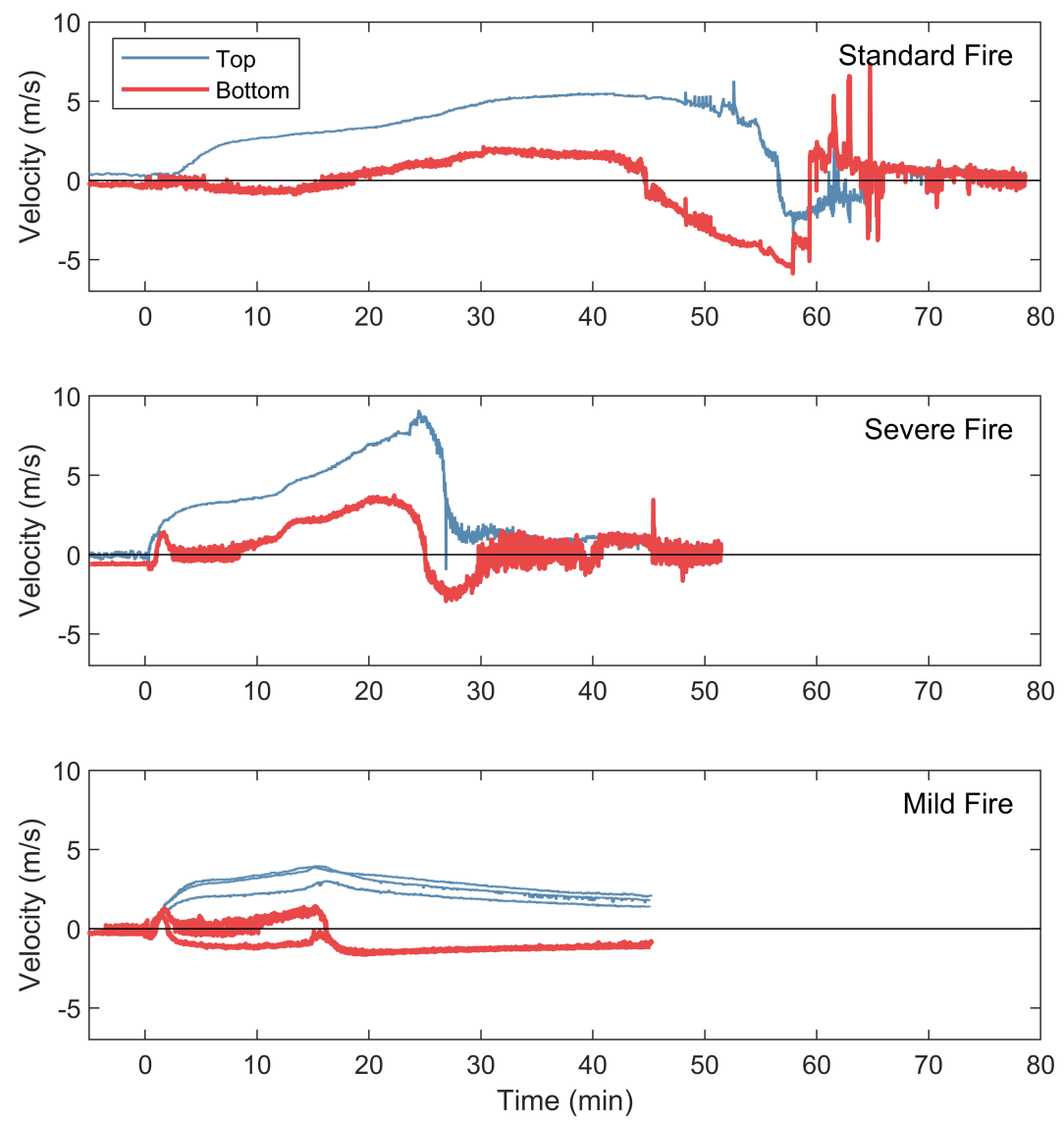

Fig. 81. Velocity of air flow at the top and bottom knockouts of the chord stud for OSB sheathed walls.

Cycling the OSB sheathed wall to $0.45 \%$ story drift prior to the fire resulted in only minor damage to the skim coat on the gypsum board joints (Fig. 82a) and had no significant effect on the subsequent fire (Fig. 83) or post-fire cyclic performance; compare Fig. 71b to Fig. 84a ( solid line $=$ cycling prior to fire; dashed line $=$ cycling after fire). The fire still reduced the post-fire capacity as in the case of undamaged walls, but the reduction is not worsened by this level of pre-damage. This is also illustrated by Fig. 74, where the post-fire response of OSB06 (Mild Fire with $0.45 \%$ SDR pre-damage) closely follows that of OSB03 and OSB03R (Mild Fire without pre-damage).

Cycling to $1.5 \%$ story drift prior to the fire tore the tape along the joints (Fig. $82 \mathrm{~b}$ ) and one of the OSB panels ignited during the Mild Fire. The fire was suppressed $10 \mathrm{~min}$ after the burner was extinguished. The joint damage increased the interior stud temperature (Fig. 83) and degraded the post-fire capacity of the wall; compare Fig. $71 \mathrm{~b}$ to Fig. $84 \mathrm{~b}$. This is better illustrated by Fig. 74, where the post-fire response of OSB05 (Mild Fire with $1.5 \%$ SDR predamage) drops below that of OSB03 and OSB03R (Mild Fire without pre-damage). The capacity would have gone to zero had the fire not been suppressed after $10 \mathrm{~min}$. 

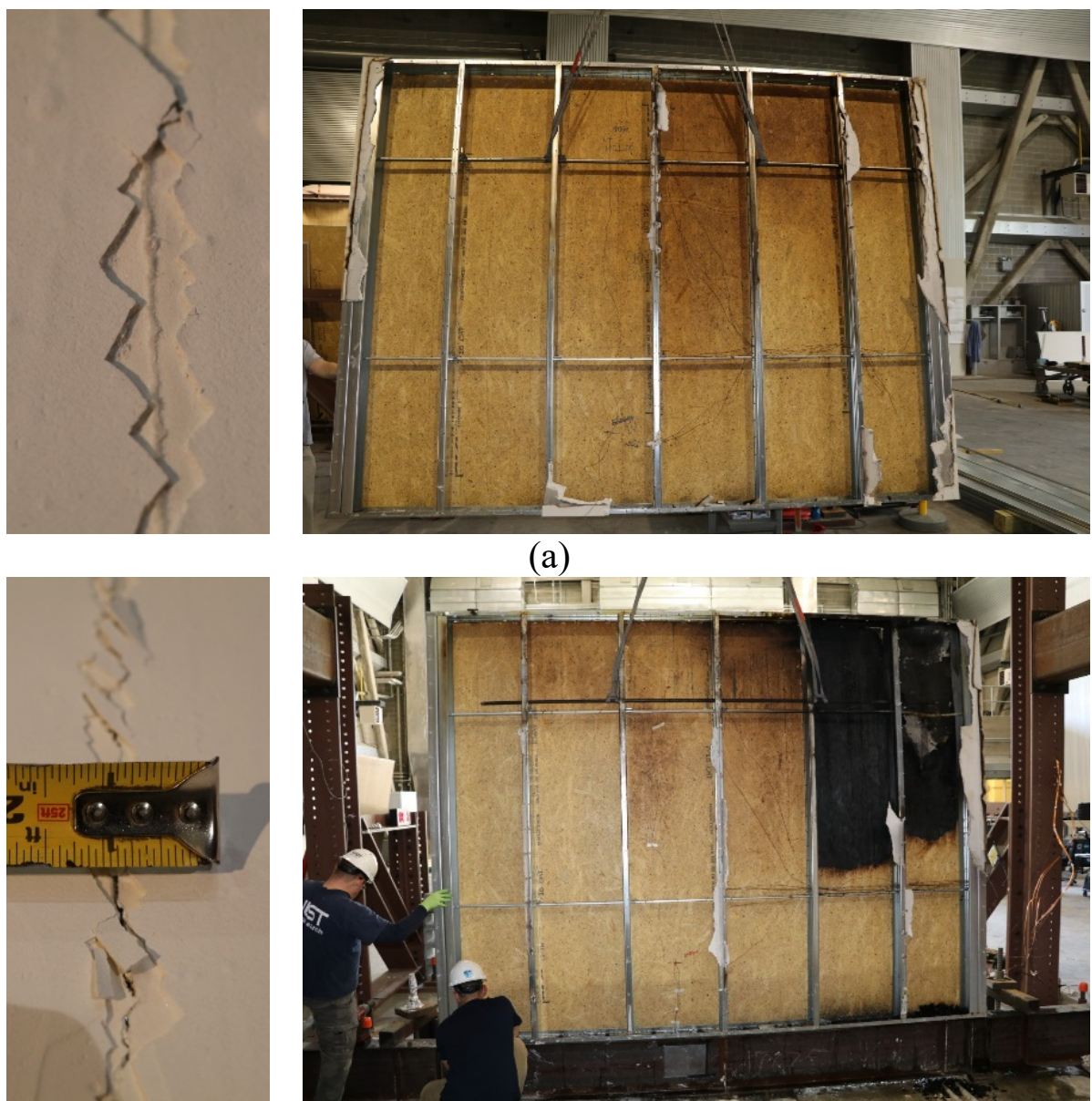

(b)

Fig. 82. Influence of pre-damage to gypsum board seams (left image; pre-fire) and OSB (right image; after cycling following fire): (a) cycling to $0.45 \%$ drift before Mild Fire; (b) cycling to $1.5 \%$ drift before Mild Fire. 


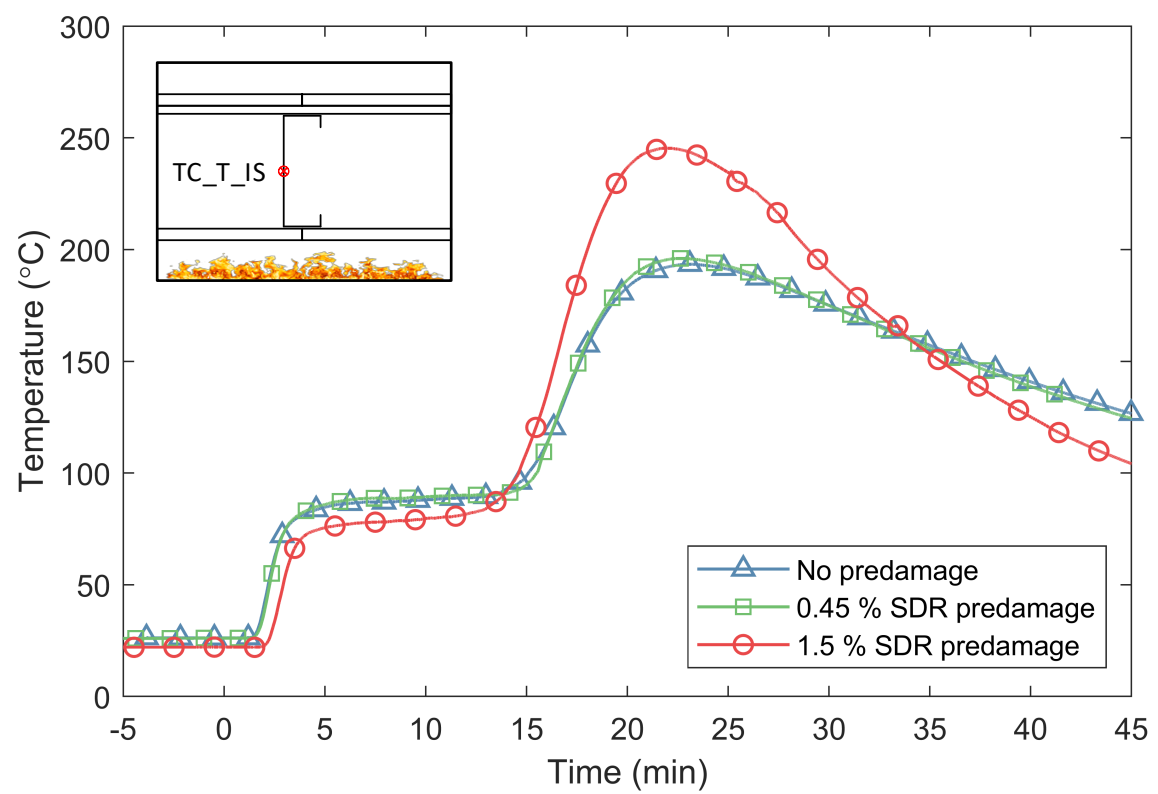

Fig. 83. Interior stud temperatures $46 \mathrm{~cm}$ from the top of the wall (TC_T_IS) for OSB sheathed wall exposed to mild fire with and without pre-damage of the walls.

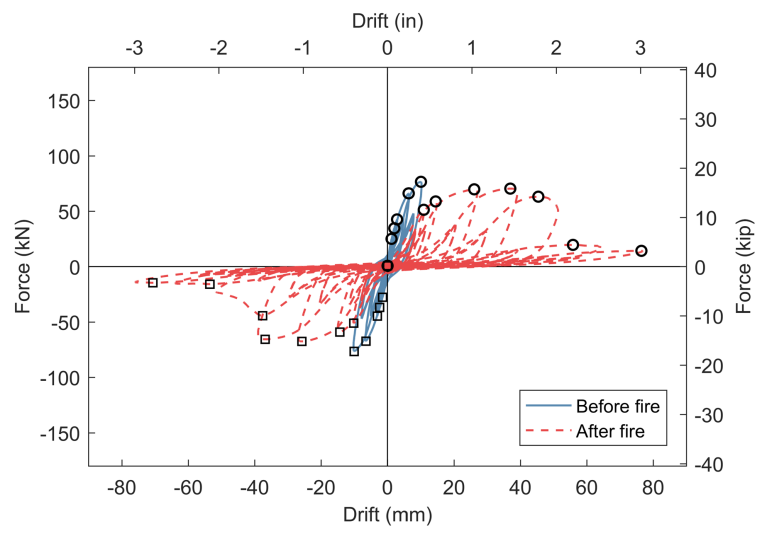

(a)

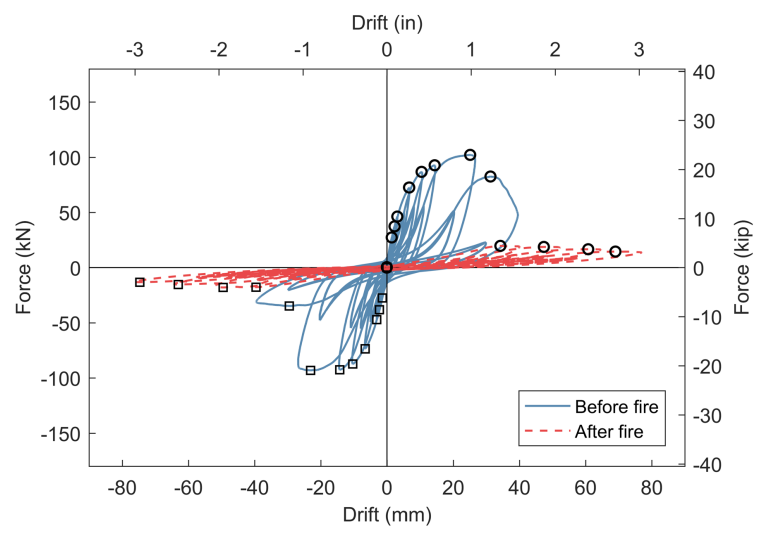

(b)

Fig. 84. Lateral load versus drift during mechanical loading of OSB sheathed walls: (a) cycling to $0.45 \%$ drift before Mild Fire; (b) cycling to $1.5 \%$ drift before Mild Fire.

\subsection{Steel Strap Braced Wall Performance}

Fig. 85 plots the lateral load versus drift during mechanical loading of steel strap braced walls with no pre-damage prior to the fire. The baseline hysteretic behavior Fig. 85a (ambient temperature) shows a peak near maximum load followed by a long plateau as the steel straps yielded. This initial peak is caused by the contribution of the gypsum boards on both sides of the wall. The ultimate failure mode was rupture of the straps at the gusset plate connections (Fig. 86a, Fig. 87a) and crippling of the chord stud just above the holdown (Fig. 88) after significant yielding of the straps (>6\% drift). The hysteresis loops are pinched after yielding because the wall could displace freely until the yielded strap began to take up load again. The Mild Fire effectively eliminated the gypsum on the fire-exposed side of the wall and reduced 
the residual lateral capacity by $15 \%$ (Fig. $85 \mathrm{~b}$ ), but the failure mode was the same as without fire (Fig. 86b). The reduction of $15 \%$ load capacity appears consistent with the loss of gypsum on the fire-exposed side of the wall. The response during the Standard Fire was similar to that during the Mild Fire, however the gypsum paper on the inside of the wall on the unexposed side was blackened indicating higher wall temperatures. The reduction to the residual capacity (Fig. 85c) and failure mode (Fig. 86c) were similar to the Mild Fire results. The Severe Fire burned through the gypsum on both sides of the wall at the top center of the wall (slightly shifted south) toward the end of the heating phase. During subsequent cyclic loading, when cycling in the direction that put the oxidized straps in tension (Fig. 86d, Fig. 87b), the wall had limited residual load capacity (Fig. 85d, negative), while in the opposite loading direction close to the full ambient post-yielding load capacity was reached (Fig. 85d, positive). Interestingly, the post-fire ductility in this direction increase significantly (note axes scale change in Fig. $85 \mathrm{~d}$ ) and there was a more pronounced post-yielding hardening behavior. This may due to annealing of the cold-formed steel strap during the fire, but further study is required.

Peak forces and story drift ratio at the peak force are provided along with the force reduction relative to the wall capacity at ambient temperature (S01R) for all tests in Table 8 . The peak force versus displacement envelopes are shown in Fig. 89.

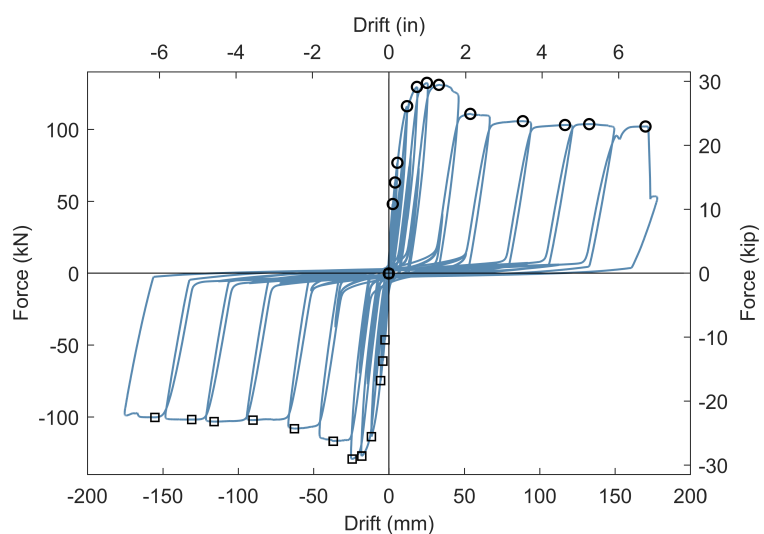

(a)

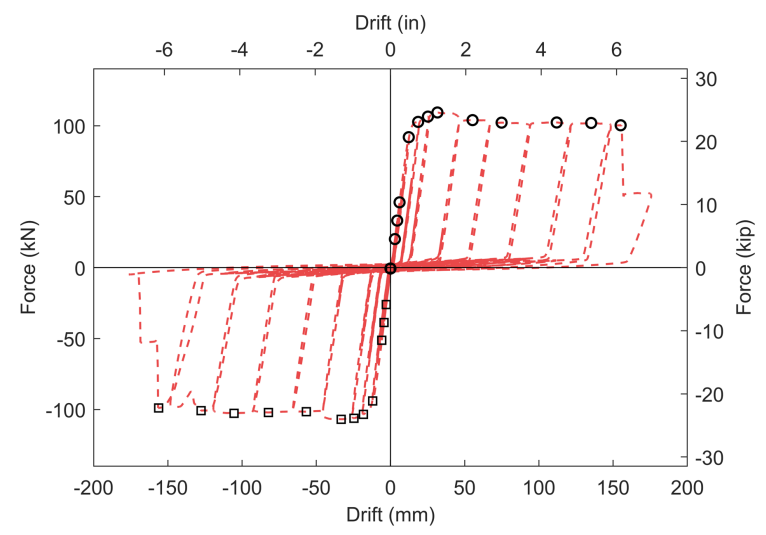

(c)

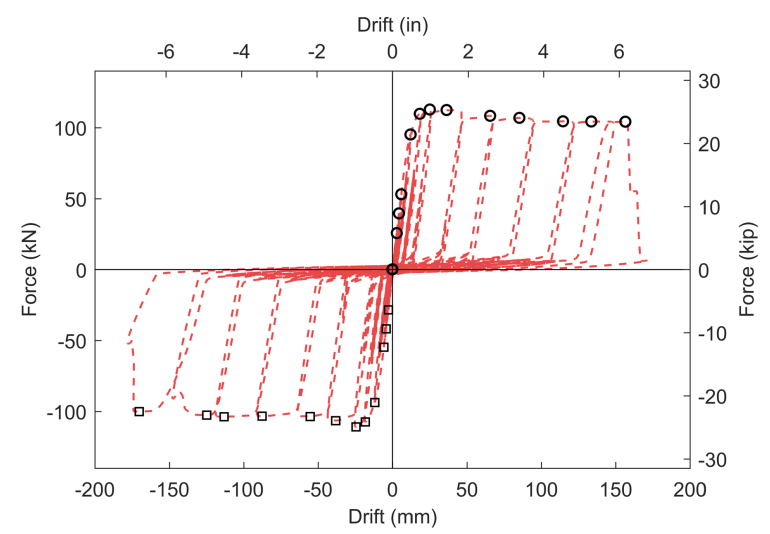

(b)

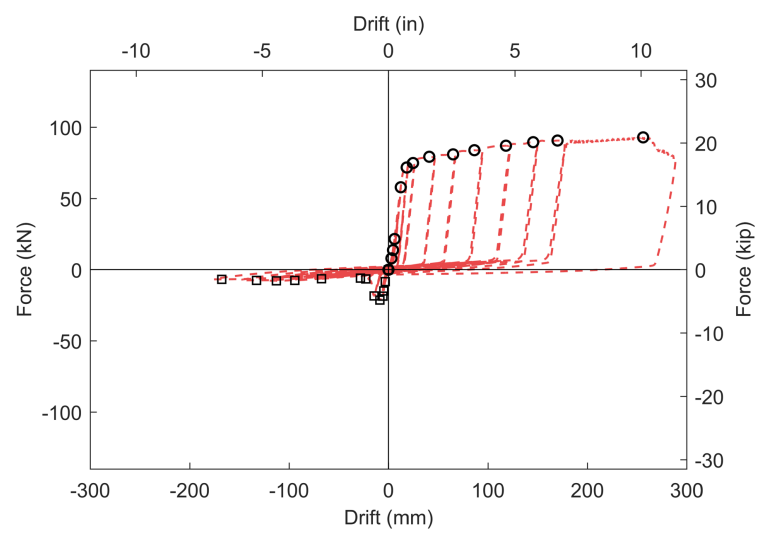

(d)

Fig. 85. Lateral load versus drift during mechanical loading of steel strap braced walls: (a) cycling without fire (S01R); (b) cycling after Mild Fire (S03); (c) cycling after Standard Fire (S04); (d) cycling after Severe Fire (S02). 


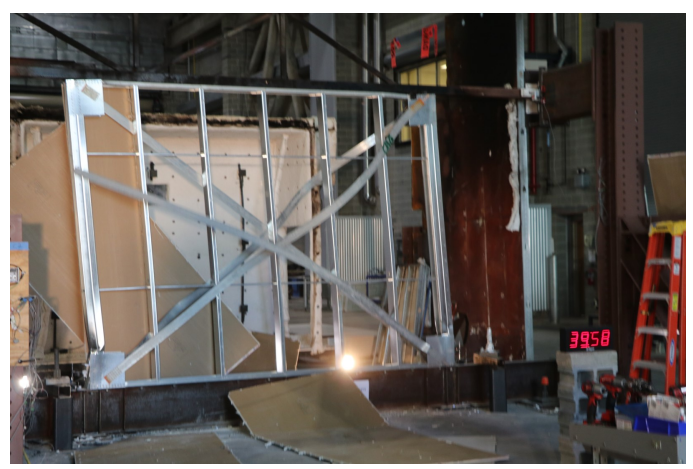

(a)

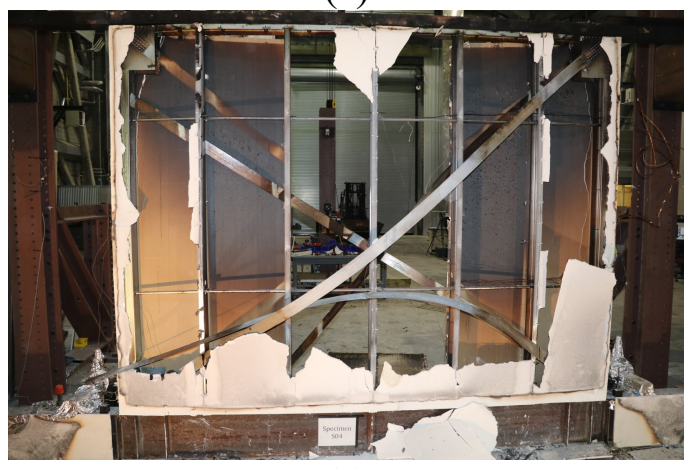

(c)

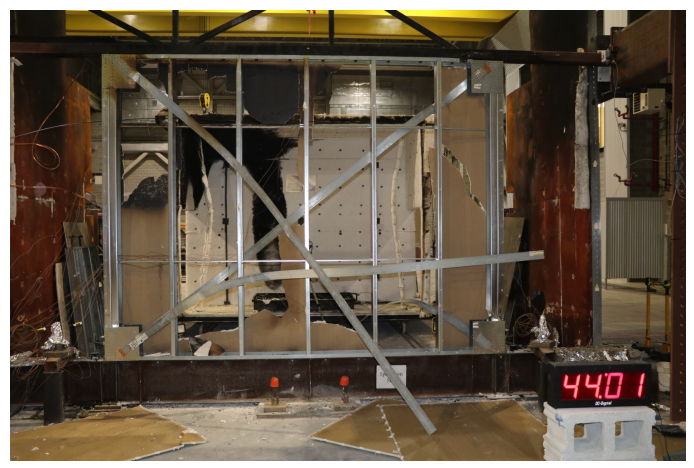

(b)

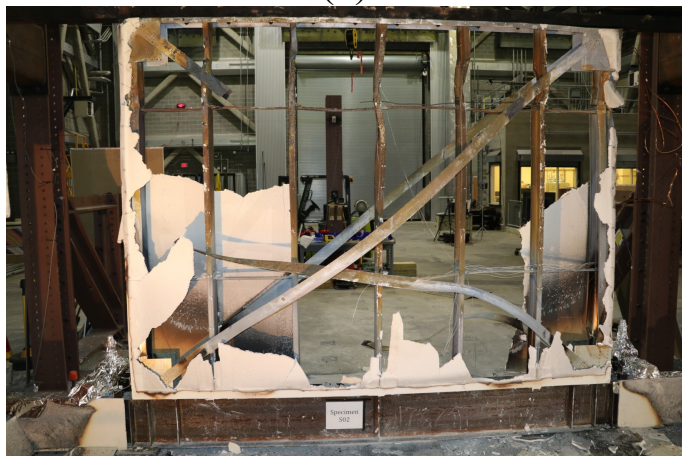

(d)

Fig. 86. Photographs of steel strap braced walls after: (a) cycling without fire (S01R); (b) cycling after Mild Fire; (c) cycling after Standard Fire; (d) cycling after Severe Fire.

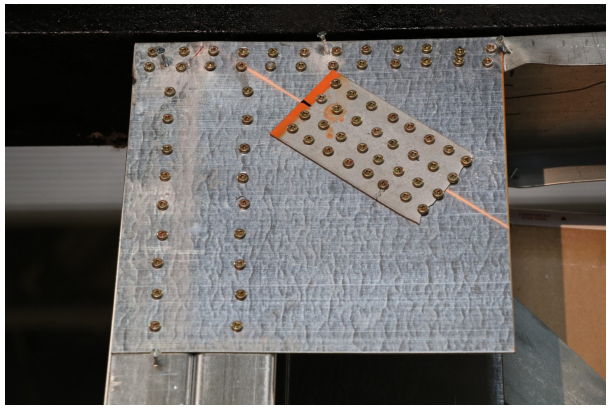

(a)

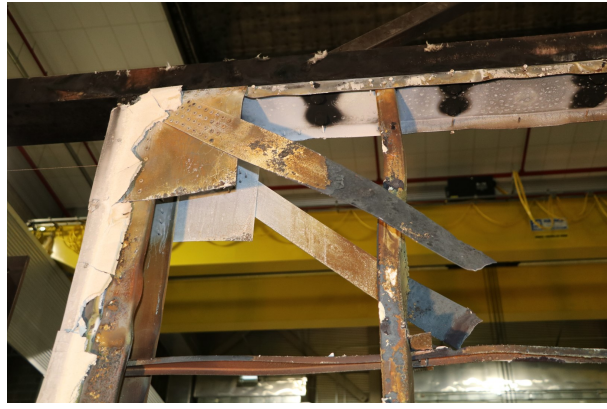

(b)

Fig. 87. Photograph of failure modes for steel strap braced walls during cycling: (a) postyielding strap rupture without fire; (b) rupture at oxidized strap after the Severe Fire.

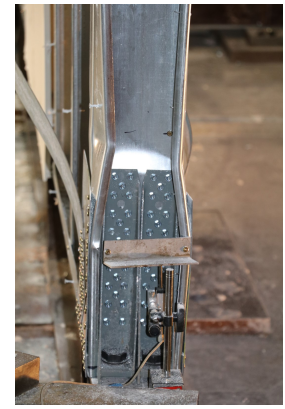

(a)

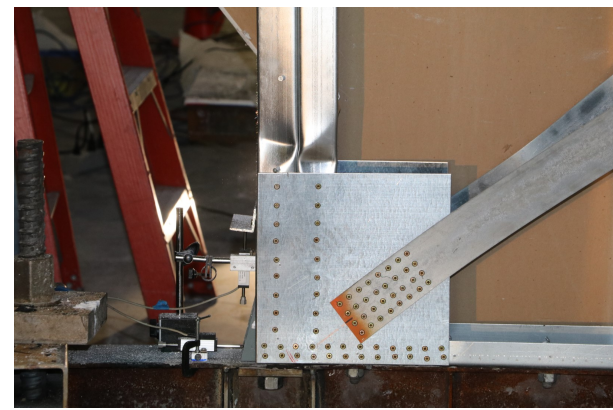

(b)

Fig. 88. Photographs of crippling of chords after strap yielding: (a) end view; (b) side view. 
Table 8. Peak forces and story drift ratios for steel strap braced walls.

\begin{tabular}{c|c|c|c|c|c|c}
\hline Specimen & $\begin{array}{c}\text { Peak } \\
\text { Force, kN }\end{array}$ & & $\begin{array}{c}\text { Force } \\
\text { reduction, \% }\end{array}$ & $\begin{array}{c}\text { Peak } \\
\text { Force, } \mathbf{k N}\end{array}$ & & \\
\hline S01 ${ }^{\mathrm{a}}$ & 92.5 & 0.37 & $-{ }^{\mathrm{b}}$ & -102.8 & -0.39 & $-{ }^{\mathrm{b}}$ \\
S01R & 132.3 & 0.92 & 0 & -129.3 & -0.89 & 0 \\
S02 & 92.9 & 9.34 & 30 & -21.4 & -0.31 & 83 \\
S03 & 112.8 & 0.91 & 15 & -110.9 & -0.9 & 14 \\
S04 & 109.3 & 1.15 & 17 & -106.8 & -1.21 & 17 \\
S05 & 127 & 1.27 & $-{ }^{\mathrm{b}}$ & -124.7 & -0.89 & $-{ }^{\mathrm{b}}$ \\
S06 & 111.4 & 0.43 & $-{ }^{\mathrm{b}}$ & -111.3 & -0.43 & $-{ }^{\mathrm{b}}$ \\
\hline
\end{tabular}

a Asymmetric strap design

${ }^{\mathrm{b}}$ Comparison not applicable

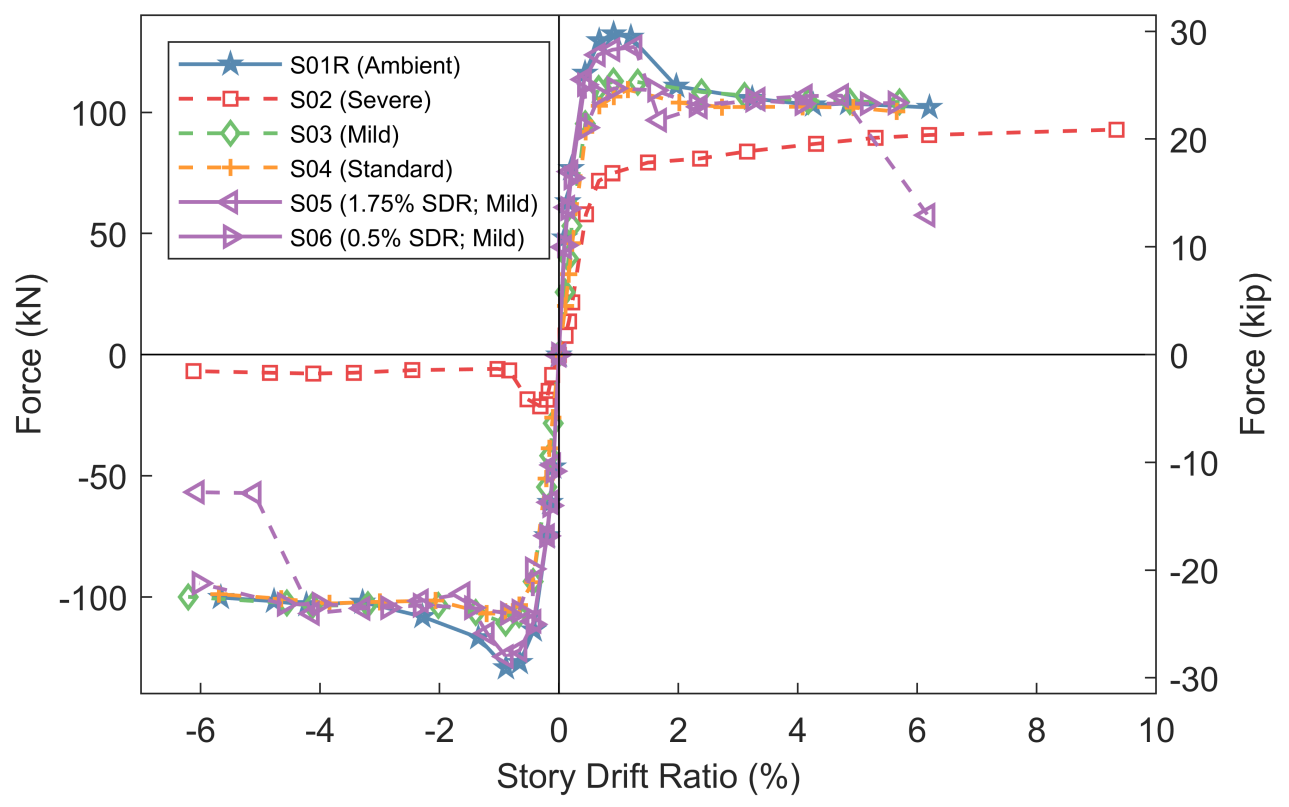

Fig. 89. Lateral load versus story drift ratio during mechanical loading of steel strap braced walls.

For the steel strap braced walls, the temperatures on the unexposed side of the wall remained below $100^{\circ} \mathrm{C}$ for the Mild Fire and Standard Fire (Fig. 90). The temperatures of the unexposed side reached higher values as the paper on the unexposed side ignited and a large hole opened through the top of the wall (Fig. 91c) in the Severe Fire. Fig. 91a,b indicate little damage on the unexposed side for the Mild Fire and Standard Fire.

Fig. 92 plots temperatures through the specimen cross section $46 \mathrm{~cm}$ from the top of the wall at an interior stud. A comparison of just the interior stud temperatures for the investigated fires is shown in Fig. 93. The interior studs sustained temperatures above $900{ }^{\circ} \mathrm{C}$ for $15 \mathrm{~min}$ in the Severe Fire. 
Fig. 94 shows the measured pressure in the wall cavity between the center studs approximately $56 \mathrm{~cm}$ from the top of the wall for the investigated fires. The peak pressure differential between the cavity and the ambient pressure ranged from $6 \mathrm{~Pa}$ (Mild Fire) to $13 \mathrm{~Pa}$ (Severe Fire). During the Severe Fire, the pressure dropped abruptly 32 min after ignition when the gypsum board on the unexposed side of the wall was breached. Fig. 95 compares the air flow velocities at the top and bottom knockout of the north chord stud.

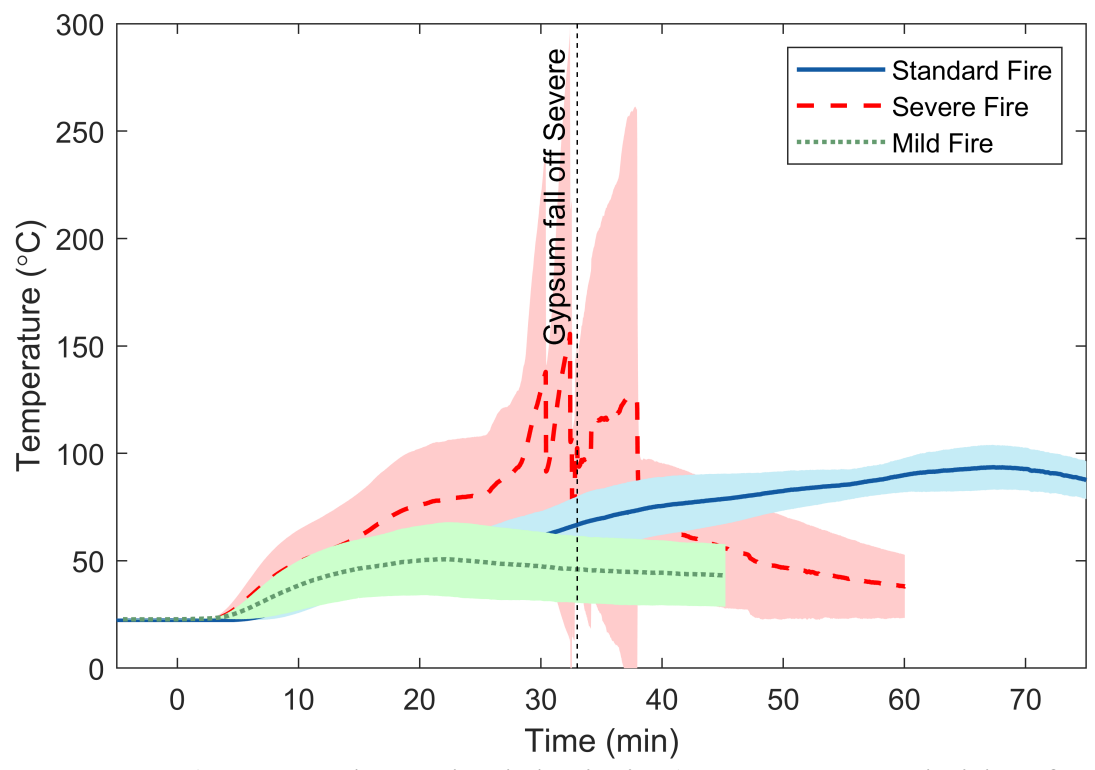

Fig. 90. Temperatures (mean and standard deviation) on unexposed side of steel strap braced walls.

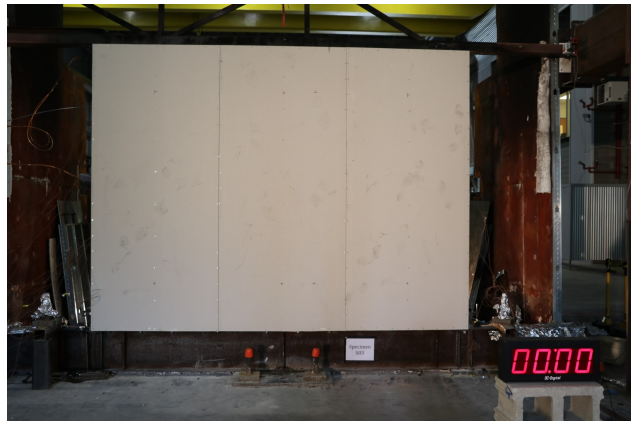

(a)

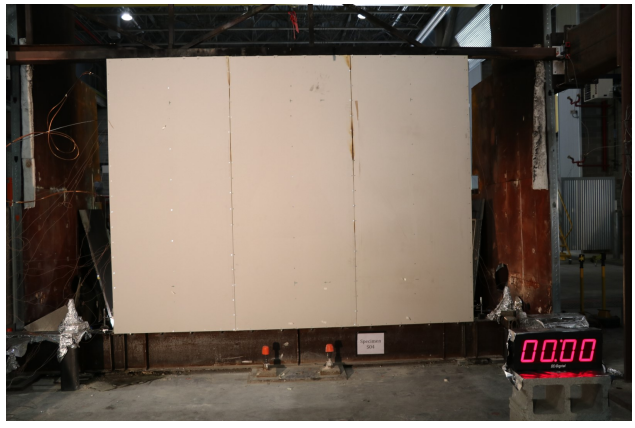

(b)

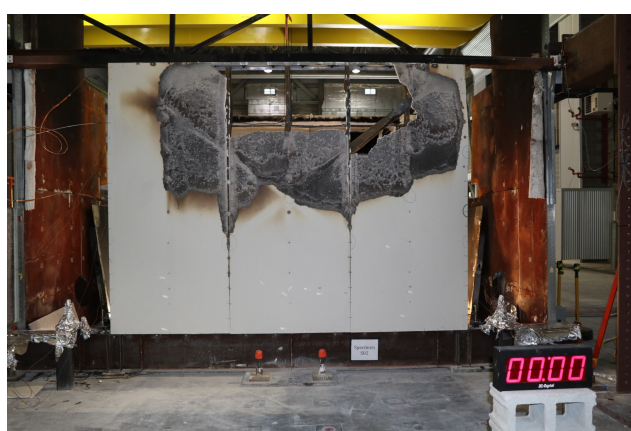

(c)

Fig. 91. Photographs of unexposed side of steel strap braced walls after fire test (before cycling): (a) Mild Fire (S03); (b) Standard Fire (S04); (c) Severe Fire (S02). 


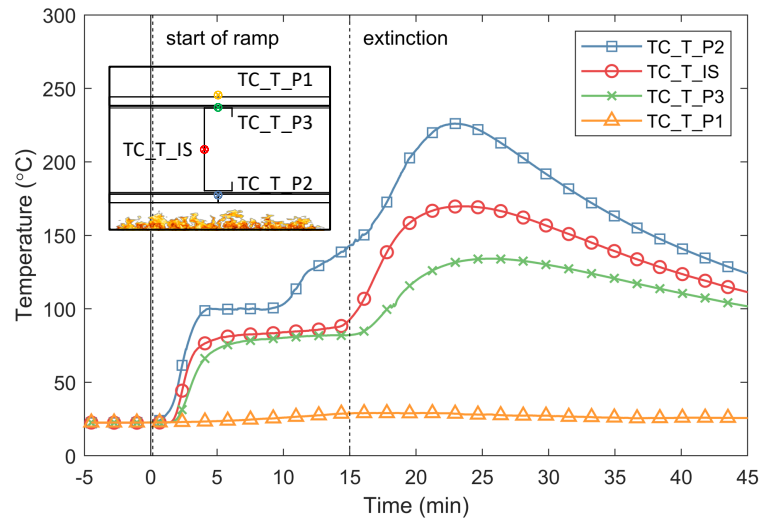

(a)

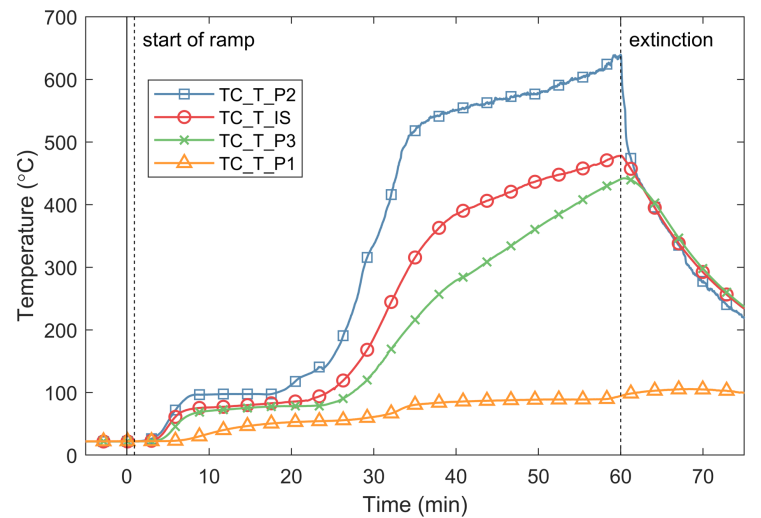

(b)

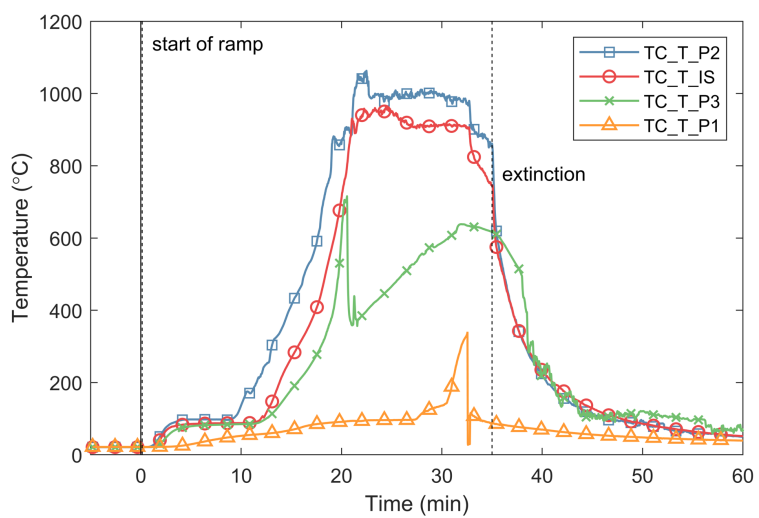

(c)

Fig. 92. Temperatures through the specimen at an interior stud $46 \mathrm{~cm}$ from the top of steel strap braced walls: (a) Mild Fire (S03); (b) Standard Fire (S04); (c) Severe Fire (S02).

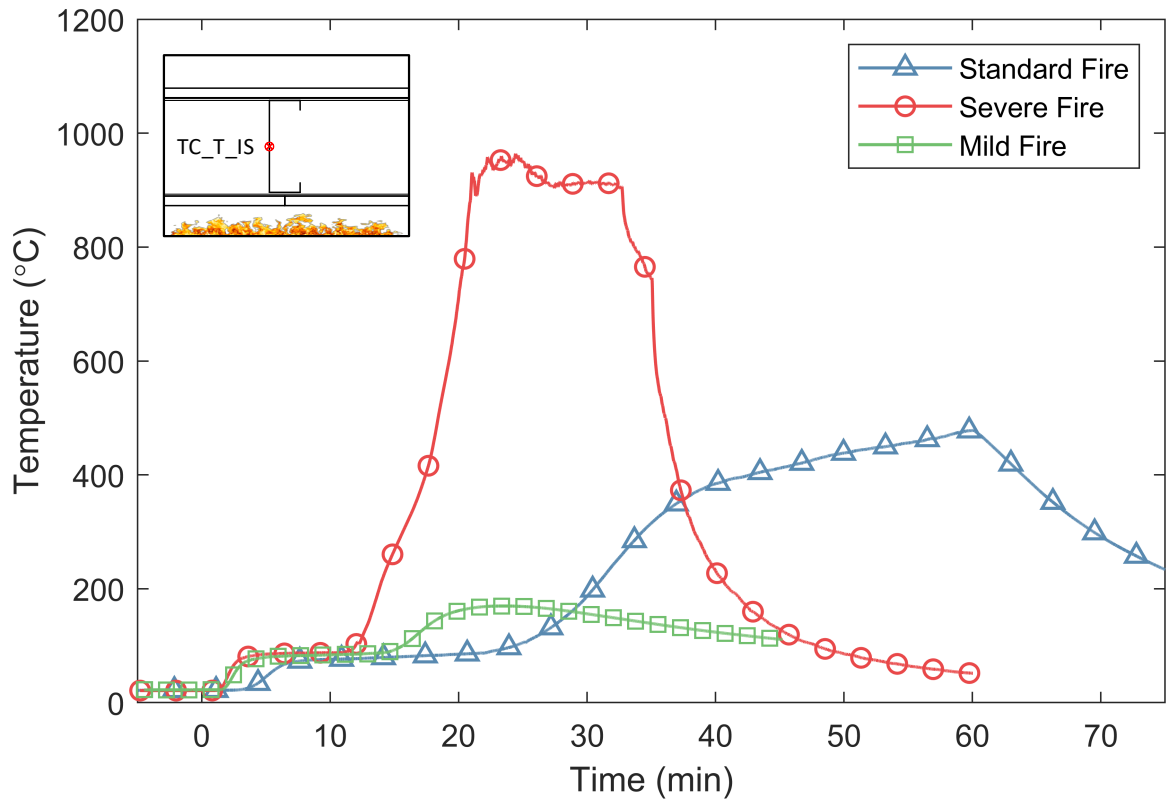

Fig. 93. Interior stud temperatures $46 \mathrm{~cm}$ from the top of the wall (TC_ $\left.\mathrm{T}_{-} \mathrm{IS}\right)$ for steel strap braced walls. 


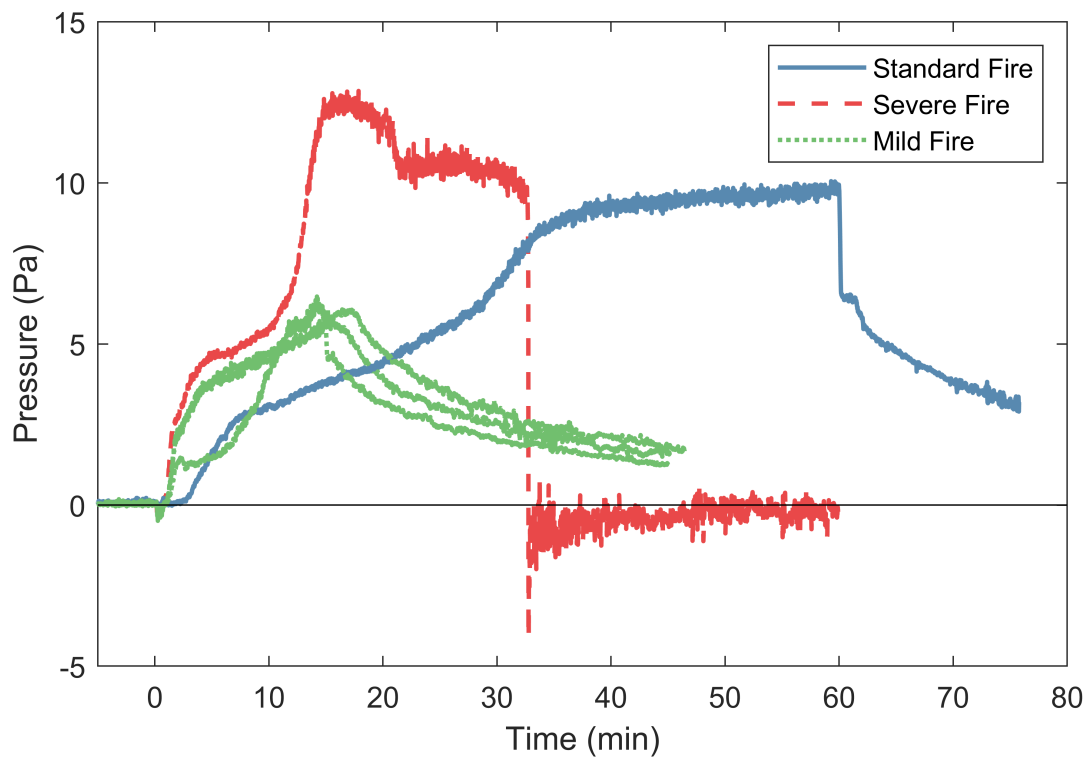

Fig. 94. Pressure in the wall cavity between the center studs approximately $56 \mathrm{~cm}$ from the top of the wall for steel strap braced walls.
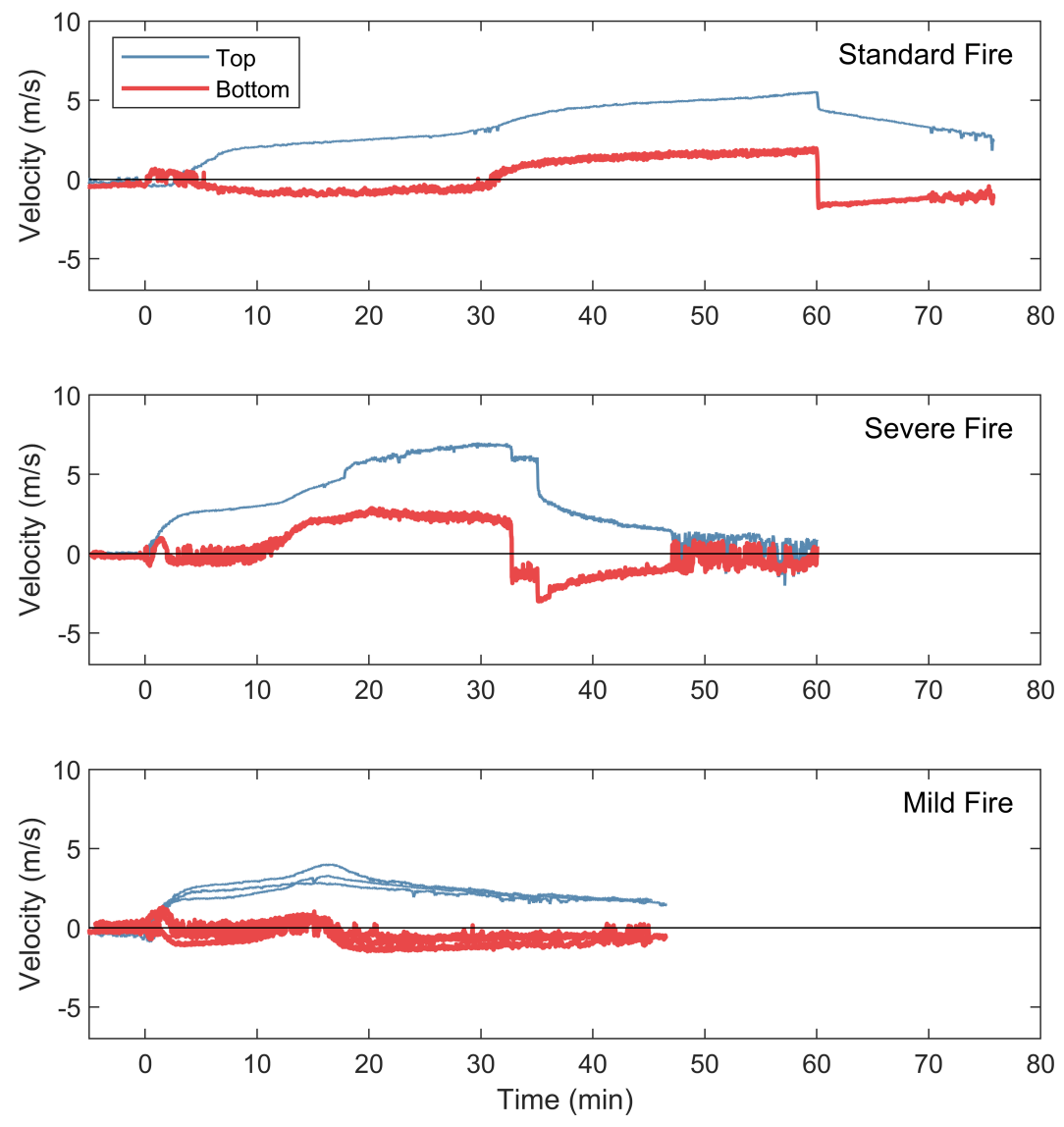

Fig. 95. Velocity of air flow at the top and bottom knockouts of the chord stud for steel strap braced walls. 
Cycling the steel strap braced wall to $0.5 \%$ story drift prior to the fire resulted in only minor damage to the skim coat on the gypsum board joints (Fig. 96a) and had no significant effect on the subsequent fire (Fig. 97) or post-fire cyclic performance; compare Fig. 85b to Fig. 98a. The fire still reduced the post-fire capacity as in the case of undamaged walls, but the reduction is not worsened by this level of pre-damage.

Cycling to $1.75 \%$ story drift prior to the fire tore the tape along the joints (Fig. 96b) and the paper on the back of the unexposed gypsum board was burned off near the top center of the wall. The joint damage increased the interior stud temperature (Fig. 97) but did not affect the post fire capacity of the wall; compare Fig. $85 \mathrm{~b}$ to Fig. $98 \mathrm{~b}$.
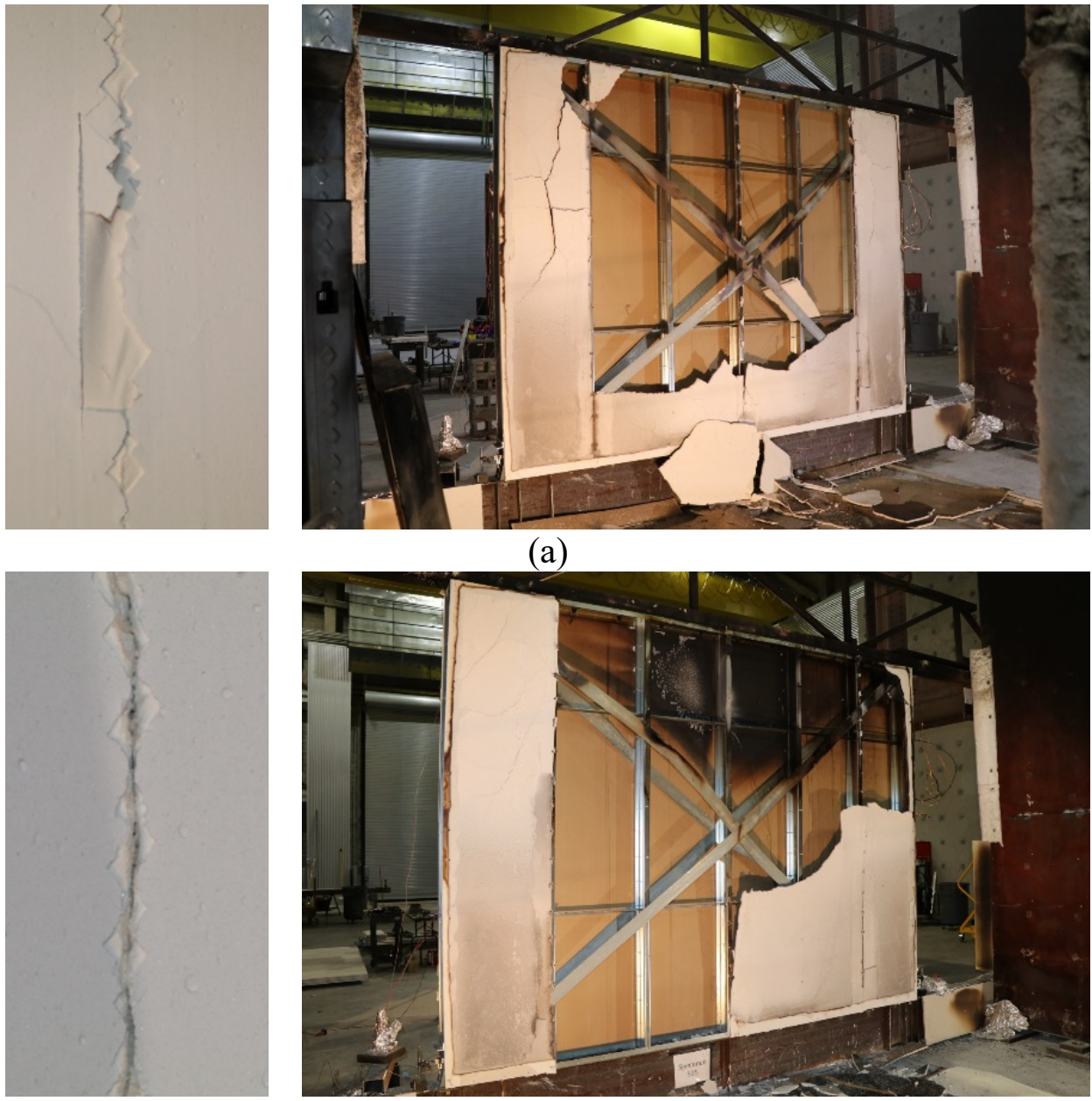

(b)

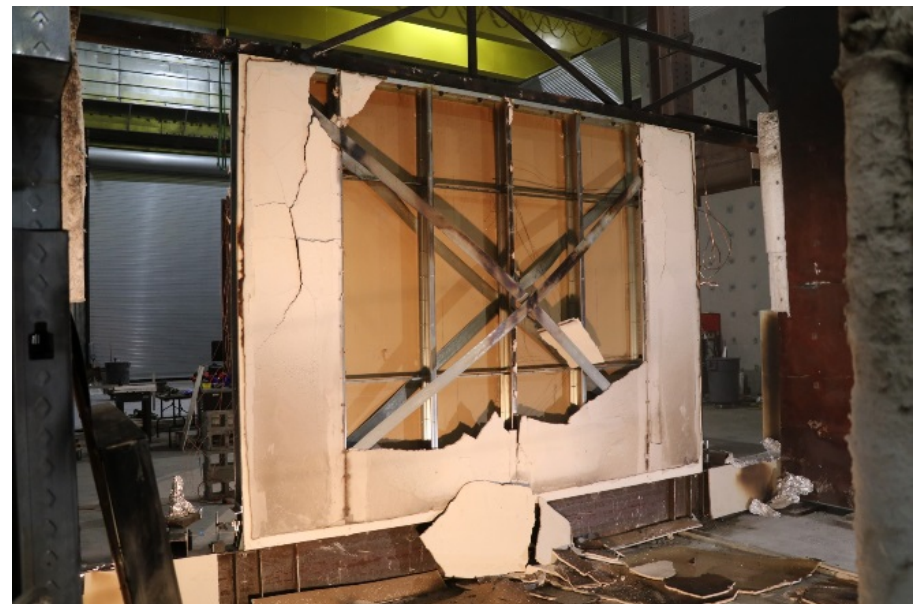

(a)

Fig. 96. Influence of pre-damage to gypsum board seams (left image; pre-fire) and straps
(right image; after cycling following fire): (a) cycling to $0.5 \%$ drift before Mild Fire; (b) cycling to $1.75 \%$ drift before Mild Fire. 


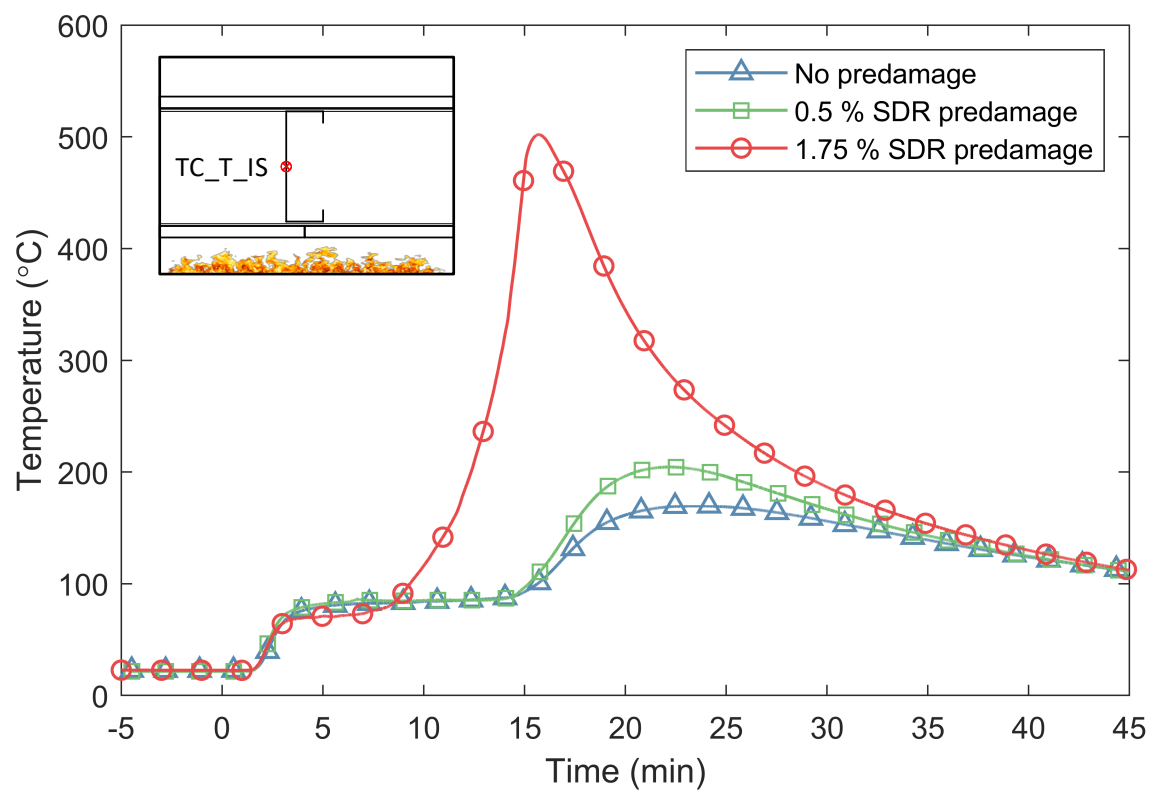

Fig. 97. Interior stud temperatures $46 \mathrm{~cm}$ from the top of the wall (TC_ $T_{-}$IS) for steel strap braced wall exposed to Mild Fire with and without pre-damage of the walls.

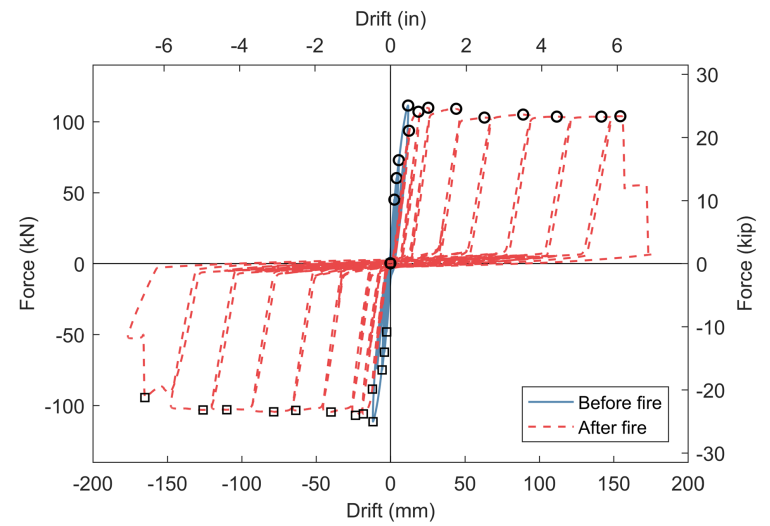

(a)

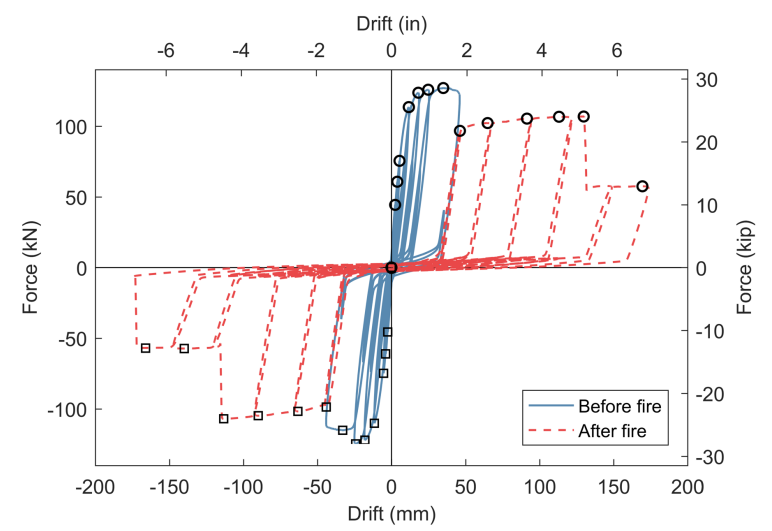

(b)

Fig. 98. Lateral load versus drift during mechanical loading of steel strap braced walls: (a) cycling to $0.5 \%$ drift before Mild Fire; (b) cycling to $1.75 \%$ drift before Mild Fire.

\subsection{Kitchen Fire}

The Kitchen Fire was conducted to compare the fire conditions used in this study to those of an actual kitchen furnishings fire. The Kitchen Fire represented the fire load density and ventilation conditions used to develop the Mild Fire (see Appendices). The thermal exposures achieved - in terms of upper layer temperature and heat flux - were discussed in Section 3.1.

The development of the Kitchen Fire is depicted in Fig. 99 and Fig. 100. The smoke alarm on the ceiling of the compartment went off $12 \mathrm{~min} 38 \mathrm{~s}$ after burner ignition. The oil in the pan ignited $17 \mathrm{~min} 31 \mathrm{~s}$ after burner ignition (Fig. 99a). After the oil ignited, the fire spread to the cabinets above the pan in about 2 min (Fig. 99b). The compartment flashed over 26 min $52 \mathrm{~s}$ after burner ignition (Fig. 99c). $35 \mathrm{~min}$ after burner ignition, there were indications of pyrolysis 
of the OSB inside the wall cavity (darker smoke emitted from knockout holes in chord studs), but no flaming combustion of the OSB was observed. Most of the room furnishings were consumed 40 min after burner ignition (Fig. 99d) and the oxygen content started to raise in the compartment; reaching $15 \% 45$ min after burner ignition. Flaming combustion of the OSB was clearly visible by 54 min after burner ignition (Fig. 99e). The gypsum boards screwed to the OSB fell off the unexposed side around $65 \mathrm{~min}$ after burner ignition. Remaining fire was suppressed using water $80 \mathrm{~min} 38 \mathrm{~s}$ after burner ignition when almost all the OSB has been burnt (Fig. 99e).

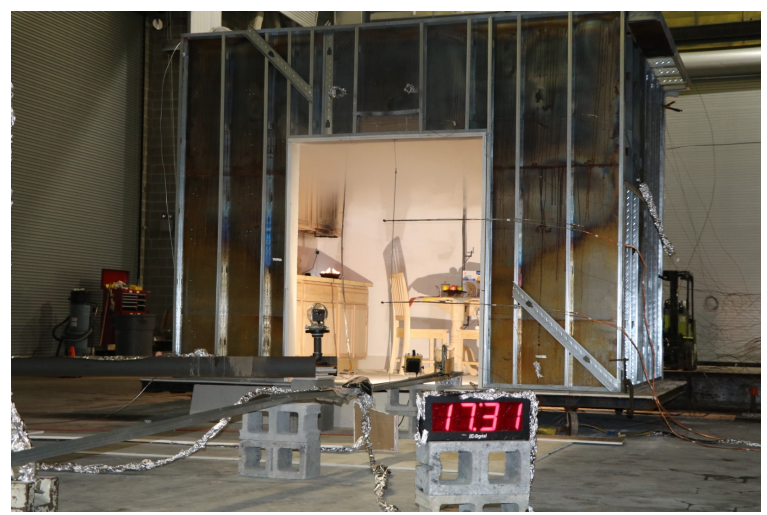

(a)

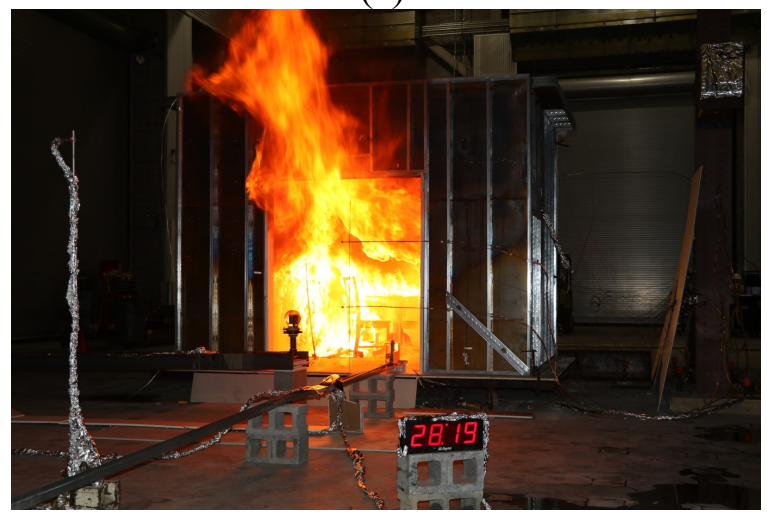

(c)

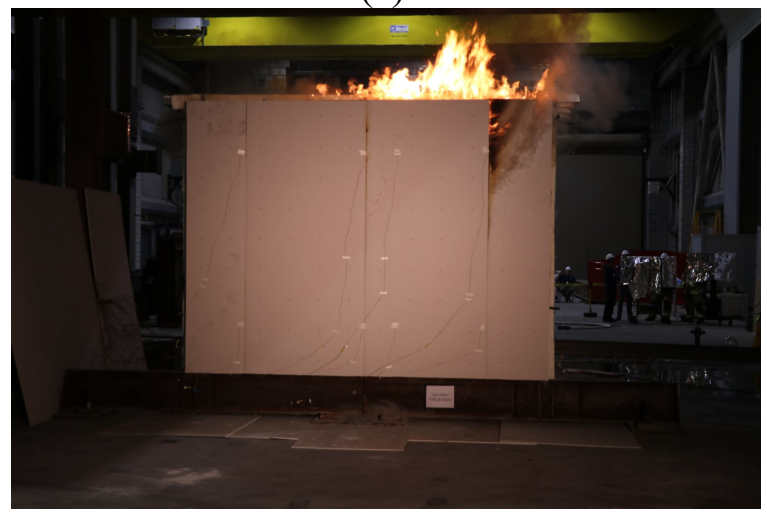

(e)

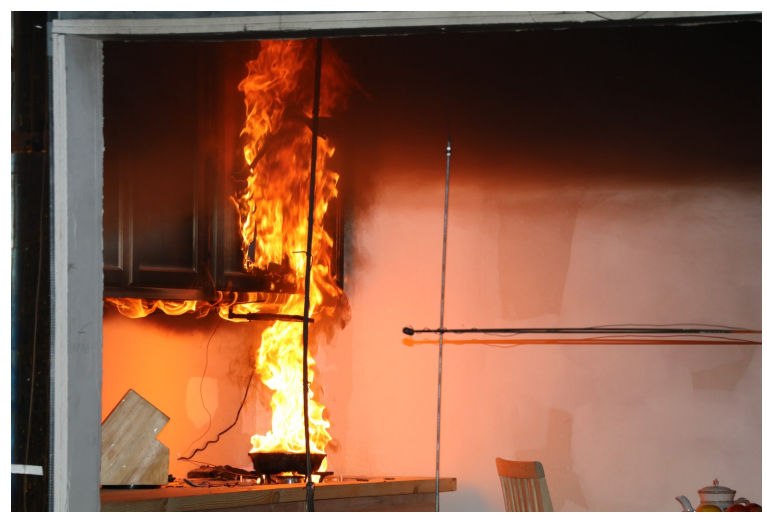

(b)

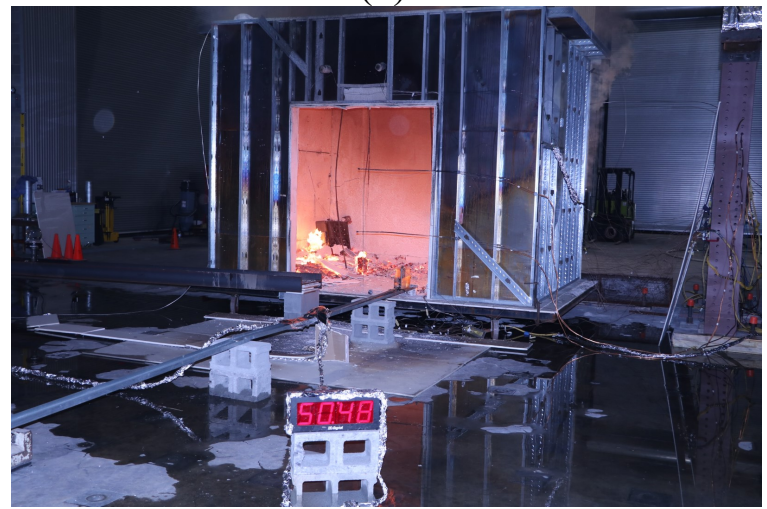

(d)

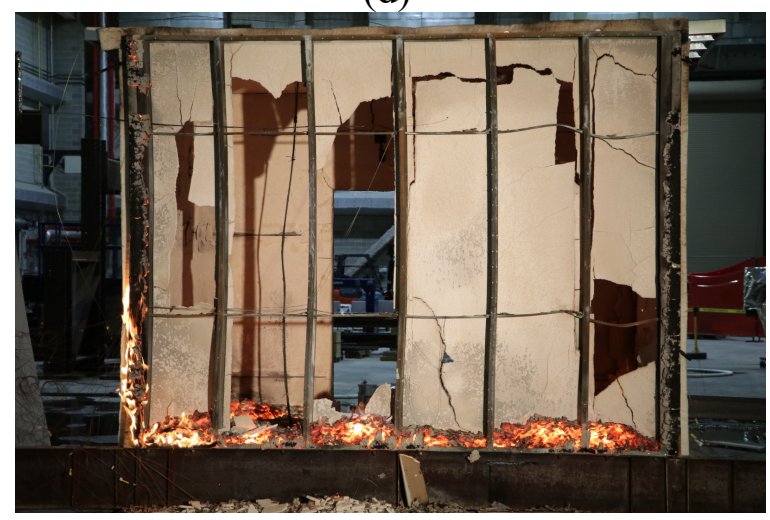

(f)

Fig. 99. Photographs of growth and decay of Kitchen Fire: (a) oil ignition; (b) flame spread to cabinets; (c) compartment flashover; (d) furnishings consumed; (e) burning of combustible sheathing; (f) end of experiment. 


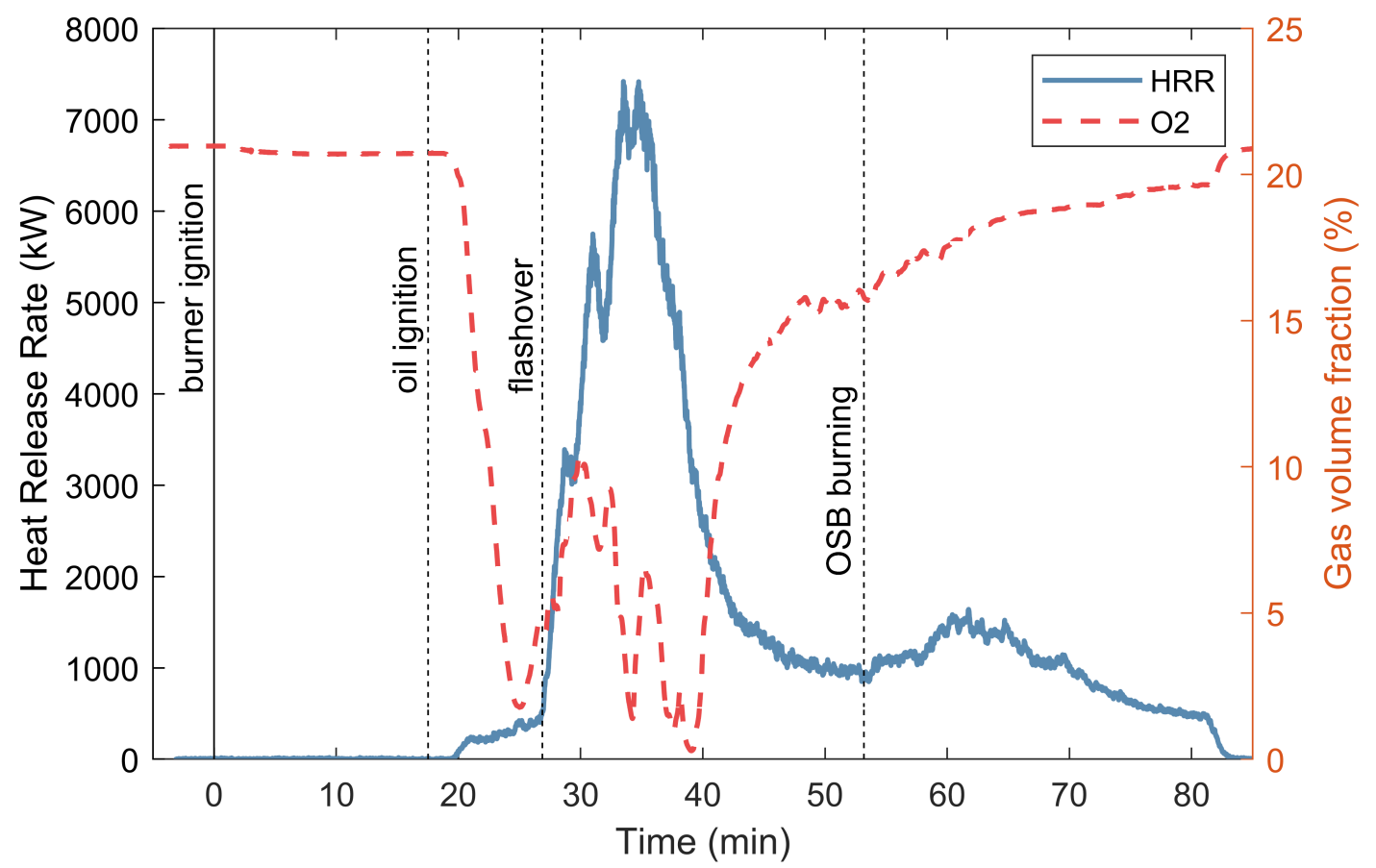

Fig. 100. Heat Release Rate and compartment oxygen concentration during kitchen furnishings fire.

Fig. 100 shows that the combustible sheathing material (OSB) began to contribute to the heat release rate only well into the decay phase of the fire, after most of the kitchen furnishings had been consumed. While there is not sufficient data in this study to draw definite conclusions, it appeared that the increase in oxygen concentration in the compartment when the furnishings burnt out coincided with the start of flaming combustion and fire growth on the OSB. This is an important finding because this type of decay-phase failure of the wall would not be captured in a standard fire test such as ASTM E119. Cracking of the gypsum board was observed on the fire-exposed side of the wall specimen during the fire decay that allowed the oxygen in the compartment to get to the pyrolyzing OSB in the wall cavity (Fig. 101). Further study of the interplay between compartment oxygen content and fire performance (including a fire decay phase) of walls with combustible materials is recommended based on these observations.

Fig. 102 plots temperatures through the specimen cross section $46 \mathrm{~cm}$ from the top of the wall at an interior stud. The figure shows that the time between compartment flashover and when the gypsum board on the fire exposed side of the wall begins to lose it fire protection capacity (rapid temperature increases above $100{ }^{\circ} \mathrm{C}$ ) is only about $13 \mathrm{~min}$. The comparison of just the interior stud temperatures for all the investigated fires in Fig. 79 showed that this 13 min duration agreed well with the $100^{\circ} \mathrm{C}$ plateau lengths in the Mild Fire and Severe Fire. 


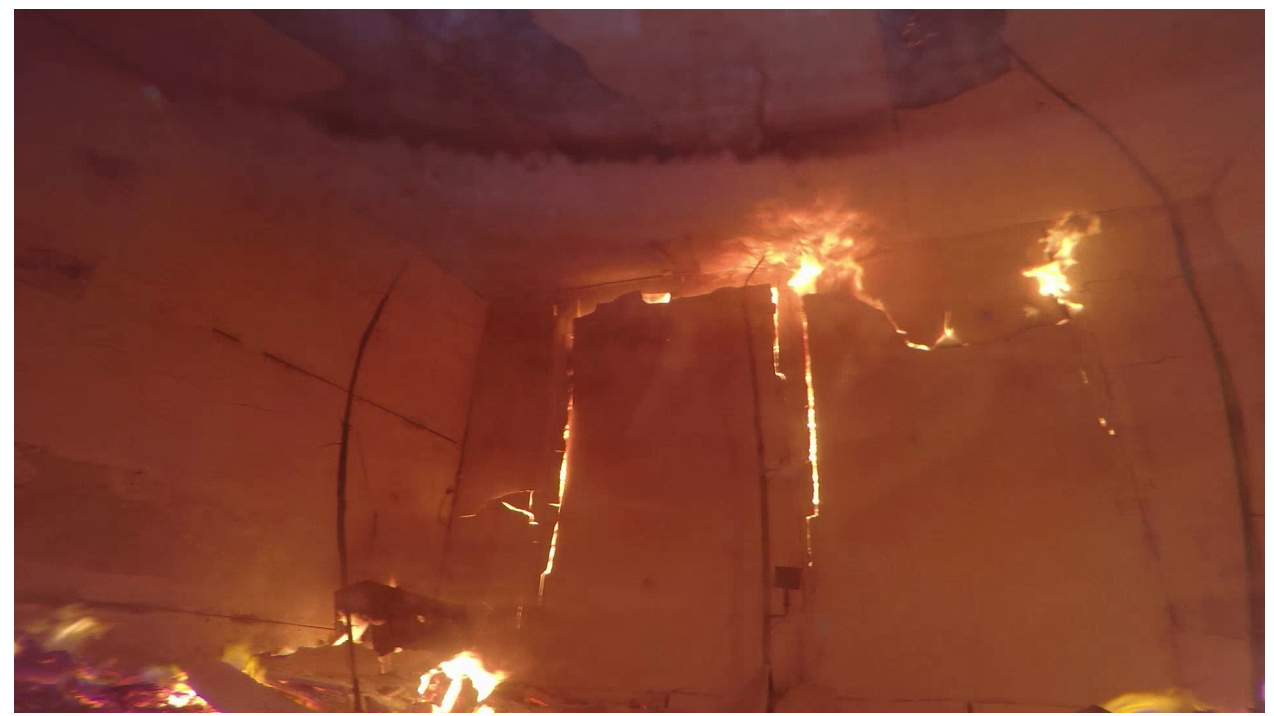

Fig. 101. Cracking of gypsum board and flaming combustion of the OSB.

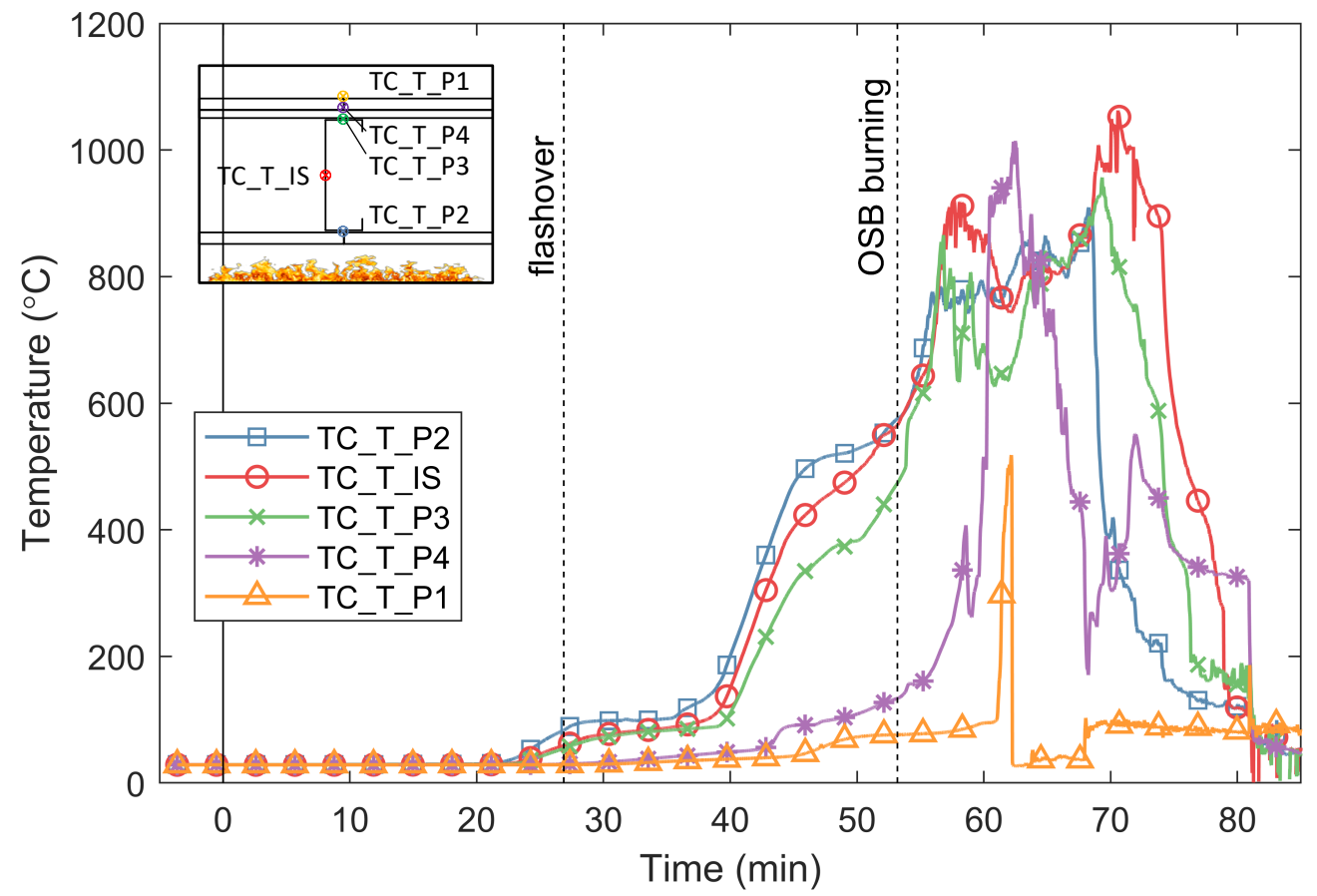

Fig. 102. Temperatures through the specimen at an interior stud $46 \mathrm{~cm}$ from the top of the wall during the Kitchen Fire. 


\section{Summary and Conclusions}

This study investigated the interplay between the thermal (fire) and mechanical (cyclic) response of cold-formed steel lateral force-resisting systems (CFS-LFRS). The influence of fire on the post-fire response differed significantly for the investigated shear walls and fire scenarios. The results are a limited set of data and the findings presented should not be extrapolated beyond the conditions tested. It is important to note that the absence of vertical load in this study may affect the relative capacity reductions reported for the various shear wall systems.

The target fire loads, generated using a natural gas diffusion burner, represented varying fire severities including 1-hour of temperature-time exposure similar to ASTM E119 (Standard Fire), a post-flashover fire of relatively long duration $(35 \mathrm{~min})$ and a peak upper layer gas temperature of $1100{ }^{\circ} \mathrm{C}$ (Severe Fire), and a post-flashover fire of relatively short duration (15 min) and a peak upper layer gas temperature of $900^{\circ} \mathrm{C}$ (Mild Fire). The three fires provide a range of Intensity Measures necessary for Performance-Based Design. Additionally, a furnished kitchen (Kitchen Fire) was tested with fire load density $\left(804 \mathrm{MJ} / \mathrm{m}^{2}\right)$ and ventilation condition (opening factor $0.08 \mathrm{~m}^{1 / 2}$ ) that mimicked the prototype for the Mild Fire. The more rapid compartment temperature rises and presence of decay phases in the Severe, Mild, and Kitchen fires - characteristics representative of actual building fires not captured by the Standard Fire - provide insight into the behavior of cold-formed steel shear walls in realistic fire conditions.

The measured heat fluxes to the specimens ( $>200 \mathrm{~kW} / \mathrm{m}^{2}$ at top of wall) in the Severe Fire and Kitchen Fire, as well as in the Mild Fire $\left(\approx 135 \mathrm{~kW} / \mathrm{m}^{2}\right.$ at top of wall), were significantly larger than in the Standard Fire $\left(\approx 85 \mathrm{~kW} / \mathrm{m}^{2}\right)$ at one hour.

The gypsum-sheet steel composite panel sheathing exhibited increasingly reduced post-fire capacity with increasing fire severity. The maximum reduction in the peak force capacity (based on first positive displacement excursions) was $23 \%, 58 \%$, and $68 \%$ for the Mild, Standard and Severe Fire, respectively. A nontrivial portion of this force reduction (> 10\%) was attributed to the severely degraded mechanical strength of the gypsum on the fire-exposed side of the wall, which contributed less to the load capacity after the fire. The remainder of the capacity reduction appeared due to damage to the adhesive between the sheet steel and the gypsum in the composite panels. This reduced the out-of-plane stiffness of the panels changing the specimen from a composite panel sheathed wall to a plain sheet steel shear wall with an accompanying capacity reduction, and to damage of the perimeter connections by the fire. However, the sheet steel helped to prevent flame spread out of the compartment and allowed the walls to maintain lateral load capacity under reversed load cycling following the most severe fire investigated. Even when some perimeter fasteners had burned away (oxidized) and the steel sheet had been comprised locally, shear loads were redistributed. The Phase 1 tests reported previously (Hoehler et al., 2017) showed the post-fire mechanical response of the composite panel system to be insensitive to cyclic damage prior to the fire.

The strap braced walls were the most ductile of the investigated systems achieving story drift ratio over $6 \%$ and were largely insensitive to the thermal loading. The maximum reduction in the peak force capacity was $15 \%$ and $17 \%$ for the Mild Fire and Standard Fire, respectively. The reduced capacity is attributed to the degraded mechanical strength of the gypsum 
following the fire. However, in the case of the Severe Fire, where a hotspot developed at a strap location, the residual lateral load capacity was reduced to essentially zero. The post-fire mechanical response of strap braced wall appeared insensitive to cyclic damage prior to the Mild Fire. However, when all layers of drywall joint compound and paper tape were damaged during pre-fire cycling to $1.75 \%$ story drift ratio, the temperature of the cold-formed steel studs behind the joint rapidly rose $(<15 \mathrm{~min})$ to $500{ }^{\circ} \mathrm{C}$ during the fire, suggesting that the studs would have been structurally compromised for fires of longer duration.

For this limited set of experiments, the oriented strand board (OSB) sheathed walls demonstrated significant impact from the fire. Both the Standard Fire and Severe Fires caused the OSB to ignite, resulting in a total loss of residual capacity. Moreover, cycling to $1.5 \% \mathrm{drift}$ (as might occur in a major earthquake) prior to the fire allowed even the Mild Fire to penetrate the wall and ignite the OSB.

The duration of the post-flashover kitchen compartment fire was similar to the Mild Fire, but the upper layer gas temperature achieved was higher; peaking to a value of $1152^{\circ} \mathrm{C}$. Notably, the temperature rise rate and peak temperature in the Kitchen Fire were significantly higher than for the Standard Fire. The test showed that the combustible sheathing material (OSB) began to contribute to the heat release rate well into the decay phase of the fire after most of the kitchen furnishings had been consumed. While there are insufficient data to draw definite conclusions, it appeared that the increase in oxygen concentration in the compartment when the furnishings burnt out coincided with the start of flaming combustion and fire growth on the OSB. This is an important finding because this type of decay-phase failure of the wall would not be captured in a standard fire test such as ASTM E119. 


\section{References}

American Iron and Steel Institute (2016a) AISI S100-16 North American Specification for the Design of Cold-Formed Steel Structural Members. Washington, DC: American Iron and Steel Institute (AISI).

American Iron and Steel Institute (2016b) AISI S400-15 w/S1-16, North American Standard for Seismic Design of Cold-Formed Steel Structural Systems (with Supplement 1).

Washington, DC: American Iron and Steel Institute (AISI).

American Iron and Steel Institute (2018) Cold-Formed Steel Framing. Available at: https://www.buildusingsteel.org/build-using-steel/cold-formed-steel-framing (Accessed: 13 September 2018).

American Society of Civil Engineers (2013) ASCE/SEI 7-10 Minimum Design Loads for Buildings and Other Structures. Reston, VA: American Society of Civil Engineers. doi: 10.1061/9780784412916.

ASTM International (2011) ASTM E2126-11 Standard Test Methods for Cyclic (Reversed) Load Test for Shear Resistance of Vertical Elements of the Lateral Force Resisting Systems for Buildings. West Conshohocken, PA: ASTM International. doi: 10.1520/E2126-11.

ASTM International (2015) ASTM A1003/A1003M-15 Standard Specification for Steel Sheet, Carbon, Metallic- and Nonmetallic-Coated for Cold-Formed Framing Members. West Conshohocken, PA: ASTM International. doi: 10.1520/A1003.

ASTM International (2016) ASTM E119-16a Standard Test Methods for Fire Tests of Building Construction and Materials. West Conshohocken, PA: ASTM International. doi: 10.1520/E0119.

Ayhan, D. et al. (2018) 'Cold-Formed Steel Framed Shear Wall Database', in Int'l Spec. Conference on Cold-Formed Steel Structures. St. Louis, MO.

Bryant, R. A. et al. (2004) The NIST 3 Megawatt Quantitative Heat Release Rate Facility. Bwalya, A. C. et al. (2008) Survey Results of Combustible Contents and Floor Areas in Multi-Family Dwellings.

Häggkvist, A., Sjöström, J. and Wickström, U. (2013) 'Using plate thermometer measurements to calculate incident heat radiation', Journal of Fire Sciences, 31(2), pp. 166177. doi: $10.1177 / 0734904112459264$.

Hoehler, M. S. et al. (2017) 'Behavior of steel-sheathed shear walls subjected to seismic and fire loads', Fire Safety Journal, 91, pp. 524-531. doi: 10.1016/j.firesaf.2017.03.021.

Hoehler, M. S. and Smith, C. M. (2016) Influence of fire on the lateral load capacity of steelsheathed cold-formed steel shear walls - report of test (NISTIR 8160). Gaithersburg, MD. doi: 10.6028/NIST.IR.8160.

Hoehler, M. S. and Smith, C. M. (2018) Dataset from Influence of Fire on the Lateral Resistance of Cold-Formed Steel Shear Walls - Phase 1. doi: 
https://doi.org/10.18434/T4/1422515.

Hunt, S. P., Cutonilli, J. and Hurley, M. (2010) Evaluation of Enclosure Temperature Empirical Models. Bethesda.

IAPMO (2018) IAPMO-ER-1261 Sure-Board Series 200, 200W, and 200B Structural Panels Installed on Cold-Formed Steel or Wood Framed Shear Walls. International Association of Plumbing and Mechanical Officials (IAPMO).

Intertek (2010) Test Report on the fire resistance of Sure Board Series 200 and 200W Panels (Report Number: 3197053COQ-004 EEV).

McCaffrey, B. J. and Heskestad, G. (1976) 'A robust bidirectional low-velocity probe for flame and fire application', Combustion and Flame, 26, pp. 125-127. doi: 10.1016/00102180(76)90062-6.

Schafer, B. W. et al. (2016) 'Seismic Response and Engineering of Cold-formed Steel Framed Buildings’, Structures, 8, pp. 197-212. doi: 10.1016/j.istruc.2016.05.009.

Simpson Strong-Tie (2017) 'S/HDS and S/HDB Holdowns', in Connectors for Cold-Formed Steel Construction, pp. 245-246.

Smith, C. M. and Hoehler, M. S. (2018) 'Imaging Through Fire Using Narrow-Spectrum Illumination', Fire Technology. doi: 10.1007/s10694-018-0756-5.

Society of Fire Protection Engineers (2016) SFPE Handbook of Fire Protection Engineering. Edited by M. J. Hurley et al. New York, NY: Springer New York. doi: 10.1007/978-1-49392565-0.

Steel Framing Industry Association (2016) Market Share and Comparative Report: Coldformed Steel Framing and Project Specification Trends. Falls Church, VA.

Su, J. et al. (2018) Fire Safety Challenges of Tall Wood Buildings - Phase 2: Task 2 \& 3 Cross Laminated Timber Compartment Fire Tests. Fire Protection Research Foundation, Quincy, MA.

Sultan, M. A. (1996) 'A Model for Predicting Heat Transfer through Noninsulated Unloaded Steel-Stud Gypsum Board Wall Assemblies Exposed to Fire', Fire Technology, 32(1), pp. 239-257.

Takeda, H. (2003) 'A model to predict fire resistance of non-load bearing wood-stud walls', Fire and Materials, 27(1), pp. 19-39. doi: 10.1002/fam.816.

Taylor, B. N. and Kuyatt, C. E. (1994) 'Guidelines for Evaluating and Expressing the Uncertainty of NIST Measurement Results', NIST Technical Note 1297. doi: NIST Technical Note 1297.

The Engineered Wood Association (2018) APA Builder Tips: Prevent Buckling With Proper Spacing, Form M300. Available at: http://www.apawood.org/buildertips/pages/M300.html (Accessed: 19 September 2018).

U.S. Department of Commerce (2015) Characteristics of New Housing. Washington, DC. 
Underwriters Laboratory (2017a) Fire-resistance Ratings - ANSI/UL 263. Underwriters Laboratory (UL).

Underwriters Laboratory (2017b) UL Design No. 423 Fire Resistance Ratings - ANSI/UL 263.

United Nations Department of Economic and Social Affairs (2014) World Urbanization Prospects: The 2014 Revision, Demographic Research. New York. Available at: http://esa.un.org/unpd/wup/Highlights/WUP2014-Highlights.pdf.

Wang, X. et al. (2015) 'Seismic Performance of Cold-Formed Steel Wall Systems in a FullScale Building', Journal of Structural Engineering, 141(10), p. 04015014. doi: 10.1061/(ASCE)ST.1943-541X.0001245.

Wang, X. et al. (2018) 'Earthquake and fire performance of a mid-rise cold-formed steel framed building - test program and test results: Final Report (SSRP-2016/08)', (December).

Whitmore, R. E. (1952) Experimental Investigation of Stresses in Gusset Plates (Bulletin No. 16.). Knoxville, TN. 


\section{Appendix A: Detailing of Asymmetric Steel Strap Braced Wall}

The details in this appendix apply to Specimen S01 only.
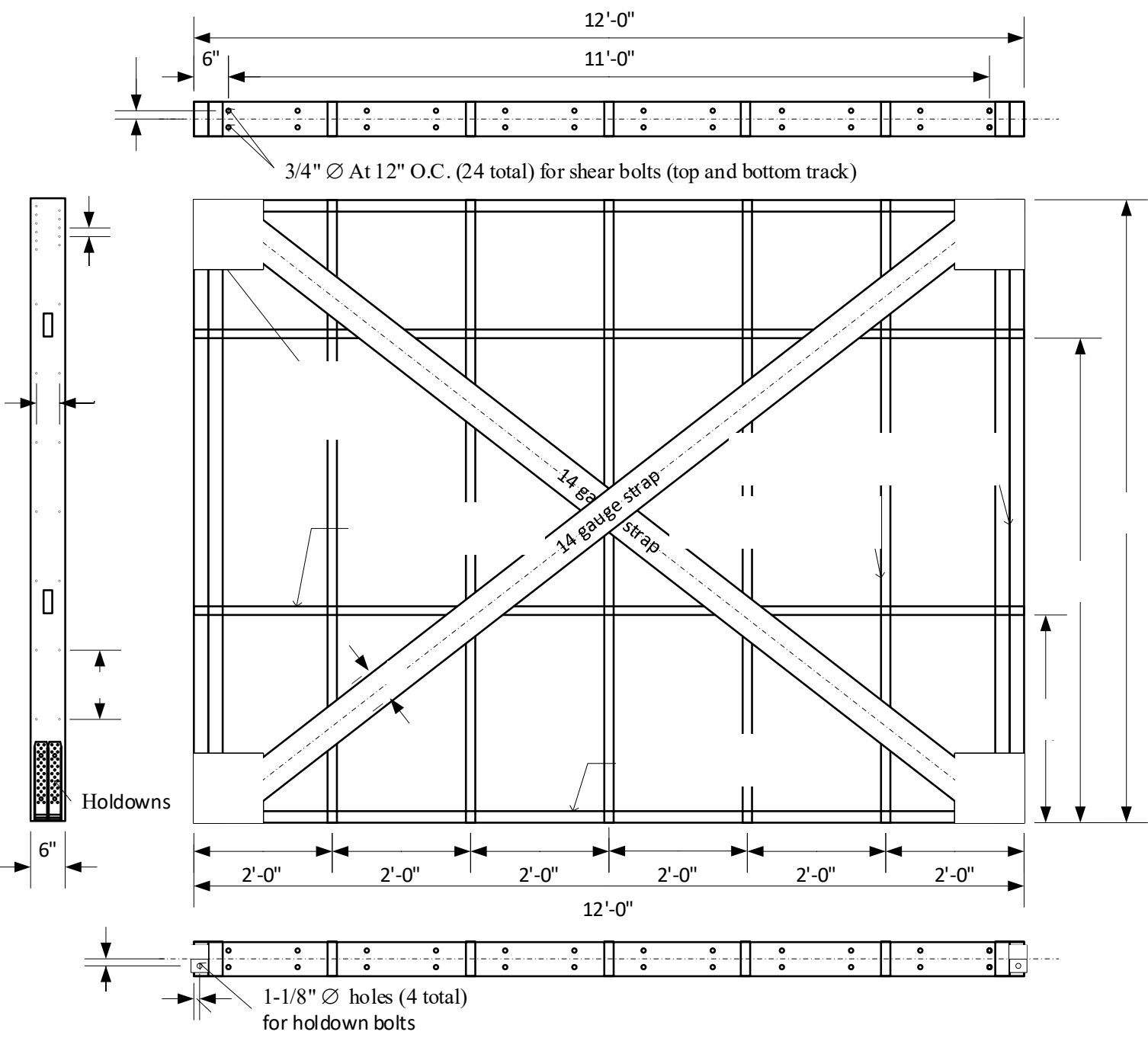

Fig. 103. Drawing of framing for the asymmetric strap braced wall $(1 \mathrm{ft} .=30.5 \mathrm{~cm})$. 


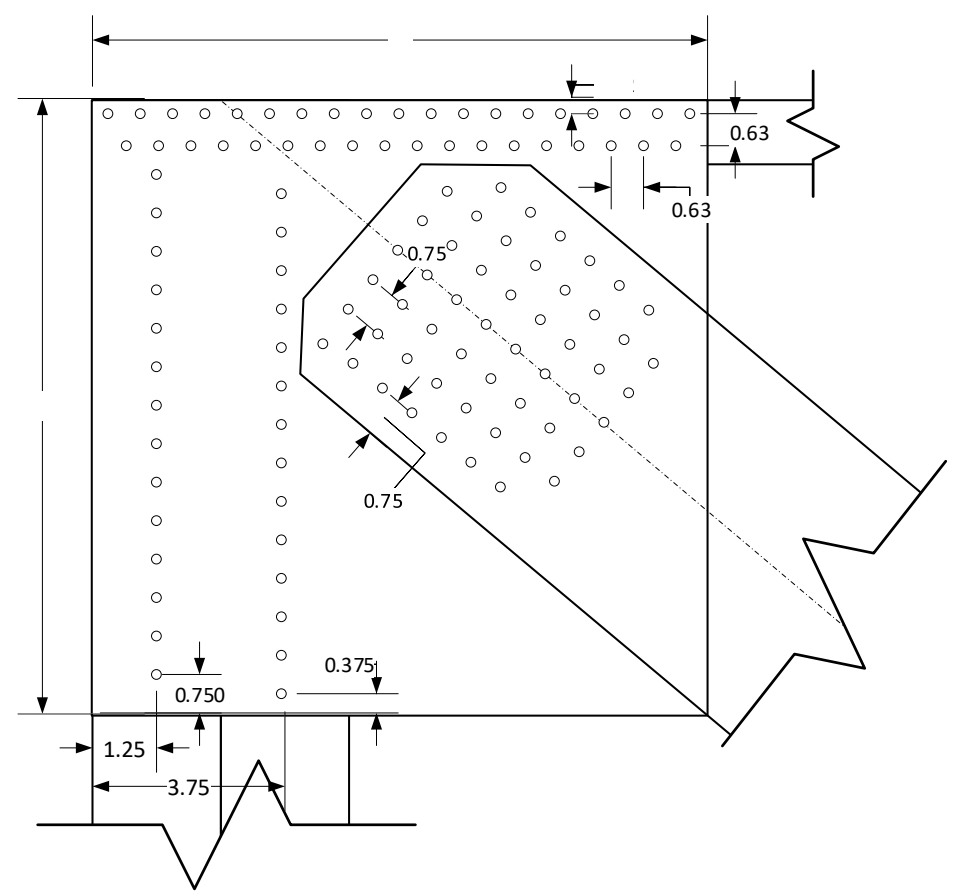

Fig. 104. Drawing of gusset detail for the asymmetric strap braced wall (units in inches; 12 in. $=30.5 \mathrm{~cm}$ ).

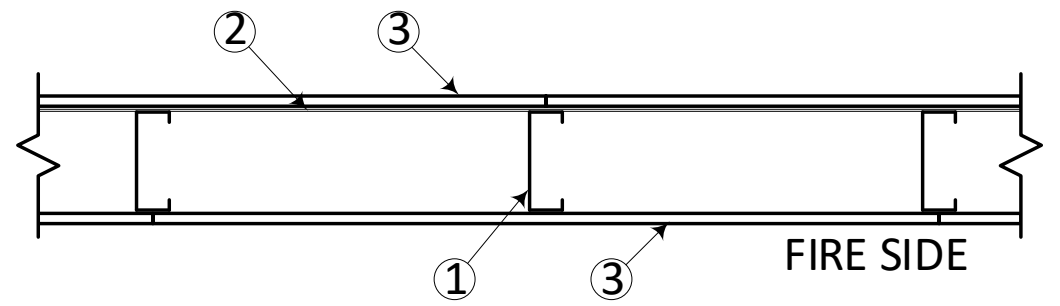

Fig. 105. Cross section of asymmetric steel strap braced wall (1 - steel framing; 2 - steel strap; 3 - gypsum board). 


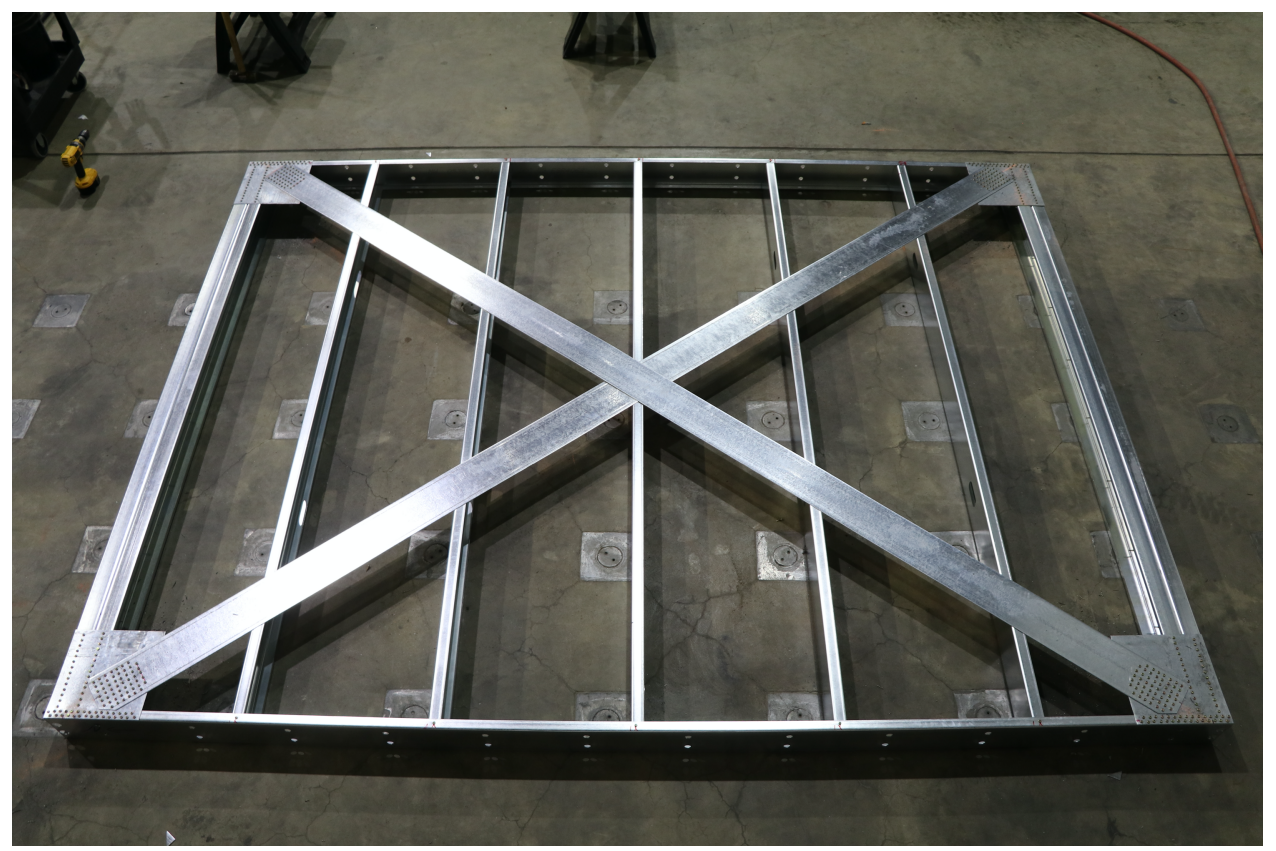

Fig. 106. Photograph of framing for the asymmetric strap braced wall (bridging not yet installed).

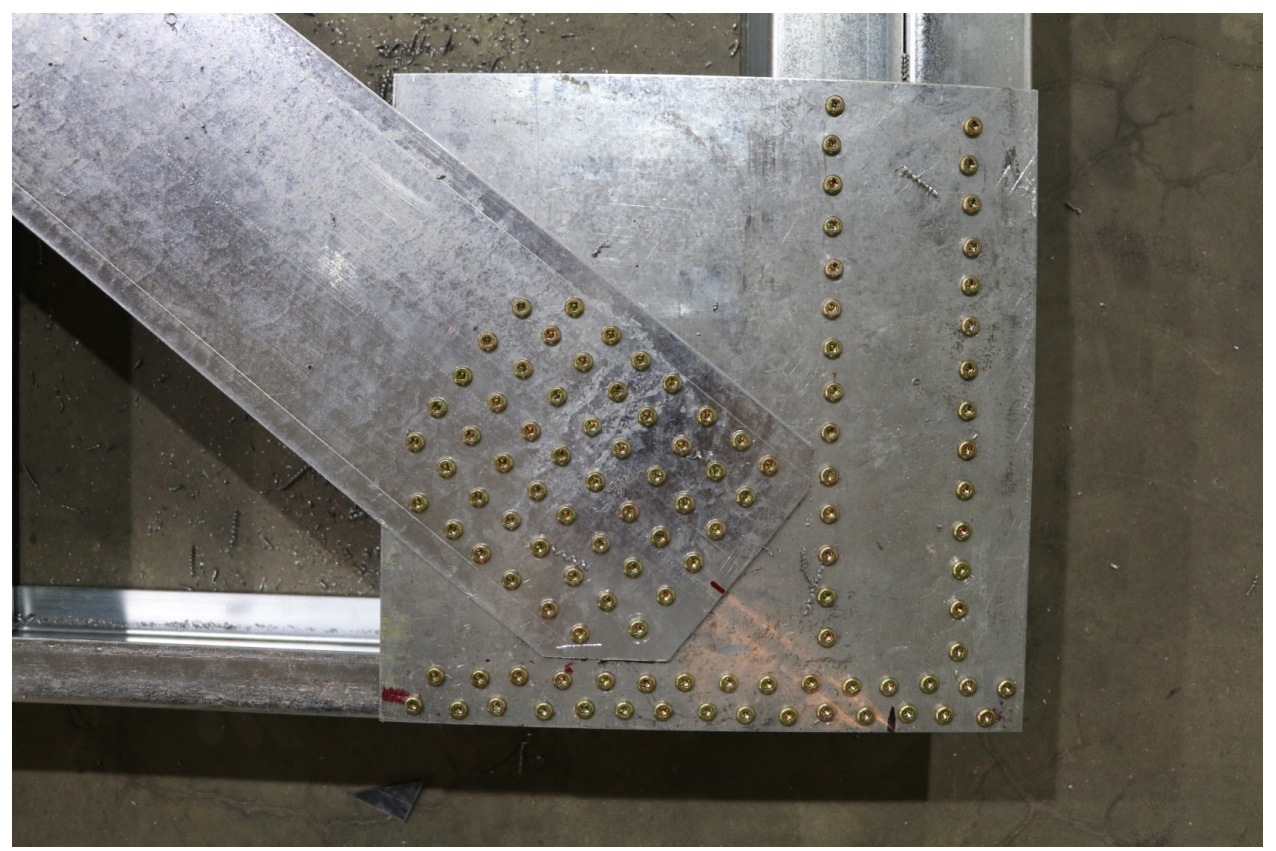

Fig. 107. Photograph of gusset detail for the asymmetric strap braced wall. 


\section{Appendix B: Screw Patterns}

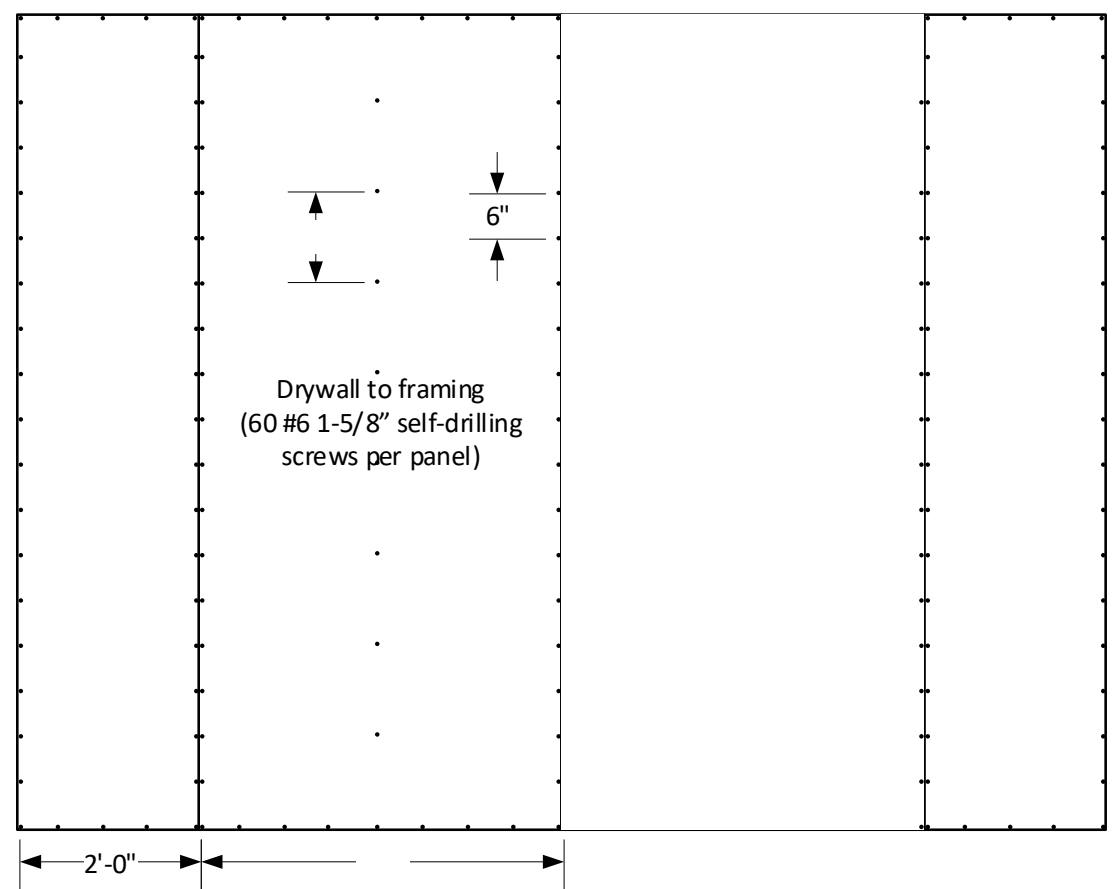

Fig. 108. Screw pattern for attachment of gypsum board to framing on fire-exposed side of wall for all wall types $(1 \mathrm{ft} .=30.5 \mathrm{~cm})$.

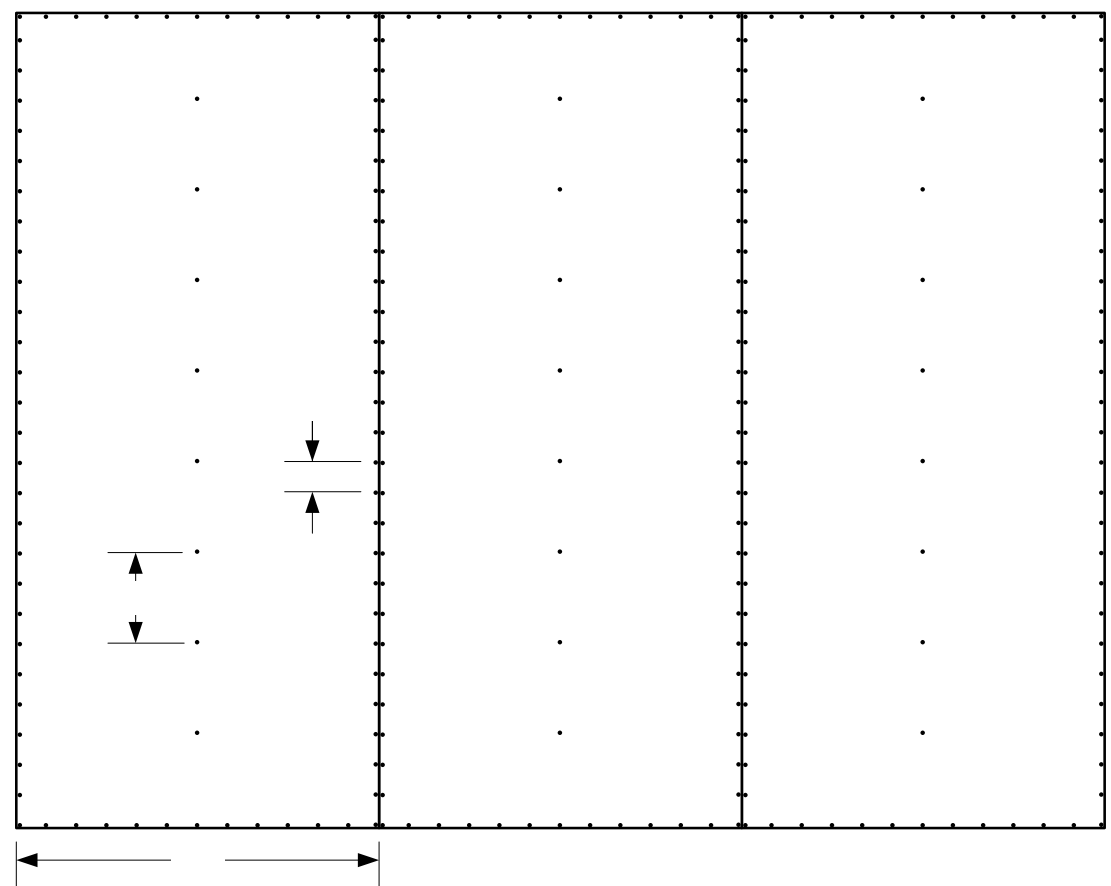

Fig. 109. Screw pattern for attachment of Sure-Board Series 200 to framing on unexposed side of wall $(1 \mathrm{ft} .=30.5 \mathrm{~cm})$. 


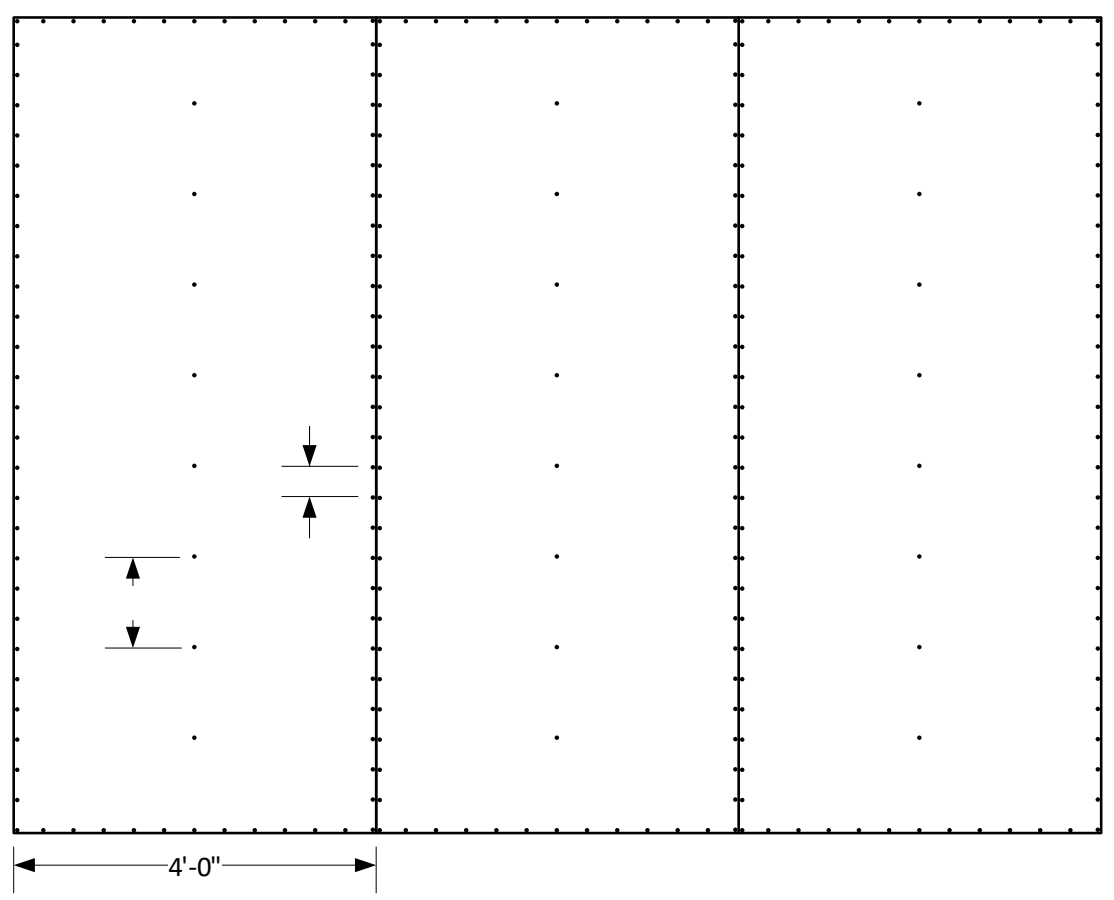

Fig. 110. Screw pattern for attachment of oriented strand board (OSB) to framing on unexposed side of wall $(1 \mathrm{ft} .=30.5 \mathrm{~cm})$.

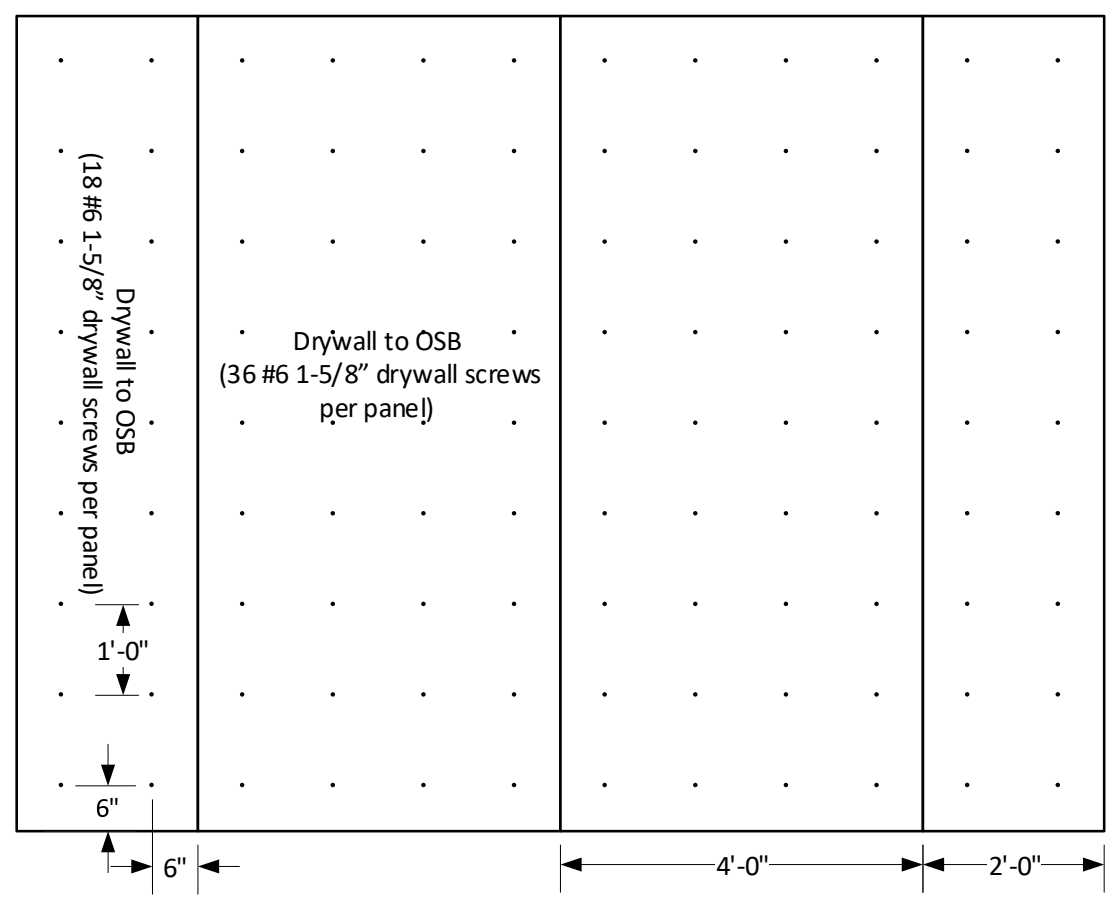

Fig. 111. Screw pattern for attachment of gypsum board to oriented strand board (OSB) on unexposed side of wall $(1 \mathrm{ft} .=30.5 \mathrm{~cm})$. 


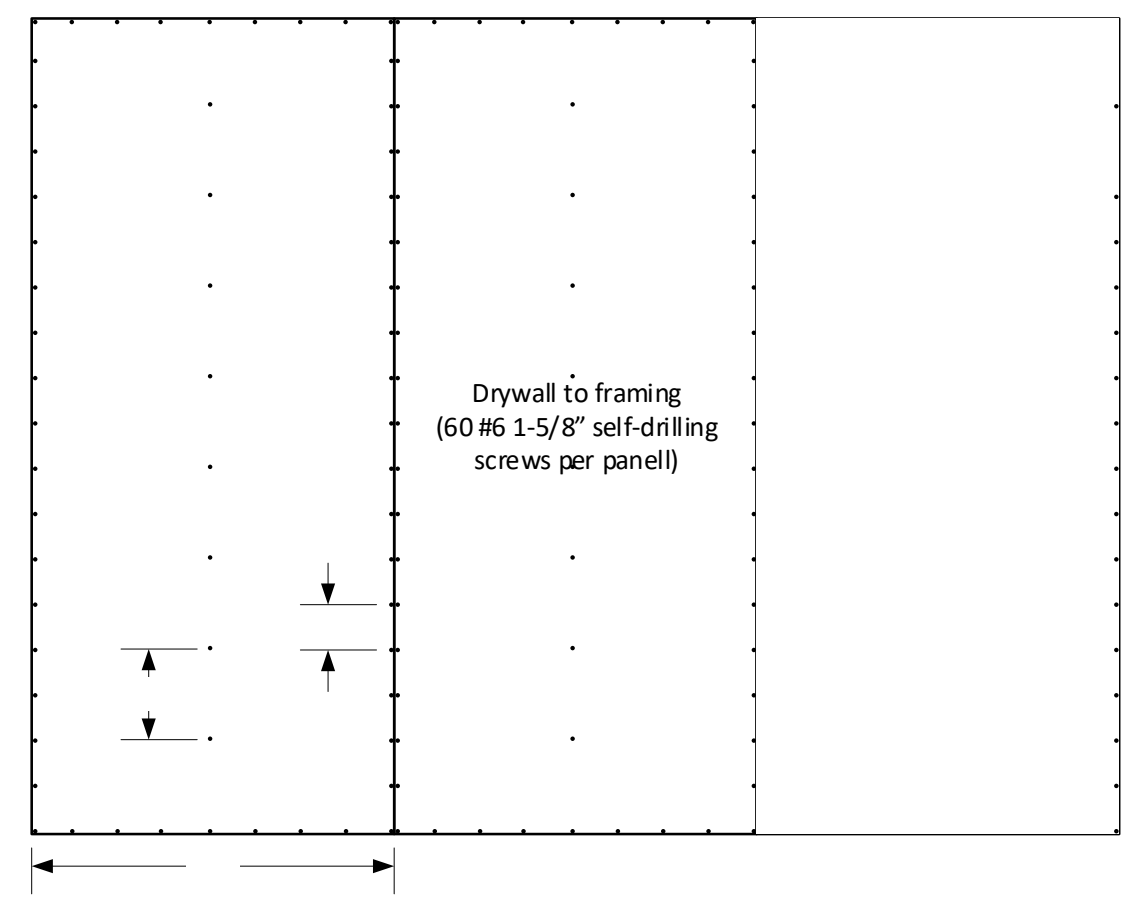

Fig. 112. Screw pattern for attachment of gypsum board to framing on unexposed side of wall for strap braced walls $(1 \mathrm{ft} .=30.5 \mathrm{~cm})$. 


\section{Appendix C: Uncertainty of Measurements}

The measurements presented in this report include length, force, displacement, temperature, heat flux, differential pressure, gas flow velocity, calorimeter and burner heat release rate, fuel mass, and gas species concentration. For each measurand, Type A and/or Type B uncertainties, combined standard uncertainties, and total expanded uncertainties were estimated. As defined in Taylor and Kuyatt (Taylor and Kuyatt, 1994), Type A uncertainty was evaluated using statistical methods; Type B uncertainty was estimated by other means such as the information available in manufacturer's specifications, from past-experience, or engineering judgement. The combined standard uncertainty was estimated by combining the individual uncertainties using "root-sum-of-squares". The expended uncertainty was then computed by multiplying the combined uncertainty by a coverage factor of 2 corresponding to an approximately $95 \%$ confidence interval.

Table 9 summarizes the components of the measurement uncertainty. All uncertainties are assumed to be symmetric $( \pm)$. The following definitions are used:

Precision: Uncertainty in the ability of the measurement instrument to resolve information from the sensor.

Bias: Uncertainties from the calibration of the sensor or estimated based on the resolution of the sensor, as well as uncertainties from other known sources of error.

Random error: Uncertainty due to random, unpredictable variations in the measurement process during a typical steady-state period.

Table 9. Uncertainty in the reported data.

\begin{tabular}{|c|c|c|c|c|}
\hline Measurement / Component & $\begin{array}{c}\text { Estimation } \\
\text { Method }\end{array}$ & $\begin{array}{c}\text { Component } \\
\text { Standard } \\
\text { Uncertainty }\end{array}$ & $\begin{array}{c}\text { Combined } \\
\text { Standard } \\
\text { Uncertainty }\end{array}$ & $\begin{array}{c}\text { Total } \\
\text { Expanded } \\
\text { Uncertainty }\end{array}$ \\
\hline \multicolumn{5}{|l|}{ Instrument location, $\mathrm{mm}$} \\
\hline Precision (ability to read tape measure with eye) & Type B & 0.8 & \multirow{3}{*}{25} & \multirow{3}{*}{50} \\
\hline Bias (accuracy of tape measure increments) & Type B & 0.8 & & \\
\hline Random error (estimate) & Type B & 25 & & \\
\hline \multicolumn{5}{|l|}{ Actuator force, $\% \mathrm{FS}$} \\
\hline Precision & Type B & 0.001 & \multirow{3}{*}{1.0} & \multirow{3}{*}{2.0} \\
\hline Bias (sensor resolution $/ \sqrt{ } 3$ ) & Type B & 0.12 & & \\
\hline Random error (estimate) & Type B & 1.0 & & \\
\hline \multicolumn{5}{|l|}{ Actuator displacement, \% FS } \\
\hline Precision & Type B & 0.001 & \multirow{3}{*}{0.1} & \multirow{3}{*}{0.2} \\
\hline Bias (linearity) ${ }^{a}$ & Type B & 0.02 & & \\
\hline Random error (estimate) & Type B & 0.1 & & \\
\hline \multicolumn{5}{|l|}{ Displacement (PA-30), \% FS } \\
\hline Precision & Type B & 0.01 & \multirow{4}{*}{0.5} & \multirow{4}{*}{1.0} \\
\hline Bias (linearity) & Type B & 0.10 & & \\
\hline Bias (repeatability) & Type B & 0.015 & & \\
\hline Random error (estimate) & Type B & 0.5 & & \\
\hline \multicolumn{5}{|l|}{ Displacement (PA-10-L3M), \% FS } \\
\hline Precision & Type B & 0.01 & \multirow{4}{*}{0.5} & \multirow{4}{*}{1.0} \\
\hline Bias (linearity) & Type B & 0.15 & & \\
\hline Bias (repeatability) & Type B & 0.015 & & \\
\hline Random error (estimate) & Type B & 0.5 & & \\
\hline
\end{tabular}




\begin{tabular}{|c|c|c|c|c|}
\hline Measurement / Component & $\begin{array}{l}\text { Estimation } \\
\text { Method }\end{array}$ & $\begin{array}{c}\text { Component } \\
\text { Standard } \\
\text { Uncertainty }\end{array}$ & $\begin{array}{l}\text { Combined } \\
\text { Standard } \\
\text { Uncertainty }\end{array}$ & $\begin{array}{c}\text { Total } \\
\text { Expanded } \\
\text { Uncertainty }\end{array}$ \\
\hline \multicolumn{5}{|l|}{ Displacement (TR25), \% RD } \\
\hline Precision & Type B & 0.01 & \multirow{4}{*}{0.6} & \multirow{4}{*}{1.1} \\
\hline Bias (linearity) & Type B & 0.20 & & \\
\hline Bias (repeatability) & Type B & 0.20 & & \\
\hline Random error (estimate) & Type B & 0.5 & & \\
\hline \multicolumn{5}{|c|}{ Temperature (gas; bare bead thermocouple), \% RD } \\
\hline Precision & Type B & 0.01 & \multirow{3}{*}{1.5} & \multirow{3}{*}{3.0} \\
\hline $\operatorname{Bias}^{b}$ & Type B & 0.75 & & \\
\hline Random error $(\mathrm{N}=600)$ & Type A & 1.3 & & \\
\hline \multicolumn{5}{|l|}{ Temperature (gas; sheathed thermocouple), \% RD } \\
\hline Precision & Type B & 0.01 & \multirow{3}{*}{1.4} & \multirow{3}{*}{2.8} \\
\hline Bias $^{b}$ & Type B & 0.75 & & \\
\hline Random error $(\mathrm{N}=600)$ & Type A & 1.2 & & \\
\hline \multicolumn{5}{|c|}{ Temperature (specimen; bare bead thermocouple), \% RD } \\
\hline Precision & Type B & 0.01 & \multirow{3}{*}{3.1} & \multirow{3}{*}{6.2} \\
\hline $\operatorname{Bias}^{b}$ & Type B & 0.75 & & \\
\hline Random error $(\mathrm{N}=600)$ & Type A & 3.0 & & \\
\hline \multicolumn{5}{|l|}{ Temperature (plate thermometer), \% RD } \\
\hline Precision & Type B & 0.01 & \multirow{3}{*}{0.9} & \multirow{3}{*}{1.8} \\
\hline $\operatorname{Bias}^{b}$ & Type B & 0.75 & & \\
\hline Random error $(\mathrm{N}=600)$ & Type A & 0.5 & & \\
\hline \multicolumn{5}{|l|}{ Differential pressure, $\% \mathrm{RD}$} \\
\hline Precision & Type B & 0.01 & \multirow{3}{*}{3.4} & \multirow{3}{*}{6.8} \\
\hline Bias (calibration) & Type B & 0.15 & & \\
\hline Random error $(\mathrm{N}=600)$ & Type A & 3.4 & & \\
\hline \multicolumn{5}{|l|}{ Gas flow velocity, $\% \mathrm{RD}$} \\
\hline Precision & Type B & 0.01 & \multirow{3}{*}{7.6} & \multirow{3}{*}{15.2} \\
\hline Bias (Probe constant) & Type B & 5 & & \\
\hline Random error $(\mathrm{N}=300)$ & Type A & 5.7 & & \\
\hline \multicolumn{5}{|l|}{ Calorimeter heat release rate, $\% \mathrm{RD}$} \\
\hline Precision & Type B & 0.1 & \multirow{3}{*}{7.4} & \multirow{3}{*}{14.8} \\
\hline Bias & Type B & 4.5 & & \\
\hline Random error $(\mathrm{N}=300)$ & Type A & 5.9 & & \\
\hline Burner heat release rate, $\% \mathrm{RD}$ & & & & \\
\hline Precision & Type B & 0.2 & & \\
\hline Bias & Type B & 0.6 & 0.8 & 1.6 \\
\hline Random error $(\mathrm{N}=300)$ & Type A & 0.5 & & \\
\hline Fuel positions and dimensions, $\mathrm{mm}$ & & & & \\
\hline Precision & Type B & 0.8 & & \\
\hline Bias & Type B & 0.8 & 13 & 25 \\
\hline Random error (estimate) & Type B & 13 & & \\
\hline Fuel mass, kg & & & & \\
\hline Precision & Type B & 0.001 & & \\
\hline Bias & Type B & 0.001 & 0.01 & 0.02 \\
\hline Random error $(\mathrm{N}=5)$ & Type A & 0.01 & & \\
\hline
\end{tabular}

$\mathrm{FS}=$ full scale; $\mathrm{RD}=$ reading; $\mathrm{N}=$ number of samples

${ }^{\text {a }}$ Minimum $\pm 60 \mu \mathrm{m}$

${ }^{b}$ The standard limit of error is the greater of $\pm 0.75 \%$ or $2.2^{\circ} \mathrm{C}$. 


\section{Appendix D: Fire Load Development}

\section{Severe and Mild Fires}

The 'severe' and the 'mild' fires used in this study are intended to encompass a range of postflashover (fully-developed) fire conditions that could occur in a modern residential kitchen. A combination of experimental and statistical data was used, empirical formulations and engineering judgement to define these fire scenarios. The fire duration is estimated for a prototypical kitchen with a range of ventilation conditions, whereas the target temperatures are based on statistical analysis of experimental compartment fire data.

In the experimental setup, although a mass flow controller was used for the natural gas burner to control the thermal conditions in the compartment, it was decided not to control the fire during the decay phase, but rather to extinguish the burner and let the compartment characteristics dictate temperature decay.

The following considerations guided the development of the design fires:

- It is assumed that the compartment has a square floor plan, is ventilation controlled during the fully-developed phase of the fire, has predominantly wood fuel, and that all combustion takes place within the compartment.

- A room height of $2.7 \mathrm{~m}$ and an opening height of $2 \mathrm{~m}$ were assumed fixed.

- For kitchens in multi-family dwellings in Canada (where statistics were available), Bwalya reports a mean floor area of $(9.8 \pm 3.6) \mathrm{m}^{2}$ and an average fire load density of $(807 \pm 123) \mathrm{MJ} / \mathrm{m}_{\text {floor }}{ }^{2}$, where the reported uncertainty is the standard deviation for a sample size of 515 housing units (Bwalya et al., 2008).

Severe Fire

- For an opening width of $0.7 \mathrm{~m}$ the ventilation factor is $0.04 \mathrm{~m}^{1 / 2}$; defined as $A_{O} \sqrt{H_{O}} / A_{t}$, where $A_{O}$ and $H_{O}$ are the area $\left(\mathrm{m}^{2}\right)$ and height $(\mathrm{m})$ of the opening and $A_{t}$ is the total area $\left(\mathrm{m}^{2}\right)$ of the compartment interior boundary surfaces.

- The stoichiometric rate of heat release of a ventilation-controlled compartment fire is approximated as:

$$
Q_{v e n t}=1500 \cdot A_{O} \cdot \sqrt{H_{O}}=2970 \mathrm{~kW}
$$

Assuming that $20 \%$ of the fuel is consumed during the decay phase of the fire and neglecting the variable rate of fuel consumption during fire growth, the duration of burning from ignition to the end of the peak temperature plateau $\left(\mathrm{t}_{\mathrm{b}} *\right)$ would be:

$$
t_{b *}=\frac{E n e r g y}{Q_{v e n t}}=\frac{0.8 \cdot\left(807 M J / m^{2} \cdot 9.8 m^{2}\right)}{2970 M J / s}=35.5 \mathrm{~min}
$$

This is rounded down to $35 \mathrm{~min}$ for the target fire curves. 
- A maximum upper gas layer temperature of $1100{ }^{\circ} \mathrm{C}$ is the $95^{\text {th }}$ percentile $(95 \%$ of the data points are below this value) of the 146 vetted, fully-developed compartment fire tests in the Society of Fire Protection Engineers (SFPE) report titled Evaluation of Enclosure Temperature Empirical Models (Hunt, Cutonilli and Hurley, 2010).

- As point of reference, a peak temperature plateau of $35 \mathrm{~min}$ at $1100{ }^{\circ} \mathrm{C}$ with a fire growth and decay as illustrated in Fig. 32, represents 2.2 times the demand in terms of area under the $\sigma \cdot T^{4}$ curve than the $\sigma \cdot T^{4}$ curve for a 1-hr fire resistance rating after ASTM E119 (ASTM International, 2016).

\section{Mild Fire}

- Increasing the opening width to $1.5 \mathrm{~m}$, the ventilation factor becomes $0.08 \mathrm{~m}^{1 / 2}$ and the stoichiometric rate of heat release and the duration of burning are:

$$
\begin{aligned}
& Q_{\text {vent }}=1500 \cdot A_{o} \cdot \sqrt{H_{O}}=6364 \mathrm{~kW} \\
& t_{b *}=\frac{\text { Energy }}{Q_{\text {vent }}}=\frac{0.8 \cdot\left(807 \mathrm{MJ} / \mathrm{m}^{2} \cdot 9.8 \mathrm{~m}^{2}\right)}{6364 \mathrm{MJ} / \mathrm{s}}=16.6 \mathrm{~min}
\end{aligned}
$$

This is rounded down to $15 \mathrm{~min}$ for the target fire curves.

- A maximum upper gas layer temperature of $900{ }^{\circ} \mathrm{C}$ is the $50^{\text {th }}$ percentile of the 146 vetted, fully-developed compartment fire tests in the Society of Fire Protection Engineers (SFPE) report titled Evaluation of Enclosure Temperature Empirical Models (Hunt, Cutonilli and Hurley, 2010).

- As point of reference, a peak temperature plateau of 15 min at $900{ }^{\circ} \mathrm{C}$ with a fire growth and decay as illustrated in Fig. 32, represents 0.62 times the demand in terms of area under the $\sigma \cdot T^{4}$ curve than the $\sigma \cdot T^{4}$ curve than the curve for a 1-hr fire resistance rating after ASTM E119 (ASTM International, 2016).

\section{Kitchen Compartment Fire}

Table 10 provides relevant data for the primary furnishings in the compartment. These items were made of wood or a wood-based material and had a total mass of $(411 \pm 0.1) \mathrm{kg}$. Table 11 provides the furnishing origin position and assumed mass distribution used to determine energy distribution. 
Table 10. Kitchen compartment contents mass and fire load density (FLD) calculation.

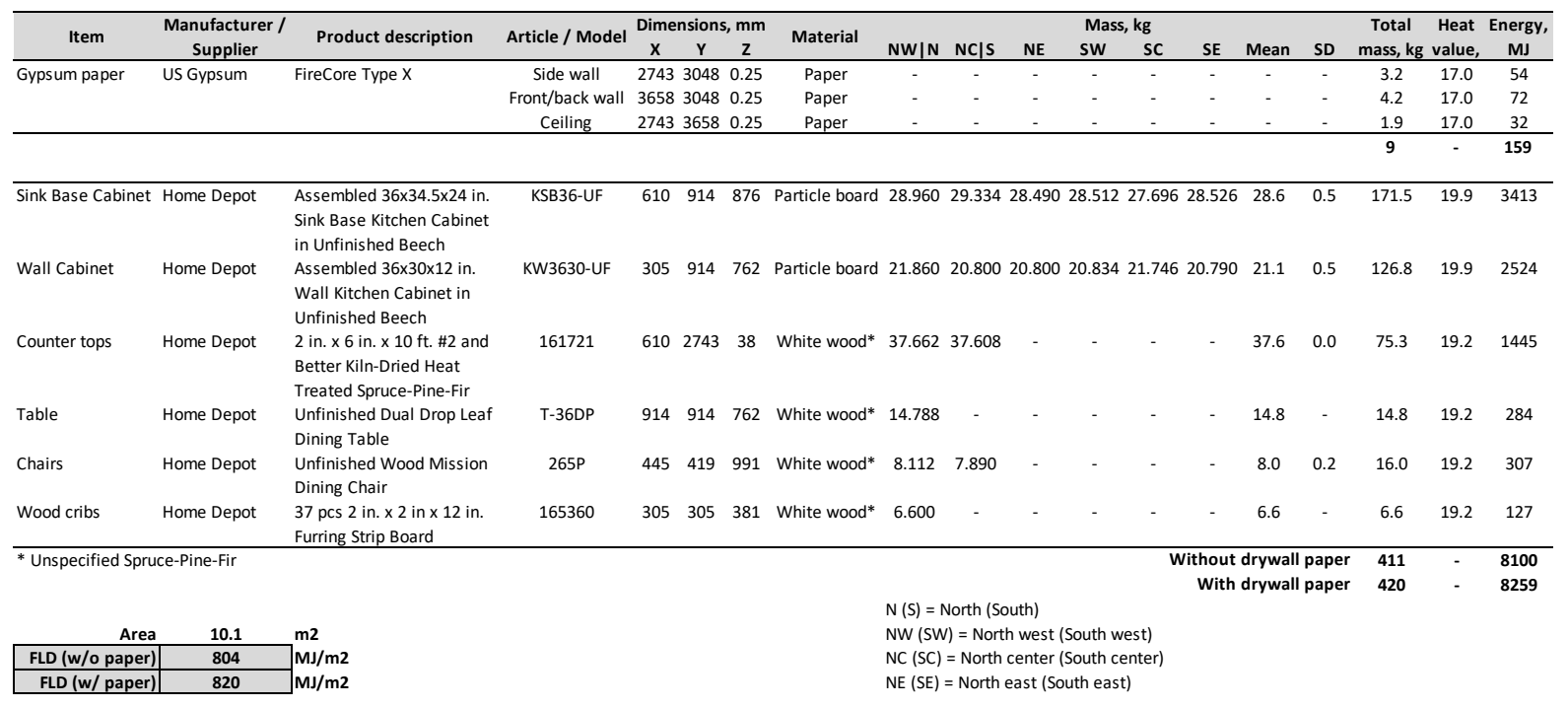

Table 11. Kitchen compartment fuel dimensions, origin position and assumed mass distribution used to determine energy distribution.

\begin{tabular}{lcccccccccccccccc}
\hline \multirow{2}{*}{ Item } & \multicolumn{1}{c}{ Dimensions, $\mathbf{m m}$} & \multicolumn{1}{c}{ Position, $\mathbf{m m}$} & \multicolumn{4}{c}{ Mass distribution, \% } & \multicolumn{4}{c}{ Total } & \multicolumn{1}{c}{ Energy, } \\
& $\mathbf{X}$ & $\mathbf{Y}$ & $\mathbf{Z}$ & $\mathbf{X X}$ & $\mathbf{Y Y}$ & $\mathbf{Z Z}$ & $\mathbf{N}$ & $\mathbf{E}$ & $\mathbf{S}$ & $\mathbf{W}$ & Top & Bot & Vert & Hor & mass, kg & $\mathbf{M J}$ \\
\hline Sink Base Cabinet & 610 & 914 & 876 & 0 & 89 & 0 & 25 & 25 & 25 & 25 & 0 & 0 & 0 & 0 & 28.960 & 576 \\
& 610 & 914 & 876 & 0 & 1003 & 0 & 25 & 25 & 25 & 25 & 0 & 0 & 0 & 0 & 29.334 & 584 \\
& 610 & 914 & 876 & 0 & 1918 & 0 & 25 & 25 & 25 & 25 & 0 & 0 & 0 & 0 & 28.490 & 567 \\
& 610 & 914 & 876 & 2946 & 89 & 0 & 25 & 25 & 25 & 25 & 0 & 0 & 0 & 0 & 28.512 & 567 \\
& 610 & 914 & 876 & 2946 & 1003 & 0 & 25 & 25 & 25 & 25 & 0 & 0 & 0 & 0 & 27.696 & 551 \\
Wall Cabinet & 610 & 914 & 876 & 2946 & 1918 & 0 & 25 & 25 & 25 & 25 & 0 & 0 & 0 & 0 & 28.526 & 568 \\
& 305 & 914 & 762 & 0 & 89 & 1422 & 25 & 25 & 25 & 25 & 0 & 0 & 0 & 0 & 21.860 & 435 \\
& 305 & 914 & 762 & 0 & 1003 & 1422 & 25 & 25 & 25 & 25 & 0 & 0 & 0 & 0 & 20.800 & 414 \\
& 305 & 914 & 762 & 0 & 1918 & 1422 & 25 & 25 & 25 & 25 & 0 & 0 & 0 & 0 & 20.800 & 414 \\
& 305 & 914 & 762 & 3251 & 89 & 1422 & 25 & 25 & 25 & 25 & 0 & 0 & 0 & 0 & 20.834 & 415 \\
Counter tops & 305 & 914 & 762 & 3251 & 1003 & 1422 & 25 & 25 & 25 & 25 & 0 & 0 & 0 & 0 & 21.746 & 433 \\
& 305 & 914 & 762 & 3251 & 1918 & 1422 & 25 & 25 & 25 & 25 & 0 & 0 & 0 & 0 & 20.790 & 414 \\
Table & 610 & 2743 & 38 & 0 & 89 & 876 & 13 & 13 & 13 & 13 & 13 & 13 & 13 & 13 & 37.662 & 723 \\
Chairs & 610 & 2743 & 38 & 2946 & 89 & 876 & 13 & 13 & 13 & 13 & 13 & 13 & 13 & 13 & 37.608 & 722 \\
& 914 & 914 & 762 & 1321 & 102 & 0 & 0 & 0 & 0 & 0 & 100 & 0 & 0 & 0 & 14.788 & 284 \\
Wood cribs & 445 & 419 & 991 & 876 & 521 & 0 & 50 & 0 & 0 & 0 & 0 & 0 & 0 & 50 & 8.112 & 156 \\
& 445 & 419 & 991 & 2235 & 521 & 0 & 0 & 0 & 50 & 0 & 0 & 0 & 0 & 50 & 7.890 & 151 \\
& 305 & 305 & 381 & 3251 & 394 & 1422 & 13 & 13 & 13 & 13 & 13 & 13 & 13 & 13 & 6.600 & 127 \\
\hline
\end{tabular}




\section{Appendix E: Test Data for Gypsum-Sheet Steel Composite Panel Sheathed Walls}

\section{SB01 Data}

SB01a (Cyclic test of undamaged wall at ambient temperature)

- The primary failure mode was failure of the shear panel connections. Connection failures were a combination of fastener failure and edge tear out of the sheet steel or pull-thorough of the fastener head through the sheet steel (Fig. 117).

- A limited amount of local deformation of one flange of an outside chord stud was observed (Fig. 118).

- Significant vertical movement at the connection between the actuator head and the loading beam was observed ( $\sim 17 \mathrm{~mm}$ drop in Fig. 115). The loading beam stiffening truss was not present in this test.

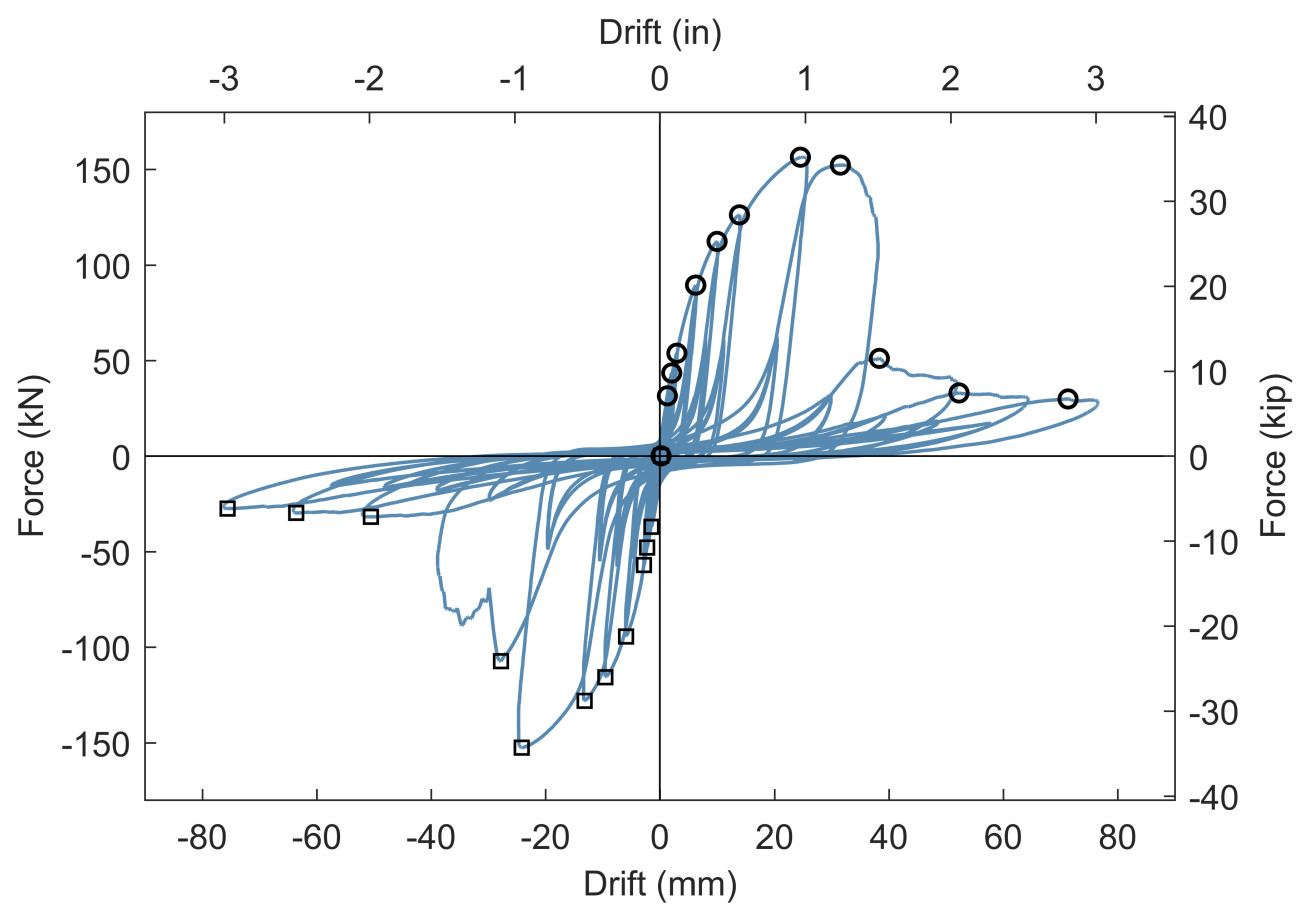

Fig. 113. SB01 - Applied load versus wall longitudinal drift during mechanical loading. 


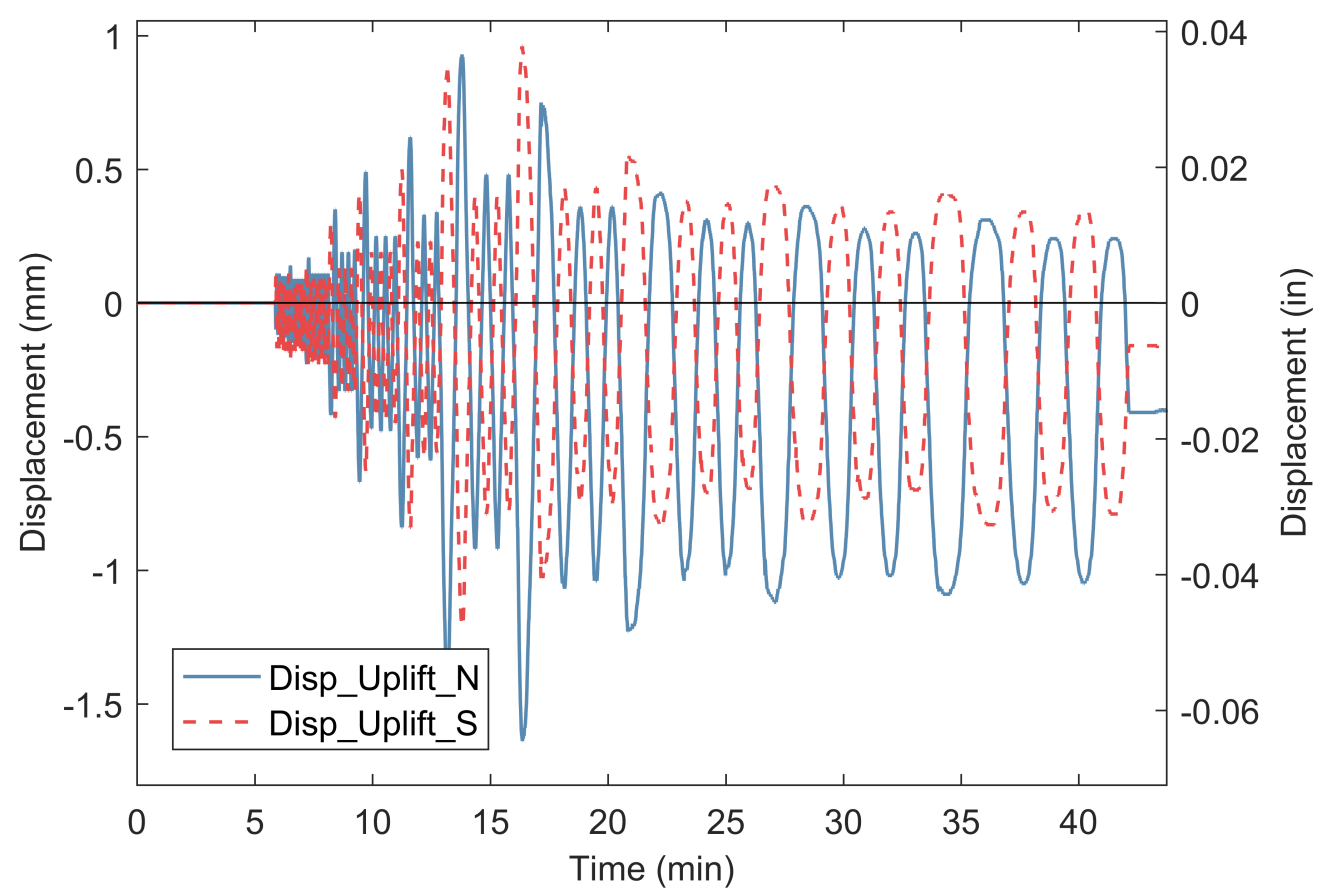

Fig. 114. SB01 - Uplift at bottom of wall during mechanical loading.

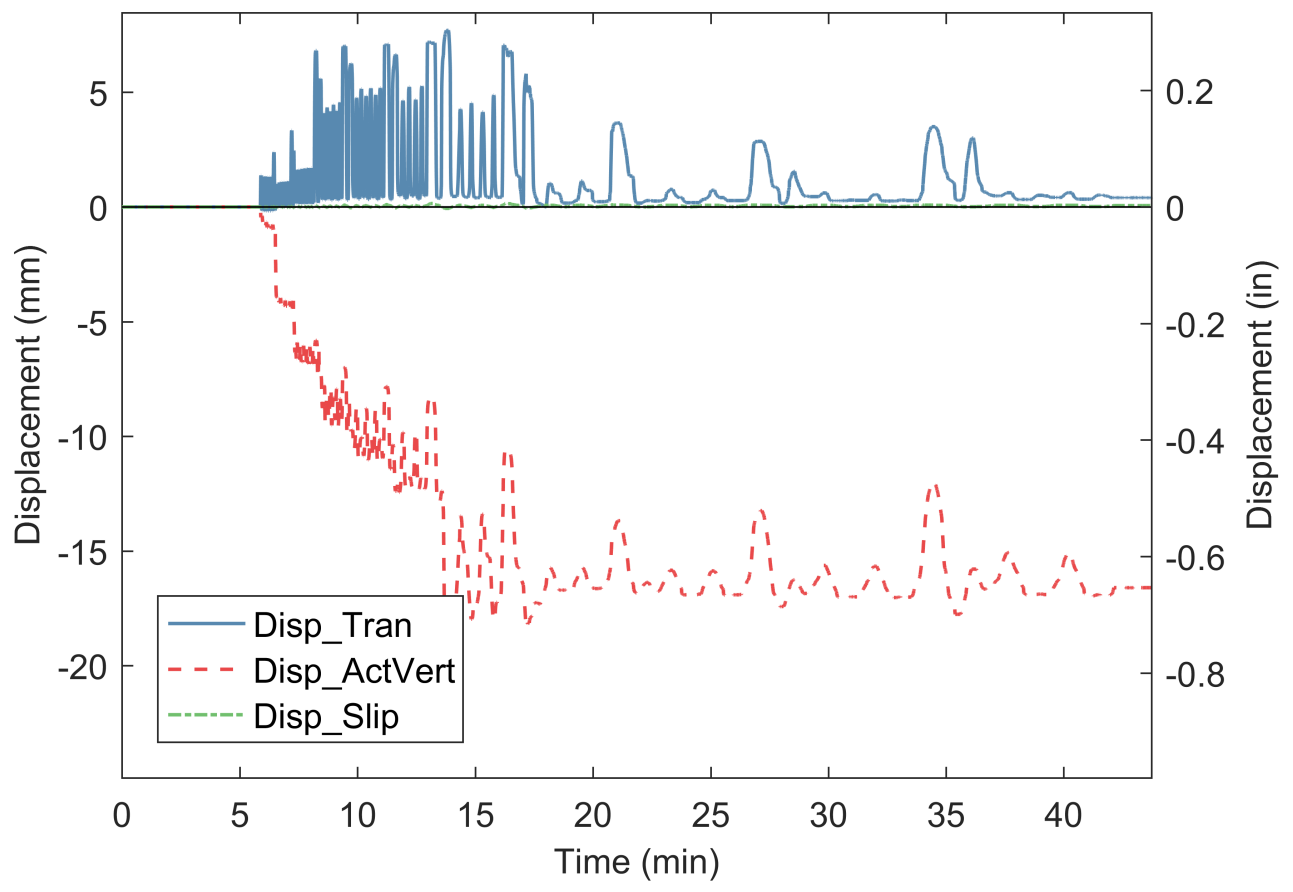

Fig. 115. SB01 - Ancillary displacement measurements during mechanical loading. 


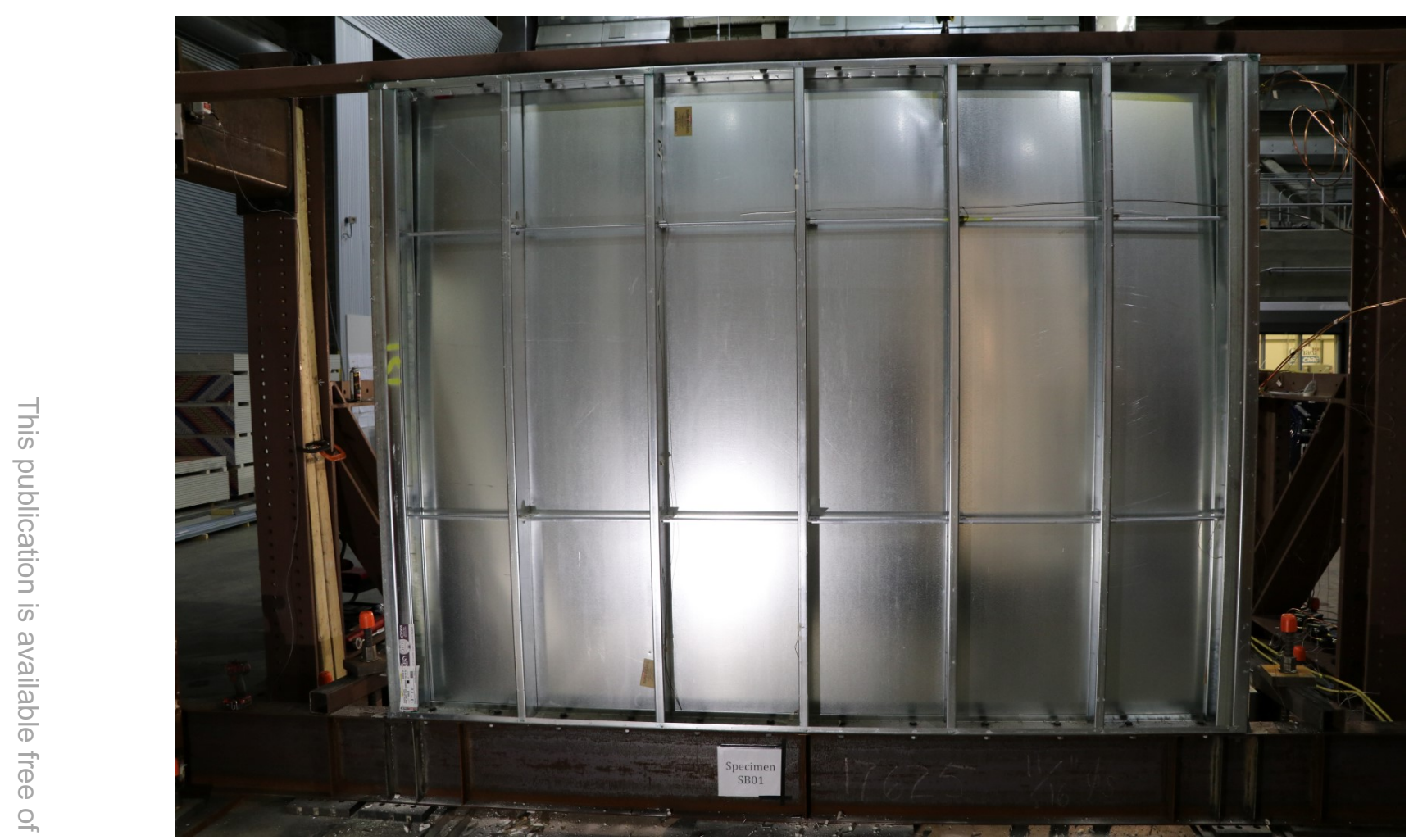

Fig. 116. SB01 - Photograph of back of metal sheathed side of wall (nonstructural gypsum removed) after mechanical loading.

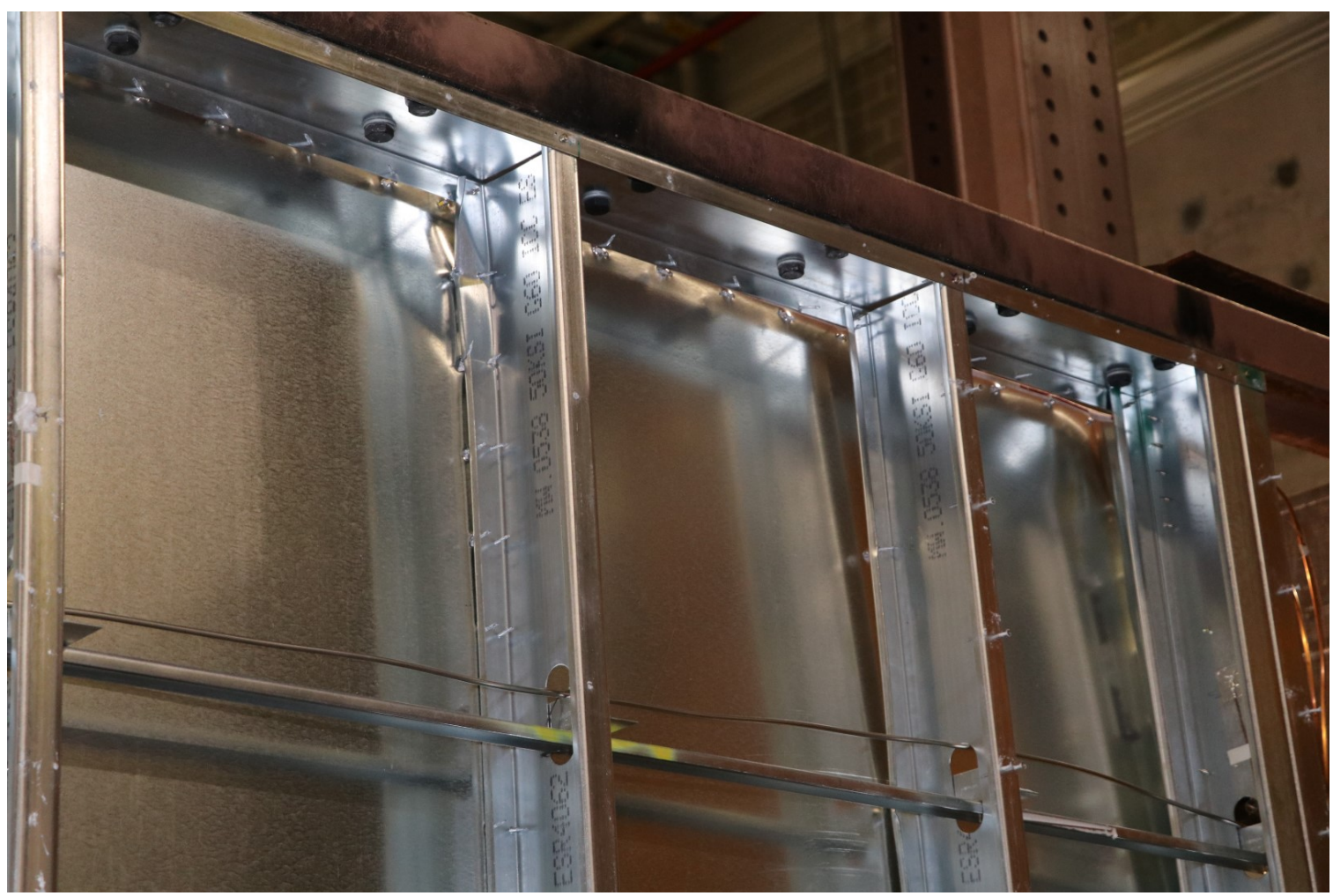

Fig. 117. SB01 - Photograph of detail of connection failure. 


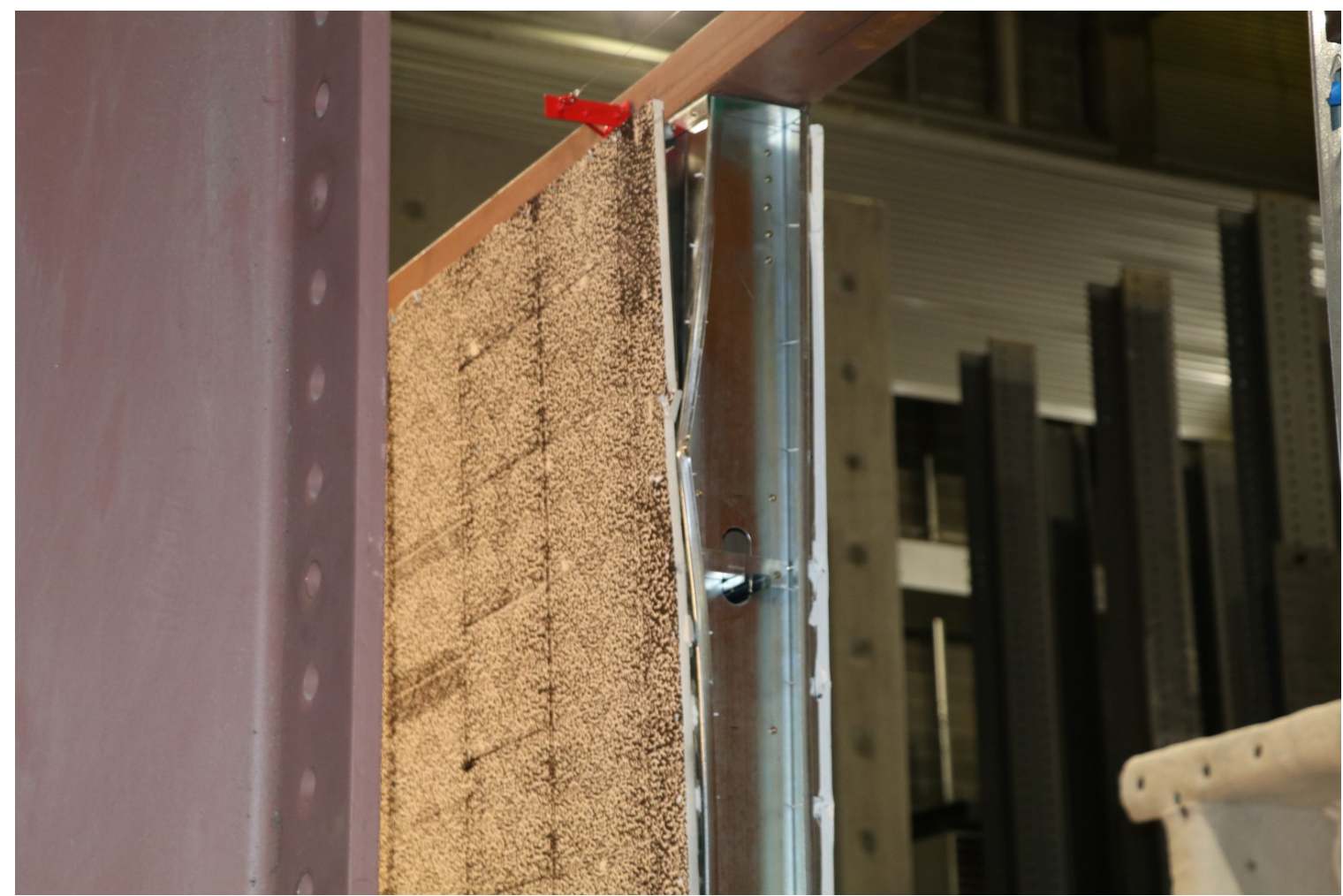

Fig. 118. SB01 - Photograph of local flange deformation of a chord stud. 


\section{SB02 Data}

SB02b (Severe Fire test of an undamaged wall)

- The gas burner was set to $2.3 \mathrm{MW}$ for $35 \mathrm{~min}$. The temperatures were also recorded during the cooling phase up to 75 min (Fig. 119).

- A puddle formed at the bottom of the wall due to water evaporated from the gypsum that condensed on the sheet steel (Fig. 133).

- At 30 min, flames were visible coming through the top of the wall.

- After the burner extinction (35 $\mathrm{min}$ ) the paper lining on the unexposed side of the wall continued to burn for some time before it self-extinguished (Fig. 133, Fig. 134), increasing the temperatures on the unexposed side thermocouples placed near the top of the wall (Fig. 128).

- After the test, deformation of the interior studs was visible where the nonstructural gypsum had fallen away on the fire exposed side of the wall (Fig. 137).

SB02c (Cyclic test of wall at ambient temperature following the Severe Fire)

- The primary failure mode was global buckling of the sheet steel (Fig. 136). The fire severely damaged (oxidized) the fasteners and steel at the top of the wall such that these connections did not contribute significantly to the wall capacity during the loading cycling (Fig. 137).

- At a few locations, local burn-through of the sheet steel was observed after the cycling when the remaining gypsum was removed (Fig. 138).

- Significant vertical movement at the connection between the actuator head and the loading beam was observed (> $50 \mathrm{~mm}$ drop in Fig. 131). The loading beam stiffening truss was not present in this test.

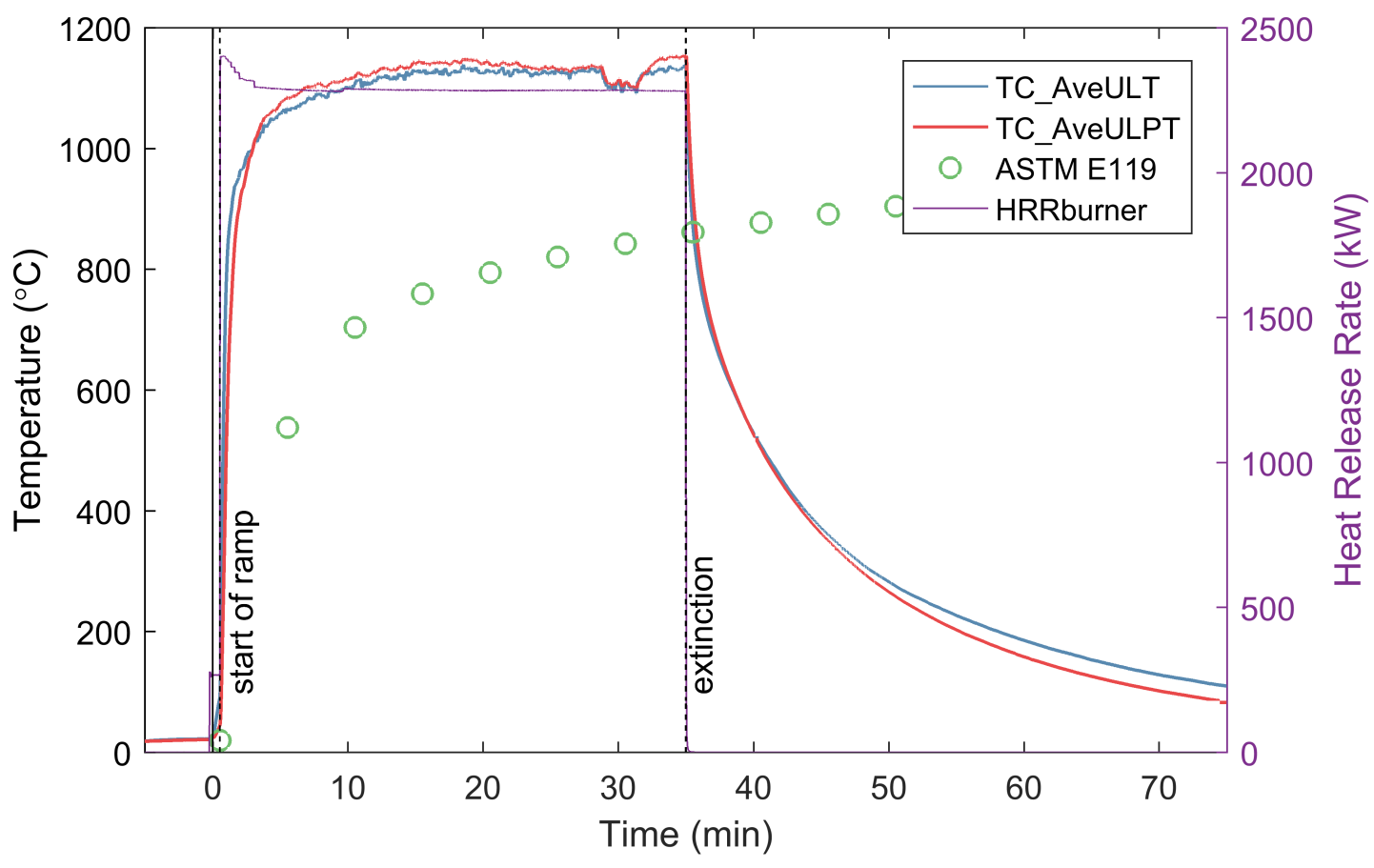

Fig. 119. SB02 - Compartment temperatures and burner Heat Release Rate. 


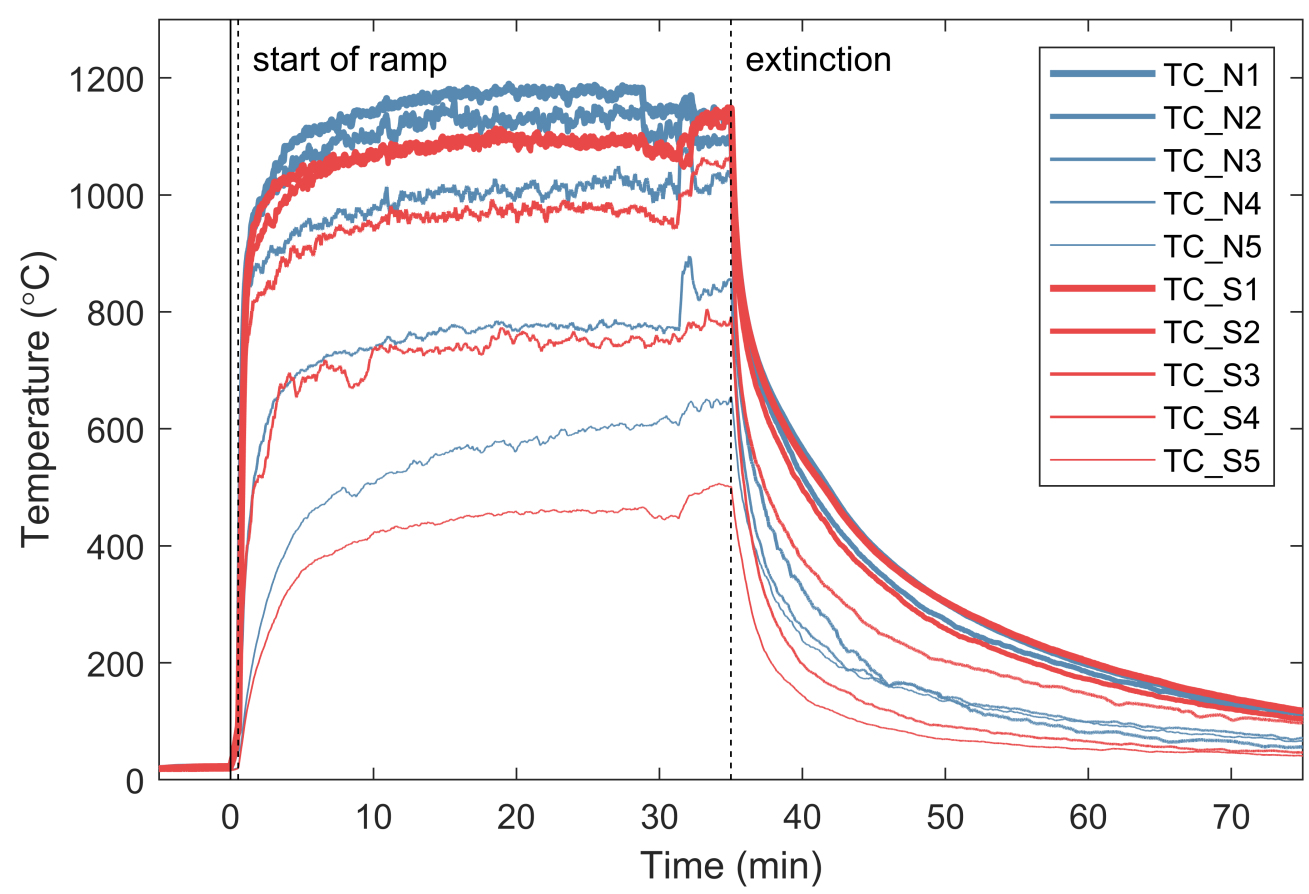

Fig. 120. SB02 - Compartment temperatures measured by the thermocouple trees.

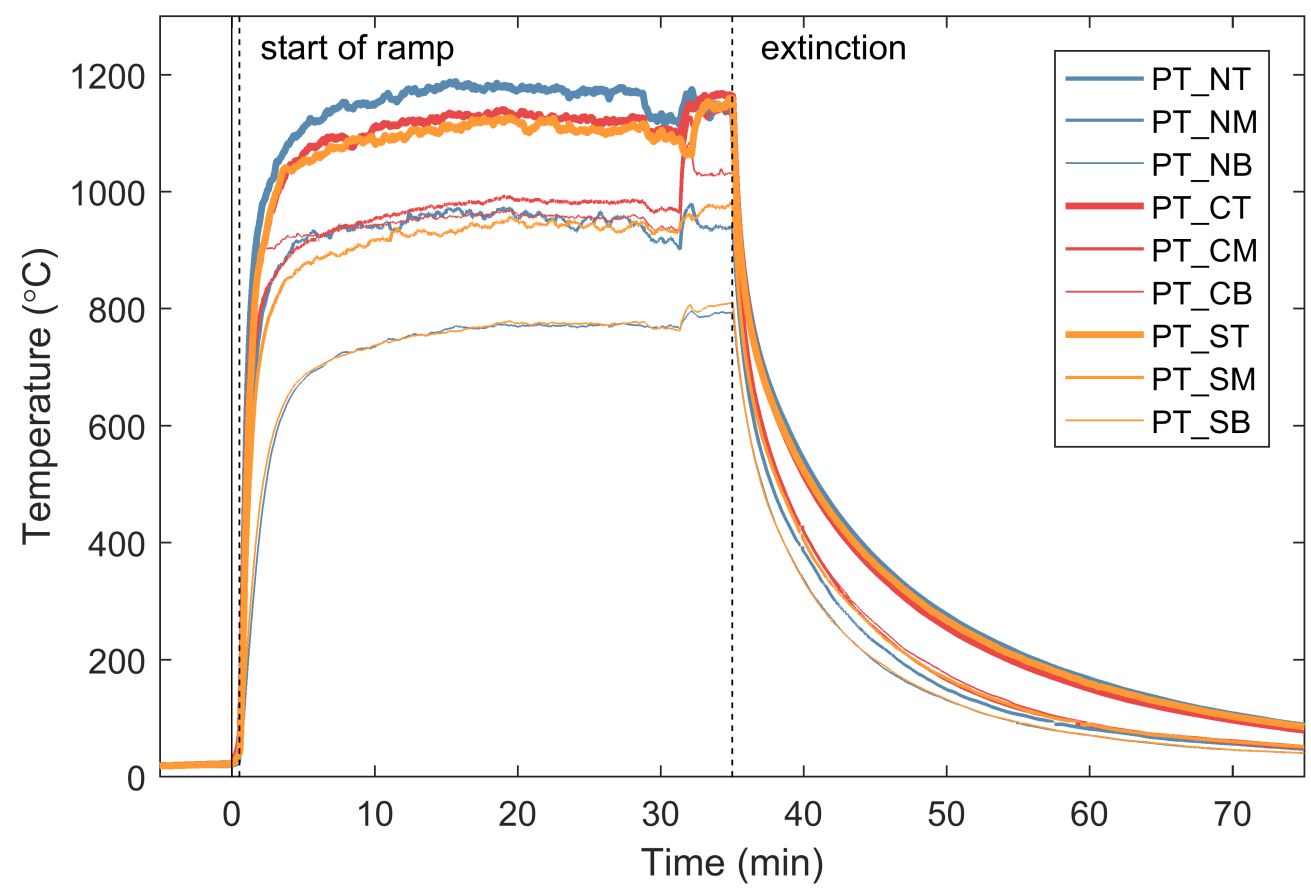

Fig. 121. SB02 - Compartment temperatures measured by the plate thermocouples. 


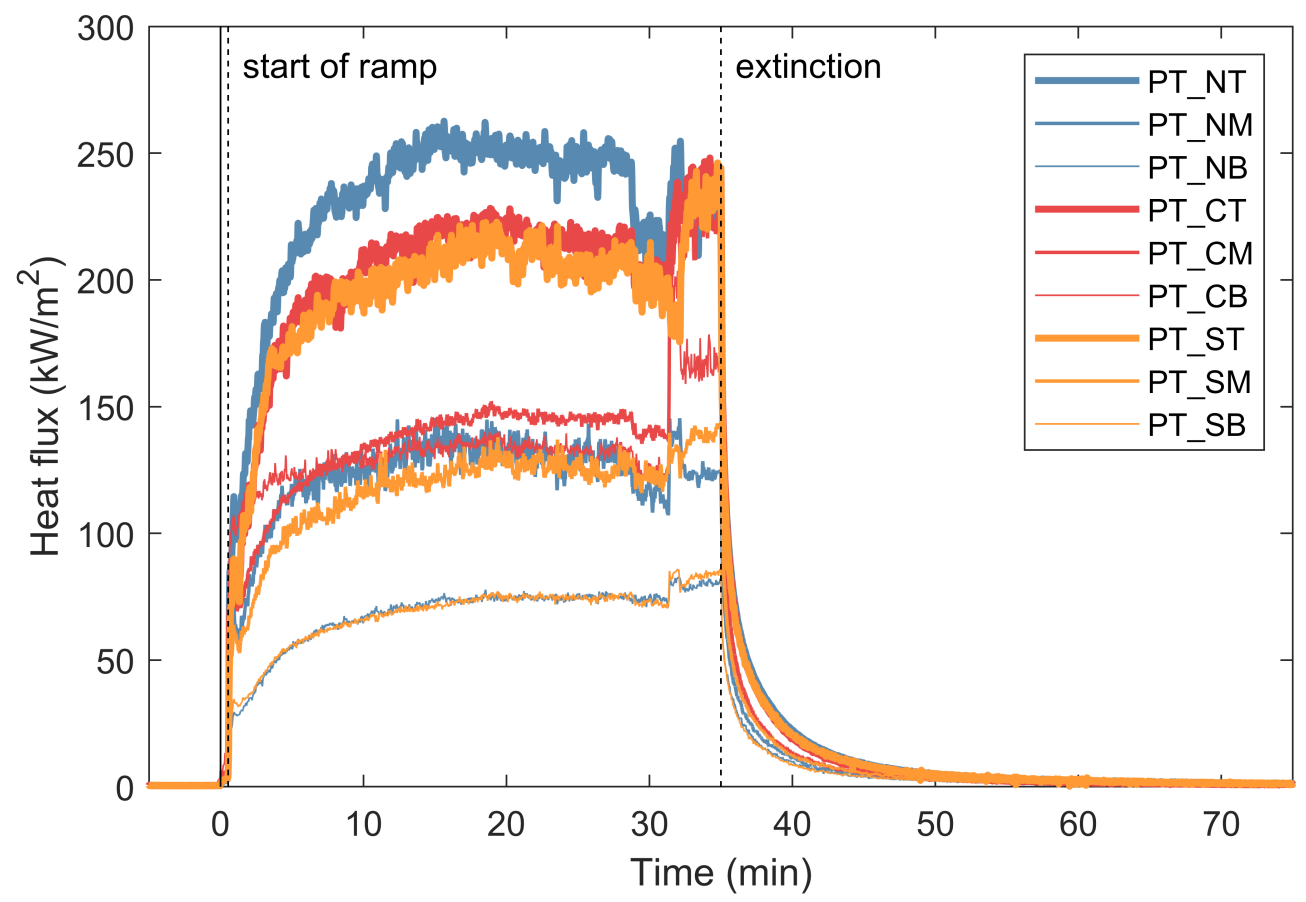

Fig. 122. SB02 - Heat fluxes in the compartment measured by the plate thermocouples.
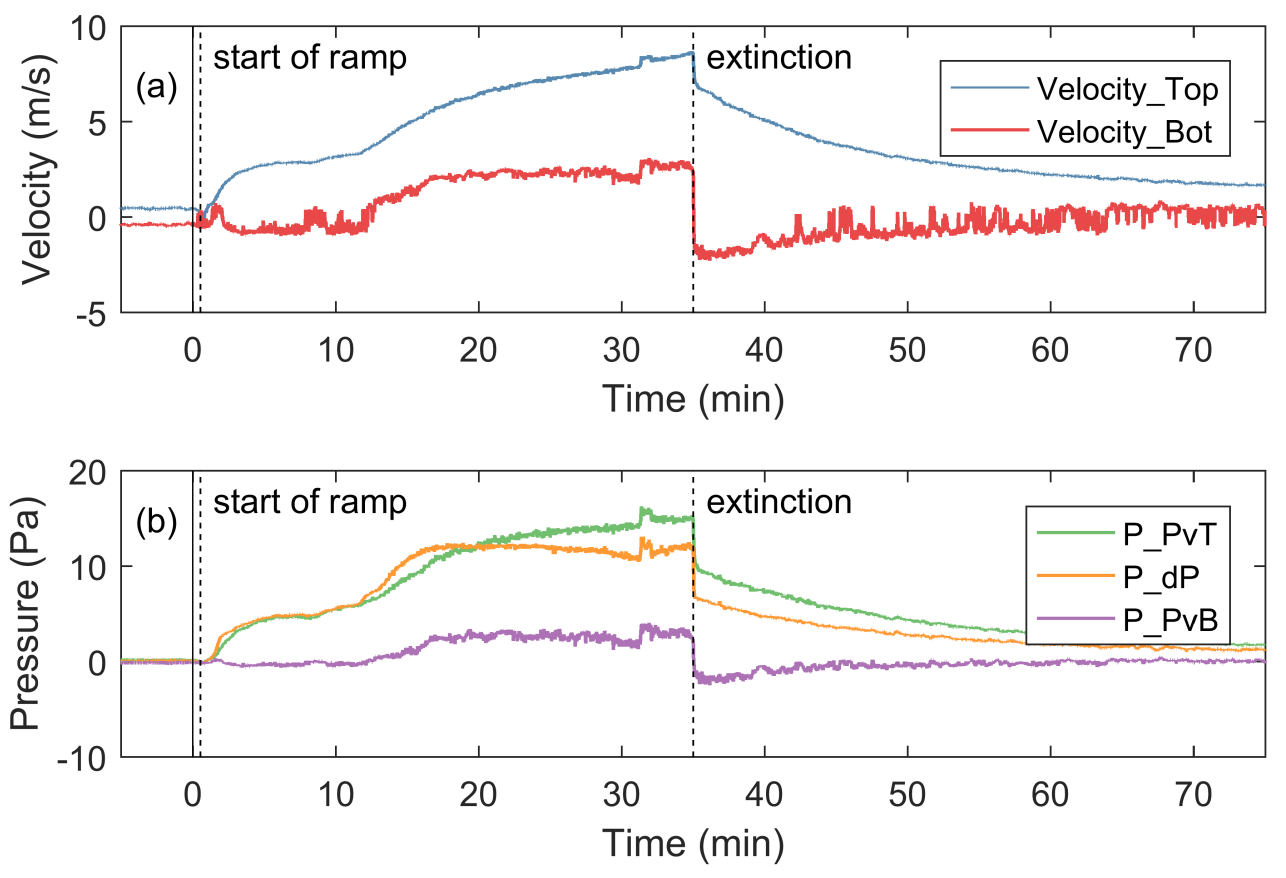

Fig. 123. SB02 - (a) Velocity of air flow at the top and bottom knockouts of the chord stud; (b) Pressure at the top and bottom knockouts of the chord stud and in the wall cavity near the top. 


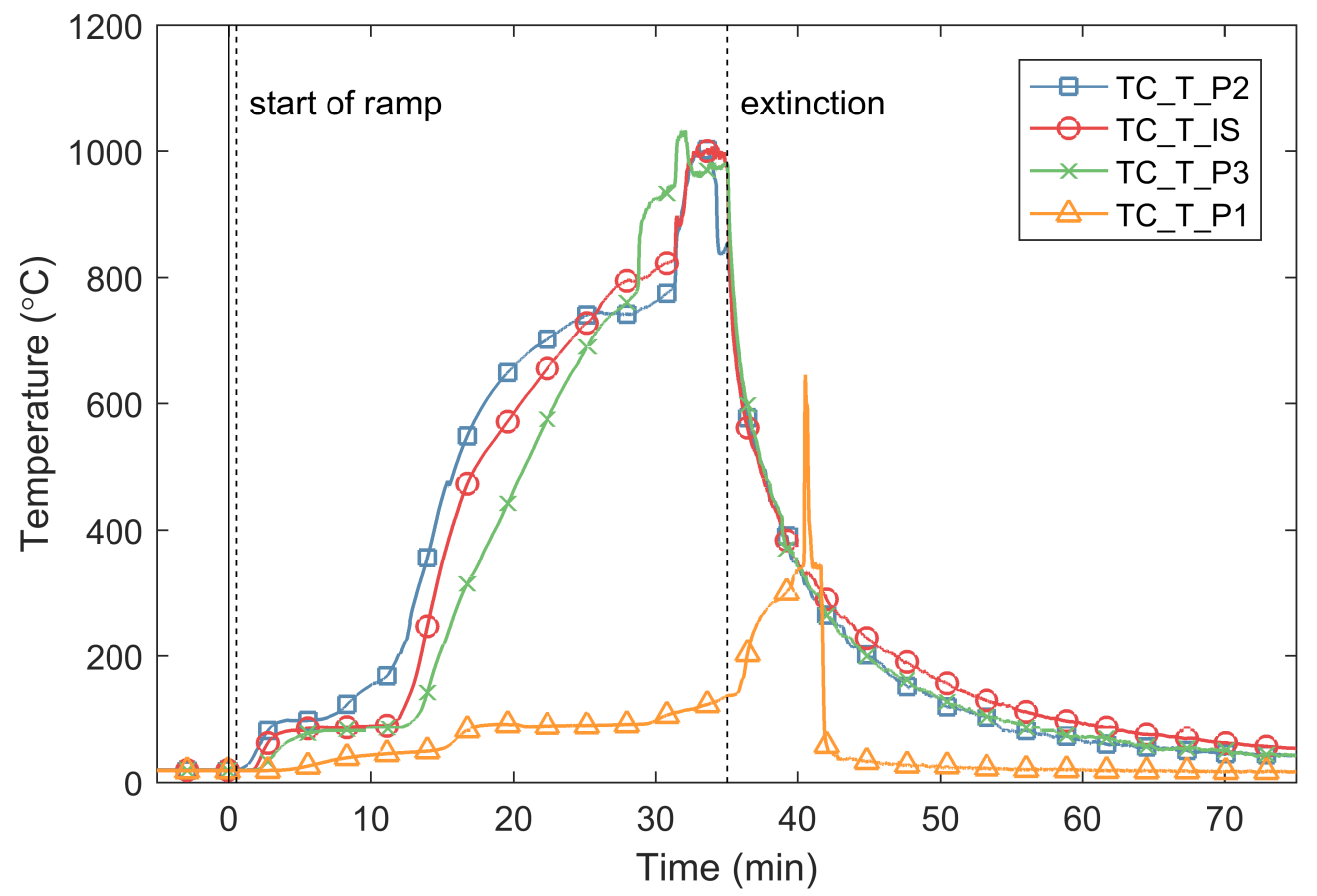

Fig. 124. SB02 - Temperatures through the specimen at an interior stud $46 \mathrm{~cm}$ from the top of the wall.

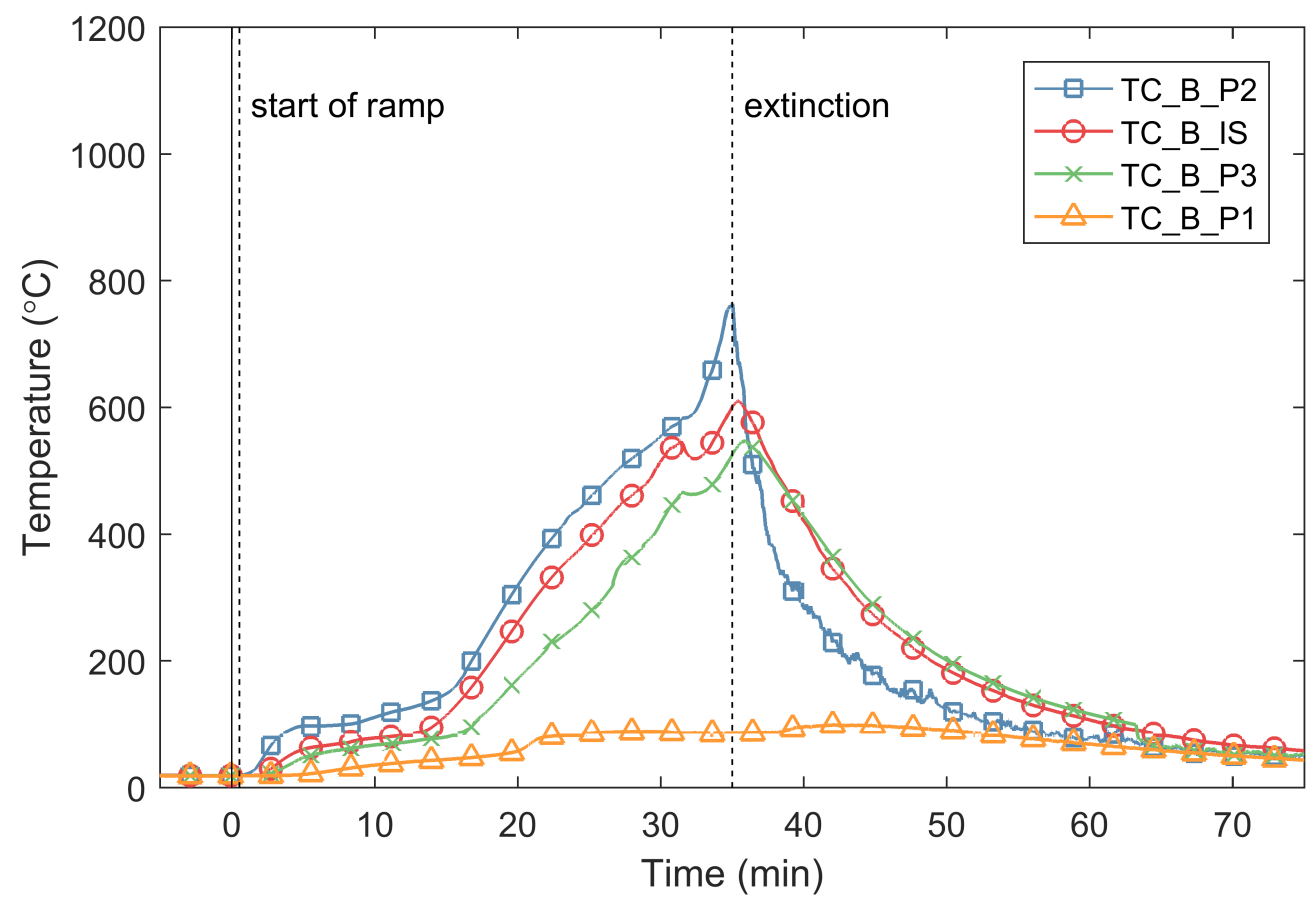

Fig. 125. SB02 - Temperatures through the specimen at an interior stud $46 \mathrm{~cm}$ from the bottom of the wall. 

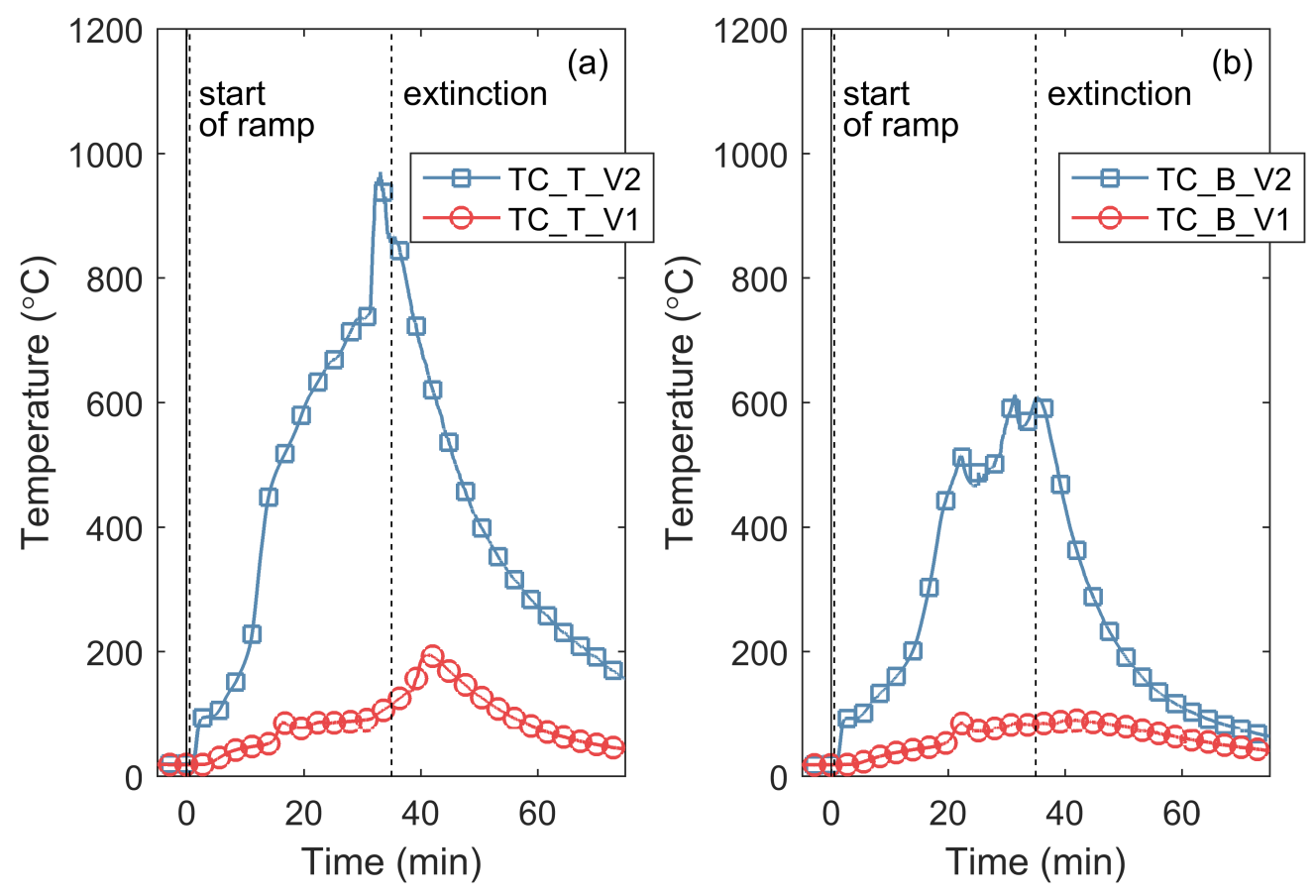

Fig. 126. SB02 - Temperatures through the specimen midway between interior studs: (a) $46 \mathrm{~cm}$ from the top of the wall; (b) $46 \mathrm{~cm}$ from the bottom of the wall.
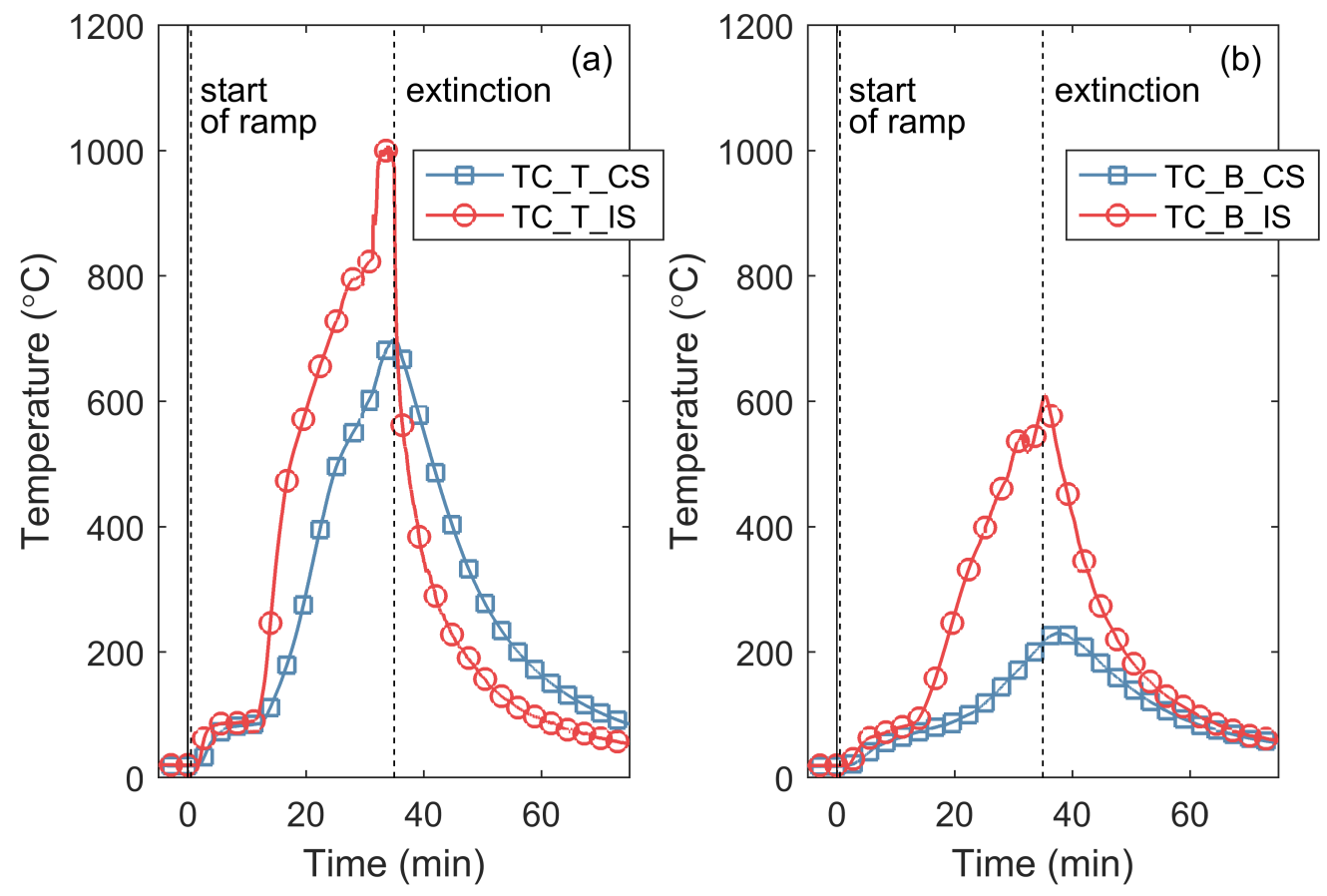

Fig. 127. SB02 - Temperatures of the framing elements: (a) $46 \mathrm{~cm}$ from the top of the wall; (b) $46 \mathrm{~cm}$ from the bottom of the wall. 


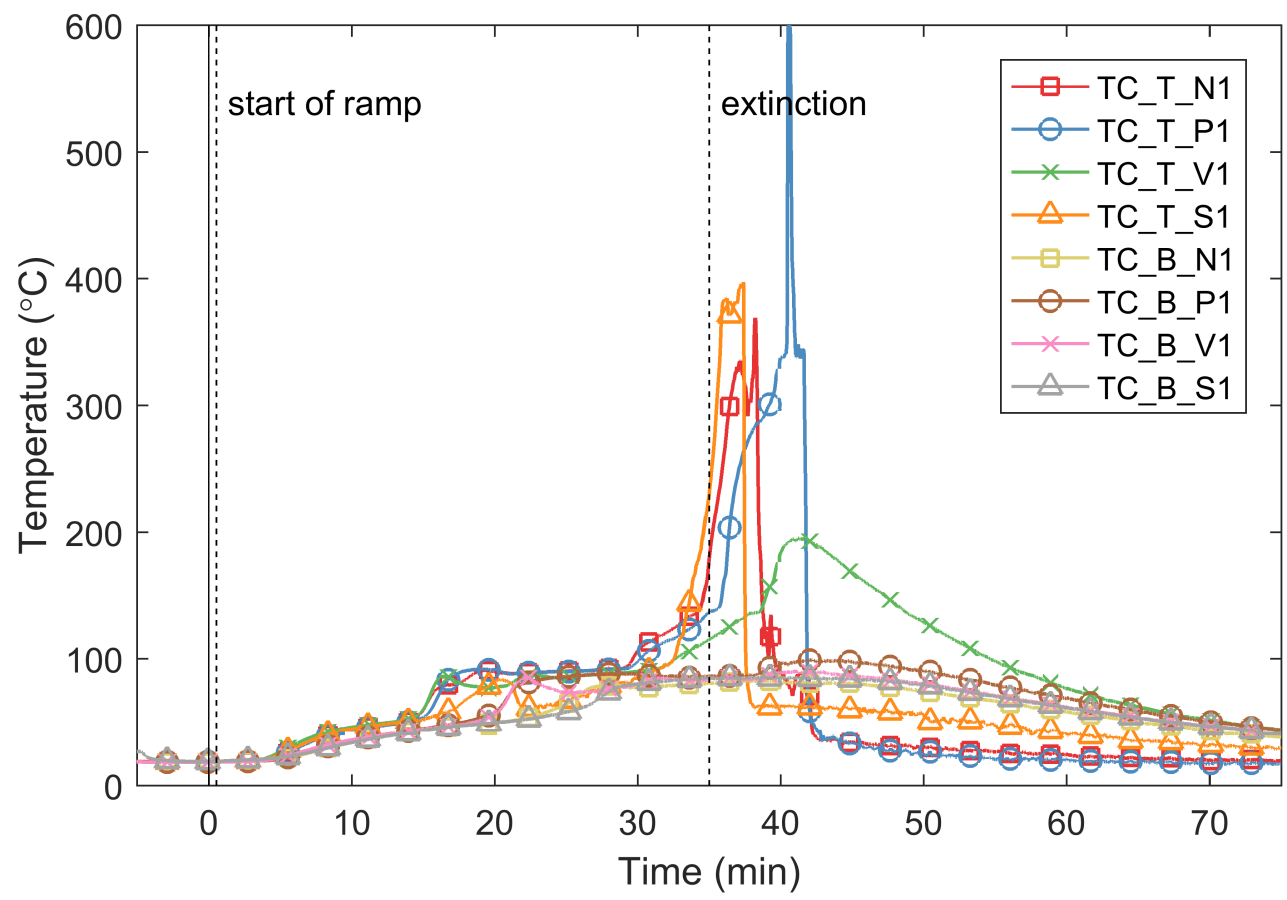

Fig. 128. SB02 - Temperatures of the gypsum on the unexposed side of the wall specimen.

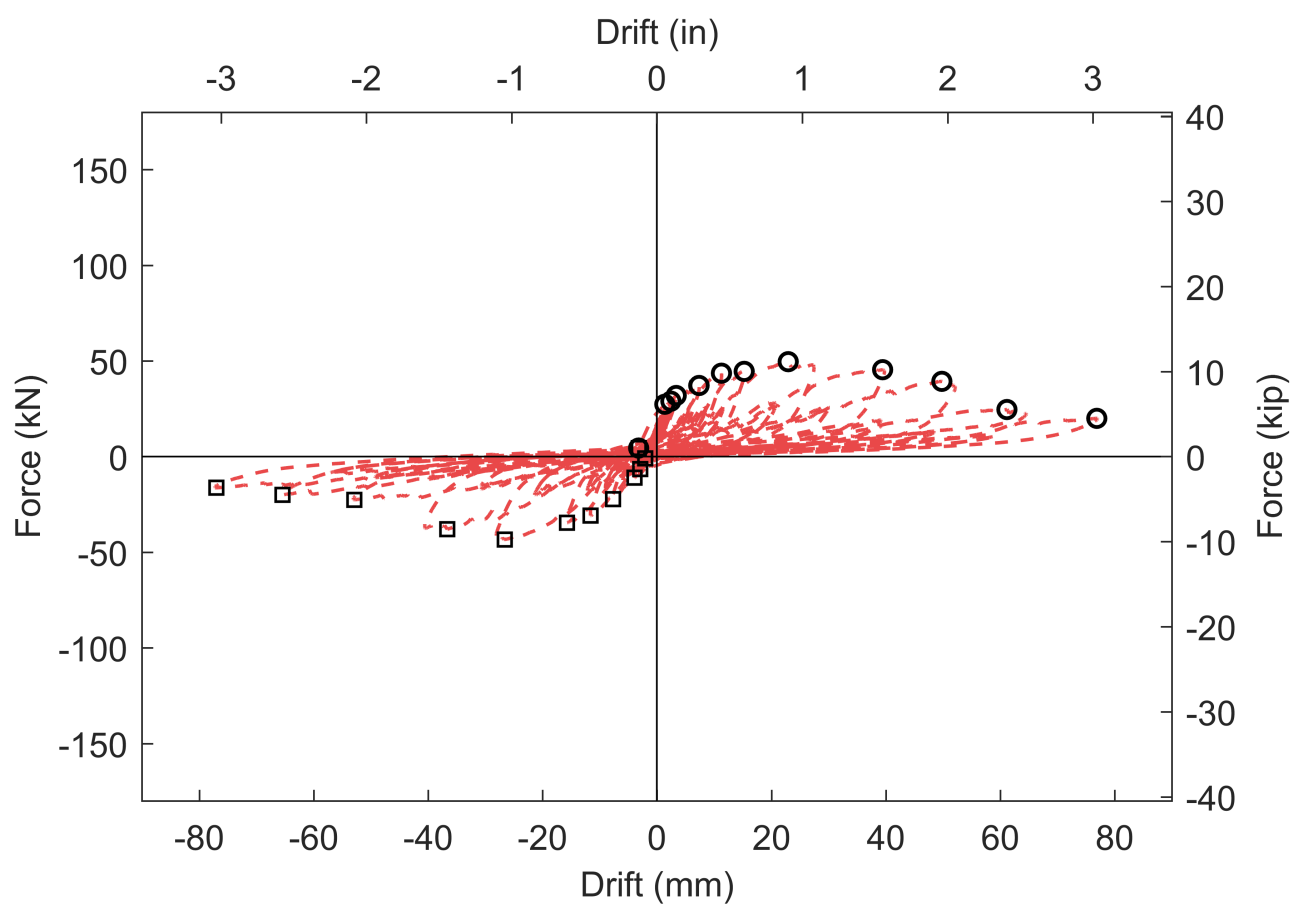

Fig. 129. SB02 - Applied load versus wall longitudinal drift during mechanical loading. 


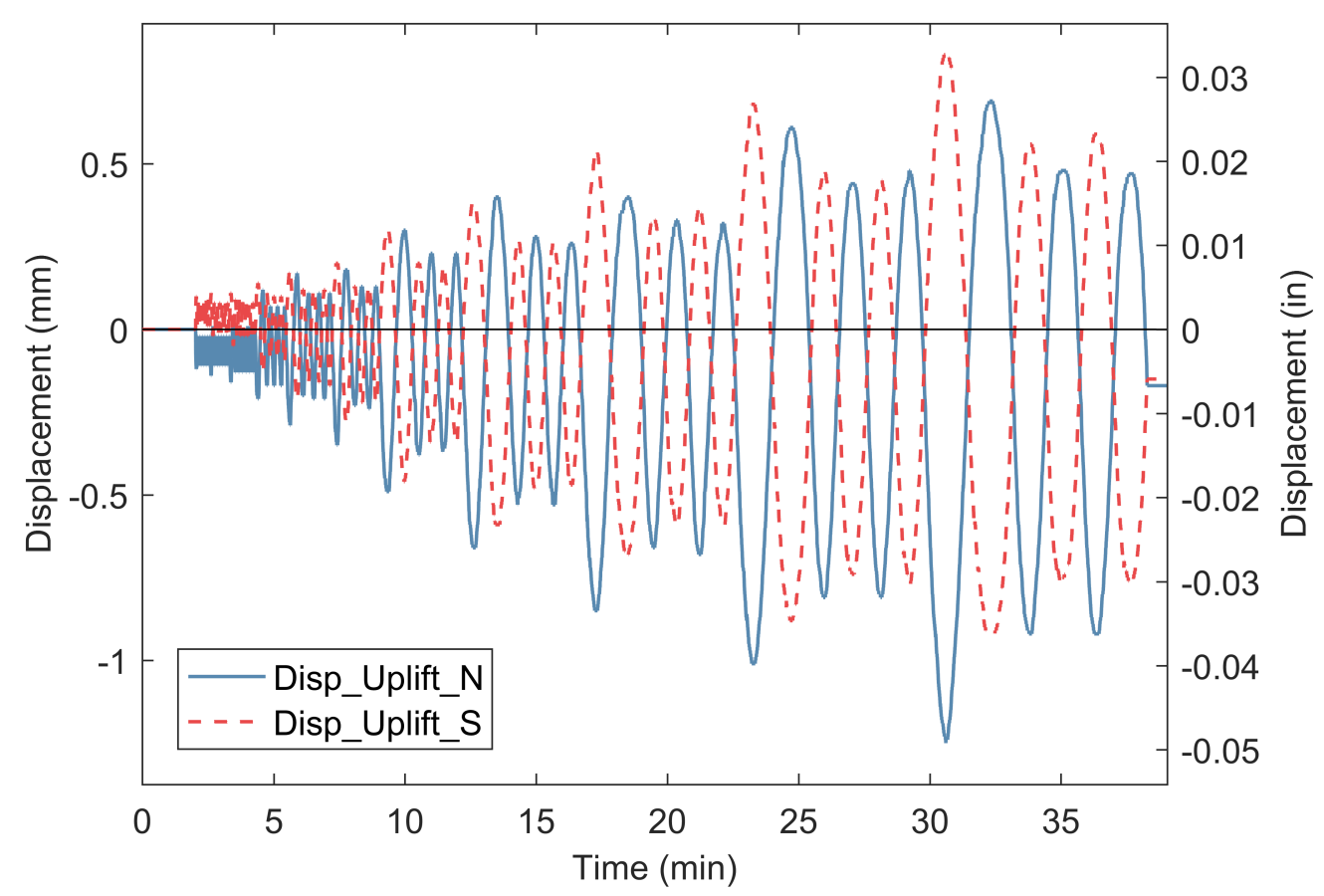

Fig. 130. SB02 - Uplift at bottom of wall during mechanical loading.

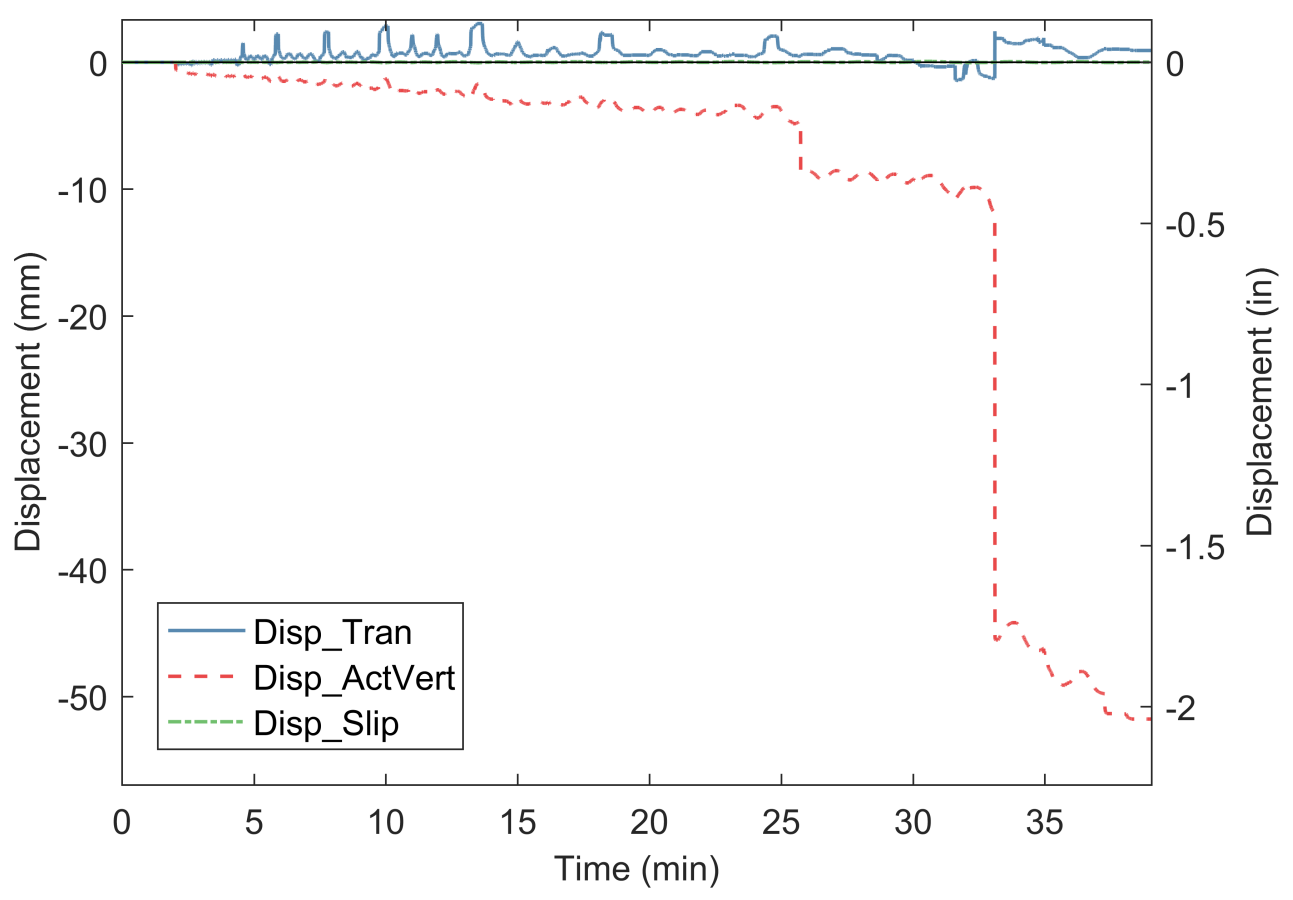

Fig. 131. SB02 - Ancillary displacement measurements during mechanical loading. 


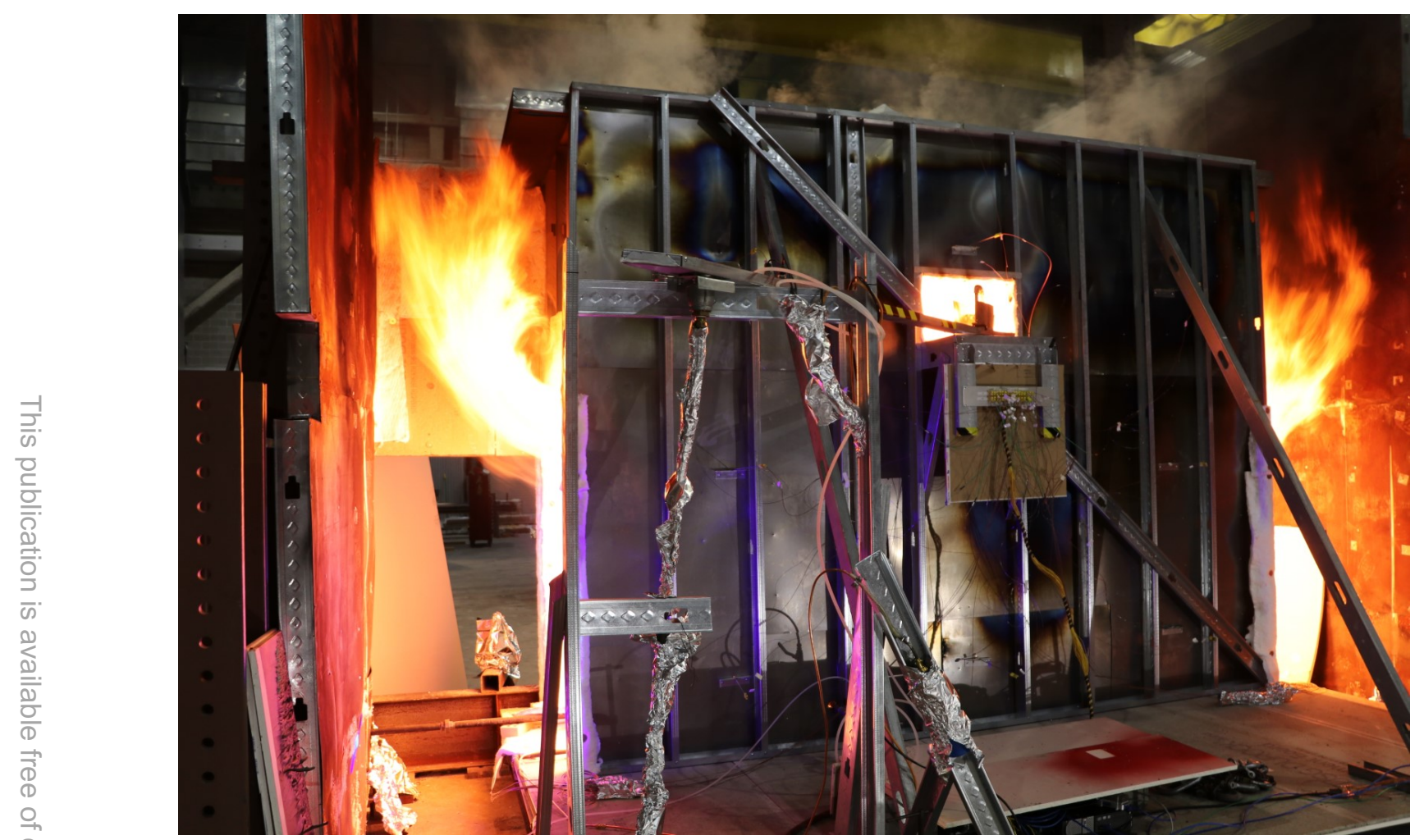

Fig. 132. SB02 - Photograph of back of the compartment during the fire test.

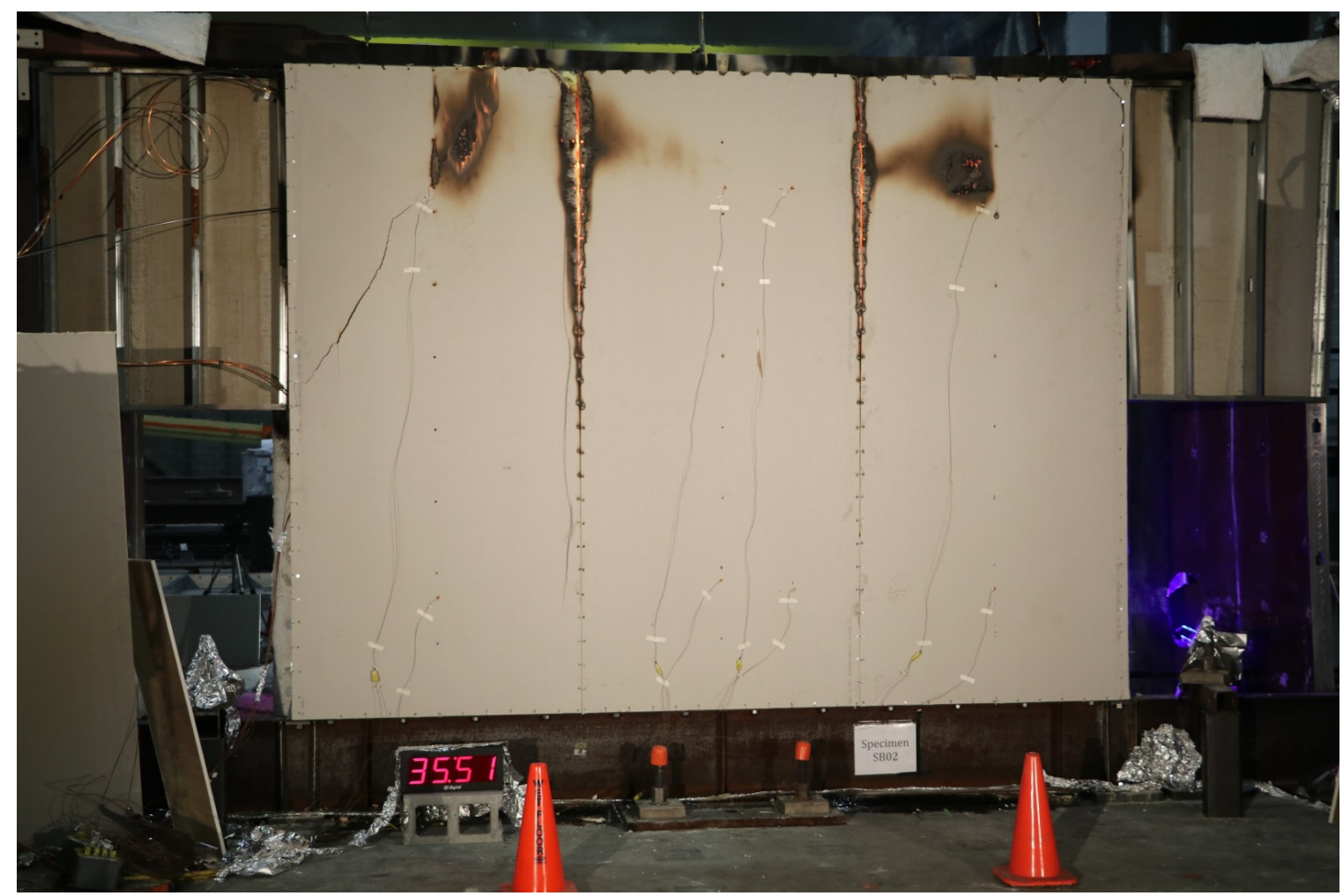

Fig. 133. SB02 - Photograph of unexposed side of wall 35 min $51 \mathrm{~s}$ after ignition. 


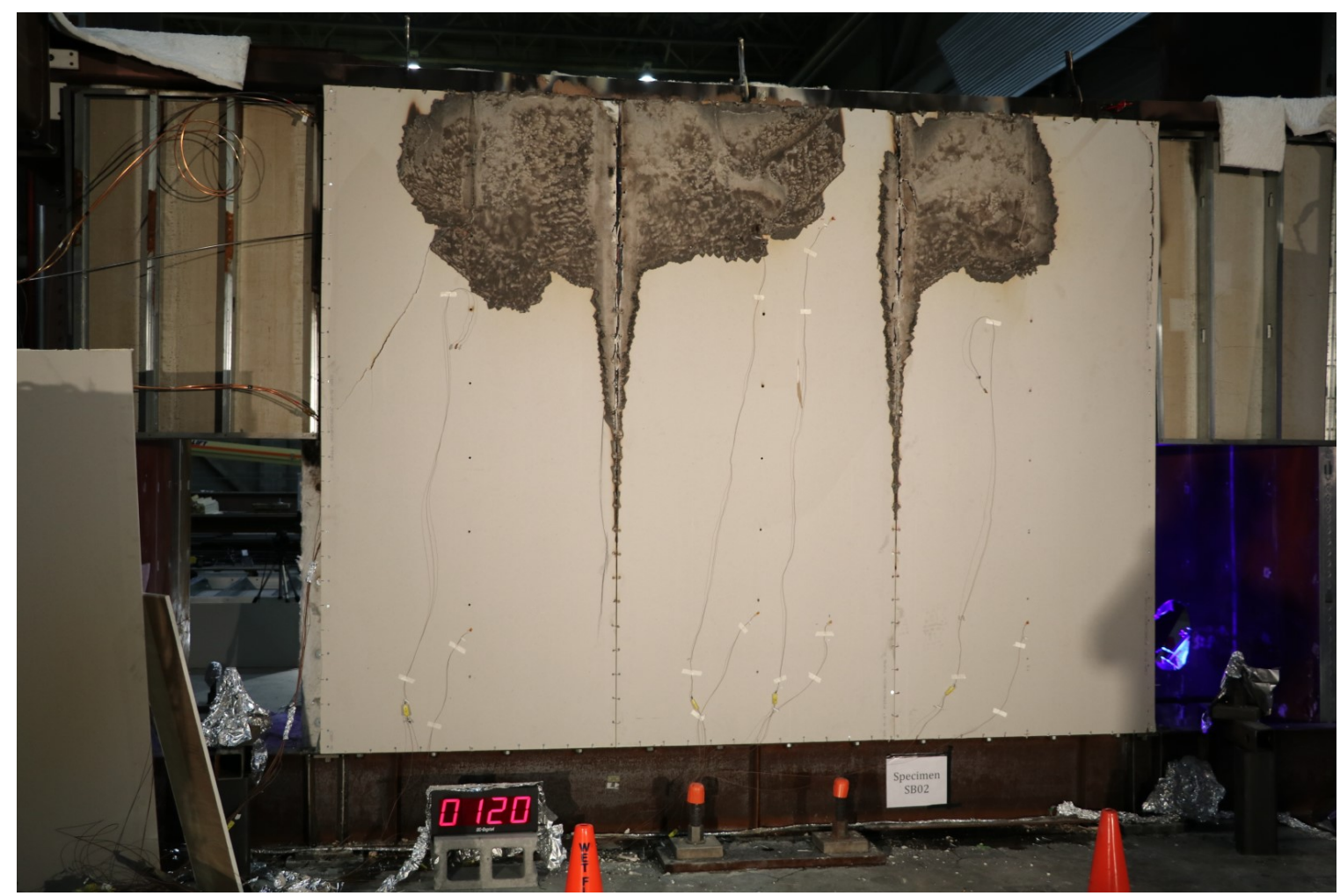

Fig. 134. SB02 - Photograph of unexposed side of the wall after the fire test.

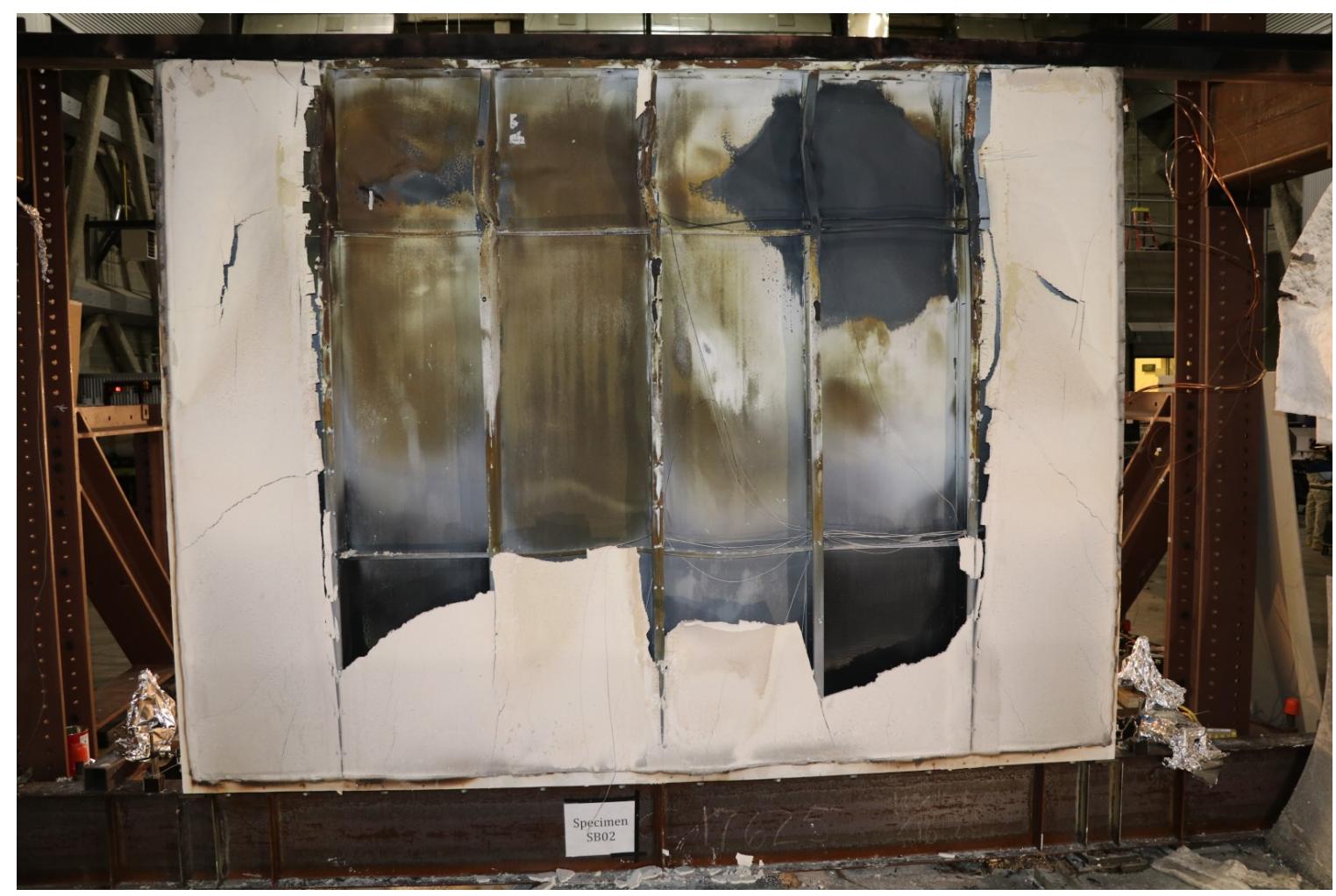

Fig. 135. SB02 - Photograph of fire exposed side of the wall after the fire test. 


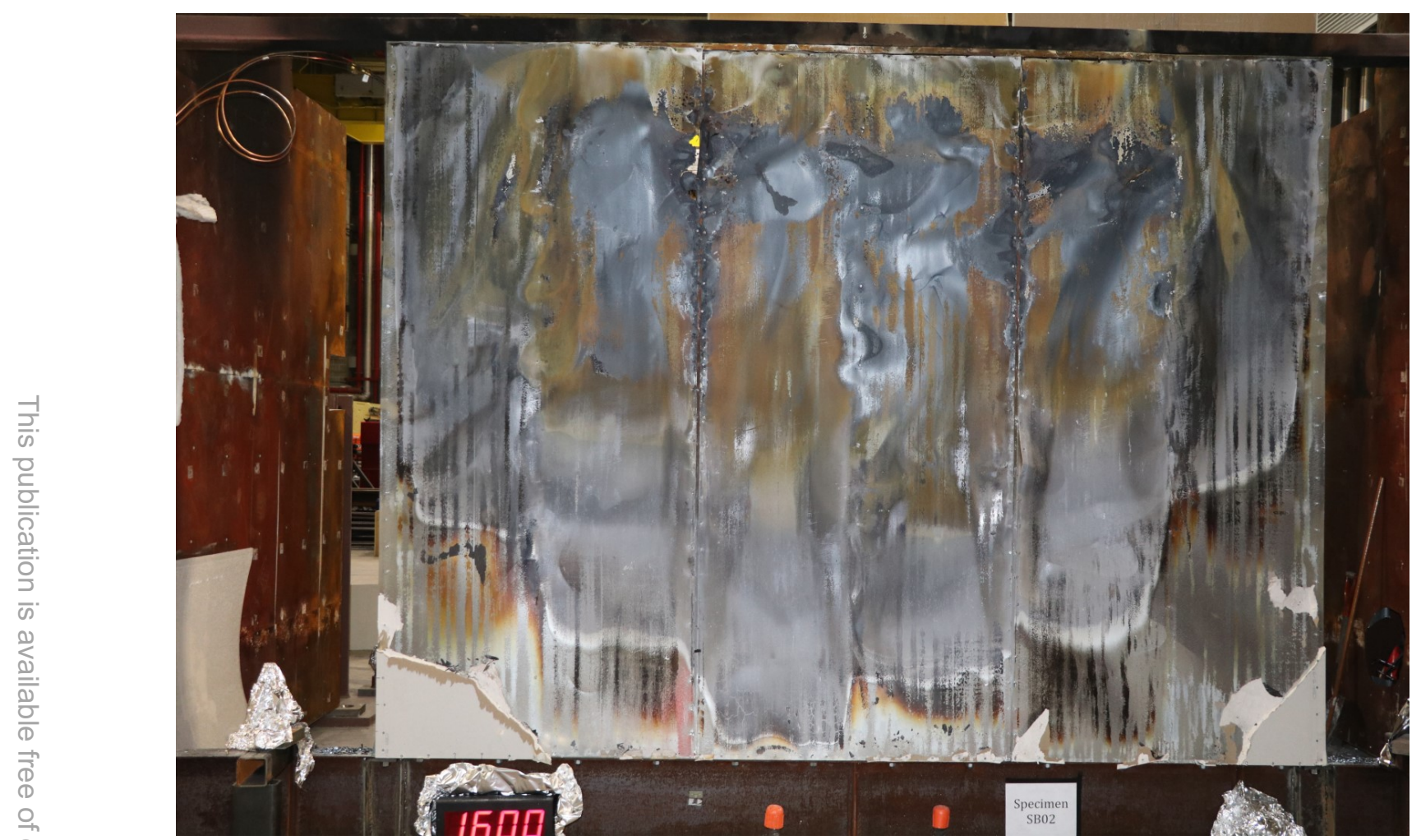

Fig. 136. SB02 - Photograph of unexposed side of the wall after load cycling following the fire.

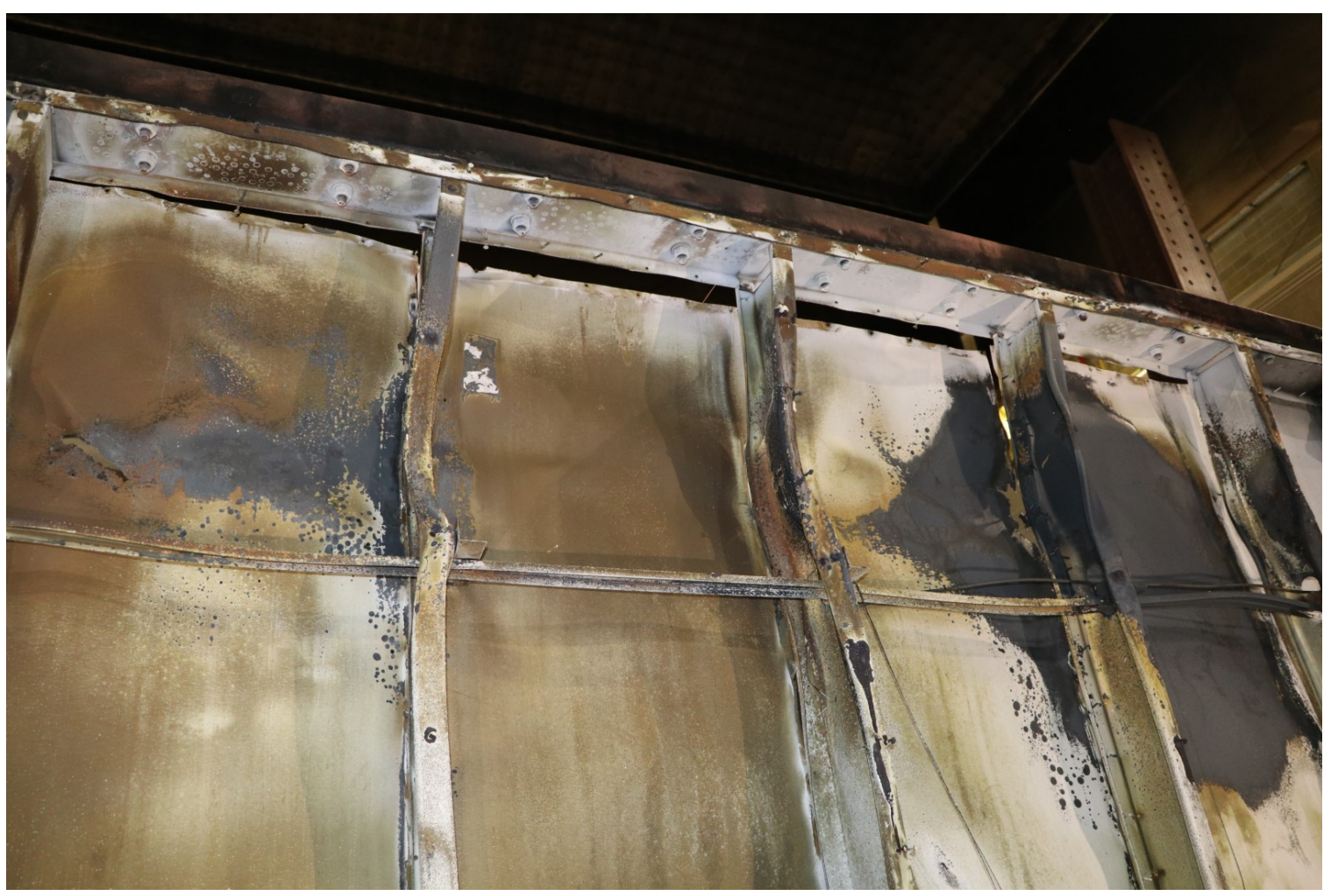

Fig. 137. SB02 - Photograph of damage after load cycling following the fire. 


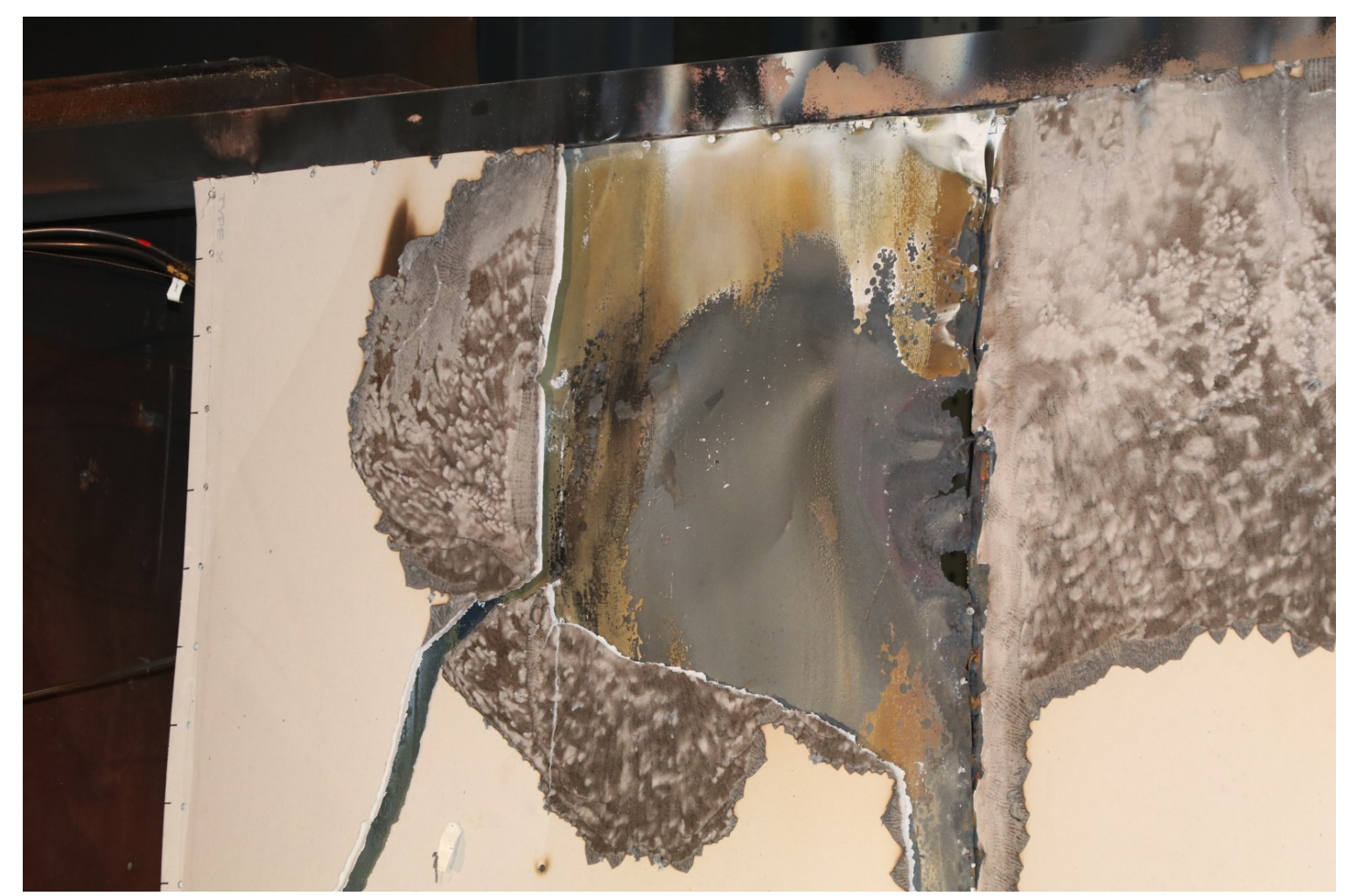

Fig. 138. SB02 - Photograph of burn-through (oxidation) of the sheet steel and pull-through of screws. 


\section{SB03 Data}

SB03b (Mild Fire test of an undamaged wall)

- The gas burner was set to $1.7 \mathrm{MW}$ for $15 \mathrm{~min}$. The temperatures were also recorded during the cooling phase up to 45 min (Fig. 139).

- There is an asymmetry in the temperatures inside the compartment, temperatures at the north side are higher than at the south side (Fig. 140), leading to more thermal damage of the wall on the north side (Fig. 152).

- A puddle formed at the bottom of the wall due to water evaporated from the gypsum that condensed on the sheet steel.

- TC_B_P3 (Fig. 145), TC_B_N1 and TC_B_V1 (Fig. 148) and show erroneous results due to cold junctions and/or detachment from the wall (disregard these data).

SB03c (Cyclic test of wall at ambient temperature following the Mild Fire)

- Failure mode was a combination of global buckling of the sheet steel and failure of the connections to the sheet steel (Fig. 152, Fig. 153).

- The loading beam stiffening truss was present in this and all subsequent tests which significantly reduced vertical movement at the connection between the actuator head and the loading beam was observed (Fig. 154). The stiffening in the vertical direction resulted in slightly more $(<5 \mathrm{~mm})$ deflection of the loading beam (top of wall) out of plane.

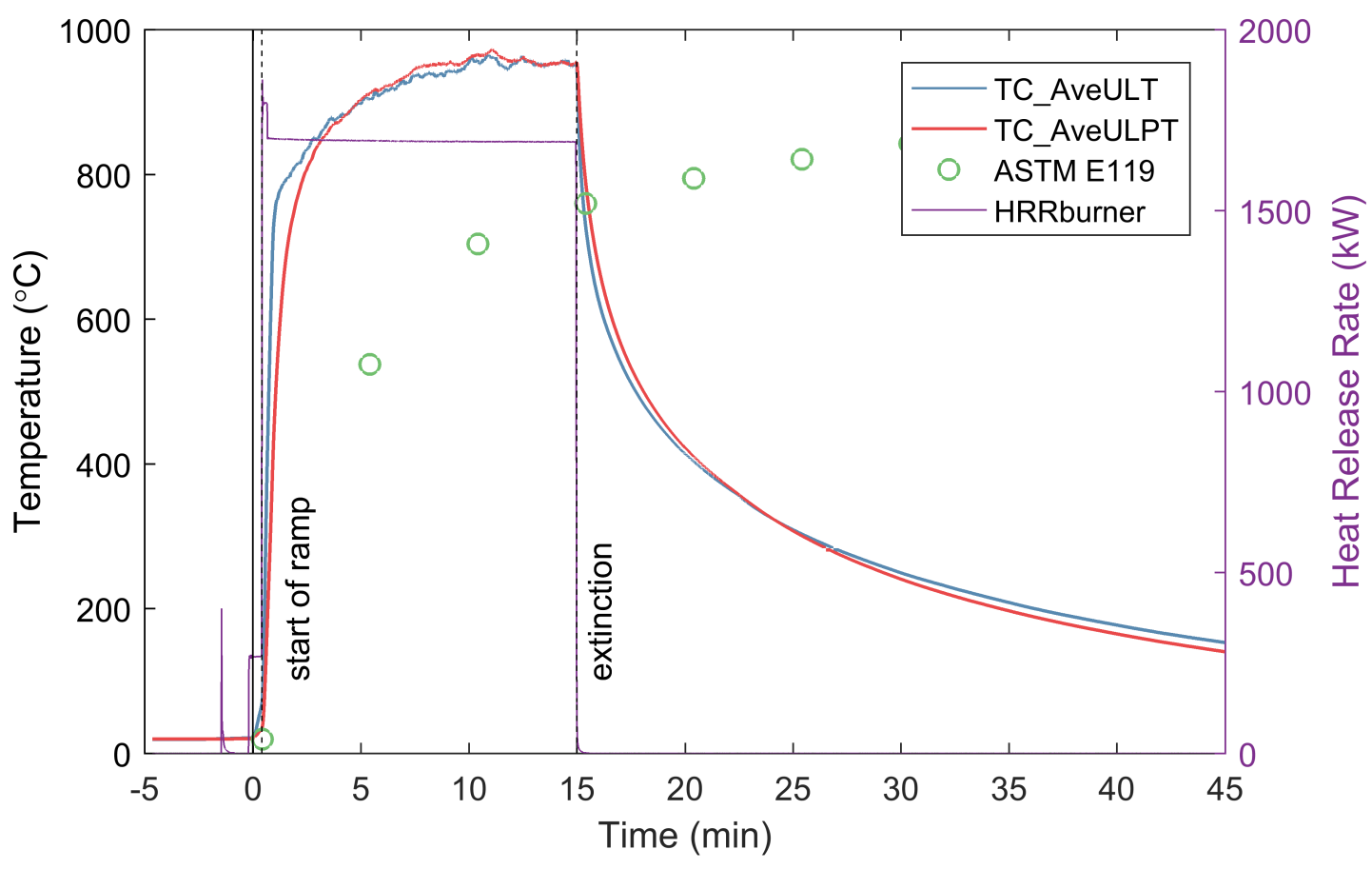

Fig. 139. SB03 - Compartment temperatures and burner Heat Release Rate. 


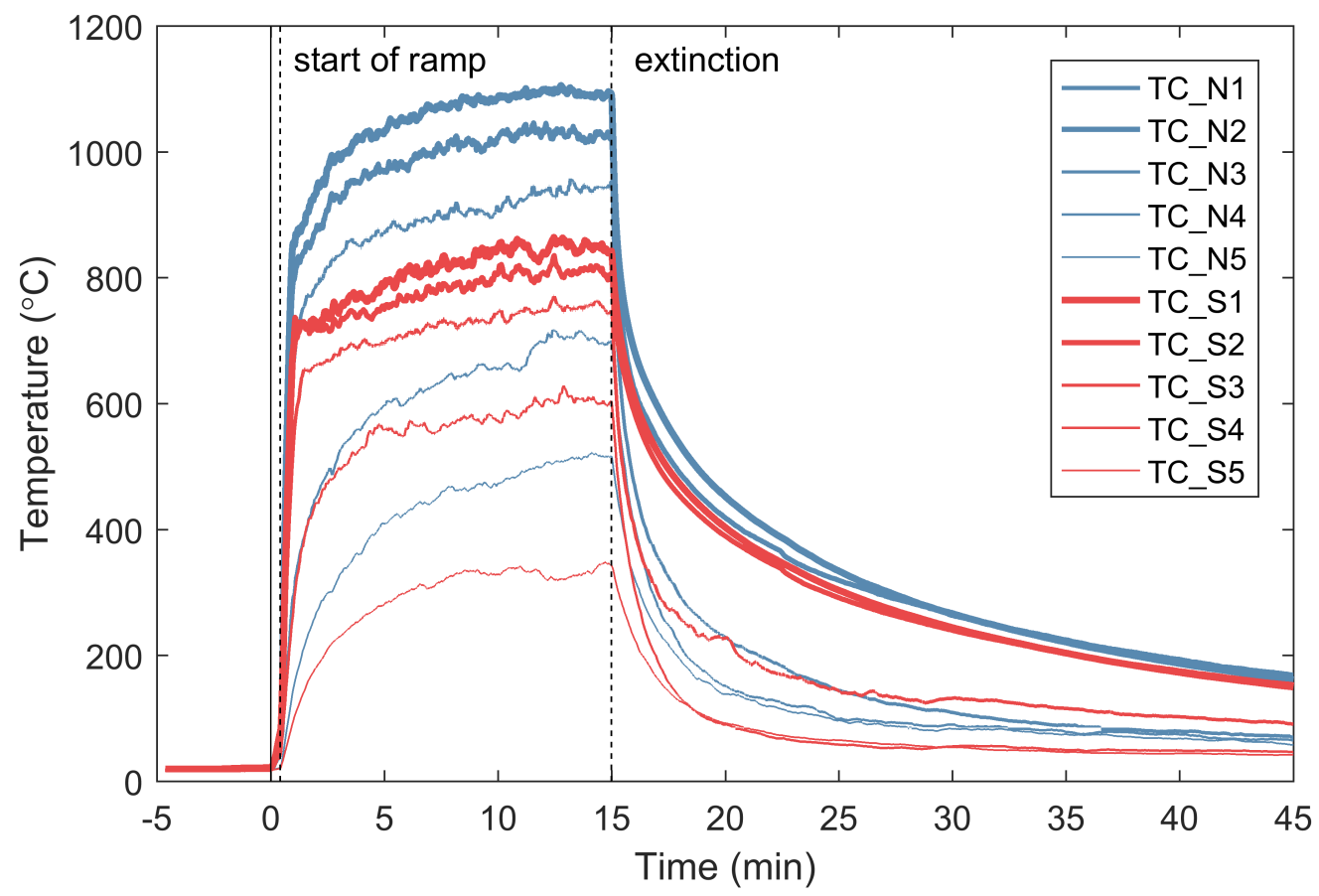

Fig. 140. SB03 - Compartment temperatures measured by the thermocouple trees.

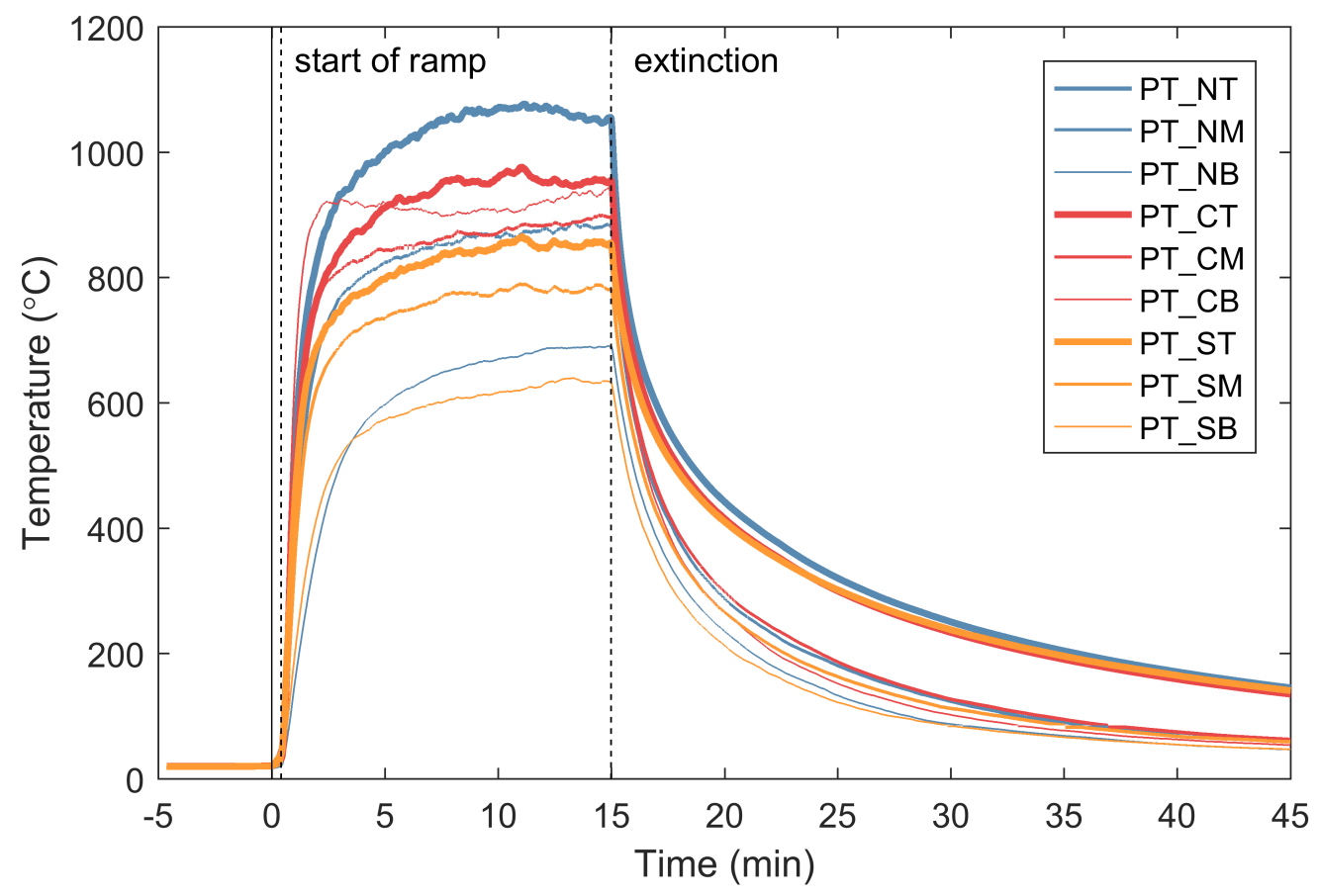

Fig. 141. SB03 - Compartment temperatures measured by the plate thermocouples. 


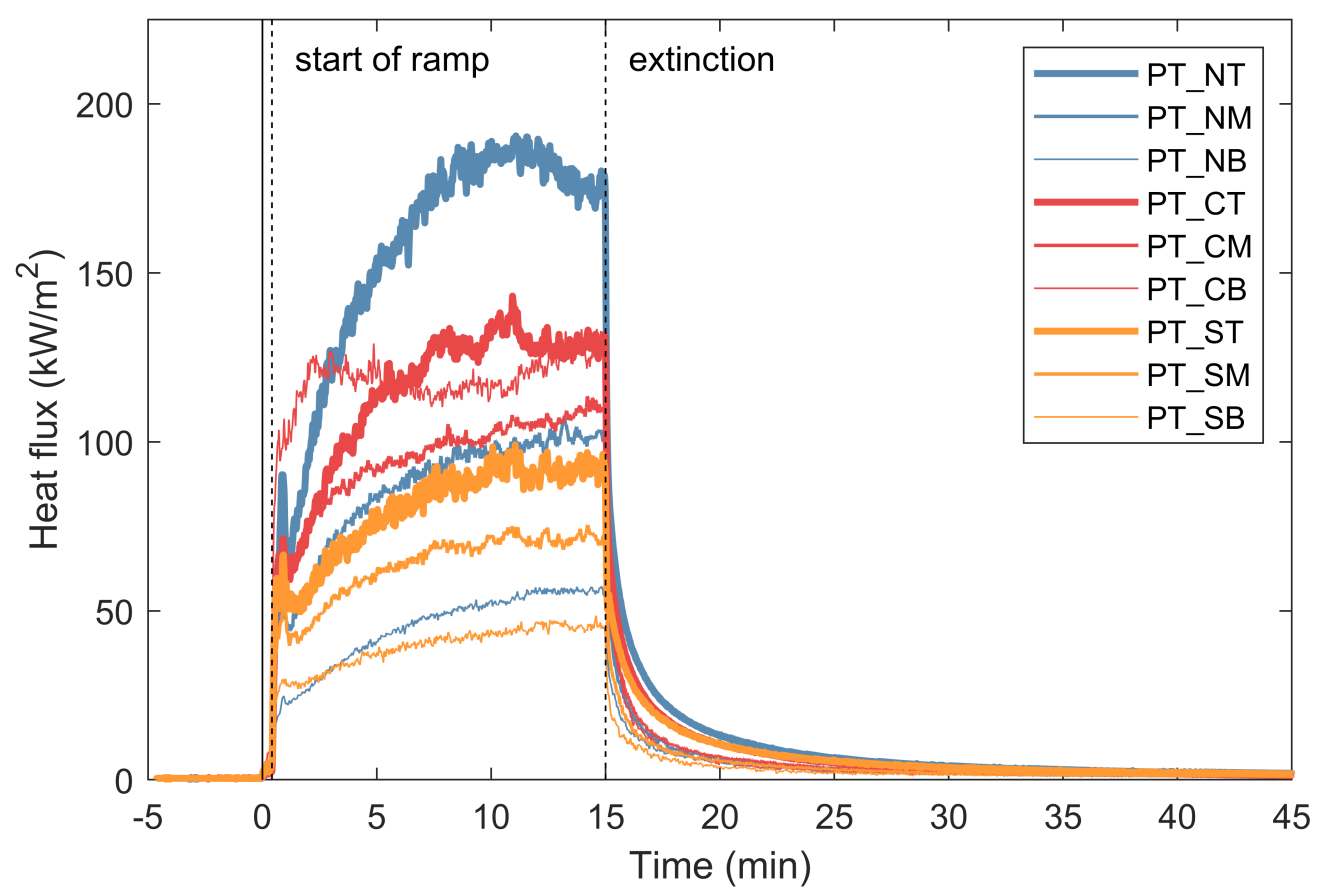

Fig. 142. SB03 - Heat fluxes in the compartment measured by the plate thermocouples.
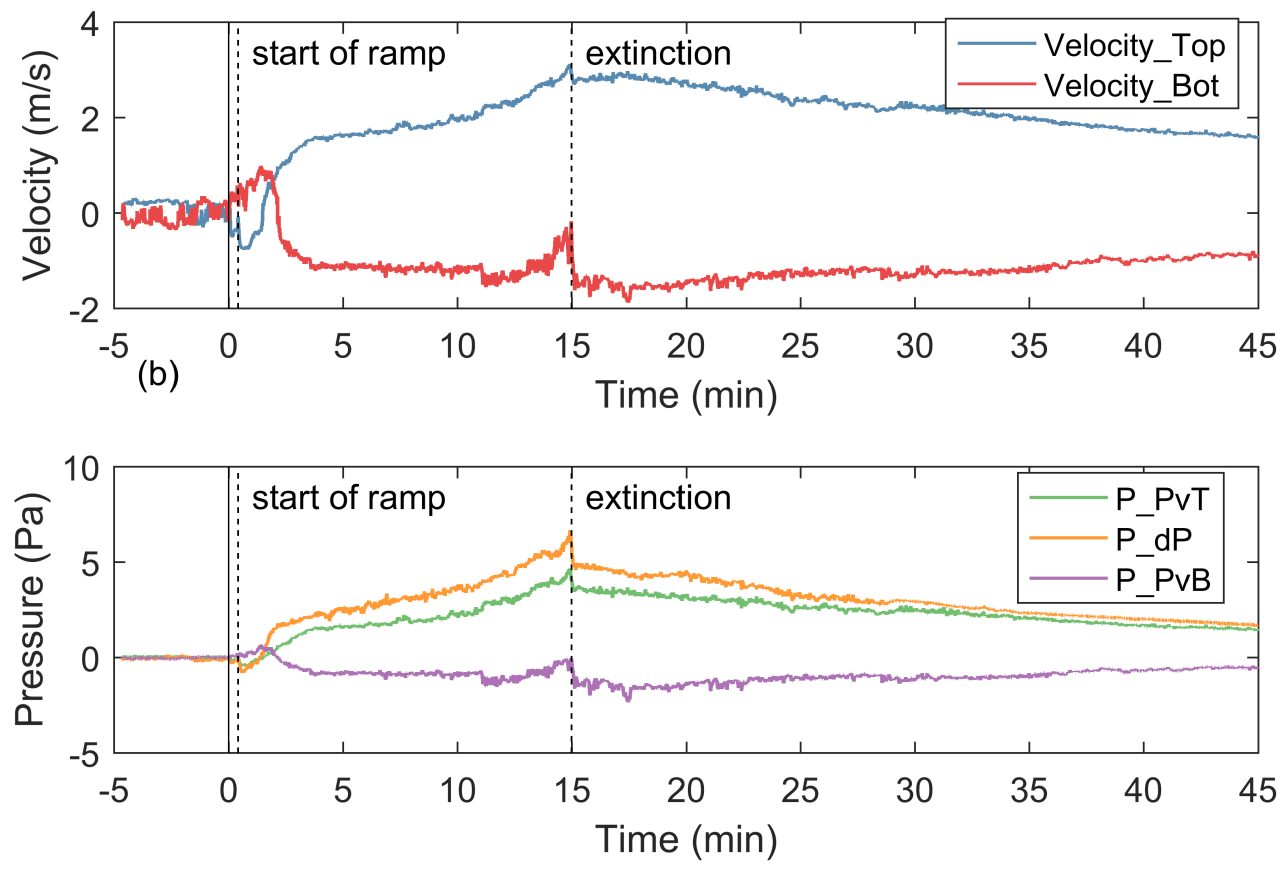

Fig. 143. SB03 - (a) Velocity of air flow at the top and bottom knockouts of the chord stud; (b) Pressure at the top and bottom knockouts of the chord stud and in the wall cavity near the top. 


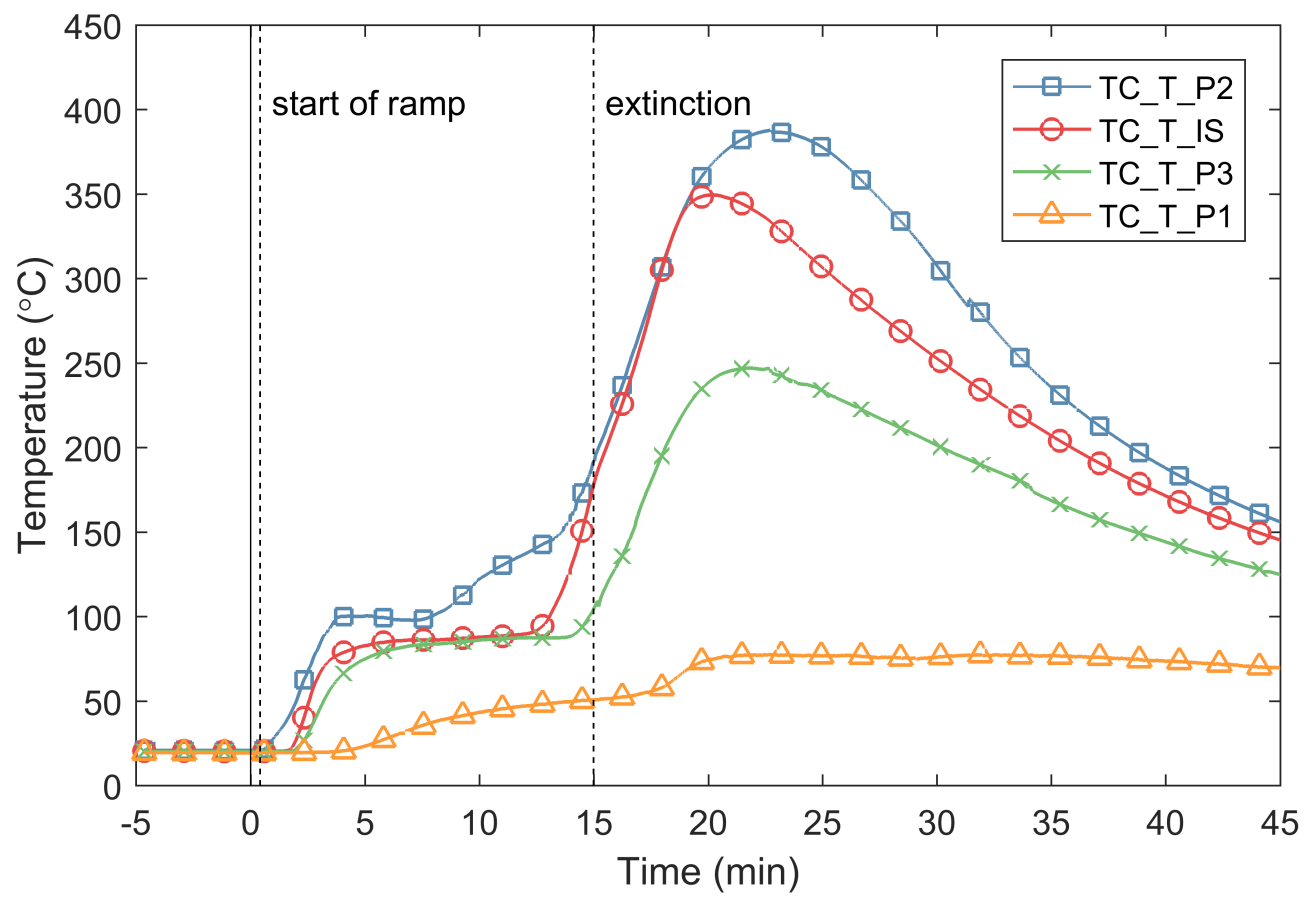

Fig. 144. SB03 - Temperatures through the specimen at an interior stud $46 \mathrm{~cm}$ from the top of the wall.

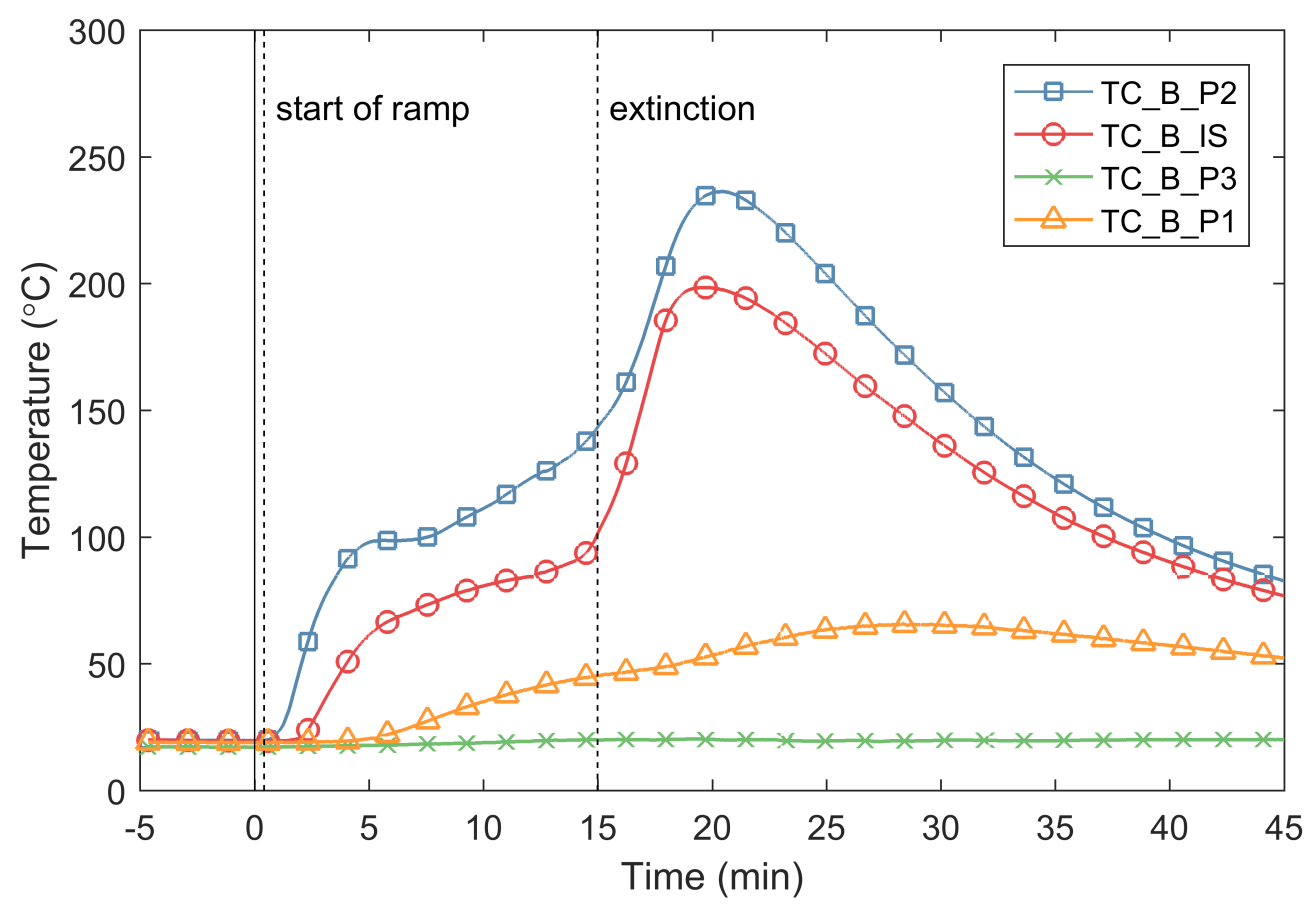

Fig. 145. SB03 - Temperatures through the specimen at an interior stud $46 \mathrm{~cm}$ from the bottom of the wall. 


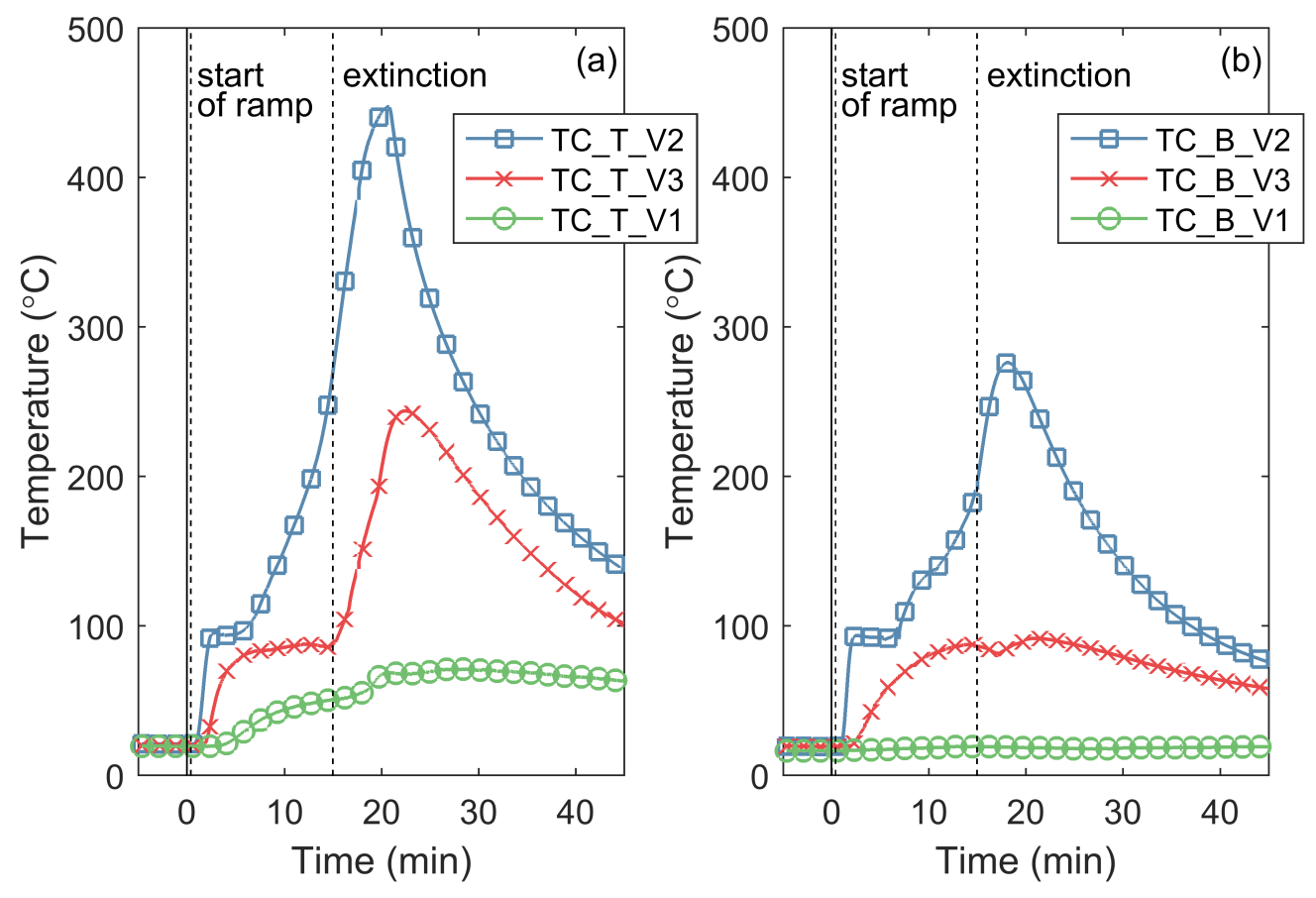

Fig. 146. SB03 - Temperatures through the specimen midway between interior studs: (a) $46 \mathrm{~cm}$ from the top of the wall; (b) $46 \mathrm{~cm}$ from the bottom of the wall.
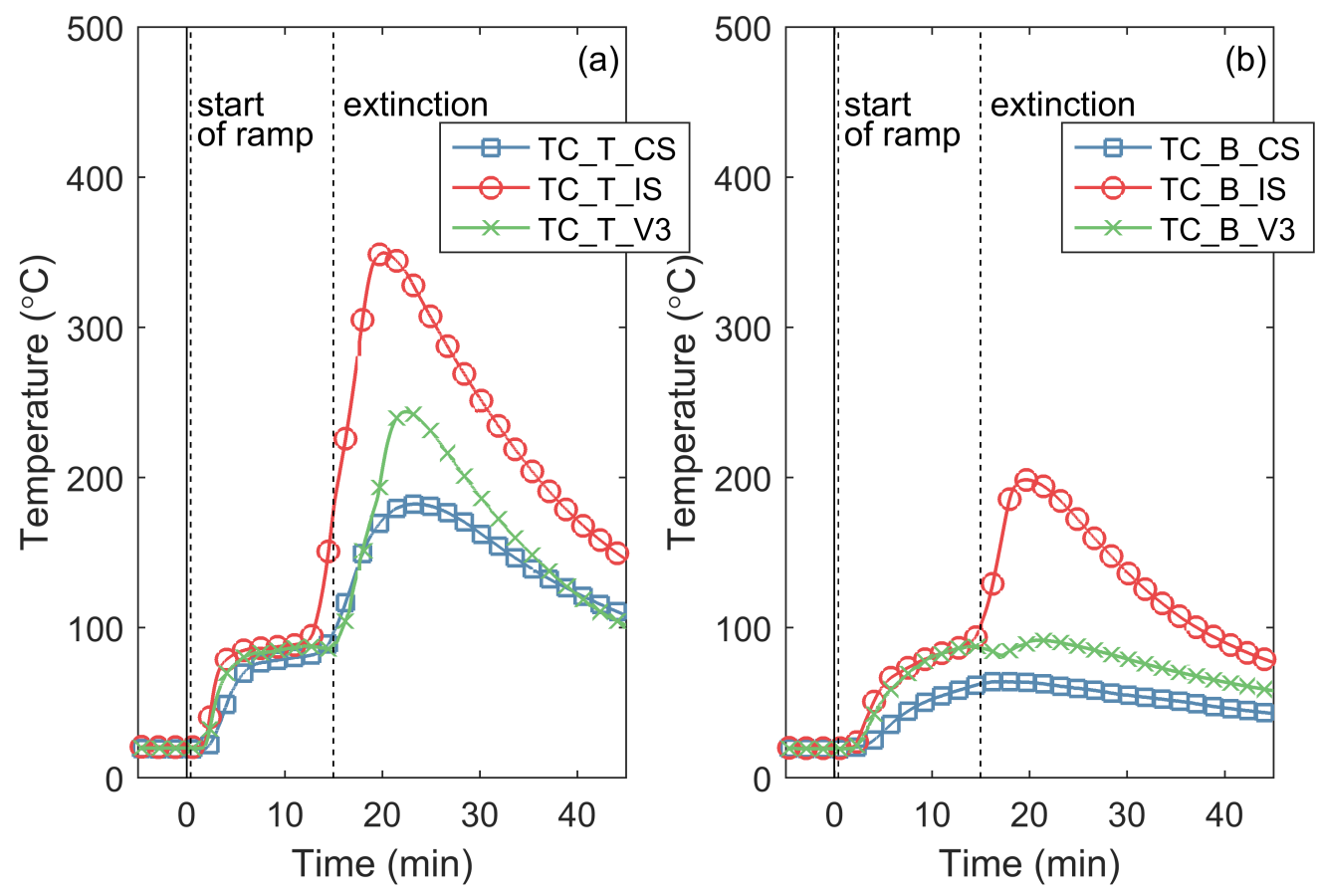

Fig. 147. SB03 - Temperatures of the framing and sheathing elements: (a) $46 \mathrm{~cm}$ from the top of the wall; (b) $46 \mathrm{~cm}$ from the bottom of the wall. 


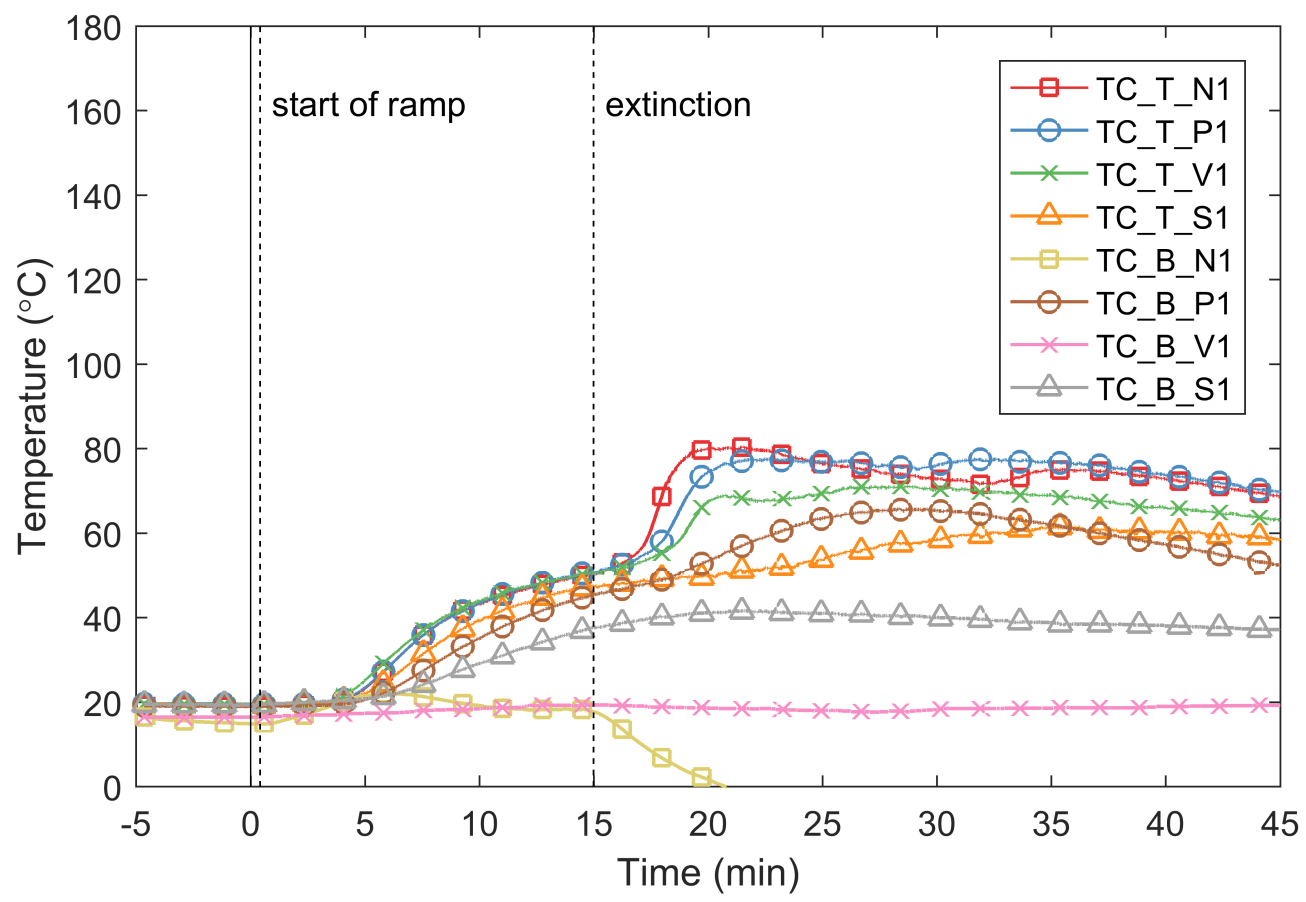

Fig. 148. SB03 - Temperatures of the gypsum on the unexposed side of the wall specimen.

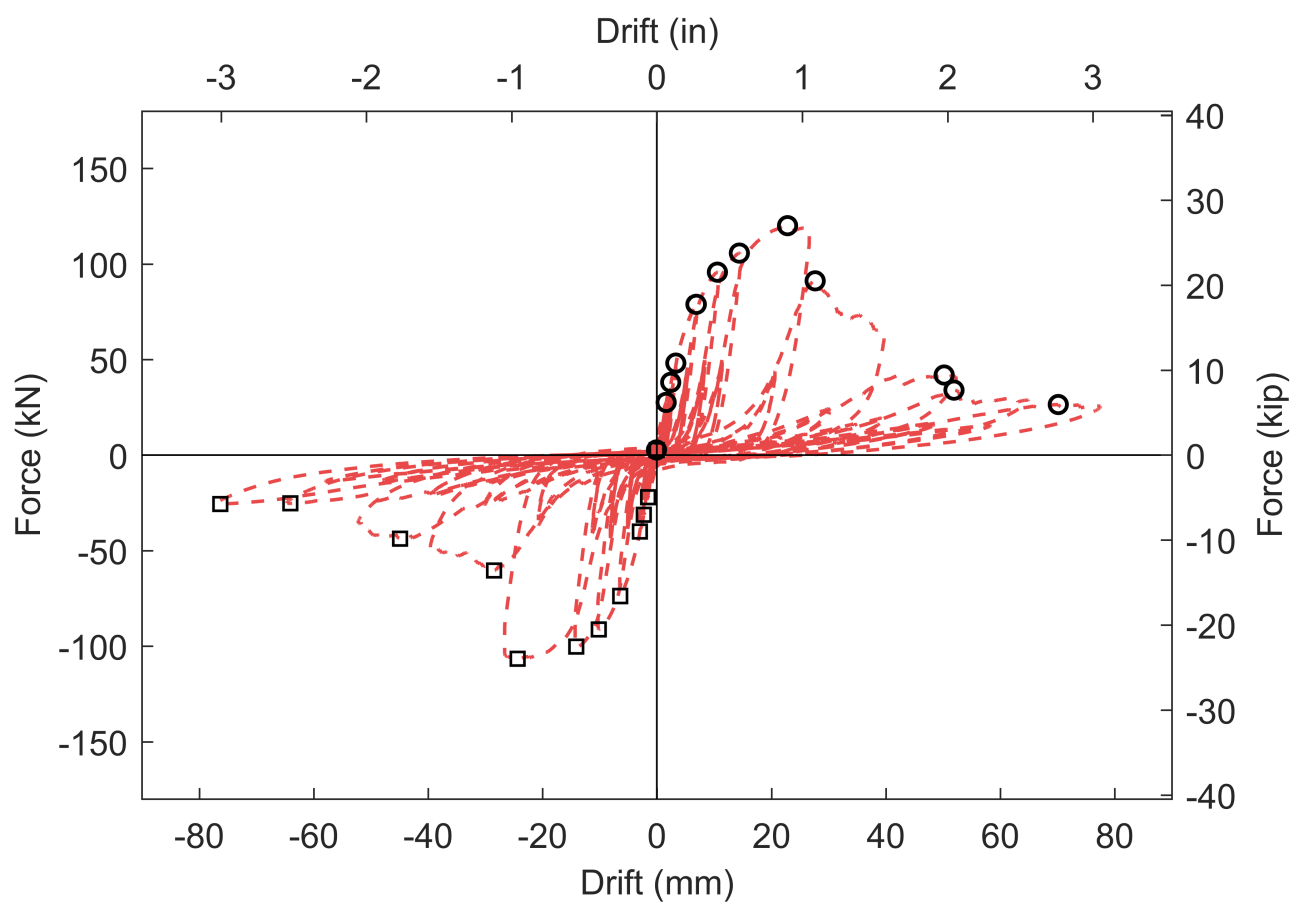

Fig. 149. SB03 - Applied load versus wall longitudinal drift during mechanical loading. 


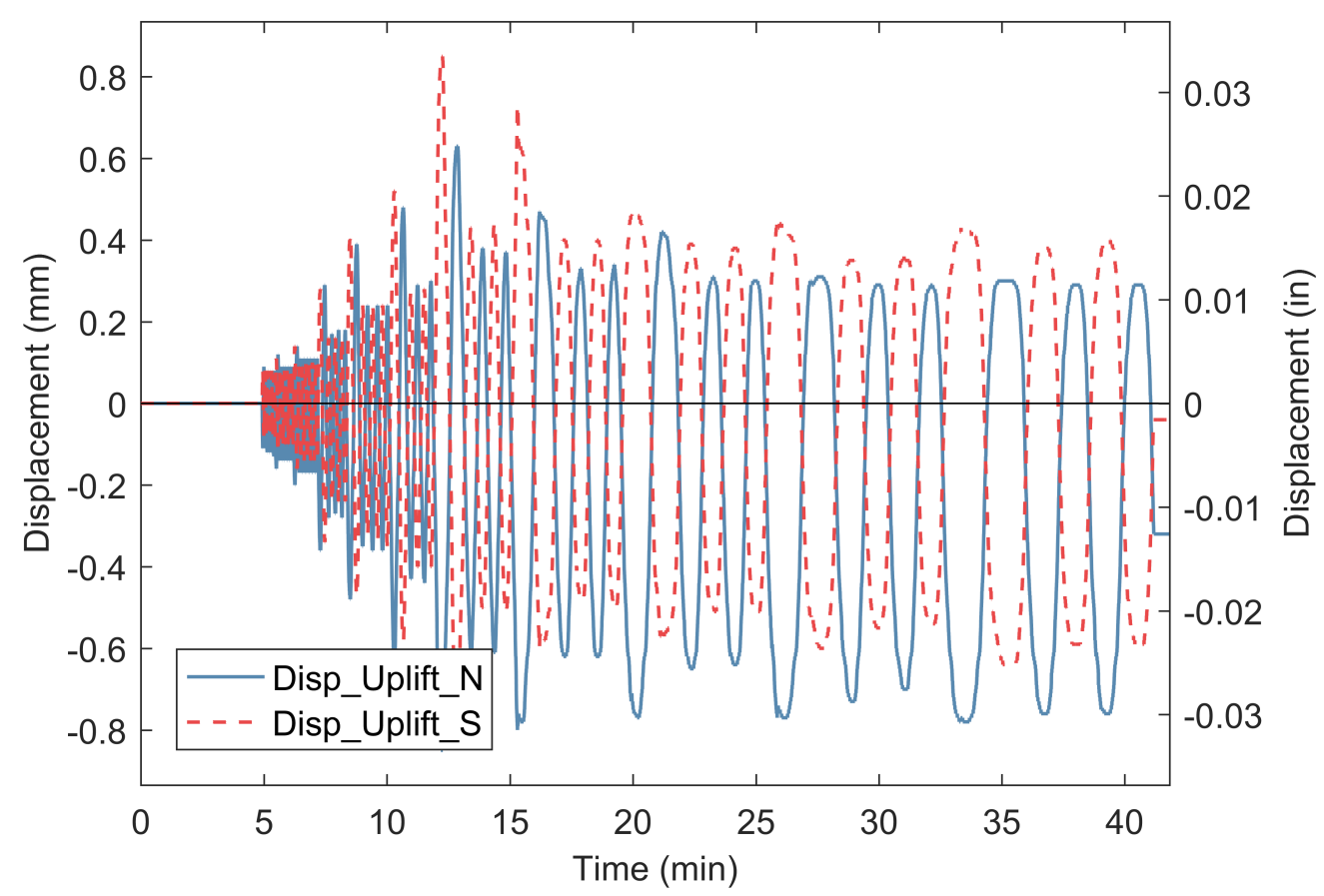

Fig. 150. SB03 - Uplift at bottom of wall during mechanical loading.

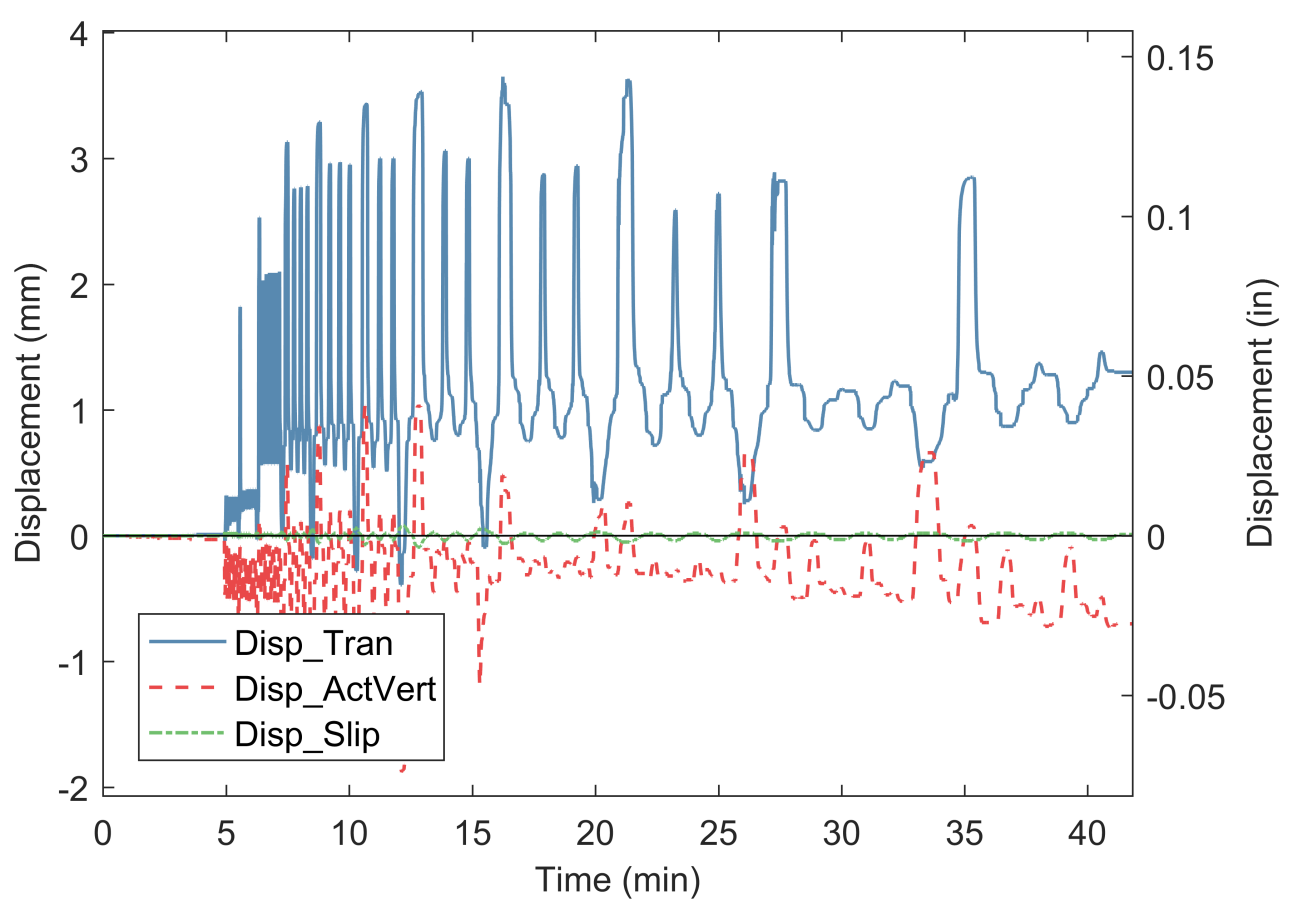

Fig. 151. SB03 - Ancillary displacement measurements during mechanical loading. 


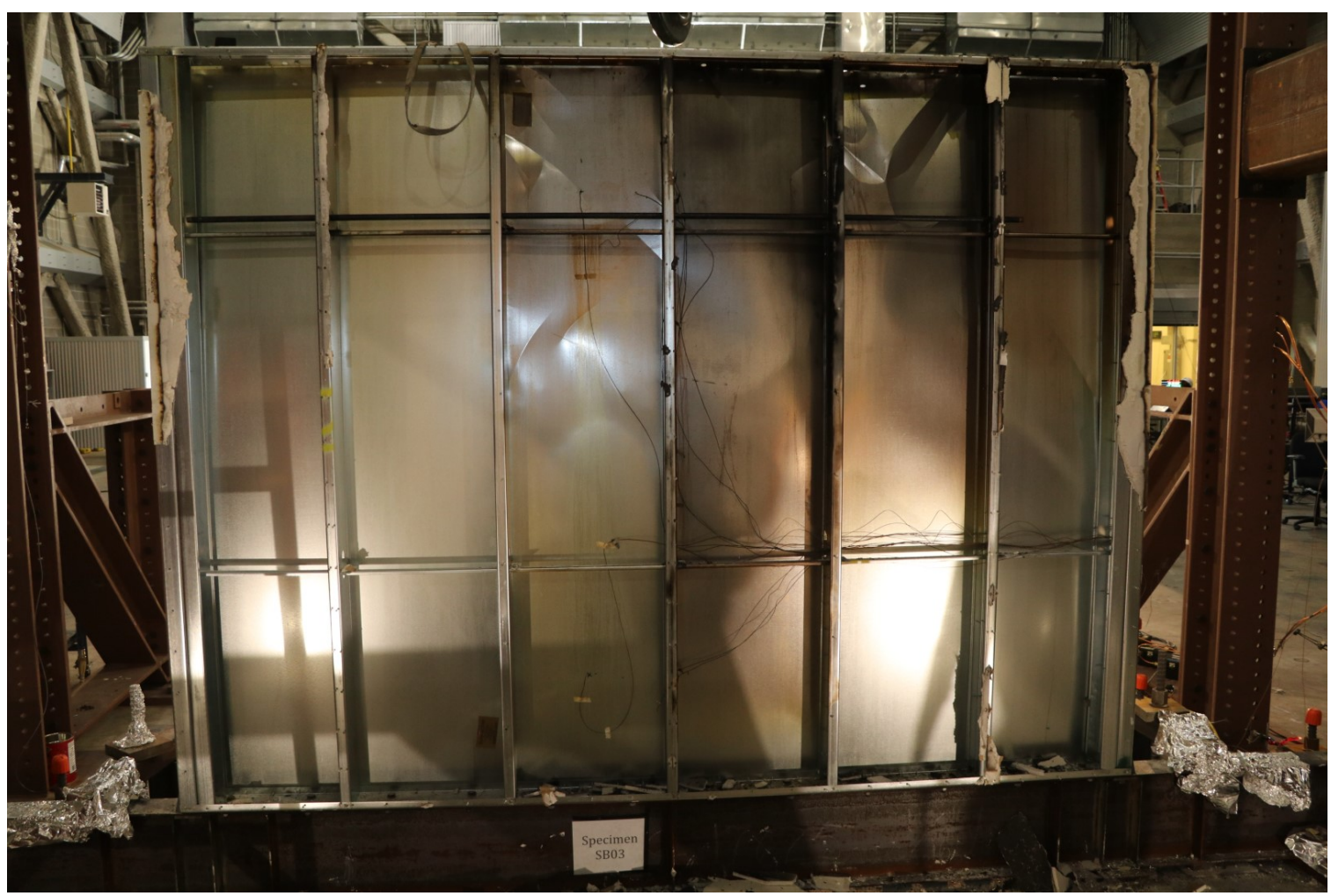

Fig. 152. SB03 - Photograph of fire exposed side of the wall (remaining drywall removed) after load cycling following the fire.

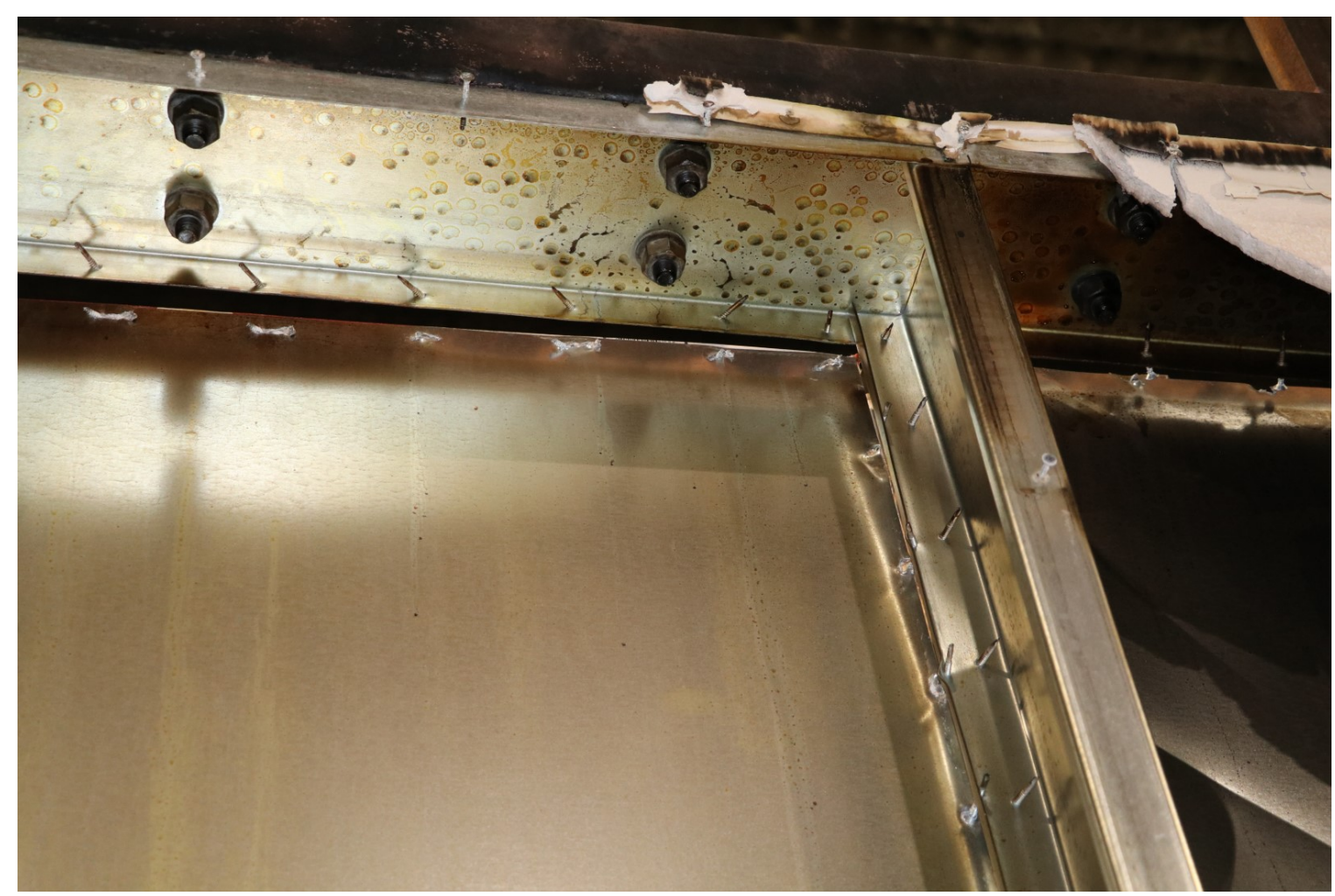

Fig. 153. SB03 - Photograph of connection failure after load cycling following the fire. 


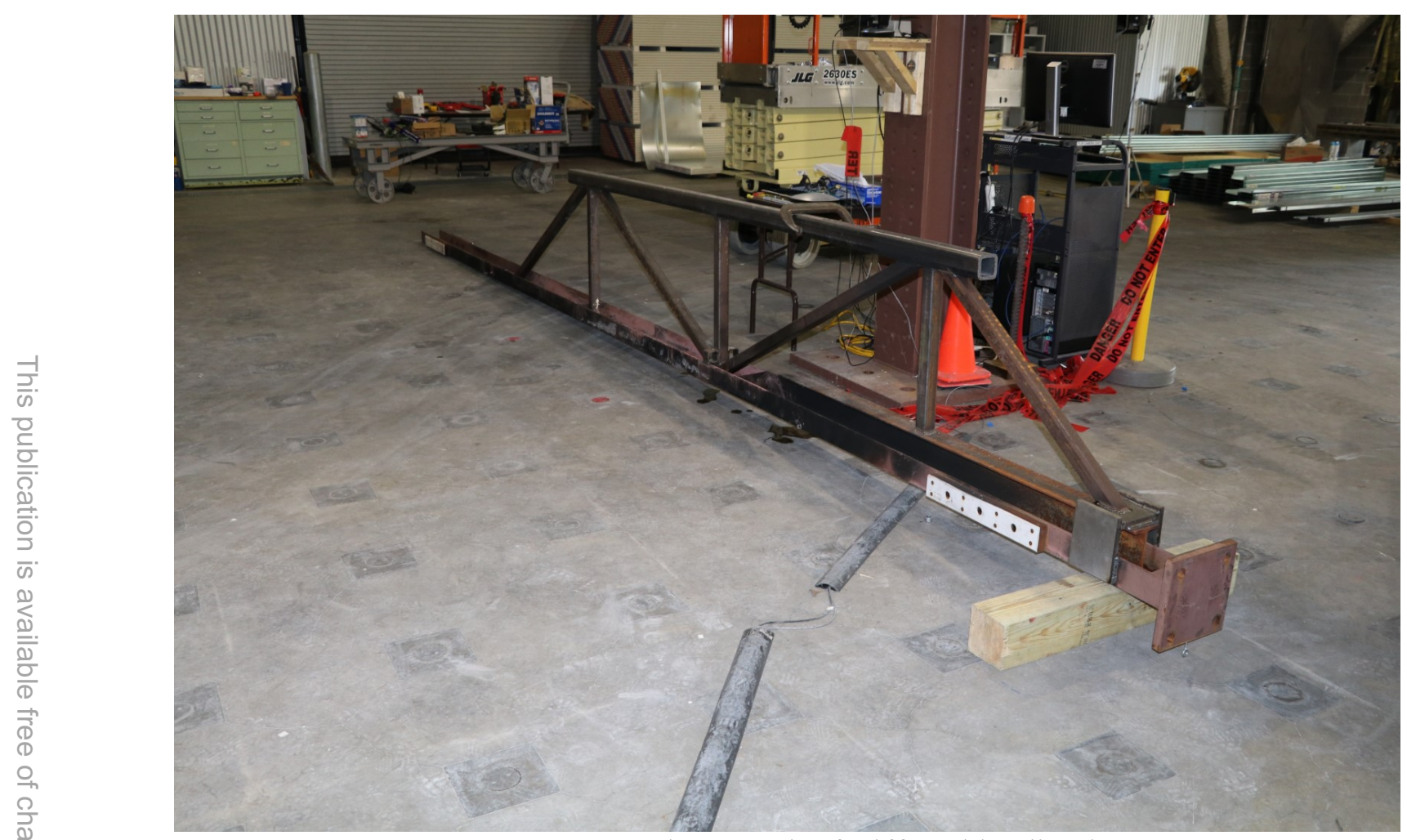

Fig. 154. SB03 - Photograph of stiffened loading beam. 


\section{SB03R Data}

$\mathrm{SB} 03 \mathrm{Rb}$ (Mild Fire test of an undamaged wall)

- This was a repeat test of mild fire with the steel sheathed wall. The gas burner was set to $1.7 \mathrm{MW}$ for $15 \mathrm{~min}$ and temperatures were recorded up to $45 \mathrm{~min}$ (Fig. 155).

- There was no asymmetry (north to south) of the temperatures recorded inside the compartment (Fig. 156) as observed in SB03b and the average temperatures reached are lower than in SB03b.

- A puddle formed at the bottom of the wall due to water evaporated from the gypsum that condensed on the sheet steel.

SB03Rc (Cyclic test of wall at ambient temperature following the Mild Fire)

- Failure mode was failure of the connections to the sheet steel. The lower wall temperatures achieved in SB03R compared to SB03 resulted in less degradation of the adhesive between the sheet steel and bond gypsum. This in turn suppressed the global buckling of the sheet steel observed in SB03 (compare Fig. 152 to Fig. 170).

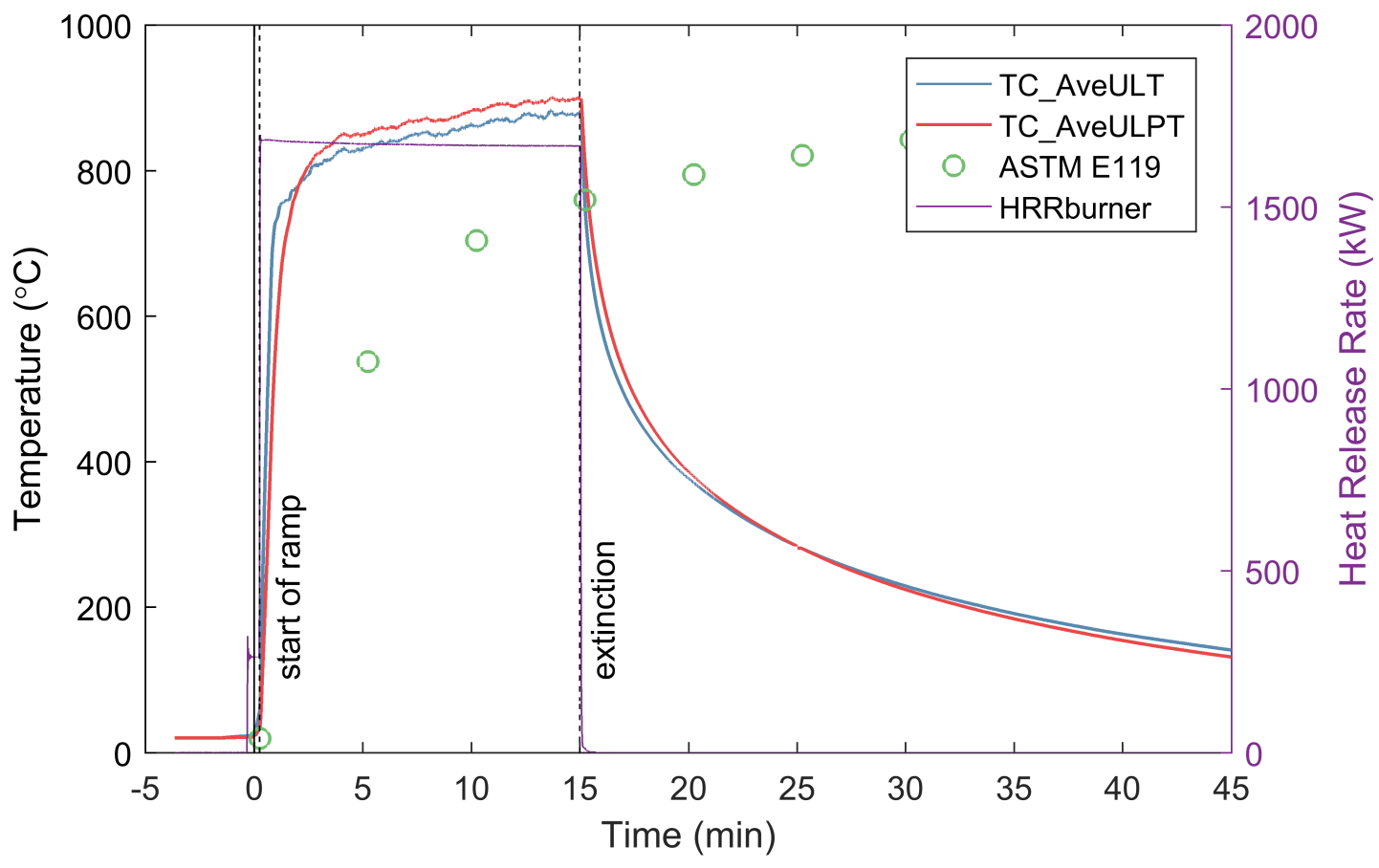

Fig. 155. SB03R - Compartment temperatures and burner Heat Release Rate. 


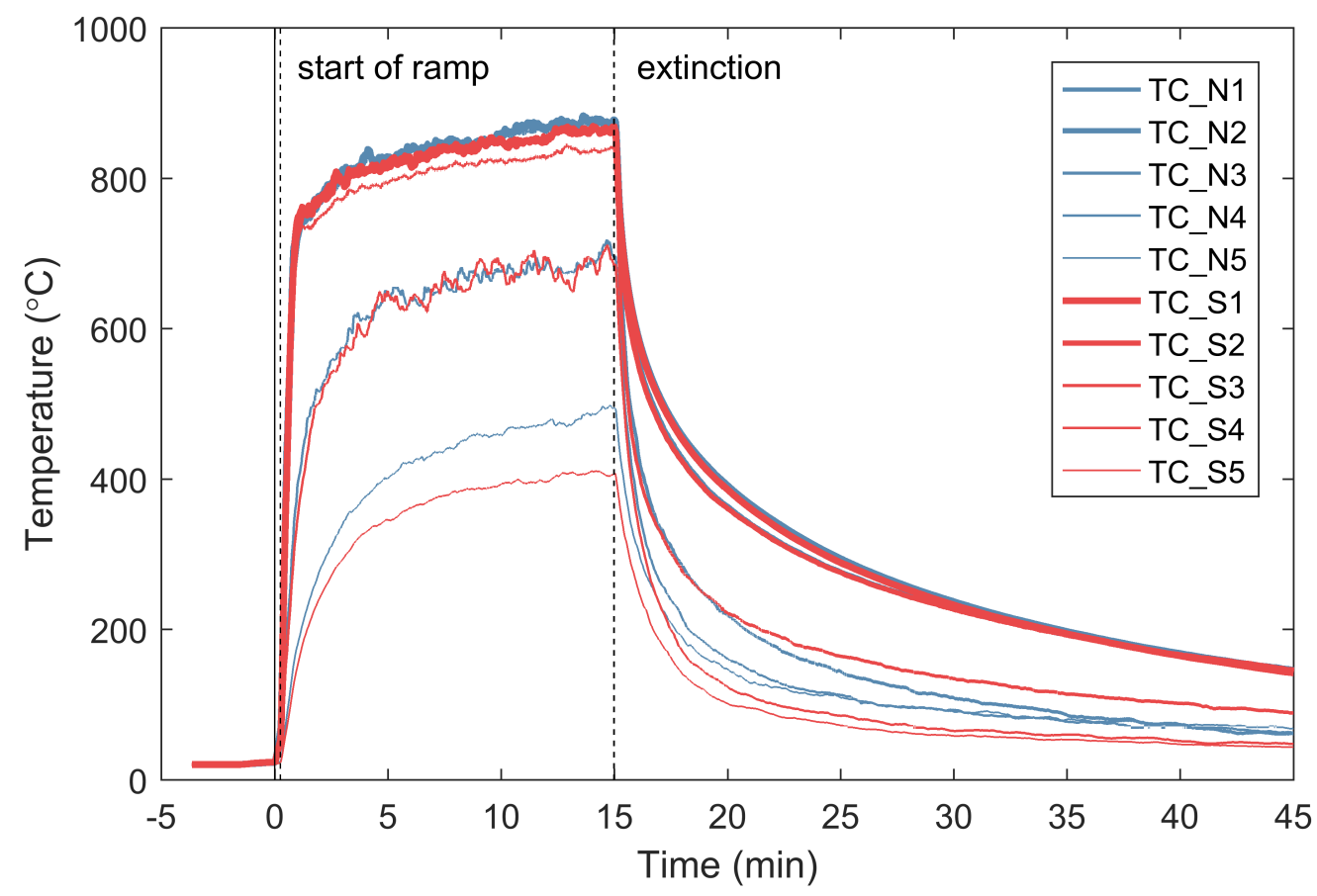

Fig. 156. SB03R - Compartment temperatures measured by the thermocouple arrays.

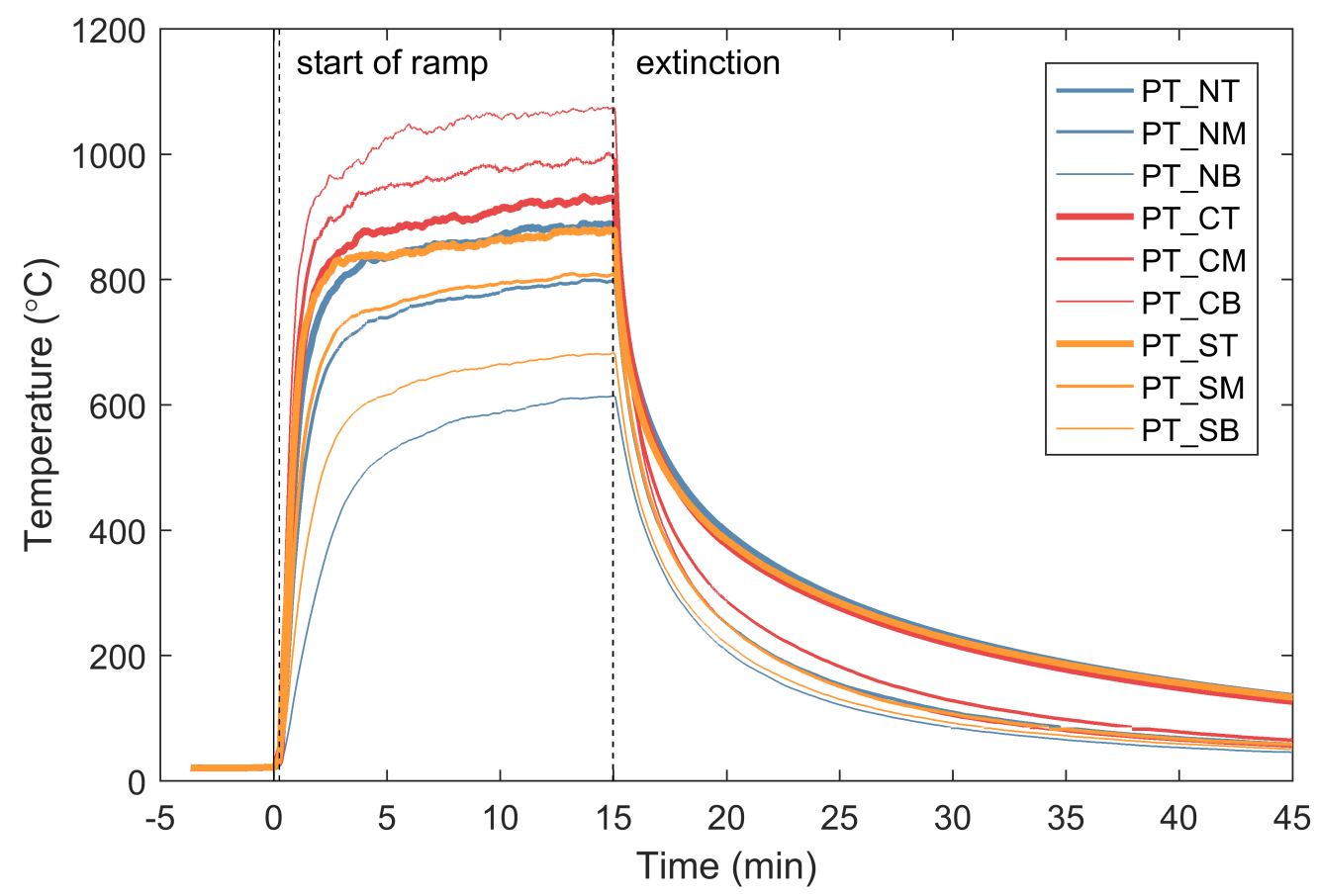

Fig. 157. SB03R - Compartment temperatures measured by the plate thermocouples. 


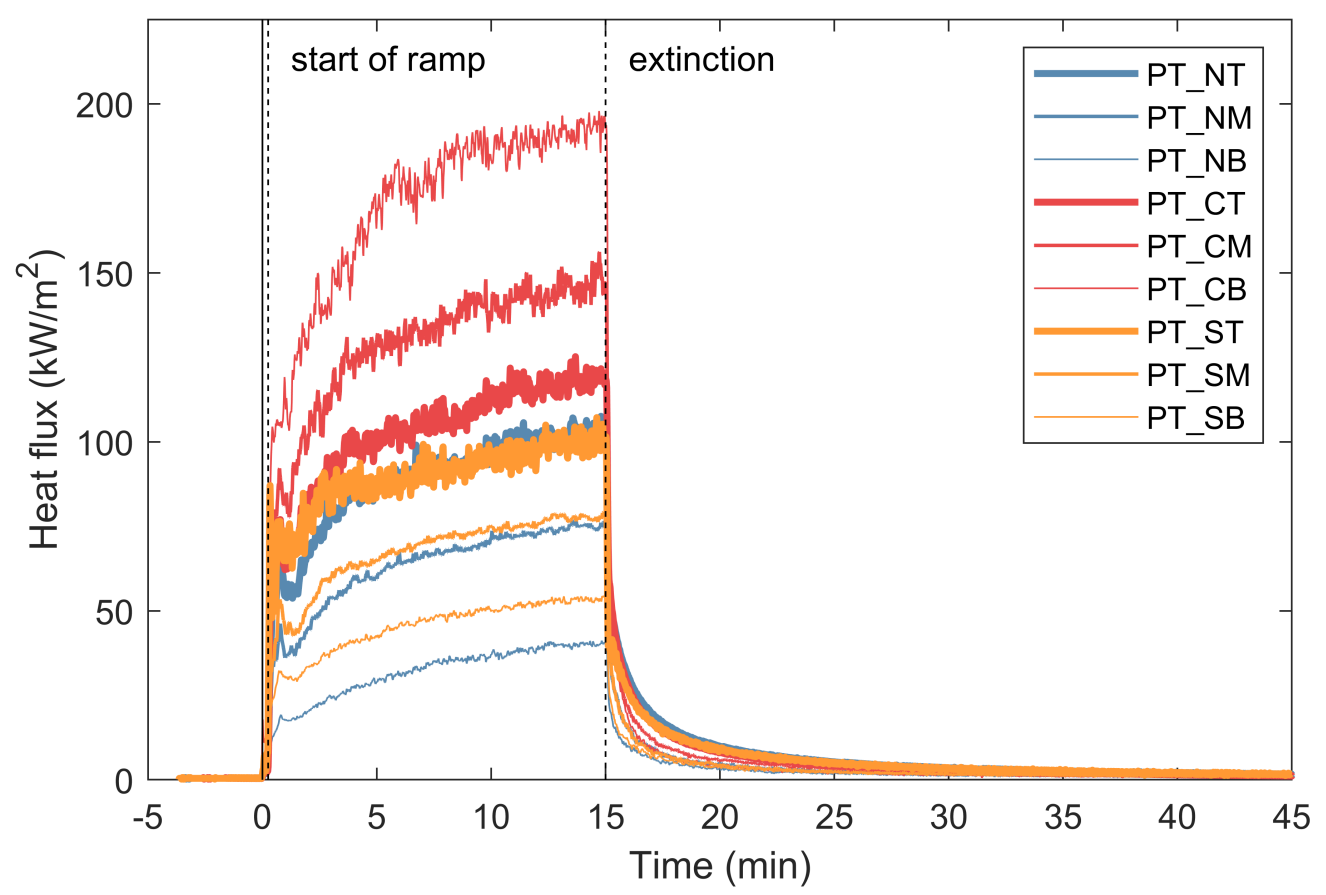

Fig. 158. SB03R - Heat fluxes in the compartment measured by the plate thermocouples.
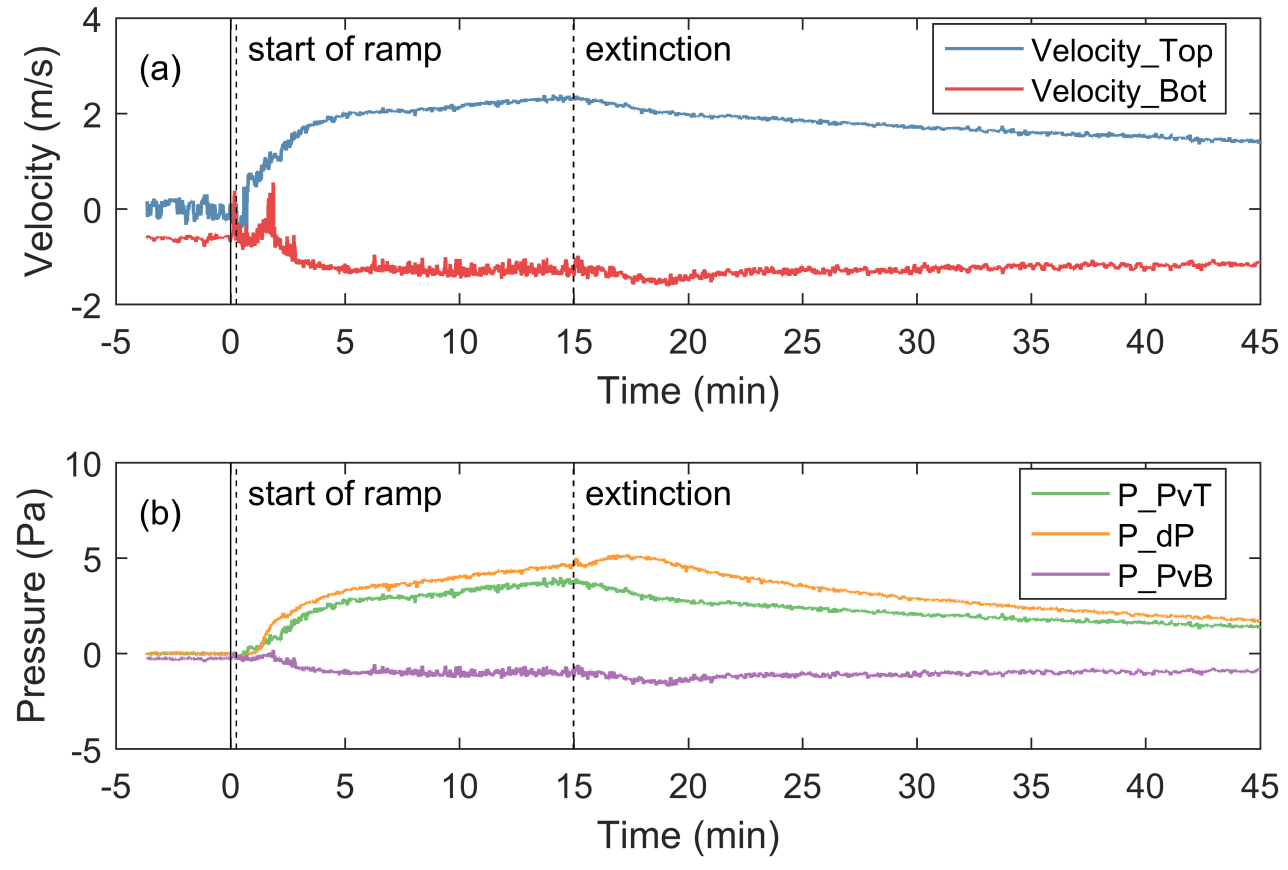

Fig. 159. SB03R - (a) Velocity of air flow at the top and bottom knockouts of the chord stud; (b) Pressure at the top and bottom knockouts of the chord stud and in the wall cavity near the top. 


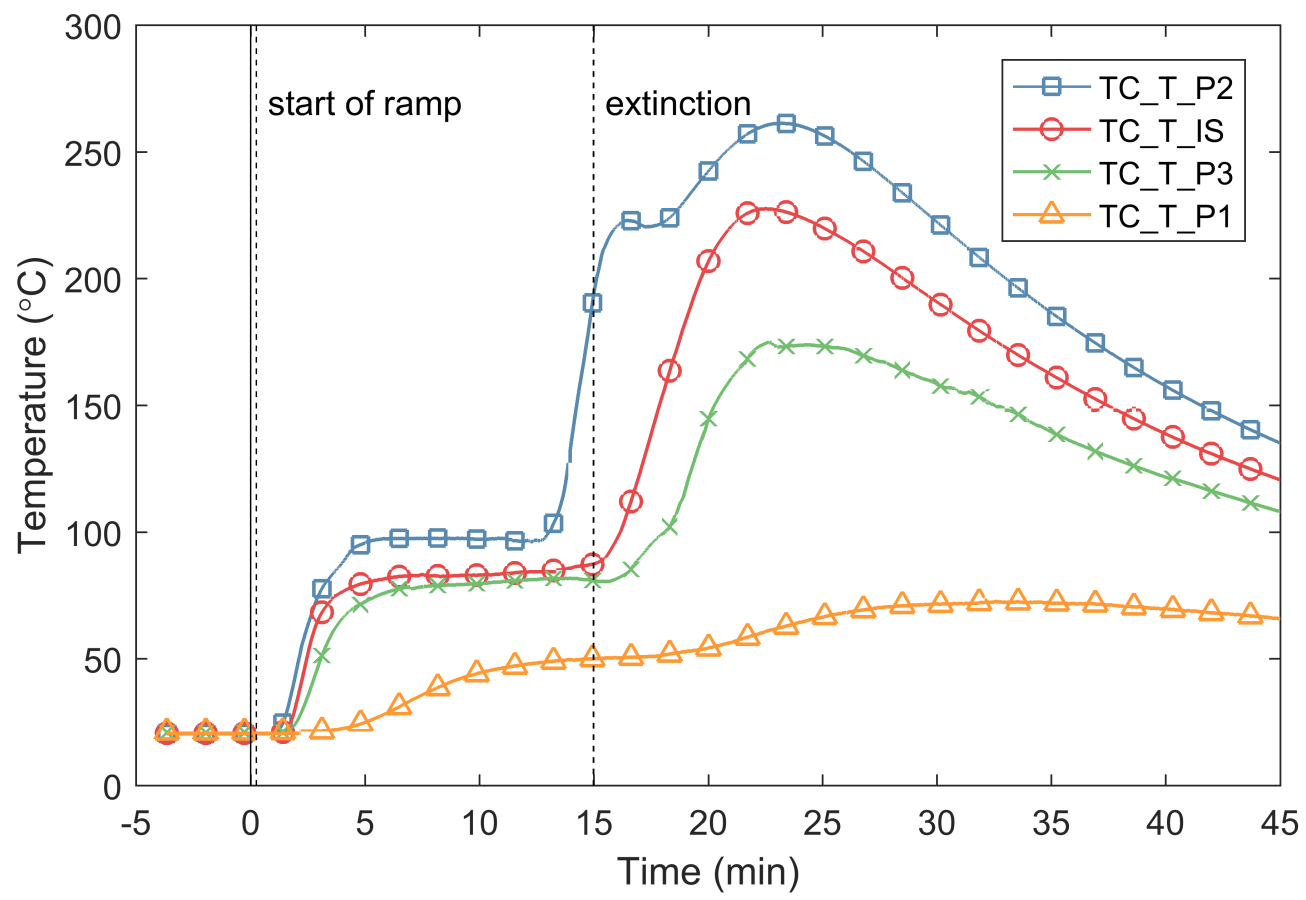

Fig. 160. SB03R - Temperatures through the specimen at an interior stud $46 \mathrm{~cm}$ from the top of the wall.

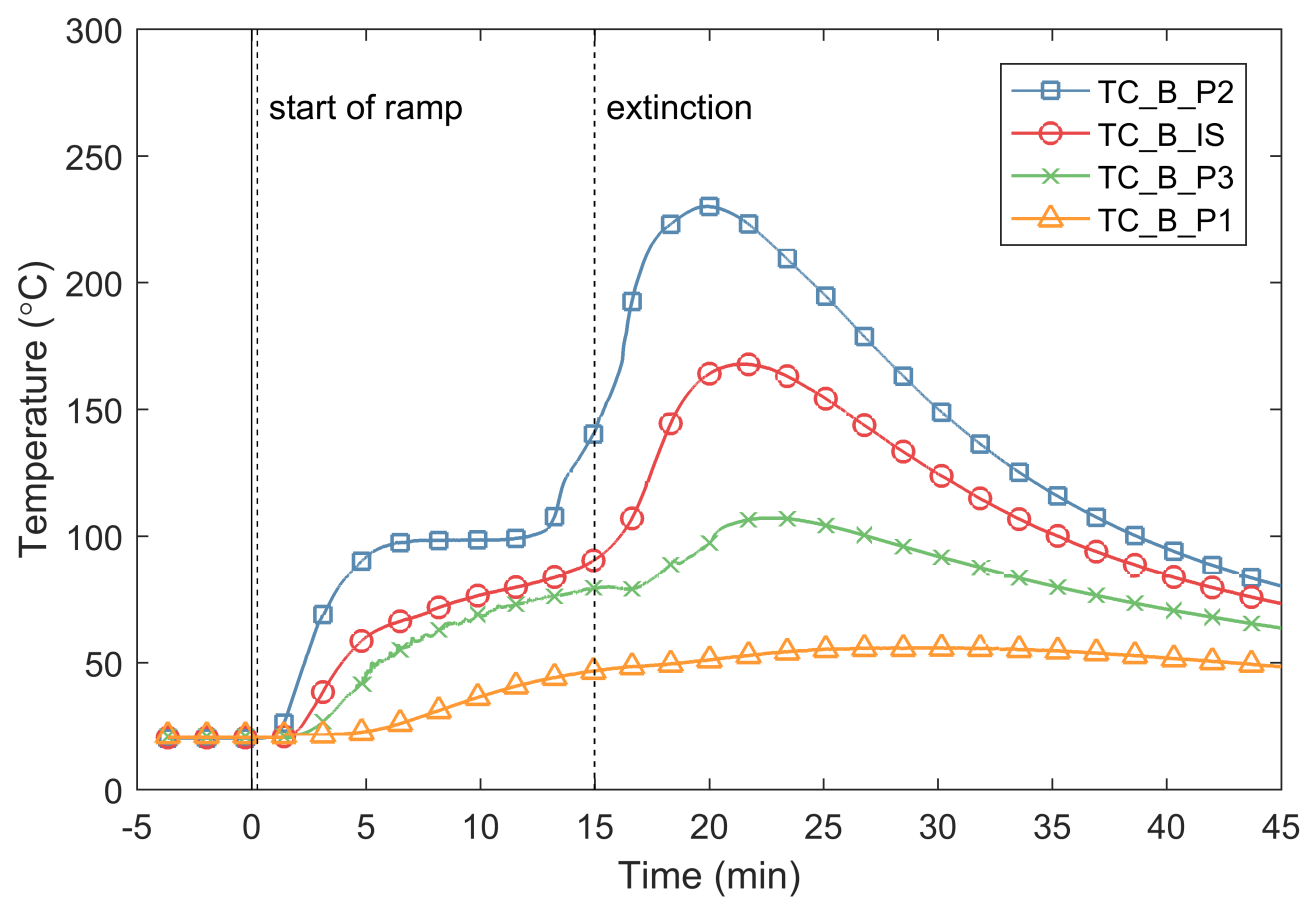

Fig. 161. SB03R - Temperatures through the specimen at an interior stud $46 \mathrm{~cm}$ from the bottom of the wall. 


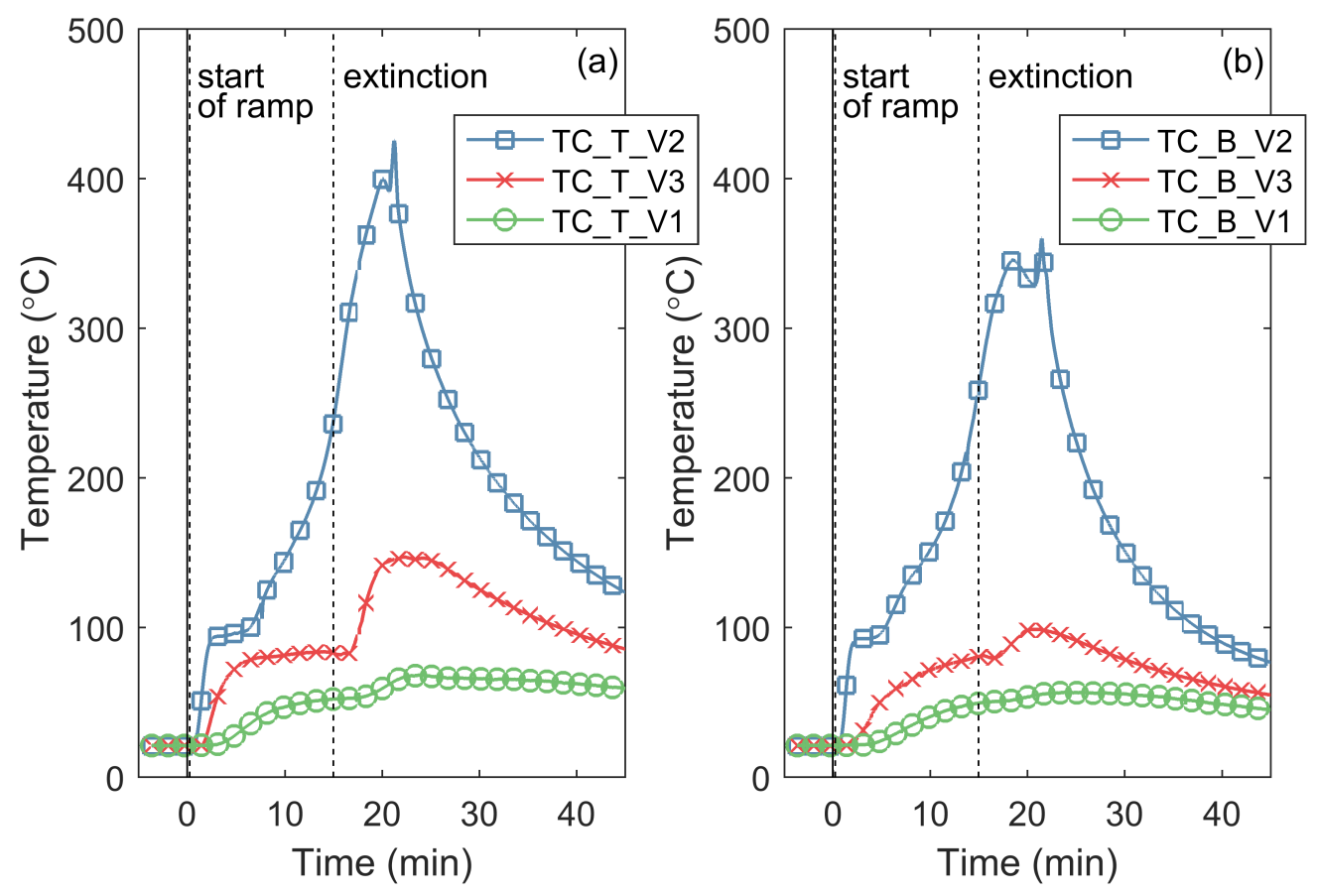

Fig. 162. SB03R - Temperatures through the specimen midway between interior studs: (a) $46 \mathrm{~cm}$ from the top of the wall; (b) $46 \mathrm{~cm}$ from the bottom of the wall.
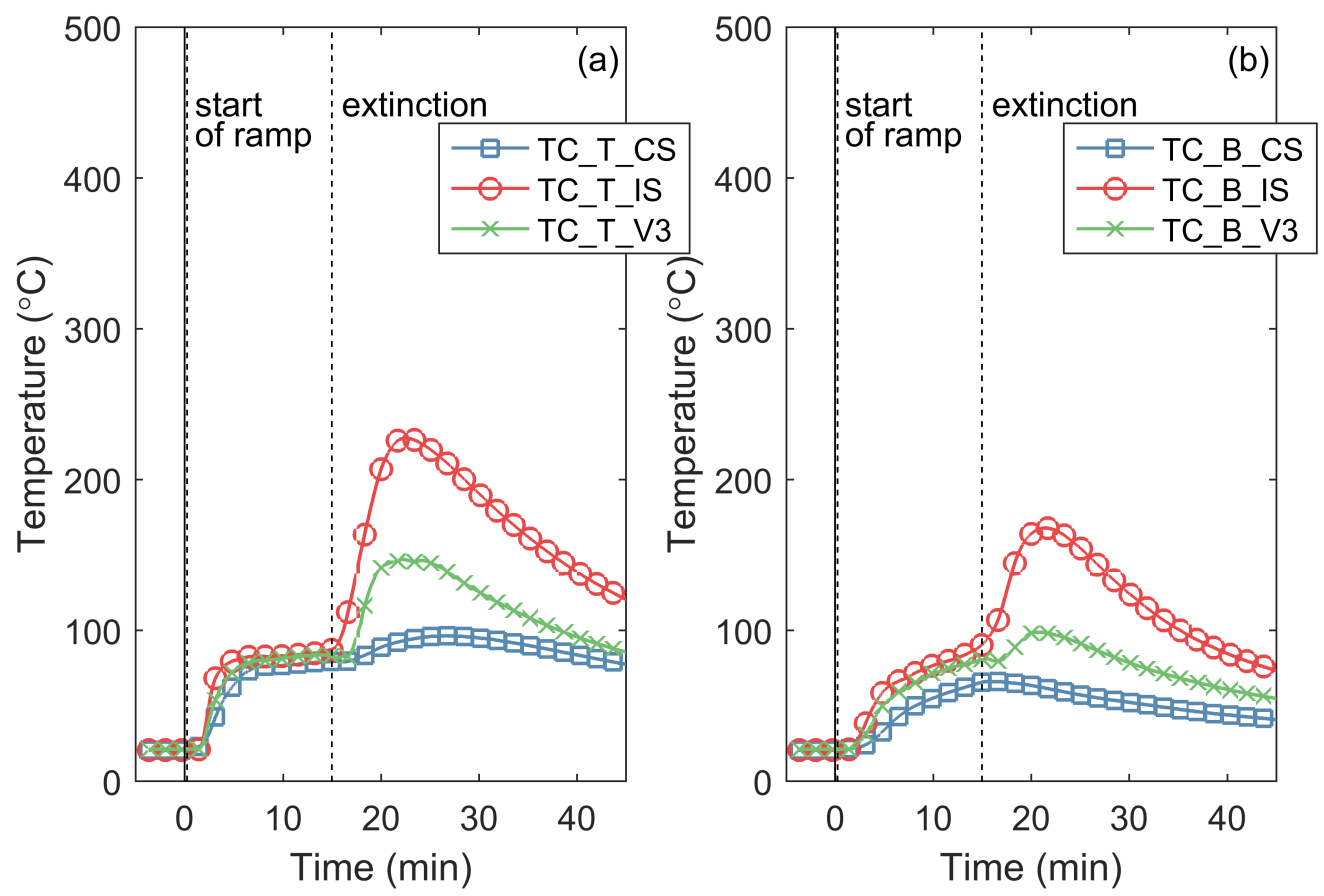

Fig. 163. SB03R - Temperatures of the framing and sheathing elements: (a) $46 \mathrm{~cm}$ from the top of the wall; (b) $46 \mathrm{~cm}$ from the bottom of the wall. 


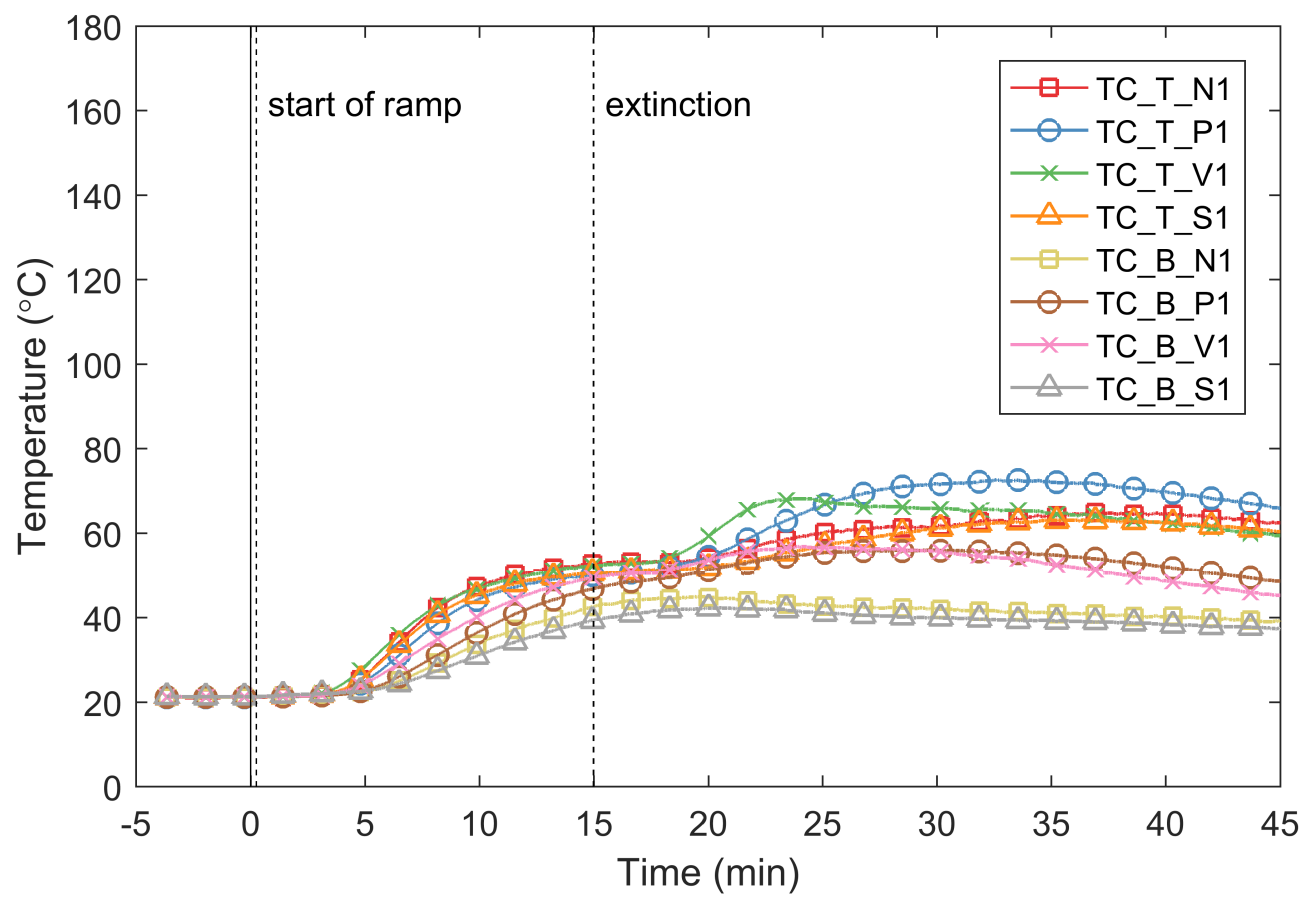

Fig. 164. SB03R - Temperatures of the gypsum on the unexposed side of the wall specimen.

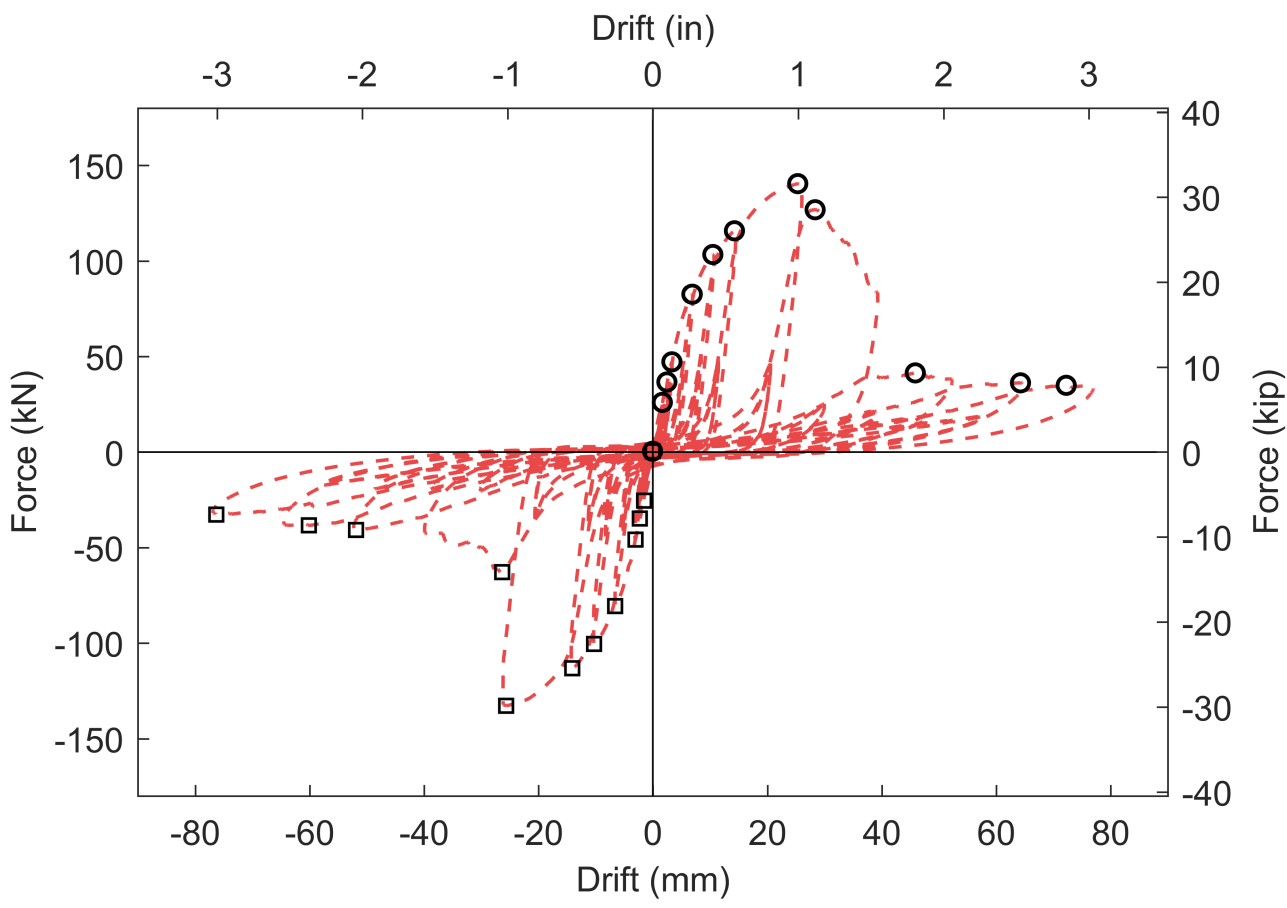

Fig. 165. SB03R - Applied load versus wall longitudinal drift during mechanical loading. 


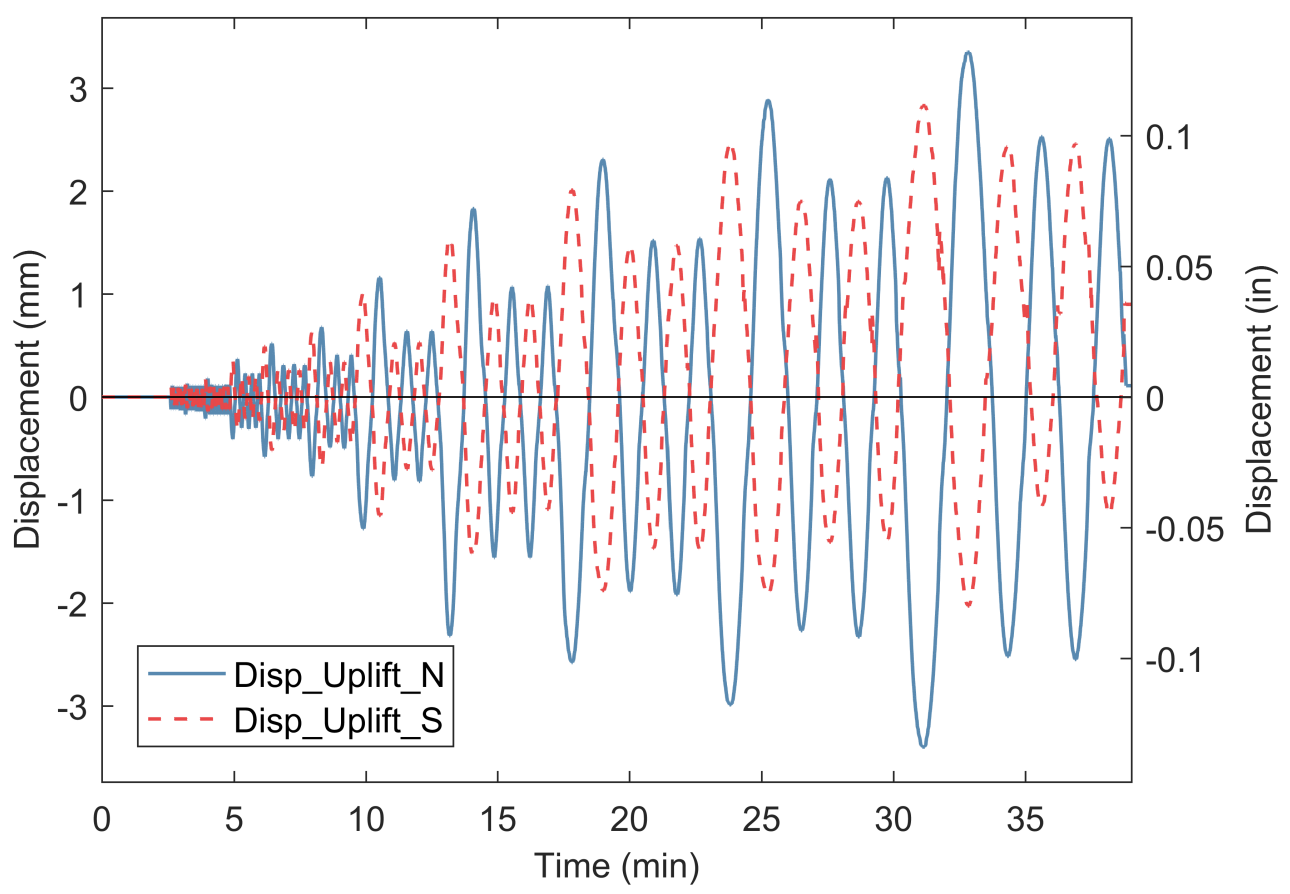

Fig. 166. SB03R - Uplift at bottom of wall during mechanical loading.

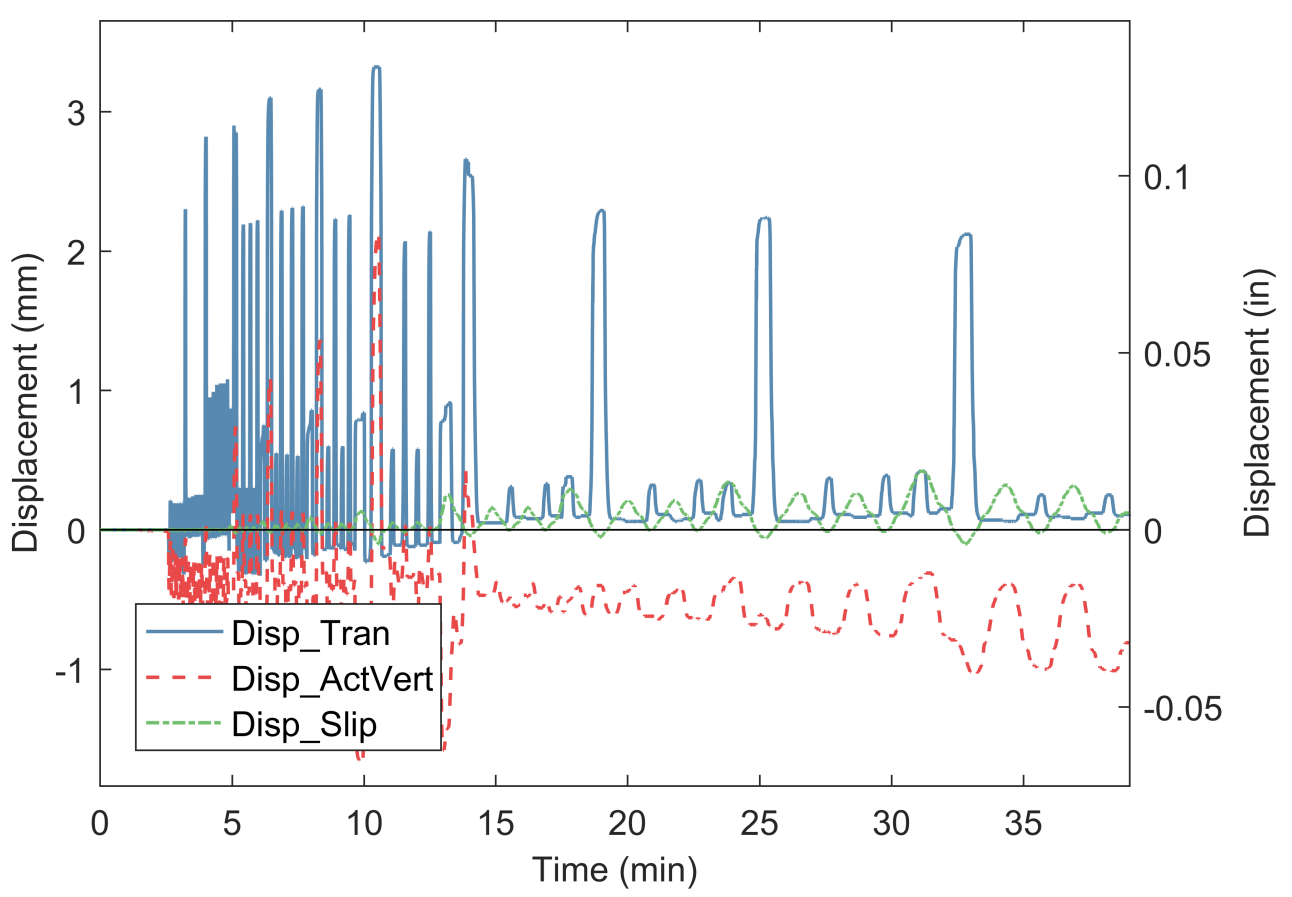

Fig. 167. SB03R - Ancillary displacement measurements during mechanical loading. 


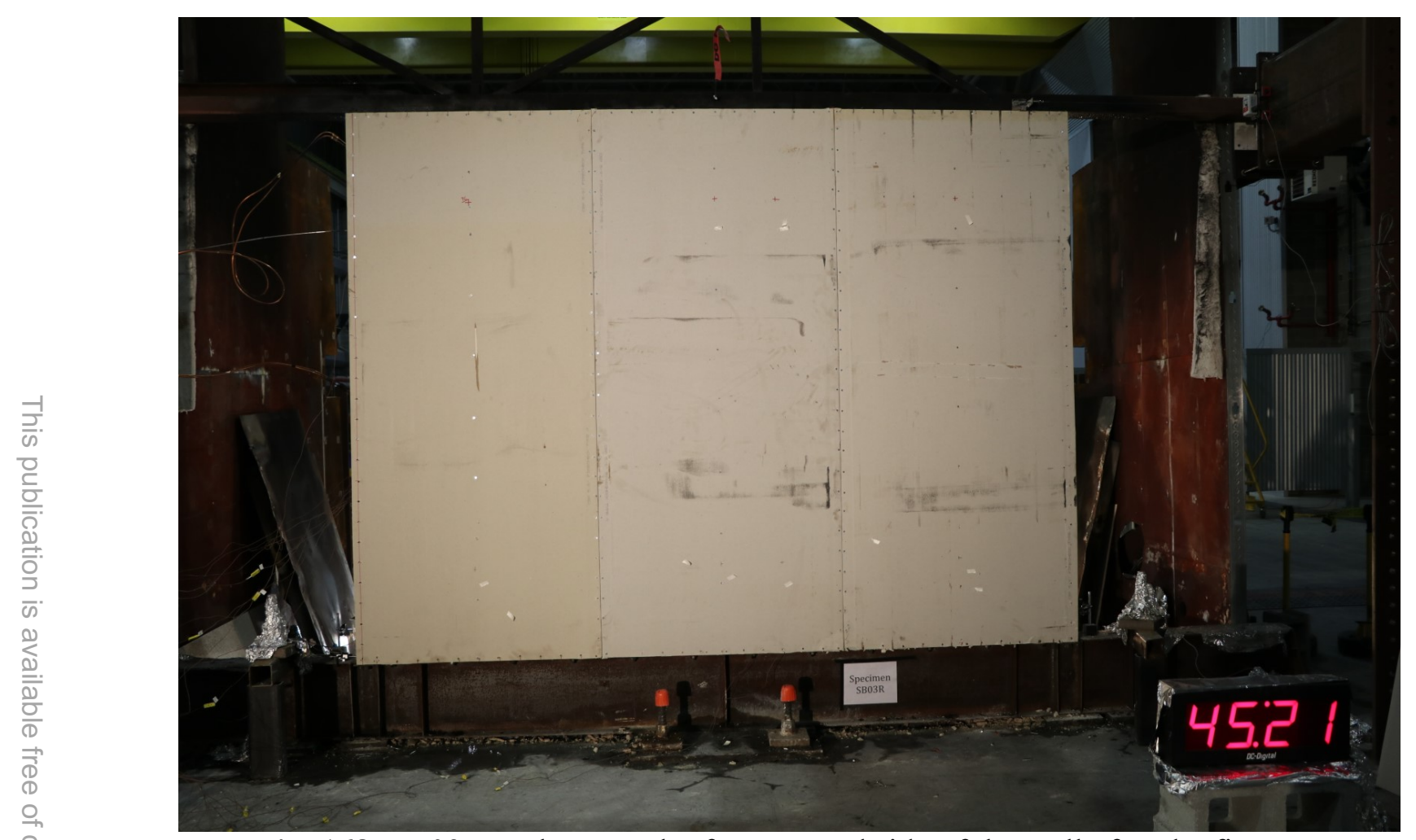

Fig. 168. SB03R - Photograph of unexposed side of the wall after the fire test.

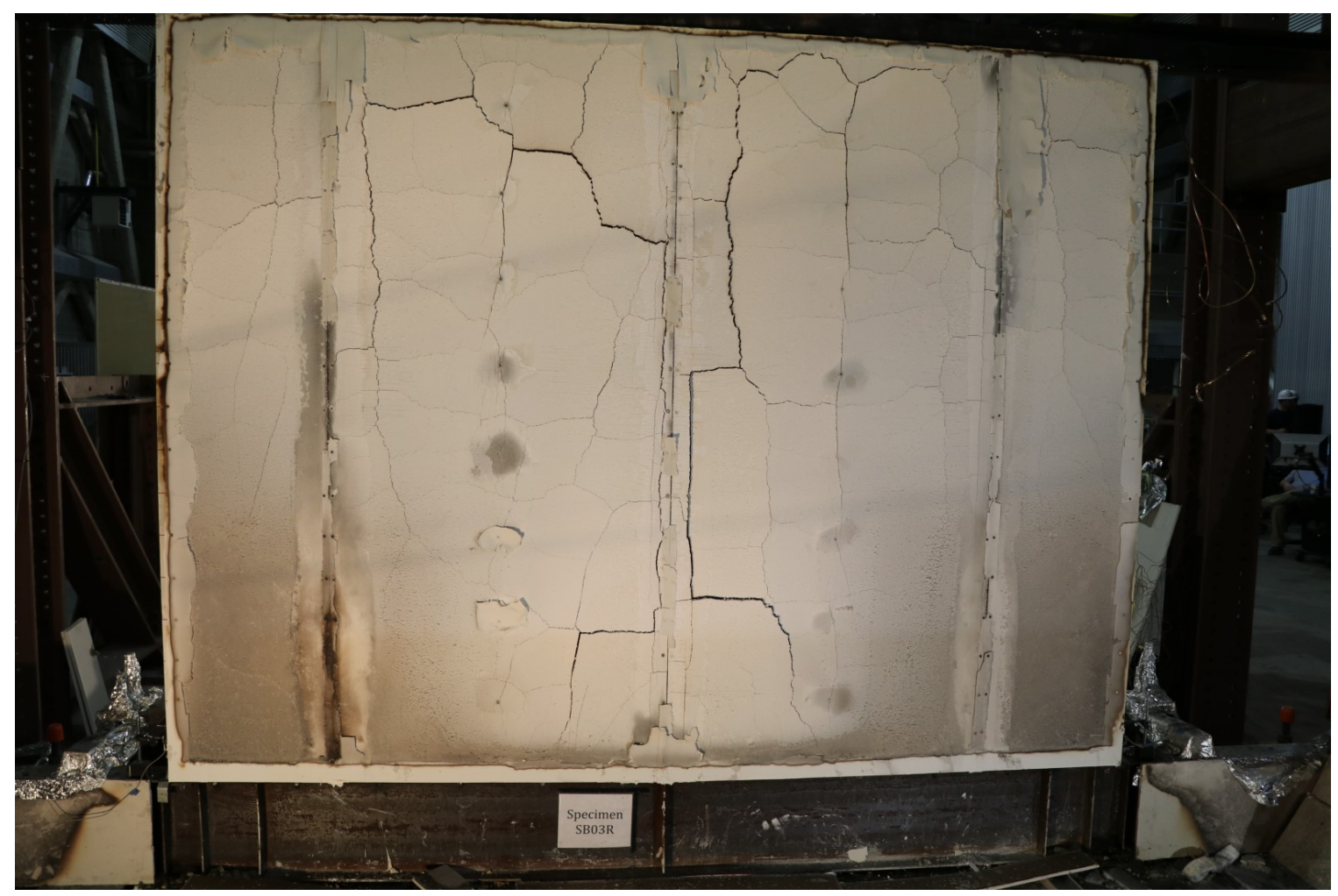

Fig. 169. SB03R - Photograph of fire exposed side of the wall after the fire test. 


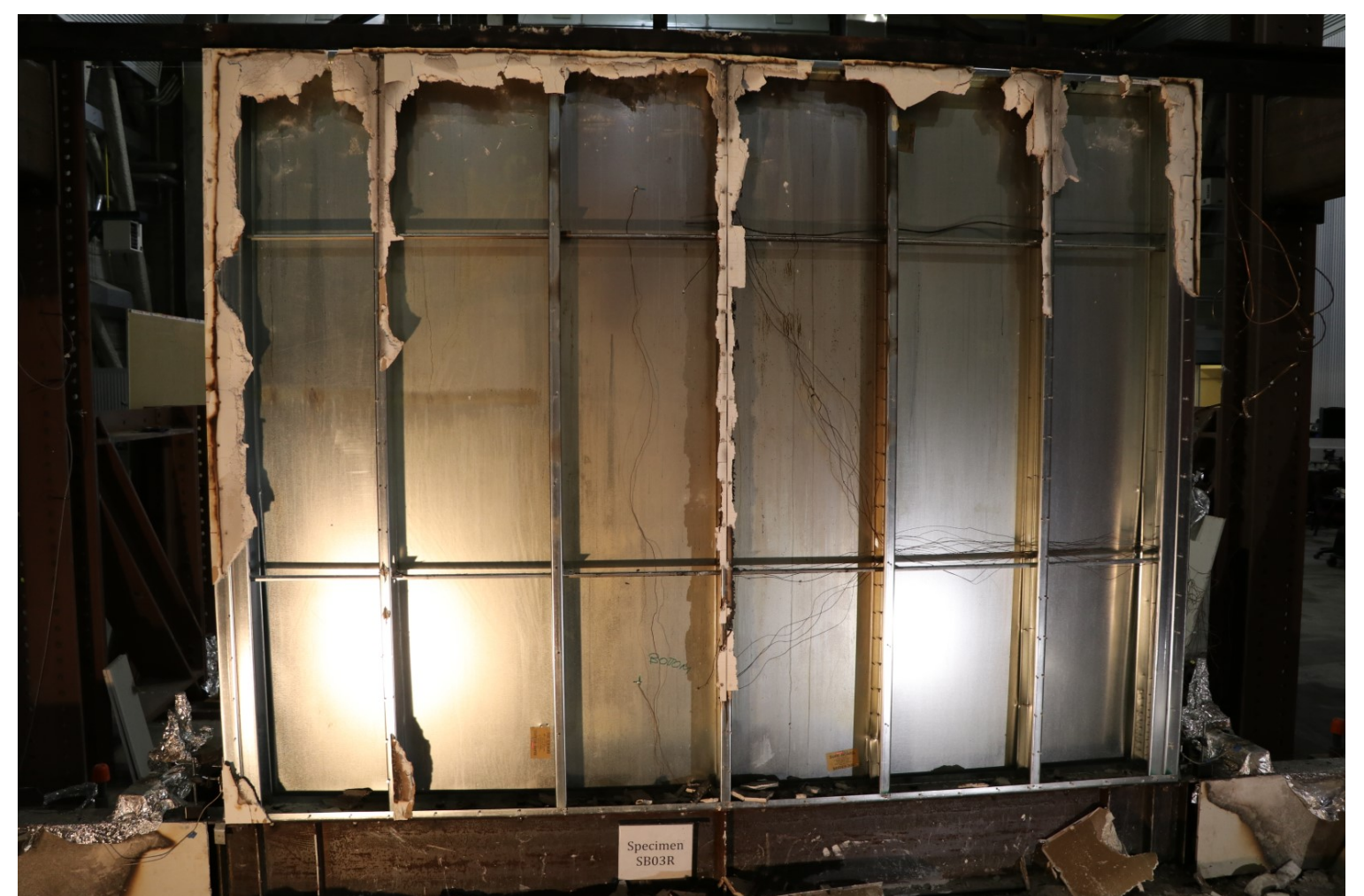

Fig. 170. SB03R - Photograph of exposed side of the wall (remaining drywall removed) after load cycling following the fire. 


\section{SB04 Data}

SB04b (Standard Fire test of an undamaged wall)

- A variable heat release rate, with peak value 1.4 MW in the gas burner, was used to approximate upper layer gas temperatures in ASTM E119 for 60 minutes (Fig. 171).

- A puddle formed at the bottom of the wall due to water evaporated from the gypsum that condensed on the sheet steel.

- The maximum temperature raise reached on the unexposed side was $133{ }^{\circ} \mathrm{C}$ from the initial temperature (Fig. 180). The ASTM E119 limit is $139^{\circ} \mathrm{C}$.

- Thermocouples TC_T_P1 and TC_B_V1 detached from the surface during the test (Fig. 180).

SB04c (Cyclic test of wall at ambient temperature following the Standard Fire)

- The failure mode was a combination of global buckling of the sheet steel and failure of the connections to the sheet steel. The effect of temperature distribution during the fire can be seen in the discoloration and melting of zinc on the sheet steel (Fig. 186). At the top center - heating was highest and oxidized the screws which failed early in the cycling, thus there was little buckling of the sheet steel here. At top south, heating was sufficient to destroy the adhesive, but the screws were less affected, and buckling of the sheet steel was observed. At bottom of wall the screws and adhesive were not affected by the heating.

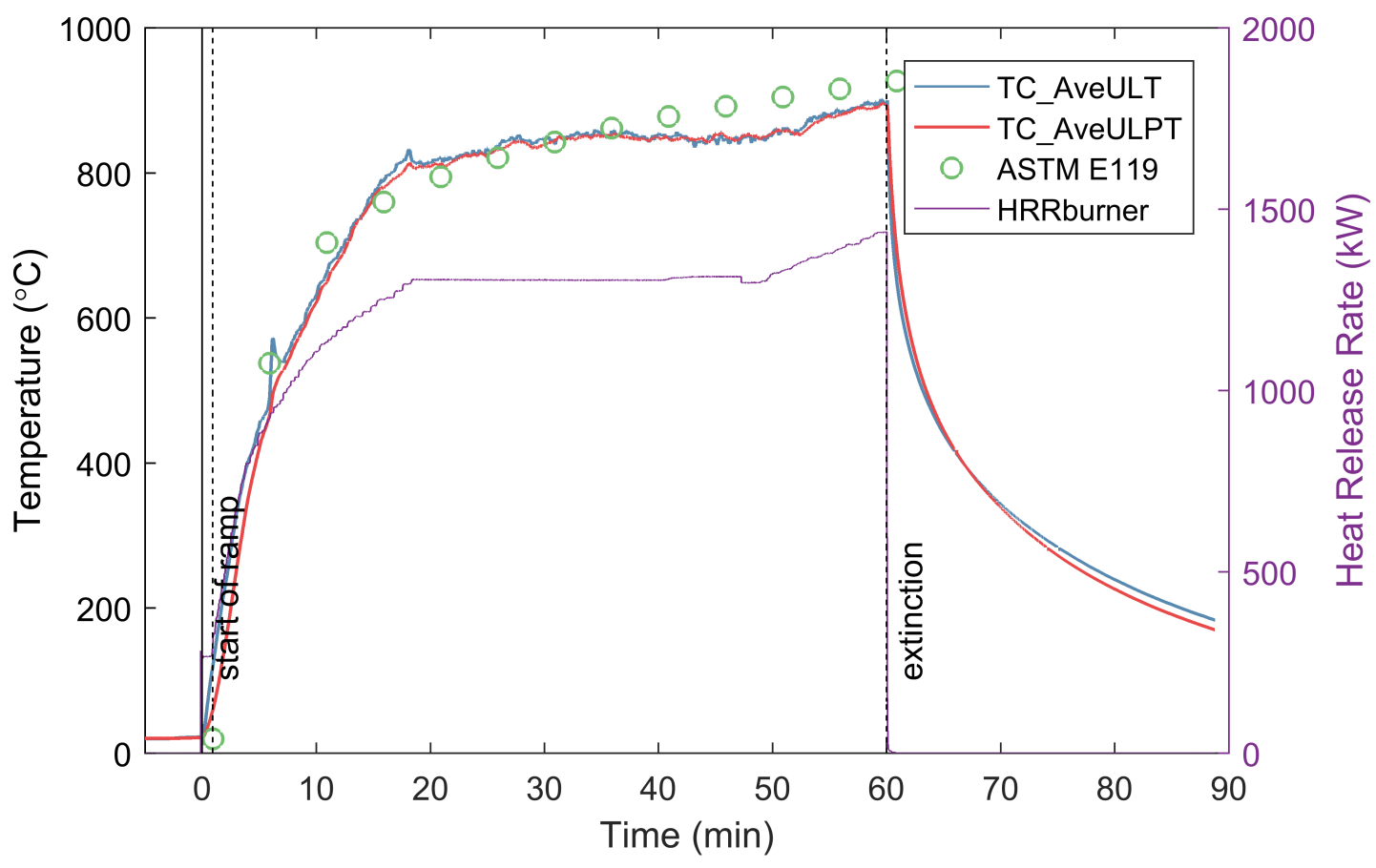

Fig. 171. SB04 - Compartment temperatures and burner Heat Release Rate. 


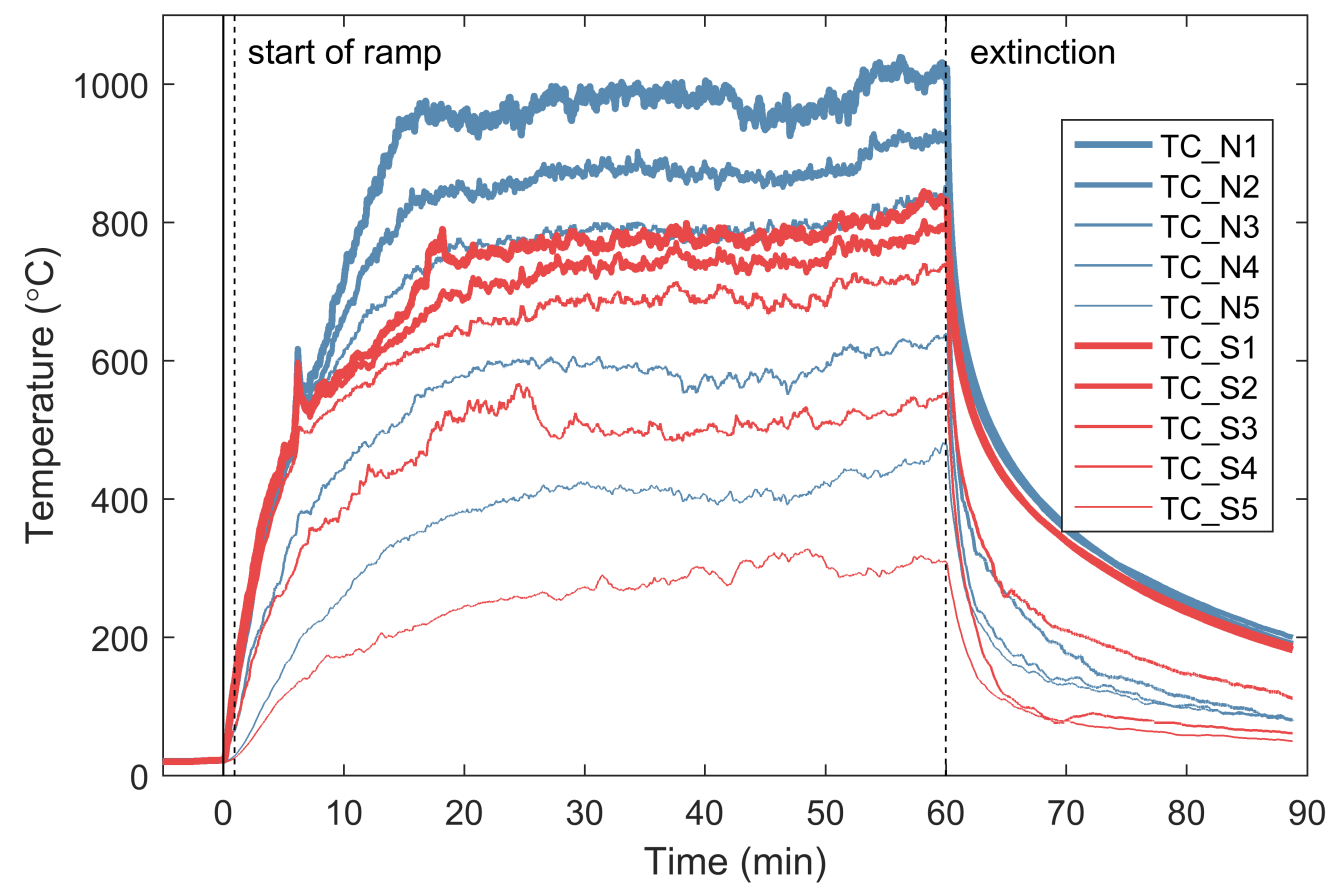

Fig. 172. SB04 - Compartment temperatures measured by the thermocouple arrays.

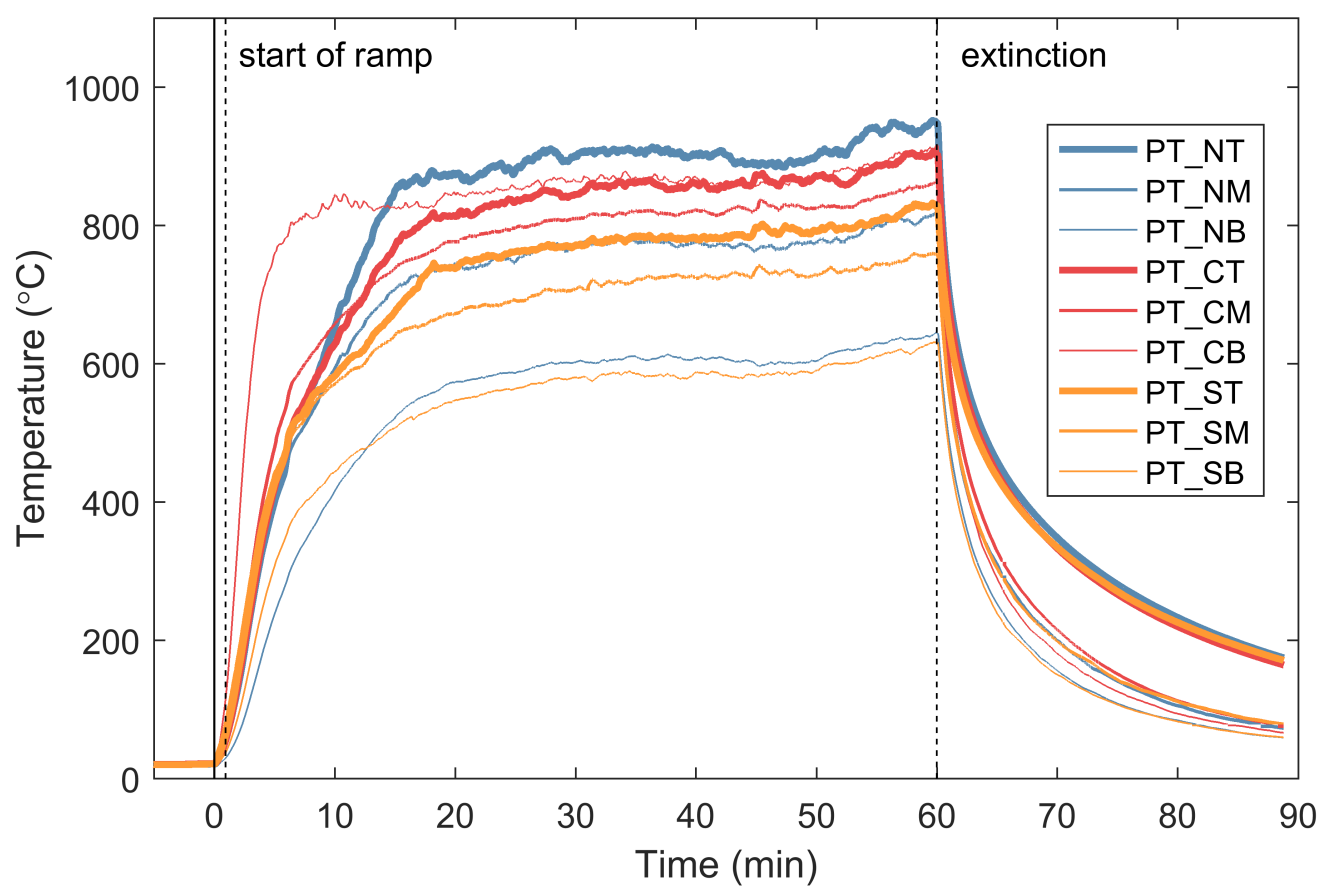

Fig. 173. SB04 - Compartment temperatures measured by the plate thermocouples. 


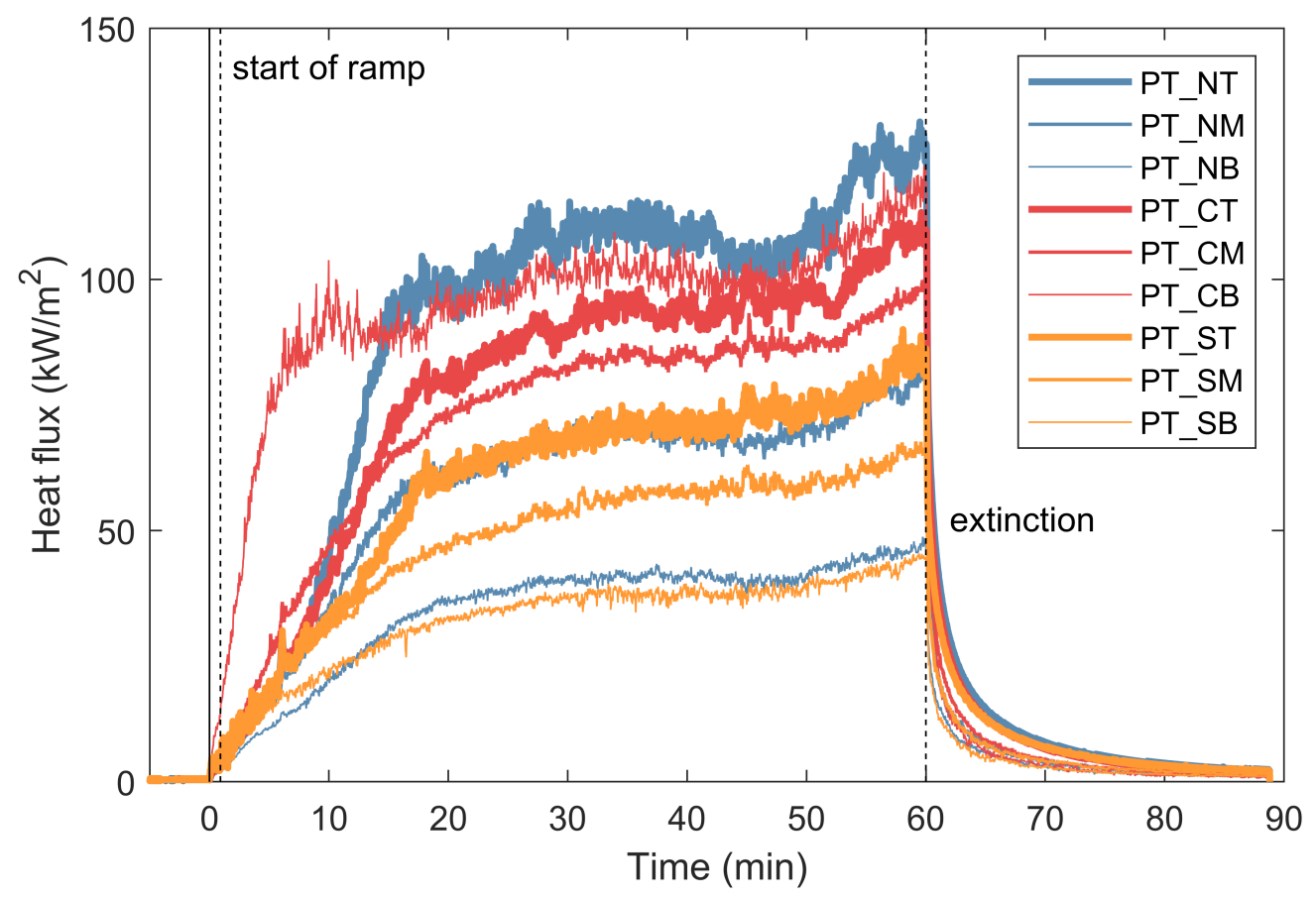

Fig. 174. SB04 - Heat fluxes in the compartment measured by the plate thermocouples.
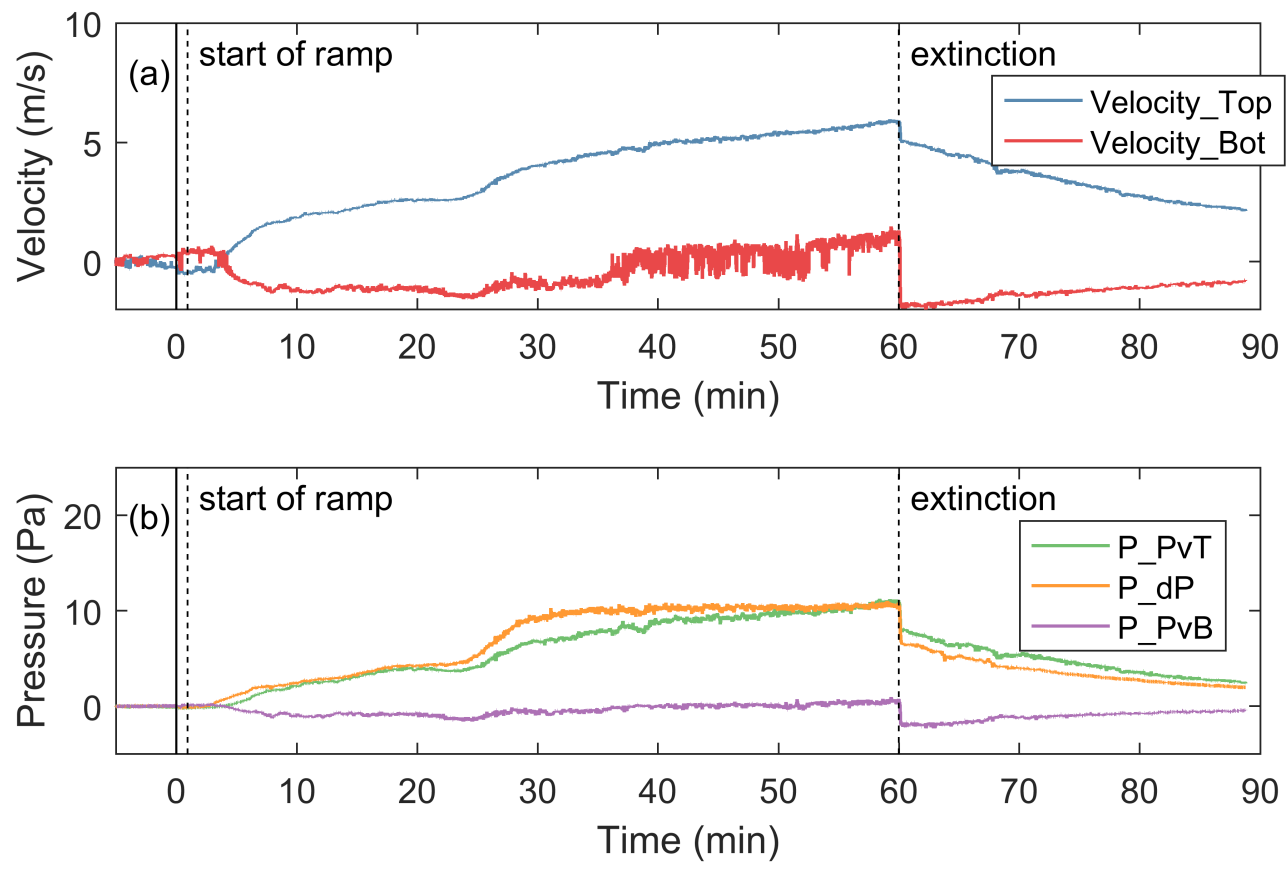

Fig. 175. SB04 - (a) Velocity of air flow at the top and bottom knockouts of the chord stud; (b) Pressure at the top and bottom knockouts of the chord stud and in the wall cavity near the top. 


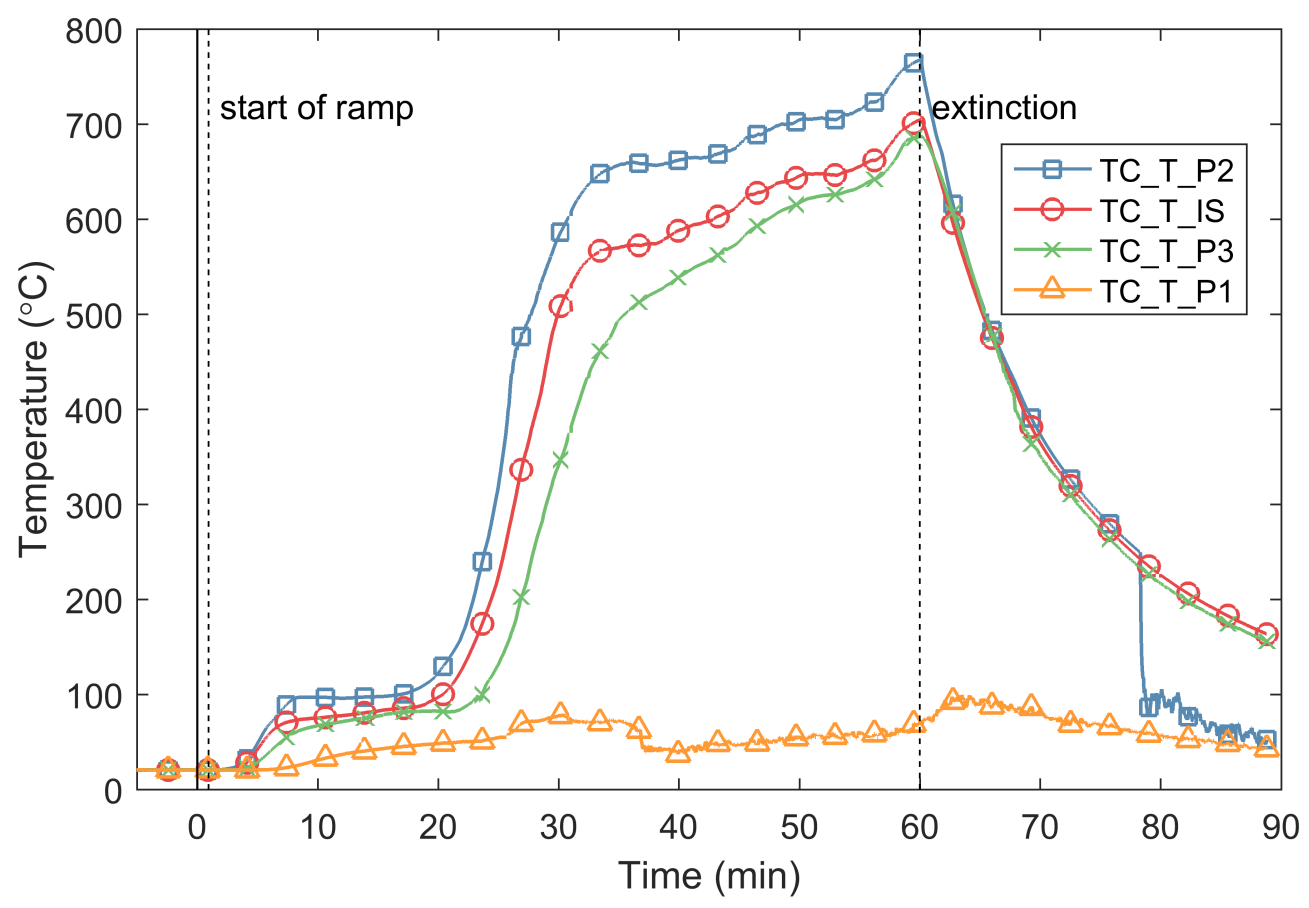

Fig. 176. SB04 - Temperatures through the specimen at an interior stud $46 \mathrm{~cm}$ from the top of the wall.

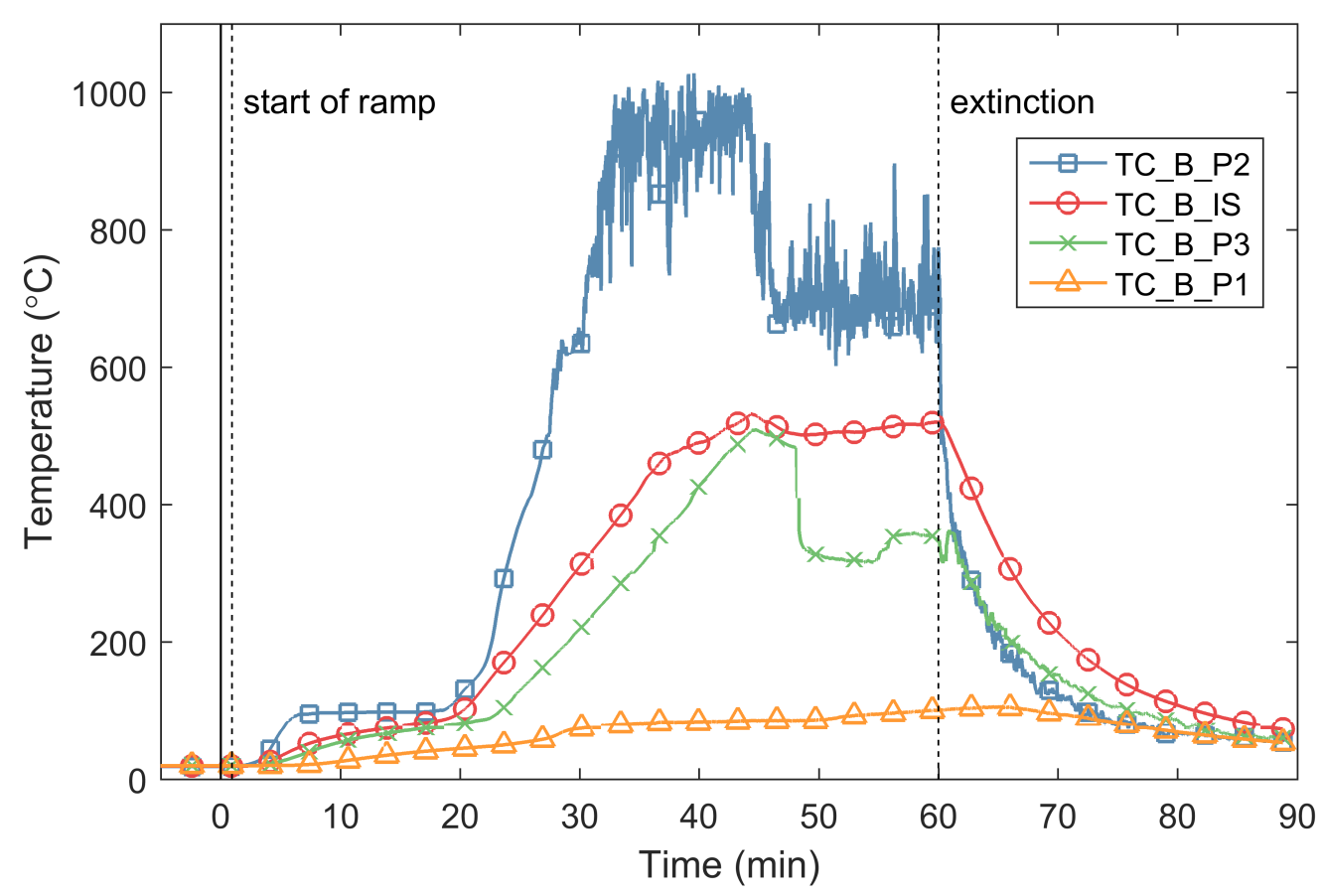

Fig. 177. SB04 - Temperatures through the specimen at an interior stud $46 \mathrm{~cm}$ from the bottom of the wall. 

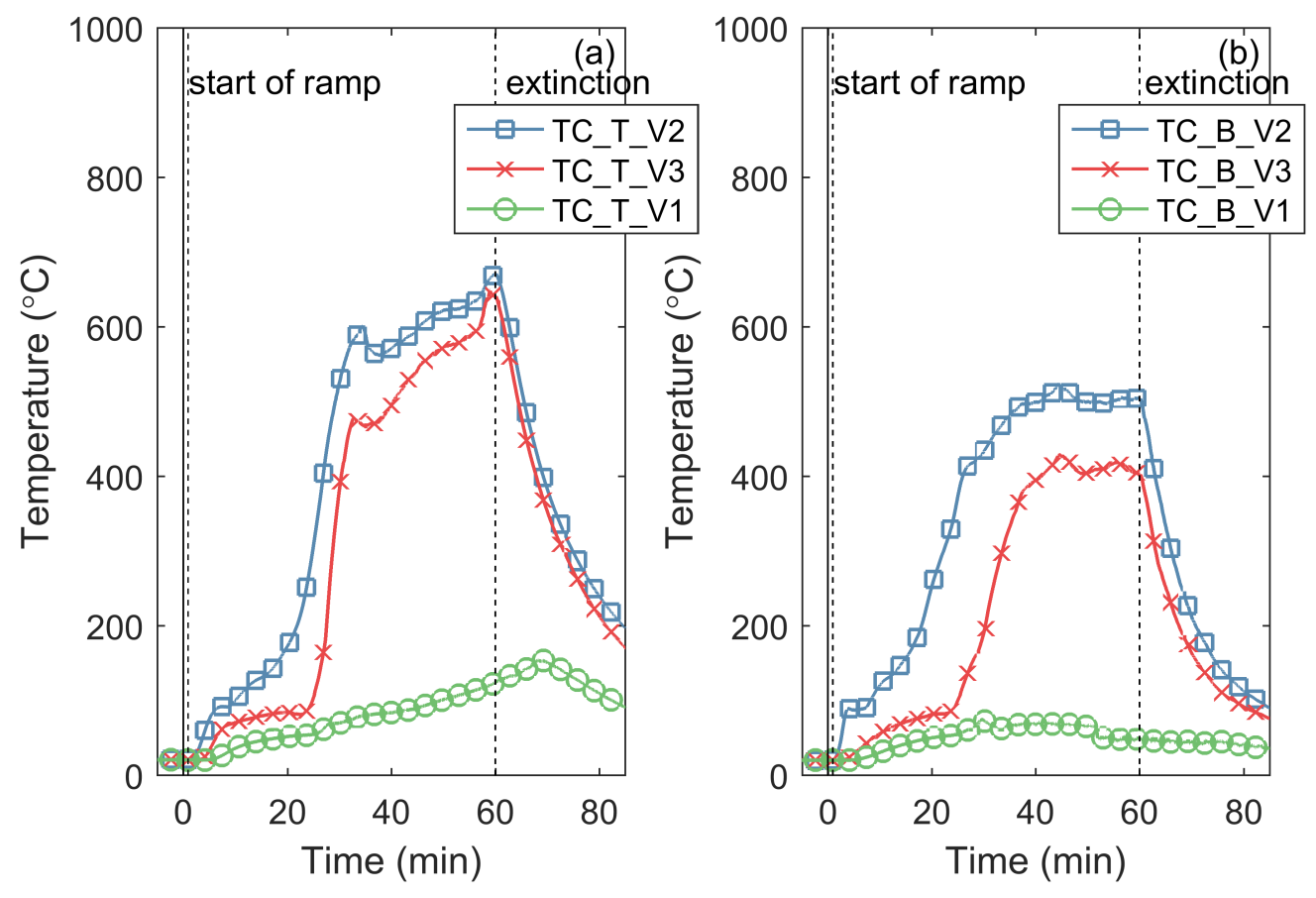

Fig. 178. SB04 - Temperatures through the specimen midway between interior studs: (a) $46 \mathrm{~cm}$ from the top of the wall; (b) $46 \mathrm{~cm}$ from the bottom of the wall.

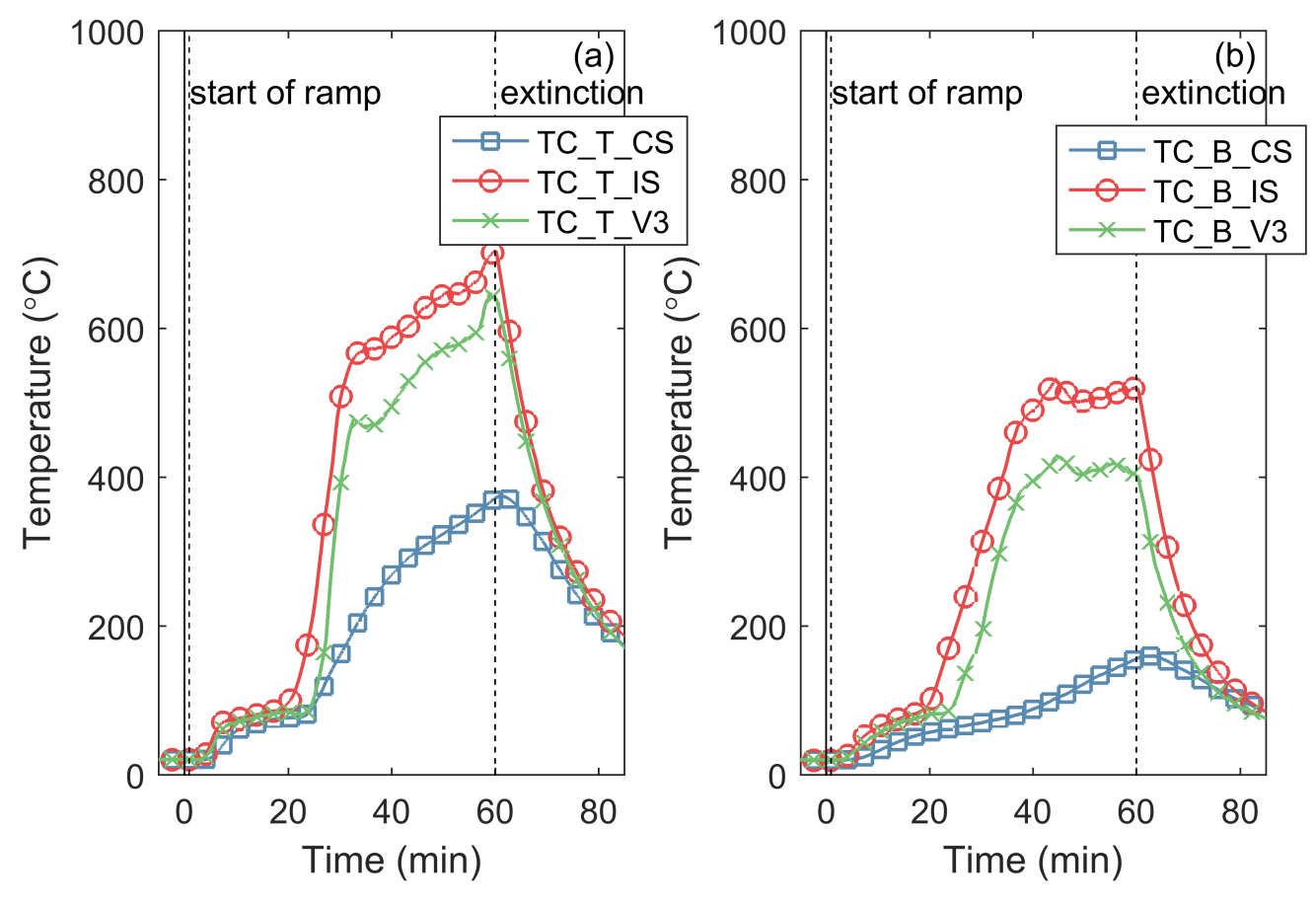

Fig. 179. SB04 - Temperatures of the framing and sheathing elements: (a) $46 \mathrm{~cm}$ from the top of the wall; (b) $46 \mathrm{~cm}$ from the bottom of the wall. 


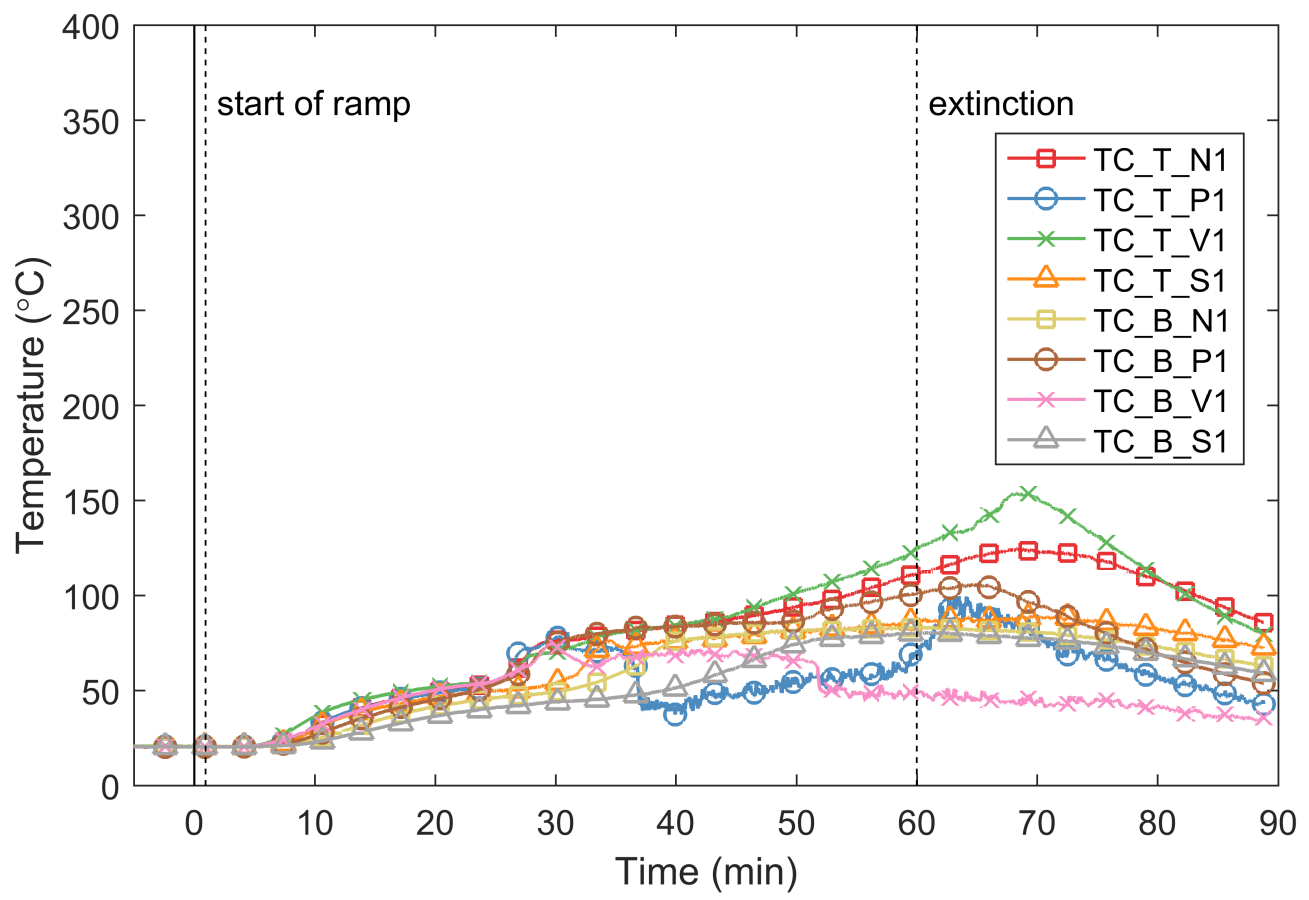

Fig. 180. SB04 - Temperatures of the gypsum on the unexposed side of the wall specimen.

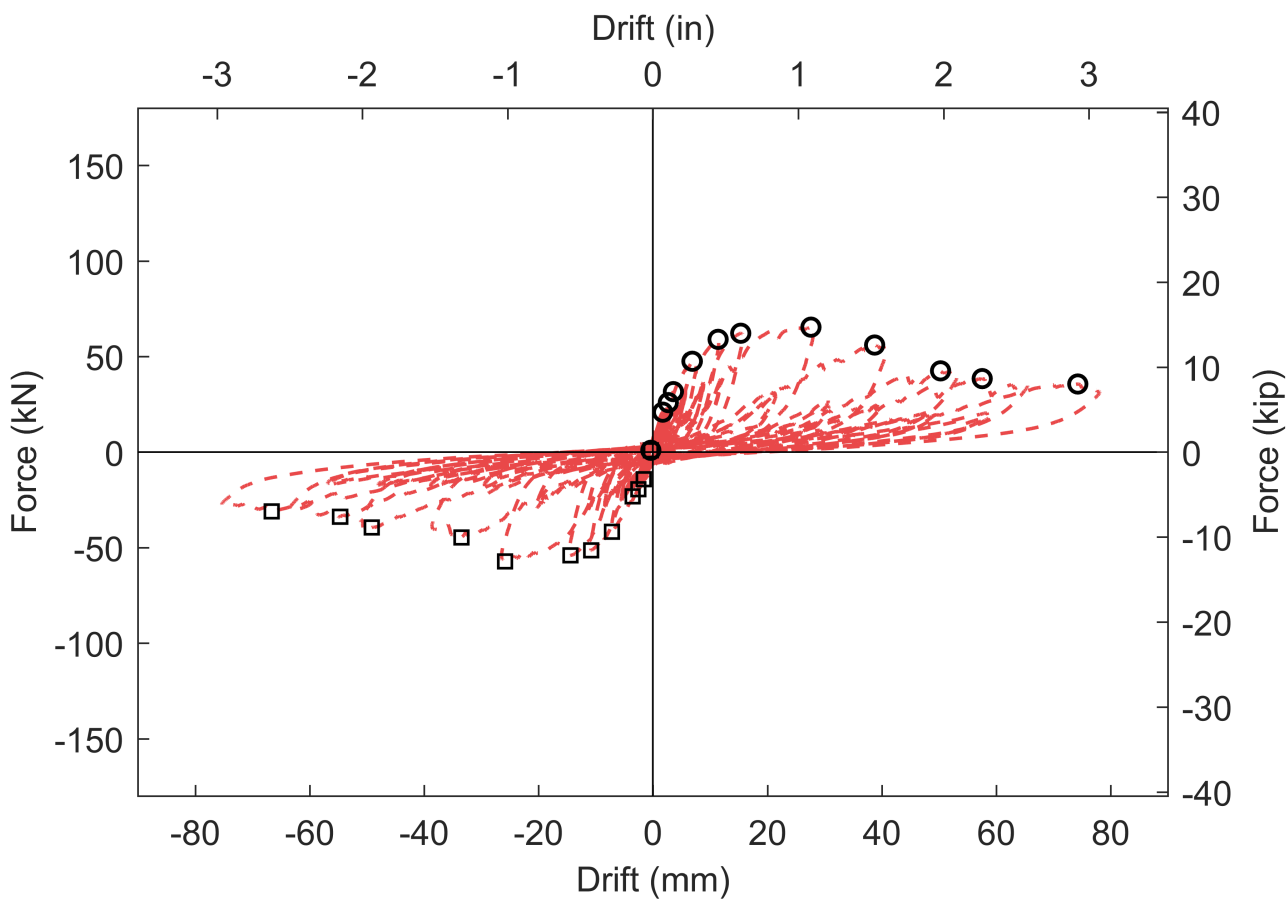

Fig. 181. SB04 - Applied load versus wall longitudinal drift during mechanical loading. 


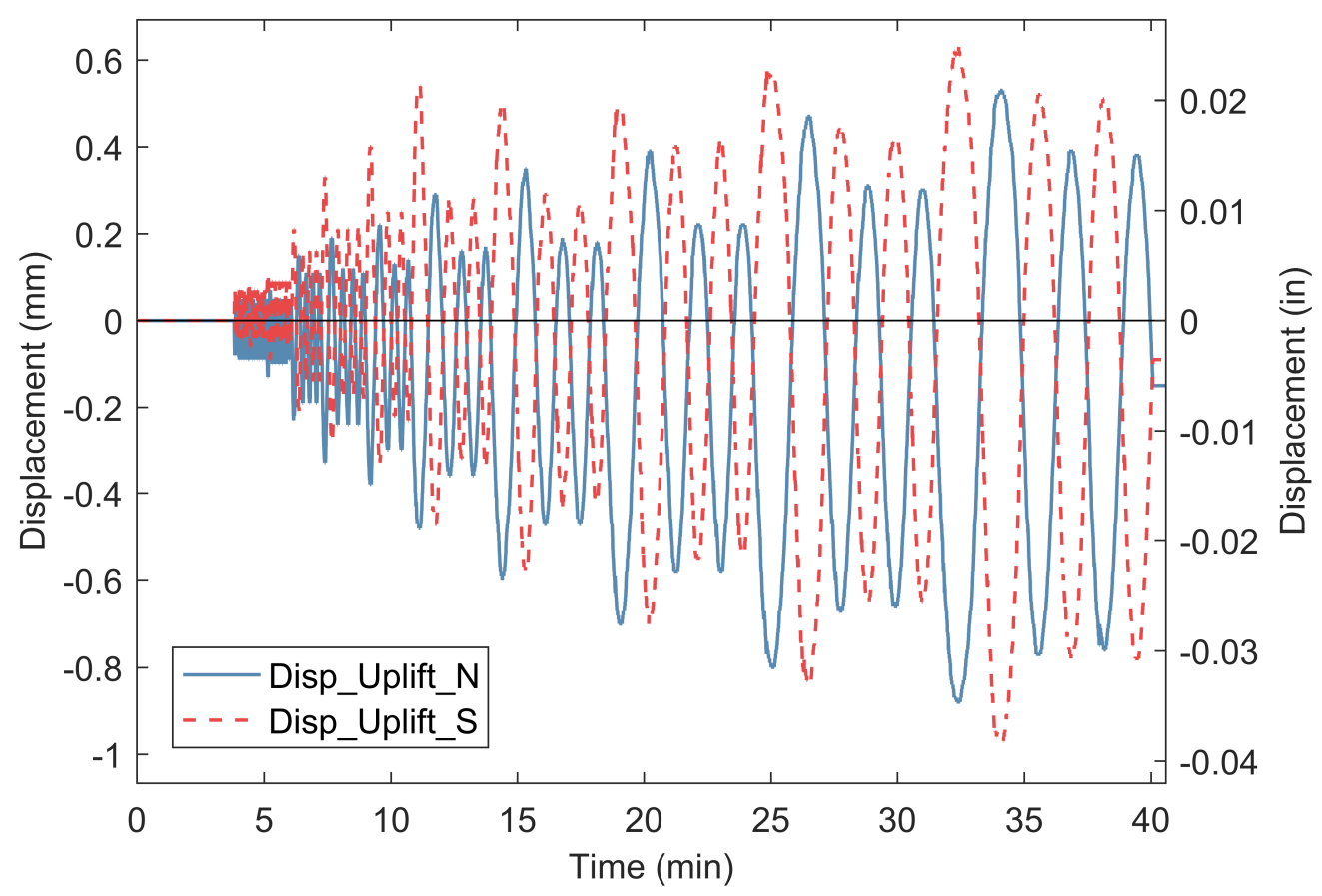

Fig. 182. SB04 - Uplift at bottom of wall during mechanical loading.

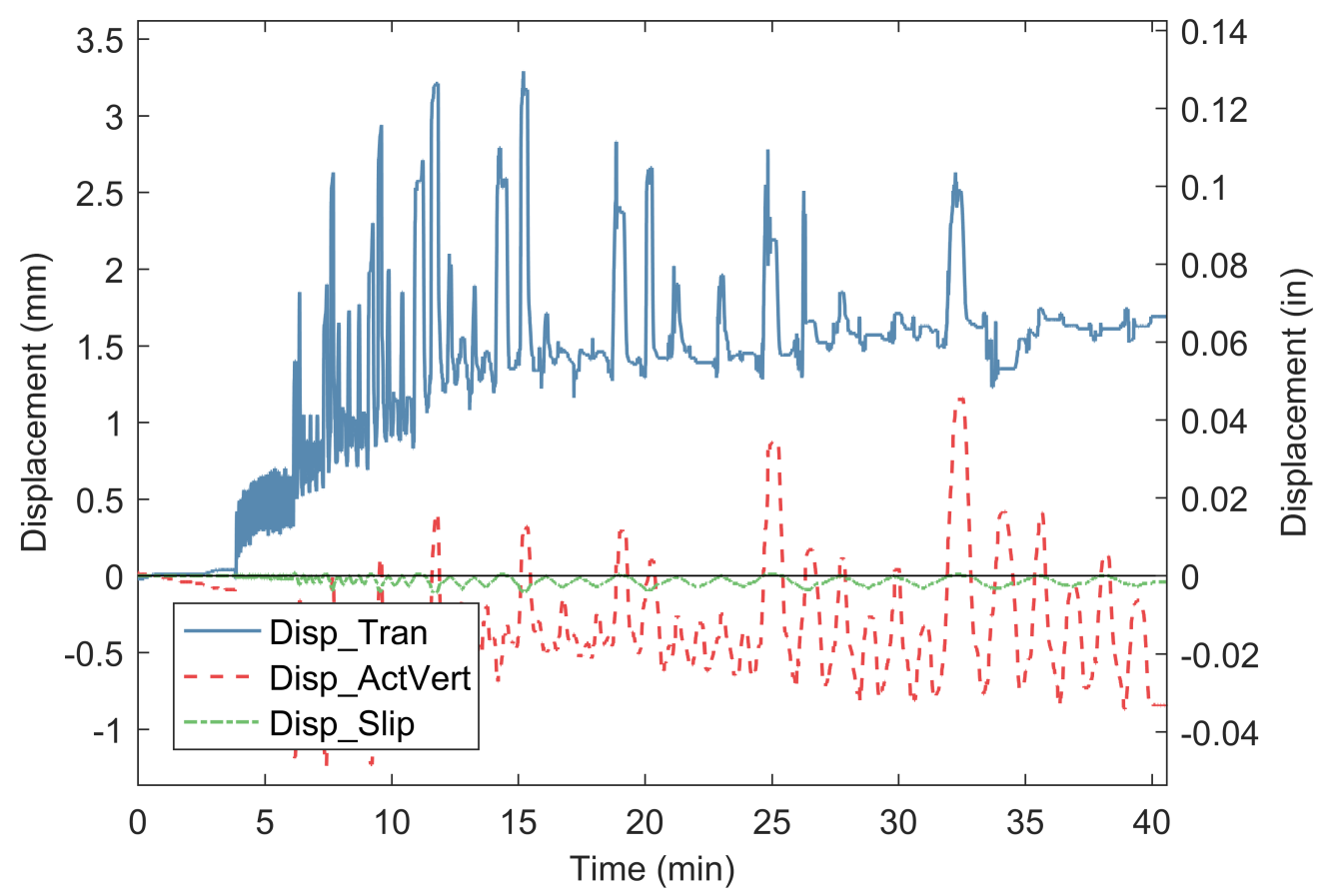

Fig. 183. SB04 - Ancillary displacement measurements during mechanical loading. 


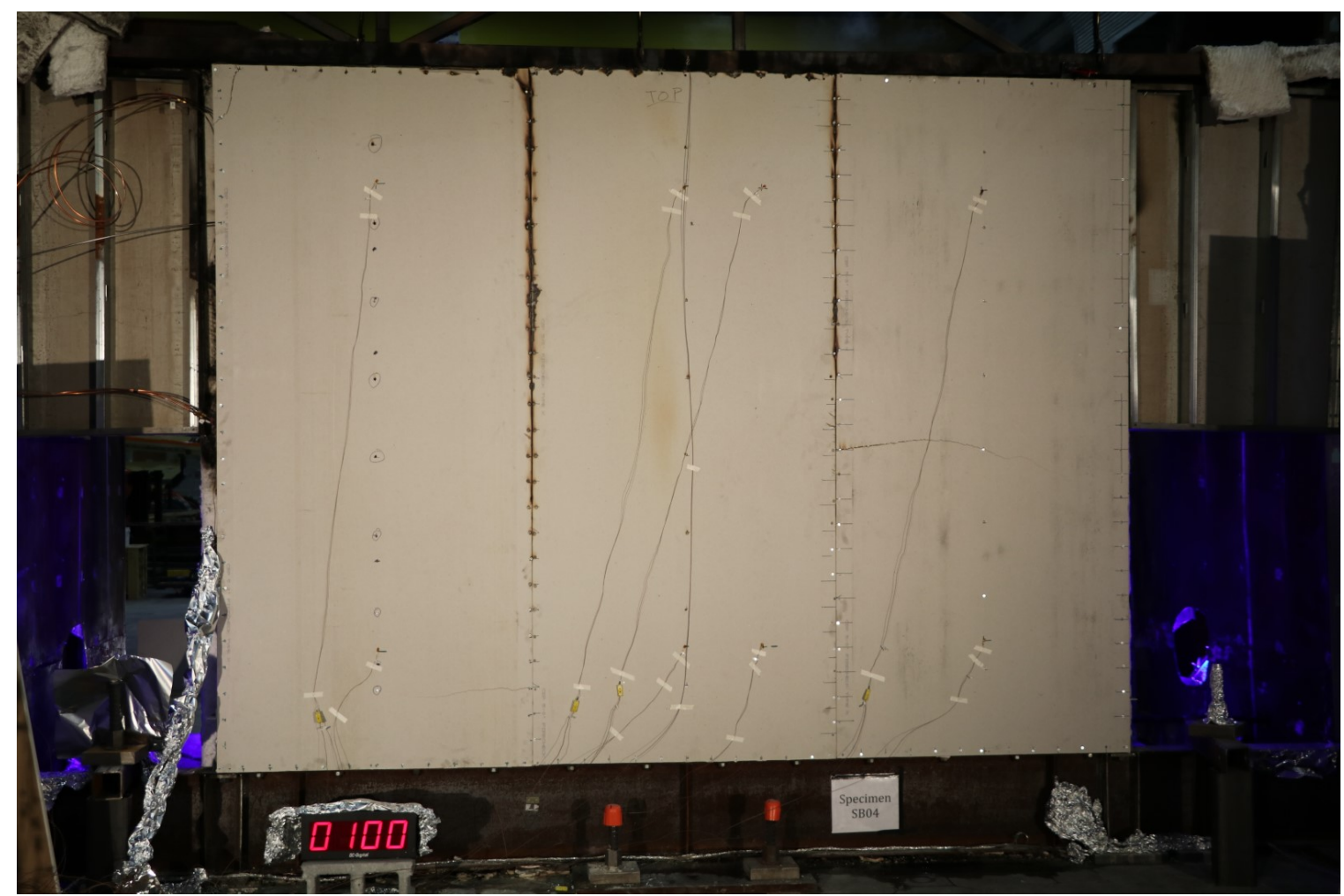

Fig. 184. SB04 - Photograph of unexposed side of the wall after the fire test.

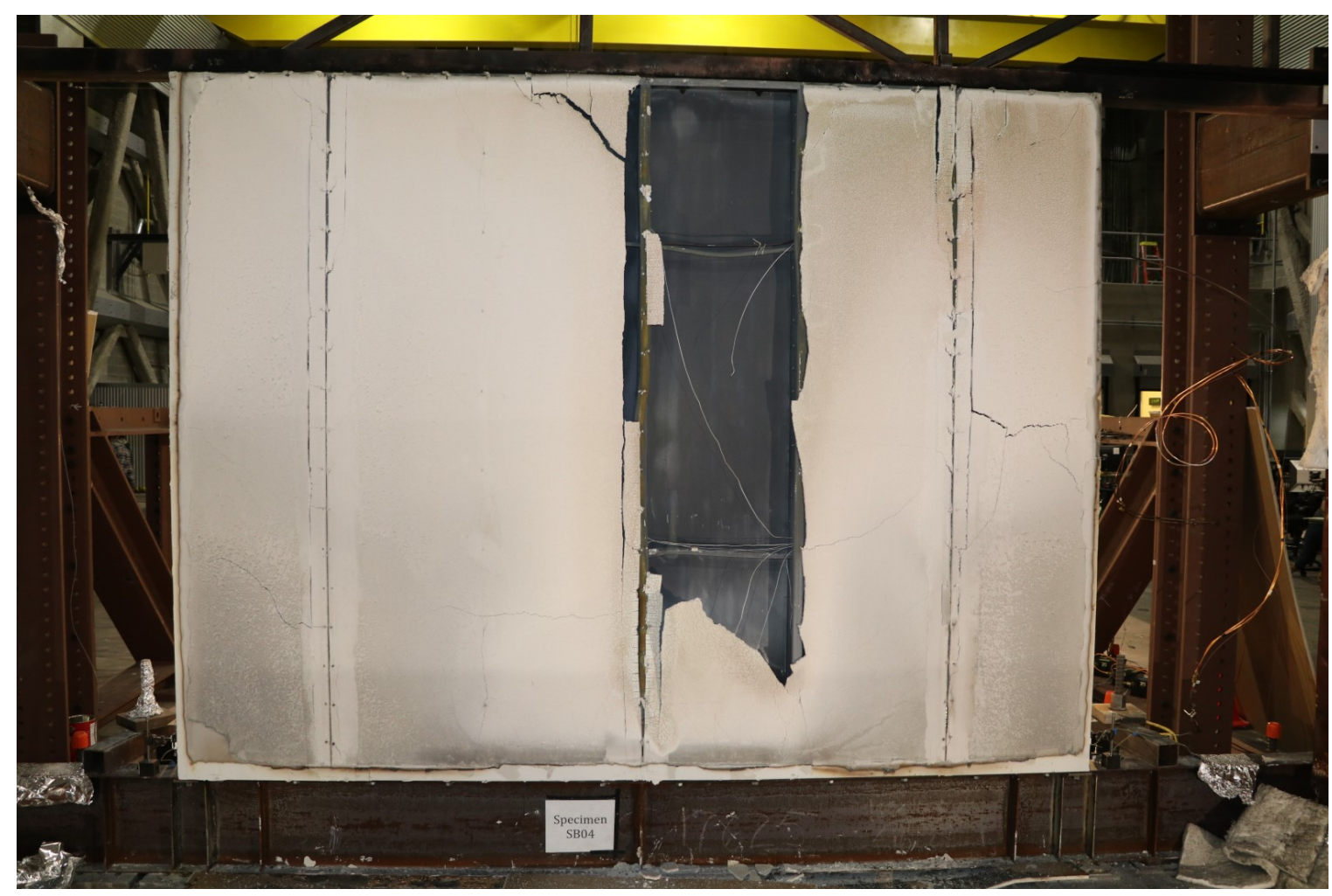

Fig. 185. SB04 - Photograph of fire exposed side of the wall after the fire test. 


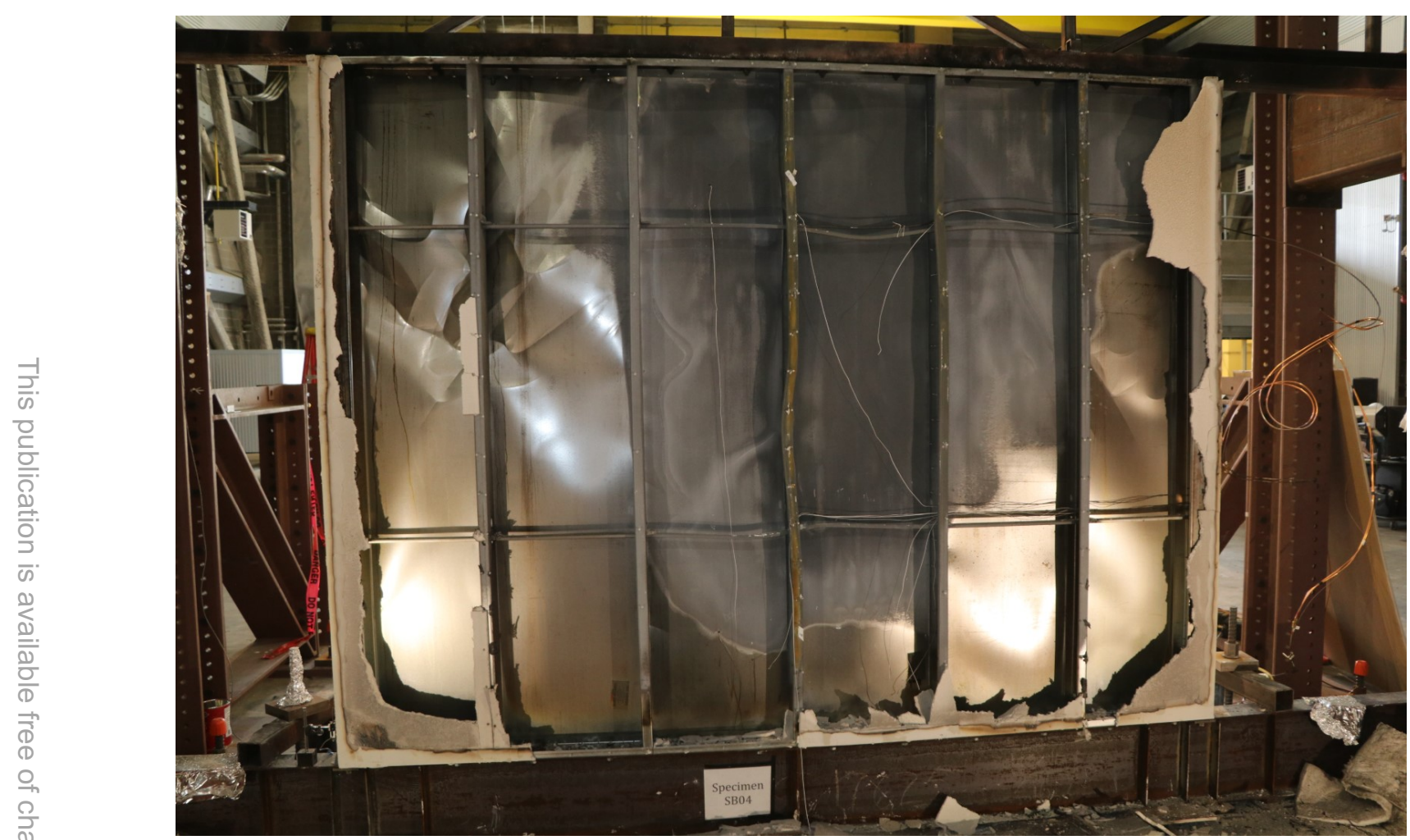

Fig. 186. SB04 - Photograph of fire exposed side of the wall (remaining nonstructural drywall removed) after load cycling following the fire.

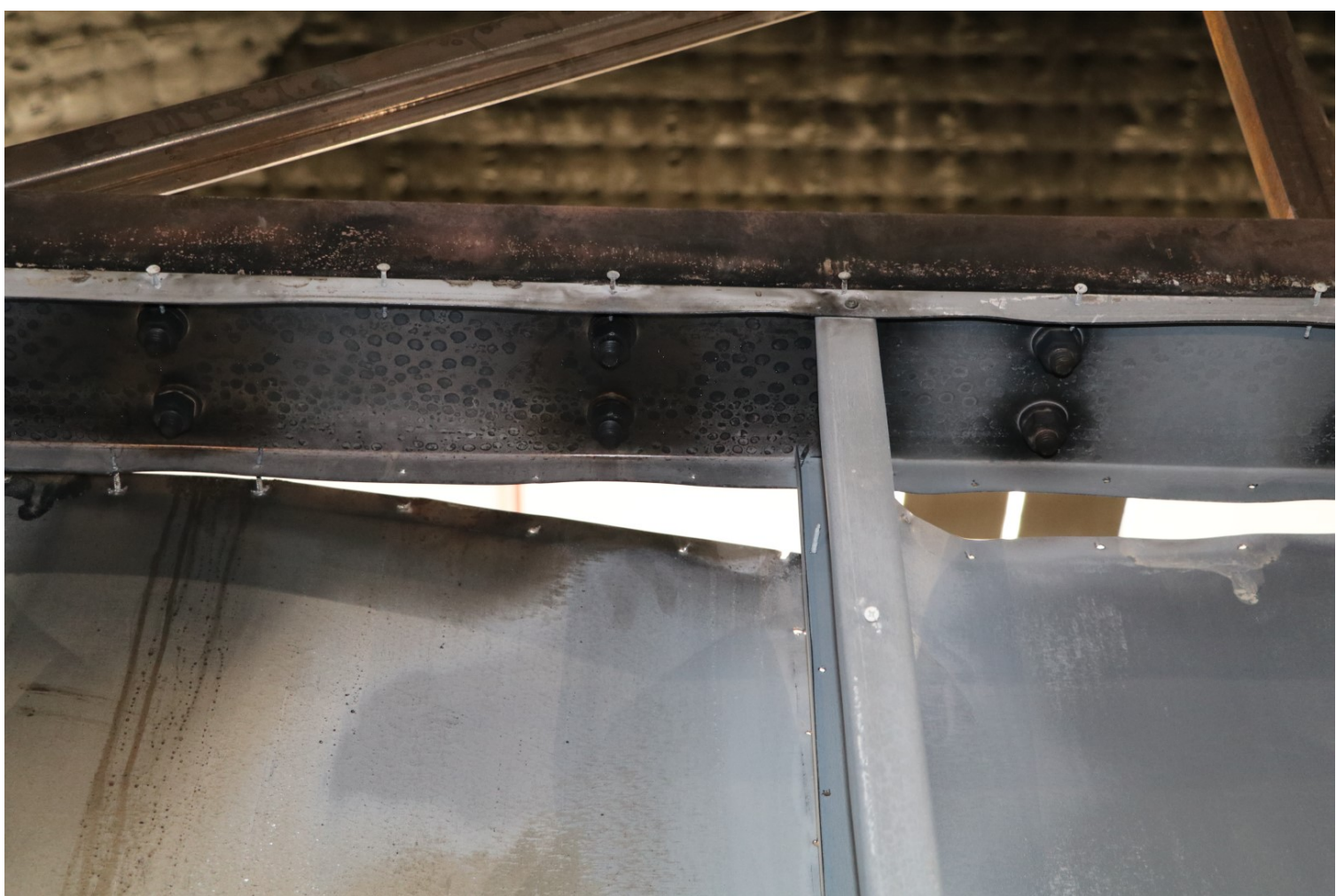

Fig. 187. SB04 - Photograph of connection failure after load cycling following the fire. 


\section{Appendix F: Test Data for Oriented Strand Board Sheathed Walls}

\section{OSB01 Data}

OSB01a (Cyclic test of undamaged wall at ambient temperature)

- Screws pulled though the OSB or caused edge breakout of OSB leading to failure. Very little visible damage to drywall on either side of the wall (Fig. 194).

- A $3 \mathrm{~mm}\left(1 / 8\right.$ ") gap between OSB boards was maintained. A $12 \mathrm{~mm}\left(1 / 2^{\text {" }}\right)$ spacing between the screw and edge of OSB was not maintained at all locations.

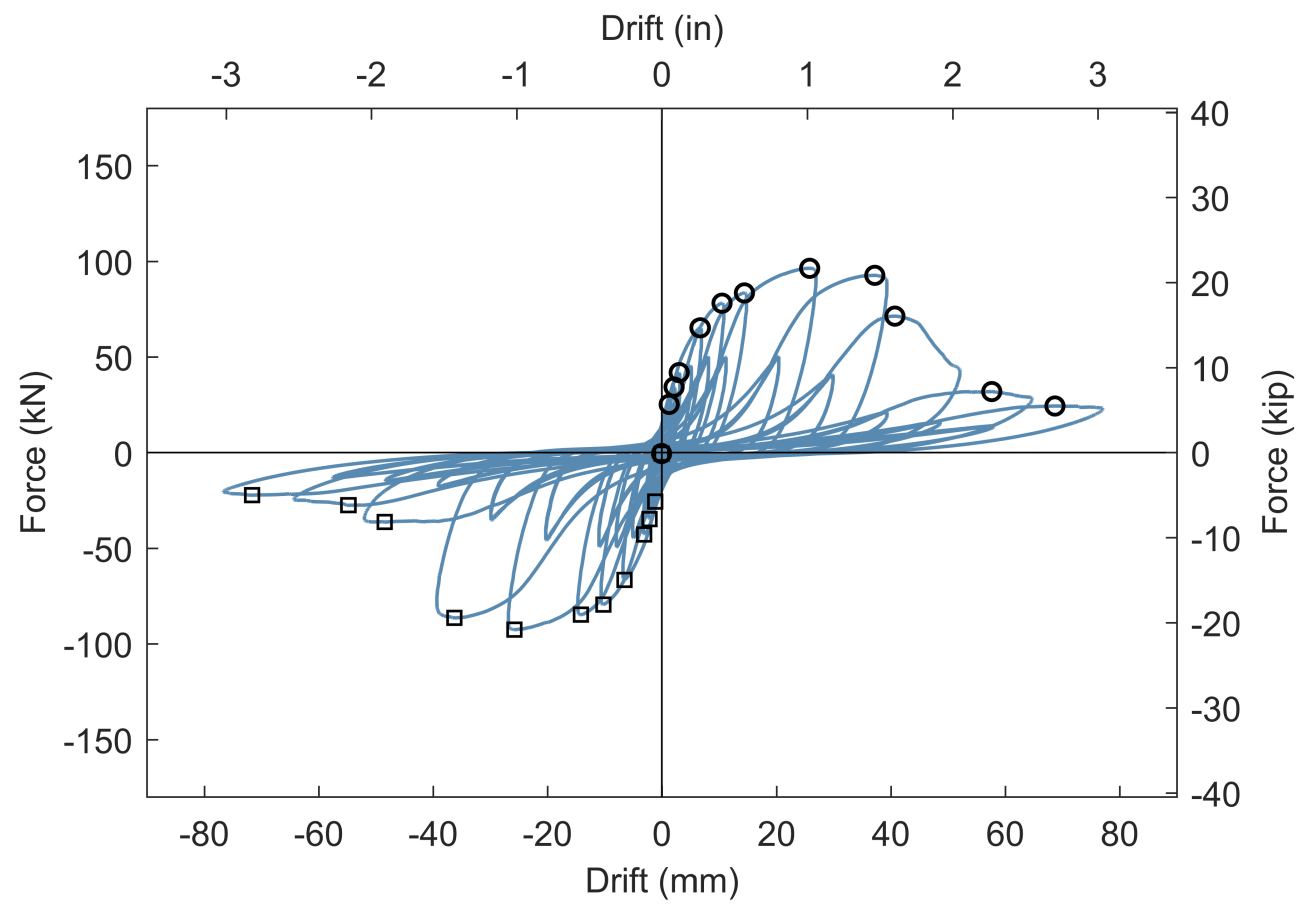

Fig. 188. OSB01 - Applied load versus wall longitudinal drift during mechanical loading. 


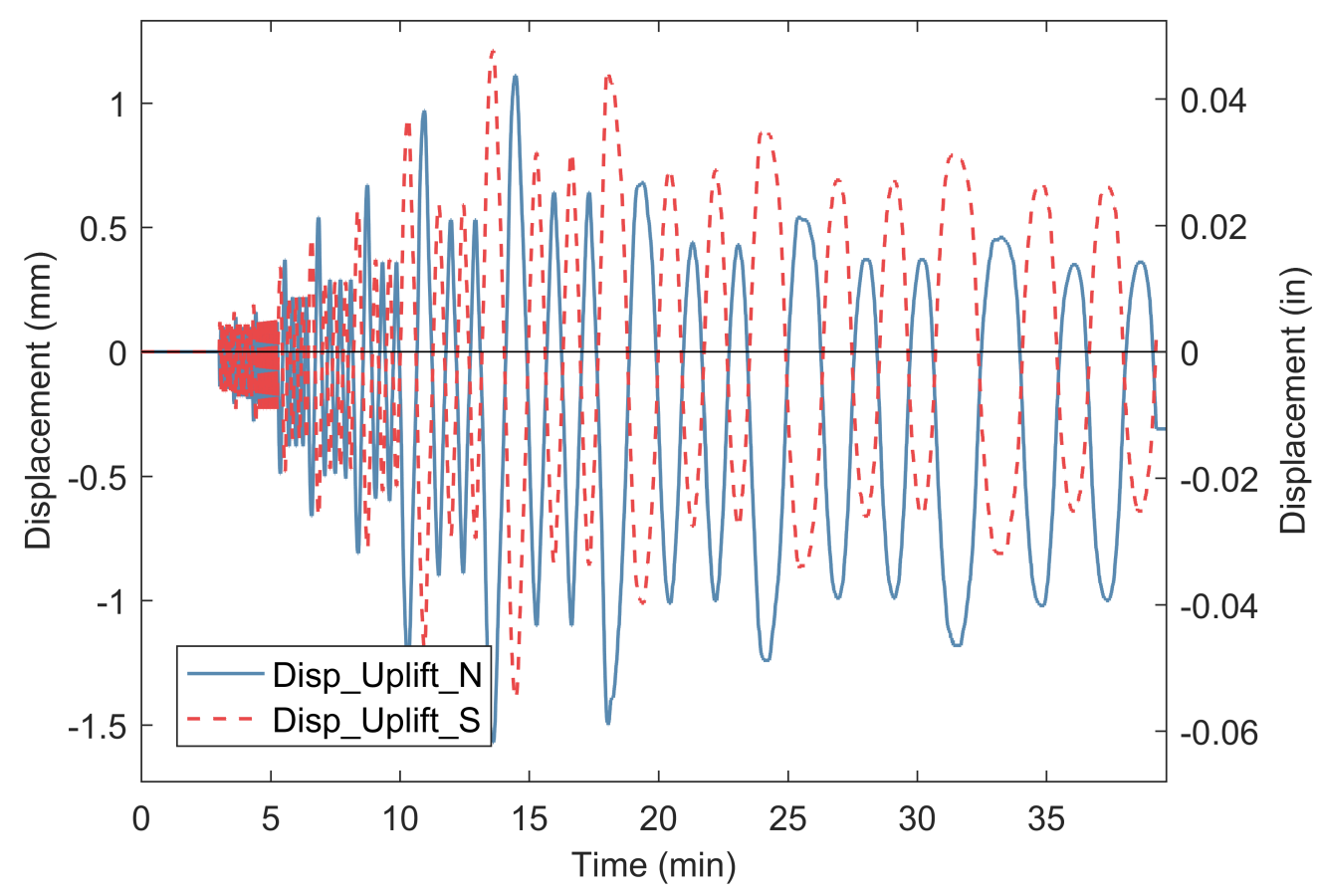

Fig. 189. OSB01 - Uplift at bottom of wall during mechanical loading.

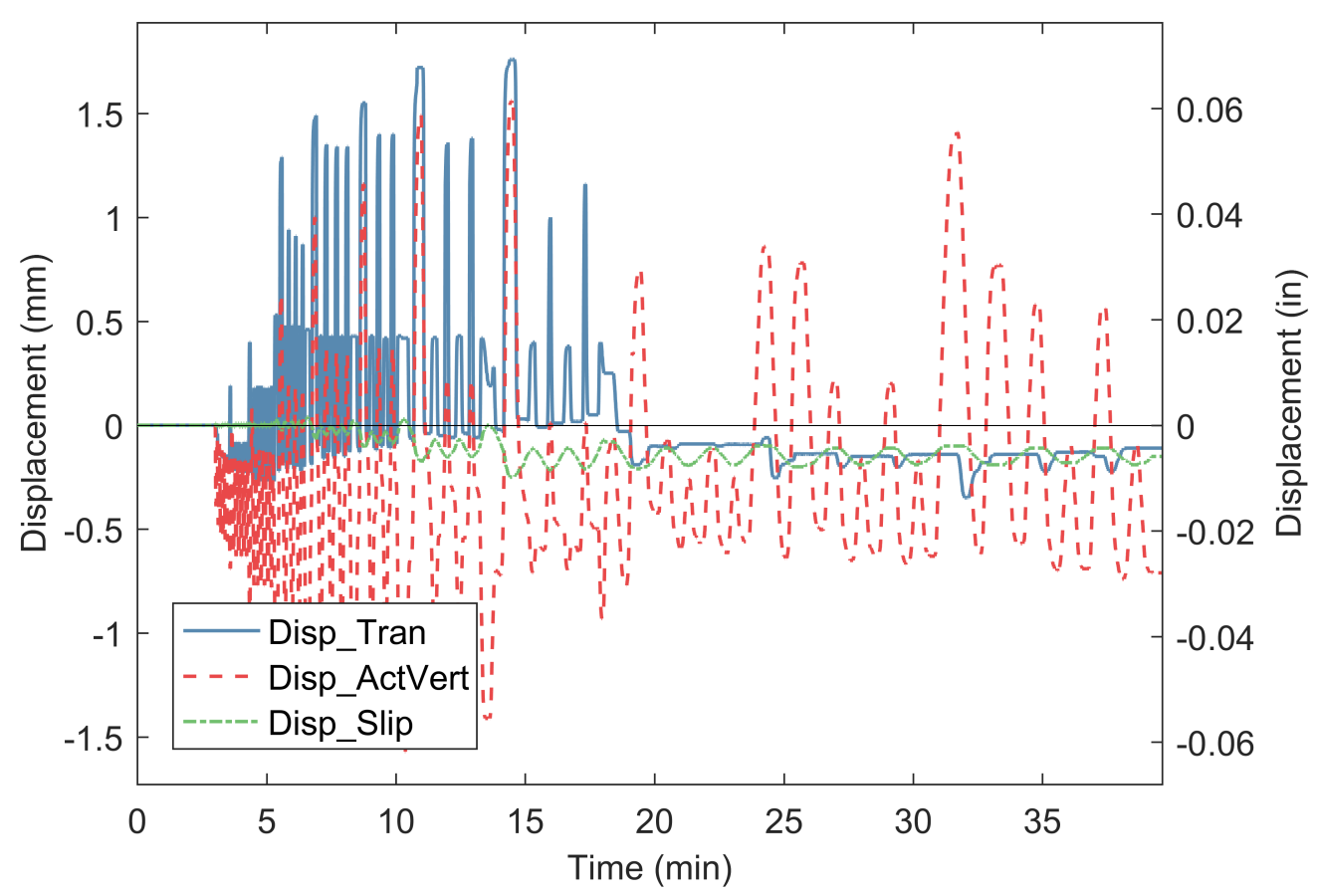

Fig. 190. OSB01 - Ancillary displacement measurements during mechanical loading. 


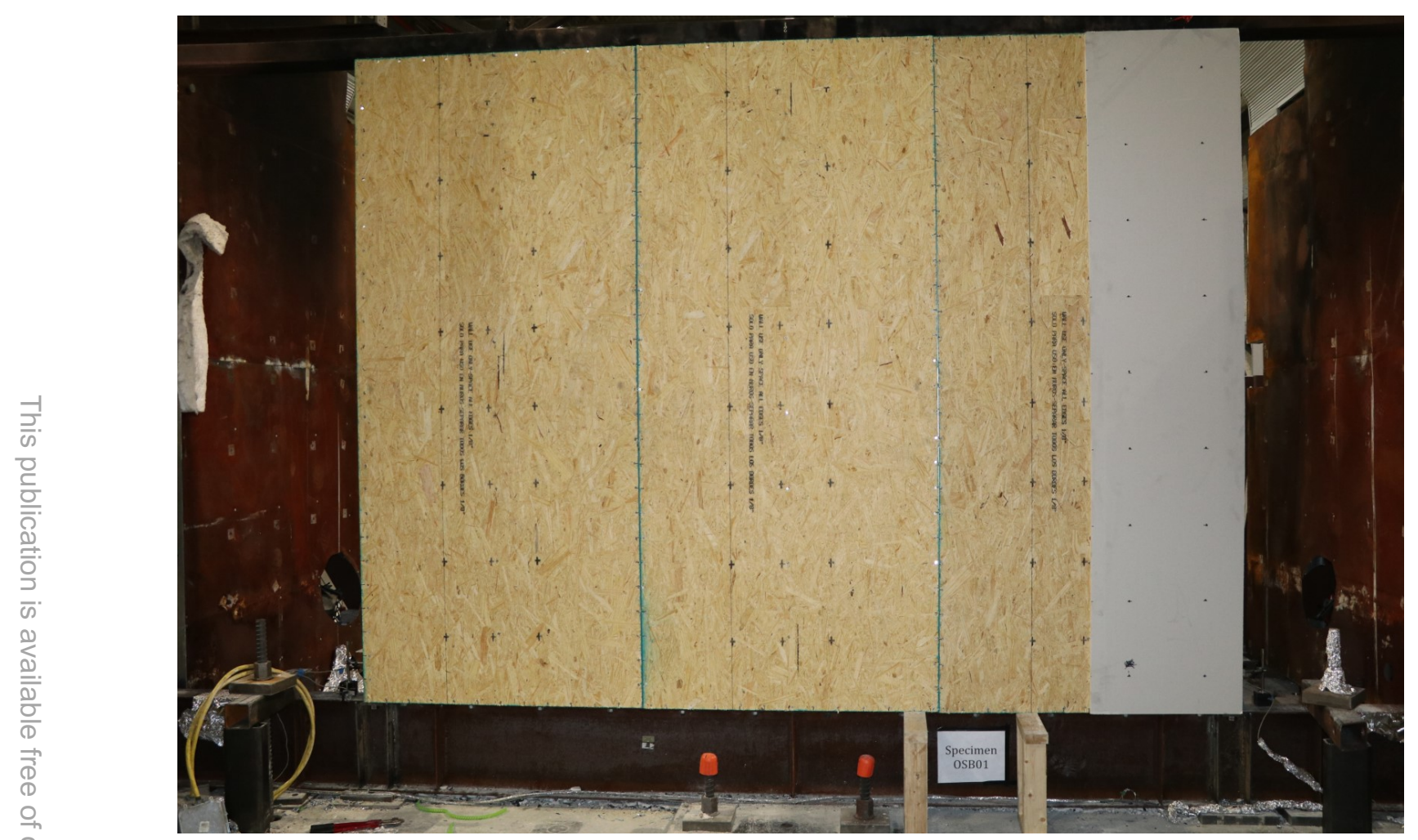

Fig. 191. OSB01 - Photograph of west side of the wall during gypsum installation.

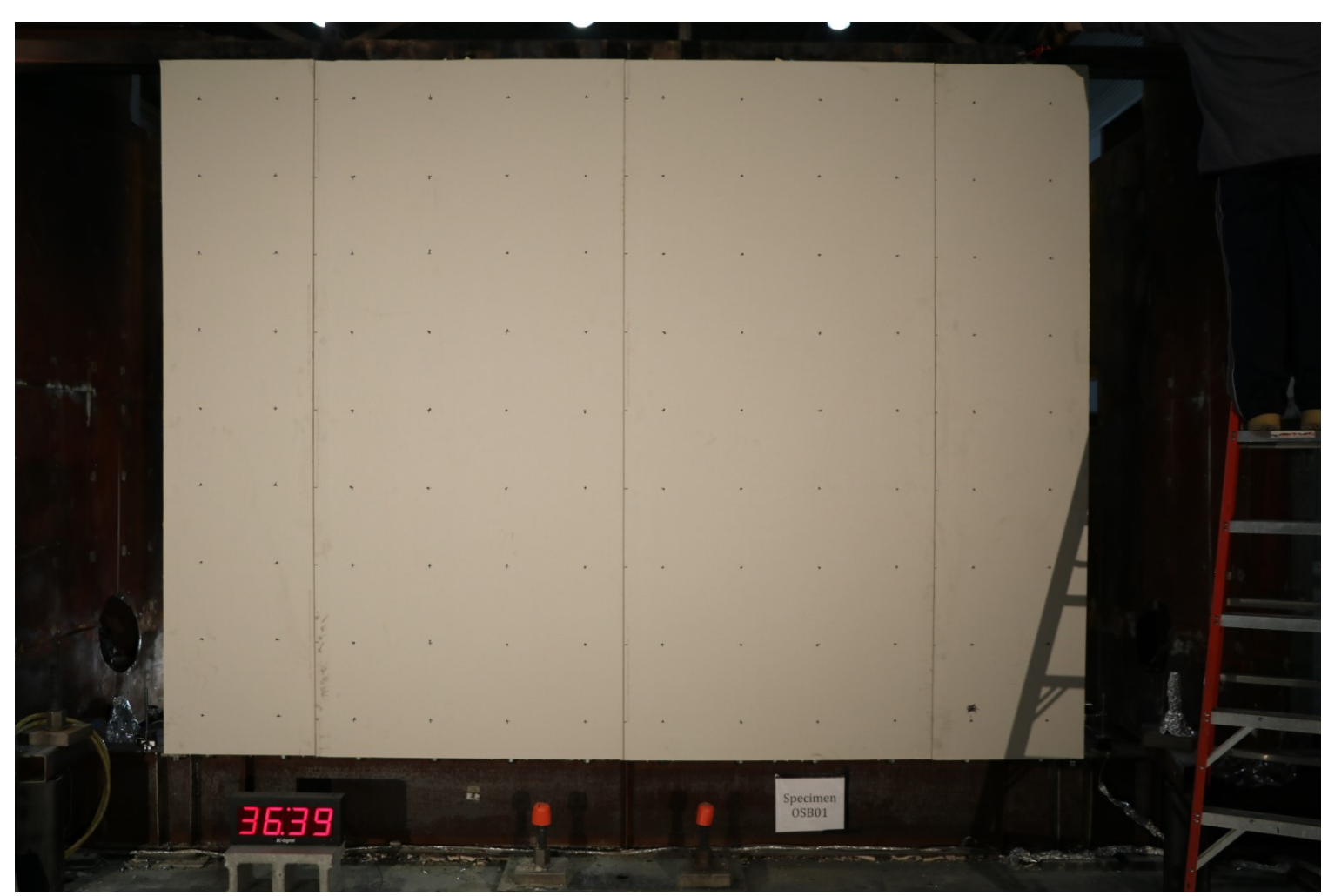

Fig. 192. OSB01 - Photograph of west side of the wall after load cycling. 


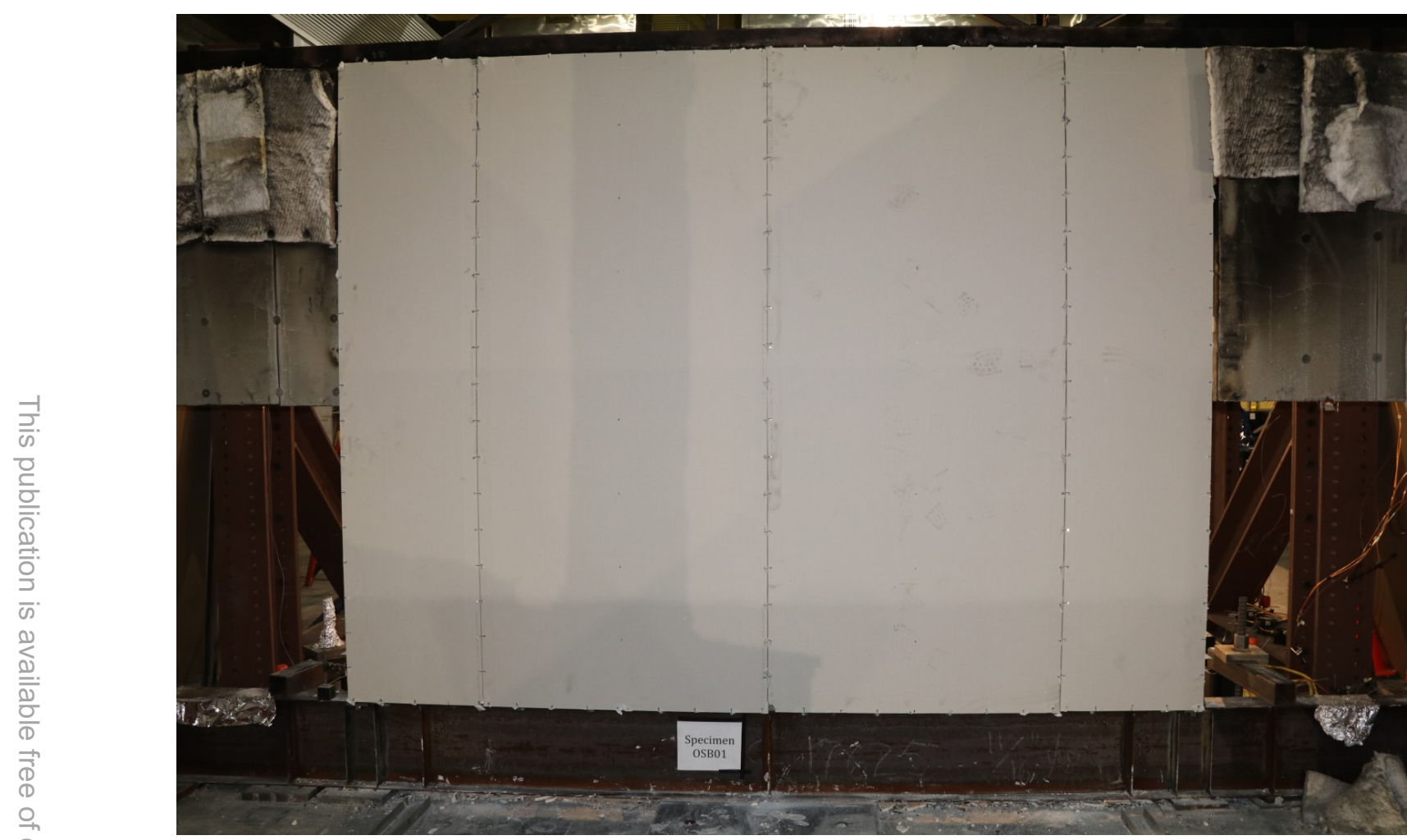

Fig. 193. OSB01 - Photograph of east side of the wall after load cycling.

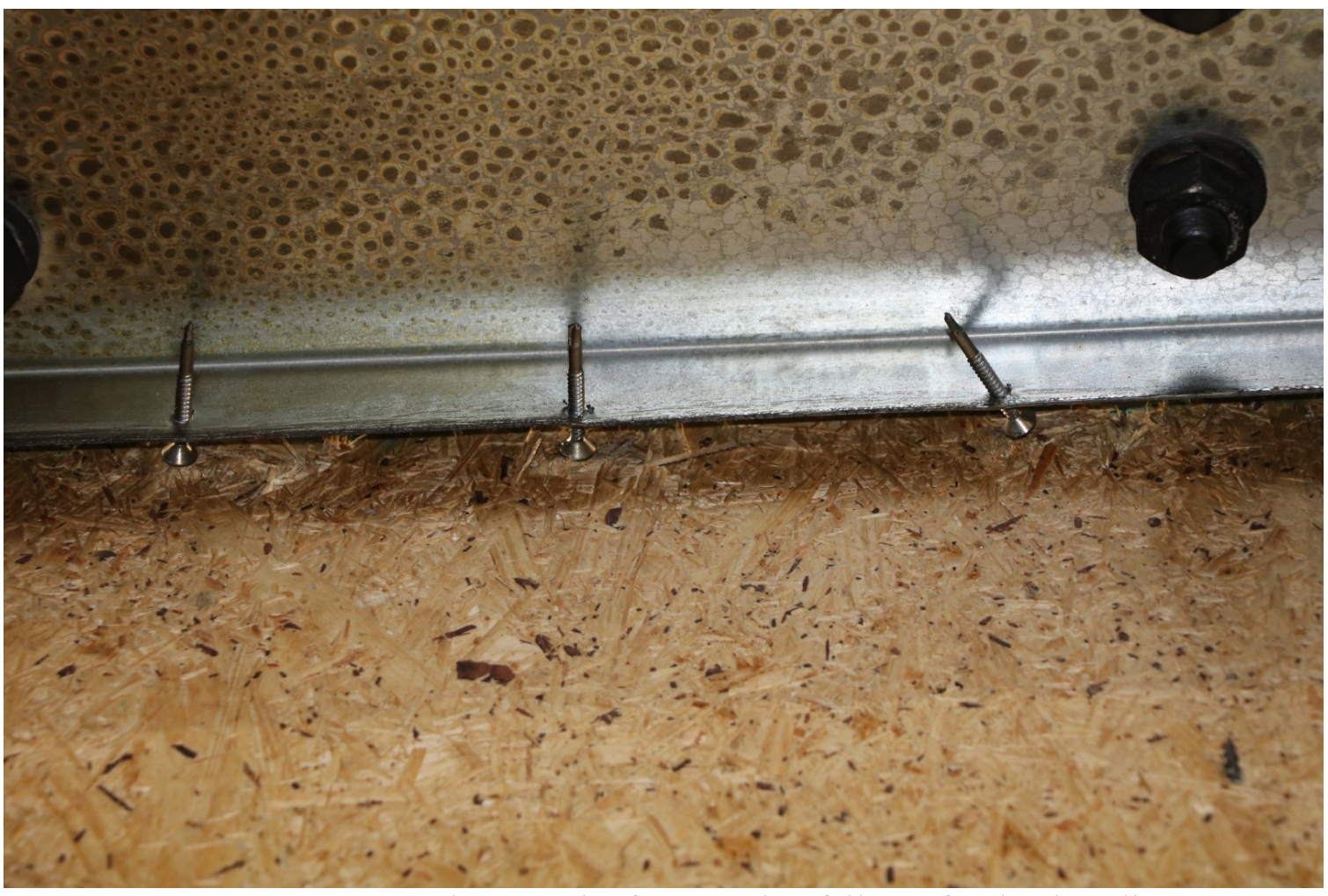

Fig. 194. OSB01 - Photograph of connection failure after load cycling. 


\section{OSB01R Data}

OSB01Ra (Cyclic test of undamaged wall at ambient temperature)

- The $3 \mathrm{~mm}$ (1/8”) gap between OSB boards was eliminated and a $12 \mathrm{~mm}\left(1 / 2^{\prime \prime}\right)$ spacing between the screw and edge of OSB was maintained at all locations.

- Failure mode was pull-through of the screw head through the OSB board (Fig. 200) at nearly all locations ( $<5 \%$ with edge damage). OSB side of chord stud flange bent outwards (Fig. 201) around $100 \%$ of the target displacement $(\Delta)$; this does not appear to play a significant role in the wall performance.

- Very little visible damage to drywall on either side of the wall (Fig. 198).

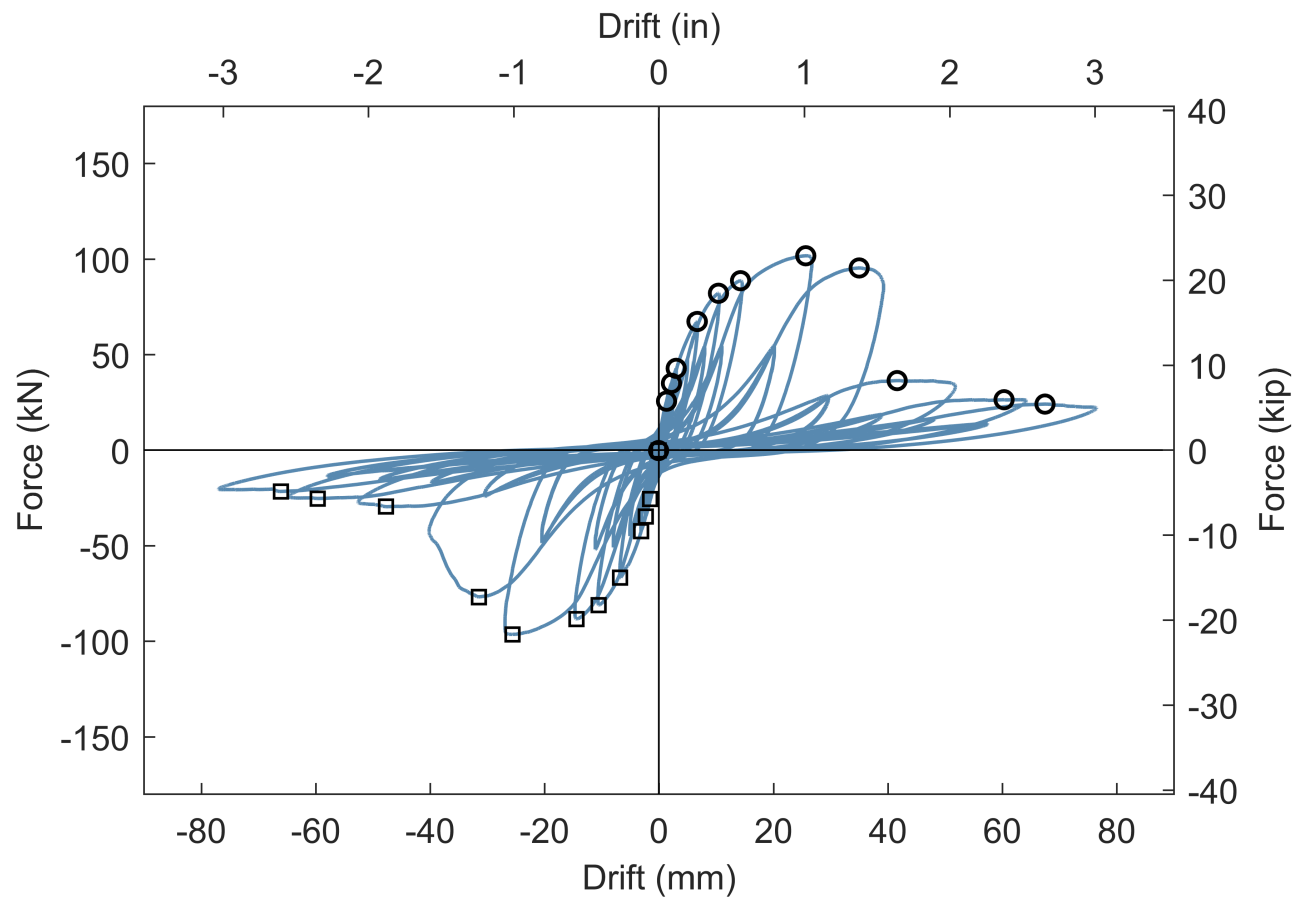

Fig. 195. OSB01R - Applied load versus wall longitudinal drift during mechanical loading. 


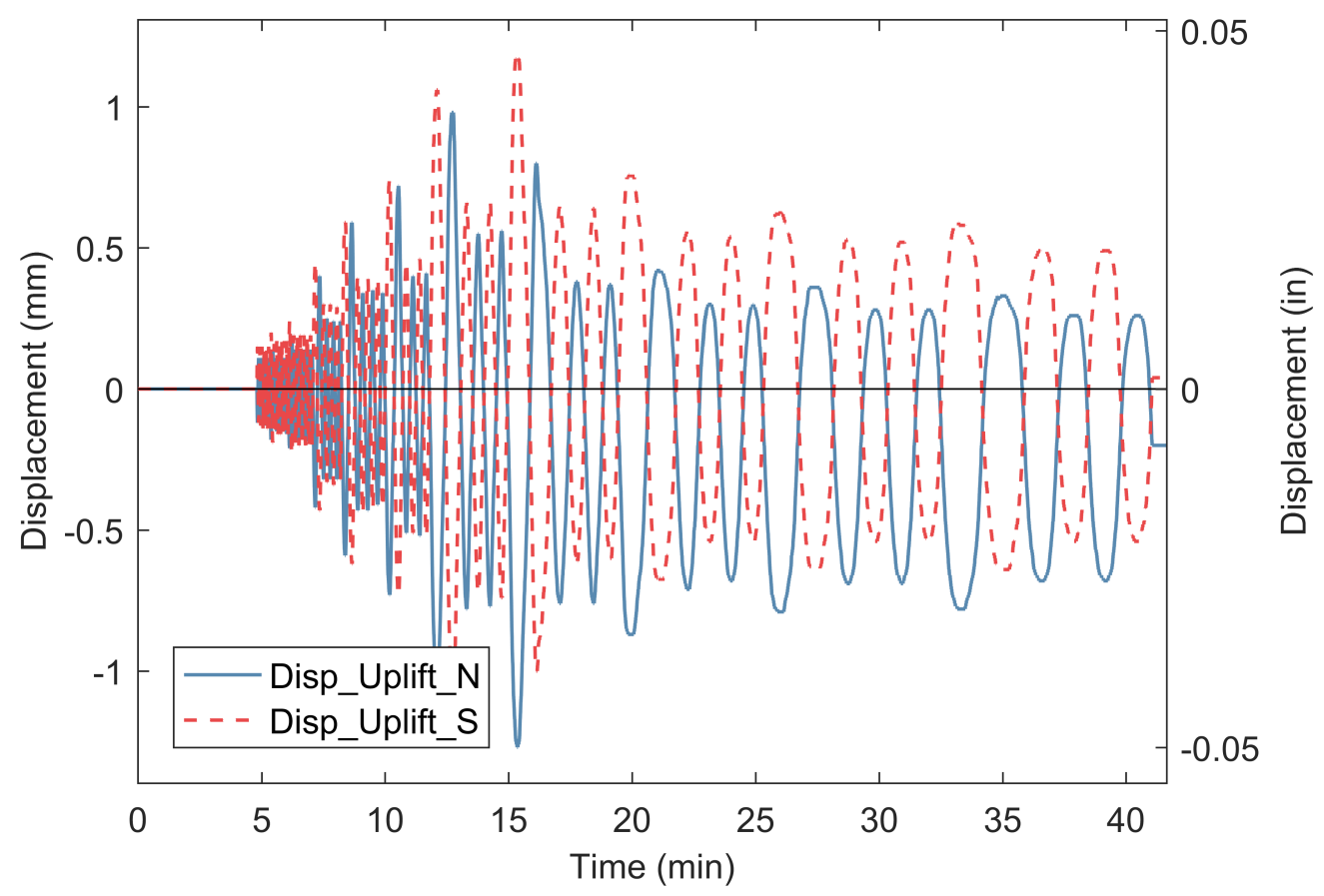

Fig. 196. OSB01R - Uplift at bottom of wall during mechanical loading.

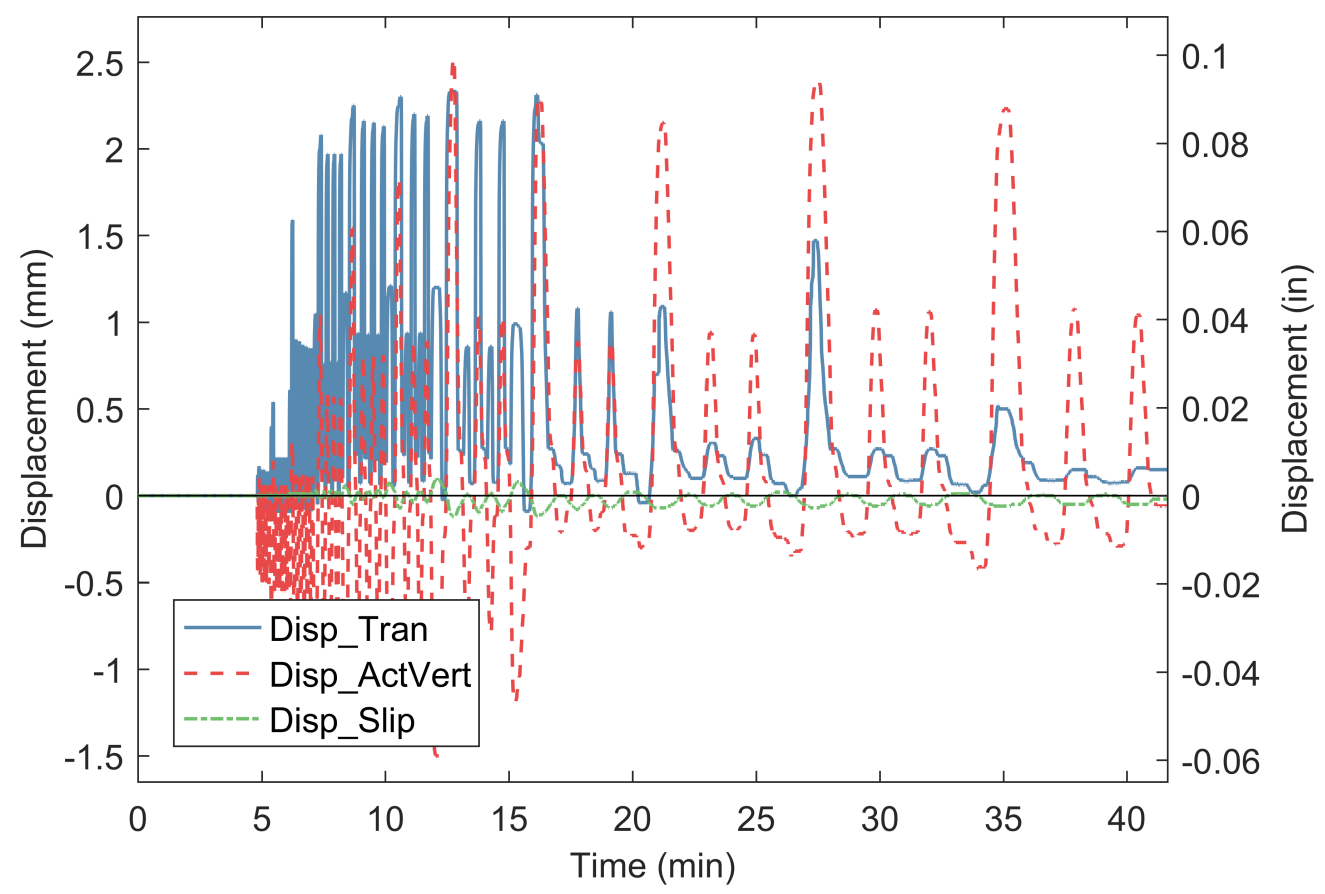

Fig. 197. OSB01R - Ancillary displacement measurements during mechanical loading. 


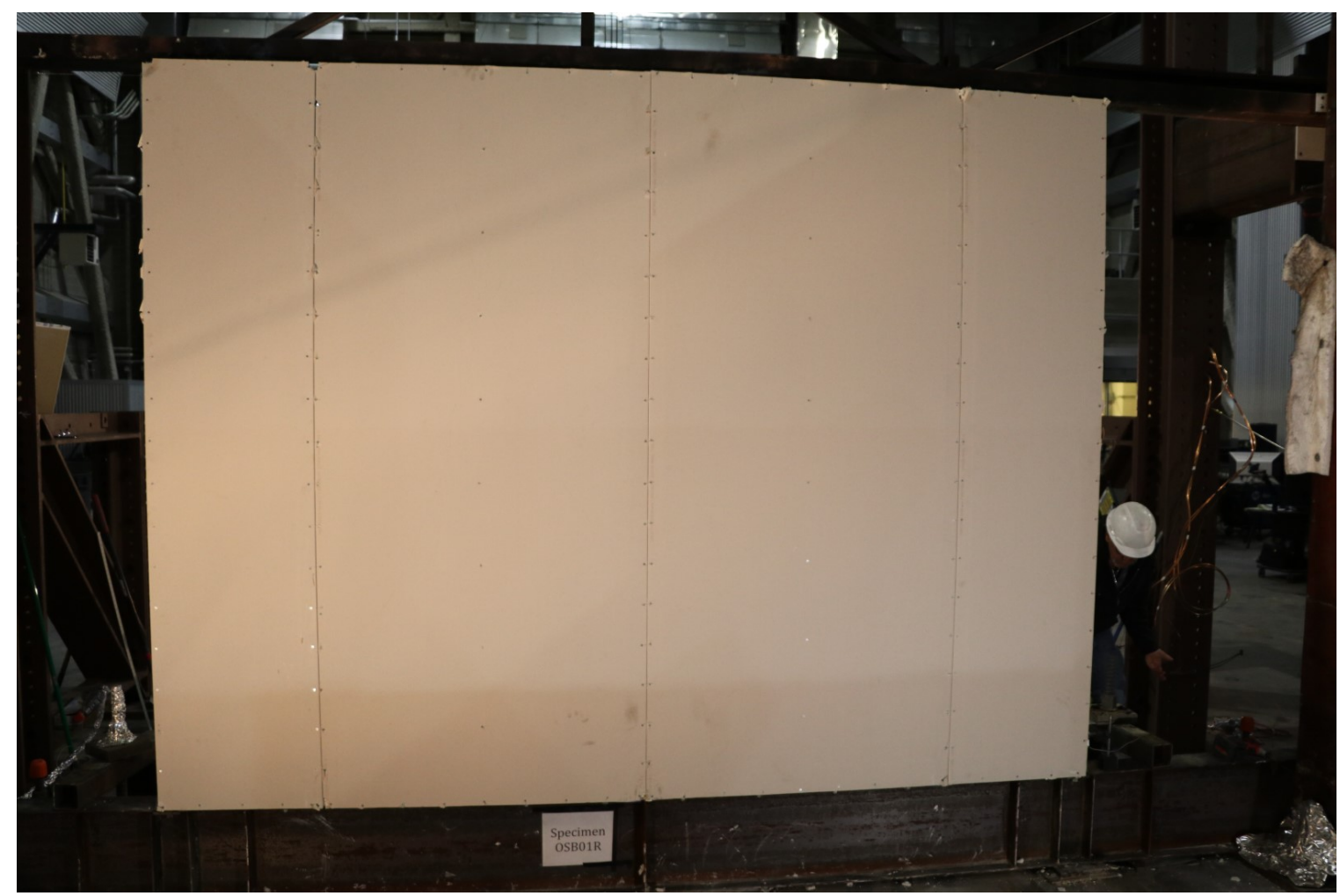

Fig. 198. OSB01R - Photograph of east side of the wall after load cycling.

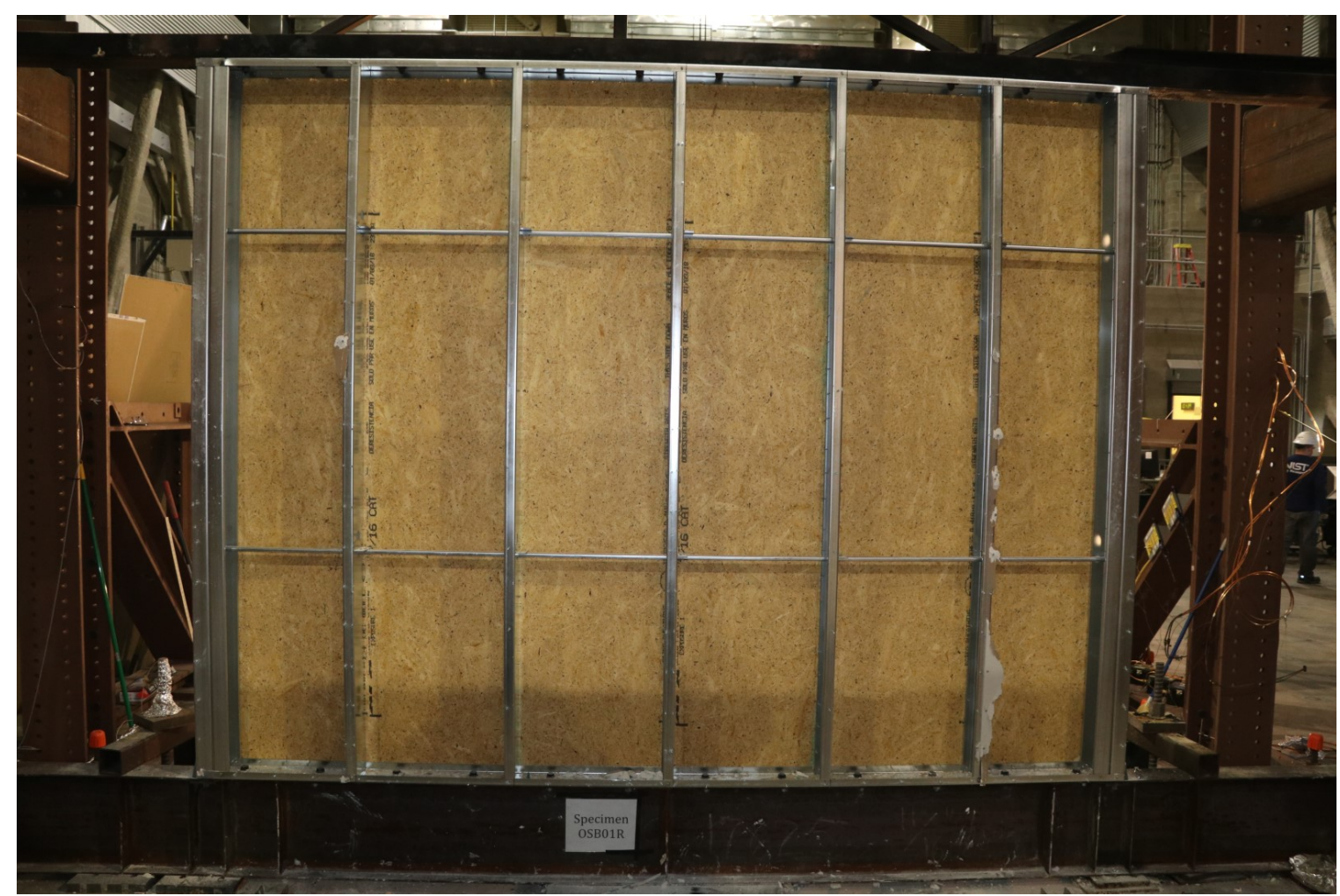

Fig. 199. OSB01R - Photograph of back of sheathed side of wall (nonstructural gypsum removed) after load cycling. 


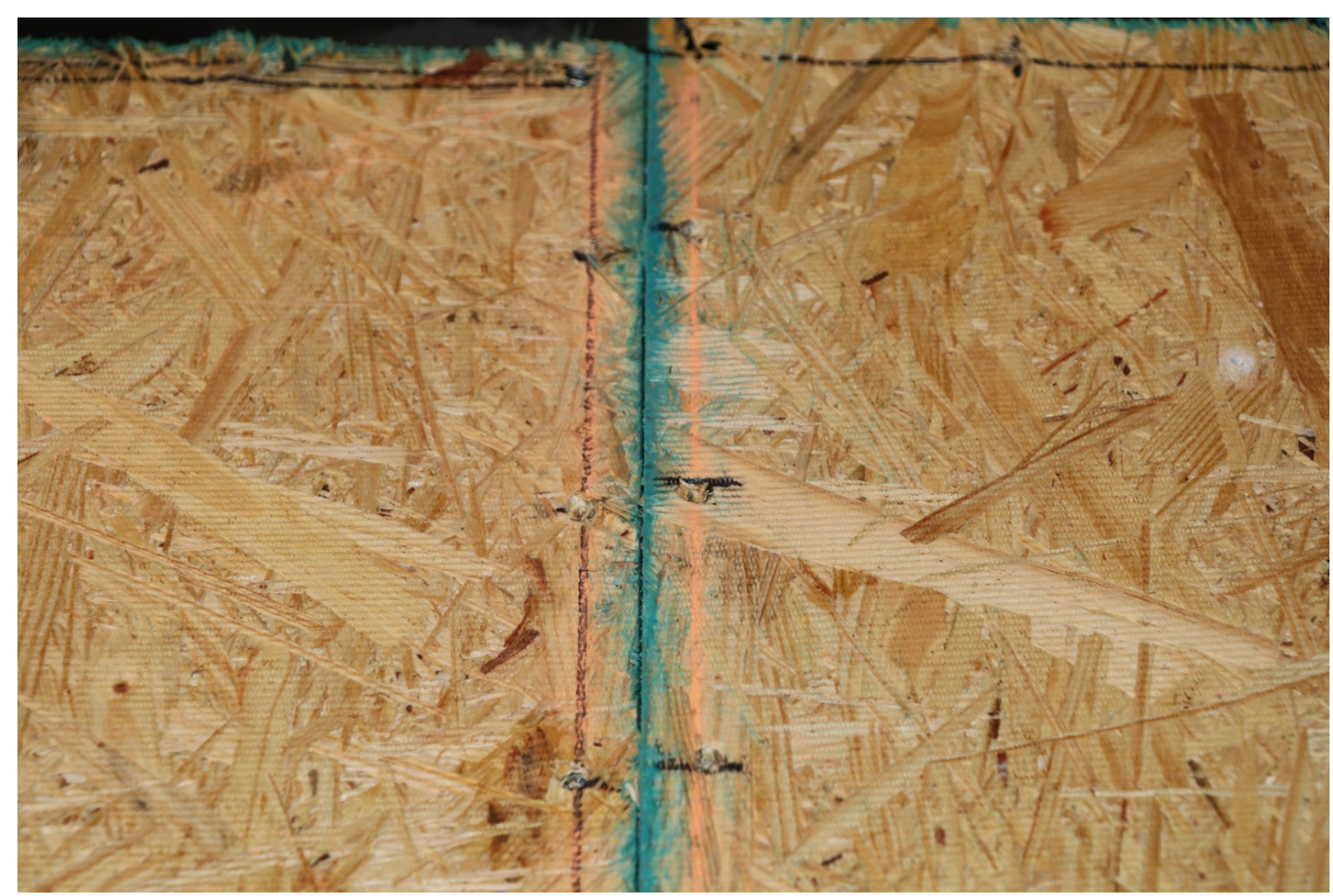

Fig. 200. OSB01R - Photograph of pull-though of screws through OSB.

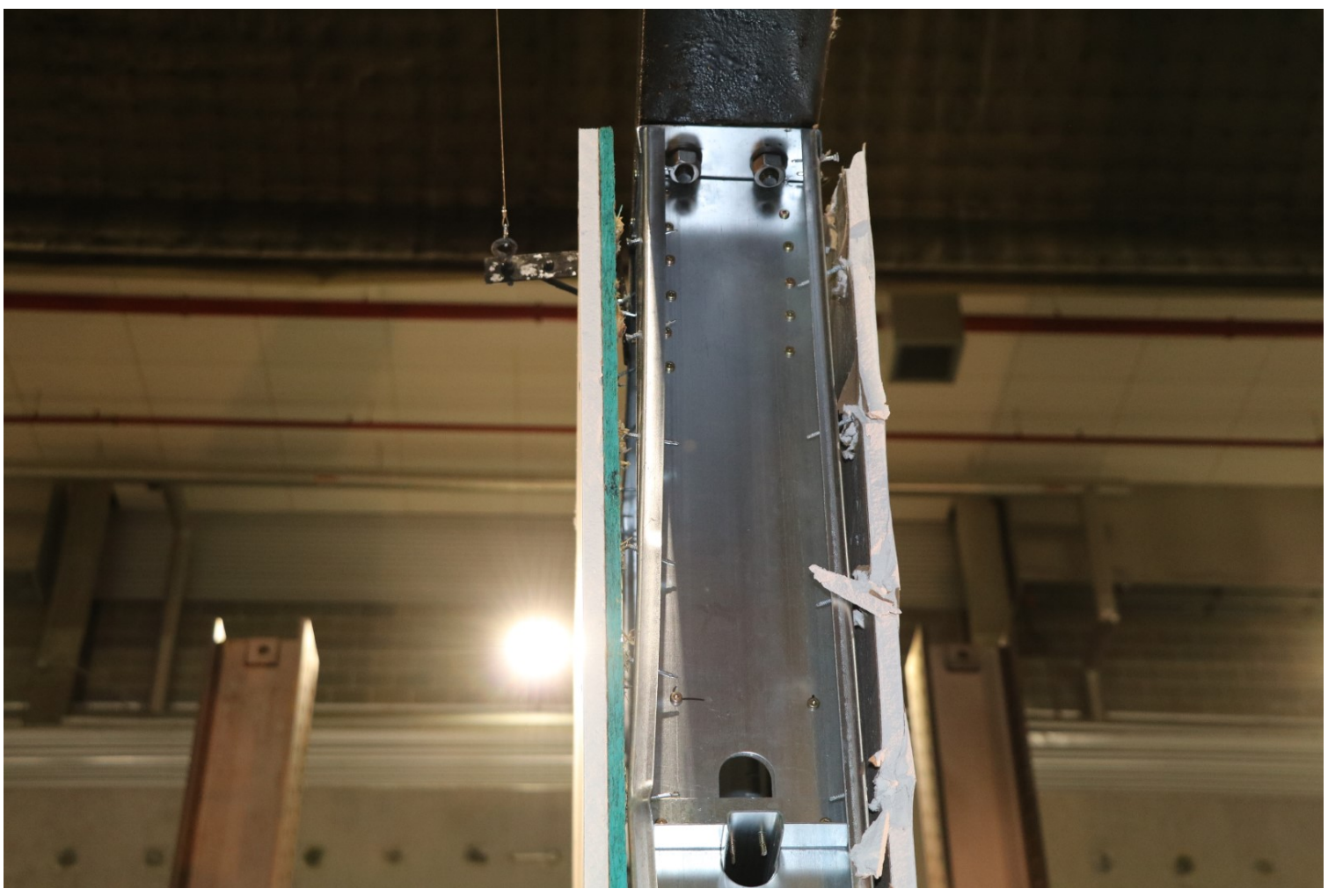

Fig. 201. OSB01R - Photograph of south chord stud after load cycling. 


\section{OSB01NG Data}

OSB01NGa (Cyclic test of undamaged wall at ambient temperature)

- Nonstructural gypsum was not installed on east side of wall to simulate total thermal damage to the fire exposed side of the wall and determine the contribution of this gypsum to the lateral capacity (Fig. 206).

- Screws pulled-though the OSB leading to failure (Fig. 207).

- A $12 \mathrm{~mm}\left(1 / 2^{\prime \prime}\right)$ spacing between the screw and edge of OSB was maintained at all locations.

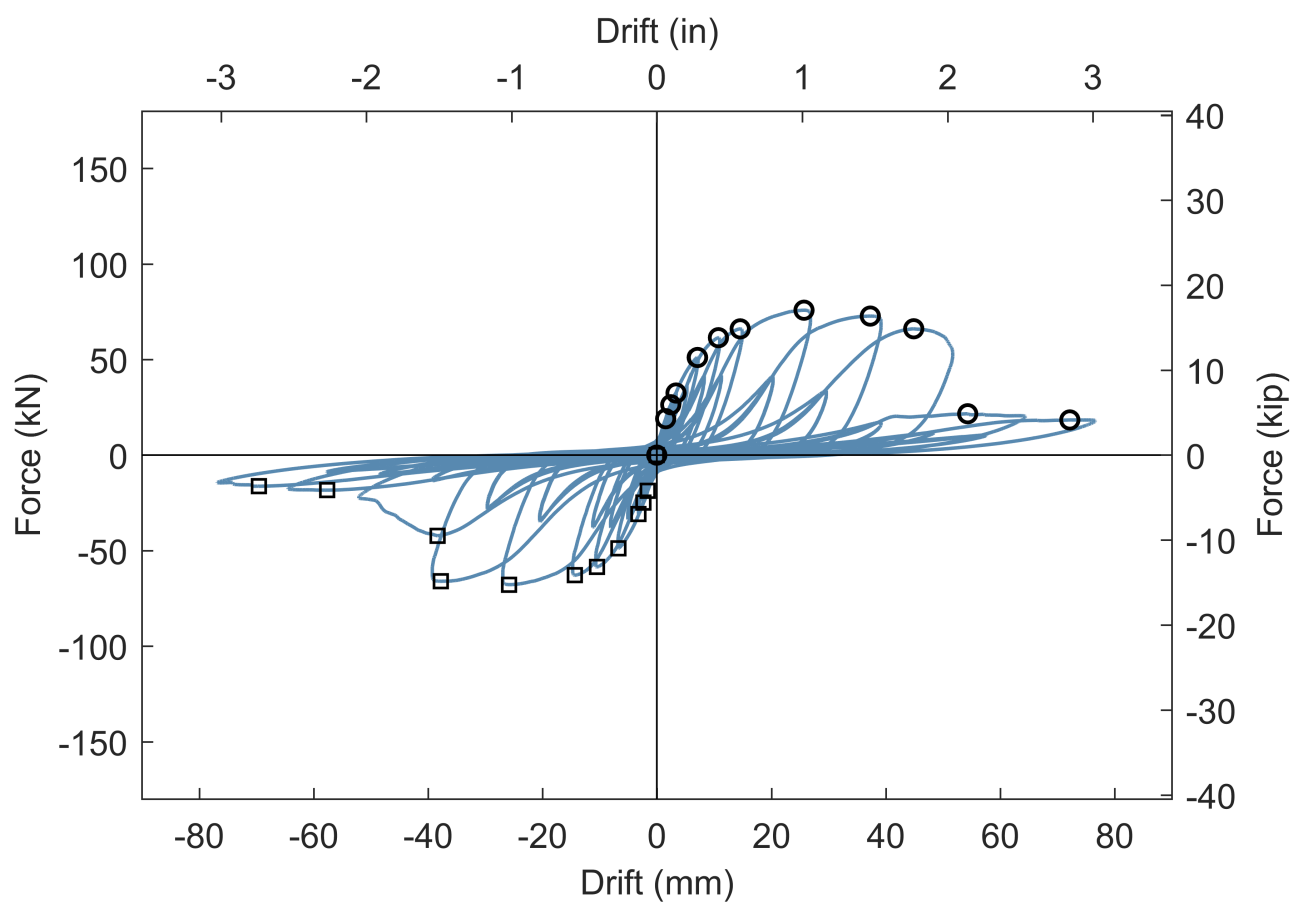

Fig. 202. OSB01NG - Applied load versus wall longitudinal drift during mechanical loading. 


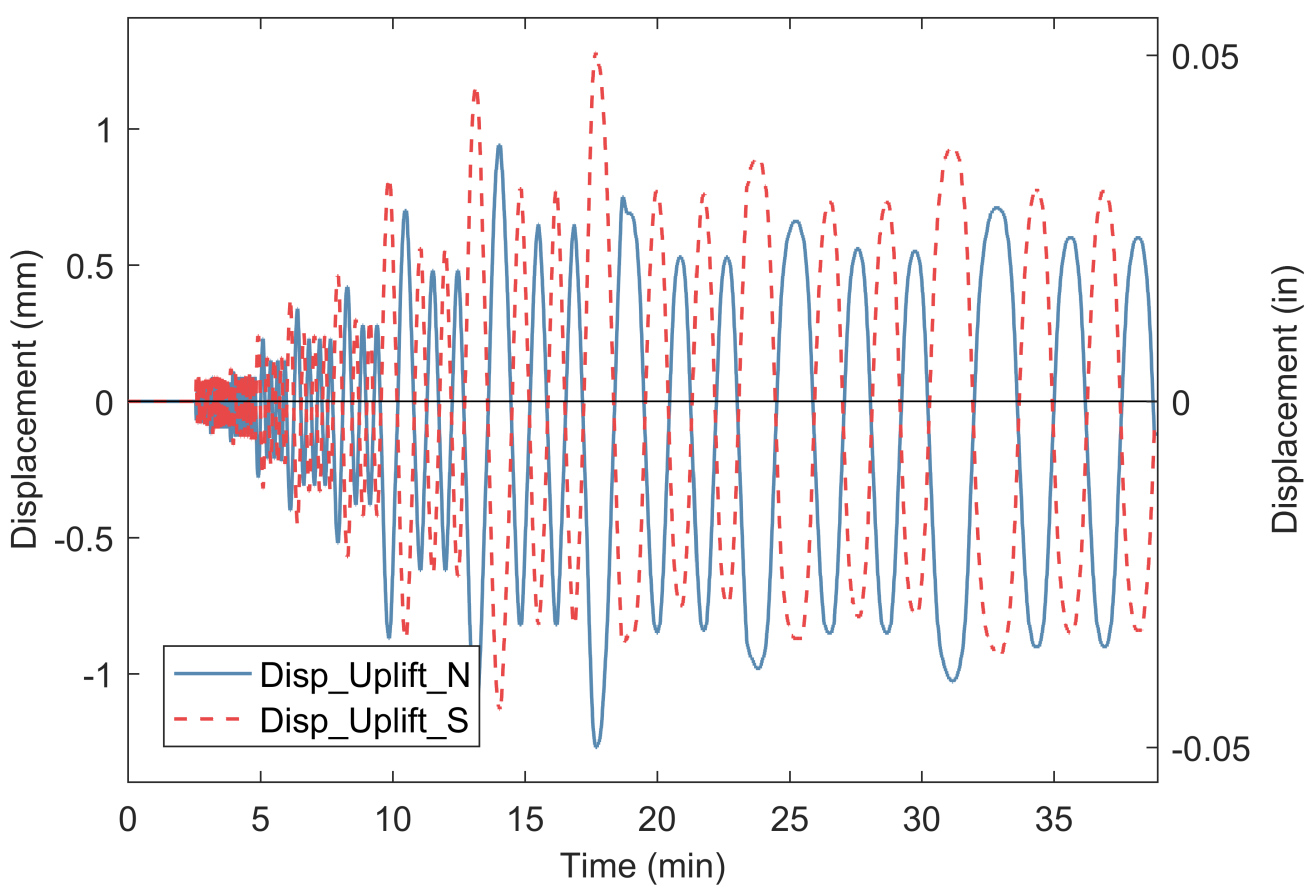

Fig. 203. OSB01NG - Uplift at bottom of wall during mechanical loading.

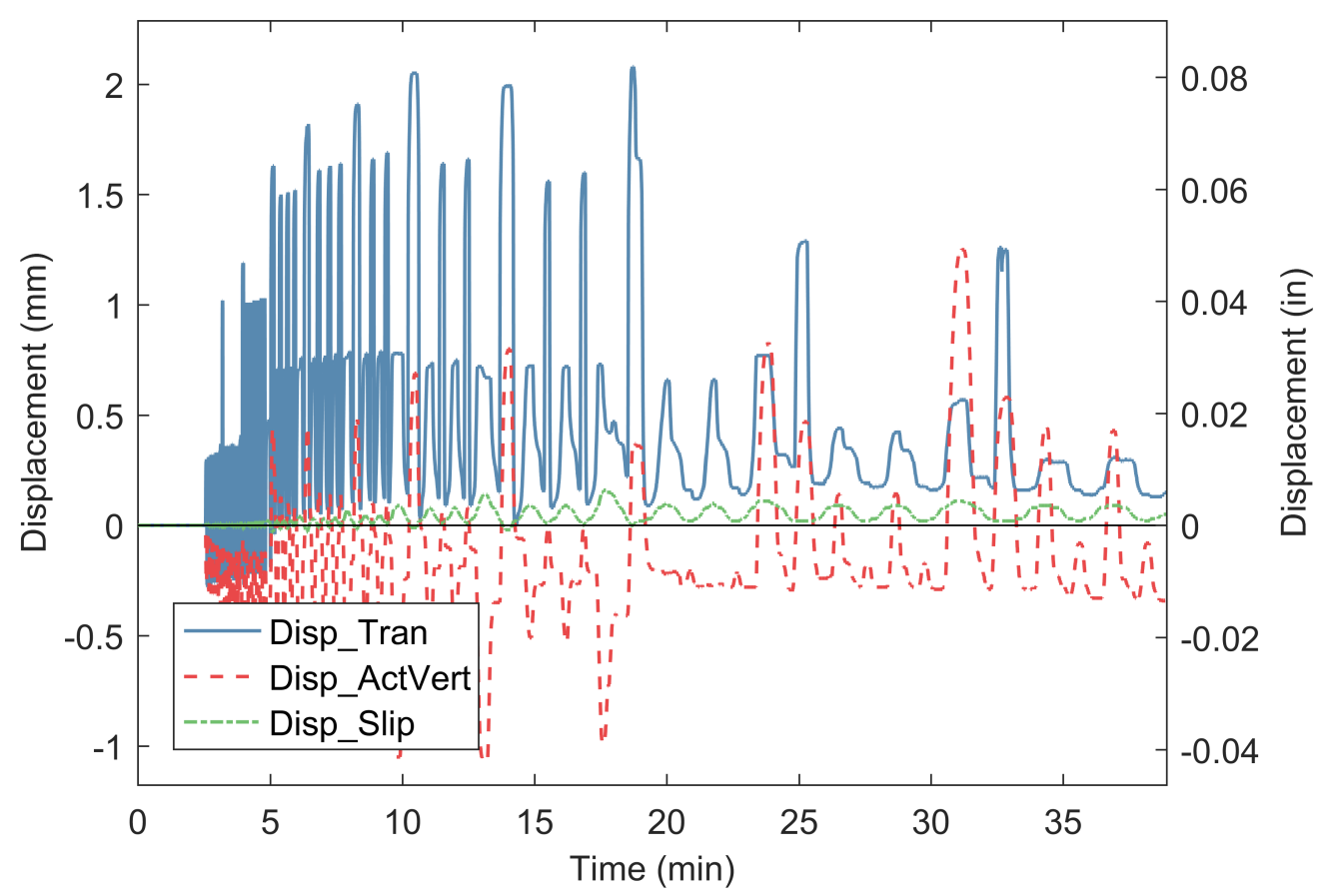

Fig. 204. OSB01NG - Ancillary displacement measurements during mechanical loading. 


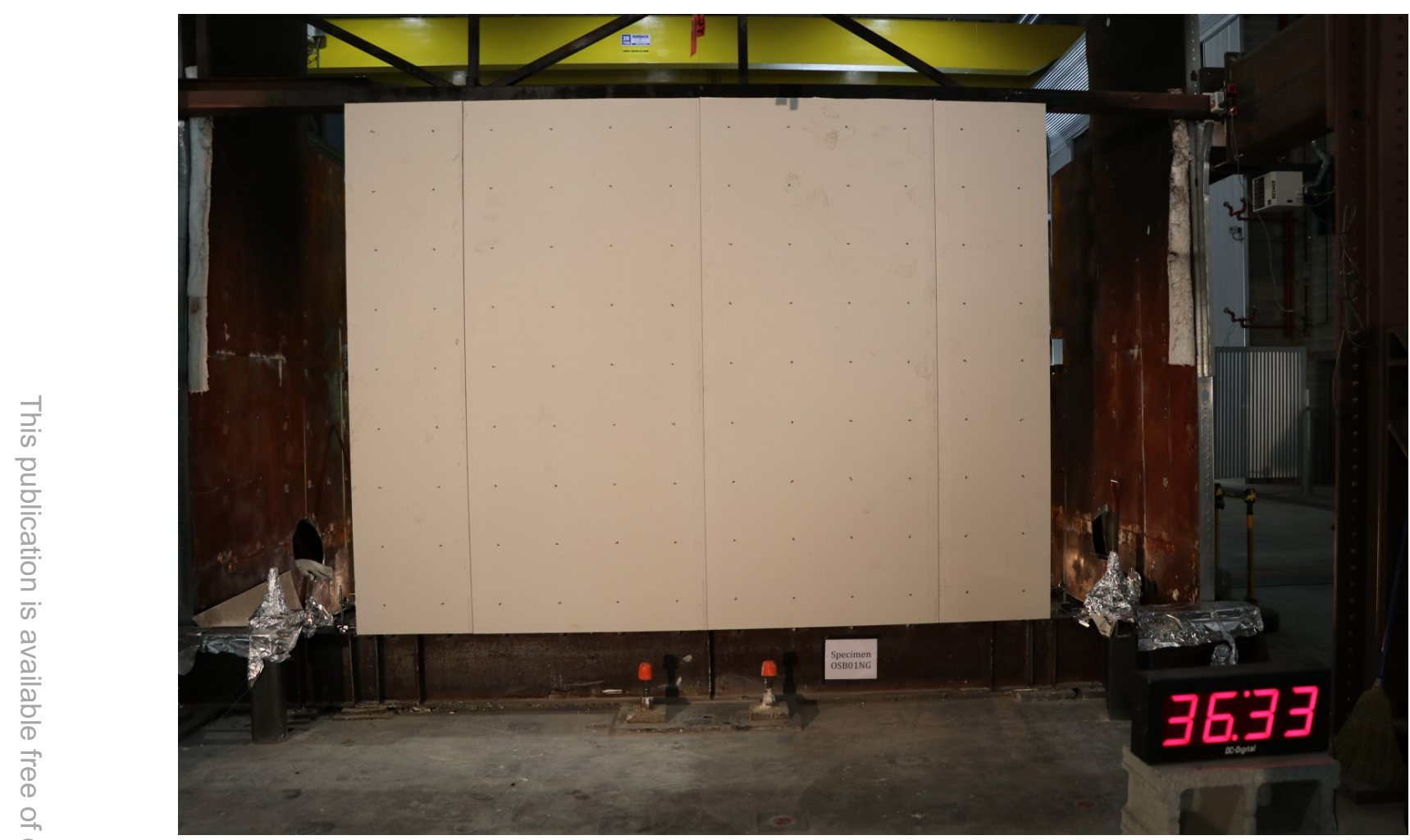

Fig. 205. OSB01NG - Photograph of west side of the wall after load cycling.

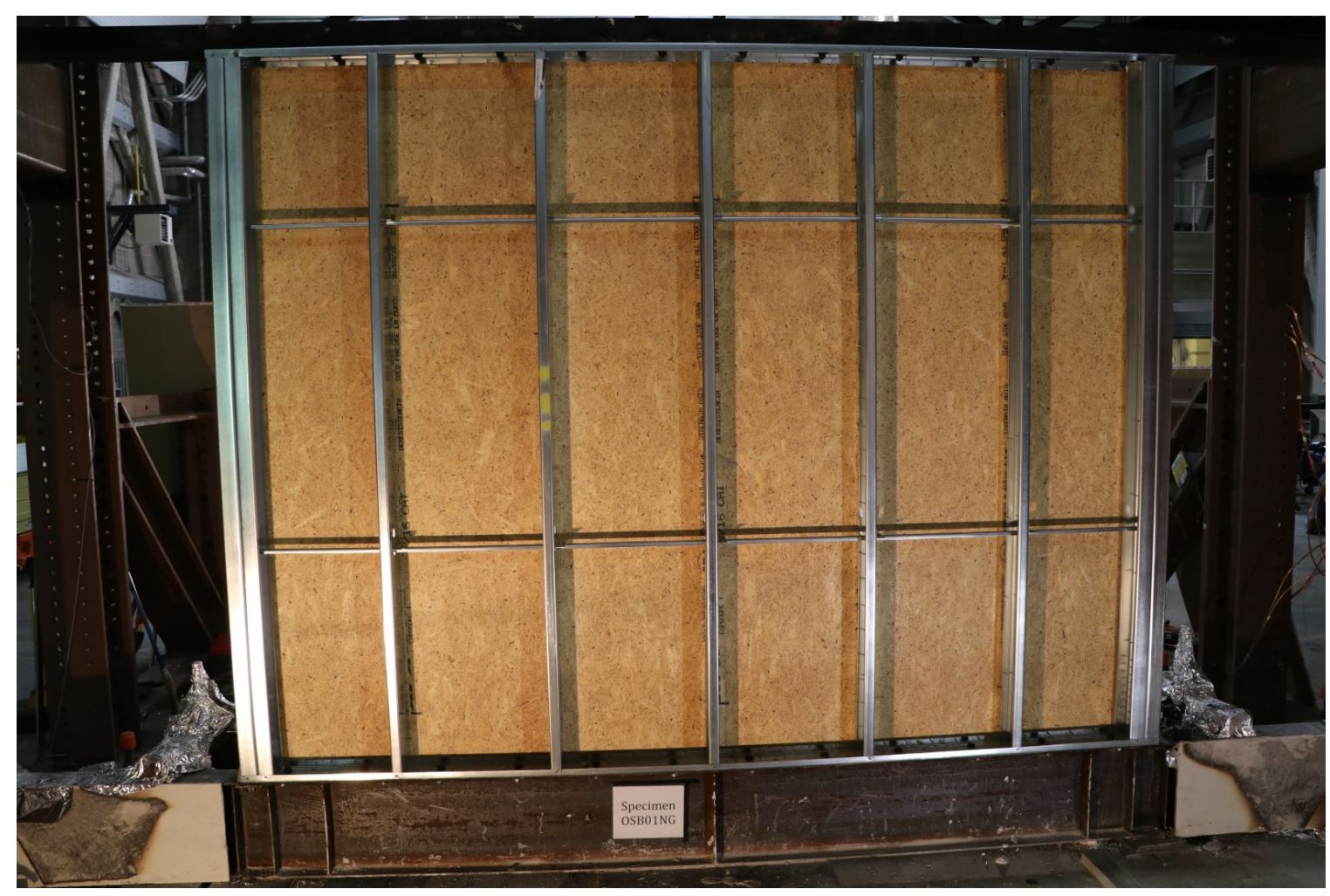

Fig. 206. OSB01NG - Photograph of east side of the wall after load cycling. 


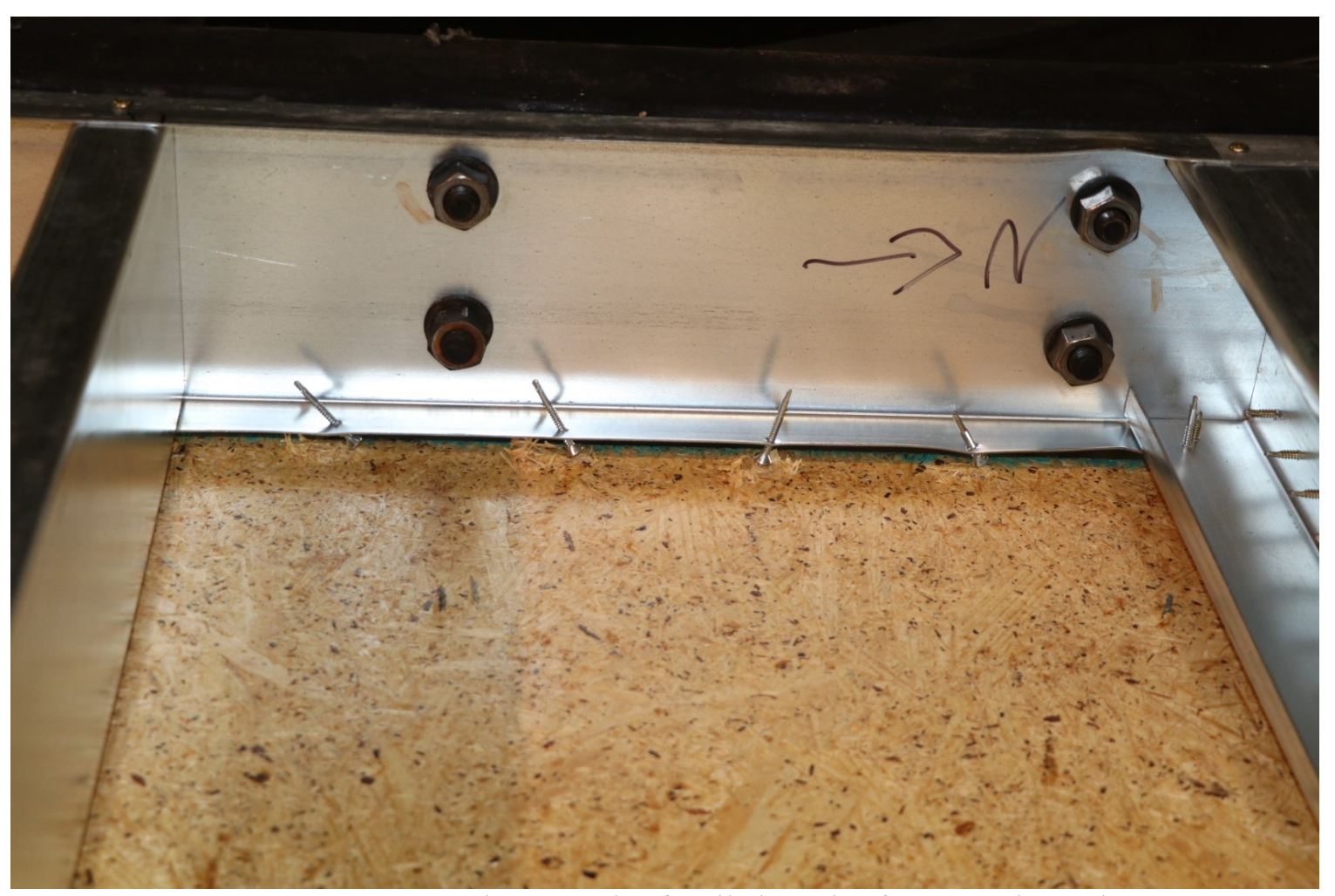

Fig. 207. OSB01NG - Photograph of pull-though of screws through OSB. 


\section{OSB02 Data}

OSB02b (Severe Fire test of an undamaged wall)

- The gas burner was set to $2.3 \mathrm{MW}$ for $35 \mathrm{~min}$. At $19 \mathrm{~min}$ the OSB started to burn, and at 21 min flaming combustion was observed at the top of the wall (Fig. 222).

- At 27 min about $80 \%$ of the OSB has burned through (Fig. 224). From that time point, temperature measurements through the cross-section and unexposed side are not reliable. Especially the measurements located on the OSB. However, data was collected for $50 \mathrm{~min}$.

OSB02c (Cyclic test of wall at ambient temperature following the Severe Fire)

- Because the fire consumed nearly all the OSB sheathing, the wall had nearly zero lateral force-resistance capacity during cycling (Fig. 218).

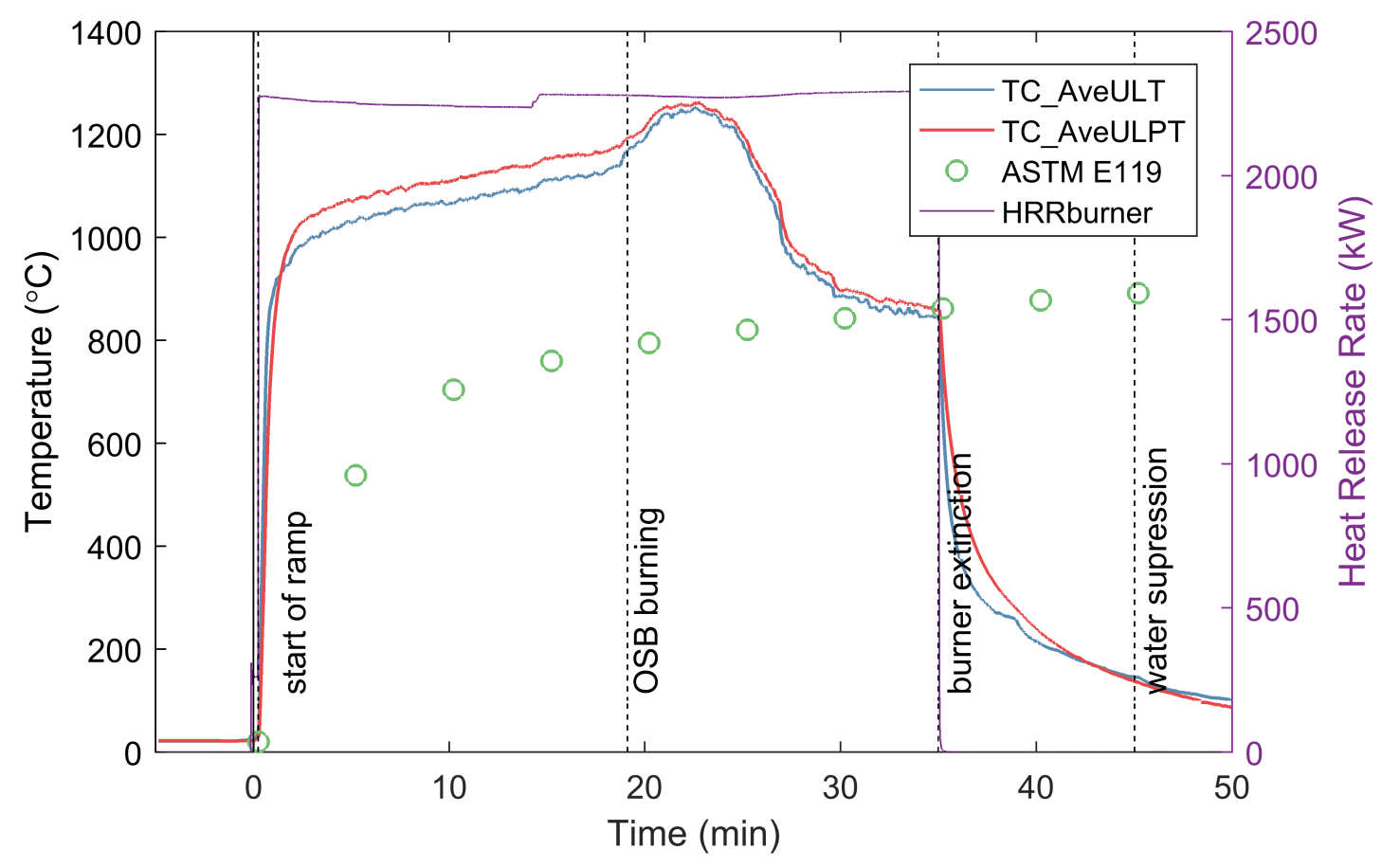

Fig. 208. OSB02 - Compartment temperature and burner Heat Release Rate. 


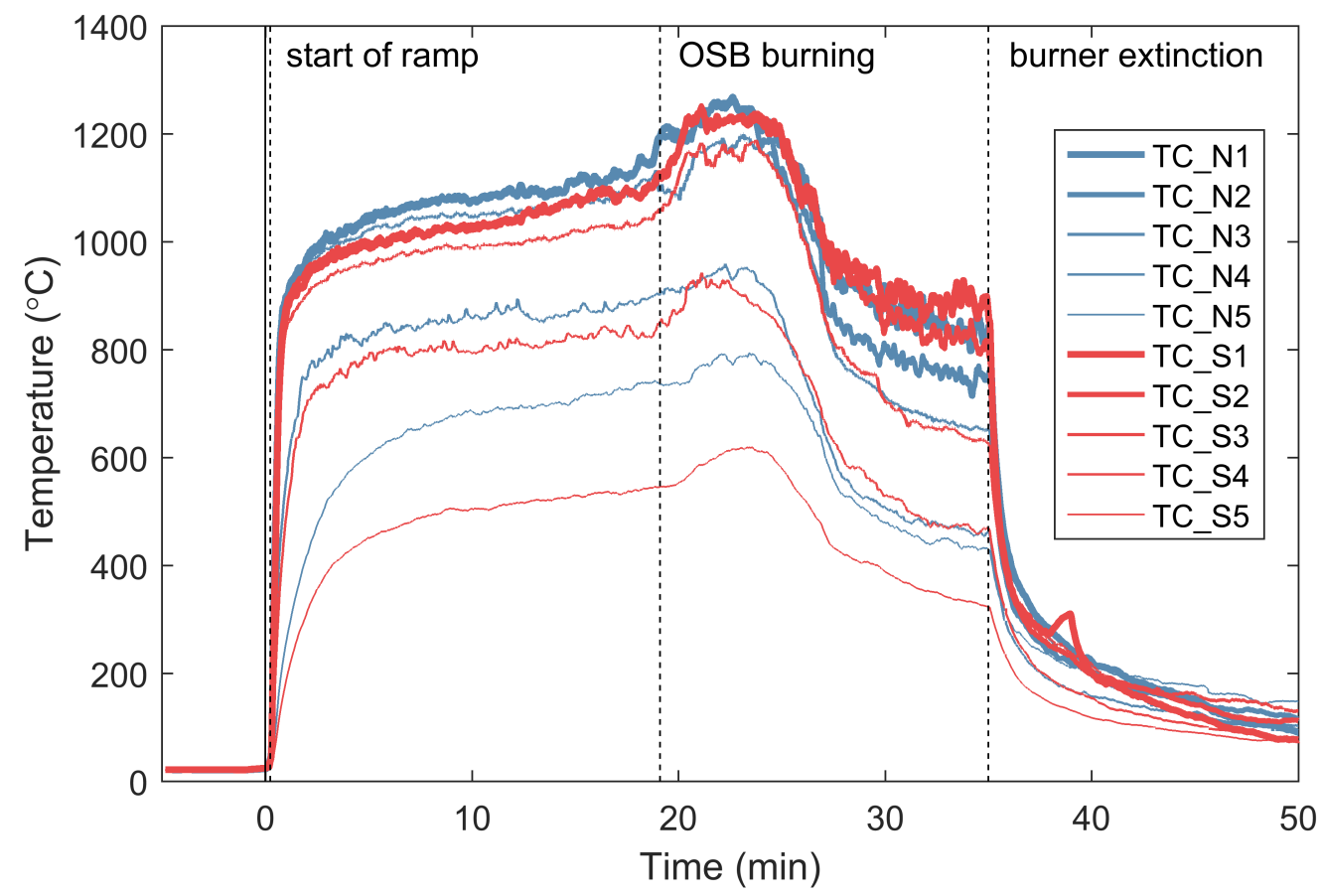

Fig. 209. OSB02 - Compartment temperatures measured by the thermocouple arrays.

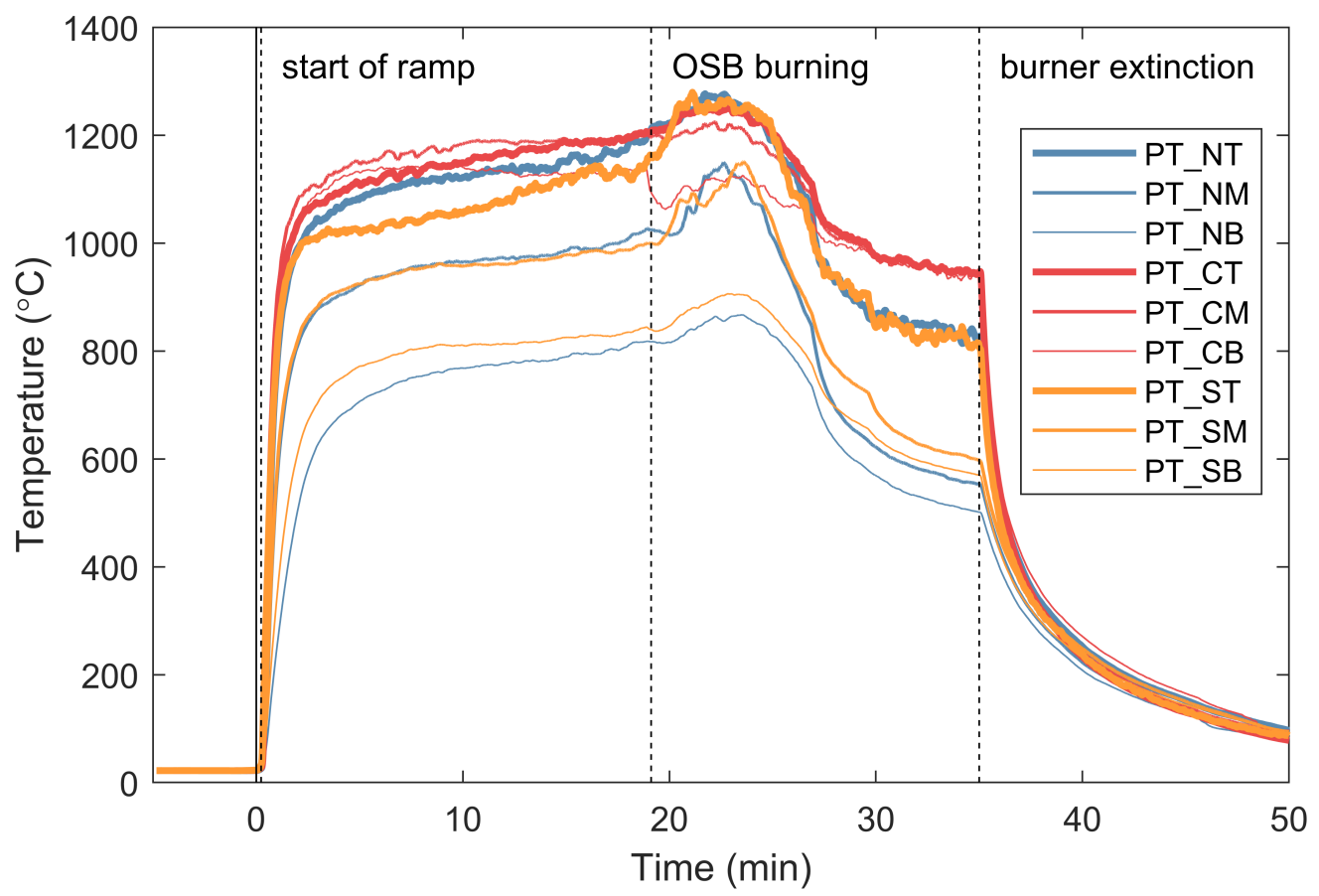

Fig. 210. OSB02 - Compartment temperatures measured by the plate thermocouples. 


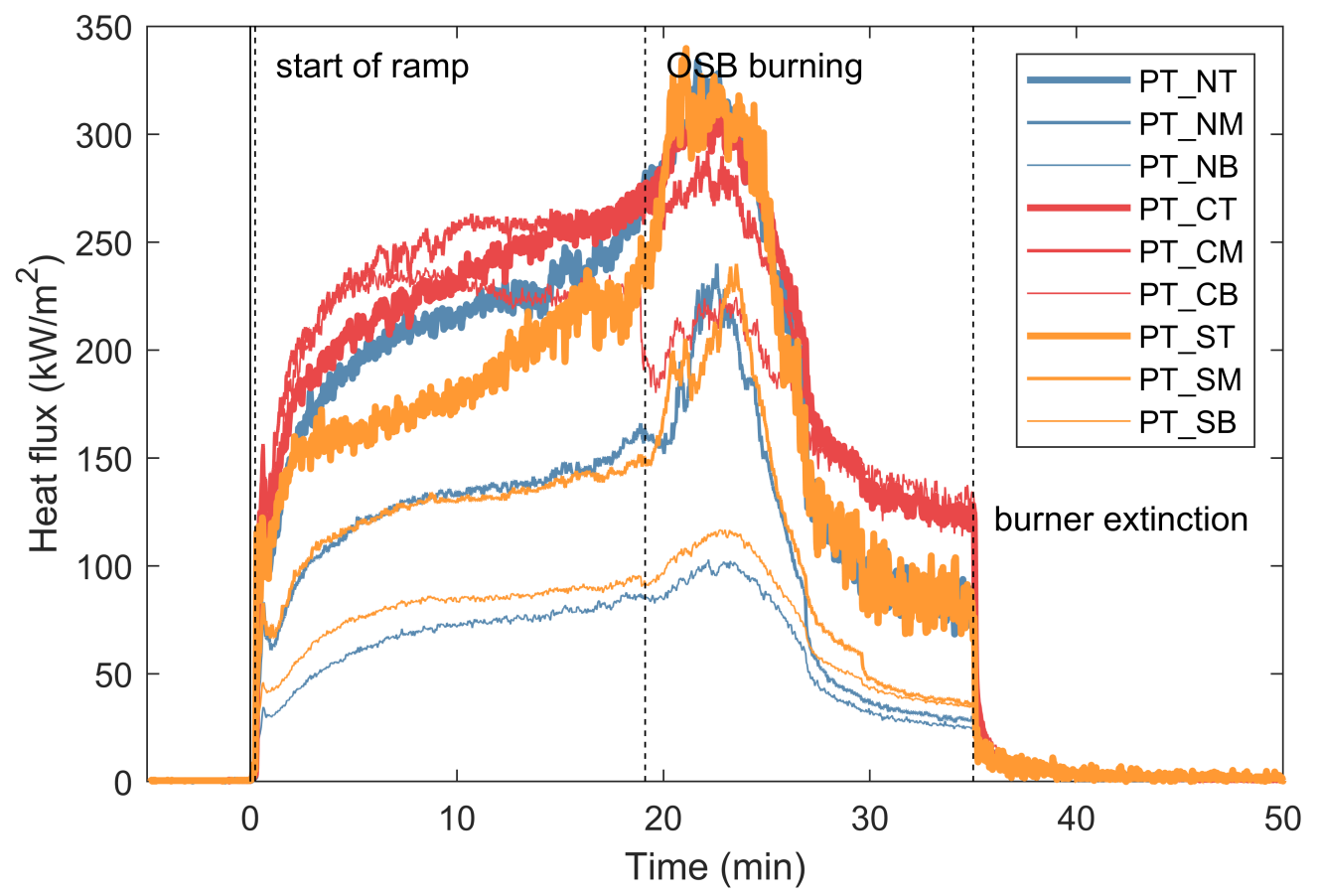

Fig. 211. OSB02 - Heat fluxes in the compartment measured by the plate thermocouples.
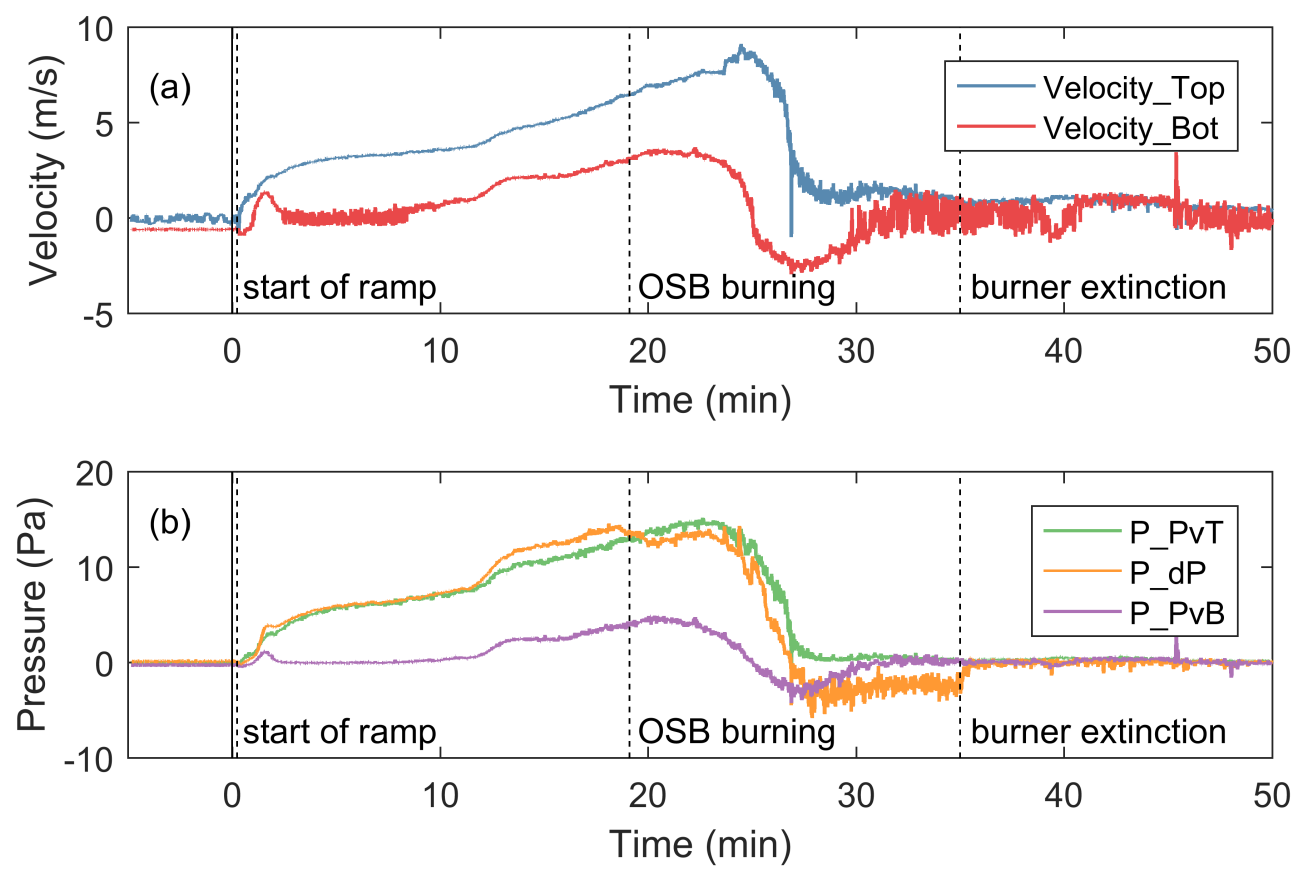

Fig. 212. OSB02 - (a) Velocity of air flow at the top and bottom knockouts of the chord stud; (b) Pressure at the top and bottom knockouts of the chord stud and in the wall cavity near the top. 


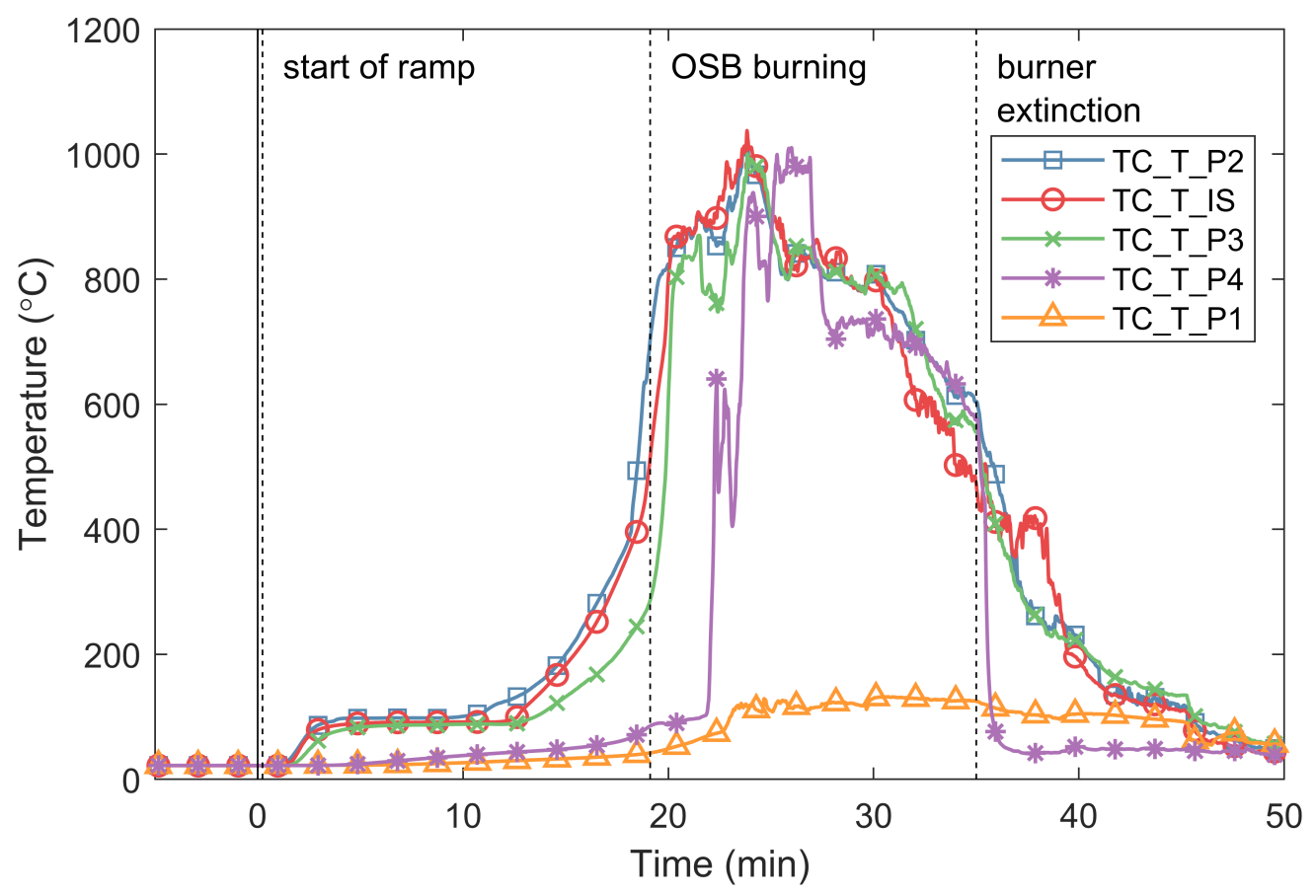

Fig. 213. OSB02 - Temperatures through the specimen at an interior stud $46 \mathrm{~cm}$ from the top of the wall.

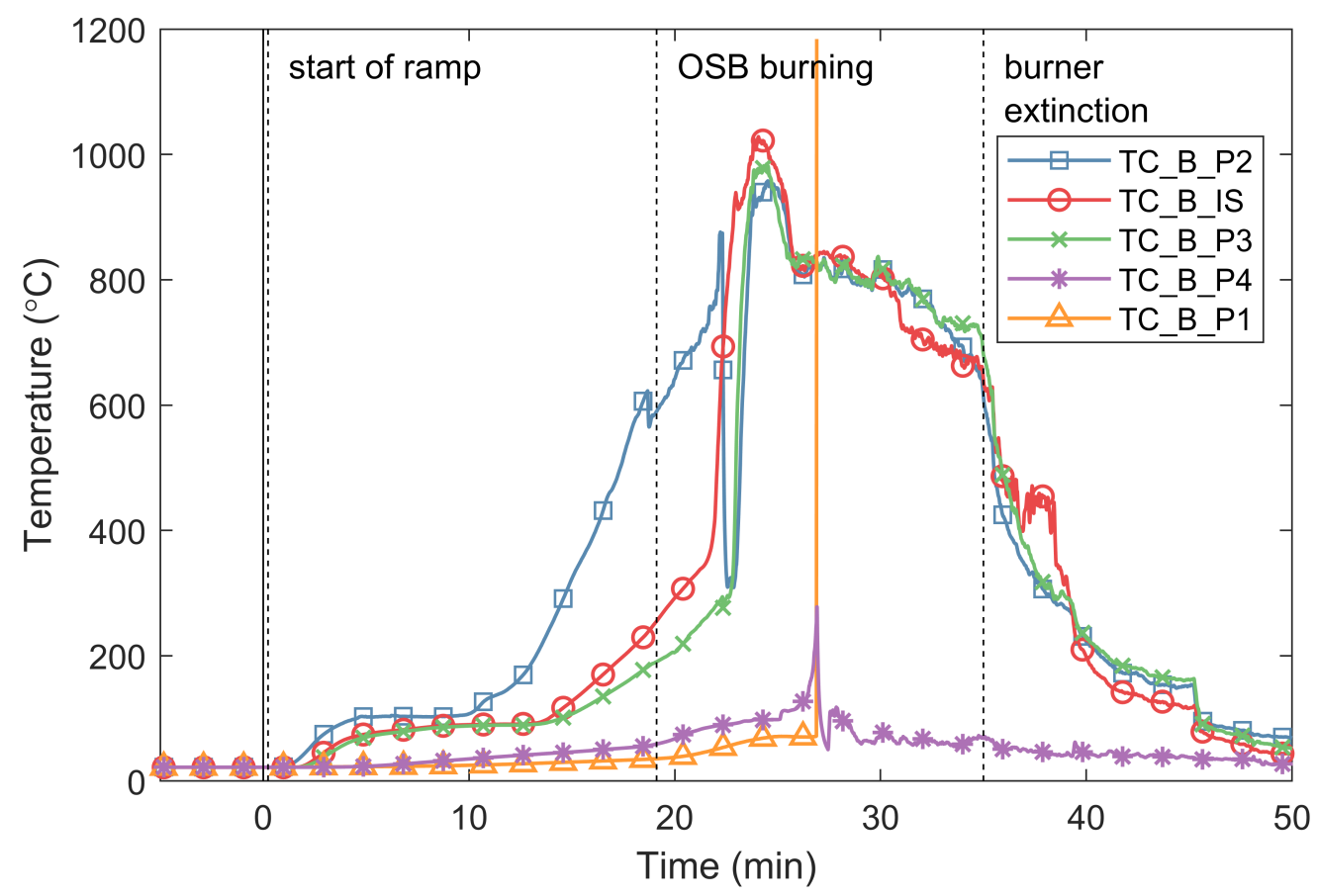

Fig. 214. OSB02 - Temperatures through the specimen at an interior stud $46 \mathrm{~cm}$ from the bottom of the wall. 


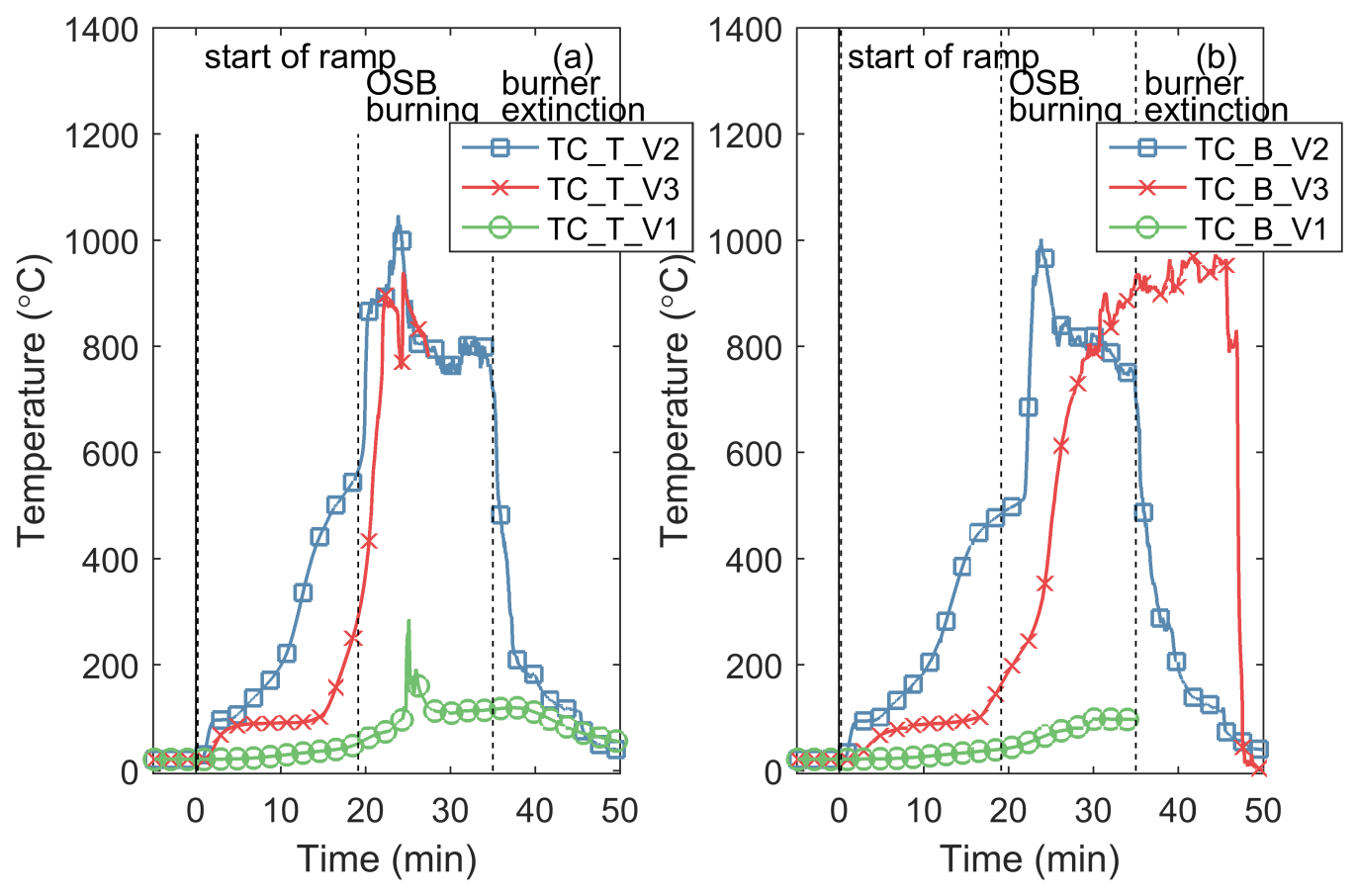

Fig. 215. OSB02 - Temperatures through the specimen midway between interior studs: (a) $46 \mathrm{~cm}$ from the top of the wall; (b) $46 \mathrm{~cm}$ from the bottom of the wall.
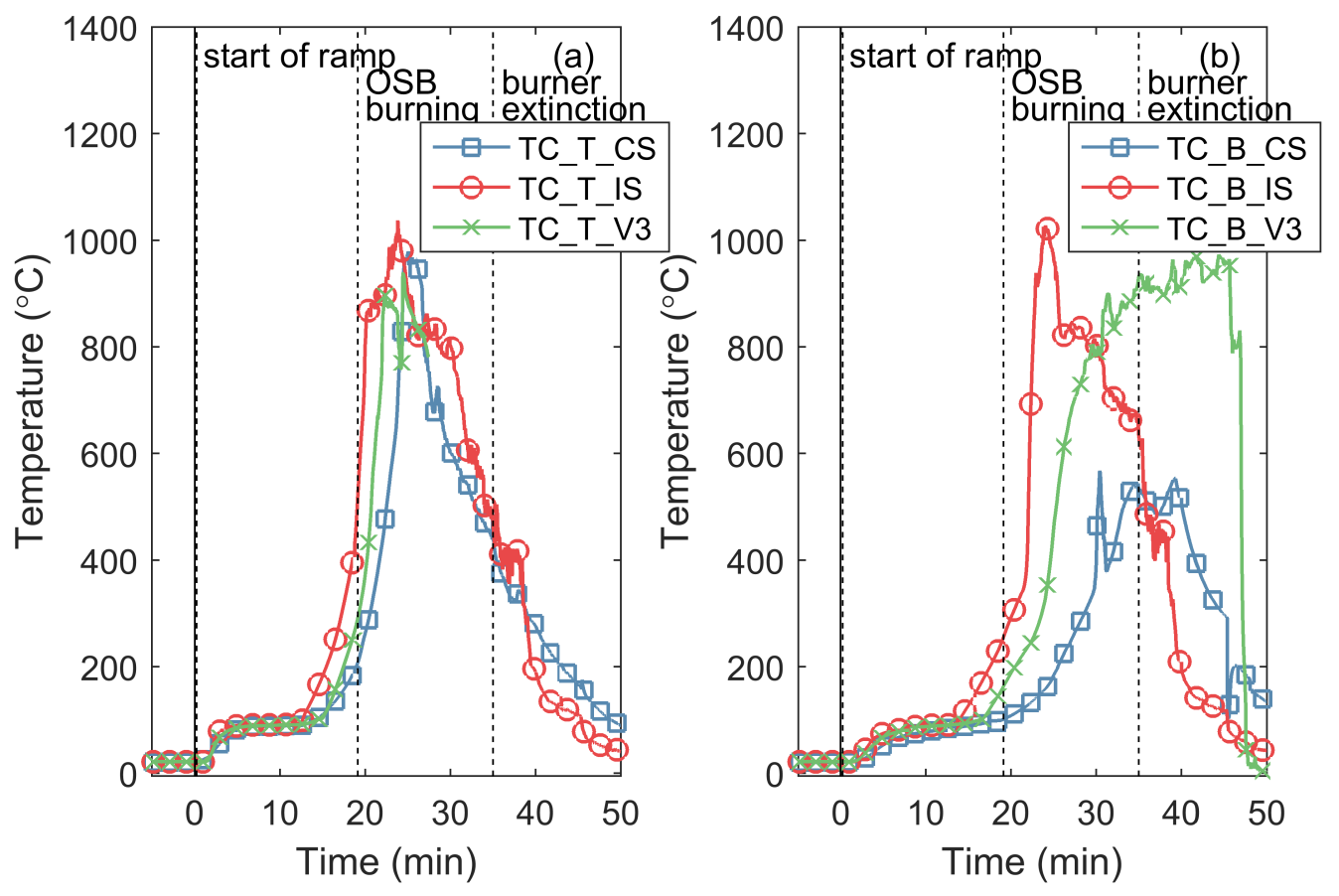

Fig. 216. OSB02 - Temperatures of the framing and sheathing elements: (a) $46 \mathrm{~cm}$ from the top of the wall; (b) $46 \mathrm{~cm}$ from the bottom of the wall. 


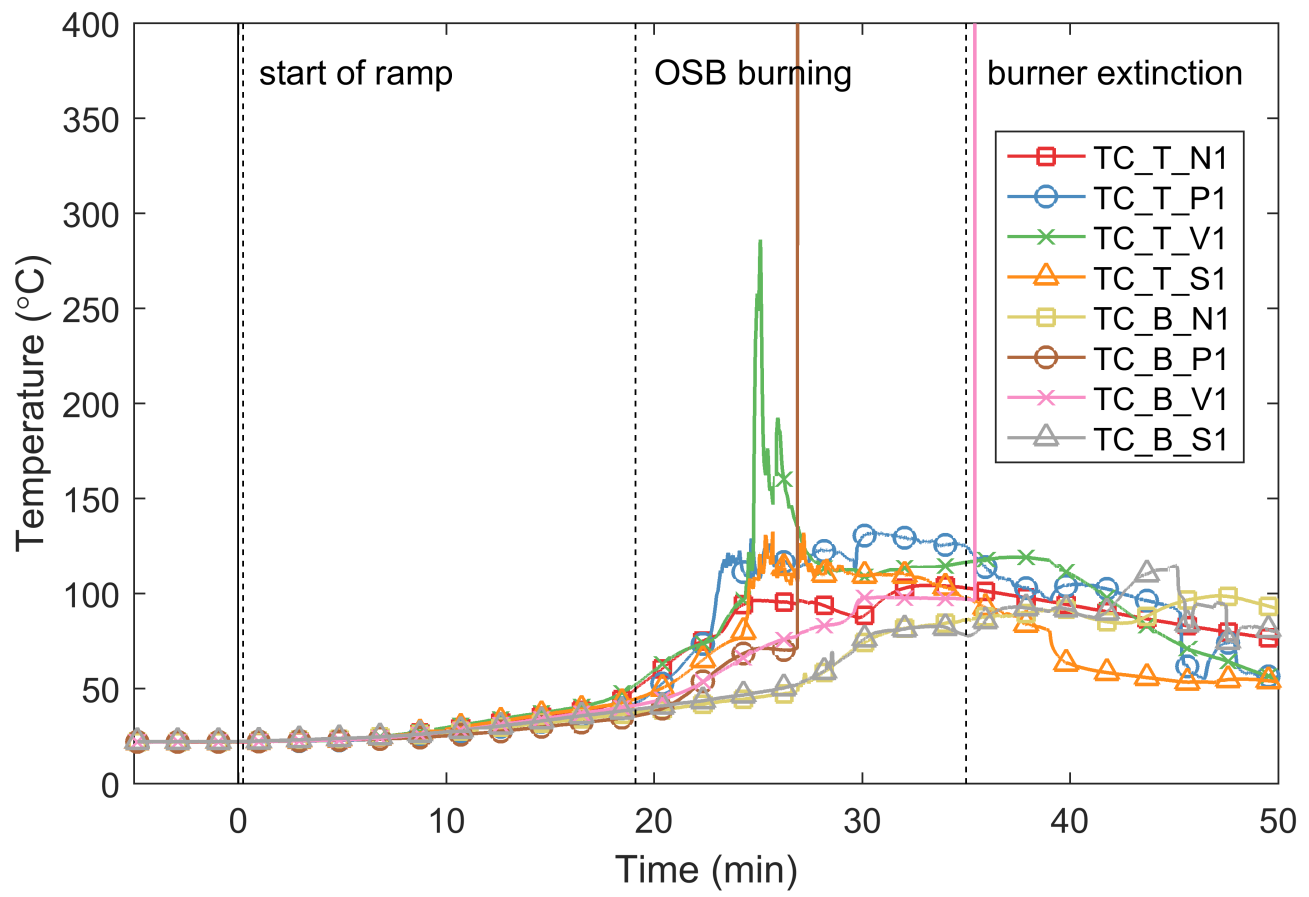

Fig. 217. OSB02 - Temperatures of the gypsum on the unexposed side of the wall specimen.

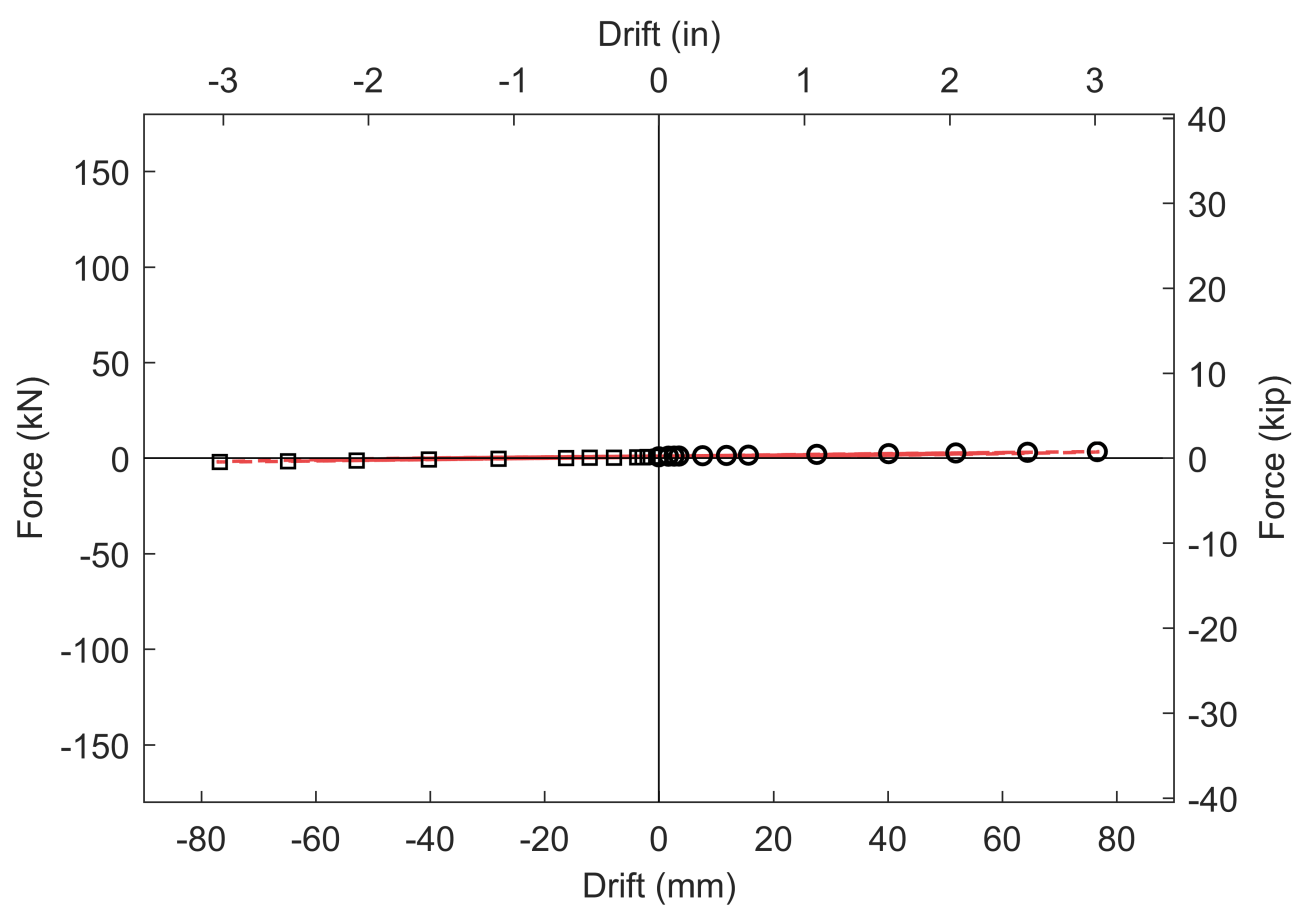

Fig. 218. OSB02 - Applied load versus wall longitudinal drift during mechanical loading. 


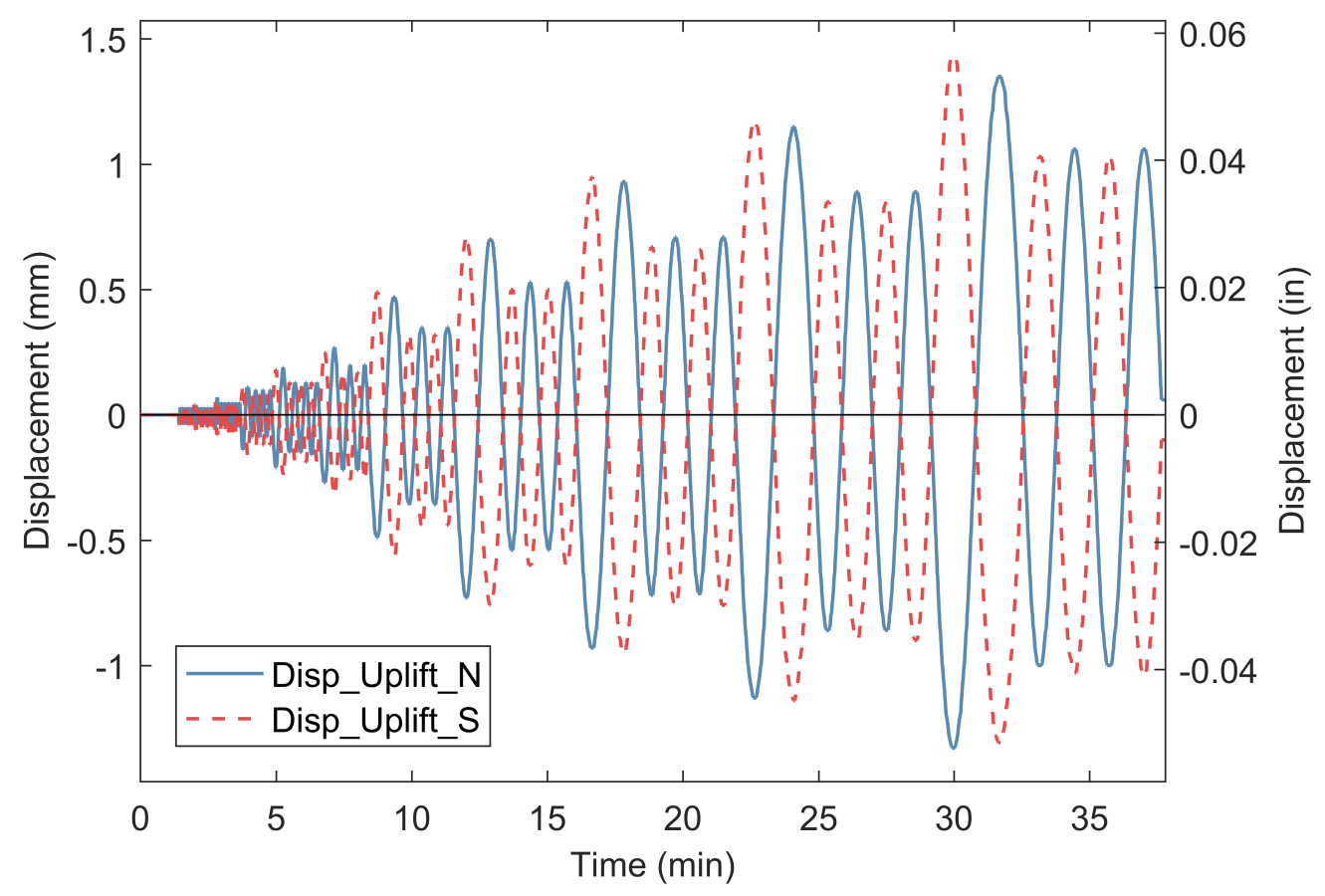

Fig. 219. OSB02 - Uplift at bottom of wall during mechanical loading.

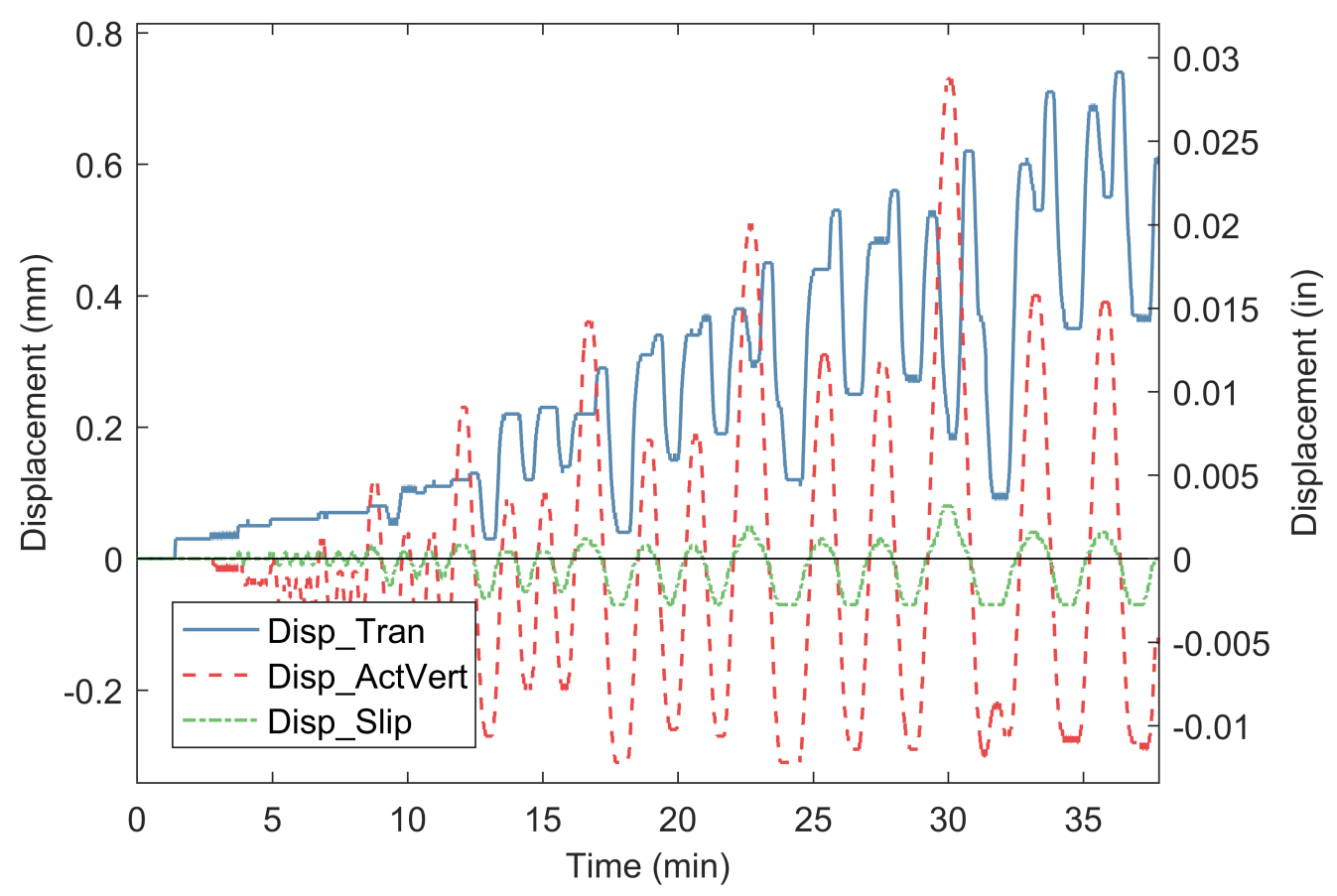

Fig. 220. OSB02 - Ancillary displacement measurements during mechanical loading. 


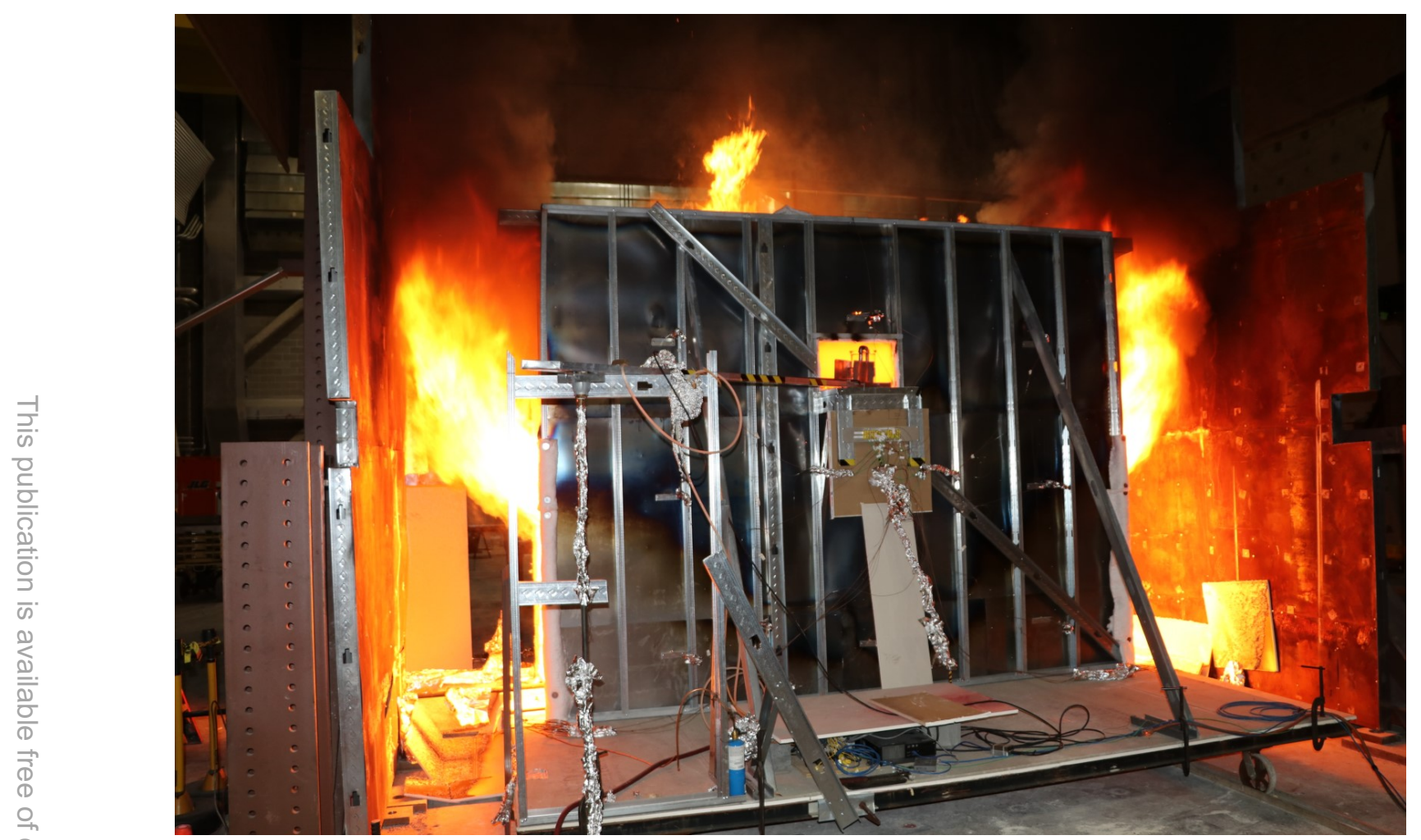

Fig. 221. OSB02 - Photograph of back of the compartment during the fire test.

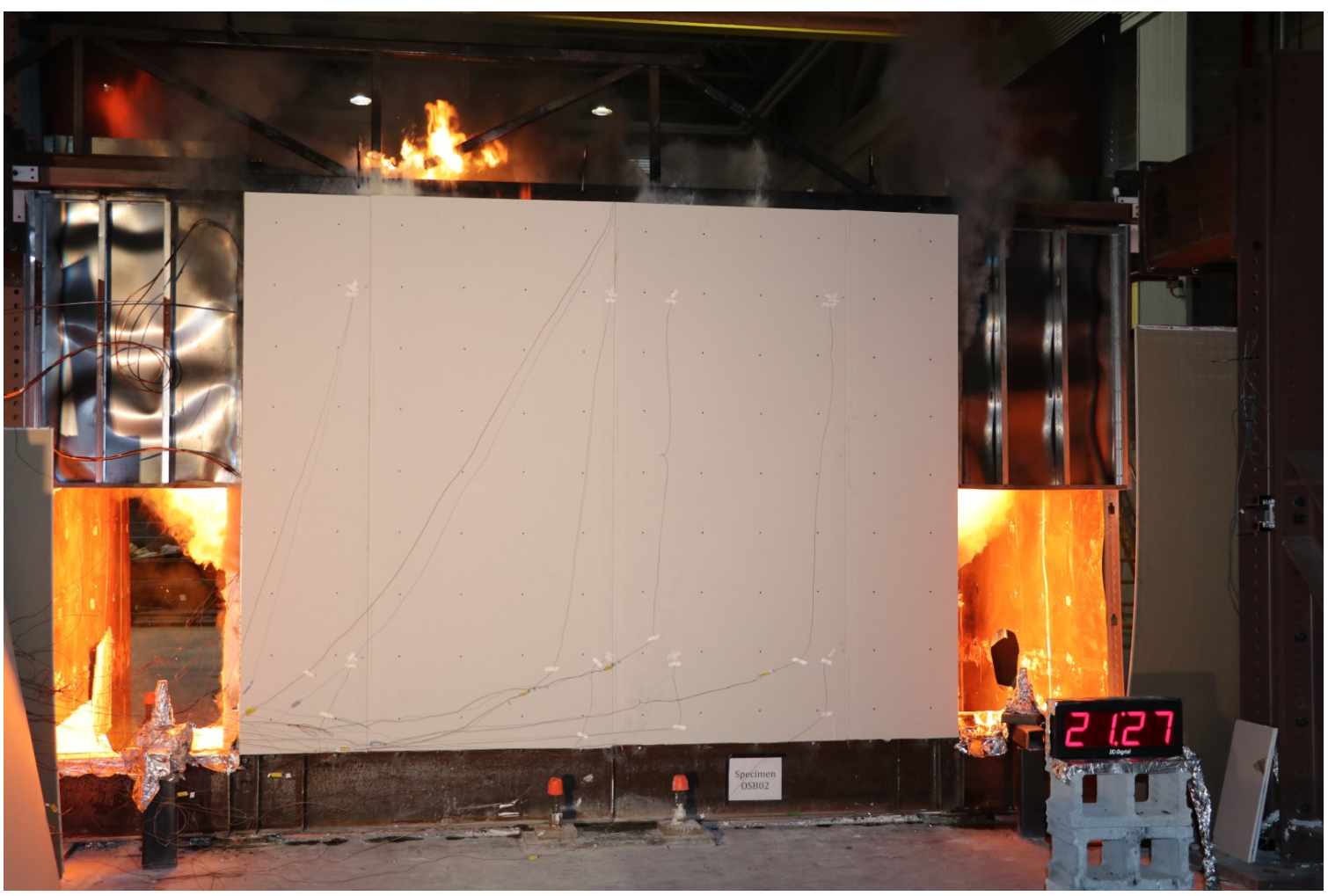

Fig. 222. OSB02 - Photograph of unexposed side of wall $21 \mathrm{~min} 27 \mathrm{~s}$ after ignition. 


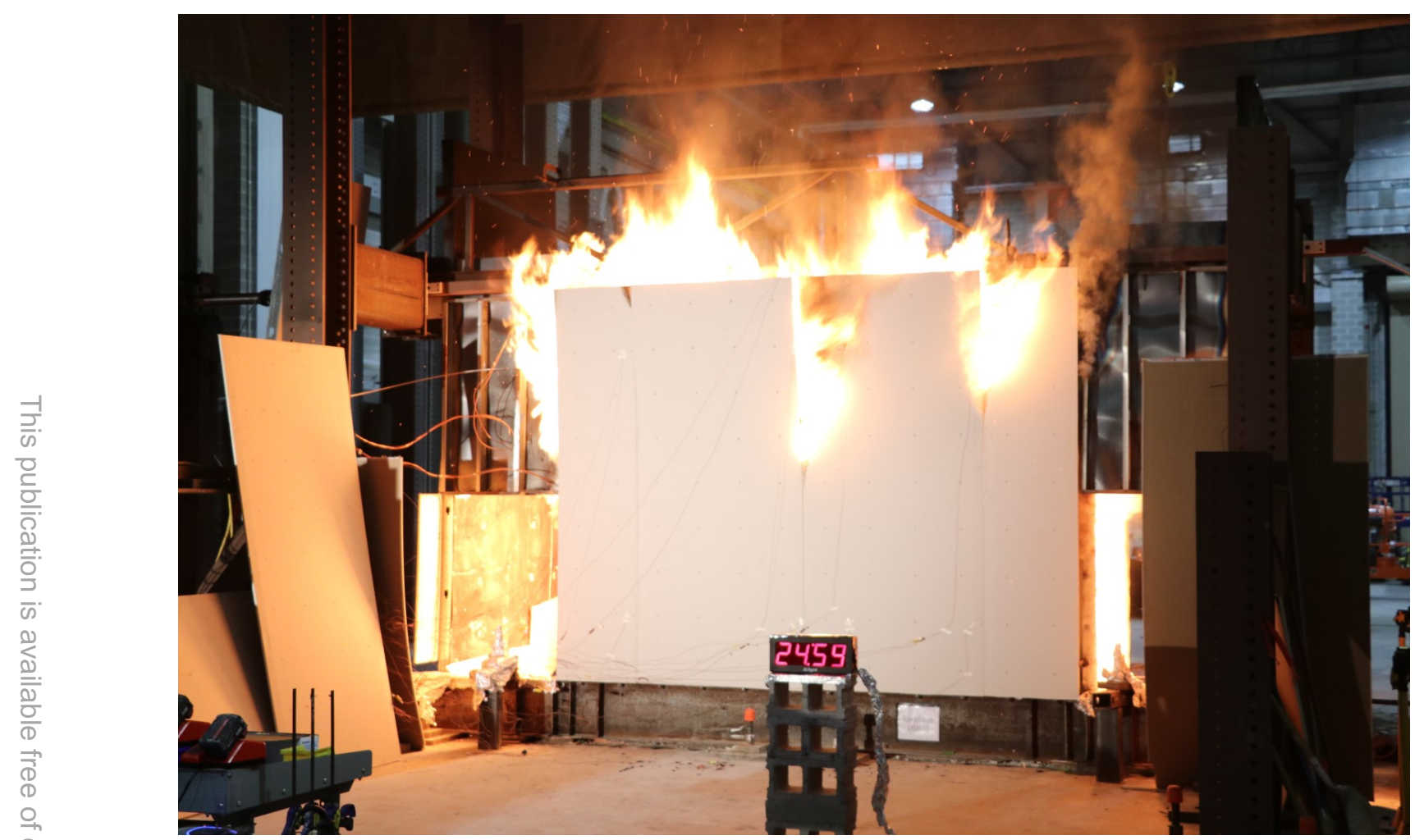

Fig. 223. OSB02 - Photograph of unexposed side of wall 24 min $59 \mathrm{~s}$ after ignition.

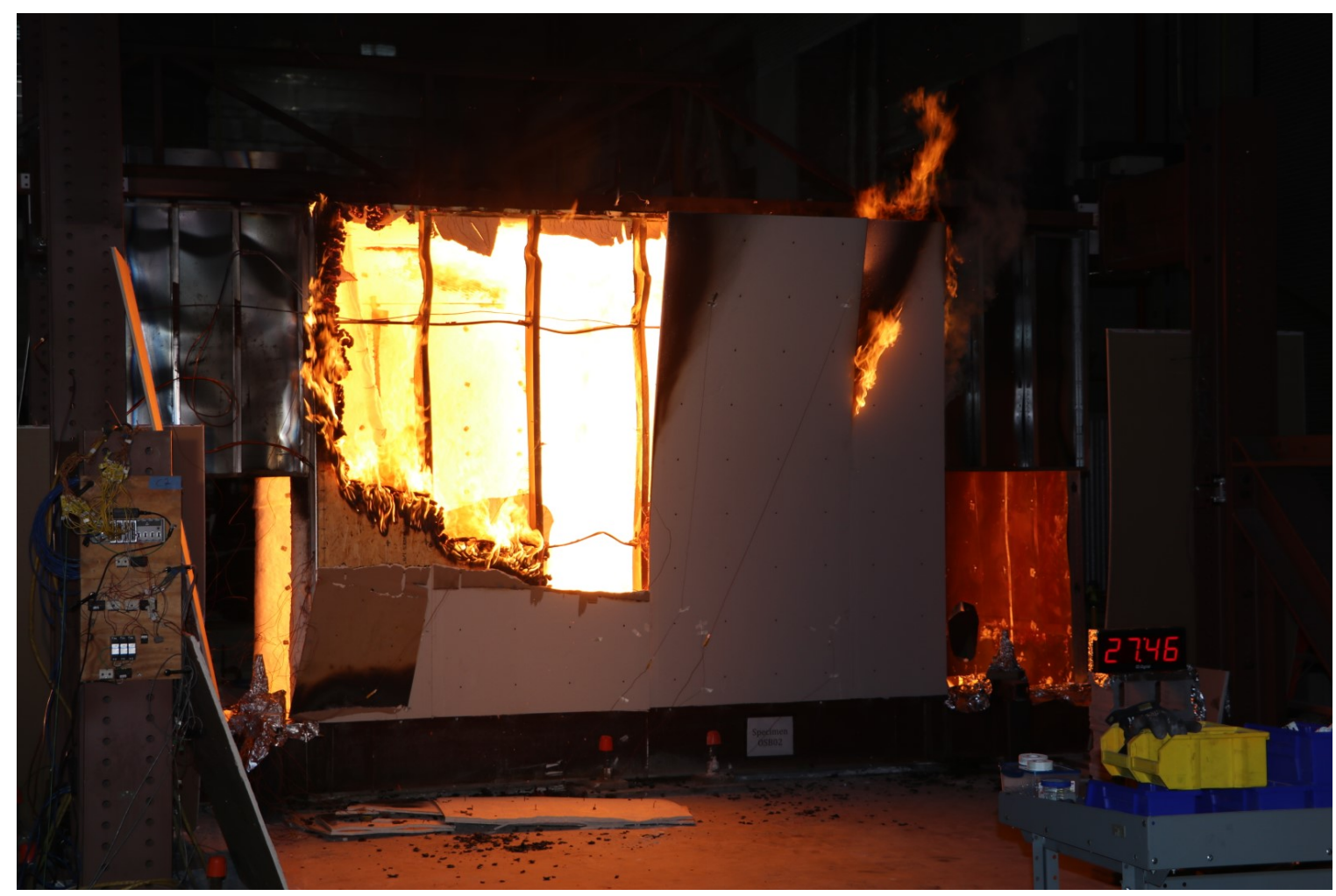

Fig. 224. OSB02 - Photograph of unexposed side of wall $27 \mathrm{~min} 46 \mathrm{~s}$ after ignition. 


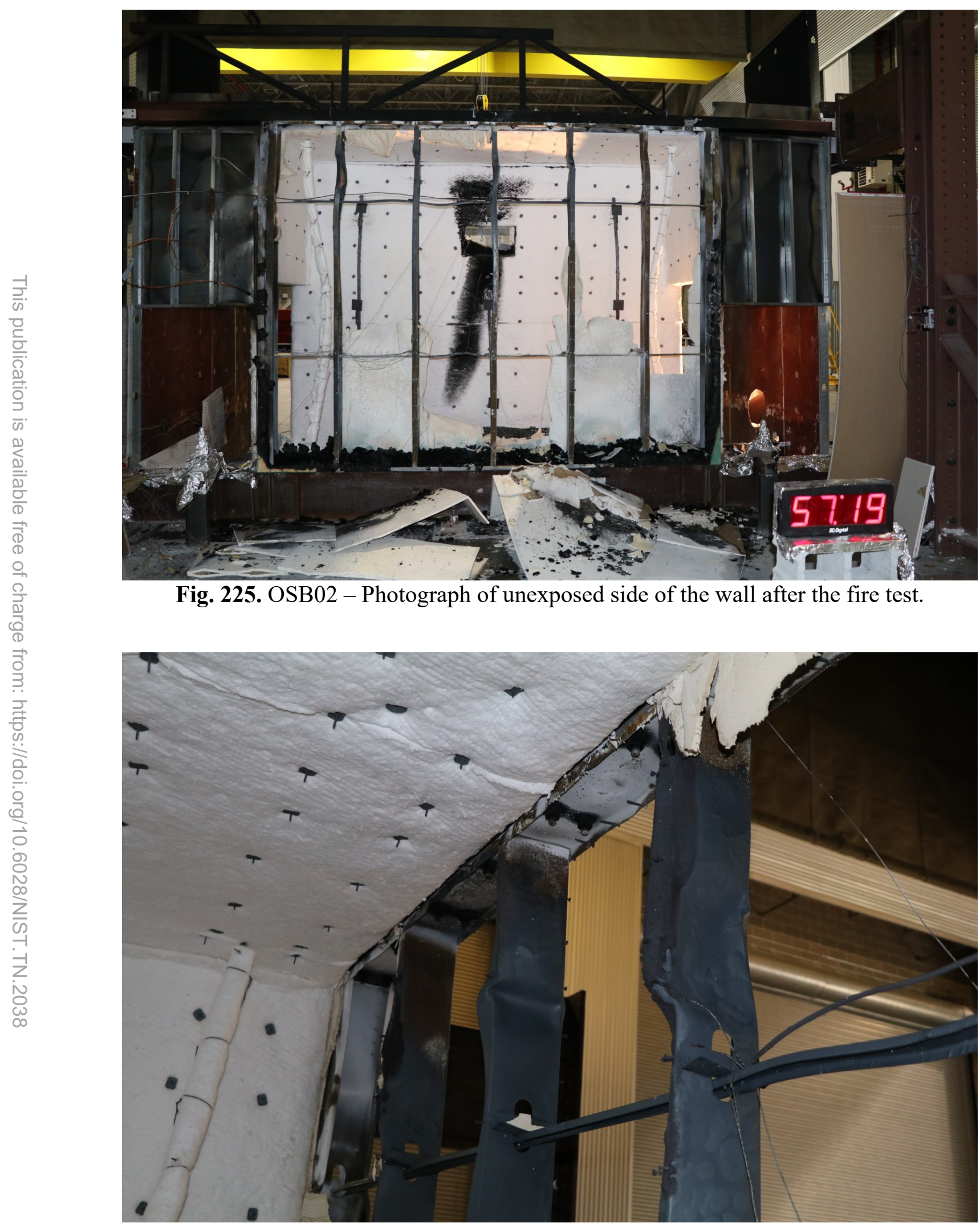

Fig. 226. OSB02 - Photograph of fire damage to interior studs following the fire. 


\section{OSB03 Data}

OSB03b (Mild Fire test of an undamaged wall)

- The gas burner was set to $1.7 \mathrm{MW}$ for $15 \mathrm{~min}$, and temperatures were recorded up to 45 min (Fig. 227).

- No ignition of the OSB was observed. After the fire, there was only discoloration of the OSB in the center panel (Fig. 241), but OSB was mostly undamaged.

OSB03c (Cyclic test of wall at ambient temperature following Mild Fire)

- Screws pulled though the OSB or caused edge breakout of OSB leading to failure (Fig. 242).

- A $3 \mathrm{~mm}$ (1/8") gap between OSB boards was maintained. A $12 \mathrm{~mm}\left(1 / 2^{\text {" }}\right)$ spacing between the screw and edge of OSB was not maintained at all locations (Fig. 244).

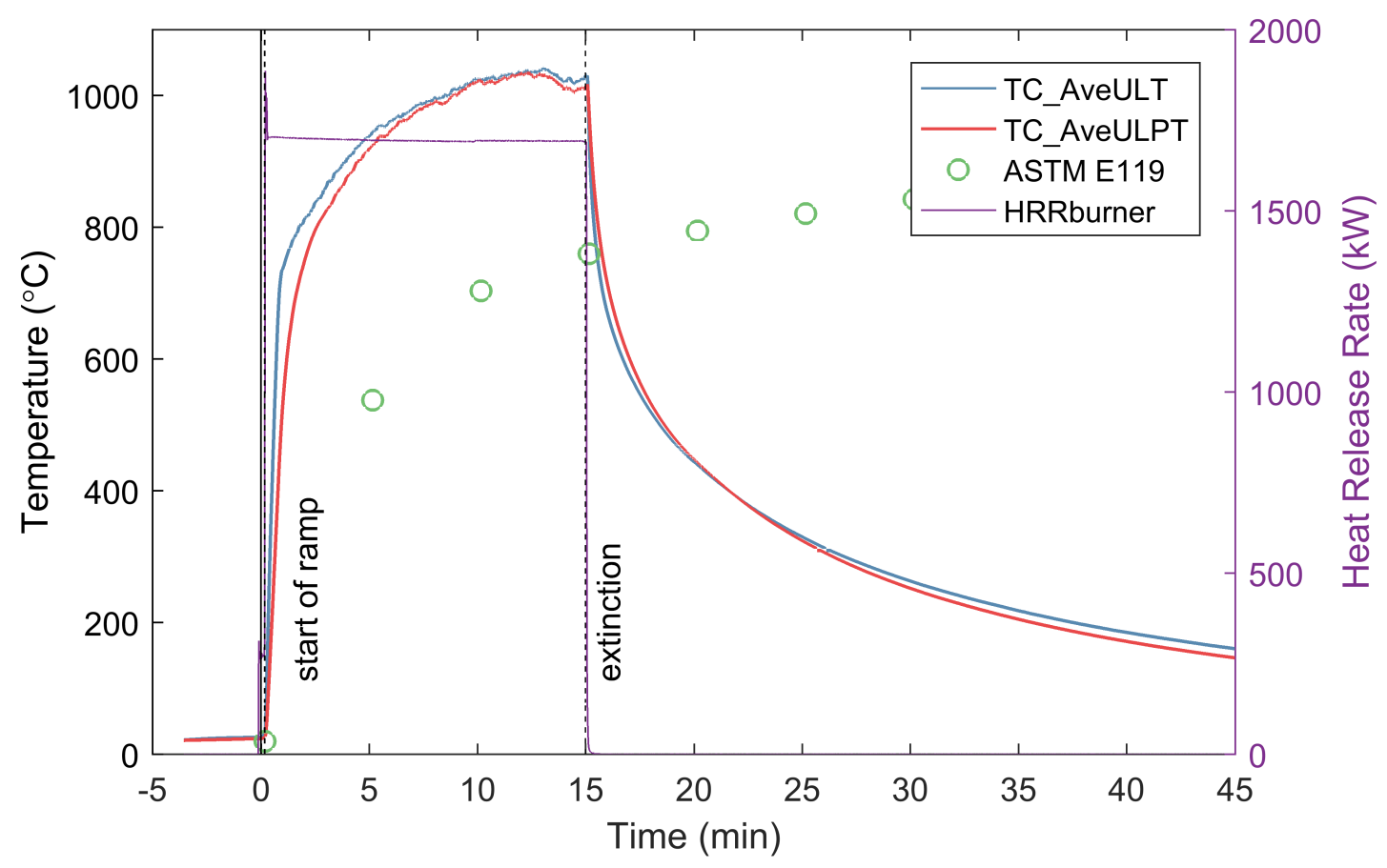

Fig. 227. OSB03 - Compartment temperature and burner Heat Release Rate. 


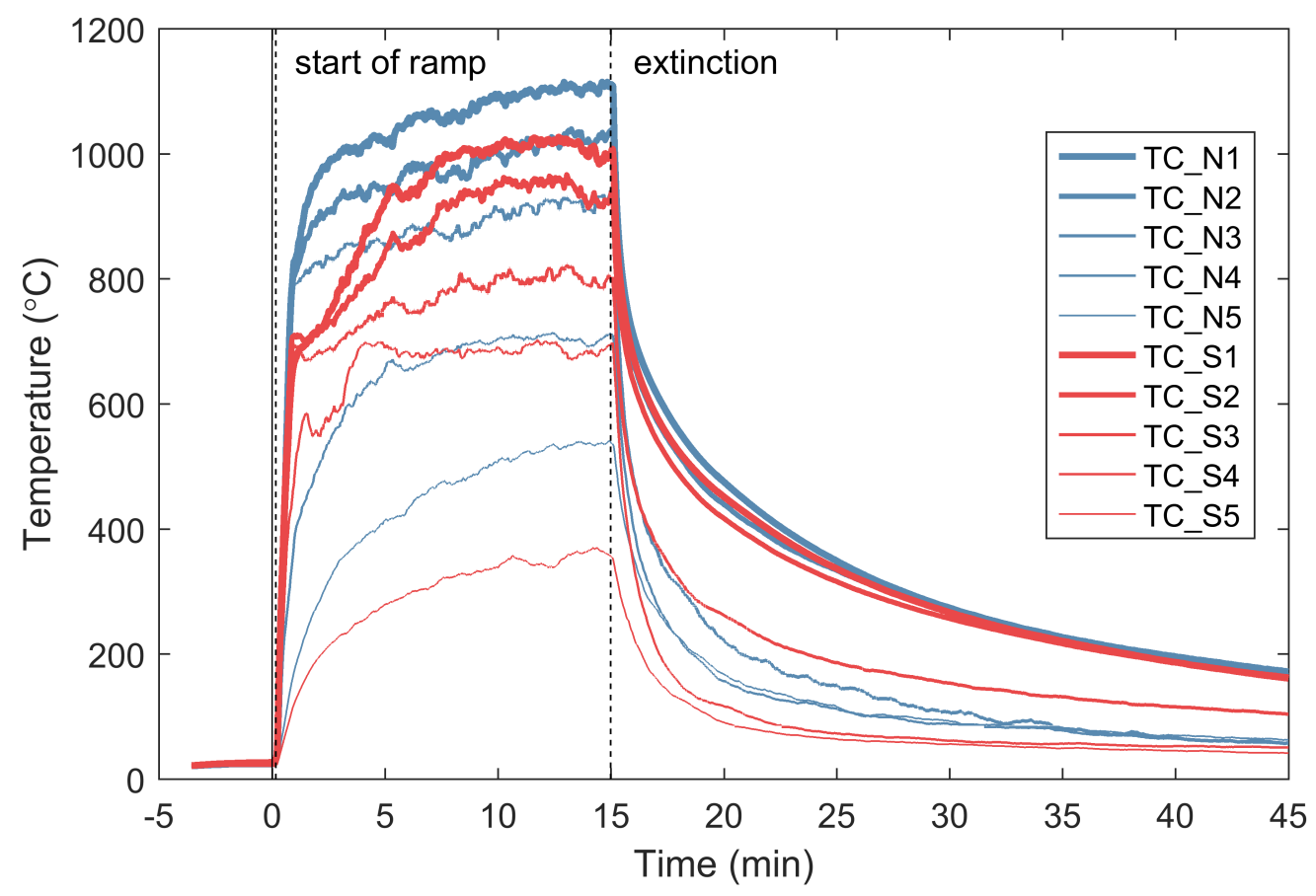

Fig. 228. OSB03 - Compartment temperatures measured by the thermocouple arrays.

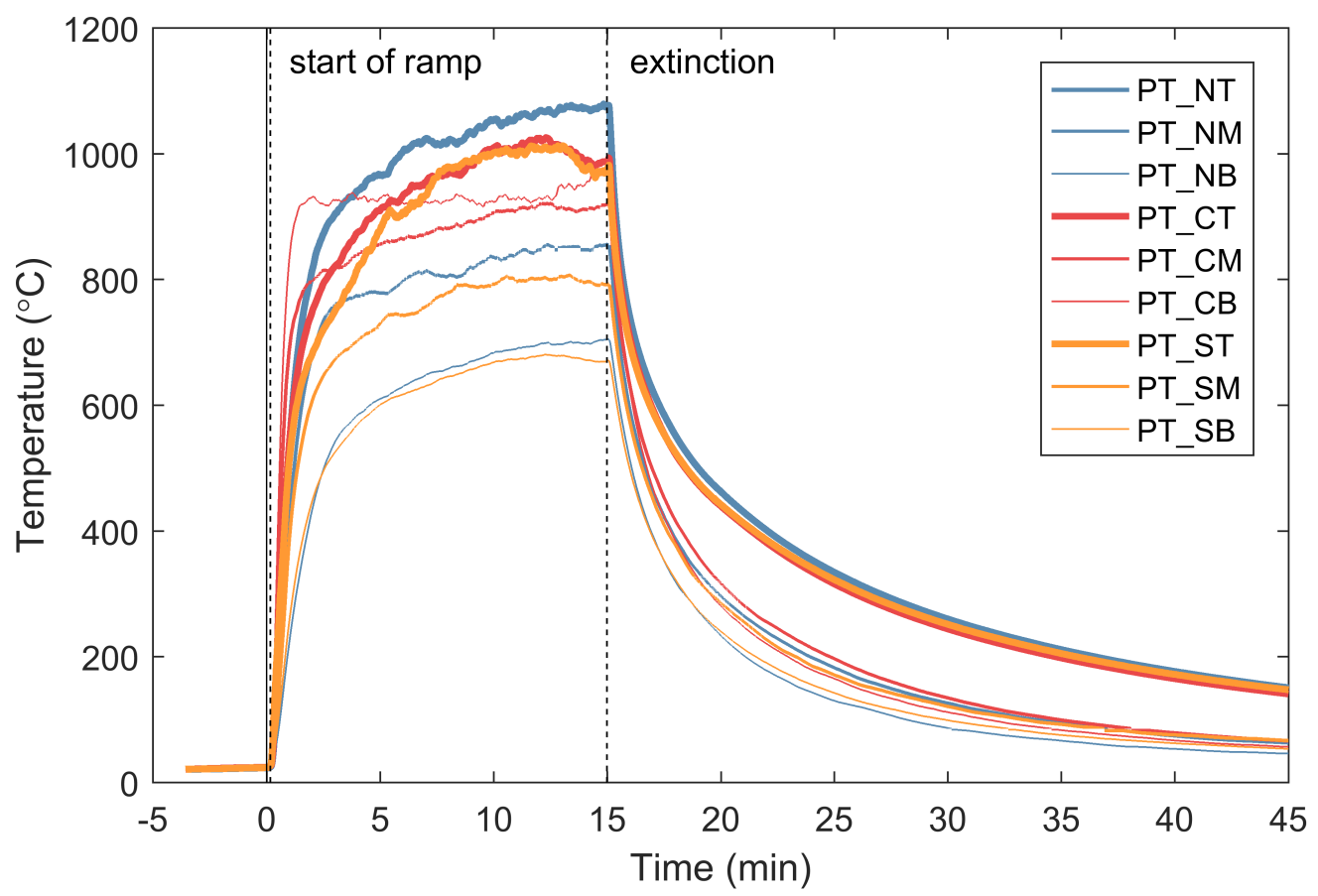

Fig. 229. OSB03 - Compartment temperatures measured by the plate thermocouples. 


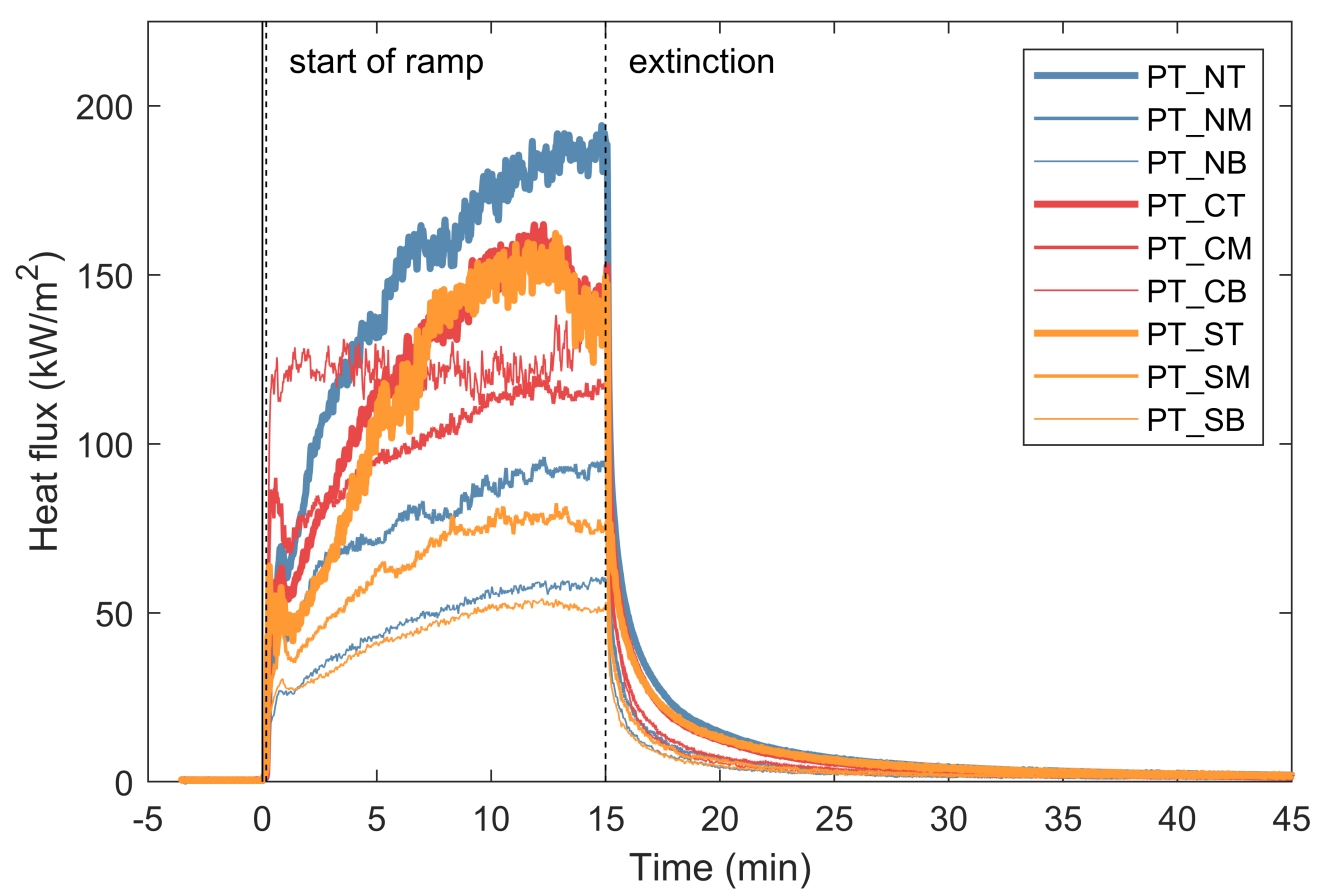

Fig. 230. OSB03 - Heat fluxes in the compartment measured by the plate thermocouples.
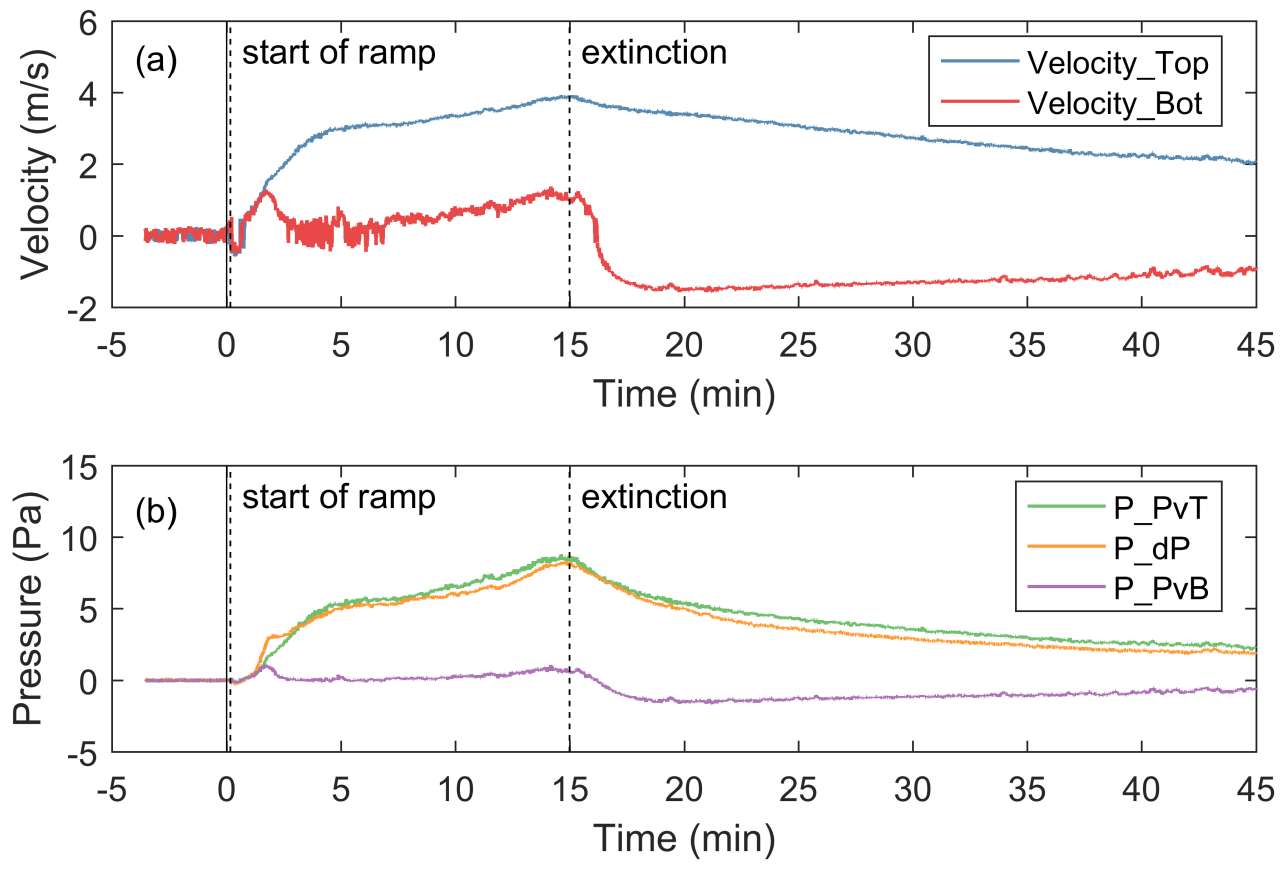

Fig. 231. OSB03 - (a) Velocity of air flow at the top and bottom knockouts of the chord stud; (b) Pressure at the top and bottom knockouts of the chord stud and in the wall cavity near the top. 


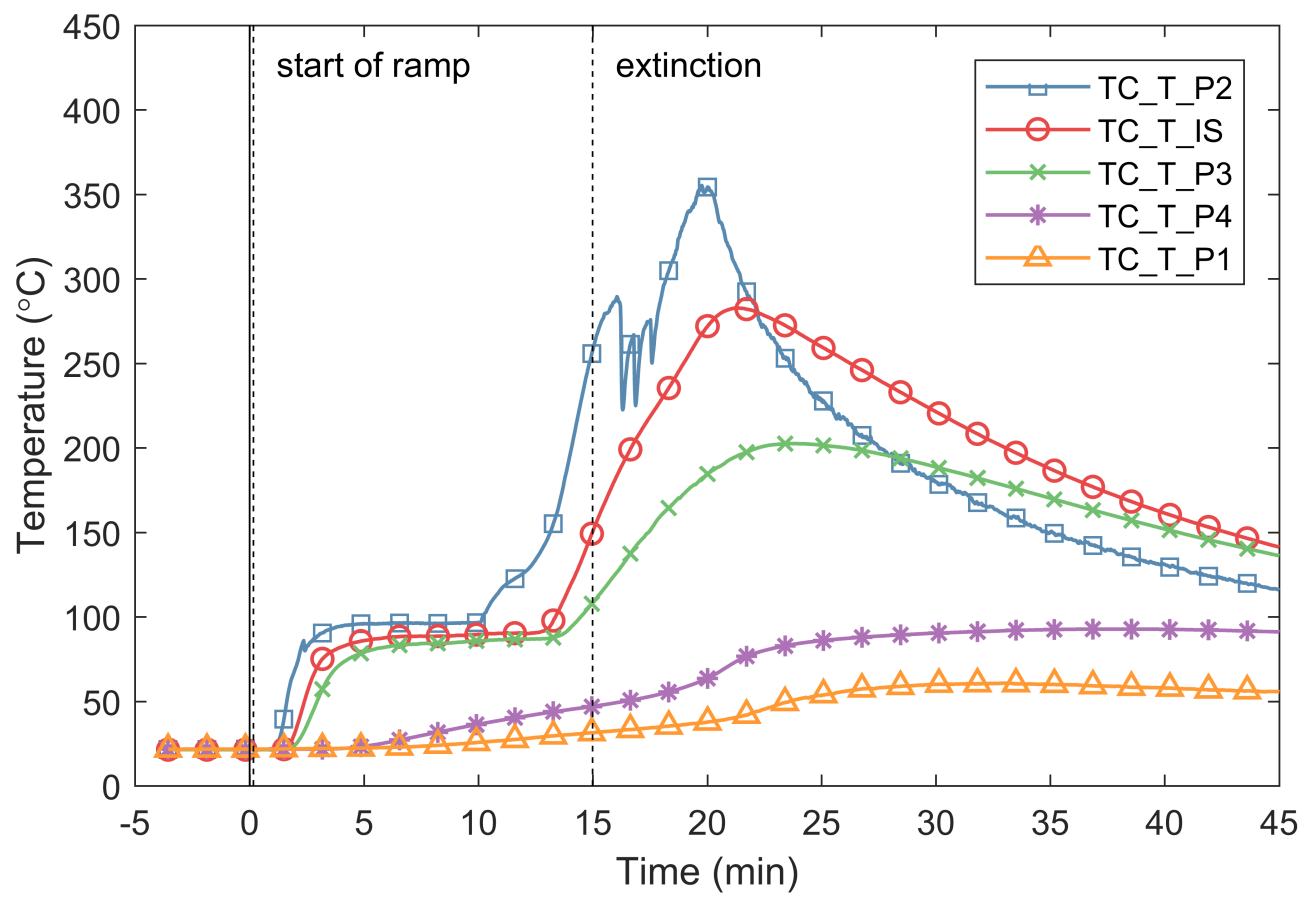

Fig. 232. OSB03 - Temperatures through the specimen at an interior stud $46 \mathrm{~cm}$ from the top of the wall.

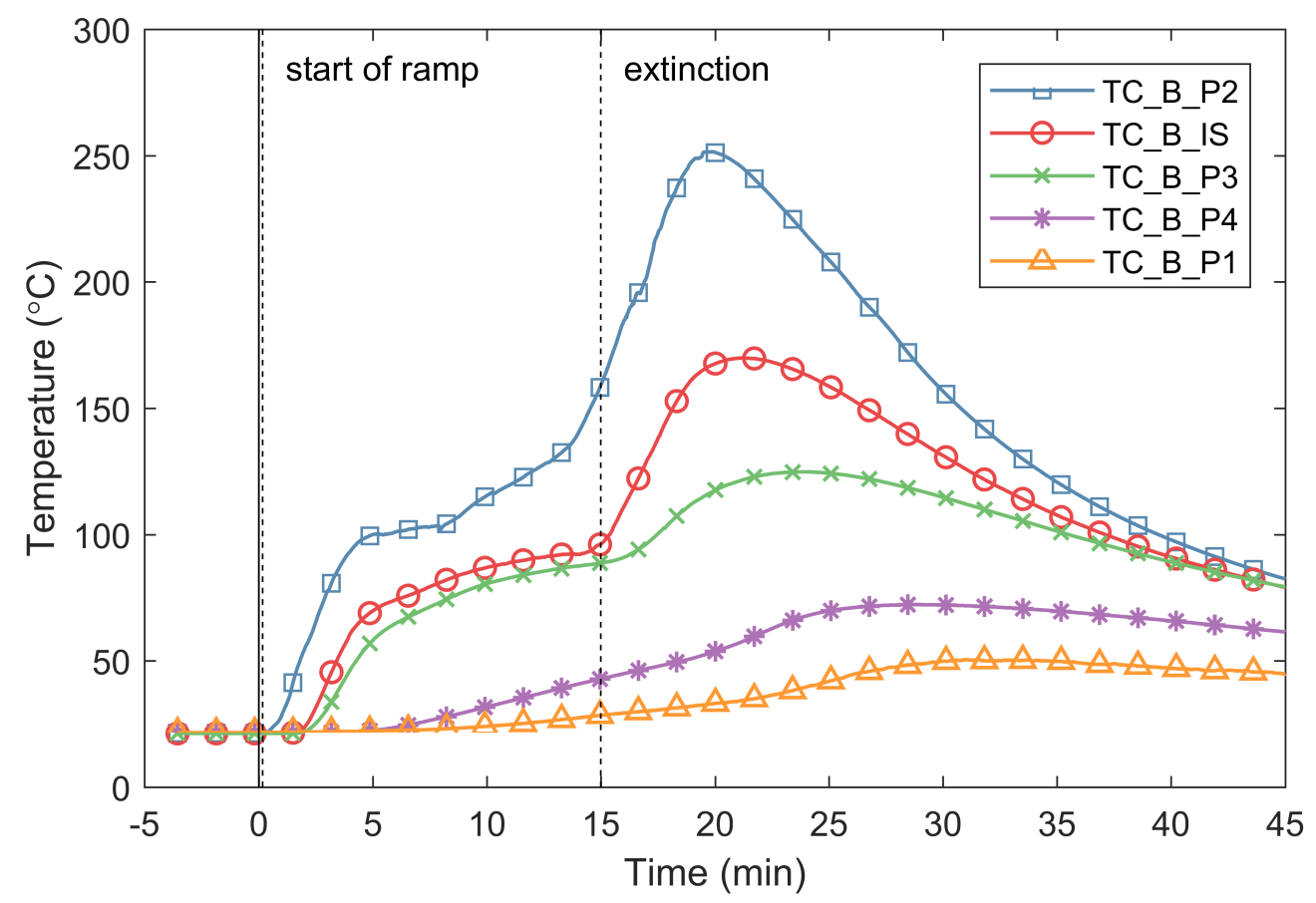

Fig. 233. OSB03 - Temperatures through the specimen at an interior stud $46 \mathrm{~cm}$ from the bottom of the wall. 

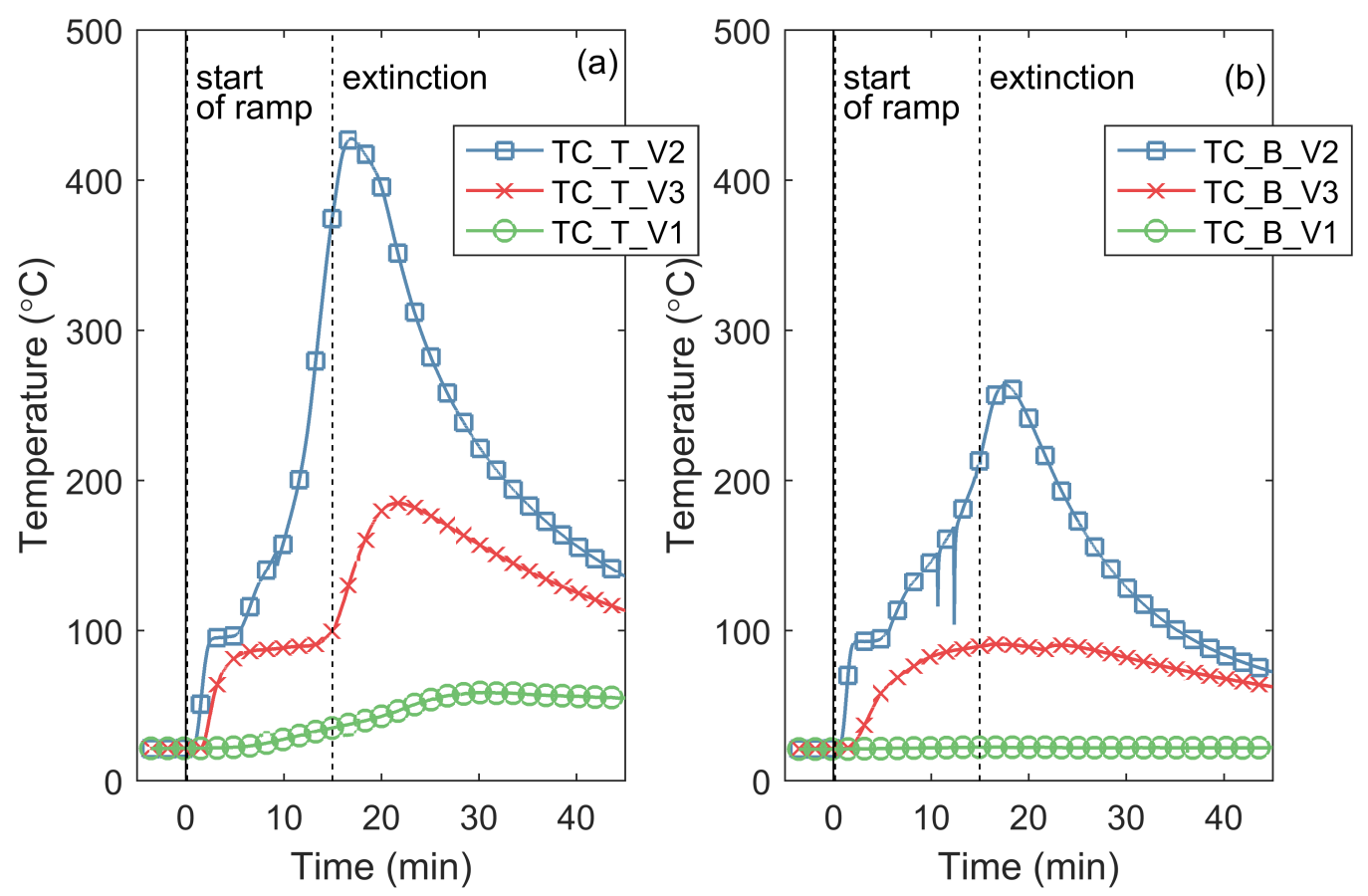

Fig. 234. OSB03 - Temperatures through the specimen midway between interior studs: (a) $46 \mathrm{~cm}$ from the top of the wall; (b) $46 \mathrm{~cm}$ from the bottom of the wall.
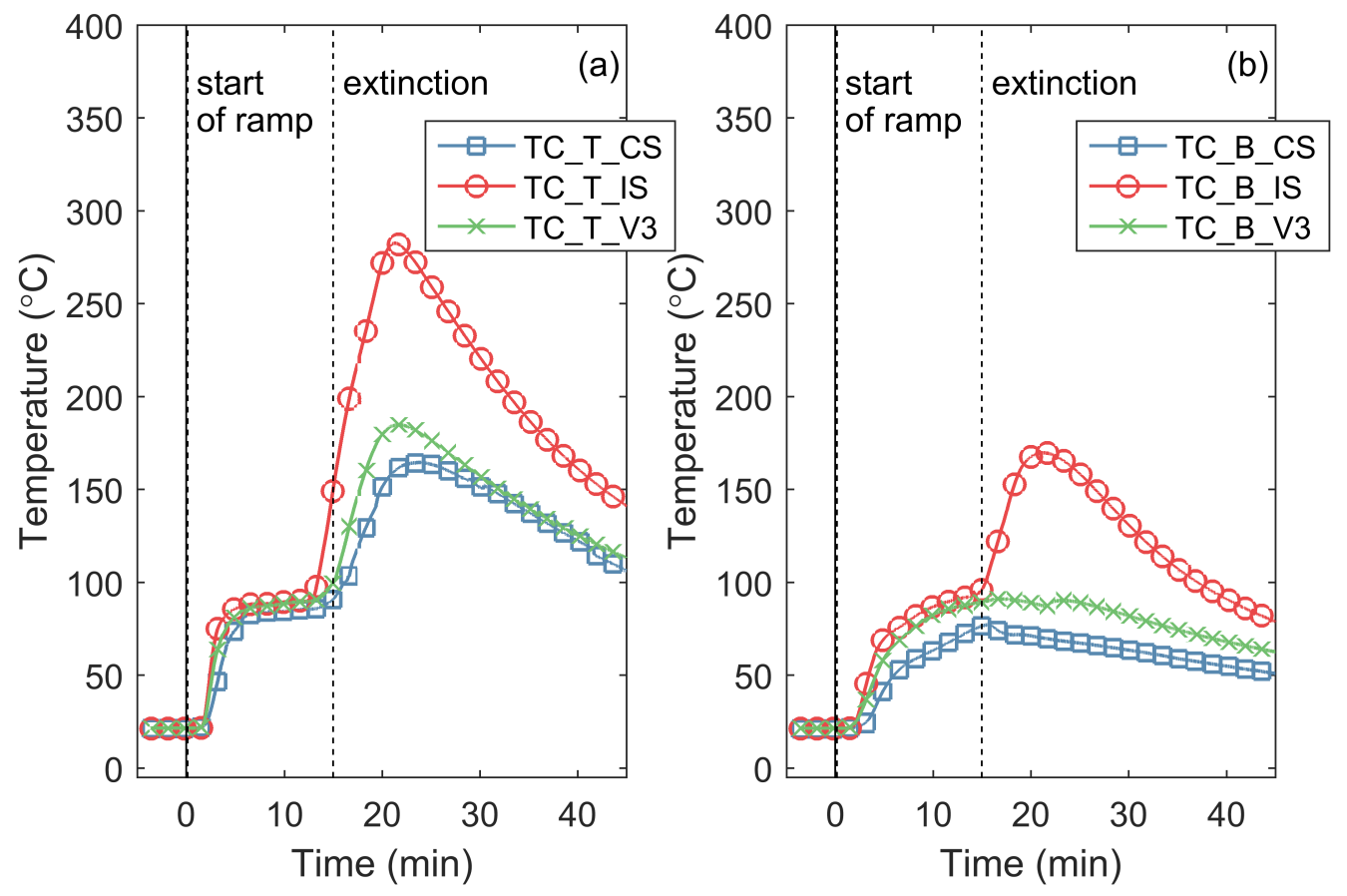

Fig. 235. OSB03 - Temperatures of the framing and sheathing elements: (a) $46 \mathrm{~cm}$ from the top of the wall; (b) $46 \mathrm{~cm}$ from the bottom of the wall. 


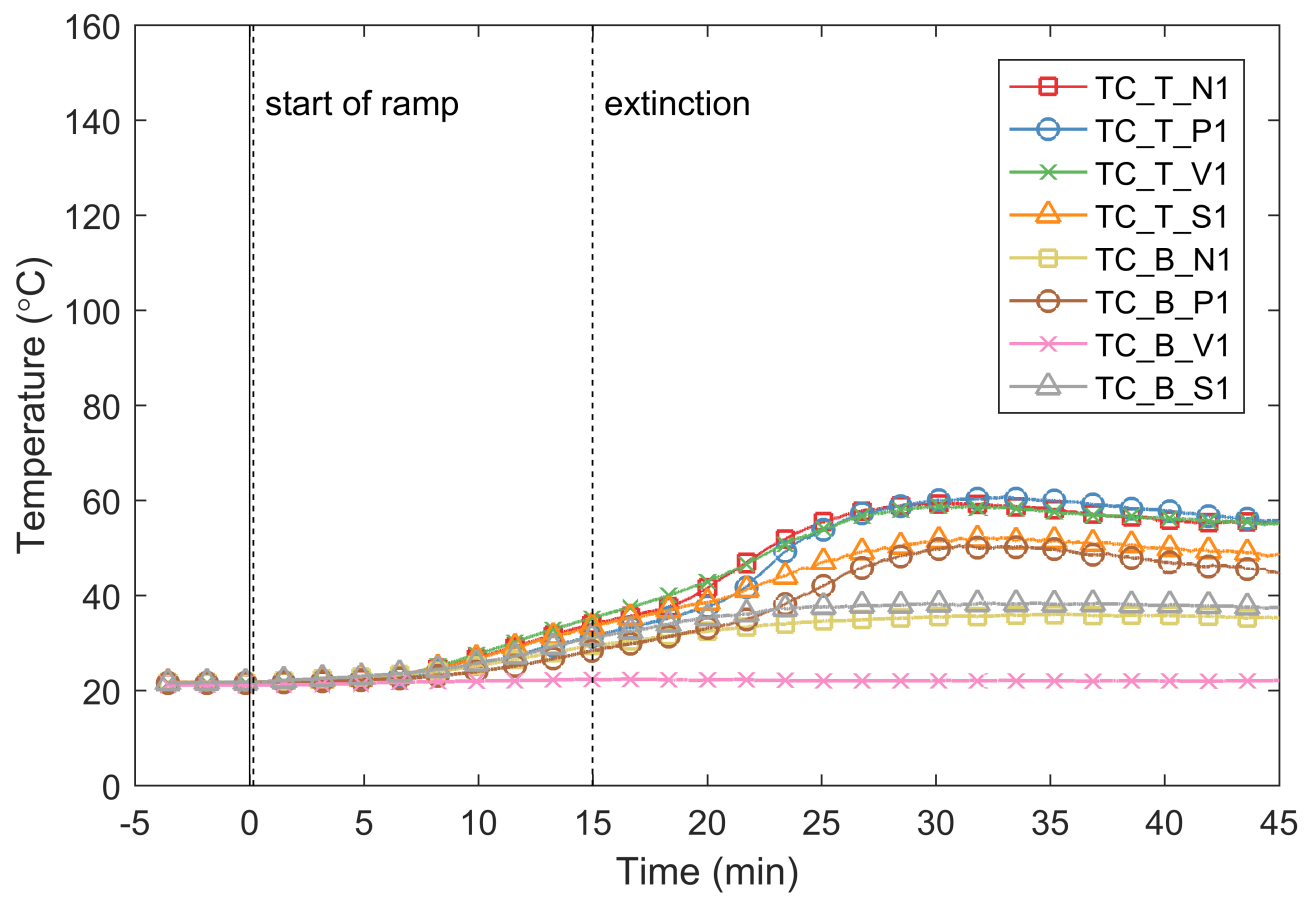

Fig. 236. OSB03 - Temperatures of the gypsum on the unexposed side of the wall specimen.

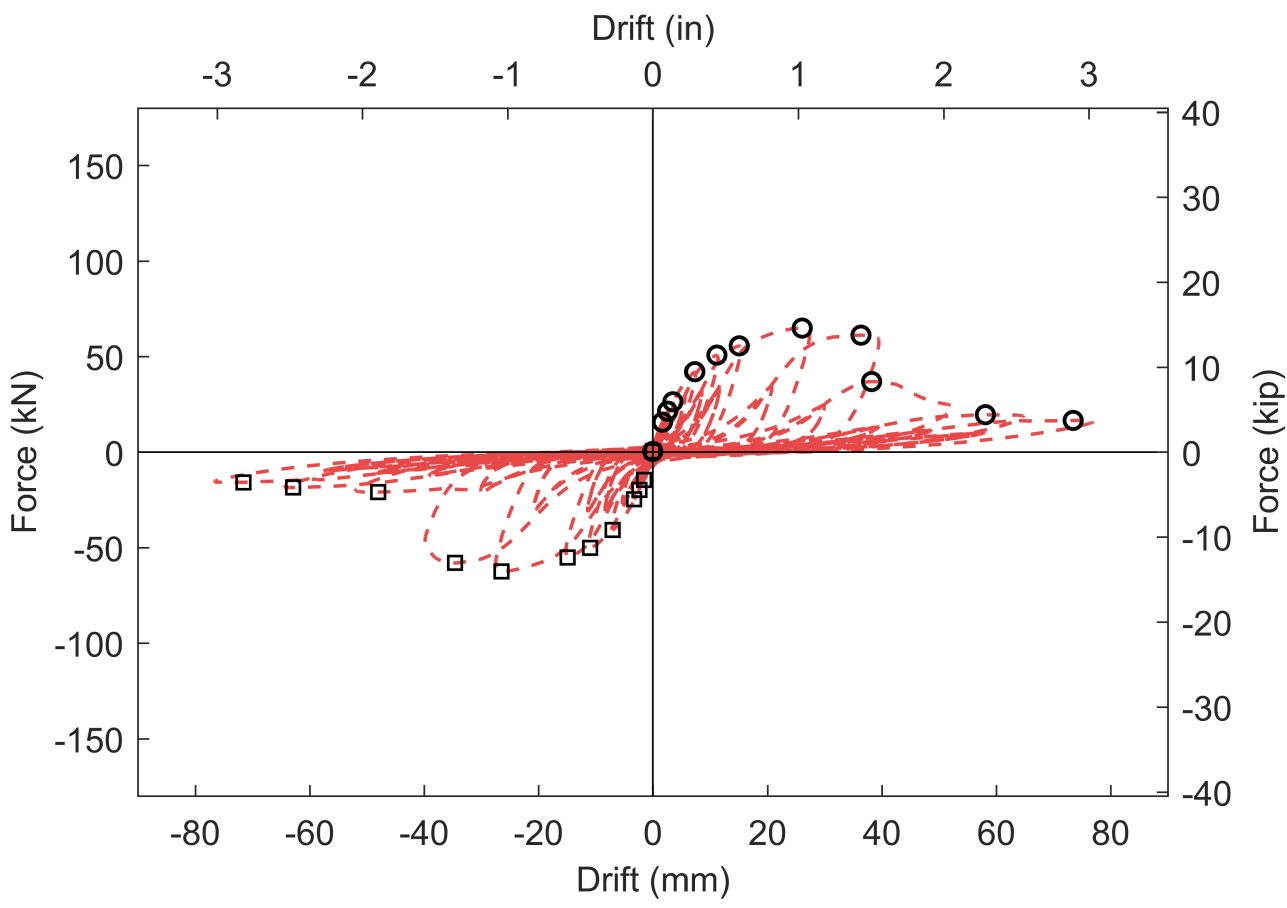

Fig. 237. OSB03 - Applied load versus wall longitudinal drift during mechanical loading. 


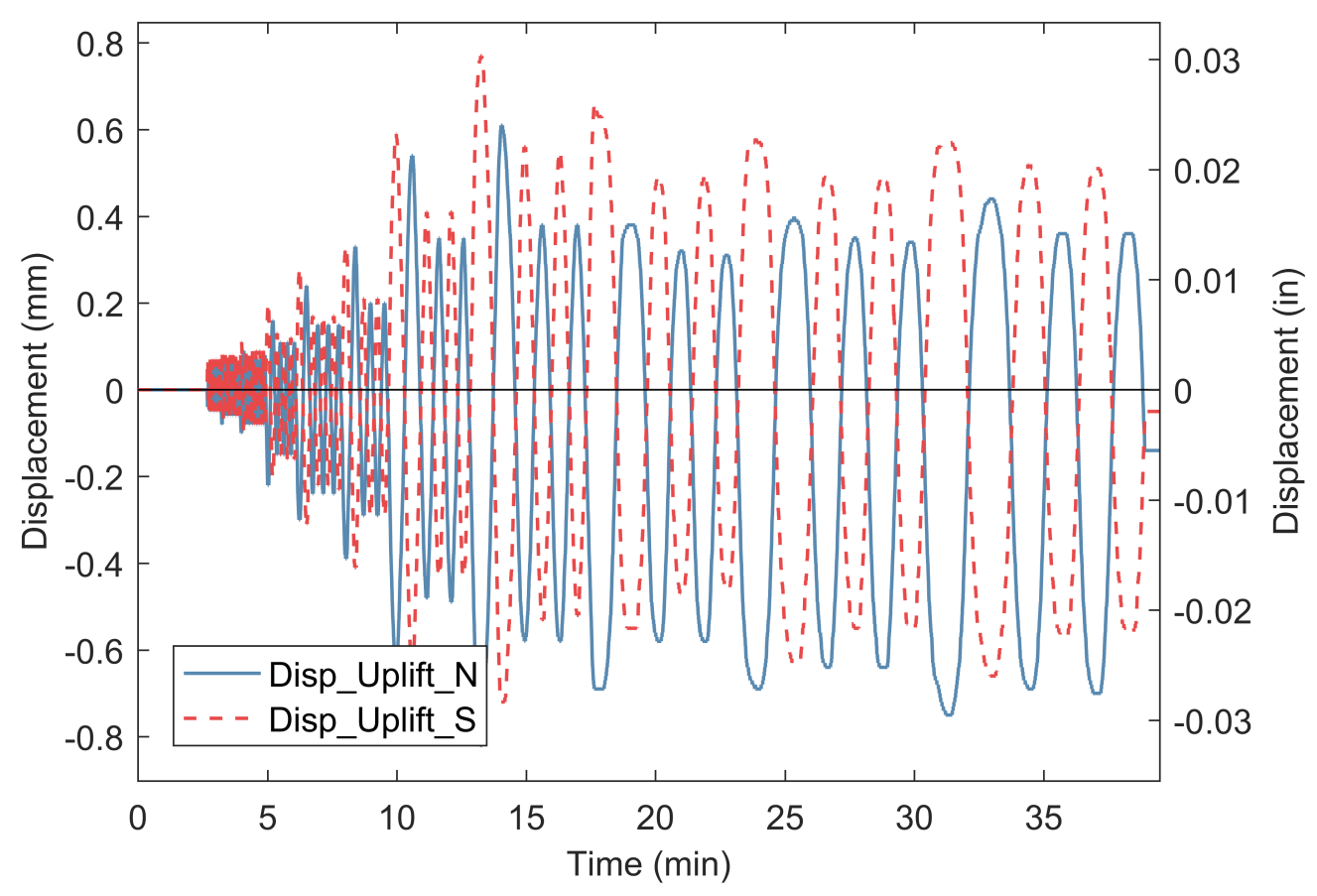

Fig. 238. OSB03 - Uplift at bottom of wall during mechanical loading.

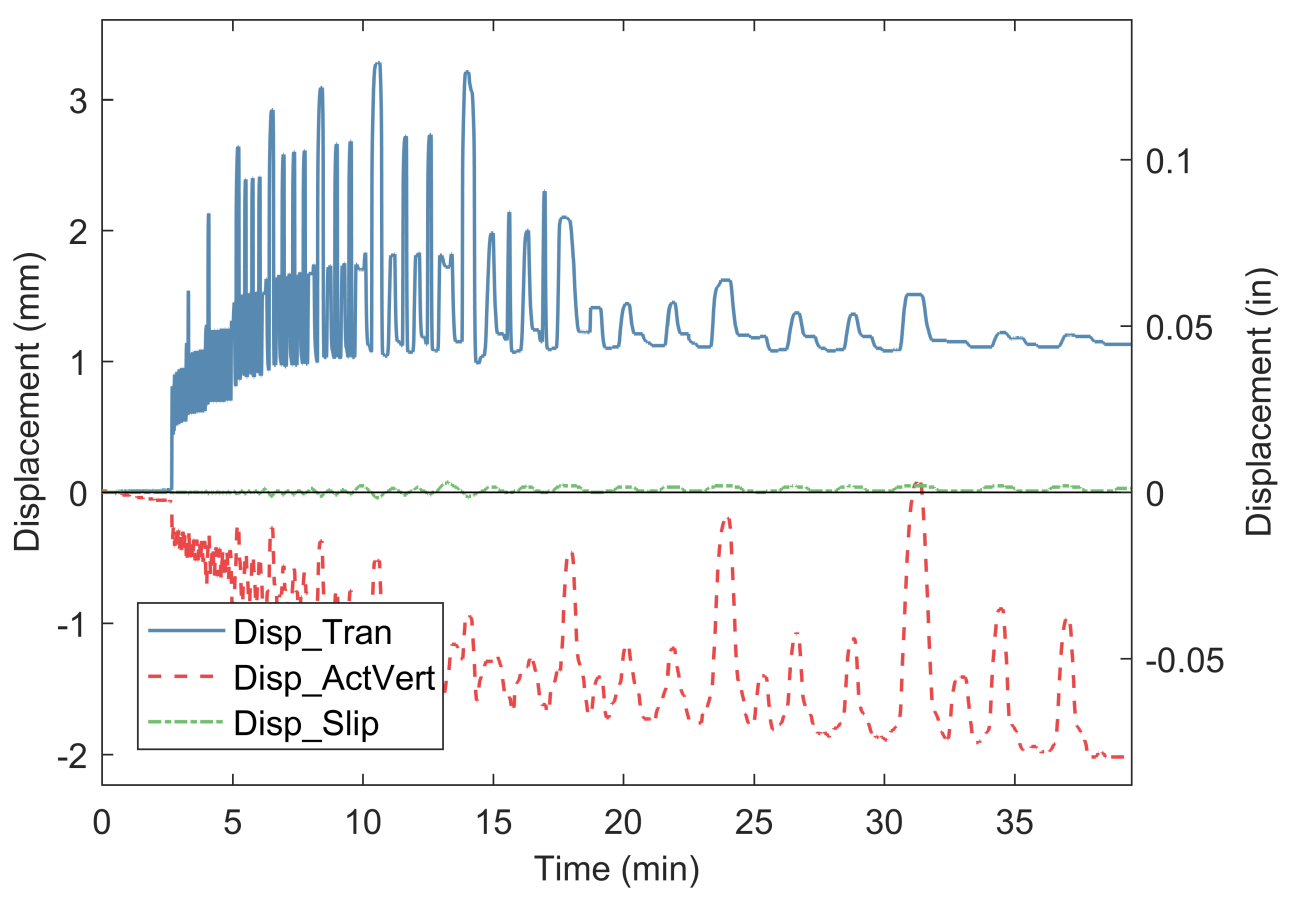

Fig. 239. OSB03 - Ancillary displacement measurements during mechanical loading. 


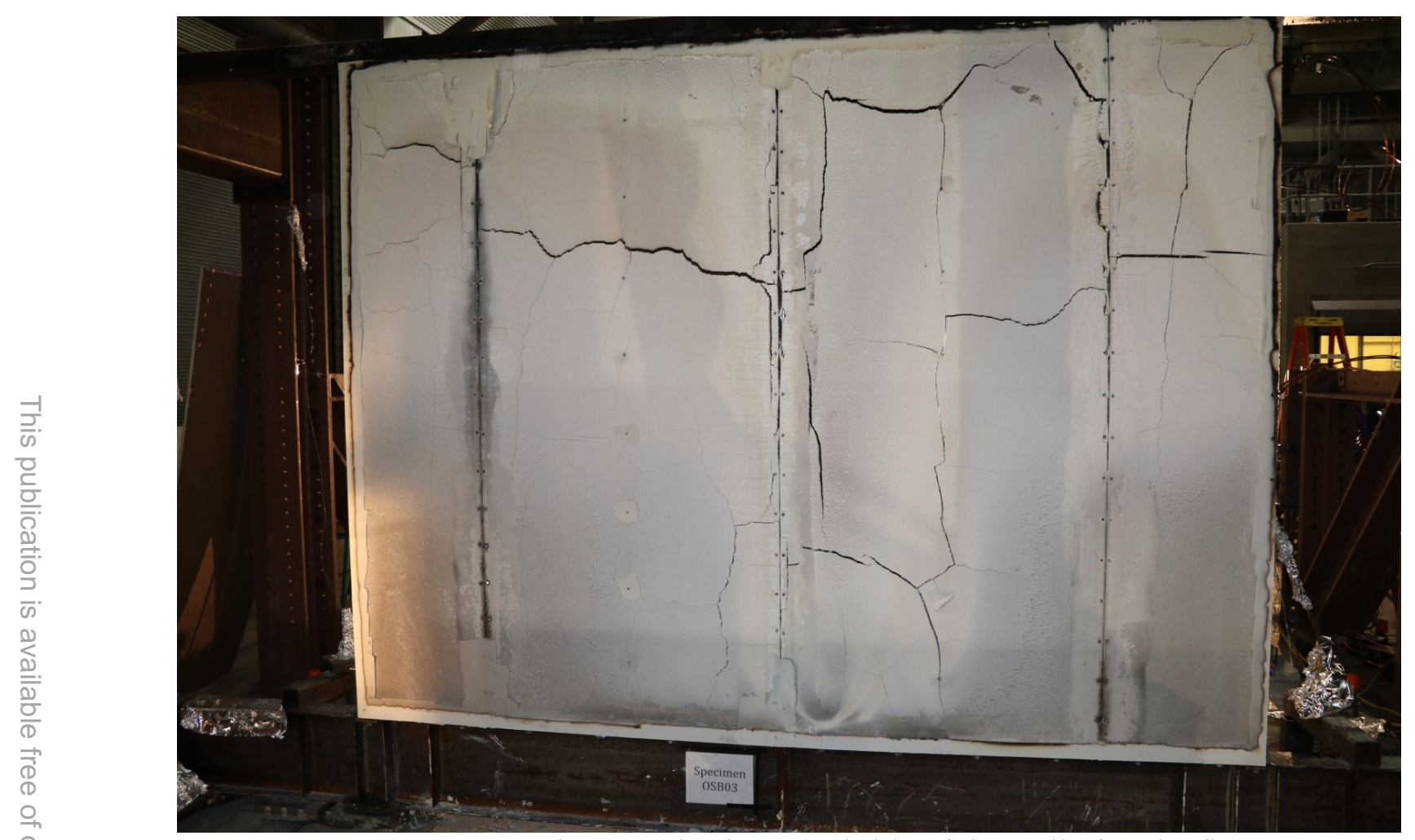

Fig. 240. OSB03 - Photograph of exposed side of the wall after the fire test.

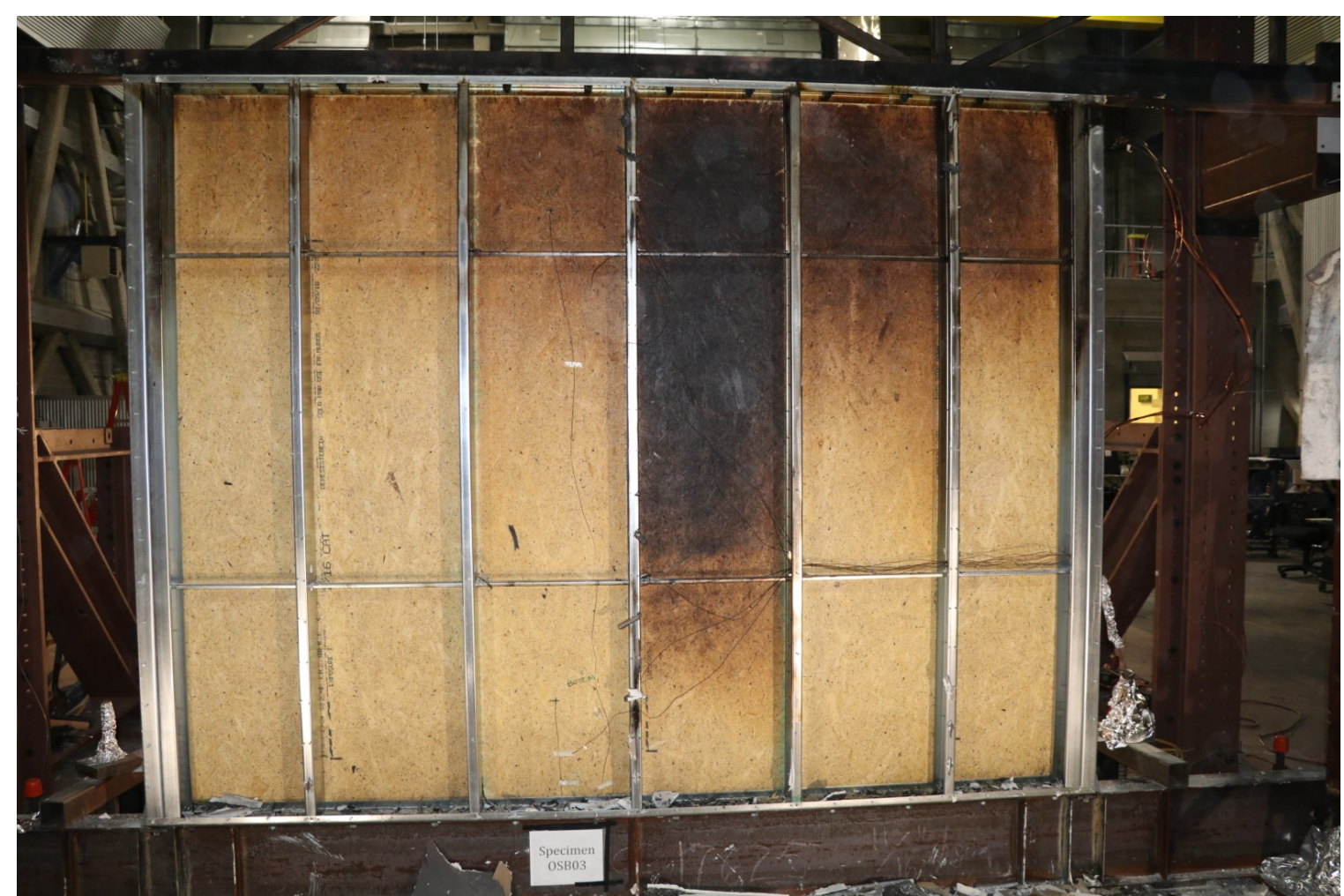

Fig. 241. OSB03 - Photograph of fire exposed side of the wall (remaining drywall removed) after load cycling following the fire. 


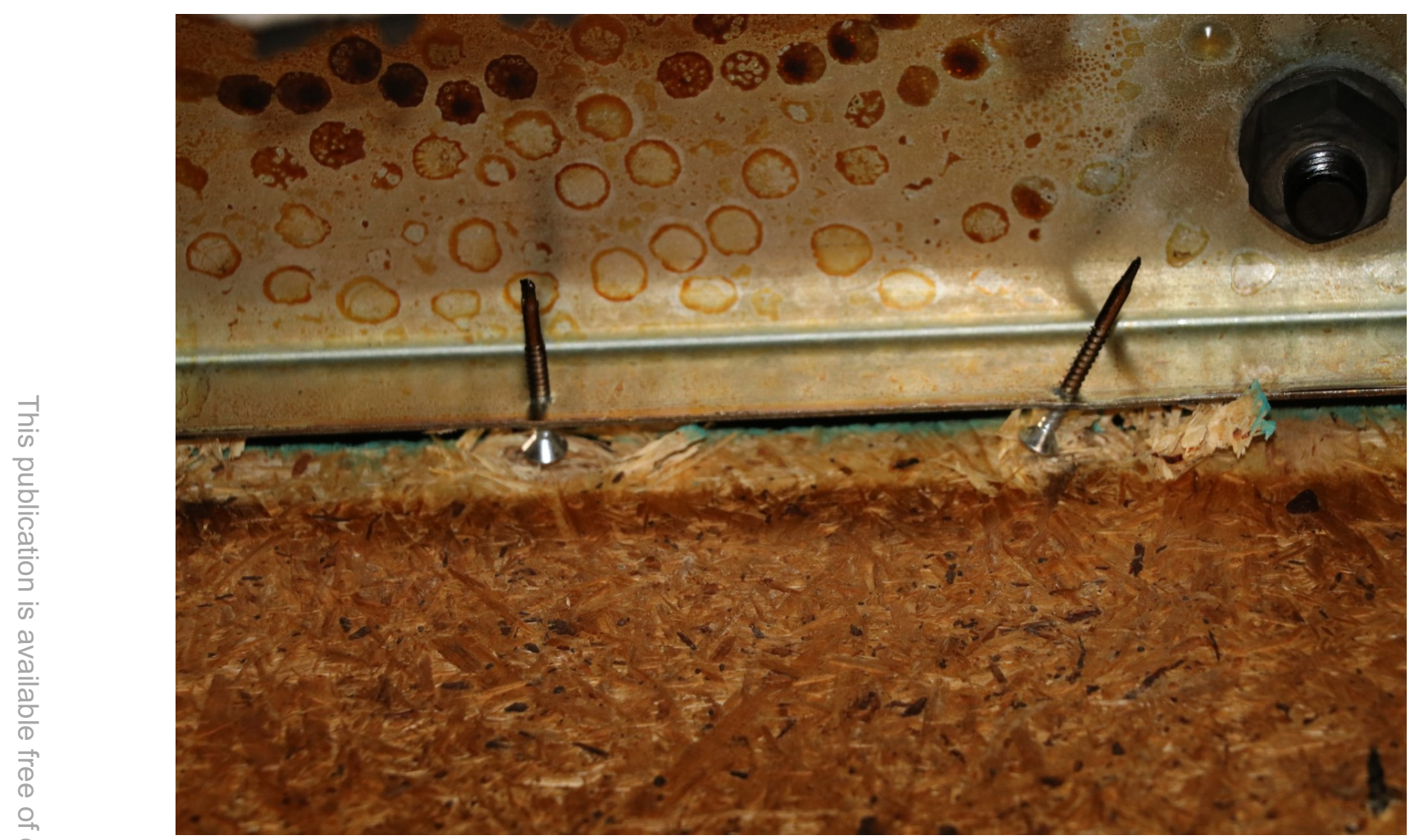

Fig. 242. OSB03 - Photograph of connection failure at top of wall after load cycling following the fire.

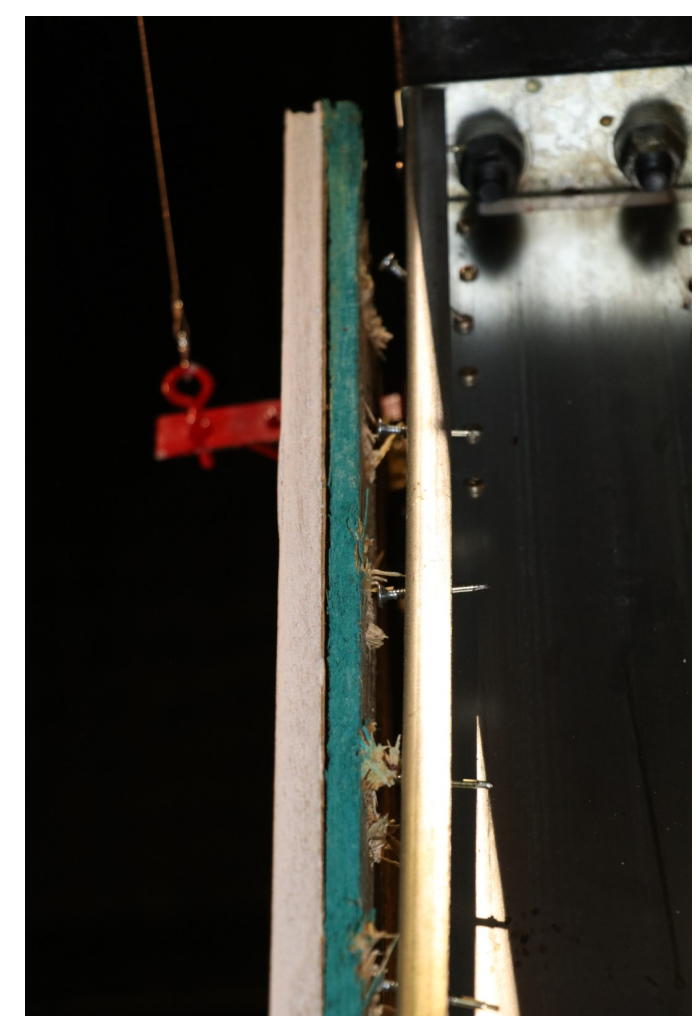

Fig. 243. OSB03 - Photograph of connection failure at south chord stud after load cycling following the fire. 


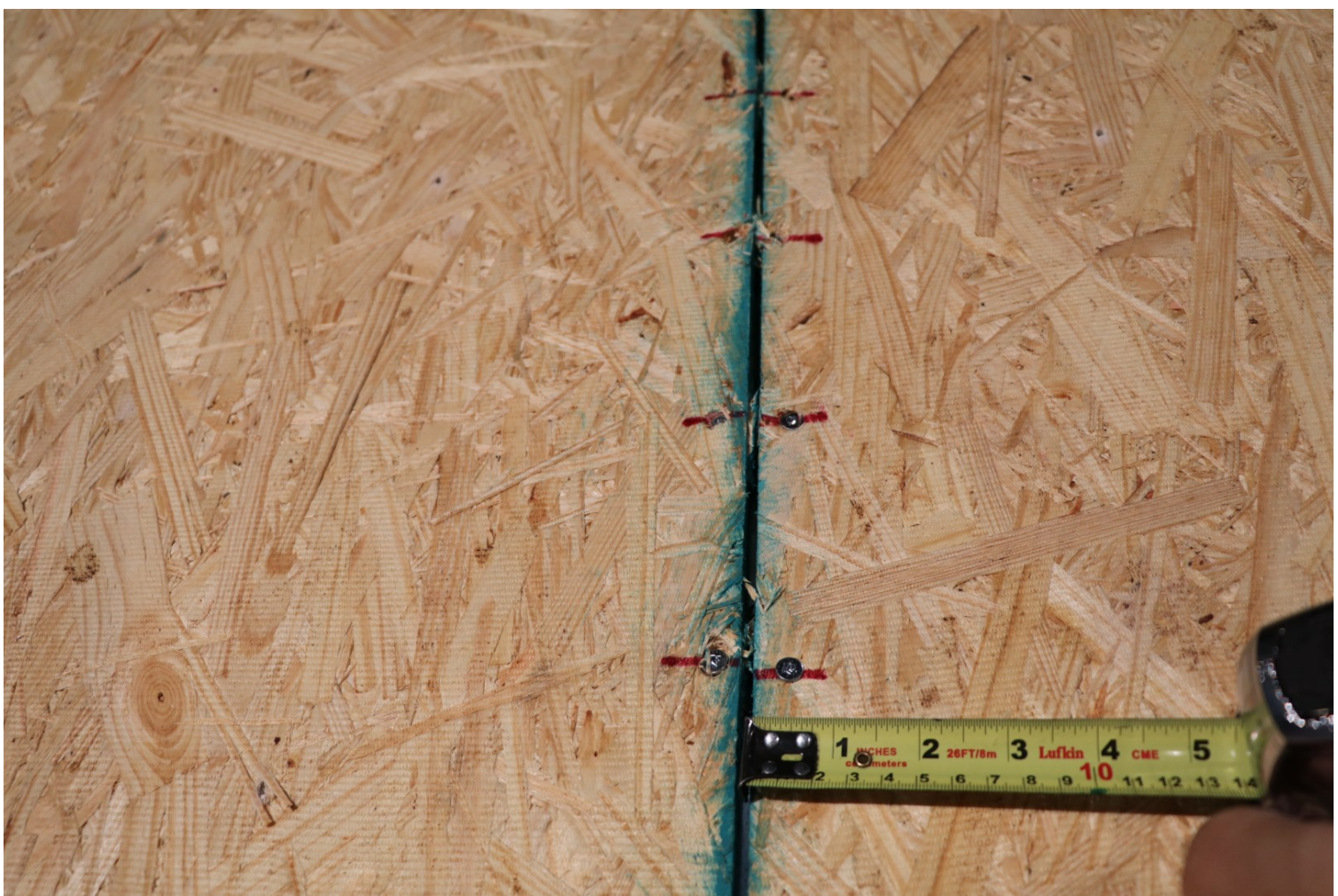

Fig. 244. OSB03 - Photograph of edge breakout of OSB along vertical seam. 


\section{OSB03R Data}

OSB03Rb (Mild Fire test of an undamaged wall)

- This was a mild fire test repeated. The gas burner was set to $1.7 \mathrm{MW}$ for $15 \mathrm{~min}$ and temperatures were recorded up to $45 \mathrm{~min}$. The difference between this test and OSB03 are that there is no $3 \mathrm{~mm}\left(1 / 8^{\prime \prime}\right)$ gap between the OSB panels and $12 \mathrm{~mm}(1 / 2$ ") distance between screws and edges of the panel was maintained.

- There was no ignition of OSB. Local discoloration of the OSB on the inside of wall near top of wall was less extensive than in OSB03 (Fig. 260).

- TC_T_P1 and TC_T_V2 provide wrong readings probably due to a cold junction. OSB03Rc (Cyclic test of wall at ambient temperature following the Mild Fire)

- The wall was tested after it had cooled down to observed if there was hardening of the heated glue and some regain strength after temperatures drop to ambient conditions.

- Screws pulled though the OSB leading to failure (Fig. 261).

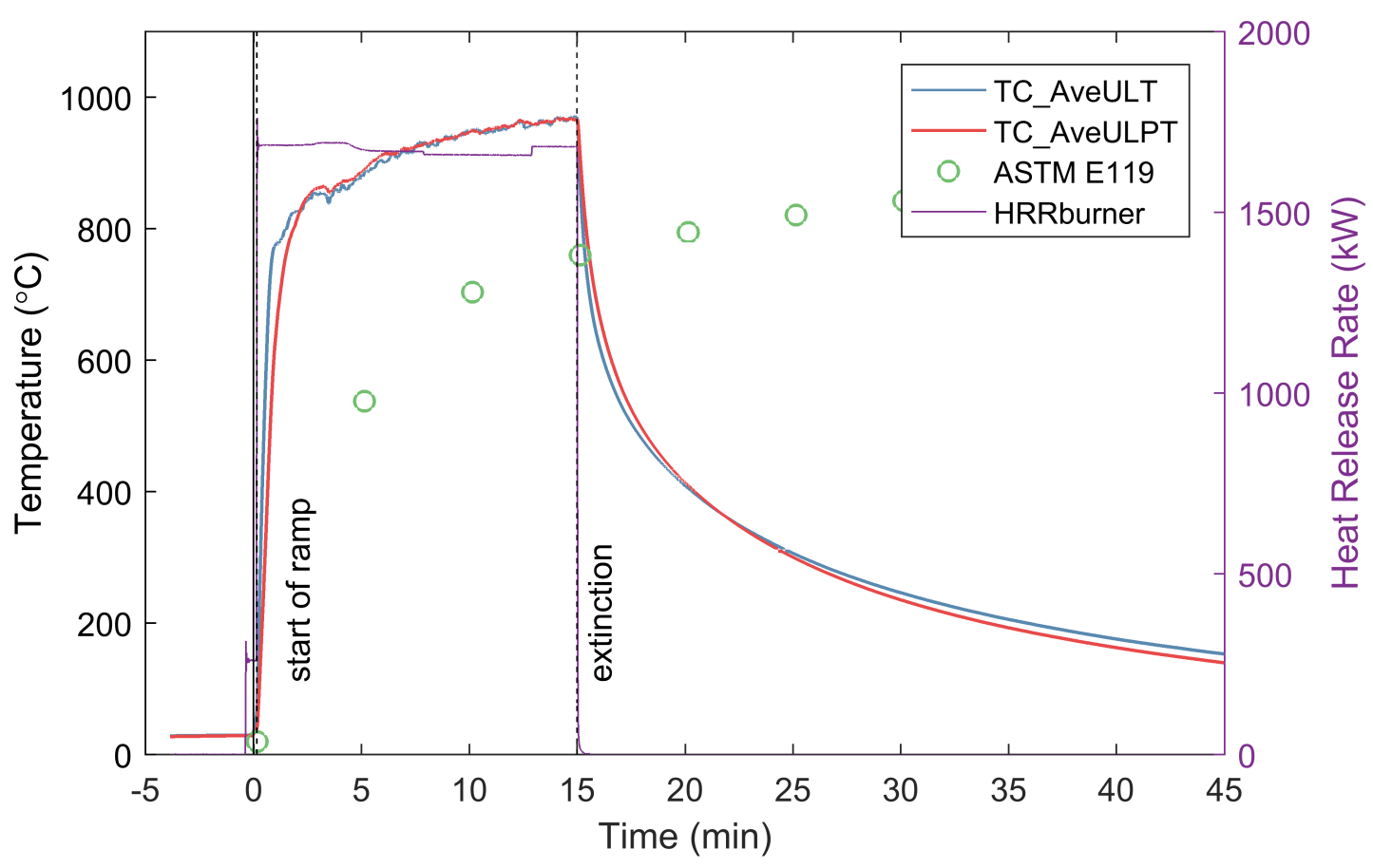

Fig. 245. OSB03R - Compartment temperatures and burner Heat Release Rate. 


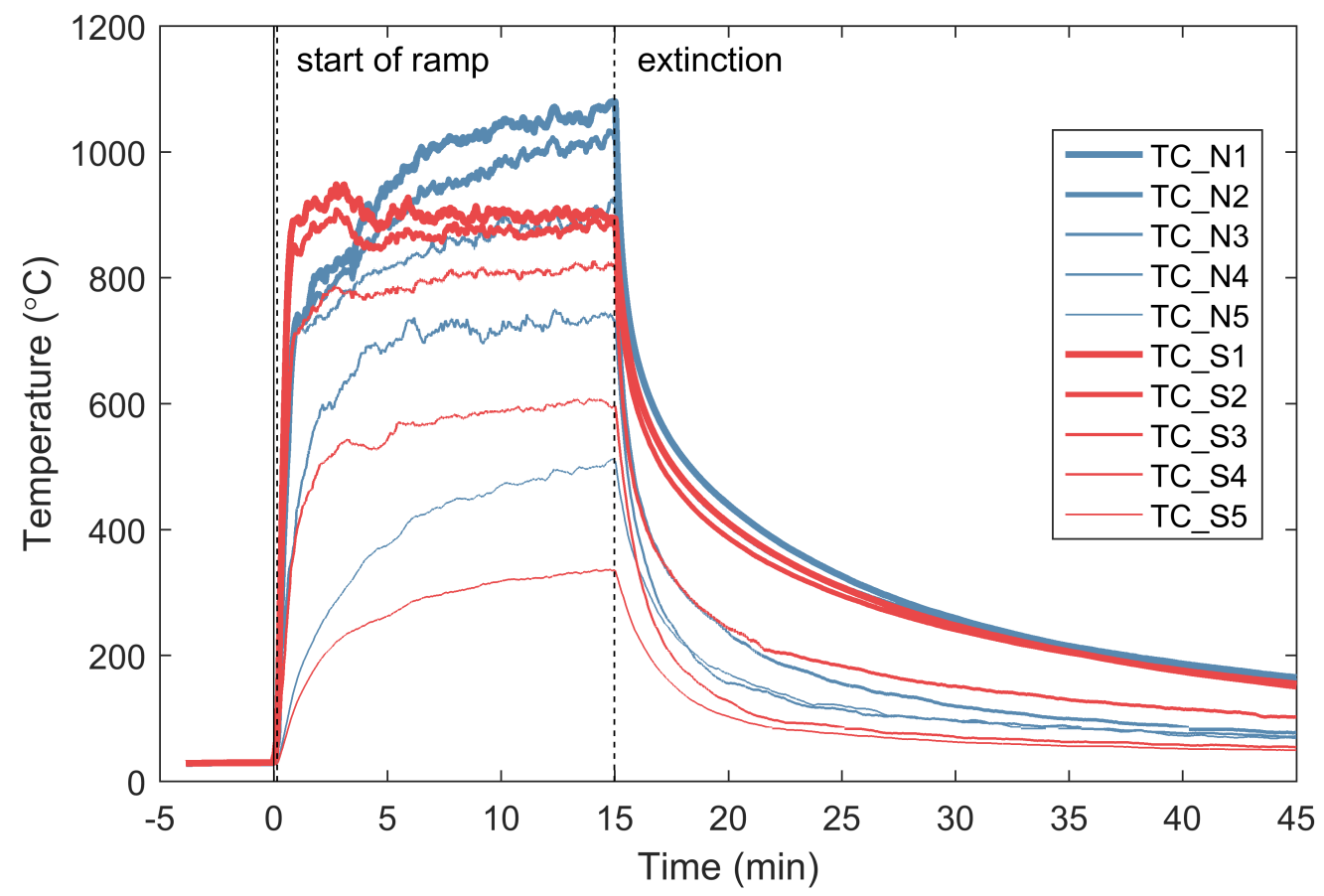

Fig. 246. OSB03R - Compartment temperatures measured by the thermocouple arrays.

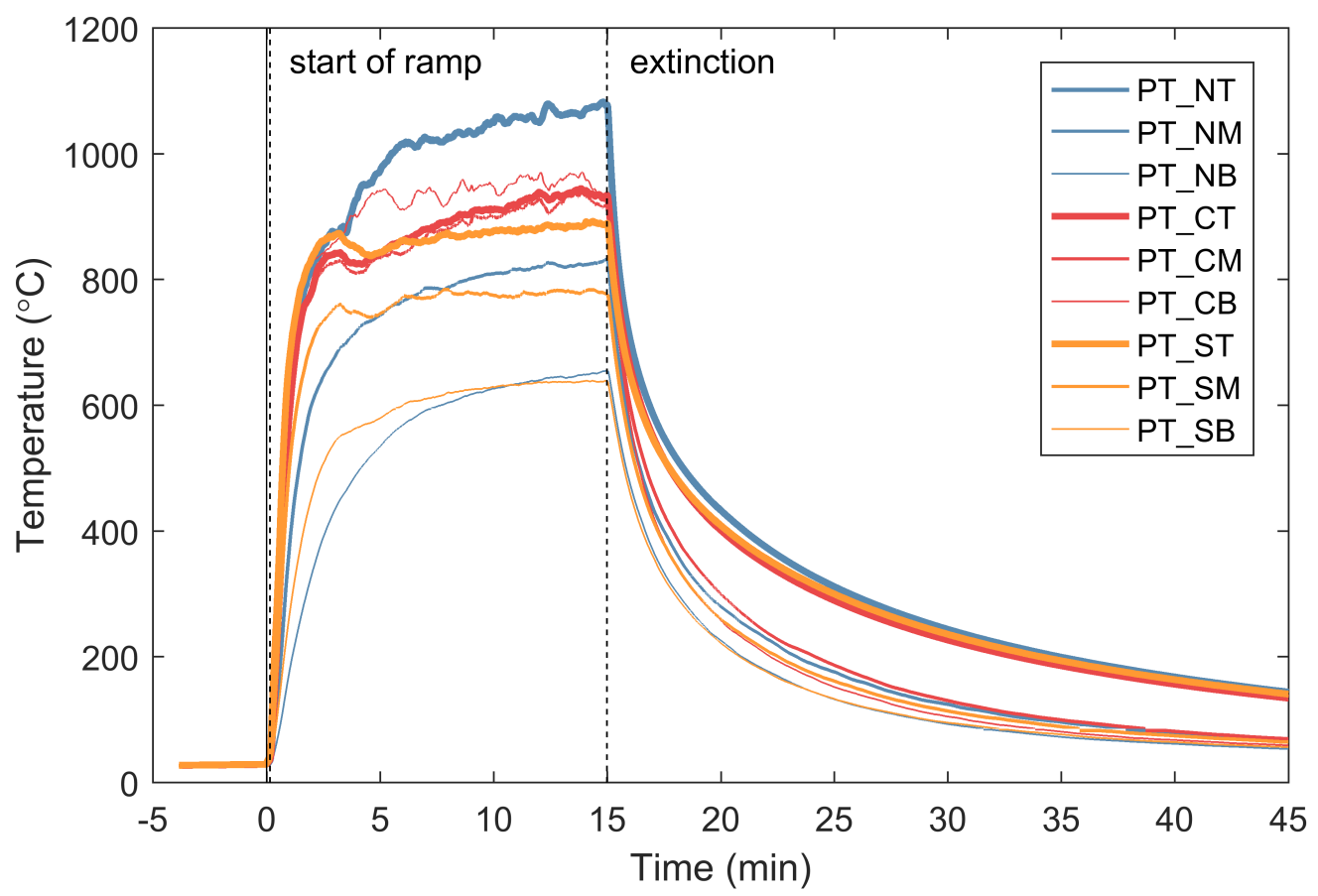

Fig. 247. OSB03R - Compartment temperatures measured by the plate thermocouples. 


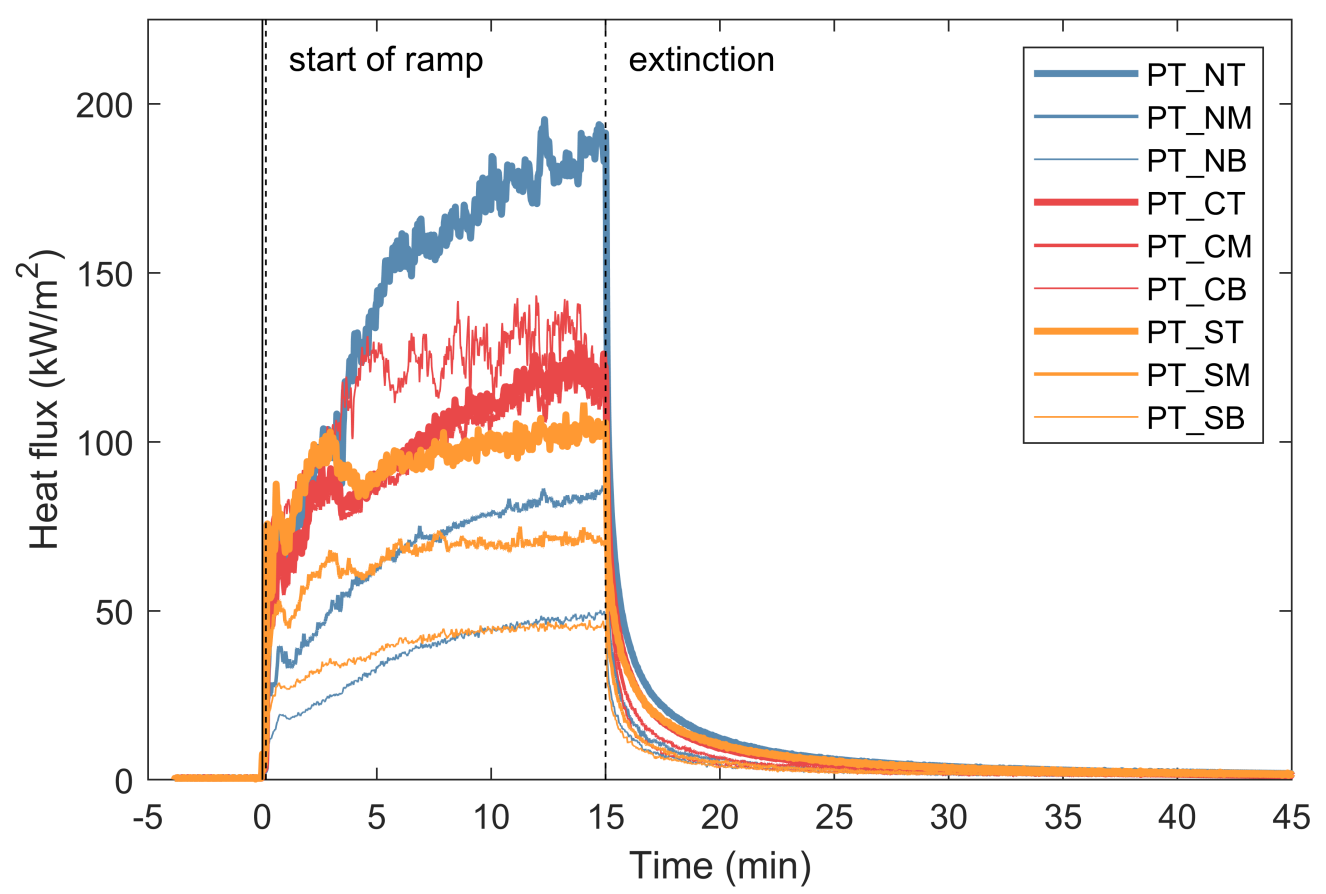

Fig. 248. OSB03R - Heat fluxes in the compartment measured by the plate thermocouples.
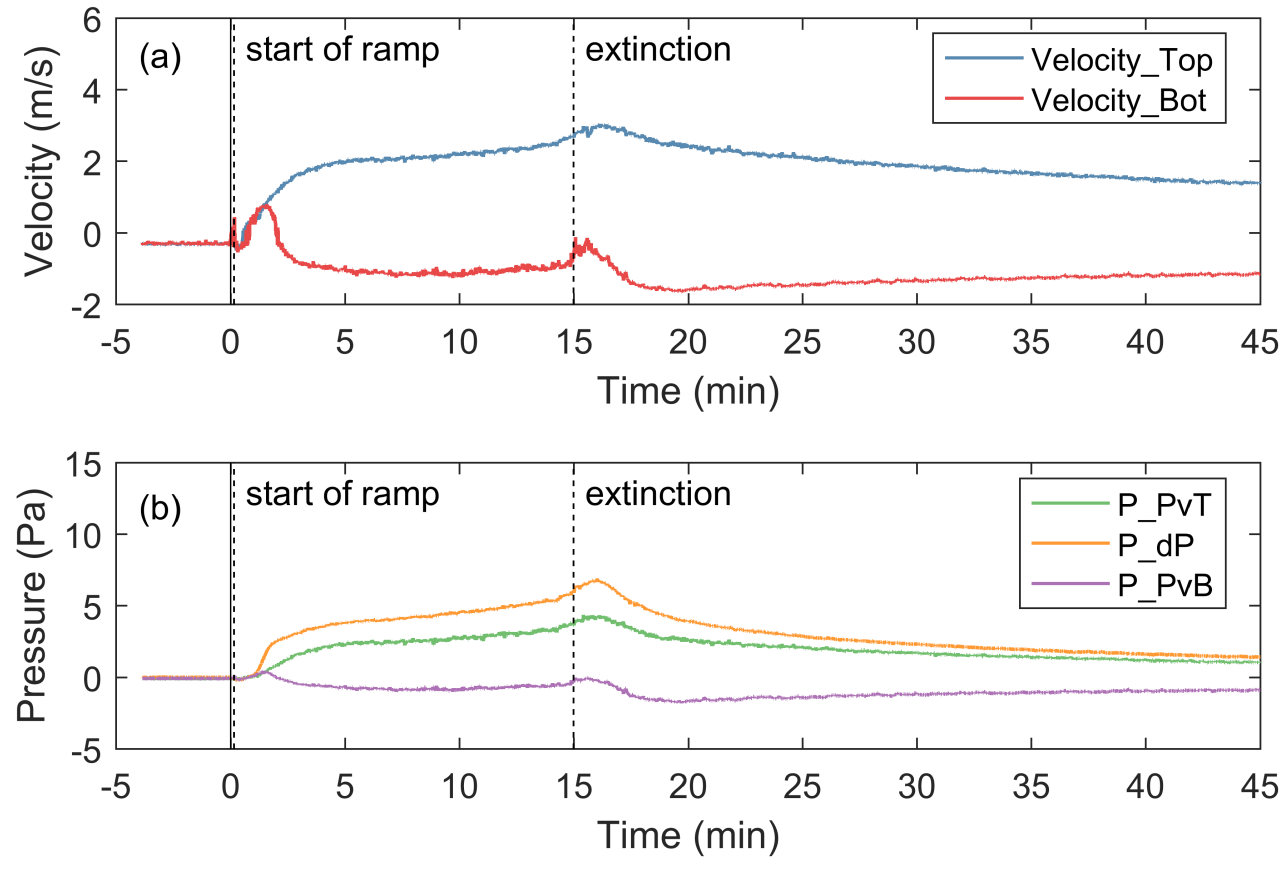

Fig. 249. OSB03R - (a) Velocity of air flow at the top and bottom knockouts of the chord stud; (b) Pressure at the top and bottom knockouts of the chord stud and in the wall cavity near the top. 


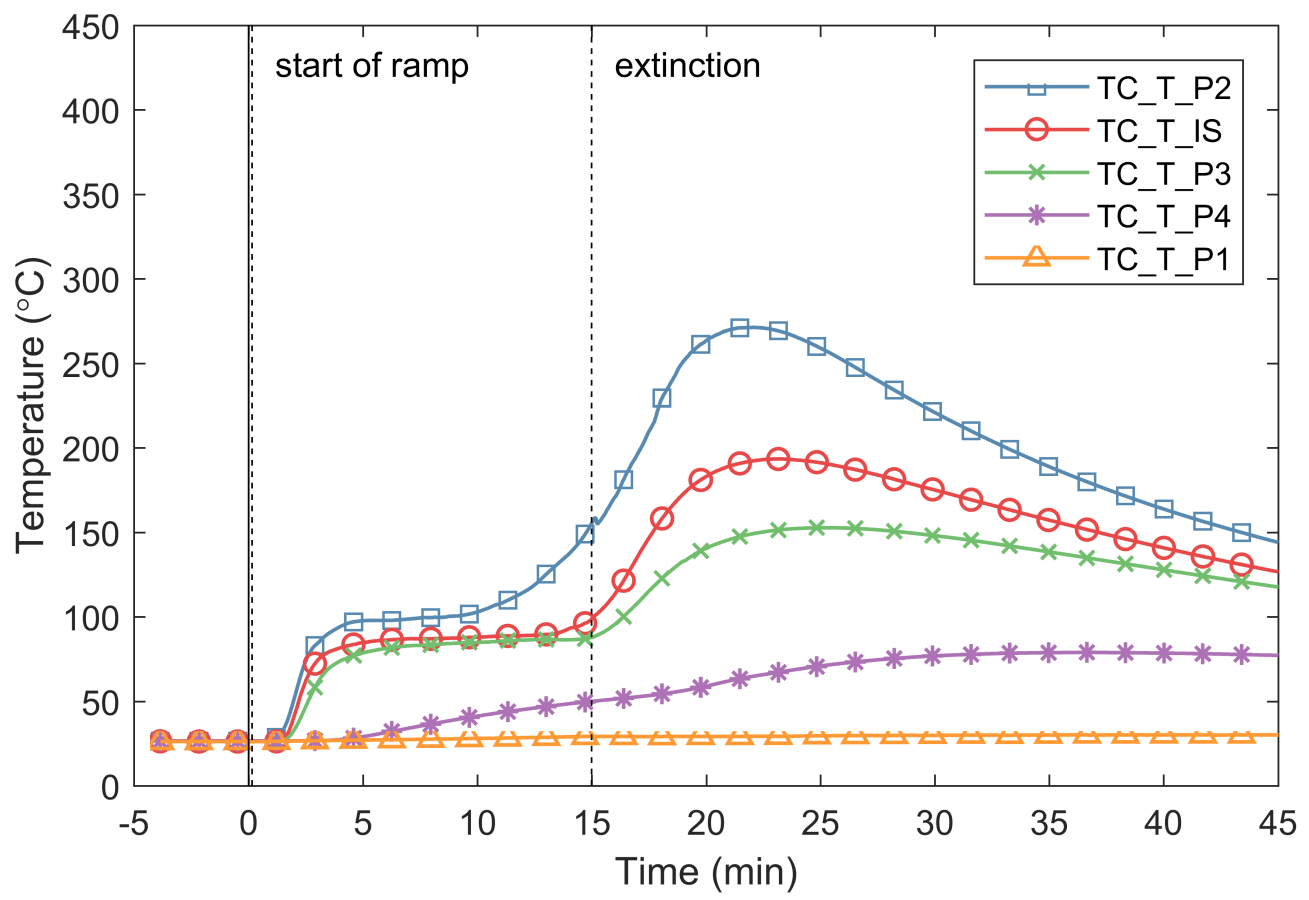

Fig. 250. OSB03R - Temperatures through the specimen at an interior stud $46 \mathrm{~cm}$ from the top of the wall.

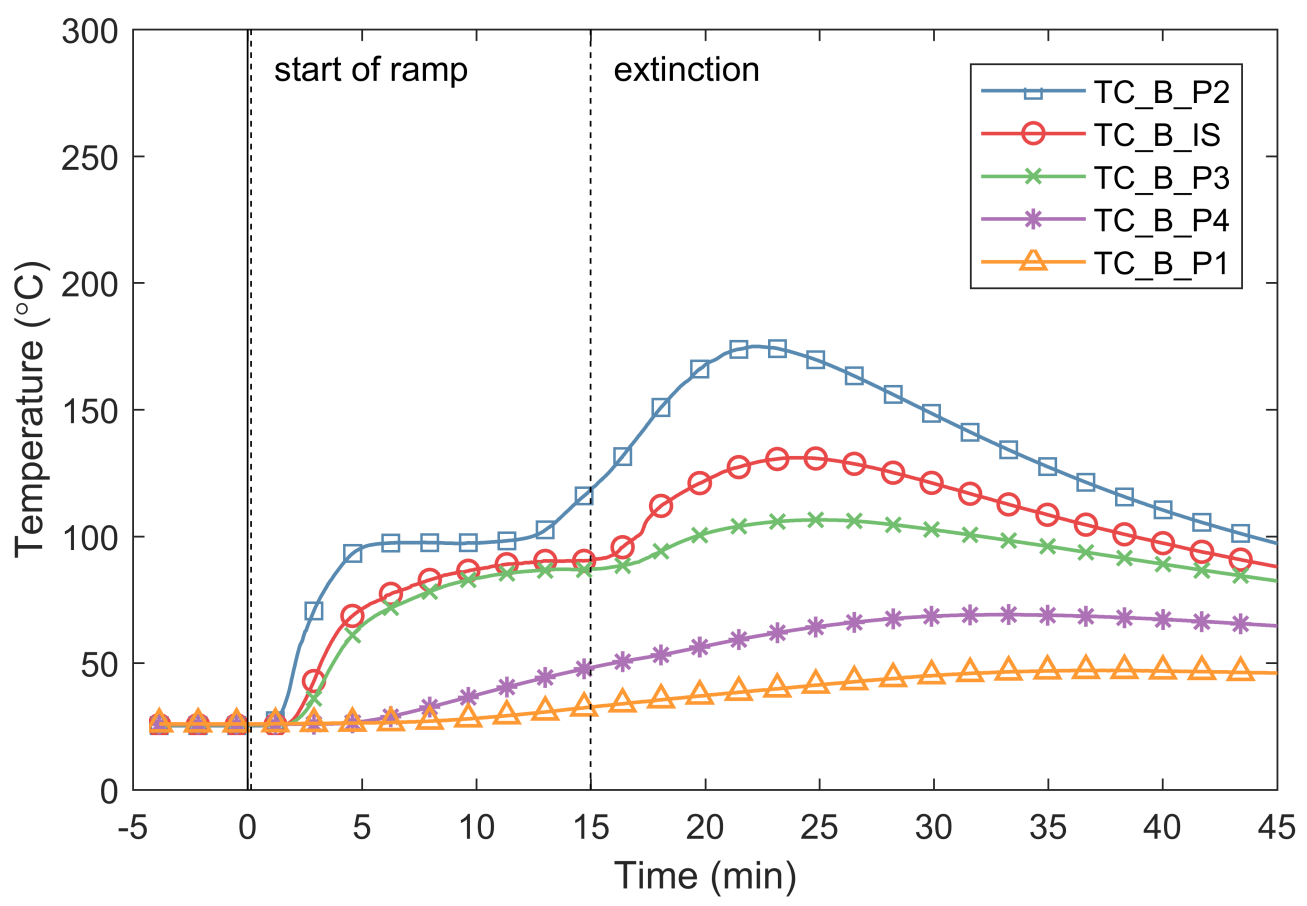

Fig. 251. OSB03R - Temperatures through the specimen at an interior stud $46 \mathrm{~cm}$ from the bottom of the wall. 


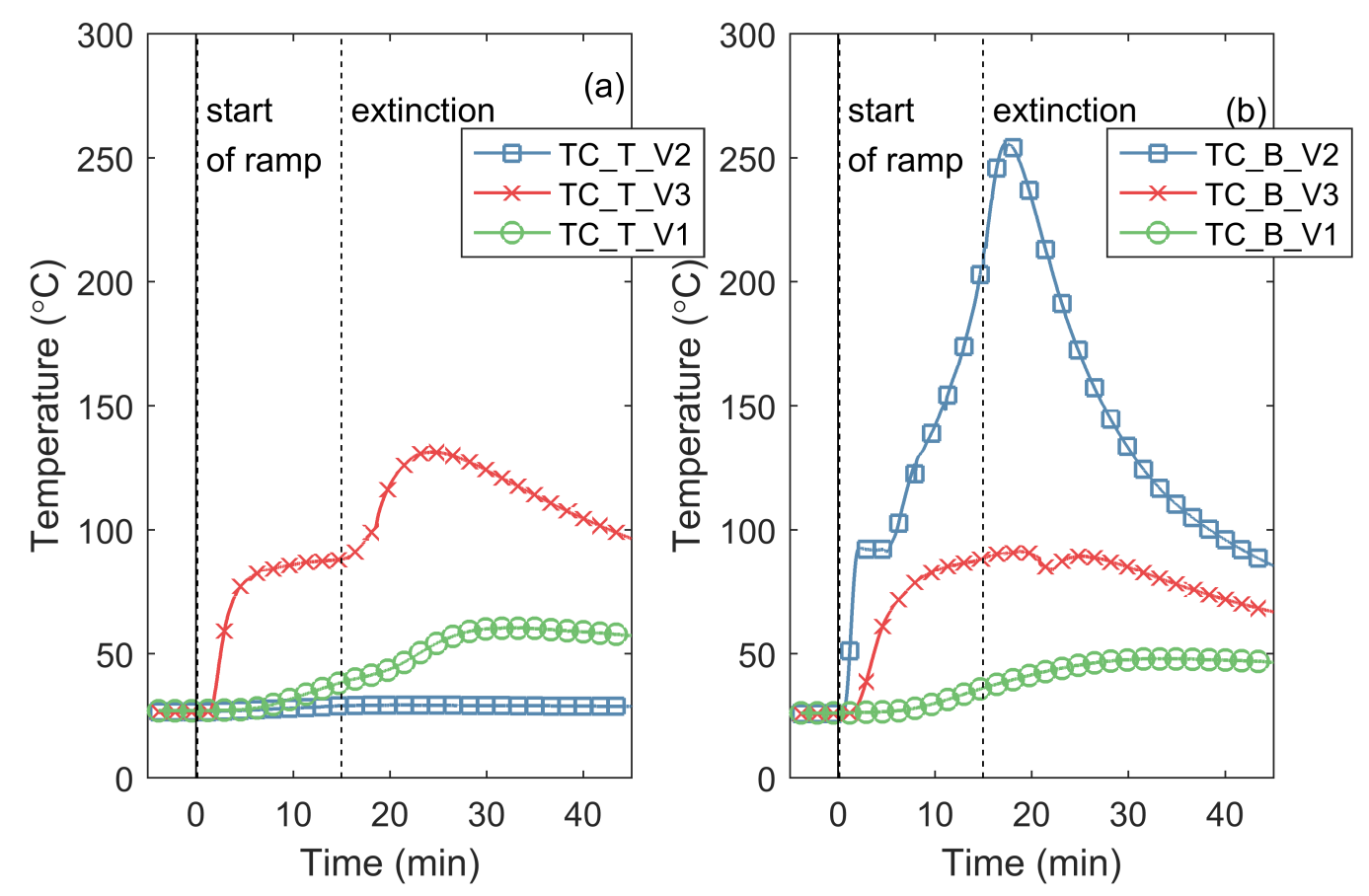

Fig. 252. OSB03R-Temperatures through the specimen midway between interior studs: (a) $46 \mathrm{~cm}$ from the top of the wall; (b) $46 \mathrm{~cm}$ from the bottom of the wall.
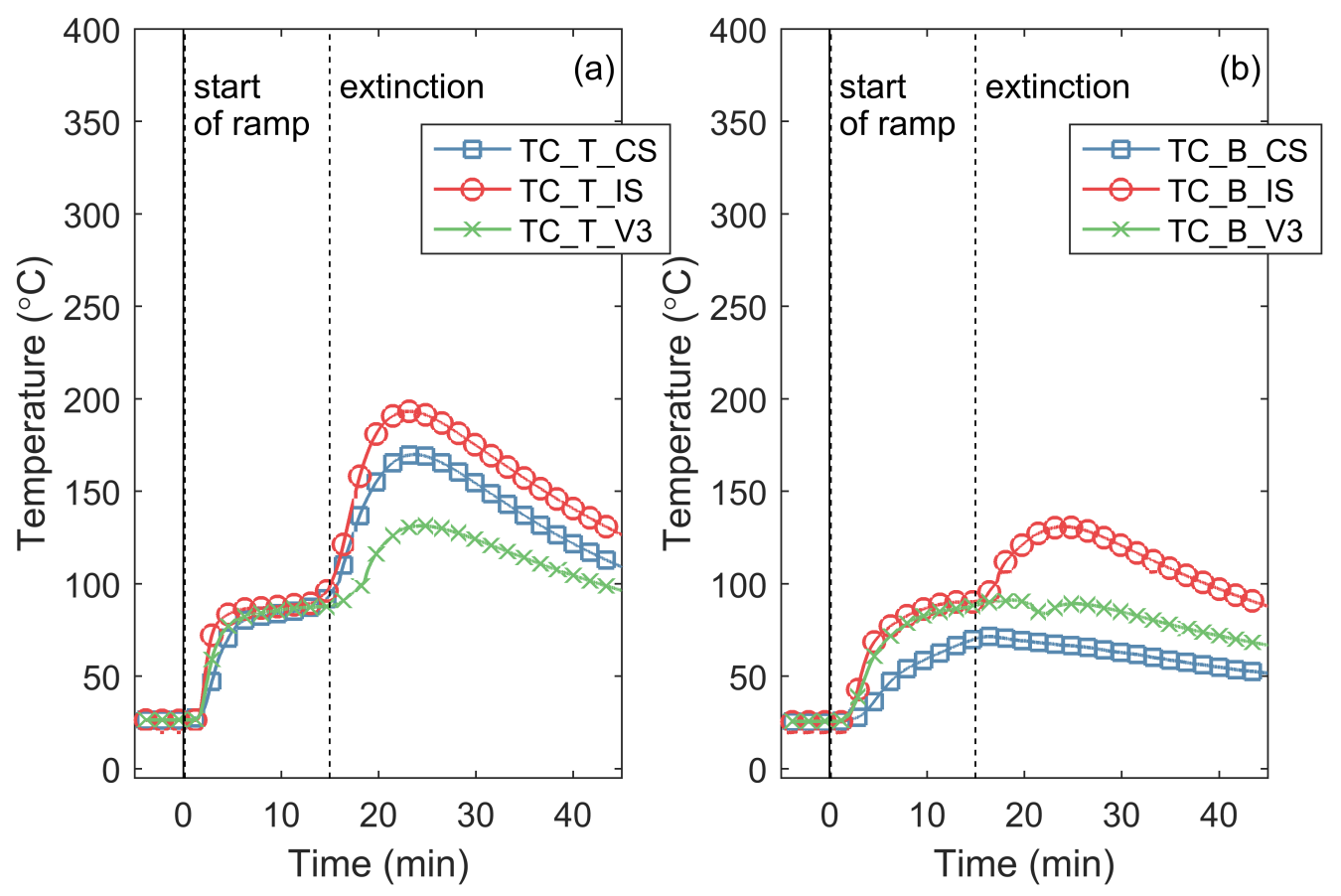

Fig. 253. OSB03R - Temperatures of the framing and sheathing elements: (a) $46 \mathrm{~cm}$ from the top of the wall; (b) $46 \mathrm{~cm}$ from the bottom of the wall. 


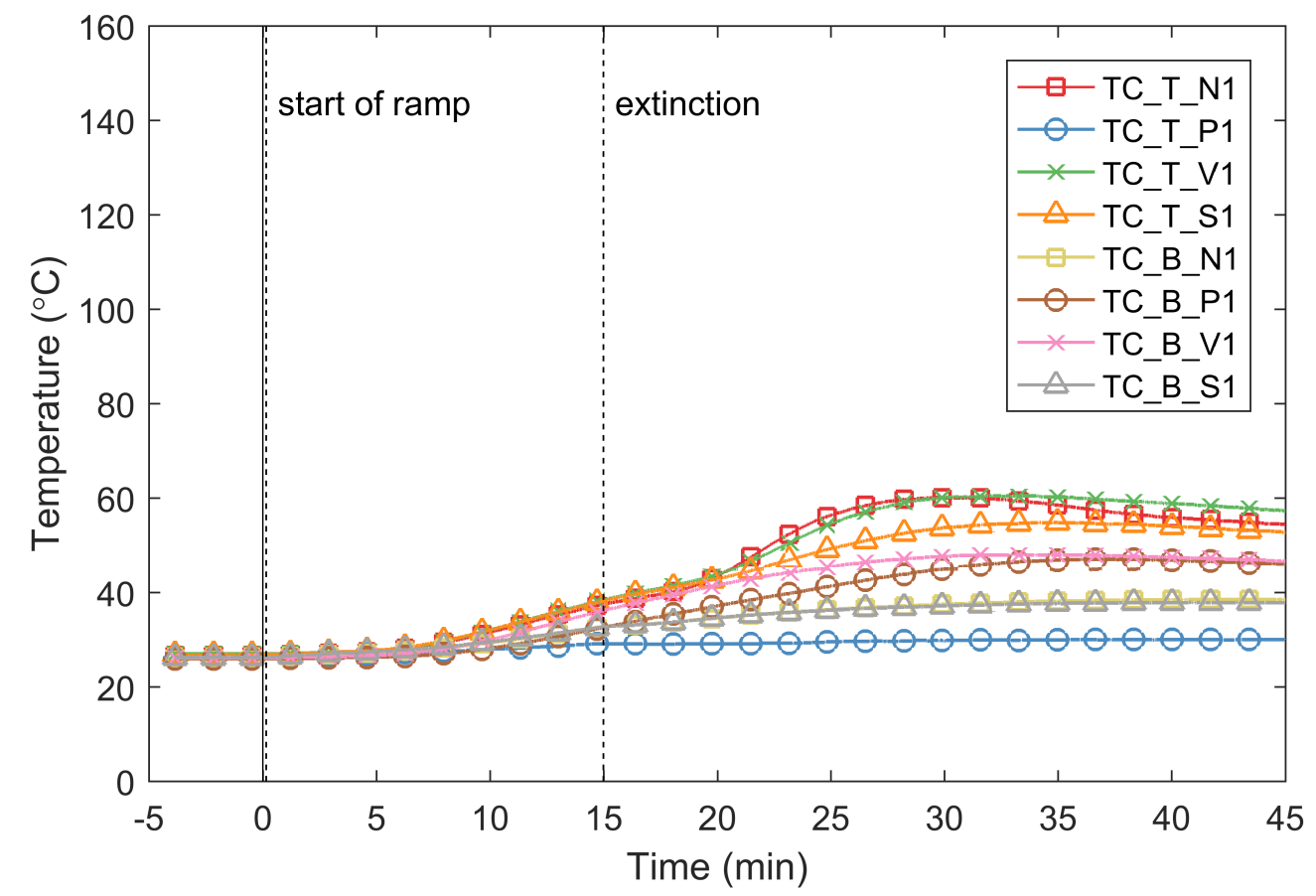

Fig. 254. OSB03R - Temperatures of the gypsum on the unexposed side of the wall specimen.

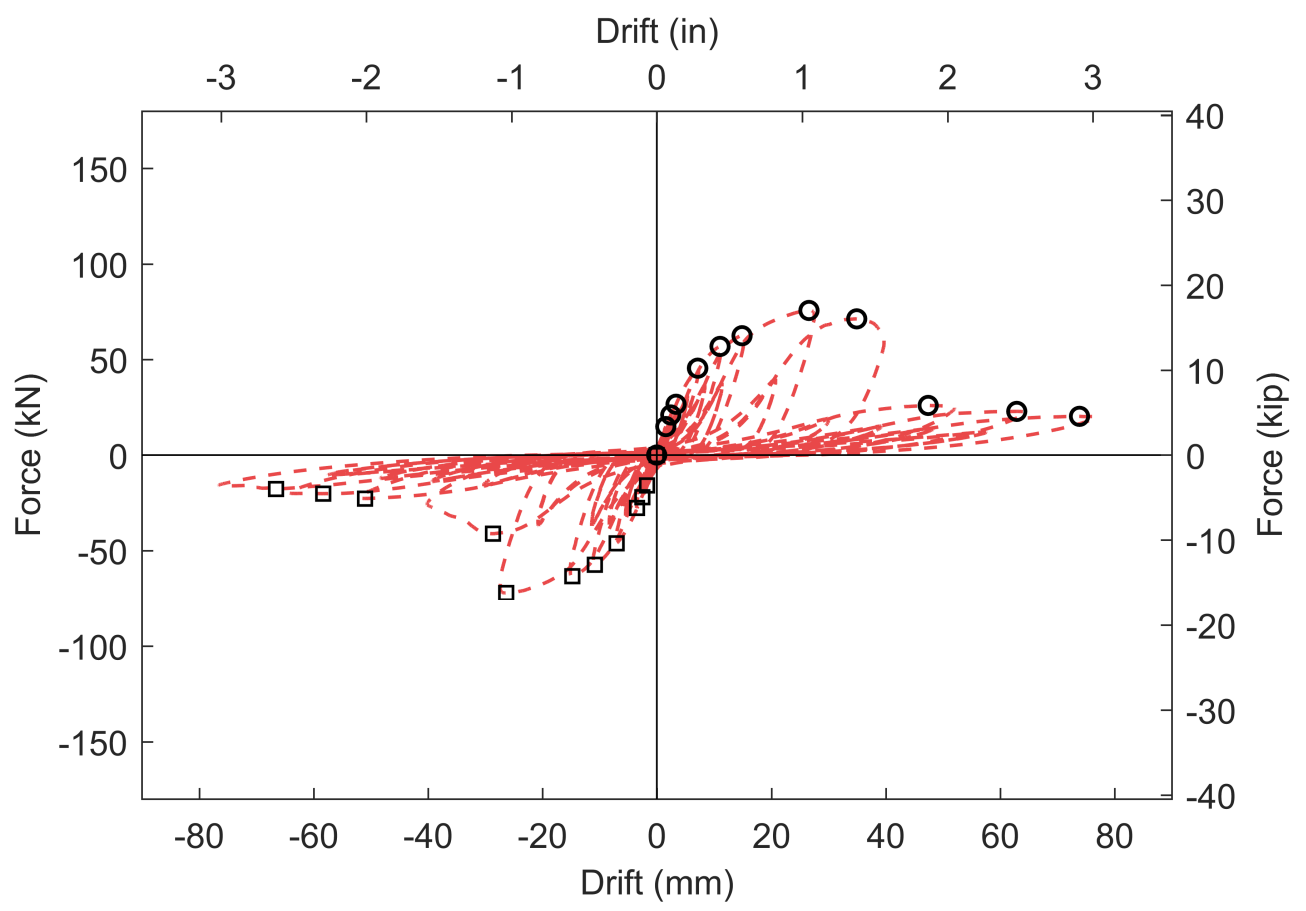

Fig. 255. OSB03R - Applied load versus wall longitudinal drift during mechanical loading. 


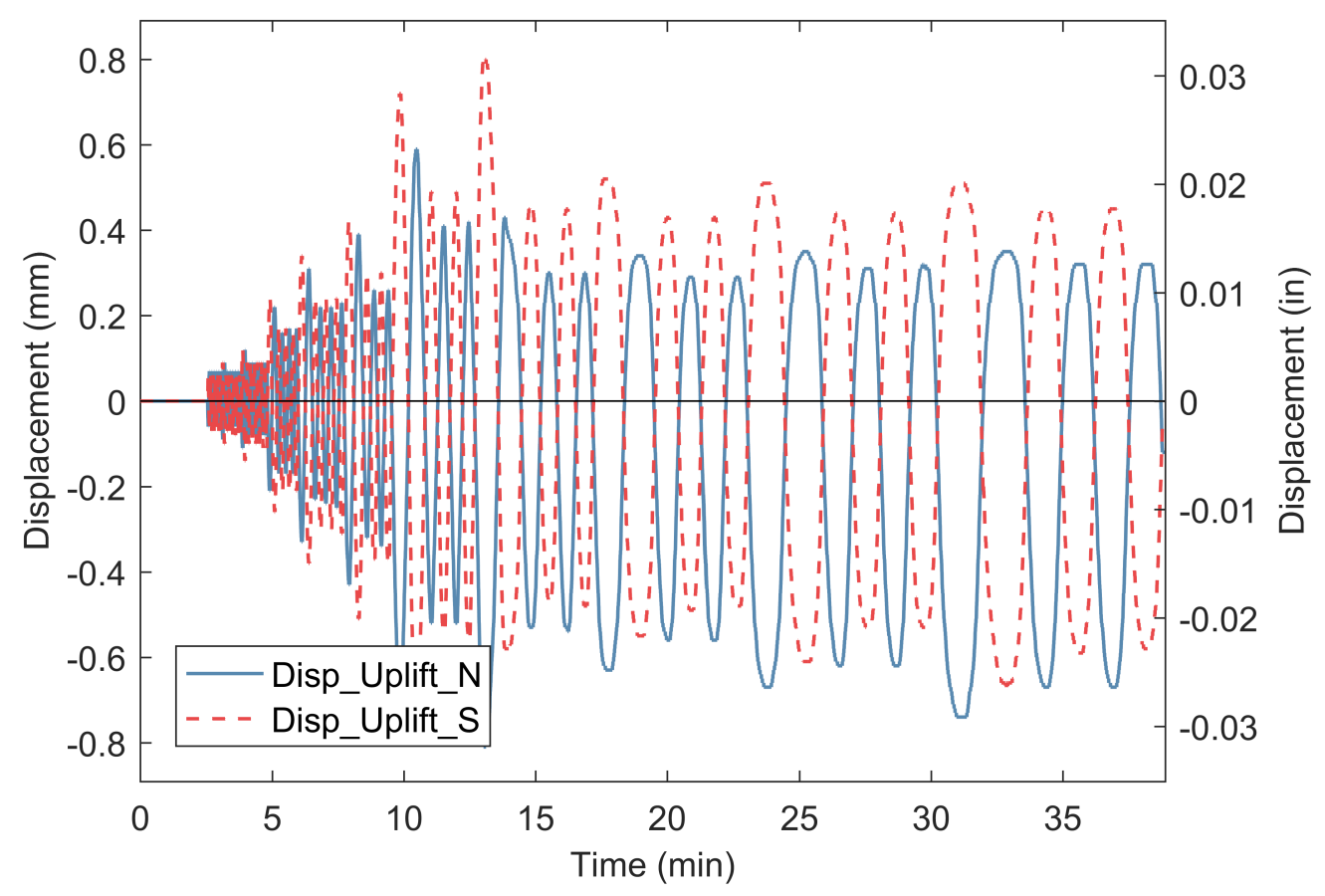

Fig. 256. OSB03R - Uplift at bottom of wall during mechanical loading.

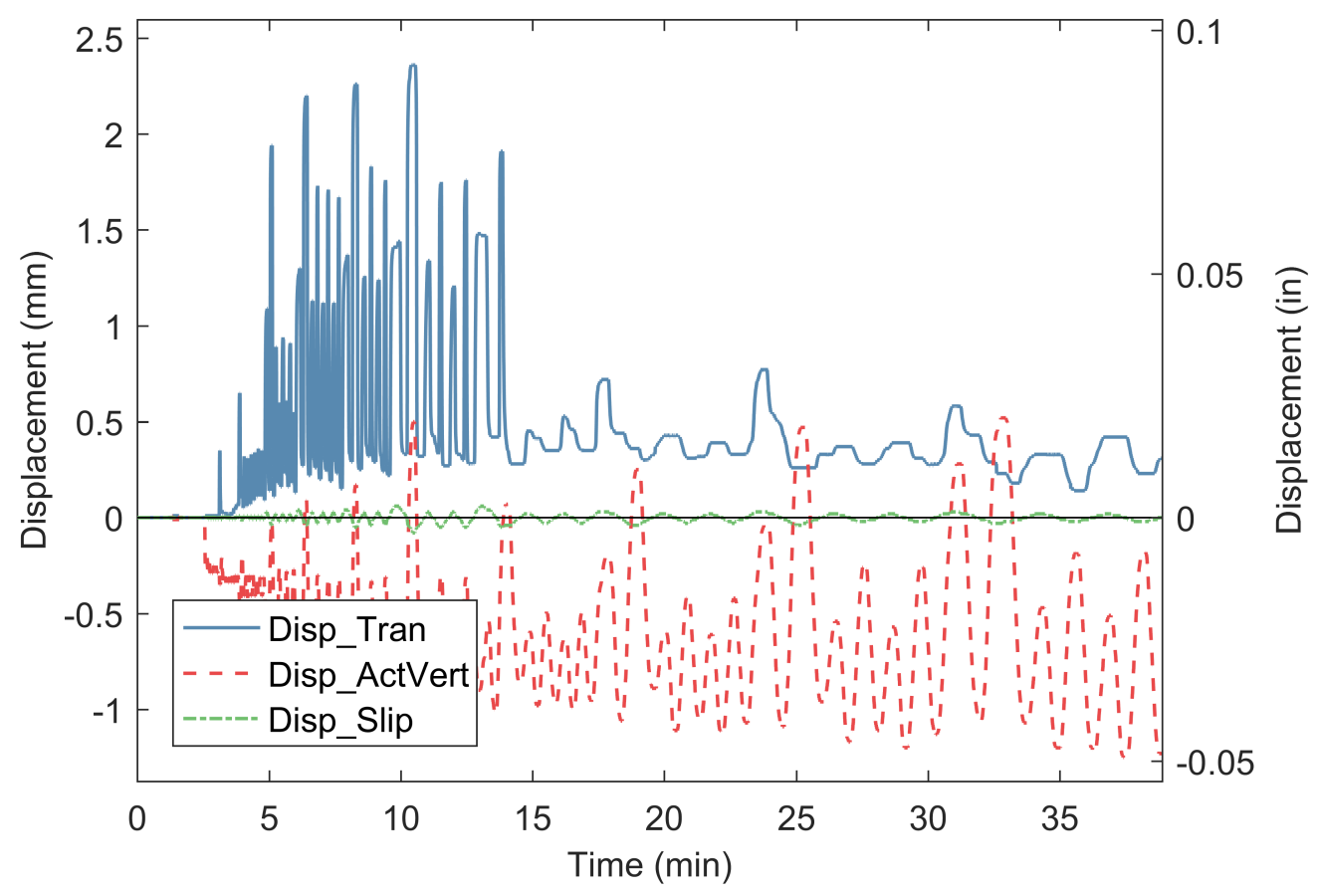

Fig. 257. OSB03R - Ancillary displacement measurements during mechanical loading. 


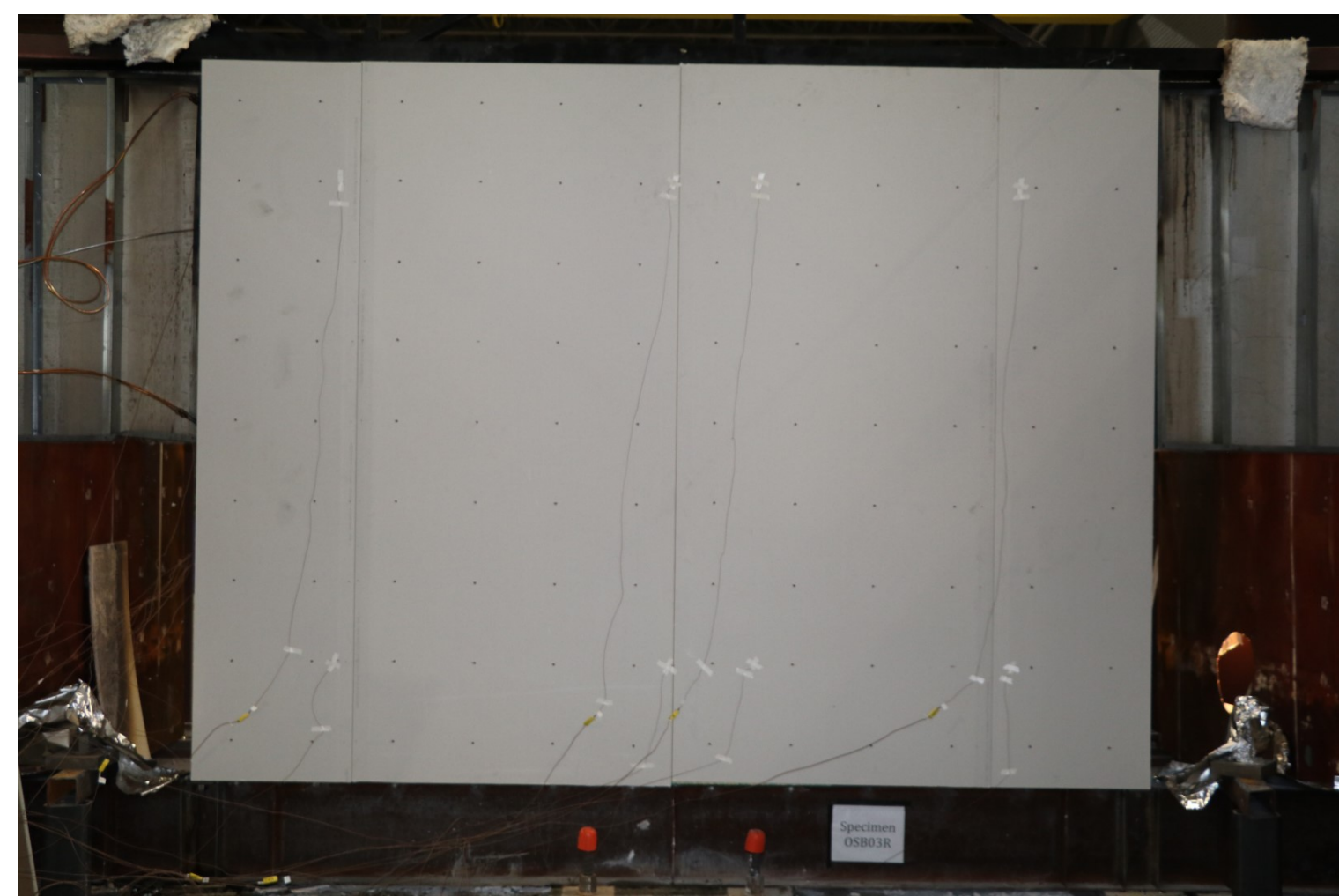

Fig. 258. OSB03R - Photograph of unexposed side of the wall after the fire test.

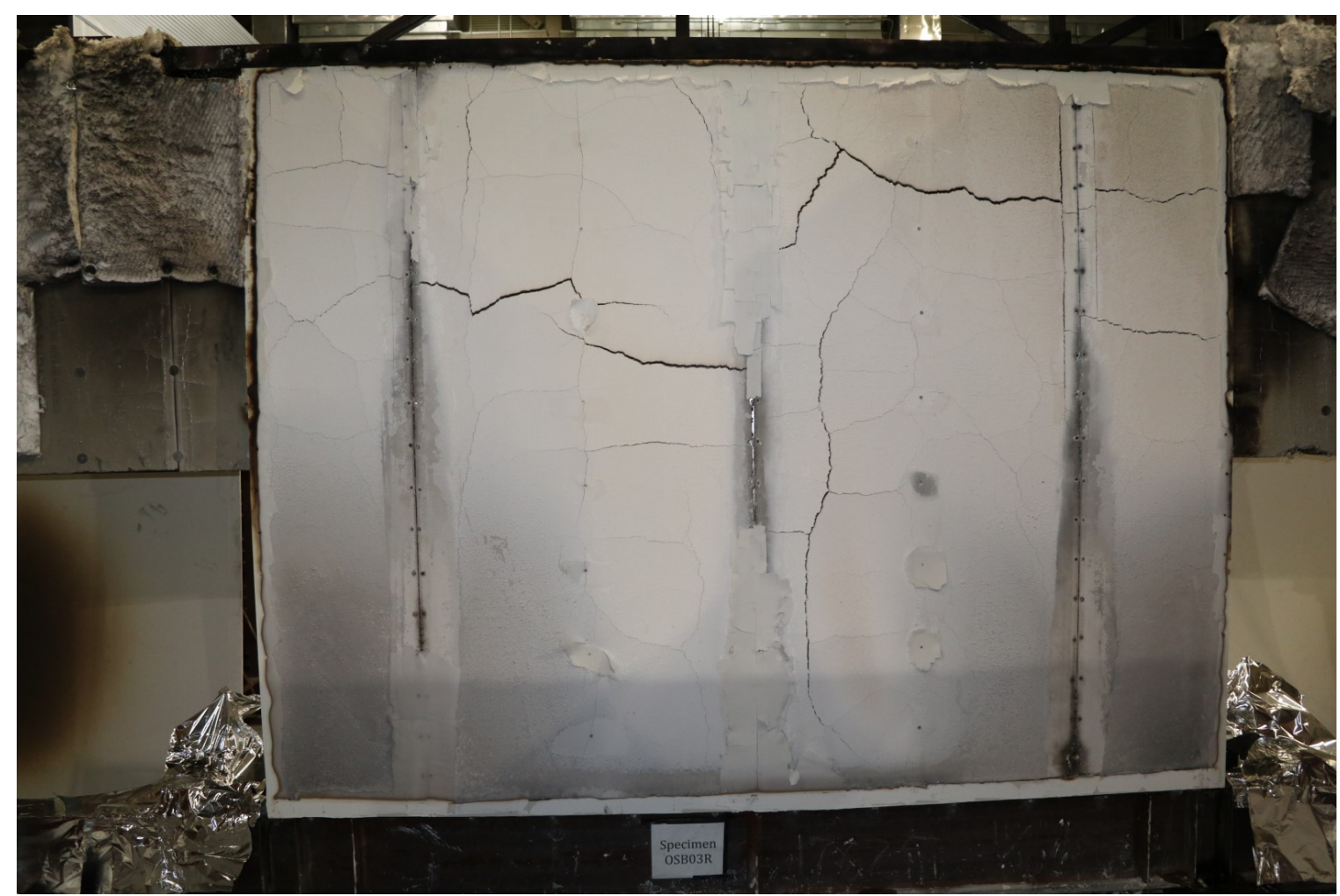

Fig. 259. OSB03R - Photograph of fire exposed side of the wall after the fire test. 


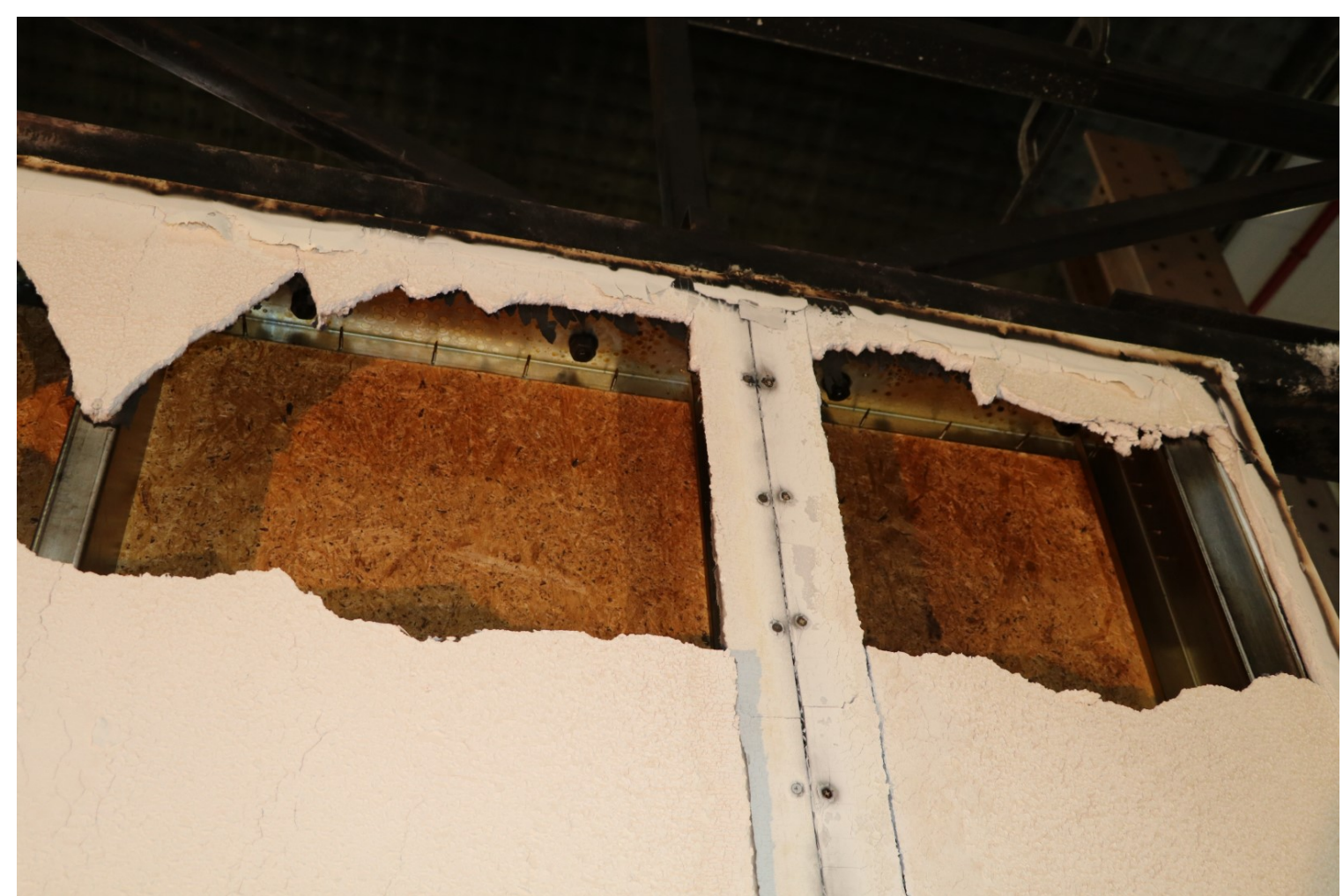

Fig. 260. OSB03R - Photograph of fire exposed side of the wall after load cycling following the fire.

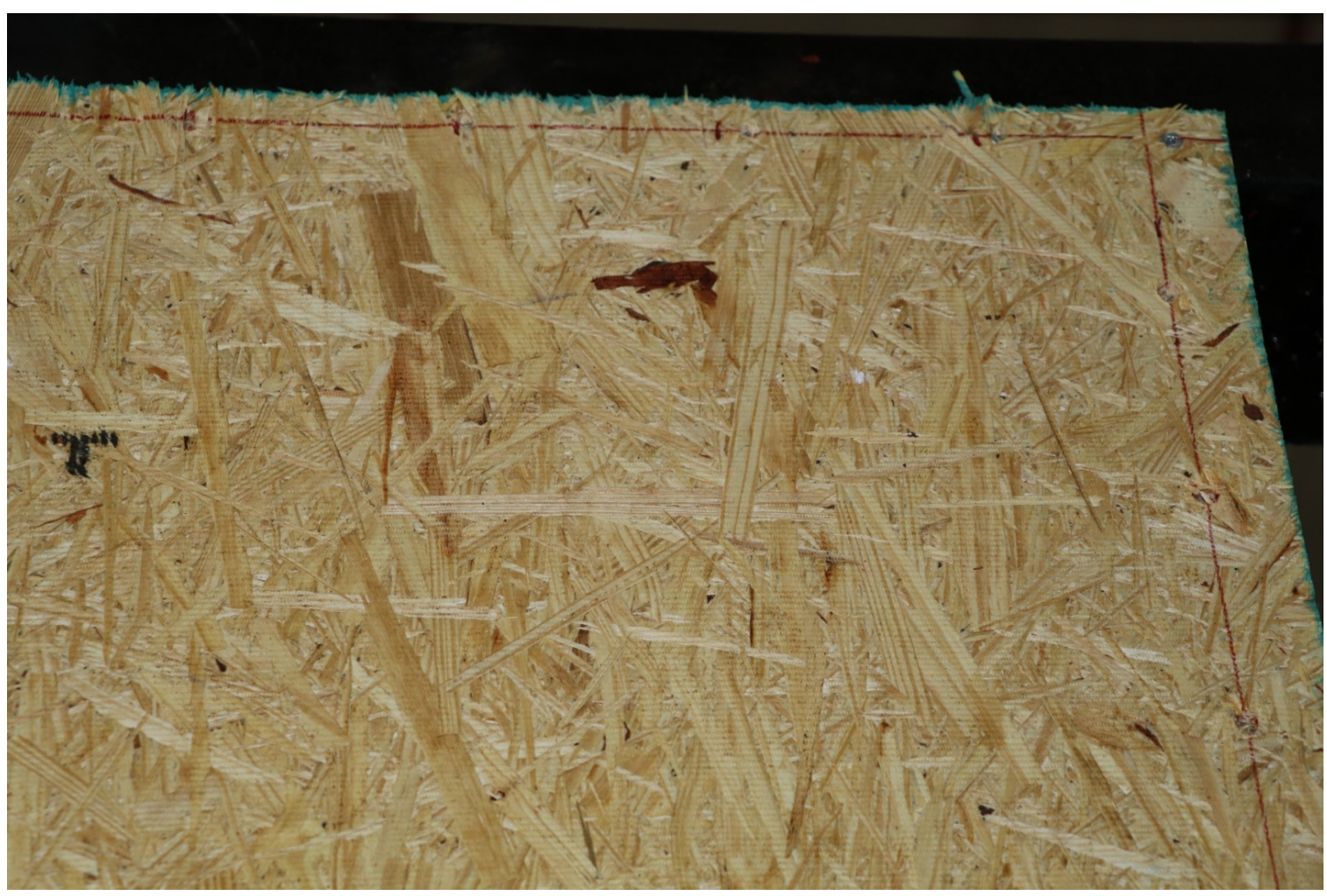

Fig. 261. OSB03R - Photograph of screw pull-through through the OSB. 


\section{OSB04 Data}

OSB04b (Standard Fire test of an undamaged wall)

- The gas burner was set to follow the same heat release rate curve as in SB04b (Fig. 262). The temperatures follow quite closely the ASTM E119 temperature-time curve up to 30 minutes at which point there is a drop in the temperatures inside the compartment (Fig. 263). There is a strong asymmetry in the temperatures inside the compartment from the north to the south.

- At 42 min the OSB panel started burning with flames and smoke appearing on the top of the wall (Fig. 276).

- From around $55 \mathrm{~min}$ the temperature measurements through the cross-section and unexposed side are not reliable, as almost all the OSB is burning.

- After 60 min nearly all the OSB has been consumed by the fire (Fig. 278).

OSB04c (Cyclic test of wall at ambient temperature following the Standard Fire)

- Because the fire consumed nearly all the OSB sheathing, the wall had nearly zero lateral force-resistance capacity during cycling.

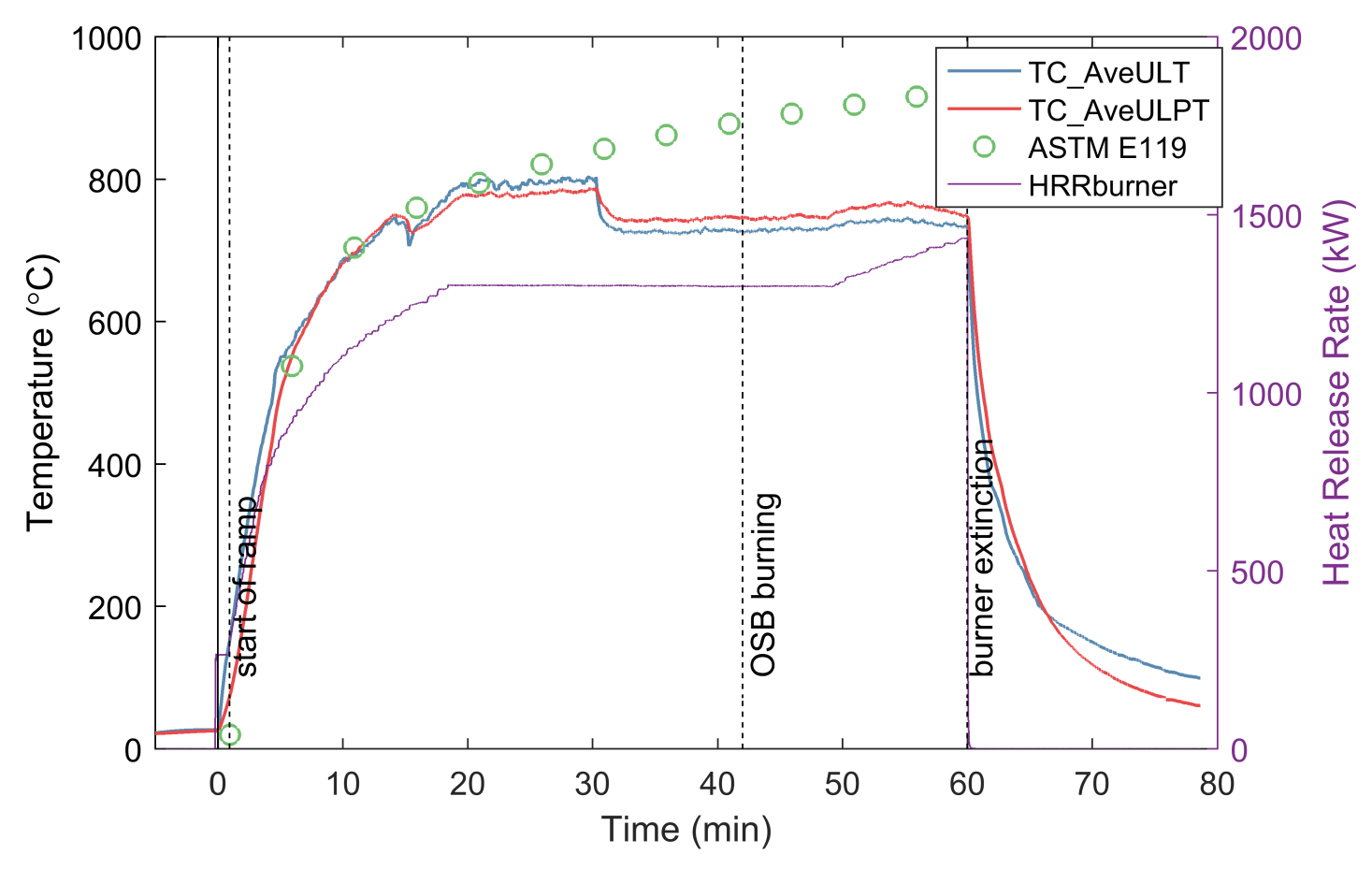

Fig. 262. OSB04 - Compartment temperature and burner Heat Release Rate. 


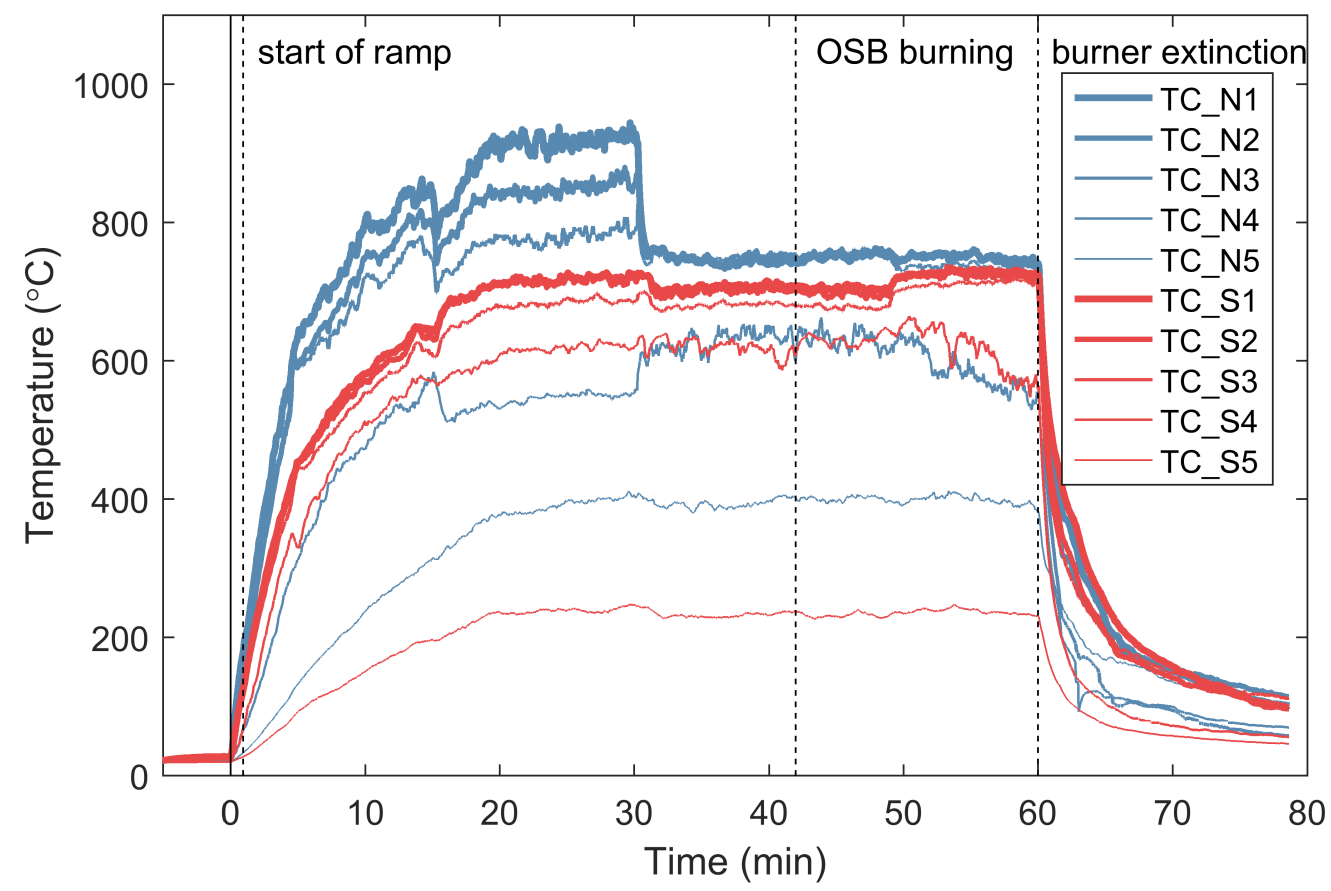

Fig. 263. OSB04 - Compartment temperatures measured by the thermocouple arrays.

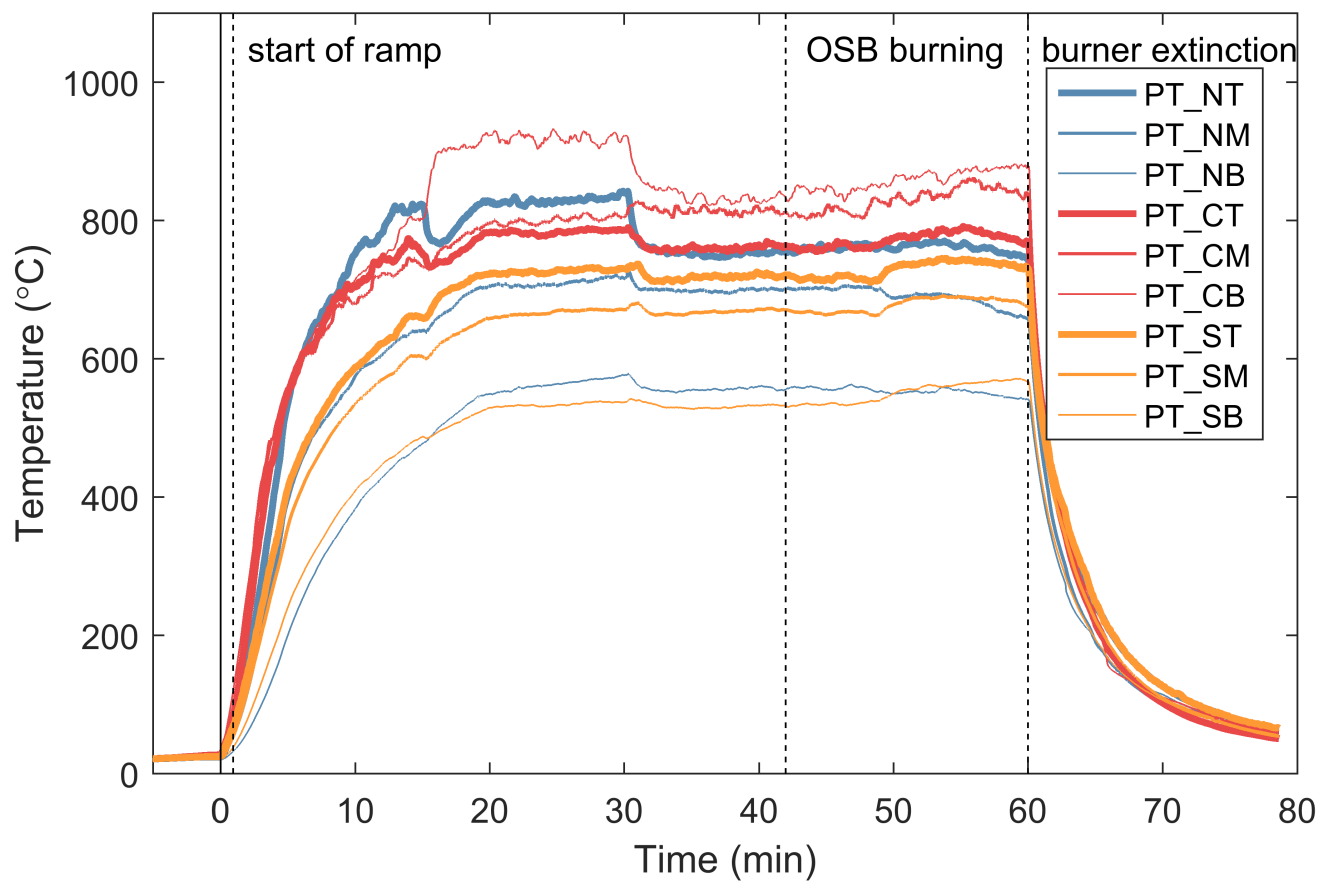

Fig. 264. OSB04 - Compartment temperatures measured by the plate thermocouples. 


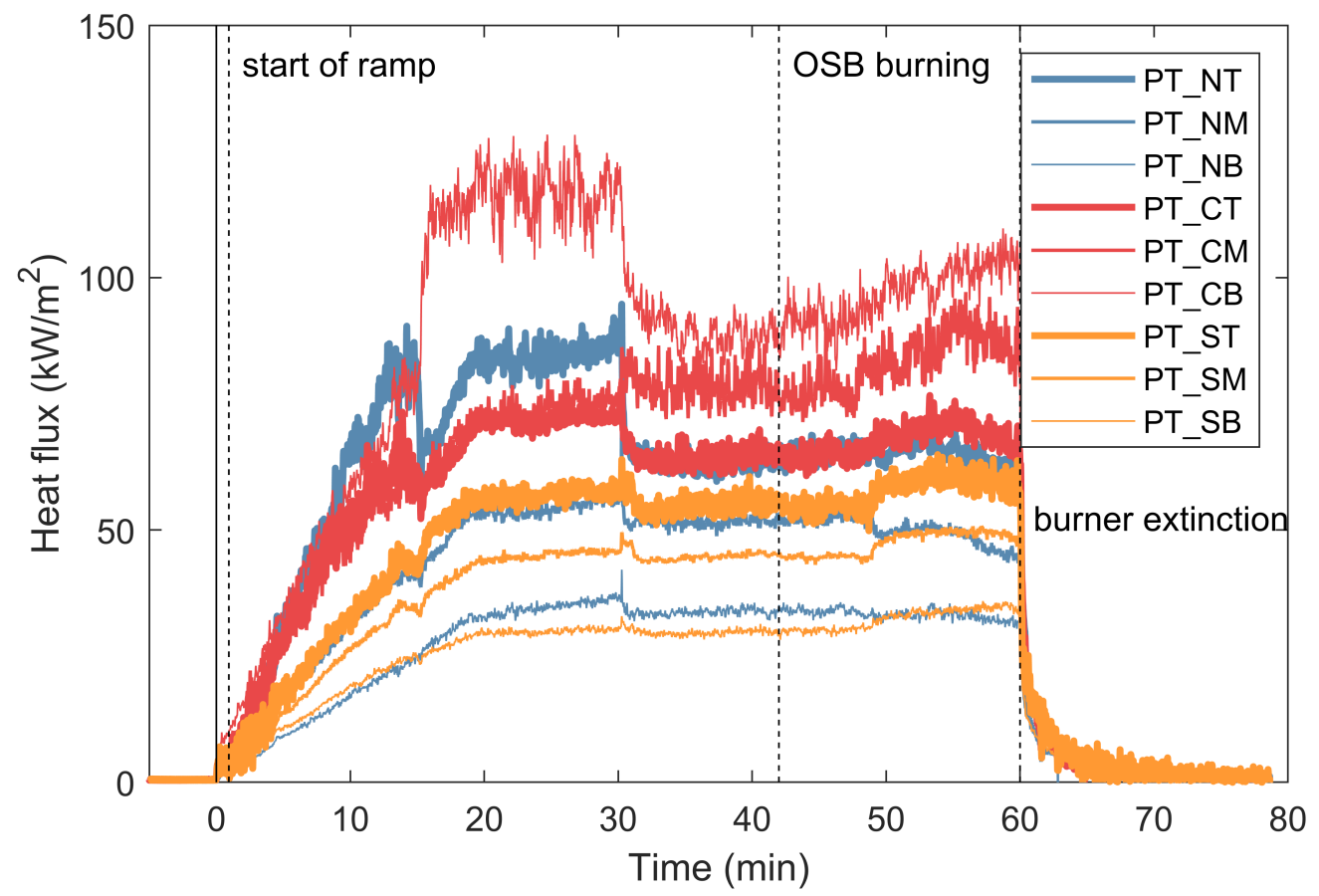

Fig. 265. OSB04 - Heat fluxes in the compartment measured by the plate thermocouples.
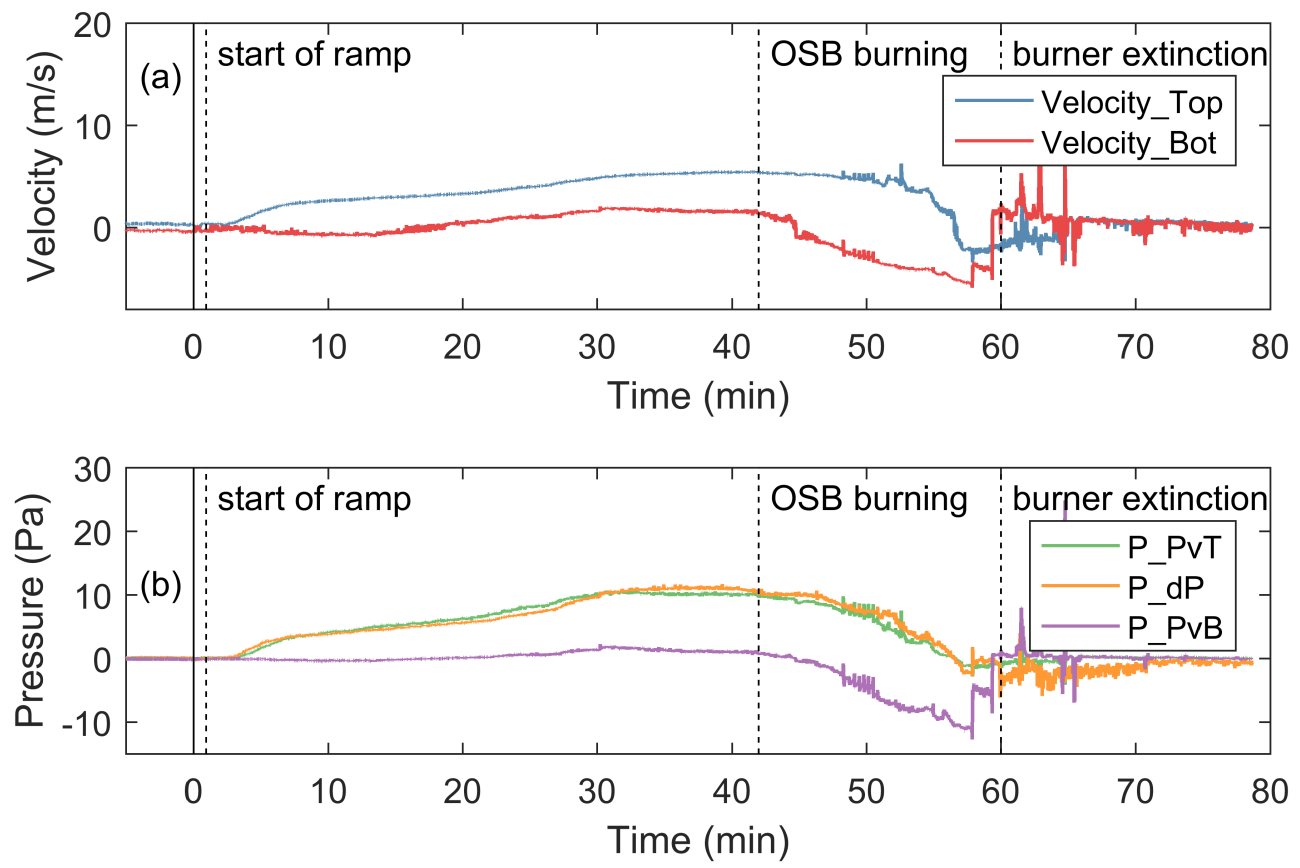

Fig. 266. OSB04 - (a) Velocity of air flow at the top and bottom knockouts of the chord stud; (b) Pressure at the top and bottom knockouts of the chord stud and in the wall cavity near the top. 


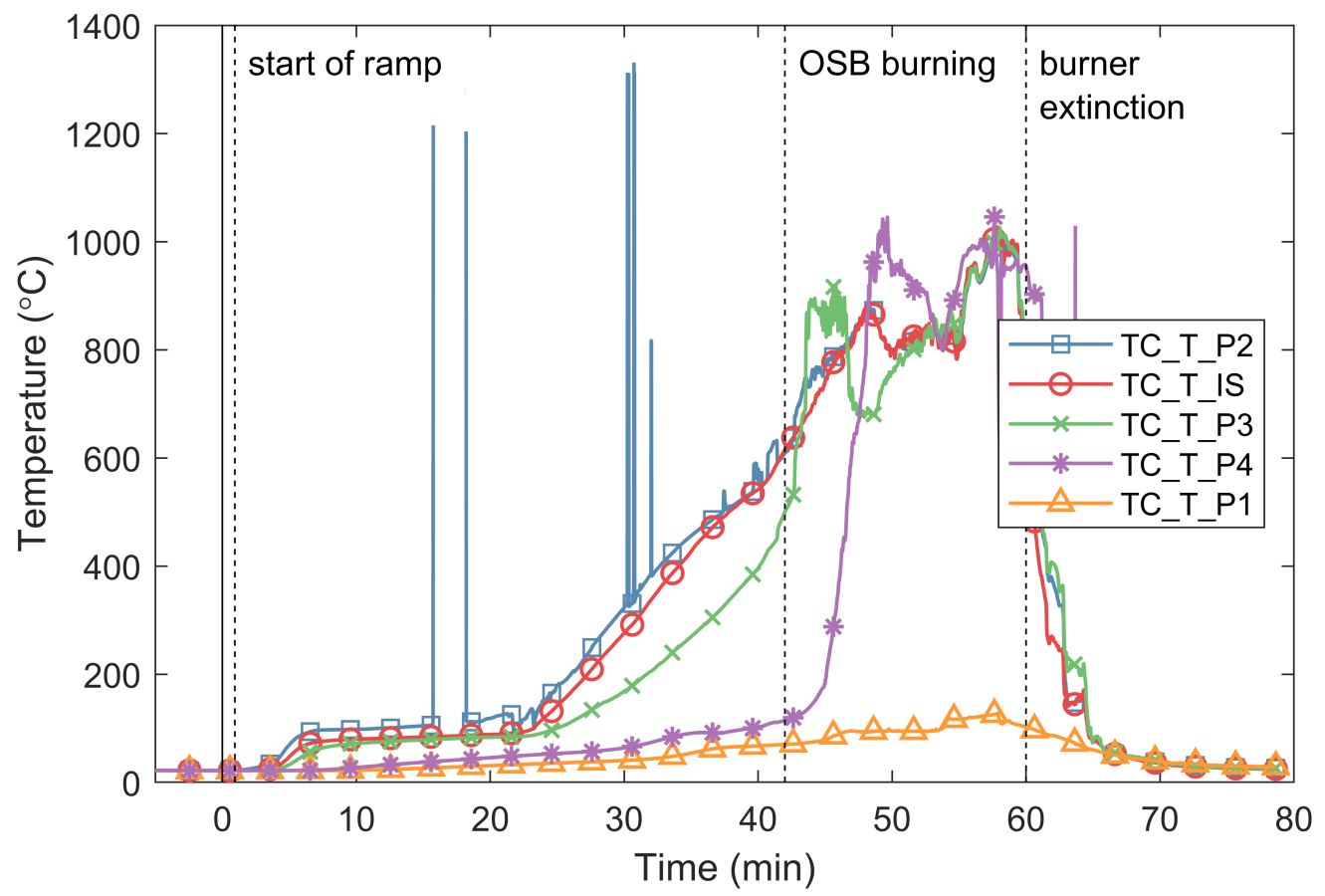

Fig. 267. OSB04 - Temperatures through the specimen at an interior stud $46 \mathrm{~cm}$ from the top of the wall.

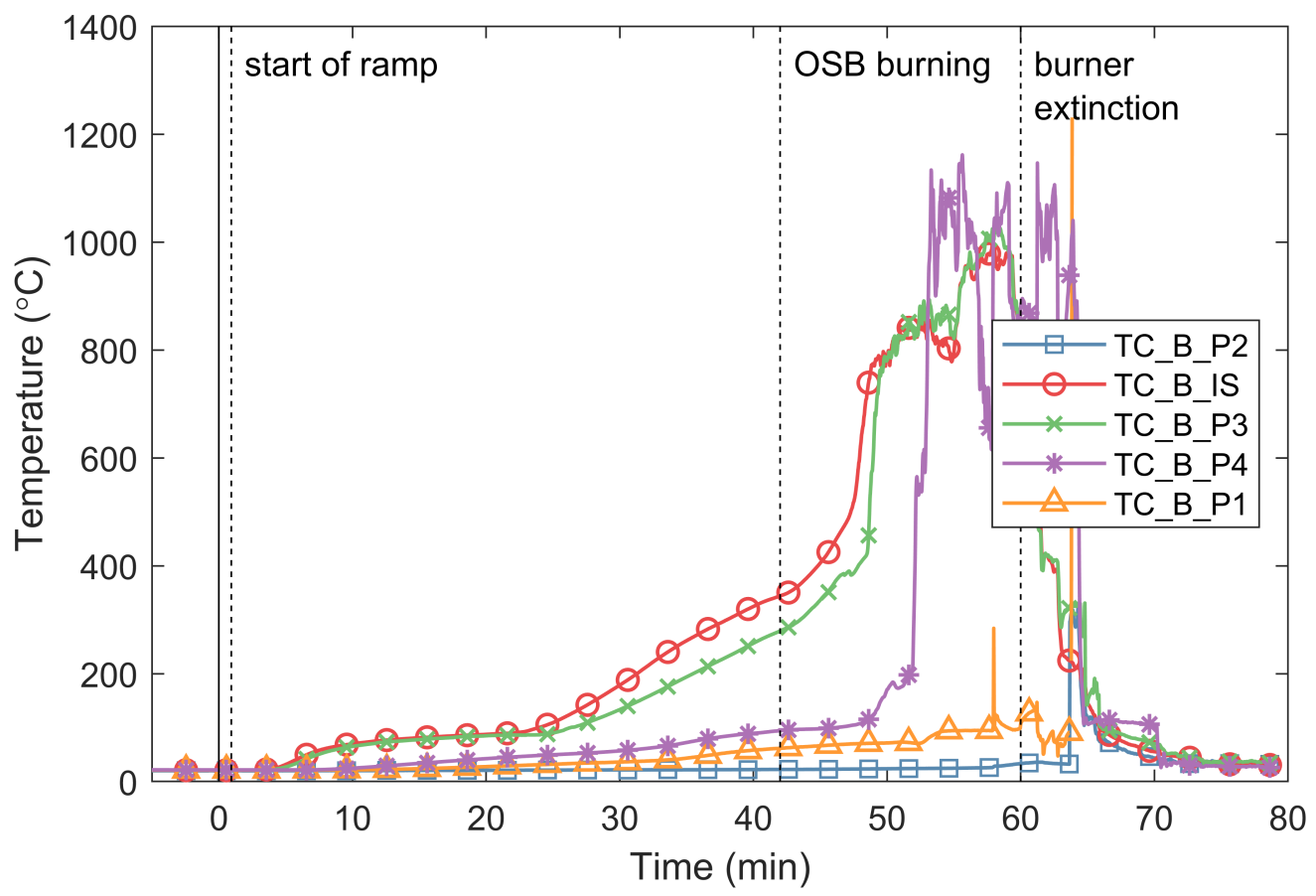

Fig. 268. OSB04 - Temperatures through the specimen at an interior stud $46 \mathrm{~cm}$ from the bottom of the wall. 

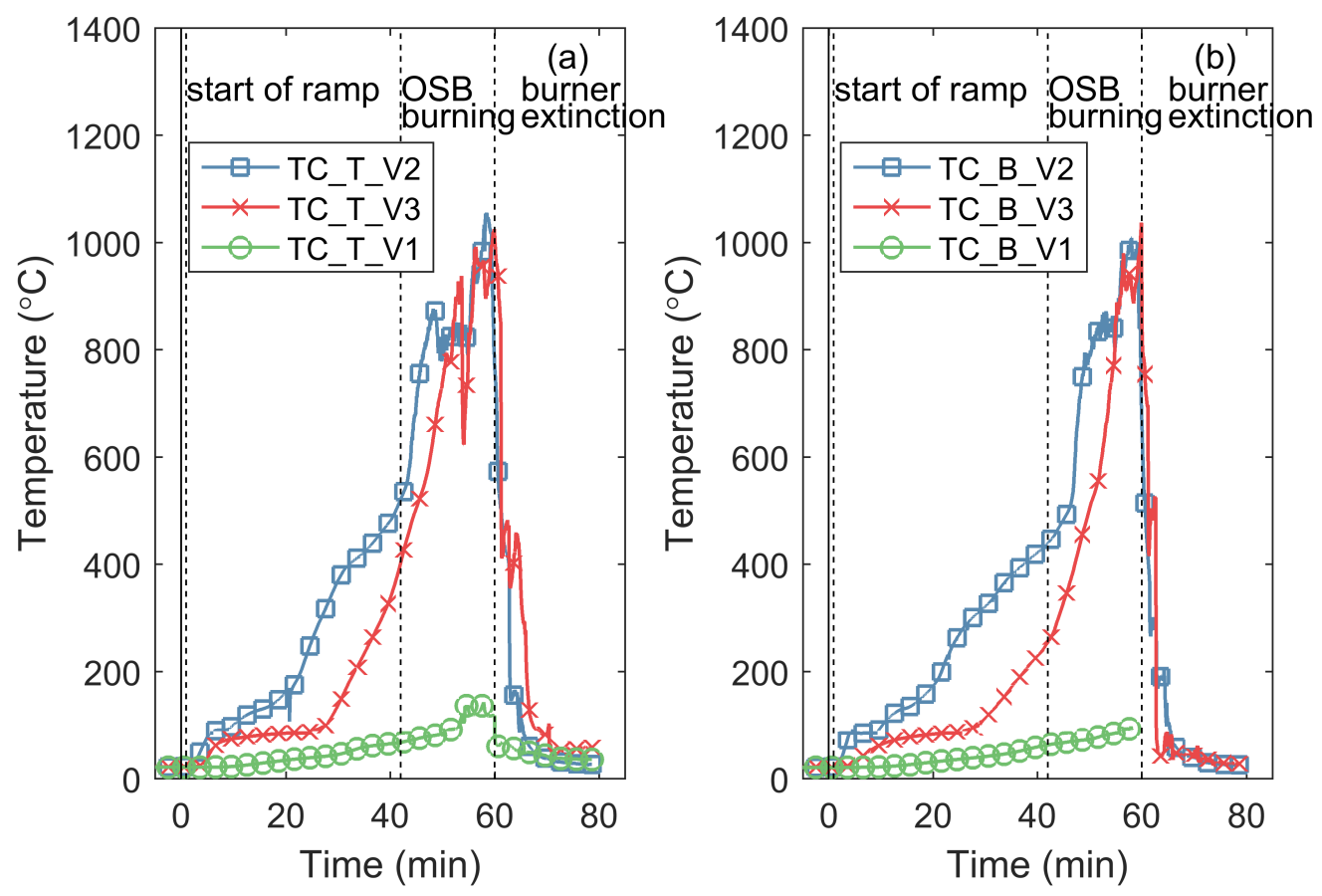

Fig. 269. OSB04 - Temperatures through the specimen midway between interior studs: (a) $46 \mathrm{~cm}$ from the top of the wall; (b) $46 \mathrm{~cm}$ from the bottom of the wall.
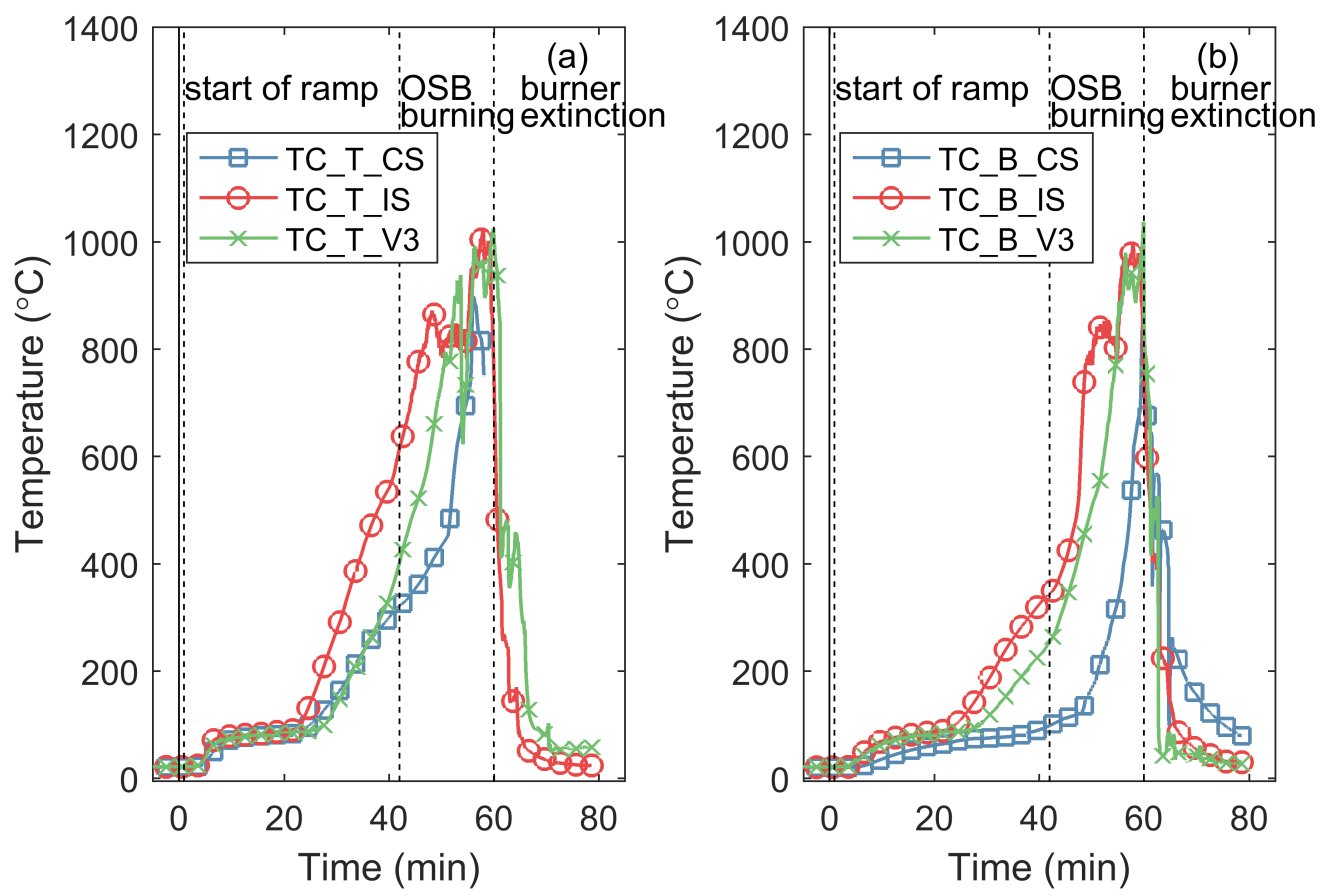

Fig. 270. OSB04 - Temperatures of the framing and sheathing elements: (a) $46 \mathrm{~cm}$ from the top of the wall; (b) $46 \mathrm{~cm}$ from the bottom of the wall. 


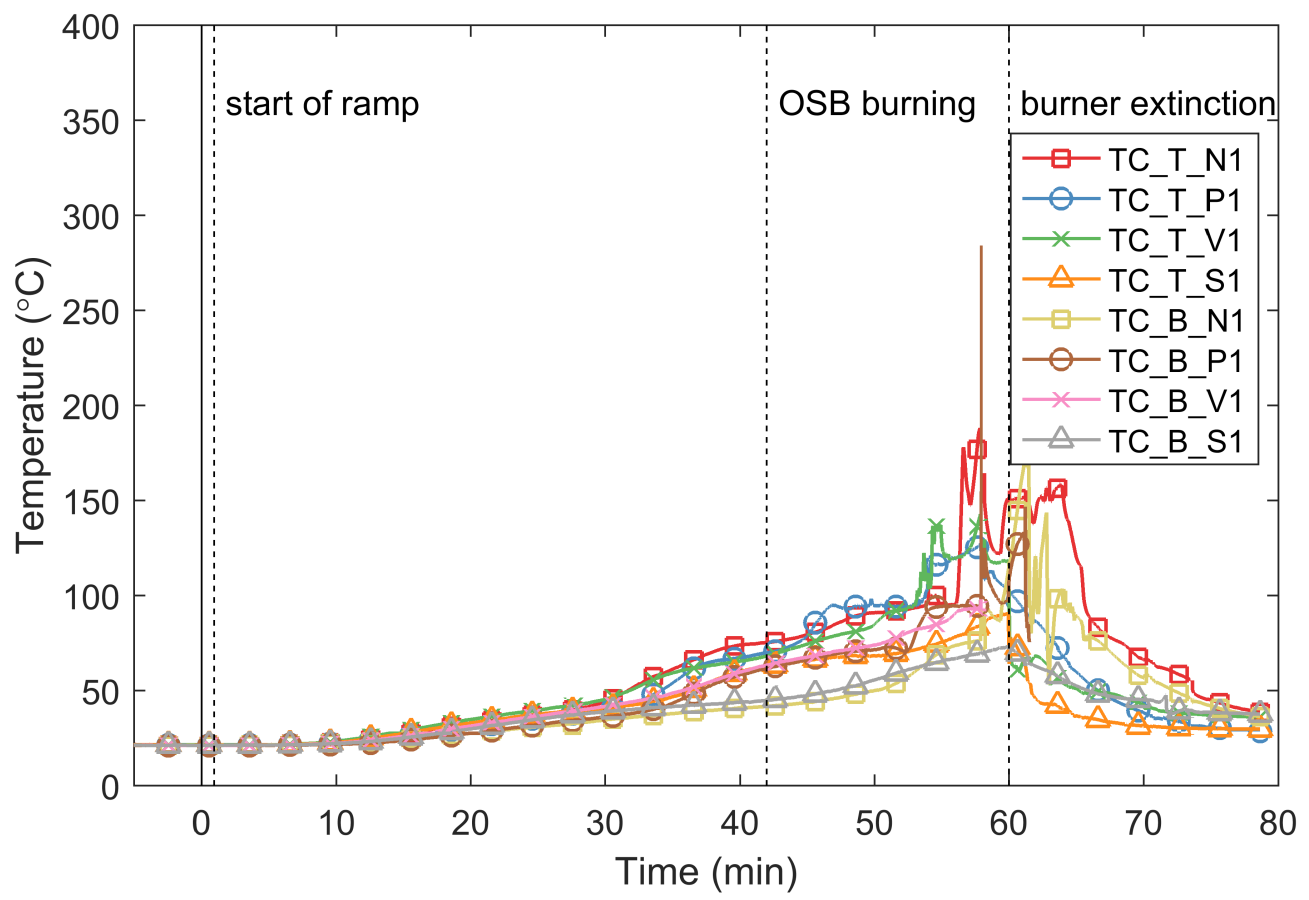

Fig. 271. OSB04 - Temperatures of the gypsum on the unexposed side of the wall specimen.

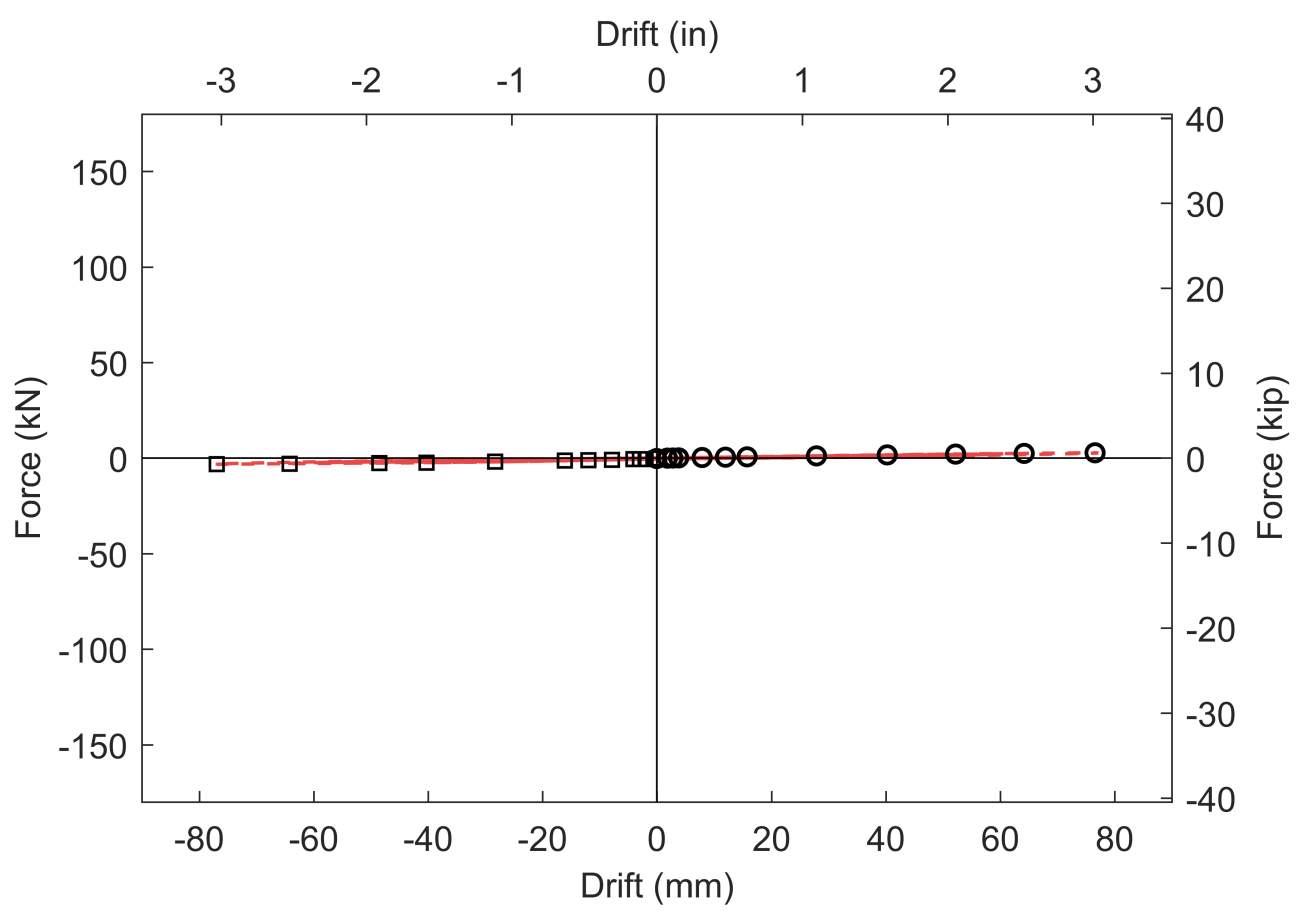

Fig. 272. OSB04 - Applied load versus wall longitudinal drift during mechanical loading. 


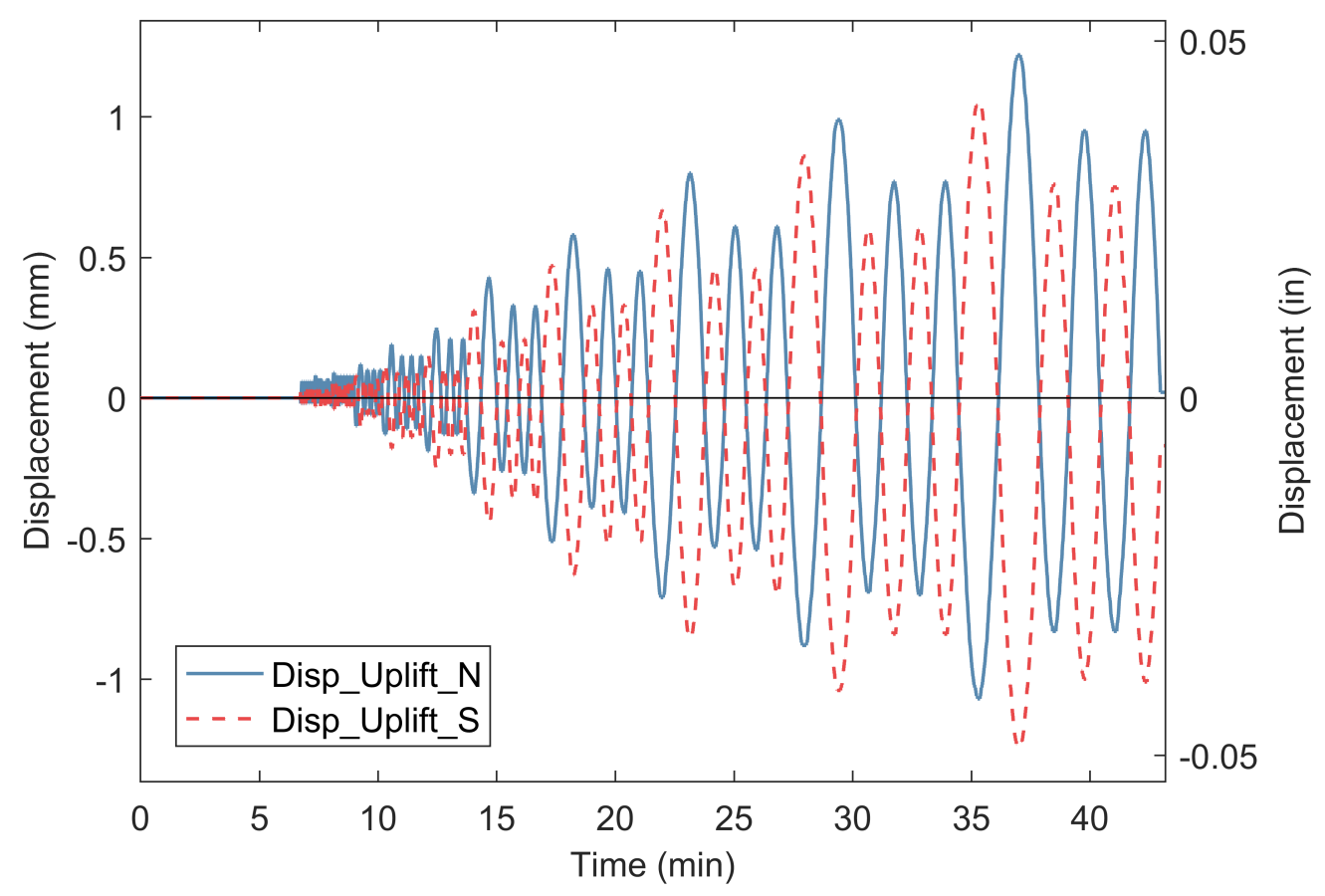

Fig. 273. OSB04 - Uplift at bottom of wall during mechanical loading.

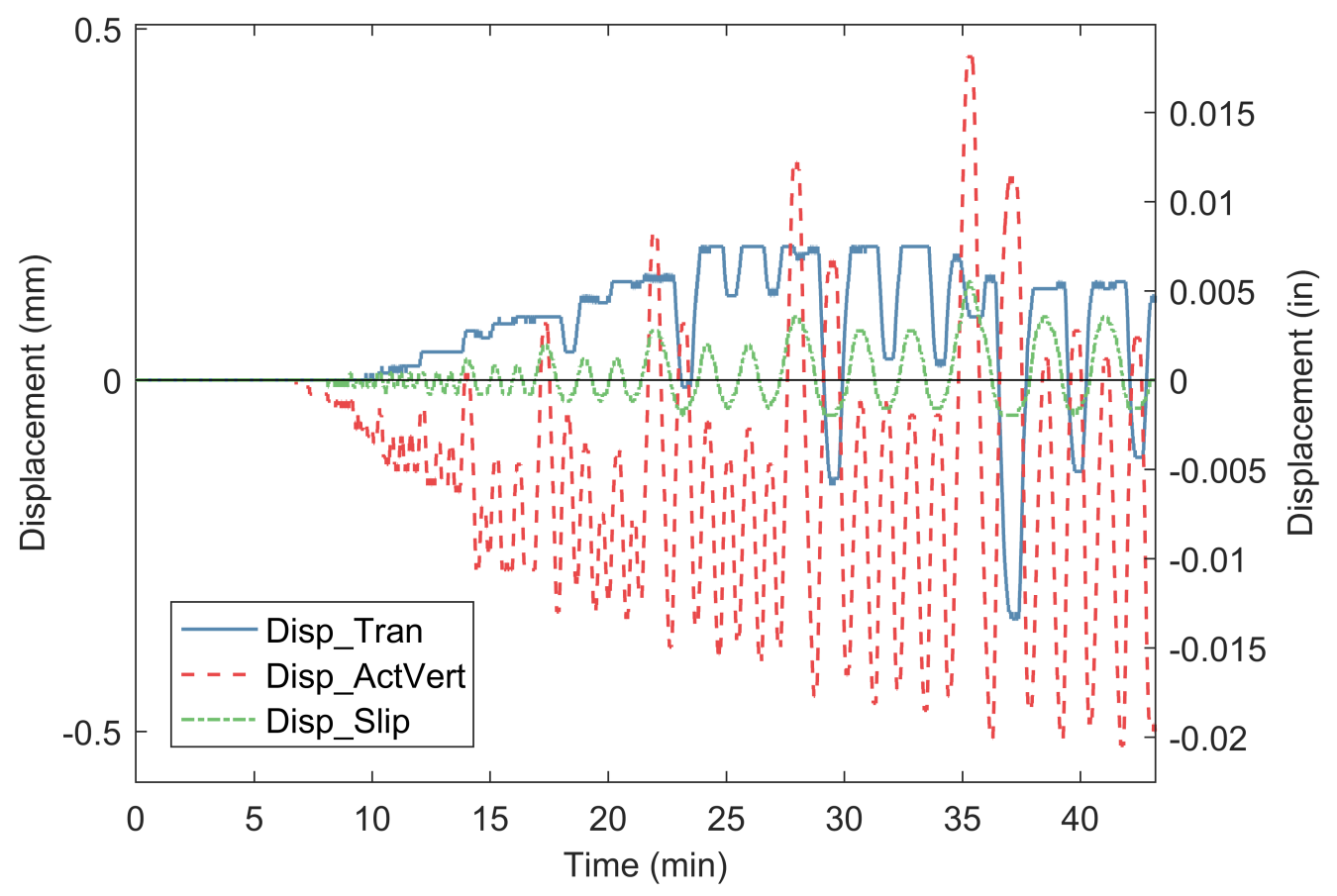

Fig. 274. OSB04 - Ancillary displacement measurements during mechanical loading. 


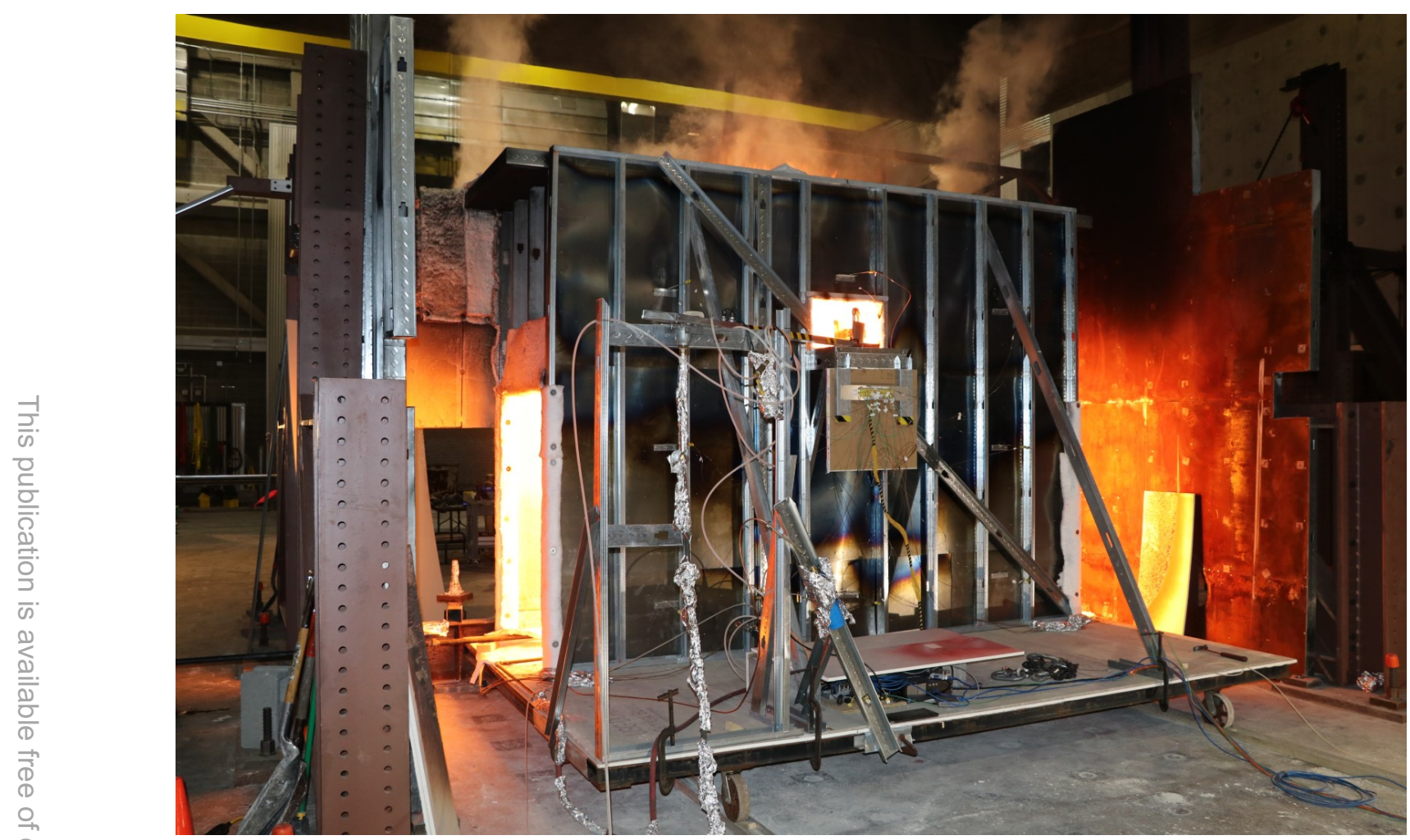

Fig. 275. OSB04 - Photograph of back of the compartment during the fire test.

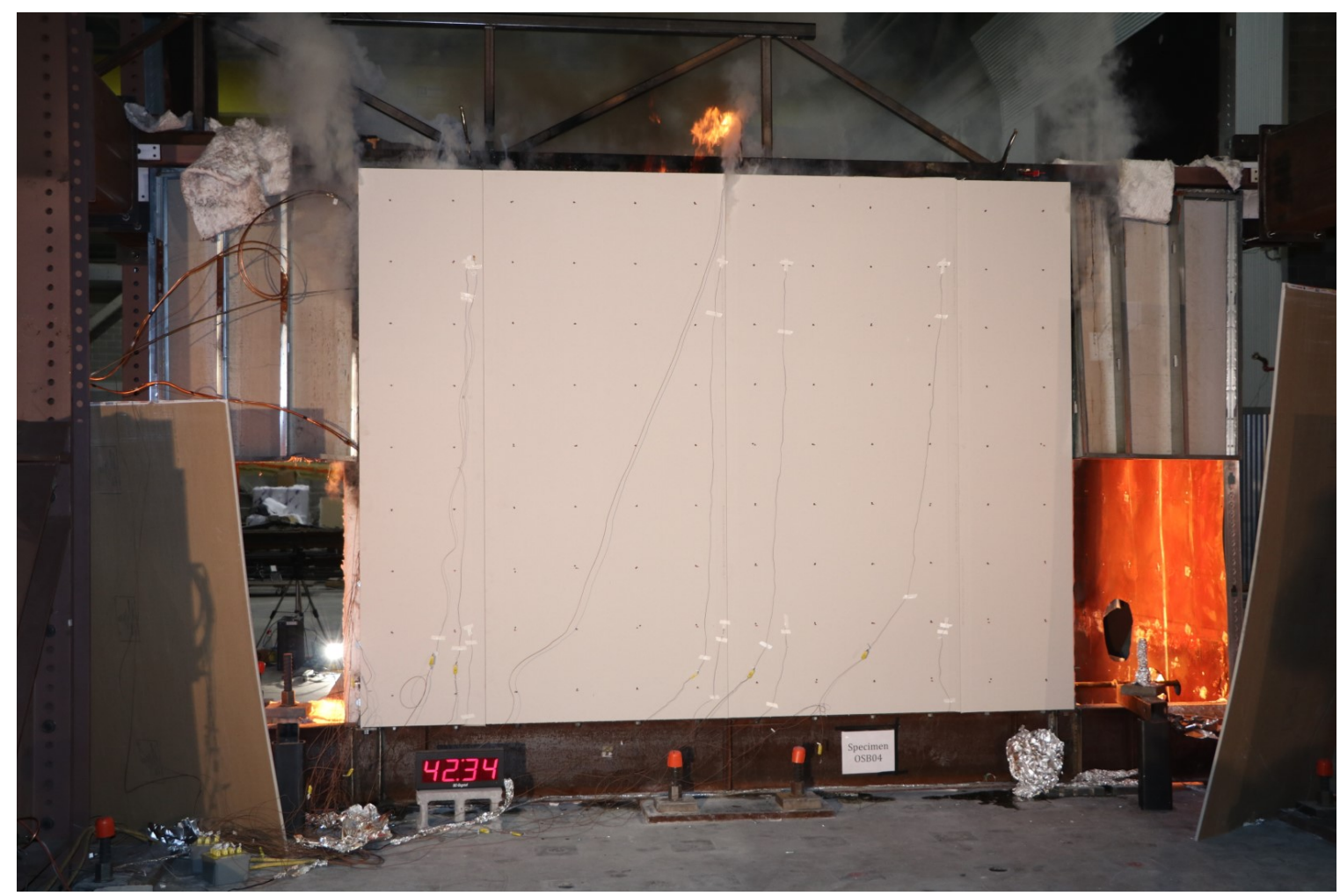

Fig. 276. OSB04 - Photograph of unexposed side of wall $42 \mathrm{~min} 34 \mathrm{~s}$ after ignition. 


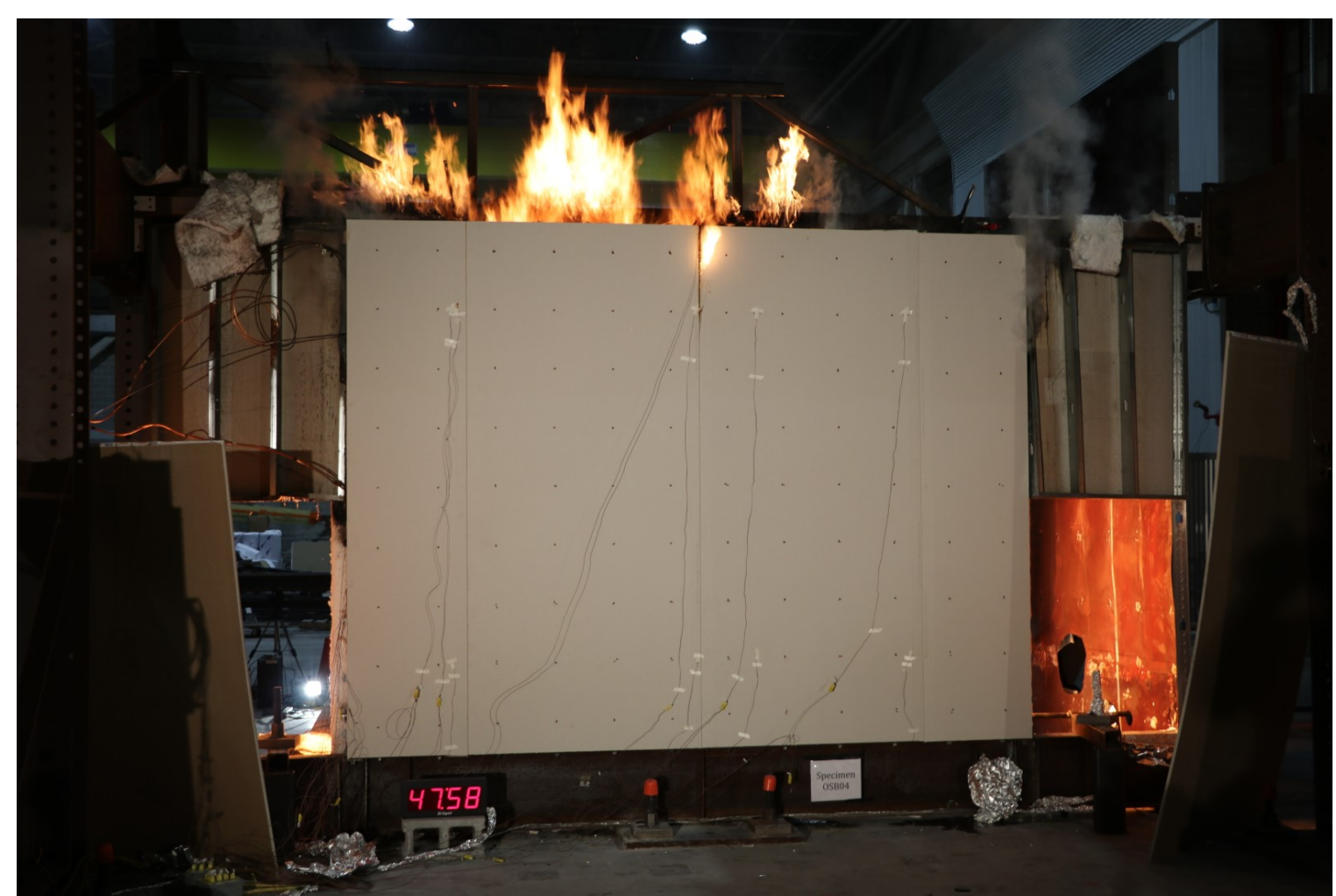

Fig. 277. OSB04 - Photograph of unexposed side of wall $47 \mathrm{~min} 58 \mathrm{~s}$ after ignition.

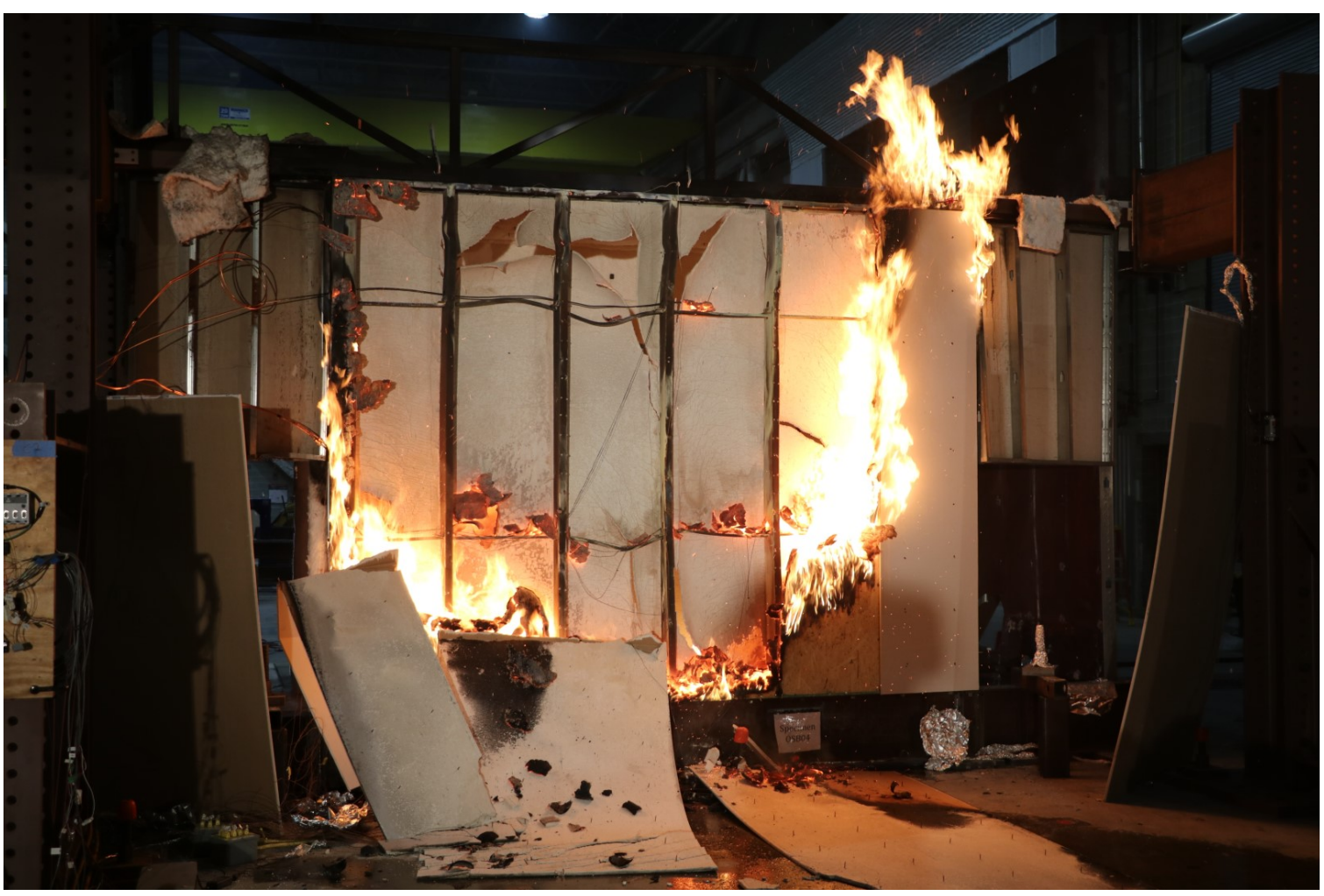

Fig. 278. OSB04 - Photograph of unexposed side of wall 60 min after ignition (just after extinction of burner). 


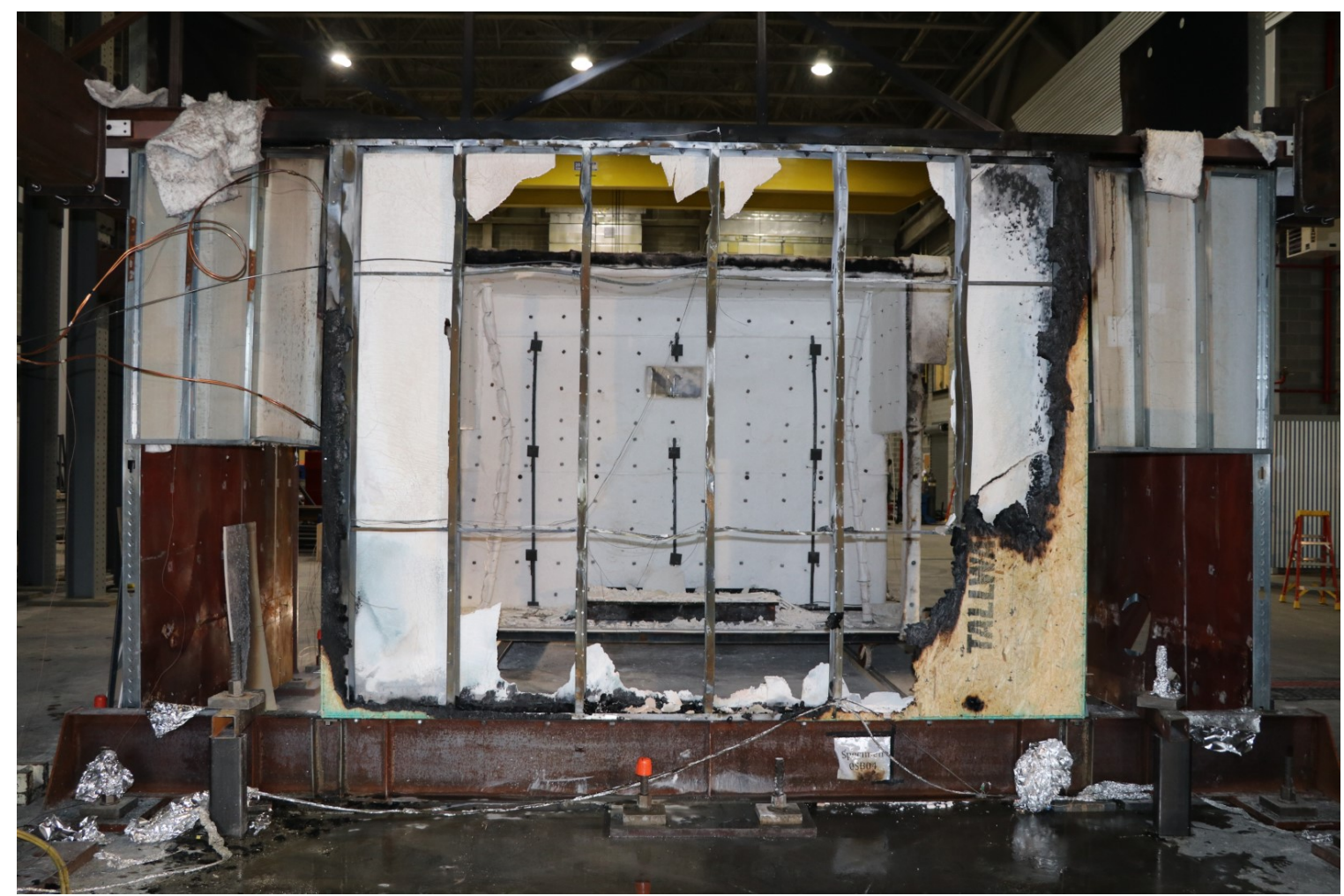

Fig. 279. OSB04 - Photograph of unexposed side of the wall after the fire test.

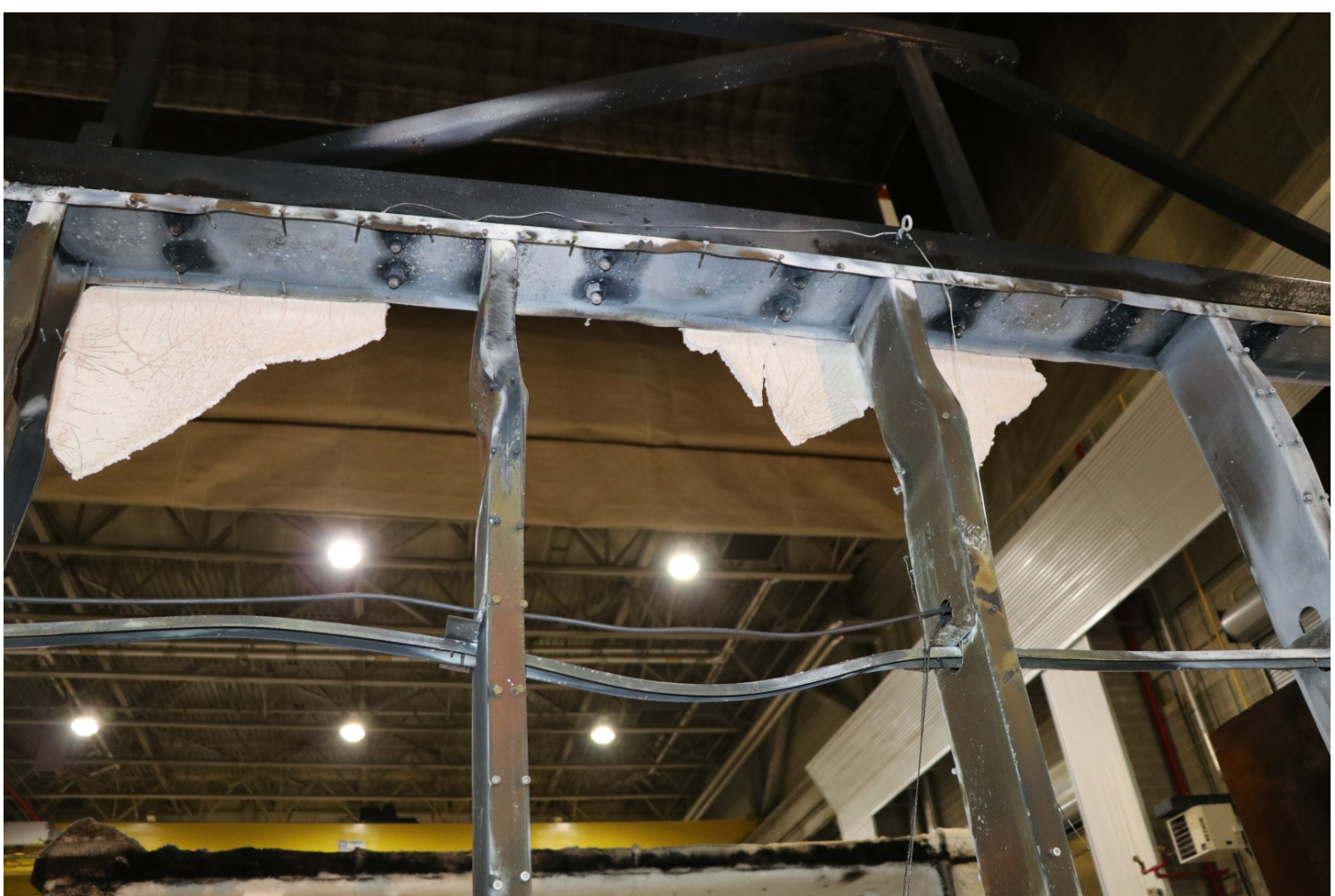

Fig. 280. OSB04 - Photograph of damage to interior studs following the fire. 


\section{OSB05 Data}

OSB05a (Cyclic test of wall to $1.5 \%$ SDR at ambient temperature)

- Behavior was similar to comparable ambient test OSB01Ra.

- Tore mud and tape along entire length of north-east seam. $\sim 1 \mathrm{~mm}$ opening at top of wall (Fig. 296) tapering to $<0.1 \mathrm{~mm}$ at bottom (Fig. 297).

- Tore mud and tape along lower $1 \mathrm{~m}$ of center-east seam. $\sim 0.1 \mathrm{~mm}$ opening at bottom of wall tapering to $0 \mathrm{~mm}$ at $1 \mathrm{~m}$ up.

- Corner screws in north-east and south-east top corner broke out of the gypsum (Fig. 298).

- No damage visible on front of west wall (unexposed side; Fig. 294).

- The OSB pulled away from the chord stud about $12 \mathrm{~mm}$ at the top of the north and south sides of the wall (Fig. 299).

OSB05b (Mild Fire test after cyclic test to $1.5 \%$ SDR)

- The heat release in the burner was set to $1.7 \mathrm{MW}$ for 15 minutes. After the burner was turn off, a crack appeared on the north exposed gypsum panel, and smoking occurred. After 16 min flames appear on the north top corner of the wall (Fig. 300).

- After about 10 min of burning, the wall was extinguished using water suppression.

- After the test there is charring on the north end of the wall and the rest remains (visibly) undamaged (Fig. 305).

OSB05c (Cyclic test of wall at ambient temperature following the Mild Fire)

- No comments.

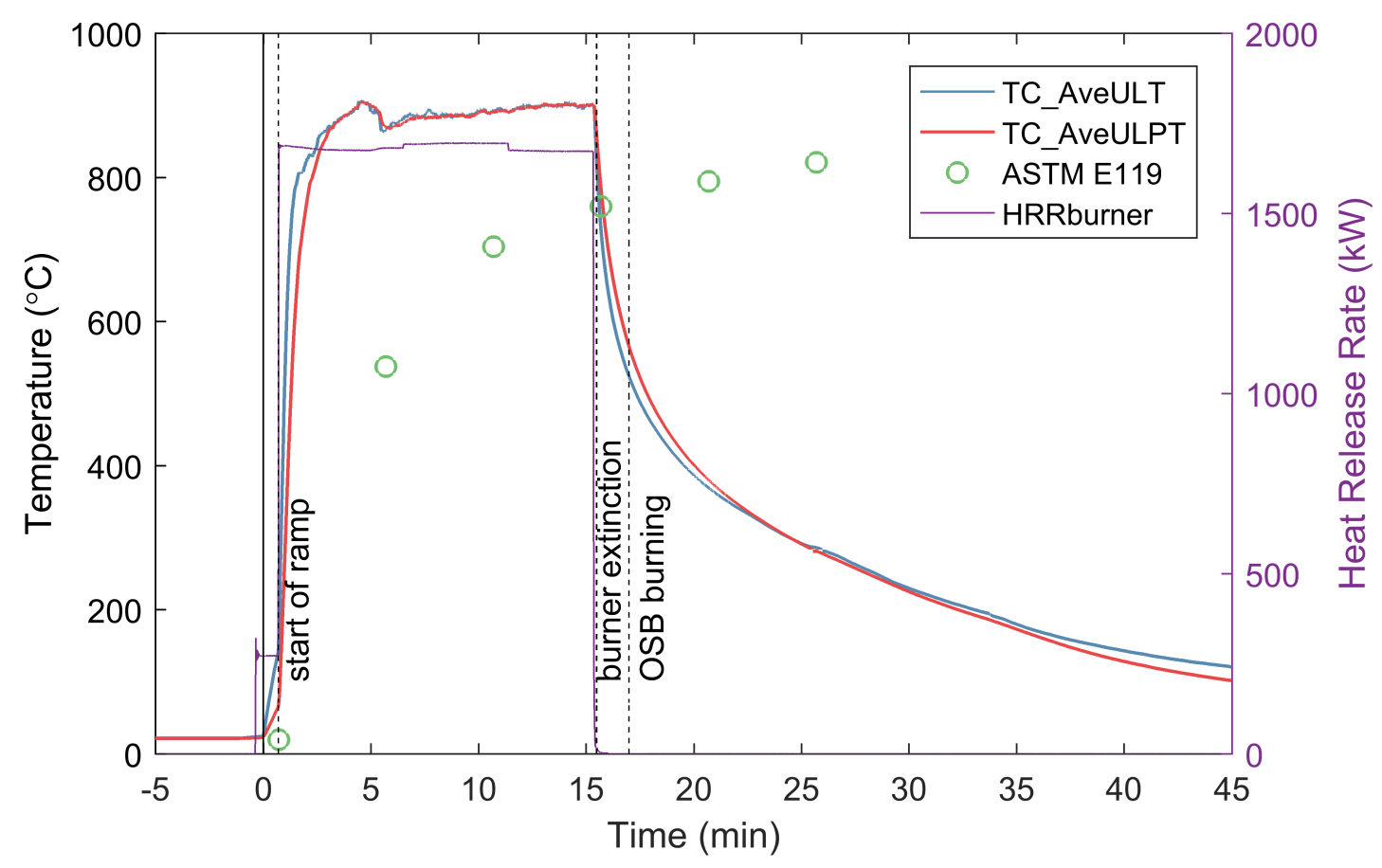

Fig. 281. OSB05 - Compartment temperature and burner Heat Release Rate. 


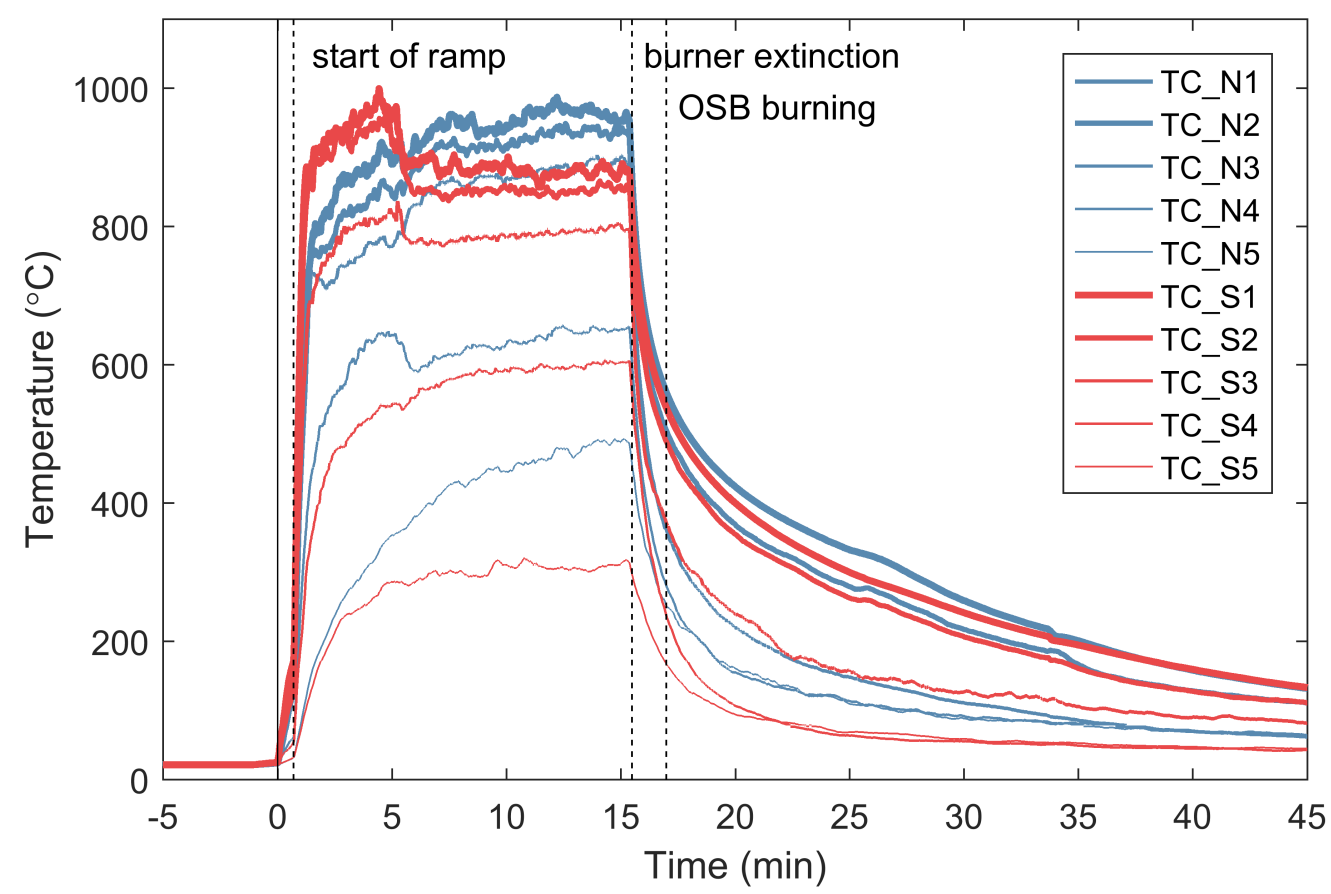

Fig. 282. OSB05 - Compartment temperatures measured by the thermocouple arrays.

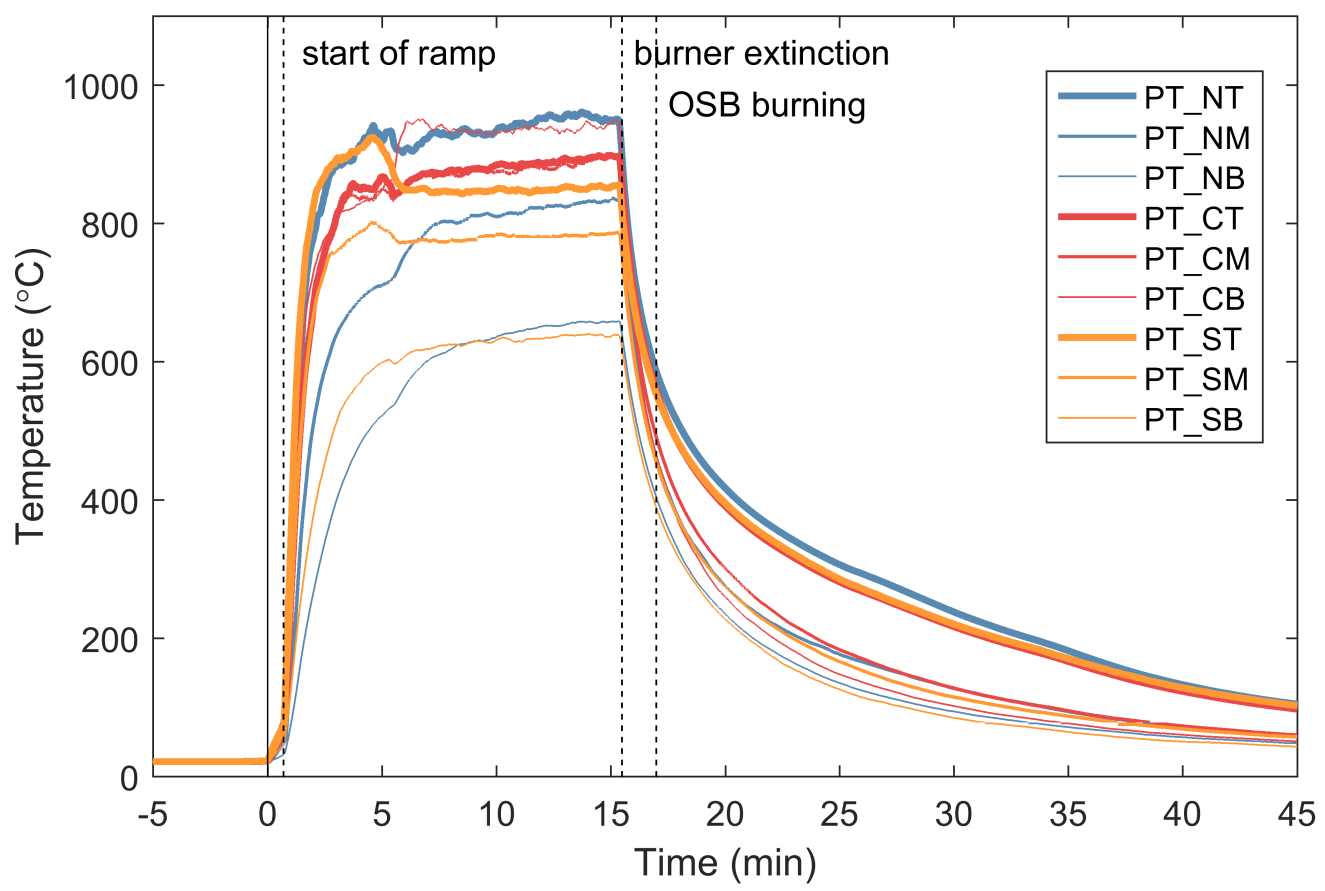

Fig. 283. OSB05 - Compartment temperatures measured by the plate thermocouples. 


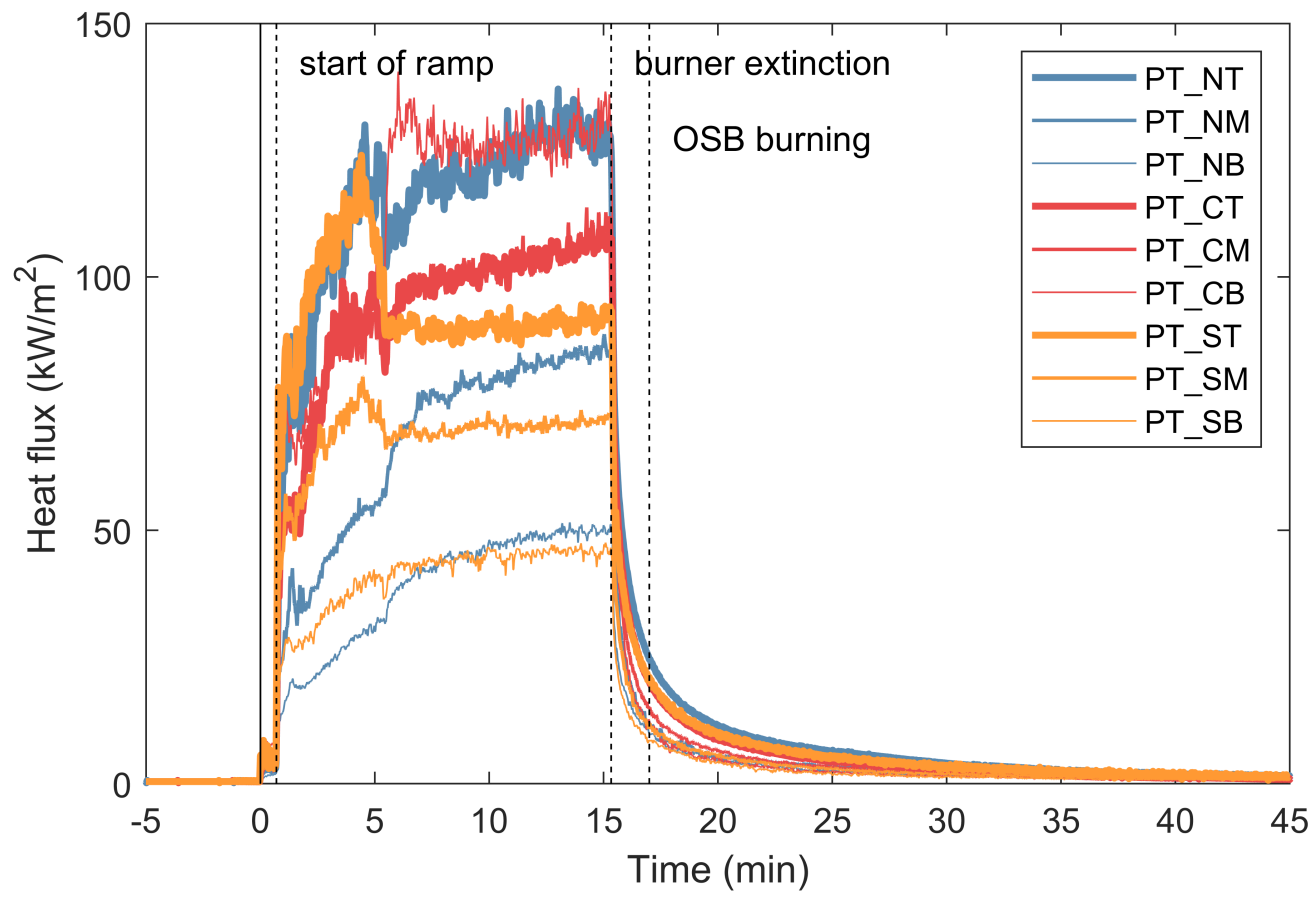

Fig. 284. OSB05 - Heat fluxes in the compartment measured by the plate thermocouples.
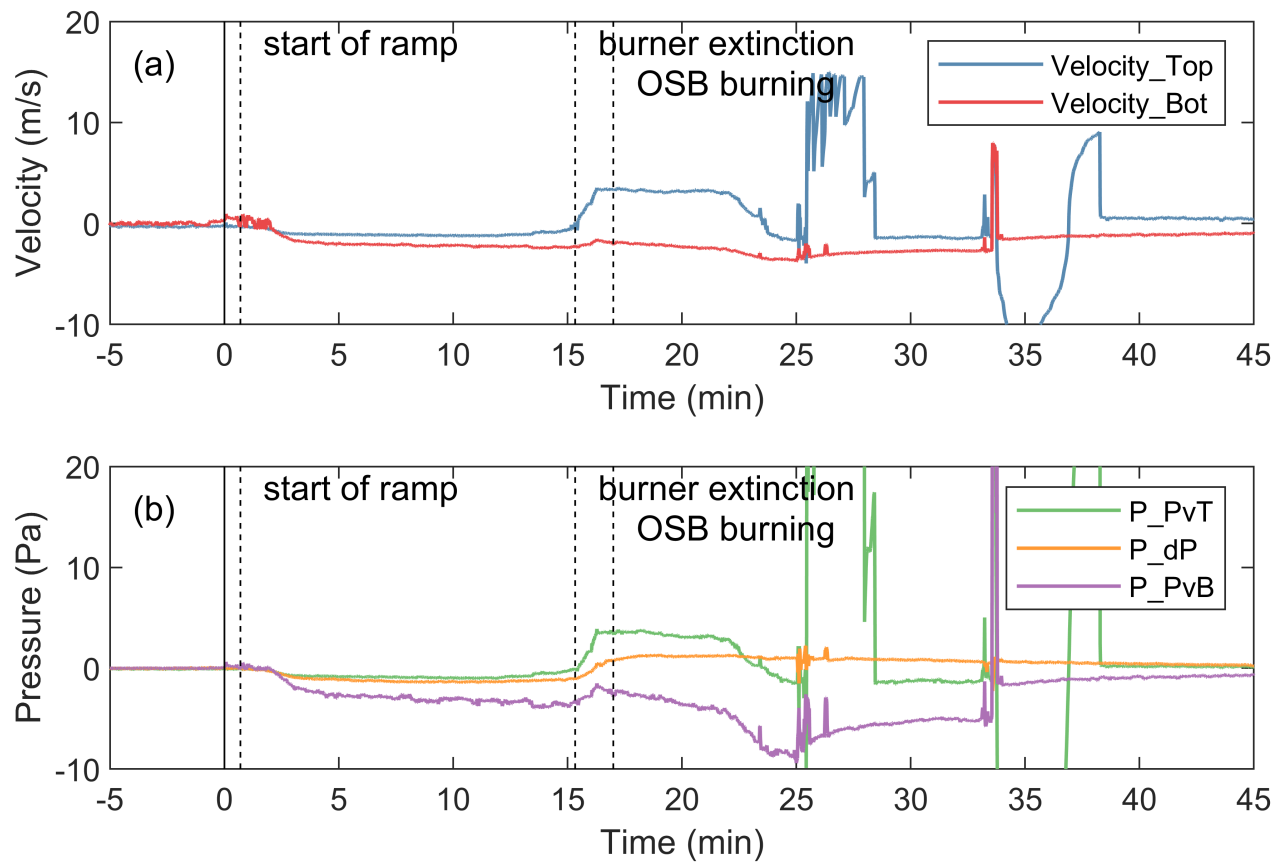

Fig. 285. OSB05 - (a) Velocity of air flow at the top and bottom knockouts of the chord stud; (b) Pressure at the top and bottom knockouts of the chord stud and in the wall cavity near the top. 


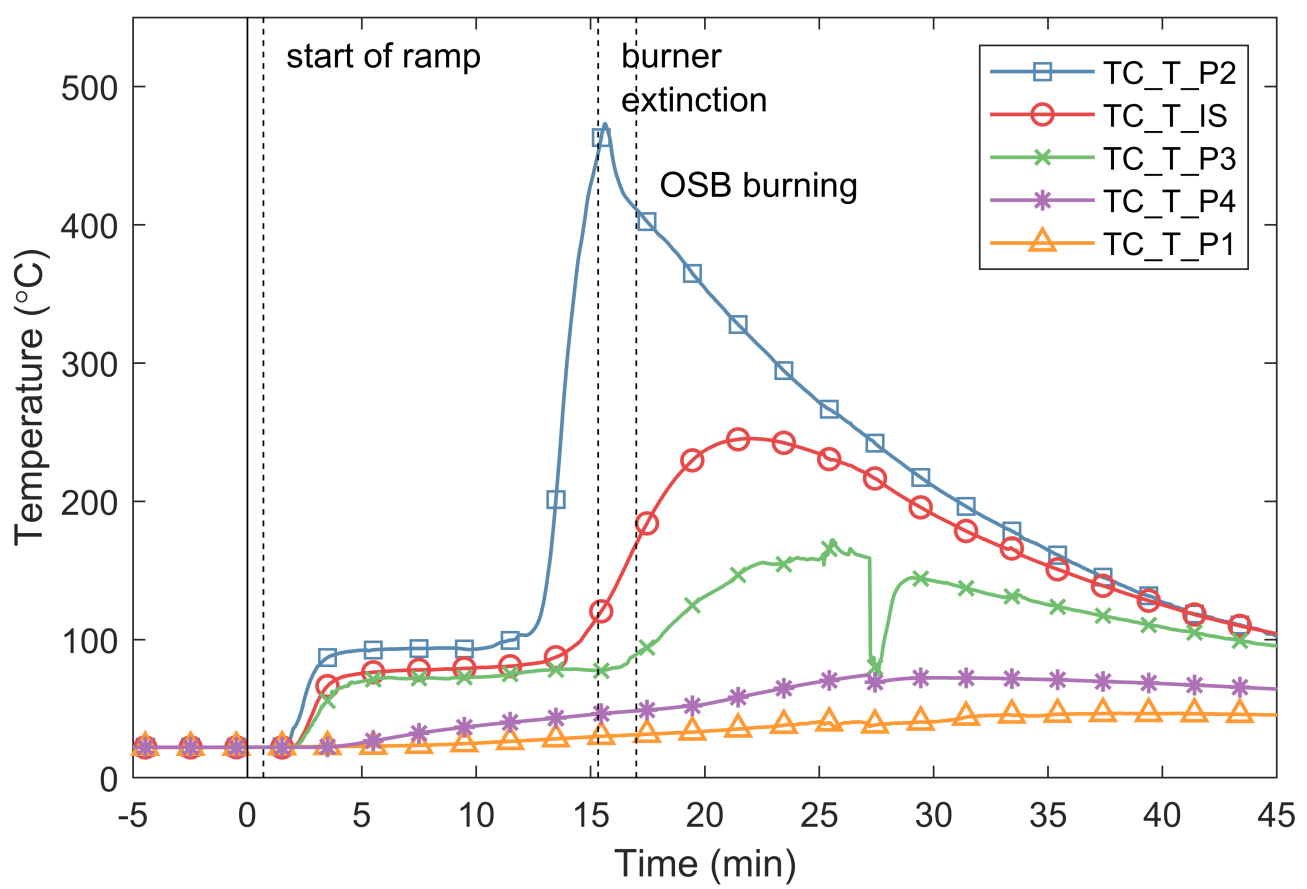

Fig. 286. OSB05 - Temperatures through the specimen at an interior stud $46 \mathrm{~cm}$ from the top of the wall.

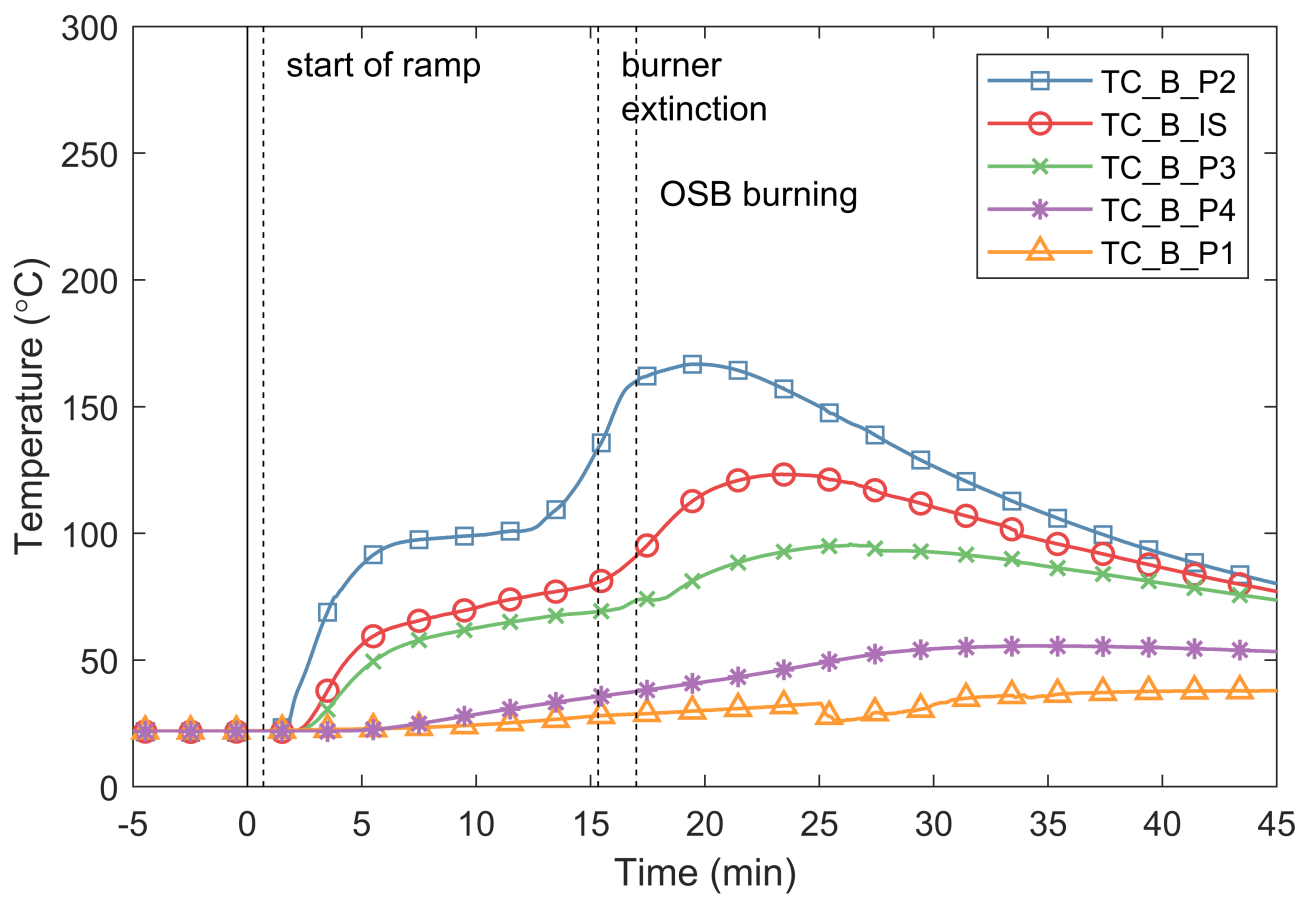

Fig. 287. OSB05 - Temperatures through the specimen at an interior stud $46 \mathrm{~cm}$ from the bottom of the wall. 


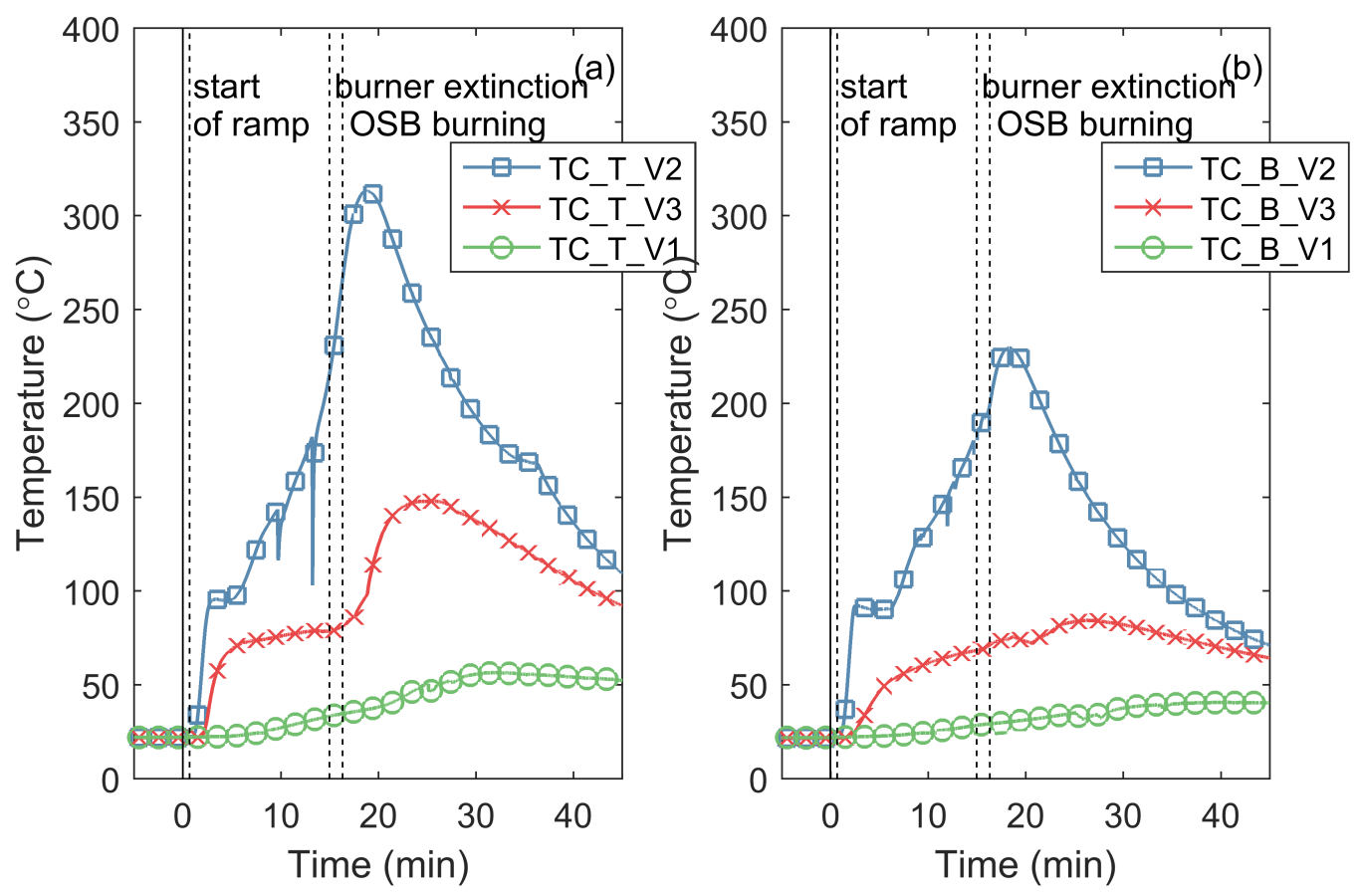

Fig. 288. OSB05 - Temperatures through the specimen midway between interior studs: (a) $46 \mathrm{~cm}$ from the top of the wall; (b) $46 \mathrm{~cm}$ from the bottom of the wall.

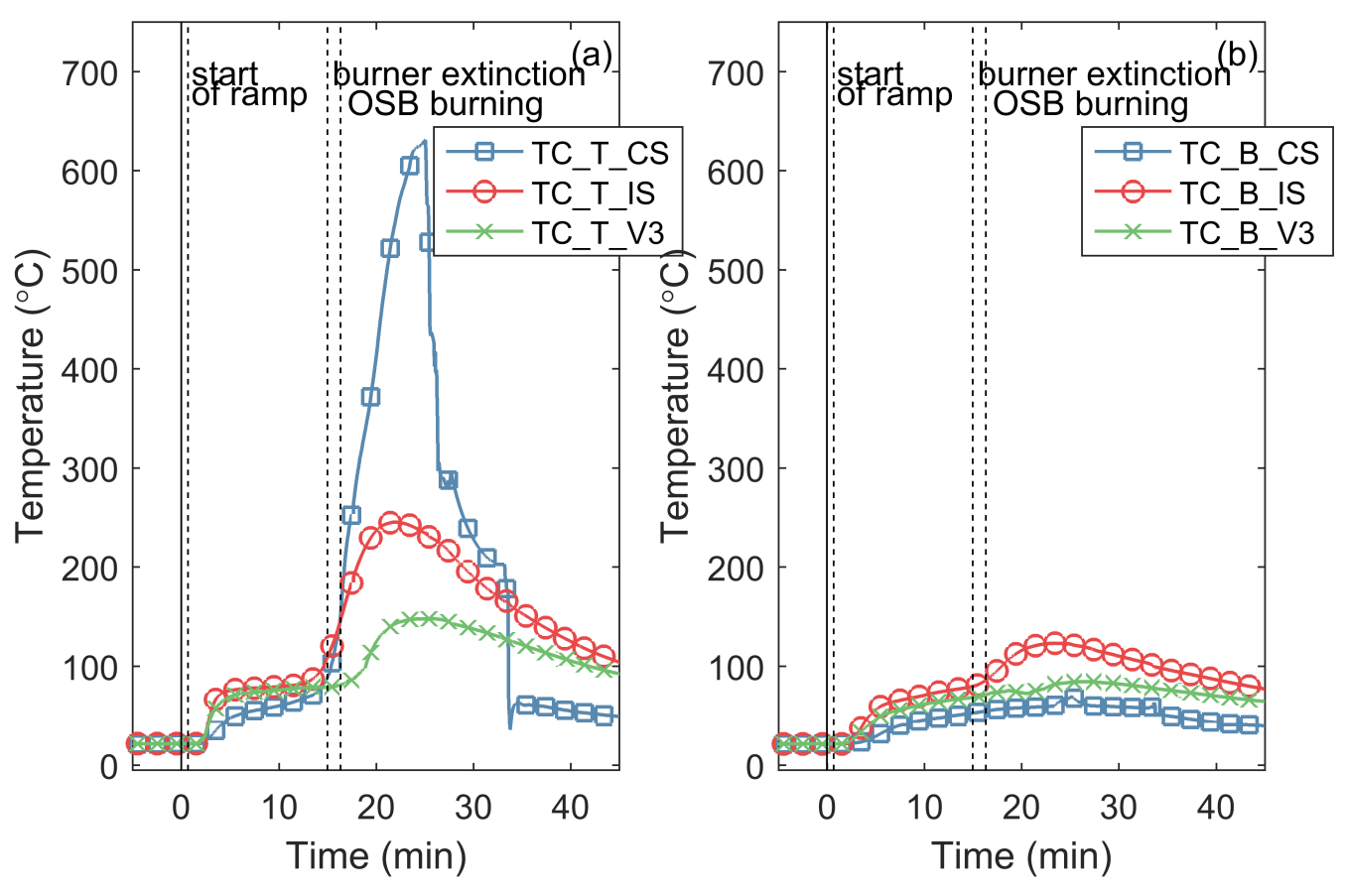

Fig. 289. OSB05 - Temperatures of the framing and sheathing elements: (a) $46 \mathrm{~cm}$ from the top of the wall; (b) $46 \mathrm{~cm}$ from the bottom of the wall. 


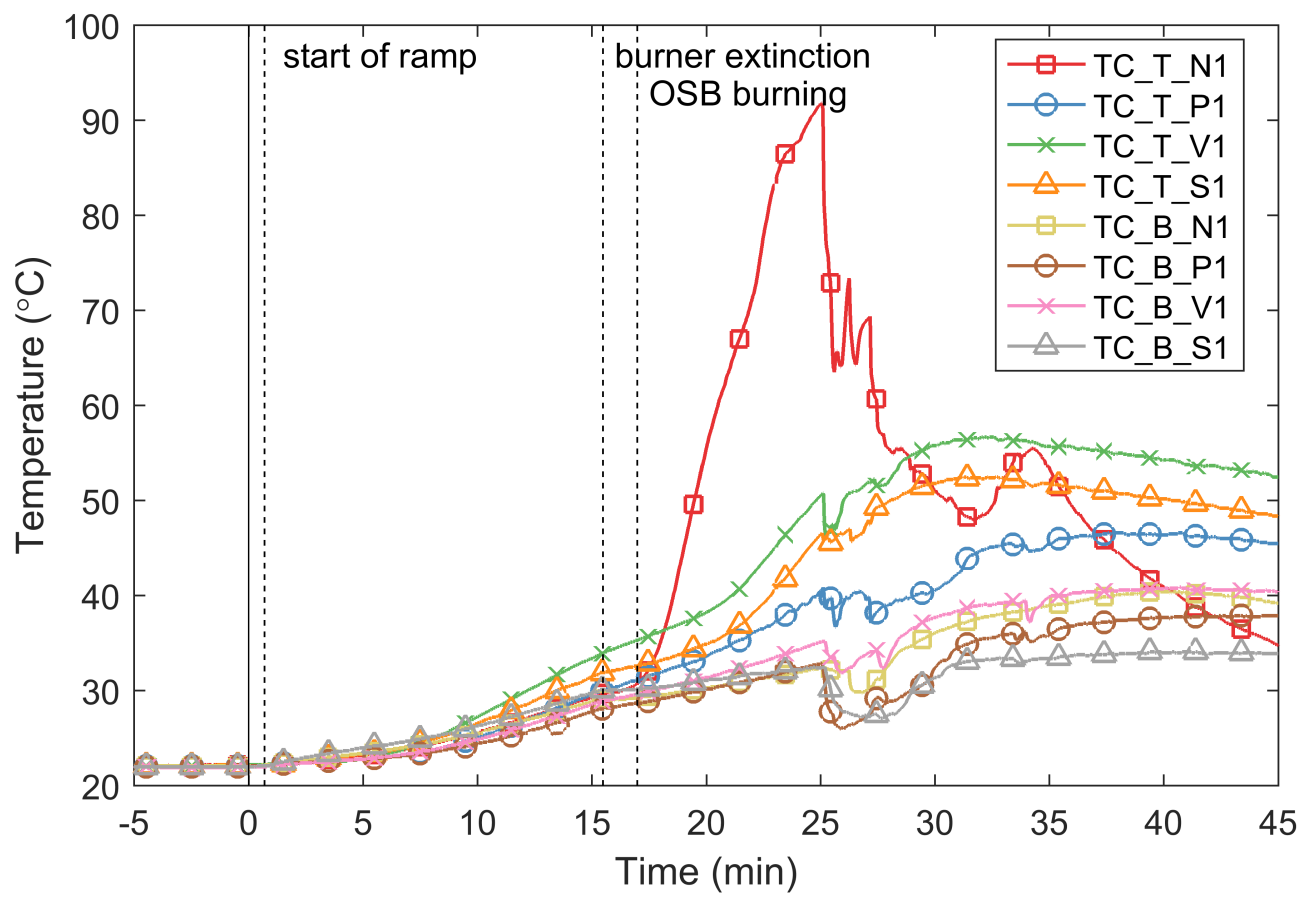

Fig. 290. OSB05 - Temperatures of the gypsum on the unexposed side of the wall specimen.

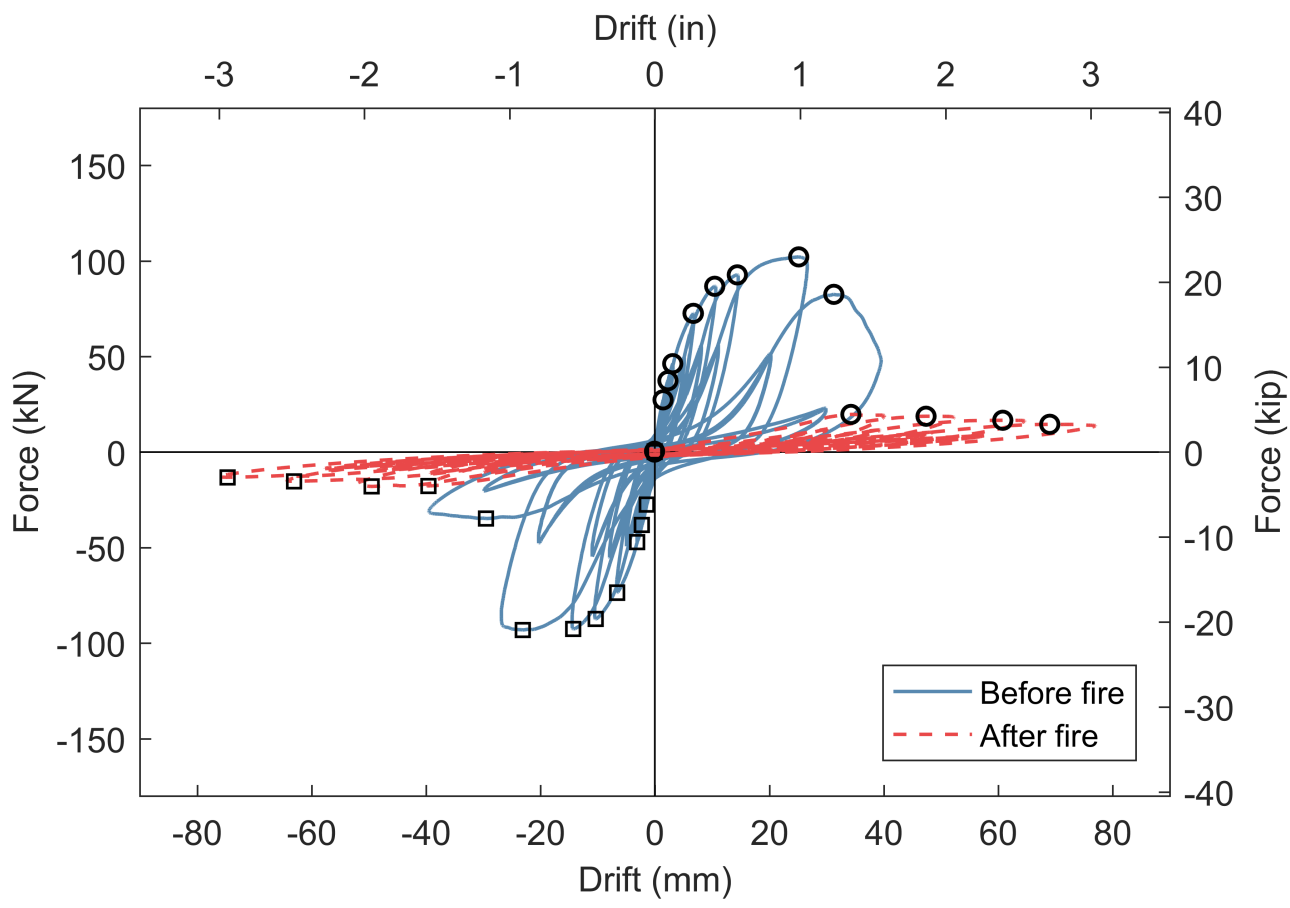

Fig. 291. OSB05 - Applied load versus wall longitudinal drift during mechanical loading. 


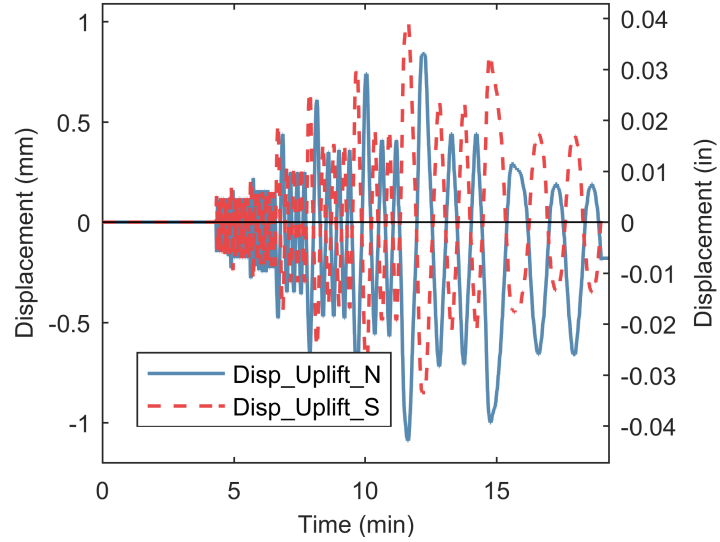

(a)

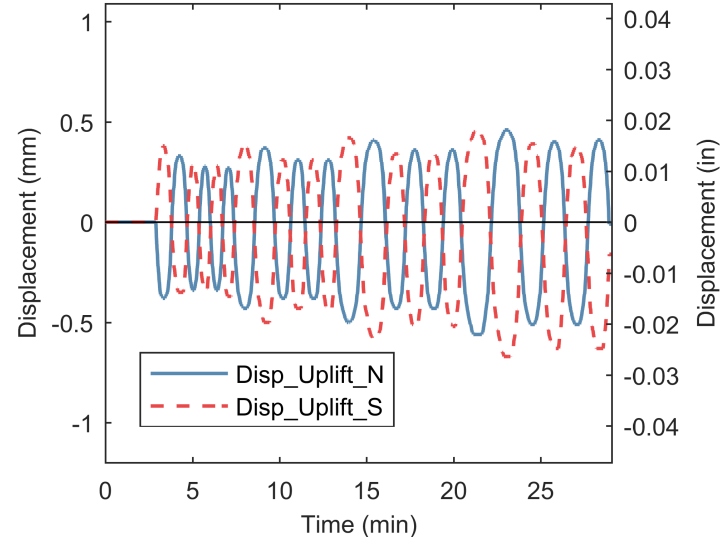

(b)

Fig. 292. OSB05 - Uplift at bottom of wall during mechanical loading: (a) before fire; (b) after fire.

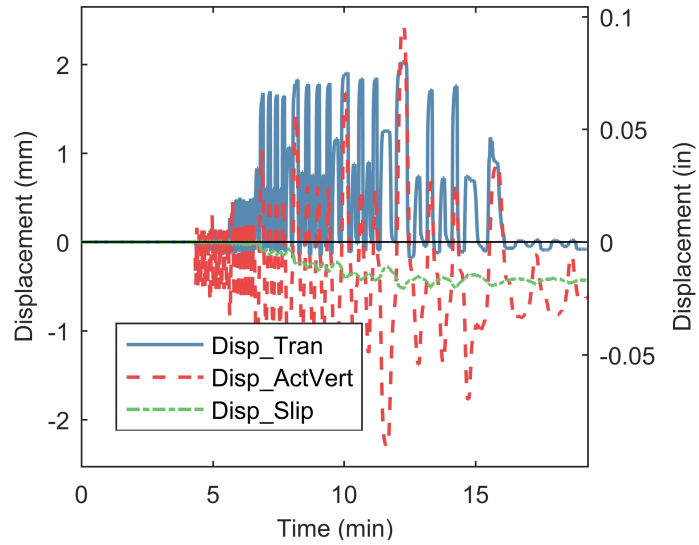

(a)

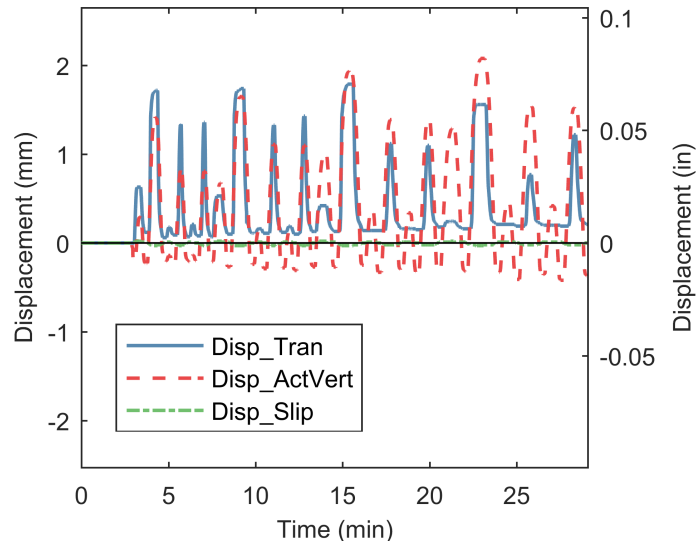

(b)

Fig. 293. OSB05 - Ancillary displacement measurements during mechanical loading: (a) before fire; (b) after fire. 


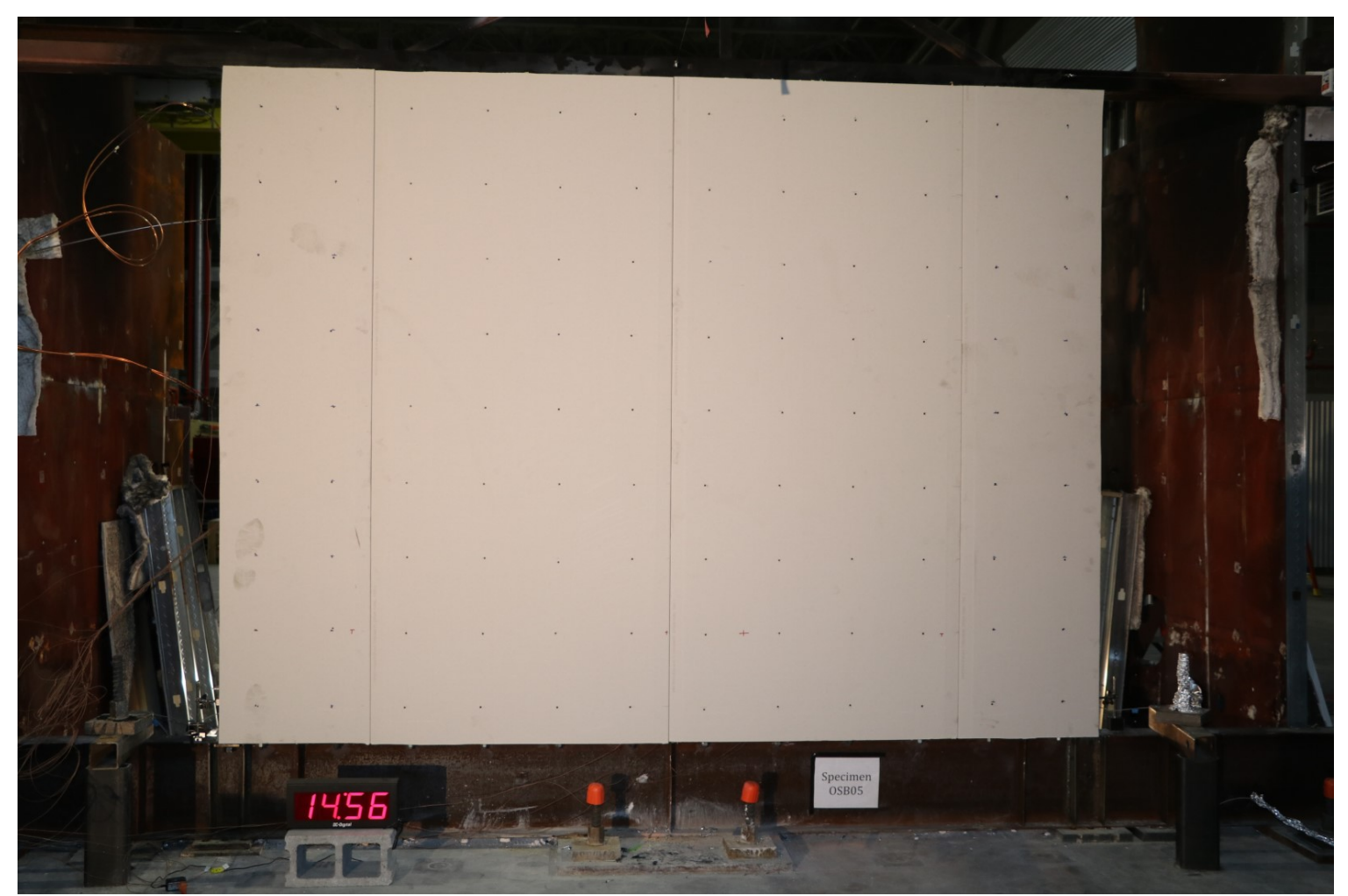

Fig. 294. OSB05 - Photograph of west (unexposed) side of wall after cycling to $1.5 \%$ drift (before fire).

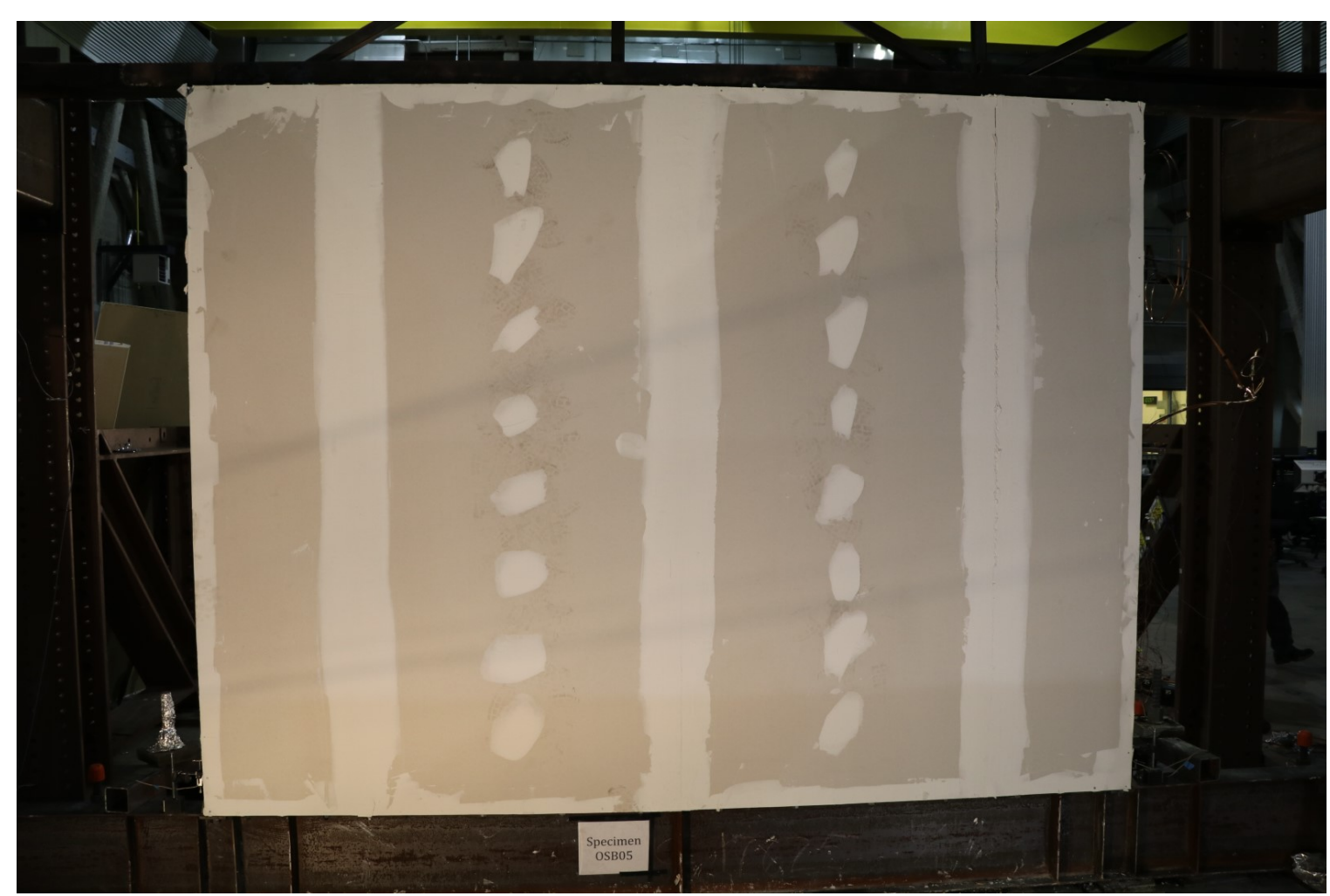

Fig. 295. OSB05 - Photograph of east (exposed) side of wall after cycling to $1.5 \%$ drift (before fire). 


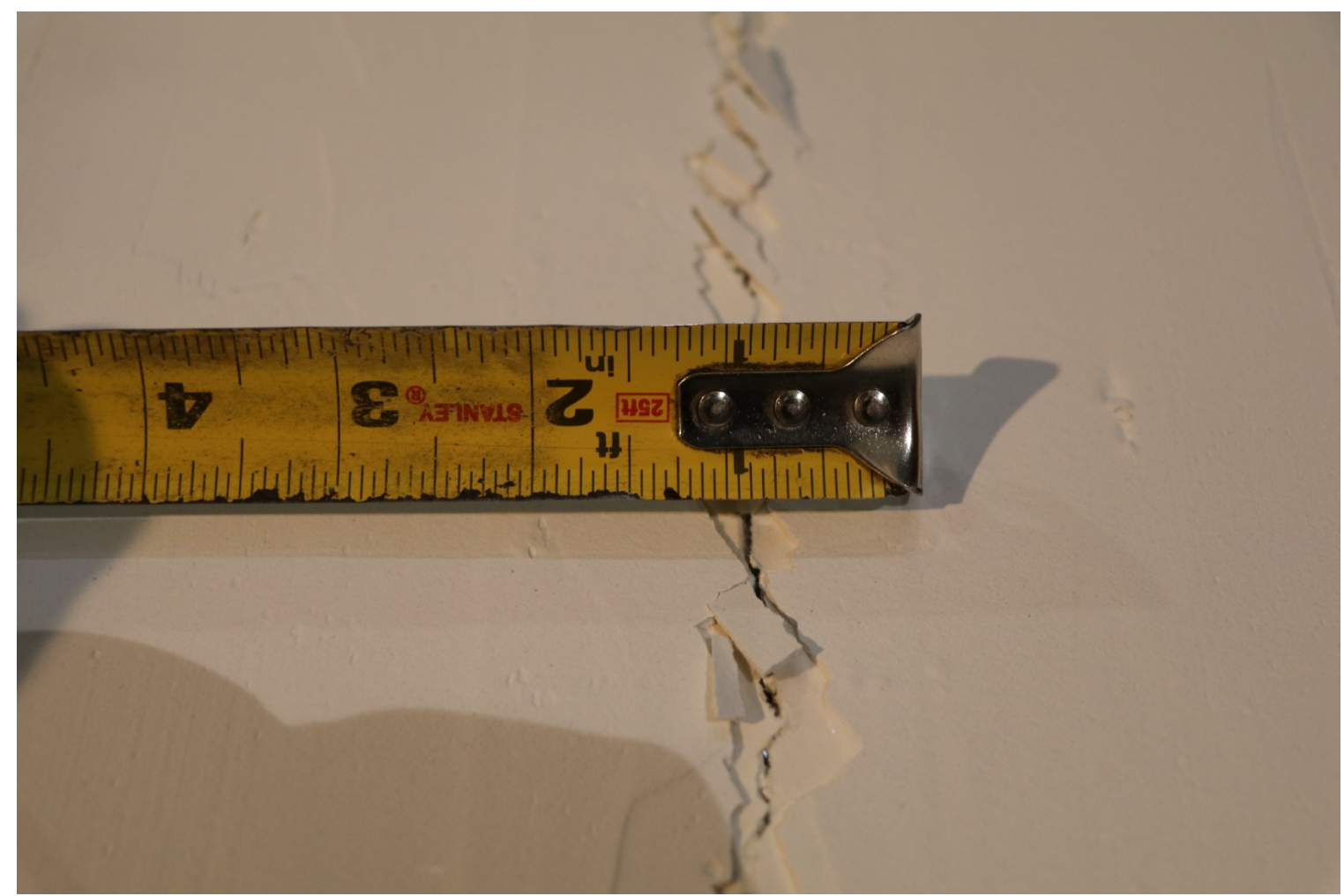

Fig. 296. OSB05 - Photograph of damage to mud and tape at top of east (exposed) side of wall after cycling to $1.5 \% \mathrm{drift}$ (before fire) $(1 \mathrm{in} .=25.4 \mathrm{~mm})$.

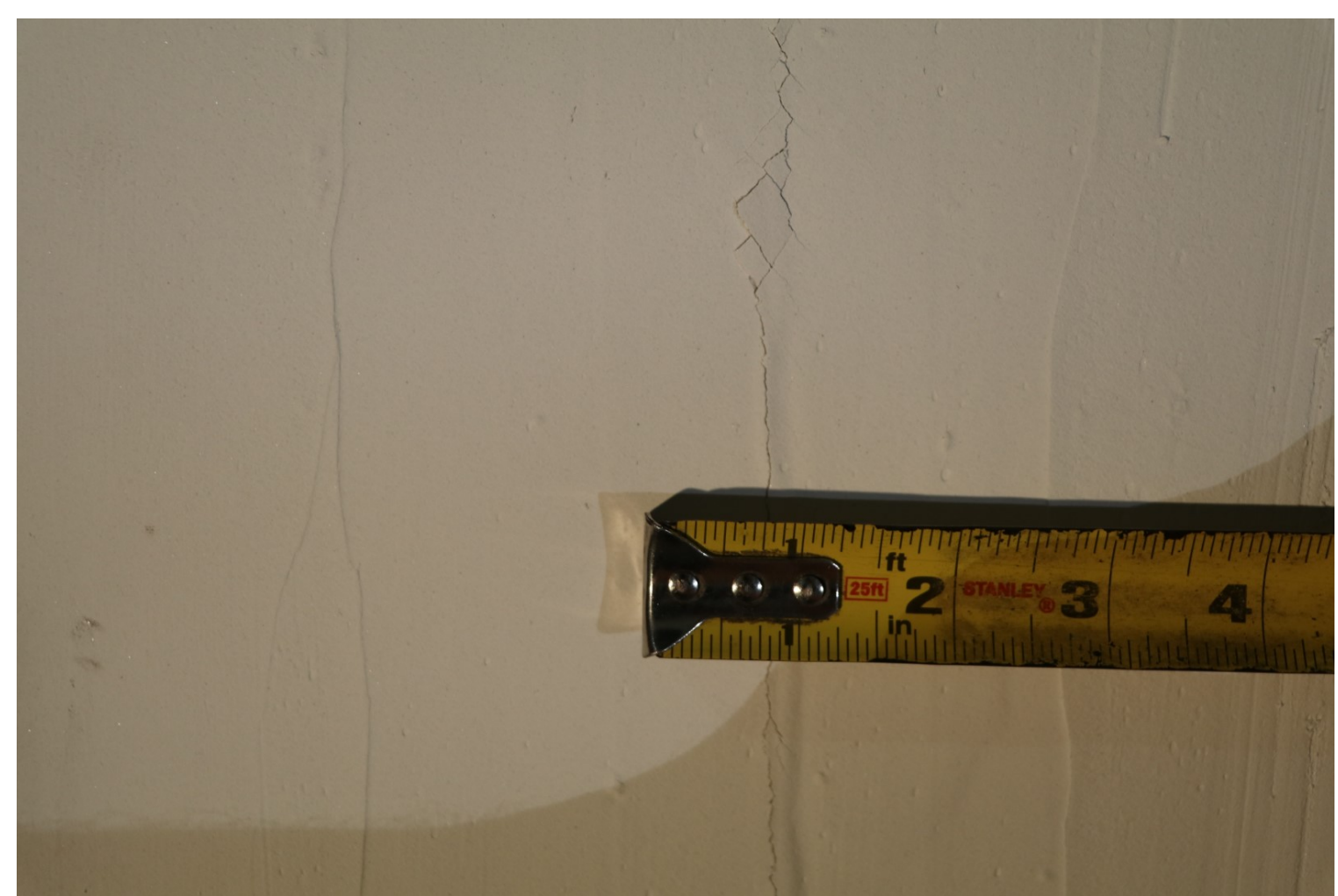

Fig. 297. OSB05 - Photograph of damage to mud and tape at bottom of east (exposed) side of wall after cycling to $1.5 \% \mathrm{drift}$ (before fire) $(1 \mathrm{in} .=25.54 \mathrm{~mm})$. 


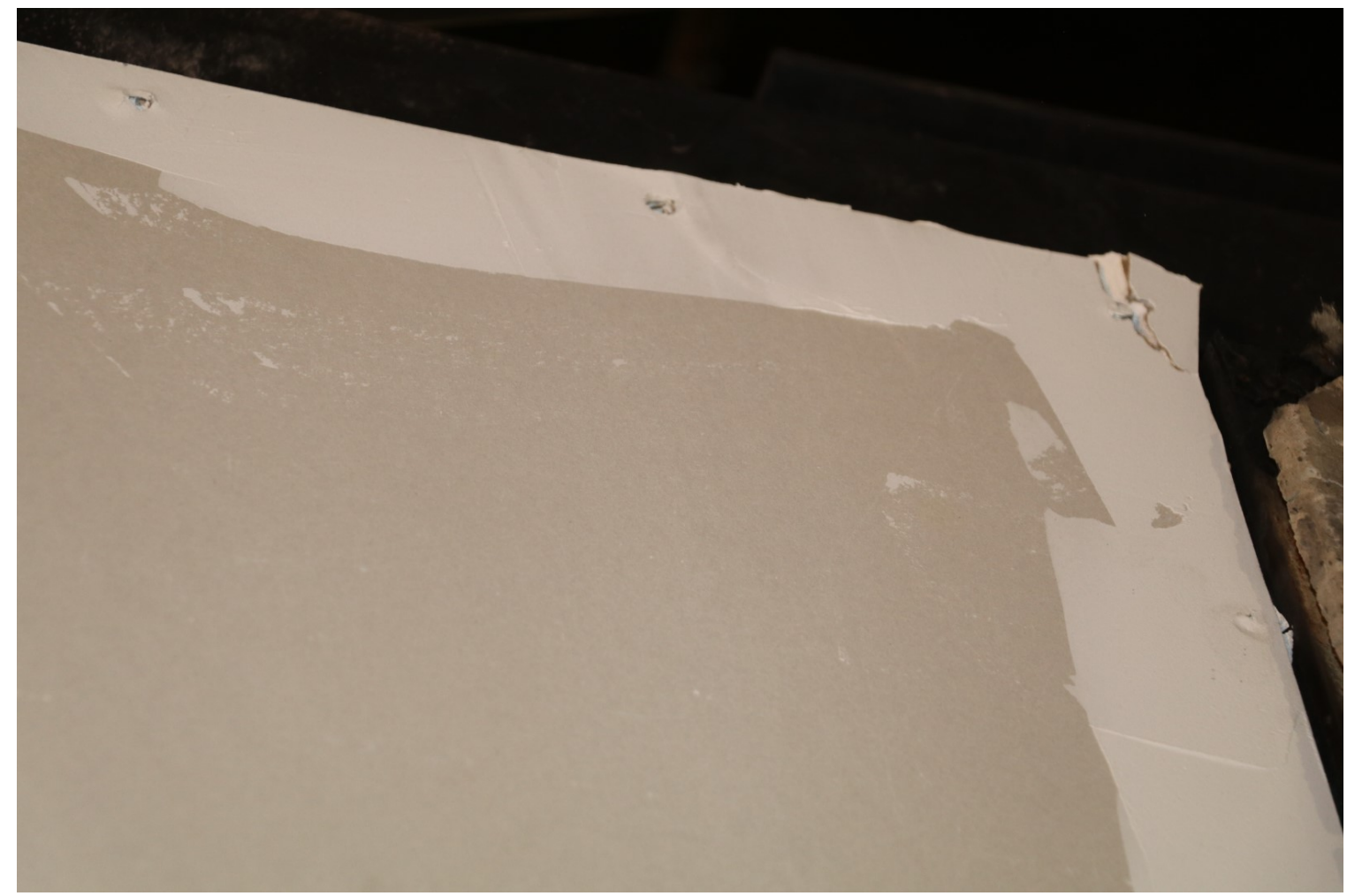

Fig. 298. OSB05 - Photograph of damage to screws on east (fire exposed) side of wall after cycling to $1.5 \%$ drift (before fire).

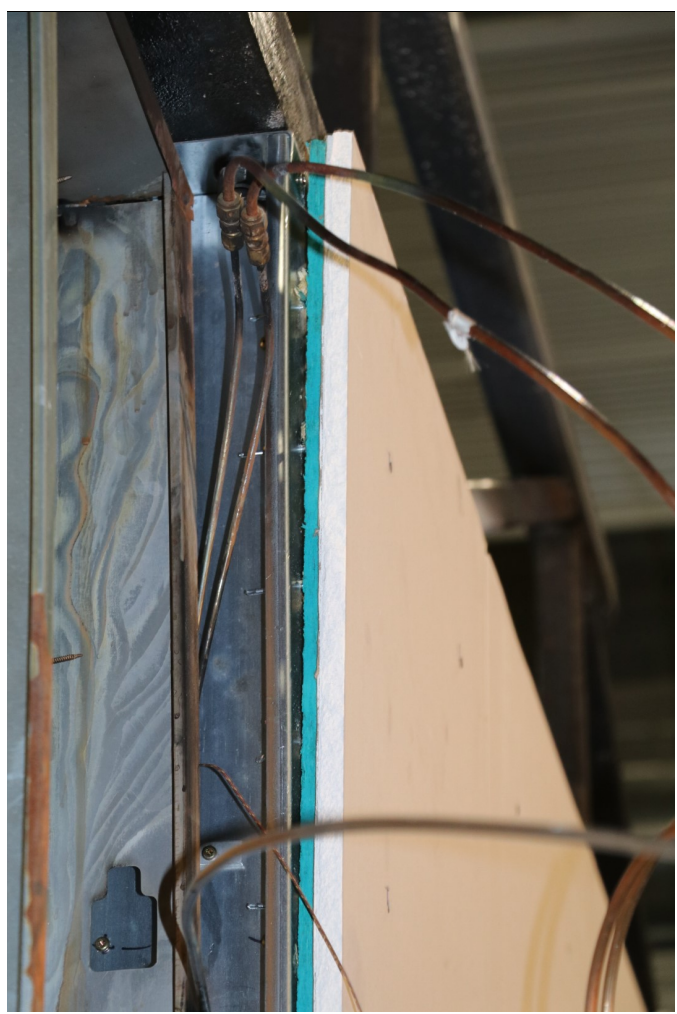

Fig. 299. OSB05 - Photograph of separation of OSB from chord stud after cycling to $1.5 \%$ drift (before fire). 


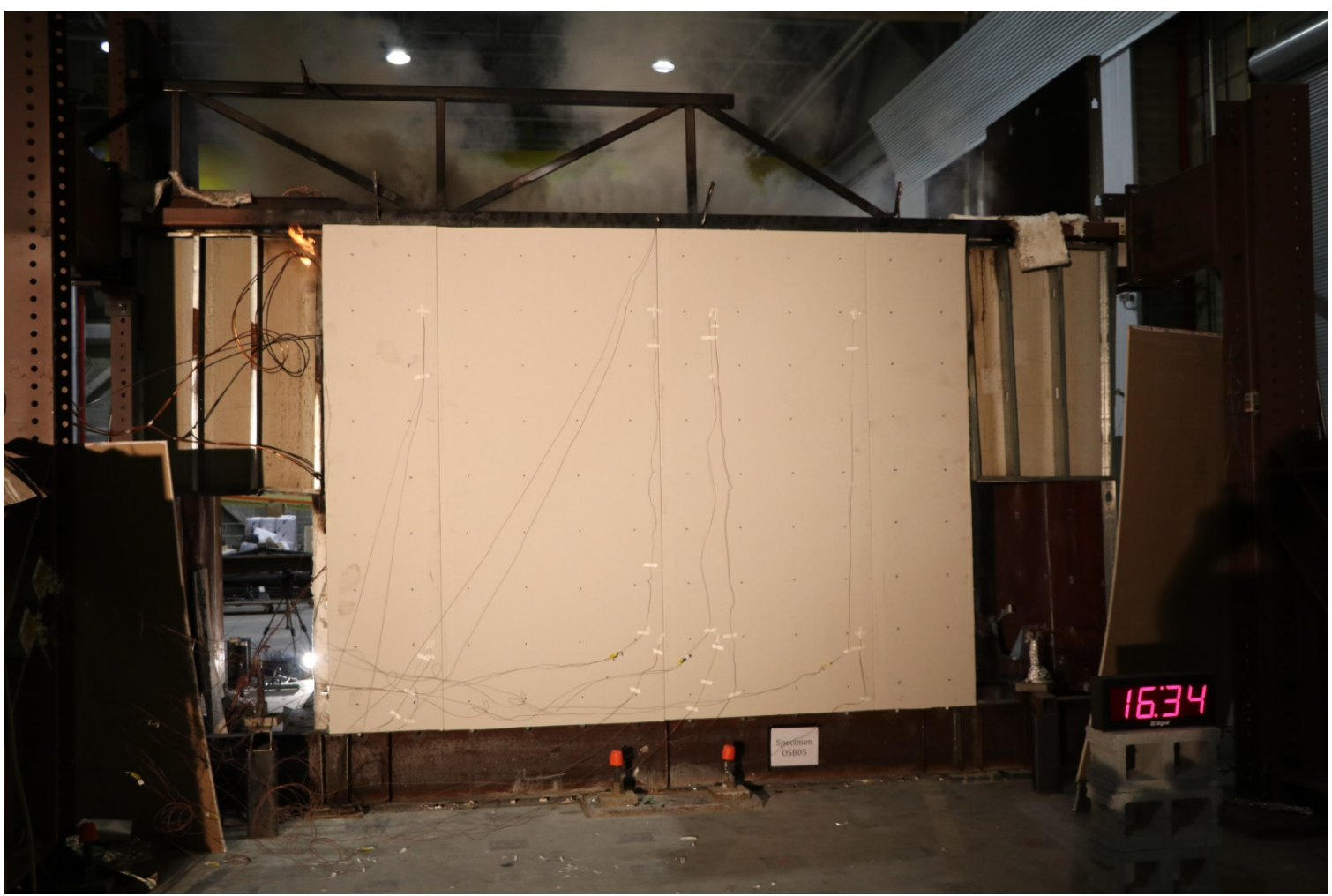

Fig. 300. OSB05 - Photograph of unexposed side of wall $16 \mathrm{~min} 34 \mathrm{~s}$ after ignition (just after extinction of the burner).

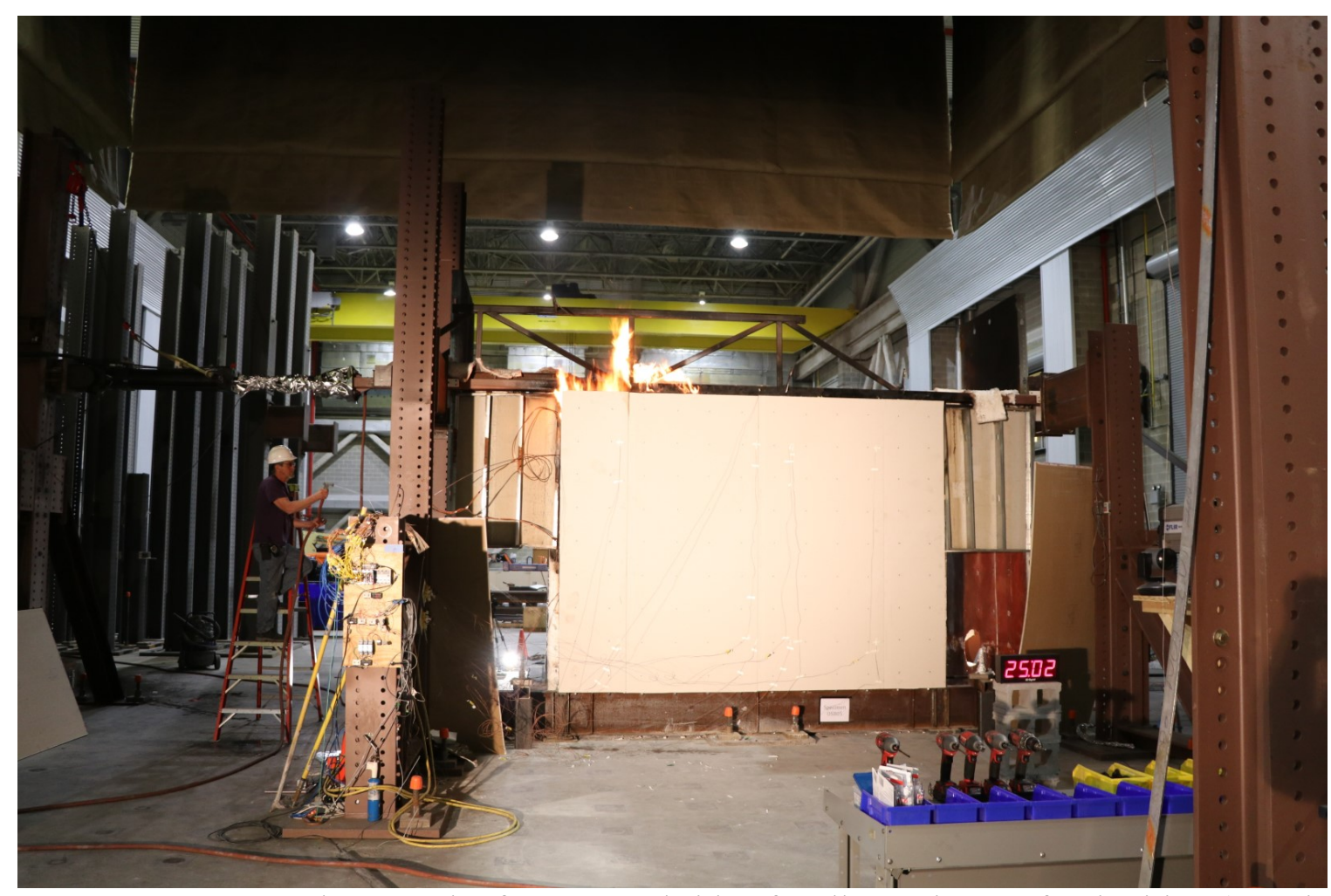

Fig. 301. OSB05 - Photograph of unexposed side of wall $25 \mathrm{~min} 2 \mathrm{~s}$ after ignition (10 min after extinction of the burner). 


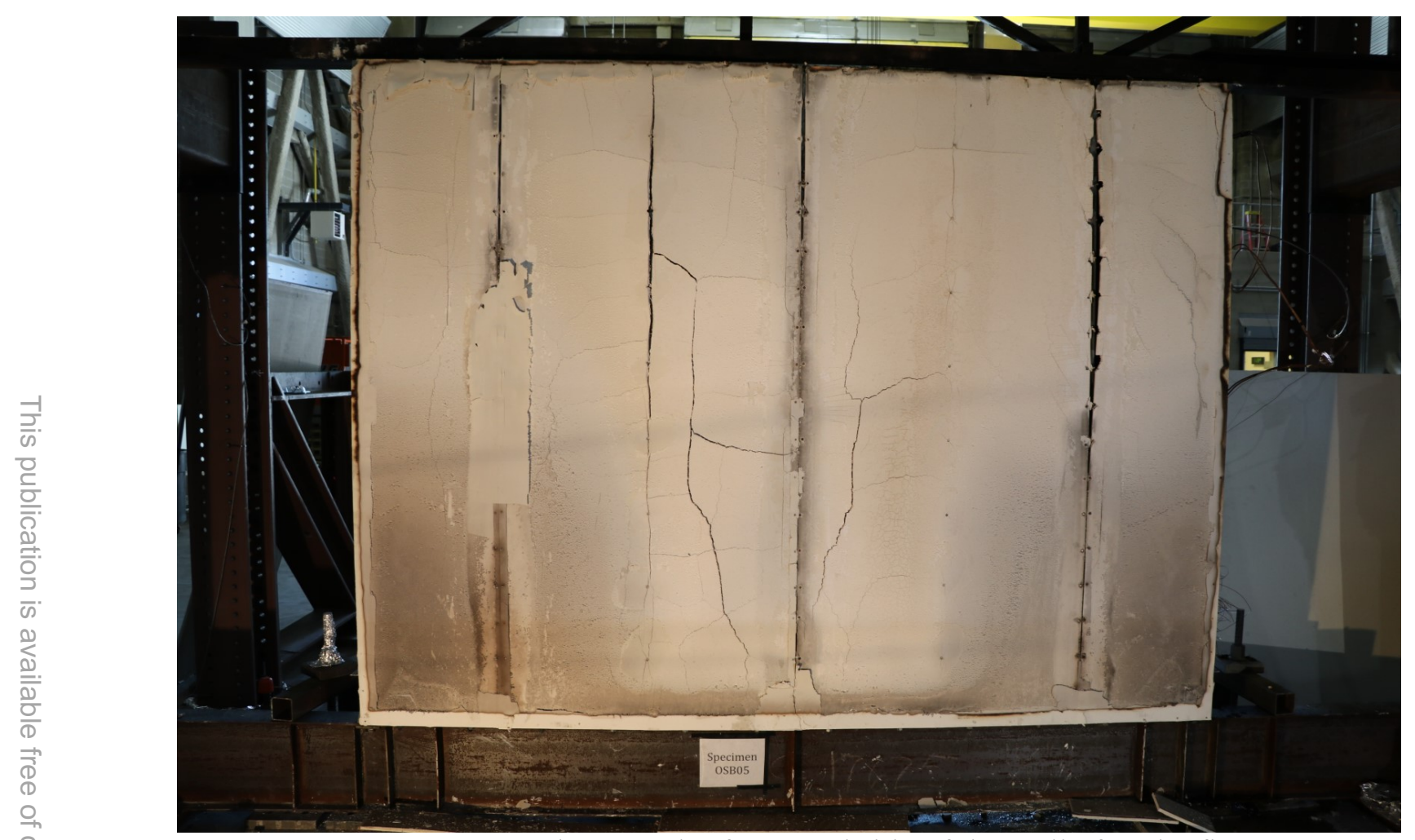

Fig. 302. OSB05 - Photograph of exposed side of the wall after the fire test.

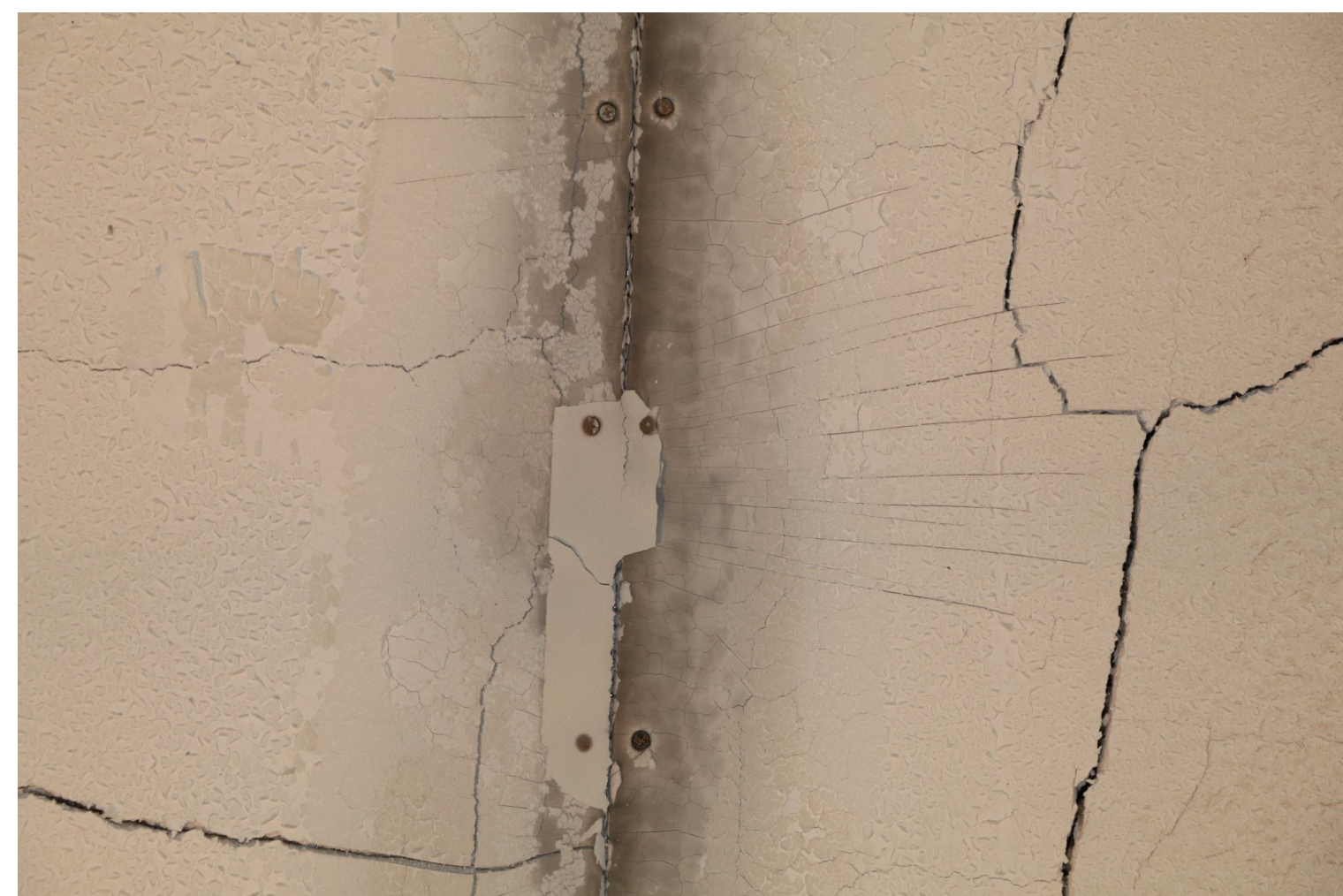

Fig. 303. OSB05 - Photograph of detail of exposed side of the wall after the fire test. 


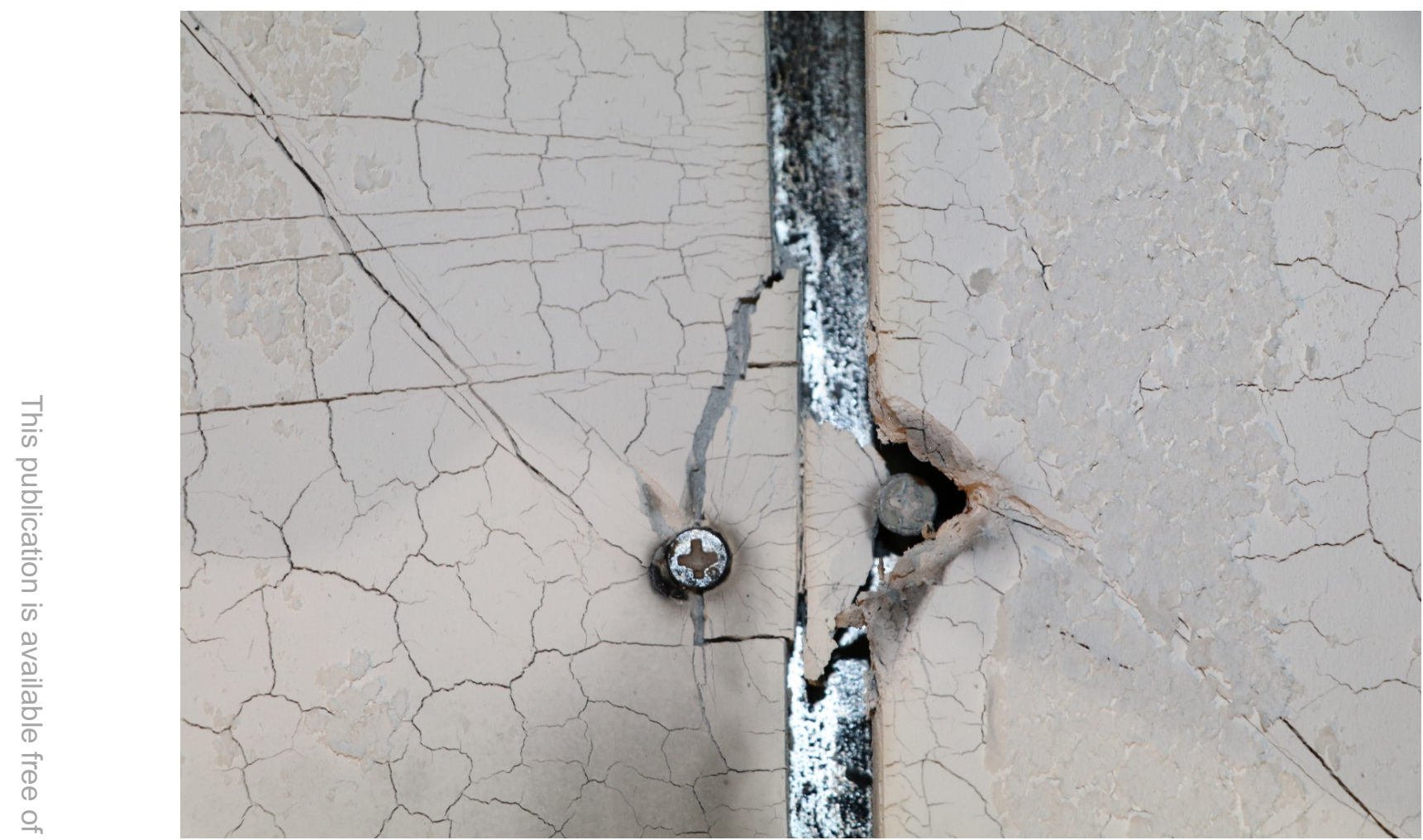

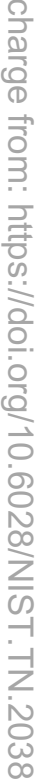

Fig. 304. OSB05 - Photograph of detail of screws on exposed side of the wall after the fire test.

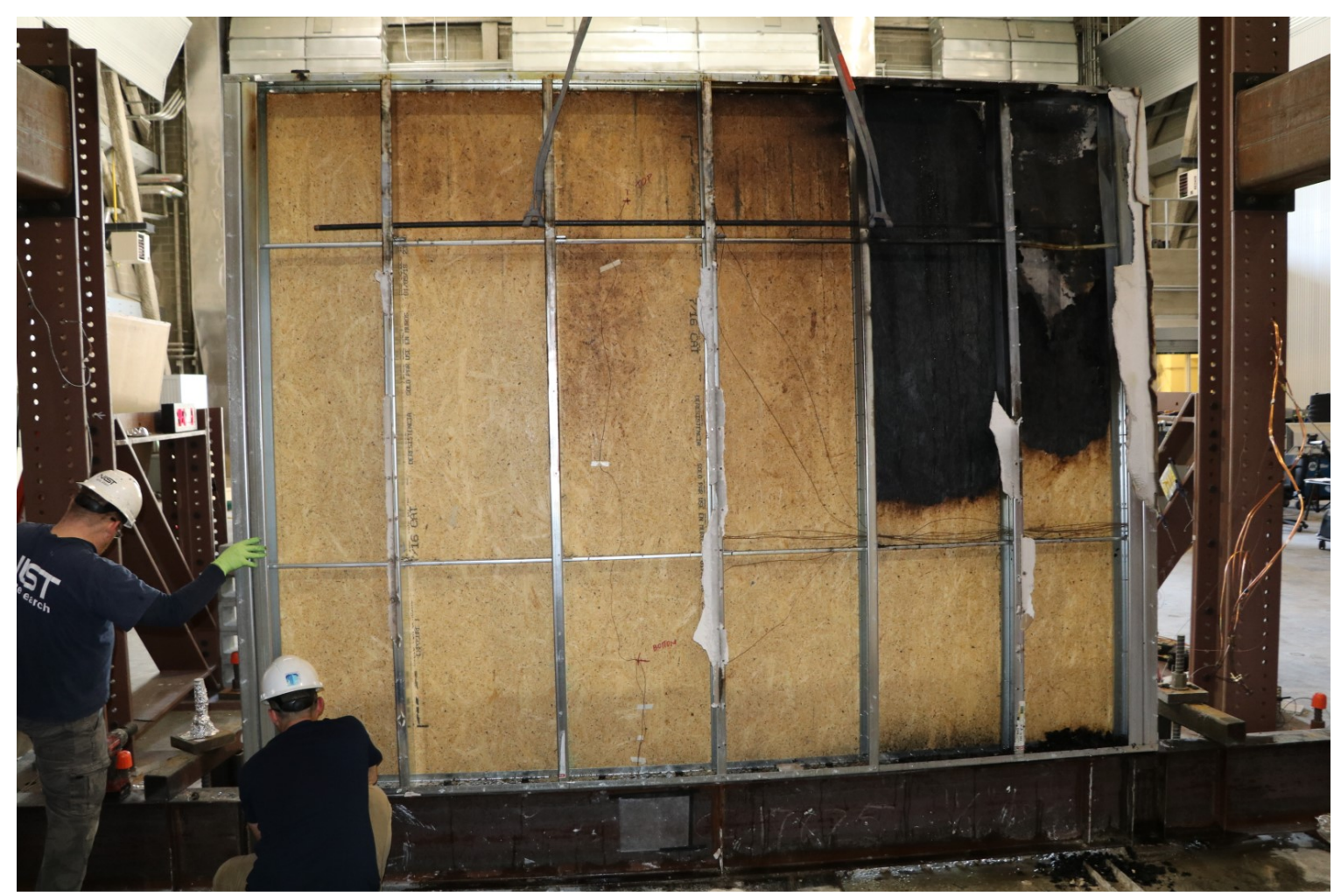

Fig. 305. OSB05 - Photograph of fire exposed side of the wall (remaining drywall removed) after load cycling following the fire. 


\section{OSB06 Data}

OSB06a (Cyclic test of wall to $0.45 \%$ SDR at ambient temperature)

- Behavior similar to comparable ambient test OSB01R.

- No damage visible on west wall (unexposed side); no mud and tape on the joints (Fig. 319).

- Cracked skim coat along entire length of on north-east and south east seams (exposed side). Tape and bottom mud layer still intact (Fig. 321)

OSB06b (Mild Fire test after cyclic test to $0.45 \%$ SDR)

- Heat release rate in the burner was kept to $1.7 \mathrm{MW}$ for $15 \mathrm{~min}$. The temperature recordings inside the compartment are slightly lower than in the rest of the mild fire tests (Fig. 306), with some asymmetry inside the compartment after 5 min into the test (Fig. 307).

- The OSB did not ignite (Fig. 324).

- Cut $400 \mathrm{~mm}$ by $400 \mathrm{~mm}$ opening in north-east corner of fire damaged drywall to inspect for smoldering; there was none.

- Waited overnight to let the OSB cool back to ambient before testing; to eliminate possible adhesive temperature effect.

- TC_T_P4 not working

OSB06c (Cyclic test of wall at ambient temperature following the Mild Fire)

- No comments.

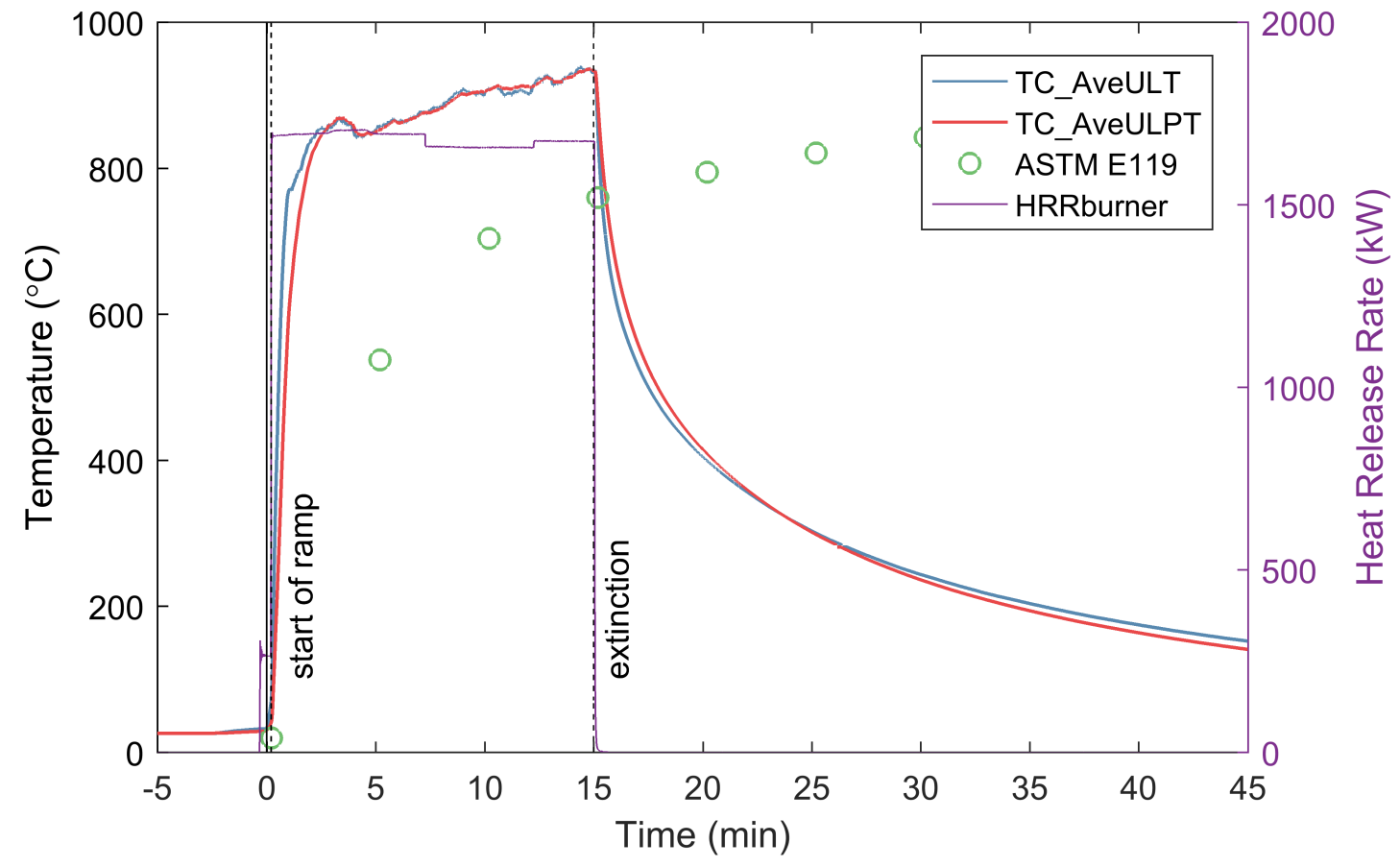

Fig. 306. OSB06 - Compartment temperature and burner Heat Release Rate. 


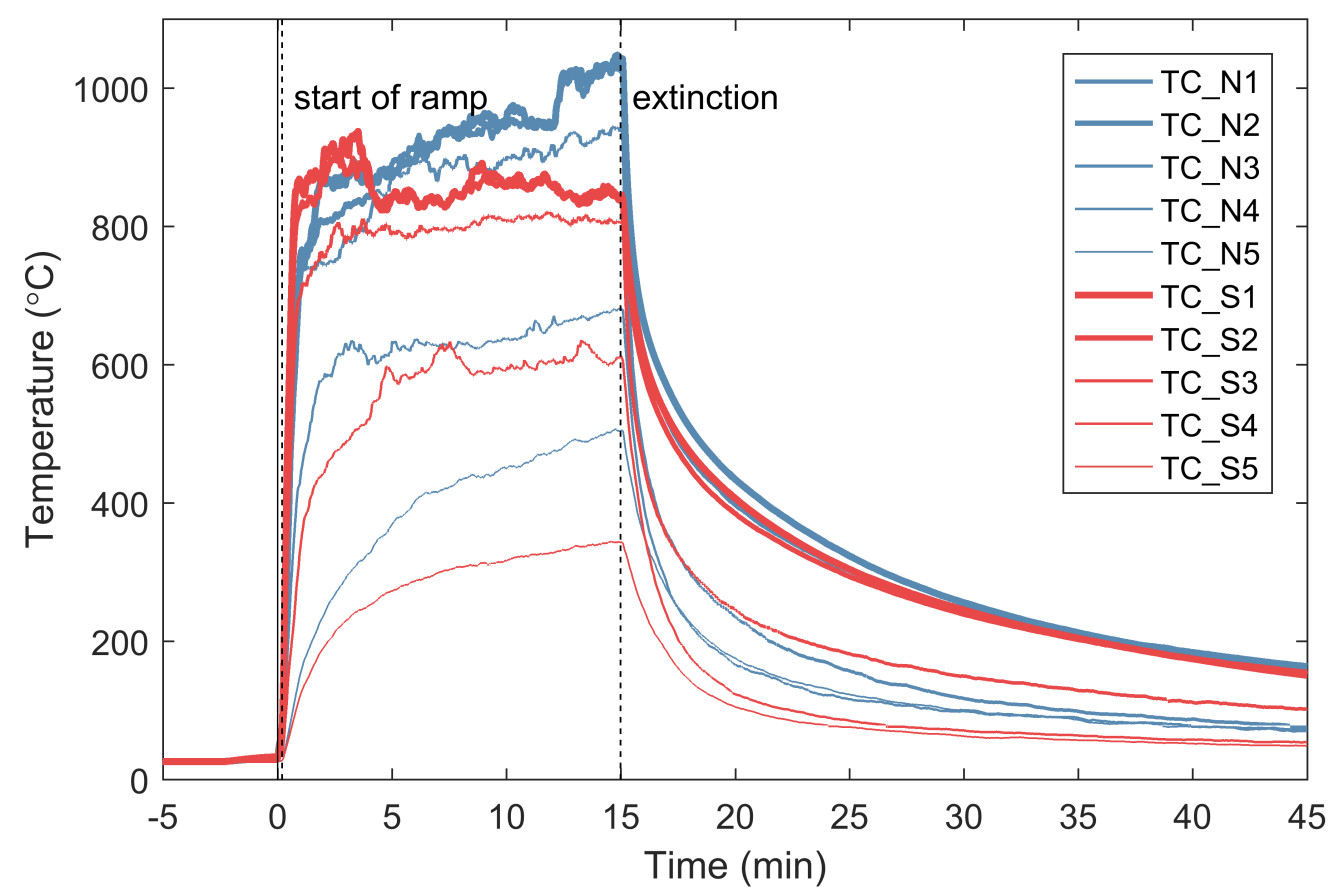

Fig. 307. OSB06 - Compartment temperatures measured by the thermocouple arrays.

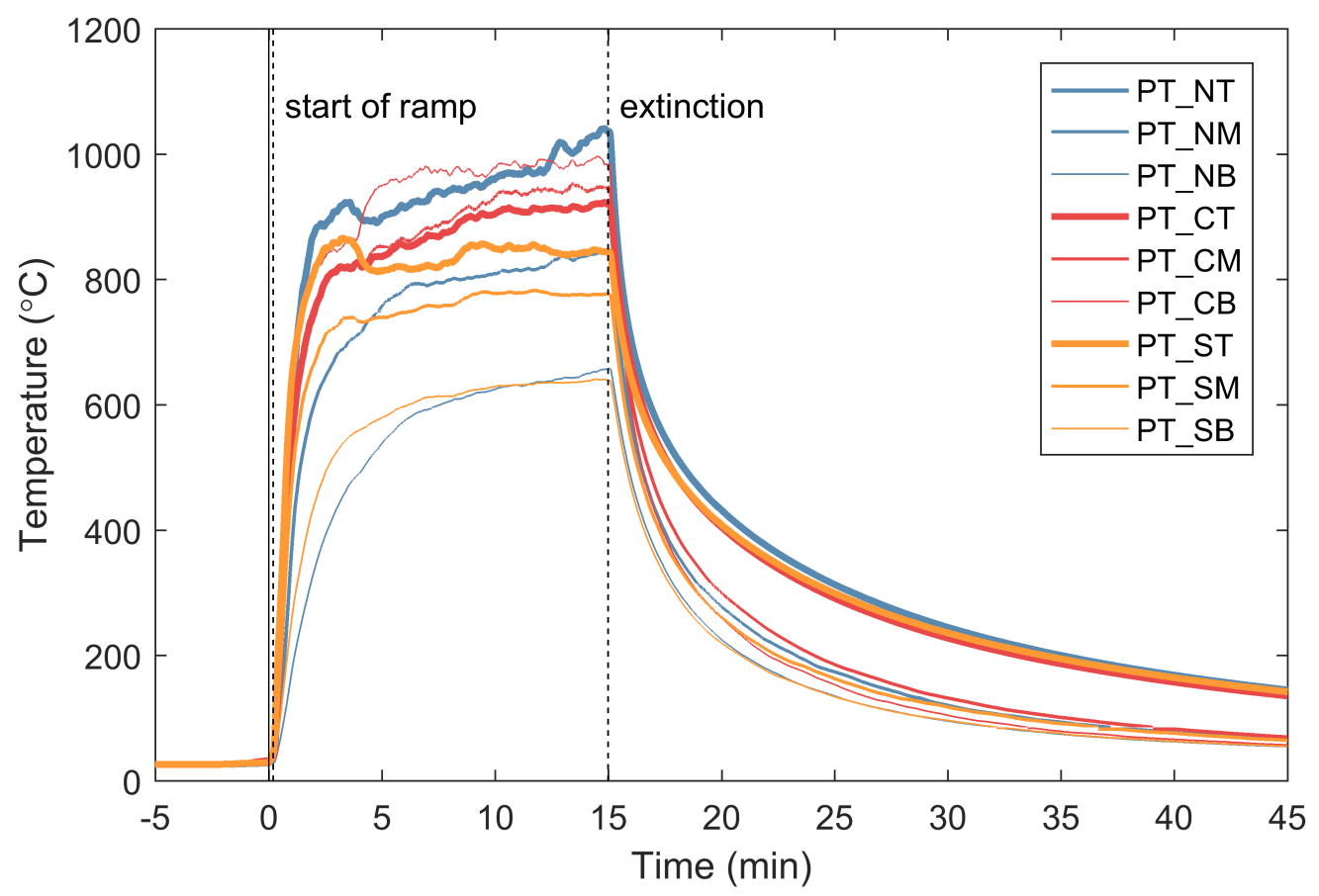

Fig. 308. OSB06 - Compartment temperatures measured by the plate thermocouples. 


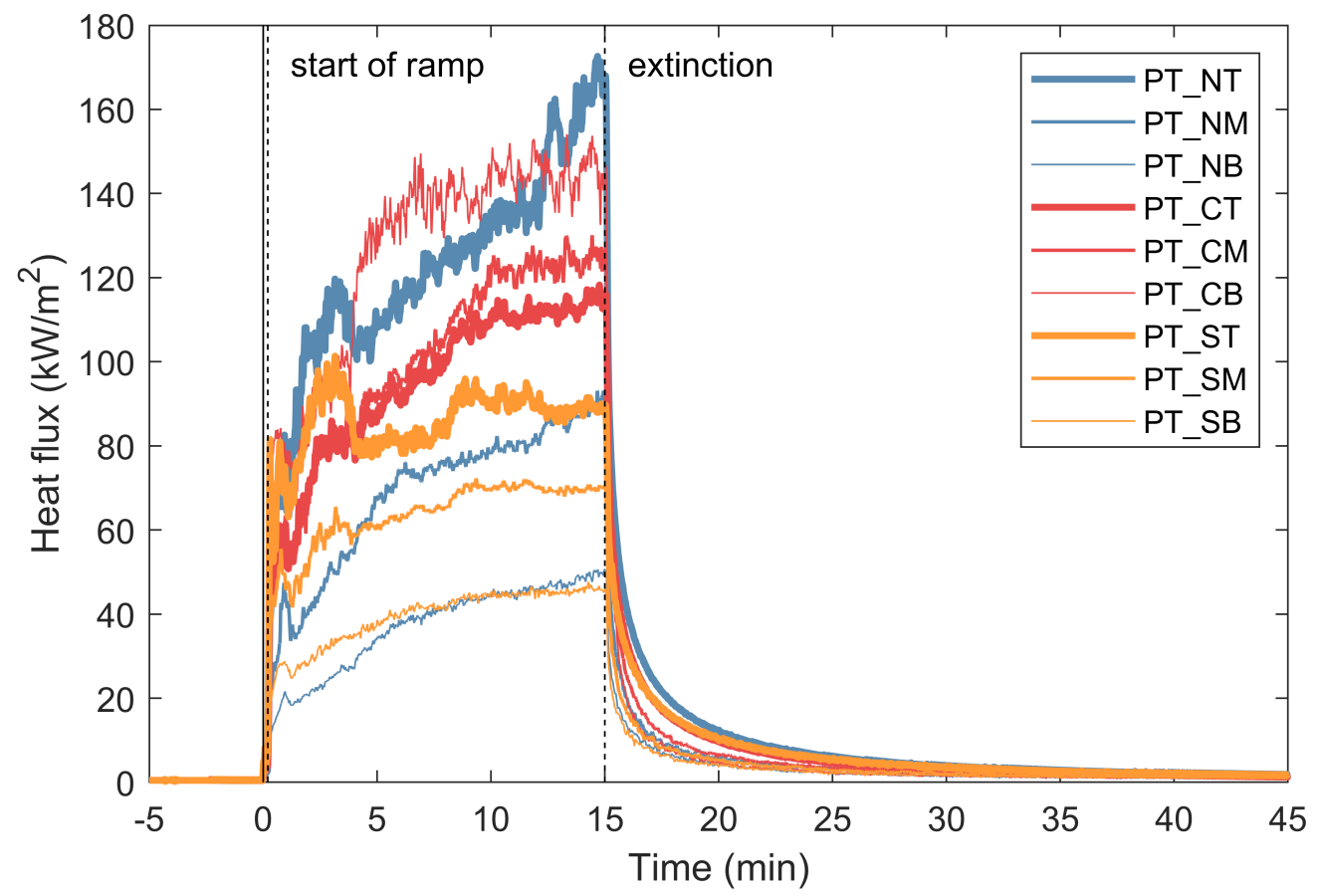

Fig. 309. OSB06 - Heat fluxes in the compartment measured by the plate thermocouples.
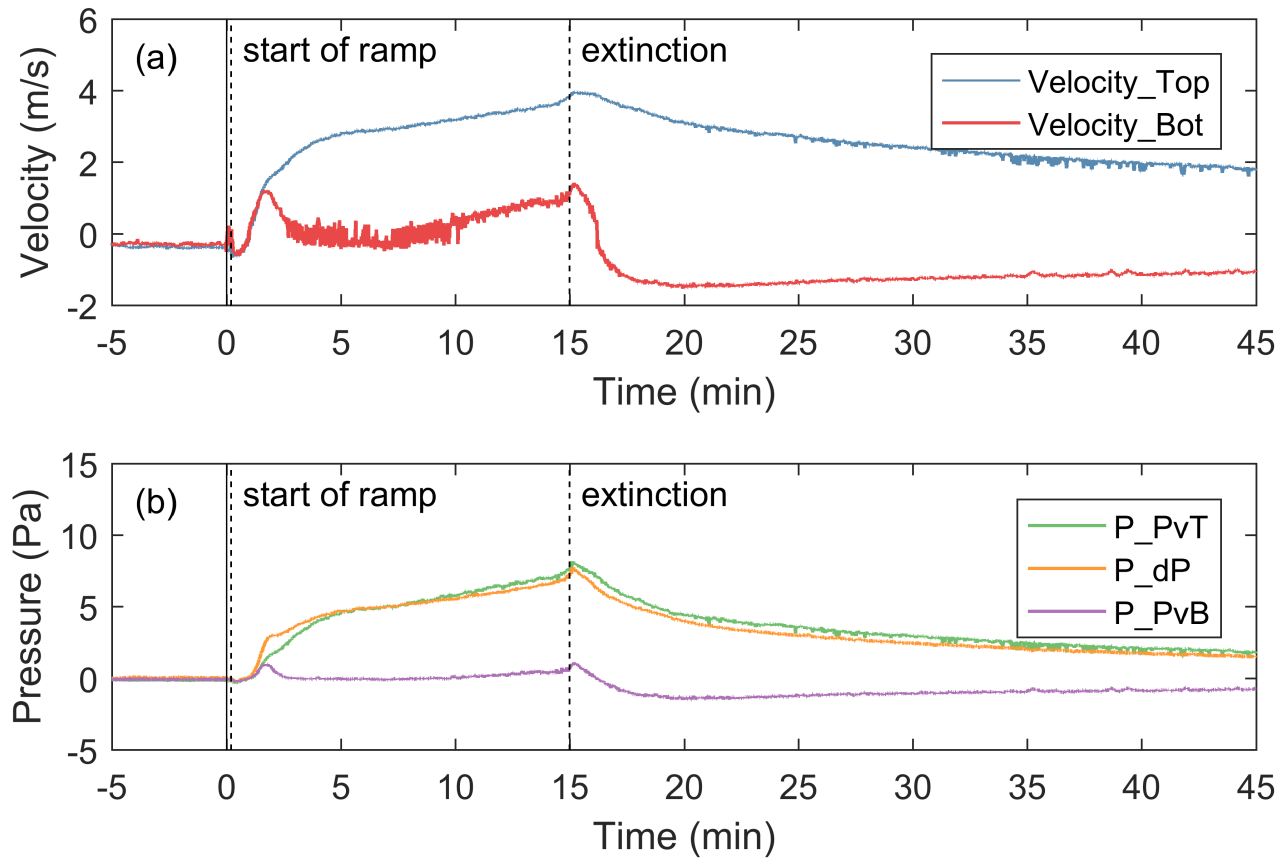

Fig. 310. OSB06 - (a) Velocity of air flow at the top and bottom knockouts of the chord stud; (b) Pressure at the top and bottom knockouts of the chord stud and in the wall cavity near the top. 


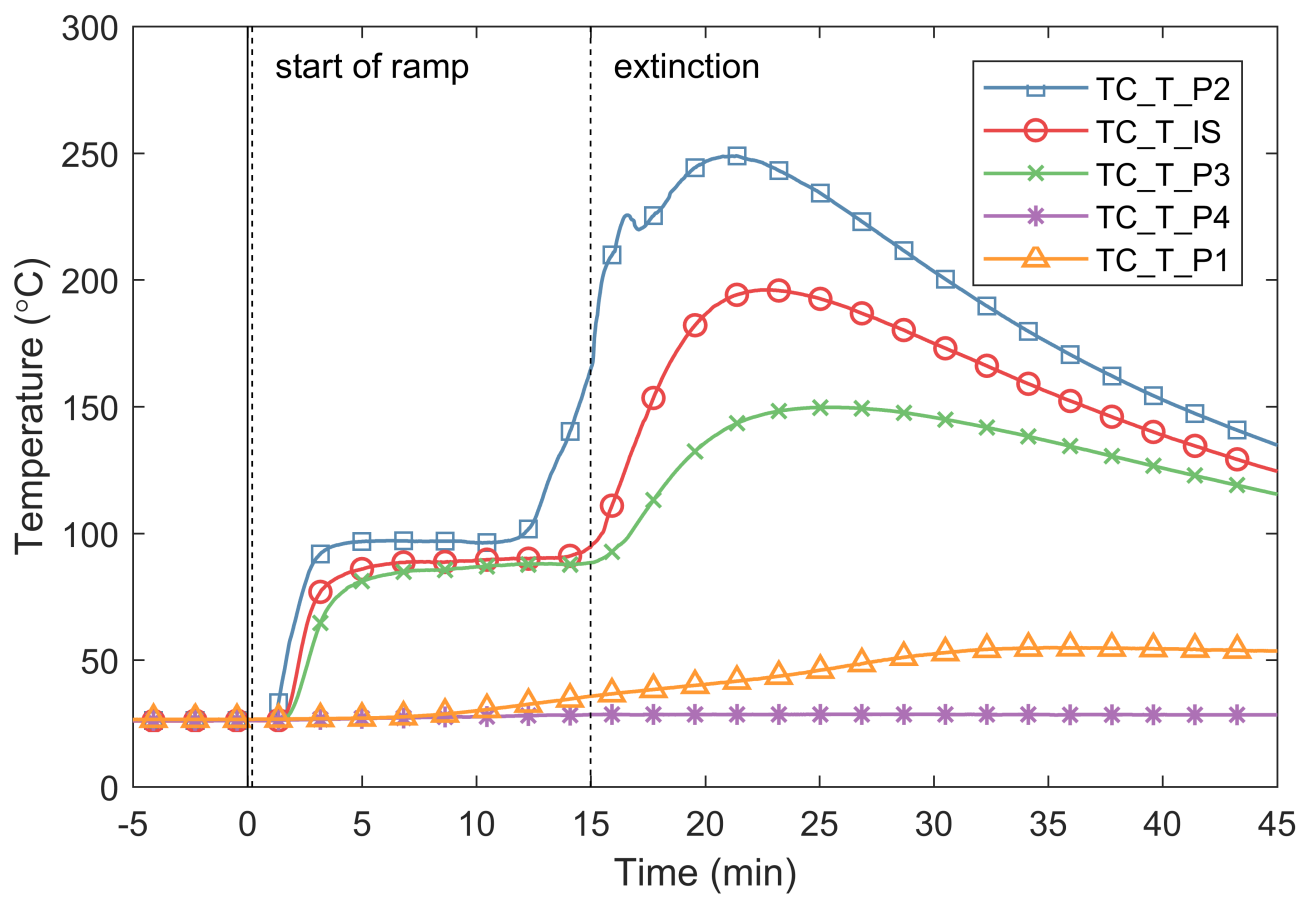

Fig. 311. OSB06 - Temperatures through the specimen at an interior stud $46 \mathrm{~cm}$ from the top of the wall.

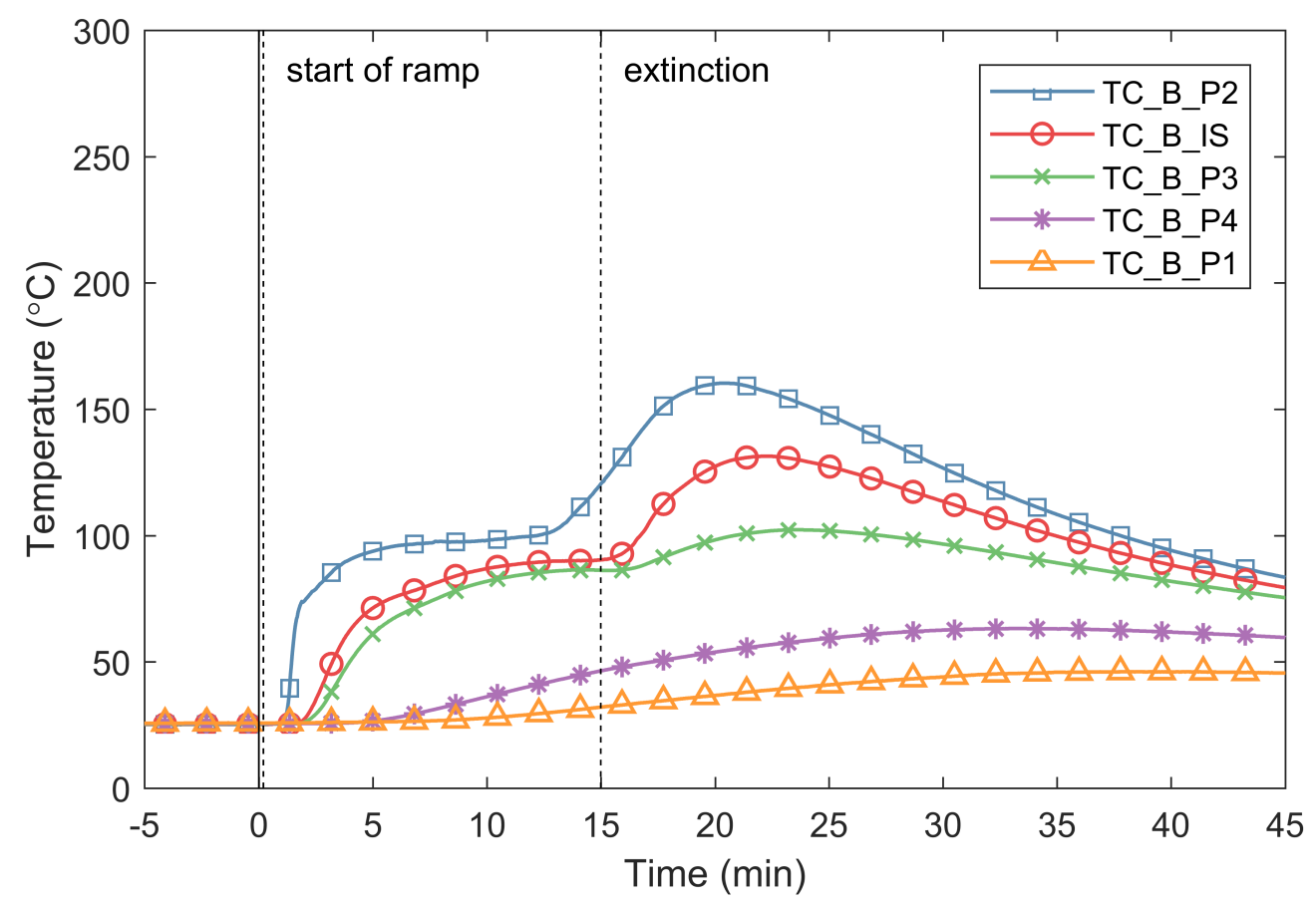

Fig. 312. OSB06 - Temperatures through the specimen at an interior stud $46 \mathrm{~cm}$ from the bottom of the wall. 


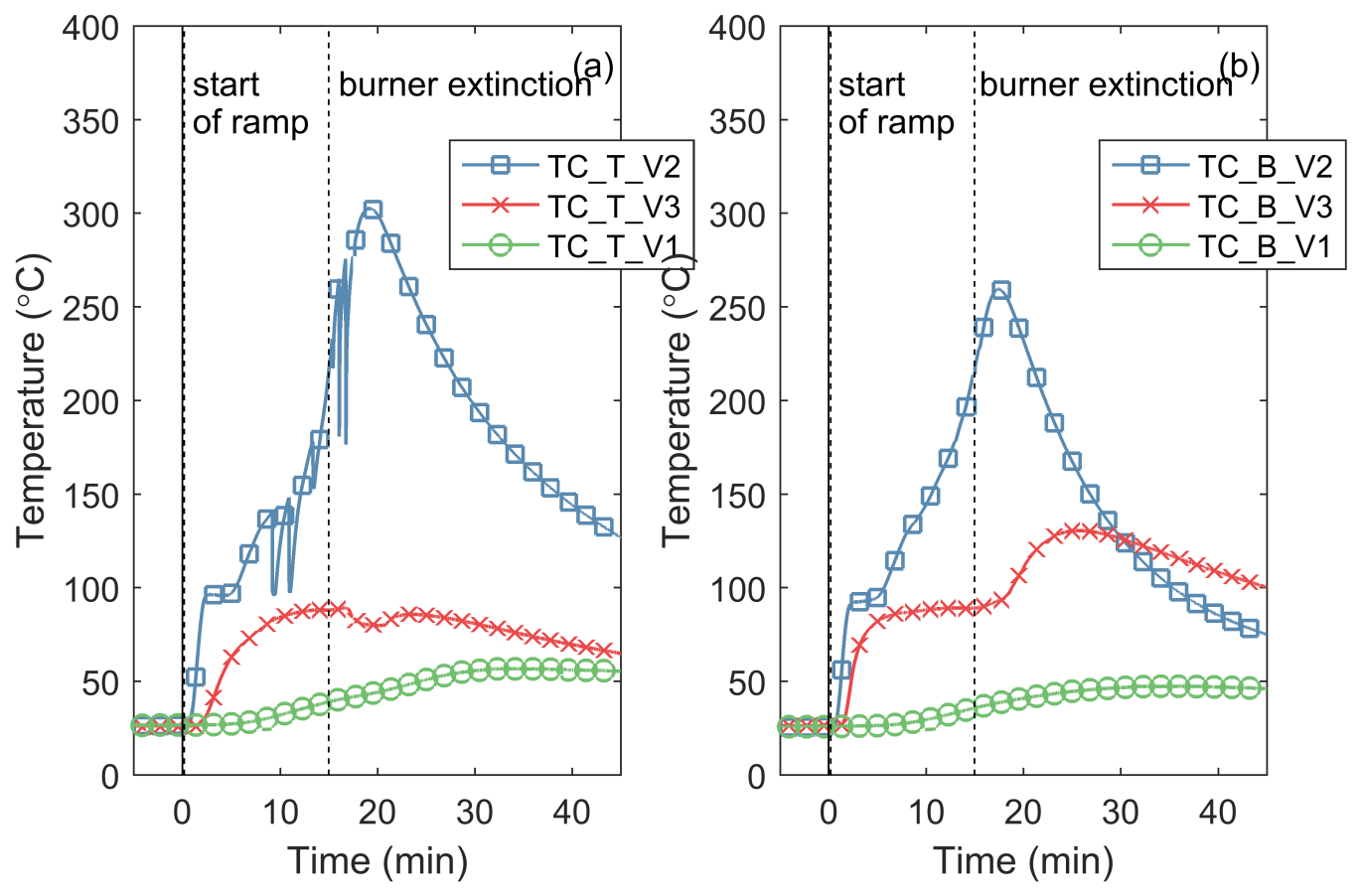

Fig. 313. OSB06 - Temperatures through the specimen midway between interior studs: (a) $46 \mathrm{~cm}$ from the top of the wall; (b) $46 \mathrm{~cm}$ from the bottom of the wall.
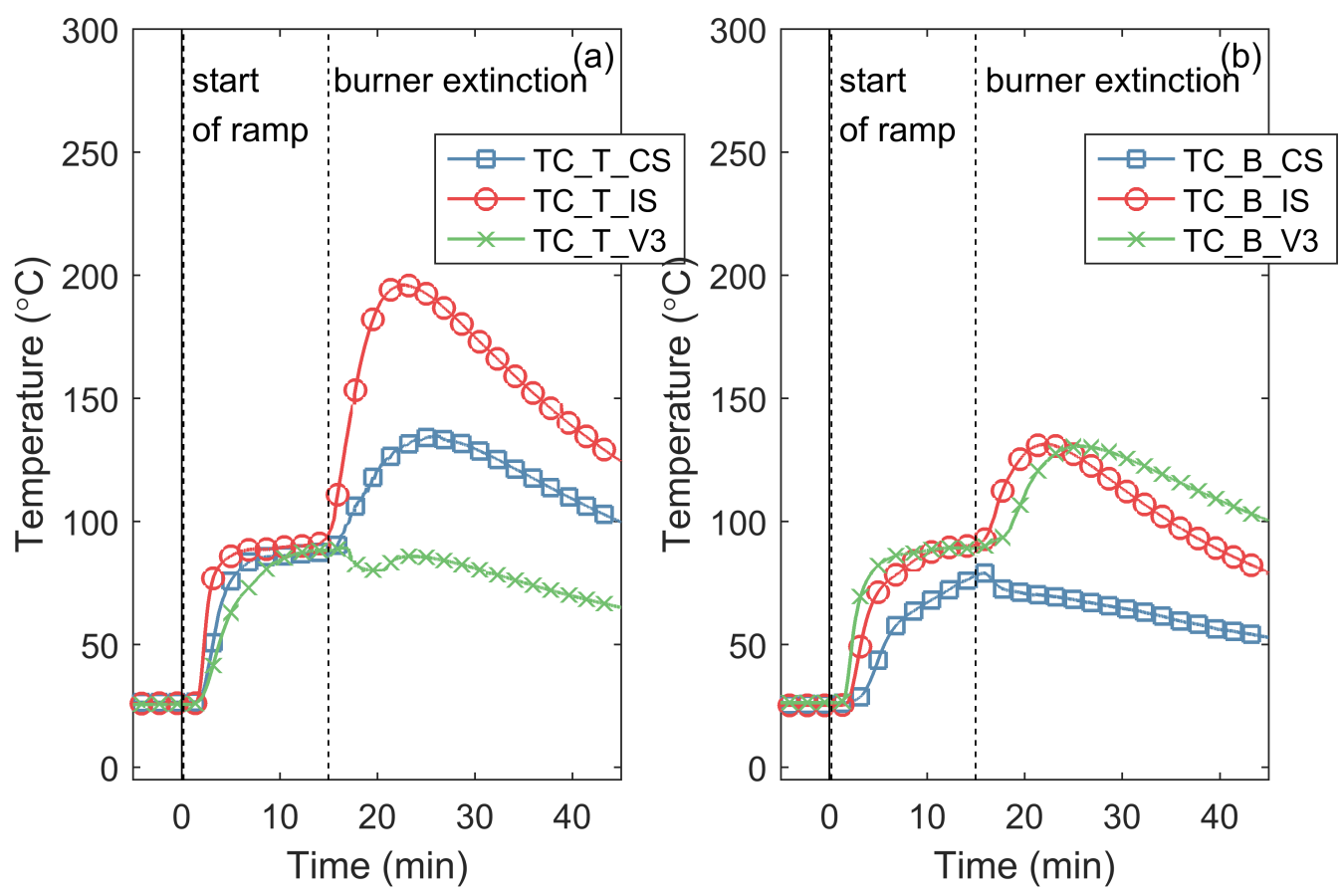

Fig. 314. OSB06 - Temperatures of the framing and sheathing elements: (a) $46 \mathrm{~cm}$ from the top of the wall; (b) $46 \mathrm{~cm}$ from the bottom of the wall. 


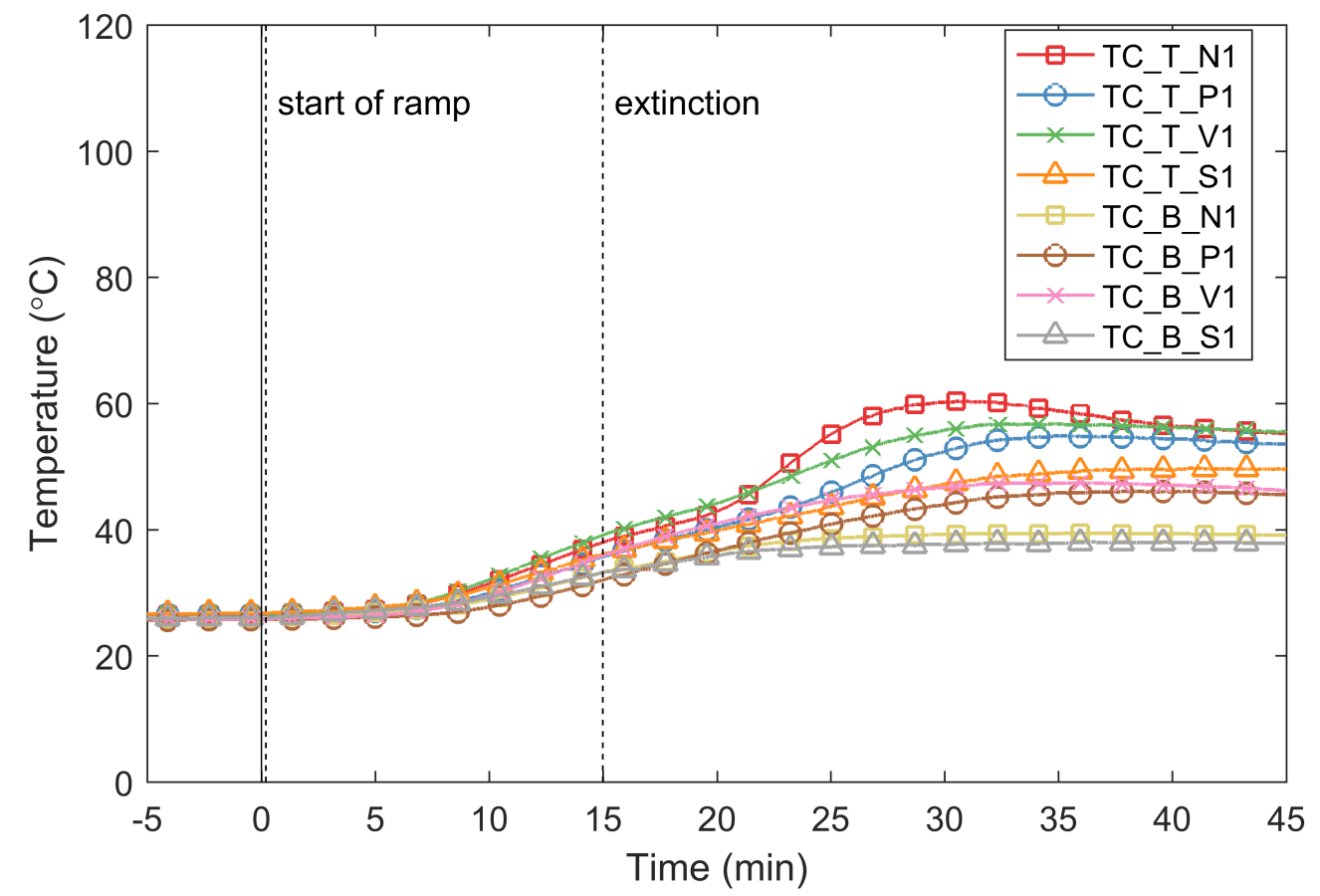

Fig. 315. OSB06 - Temperatures of the gypsum on the unexposed side of the wall specimen.

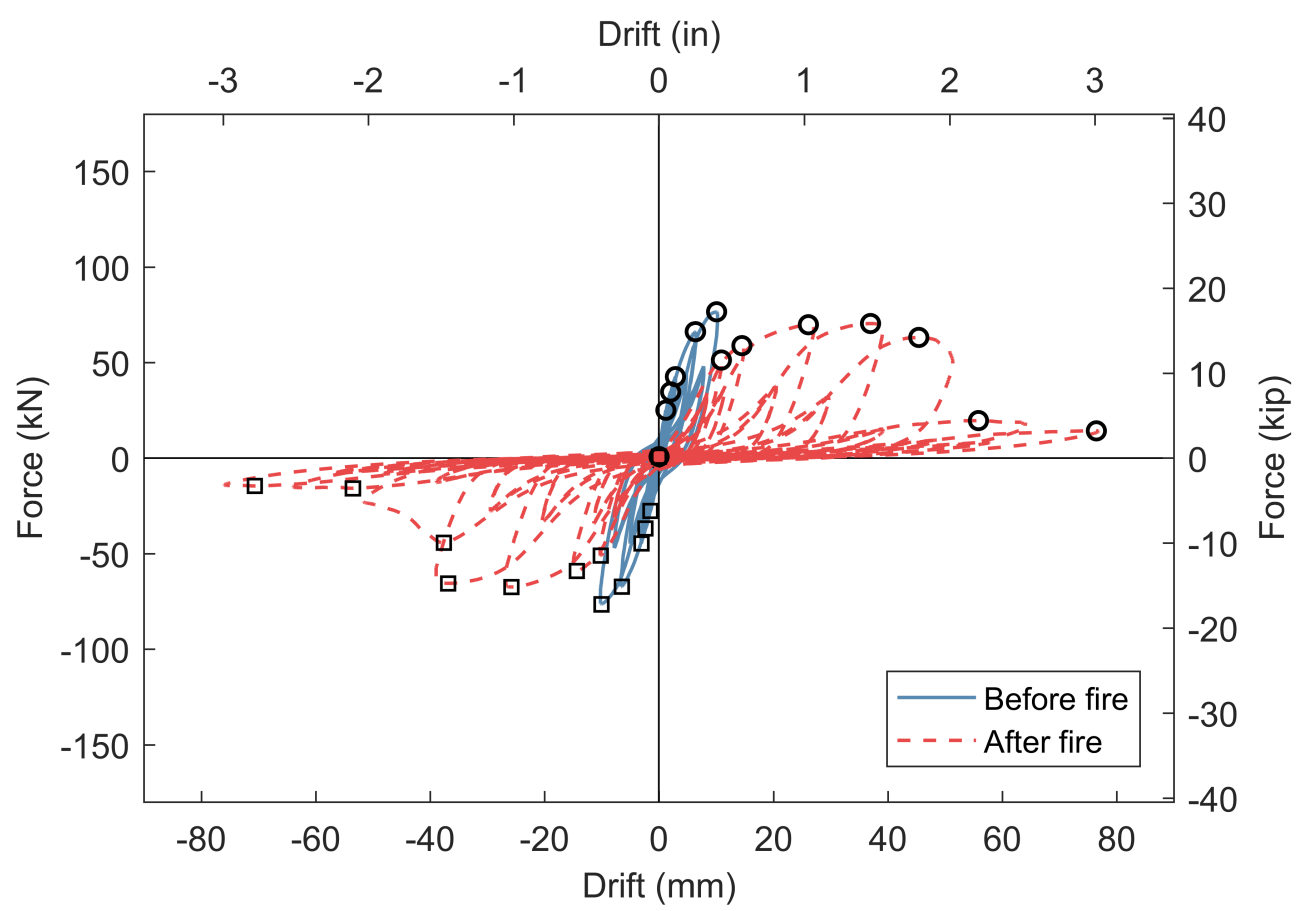

Fig. 316. OSB06 - Applied load versus wall longitudinal drift during mechanical loading. 


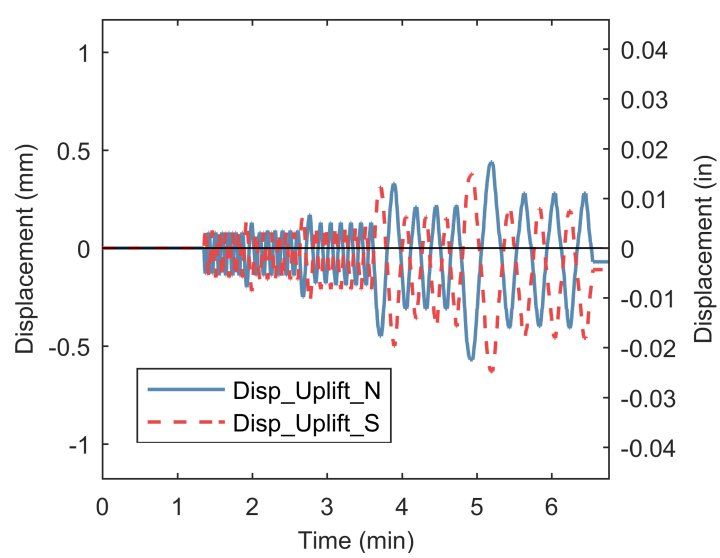

(a)

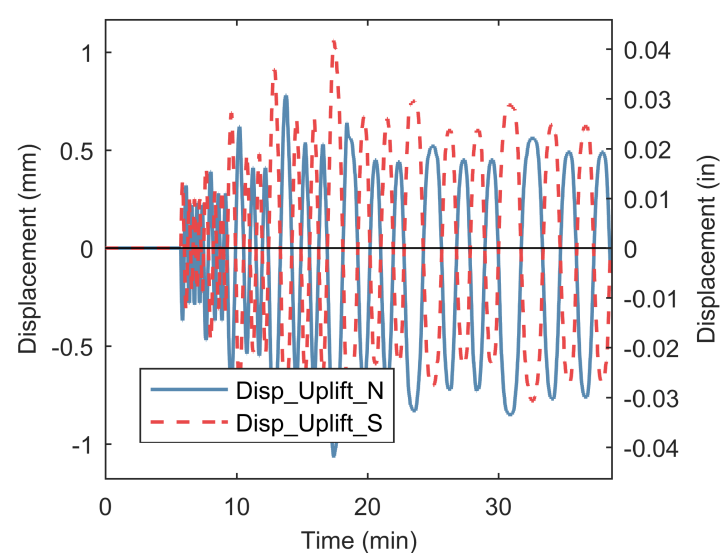

(b)

Fig. 317. OSB06 - Uplift at bottom of wall during mechanical loading(a) before fire; (b) after fire.

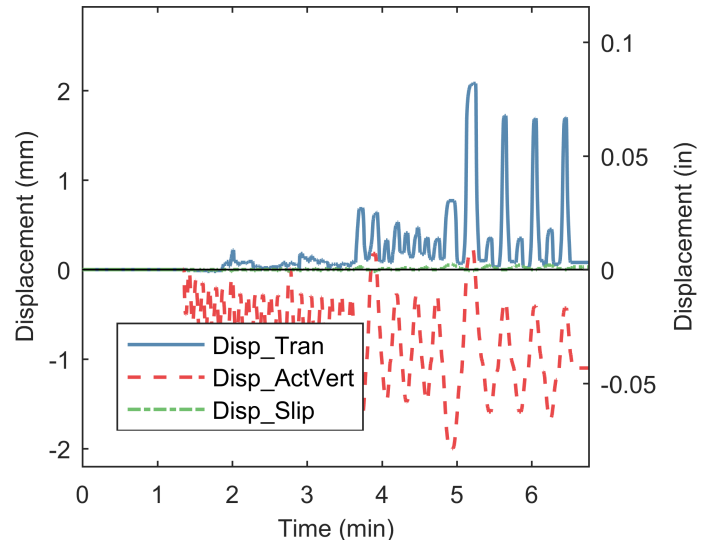

(a)

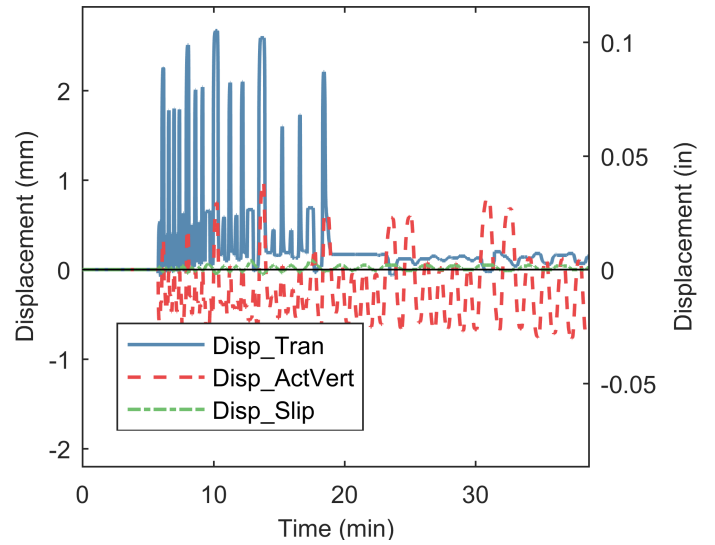

(b)

Fig. 318. OSB06 - Ancillary displacement measurements during mechanical loading: (a) before fire; (b) after fire. 


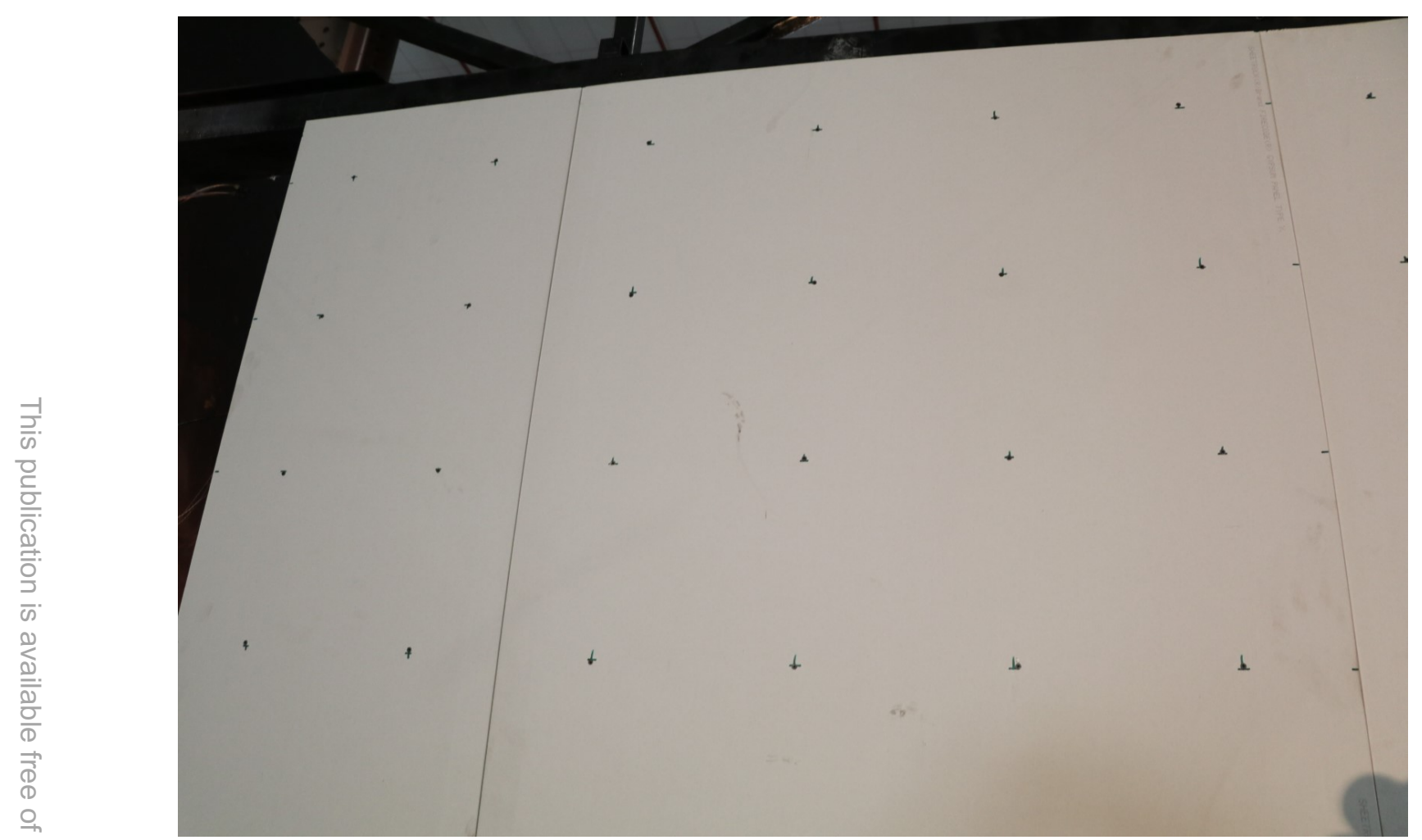

Fig. 319. OSB06 - Photograph of west (unexposed) side of wall after cycling to $0.45 \% \mathrm{drift}$ (before fire).

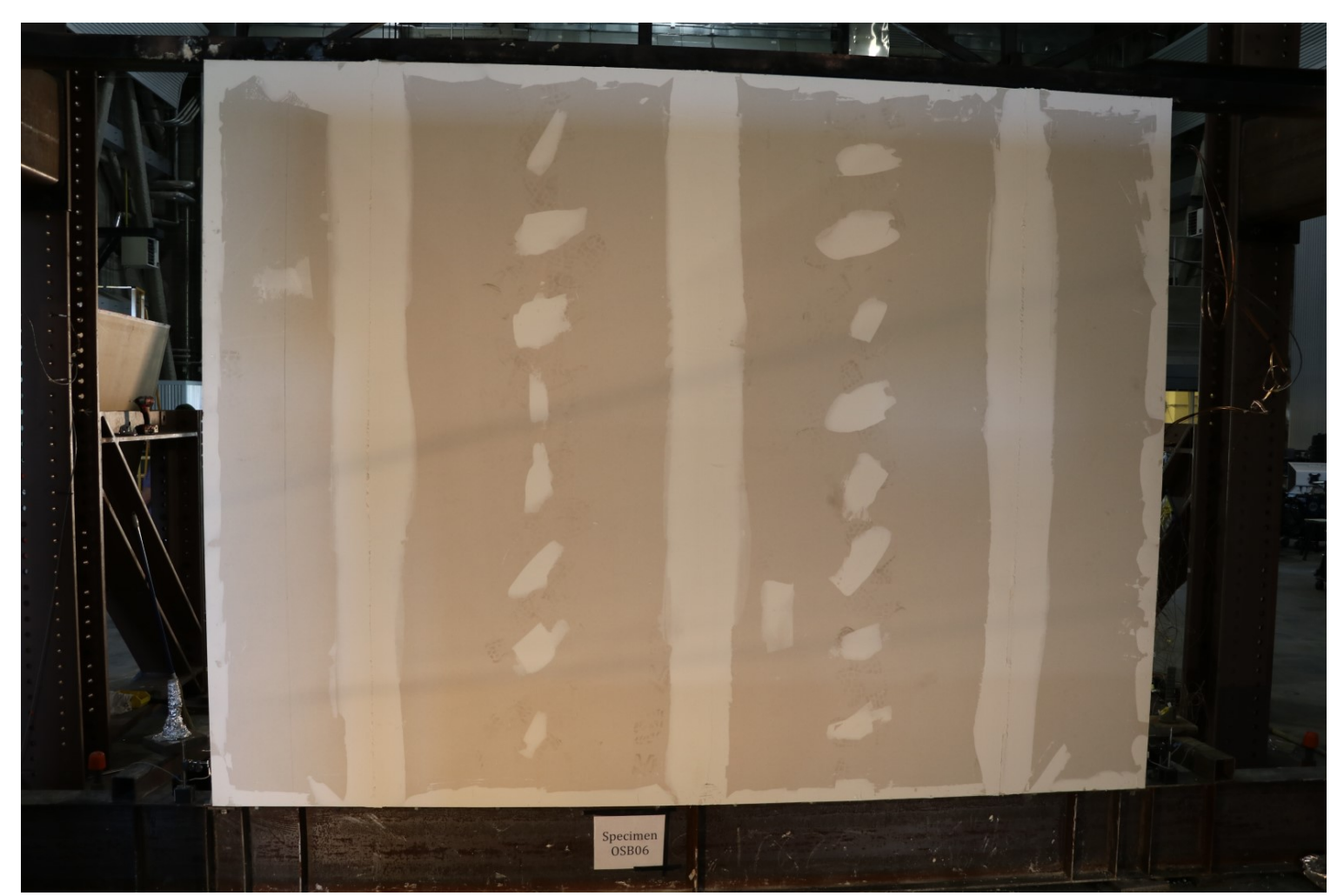

Fig. 320. OSB06 - Photograph of east (fire exposed) side of wall after cycling to $0.45 \% \mathrm{drift}$ (before fire). 


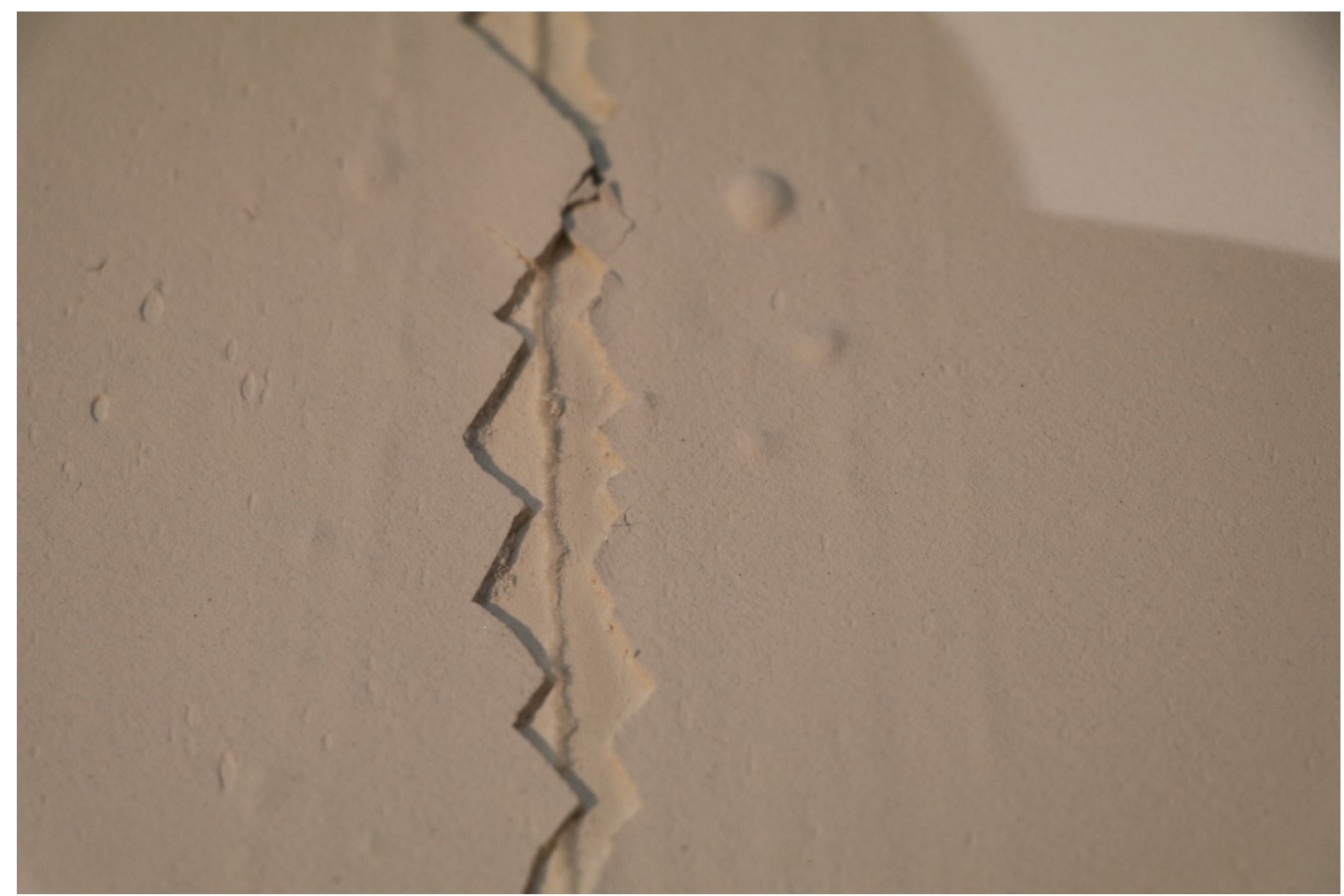

Fig. 321. OSB06 - Photograph of damage to skim coat only on east (fire exposed) side of wall after cycling to $0.45 \% \mathrm{drift}$ (before fire).

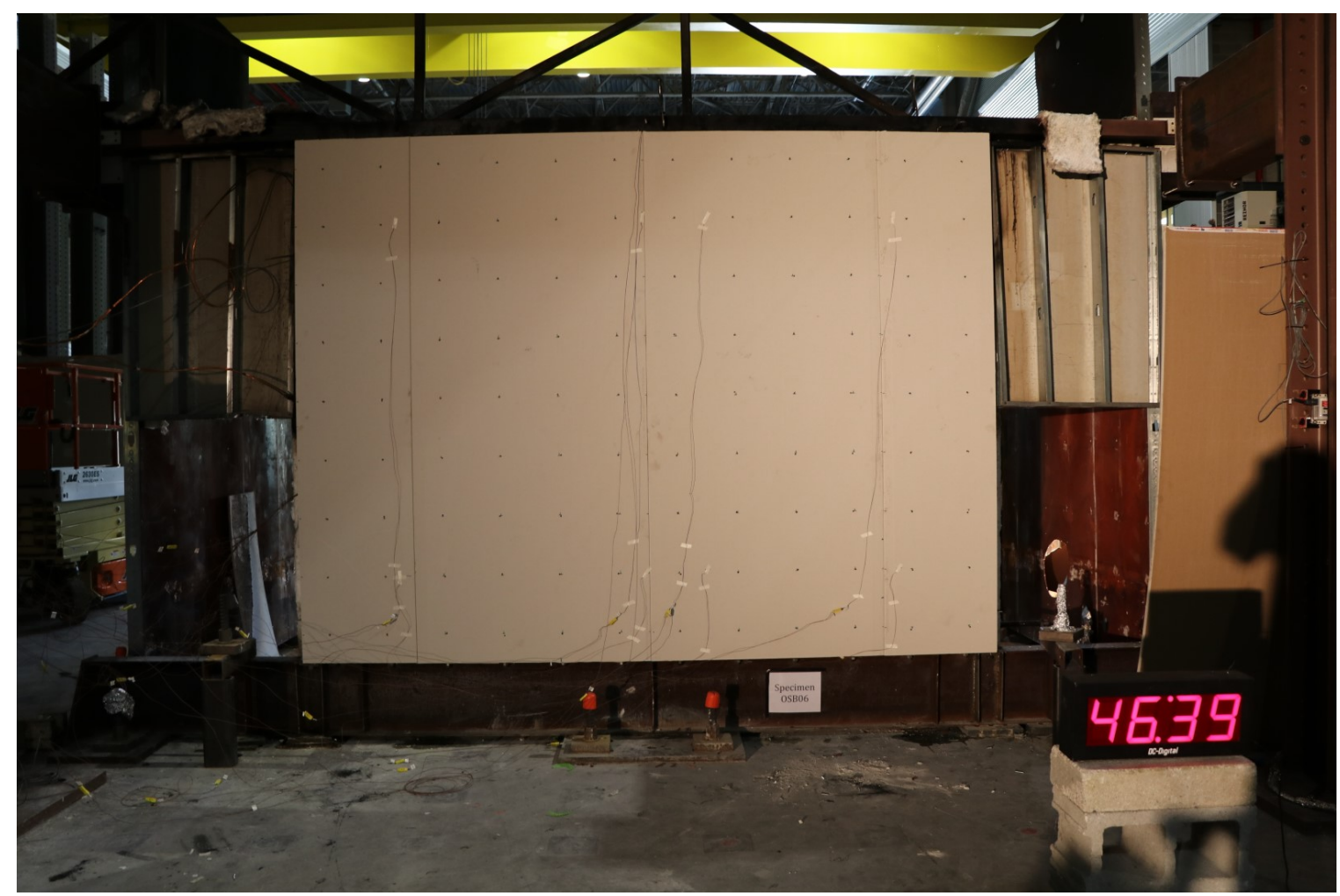

Fig. 322. OSB06 - Photograph of unexposed side of the wall after the fire test (before cycling). 


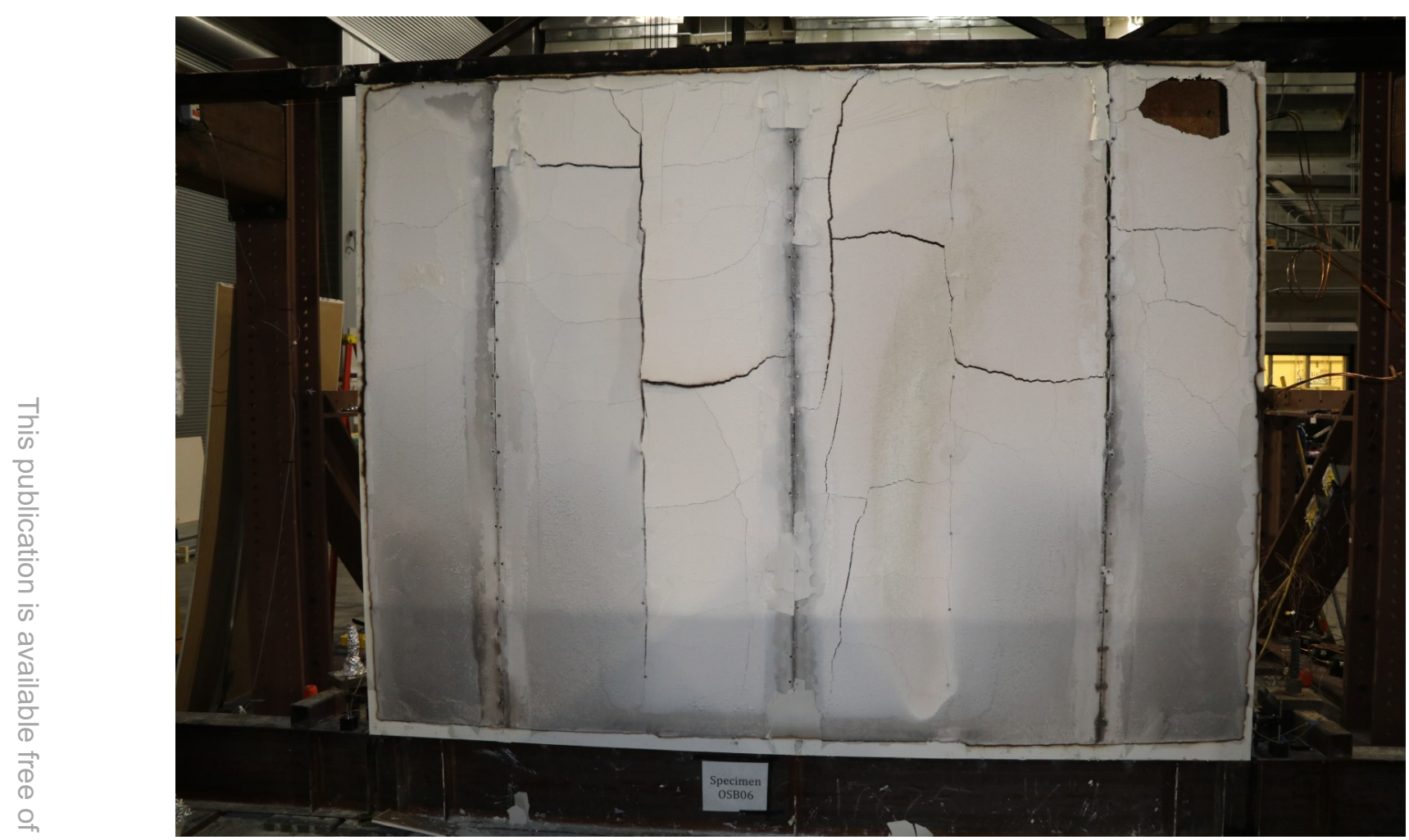

Fig. 323. OSB06 - Photograph of fire exposed side of the wall after the fire test (before cycling).

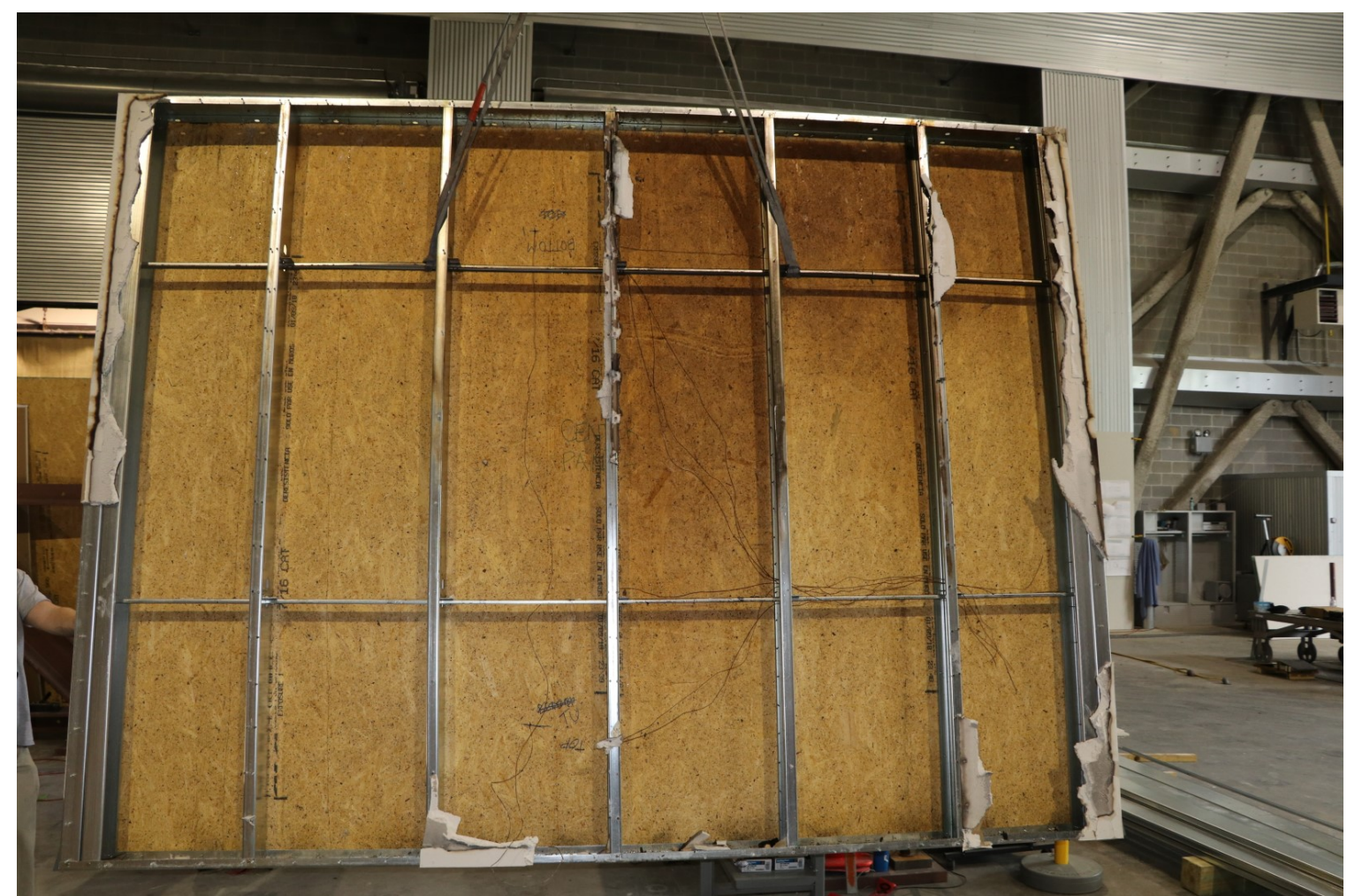

Fig. 324. OSB06 - Photograph of exposed side of the wall (remaining drywall removed) after load cycling following the fire. 


\section{Appendix G: Test Data for Steel Strap Braced Walls}

\section{S01 Data}

S01a (Cyclic test of undamaged wall at ambient temperature)

- Strap bracing on one side of wall only (asymmetric).

- There was a small amount of slack in one strap after placing the wall in the loading frame (Fig. 329).

- Failure mode was buckling of top track and torsional failure of south-west chord stud (Fig. 330 to Fig. 333).

- This test must be rerun with new wall design (see S01R): Add bolts outside of chord stud at top, use thicker top track (14 gauge); use symmetric $83 \mathrm{~mm}$ (3.25") braces.

- Significant vertical movement at the connection between the actuator head and the loading beam was observed (Fig. 327). The loading beam stiffening truss was not present in this test.

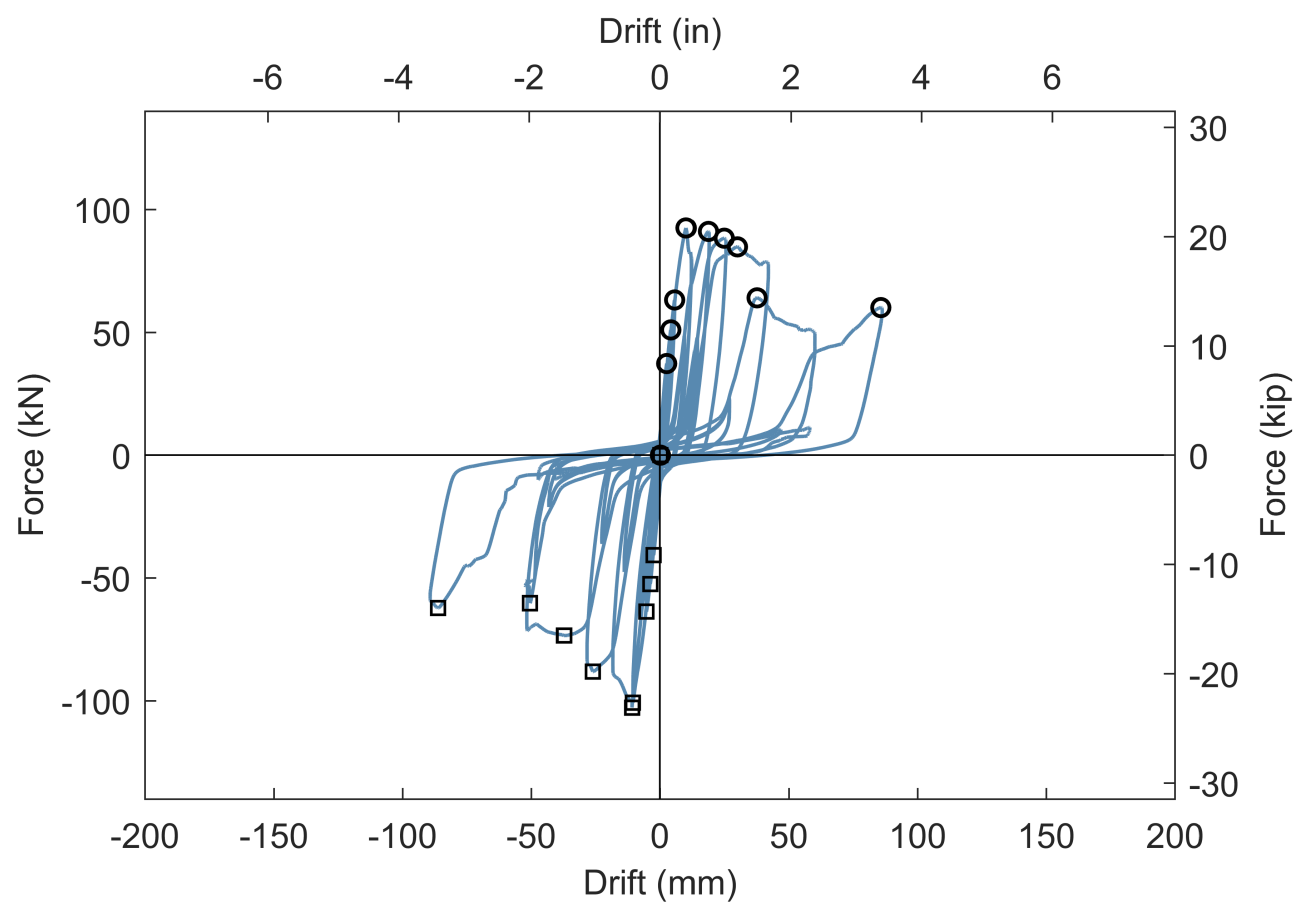

Fig. 325. S01 - Applied load versus wall longitudinal drift during mechanical loading. 


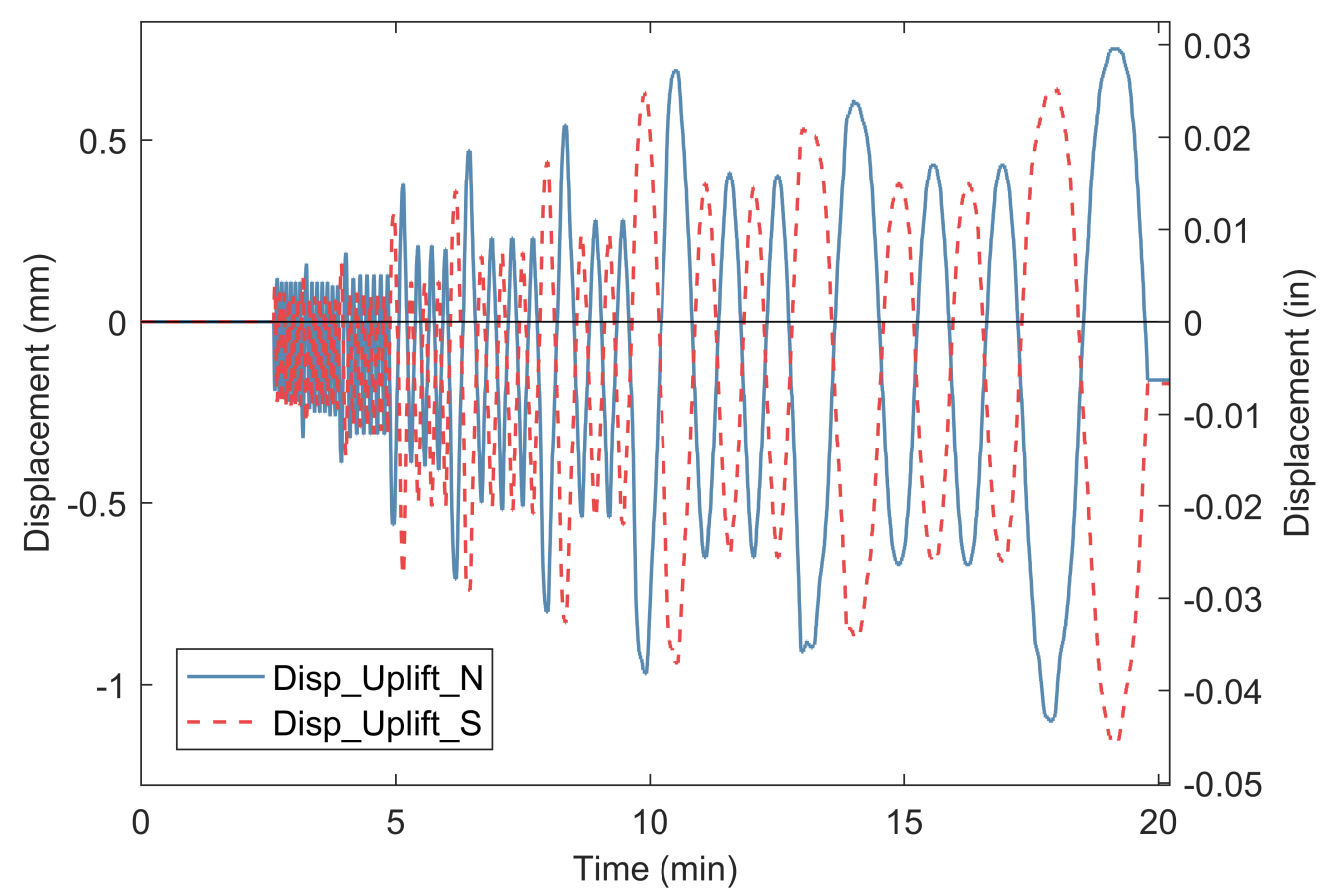

Fig. 326. S01 - Uplift at bottom of wall during mechanical loading.

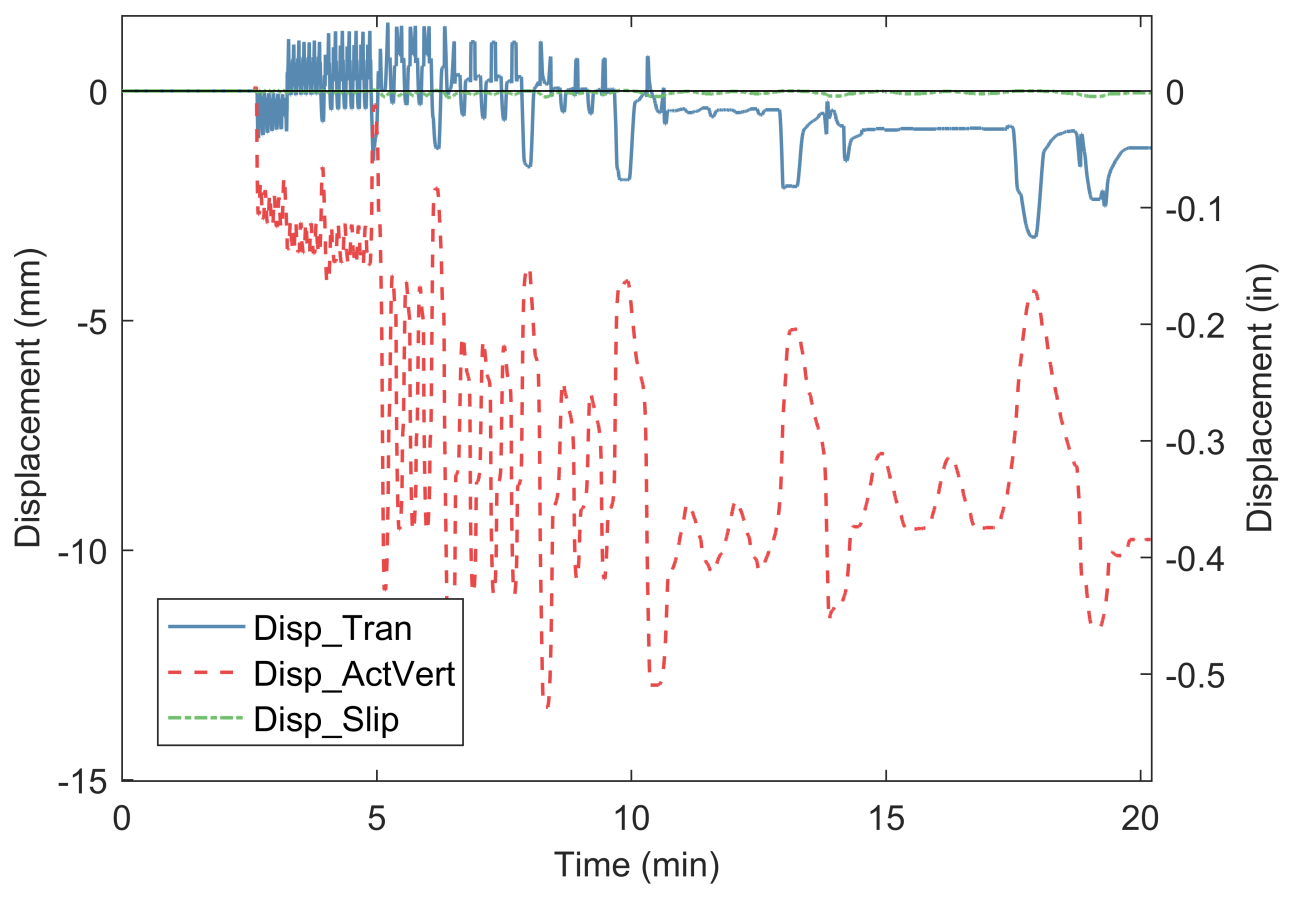

Fig. 327. S01 - Ancillary displacement measurements during mechanical loading. 


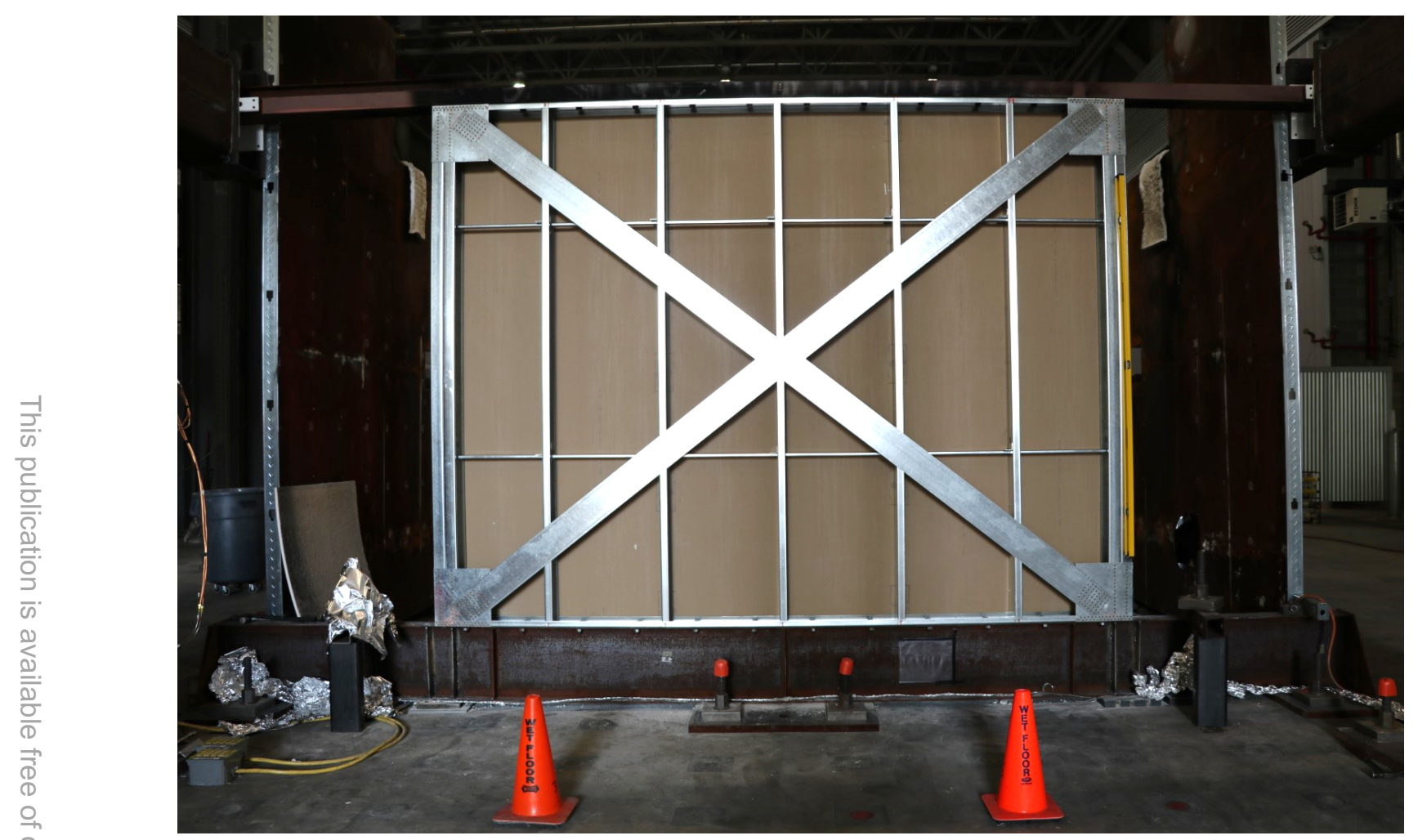

Fig. 328. S01 - Photograph of east side of the wall before gypsum was installation.

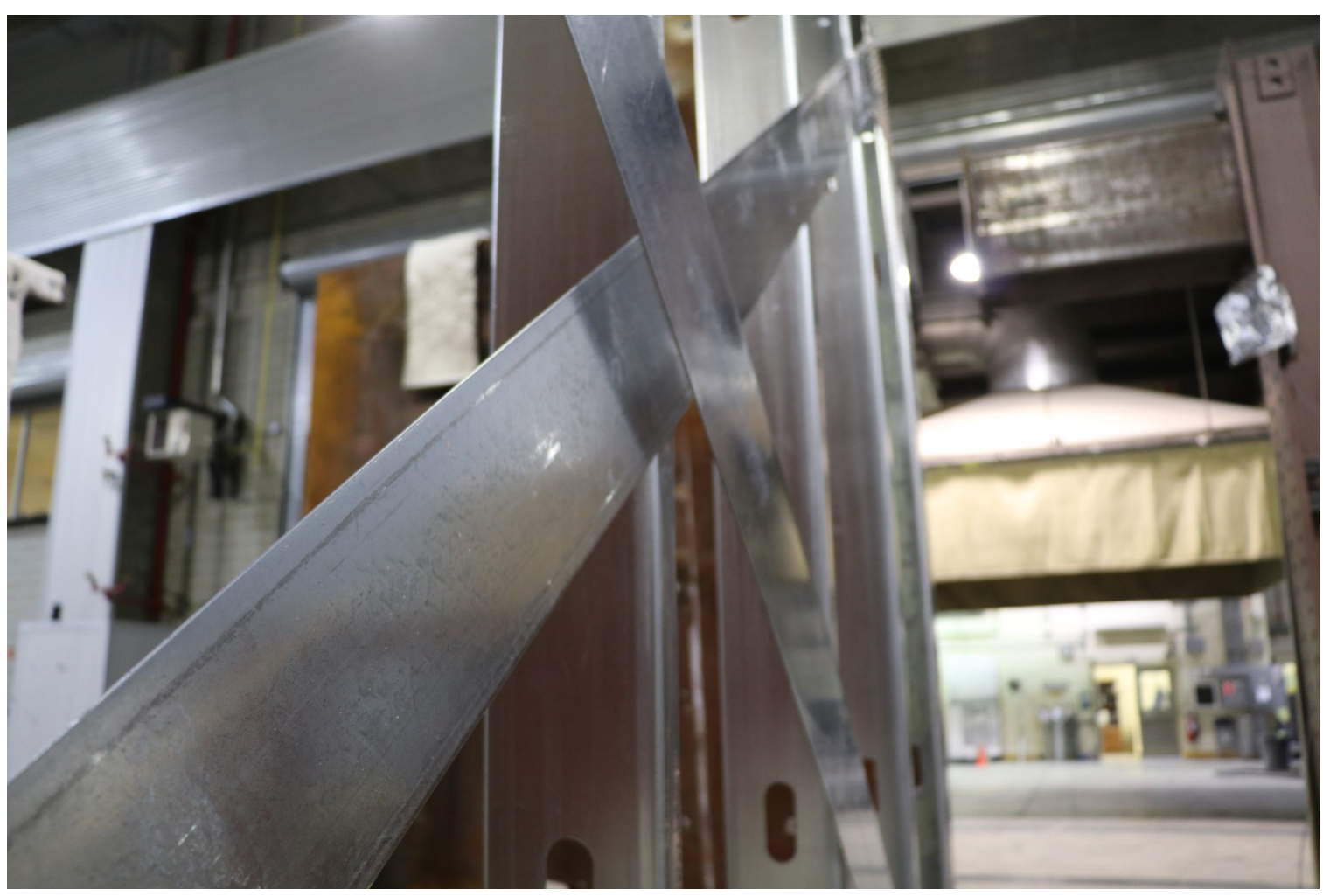

Fig. 329. S01 - Photograph of strap slack prior to testing. 


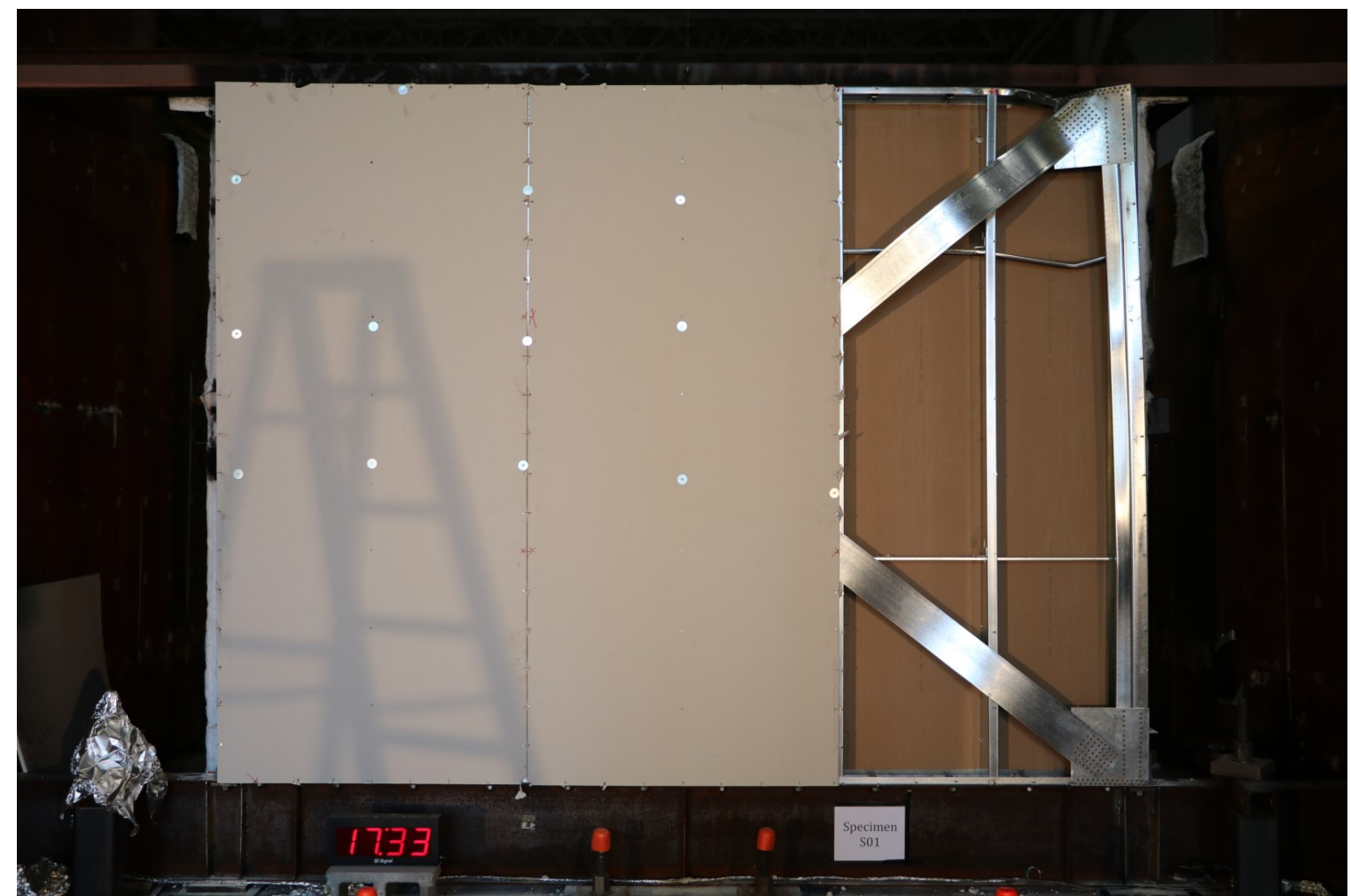

Fig. 330. S01 - Photograph of west (unexposed) side of wall during load cycling after bucking of top track and torsional failure of south chord.

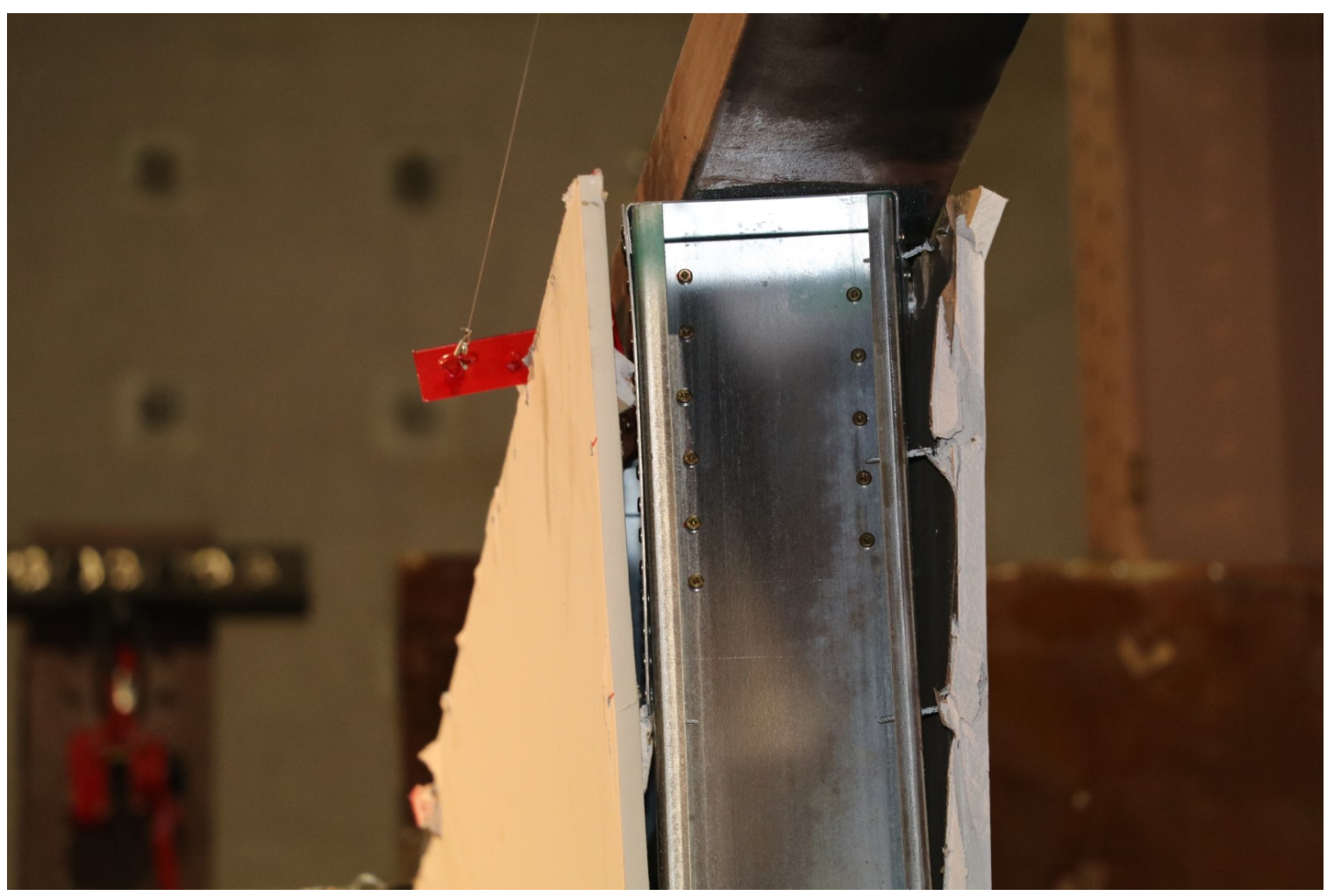

Fig. 331. S01 - Photograph of south chord after torsional failure. 


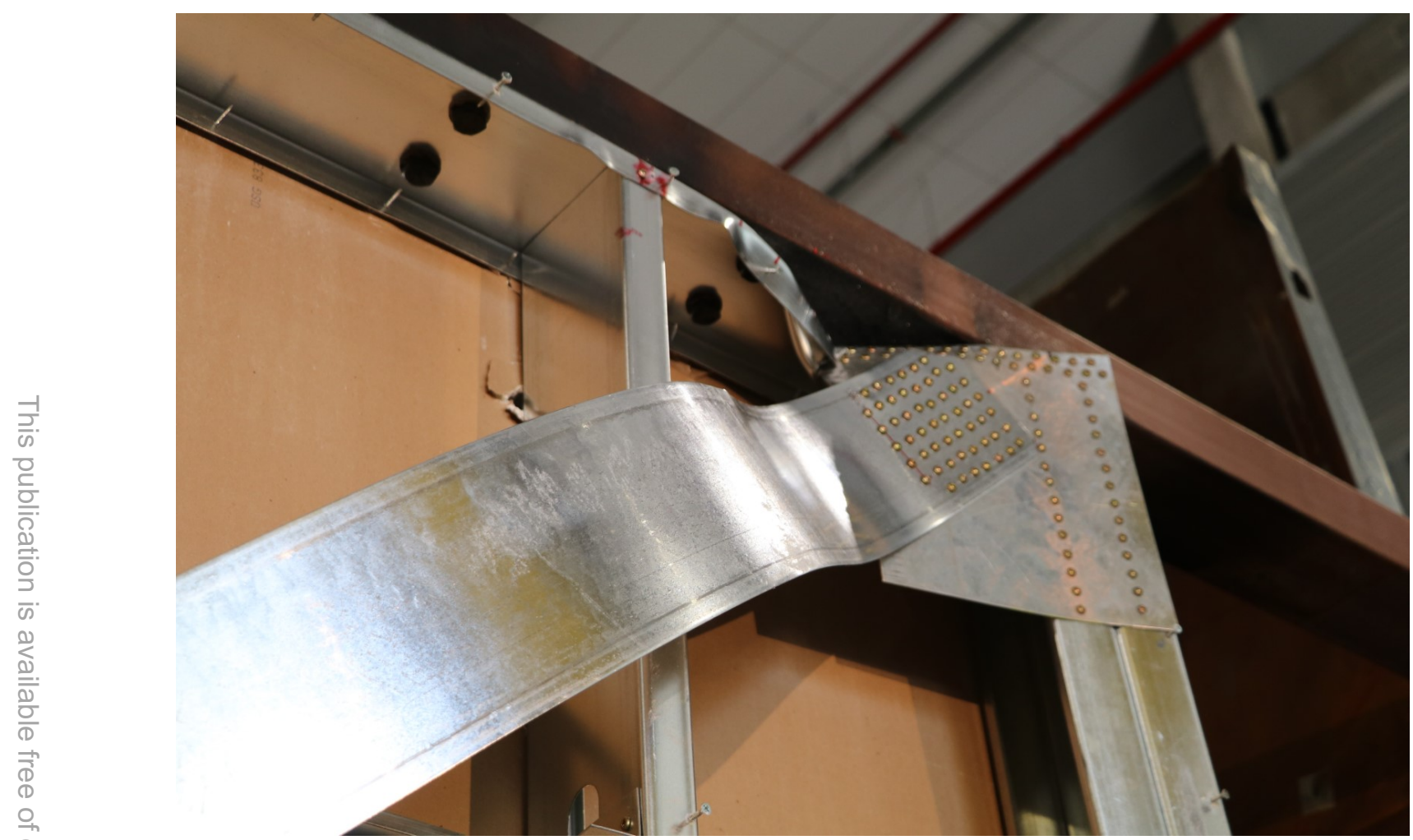

Fig. 332. S01 - Photograph of south-west gusset where failure occurred.

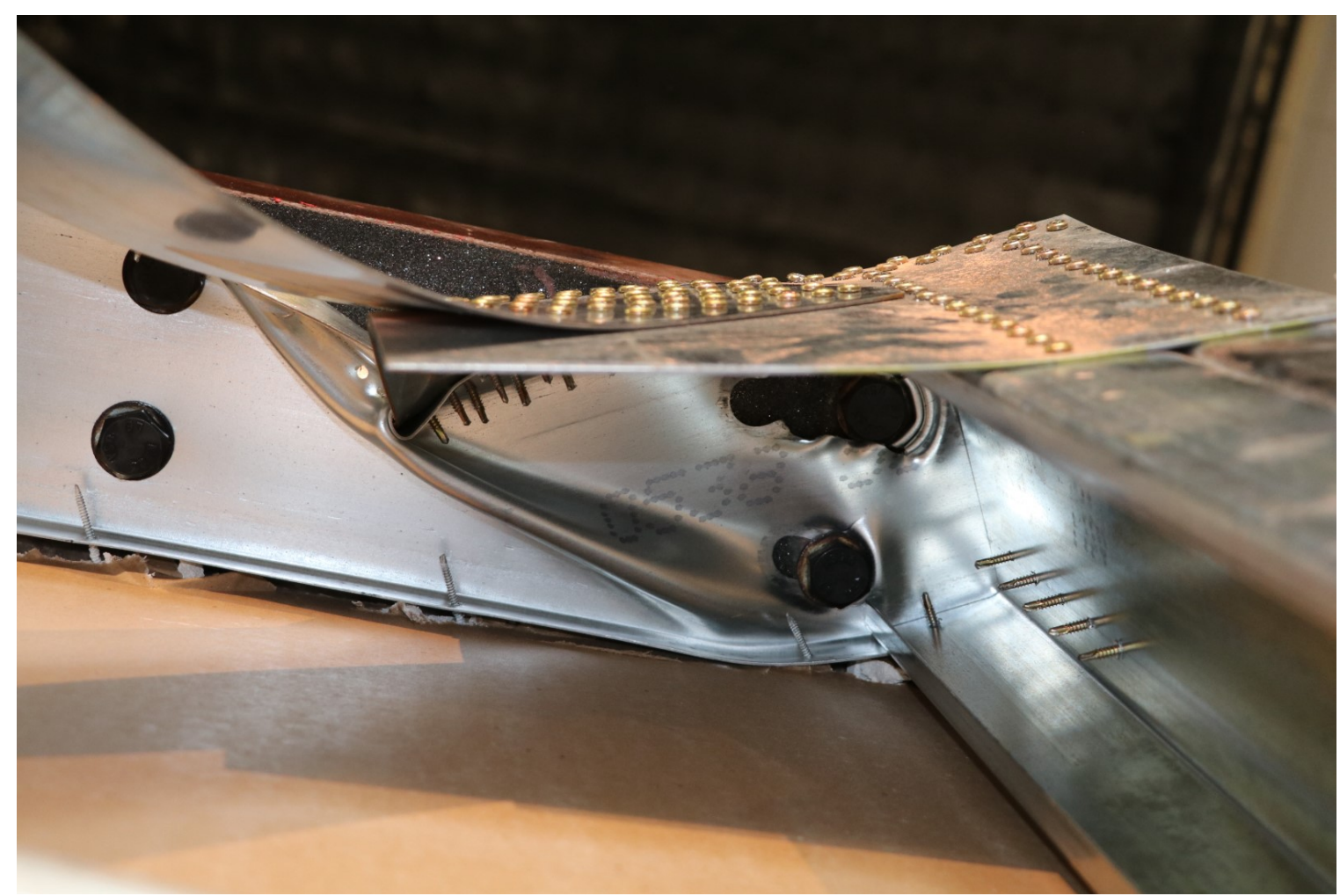

Fig. 333. S01 - Photograph of top track at south-west corner where failure occurred. 


\section{S01R Data}

S01Ra (Cyclic test of undamaged wall at ambient temperature)

- Redesigned wall with symmetric bracing (both sides of wall) and heavier top and bottom track (Fig. 338 to Fig. 339).

- Tensioning method used to remove strap slack (Fig. 337) on all symmetrically braced walls.

- Strap yielding plateau around $100 \mathrm{kN}$.

- The peak strength went above the yield plateau $(\approx 130 \mathrm{kN})$; due to drywall. There was lots of drywall screw fracture/pull-through of the heads through the gypsum around the time when the strength started dropping to the yield plateau level.

- Ultimate failure in one direction was strap rupture at the north-west gusset (Fig. 344) and in the opposite direction chord crippling was observed just about the stiff holdown brackets (Fig. 346).

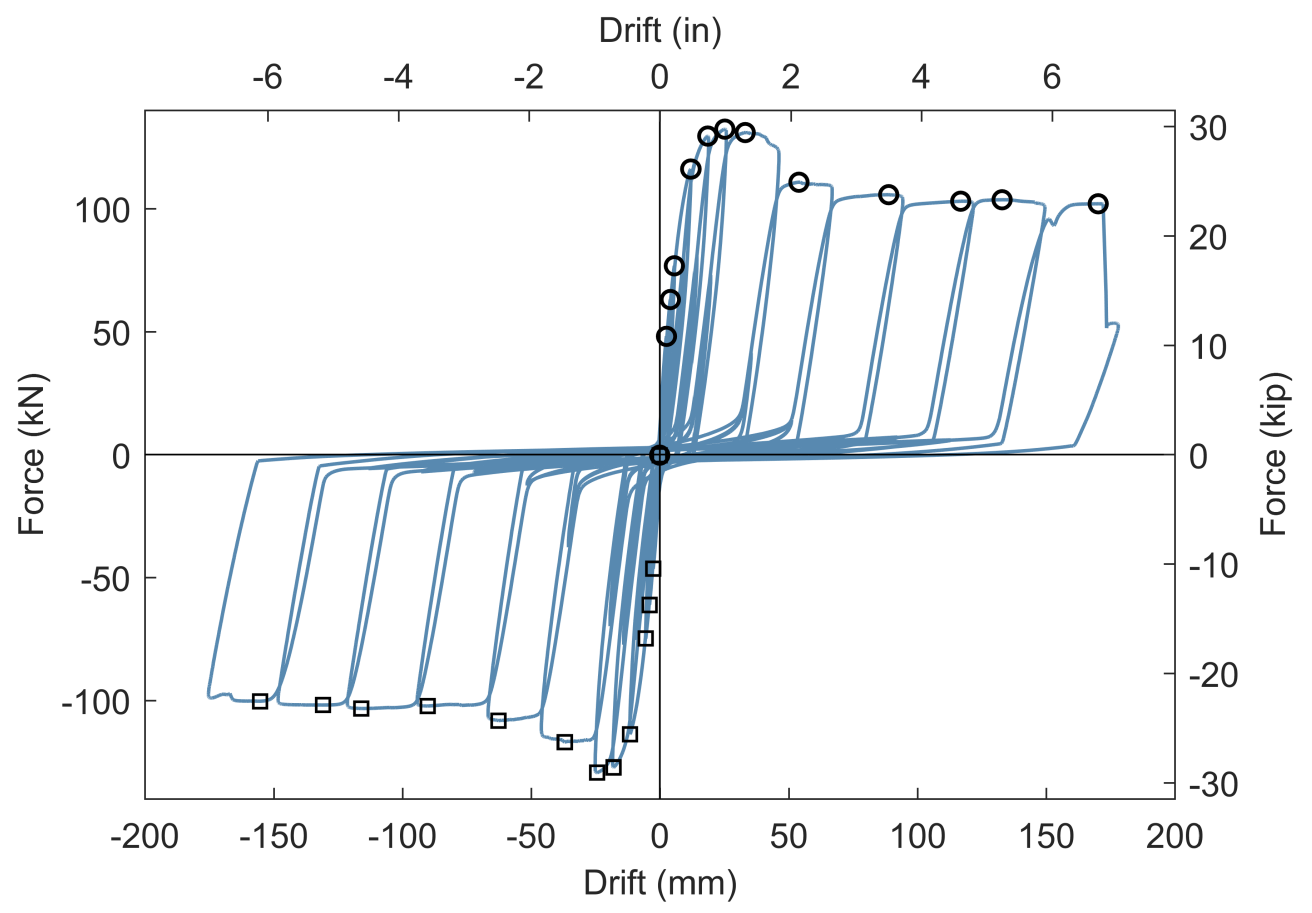

Fig. 334. S01R - Applied load versus wall longitudinal drift during mechanical loading. 


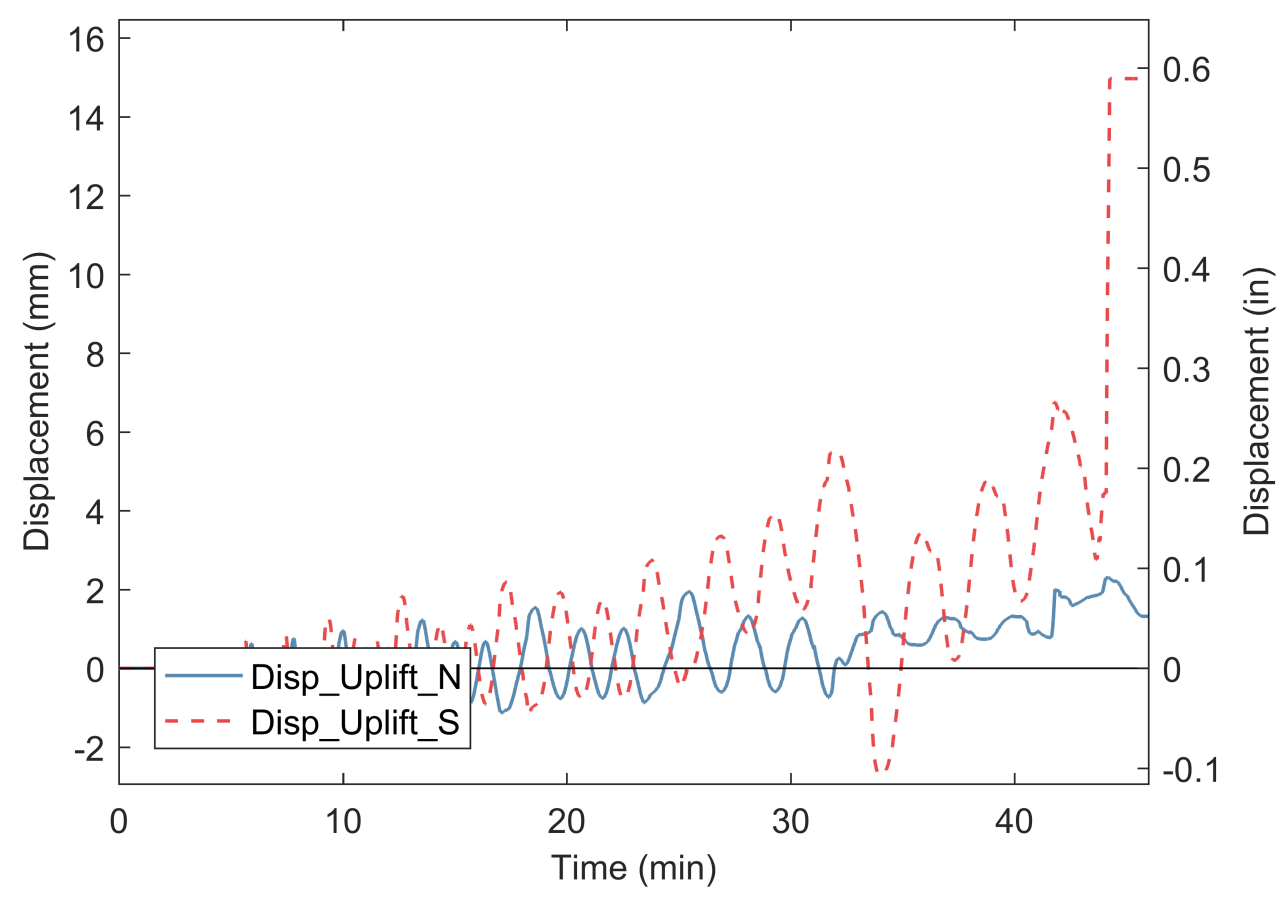

Fig. 335. S01R - Uplift at bottom of wall during mechanical loading.

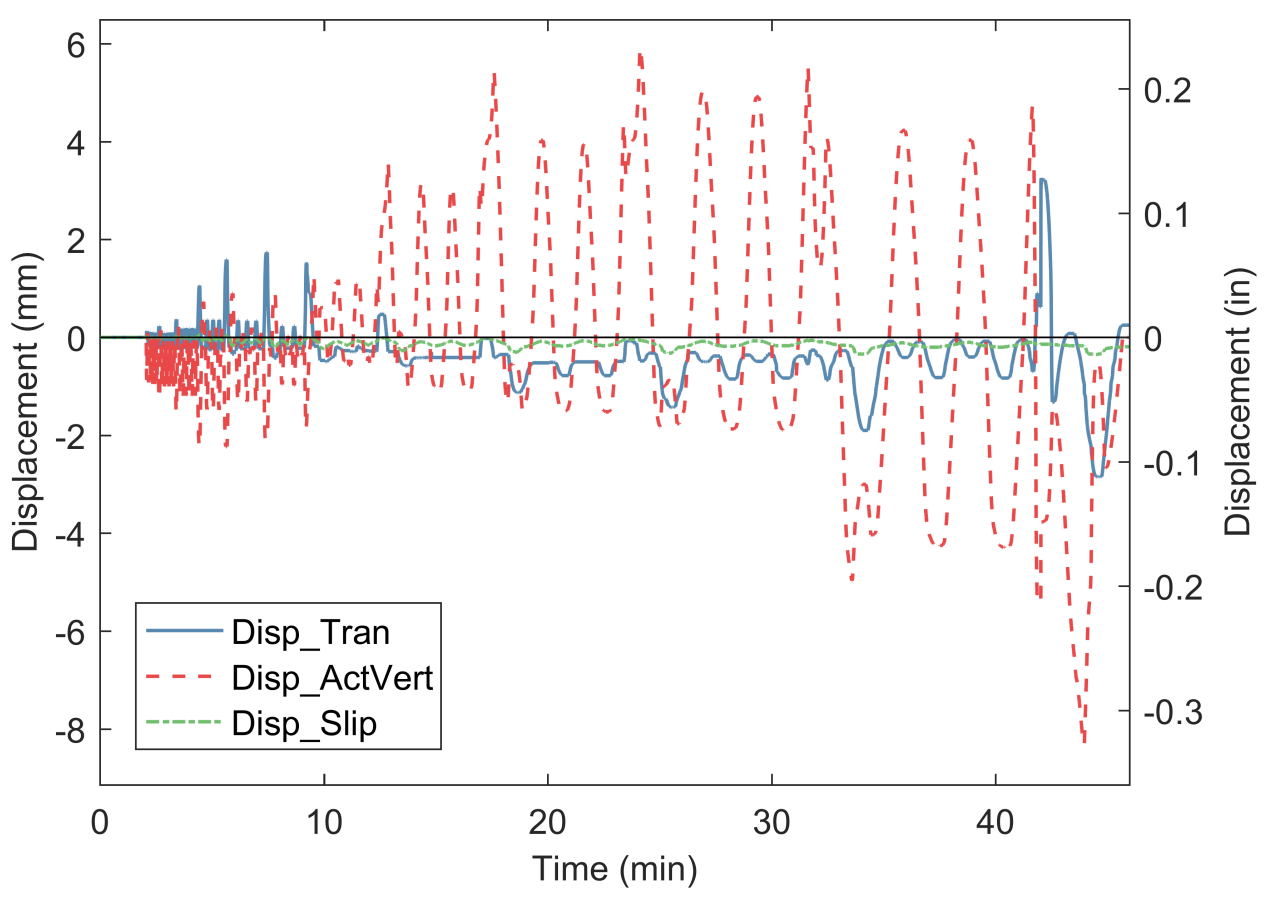

Fig. 336. S01R - Ancillary displacement measurements during mechanical loading. 

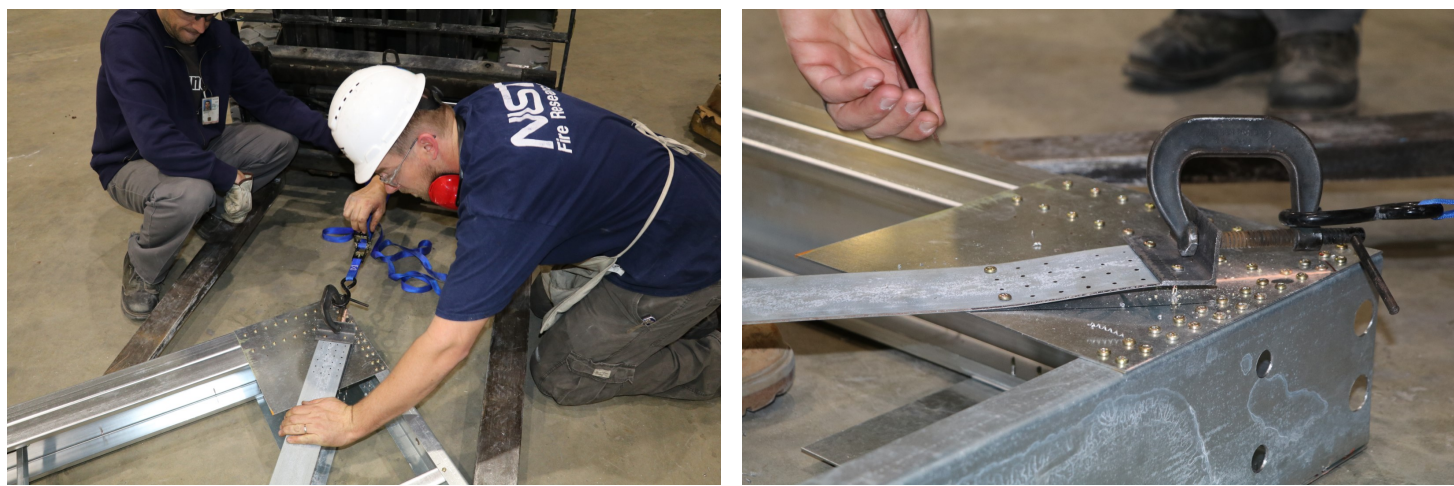

Fig. 337. S01R - Photograph of method to reduce strap slack.

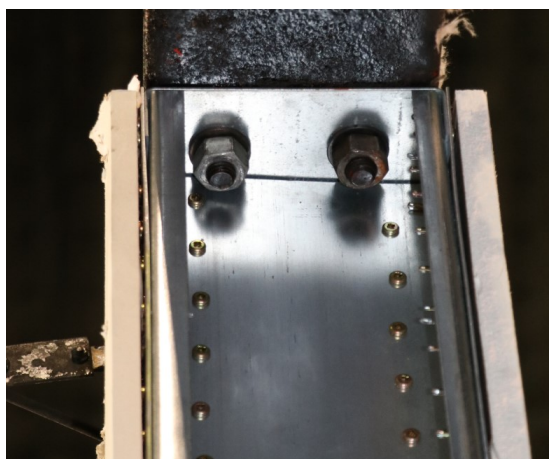

Fig. 338. S01R - Photograph of bolts added to top track outside of chord studs.

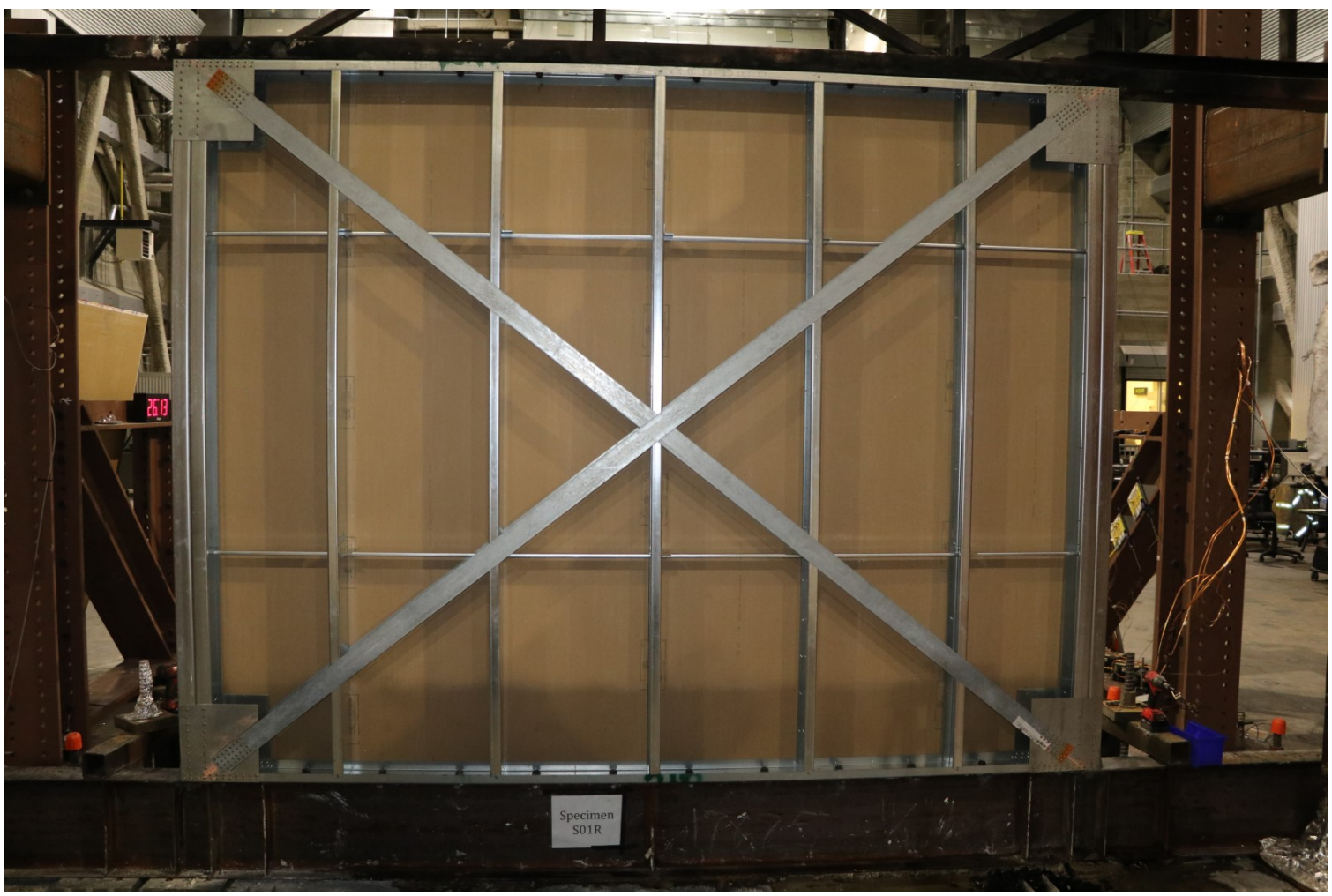

Fig. 339. S01R - Photograph of east side of the wall before gypsum installation. 


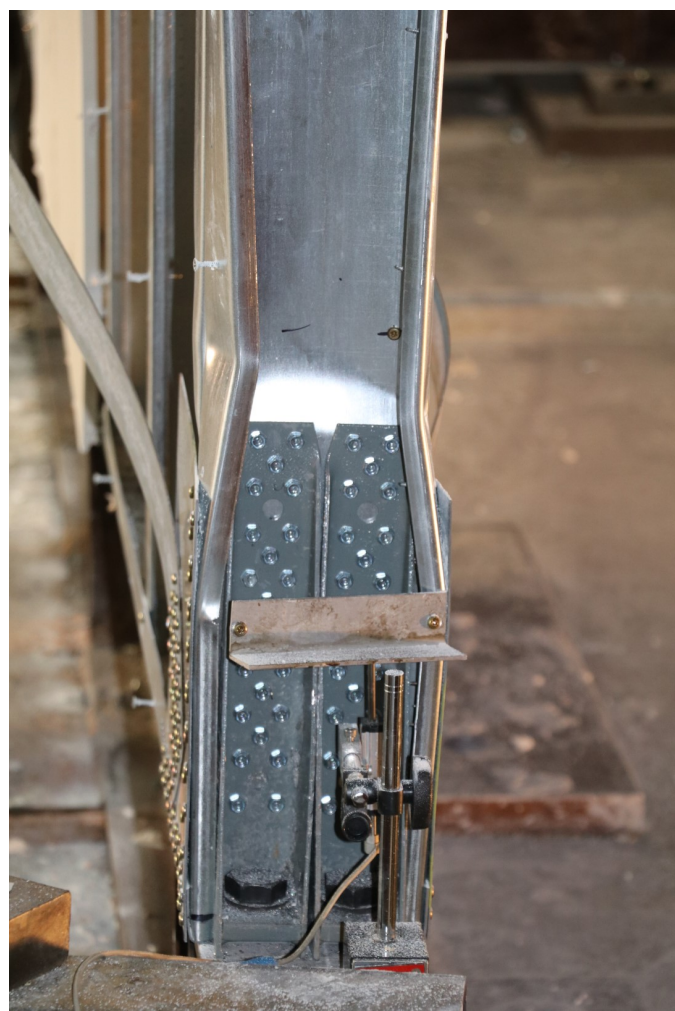

Fig. 340. S01R - Photograph of start of crippling of chord stud well after strap yielding, but prior to strap rupture.

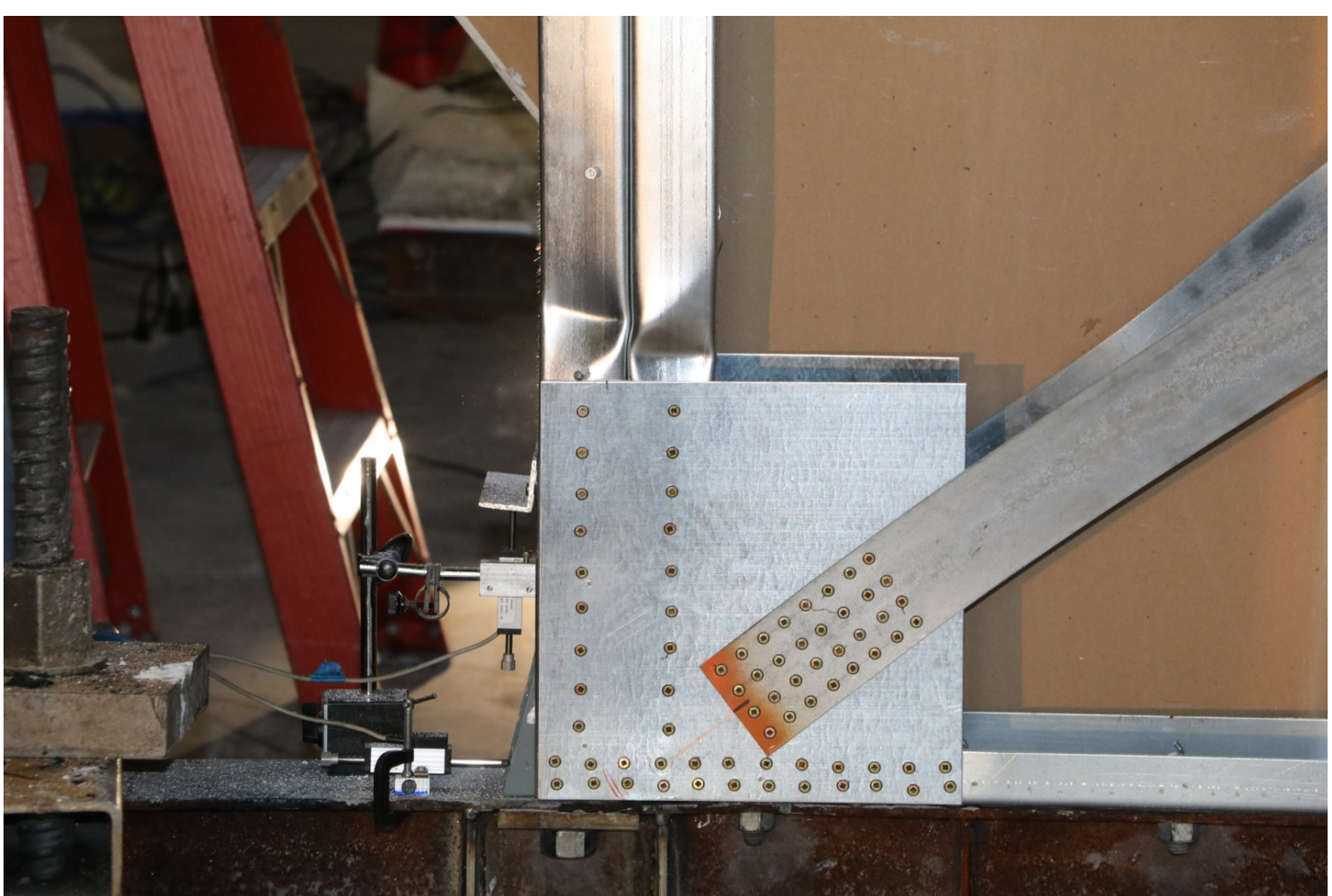

Fig. 341. S01R - Photograph of start of crippling of chord stud well after strap yielding, but prior to strap rupture (side view). 


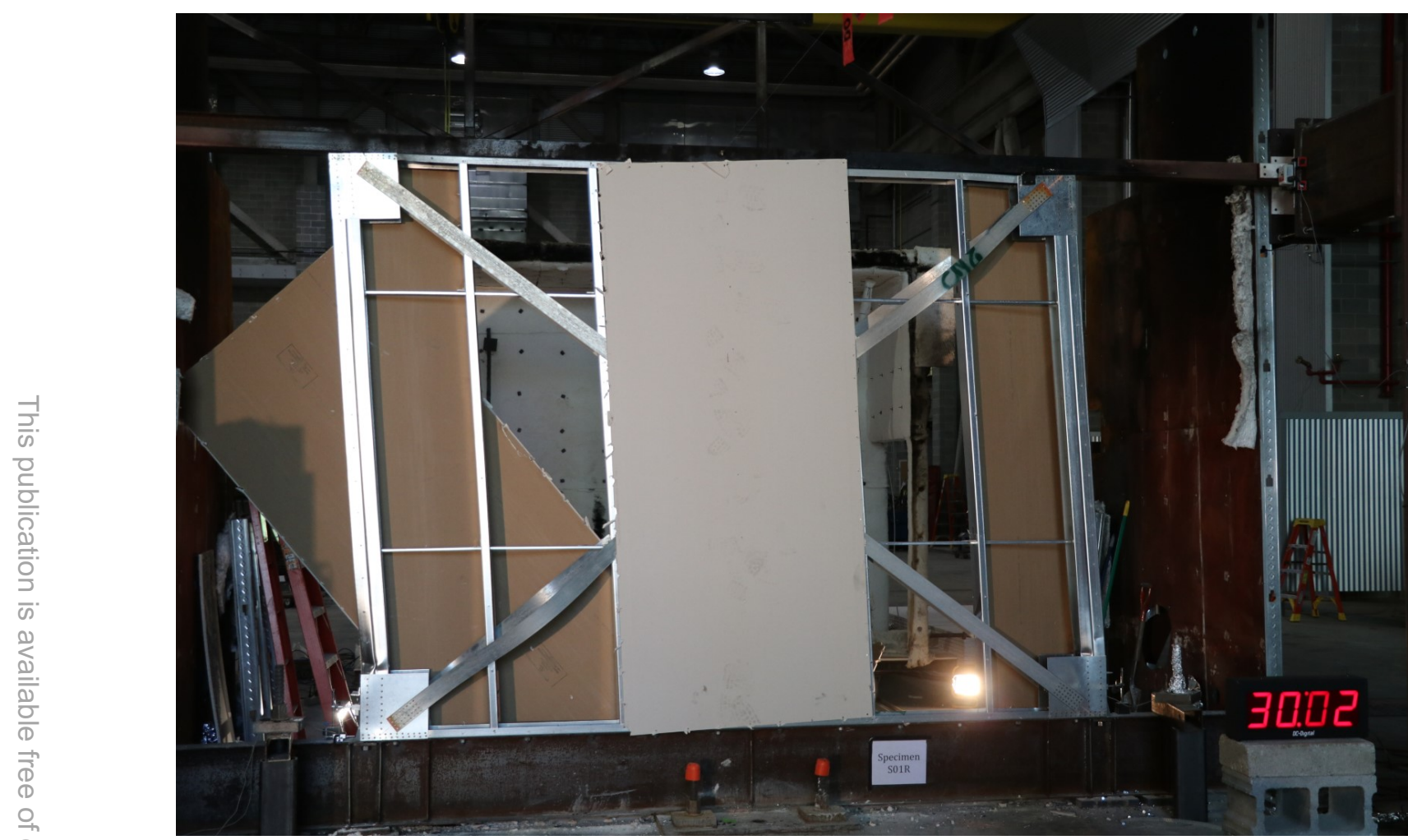

Fig. 342. S01R - Photograph of wall at large drift prior to strap rupture; strap in unloaded direction is deforming out plane.

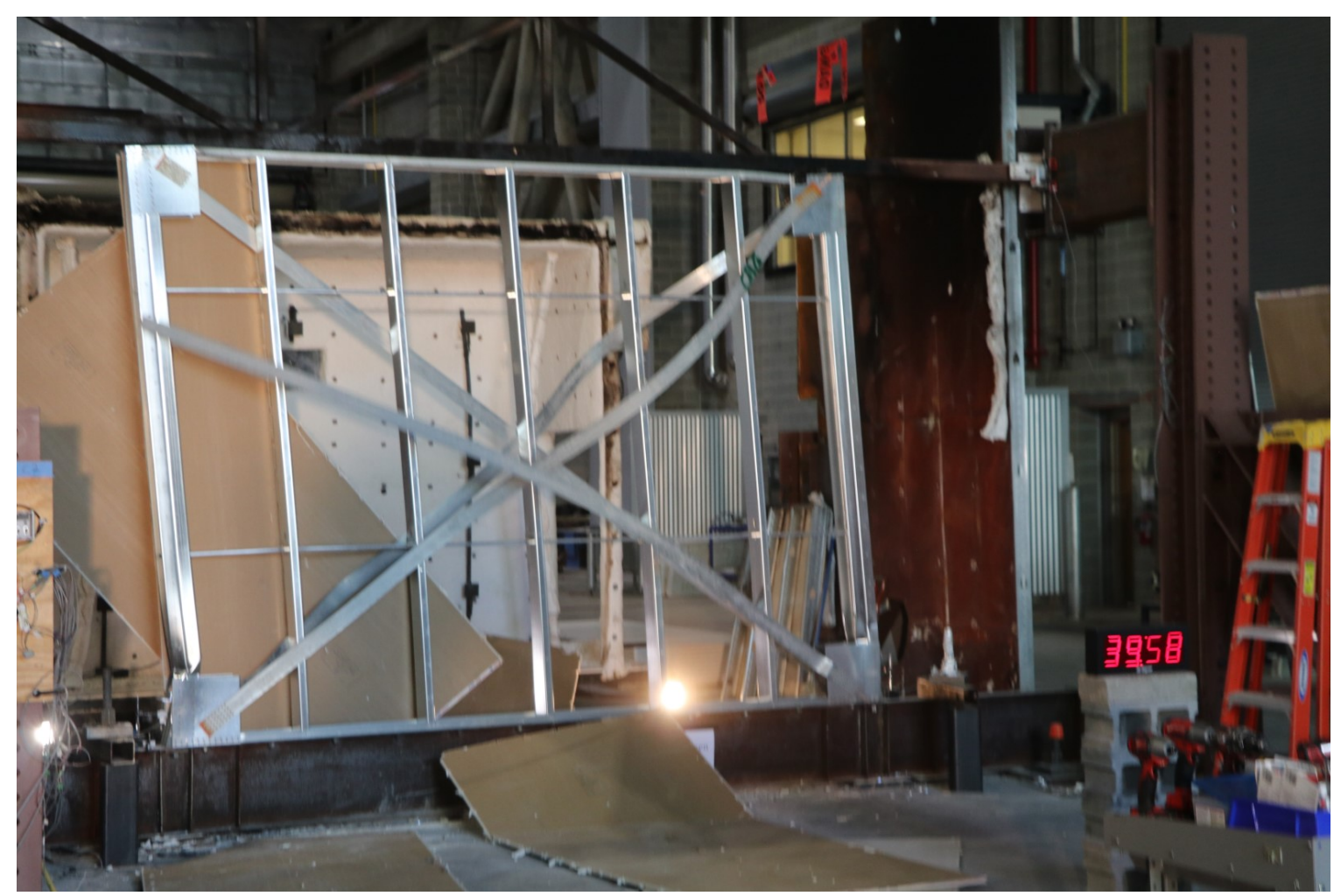

Fig. 343. S01R - Photograph of wall at first strap rupture. 


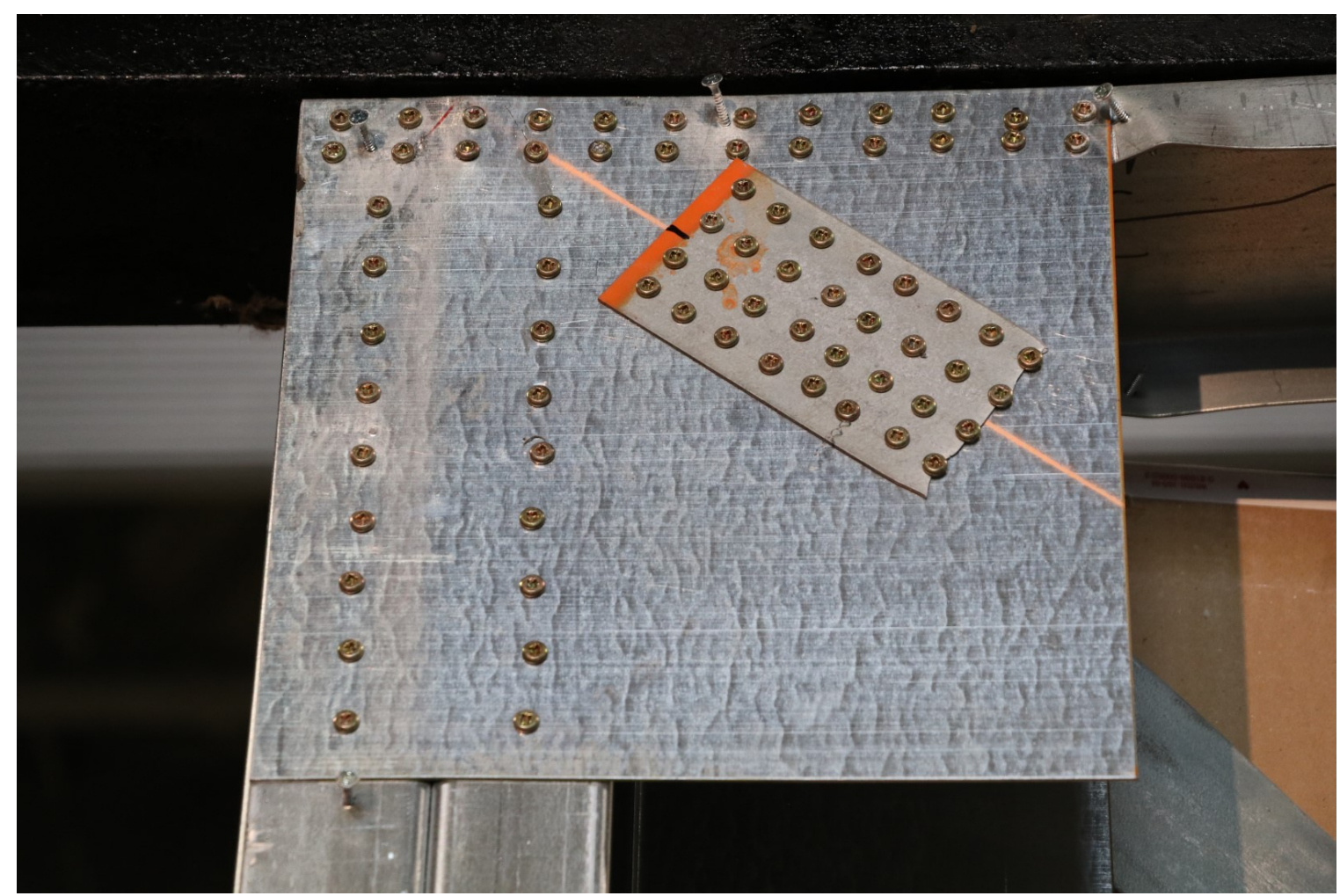

Fig. 344. S01R - Photograph of gusset at strap rupture location.

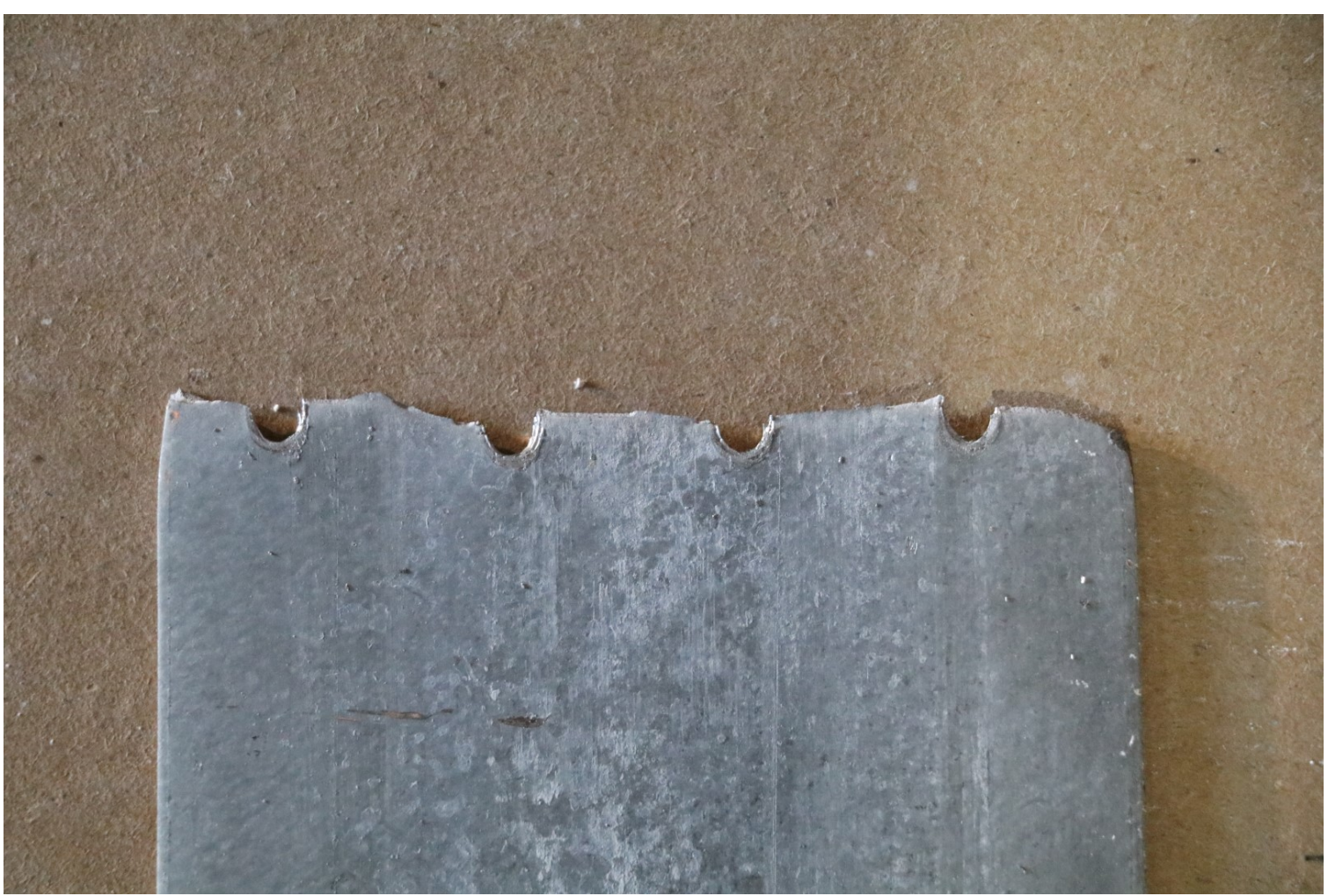

Fig. 345. S01R - Photograph of strap at rupture location. 


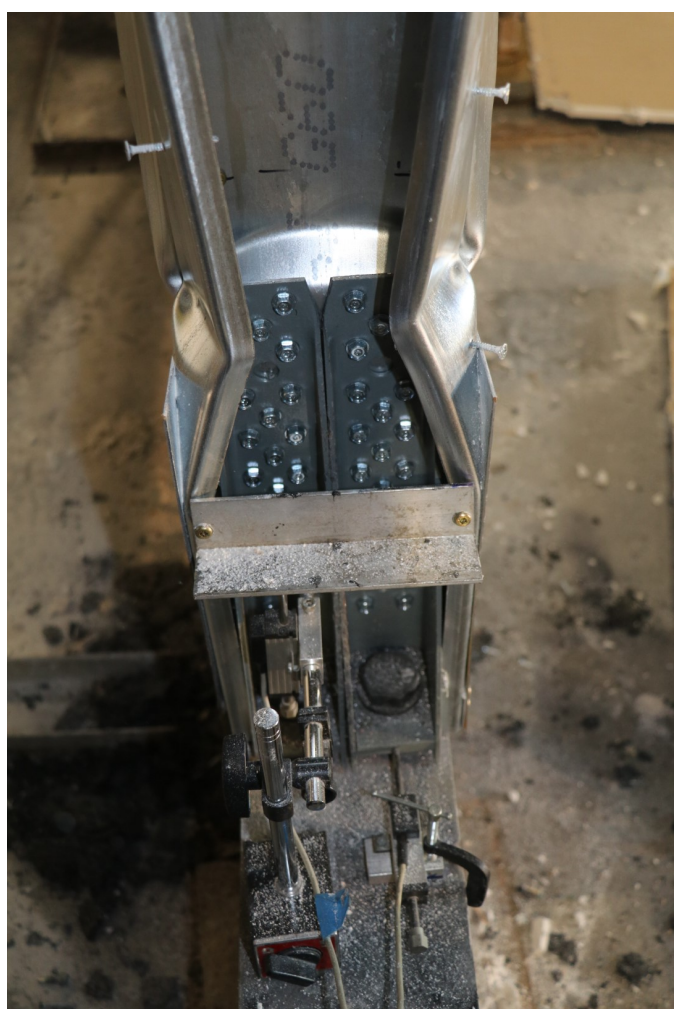

Fig. 346. S01R - Photograph of crippling of chord stud after load cycling is complete. 


\section{S02 Data}

S02b (Severe Fire test of an undamaged wall)

- The gas burner was set to 2.3 MW for 35 min (Fig. 347), and data was recorded during the cooling phase up to $60 \mathrm{~min}$.

- At 19 min after ignition flaming was observed in the top of the wall (Fig. 361) due to the paper lining of the gypsum in the cavity. At $21 \mathrm{~min}$ the paper on the top of the unexposed side started burning (Fig. 362) and smoking through the joints. This is also observed in the unexposed side temperatures (Fig. 356).

- At 33 min a large opening in the unexposed side gypsum (Fig. 363) can be seen and the temperatures in the compartment drop.

- The interior studs and the strap braces are highly damaged after the fire test (Fig. 365 to Fig. 366).

- Thermocouple TC_T_P1 stopped working after 10 minutes, and TC_B_P1 provided incorrect readings probably due to a cold junction.

S02c (Cyclic test of wall at ambient temperature following the Severe Fire)

- 1 st strap failure south-east top; due to reduced (oxidized) cross section.

- 2nd strap failure south-west top; due to reduced (oxidized) cross section.

- Appears that strap yield limit decreased and the ductility increased post fire for straps that did not get oxidized.

- Cyclic test was stopped after step 12a and the wall was pulled until the north chord buckled at more than $10 \%$ story drift ratio.

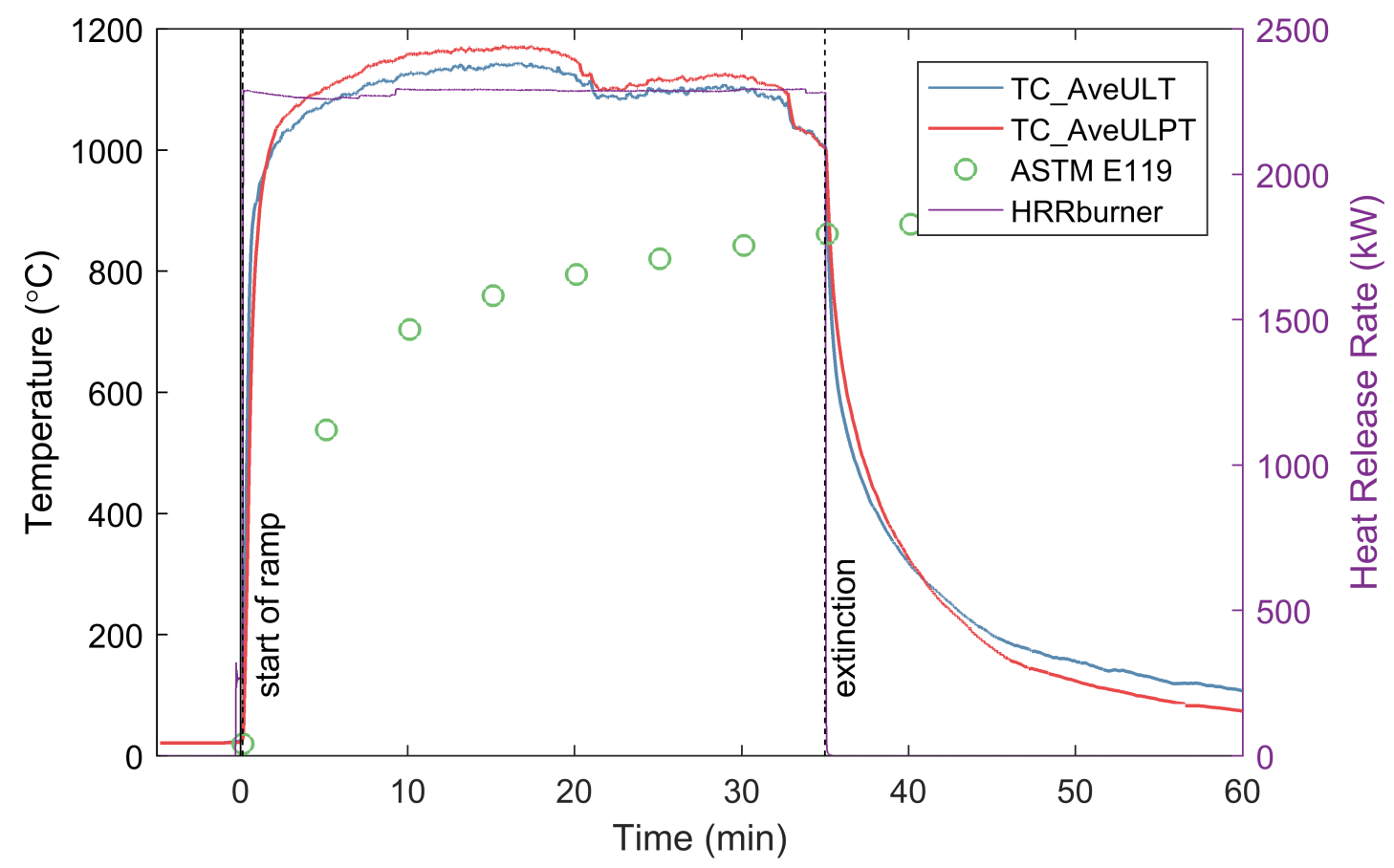

Fig. 347. S02 - Compartment temperatures and burner Heat Release Rate. 


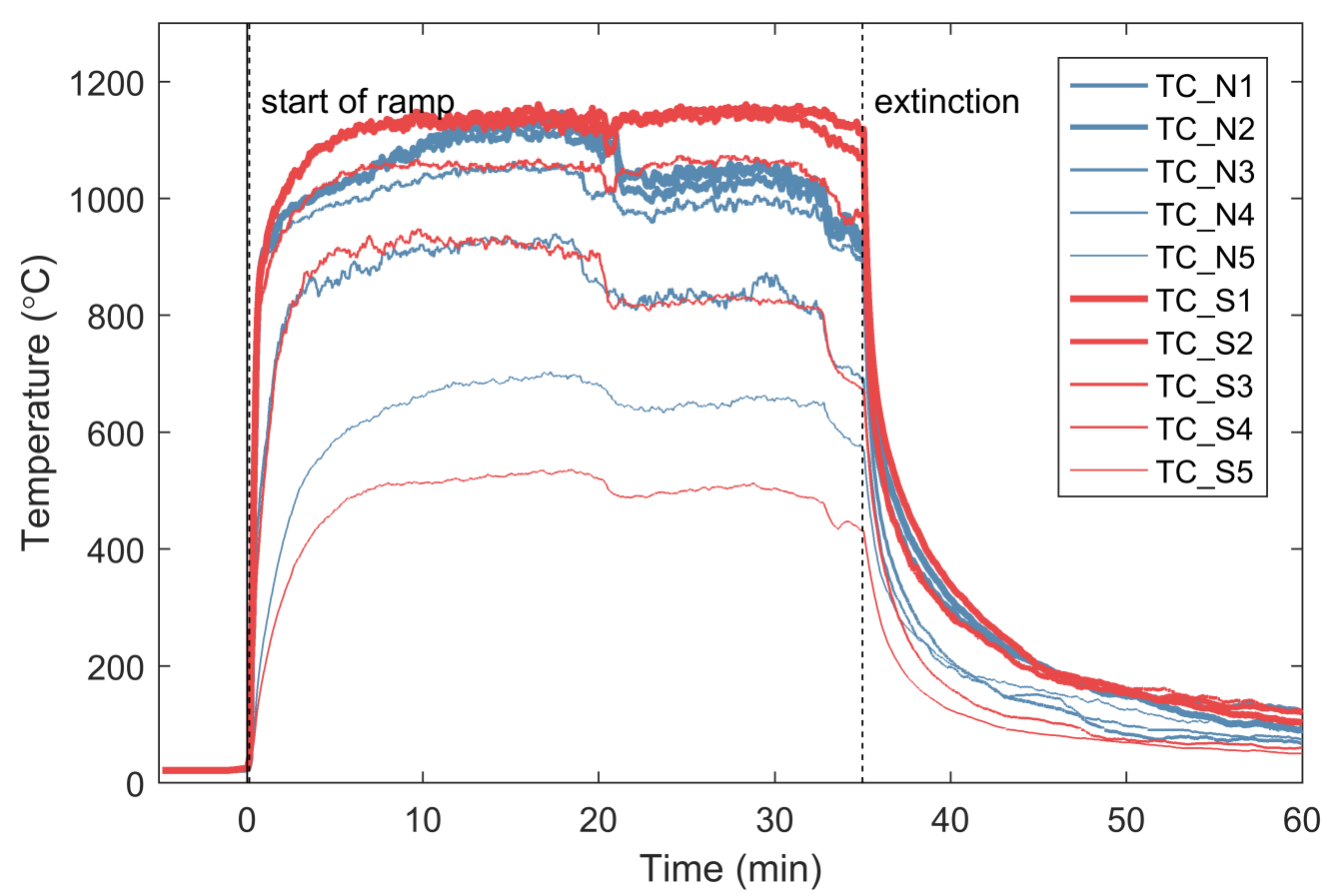

Fig. 348. S02 - Compartment temperatures measured by the thermocouple arrays.

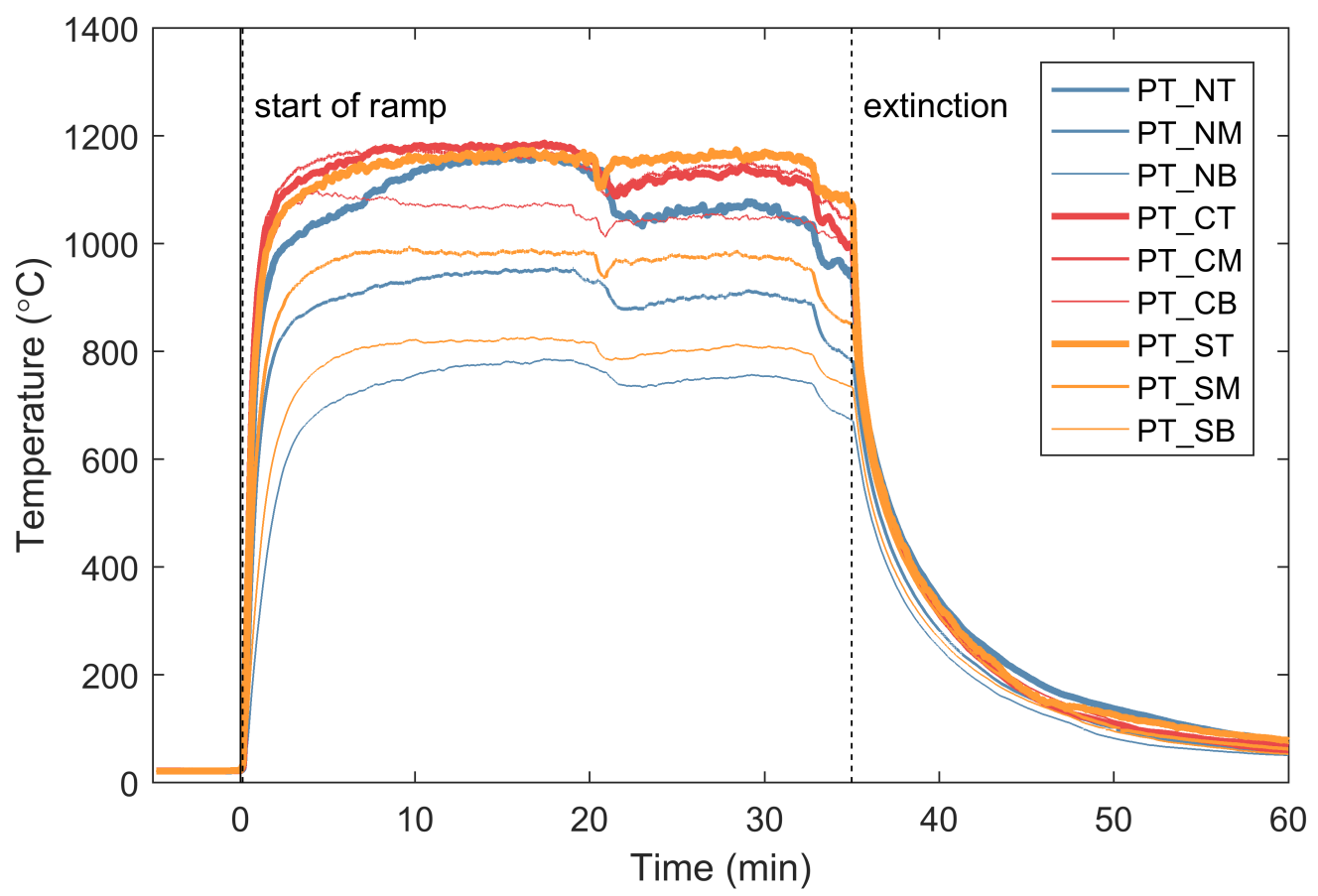

Fig. 349. S02 - Compartment temperature measured by the plate thermocouples. 


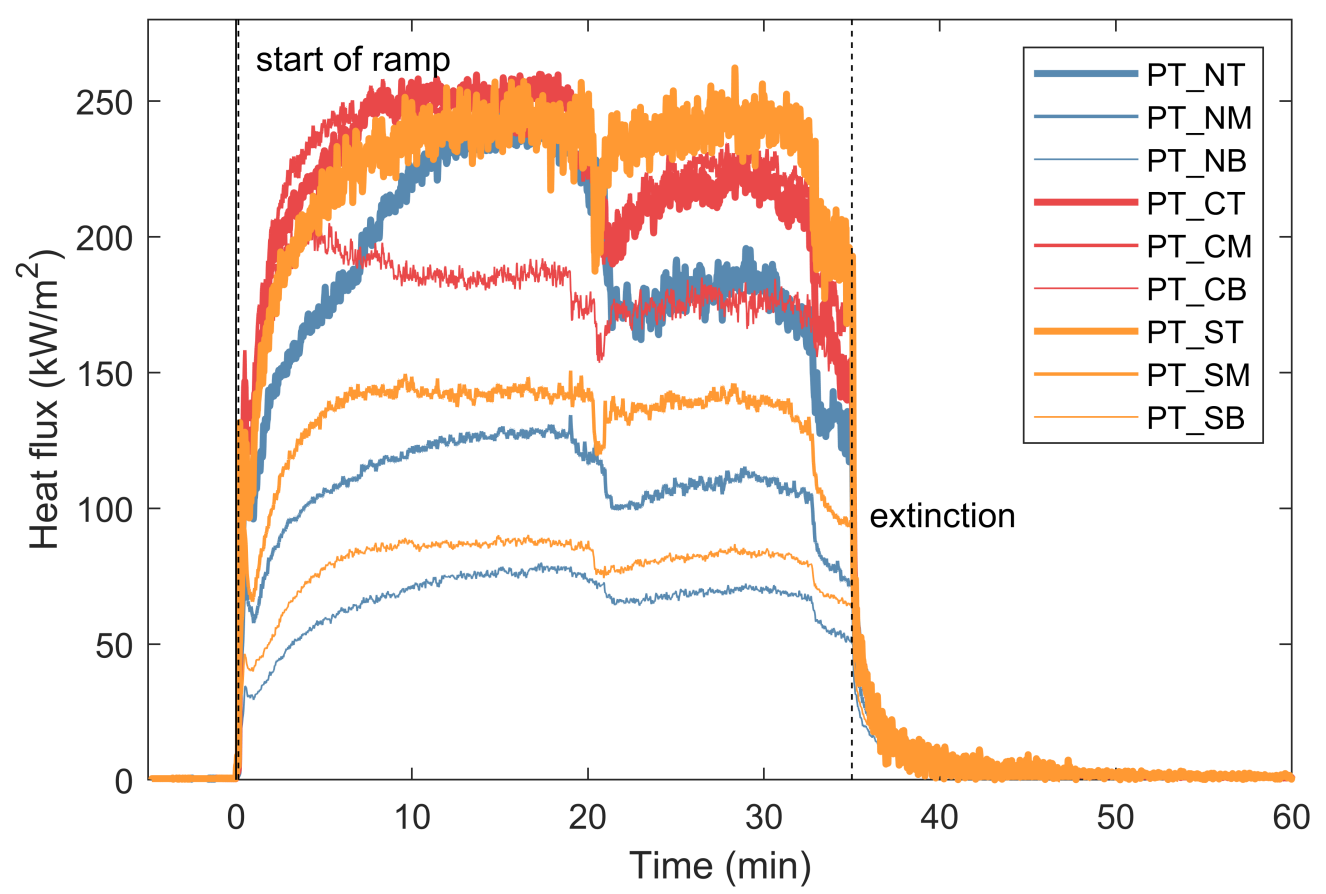

Fig. 350. S02 - Heat fluxes in the compartment measured by the plate thermocouples.
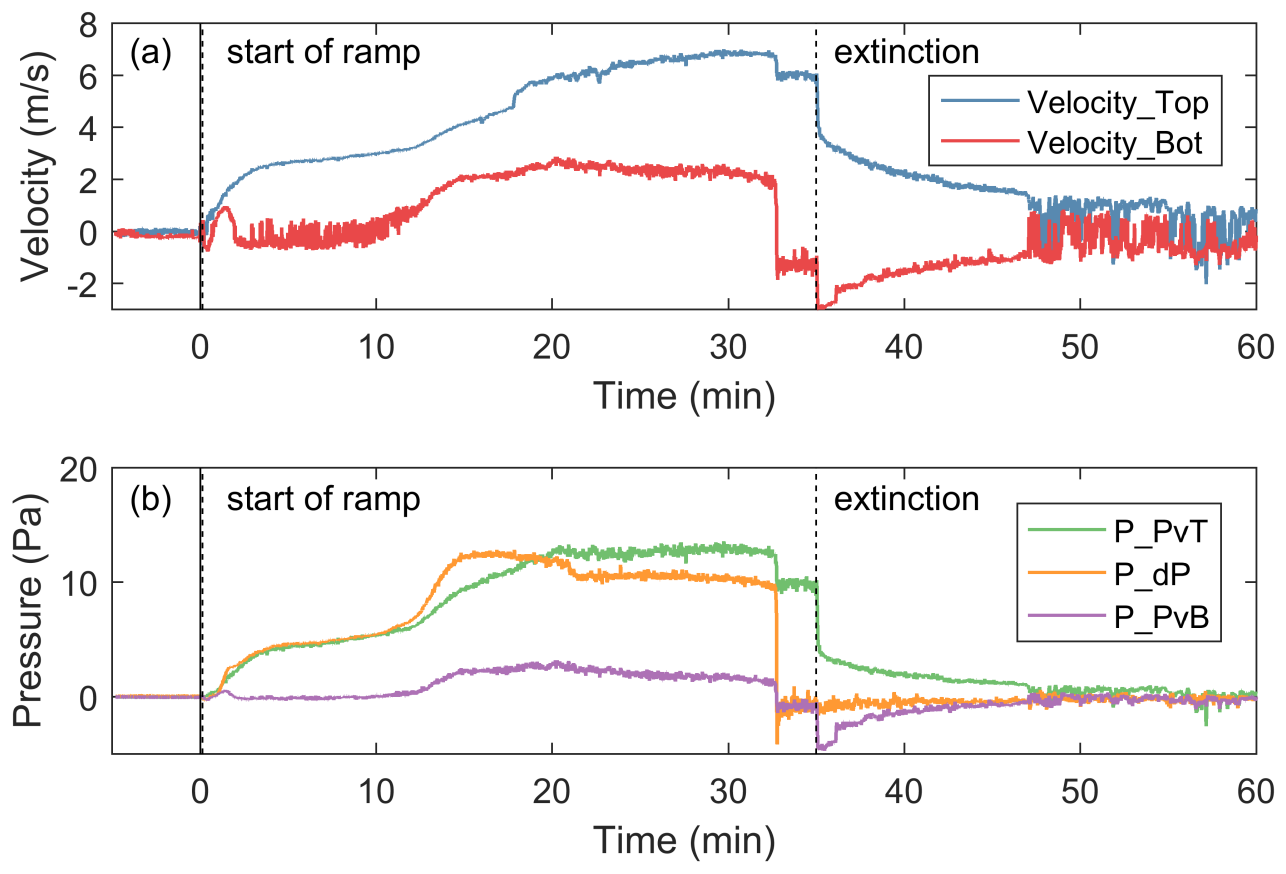

Fig. 351. S02 - (a) Velocity of air flow at the top and bottom knockouts of the chord stud; (b) Pressure at the top and bottom knockouts of the chord stud and in the wall cavity near the top. 


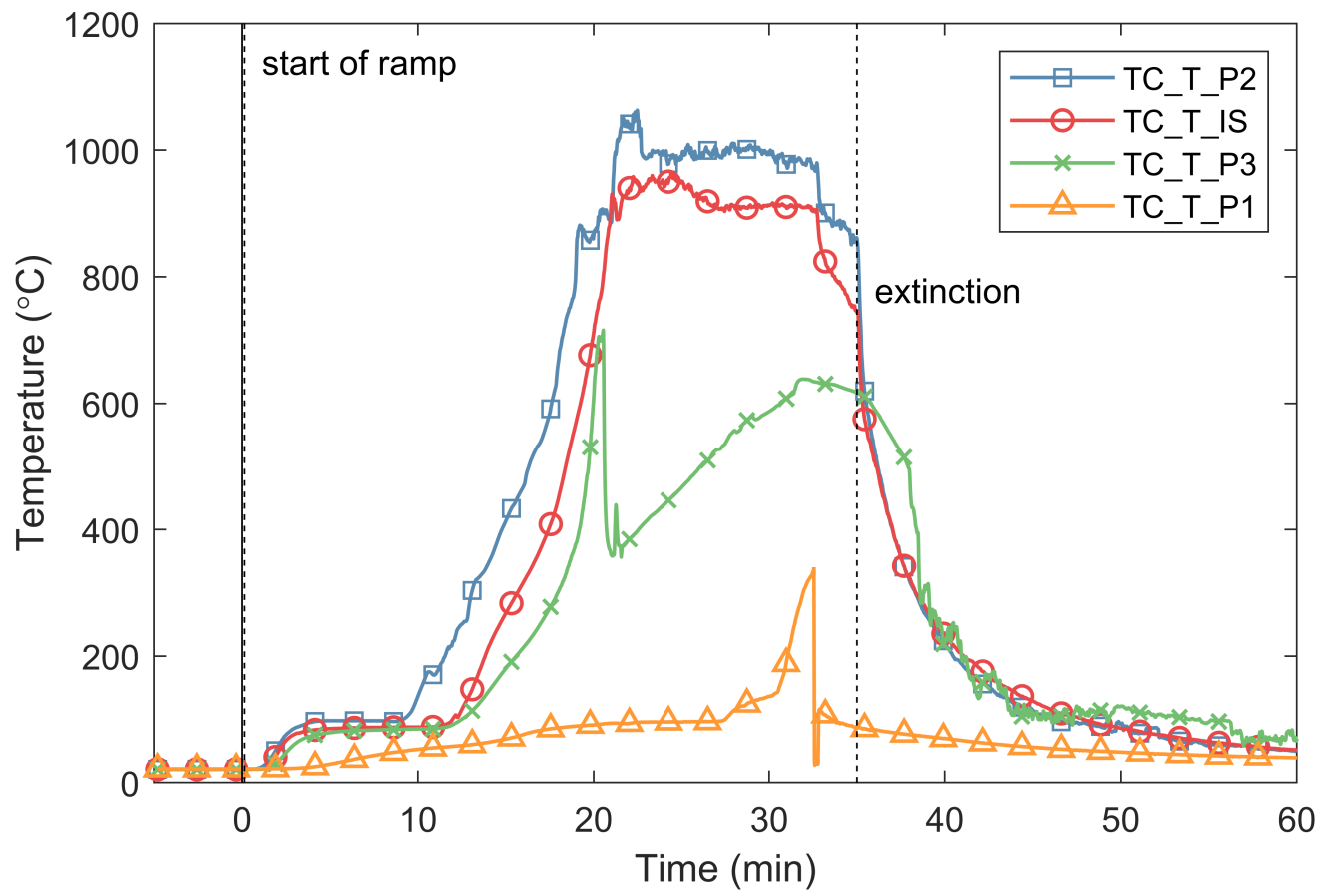

Fig. 352. S02 - Temperatures through the specimen at an interior stud $46 \mathrm{~cm}$ from the top of the wall.

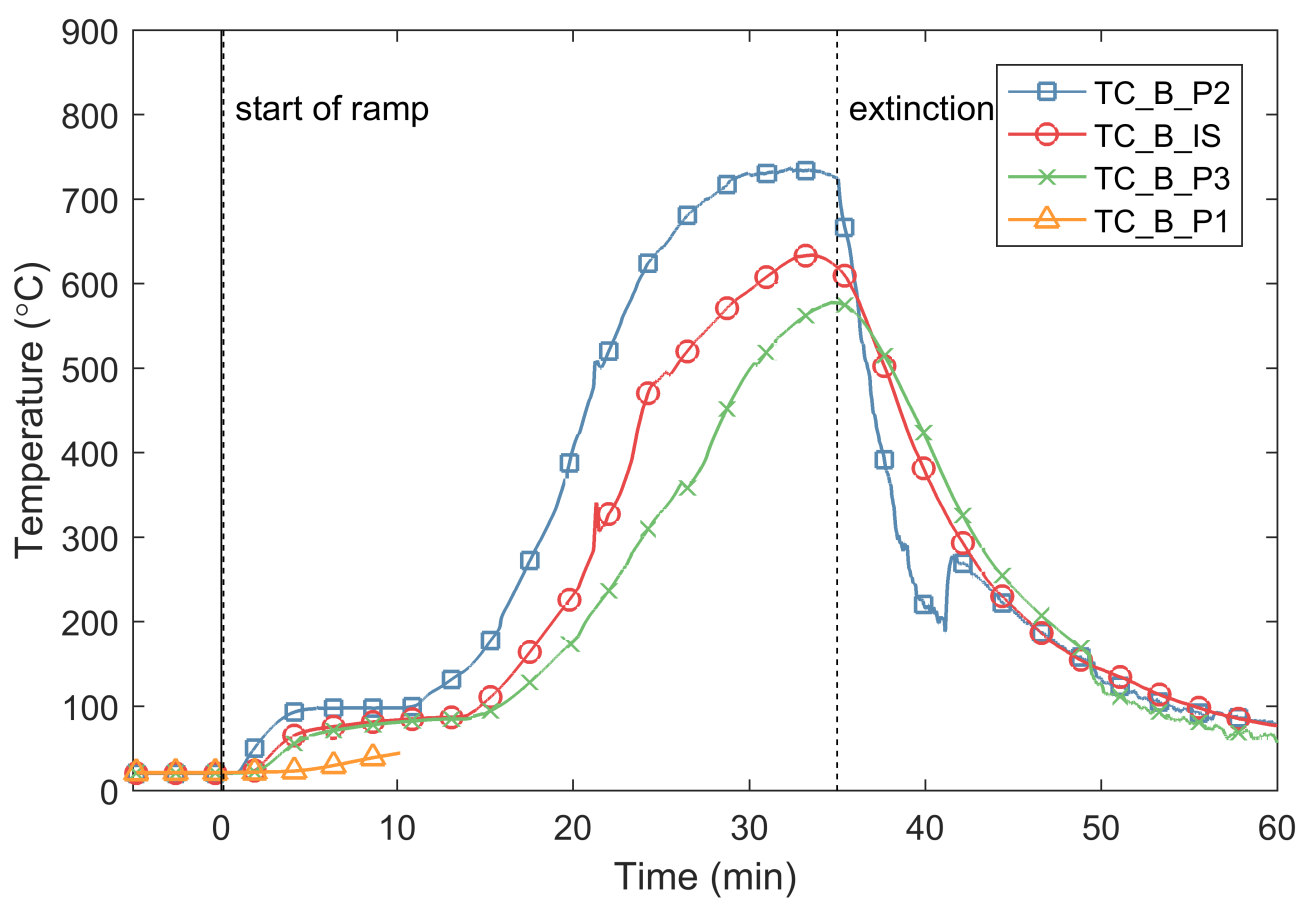

Fig. 353. S02 - Temperatures through the specimen at an interior stud $46 \mathrm{~cm}$ from the bottom of the wall. 

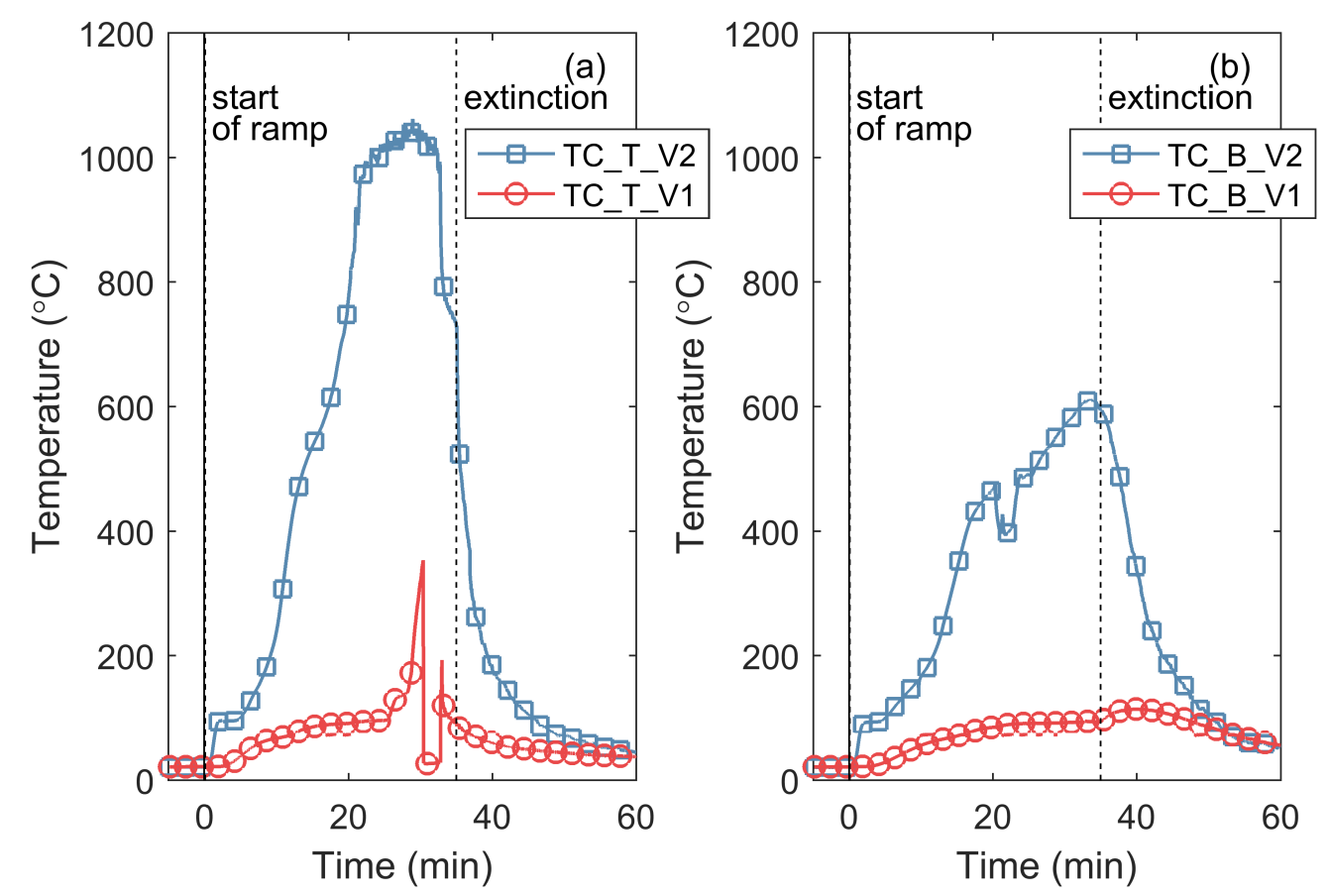

Fig. 354. S02 - Temperatures through the specimen midway between interior studs: (a) $46 \mathrm{~cm}$ from the top of the wall; (b) $46 \mathrm{~cm}$ from the bottom of the wall.
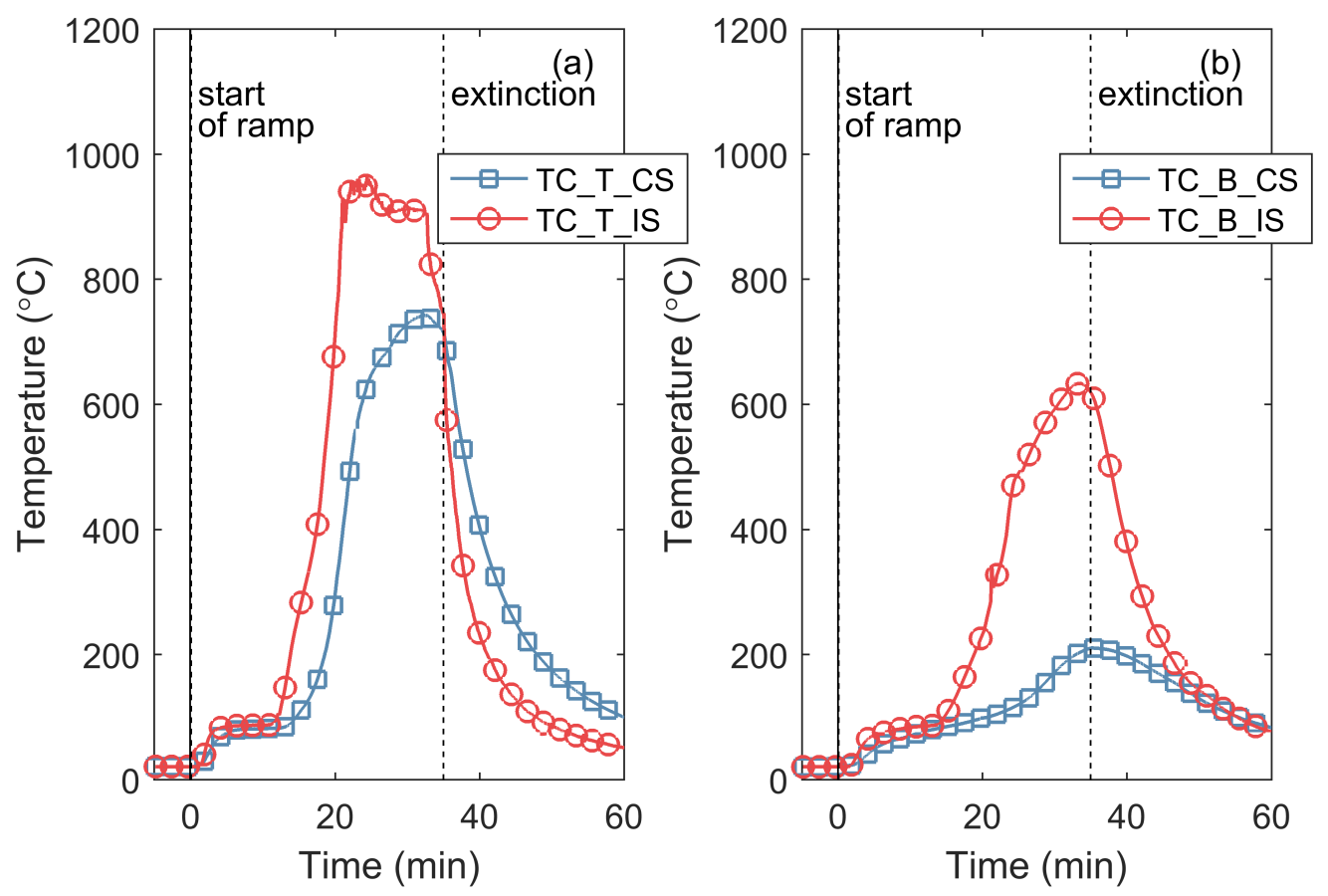

Fig. 355. S02 - Temperatures of the framing elements: (a) $46 \mathrm{~cm}$ from the top of the wall; (b) $46 \mathrm{~cm}$ from the bottom of the wall. 


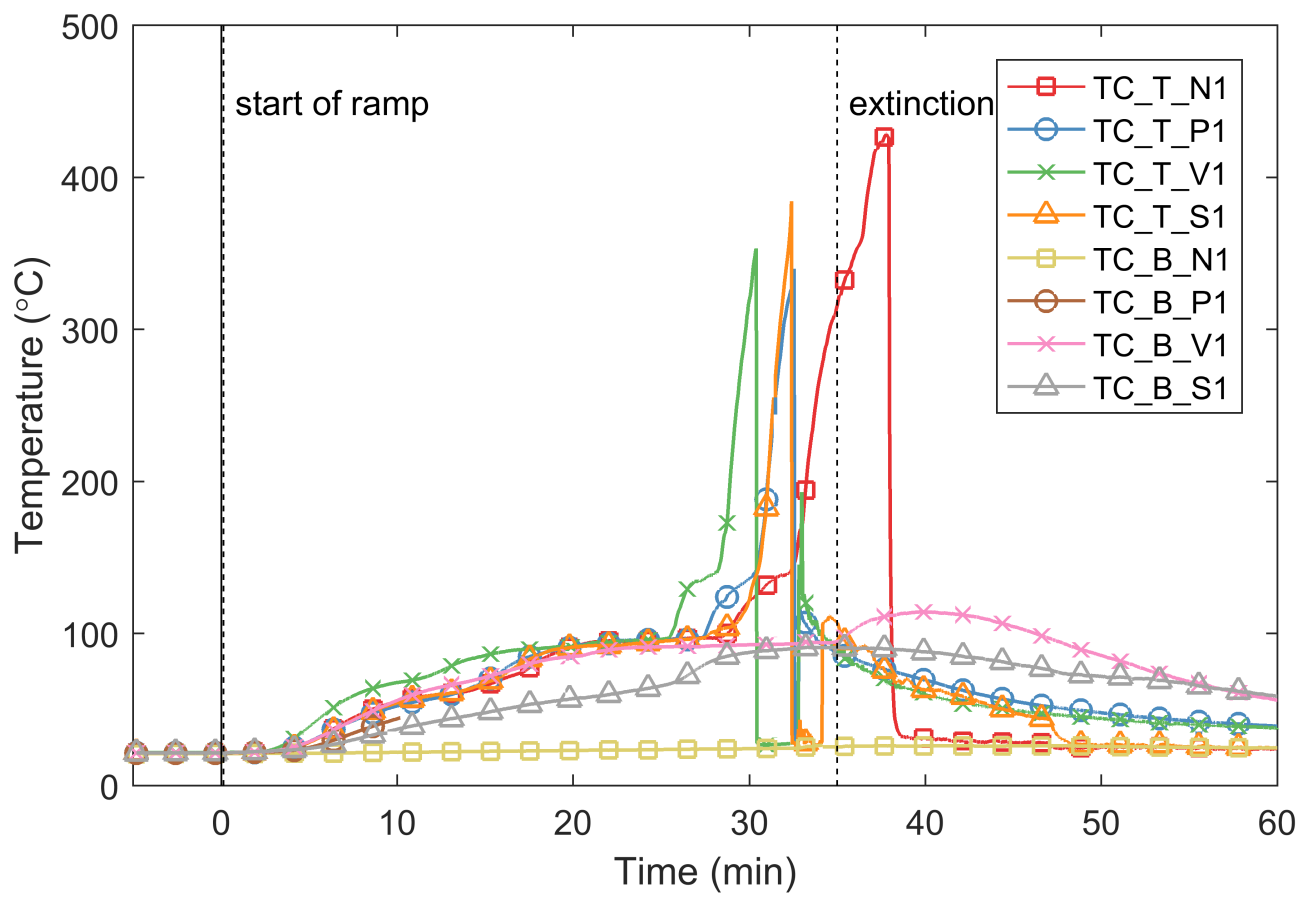

Fig. 356. S02 - Temperature of the gypsum on the unexposed side of the wall specimen.

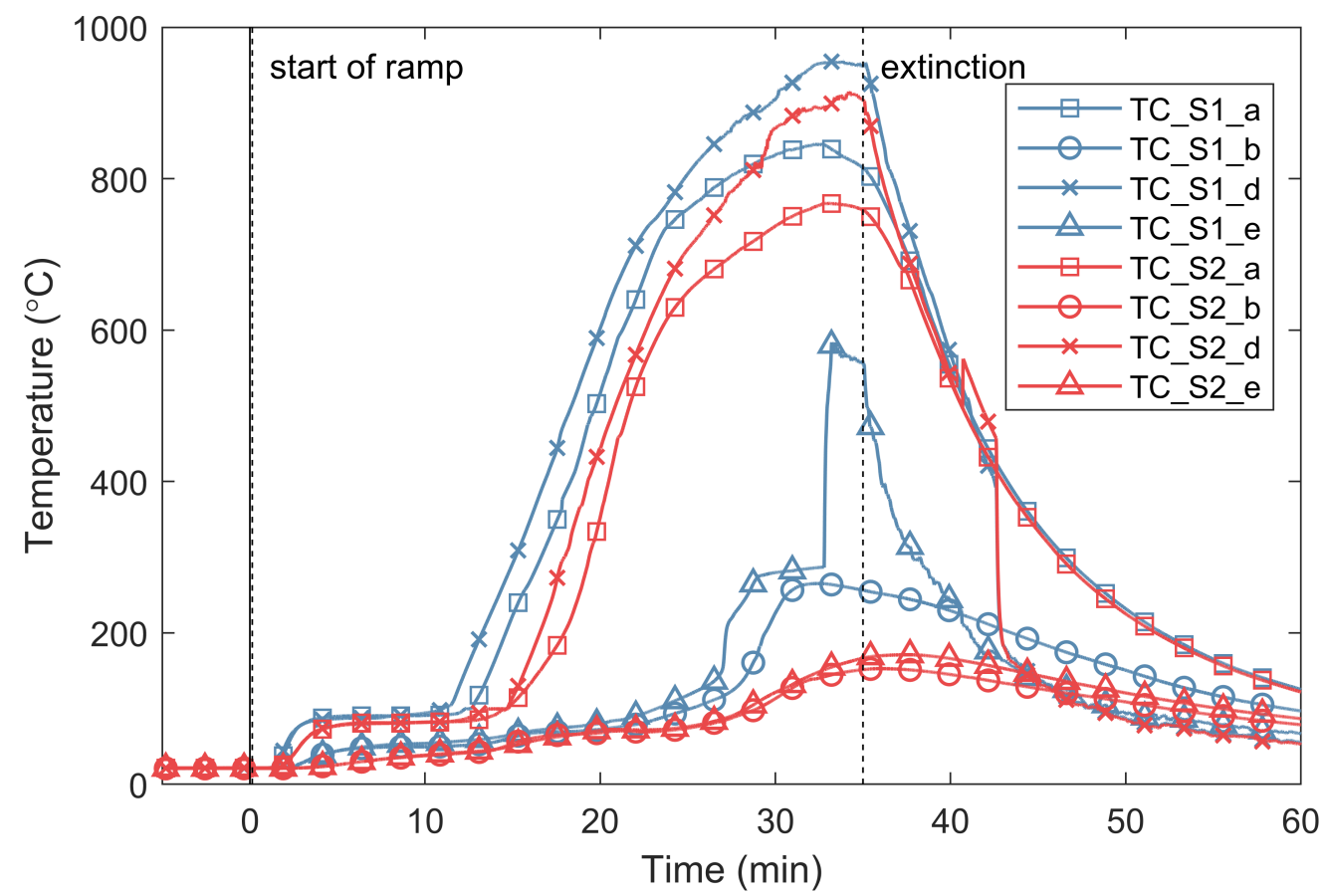

Fig. 357. S02 - Temperature of the connection between gusset plates and strap braces. 


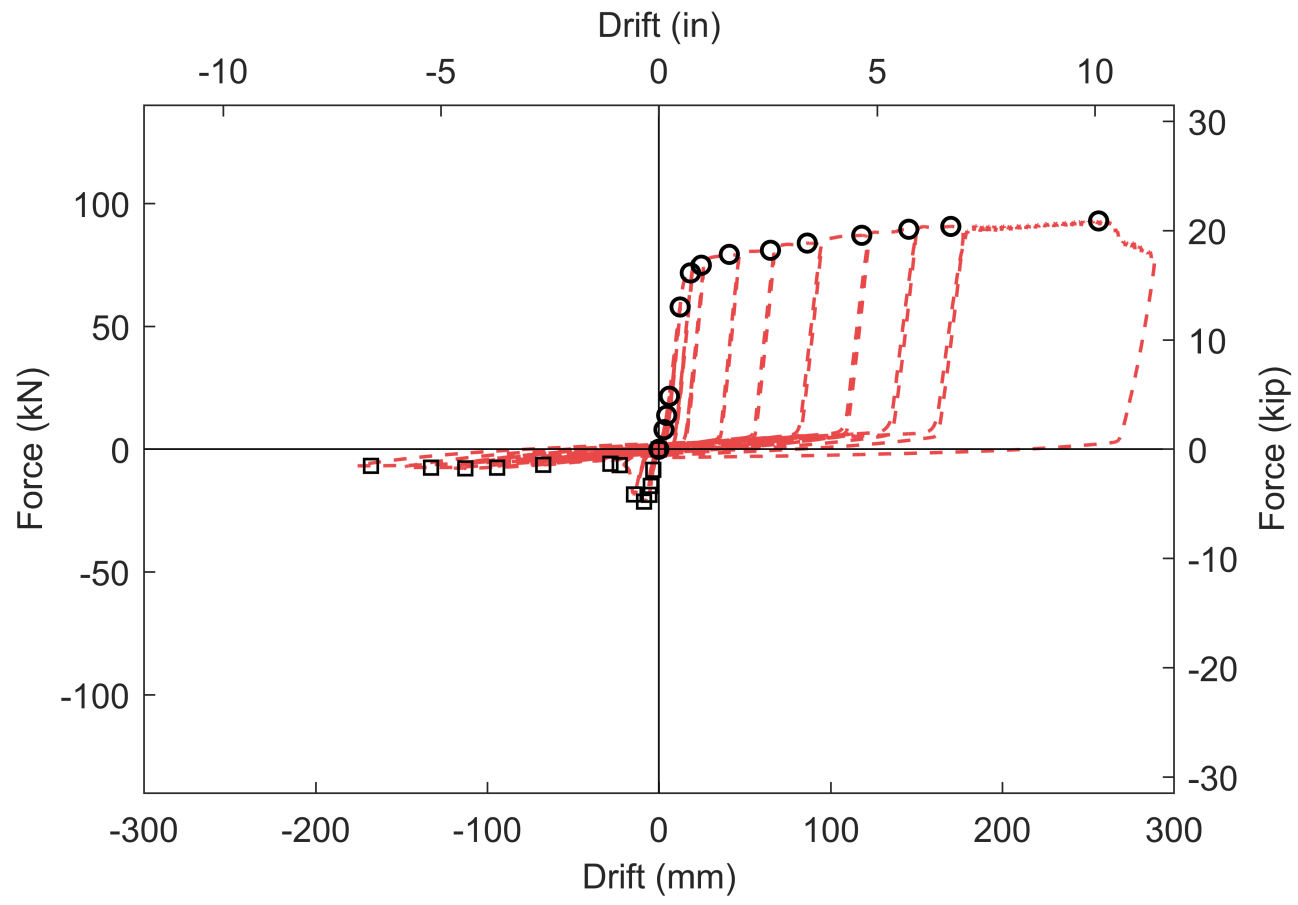

Fig. 358. S02 - Applied load versus wall longitudinal drift during mechanical loading.

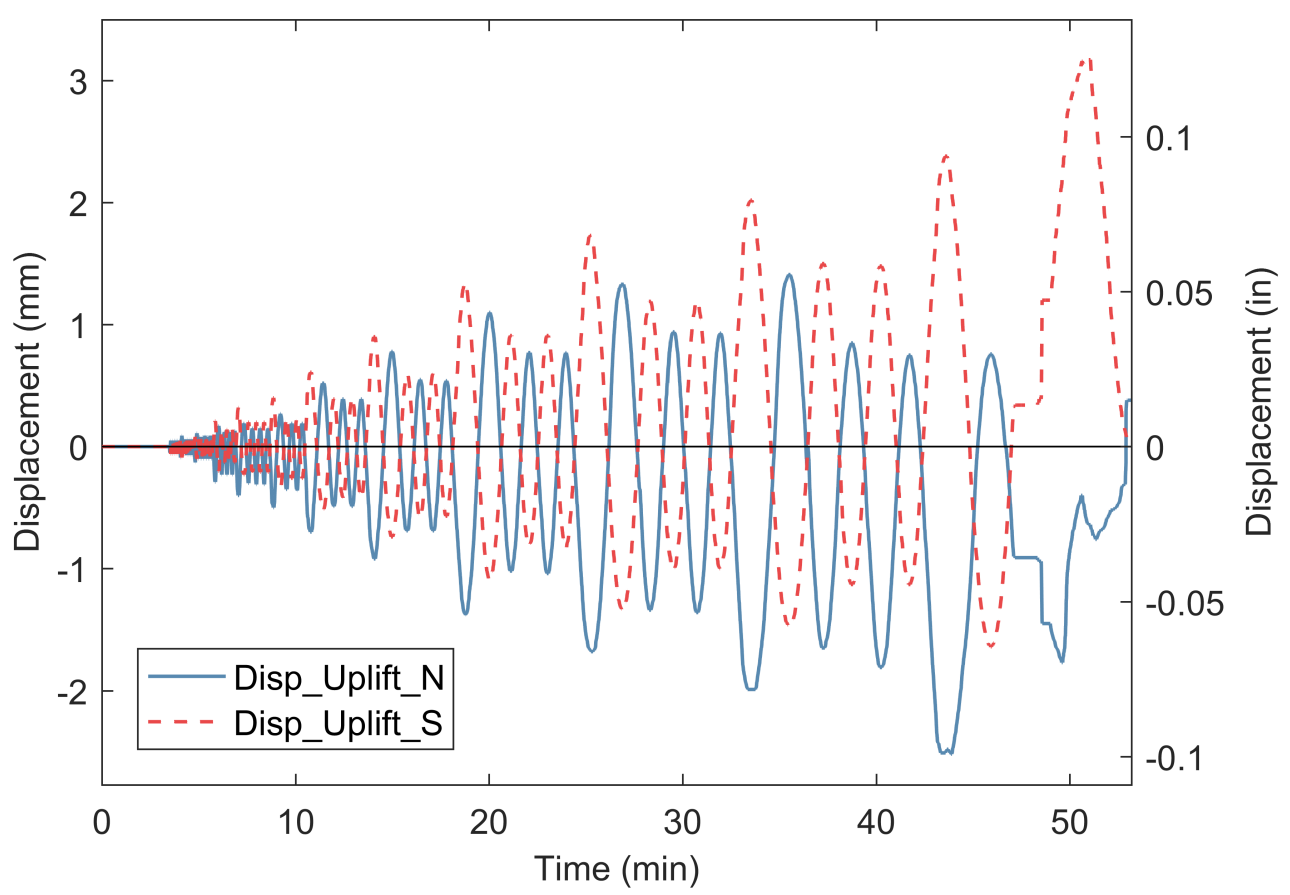

Fig. 359. S02 - Uplift at bottom of wall during mechanical loading. 


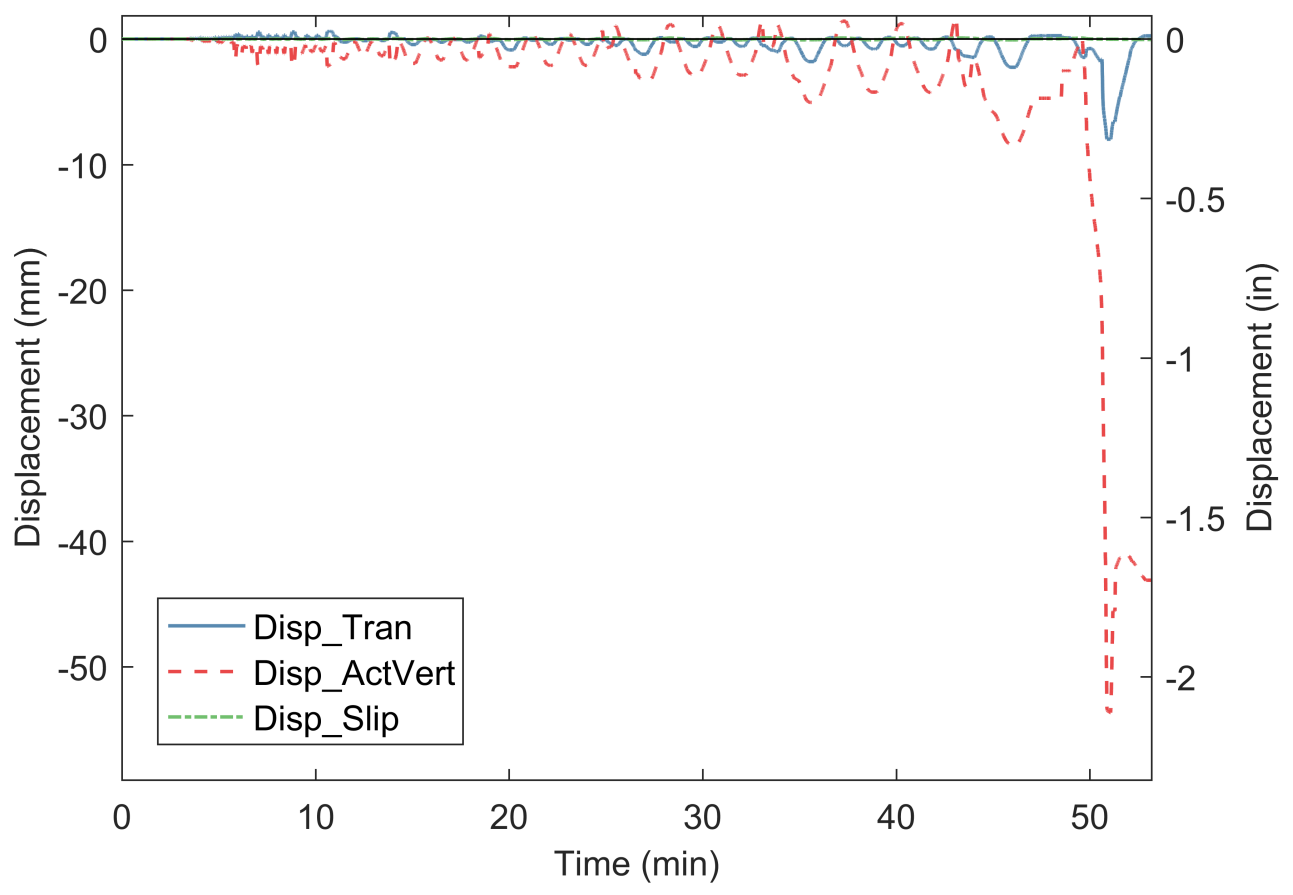

Fig. 360. S02 - Ancillary displacement measurements during mechanical loading.

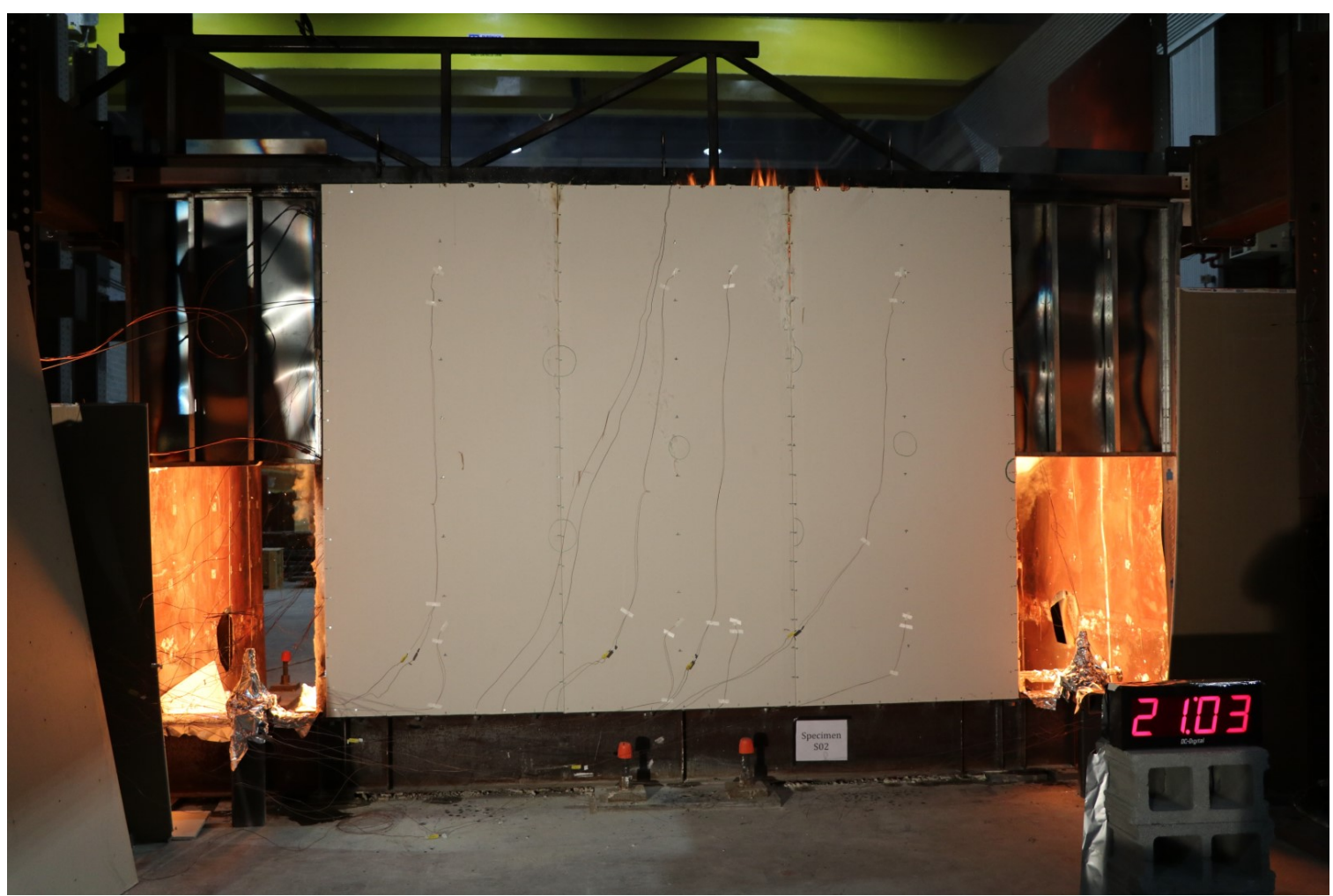

Fig. 361. S02 - Photograph of unexposed side of wall $21 \mathrm{~min} 3 \mathrm{~s}$ after ignition. 


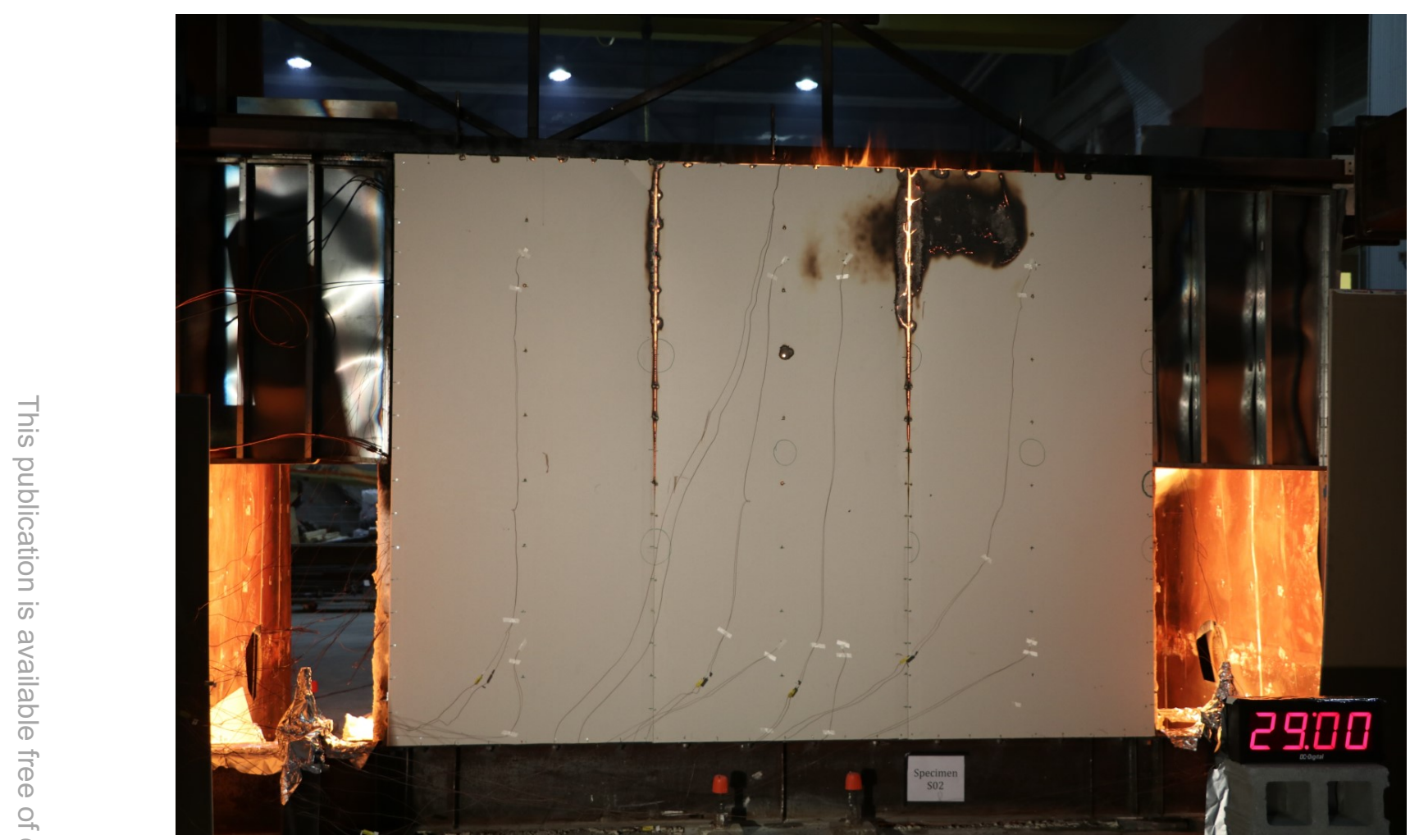

Fig. 362. S02 - Photograph of unexposed side of wall 29 min $0 \mathrm{~s}$.

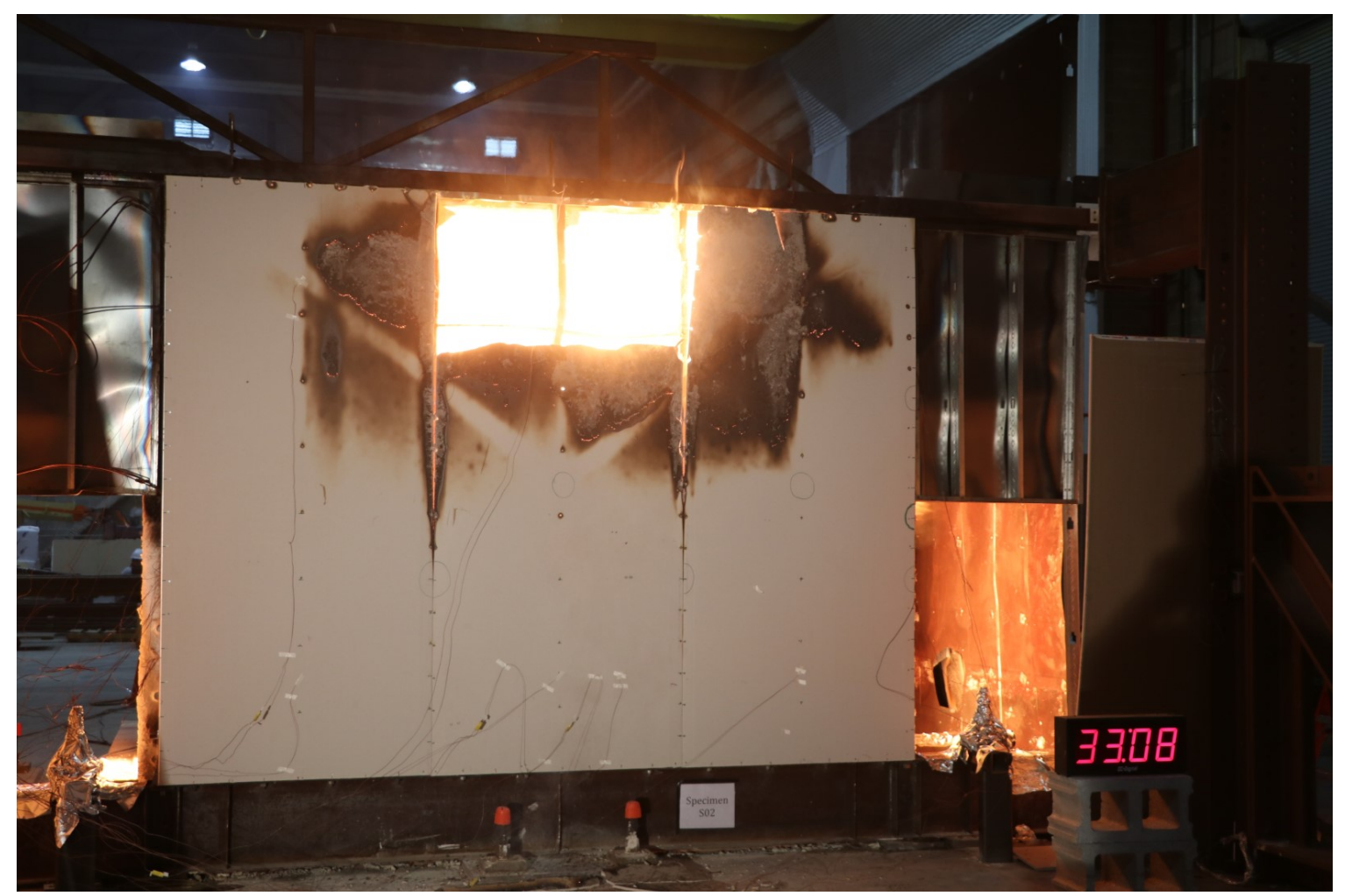

Fig. 363. S02 - Photograph of unexposed side of wall 33 min 8 s after ignition. 


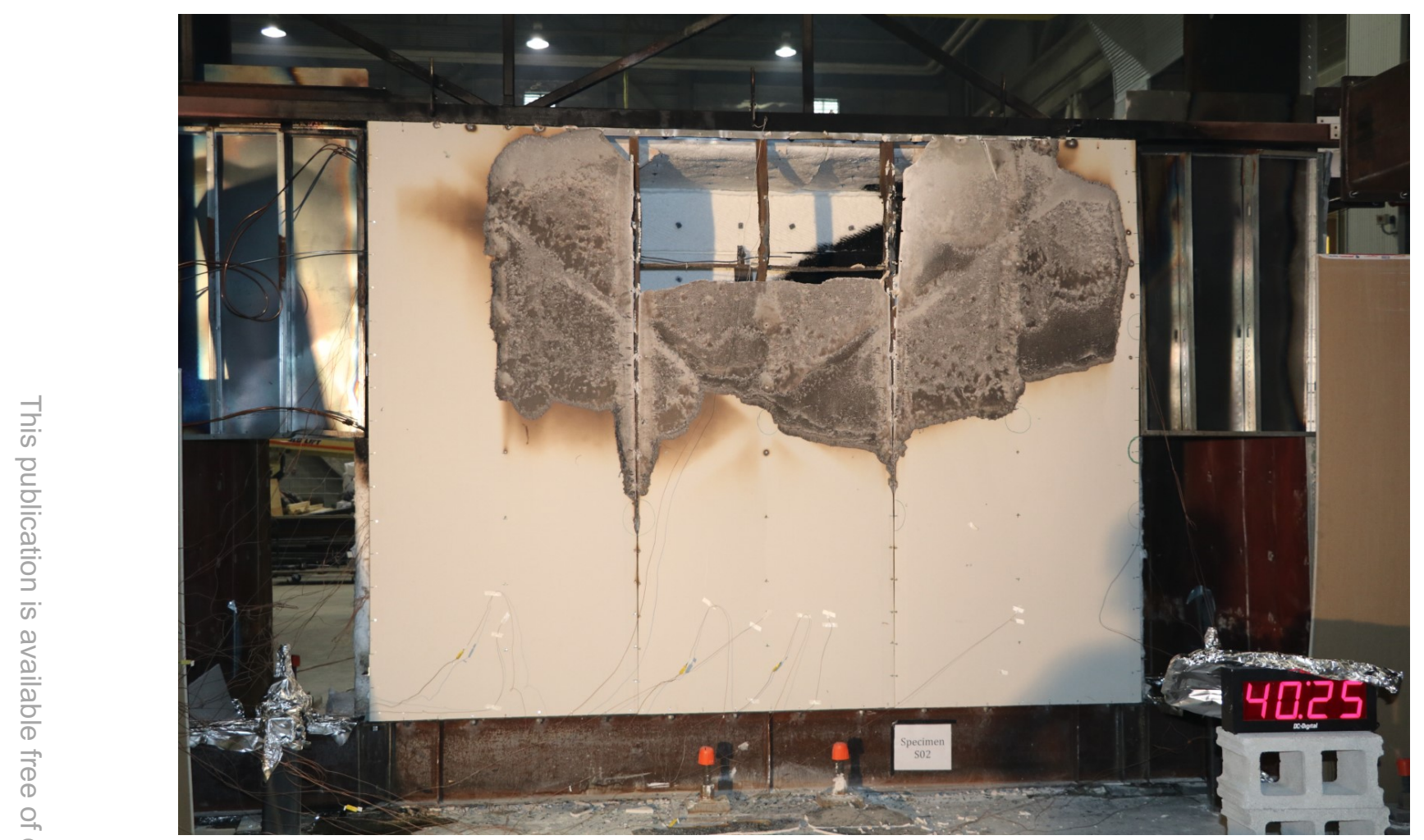

Fig. 364. S02 - Photograph of unexposed side of the wall after the fire test.

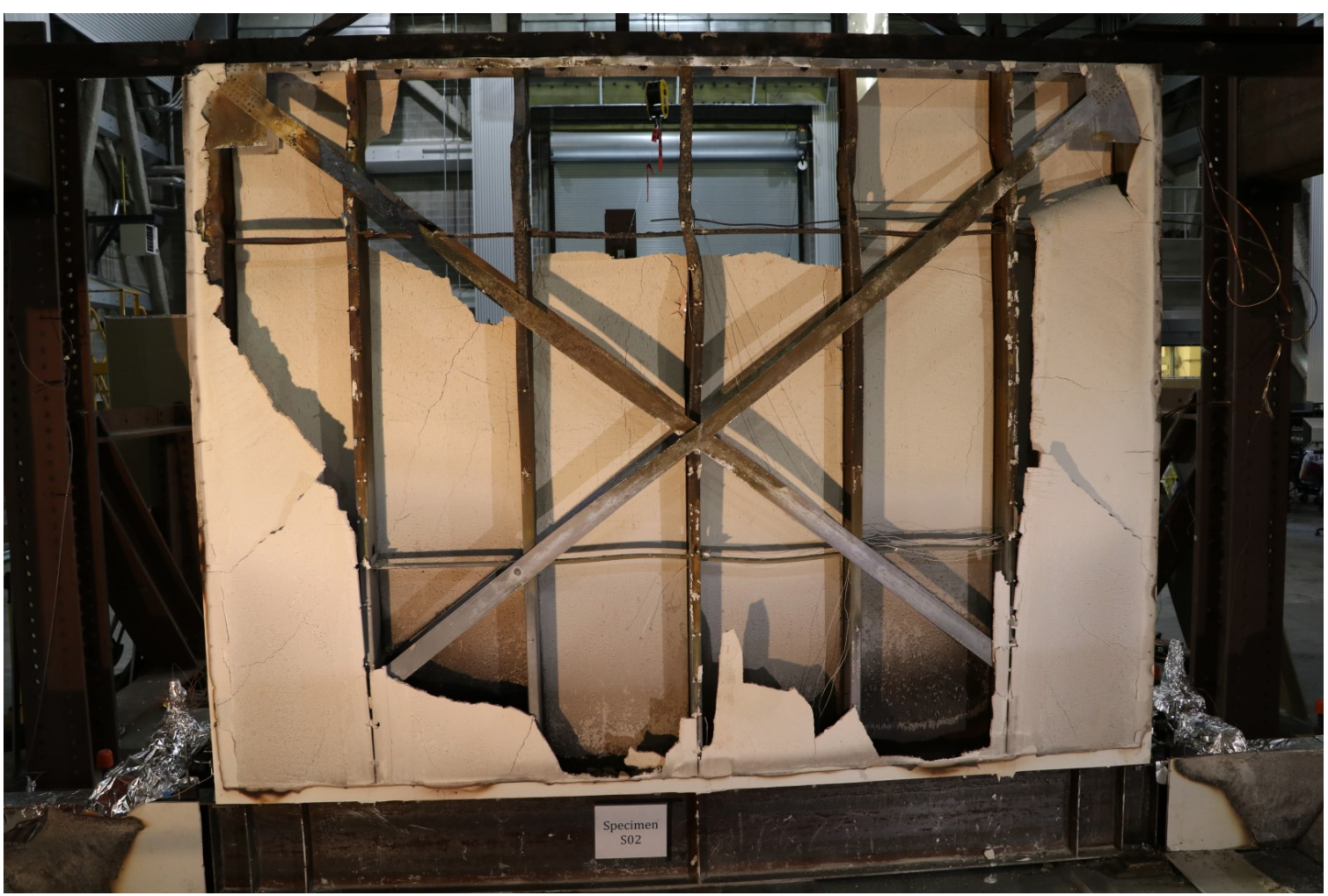

Fig. 365. S02 - Photograph of fire exposed side of wall after the fire test (before cycling). 


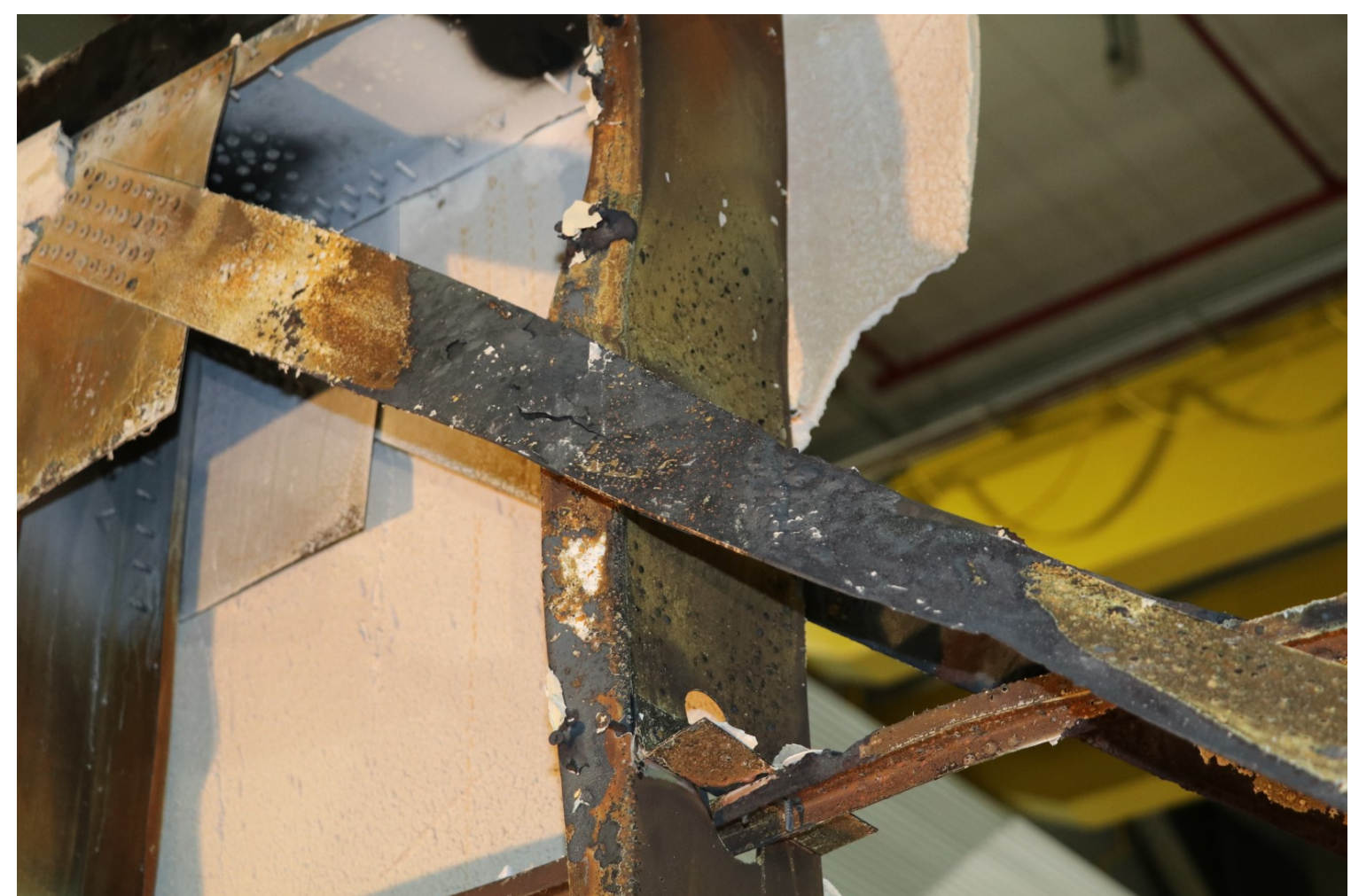

Fig. 366. S02 - Photograph of damage (oxidation) to straps at south top end (before cycling).

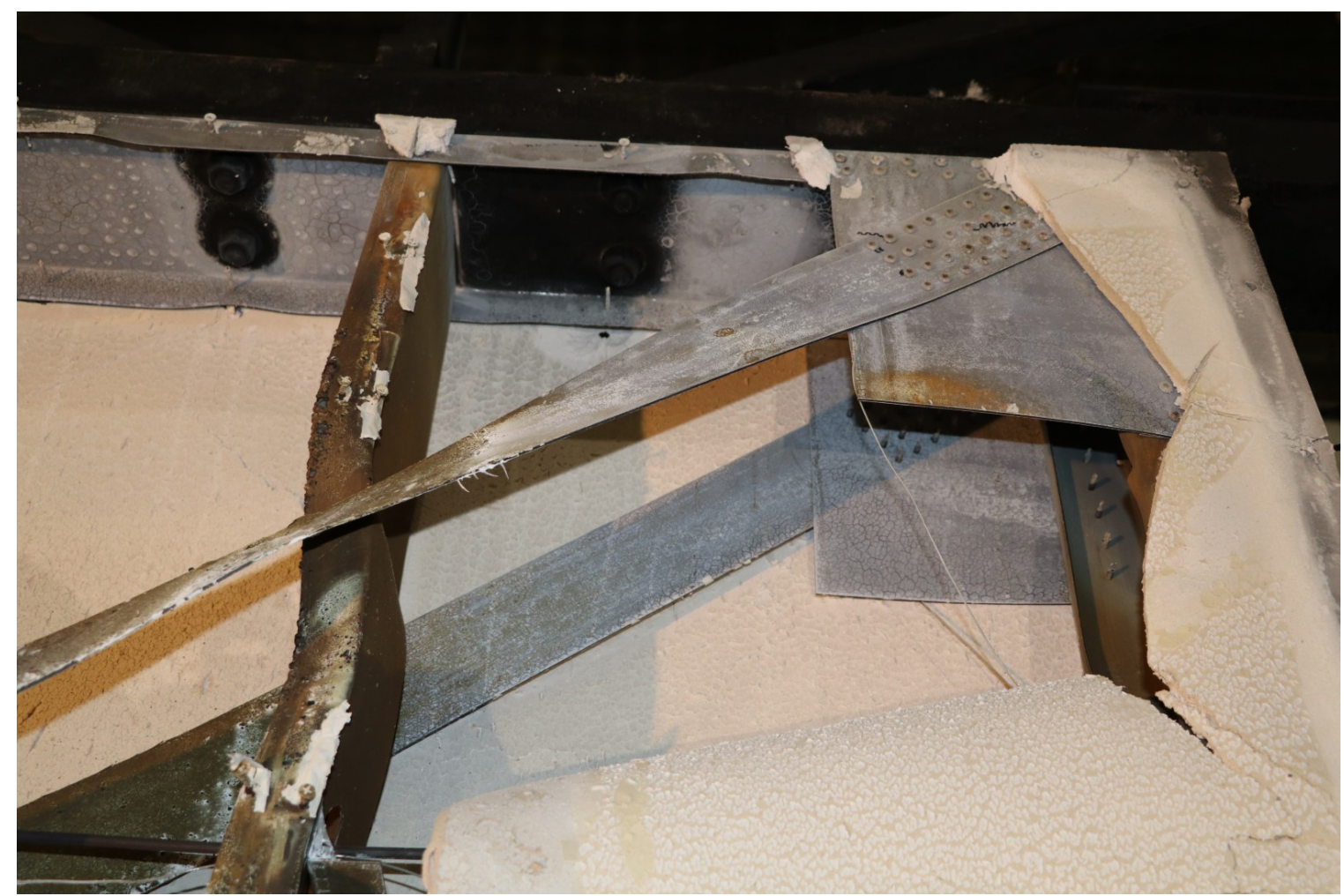

Fig. 367. S02 - Photograph of straps at north top end (before cycling). 


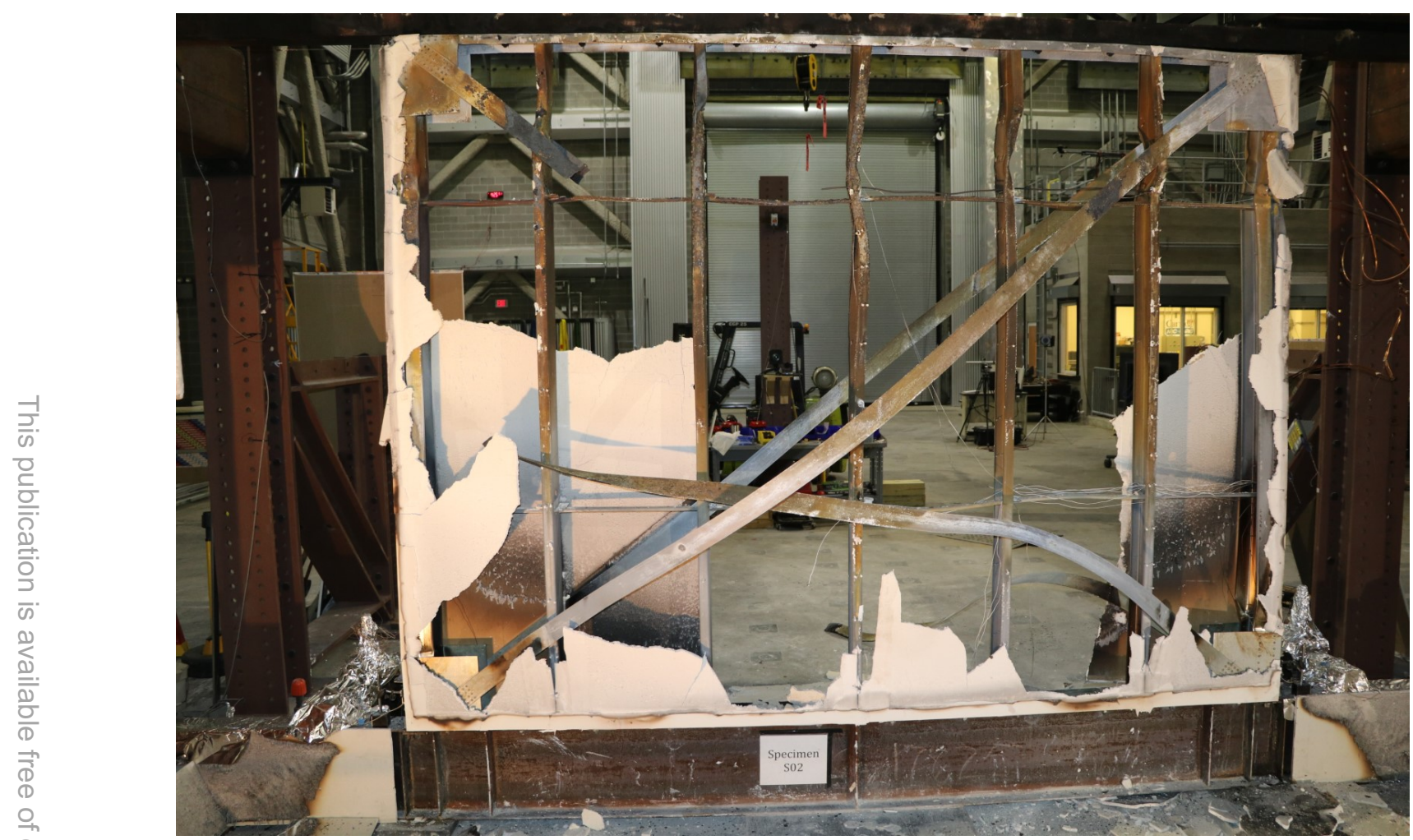

Fig. 368. S02 - Photograph of wall from east (fire exposed) side after failure of the straps.

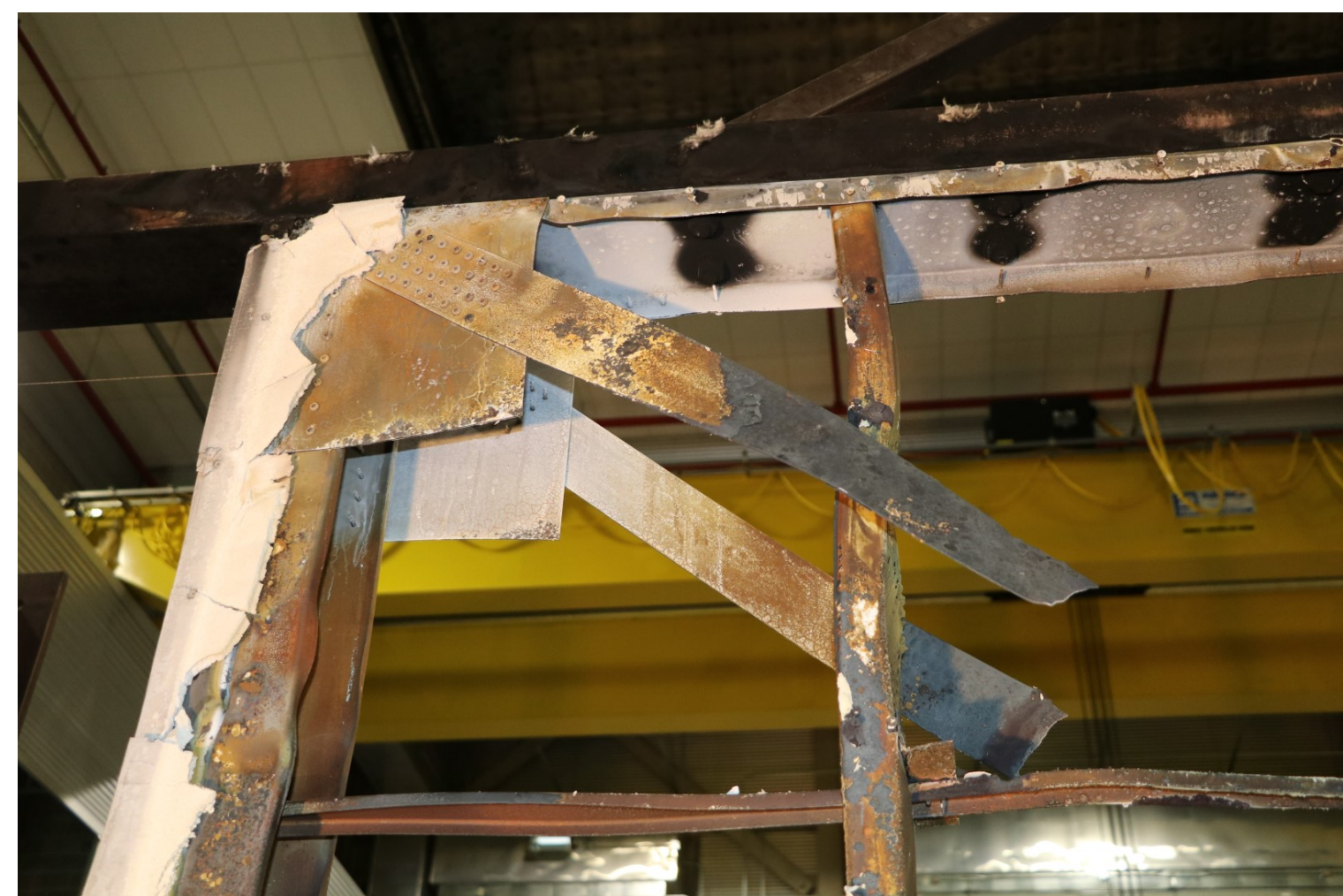

Fig. 369. S02 - Photograph of wall from east (fire exposed) side after load cycling following the fire. 


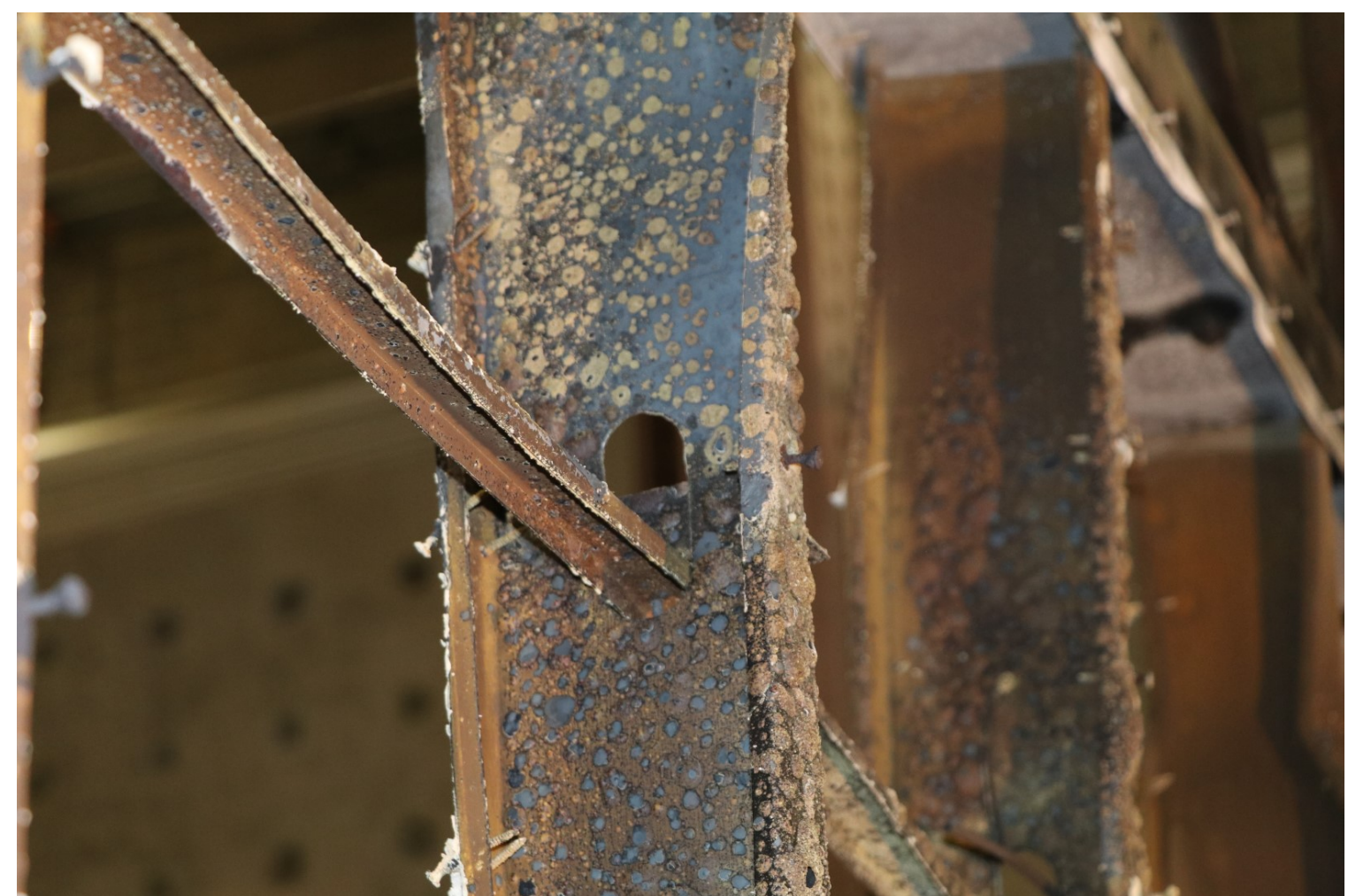

Fig. 370. S02 - Photograph of fire damage to the interior studs after load cycling following the fire. 


\section{S03 Data}

S03b (Mild Fire test of an undamaged wall)

- Strong asymmetry on the temperatures inside the compartment (Fig. 372) of up to $300{ }^{\circ} \mathrm{C}$ from the north to the south thermocouple arrays.

- The heat release rate in the burner was kept to $1.7 \mathrm{MW}$ for $15 \mathrm{~min}$. After extinction of the burner, the exposed side gypsum started cracking (Fig. 385).

S03c (Cyclic test of wall at ambient temperature following the Mild Fire)

- Failure sequence: local buckling of south chord stud, strap rupture at north east top, strap rupture at south west bottom, strap rupture at south-west top.

- Gypsum appears to add about $15 \mathrm{kN}$ per side. Mix of screw shear (heard fractures near peak load) and pull-through through the gypsum, top track was nearly all screw fracture.

- Similar behavior to S01R, but minus one layer of gypsum due to the fire (exposed side).

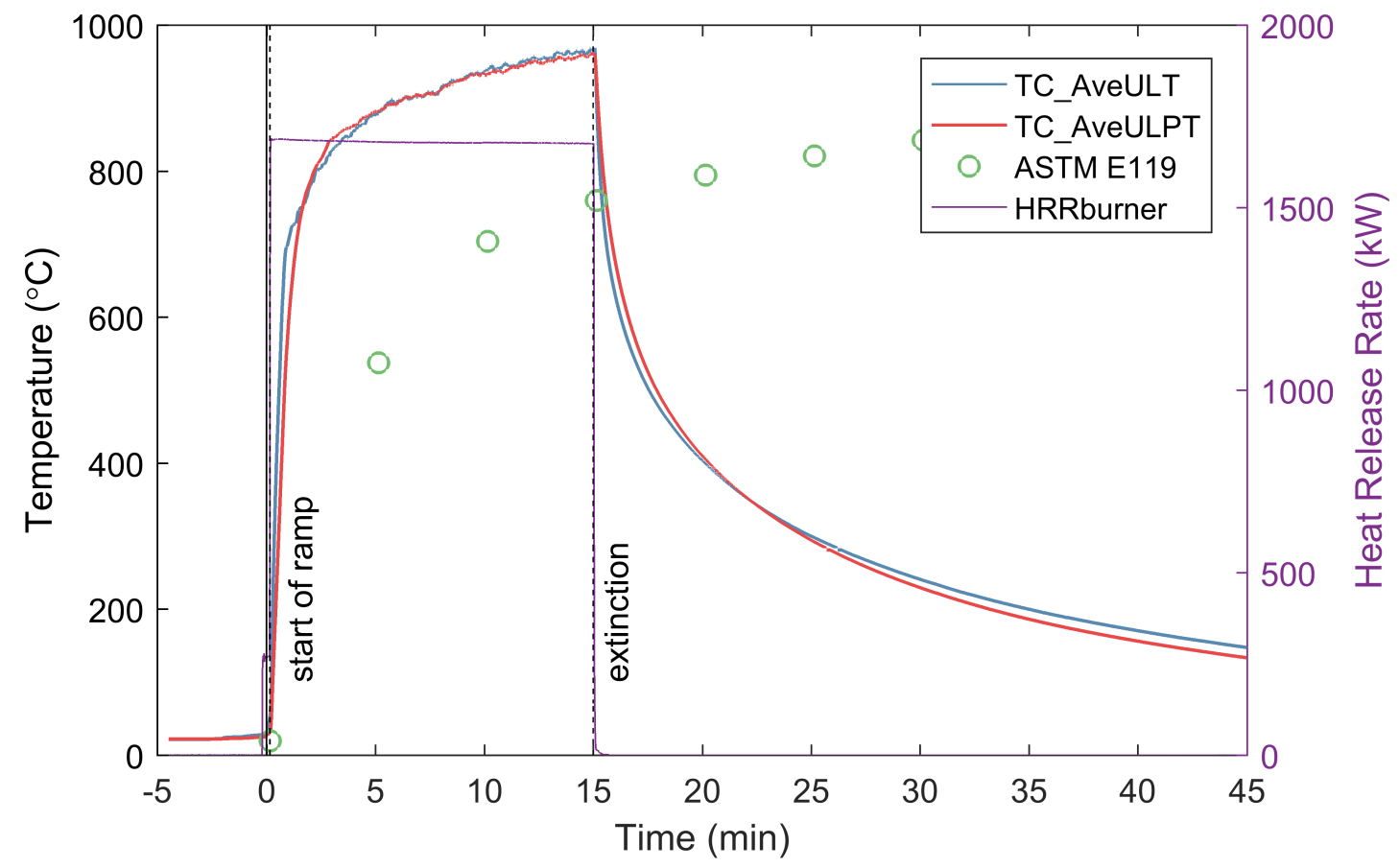

Fig. 371. S03 - Compartment temperatures and burner Heat Release Rate. 


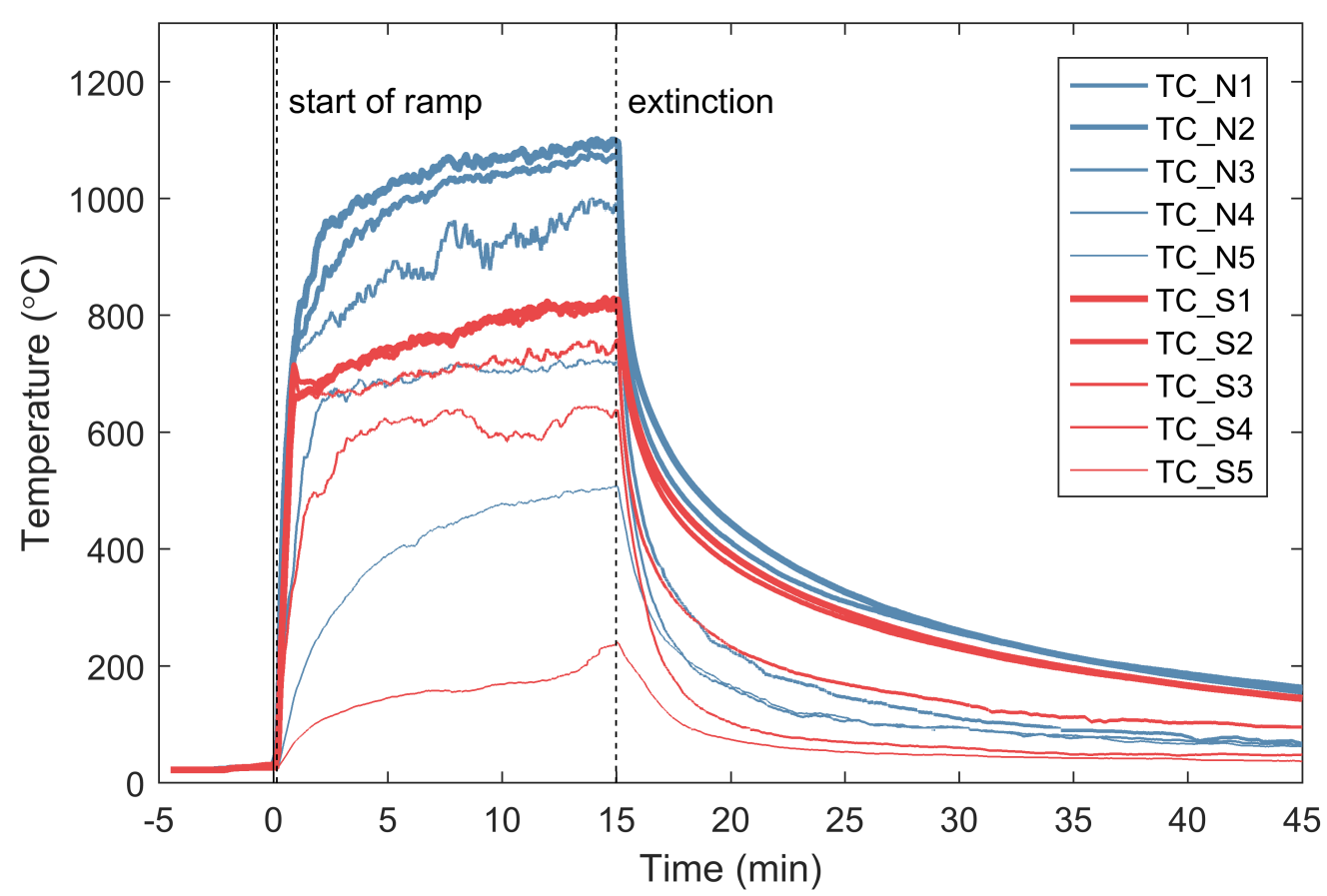

Fig. 372. S03 - Compartment temperatures measured by the thermocouple arrays.

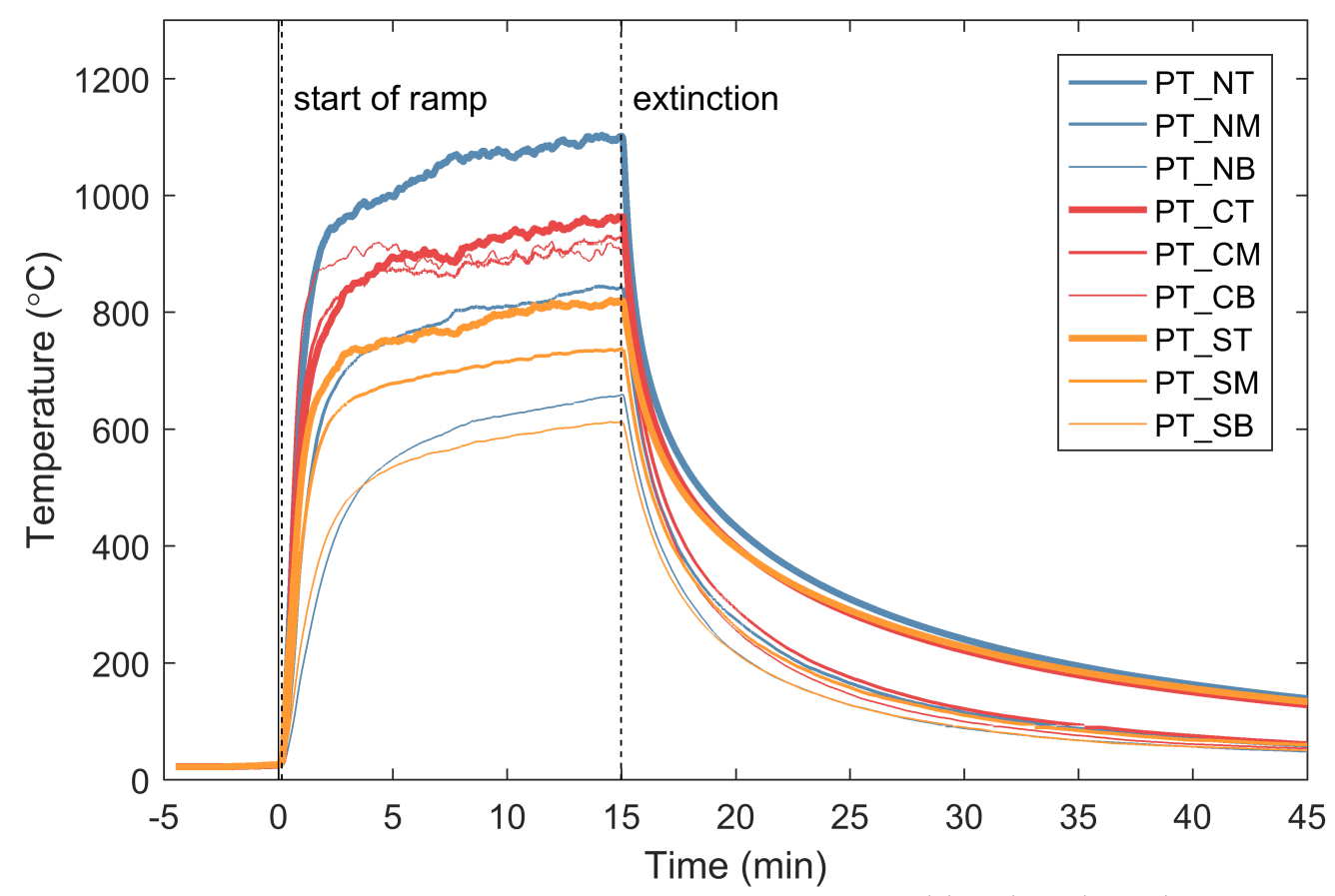

Fig. 373. S03 - Compartment temperatures measured by the plate thermocouples. 


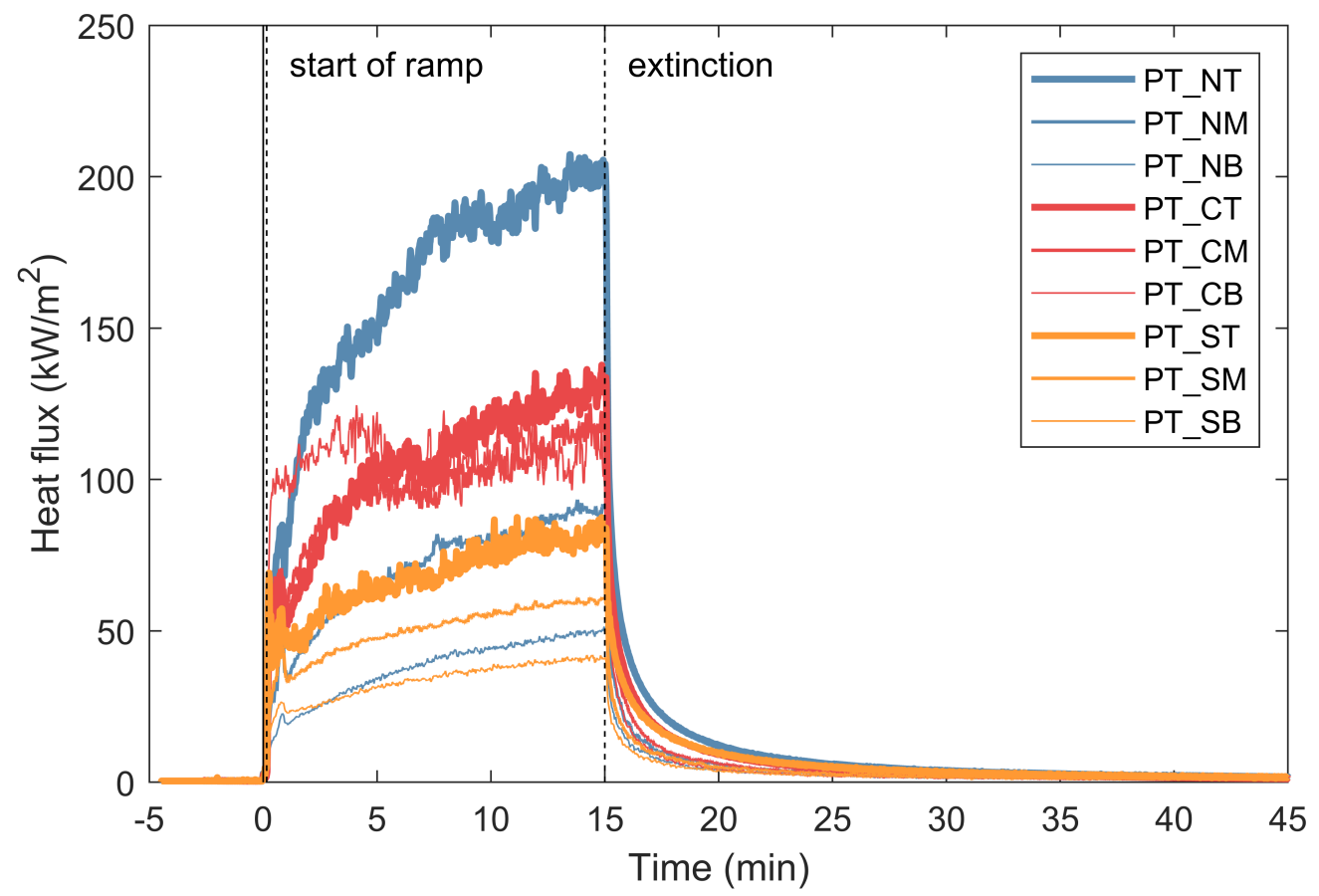

Fig. 374. S03 - Heat fluxes in the compartment measured by the plate thermocouples.
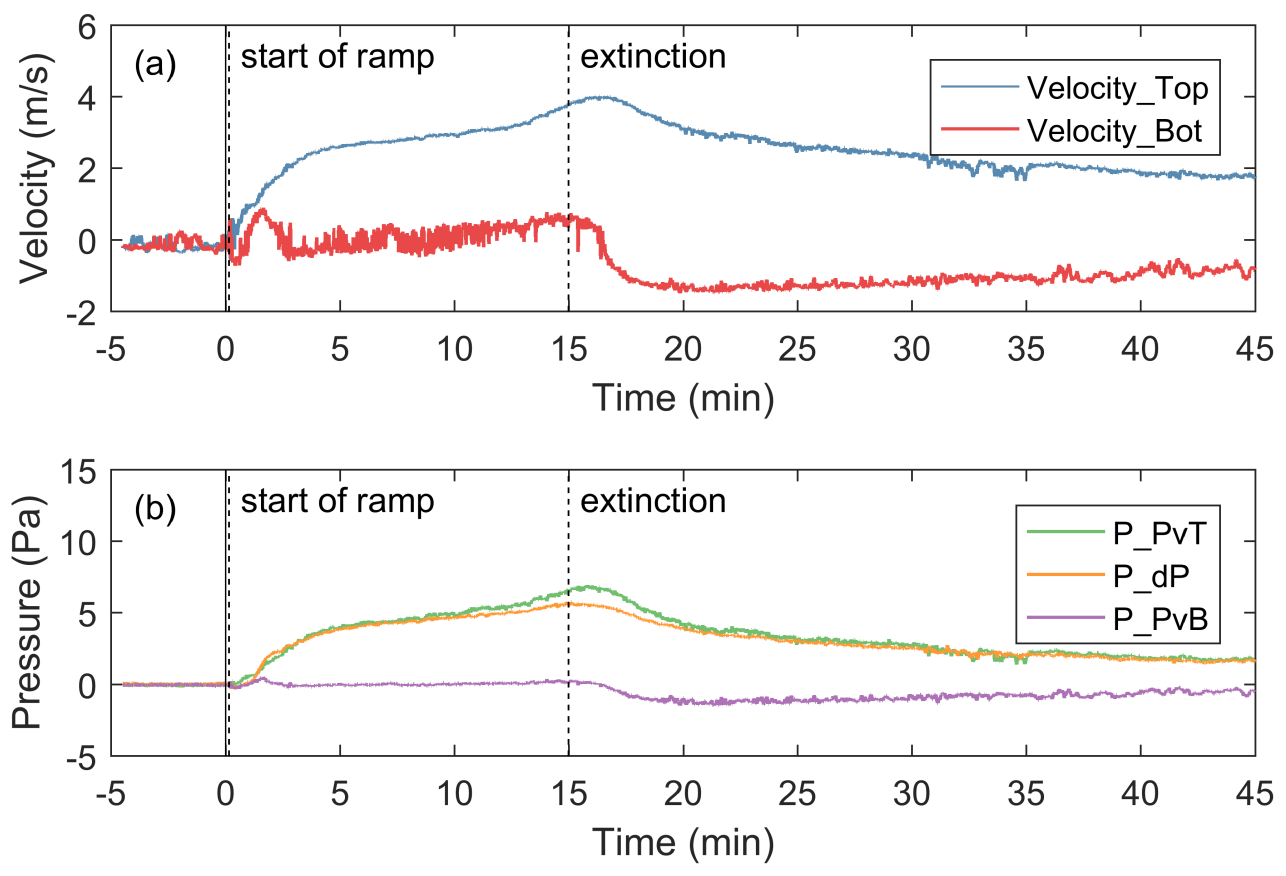

Fig. 375. S03 - (a) Velocity of air flow at the top and bottom knockouts of the chord stud; (b) Pressure at the top and bottom knockouts of the chord stud and in the wall cavity near the top. 


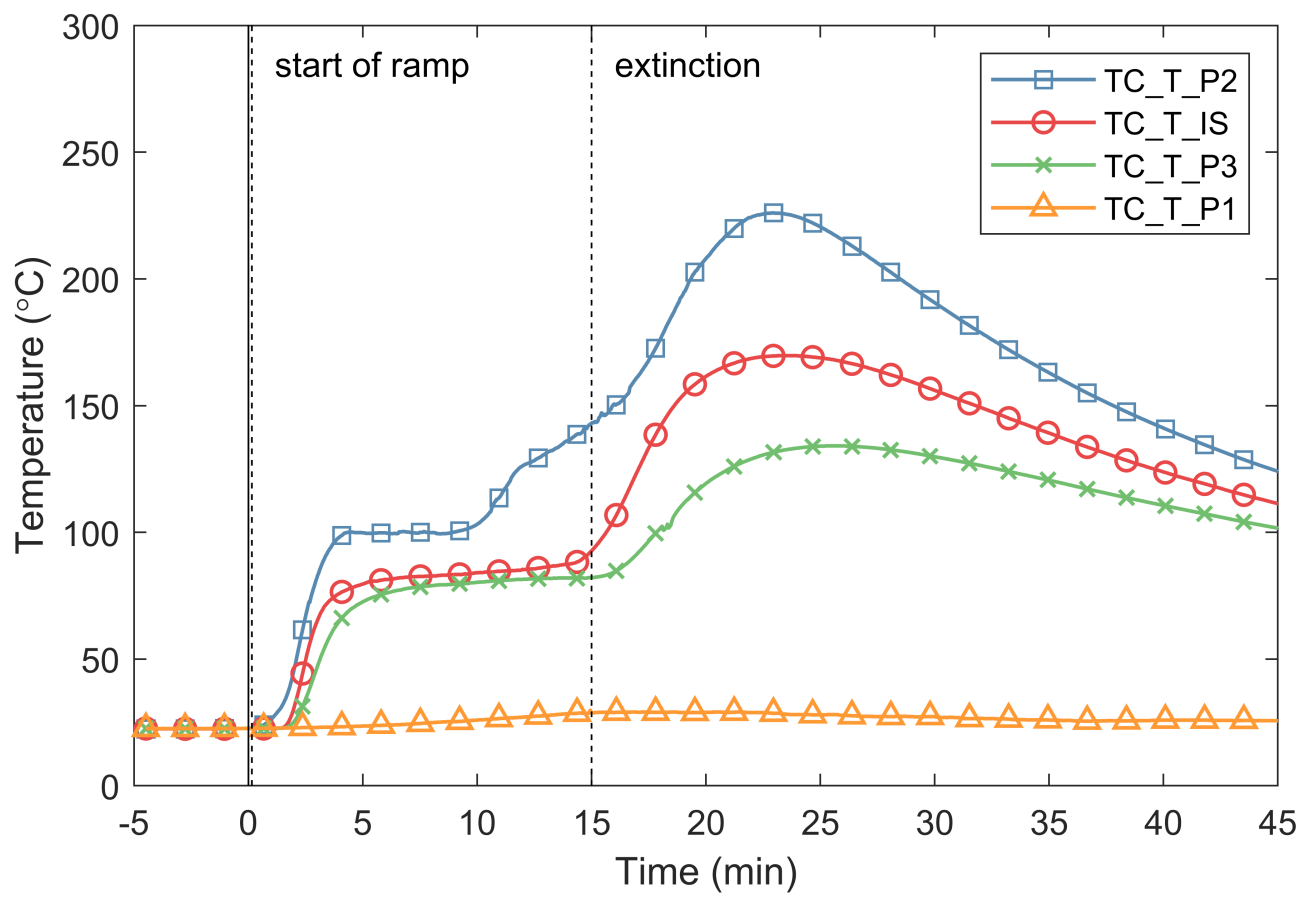

Fig. 376. S03 - Temperatures through the specimen at an interior stud $46 \mathrm{~cm}$ from the top of the wall.

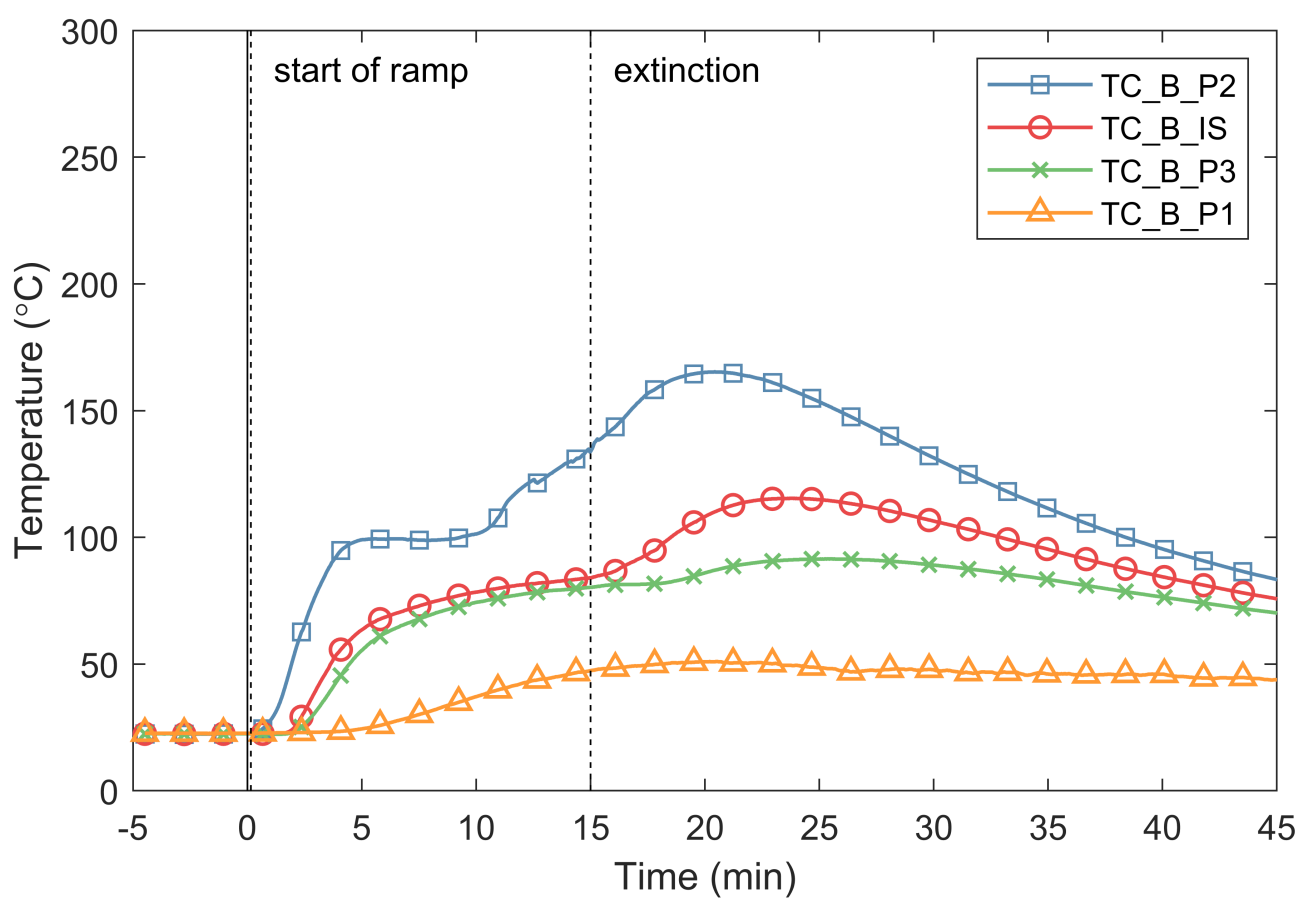

Fig. 377. S03 - Temperatures through the specimen at an interior stud $46 \mathrm{~cm}$ from the bottom of the wall. 


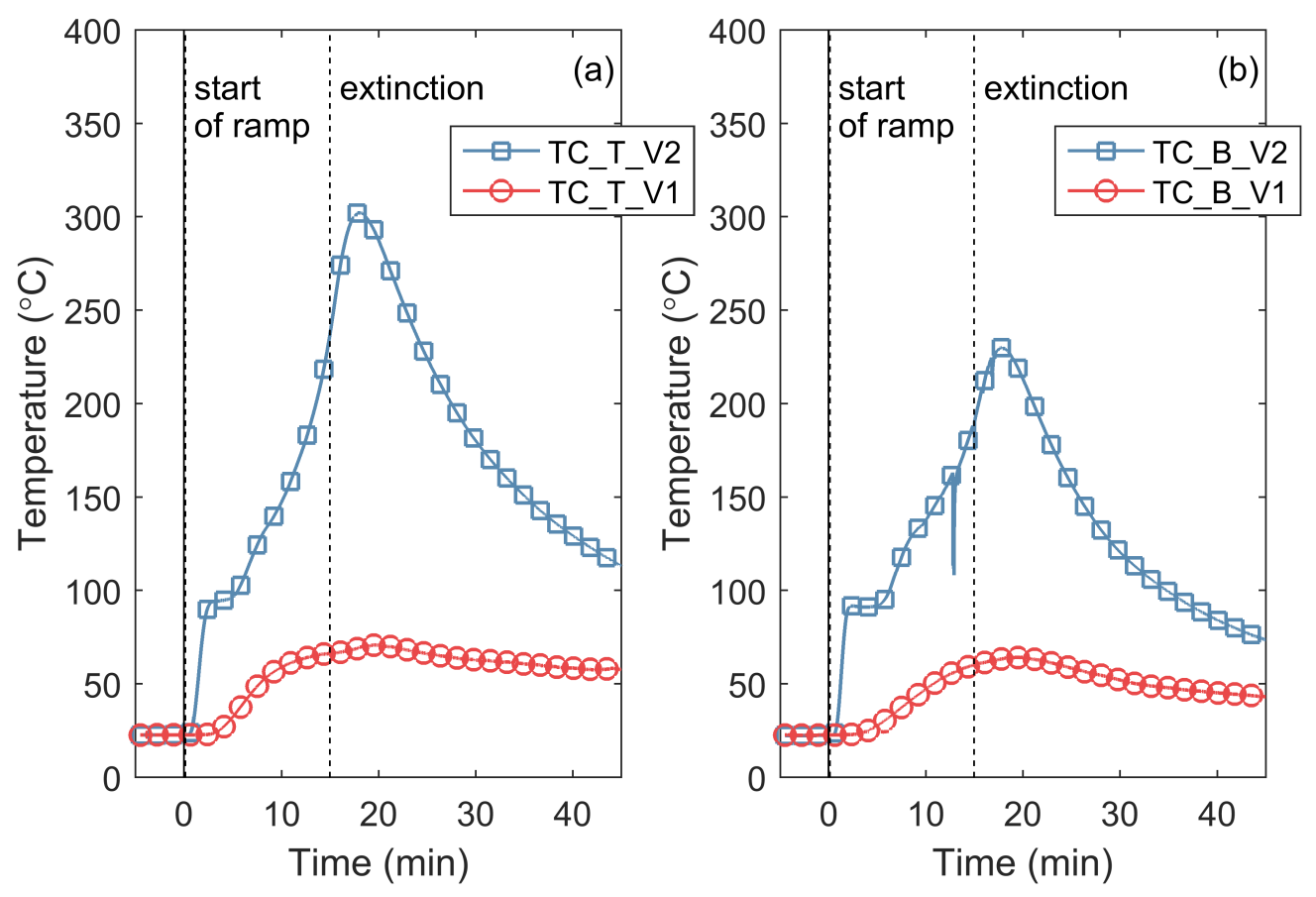

Fig. 378. S03 - Temperatures through the specimen midway between interior studs: (a) $46 \mathrm{~cm}$ from the top of the wall; (b) $46 \mathrm{~cm}$ from the bottom of the wall.
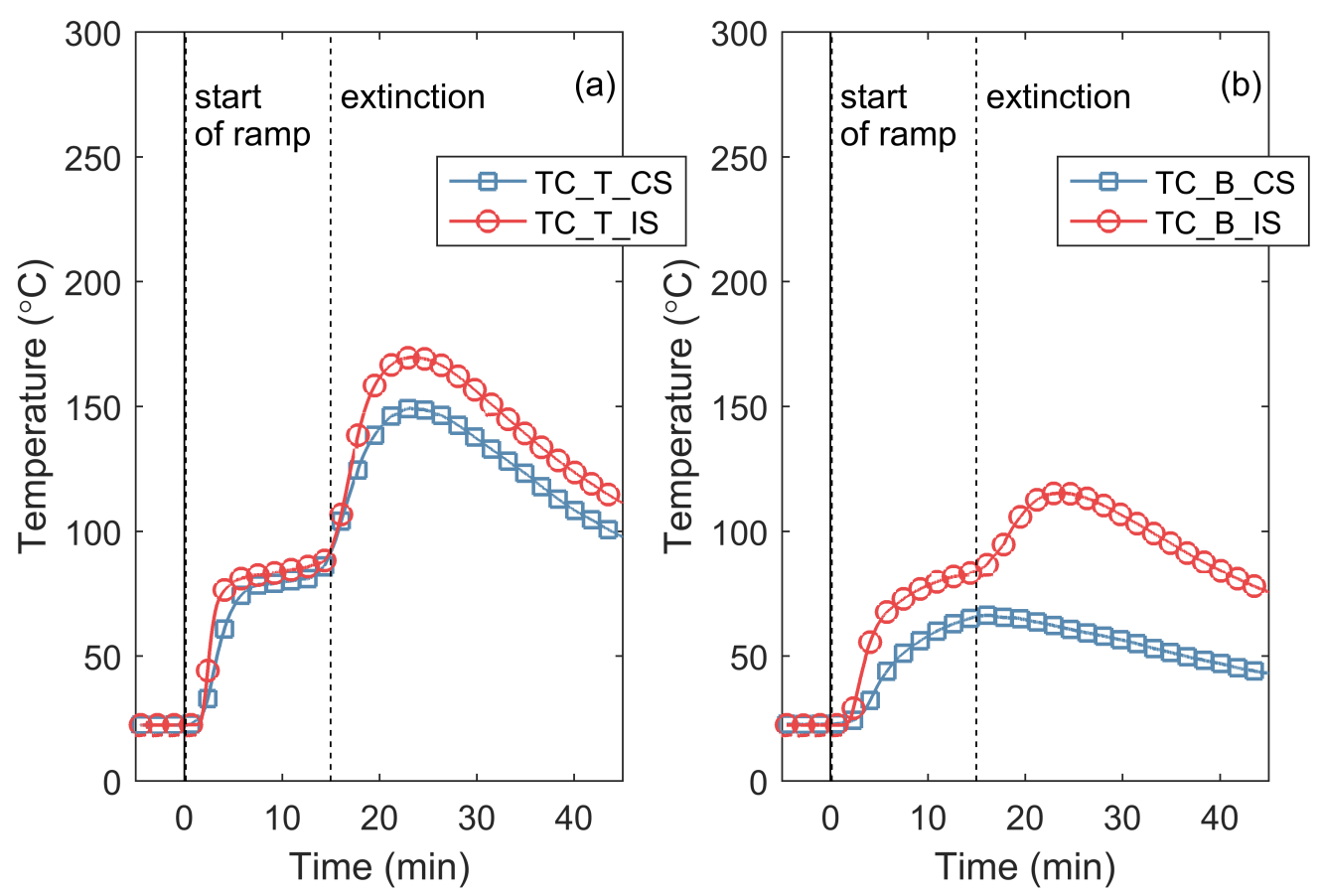

Fig. 379. S03 - Temperatures of the framing elements: (a) $46 \mathrm{~cm}$ from the top of the wall; (b) $46 \mathrm{~cm}$ from the bottom of the wall. 


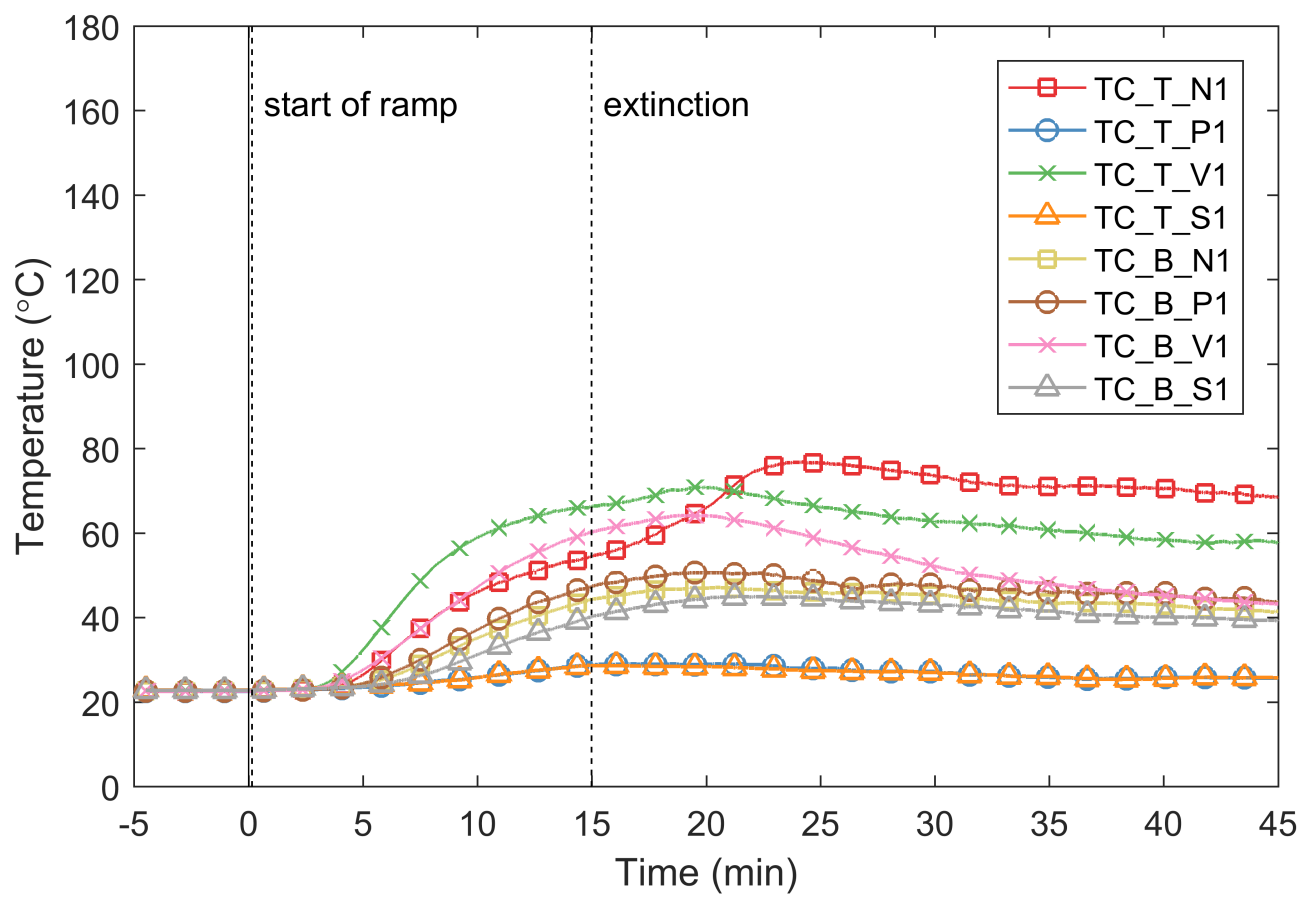

Fig. 380. S03 - Temperatures of the gypsum on the unexposed side of the wall specimen.

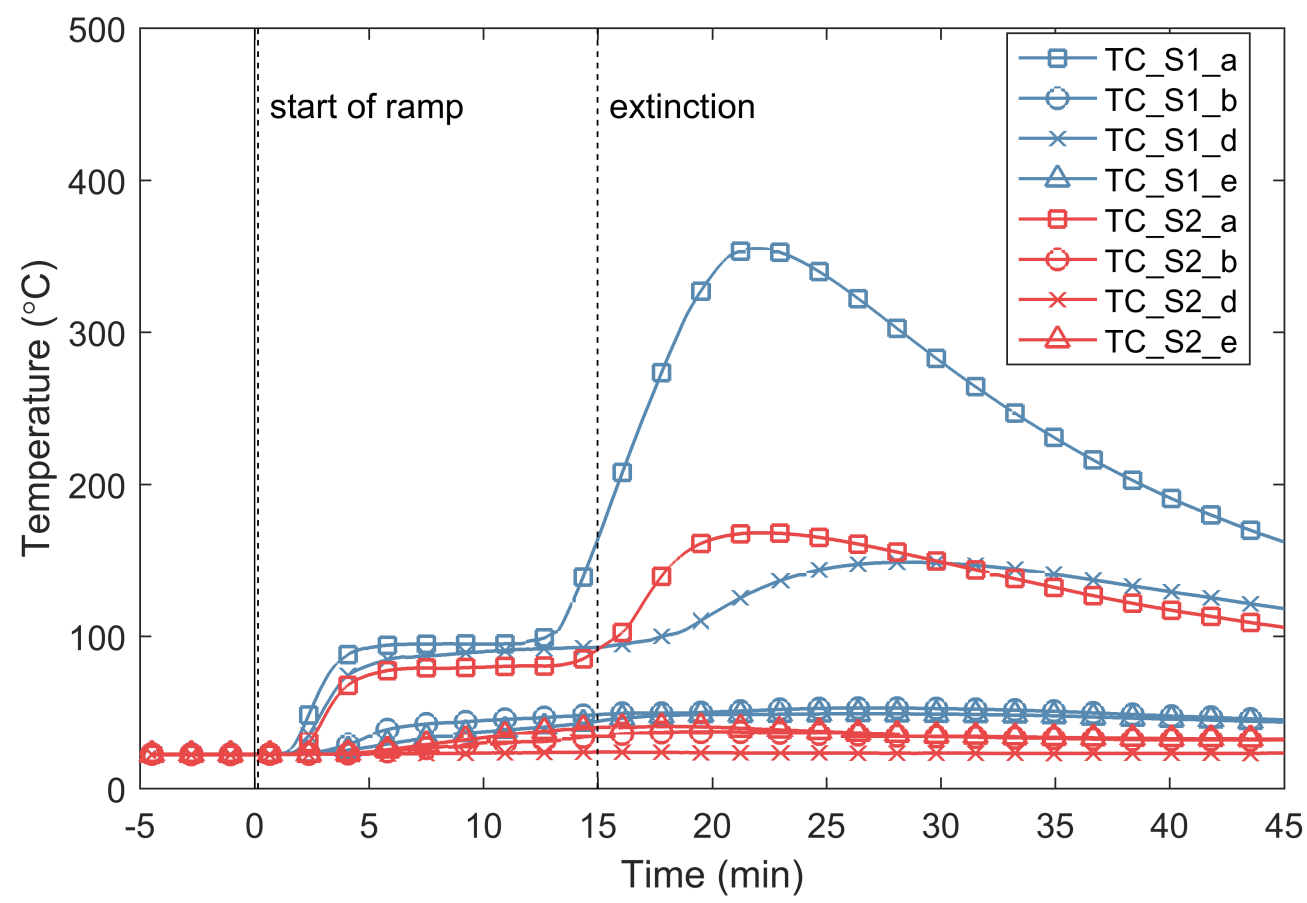

Fig. 381. S03 - Temperatures of the connection between gusset plates and strap braces. 


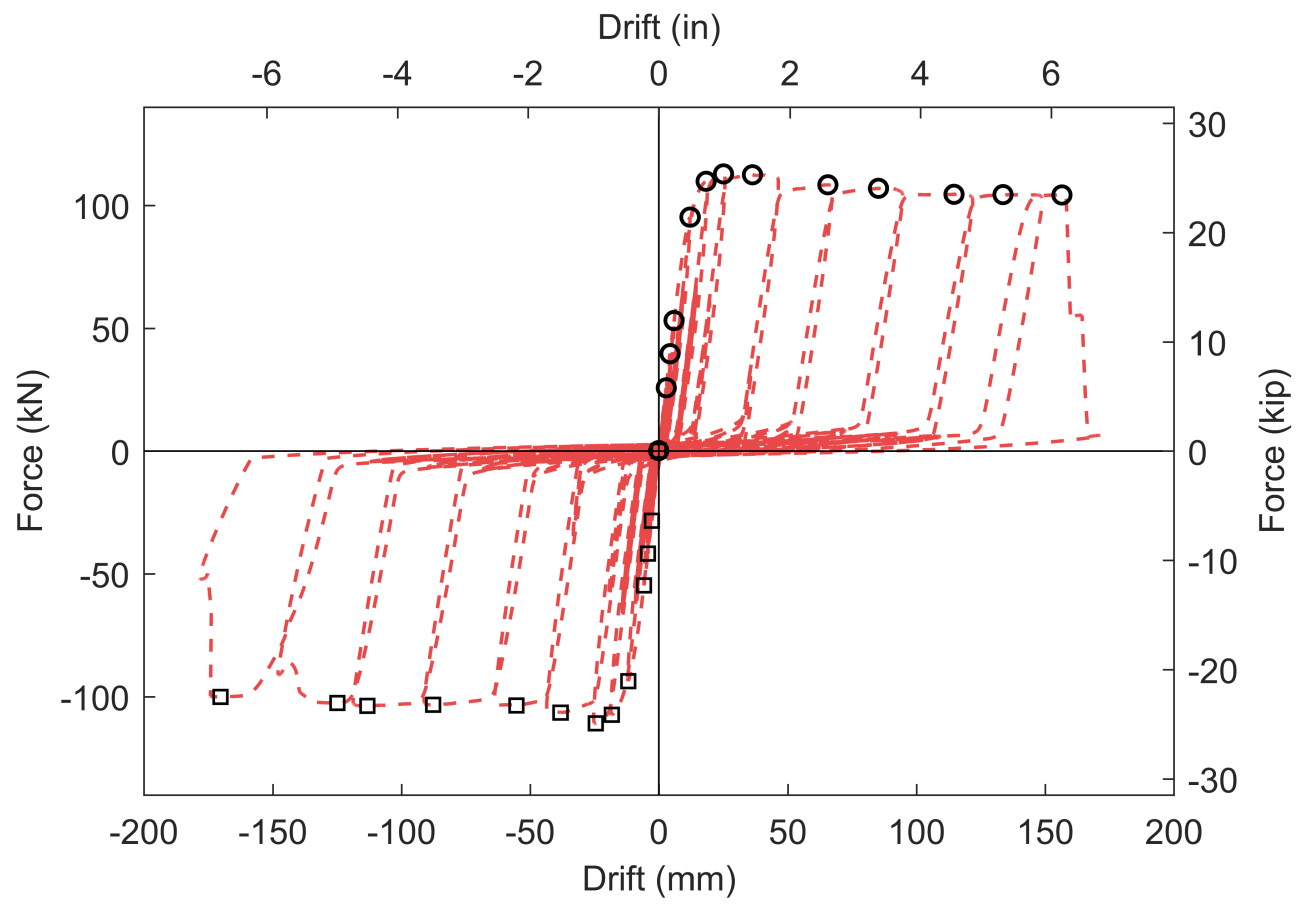

Fig. 382. S03 - Applied load versus wall longitudinal drift during mechanical loading.

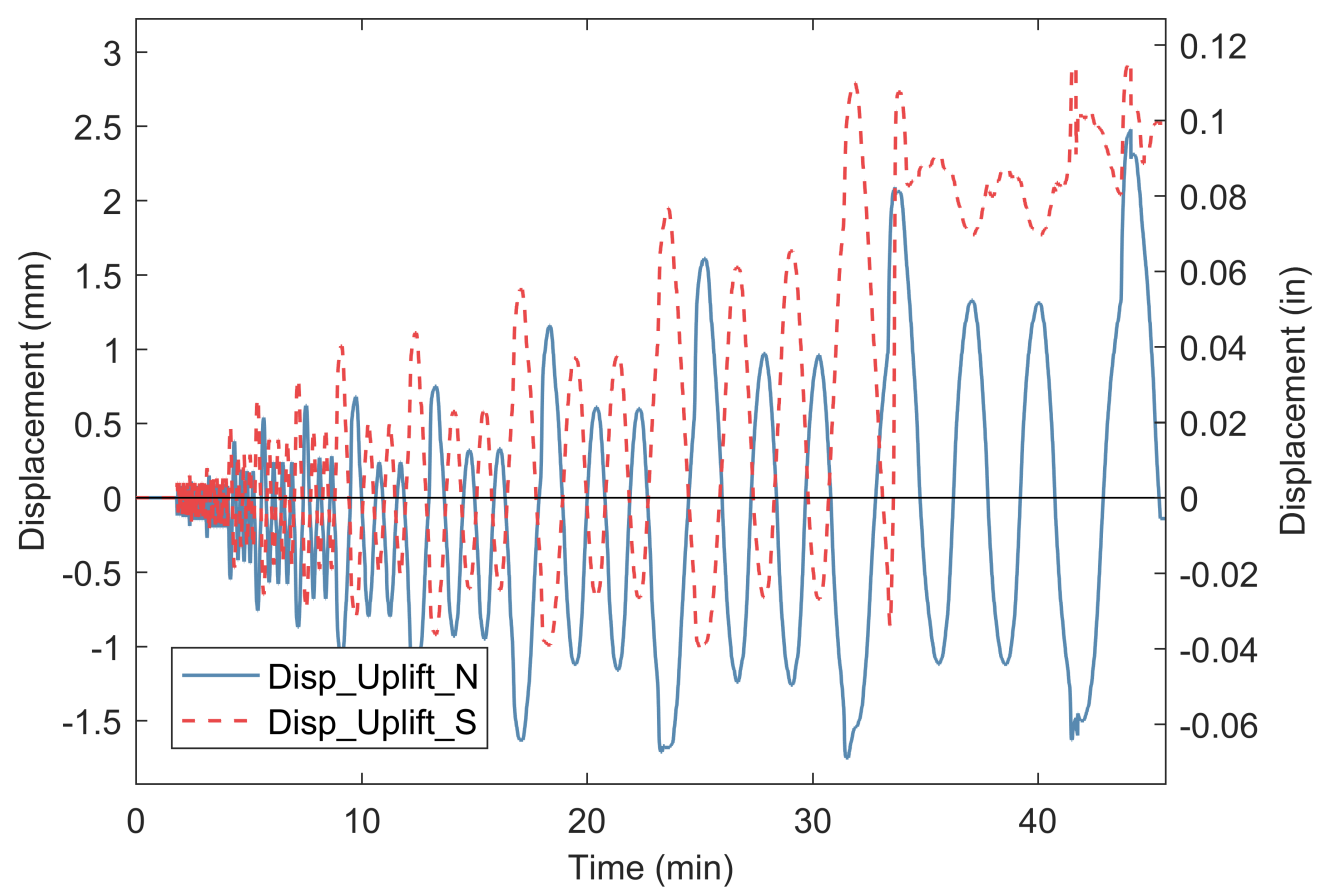

Fig. 383. S03 - Uplift at bottom of wall during mechanical loading. 


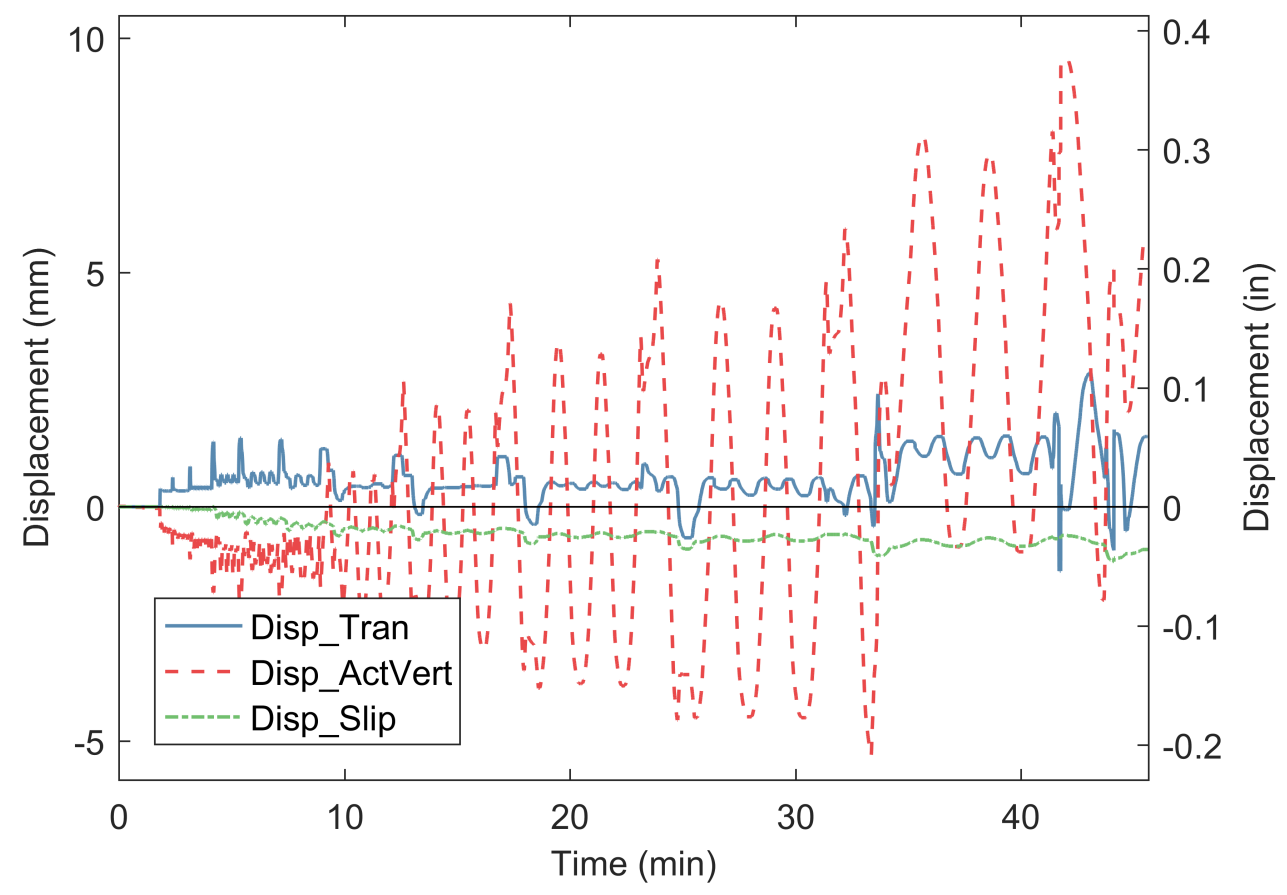

Fig. 384. S03 - Ancillary displacement measurements during mechanical loading.

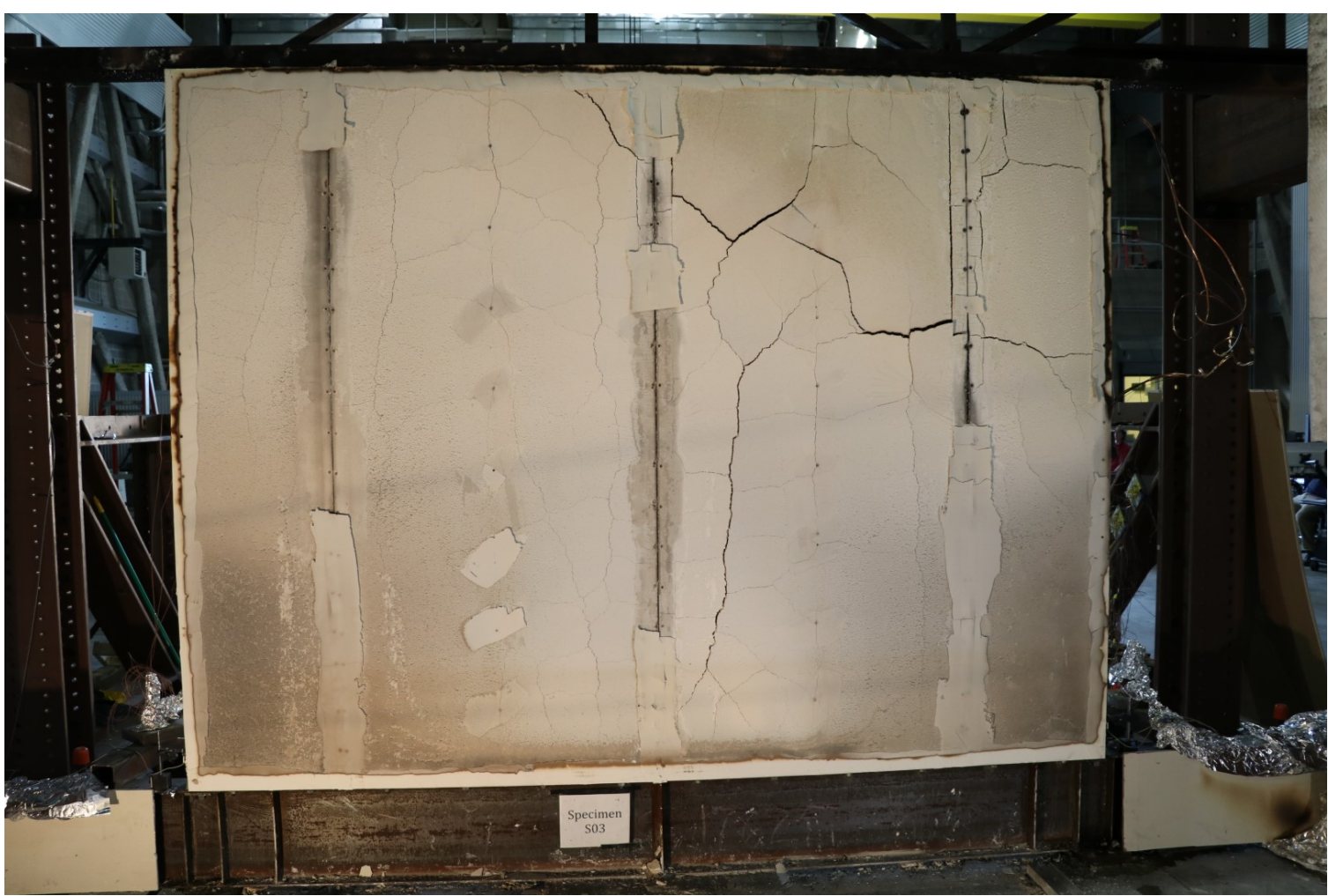

Fig. 385. S03 - Photograph of exposed side of the wall after the fire test (before cycling). 


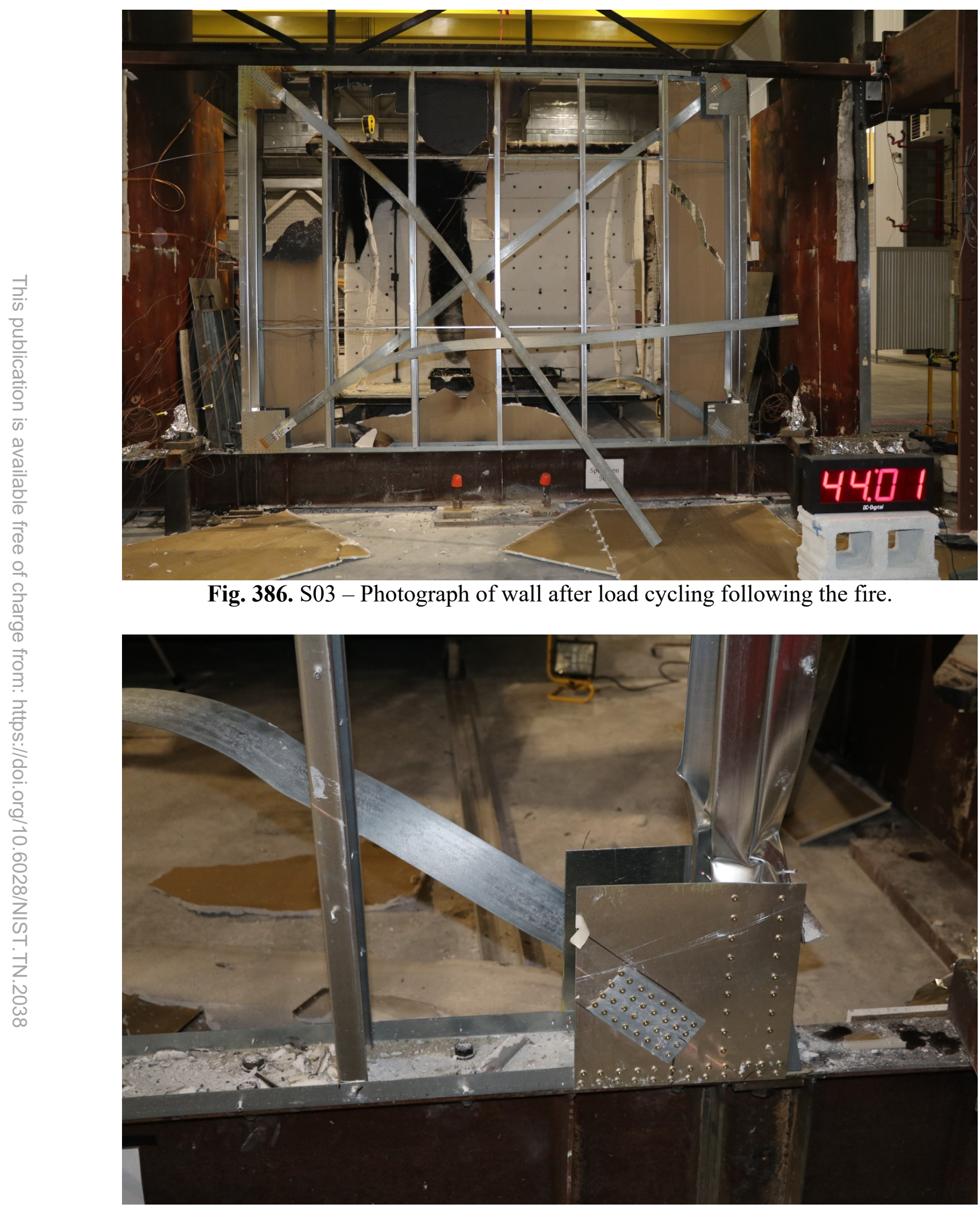

Fig. 387. S03 - Photograph showing both chord stud crippling and strap rupture; both occurred after yielding of the strap. 


\section{S04 Data}

S04b (Standard Fire test of an undamaged wall)

- The gas burner was set to follow the same heat release rate curve as in SB04b (Fig. 388). The temperatures are below the ASTM E119 throughout the 60 min duration of the test.

- No significant damage observed beyond drywall on fire exposed side (Fig. 404).

- The maximum temperature raise on the unexposed side does not exceed $83{ }^{\circ} \mathrm{C}$ from the initial temperature.

- A gasket of ceramic blanket and steel weights were placed on burner blanket to prevent lift-up at the edges to reduced temperature asymmetry in the compartment (Fig. 402)

S04c (Cyclic test of wall at ambient temperature following the Standard Fire)

- Chord crippled in compression direction long after strap yielding, but the strap continued yielding to rupture.

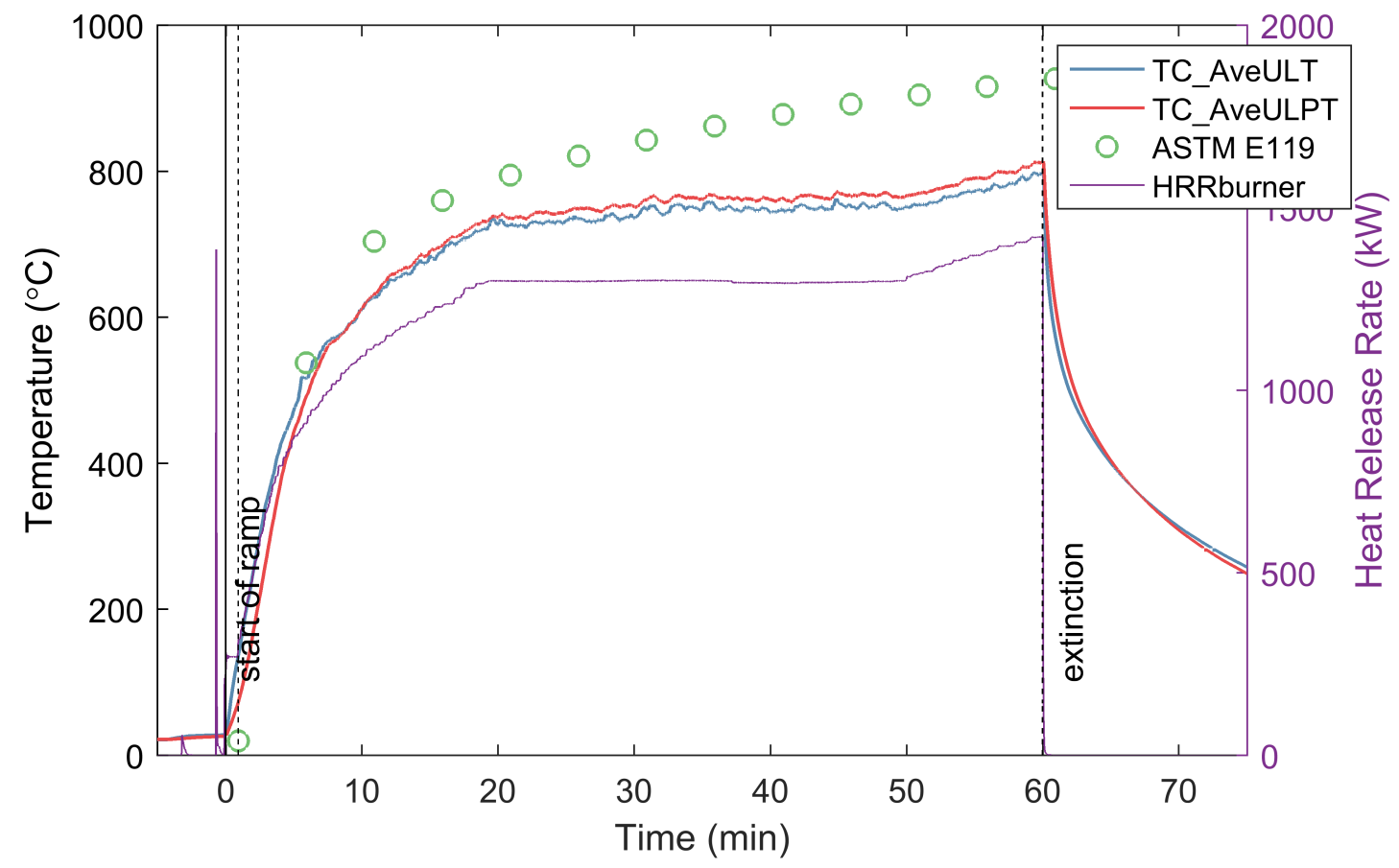

Fig. 388. S04 - Compartment temperatures and burner Heat Release Rate. 


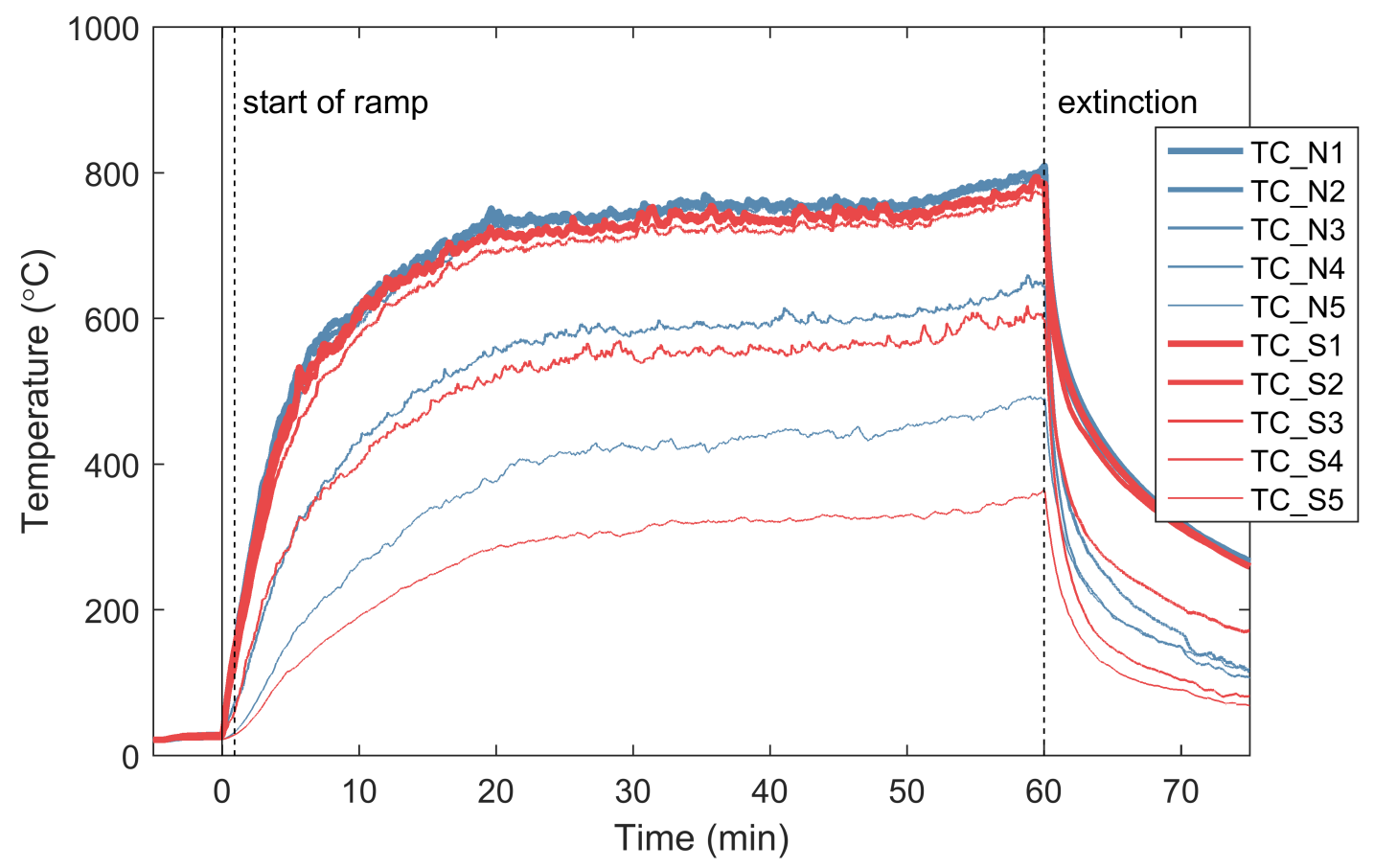

Fig. 389. S04 - Compartment temperatures measured by the thermocouple arrays.

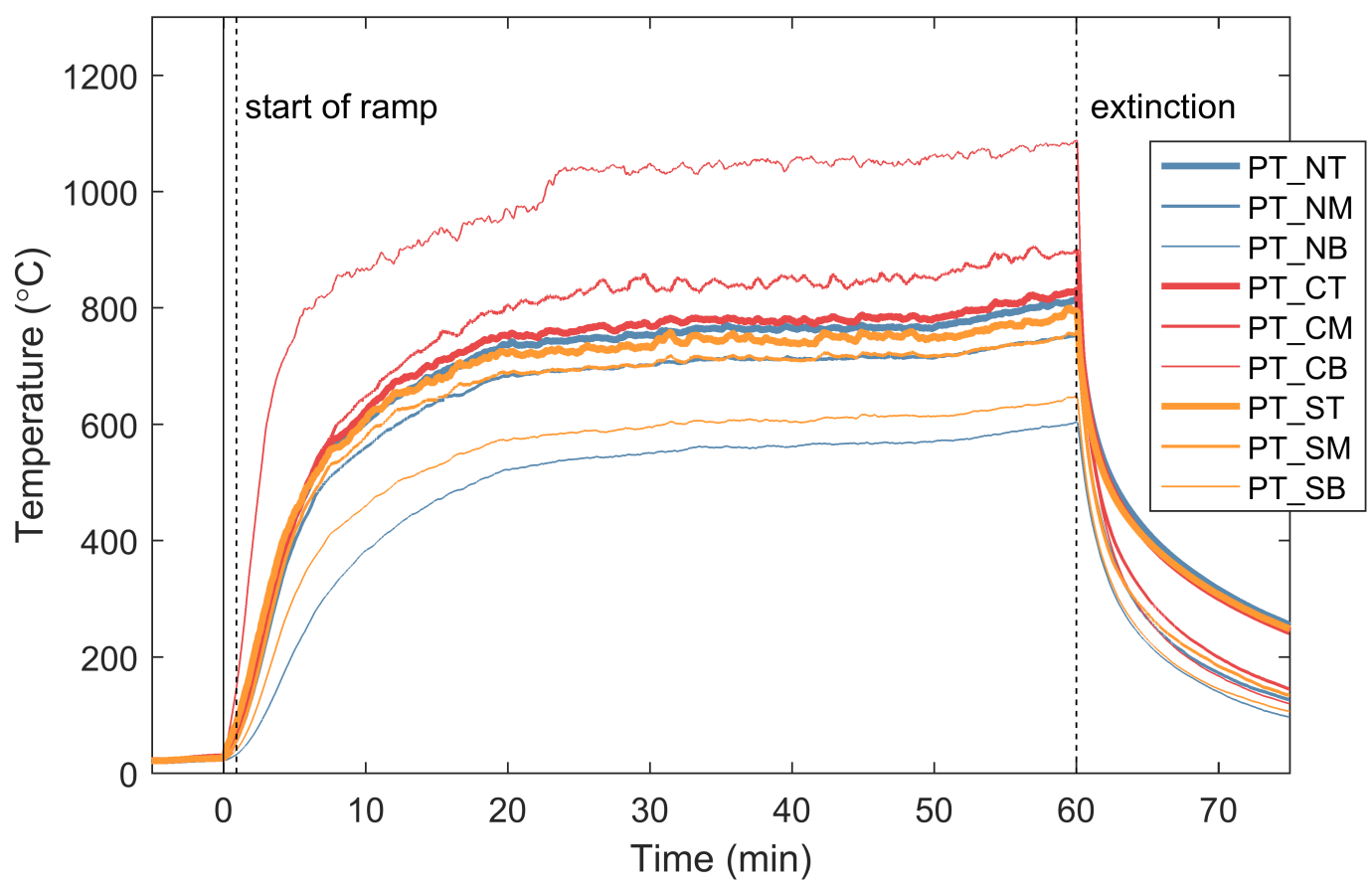

Fig. 390. S04 - Compartment temperatures measured by the plate thermocouples. 


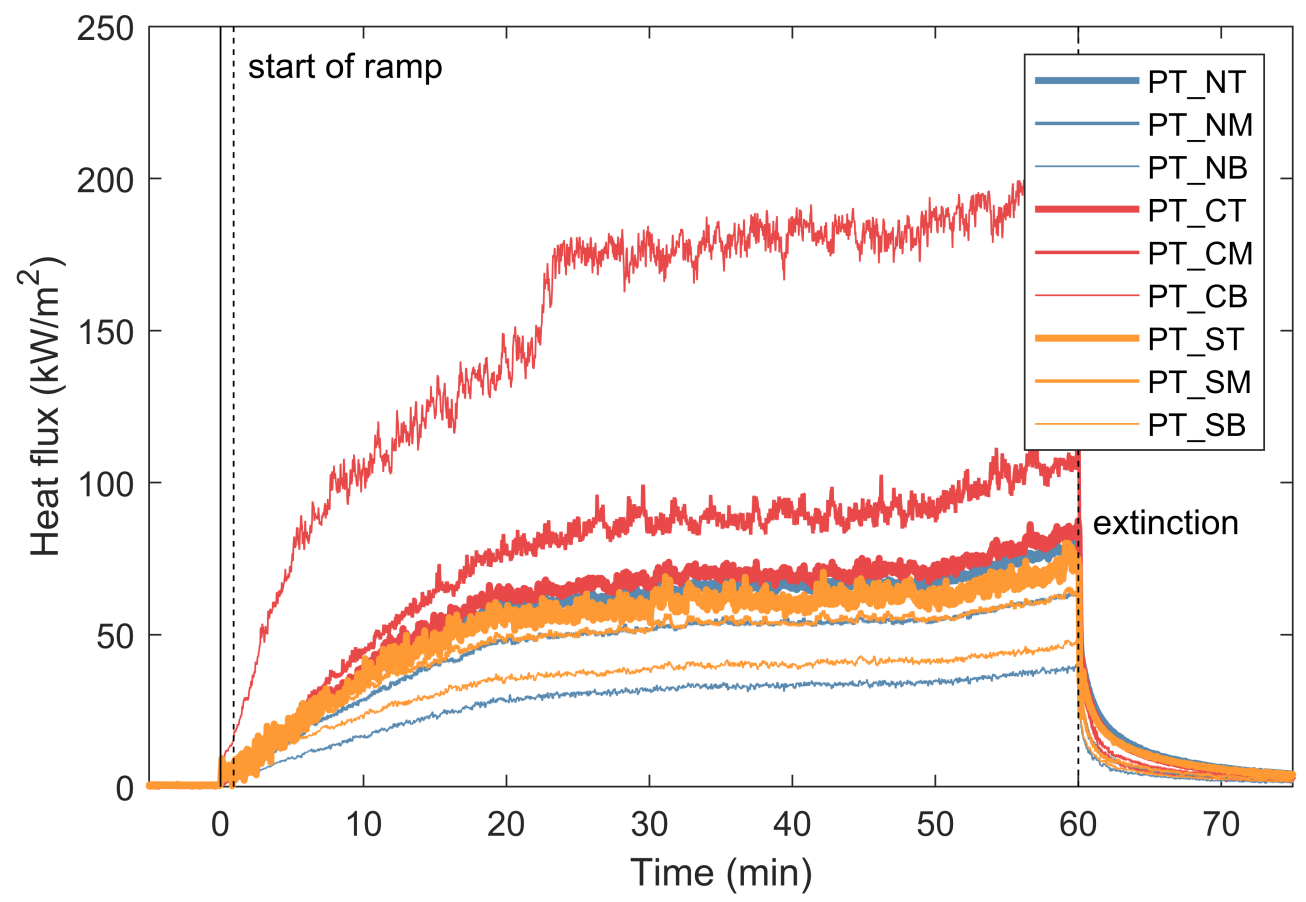

Fig. 391. S04 - Heat fluxes in the compartment measured by the plate thermocouples.
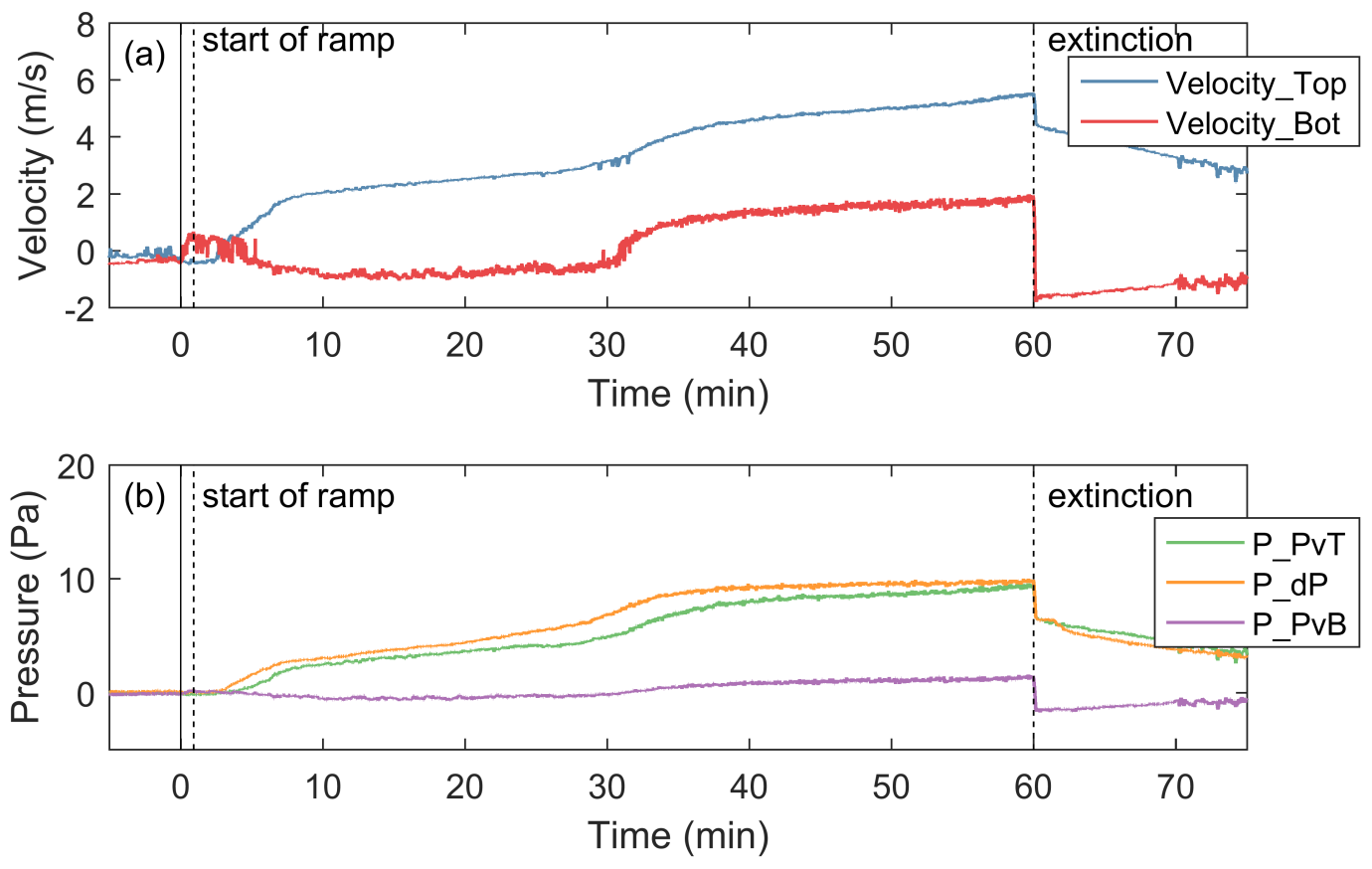

Fig. 392. S04 - (a) Velocity of air flow at the top and bottom knockouts of the chord stud; (b) Pressure at the top and bottom knockouts of the chord stud and in the wall cavity near the top. 


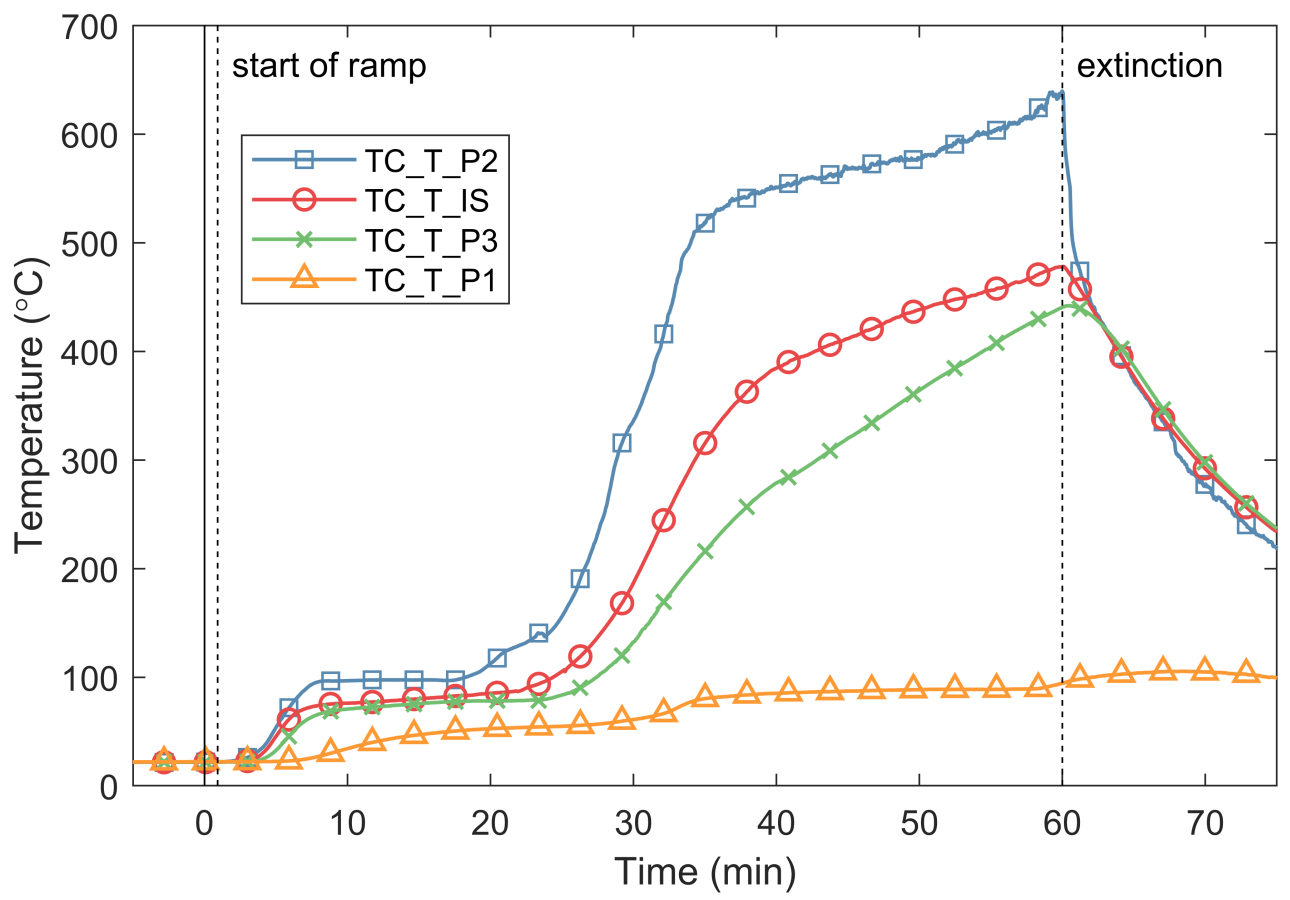

Fig. 393. S04 - Temperatures through the specimen at an interior stud $46 \mathrm{~cm}$ from the top of the wall.

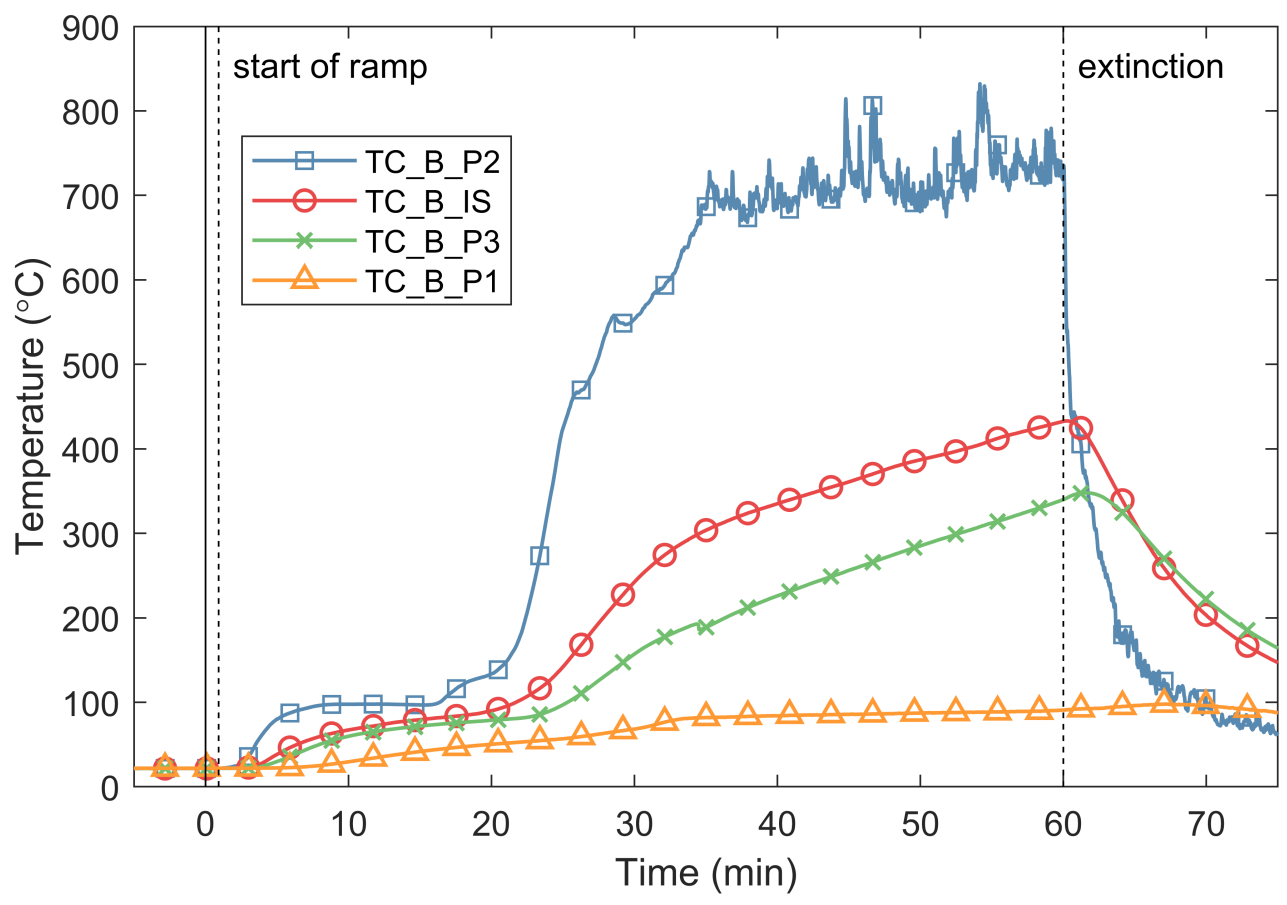

Fig. 394. S04 - Temperatures through the specimen at an interior stud $46 \mathrm{~cm}$ from the bottom of the wall. 


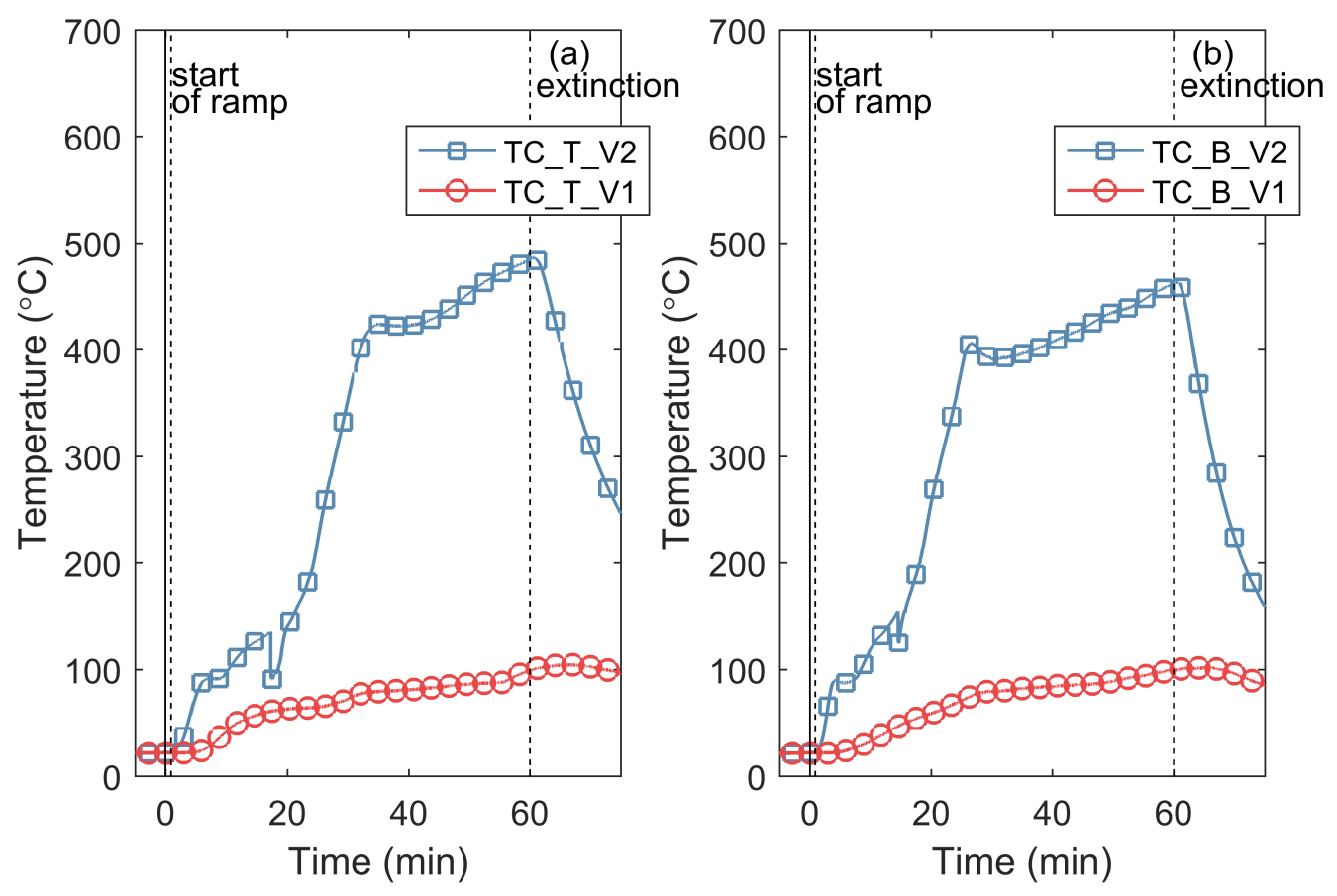

Fig. 395. S04 - Temperatures through the specimen midway between interior studs: (a) $46 \mathrm{~cm}$ from the top of the wall; (b) $46 \mathrm{~cm}$ from the bottom of the wall.

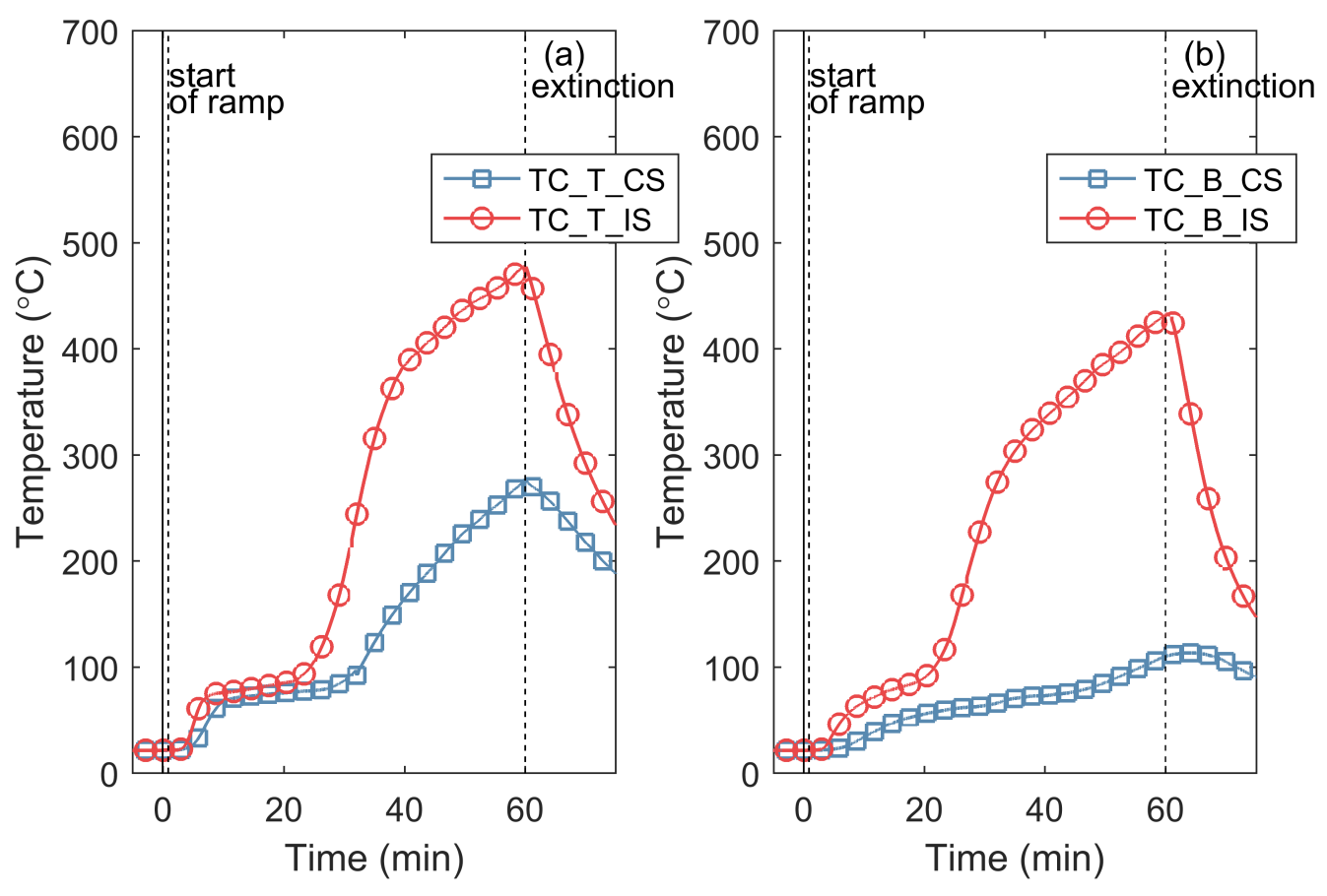

Fig. 396. S04 - Temperatures of the framing elements: (a) $46 \mathrm{~cm}$ from the top of the wall; (b) $46 \mathrm{~cm}$ from the bottom of the wall. 


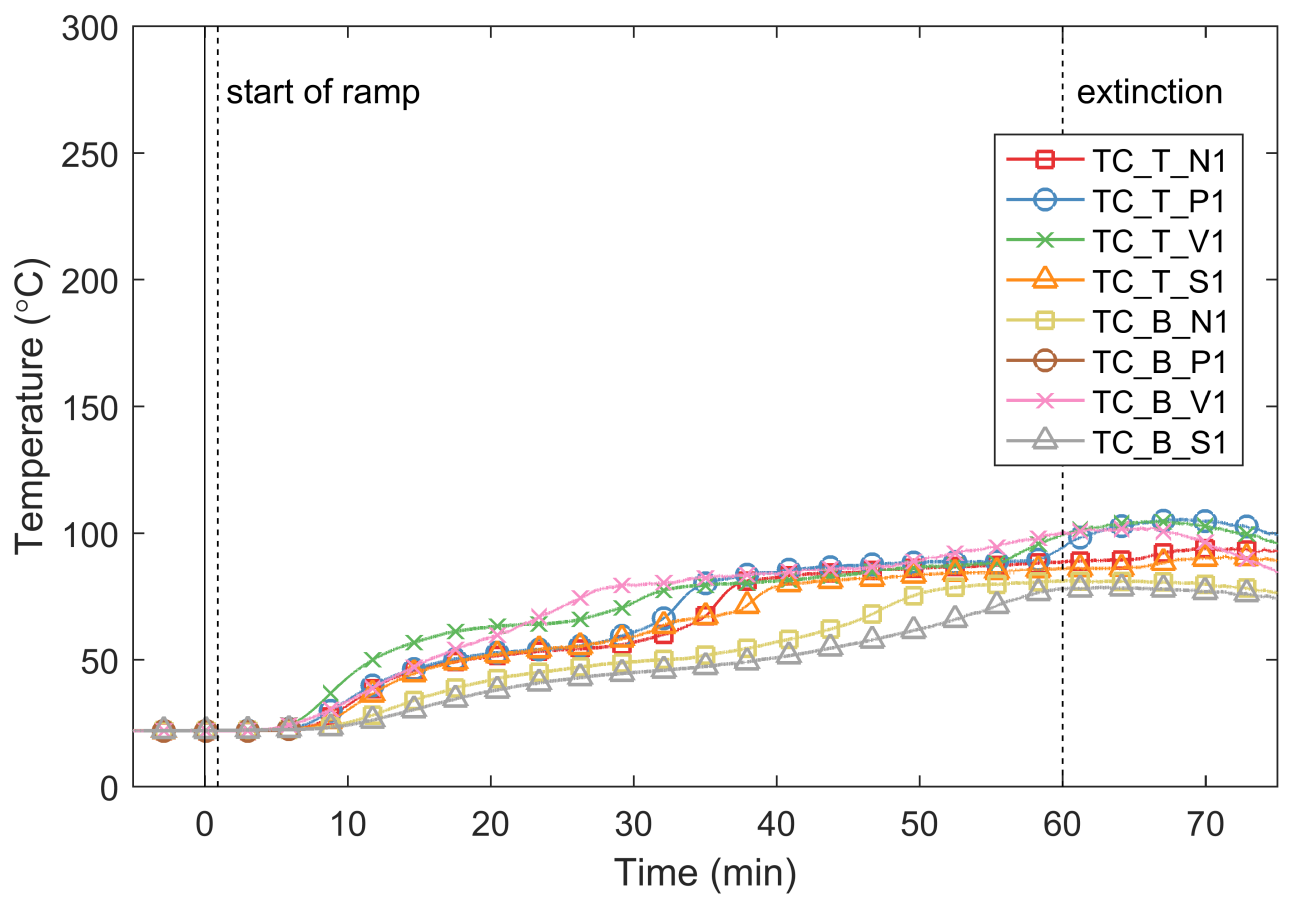

Fig. 397. S04 - Temperatures of the gypsum on the unexposed side of the wall specimen.

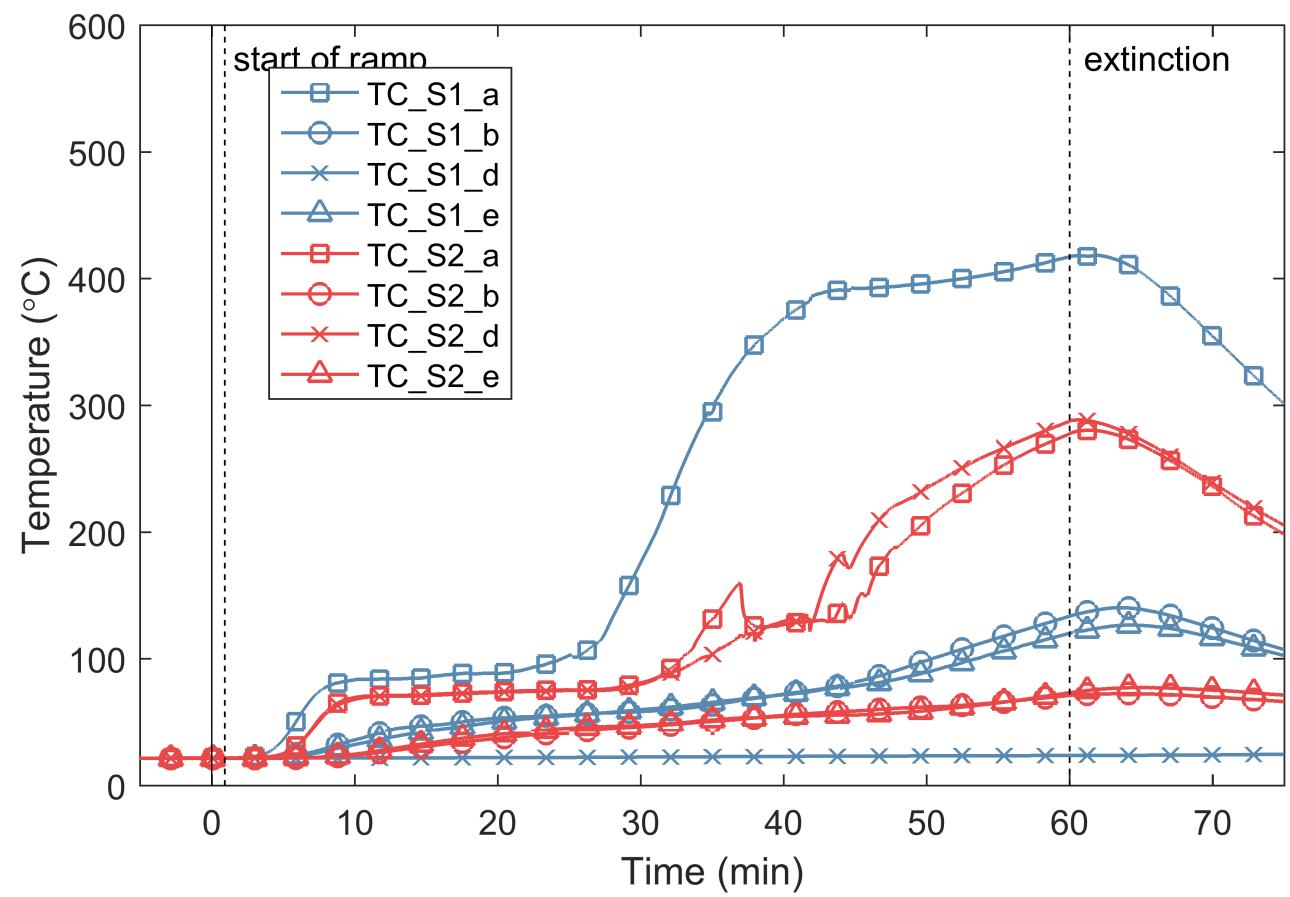

Fig. 398. S04 - Temperatures of the connection between gusset plates and strap braces. 


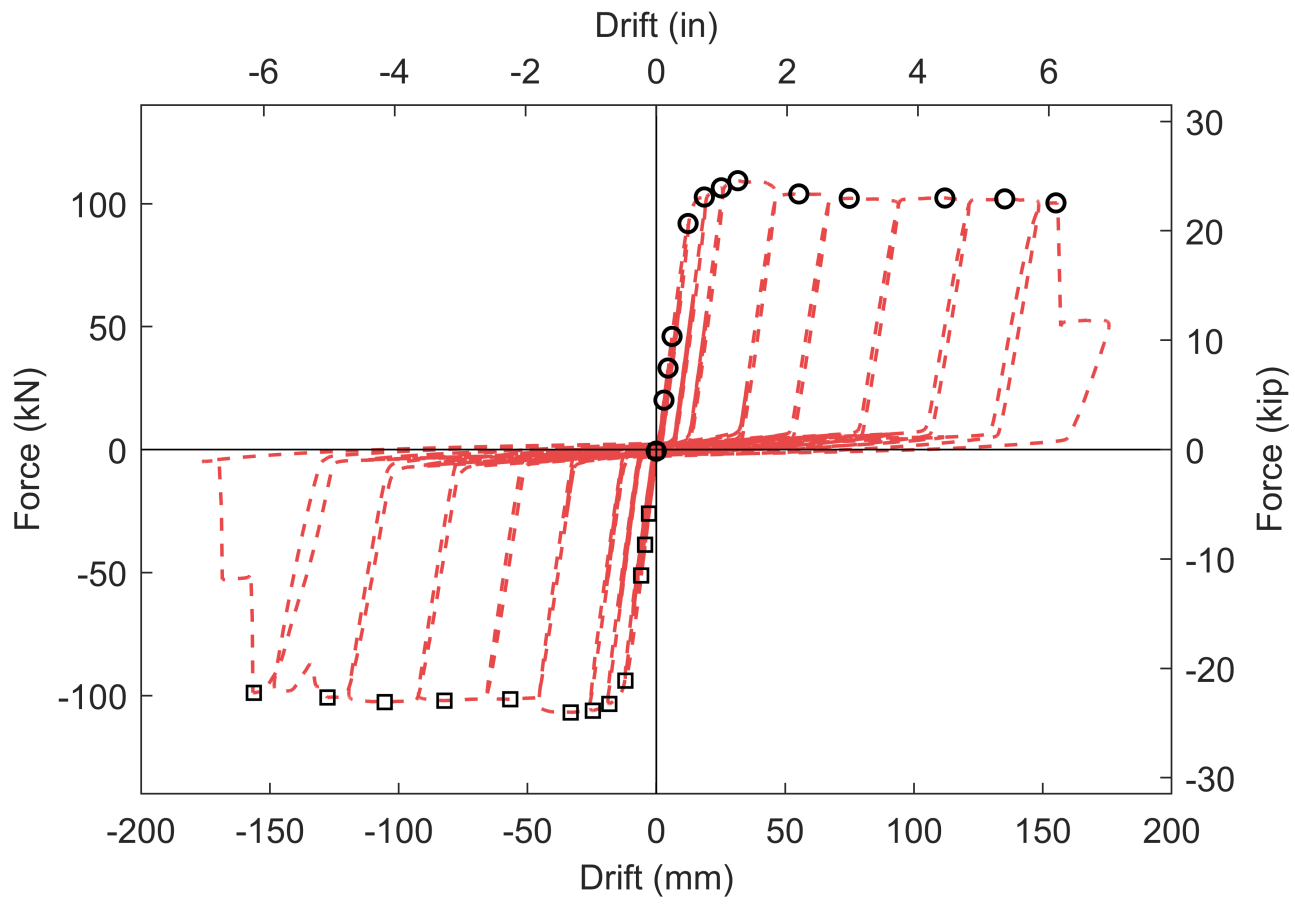

Fig. 399. S04 - Applied load versus wall longitudinal drift during mechanical loading.

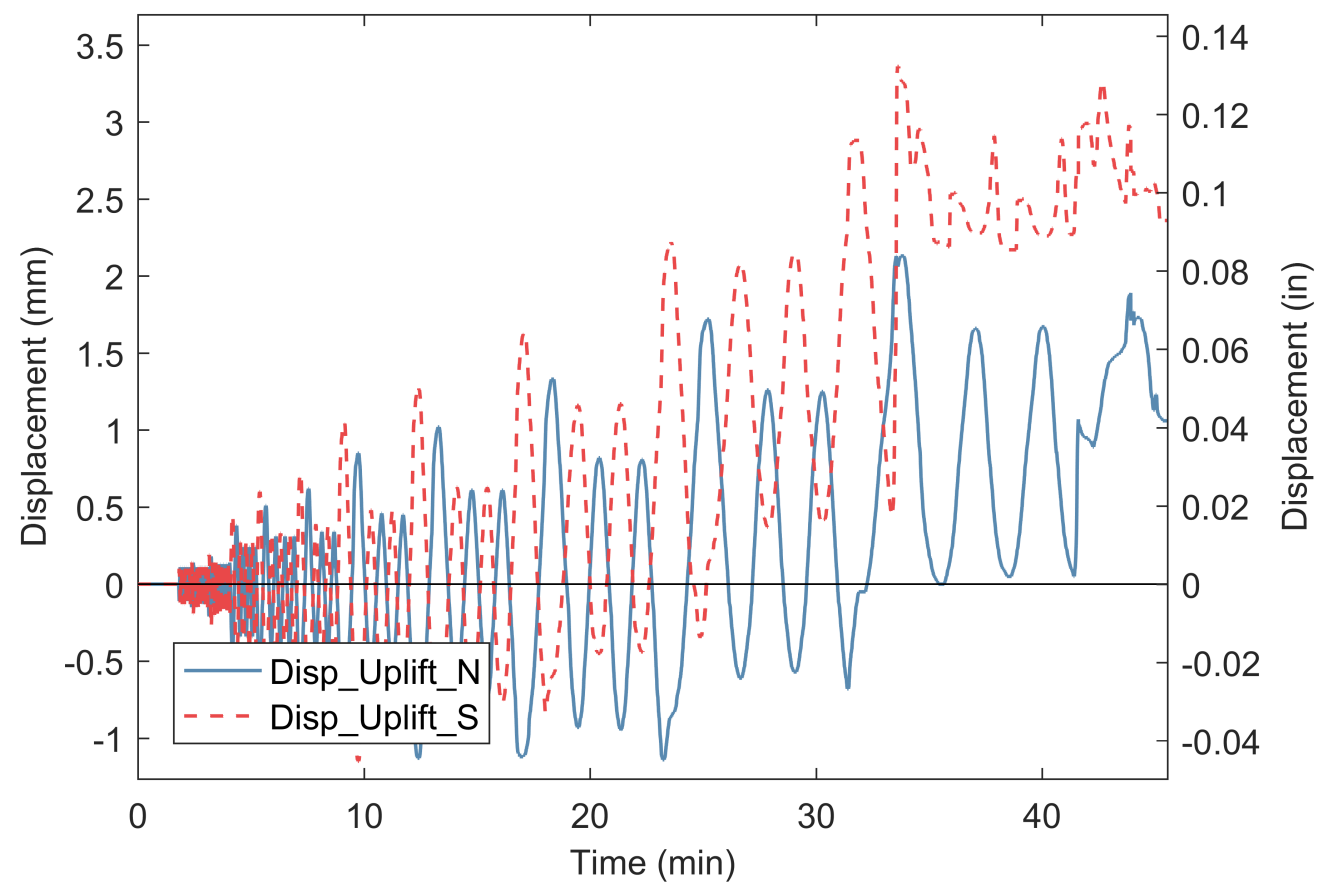

Fig. 400. S04 - Uplift at bottom of wall during mechanical loading. 


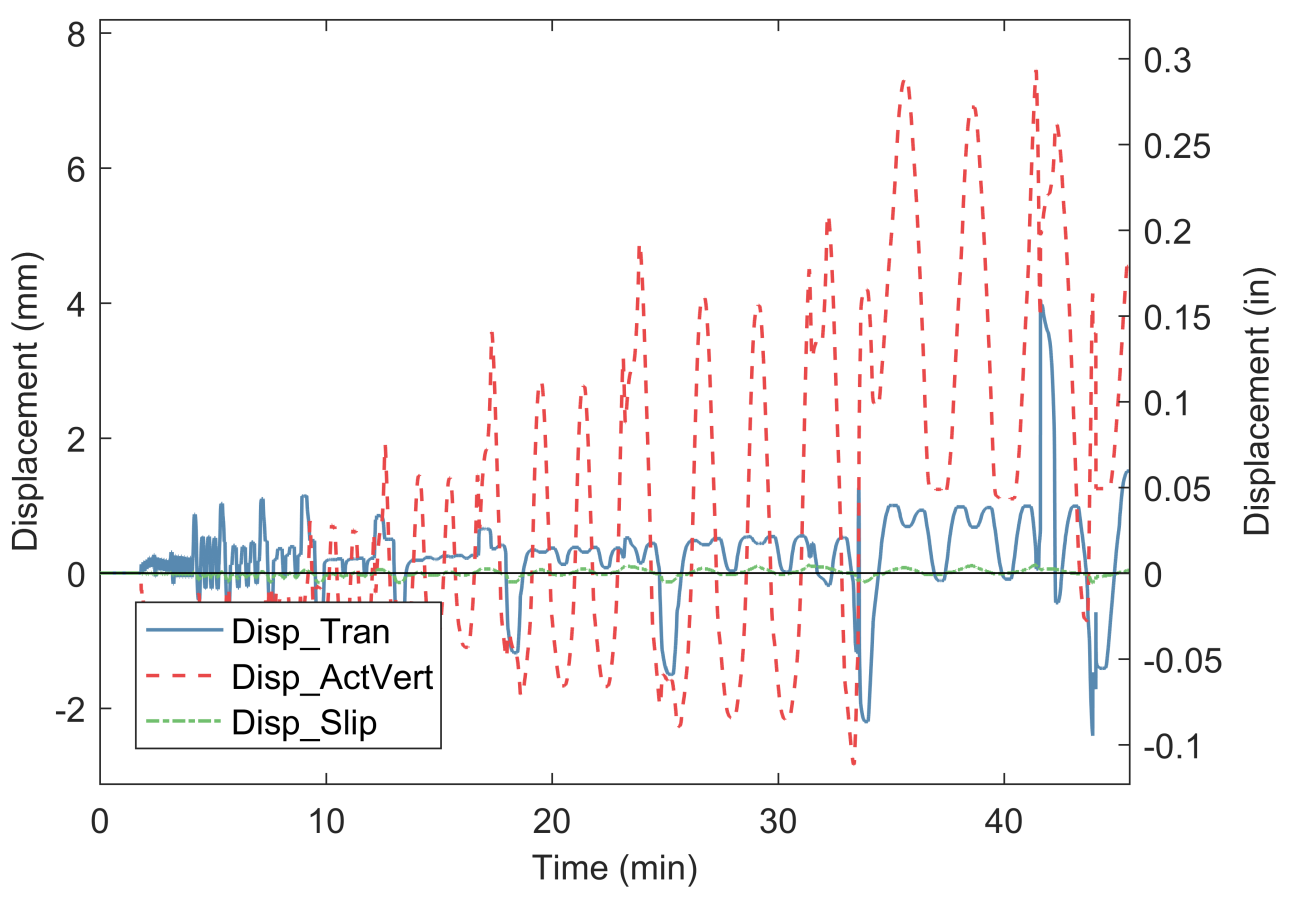

Fig. 401. S04 - Ancillary displacement measurements during mechanical loading.

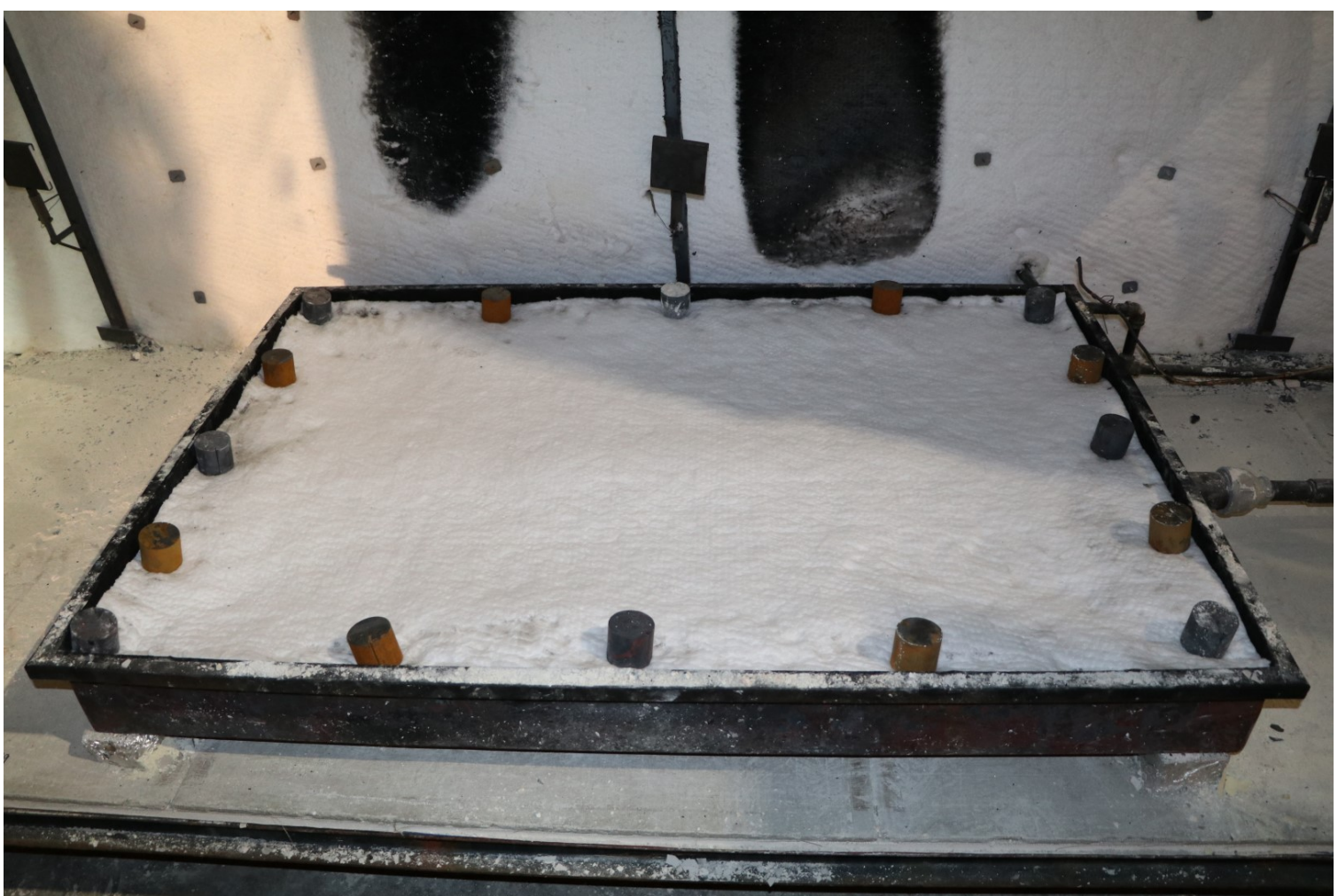

Fig. 402. S04 - Photograph of steel weights placed on burner blanket to prevent lift-up at the edges. 


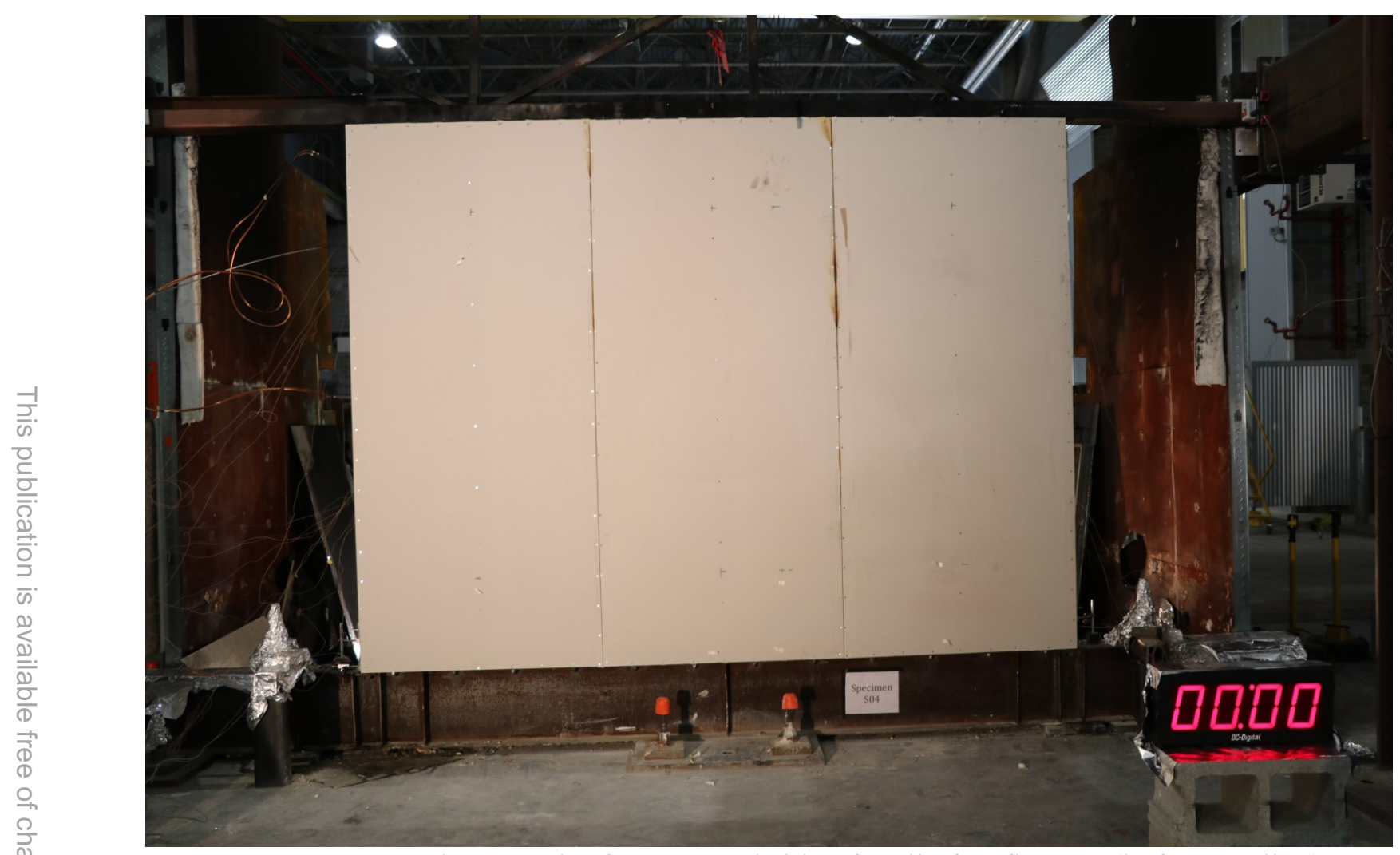

Fig. 403. S04 - Photograph of unexposed side of wall after fire test (before cycling).

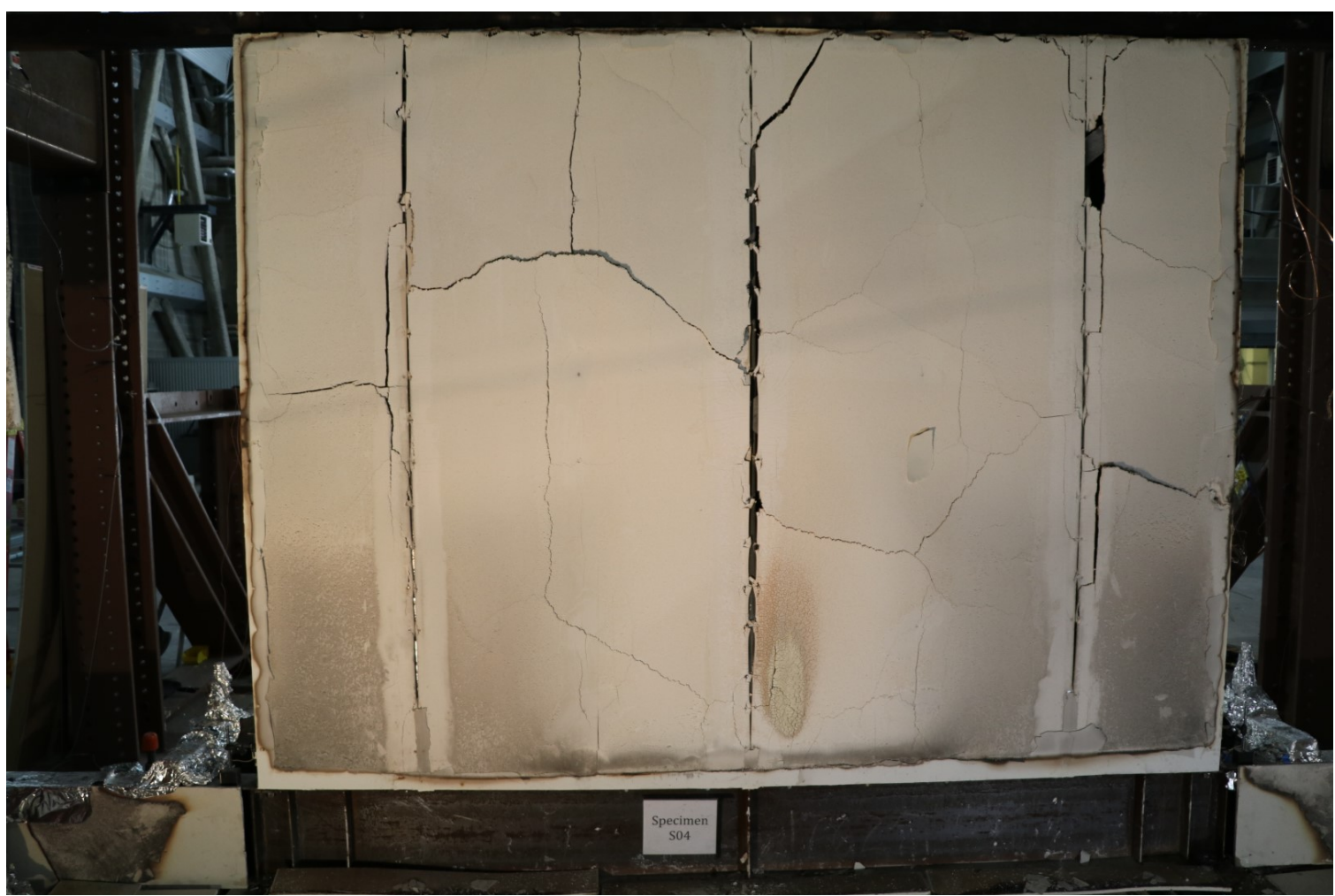

Fig. 404. S04 - Photograph of fire exposed side of wall after fire test (before cycling). 


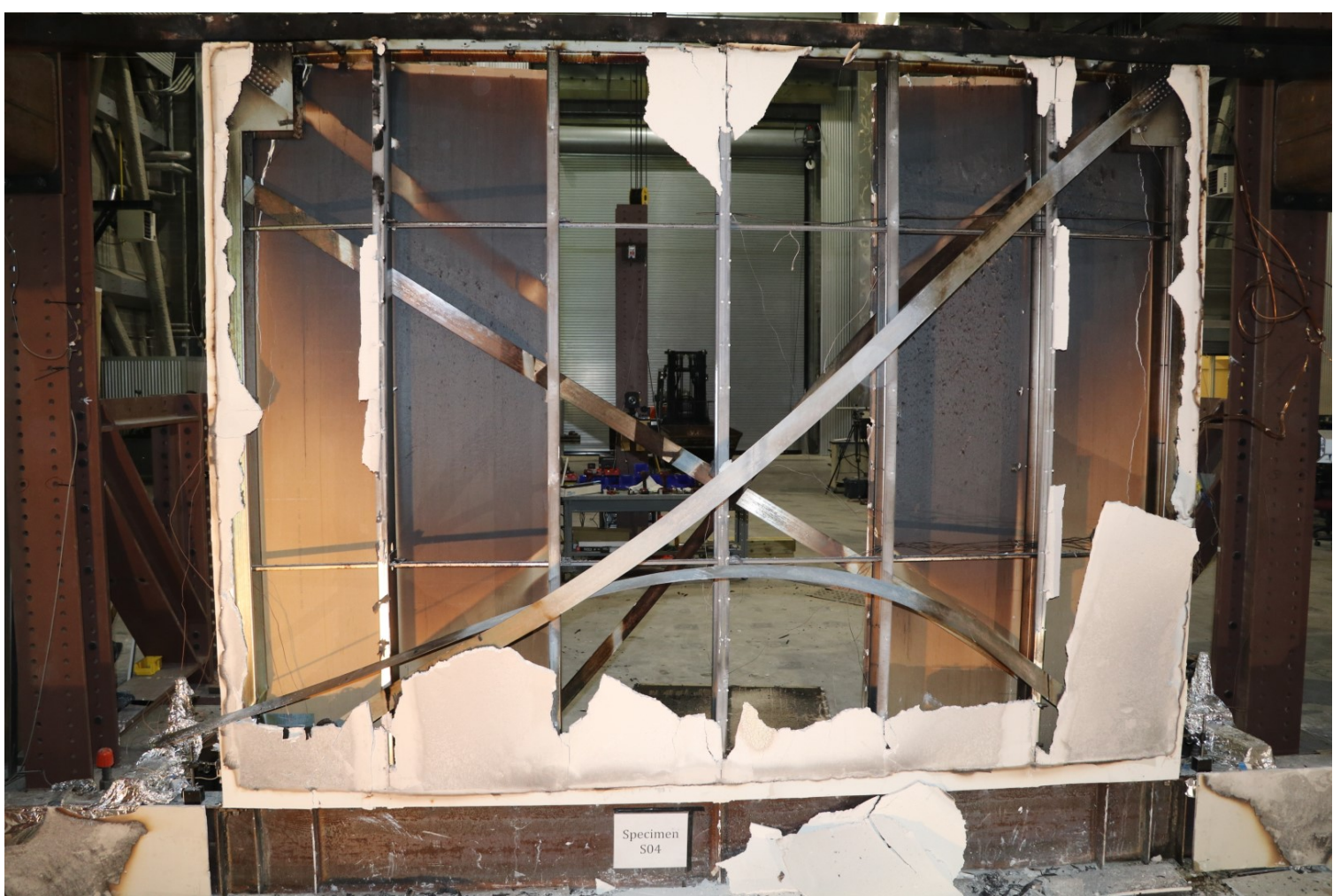

Fig. 405. S04 - Photograph of the wall from the east (fire exposed) side after load cycling following the fire.

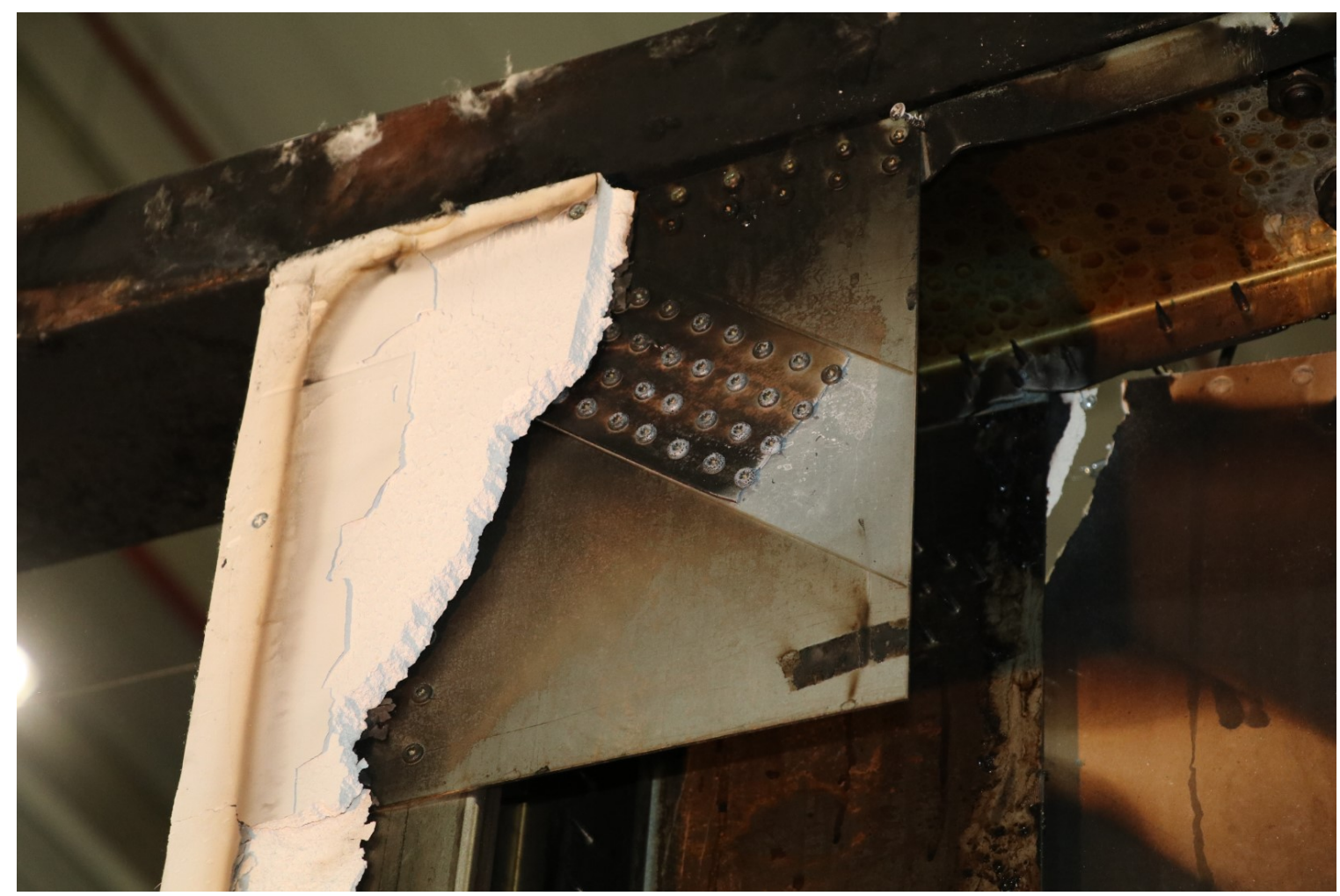

Fig. 406. S04 - Photograph of the strap rupture at a gusset on the exposed side of the wall after load cycling following the fire. 


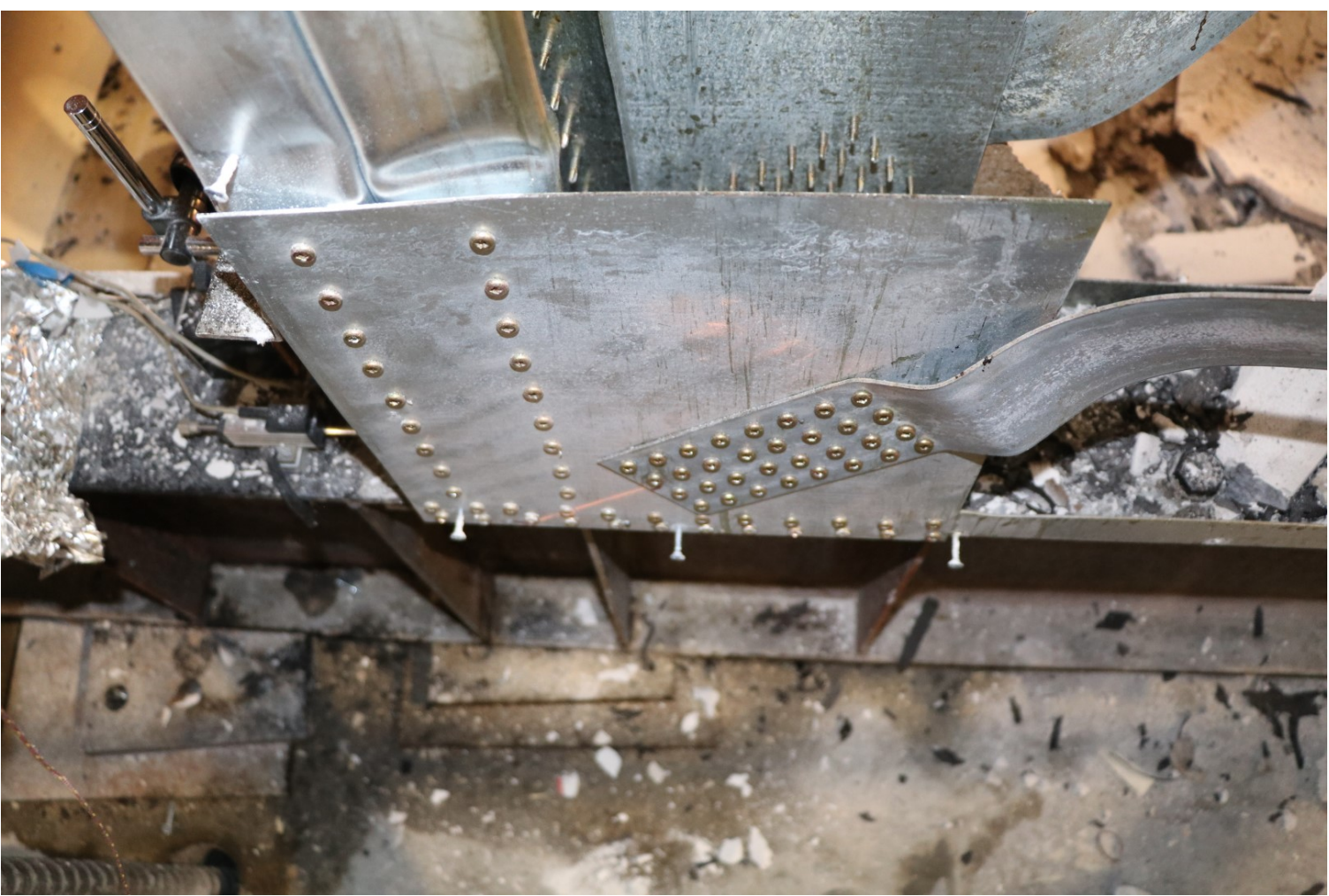

Fig. 407. S04 - Photograph of the local strap buckling at the end opposite to where the rupture occurred due to release of stored elastic energy. 


\section{S05 Data}

S05a (Cyclic test of wall to $1.75 \%$ SDR at ambient temperature)

- Tore mud and tape along entire length of all four seams on east side (exposed side). $\geq 1$ mm crack width (Fig. 422 and Fig. 423).

- No damage visible on front of west wall (unexposed side), but many of the screws were fractured.

S05b (Mild Fire test after cyclic test to $1.75 \%$ SDR)

- The heat release rate in the burner was kept to $1.7 \mathrm{MW}$ for $15 \mathrm{~min}$. There is a strong asymmetry of the temperatures inside the compartment (Fig. 409).

- Smoke visible on west (unexposed) side of wall immediately after ignition; most at top of wall and along some along the vertical seams.

- Added kaowool to north east corner of burner to try and balance the compartment temperatures (north to south). This pushed the soot column along the back wall right in front of the window which obstructed the view for most of the test.

- Minor flame leakage around the window; need to repack before next test (Fig. 424).

S05c (Cyclic test of wall at ambient temperature following the Mild Fire)

- 1st strap failed (compression cycle) at south-east top @180\% delta; sooner than in ambient test.

- 2nd strap failed (tension cycle) in south-east bottom @220\%

- 3rd strap failed (compression cycle) in south-east bottom @260\%.

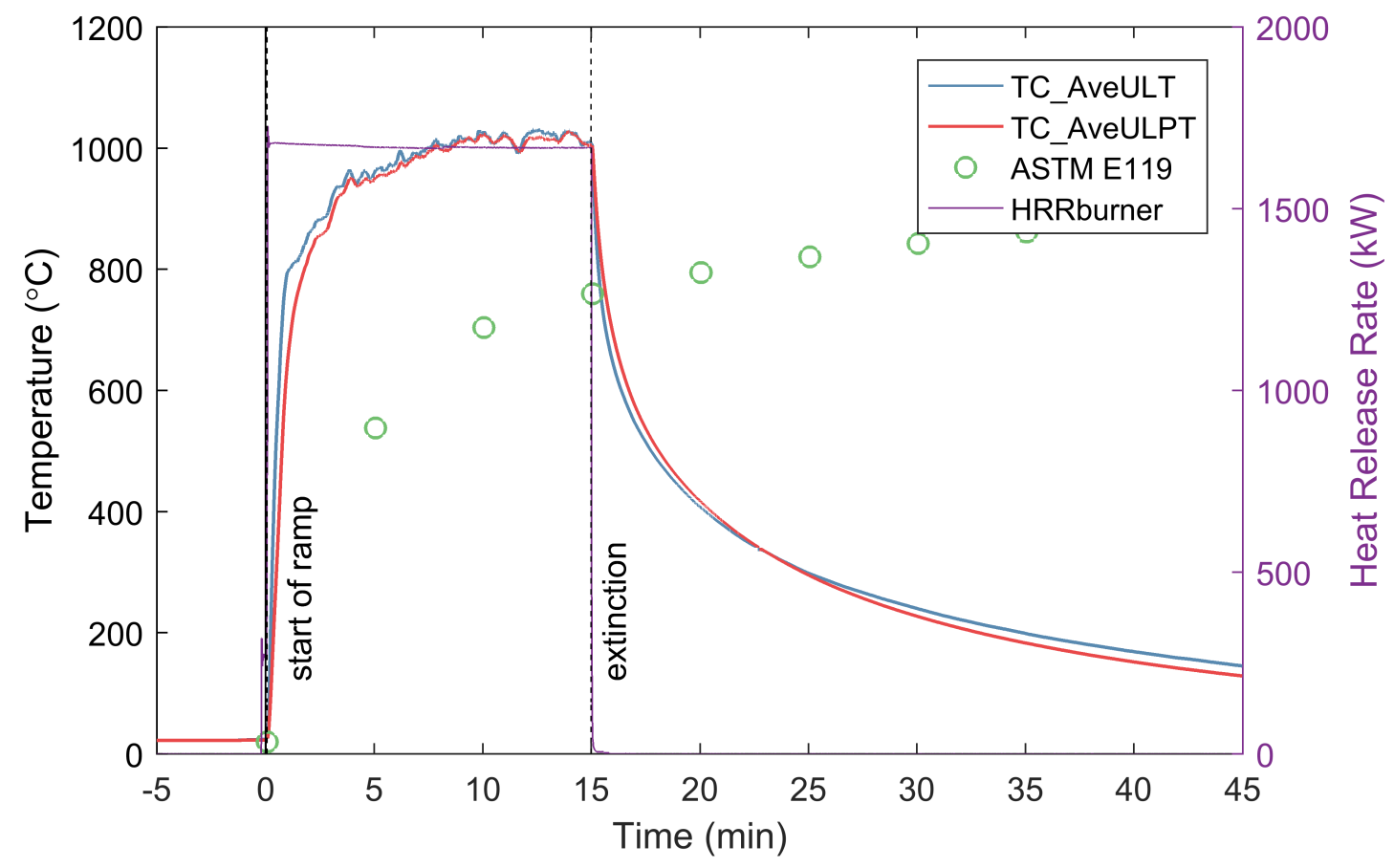

Fig. 408. S05 - Compartment temperatures and burner Heat Release Rate. 


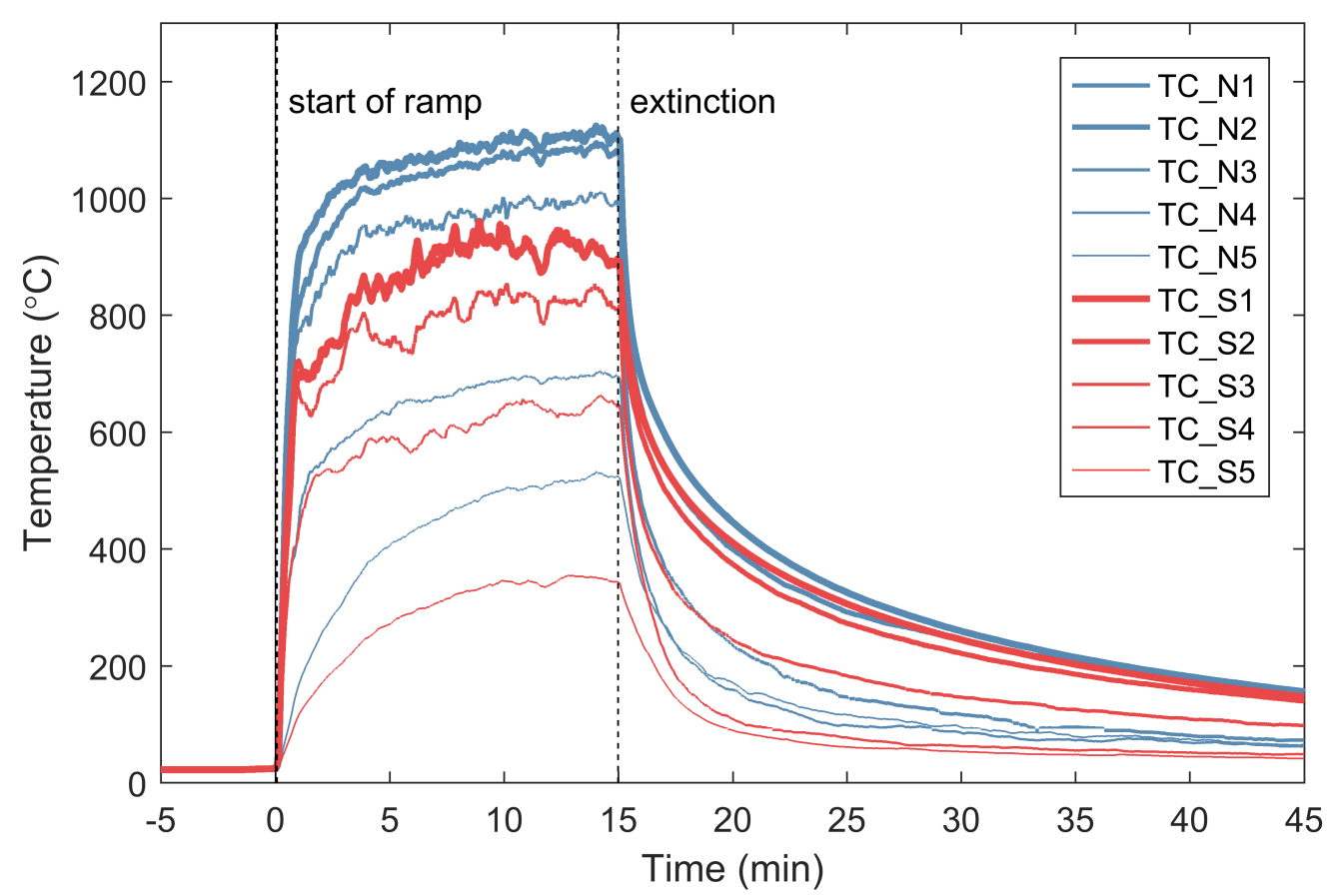

Fig. 409. S05 - Compartment temperatures measured by the thermocouple arrays.

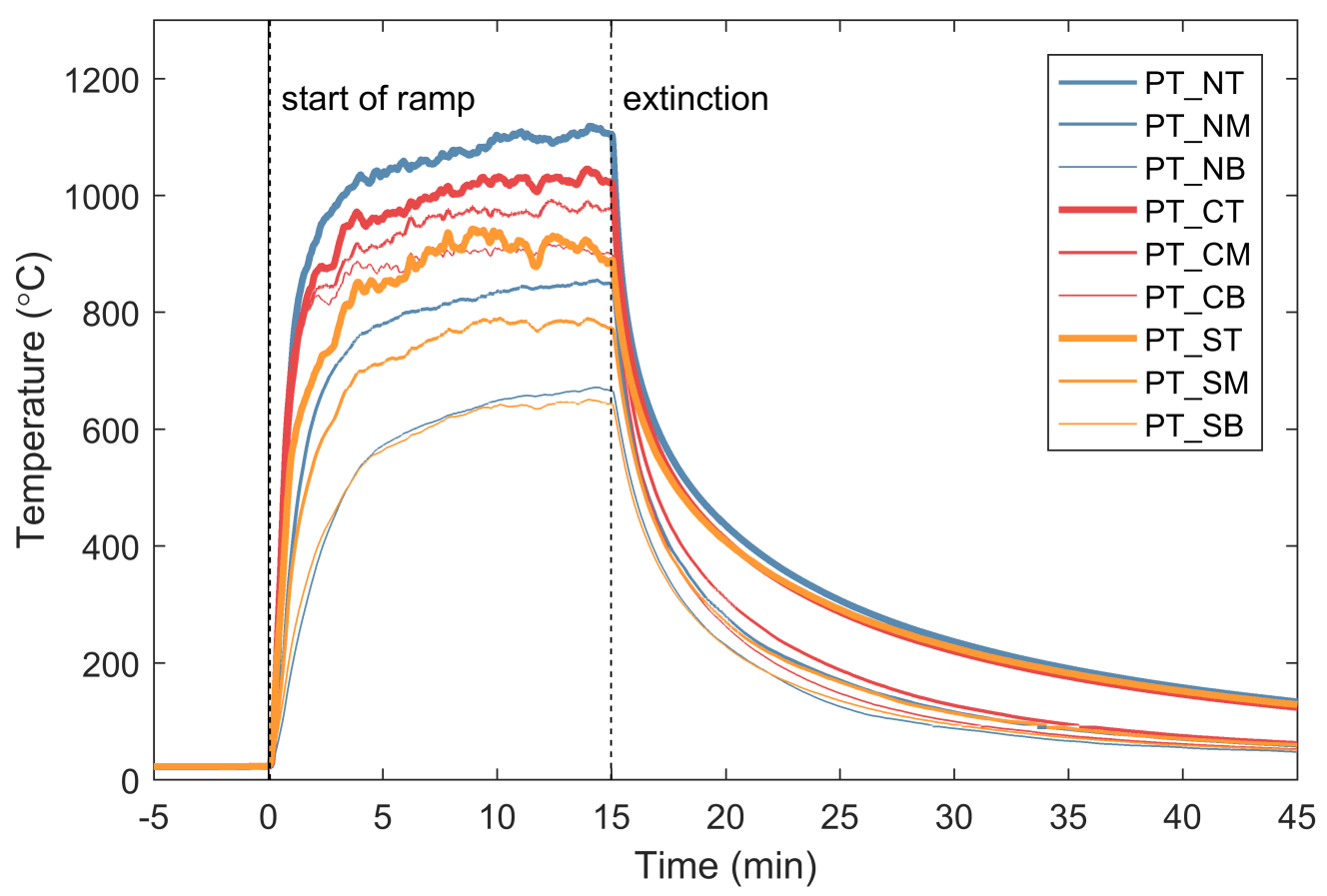

Fig. 410. S05 - Compartment temperature measured by the plate thermocouples. 


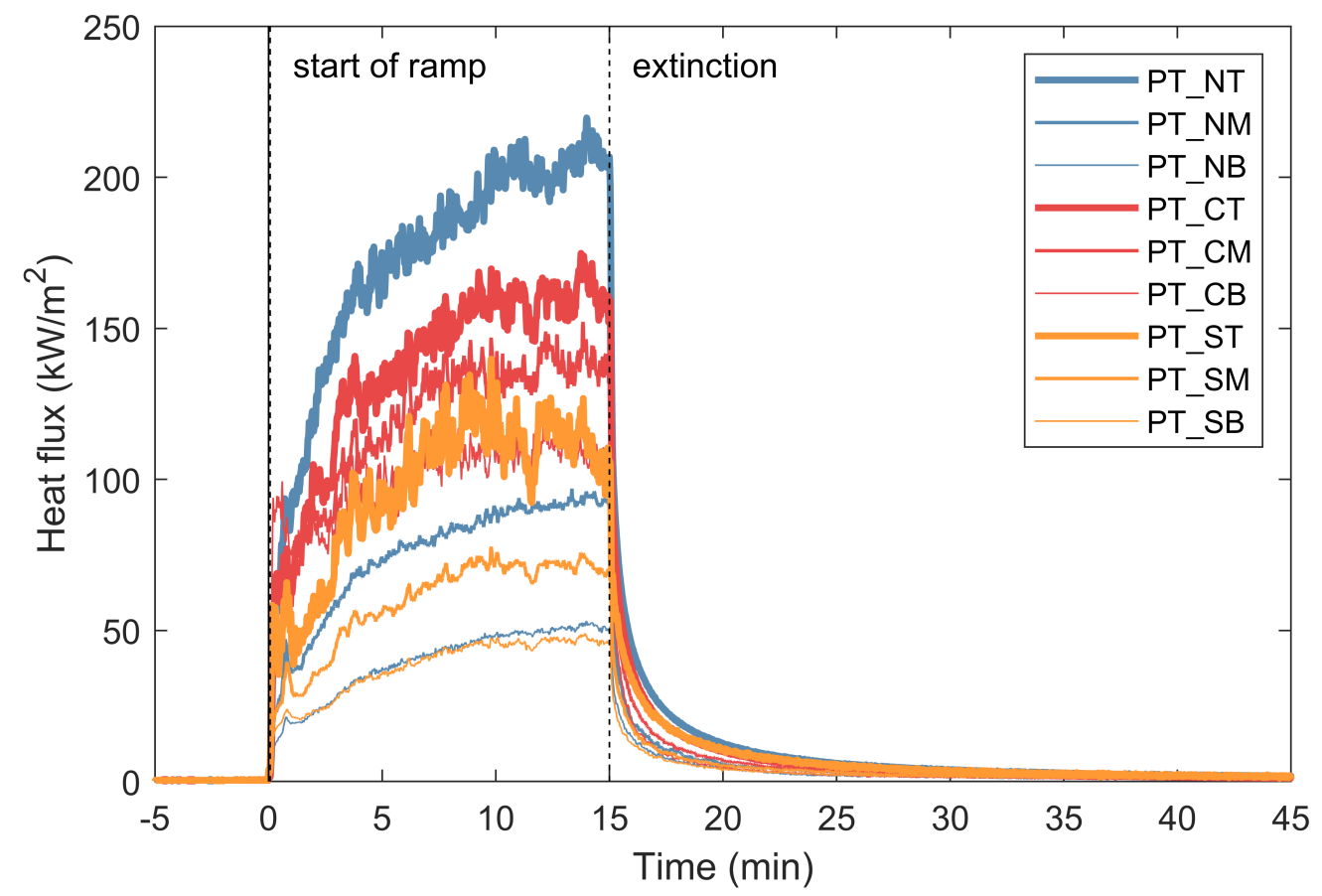

Fig. 411. S05 - Heat fluxes in the compartment measured by the plate thermocouples.
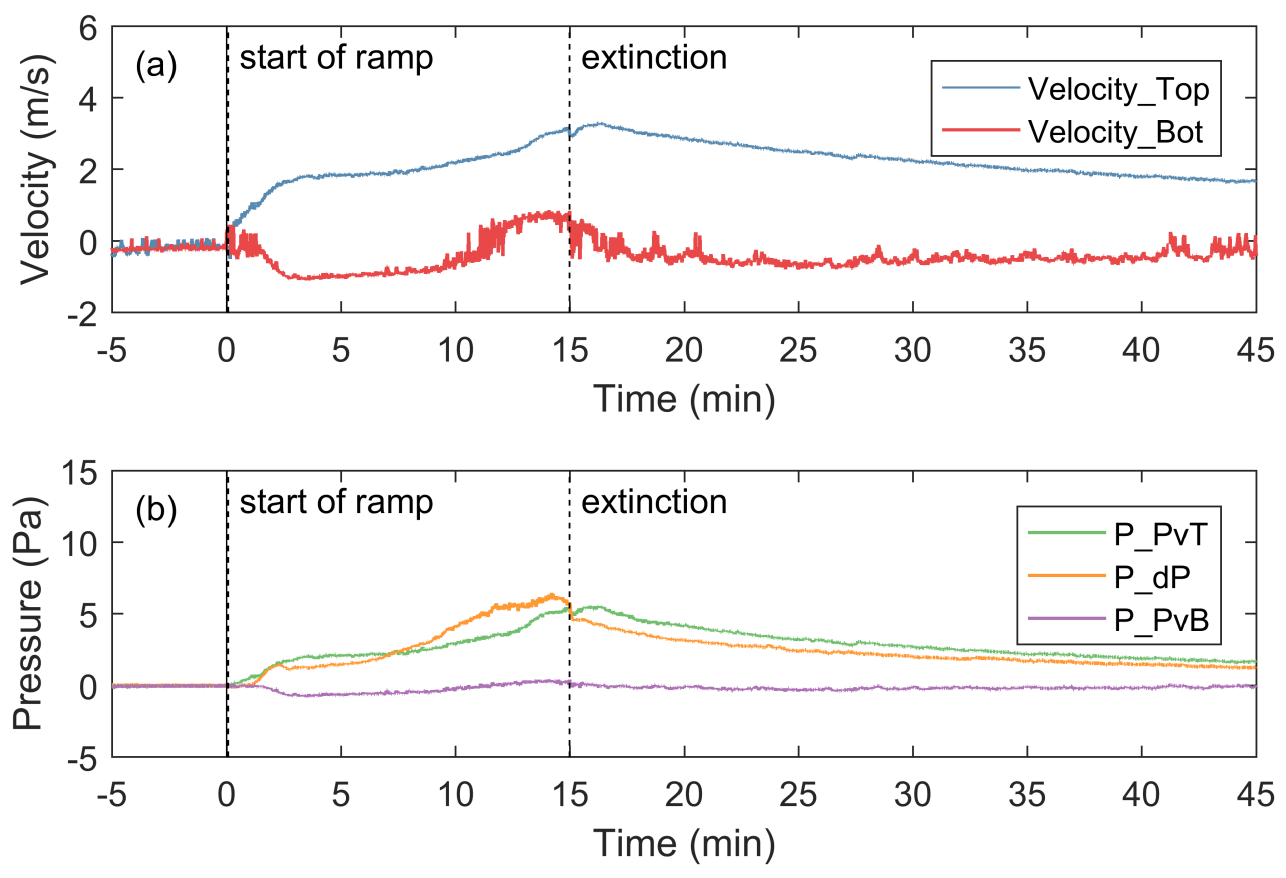

Fig. 412. S05 - (a) Velocity of air flow at the top and bottom knockouts of the chord stud; (b) Pressure at the top and bottom knockouts of the chord stud and in the wall cavity near the top. 


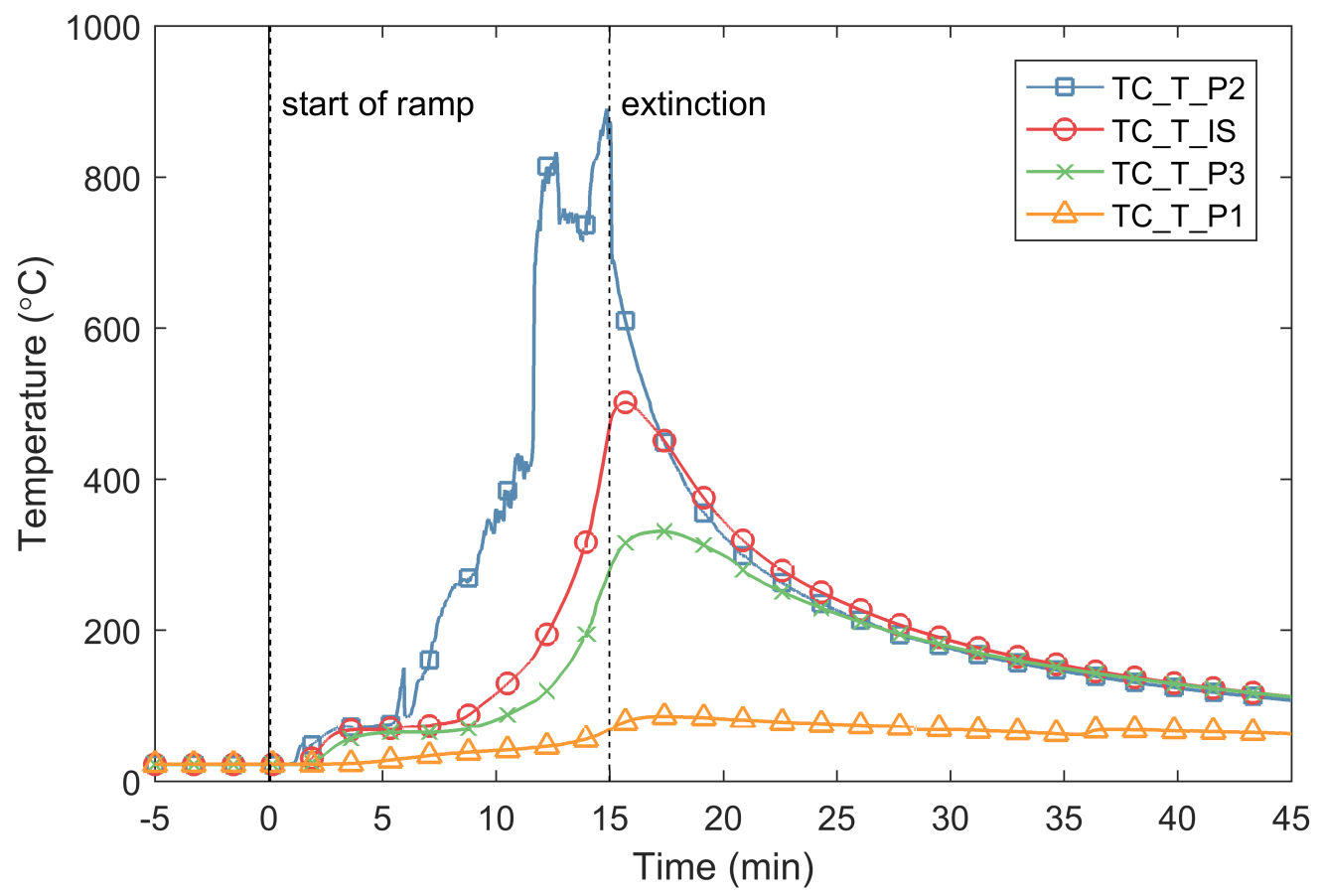

Fig. 413. S05 - Temperatures through the specimen at an interior stud $46 \mathrm{~cm}$ from the top of the wall.

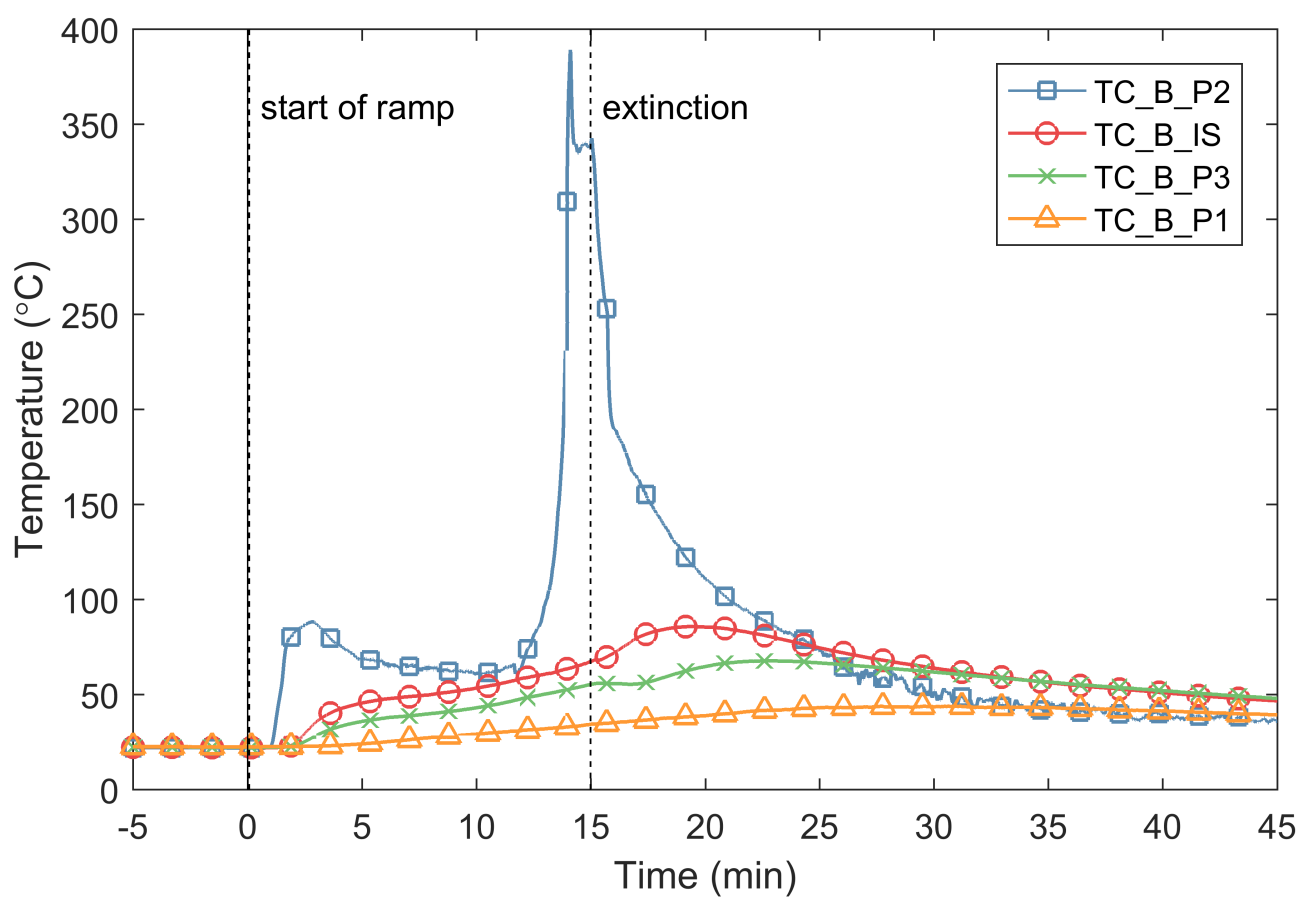

Fig. 414. S05 - Temperatures through the specimen at an interior stud $46 \mathrm{~cm}$ from the bottom of the wall. 


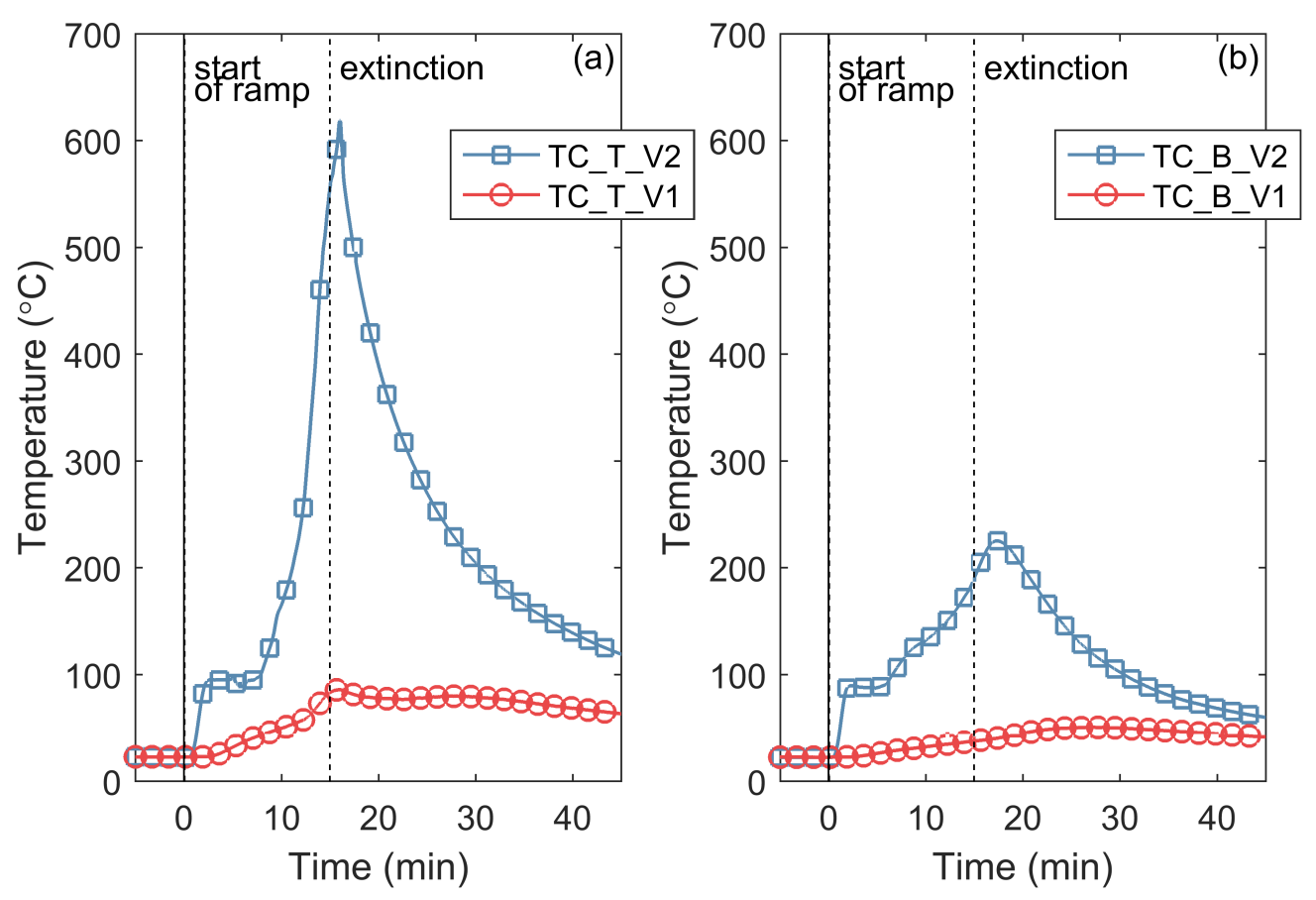

Fig. 415. S05 - Temperatures through the specimen midway between interior studs: (a) $46 \mathrm{~cm}$ from the top of the wall; (b) $46 \mathrm{~cm}$ from the bottom of the wall.
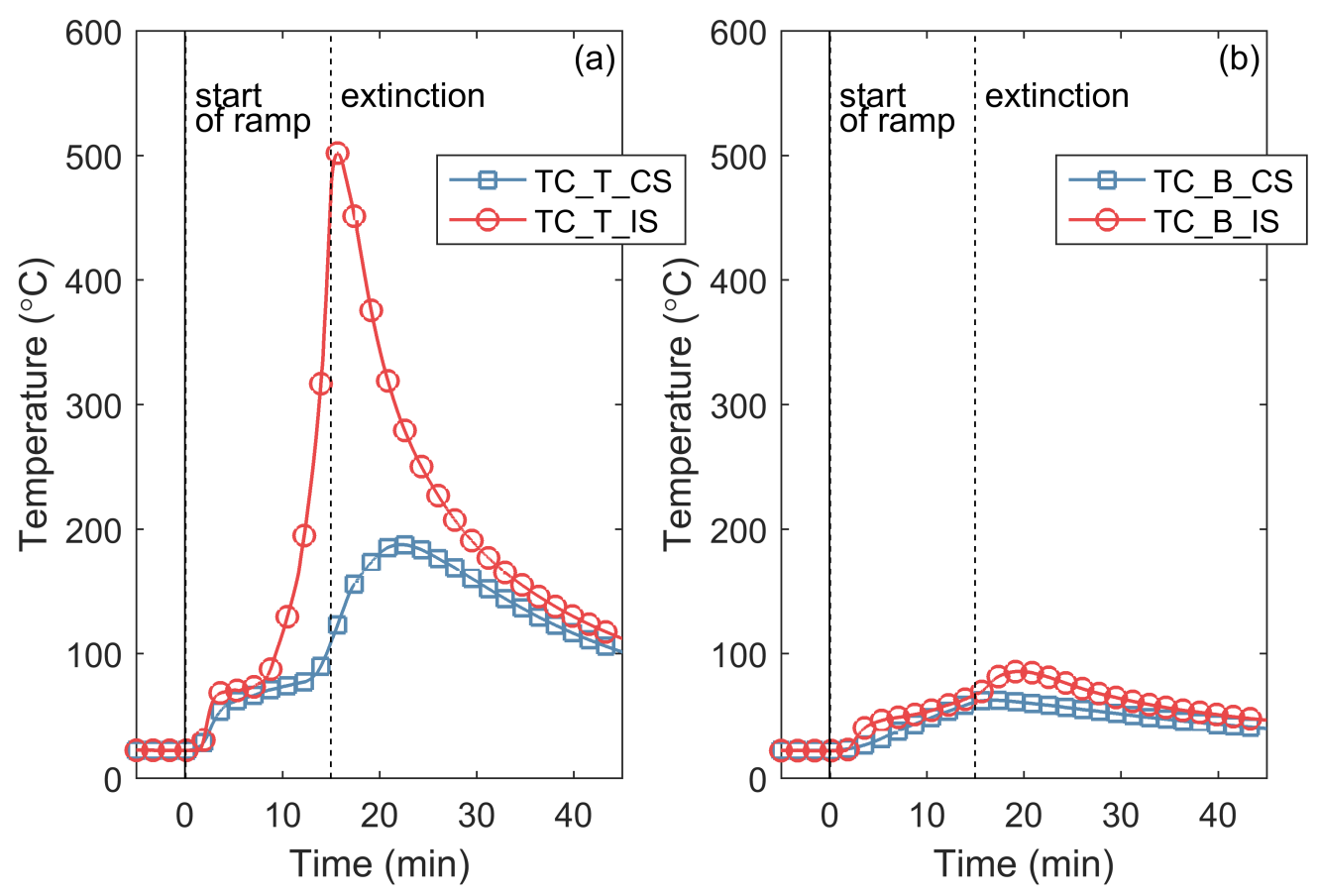

Fig. 416. S05 - Temperatures of the framing elements: (a) $46 \mathrm{~cm}$ from the top of the wall; (b) $46 \mathrm{~cm}$ from the bottom of the wall. 


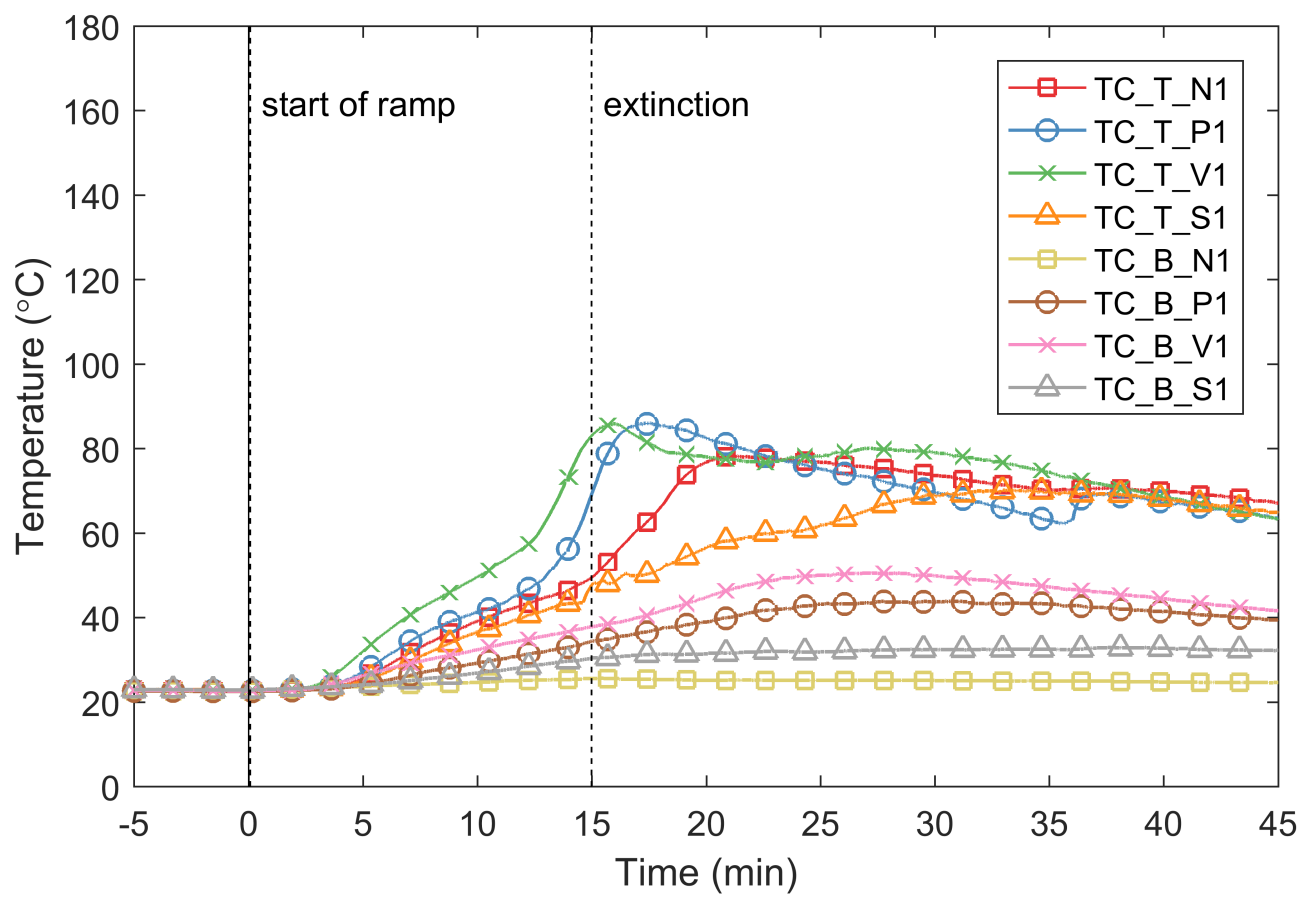

Fig. 417. S05 - Temperatures of the gypsum on the unexposed side of the wall specimen.

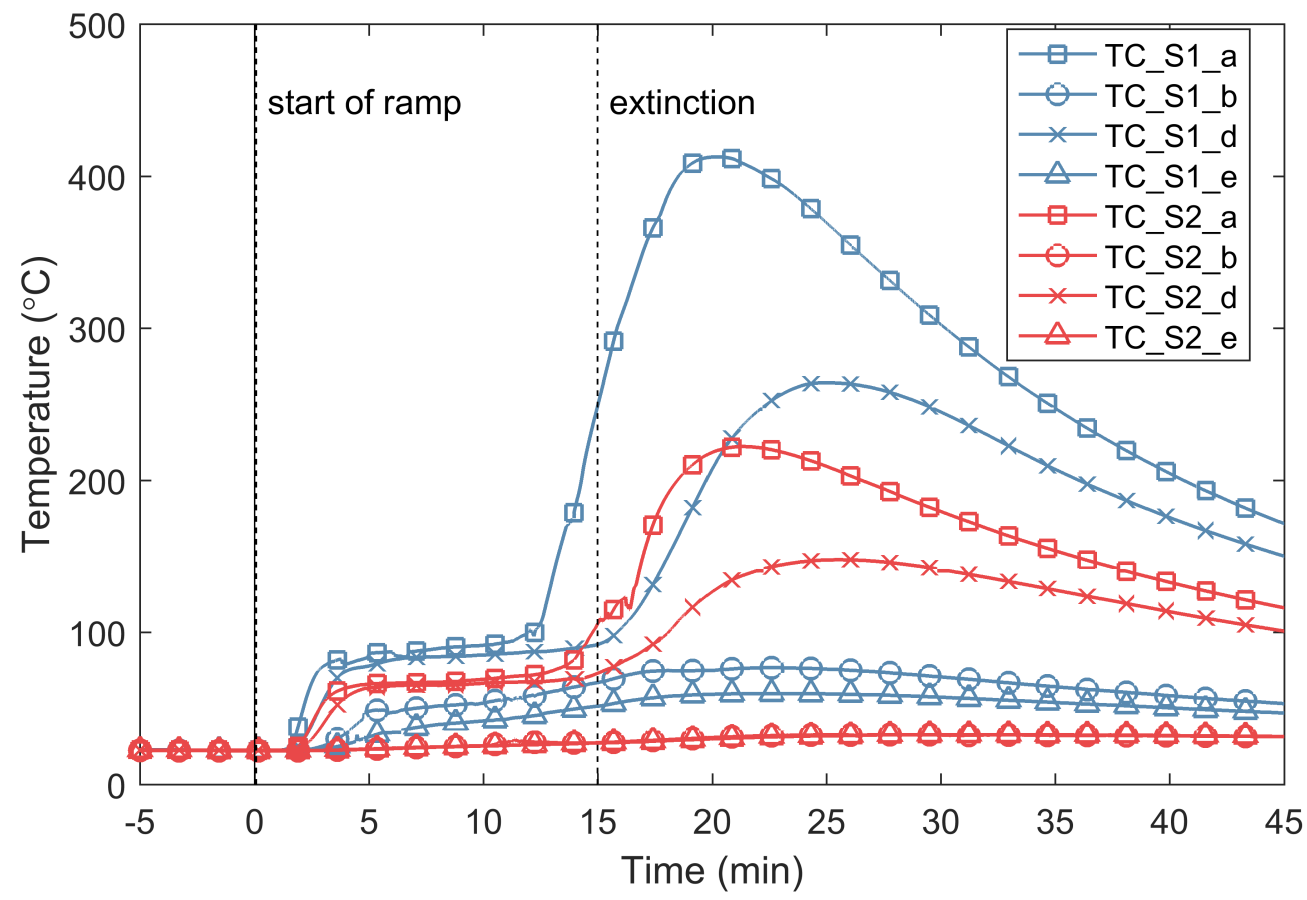

Fig. 418. S05 - Temperatures of the connection between gusset plates and strap braces. 


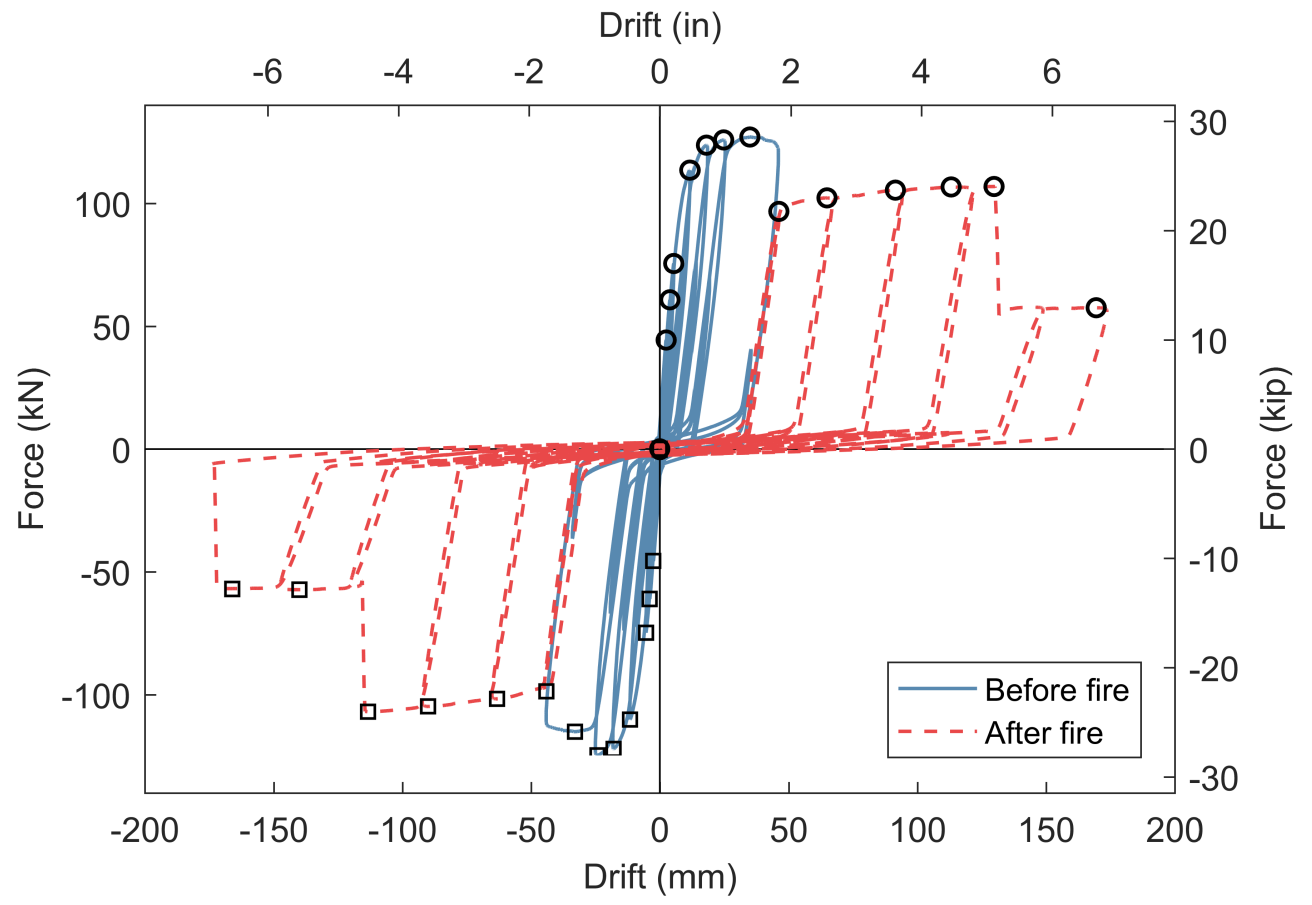

Fig. 419. S05 - Applied load versus wall longitudinal drift during mechanical loading.

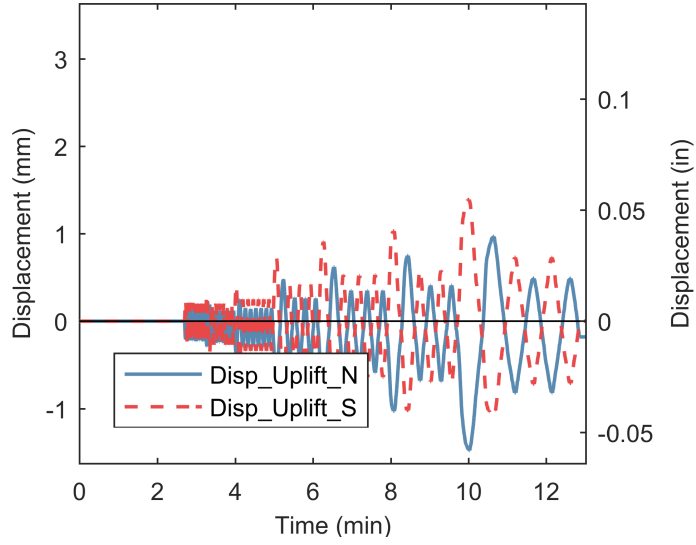

(a)

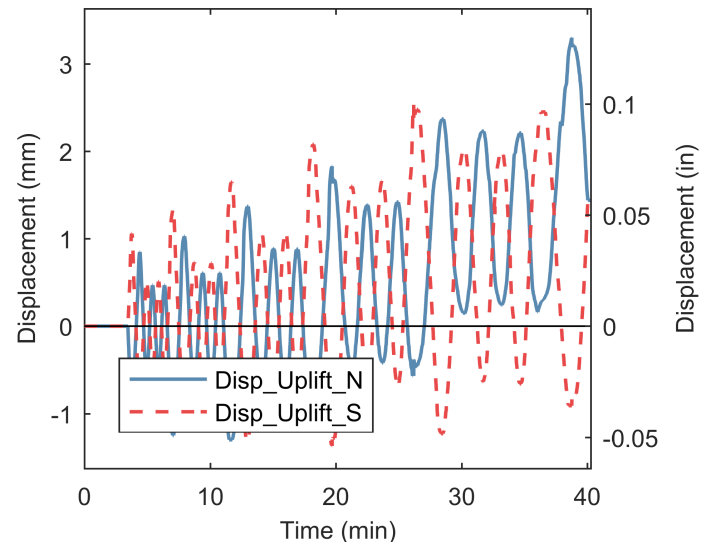

(b)

Fig. 420. S05 - Uplift at bottom of wall during mechanical loading: (a) before fire; (b) after fire. 


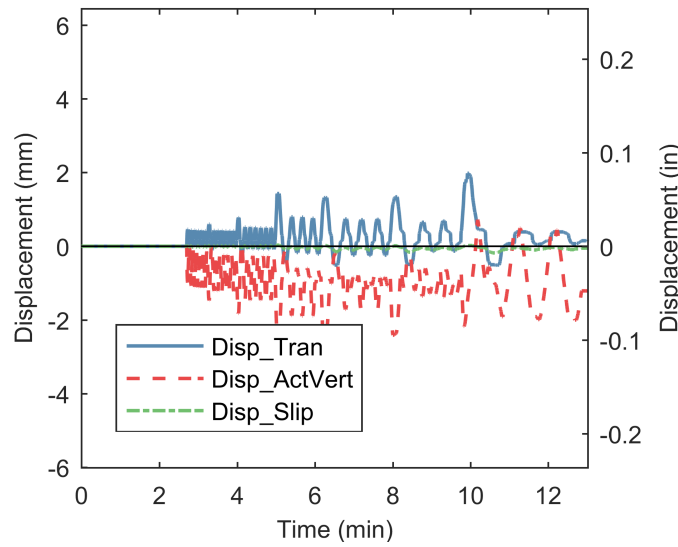

(a)

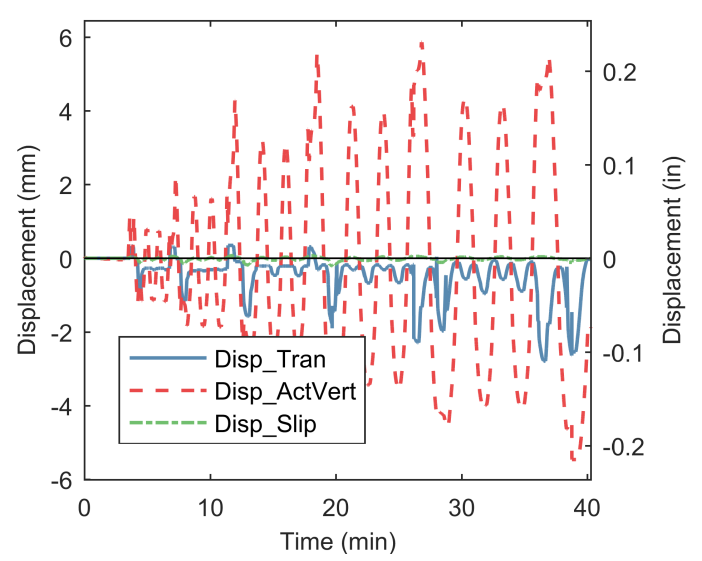

(b)

Fig. 421. S05 - Ancillary displacement measurements during mechanical loading: (a) before fire; (b) after fire.

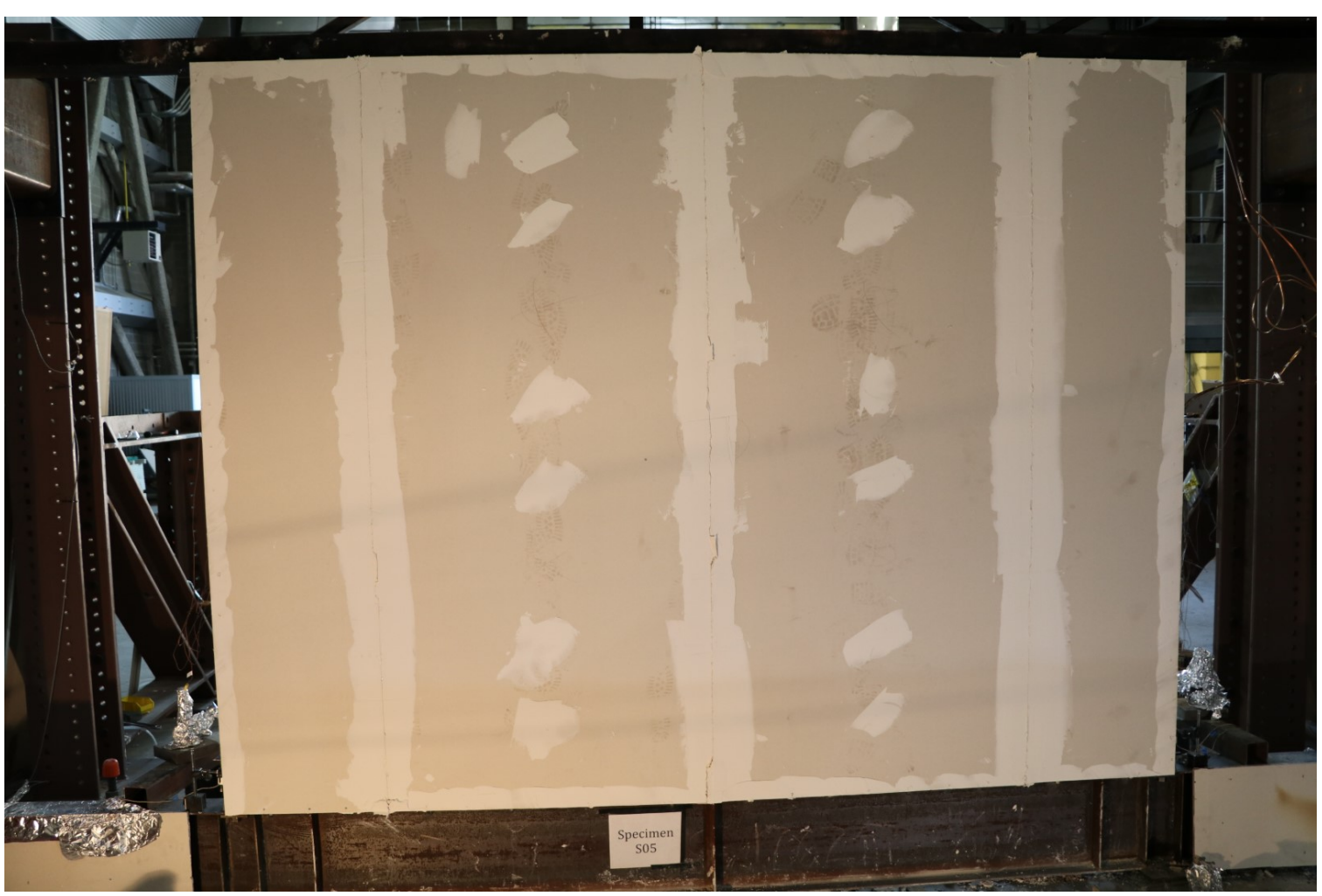

Fig. 422. S05 - Photograph of east (fire exposed) side of wall after cycling to $1.75 \%$ drift (before fire). 


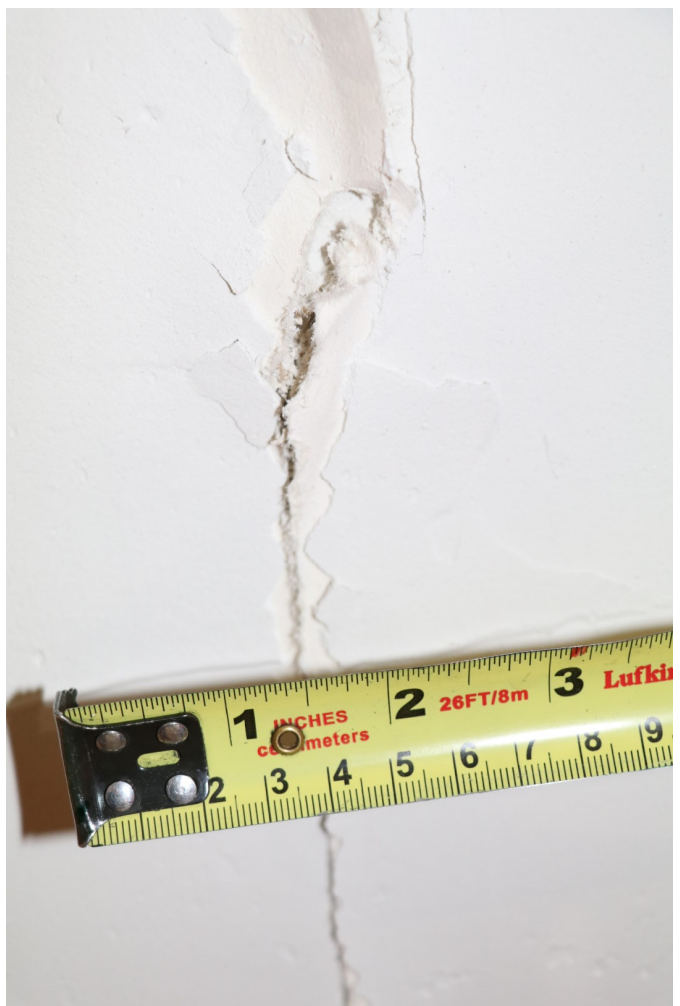

Fig. 423. S05 - Photograph of damage to mud and tape at top of east (fire exposed) side of wall after cycling to $1.75 \%$ drift (before fire) $(1 \mathrm{in} .=25.4 \mathrm{~mm})$.

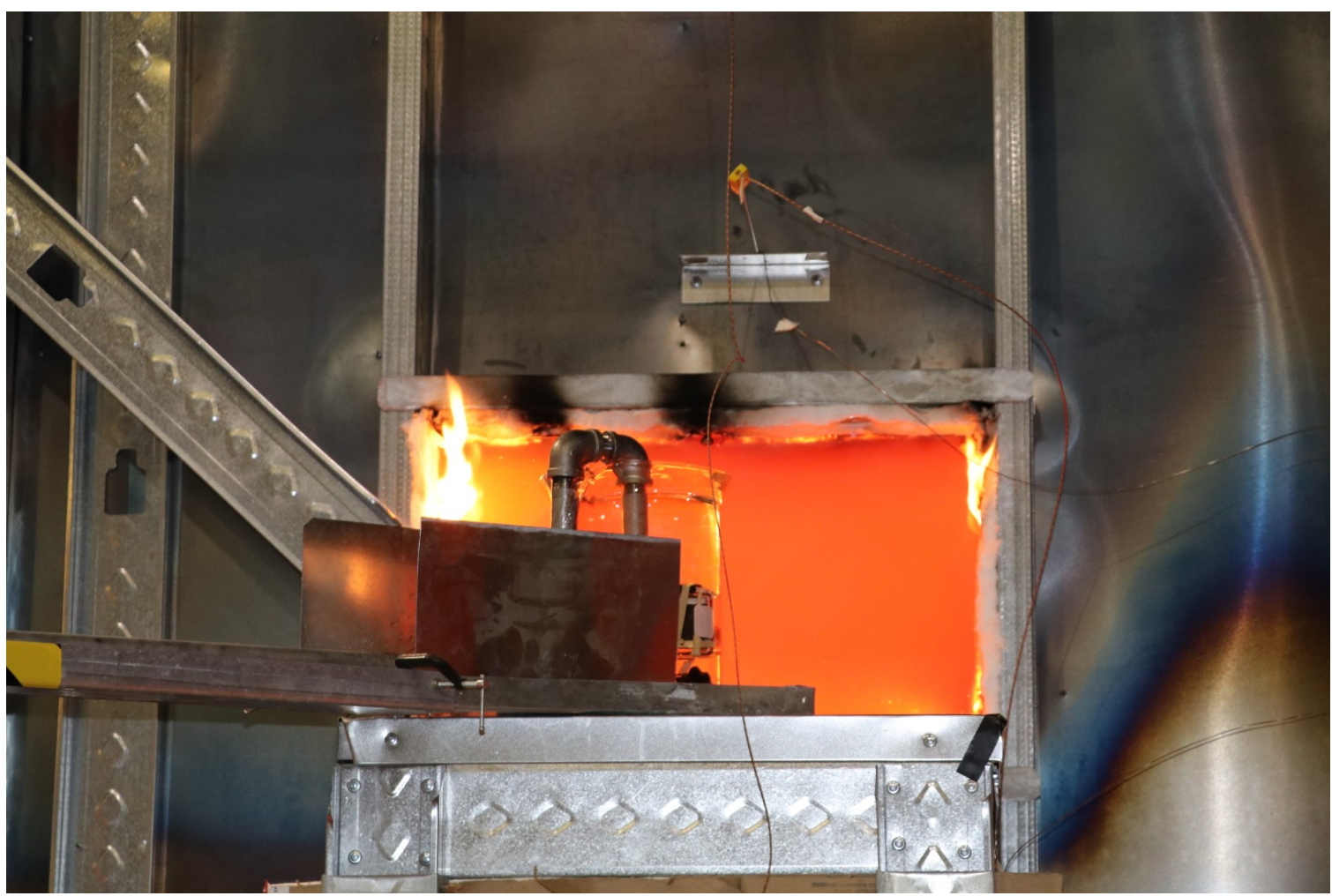

Fig. 424. S05 - Photograph of flame leakage at camera window. 


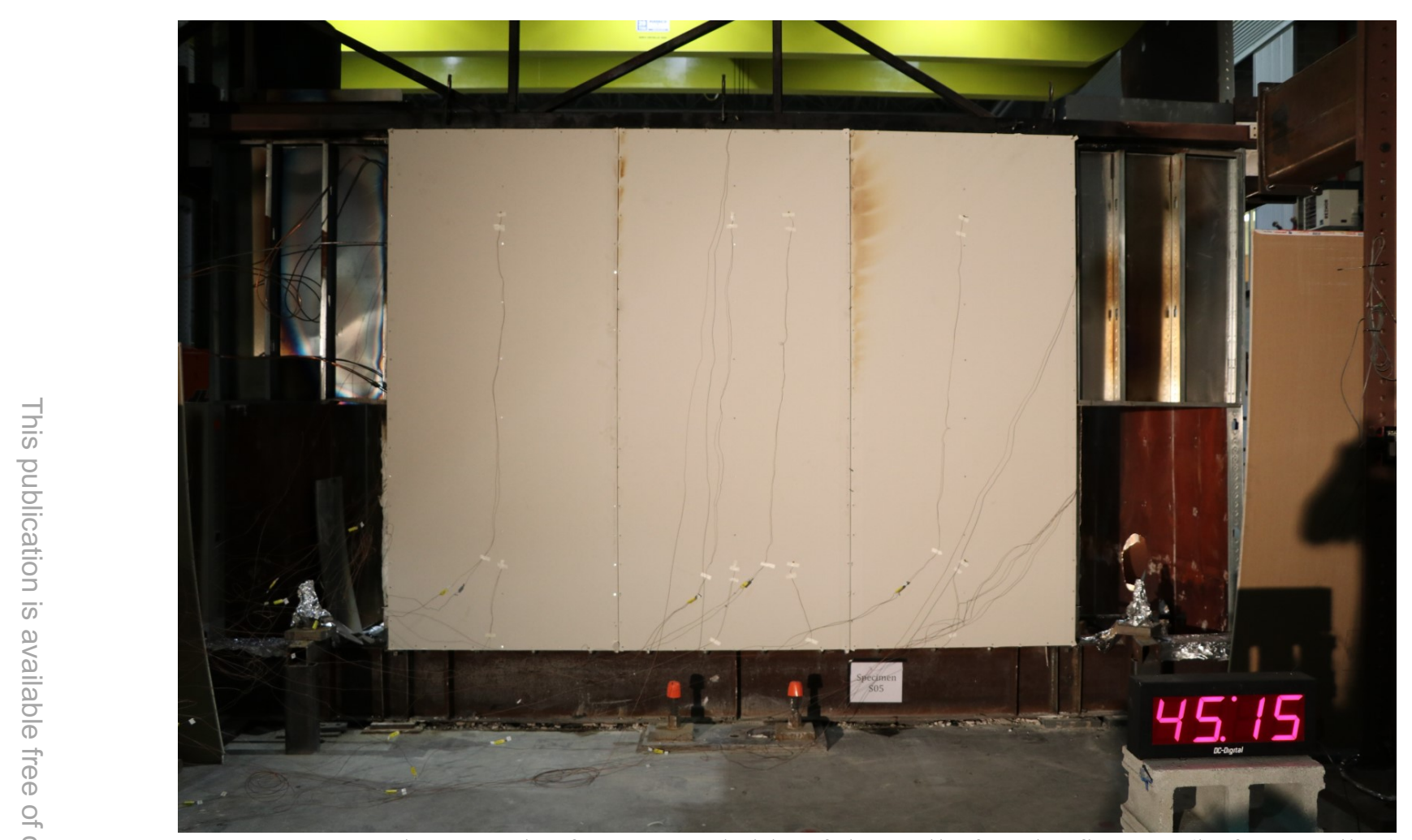

Fig. 425. S05 - Photograph of unexposed side of the wall after the fire test (before cycling).

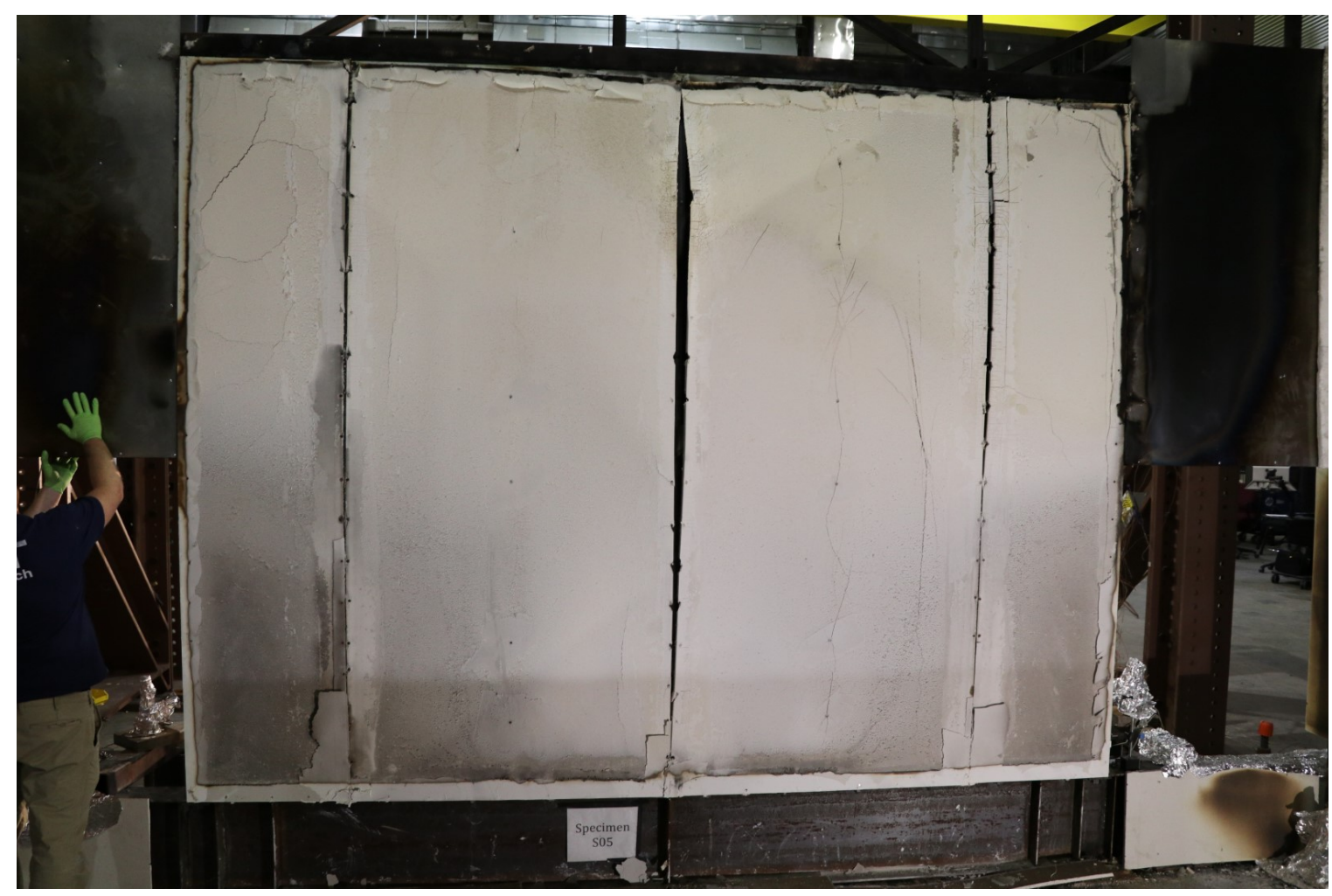

Fig. 426. S05 - Photograph of exposed side of the wall after the fire test (before cycling). 


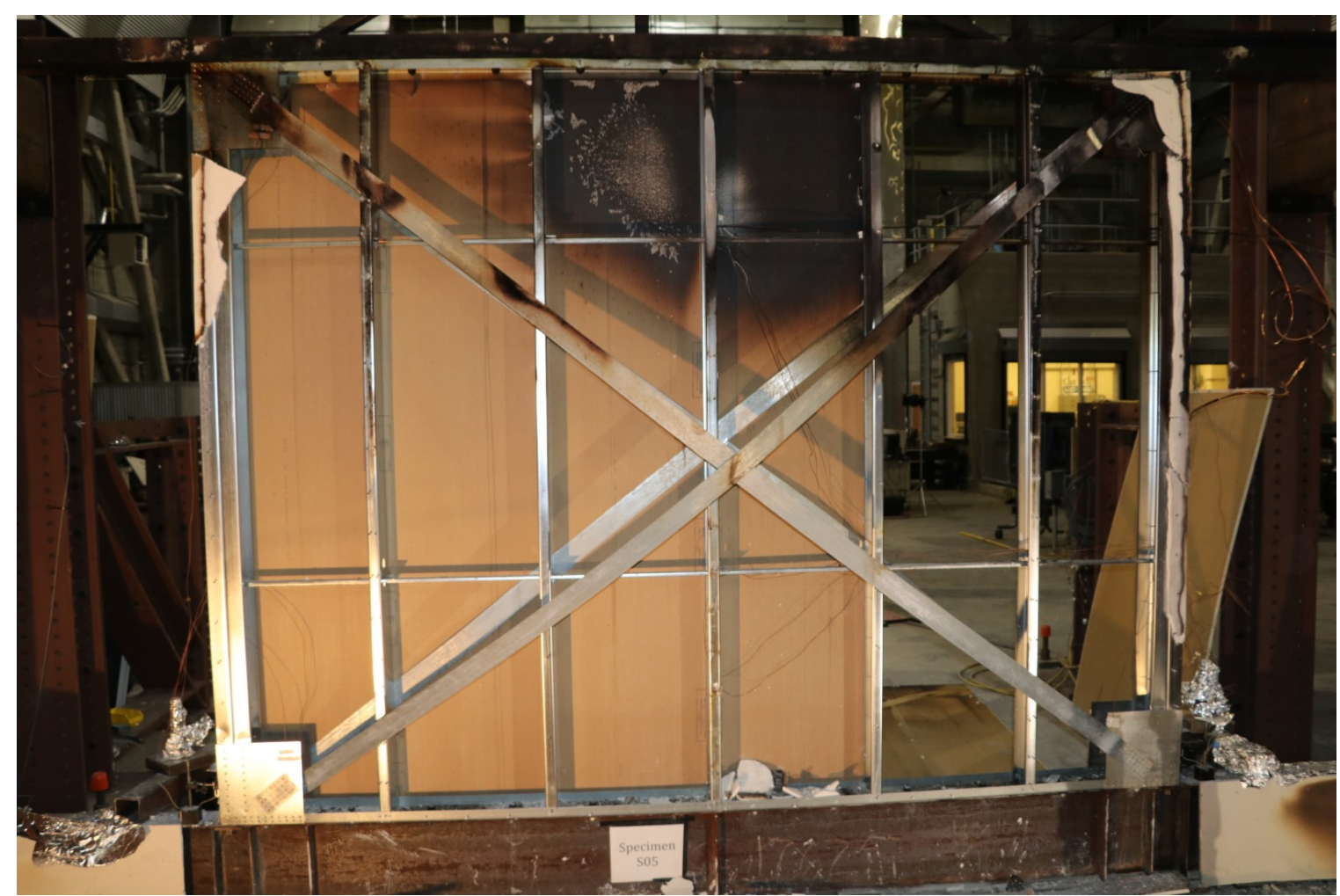

Fig. 427. S05 - Photograph of exposed side of the wall after load cycling following the fire test. 


\section{S06 Data}

S06a (Cyclic test of wall to $0.5 \%$ SDR at ambient temperature)

- Overall behavior was similar to ambient test S01R.

- No damage visible on west wall (unexposed side).

- Damage to skim coat on north and center seams (exposed side). Local uplift of tape at several locations (Fig. 442 to Fig. 444).

S06b (Mild Fire test after cyclic test to $0.5 \%$ SDR)

- Added 4" wide kaowool 'gasket' to burner under main layer at edge to reduce gas leakage at the edges.

- The temperatures inside the compartment are more symmetric in this test (Fig. 429). S06c (Cyclic test of wall at ambient temperature following mild fire)

- No comments.

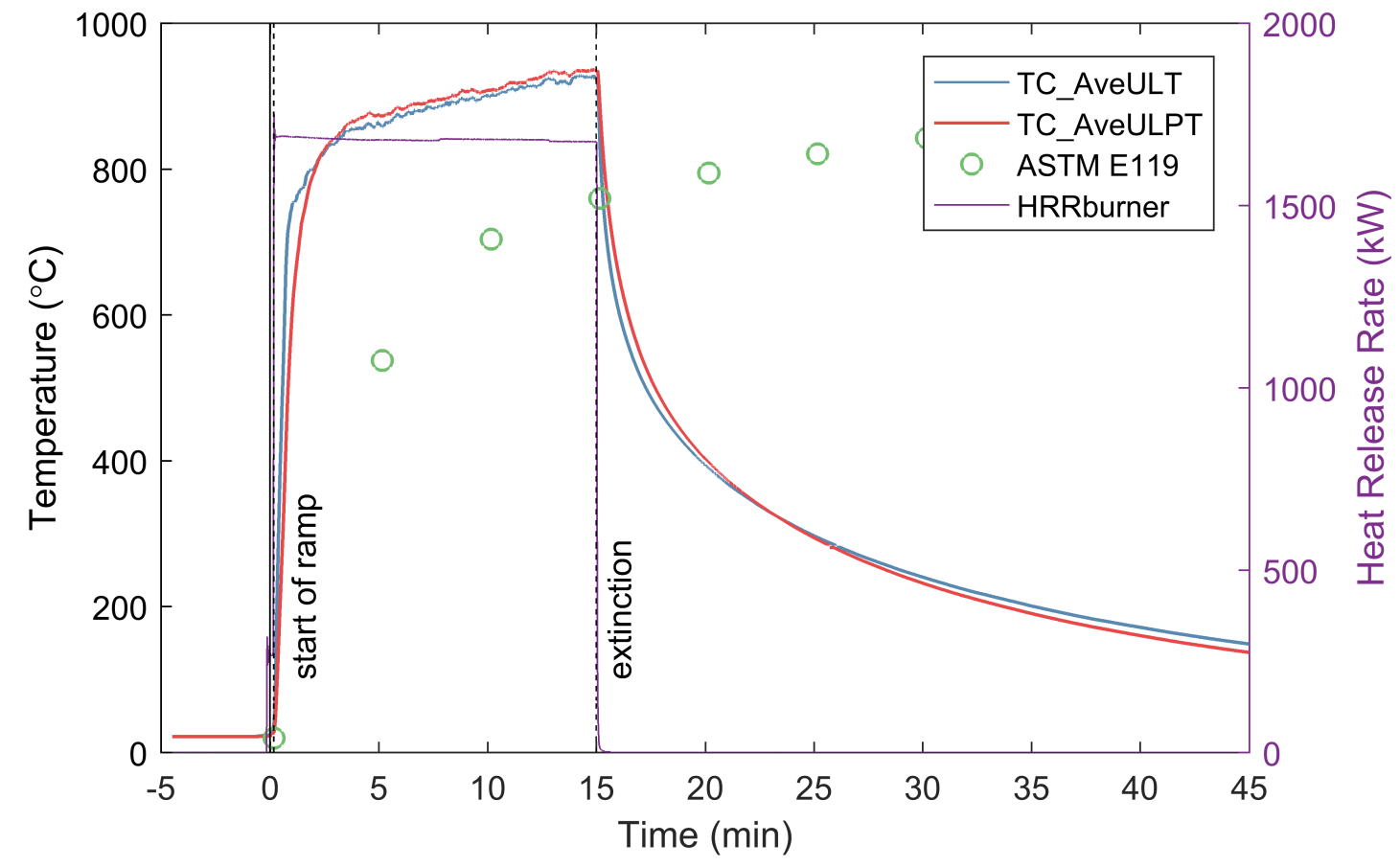

Fig. 428. S06 - Compartment temperatures and burner Heat Release Rate. 


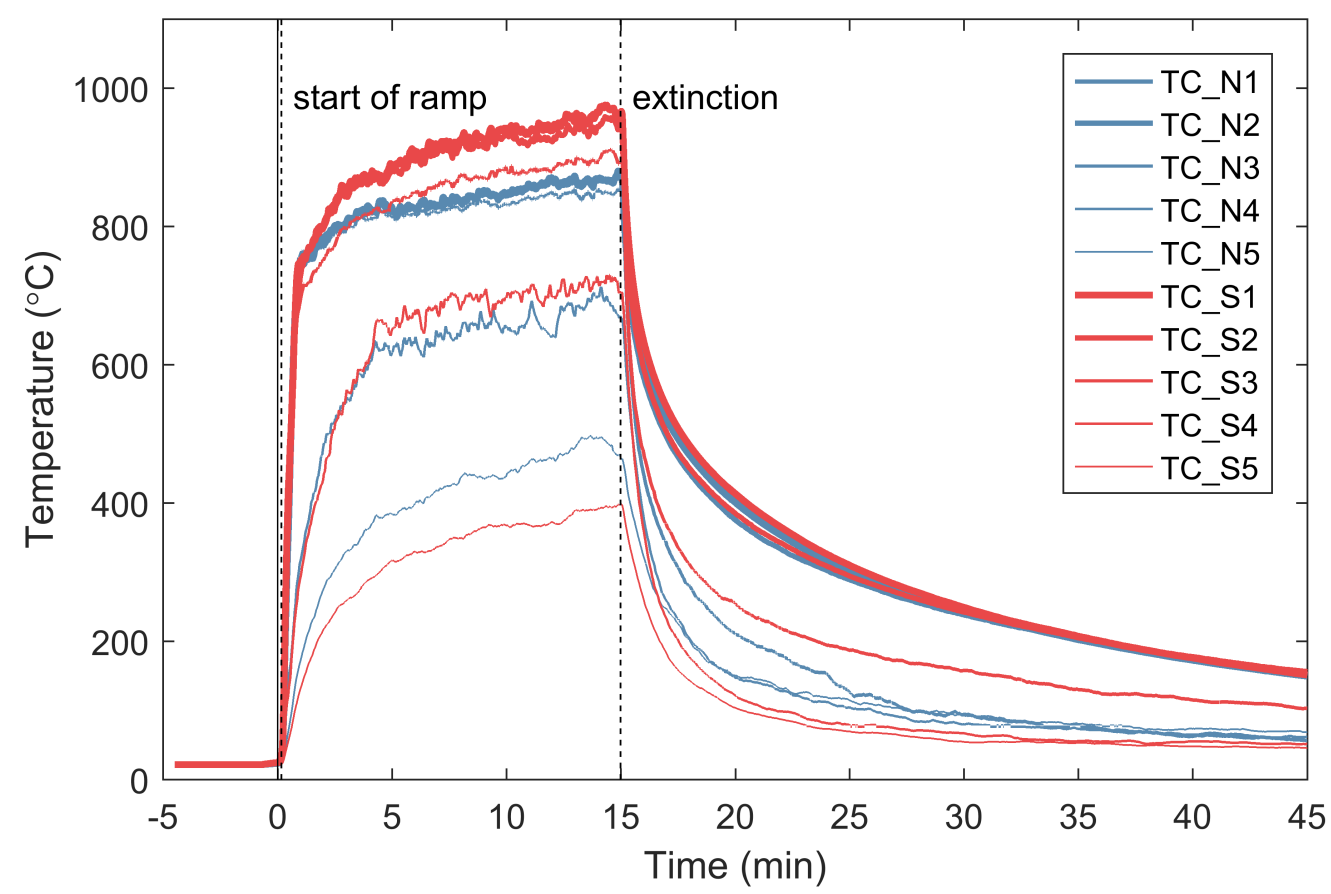

Fig. 429. S06 - Compartment temperatures measured by the thermocouple arrays.

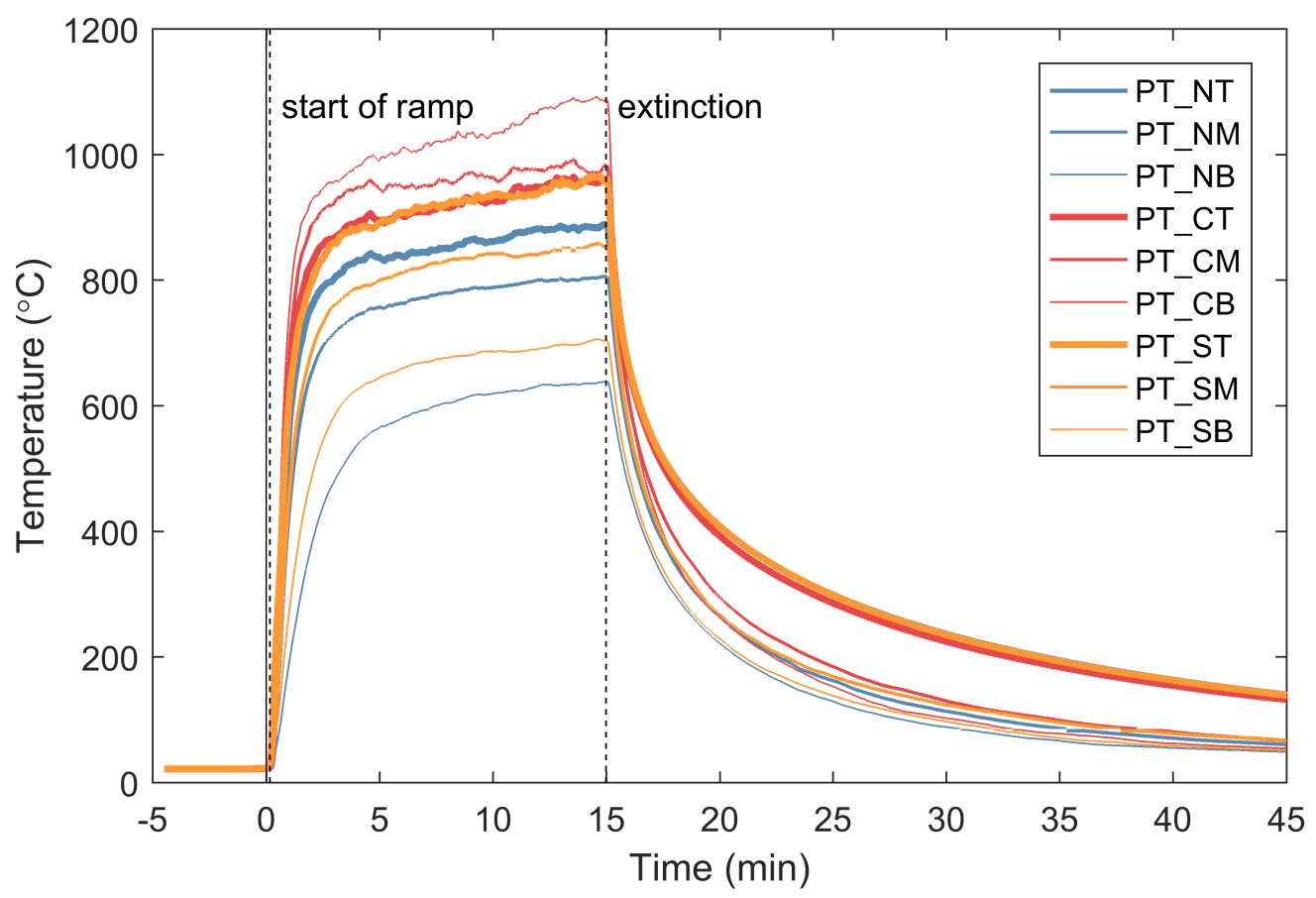

Fig. 430. S06 - Compartment temperatures measured by the plate thermocouples. 


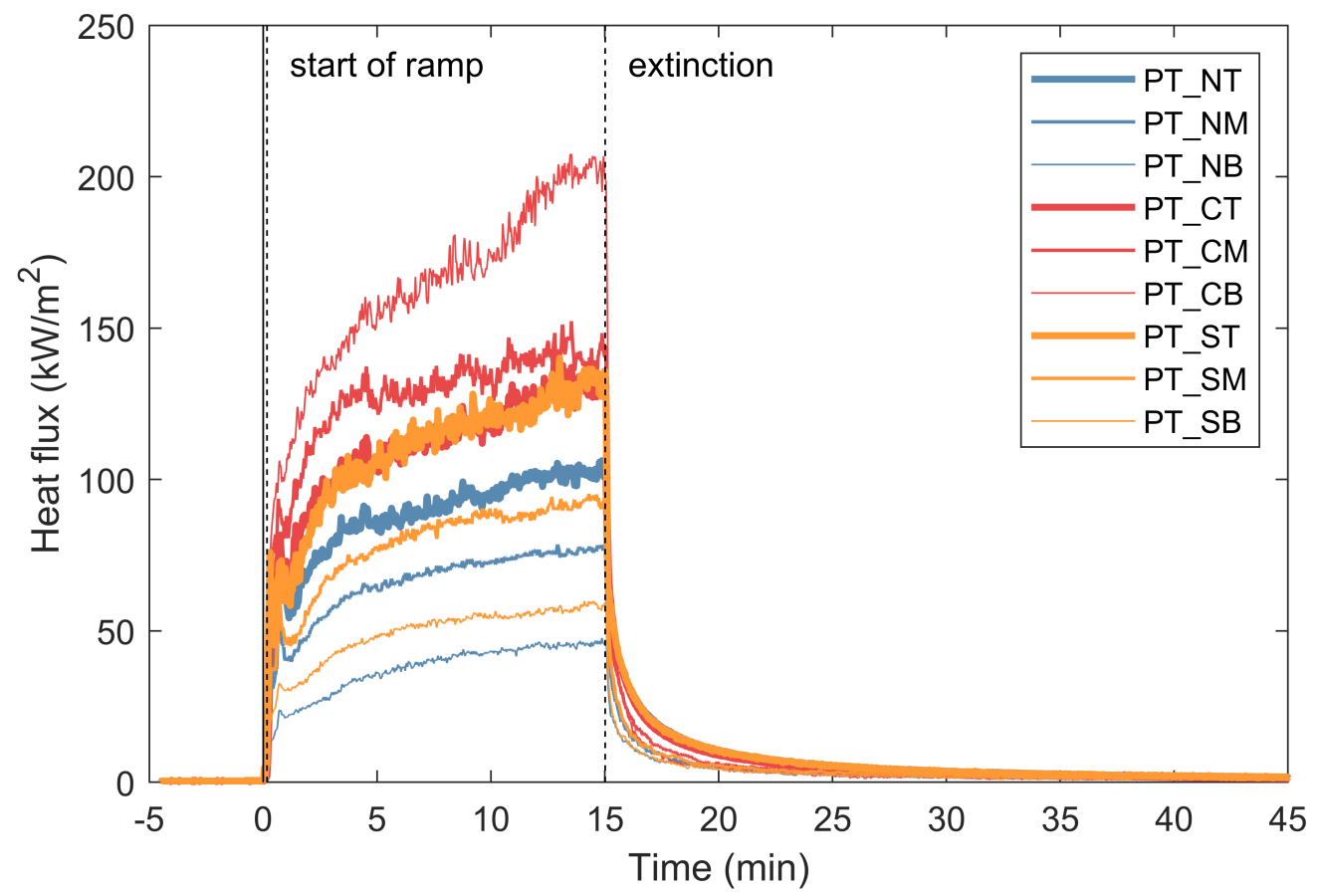

Fig. 431. S06 - Heat fluxes in the compartment measured by the plate thermocouples.
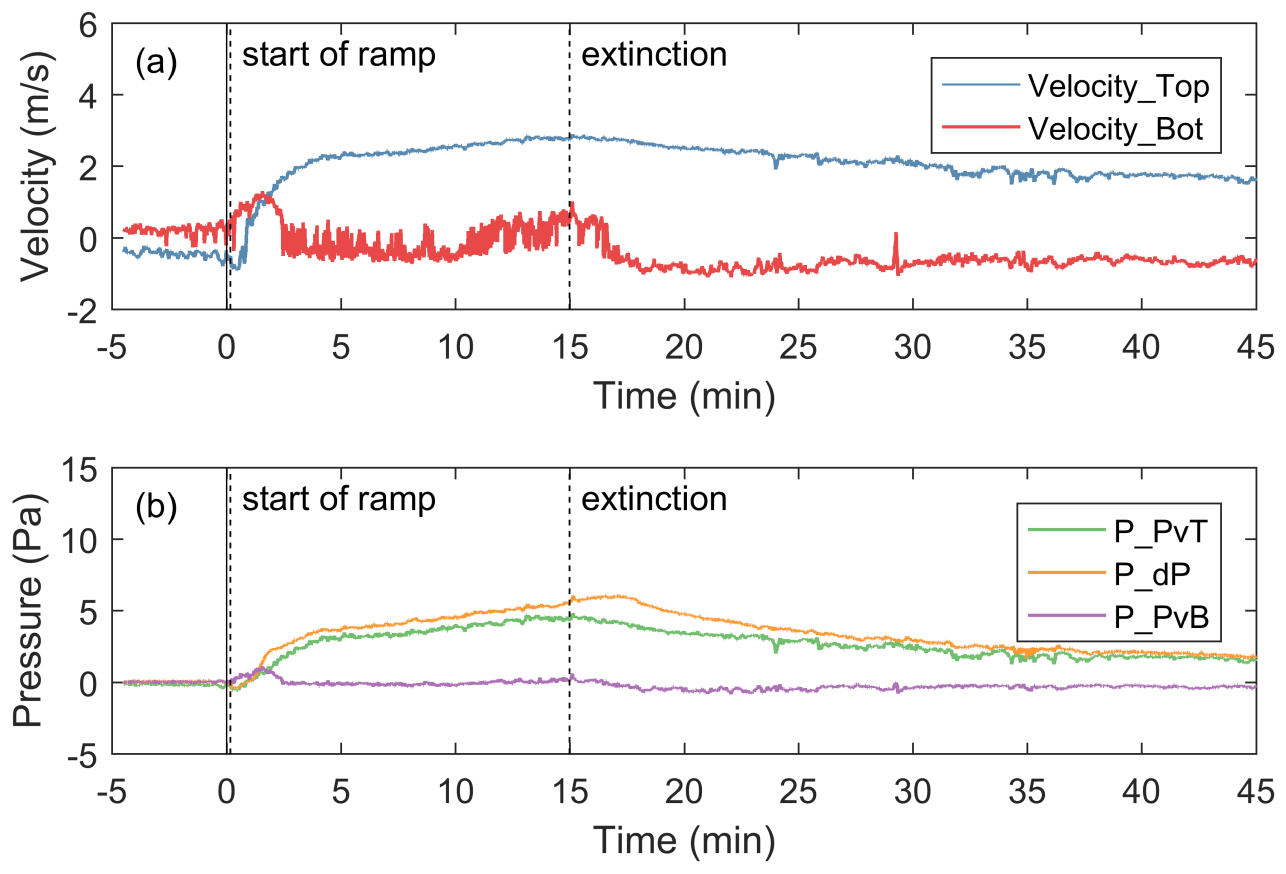

Fig. 432. S06 - (a) Velocity of air flow at the top and bottom knockouts of the chord stud; (b) Pressure at the top and bottom knockouts of the chord stud and in the wall cavity near the top. 


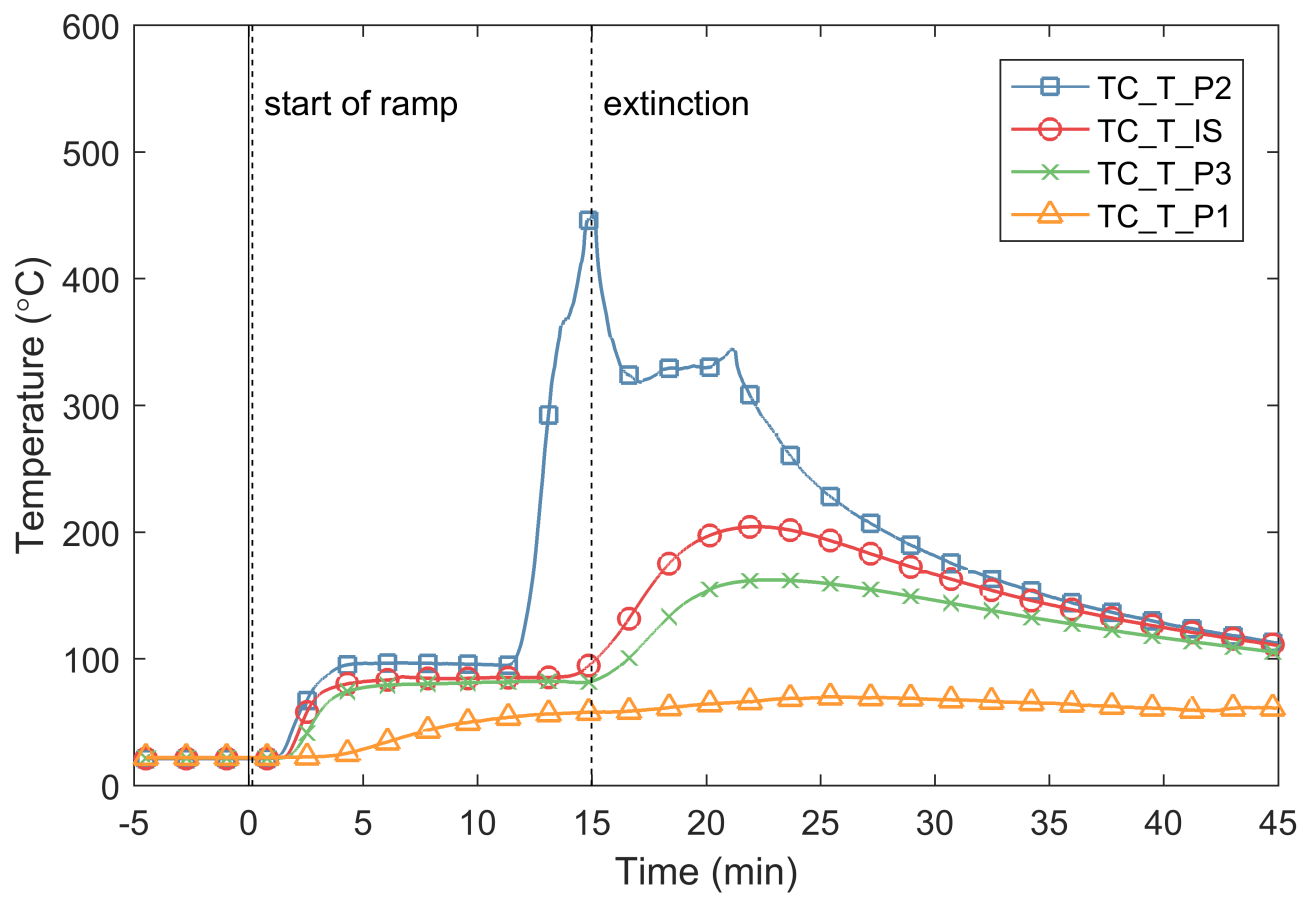

Fig. 433. S06 - Temperatures through the specimen at an interior stud $46 \mathrm{~cm}$ from the top of the wall.

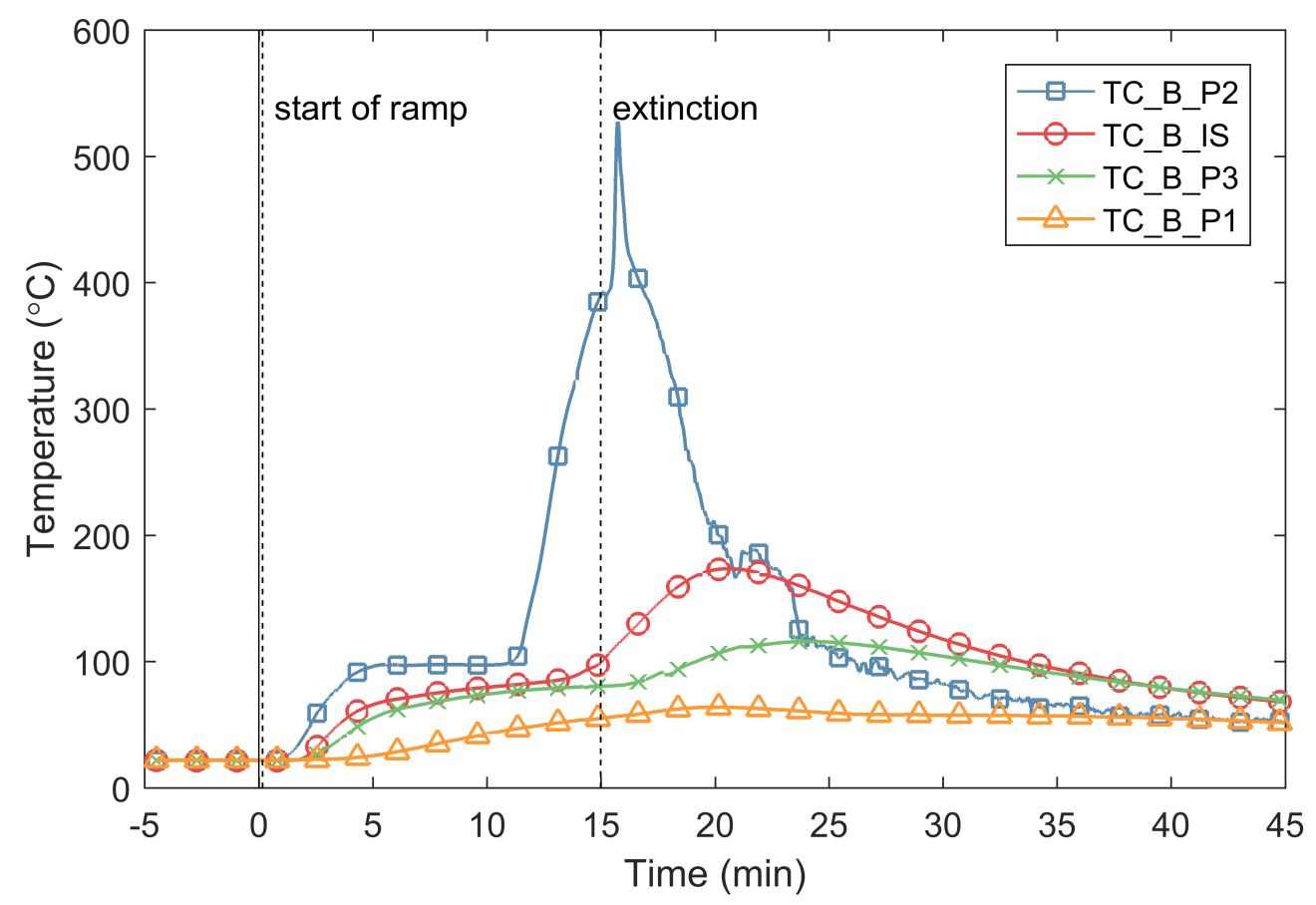

Fig. 434. S06 - Temperatures through the specimen at an interior stud $46 \mathrm{~cm}$ from the bottom of the wall. 

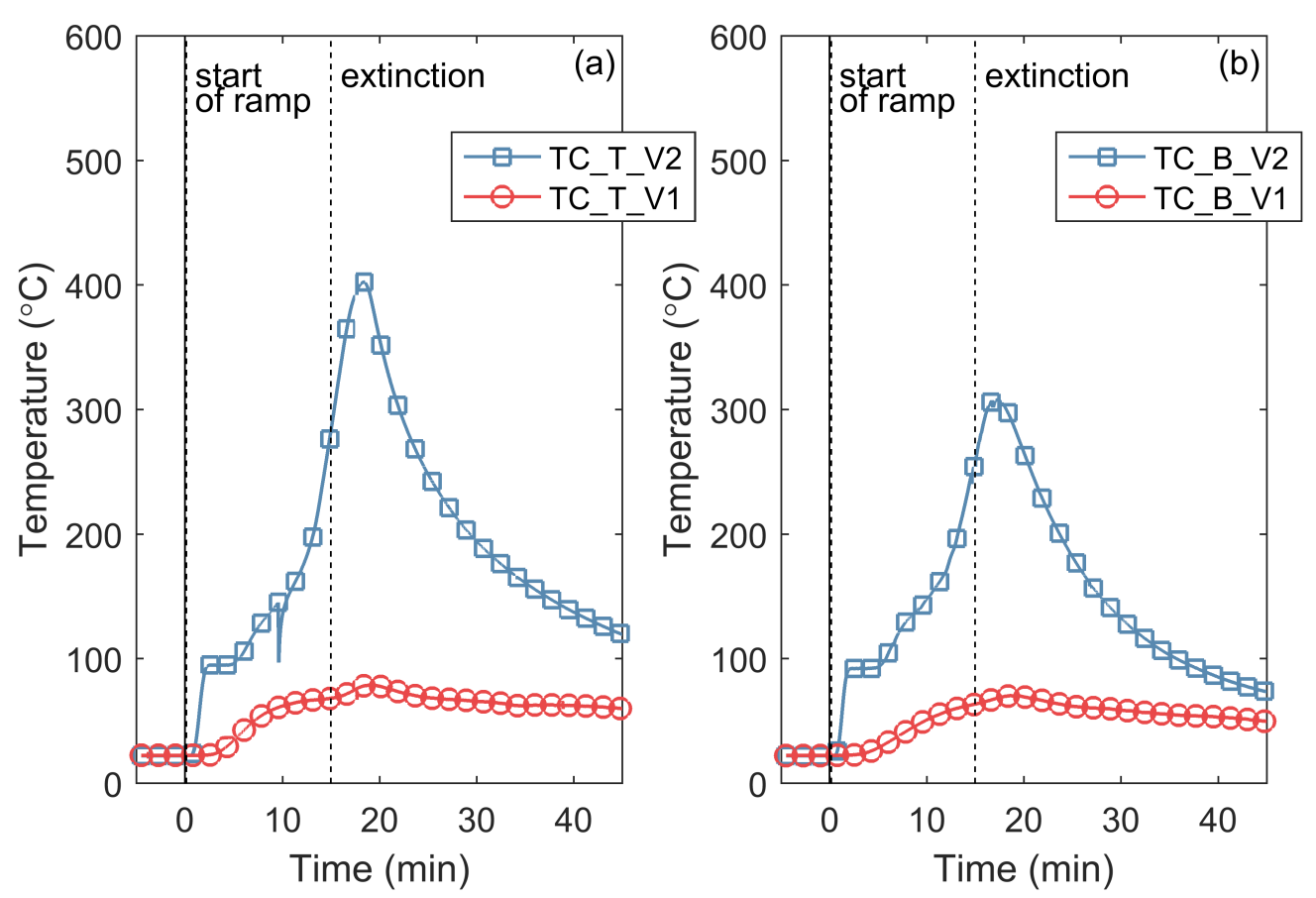

Fig. 435. S06 - Temperatures through the specimen midway between interior studs: (a) $46 \mathrm{~cm}$ from the top of the wall; (b) $46 \mathrm{~cm}$ from the bottom of the wall.
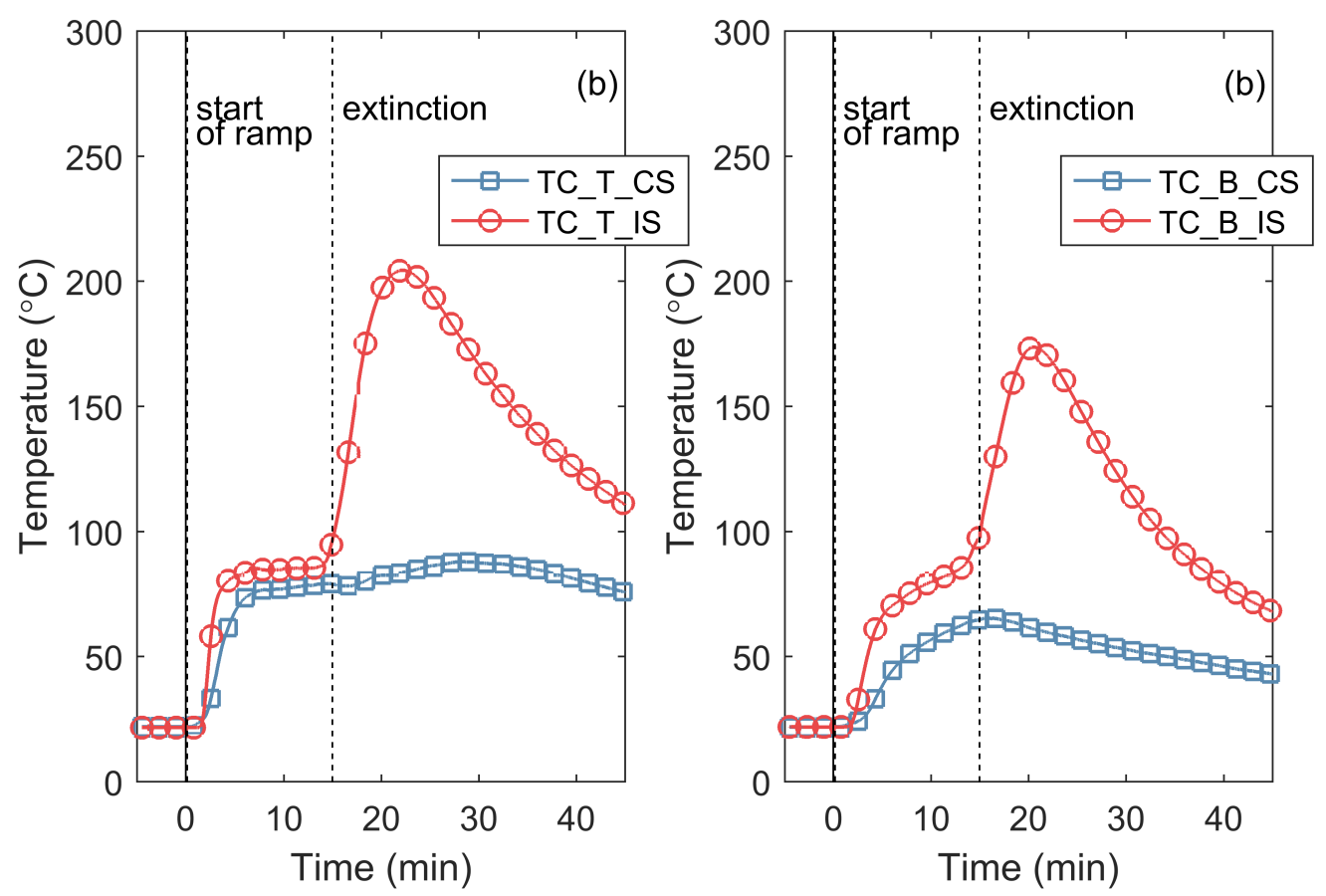

Fig. 436. S06 - Temperatures of the framing elements: (a) $46 \mathrm{~cm}$ from the top of the wall; (b) $46 \mathrm{~cm}$ from the bottom of the wall. 


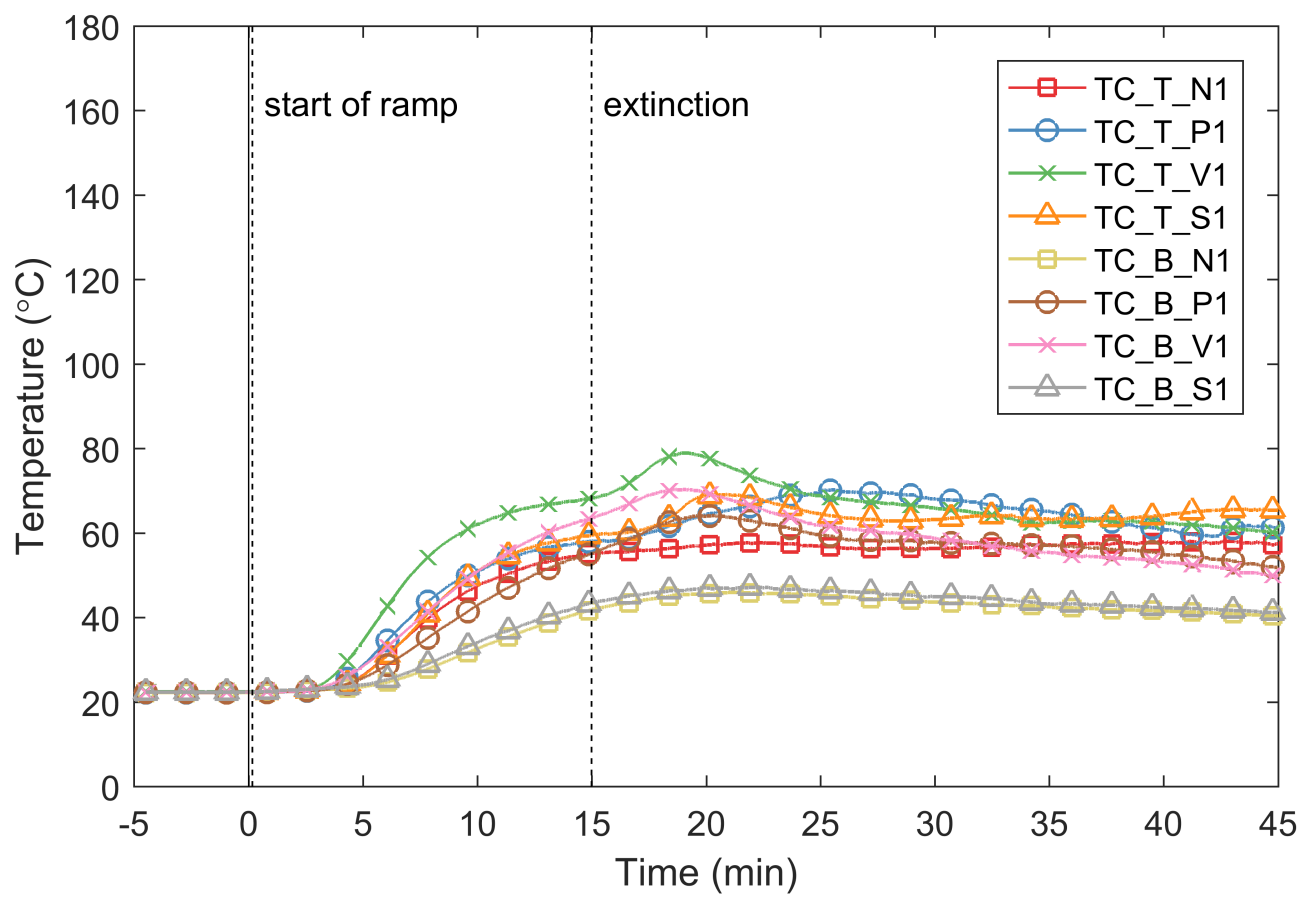

Fig. 437. S06 - Temperatures of the gypsum on the unexposed side of the wall specimen.

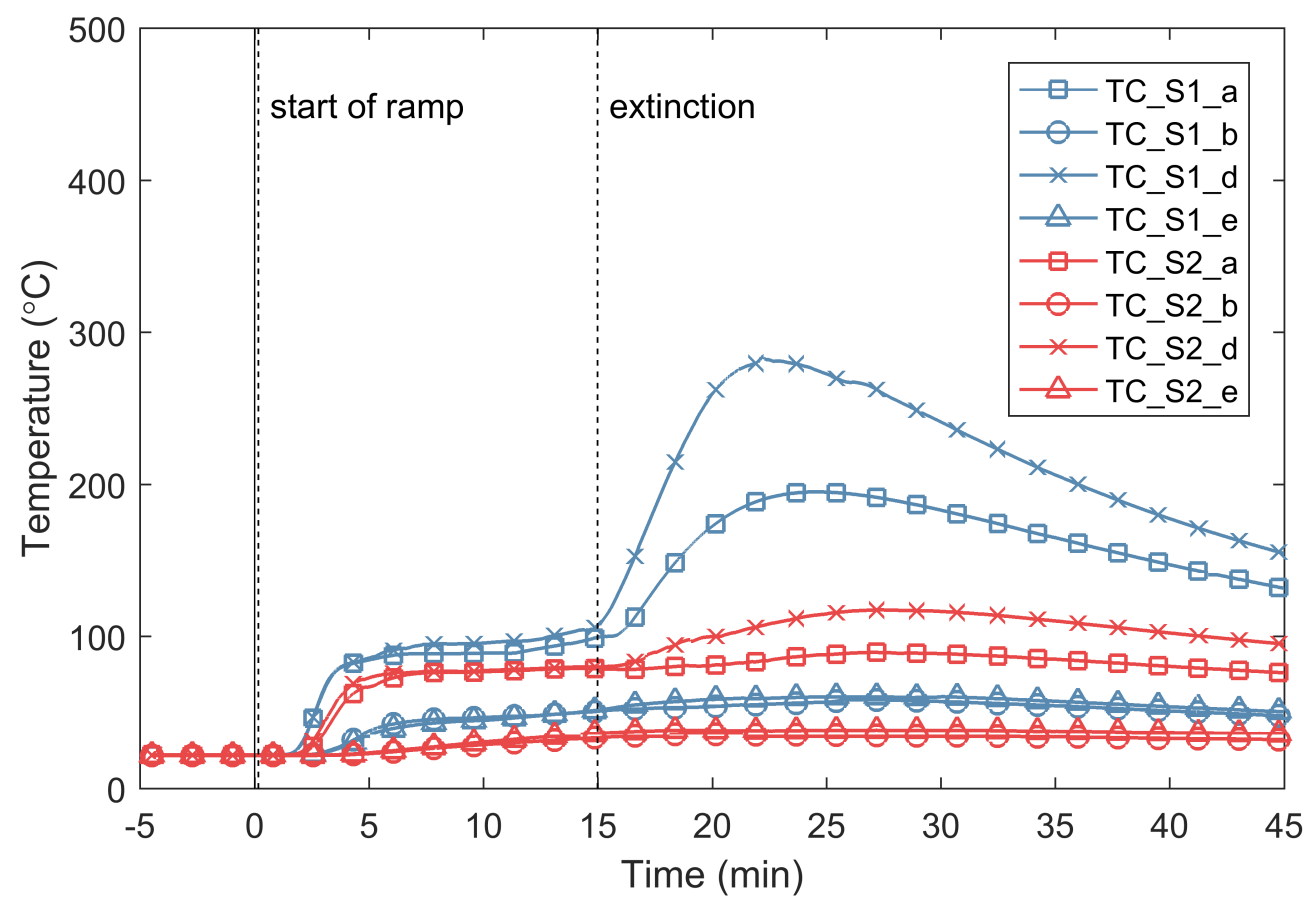

Fig. 438. S06 - Temperatures of the connection between gusset plates and strap braces. 


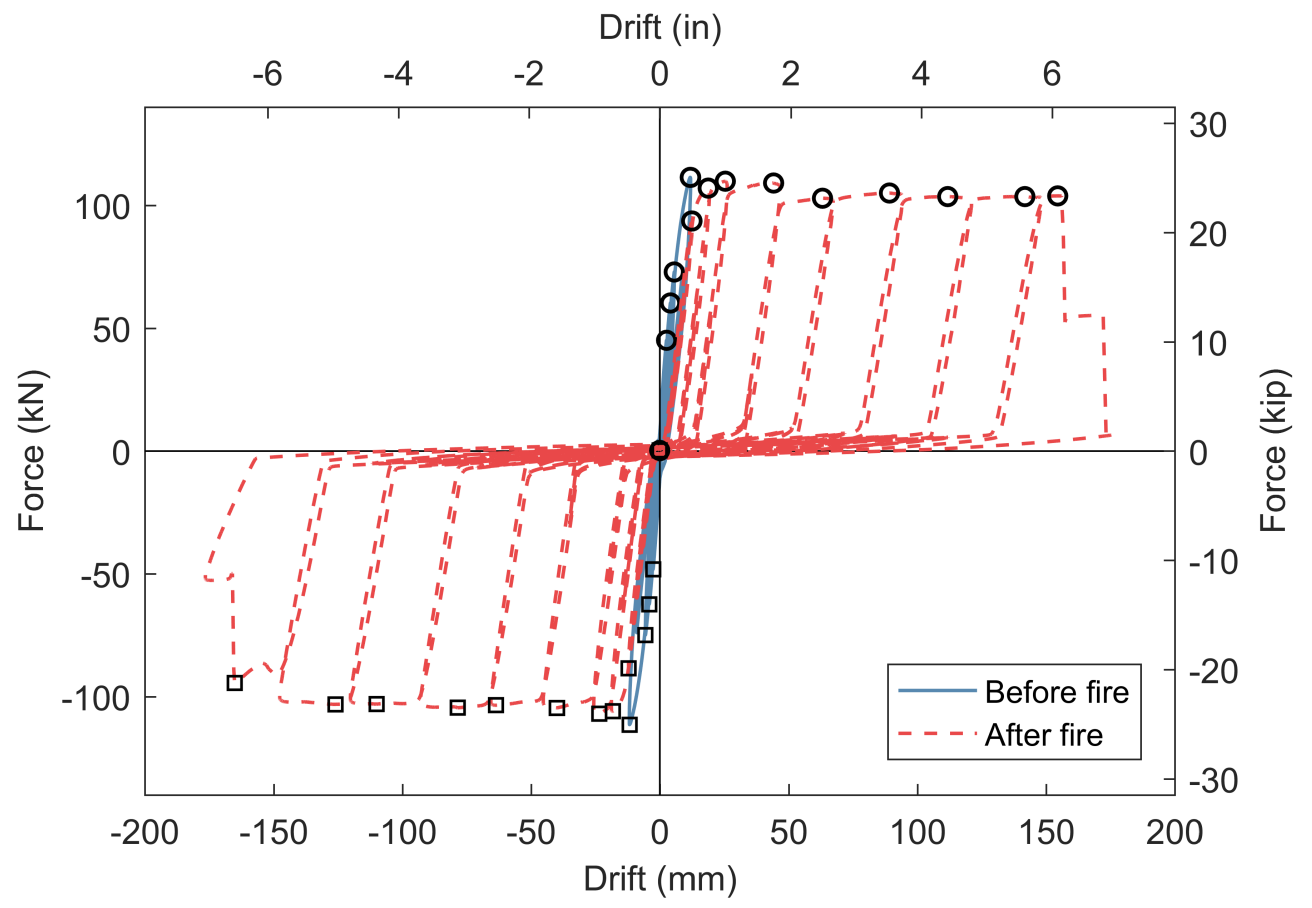

Fig. 439. S06 - Applied load versus wall longitudinal drift during mechanical loading.

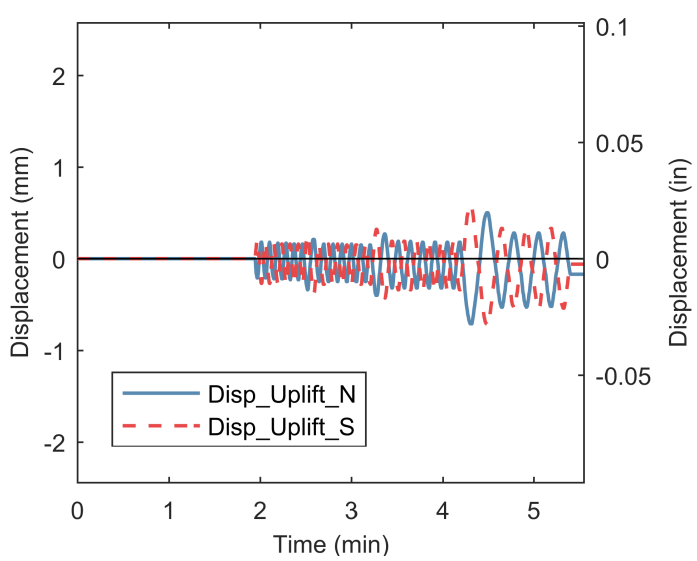

(a)

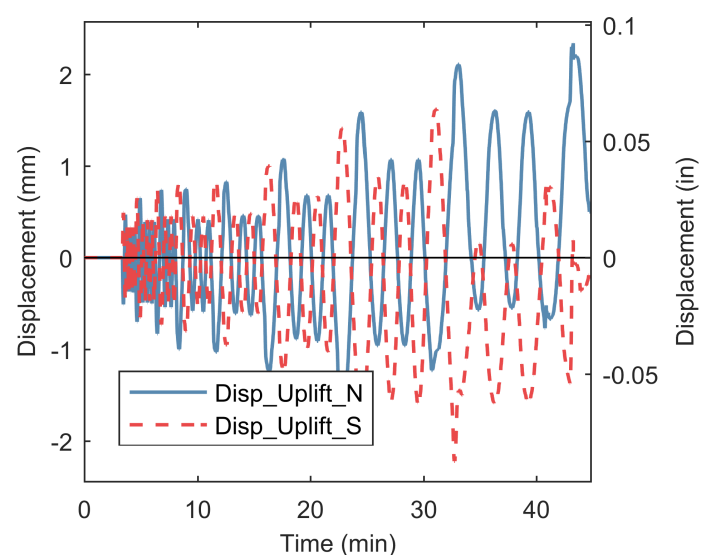

(b)

Fig. 440. S06 - Uplift at bottom of wall during mechanical loading: (a) before fire; (b) after fire. 


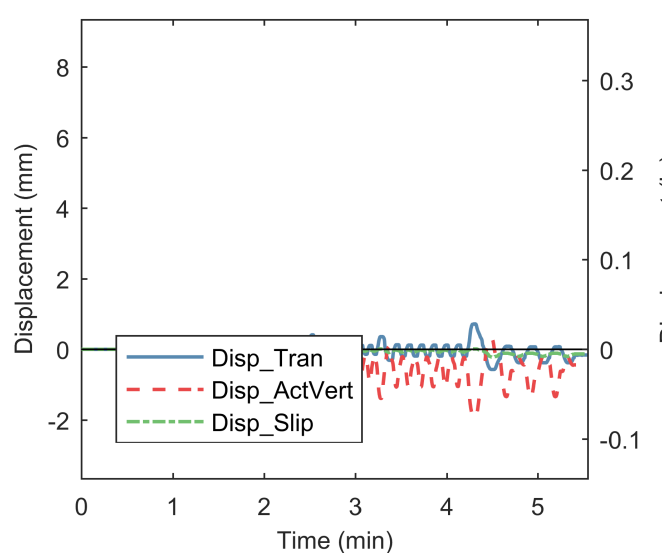

(a)

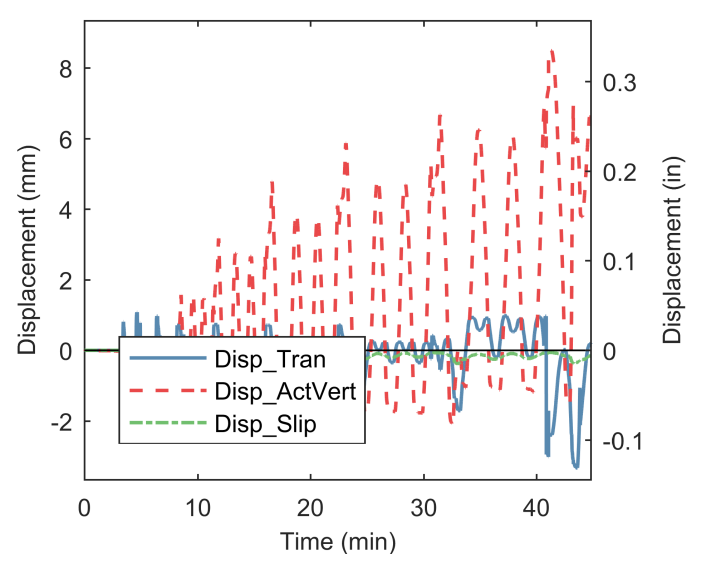

(b)

Fig. 441. S06 - Ancillary displacement measurements during mechanical loading: (a) before fire; (b) after fire.

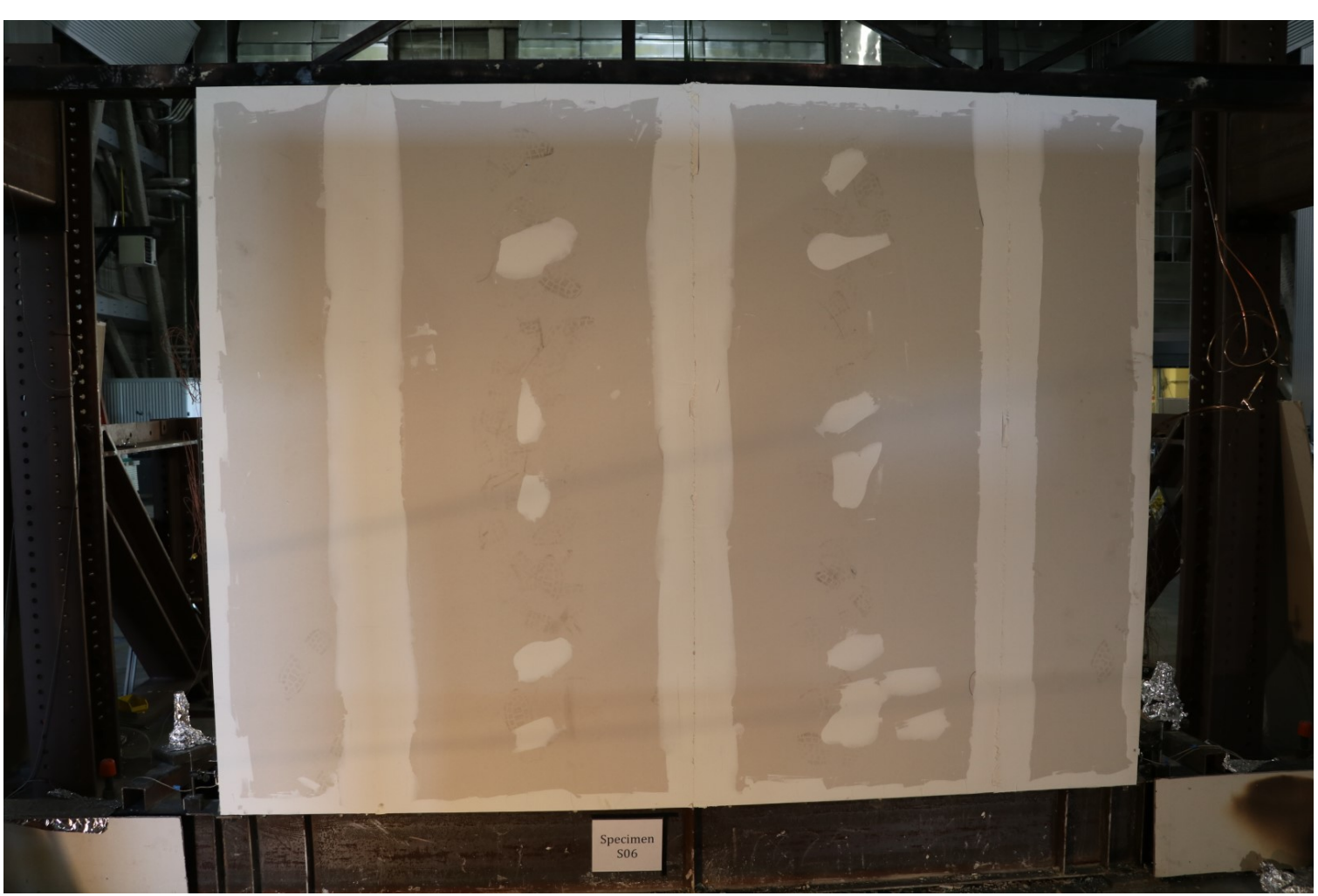

Fig. 442. S06 - Photograph of east (fire exposed) side of wall after cycling to $0.5 \%$ drift (before fire). 


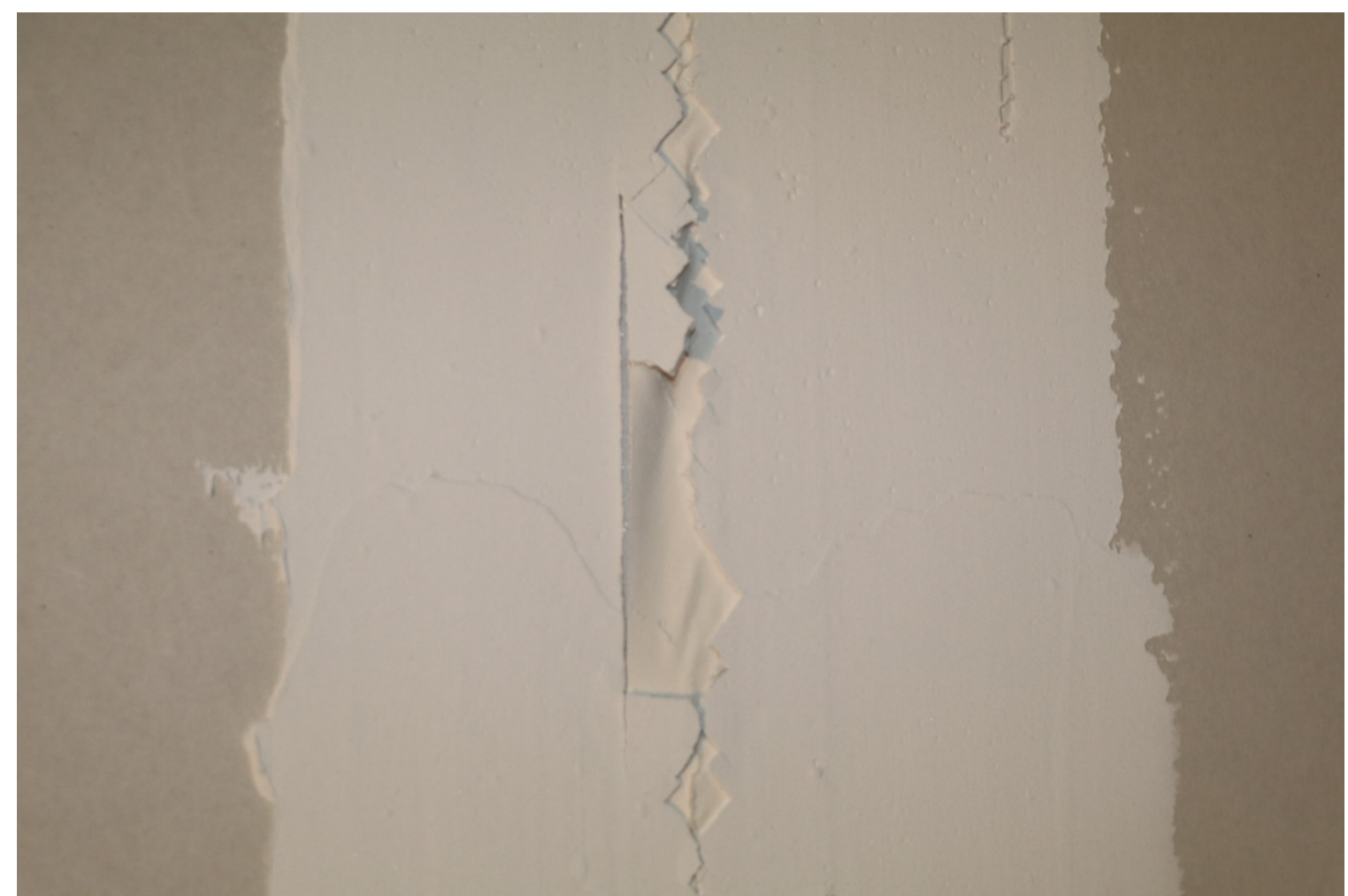

Fig. 443. S06 - Photograph of damage to skim coat only on east (fire exposed) side of wall after cycling to $0.5 \%$ drift (before fire).

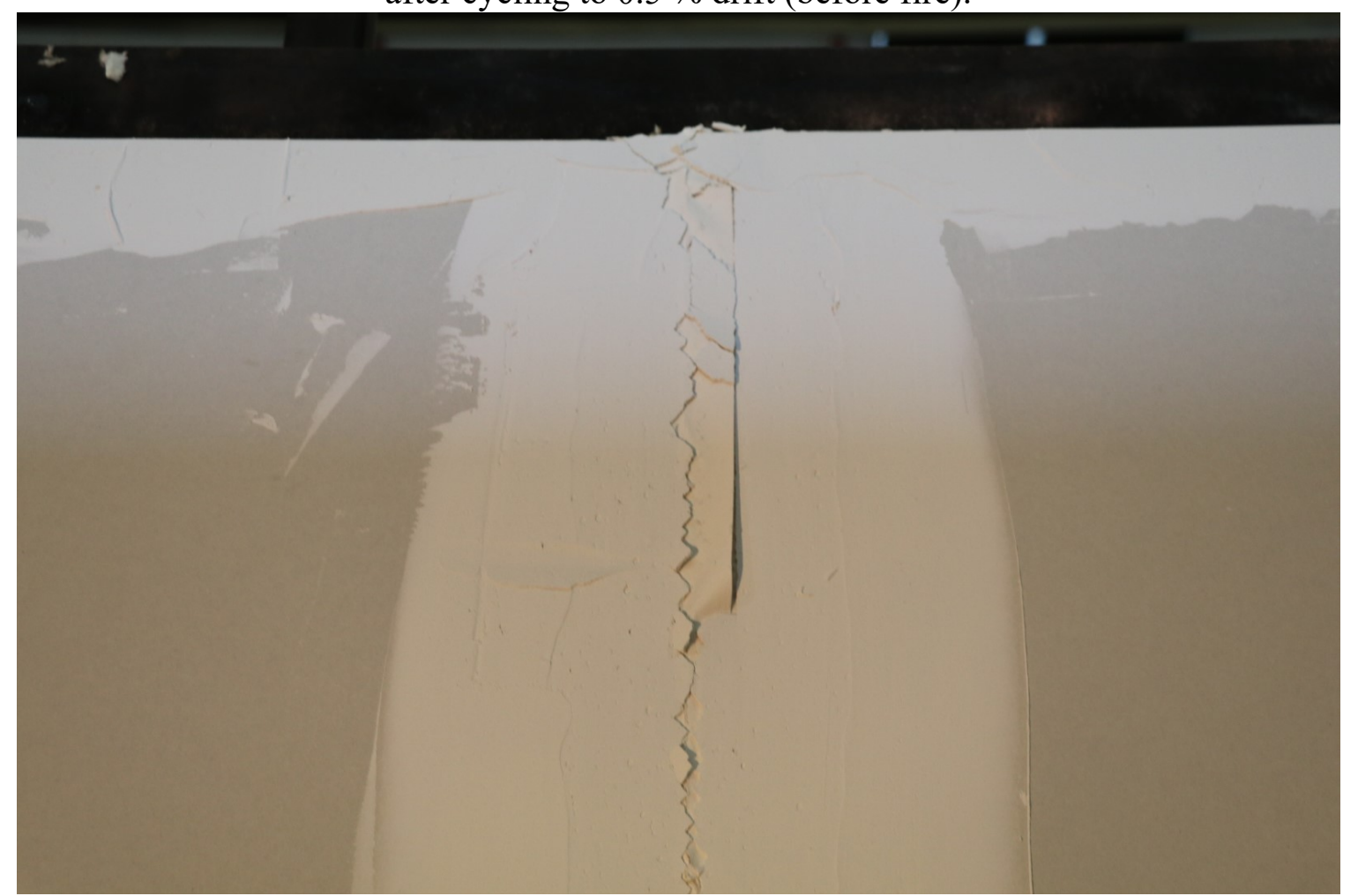

Fig. 444. S06 - Photograph of damage to skim coat and tape at top on east (fire exposed) side of wall after cycling to $0.5 \%$ drift (before fire). 


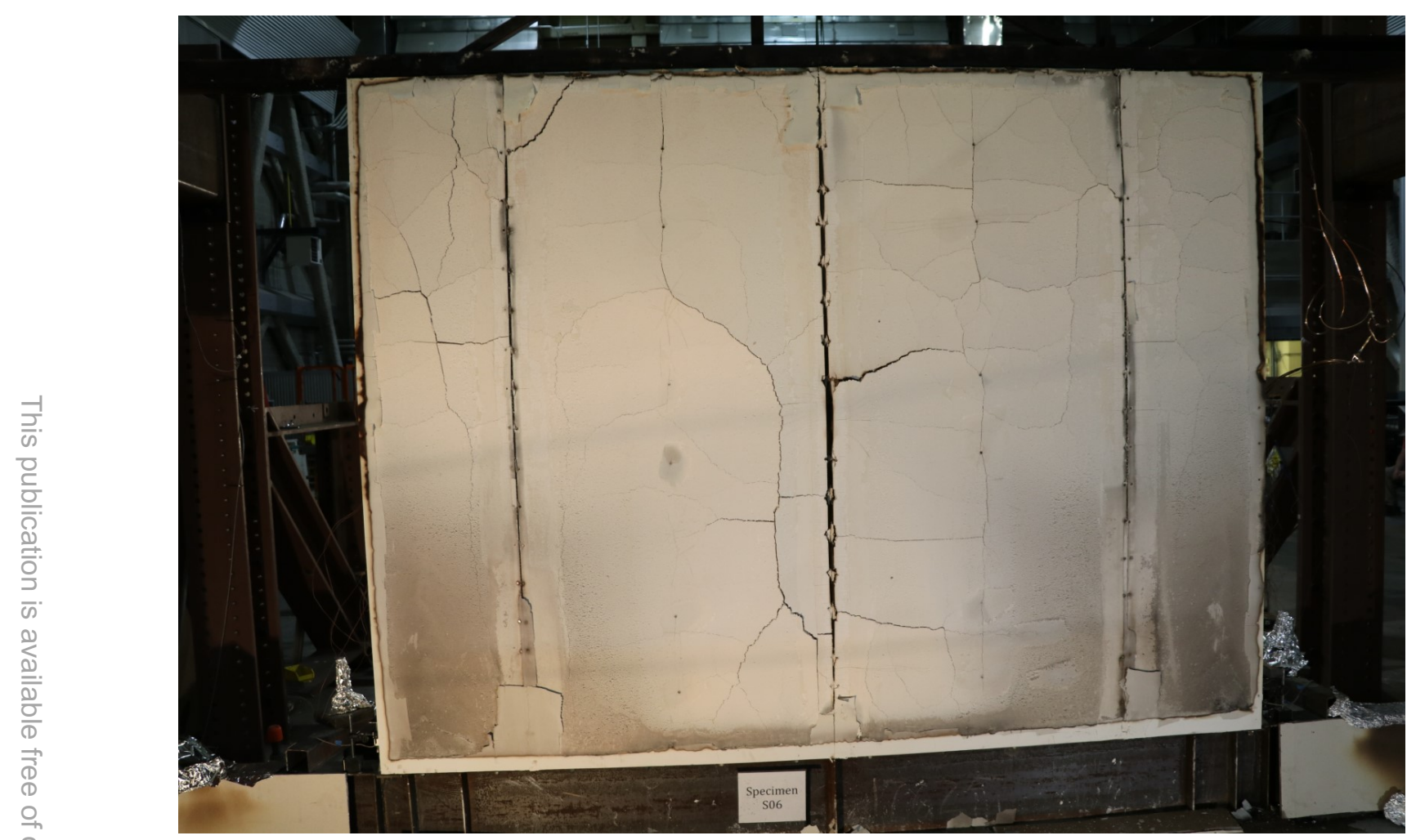

Fig. 445. S06 - Photograph of exposed side of the wall after the fire test (before cycling).

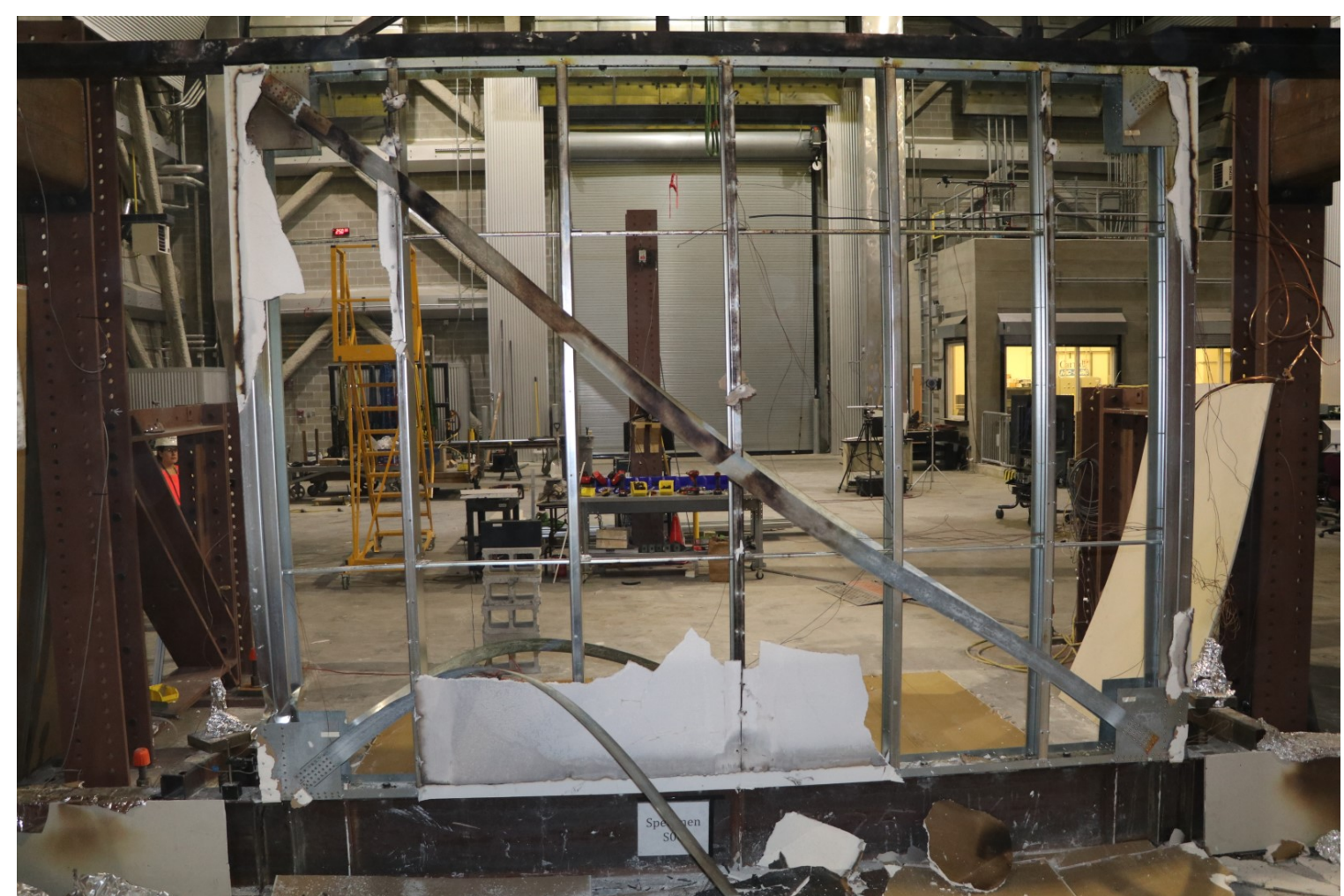

Fig. 446. S06 - Photograph of fire exposed side of the wall (remaining drywall removed) after load cycling following the fire. 


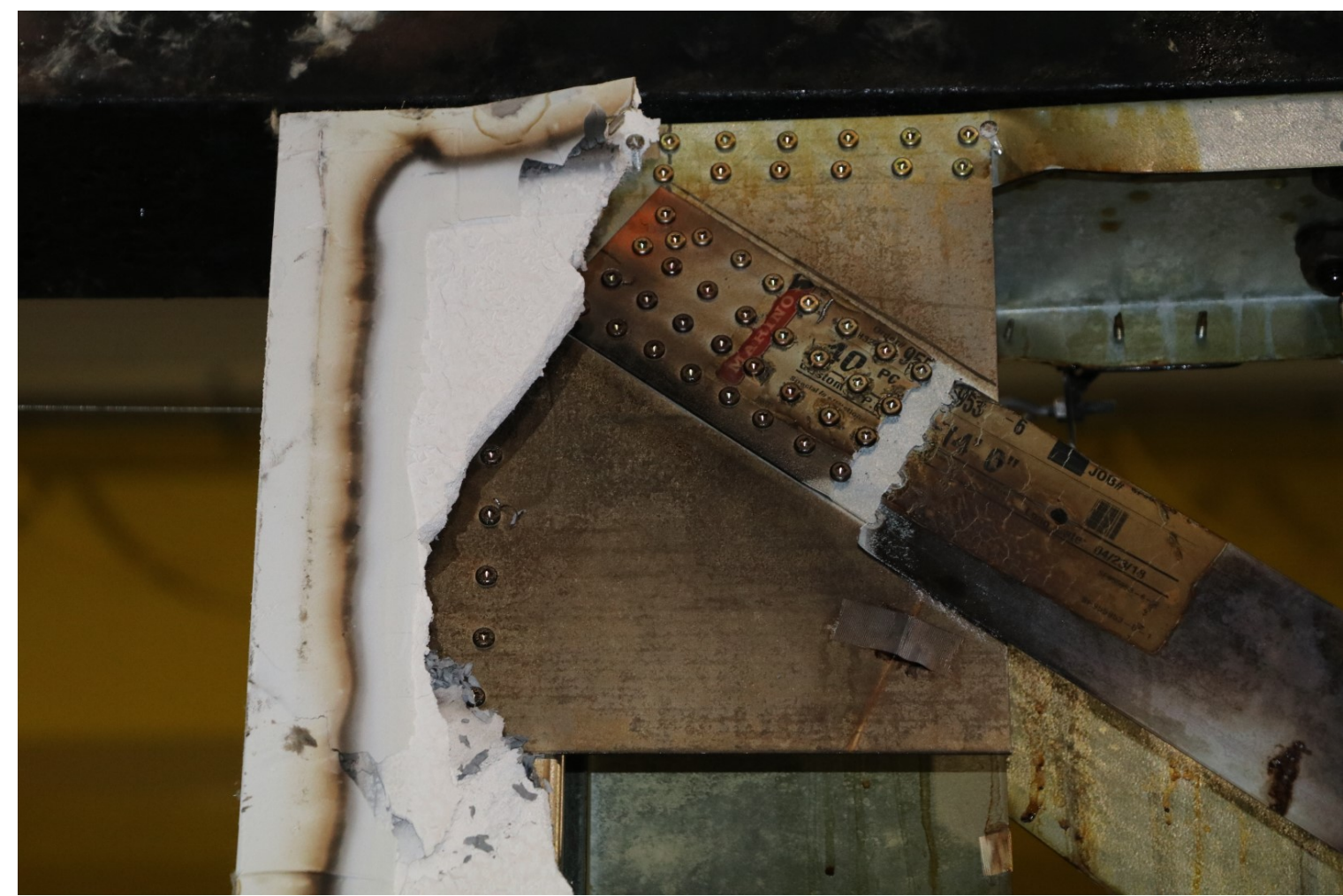

Fig. 447. S06 - Photograph of fire exposed side of the wall at top south gusset after load cycling following the fire. 


\section{Appendix H: Test Data for Kitchen Fire}

\section{OSB Kitchen 2}

Two attempts were necessary to get the pan oil fire to spread to the cabinets and achieve flashover of the room. The data files are: OSB_Kitchen and OSB_Kitchen_2. In OSB_Kitchen_2, the cabinets doors above the burner were opened slightly to allow the flames to reach the inside of the cabinet and the supplemental fuel $(6.6 \mathrm{~kg}$ wood crib and two rolls of paper towels) was moved into the cabinet above the burner. Only data from the successful ignition are presented in this report (OSB_Kitchen_2).

- The smoke alarm on the ceiling went off 12 min $38 \mathrm{~s}$ after burner ignition.

- The oil in the pan ignited $17 \mathrm{~min} 31 \mathrm{~s}$ after burner ignition.

- After the oil ignited, the fire spread to the cabinets above the pan in about $2 \mathrm{~min}$.

- Flashover in the room occurred 26 min $52 \mathrm{~s}$ after burner ignition.

- 35 min after burner ignition there were indications of pyrolysis of the OSB inside the compartment and possible flaming, although the oxygen in the room was low.

- Most of the room furnishing were consumed $40 \mathrm{~min}$ after burner ignition and the oxygen content starts to raise, reaching $15 \% 45$ min after burner ignition.

- Flaming combustion of the OSB is clearly visible 54 min after burner ignition.

- Gypsum panels fall off the unexposed side of the OSB wall specimen 63 min and 68 min after burner ignition.

- Remaining fire was suppressed using water 80 min $38 \mathrm{~s}$ after burner ignition when almost all the OSB has been burnt.

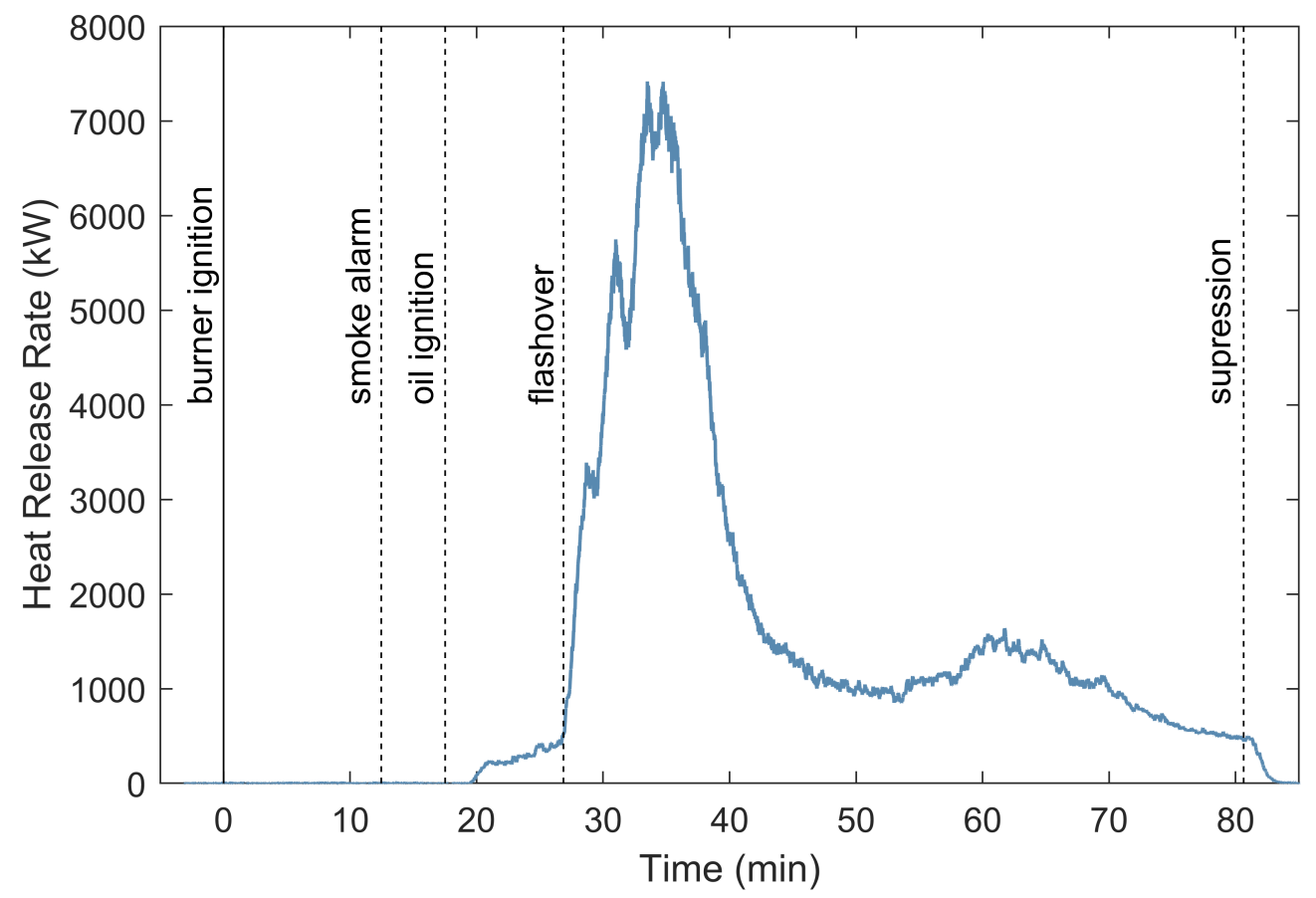

Fig. 448. OSB_Kitchen_2-Heat Release Rate measured in exhaust hood. 


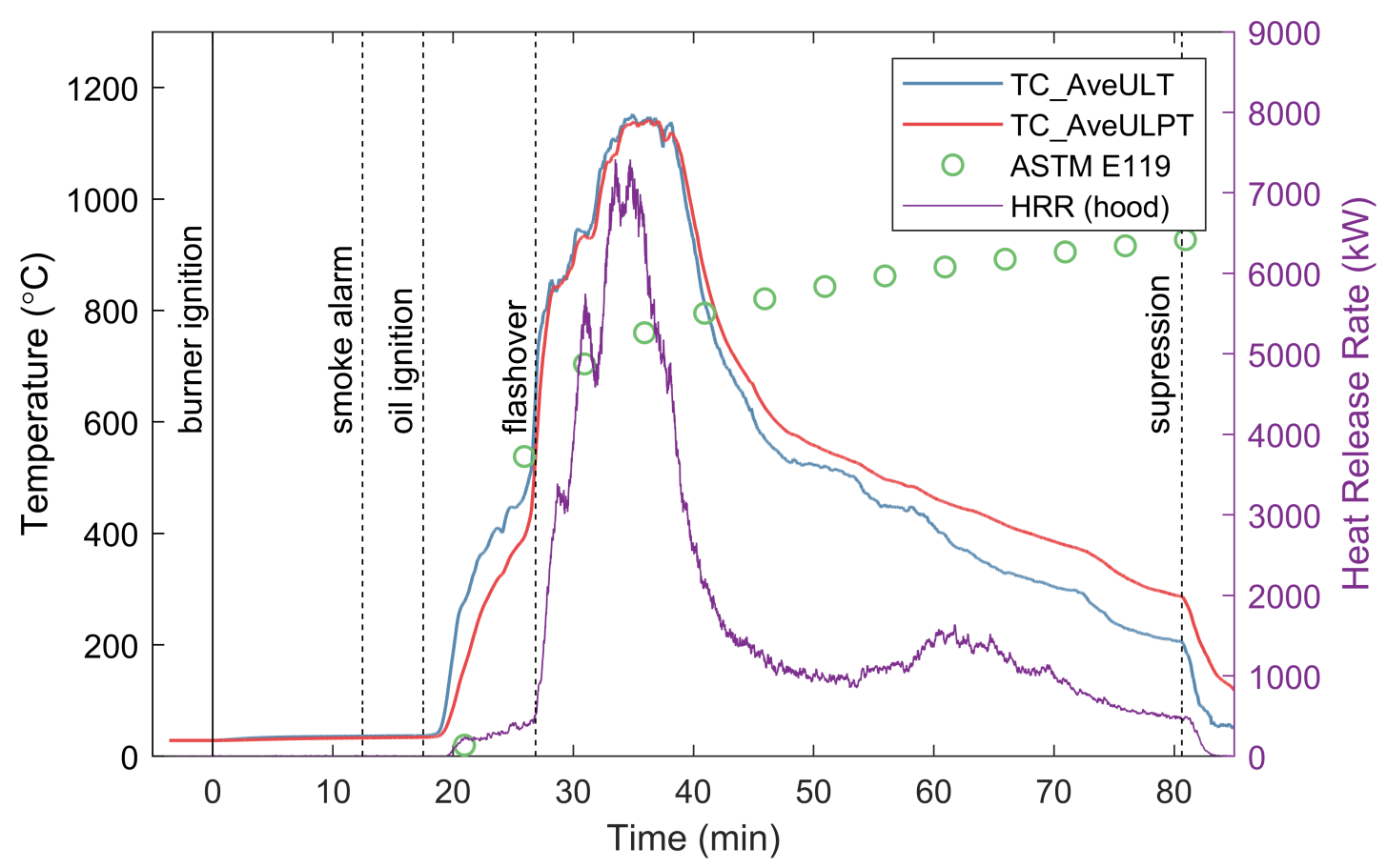

Fig. 449. OSB_Kitchen_2 - Compartment temperature and measured Heat Release Rate.

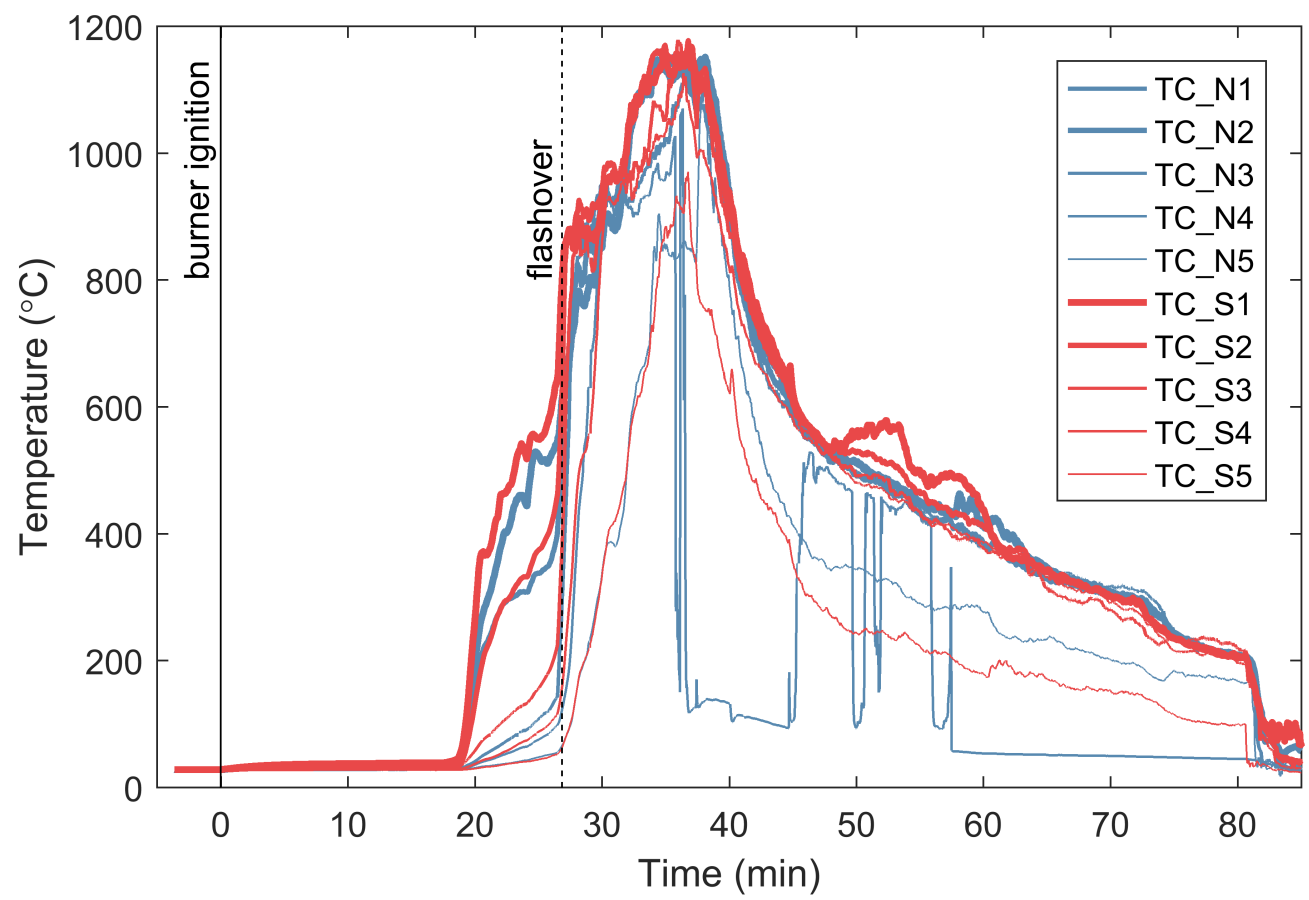

Fig. 450. OSB_Kitchen_2 - Compartment temperatures measured by the thermocouple arrays. 


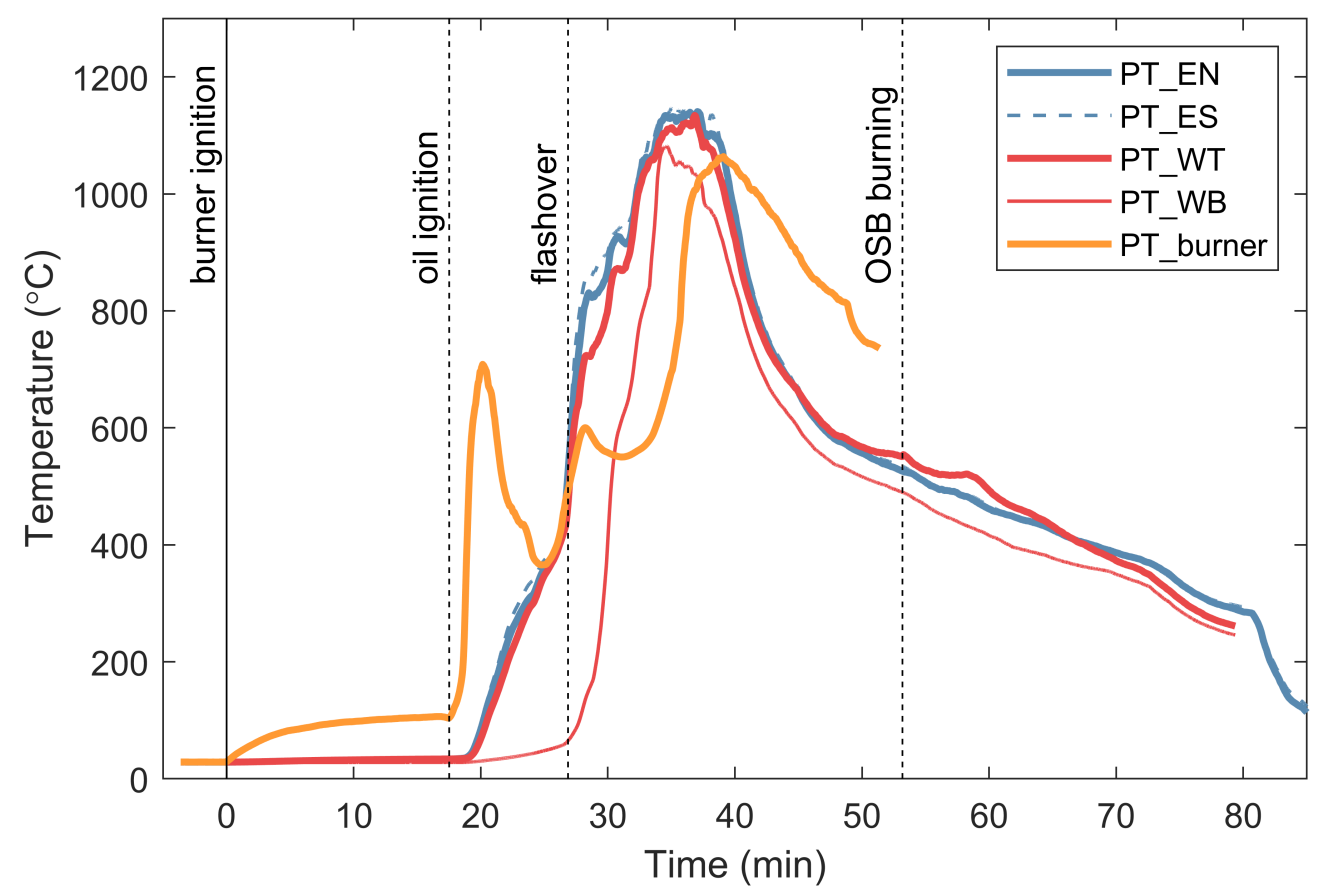

Fig. 451. OSB_Kitchen_2 - Compartment temperature measured by the plate thermocouples.

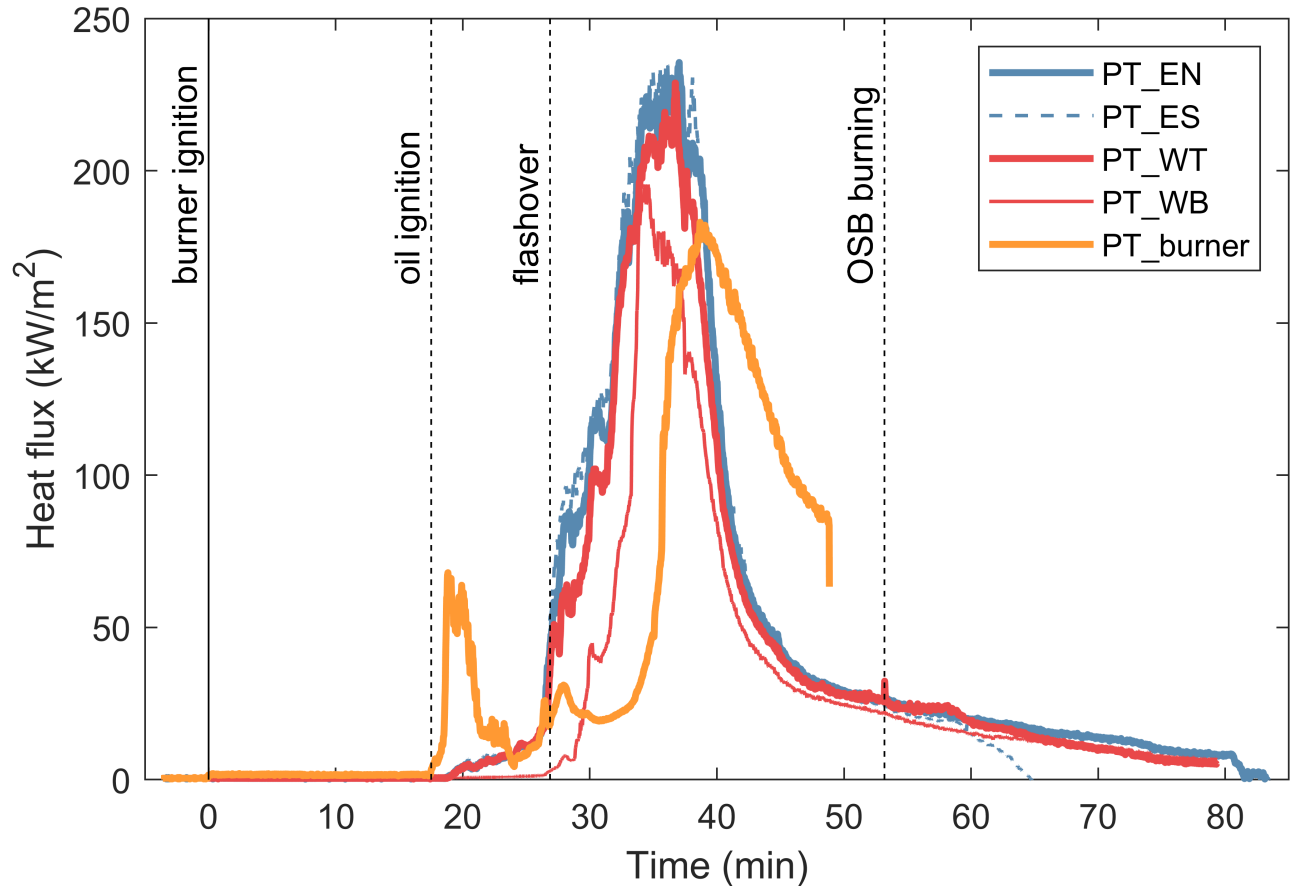

Fig. 452. OSB_Kitchen_2 - Heat fluxes in the compartment measured by the plate thermocouples. 


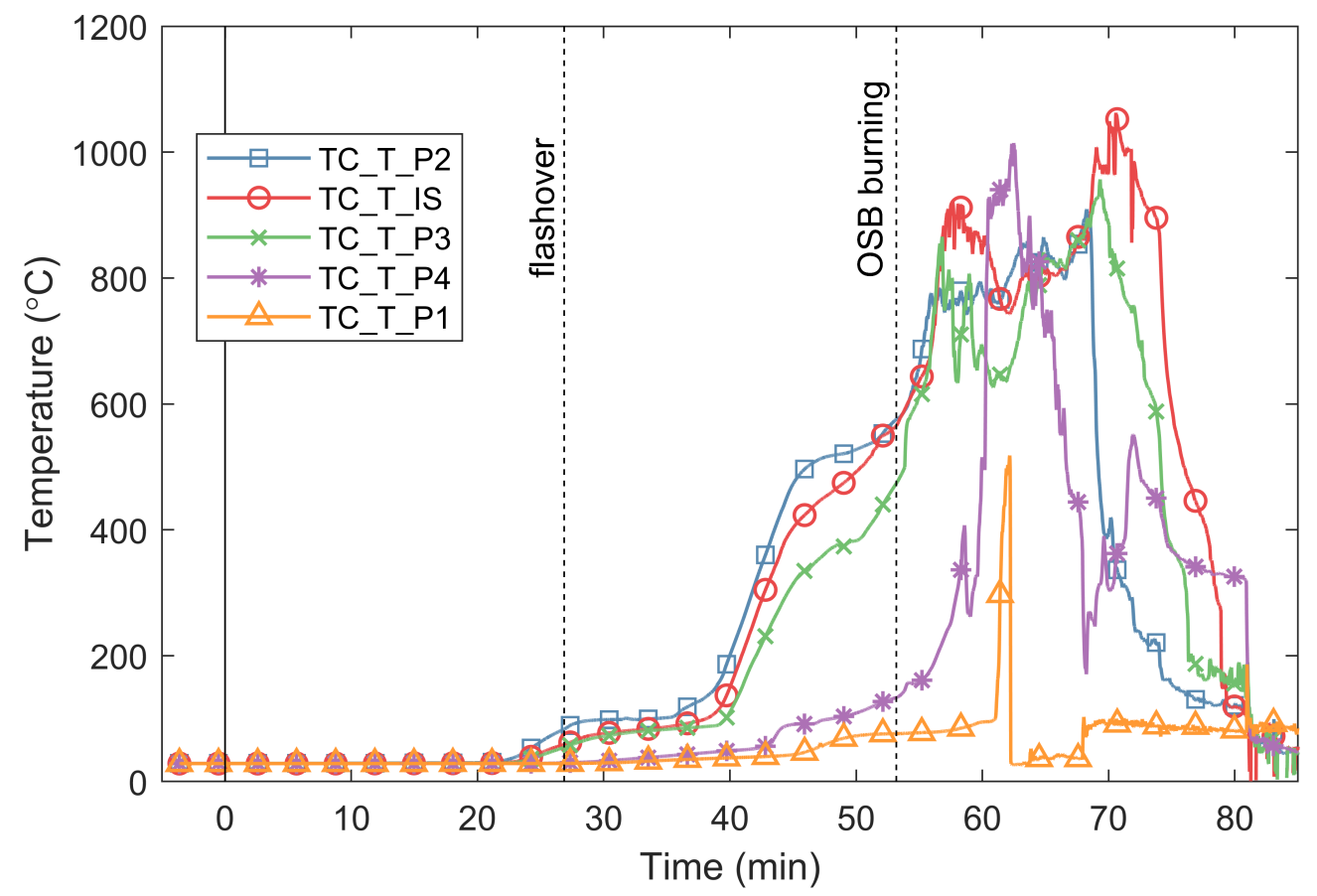

Fig. 453. OSB_Kitchen_2 - Temperatures through the wall specimen at an interior stud $46 \mathrm{~cm}$ from the top of the wall.

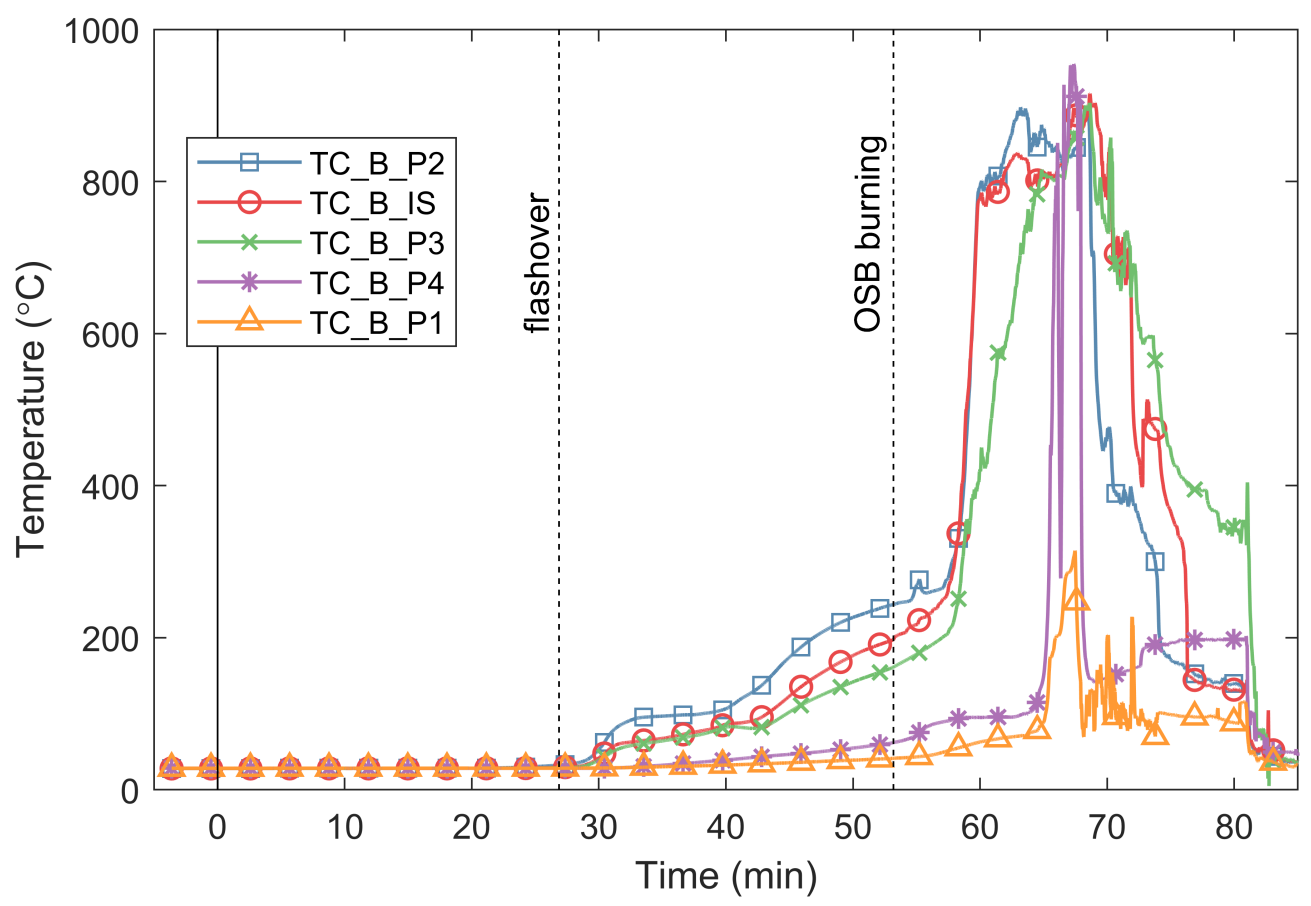

Fig. 454. OSB_Kitchen_2-Temperatures through the wall specimen at an interior stud $46 \mathrm{~cm}$ from the bottom of the wall. 

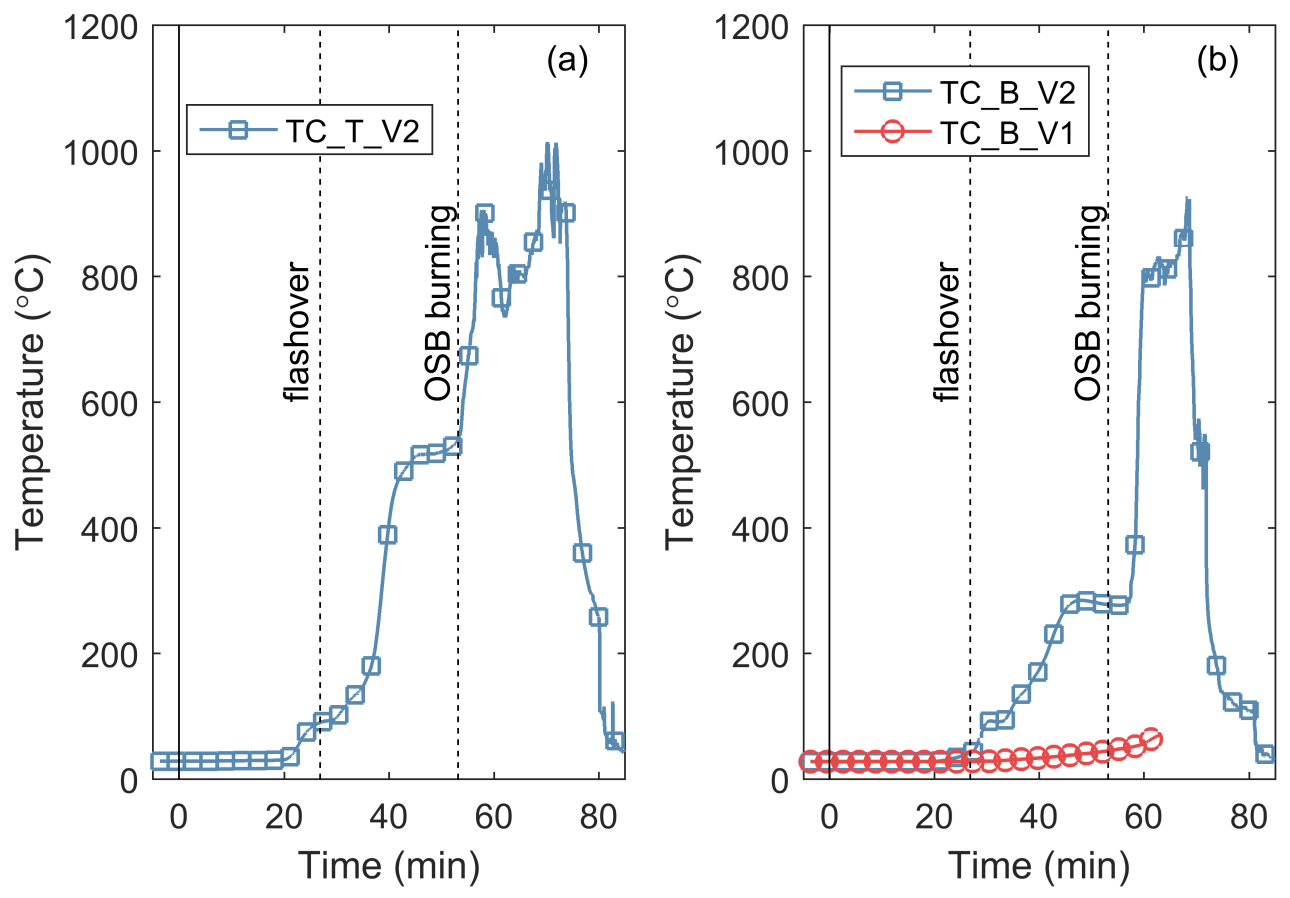

Fig. 455. OSB_Kitchen_2 - Temperatures through the specimen midway between interior studs: (a) $46 \mathrm{~cm}$ from the top of the wall (TC_T_V1 was not connected); (b) 46 $\mathrm{cm}$ from the bottom of the wall.
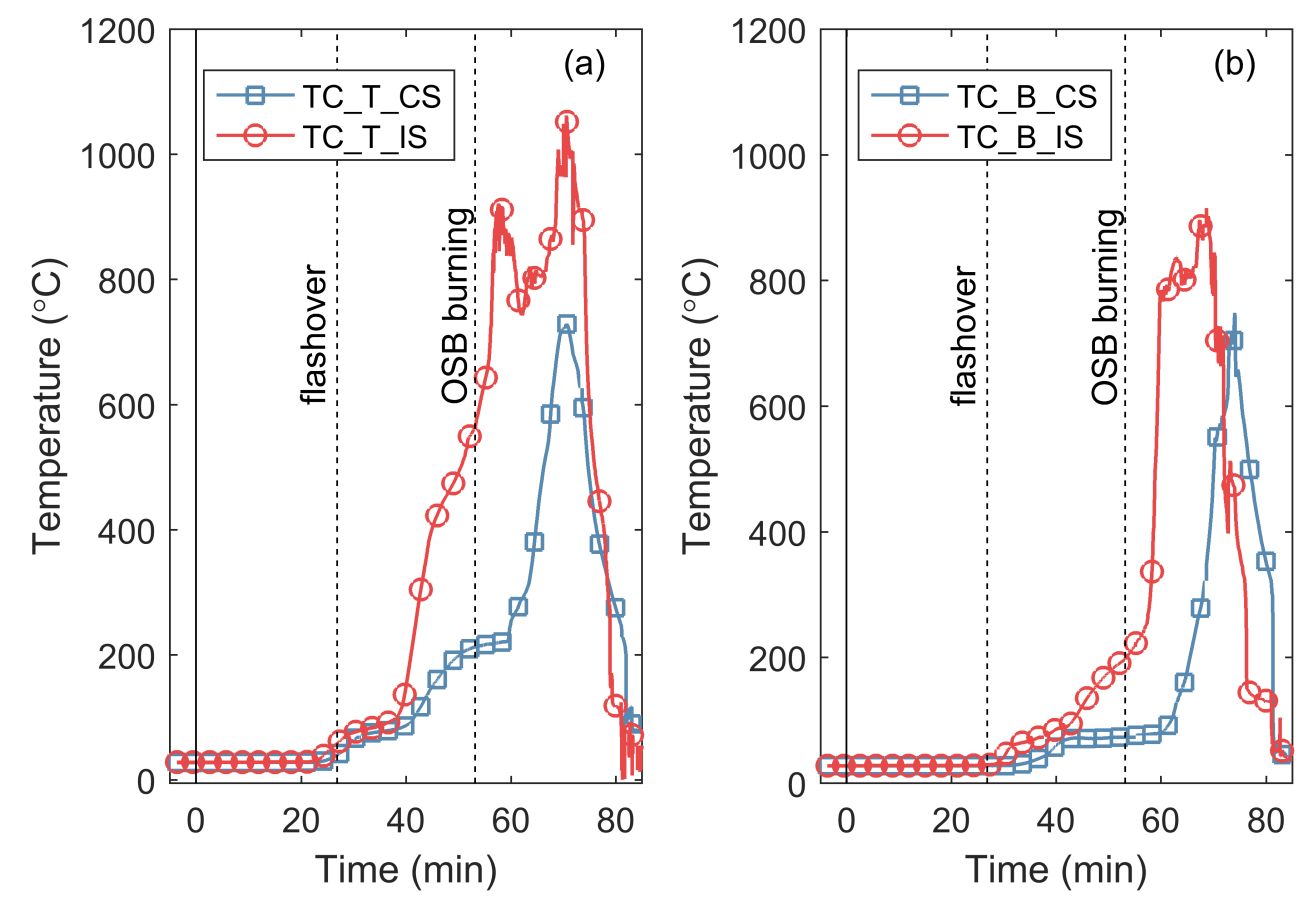

Fig. 456. OSB_Kitchen_2 - Temperatures of the framing elements: (a) $46 \mathrm{~cm}$ from the top of the wall; (b) $46 \mathrm{~cm}$ from the bottom of the wall. 


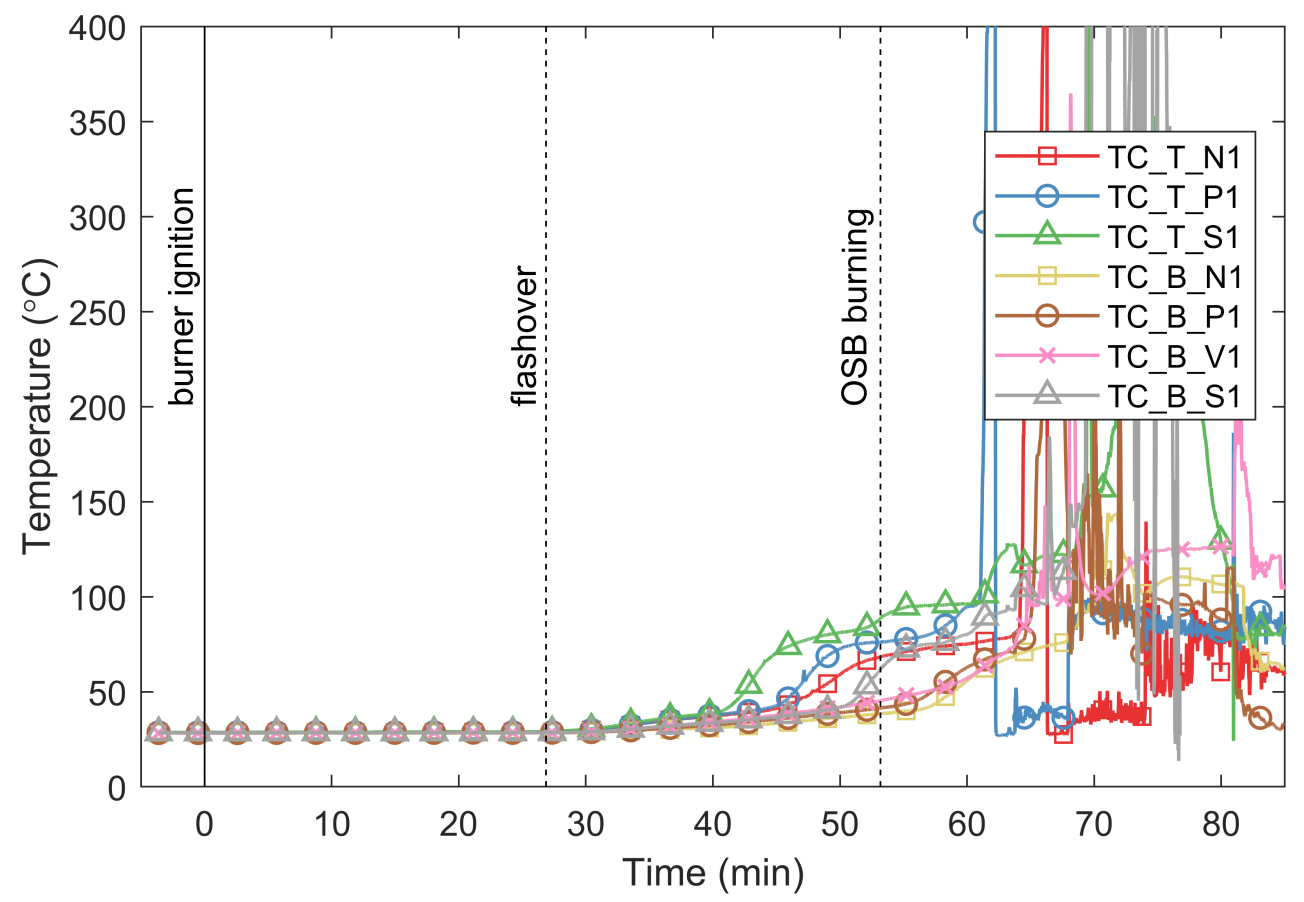

Fig. 457. OSB_Kitchen_2-Temperature of the gypsum on the unexposed side of the wall specimen.

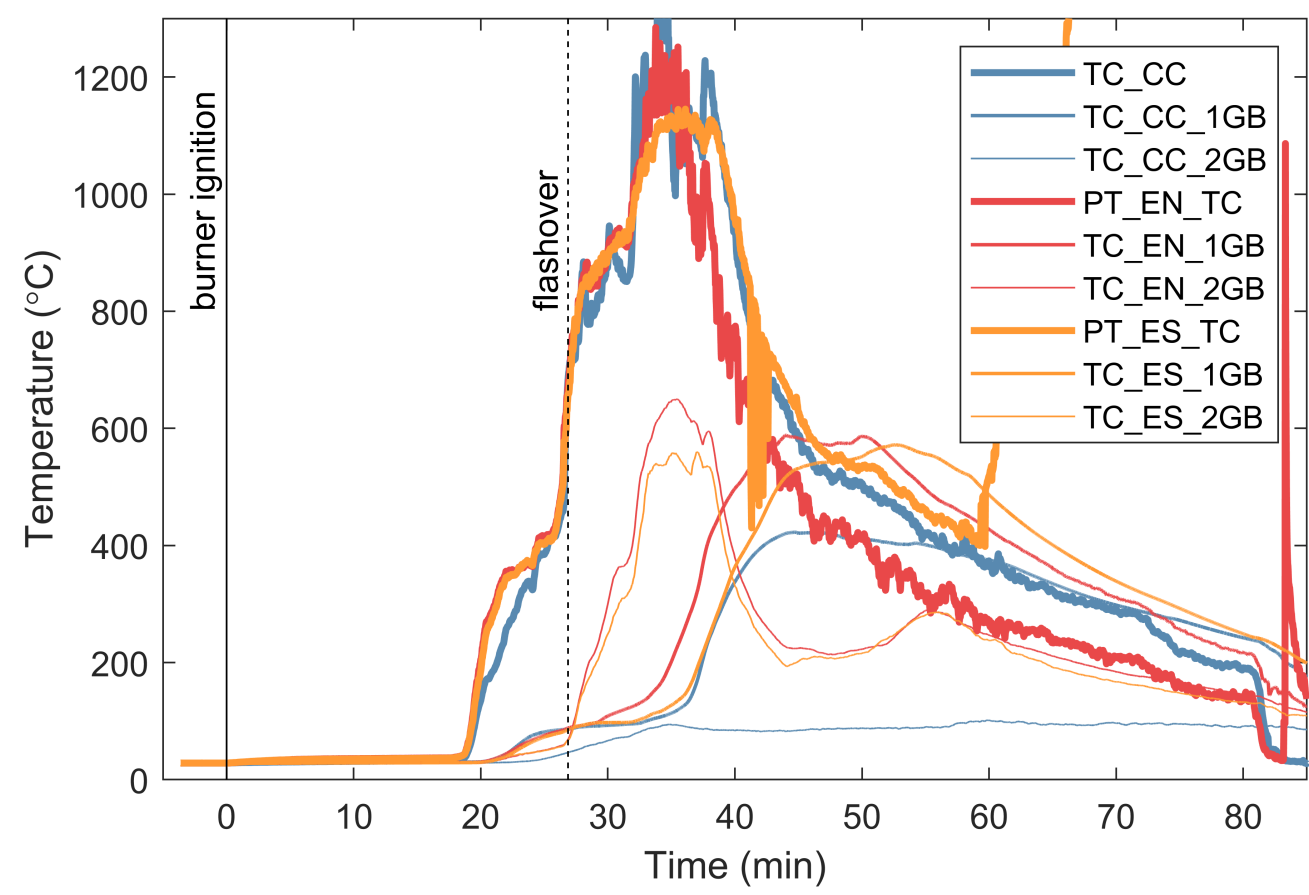

Fig. 458. OSB_Kitchen_2 - Temperature through the compartment ceiling and through the wall above the opening. 


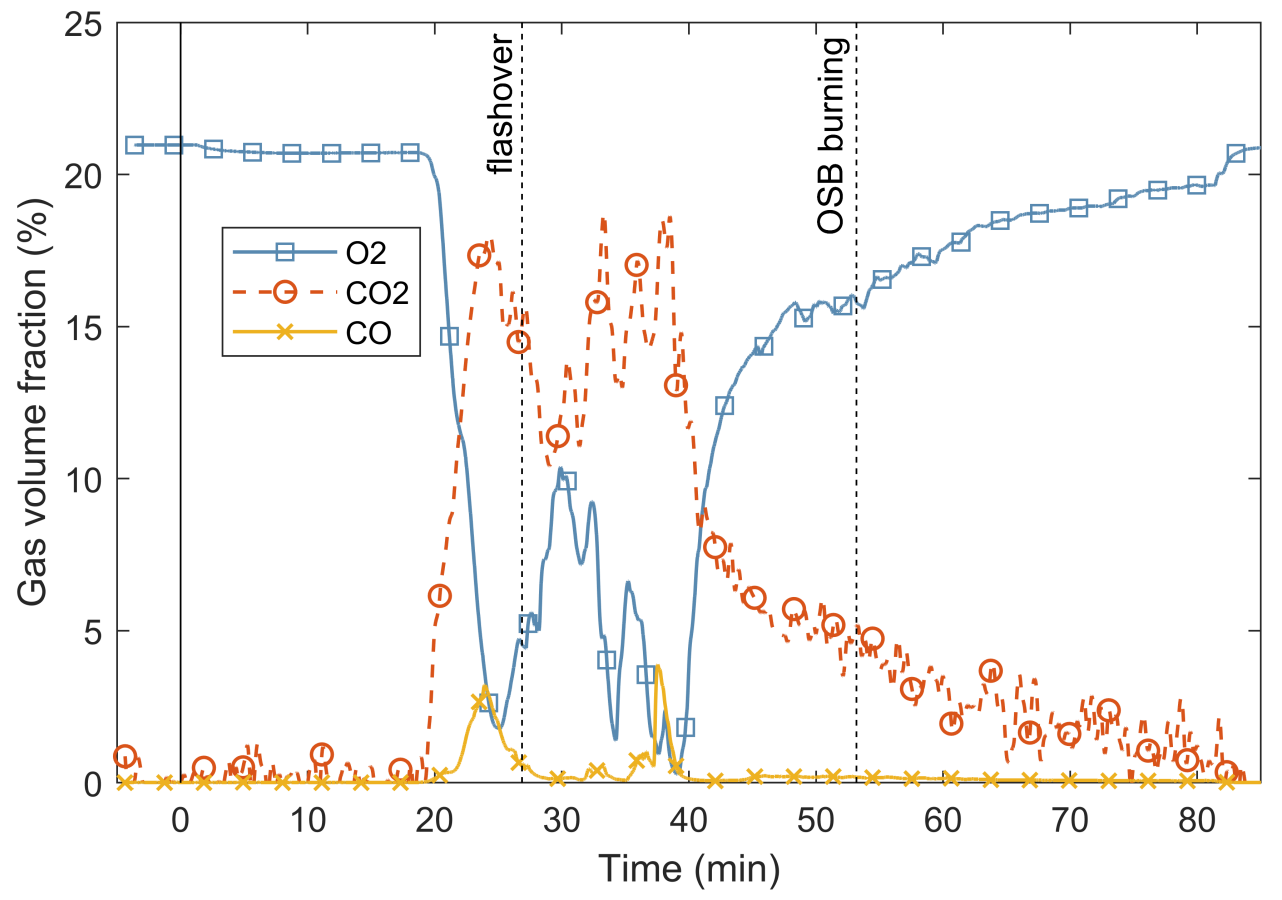

Fig. 459. OSB_Kitchen_2 $-\mathrm{O}_{2}, \mathrm{CO}_{2}$ and $\mathrm{CO}$ concentrations in the upper gas layer inside the compartment.
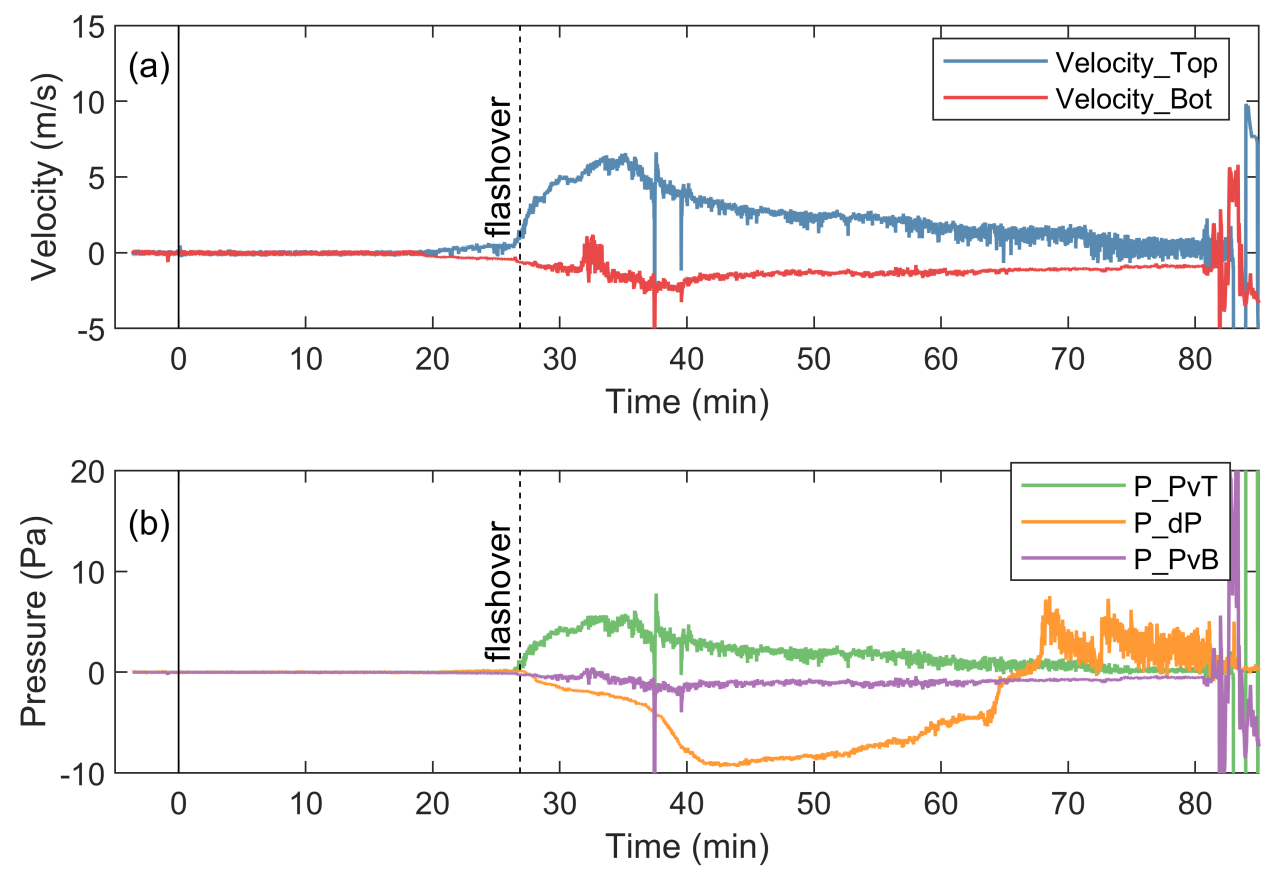

Fig. 460. OSB_Kitchen_2-(a) Velocity profiles of flow measured $0.66 \mathrm{~m}$ from the top and the bottom of the opening; (b) pressure measured $0.66 \mathrm{~m}$ from the top and the bottom if the opening and in the wall cavity near the top of the wall. 


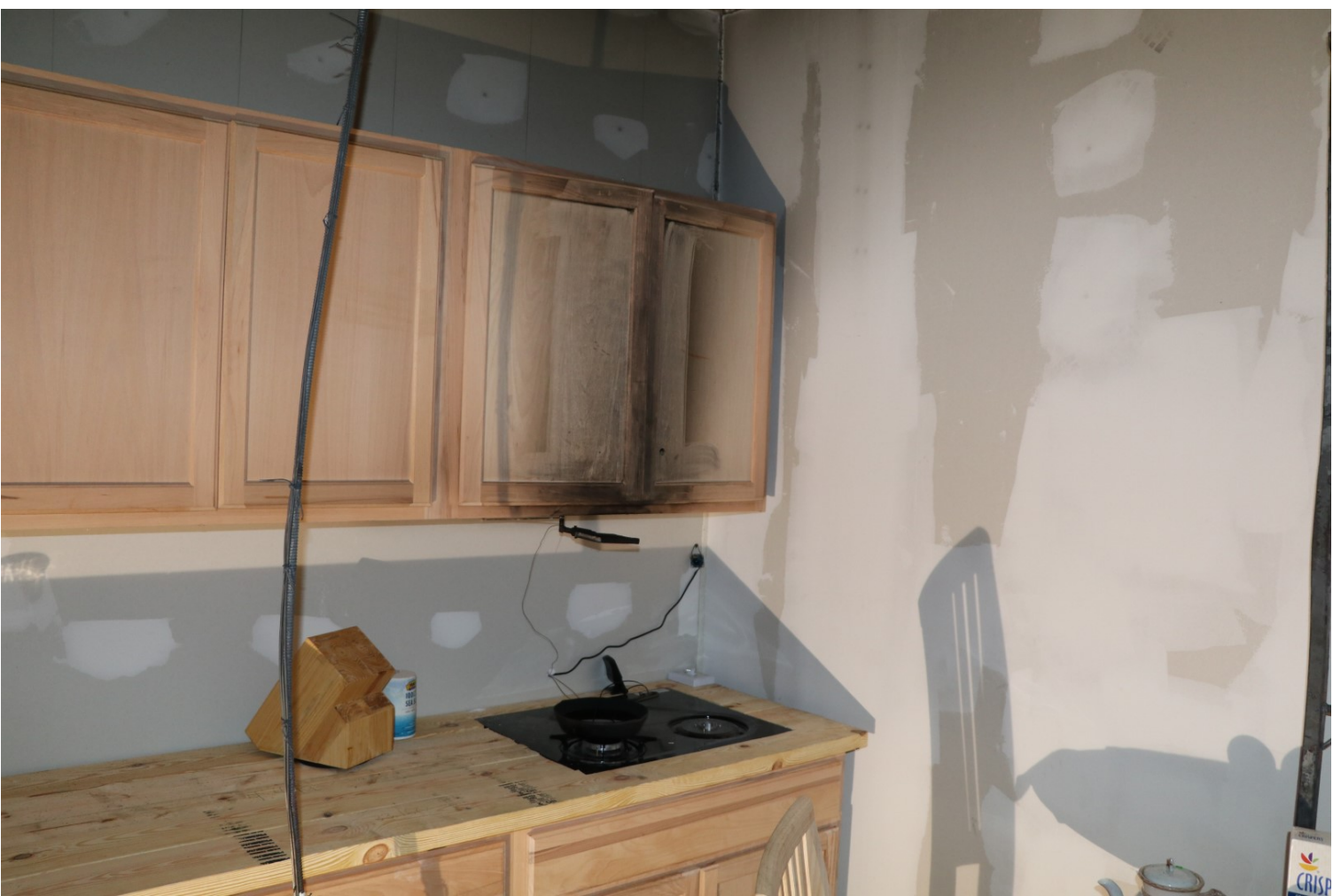

Fig. 461. OSB_Kitchen_2 - Photograph of compartment after unsuccessful ignition attempt in OSB_Kitchen.

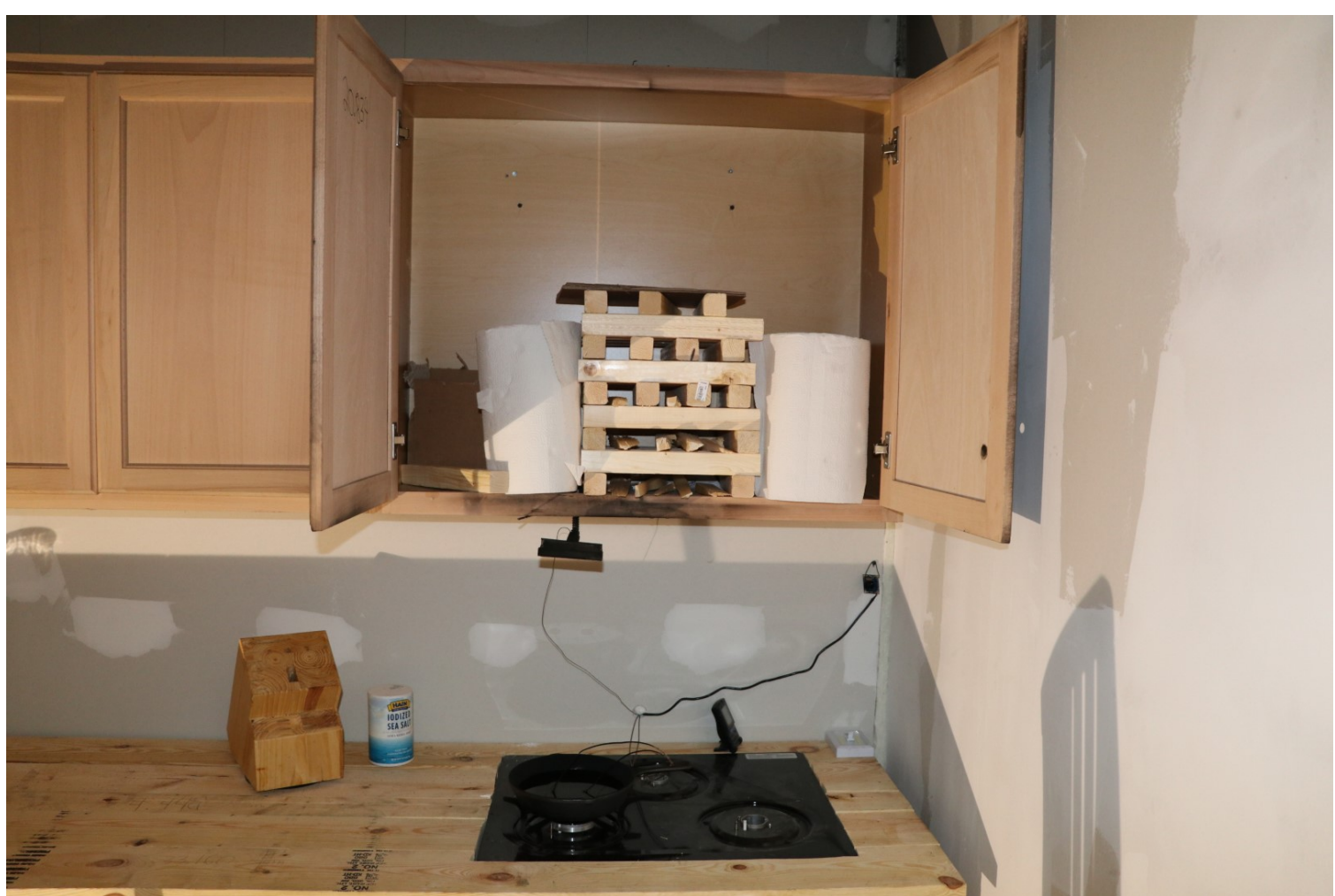

Fig. 462. OSB_Kitchen_2 - Photograph of new location of supplement fuel package for OSB_Kitchen_2. 


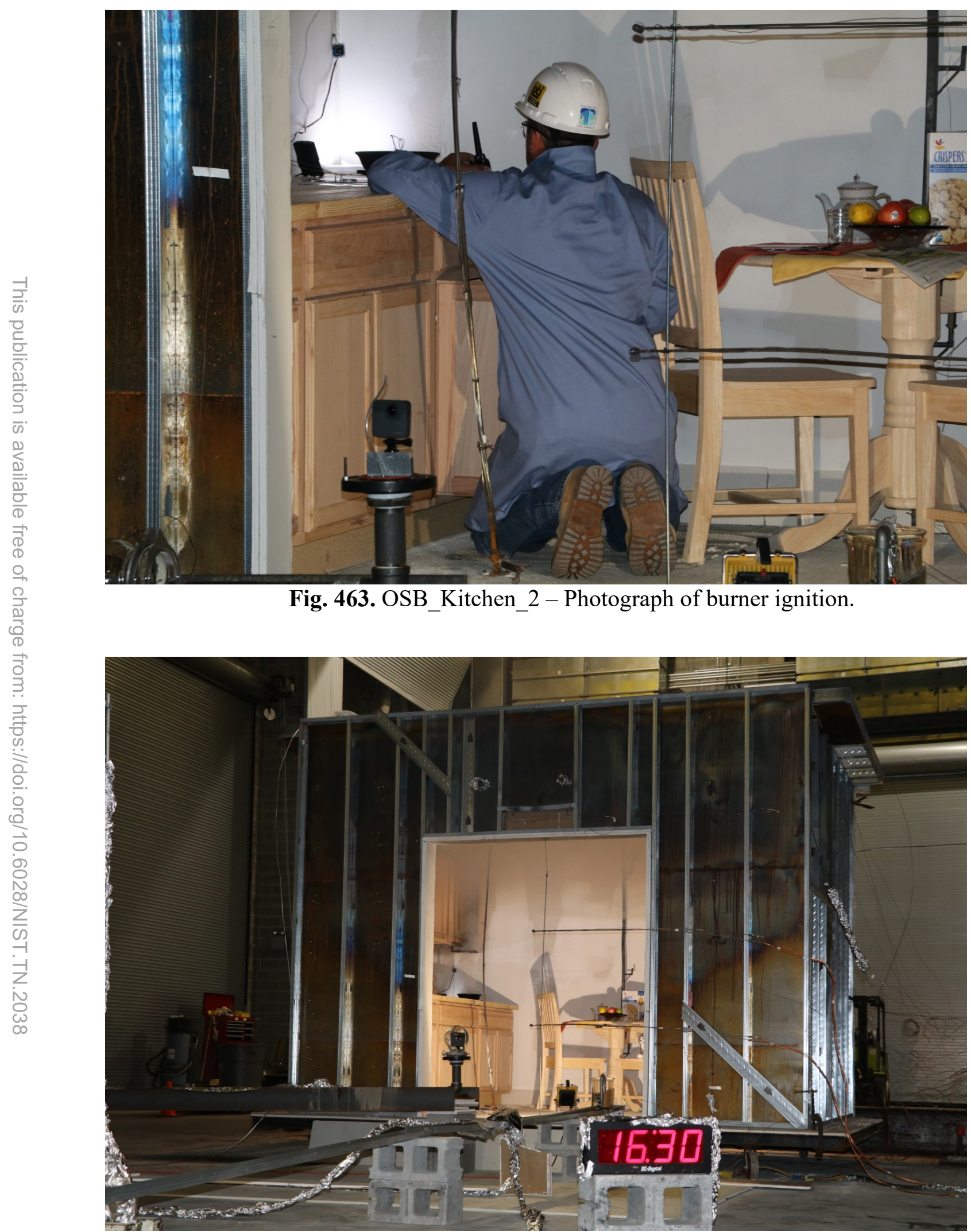

Fig. 464. OSB_Kitchen_2 - Photograph of compartment 16 min $30 \mathrm{~s}$ after burner ignition. 


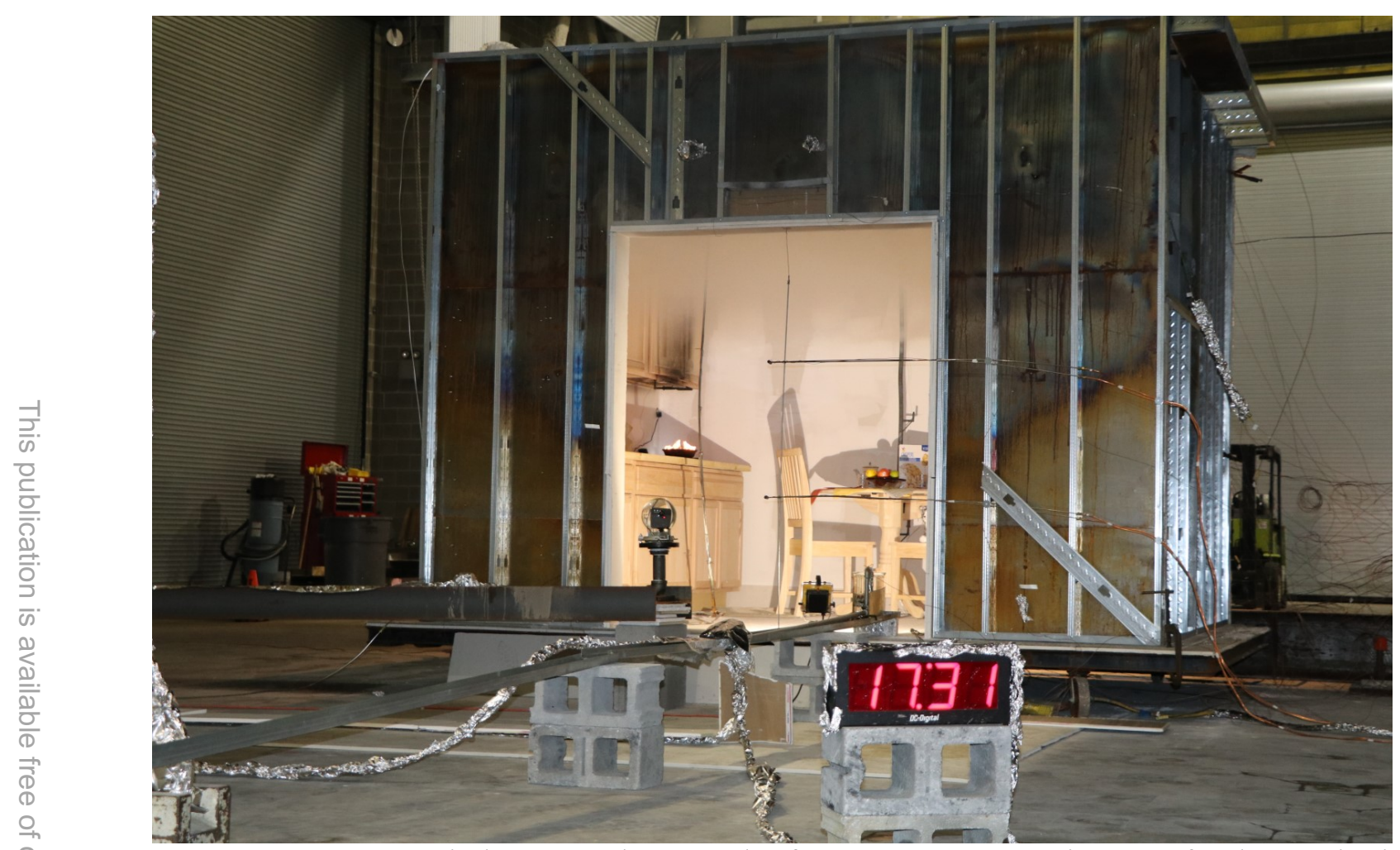

Fig. 465. OSB_Kitchen_2 - Photograph of compartment $17 \mathrm{~min} 31 \mathrm{~s}$ after burner ignition (pan oil ignition).

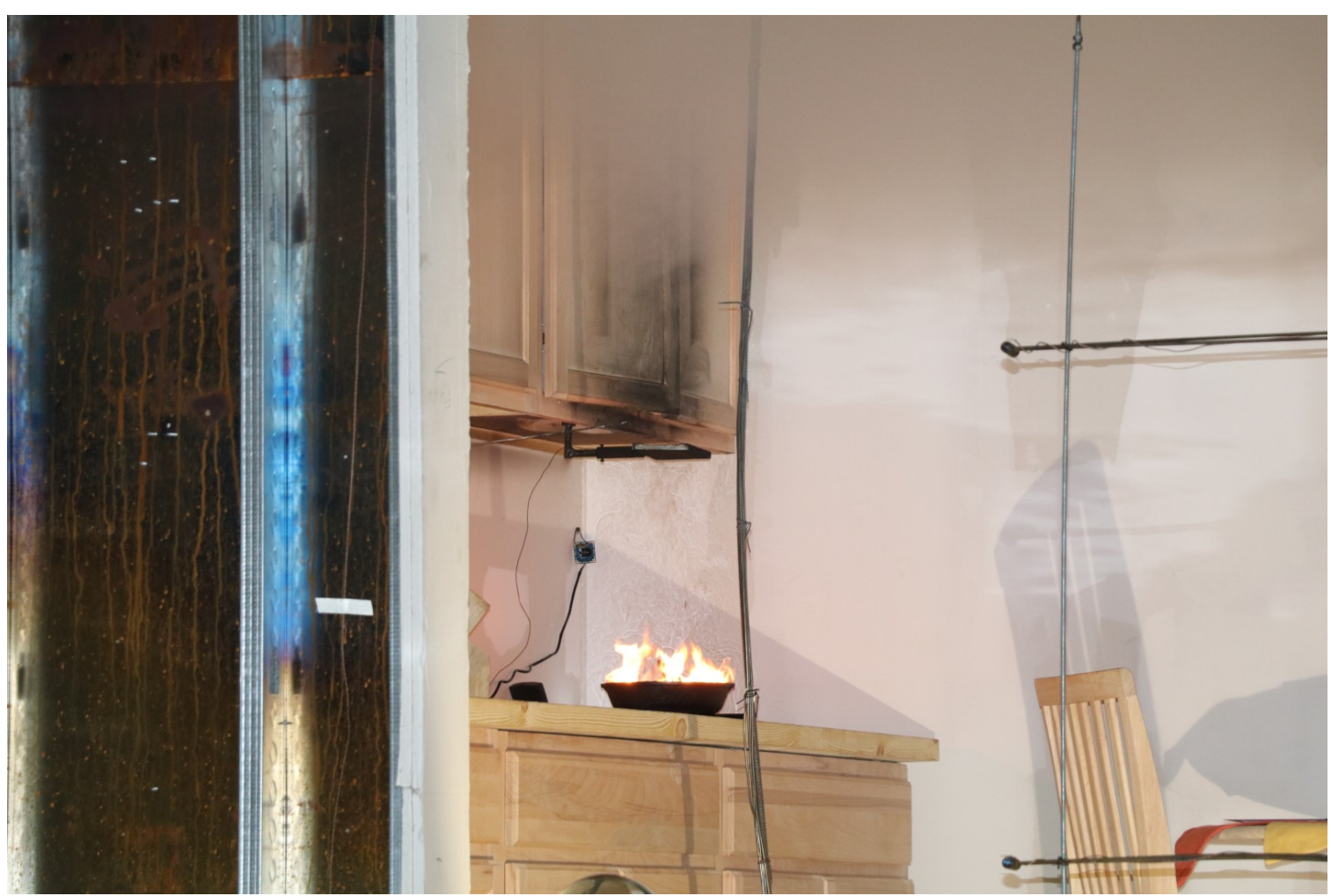

Fig. 466. OSB_Kitchen_2 - Photograph of pan fire shortly after oil ignition. 


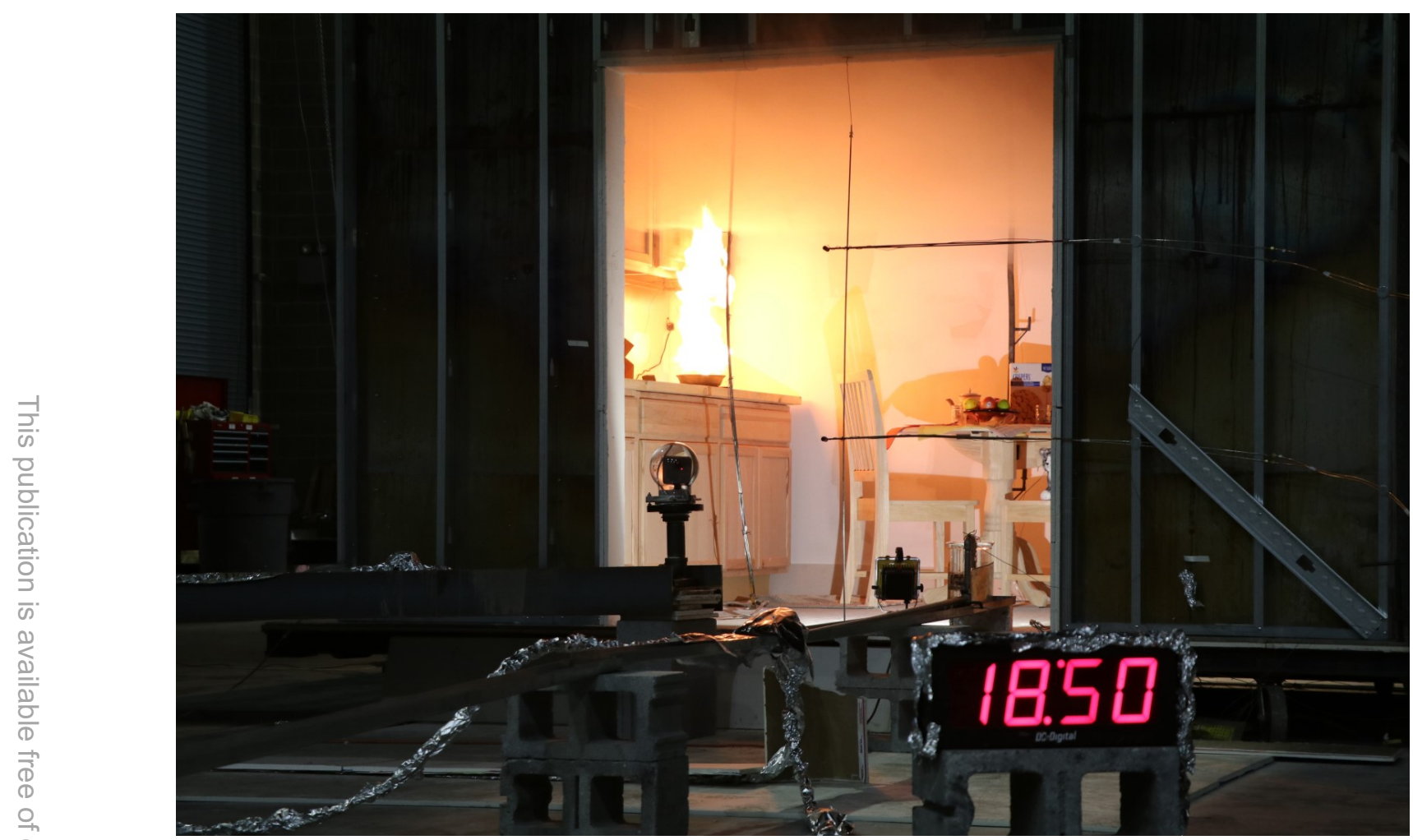

Fig. 467. OSB_Kitchen_2 - Photograph of compartment 18 min $50 \mathrm{~s}$ after burner ignition.

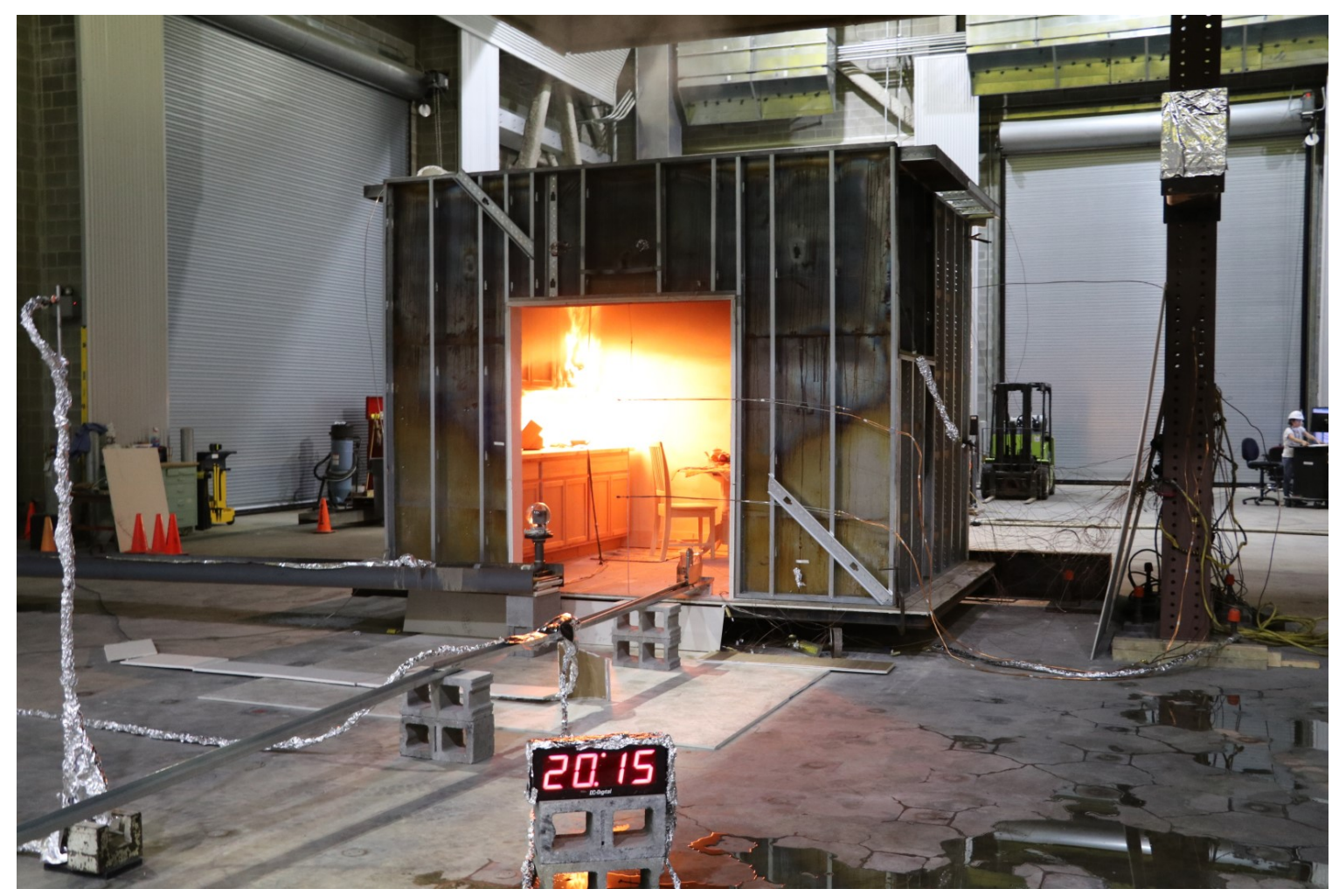

Fig. 468. OSB_Kitchen_2 - Photograph of compartment 20 min 15 s after burner ignition (cabinets burning). 


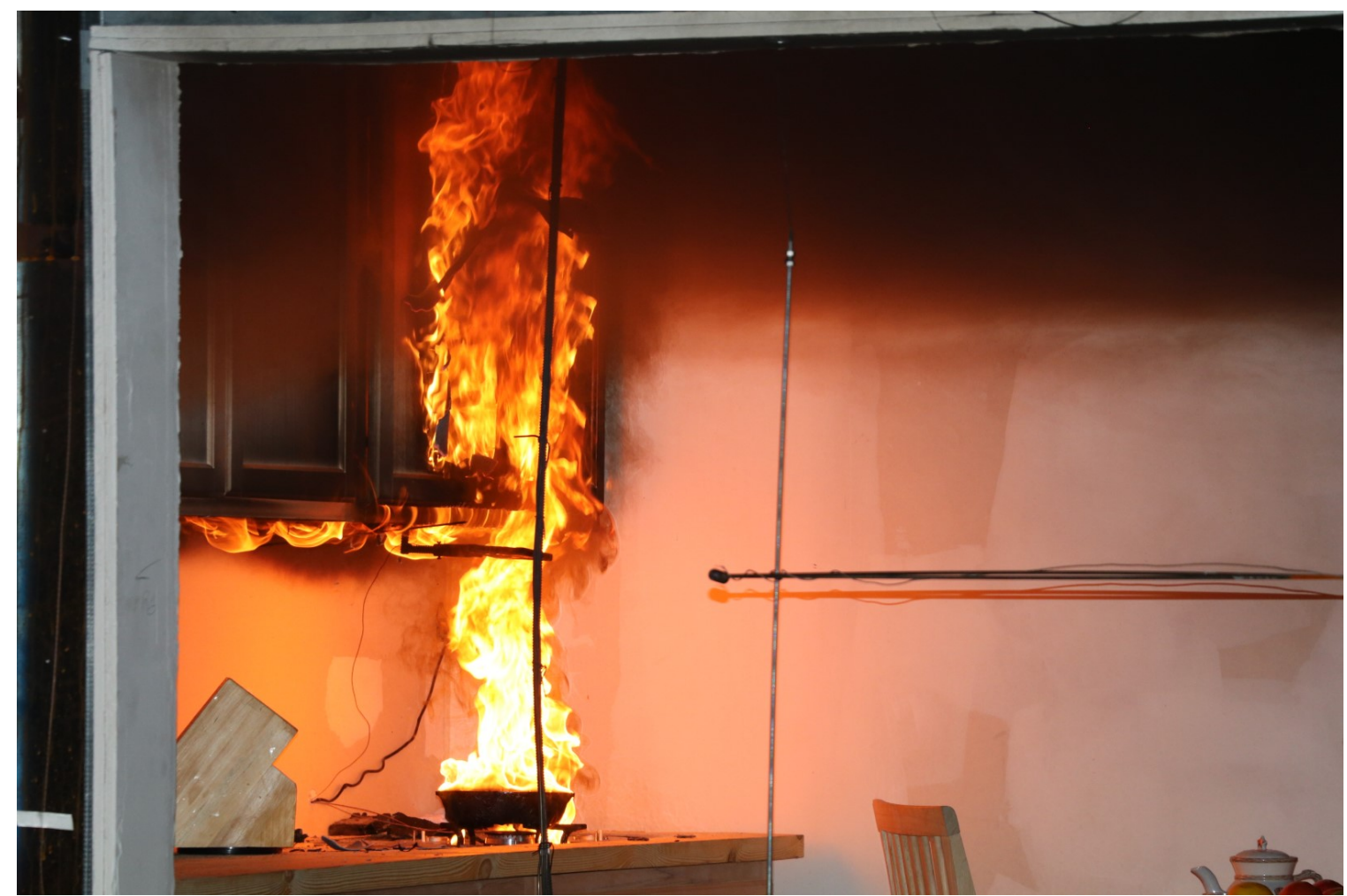

Fig. 469. OSB_Kitchen_2-Photograph of cabinet fire growth.

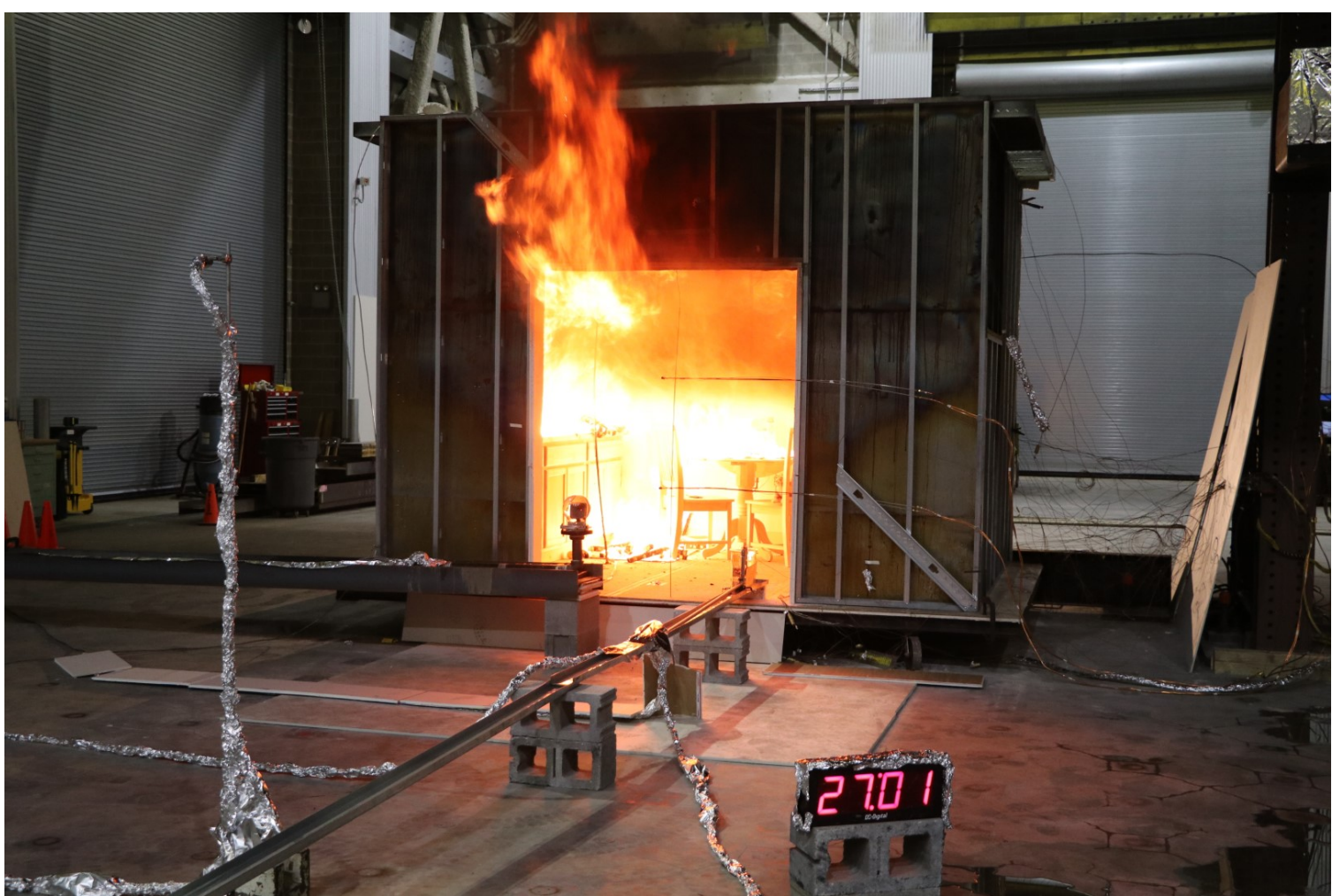

Fig. 470. OSB_Kitchen_2 - Photograph of compartment 27 min $01 \mathrm{~s}$ after burner ignition (around flashover time). 


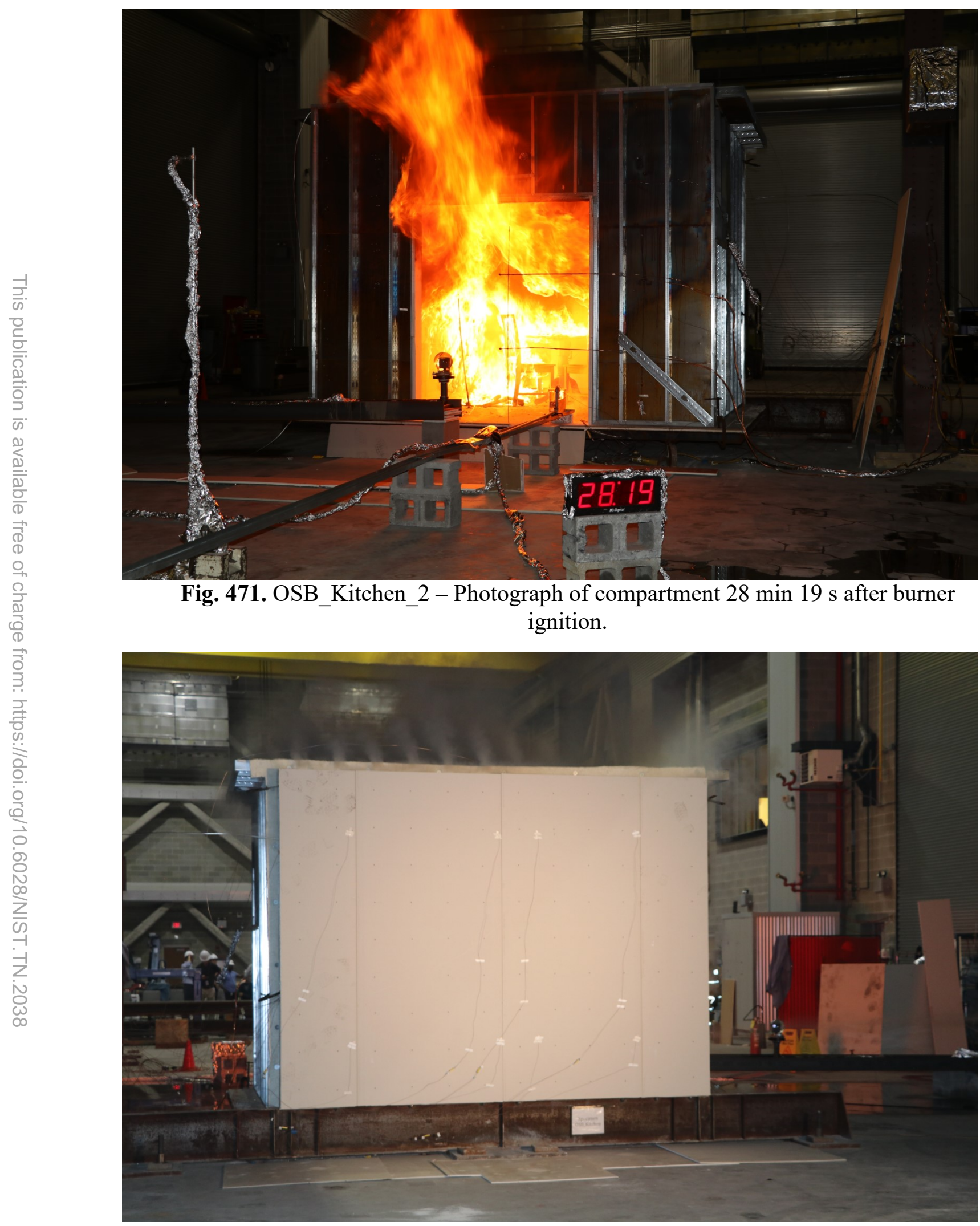

Fig. 472. OSB_Kitchen_2 - Photograph of back of OSB wall 40 min after burner ignition. 


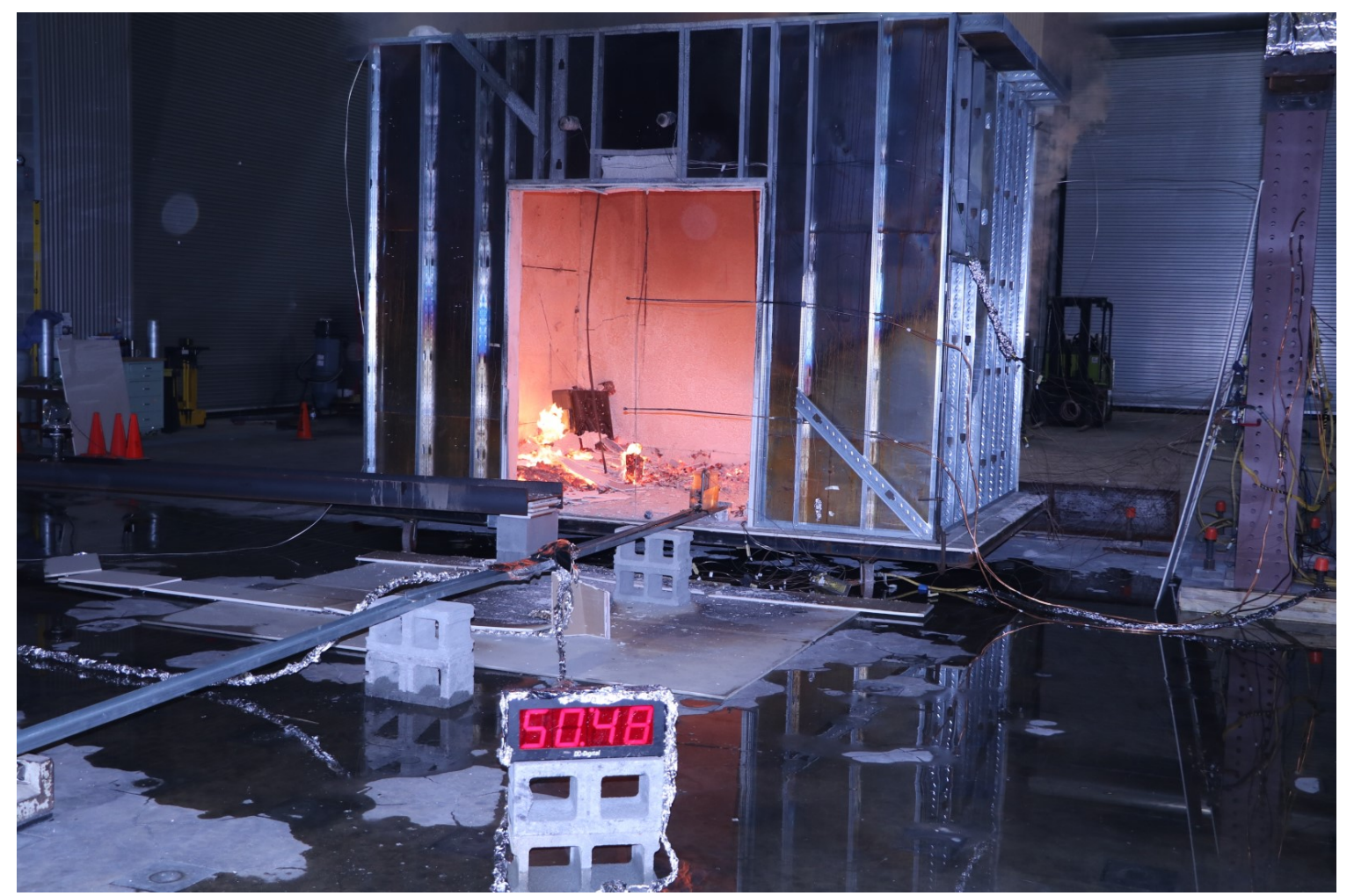

Fig. 473. OSB_Kitchen_2 - Photograph of compartment 50 min $48 \mathrm{~s}$ after burner ignition (room furnishings consumed).

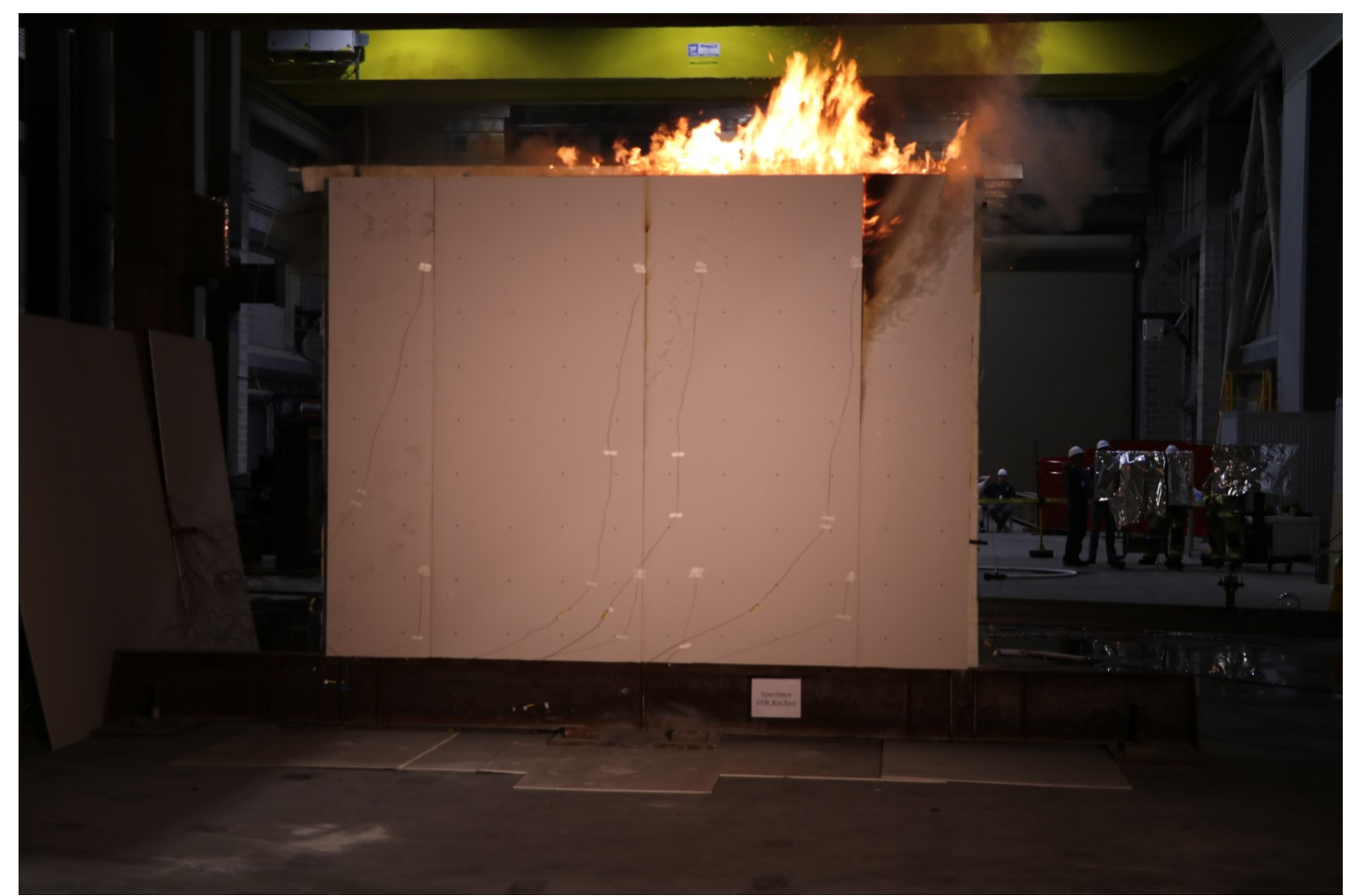

Fig. 474. OSB_Kitchen_2 - Photograph of back of OSB wall 54 min 37 s after burner ignition (flaming combustion of OSB clearly visible). 


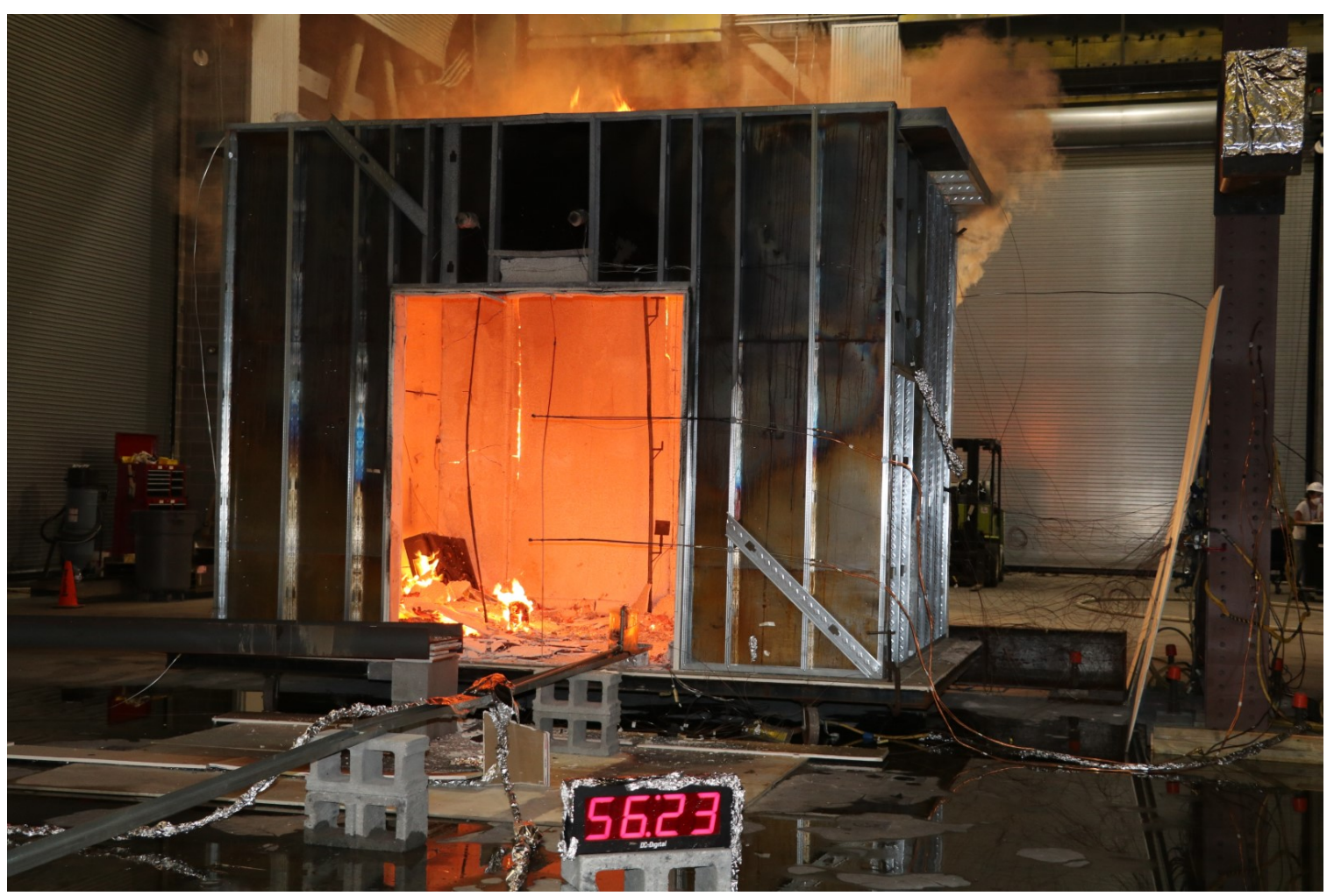

Fig. 475. OSB_Kitchen_2 - Photograph of compartment 56 min 23 s after burner ignition (flaming combustion of OSB visible through the cracks in the gypsum board).

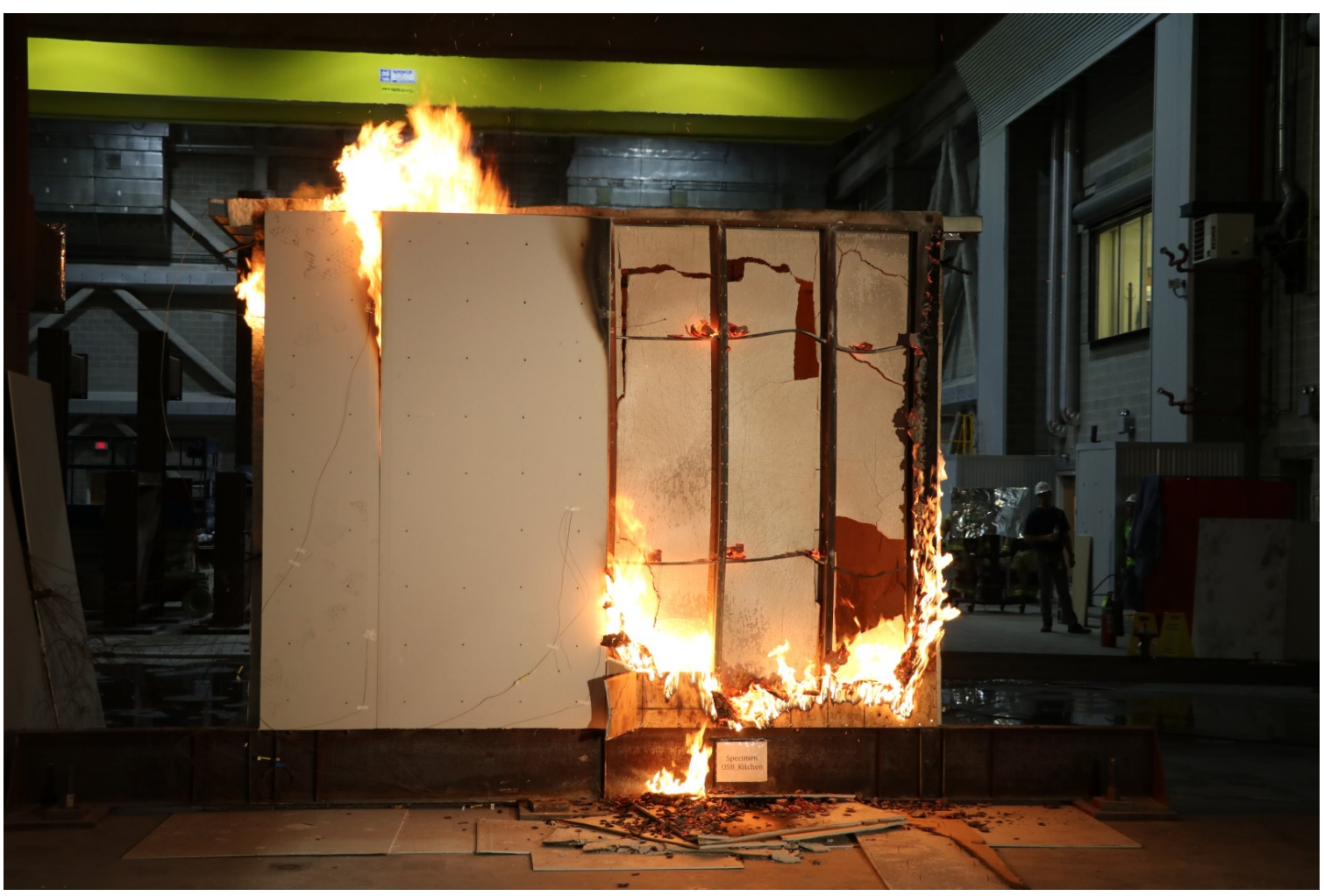

Fig. 476. OSB_Kitchen_2 - Photograph of back of OSB wall 64 min after burner ignition. 


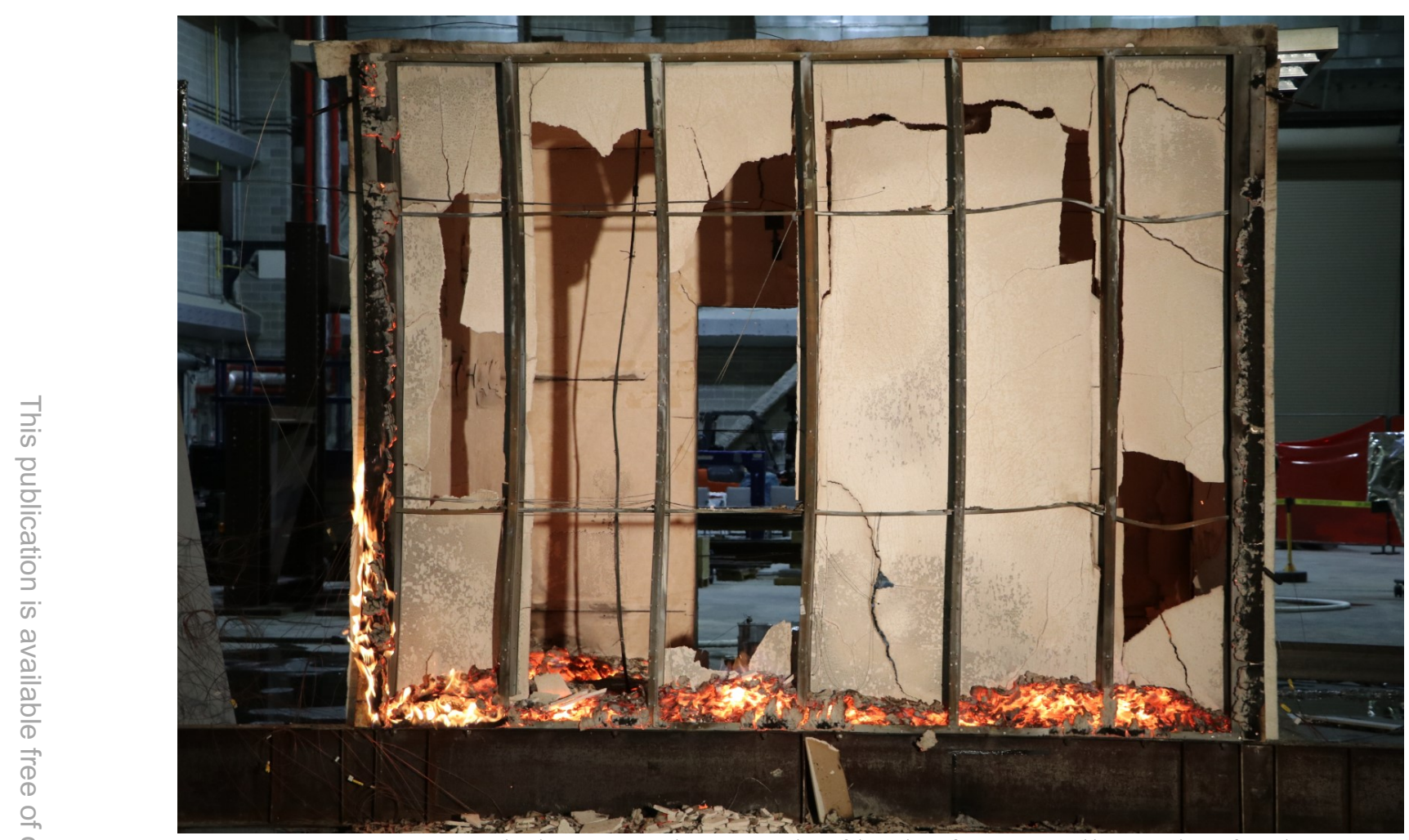

Fig. 477. OSB_Kitchen_2 - Photograph of back of OSB wall 80 min after burner ignition.

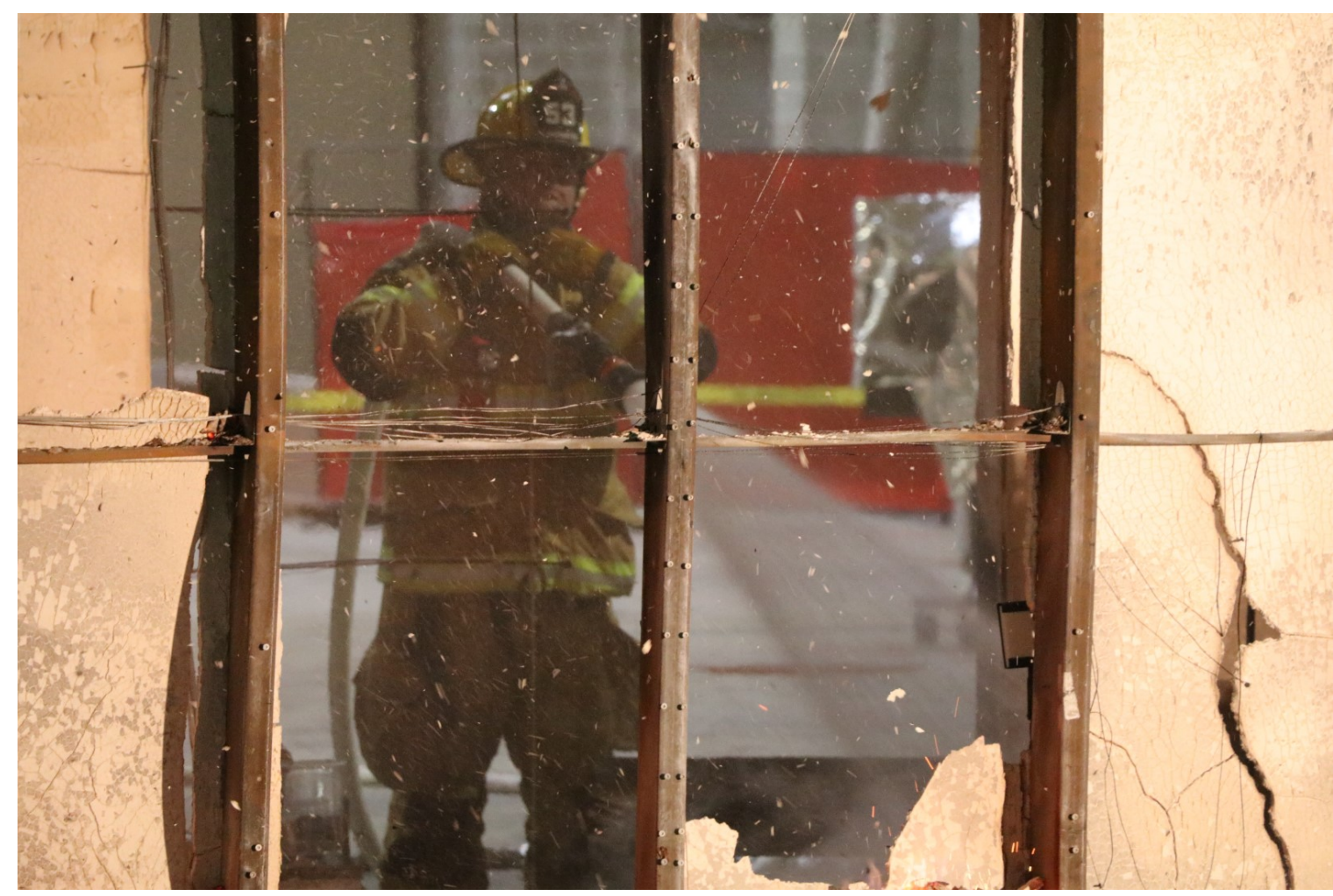

Fig. 478. OSB_Kitchen_2 - Photograph of suppression of remaining hot spots with water 81 min after burner ignition. 


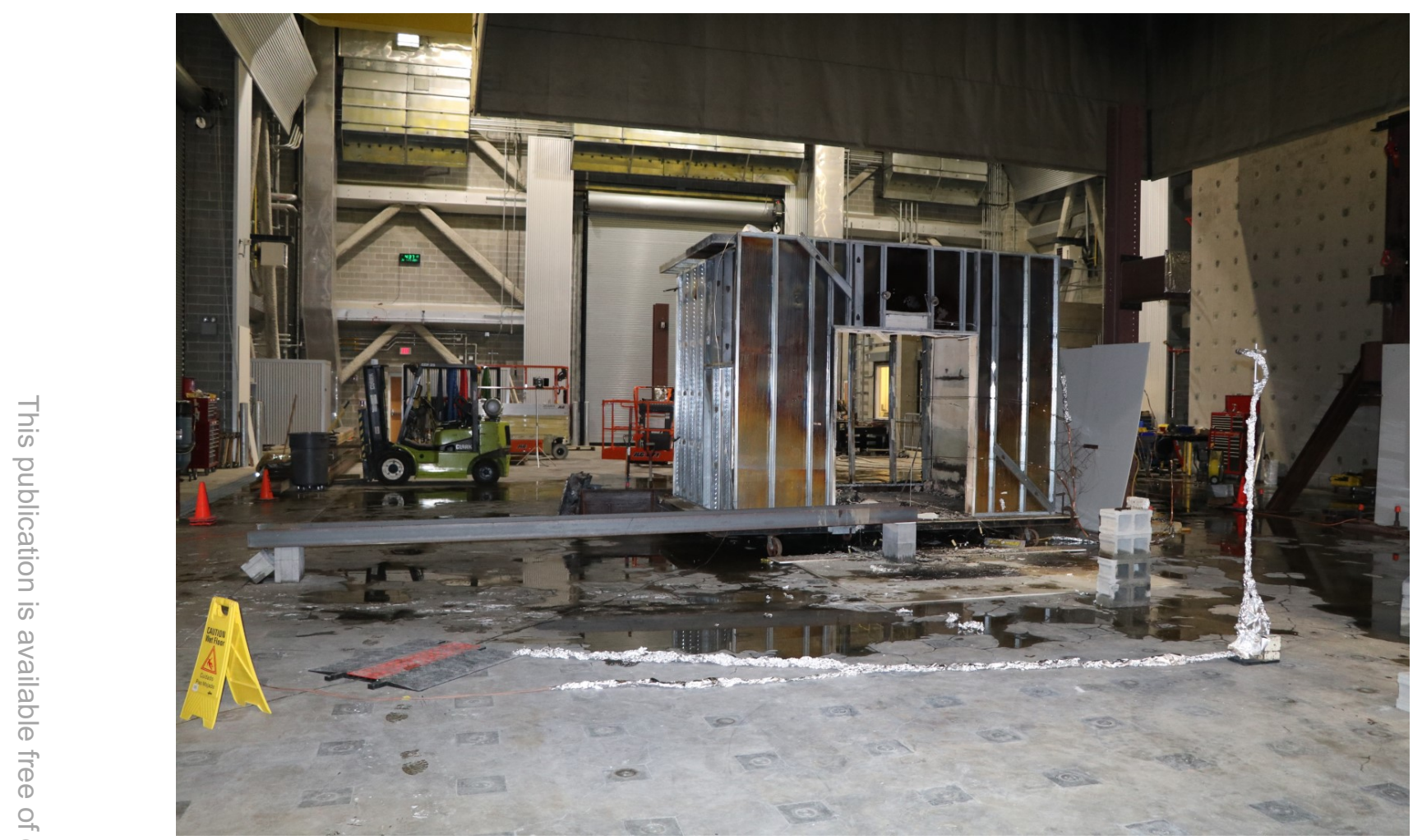

Fig. 479. OSB_Kitchen_2 - Photograph of front of compartment after fire suppression.

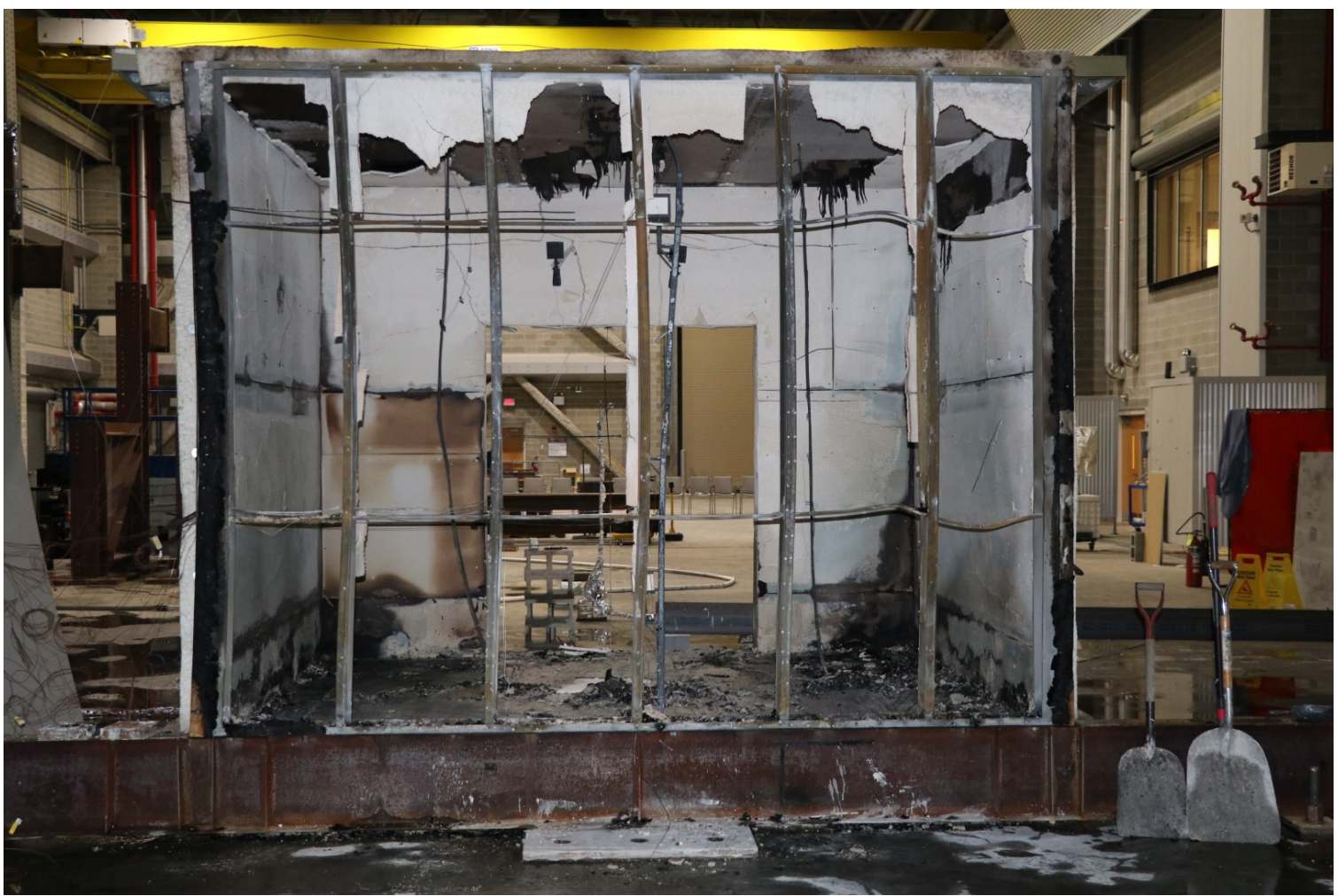

Fig. 480. OSB_Kitchen_2 - Photograph of cold-formed steel framing on OSB sheathed test wall after fire suppression. 


\section{Appendix I: Change Log}

Revision 1 - April 20, 2020

- In Section 2.5.2, corrected the sign in front of the second term of the heat flux equation to minus.

- In Section 2.5.2, corrected the units of heat flux to $\mathrm{W} / \mathrm{m}^{2}$. 